http://kitaibelia.unideb.hu/

ISSN 2064-4507 (Online) • ISSN 1219-9672 (Print)

(C) 2015, Department of Botany, University of Debrecen, Hungary

20 (1): 15-22.; 2015

DOI: $10.17542 /$ kit.20.15

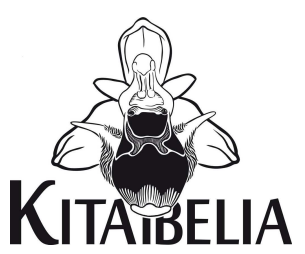

\title{
A Debreceni Egyetem Herbáriuma (DE) II.: A „Siroki Zoltán Herbárium”
}

\author{
TAKÁCS Attila ${ }^{*}$, SÜVEGES Kristóf ${ }^{1}$, LJUBKA Tibor ${ }^{1}$, LÖKI Viktor ${ }^{1}$, \\ LISZTES-SZABÓ Zsuzsa² \& MolnÁR V. Attila ${ }^{1}$
}

(1) Debreceni Egyetem TTK Növénytani Tanszék, H-4010, Debrecen, Pf. 14.; * limodorum.abortivum@gmail.com (2) Debreceni Egyetem MÉK Mezőgazdasági Növénytani, Növényélettani és Biotechnológiai Tanszék, H-4032, Debrecen, Böszörményi út 138.

\section{The Herbarium of Debrecen University (DE) II.: The „Zoltán Siroki Herbarium”}

\begin{abstract}
The paper introduces the "Zoltán Siroki Herbarium" (on the basis of the MS Excel spreadsheet database of the collection) which is a separate section within the Herbarium of Debrecen University (DE). The Zoltán Siroki Herbarium consists of ca. 20000 specimens from almost all European countries, but mainly from the historical territory of Hungary. Although ca. 400 botanists contributed to this collection, most of the specimens were collected by Zoltán Siroki in Hajdú-Bihar, Pest and Borsod-Abaúj-Zemplén counties. The most rapid growth of the Herbarium took place in the middle of the last century (from the 1940s to 1960s), but Siroki remained an active collector until the 1980s. Some specimens from the Herbarium of former Royal Seed Testing Station (Budapest) was also incorporated in this collection; they represent gatherings from the last decades of the 19th century and first decades of the 20th century. Data on the most significant part of the collection, representing native plants collected in the present-day Hungary, are summarized in Electronic Appendix 1. (incl. taxon name, settlement, collecting year, collector, file name of documentary photograph).
\end{abstract}

Keywords: Debrecen, flora of Hungary, history of hungarian botany, Košice, natural history collections

Összefoglalás - A dolgozat bemutatja a Debreceni Egyetem Herbáriumának (DE) egyik részgyűjteményét, a „Siroki Zoltán Herbáriumot”, annak MS Excel alapú adatbázisban rögzített adatai alapján. A gyưjtemény Európa szinte minden országából, főként Magyarországról és Szlovákiából (Kassa környékéről) származó, mintegy 20000 példányt őriz. Közel 400 (többségében külföldi) gyűjtő gyarapította a herbáriumot, de a legtöbb példányt Siroki Zoltán gyűjtötte, fóként Hajdú-Bihar, Pest és Borsod-Abaúj-Zemplén megyékben. Java részét a múlt század derekán (az 1940-es és 1960-as évek között) szedte, de gyűjtő tevékenységét egészen az 1980-as évekig folytatta. Az egykori Magyar Királyi Állami Vetőmagvizsgáló Állomás gyűjteményéből is átvett jó néhány lapot, ezek száma néhány százra tehető. Az adatbázis attribútum-táblájának jelentős részét (a Magyarország mai területén gyüjtött, nem kultivált növények példányainak fő adataival) az 1. Elektronikus mellékletben szabad felhasználásra közreadjuk. Igény szerint a szerzők részletesebb adatokat is közölnek.

Kulcsszavak: botanikatörténet, Debrecen, Kassa, Magyarország flórája, természettudományi gyüjtemények 


\section{Bevezetés}

A szerzők az utóbbi években jelentős idő és energia ráfordítással dolgoztak a Debreceni Egyetem Herbáriumának (DE) digitális archiválásán. Az ehhez kapcsolódó adatfeltárás első eredményeit, vagyis a Soó Rezső Herbárium részletes bemutatását nemrég tettük közzé (TAKÁCs et al. 2014). A cikksorozat második részében egy másik részgyújteményt, a Siroki Zoltán Herbáriumot mutatjuk be. E részgyűjteményt a Debreceni Egyetem Mezőgazdaság-, Élelmiszertudományi és Környezetgazdálkodási Karának Növénytudományi Intézete birtokolja. Fizikailag a Soó Rezső Herbáriummal, a Degen Árpád Herbáriummal és a kriptogám gyűjteménnyel közös szobában van elhelyezve az Egyetem téri campuson.

Jelen közlemény motivációi, célkitűzései és módszerei megegyeznek a cikksorozat első részében megfogalmazottakkal (TAKÁcs et al. l.c.).

\section{A gyưjtemény bemutatása}

A gyűjtemény története szorosan összefügg Siroki Zoltán pályafutásával (vö. PAPP \& LISZTESSzABó 2015), mivel (a Soó Rezső Herbáriummal ellentétben) ez nem annyira intézeti, mint inkább magángyűjteményként gyarapodott. Siroki első növényeit 1939-ben szedte Mosonmagyaróváron, majd a kassai Középfokú Gazdasági Tanintézetben töltött évek alatt is nagy lendülettel gyüjtött (1944-ig közel 3500 lapnyi anyagot). A taxonok azonosításában ekkoriban Rapaics Rajmund herbáriumára és Jávorka Sándor segítségére támaszkodott. A trianoni határok visszaállítását követően Siroki Debrecenbe került, ahol a Mezőgazdasági Akadémia (később Agrártudományi Főiskola, majd Egyetem) szolgálatában állt (három Budapesten töltött év kivételével) egészen nyugdíjazásáig. 1945-ben, Csehszlovákiából való kiutasítása után herbáriuma Kassán maradt anyósa lakásán, s csak 1947-ben került vissza tulajdonosához Debrecenbe. Itt aztán tovább gyarapodott a herbárium, amelynek alaposabb feldolgozására, rendezésére csak nyugalomba vonulása után tudott időt fordítani (PAPP \& LISZTES-SZABó 2015).

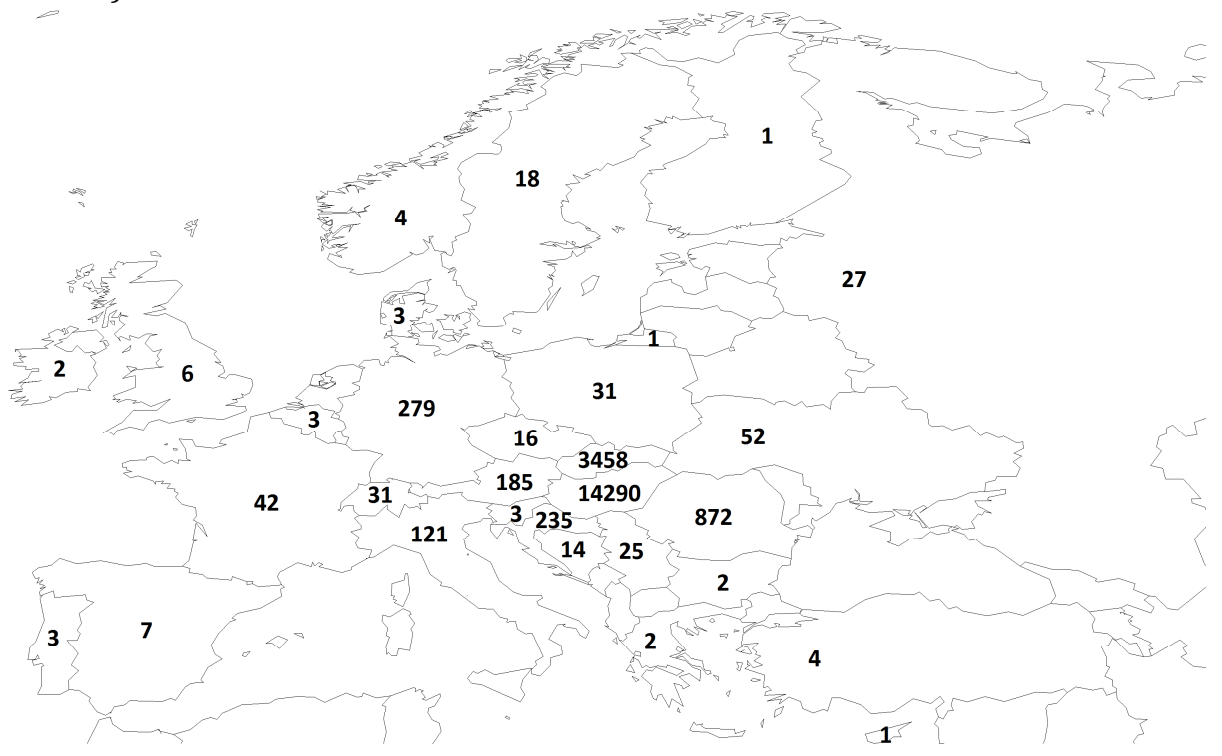

1. ábra. A Siroki Zoltán Herbáriumban őrzött példányok száma országonként.

Fig. 1. The number of collected specimens per countries as represented in the Zoltán Siroki Herbarium. 


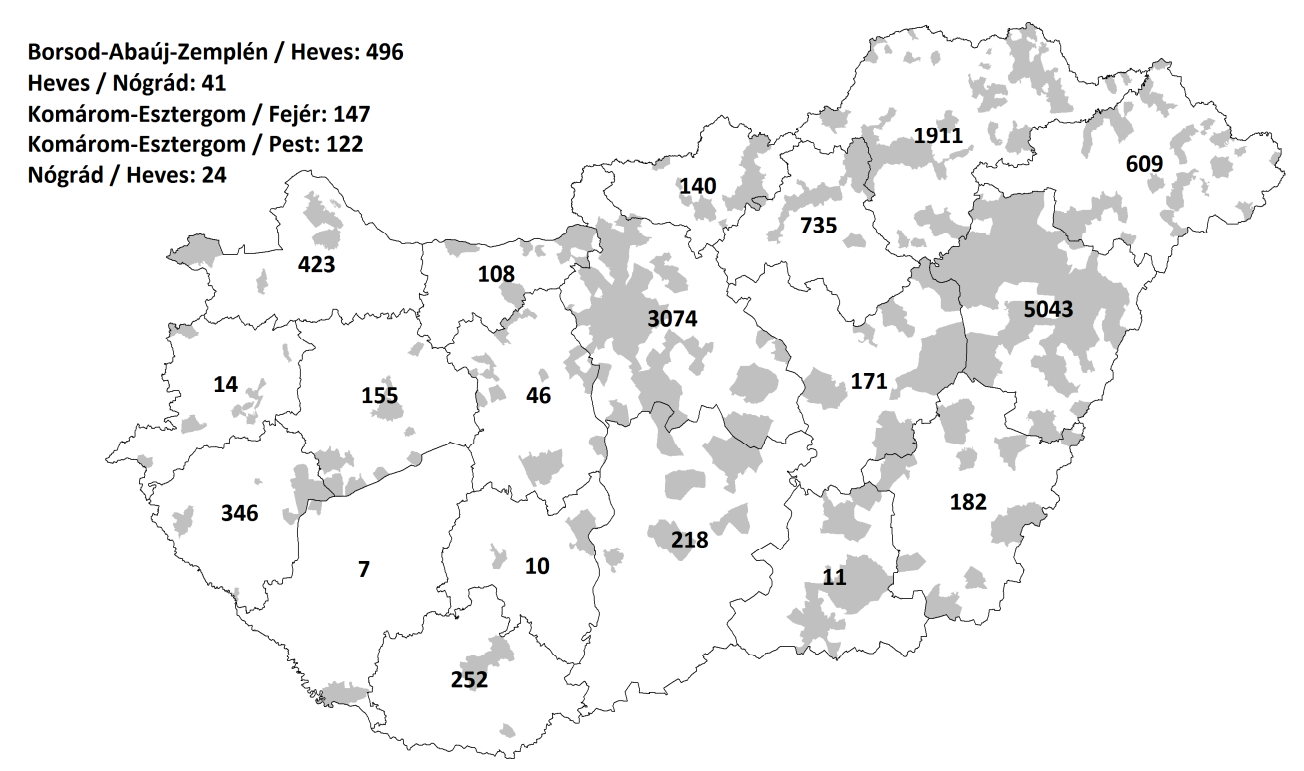

2. ábra. A Siroki Zoltán Herbáriumban őrzött hazai példányok száma megyénként. A szürke szín a példánnyal reprezentált települések közigazgatási határát jelöli.

Fig. 2. The number of collected specimens per counties as represented in the Zoltán Siroki Herbarium. The territory of Hungarian settlements represented by vouchers in the collection is indicated with grey.

A gyűjtemény egyik sajátsága, hogy szokatlanul sok duplumot tartalmaz (egyes lapoknak 8-10 kópiája is van). Hogy mi volt Siroki motivációja erre a gyakorlatra, azt nem tudjuk pontosan, de két lehetséges magyarázat képzelhető el: 1) a duplumokkal az volt a szándéka, hogy azokat cserére bocsássa, esetleg 2) a lapokat oktatási célra szánta, mint demonstrációs példányokat. Számos hazai gyűjteményben megtaláljuk lapjait, így a debreceni Soó Rezső Herbáriumban (TAKÁCS et al. 2014), az ebből elkülönített ELTE Füvészkerti herbáriumban (VIRÓK V. ex litt.), a gödöllői Szent István Egyetem herbáriumában (MoLNÁR V. et al. 2012), a kassai Pavol Jozef Safárik Egyetem herbáriumában (VIRóK V. ex litt.) illetve a keszthelyi Georgikon Kar herbáriumában (BóDIS J. ex litt.), de mindenütt csupán néhány lapról van tudomásunk. Csere helyett így valószínúbbnek tűnik, hogy a nagyszámú duplumot oktatási célokra szánta, amit az is igazol, hogy a „törzsgyűjteményből” még életében elkülönítettek egy párezer lapos demonstrációs anyagot.

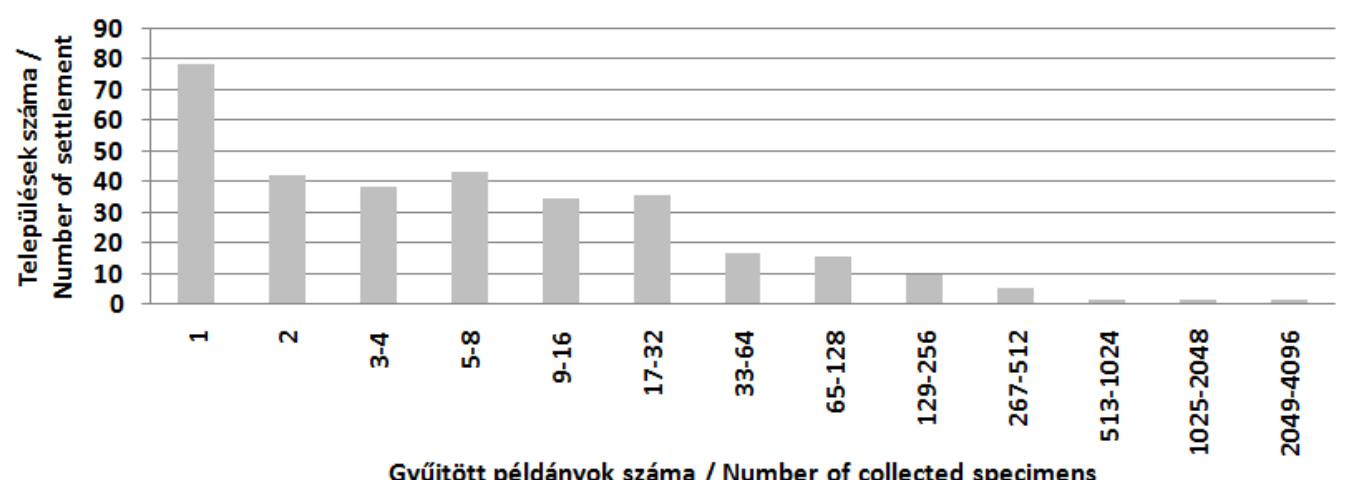

3. ábra. A településenként gyűjtött példányok száma Magyarországon. Fig. 3. The number of collected specimens per settlements in Hungary. 
TAKÁCS et al. (2015) - Kitaibelia 20 (1): 15-22.

1. táblázat. A legnagyobb példányszámmal reprezentált települések Magyarországon.

Table 1. Hungarian settlements with the highest numbers of collected specimens.

\begin{tabular}{lclc}
\hline Település / Settlement & $\begin{array}{c}\text { Példányszám / Number } \\
\text { of specimens }\end{array}$ & Település / Settlement & $\begin{array}{c}\text { Példányszám / } \\
\text { Number of } \\
\text { specimens }\end{array}$ \\
\hline Debrecen & 3555 & Gyenesdiás & 163 \\
Budapest & 1787 & Ujjléta & 145 \\
Háromhuta & 624 & Tiszafüred & 142 \\
Hortobágy & 487 & Pomáz & 134 \\
Mosonmagyaróvár & 321 & Szarvaskő & 127 \\
Szilvásvárad & 316 & Veresegyház & 123 \\
Gödöllő & 311 & Tokaj & 120 \\
Egyek & 274 & Bátorliget & 119 \\
Miskolc & 222 & Nagykovácsi & 112 \\
Budaörs & 205 & Vámospércs & 112 \\
Nagyhuta & 199 & Ágasegyháza & 102 \\
Csaroda & 187 & Keszthely & 96 \\
Pécs & 175 & Pilisszentiván & 92 \\
\hline
\end{tabular}

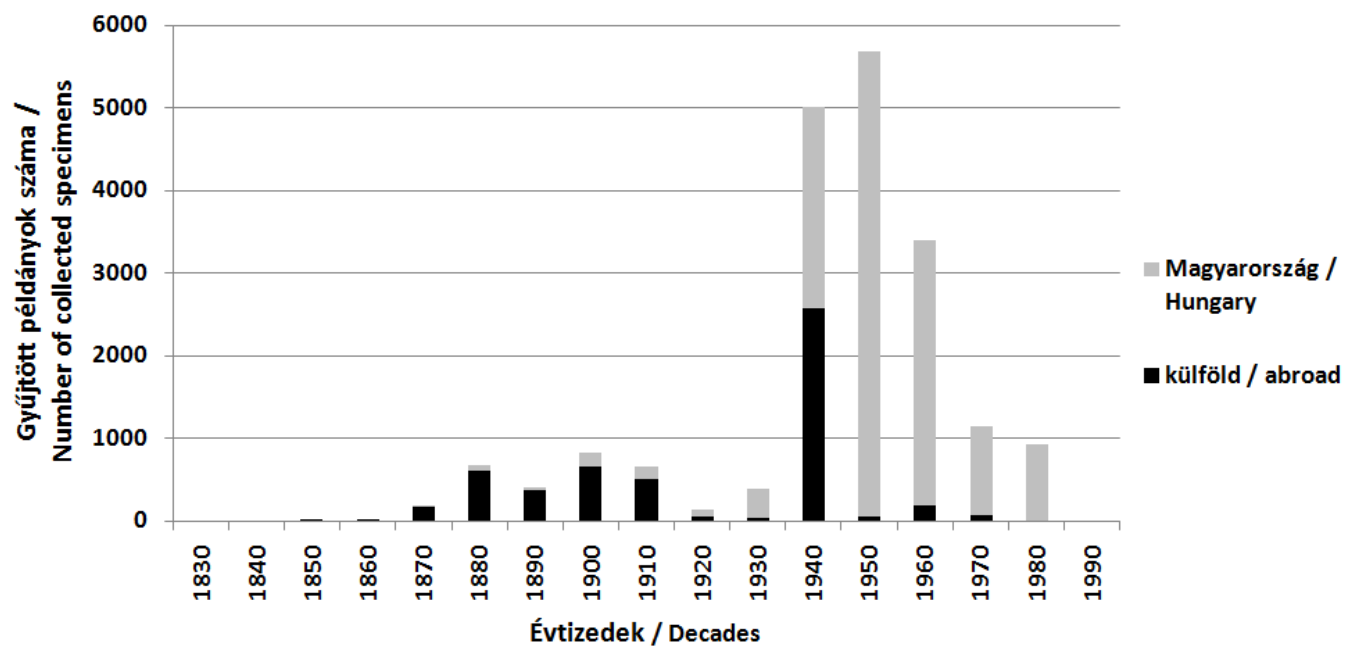

4. ábra. Az évtizedenként gyűjtött példányok száma Magyarországon és külföldön.

Fig. 4. The number of collected specimens per decades in Hungary and abroad.

A gyűjteményben kisebb számú növénytári duplum (például Filarszky Nándortól, Kümmerle J. Bélától, Timkó Györgytől, Jávorka Sándortól) mellett szembeszökő az egykori Magyar Királyi Állami Vetőmagvizsgáló Állomás munkatársai (különösen Czakó Kálmán, Kocsis István, Degen Árpád, Thaisz Lajos, Rigler József, Zsák Zoltán és mások) által jegyzett lapok magas száma. Szintén feltűnő az 1870-es és 1910-es évek közötti időszakból származó, jellemzően külföldi példányok nagy mennyisége. Közismert, hogy Degen Árpád kedvező anyagi lehetőségeinek köszönhetően számos külhoni magángyűjteményt megvásárolhatott, amelyeket saját gyüjteményébe beépített (LENGYEL 1936). Degen Árpád gyüjteményének egy részét a budapesti Vetőmagvizsgáló Állomás őrizte. Ez az anyag az említett intézmény felszámolása után a Debreceni Agrártudományi Egyetemre került. Átvételére 1971-1973 között több lépcsőben került sor, s az erről szóló dokumentumok tanúsága szerint az átvétel 
első hullámait még Siroki Zoltán bonyolította le. Bár a több tízezer lapot számláló Degengyűjtemény ma is külön kezelt része a Debreceni Egyetem Herbáriumának (vö. TAKÁcs et al. 2014 ill. cikksorozatunk jövőbeni részei), úgy tűnik, Siroki jó néhány lapot áthelyezett belőle saját gyűjteményébe (5. ábra E). Talán cél volt a két gyűjtemény egyesítése, ám ez máig nem valósult meg.

A Siroki Herbárium bővülésének kiemelkedő időszaka az 1940-es évektől az 1960-as évekig tartott (4. ábra), de maga Siroki az 1930-as évek végétől haláláig folyamatosan gyưjtött. A Degen-gyűjteményből a Siroki-gyűjteménybe áthelyezett lapoknak köszönhetően jelentősen nőtt annak tér-, idő- és taxon-beli reprezentativitása (vö. 1. ábra, 4. ábra és 1. Elektronikus melléklet).

A Jávorka-féle Magyar Flóra (JÁvoRKA 1924-25) sorszámai szerint rendezett Sirokigyưjtemény ma közel 20000 lapot számlál, amelyek 1834 és 1986 között keletkeztek. Ennek mintegy háromnegyede (14 290 lap) hazánk mai területéről származik. Nagyszámú példányt találunk Szlovákiából (3 458), elsősorban Kassa környékéről is, de Európa szinte minden országából őriz lapokat a gyűjtemény (1. ábra).

2. táblázat. A Siroki Zoltán Herbárium legjelentősebb gyűjtői.

Table 2. The most prolific collectors of the Zoltán Siroki Herbárium.

\begin{tabular}{|c|c|c|c|c|c|c|}
\hline 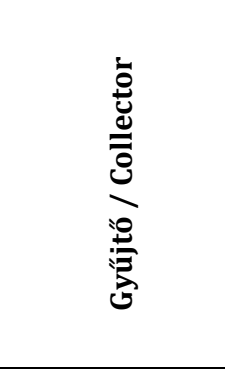 & 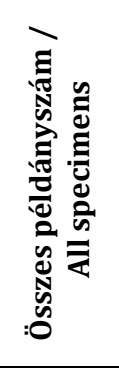 & 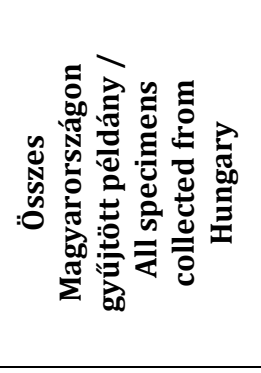 & 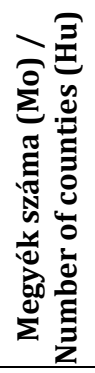 & 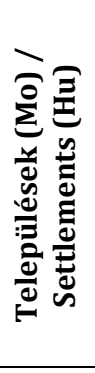 & 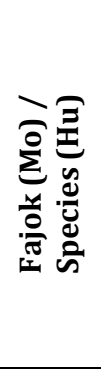 & 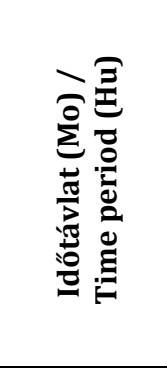 \\
\hline Siroki Zoltán & 15637 & 12852 & 18 & 193 & 1703 & 1939-1987 \\
\hline Czakó Kálmán & 446 & 64 & 3 & 6 & 48 & $1884-1890$ \\
\hline Gondola István & 283 & 272 & 10 & 53 & 91 & 1951-1981 \\
\hline Kocsis István & 249 & 156 & 3 & 20 & 101 & $1903-1920$ \\
\hline Degen Árpád & 227 & 106 & 8 & 28 & 64 & 1897-1932 \\
\hline Thaisz Lajos & 184 & 49 & 6 & 12 & 41 & $1870-1912$ \\
\hline Moesz Gusztáv & 167 & 1 & 1 & 1 & 1 & 1923 \\
\hline Farkas Attila & 147 & 147 & 6 & 8 & 79 & 1951-1955 \\
\hline Halász Tibor & 140 & 140 & 5 & 21 & 90 & 1956-1978 \\
\hline Margittai Antal & 131 & 1 & 1 & 1 & 1 & 1913 \\
\hline Kárpáti Zoltán & 99 & 99 & 11 & 33 & 91 & 1950-1961 \\
\hline Simon Tiborné & 95 & 94 & 3 & 11 & 48 & 1954-1971 \\
\hline Butujás Gyula & 82 & 1 & 1 & 1 & 1 & 1907 \\
\hline Kovács Béla & 80 & 65 & 5 & 7 & 34 & $1950-1980$ \\
\hline Hulják János & 71 & 10 & 2 & 7 & 9 & 1905-1938 \\
\hline
\end{tabular}

A példányok többsége (15 637) Siroki Zoltán gyűjtése, de további mintegy 400 gyűjtőtől is származnak lapok (2. táblázat). A cédulák tanúsága szerint Sirokit olykor felesége, máskor tanítványai is elkísérték gyűjtőútjaira. Kollégái, tanítványai által szedett érdekesebb növények is bekerültek a gyűjteménybe (például Farkas Attilától, Gondola Istvántól, Halász Tibortól, Kovács Bélától, Papp Lászlótól, Pethő Menyhérttől, Fazekas Sándortól, Koppányi Tibortól). 


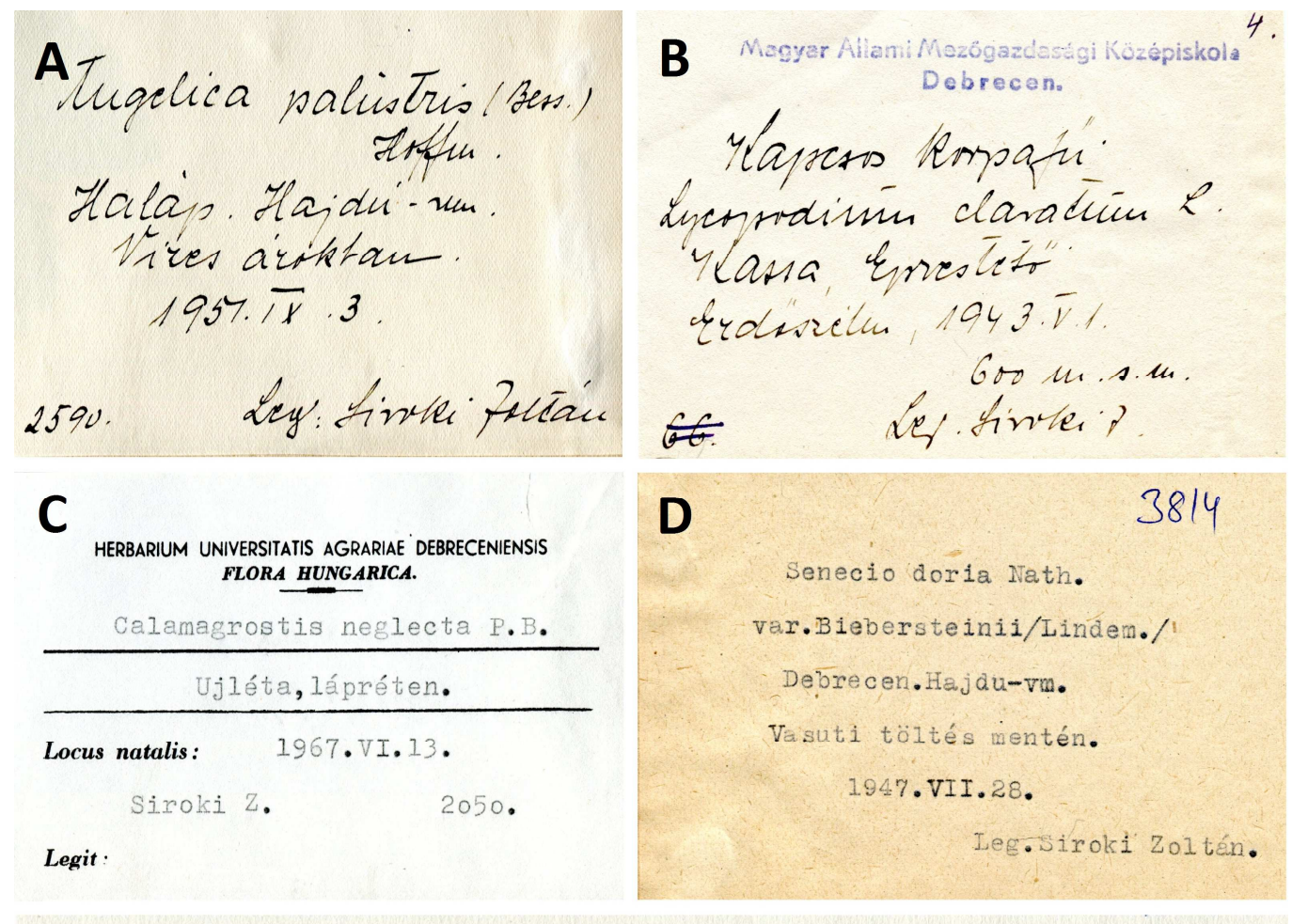

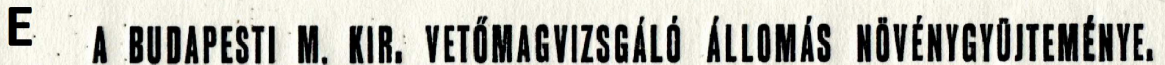 HERBARIUM INSTITUTI SEMENTI EXAMIN. REGII HUNGARICI BUDAPESTINENSIS.}

Lilene dimarica $/$ r.

Count Togaras; Kere havasai in fiosuri rupimm vallis Qullex, alt.c. Ifoo m.

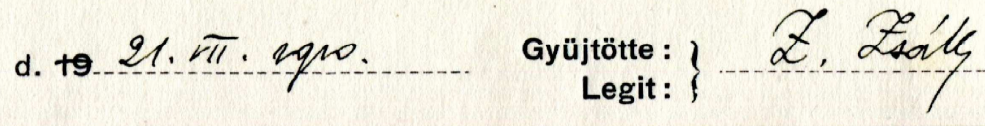

5. ábra. Néhány jellemző cédula a Siroki Zoltán Herbáriumban: Siroki Zoltán korai példányainak kézzel írott cédulái (A, B); írógéppel kitöltött cédulák Siroki Zoltántól (C, D); egy a Vetőmagvizsgáló Állomásról származó lap cédulája (E).

Fig. 5. Typical labels from the Zoltán Siroki Herbarium: handwritten labels of two early specimen from Zoltán Siroki (A, B); some labels are multipled by printing and filled by typewriter (C, D); one label of a specimen which is originated from the Royal Seed Testing Station (E). 
Legnagyobb számban Hajdú-Bihar, Pest és Borsod-Abaúj-Zemplén megyéből származnak gyűjtések, összesen mintegy 80 hazai település közigazgatási területéről (2. ábra). A példánnyal reprezentált hazai települések többségéről csak egy-két lapot őriz a gyűjtemény, míg ezres nagyságrendú lap csak Debrecen és Budapest területéről származik (1. táblázat, 3. ábra). Siroki herbáriumának gyűjtőhelyei nem meglepő módon jelentős egyezést mutatnak rovargyüjteményének gyüjtőhelyeivel (vö. KöDöвöcz 2009).

Hazánk területérôl összesen több mint 1700 taxont találunk a gyűjteményben (nem számolva a kultivált és botanikus kerti növényekkel), ami nagyjából a magyar flóra 62,5\%-át fedi le (vö. KIRÁLY 2009). Bár a gyújtemény lapjain elhelyezett revíziós cédulák tanúsága szerint sokan tanulmányozták már az anyagot (egyes példányokat revideált például: Barina Zoltán, Lisztes-Szabó Zsuzsa, Matus Gábor, Molnár V. Attila, Papp László, Pfeiffer Norbert, Pifkó Dániel, Somlyay Lajos, Sramkó Gábor, Takács Attila, Török Péter, Virók Viktor), tematikus revízióról alig lehet beszélni (de megtörtént például a Juncus compressus / J. gerardii, Chamaecytisus, Orchidaceae, Poa pratensis agg., Rumex taxonok esetében). Florisztikai csemegét jelentenek többek között az Astragalus dasyanthus illetve a Trifolium vesiculosum és a Stipa pennata debreceni lapjai (1948-ból és 1950-ből), a Calamagrostis stricta Dél-nyírségi lapjai (1950-től 1974-ig), a Glaucium corniculatum hajdúsági és hortobágyi lapjai (1948-tól 1978-ig) stb.

A gyűjteményben elhelyezett példányok döntő többsége $(94,0 \%)$ napra pontos gyújtési dátummal van feliratozva, kisebb részük hónapra $(3,4 \%)$ vagy évre $(0,6 \%)$ pontos datálású, illetve dátum nélküli $(1,9 \%)$.

$\mathrm{Az}$ 1. Elektronikus mellékletben szabad felhasználásra közreadjuk a Siroki Zoltán Herbáriumban őrzött példányok adatainak jelentős részét (hazánk területén gyűjtött, nem kultivált növények fó attribútumait). $\mathrm{Az}$ elektronikus melléklet elérhető a http://kitaibelia.unideb.hu/?download\&aid=860 webhelyen.

\section{Köszönetnyilvánítás}

A szerzők köszönetüket fejezik ki Laczkó Leventének a gyűjtemény digitalizálásában nyújtott segítségéért, valamint Bódis Juditnak a Pannon Egyetem Georgikon Karának herbáriumában található, Siroki Zoltántól származó lapok ellenőrzéséért. Hálával tartozunk Virók Viktornak a kézirathoz füzött hasznos észrevételeiért, Virók Viktornak és Vojtkó Andrásnak a Soó Rezső Herbárium adatbázisában talált hibák közléséért. A kutatást az OTKA K108992 számú pályázata támogatta.

\section{Errata}

A Soó Rezső Herbáriumot bemutató korábbi cikkünkkel (TAKÁcs et al. 2014) kapcsolatban figyelmes felhasználók felhívták a figyelmünket néhány hibára, amelyek helyreigazítását az alábbiakban adjuk közre. Emellett néhány példány taxonómiai revíziójára került sor; az alábbi táblázatban utóbbiakat * jelöli. Kérjük az adatsor felhasználóit ezek figyelembevételére! Kérjük továbbá, hogy amennyiben a Debreceni Egyetem Herbáriumát bemutató cikksorozat bármely részében hibát fedeznek fel, arról értesítsék a kapcsolattartó szerzőt! 
TAKÁCS et al. (2015) - Kitaibelia 20 (1): 15-22.

\begin{tabular}{|c|c|c|c|}
\hline $\begin{array}{l}\text { Attribútum / } \\
\text { Attribute }\end{array}$ & $\begin{array}{l}\text { Hibás adat / } \\
\text { Incorrect data }\end{array}$ & $\begin{array}{l}\text { Helyes adat / } \\
\text { Correct data }\end{array}$ & $\begin{array}{l}\text { Fájlnév / } \\
\text { File-name }\end{array}$ \\
\hline \multirow{13}{*}{$\begin{array}{l}\text { Taxon-név / Taxon- } \\
\text { name }\end{array}$} & \multirow{2}{*}{ Carex divulsa Stokes } & \multirow{2}{*}{$\begin{array}{l}\text { Carex pairaei F.W. } \\
\text { Schultz* }\end{array}$} & DE-soo-06453.jpg \\
\hline & & & DE-soo-06454.jpg \\
\hline & Cyperus flavescens L. & Cyperus glomeratus L. & DE-soo-05673.jpg \\
\hline & \multirow{2}{*}{$\begin{array}{l}\text { Dianthus pontederae A. } \\
\text { Kern. }\end{array}$} & \multirow{2}{*}{$\begin{array}{l}\text { Dianthus } \\
\text { carthusianorum L.* }\end{array}$} & DE-soo-12867.jpg \\
\hline & & & DE-soo-12904.jpg \\
\hline & Galium abaujense Borbás & Galium mollugo L.* & DE-soo-30774.jpg \\
\hline & $\begin{array}{l}\text { Leucanthemella serotina } \\
\text { (L.) Tzvelev }\end{array}$ & $\begin{array}{l}\text { Leucanthemum vulgare } \\
\text { Lam. }\end{array}$ & $\begin{array}{c}\text { DE-soo-33461.jpg } \\
- \\
\text { DE-soo-33499.jpg }\end{array}$ \\
\hline & $\begin{array}{l}\text { Pseudolysimachion } \\
\text { spicatum } \\
\text { (L.) Opiz }\end{array}$ & $\begin{array}{l}\text { Pseudolysimachion } \\
\text { orchideum } \\
\text { (Crantz) Wraber* }\end{array}$ & DE-soo-29078.jpg \\
\hline & \multirow{2}{*}{$\begin{array}{l}\text { Pseudolysimachion } \\
\text { spurium } \\
\text { (L.) Rauschert }\end{array}$} & $\begin{array}{l}\text { Pseudolysimachion } \\
\text { longifolium } \\
\text { (L.) Opiz* }\end{array}$ & $\begin{array}{l}\text { DE-soo-29046.jpg } \\
\text { DE-soo-29049.jpg }\end{array}$ \\
\hline & & Veronica serpyllifolia L.* & DE-soo-29047.jpg \\
\hline & $\begin{array}{l}\text { Rhinanthus serotinus } \\
\text { (Schönh.) Oborný }\end{array}$ & $\begin{array}{l}\text { Rhinanthus rumelicus } \\
\text { Velen.* }\end{array}$ & DE-soo-29899.jpg \\
\hline & Trifolium patens Schreb. & $\begin{array}{l}\text { Trifolium campestre } \\
\text { Schreb.* }\end{array}$ & DE-soo-19034.jpg \\
\hline & $\begin{array}{l}\text { Turgenia latifolia (L.) } \\
\text { Hoffm. }\end{array}$ & Tordylium maximum L.* & DE-soo-23799.jpg \\
\hline \multirow{4}{*}{$\begin{array}{l}\text { Település / } \\
\text { Settlement }\end{array}$} & Hajdúnánás & Hajdúdorog & $\begin{array}{l}\text { DE-soo-05636.jpg } \\
\text { DE-soo-05635.jpg }\end{array}$ \\
\hline & \multirow{3}{*}{ Varbó } & \multirow{3}{*}{ Varbóc } & $\begin{array}{l}\text { DE-soo-18551.jpg } \\
\text { DE-soo-20990.jpg }\end{array}$ \\
\hline & & & DE-soo-26644.jpg \\
\hline & & & $\begin{array}{l}\text { DE-soo-28799.jpg } \\
\text { DE-soo-36022.jpg }\end{array}$ \\
\hline Év / Year & 1935 & 1953 & DE-soo-33062.jpg \\
\hline
\end{tabular}

\section{Irodalom}

JÁvoRKA S. (1924-1925): Magyar Flóra (Flora Hungarica). Magyarország virágos és edényes virágtalan növényeinek meghatározó kézikönyve. - Magyar Nemzeti Múzeum Növénytára és Studium Könyvkiadó Rt., Budapest, 1307 pp.

KIRÁLY G. (szerk.) (2009): Új magyar füvészkönyv. Magyarország hajtásos növényei. Határozókulcsok. Aggteleki Nemzeti Park Igazgatóság, Jósvafö, 616 pp.

КӧDÖвӧCz V. (2009): A Debreceni Egyetem Siroki Zoltán gyűjteményének futóbogarai (Coleoptera: Carabidae). - Folia Historico Naturalis Musei Matrensis 33: 109-126.

LENGYel G. (1936): Degen Árpád emlékezete (1866-1934). - Botanikai Közlemények 33: 1-47.

Molnár V. A., Takács A., Horváth O., E. VojtKó A., KirÁly G., Sonkoly J., Sulyok J. \& SRAmkó G. (2012): Herbarium Database of Hungarian Orchids I. Methodology, dataset, historical aspects and taxa. Biologia 67: 79-86.

PAPP L. \& LisZTES-SzABó Zs. (2015): Siroki Zoltán (1906-1987) emlékezete. - Kitaibelia 20: 3-14.

TakÁcs A., Nagy T., Fekete R., Lovas-Kiss Á., Ljubka T., LöKi V., LiszTeS-Szabó Zs. \& Molnár V. A. (2014): A Debreceni Egyetem Herbáriuma (DE) I.: A „Soó Rezső Herbárium”. - Kitaibelia 19: 142-155.

Beérkezett / received: 2015. 01. 31. • Elfogadva / accepted: 2015. 02. 20. 
TAKÁCS Attila, SüVEgES Kristóf, LJUBKA Tibor, LöKI Viktor, LiSZTES-SzABó Zsuzsa \& MoLNÁR V. Attila (2015): A Debreceni Egyetem Herbáriuma (DE) II.: A „Siroki Zoltán Herbárium” /

The Herbarium of Debrecen University (DE) II.: The „Zoltán Siroki Herbarium”- Kitaibelia 20 (1): $15-22$. (DOI: 10.17542/kit.20.15)

1. Elektronikus melléklet - Részlet a Siroki Zoltán Herbárium adatbázisának attribútum-táblájából (Magyarországon gyűjtött, nem kultivált növények példányainak fő attribútumai).

Electronic Appendix 1. - Main attributes of specimens of non cultivated plants, collected from recent area of Hungary in the Zoltán Siroki Herbarium.

Sorszámozás és nevezéktan / Numbers and nomenclature: KIRÁLY (2009)

\begin{tabular}{|c|c|c|c|c|c|}
\hline $\begin{array}{l}\text { Sorszám / } \\
\text { Number }\end{array}$ & Taxon-név / Taxon-name & $\begin{array}{l}\text { Település / } \\
\text { Settlement }\end{array}$ & $\begin{array}{l}\text { Év / } \\
\text { Year }\end{array}$ & $\begin{array}{l}\text { Gyűjtő / } \\
\text { Collector }\end{array}$ & Fájlnév / File-name \\
\hline 1 & Huperzia selago (L.) Bernh. & Kishuta & 1954 & Simon Tiborné & DE-siroki-00333.jpg \\
\hline 3 & Diphasium complanatum (L.) Rothm. & Háromhuta & 1963 & Siroki Zoltán & DE-siroki-00356.jpg \\
\hline 3 & Diphasium complanatum (L.) Rothm. & Háromhuta & 1963 & Siroki Zoltán & DE-siroki-00358.jpg \\
\hline 3 & Diphasium complanatum (L.) Rothm. & Háromhuta & 1963 & Siroki Zoltán & DE-siroki-00359.jpg \\
\hline 3 & Diphasium complanatum (L.) Rothm. & Háromhuta & 1963 & Siroki Zoltán & DE-siroki-00360.jpg \\
\hline 3 & Diphasium complanatum (L.) Rothm. & Háromhuta & 1963 & Siroki Zoltán & DE-siroki-00361.jpg \\
\hline 3 & Diphasium complanatum (L.) Rothm. & Háromhuta & 1963 & Siroki Zoltán & DE-siroki-00362.jpg \\
\hline 3 & Diphasium complanatum (L.) Rothm. & Háromhuta & 1963 & Siroki Zoltán & DE-siroki-00363.jpg \\
\hline 3 & Diphasium complanatum (L.) Rothm. & Háromhuta & 1963 & Siroki Zoltán & DE-siroki-00364.jpg \\
\hline 3 & Diphasium complanatum (L.) Rothm. & Háromhuta & 1963 & Siroki Zoltán & DE-siroki-00365.jpg \\
\hline 3 & Diphasium complanatum (L.) Rothm. & Háromhuta & 1963 & Siroki Zoltán & DE-siroki-00366.jpg \\
\hline 3 & Diphasium complanatum (L.) Rothm. & Háromhuta & 1963 & Siroki Zoltán & DE-siroki-00367.jpg \\
\hline 3 & Diphasium complanatum (L.) Rothm. & Háromhuta & 1963 & Siroki Zoltán & DE-siroki-00370.jpg \\
\hline 3 & Diphasium complanatum (L.) Rothm. & Háromhuta & 1963 & Siroki Zoltán & DE-siroki-00368.jpg \\
\hline 3 & Diphasium complanatum (L.) Rothm. & Kishuta & 1954 & Simon Tiborné & DE-siroki-00357.jpg \\
\hline 3 & Diphasium complanatum (L.) Rothm. & Kishuta & 1954 & Siroki Zoltán & DE-siroki-00369.jpg \\
\hline 5 & Lycopodium clavatum L. & Háromhuta & 1963 & Siroki Zoltán & DE-siroki-00347.jpg \\
\hline 5 & Lycopodium clavatum L. & Háromhuta & 1963 & Siroki Zoltán & DE-siroki-00346.jpg \\
\hline 5 & Lycopodium clavatum L. & Háromhuta & 1963 & Siroki Zoltán & DE-siroki-00348.jpg \\
\hline 5 & Lycopodium clavatum L. & Háromhuta & 1984 & Siroki Zoltán & DE-siroki-00341.jpg \\
\hline 5 & Lycopodium clavatum L. & Kishuta & 1954 & Simon Tiborné & DE-siroki-00343.jpg \\
\hline 5 & Lycopodium clavatum L. & Kishuta & 1954 & Simon Tiborné & DE-siroki-00344.jpg \\
\hline 5 & Lycopodium clavatum L. & Kishuta & 1954 & Simon Tiborné & DE-siroki-00345.jpg \\
\hline 5 & Lycopodium clavatum L. & Kishuta & 1954 & $\begin{array}{l}\text { Siroki Zoltán - } \\
\text { Simon Tiborné }\end{array}$ & DE-siroki-00342.jpg \\
\hline 6 & Lycopodium annotinum L. & Kishuta & 1954 & Simon Tiborné & DE-siroki-00352.jpg \\
\hline 6 & Lycopodium annotinum L. & Kishuta & 1954 & Simon Tiborné & DE-siroki-00351.jpg \\
\hline 8 & Equisetum telmateia Ehrh. & Pécs & 1954 & Siroki Zoltán & DE-siroki-00268.jpg \\
\hline 8 & Equisetum telmateia Ehrh. & Pécs & 1954 & Siroki Zoltán & DE-siroki-00269.jpg \\
\hline 8 & Equisetum telmateia Ehrh. & Pilismarót & 1963 & Siroki Zoltán & DE-siroki-00262.jpg \\
\hline 8 & Equisetum telmateia Ehrh. & Pilismarót & 1963 & Siroki Zoltán & DE-siroki-00259.jpg \\
\hline 8 & Equisetum telmateia Ehrh. & Pilismarót & 1969 & Siroki Zoltán & DE-siroki-00267.jpg \\
\hline 8 & Equisetum telmateia Ehrh. & Pilismarót & 1969 & Siroki Zoltán & DE-siroki-00263.jpg \\
\hline 8 & Equisetum telmateia Ehrh. & Pilismarót & 1969 & Siroki Zoltán & DE-siroki-00261.jpg \\
\hline 8 & Equisetum telmateia Ehrh. & Pomáz & 1952 & Siroki Zoltán & DE-siroki-00264.jpg \\
\hline 8 & Equisetum telmateia Ehrh. & Pomáz & 1952 & Siroki Zoltán & DE-siroki-00265.jpg \\
\hline 8 & Equisetum telmateia Ehrh. & Pomáz & 1952 & Siroki Zoltán & DE-siroki-00266.jpg \\
\hline 8 & Equisetum telmateia Ehrh. & Sopron & 1950 & Kárpáti Zoltán & DE-siroki-00260.jpg \\
\hline
\end{tabular}




\begin{tabular}{|c|c|c|c|c|c|}
\hline $\begin{array}{l}\text { Sorszám / } \\
\text { Number }\end{array}$ & Taxon-név / Taxon-name & $\begin{array}{l}\text { Település / } \\
\text { Settlement }\end{array}$ & $\begin{array}{l}\text { Év / } \\
\text { Year }\end{array}$ & $\begin{array}{l}\text { Gyűjtő / } \\
\text { Collector }\end{array}$ & Fájlnév / File-name \\
\hline 9 & Equisetum arvense L. & Debrecen & 1947 & Siroki Zoltán & DE-siroki-00255.jpg \\
\hline 9 & Equisetum arvense L. & Debrecen & 1947 & Siroki Zoltán & DE-siroki-00256.jpg \\
\hline 9 & Equisetum arvense L. & Egyek & 1947 & Siroki Zoltán & DE-siroki-00253.jpg \\
\hline 9 & Equisetum arvense L. & Egyek & 1947 & Siroki Zoltán & DE-siroki-00251.jpg \\
\hline 9 & Equisetum arvense L. & Gödöllő & 1951 & Siroki Zoltán & DE-siroki-00254.jpg \\
\hline 9 & Equisetum arvense L. & Nagyhuta & 1978 & Siroki Zoltán & DE-siroki-00243.jpg \\
\hline 9 & Equisetum arvense L. & Nagyhuta & 1978 & Siroki Zoltán & DE-siroki-00244.jpg \\
\hline 9 & Equisetum arvense L. & Pécs & 1958 & Siroki Zoltán & DE-siroki-00245.jpg \\
\hline 9 & Equisetum arvense L. & Tiszacsege & 1975 & Siroki Zoltán & DE-siroki-00252.jpg \\
\hline 9 & Equisetum arvense L. & Tiszafüred & 1970 & Siroki Zoltán & DE-siroki-00250.jpg \\
\hline 9 & Equisetum arvense L. & Vámospércs & 1985 & Siroki Zoltán & DE-siroki-00248.jpg \\
\hline 9 & Equisetum arvense L. & Vámospércs & 1985 & Siroki Zoltán & DE-siroki-00249.jpg \\
\hline 10 & Equisetum sylvaticum L. & Háromhuta & 1960 & Siroki Zoltán & DE-siroki-00273.jpg \\
\hline 10 & Equisetum sylvaticum L. & Háromhuta & 1960 & Siroki Zoltán & DE-siroki-00274.jpg \\
\hline 10 & Equisetum sylvaticum L. & Háromhuta & 1960 & Siroki Zoltán & DE-siroki-00275.jpg \\
\hline 10 & Equisetum sylvaticum L. & Háromhuta & 1961 & Siroki Zoltán & DE-siroki-00272.jpg \\
\hline 10 & Equisetum sylvaticum L. & Háromhuta & 1984 & Siroki Zoltán & DE-siroki-00279.jpg \\
\hline 10 & Equisetum sylvaticum L. & Kishuta & 1954 & Siroki Zoltán & DE-siroki-00271.jpg \\
\hline 10 & Equisetum sylvaticum L. & Kishuta & 1954 & Siroki Zoltán & DE-siroki-00277.jpg \\
\hline 10 & Equisetum sylvaticum L. & Kishuta & 1961 & Siroki Zoltán & DE-siroki-00276.jpg \\
\hline 10 & Equisetum sylvaticum L. & Kishuta & 1961 & Siroki Zoltán & DE-siroki-00270.jpg \\
\hline 10 & Equisetum sylvaticum L. & Kishuta & 1961 & Siroki Zoltán & DE-siroki-00278.jpg \\
\hline 10 & Equisetum sylvaticum L. & Pilismarót & 1957 & Siroki Zoltán & DE-siroki-00283.jpg \\
\hline 10 & Equisetum sylvaticum L. & Pilismarót & 1957 & Siroki Zoltán & DE-siroki-00284.jpg \\
\hline 12 & Equisetum fluviatile L. em. Ehrh. & Kállósemjén & 1955 & Kovács Béla & DE-siroki-00299.jpg \\
\hline 12 & Equisetum fluviatile L. em. Ehrh. & Nagyhuta & 1961 & Siroki Zoltán & DE-siroki-00300.jpg \\
\hline 12 & Equisetum fluviatile L. em. Ehrh. & Nagyhuta & 1961 & Siroki Zoltán & DE-siroki-00301.jpg \\
\hline 12 & Equisetum fluviatile L. em. Ehrh. & Nagyhuta & 1961 & Siroki Zoltán & DE-siroki-00305.jpg \\
\hline 12 & Equisetum fluviatile L. em. Ehrh. & Nagyhuta & 1961 & Siroki Zoltán & DE-siroki-00306.jpg \\
\hline 12 & Equisetum fluviatile L. em. Ehrh. & Nagyhuta & 1961 & Siroki Zoltán & DE-siroki-00309.jpg \\
\hline 12 & Equisetum fluviatile L. em. Ehrh. & Nagyhuta & 1961 & Siroki Zoltán & DE-siroki-00307.jpg \\
\hline 12 & Equisetum fluviatile L. em. Ehrh. & Nagyhuta & 1961 & Siroki Zoltán & DE-siroki-00308.jpg \\
\hline 12 & Equisetum fluviatile L. em. Ehrh. & Nagyhuta & 1961 & Siroki Zoltán & DE-siroki-00303.jpg \\
\hline 12 & Equisetum fluviatile L. em. Ehrh. & Nagyhuta & 1961 & Siroki Zoltán & DE-siroki-00304.jpg \\
\hline 13 & Equisetum palustre L. & Debrecen & 1953 & Siroki Zoltán & DE-siroki-00293.jpg \\
\hline 13 & Equisetum palustre L. & Debrecen & 1955 & $\begin{array}{l}\text { Siroki Zoltán - } \\
\text { Farkas Attila }\end{array}$ & DE-siroki-00294.jpg \\
\hline 13 & Equisetum palustre L. & Hajdúbagos & 1982 & Siroki Zoltán & DE-siroki-00289.jpg \\
\hline 13 & Equisetum palustre L. & Hajdúbagos & 1982 & Siroki Zoltán & DE-siroki-00290.jpg \\
\hline 13 & Equisetum palustre L. & Újléta & 1967 & Siroki Zoltán & DE-siroki-00286.jpg \\
\hline 13 & Equisetum palustre L. & Újléta & 1967 & Siroki Zoltán & DE-siroki-00287.jpg \\
\hline 13 & Equisetum palustre L. & Újléta & 1967 & Siroki Zoltán & DE-siroki-00288.jpg \\
\hline 13 & Equisetum palustre L. & Újléta & 1967 & Siroki Zoltán & DE-siroki-00291.jpg \\
\hline 13 & Equisetum palustre L. & Újléta & 1967 & Siroki Zoltán & DE-siroki-00292.jpg \\
\hline 13 & Equisetum palustre L. & Veresegyház & 1960 & Siroki Zoltán & DE-siroki-00295.jpg \\
\hline 13 & Equisetum palustre L. & Veresegyház & 1960 & Siroki Zoltán & DE-siroki-00296.jpg \\
\hline 14 & Equisetum ramosissimum Desf. & Debrecen & 1947 & Siroki Zoltán & DE-siroki-00330.jpg \\
\hline
\end{tabular}




\begin{tabular}{|c|c|c|c|c|c|}
\hline $\begin{array}{l}\text { Sorszám / } \\
\text { Number }\end{array}$ & Taxon-név / Taxon-name & $\begin{array}{l}\text { Település / } \\
\text { Settlement }\end{array}$ & $\begin{array}{l}\text { Év / } \\
\text { Year }\end{array}$ & $\begin{array}{l}\text { Gyűjtő / } \\
\text { Collector }\end{array}$ & Fájlnév / File-name \\
\hline 14 & Equisetum ramosissimum Desf. & Debrecen & 1947 & Siroki Zoltán & DE-siroki-00329.jpg \\
\hline 14 & Equisetum ramosissimum Desf. & Hortobágy & 1947 & Siroki Zoltán & DE-siroki-00322.jpg \\
\hline 14 & Equisetum ramosissimum Desf. & Hortobágy & 1947 & Siroki Zoltán & DE-siroki-00323.jpg \\
\hline 14 & Equisetum ramosissimum Desf. & Hortobágy & 1947 & Siroki Zoltán & DE-siroki-00324.jpg \\
\hline 14 & Equisetum ramosissimum Desf. & Keszthely & 1955 & Siroki Zoltán & DE-siroki-00325.jpg \\
\hline 14 & Equisetum ramosissimum Desf. & Mosonmagyaróvár & 1939 & Siroki Zoltán & DE-siroki-00328.jpg \\
\hline 14 & Equisetum ramosissimum Desf. & Veresegyház & 1960 & Siroki Zoltán & DE-siroki-00326.jpg \\
\hline 14 & Equisetum ramosissimum Desf. & Veresegyház & 1960 & Siroki Zoltán & DE-siroki-00327.jpg \\
\hline 15 & Equisetum hyemale L. & Bátorliget & 1956 & Siroki Zoltán & DE-siroki-00310.jpg \\
\hline 15 & Equisetum hyemale L. & Bátorliget & 1956 & Siroki Zoltán & DE-siroki-00314.jpg \\
\hline 15 & Equisetum hyemale L. & Bátorliget & 1956 & Siroki Zoltán & DE-siroki-00316.jpg \\
\hline 15 & Equisetum hyemale L. & Debrecen & 1947 & Siroki Zoltán & DE-siroki-00320.jpg \\
\hline 15 & Equisetum hyemale L. & Debrecen & 1947 & Siroki Zoltán & DE-siroki-00321.jpg \\
\hline 15 & Equisetum hyemale L. & Háromhuta & 1955 & Simon Tiborné & DE-siroki-00315.jpg \\
\hline 15 & Equisetum hyemale L. & Makkoshotyka & 1955 & Simon Tiborné & DE-siroki-00311.jpg \\
\hline 15 & Equisetum hyemale L. & Makkoshotyka & 1955 & Simon Tiborné & DE-siroki-00312.jpg \\
\hline 16 & Equisetum $\times$ moorei Newman & Debrecen & 1947 & Siroki Zoltán & DE-siroki-00319.jpg \\
\hline 16 & Equisetum $\times$ moorei Newman & Hortobágy & 1947 & Siroki Zoltán & DE-siroki-00317.jpg \\
\hline 16 & Equisetum $\times$ moorei Newman & Pilisszentiván & 1952 & Siroki Zoltán & DE-siroki-00318.jpg \\
\hline 17 & Ophioglossum vulgatum L. & Debrecen & 1950 & Siroki Zoltán & DE-siroki-00238.jpg \\
\hline 17 & Ophioglossum vulgatum L. & Debrecen & 1950 & Siroki Zoltán & DE-siroki-00239.jpg \\
\hline 17 & Ophioglossum vulgatum L. & Debrecen & 1950 & Siroki Zoltán & DE-siroki-00234.jpg \\
\hline 17 & Ophioglossum vulgatum L. & Debrecen & 1955 & $\begin{array}{l}\text { Siroki Zoltán - } \\
\text { Farkas Attila }\end{array}$ & DE-siroki-00235.jpg \\
\hline 17 & Ophioglossum vulgatum L. & Debrecen & 1955 & $\begin{array}{l}\text { Siroki Zoltán - } \\
\text { Farkas Attila }\end{array}$ & DE-siroki-00236.jpg \\
\hline 17 & Ophioglossum vulgatum L. & Debrecen & 1955 & $\begin{array}{l}\text { Siroki Zoltán - } \\
\text { Farkas Attila }\end{array}$ & DE-siroki-00237.jpg \\
\hline 17 & Ophioglossum vulgatum L. & Debrecen & 1974 & $\begin{array}{l}\text { Pankucsi } \\
\text { Lászlóné }\end{array}$ & DE-siroki-00240.jpg \\
\hline 18 & Botrychium lunaria (L.) Sw. & Jávorkút & 1960 & Siroki Zoltán & DE-siroki-00241.jpg \\
\hline 18 & Botrychium lunaria (L.) Sw. & Jávorkút & 1960 & Siroki Zoltán & DE-siroki-00242.jpg \\
\hline 23 & Notholaena marantae (L.) Desv. & "Szent-György-hegy" & 1950 & $\begin{array}{l}\text { Priszter } \\
\text { Szaniszló }\end{array}$ & DE-siroki-00204.jpg \\
\hline 23 & Notholaena marantae (L.) Desv. & "Szent-György-hegy" & 1955 & Siroki Zoltán & DE-siroki-00201.jpg \\
\hline 23 & Notholaena marantae (L.) Desv. & "Szent-György-hegy" & 1955 & Siroki Zoltán & DE-siroki-00202.jpg \\
\hline 23 & Notholaena marantae (L.) Desv. & "Szent-György-hegy" & 1955 & Siroki Zoltán & DE-siroki-00203.jpg \\
\hline 23 & Notholaena marantae (L.) Desv. & "Szent-György-hegy" & 1955 & Siroki Zoltán & DE-siroki-00198.jpg \\
\hline 23 & Notholaena marantae (L.) Desv. & "Szent-György-hegy" & 1955 & Siroki Zoltán & DE-siroki-00199.jpg \\
\hline 23 & Notholaena marantae (L.) Desv. & "Szent-György-hegy" & 1955 & Siroki Zoltán & DE-siroki-00200.jpg \\
\hline 26 & Polypodium vulgare L. & "Szent-György-hegy" & 1955 & Siroki Zoltán & DE-siroki-00215.jpg \\
\hline 26 & Polypodium vulgare L. & Háromhuta & - & Simon Tiborné & DE-siroki-00211.jpg \\
\hline 26 & Polypodium vulgare L. & Keszthely & 1955 & Siroki Zoltán & DE-siroki-00216.jpg \\
\hline 26 & Polypodium vulgare L. & Szilvásvárad & 1959 & Siroki Zoltán & DE-siroki-00214.jpg \\
\hline 26 & Polypodium vulgare L. & Szilvásvárad & 1966 & Siroki Zoltán & DE-siroki-00212.jpg \\
\hline 28 & Pteridium aquilinum (L.) Kuhn & Debrecen & 1954 & Siroki Zoltán & DE-siroki-00210.jpg \\
\hline 28 & Pteridium aquilinum (L.) Kuhn & Debrecen & 1954 & Siroki Zoltán & DE-siroki-00208.jpg \\
\hline 28 & Pteridium aquilinum (L.) Kuhn & Debrecen & 1954 & Siroki Zoltán & DE-siroki-00209.jpg \\
\hline 28 & Pteridium aquilinum (L.) Kuhn & Háromhuta & 1965 & Gondola István & DE-siroki-00206.jpg \\
\hline
\end{tabular}




\begin{tabular}{|c|c|c|c|c|c|}
\hline $\begin{array}{l}\text { Sorszám / } \\
\text { Number }\end{array}$ & Taxon-név / Taxon-name & $\begin{array}{l}\text { Település / } \\
\text { Settlement }\end{array}$ & $\begin{array}{l}\text { Év / } \\
\text { Year }\end{array}$ & $\begin{array}{l}\text { Gyűjtő / } \\
\text { Collector }\end{array}$ & Fájlnév / File-name \\
\hline 29 & Thelypteris palustris Schott & Debrecen & 1950 & Siroki Zoltán & DE-siroki-00069.jpg \\
\hline 29 & Thelypteris palustris Schott & Debrecen & 1954 & Siroki Zoltán & DE-siroki-00068.jpg \\
\hline 29 & Thelypteris palustris Schott & Debrecen & 1956 & Siroki Zoltán & DE-siroki-00066.jpg \\
\hline 29 & Thelypteris palustris Schott & Háromhuta & 1961 & Siroki Zoltán & DE-siroki-00067.jpg \\
\hline 29 & Thelypteris palustris Schott & Háromhuta & 1983 & Siroki Zoltán & DE-siroki-00065.jpg \\
\hline 29 & Thelypteris palustris Schott & Kállósemjén & 1955 & Kovács Béla & DE-siroki-00062.jpg \\
\hline 29 & Thelypteris palustris Schott & Nyírábrány & 1984 & Siroki Zoltán & DE-siroki-00063.jpg \\
\hline 29 & Thelypteris palustris Schott & Nyírábrány & 1984 & Siroki Zoltán & DE-siroki-00064.jpg \\
\hline 31 & Phegopteris connectilis (Michx.) Watt & Kishuta & 1954 & Simon Tiborné & DE-siroki-00056.jpg \\
\hline 31 & Phegopteris connectilis (Michx.) Watt & Miskolc & 1959 & Siroki Zoltán & DE-siroki-00051.jpg \\
\hline 31 & Phegopteris connectilis (Michx.) Watt & Miskolc & 1959 & Siroki Zoltán & DE-siroki-00052.jpg \\
\hline 31 & Phegopteris connectilis (Michx.) Watt & Miskolc & 1959 & Siroki Zoltán & DE-siroki-00053.jpg \\
\hline 31 & Phegopteris connectilis (Michx.) Watt & Miskolc & 1959 & Siroki Zoltán & DE-siroki-00054.jpg \\
\hline 31 & Phegopteris connectilis (Michx.) Watt & Nagyhuta & 1954 & Simon Tiborné & DE-siroki-00057.jpg \\
\hline 31 & Phegopteris connectilis (Michx.) Watt & Nagyhuta & 1961 & Siroki Zoltán & DE-siroki-00043.jpg \\
\hline 31 & Phegopteris connectilis (Michx.) Watt & Nagyhuta & 1961 & Siroki Zoltán & DE-siroki-00045.jpg \\
\hline 31 & Phegopteris connectilis (Michx.) Watt & Nagyhuta & 1961 & Siroki Zoltán & DE-siroki-00044.jpg \\
\hline 31 & Phegopteris connectilis (Michx.) Watt & Pálháza & 1951 & Kárpáti Zoltán & DE-siroki-00058.jpg \\
\hline 31 & Phegopteris connectilis (Michx.) Watt & Sopron & 1956 & Kovács Béla & DE-siroki-00050.jpg \\
\hline 31 & Phegopteris connectilis (Michx.) Watt & Sopron & 1956 & Siroki Zoltán & DE-siroki-00049.jpg \\
\hline 32 & Asplenium scolopendrium L. & Pilismarót & 1950 & Papp József & DE-siroki-00154.jpg \\
\hline 32 & Asplenium scolopendrium L. & Rezi & 1955 & Siroki Zoltán & DE-siroki-00153.jpg \\
\hline 32 & Asplenium scolopendrium L. & Rezi & 1955 & Siroki Zoltán & DE-siroki-00152.jpg \\
\hline 32 & Asplenium scolopendrium L. & Szilvásvárad & 1954 & Farkas Attila & DE-siroki-00145.jpg \\
\hline 32 & Asplenium scolopendrium L. & Szilvásvárad & 1954 & Farkas Attila & DE-siroki-00149.jpg \\
\hline 32 & Asplenium scolopendrium L. & Szilvásvárad & 1954 & Farkas Attila & DE-siroki-00150.jpg \\
\hline 32 & Asplenium scolopendrium L. & Szilvásvárad & 1954 & Siroki Zoltán & DE-siroki-00146.jpg \\
\hline 32 & Asplenium scolopendrium L. & Szilvásvárad & 1954 & Siroki Zoltán & DE-siroki-00147.jpg \\
\hline 32 & Asplenium scolopendrium L. & Szilvásvárad & 1954 & Siroki Zoltán & DE-siroki-00148.jpg \\
\hline 32 & Asplenium scolopendrium L. & Szilvásvárad & 1954 & Siroki Zoltán & DE-siroki-00151.jpg \\
\hline 34 & Asplenium javorkaeanum Vida & "Szent-György-hegy" & 1955 & Siroki Zoltán & DE-siroki-00183.jpg \\
\hline 34 & Asplenium javorkaeanum Vida & "Szent-György-hegy" & 1955 & Siroki Zoltán & DE-siroki-00186.jpg \\
\hline 34 & Asplenium javorkaeanum Vida & "Szent-György-hegy" & 1955 & Siroki Zoltán & DE-siroki-00187.jpg \\
\hline 34 & Asplenium javorkaeanum Vida & "Szent-György-hegy" & 1955 & Siroki Zoltán & DE-siroki-00188.jpg \\
\hline 34 & Asplenium javorkaeanum Vida & "Szent-György-hegy" & 1955 & Siroki Zoltán & DE-siroki-00190.jpg \\
\hline 34 & Asplenium javorkaeanum Vida & "Szent-György-hegy" & 1955 & Siroki Zoltán & DE-siroki-00191.jpg \\
\hline 34 & Asplenium javorkaeanum Vida & "Szent-György-hegy" & 1955 & Siroki Zoltán & DE-siroki-00184.jpg \\
\hline 34 & Asplenium javorkaeanum Vida & "Szent-György-hegy" & 1955 & Siroki Zoltán & DE-siroki-00185.jpg \\
\hline 34 & Asplenium javorkaeanum Vida & "Szent-György-hegy" & 1955 & Siroki Zoltán & DE-siroki-00189.jpg \\
\hline 34 & Asplenium javorkaeanum Vida & "Szent-György-hegy" & 1955 & Siroki Zoltán & DE-siroki-00192.jpg \\
\hline 34 & Asplenium javorkaeanum Vida & Bajót & 1951 & Kárpáti Zoltán & DE-siroki-00194.jpg \\
\hline 34 & Asplenium javorkaeanum Vida & Tapolca & 1950 & Papp József & DE-siroki-00193.jpg \\
\hline 35 & Asplenium septentrionale (L.) Hoffm. & Kishuta & 1954 & Siroki Zoltán & DE-siroki-00155.jpg \\
\hline 35 & Asplenium septentrionale (L.) Hoffm. & Kishuta & 1954 & Siroki Zoltán & DE-siroki-00156.jpg \\
\hline 35 & Asplenium septentrionale (L.) Hoffm. & Sátoraljaújhely & 1944 & Siroki Zoltán & DE-siroki-00161.jpg \\
\hline 35 & Asplenium septentrionale (L.) Hoffm. & Sátoraljaújhely & 1944 & Siroki Zoltán & DE-siroki-00162.jpg \\
\hline
\end{tabular}




\begin{tabular}{|c|c|c|c|c|c|}
\hline $\begin{array}{l}\text { Sorszám / } \\
\text { Number }\end{array}$ & Taxon-név / Taxon-name & $\begin{array}{l}\text { Település / } \\
\text { Settlement }\end{array}$ & $\begin{array}{l}\text { Év / } \\
\text { Year }\end{array}$ & $\begin{array}{l}\text { Gyűjtő / } \\
\text { Collector }\end{array}$ & Fájlnév / File-name \\
\hline 35 & Asplenium septentrionale (L.) Hoffm. & Szarvaskő & 1957 & Siroki Zoltán & DE-siroki-00157.jpg \\
\hline 35 & Asplenium septentrionale (L.) Hoffm. & Szarvaskő & 1957 & Siroki Zoltán & DE-siroki-00158.jpg \\
\hline 35 & Asplenium septentrionale (L.) Hoffm. & Szarvaskő & 1966 & Siroki Zoltán & DE-siroki-00159.jpg \\
\hline 35 & Asplenium septentrionale (L.) Hoffm. & Szarvaskő & 1966 & Siroki Zoltán & DE-siroki-00160.jpg \\
\hline 37 & Asplenium trichomanes L. & "Fáni-völgy" & 1955 & $\begin{array}{l}\text { Siroki Zoltán - } \\
\text { Farkas Attila }\end{array}$ & DE-siroki-00171.jpg \\
\hline 37 & Asplenium trichomanes L. & "Szent-György-hegy" & 1955 & Siroki Zoltán & DE-siroki-00173.jpg \\
\hline 37 & Asplenium trichomanes L. & Szilvásvárad & 1954 & Siroki Zoltán & DE-siroki-00170.jpg \\
\hline 37 & Asplenium trichomanes L. & Szilvásvárad & 1954 & Siroki Zoltán & DE-siroki-00165.jpg \\
\hline 37 & Asplenium trichomanes L. & Szilvásvárad & 1954 & Siroki Zoltán & DE-siroki-00169.jpg \\
\hline 37 & Asplenium trichomanes L. & Szilvásvárad & 1966 & Siroki Zoltán & DE-siroki-00166.jpg \\
\hline 37 & Asplenium trichomanes L. & Szilvásvárad & 1966 & Siroki Zoltán & DE-siroki-00167.jpg \\
\hline 37 & Asplenium trichomanes L. & Szilvásvárad & 1966 & Siroki Zoltán & DE-siroki-00168.jpg \\
\hline 39 & Asplenium adiantum-nigrum L. & Tapolca & 1950 & Kárpáti Zoltán & DE-siroki-00181.jpg \\
\hline 40 & Asplenium ruta-muraria L. & "Nagymező" & 1959 & Siroki Zoltán & DE-siroki-00175.jpg \\
\hline 40 & Asplenium ruta-muraria L. & Keszthely & 1955 & Siroki Zoltán & DE-siroki-00177.jpg \\
\hline 42 & Athyrium filix-femina (L.) Roth & Debrecen & 1954 & Siroki Zoltán & DE-siroki-00122.jpg \\
\hline 42 & Athyrium filix-femina (L.) Roth & Debrecen & 1955 & Siroki Zoltán & DE-siroki-00123.jpg \\
\hline 42 & Athyrium filix-femina (L.) Roth & Debrecen & 1956 & Siroki Zoltán & DE-siroki-00124.jpg \\
\hline 42 & Athyrium filix-femina (L.) Roth & Debrecen & 1985 & $\begin{array}{l}\text { Siroki Zoltán - } \\
\text { Papp László }\end{array}$ & DE-siroki-00127.jpg \\
\hline 42 & Athyrium filix-femina (L.) Roth & Debrecen & 1985 & $\begin{array}{l}\text { Siroki Zoltán - } \\
\text { Papp László }\end{array}$ & DE-siroki-00128.jpg \\
\hline 42 & Athyrium filix-femina (L.) Roth & Debrecen & 1985 & $\begin{array}{l}\text { Siroki Zoltán - } \\
\text { Papp László }\end{array}$ & DE-siroki-00129.jpg \\
\hline 42 & Athyrium filix-femina (L.) Roth & Debrecen & 1985 & $\begin{array}{l}\text { Siroki Zoltán - } \\
\text { Papp László }\end{array}$ & DE-siroki-00130.jpg \\
\hline 42 & Athyrium filix-femina (L.) Roth & Debrecen & 1985 & $\begin{array}{l}\text { Siroki Zoltán - } \\
\text { Papp László }\end{array}$ & DE-siroki-00131.jpg \\
\hline 42 & Athyrium filix-femina (L.) Roth & Debrecen & 1986 & Siroki Zoltán & DE-siroki-00107.jpg \\
\hline 42 & Athyrium filix-femina (L.) Roth & Debrecen & 1986 & Siroki Zoltán & DE-siroki-00108.jpg \\
\hline 42 & Athyrium filix-femina (L.) Roth & Háromhuta & 1960 & Siroki Zoltán & DE-siroki-00134.jpg \\
\hline 42 & Athyrium filix-femina (L.) Roth & Háromhuta & 1960 & Siroki Zoltán & DE-siroki-00135.jpg \\
\hline 42 & Athyrium filix-femina (L.) Roth & Háromhuta & 1960 & Siroki Zoltán & DE-siroki-00136.jpg \\
\hline 42 & Athyrium filix-femina (L.) Roth & Háromhuta & 1960 & Siroki Zoltán & DE-siroki-00138.jpg \\
\hline 42 & Athyrium filix-femina (L.) Roth & Háromhuta & 1960 & Siroki Zoltán & DE-siroki-00139.jpg \\
\hline 42 & Athyrium filix-femina (L.) Roth & Háromhuta & 1960 & Siroki Zoltán & DE-siroki-00137.jpg \\
\hline 42 & Athyrium filix-femina (L.) Roth & Miskolc & 1959 & Siroki Zoltán & DE-siroki-00121.jpg \\
\hline 42 & Athyrium filix-femina (L.) Roth & Pásztó & 1952 & Siroki Zoltán & DE-siroki-00133.jpg \\
\hline 42 & Athyrium filix-femina (L.) Roth & Pécs & 1964 & Siroki Zoltán & DE-siroki-00119.jpg \\
\hline 42 & Athyrium filix-femina (L.) Roth & Répáshuta & 1956 & Halász Tibor & DE-siroki-00120.jpg \\
\hline 42 & Athyrium filix-femina (L.) Roth & Sopron & 1956 & Kovács Béla & DE-siroki-00140.jpg \\
\hline 42 & Athyrium filix-femina (L.) Roth & Sopron & 1956 & Kovács Béla & DE-siroki-00141.jpg \\
\hline 42 & Athyrium filix-femina (L.) Roth & Sopron & - & Kovács Béla & DE-siroki-00142.jpg \\
\hline 42 & Athyrium filix-femina (L.) Roth & Uzsa & 1955 & Kovács Béla & DE-siroki-00125.jpg \\
\hline 42 & Athyrium filix-femina (L.) Roth & Uzsa & 1956 & Kovács Béla & DE-siroki-00126.jpg \\
\hline 43 & Cystopteris fragilis (L.) Bernh. & $\begin{array}{l}\text { "Bükk-hg, } \\
\text { Kiskerekhegy" }\end{array}$ & 1959 & Halász Tibor & DE-siroki-00014.jpg \\
\hline 43 & Cystopteris fragilis (L.) Bernh. & "Fáni-völgy" & 1955 & $\begin{array}{l}\text { Siroki Zoltán - } \\
\text { Farkas Attila }\end{array}$ & DE-siroki-00017.jpg \\
\hline 43 & Cystopteris fragilis (L.) Bernh. & Badacsonytomaj & 1953 & ??? & DE-siroki-00005.jpg \\
\hline
\end{tabular}




\begin{tabular}{|c|c|c|c|c|c|}
\hline $\begin{array}{l}\text { Sorszám / } \\
\text { Number }\end{array}$ & Taxon-név / Taxon-name & $\begin{array}{l}\text { Település / } \\
\text { Settlement }\end{array}$ & $\begin{array}{l}\text { Év / } \\
\text { Year }\end{array}$ & $\begin{array}{l}\text { Gyűjtő / } \\
\text { Collector }\end{array}$ & Fájlnév / File-name \\
\hline 43 & Cystopteris fragilis (L.) Bernh. & Gödöllő & 1952 & Siroki Zoltán & DE-siroki-00018.jpg \\
\hline 43 & Cystopteris fragilis (L.) Bernh. & Miskolc & 1959 & Siroki Zoltán & DE-siroki-00013.jpg \\
\hline 43 & Cystopteris fragilis (L.) Bernh. & Nagyvisnyó & 1959 & Siroki Zoltán & DE-siroki-00006.jpg \\
\hline 43 & Cystopteris fragilis (L.) Bernh. & Nagyvisnyó & 1959 & Siroki Zoltán & DE-siroki-00007.jpg \\
\hline 43 & Cystopteris fragilis (L.) Bernh. & Nagyvisnyó & 1966 & Siroki Zoltán & DE-siroki-00015.jpg \\
\hline 43 & Cystopteris fragilis (L.) Bernh. & Répáshuta & 1956 & Halász Tibor & DE-siroki-00016.jpg \\
\hline 43 & Cystopteris fragilis (L.) Bernh. & Szilvásvárad & 1954 & Siroki Zoltán & DE-siroki-00009.jpg \\
\hline 43 & Cystopteris fragilis (L.) Bernh. & Szilvásvárad & 1954 & Siroki Zoltán & DE-siroki-00008.jpg \\
\hline 43 & Cystopteris fragilis (L.) Bernh. & Szilvásvárad & 1954 & Siroki Zoltán & DE-siroki-00012.jpg \\
\hline 43 & Cystopteris fragilis (L.) Bernh. & Szilvásvárad & 1954 & Siroki Zoltán & DE-siroki-00010.jpg \\
\hline 43 & Cystopteris fragilis (L.) Bernh. & Szilvásvárad & 1966 & Siroki Zoltán & DE-siroki-00011.jpg \\
\hline 47 & Woodsia ilvensis (L.) R. Br. & Füzér & 1951 & Kárpáti Zoltán & DE-siroki-00003.jpg \\
\hline 47 & Woodsia ilvensis (L.) R. Br. & Szarvaskő & 1966 & Siroki Zoltán & DE-siroki-00004.jpg \\
\hline 48 & Matteuccia struthiopteris (L.) Tod. & Ágfalva & 1950 & Kárpáti Zoltán & DE-siroki-00041.jpg \\
\hline 48 & Matteuccia struthiopteris (L.) Tod. & Kishuta & 1954 & Simon Tiborné & DE-siroki-00040.jpg \\
\hline 48 & Matteuccia struthiopteris (L.) Tod. & Nagyhuta & 1951 & Kárpáti Zoltán & DE-siroki-00042.jpg \\
\hline 48 & Matteuccia struthiopteris (L.) Tod. & Nagyhuta & 1954 & Simon Tiborné & DE-siroki-00039.jpg \\
\hline 48 & Matteuccia struthiopteris (L.) Tod. & Nagyhuta & 1955 & Siroki Zoltán & DE-siroki-00038.jpg \\
\hline 48 & Matteuccia struthiopteris (L.) Tod. & Nagyhuta & 1961 & Siroki Zoltán & DE-siroki-00032.jpg \\
\hline 48 & Matteuccia struthiopteris (L.) Tod. & Nagyhuta & 1961 & Siroki Zoltán & DE-siroki-00033.jpg \\
\hline 48 & Matteuccia struthiopteris (L.) Tod. & Nagyhuta & 1961 & Siroki Zoltán & DE-siroki-00034.jpg \\
\hline 48 & Matteuccia struthiopteris (L.) Tod. & Nagyhuta & 1961 & Siroki Zoltán & DE-siroki-00035.jpg \\
\hline 48 & Matteuccia struthiopteris (L.) Tod. & Nagyhuta & 1961 & Siroki Zoltán & DE-siroki-00036.jpg \\
\hline 48 & Matteuccia struthiopteris (L.) Tod. & Nagyhuta & 1961 & Siroki Zoltán & DE-siroki-00037.jpg \\
\hline 48 & Matteuccia struthiopteris (L.) Tod. & Nagyhuta & 1962 & Siroki Zoltán & DE-siroki-00028.jpg \\
\hline 48 & Matteuccia struthiopteris (L.) Tod. & Nagyhuta & 1962 & Siroki Zoltán & DE-siroki-00029.jpg \\
\hline 48 & Matteuccia struthiopteris (L.) Tod. & Nagyhuta & 1962 & Siroki Zoltán & DE-siroki-00030.jpg \\
\hline 48 & Matteuccia struthiopteris (L.) Tod. & Nagyhuta & 1962 & Siroki Zoltán & DE-siroki-00031.jpg \\
\hline 48 & Matteuccia struthiopteris (L.) Tod. & Nagyhuta & 1985 & Siroki Zoltán & DE-siroki-00027.jpg \\
\hline 52 & Polystichum braunii (Spenn.) Fée & Pálháza & 1951 & Kárpáti Zoltán & DE-siroki-00096.jpg \\
\hline 55 & Dryopteris filix-mas (L.) Schott & $\begin{array}{l}\text { "Bükk-hg., } \\
\text { Nagytölgyes" }\end{array}$ & 1956 & Halász Tibor & DE-siroki-00073.jpg \\
\hline 55 & Dryopteris filix-mas (L.) Schott & "Szent-György-hegy" & 1955 & Siroki Zoltán & DE-siroki-00075.jpg \\
\hline 55 & Dryopteris filix-mas (L.) Schott & "Szent-György-hegy" & 1955 & Siroki Zoltán & DE-siroki-00076.jpg \\
\hline 55 & Dryopteris filix-mas (L.) Schott & Balatonederics & 1955 & Siroki Zoltán & DE-siroki-00077.jpg \\
\hline 55 & Dryopteris filix-mas (L.) Schott & Balatonederics & 1955 & Siroki Zoltán & DE-siroki-00078.jpg \\
\hline 55 & Dryopteris filix-mas (L.) Schott & Balatonederics & 1955 & Siroki Zoltán & DE-siroki-00079.jpg \\
\hline 55 & Dryopteris filix-mas (L.) Schott & Balatonederics & 1955 & Siroki Zoltán & DE-siroki-00080.jpg \\
\hline 55 & Dryopteris filix-mas (L.) Schott & Debrecen & 1954 & Siroki Zoltán & DE-siroki-00082.jpg \\
\hline 55 & Dryopteris filix-mas (L.) Schott & Hajdúbagos & 1985 & Siroki Zoltán & DE-siroki-00081.jpg \\
\hline 55 & Dryopteris filix-mas (L.) Schott & Miskolc & 1959 & Siroki Zoltán & DE-siroki-00072.jpg \\
\hline 55 & Dryopteris filix-mas (L.) Schott & Nagyhuta & 1961 & Siroki Zoltán & DE-siroki-00070.jpg \\
\hline 55 & Dryopteris filix-mas (L.) Schott & Szilvásvárad & 1954 & Siroki Zoltán & DE-siroki-00074.jpg \\
\hline 56 & $\begin{array}{l}\text { Dryopteris carthusiana } \\
\text { (Vill.) H.P. Fuchs }\end{array}$ & Miskolc & 1959 & Siroki Zoltán & DE-siroki-00083.jpg \\
\hline 56 & $\begin{array}{l}\text { Dryopteris carthusiana } \\
\text { (Vill.) H.P. Fuchs }\end{array}$ & Ócsa & 1928 & Boros Ádám & DE-siroki-00088.jpg \\
\hline 57 & Dryopteris dilatata (Hoffm.) A. Gray & Sopron & 1956 & Kovács Béla & DE-siroki-00093.jpg \\
\hline
\end{tabular}




\begin{tabular}{|c|c|c|c|c|c|}
\hline $\begin{array}{l}\text { Sorszám / } \\
\text { Number }\end{array}$ & Taxon-név / Taxon-name & $\begin{array}{l}\text { Település / } \\
\text { Settlement }\end{array}$ & $\begin{array}{l}\text { Év / } \\
\text { Year }\end{array}$ & $\begin{array}{l}\text { Gyűjtő / } \\
\text { Collector }\end{array}$ & Fájlnév / File-name \\
\hline 60 & Marsilea quadrifolia L. & Biharugra & 1961 & Siroki Zoltán & DE-siroki-00221.jpg \\
\hline 60 & Marsilea quadrifolia L. & Biharugra & 1961 & Siroki Zoltán & DE-siroki-00224.jpg \\
\hline 60 & Marsilea quadrifolia L. & Biharugra & 1961 & Siroki Zoltán & DE-siroki-00225.jpg \\
\hline 60 & Marsilea quadrifolia L. & Hortobágy & 1955 & Siroki Zoltán & DE-siroki-00223.jpg \\
\hline 60 & Marsilea quadrifolia L. & Hortobágy & 1955 & Siroki Zoltán & DE-siroki-00222.jpg \\
\hline 60 & Marsilea quadrifolia L. & Hortobágy & 1955 & Siroki Zoltán & DE-siroki-00228.jpg \\
\hline 60 & Marsilea quadrifolia L. & Hortobágy & 1956 & Siroki Zoltán & DE-siroki-00227.jpg \\
\hline 60 & Marsilea quadrifolia L. & Hortobágy & 1975 & Siroki Zoltán & DE-siroki-00226.jpg \\
\hline 61 & Salvinia natans (L.) All. & Hortobágy & 1947 & Siroki Zoltán & DE-siroki-00230.jpg \\
\hline 61 & Salvinia natans (L.) All. & Hortobágy & 1955 & Siroki Zoltán & DE-siroki-00233.jpg \\
\hline 61 & Salvinia natans (L.) All. & Sárospatak & 1951 & Siroki Zoltán & DE-siroki-00231.jpg \\
\hline 61 & Salvinia natans (L.) All. & Sárospatak & 1951 & Siroki Zoltán & DE-siroki-00232.jpg \\
\hline 61 & Salvinia natans (L.) All. & Újszentmargita & 1963 & Siroki Zoltán & DE-siroki-00229.jpg \\
\hline 65 & Ginkgo biloba L. & Debrecen & 1976 & Siroki Zoltán & DE-siroki-00465.jpg \\
\hline 65 & Ginkgo biloba L. & Debrecen & 1976 & Siroki Zoltán & DE-siroki-00466.jpg \\
\hline 78 & Pinus strobus L. & Debrecen & 1965 & Siroki Zoltán & DE-siroki-00419.jpg \\
\hline 80 & Pinus sylvestris L. & Kishuta & 1961 & Siroki Zoltán & DE-siroki-00426.jpg \\
\hline 80 & Pinus sylvestris L. & Kishuta & 1961 & Siroki Zoltán & DE-siroki-00427.jpg \\
\hline 93 & Ephedra distachya L. & Budapest & 1904 & $\begin{array}{l}\text { Thaisz Lajos - } \\
\text { Baán Lajos }\end{array}$ & DE-siroki-00472.jpg \\
\hline 93 & Ephedra distachya L. & Budapest & 1951 & Siroki Zoltán & DE-siroki-00469.jpg \\
\hline 93 & Ephedra distachya L. & Budapest & 1951 & Siroki Zoltán & DE-siroki-00470.jpg \\
\hline 93 & Ephedra distachya L. & Budapest & 1951 & Siroki Zoltán & DE-siroki-00473.jpg \\
\hline 93 & Ephedra distachya L. & Budapest & 1951 & Siroki Zoltán & DE-siroki-00471.jpg \\
\hline 94 & Salix alba L. & Debrecen & 1950 & Siroki Zoltán & DE-siroki-05168.jpg \\
\hline 95 & Salix fragilis L. & Debrecen & 1950 & Siroki Zoltán & DE-siroki-05071.jpg \\
\hline 95 & Salix fragilis L. & Debrecen & 1950 & Siroki Zoltán & DE-siroki-05075.jpg \\
\hline 95 & Salix fragilis L. & Debrecen & 1950 & Siroki Zoltán & DE-siroki-05077.jpg \\
\hline 95 & Salix fragilis $\mathrm{L}$. & Debrecen & 1950 & Siroki Zoltán & DE-siroki-05078.jpg \\
\hline 95 & Salix fragilis L. & Debrecen & 1957 & Siroki Zoltán & DE-siroki-05070.jpg \\
\hline 96 & Salix triandra L. & Debrecen & 1948 & Siroki Zoltán & DE-siroki-05086.jpg \\
\hline 96 & Salix triandra L. & Debrecen & 1948 & Siroki Zoltán & DE-siroki-05087.jpg \\
\hline 96 & Salix triandra L. & Debrecen & 1948 & Siroki Zoltán & DE-siroki-05089.jpg \\
\hline 96 & Salix triandra L. & Debrecen & 1950 & Siroki Zoltán & DE-siroki-05096.jpg \\
\hline 96 & Salix triandra L. & Újléta & 1965 & Siroki Zoltán & DE-siroki-05094.jpg \\
\hline 97 & Salix pentandra L. & Bátorliget & 1955 & Jeney Endre & DE-siroki-05062.jpg \\
\hline 97 & Salix pentandra L. & Bátorliget & 1956 & Siroki Zoltán & DE-siroki-05059.jpg \\
\hline 97 & Salix pentandra L. & Bátorliget & 1956 & Siroki Zoltán & DE-siroki-05060.jpg \\
\hline 97 & Salix pentandra L. & Bátorliget & 1956 & Siroki Zoltán & DE-siroki-05061.jpg \\
\hline 97 & Salix pentandra L. & Bátorliget & 1956 & Siroki Zoltán & DE-siroki-05066.jpg \\
\hline 97 & Salix pentandra L. & Bátorliget & 1956 & Siroki Zoltán & DE-siroki-05067.jpg \\
\hline 97 & Salix pentandra L. & Bátorliget & 1956 & Siroki Zoltán & DE-siroki-05068.jpg \\
\hline 97 & Salix pentandra L. & Bátorliget & 1956 & Siroki Zoltán & DE-siroki-05069.CR2 \\
\hline 97 & Salix pentandra L. & Bátorliget & 1956 & Siroki Zoltán & DE-siroki-05064.jpg \\
\hline 97 & Salix pentandra L. & Csaroda & 1960 & Siroki Zoltán & DE-siroki-05054.jpg \\
\hline 97 & Salix pentandra L. & Csaroda & 1960 & Siroki Zoltán & DE-siroki-05055.jpg \\
\hline 97 & Salix pentandra L. & Csaroda & 1960 & Siroki Zoltán & DE-siroki-05056.jpg \\
\hline
\end{tabular}




\begin{tabular}{|c|c|c|c|c|c|}
\hline $\begin{array}{l}\text { Sorszám / } \\
\text { Number }\end{array}$ & Taxon-név / Taxon-name & $\begin{array}{l}\text { Település / } \\
\text { Settlement }\end{array}$ & $\begin{array}{l}\text { Év / } \\
\text { Year }\end{array}$ & $\begin{array}{l}\text { Gyűjtő / } \\
\text { Collector }\end{array}$ & Fájlnév / File-name \\
\hline 97 & Salix pentandra L. & Csaroda & 1960 & Siroki Zoltán & DE-siroki-05057.jpg \\
\hline 97 & Salix pentandra L. & Csaroda & 1960 & Siroki Zoltán & DE-siroki-05058.jpg \\
\hline 97 & Salix pentandra L. & Csaroda & 1960 & Siroki Zoltán & DE-siroki-05063.jpg \\
\hline 97 & Salix pentandra L. & Csaroda & 1960 & Siroki Zoltán & DE-siroki-05065.jpg \\
\hline 98 & Salix rosmarinifolia L. & Ágasegyháza & 1956 & Siroki Zoltán & DE-siroki-05142.jpg \\
\hline 98 & Salix rosmarinifolia L. & Csaroda & 1960 & Siroki Zoltán & DE-siroki-05136.jpg \\
\hline 98 & Salix rosmarinifolia L. & Csaroda & 1960 & Siroki Zoltán & DE-siroki-05139.jpg \\
\hline 98 & Salix rosmarinifolia L. & Csaroda & 1960 & Siroki Zoltán & DE-siroki-05140.jpg \\
\hline 98 & Salix rosmarinifolia L. & Csaroda & 1960 & Siroki Zoltán & DE-siroki-05150.jpg \\
\hline 98 & Salix rosmarinifolia L. & Csaroda & 1960 & Siroki Zoltán & DE-siroki-05151.jpg \\
\hline 98 & Salix rosmarinifolia L. & Debrecen & 1950 & Siroki Zoltán & DE-siroki-05146.jpg \\
\hline 98 & Salix rosmarinifolia L. & Debrecen & 1950 & Siroki Zoltán & DE-siroki-05148.jpg \\
\hline 98 & Salix rosmarinifolia L. & Debrecen & 1950 & Siroki Zoltán & DE-siroki-05137.jpg \\
\hline 98 & Salix rosmarinifolia L. & Debrecen & 1950 & Siroki Zoltán & DE-siroki-05138.jpg \\
\hline 98 & Salix rosmarinifolia L. & Debrecen & 1950 & Siroki Zoltán & DE-siroki-05141.jpg \\
\hline 98 & Salix rosmarinifolia L. & Debrecen & 1950 & Siroki Zoltán & DE-siroki-05147.jpg \\
\hline 98 & Salix rosmarinifolia L. & Debrecen & 1950 & Siroki Zoltán & DE-siroki-05149.jpg \\
\hline 98 & Salix rosmarinifolia L. & Debrecen & 1950 & Siroki Zoltán & DE-siroki-05152.jpg \\
\hline 98 & Salix rosmarinifolia L. & Debrecen & 1954 & Siroki Zoltán & DE-siroki-05145.jpg \\
\hline 98 & Salix rosmarinifolia L. & Hortobágy & 1949 & Siroki Zoltán & DE-siroki-05144.jpg \\
\hline 98 & Salix rosmarinifolia L. & Kimle & 1962 & Siroki Zoltán & DE-siroki-05134.jpg \\
\hline 98 & Salix rosmarinifolia L. & Kimle & 1962 & Siroki Zoltán & DE-siroki-05135.jpg \\
\hline 98 & Salix rosmarinifolia L. & Kimle & 1962 & Siroki Zoltán & DE-siroki-05165.jpg \\
\hline 98 & Salix rosmarinifolia L. & Szigetszentmiklós & 1951 & Siroki Zoltán & DE-siroki-05143.jpg \\
\hline 99 & Salix purpurea L. & Debrecen & 1950 & Siroki Zoltán & DE-siroki-05098.jpg \\
\hline 99 & Salix purpurea L. & Debrecen & 1950 & Siroki Zoltán & DE-siroki-05099.jpg \\
\hline 99 & Salix purpurea L. & Debrecen & 1950 & Siroki Zoltán & DE-siroki-05100.jpg \\
\hline 99 & Salix purpurea L. & Debrecen & 1950 & Siroki Zoltán & DE-siroki-05101.jpg \\
\hline 99 & Salix purpurea L. & Debrecen & 1950 & Siroki Zoltán & DE-siroki-05102.jpg \\
\hline 99 & Salix purpurea L. & Debrecen & 1950 & Siroki Zoltán & DE-siroki-05103.jpg \\
\hline 99 & Salix purpurea L. & Debrecen & 1950 & Siroki Zoltán & DE-siroki-05104.jpg \\
\hline 101 & Salix viminalis L. & Debrecen & 1950 & Siroki Zoltán & DE-siroki-05154.jpg \\
\hline 101 & Salix viminalis L. & Debrecen & 1950 & Siroki Zoltán & DE-siroki-05155.jpg \\
\hline 101 & Salix viminalis $\mathrm{L}$. & Debrecen & 1950 & Siroki Zoltán & DE-siroki-05157.jpg \\
\hline 101 & Salix viminalis L. & Debrecen & 1950 & Siroki Zoltán & DE-siroki-05157.jpg \\
\hline 101 & Salix viminalis L. & Debrecen & 1950 & Siroki Zoltán & DE-siroki-05162.jpg \\
\hline 101 & Salix viminalis $\mathrm{L}$. & Debrecen & 1950 & Siroki Zoltán & DE-siroki-05162.jpg \\
\hline 102 & Salix caprea L. & "Bükk-hg." & 1960 & Siroki Zoltán & DE-siroki-05216.jpg \\
\hline 102 & Salix caprea L. & "Bükk-hg." & 1960 & Siroki Zoltán & DE-siroki-05217.jpg \\
\hline 102 & Salix caprea L. & "Bükk-hg." & 1960 & Siroki Zoltán & DE-siroki-05218.jpg \\
\hline 102 & Salix caprea L. & "Bükk-hg." & 1960 & Siroki Zoltán & DE-siroki-05219.jpg \\
\hline 102 & Salix caprea L. & "Bükk-hg." & 1960 & Siroki Zoltán & DE-siroki-05220.jpg \\
\hline 102 & Salix caprea L. & "Bükk-hg." & 1960 & Siroki Zoltán & DE-siroki-05221.jpg \\
\hline 102 & Salix caprea L. & "Nagymező" & 1968 & Siroki Zoltán & DE-siroki-05164.jpg \\
\hline 102 & Salix caprea L. & "Nagymező" & 1968 & Siroki Zoltán & DE-siroki-05210.jpg \\
\hline 102 & Salix caprea L. & Budapest & 1964 & Siroki Zoltán & DE-siroki-05213.jpg \\
\hline
\end{tabular}




\begin{tabular}{|c|c|c|c|c|c|}
\hline $\begin{array}{l}\text { Sorszám / } \\
\text { Number }\end{array}$ & Taxon-név / Taxon-name & $\begin{array}{l}\text { Település / } \\
\text { Settlement }\end{array}$ & $\begin{array}{l}\text { Év / } \\
\text { Year }\end{array}$ & $\begin{array}{l}\text { Gyüjtő / } \\
\text { Collector }\end{array}$ & Fájlnév / File-name \\
\hline 102 & Salix caprea L. & Budapest & 1964 & Siroki Zoltán & DE-siroki-05214.jpg \\
\hline 102 & Salix caprea L. & Budapest & 1985 & Siroki Zoltán & DE-siroki-05211.jpg \\
\hline 102 & Salix caprea L. & Budapest & 1985 & Siroki Zoltán & DE-siroki-05212.jpg \\
\hline 102 & Salix caprea L. & Gyenesdiás & 1972 & Siroki Zoltán & DE-siroki-05224.jpg \\
\hline 102 & Salix caprea L. & Gyenesdiás & 1972 & Siroki Zoltán & DE-siroki-05225.jpg \\
\hline 102 & Salix caprea L. & Nagyhuta & 1978 & Siroki Zoltán & DE-siroki-05222.jpg \\
\hline 102 & Salix caprea L. & Nagyhuta & 1978 & Siroki Zoltán & DE-siroki-05223.jpg \\
\hline 102 & Salix caprea L. & Pásztó & 1952 & Siroki Zoltán & DE-siroki-05215.jpg \\
\hline 102 & Salix caprea L. & Újléta & 1967 & Siroki Zoltán & DE-siroki-05209.jpg \\
\hline 104 & Salix cinerea L. & "Vértes" & 1957 & Siroki Zoltán & DE-siroki-05185.jpg \\
\hline 104 & Salix cinerea L. & Bátorliget & 1954 & Siroki Zoltán & DE-siroki-05182.jpg \\
\hline 104 & Salix cinerea L. & Bátorliget & 1954 & Siroki Zoltán & DE-siroki-05184.jpg \\
\hline 104 & Salix cinerea L. & Csaroda & 1954 & Siroki Zoltán & DE-siroki-05183.jpg \\
\hline 104 & Salix cinerea L. & Debrecen & 1950 & Siroki Zoltán & DE-siroki-05178.jpg \\
\hline 104 & Salix cinerea L. & Debrecen & 1950 & Siroki Zoltán & DE-siroki-05196.jpg \\
\hline 104 & Salix cinerea L. & Debrecen & 1950 & Siroki Zoltán & DE-siroki-05177.jpg \\
\hline 104 & Salix cinerea L. & Debrecen & 1950 & Siroki Zoltán & DE-siroki-05181.jpg \\
\hline 104 & Salix cinerea L. & Debrecen & 1954 & Siroki Zoltán & DE-siroki-05180.jpg \\
\hline 104 & Salix cinerea L. & Debrecen & 1955 & Jeney Endre & DE-siroki-05188.jpg \\
\hline 104 & Salix cinerea L. & Gödöllő & 1951 & Siroki Zoltán & DE-siroki-05186.jpg \\
\hline 104 & Salix cinerea L. & Gödöllő & 1951 & Siroki Zoltán & DE-siroki-05187.jpg \\
\hline 104 & Salix cinerea L. & Háromhuta & 1961 & Siroki Zoltán & DE-siroki-05163.jpg \\
\hline 104 & Salix cinerea L. & Háromhuta & 1961 & Siroki Zoltán & DE-siroki-05176.jpg \\
\hline 104 & Salix cinerea L. & Háromhuta & 1961 & Siroki Zoltán & DE-siroki-05189.jpg \\
\hline 104 & Salix cinerea L. & Nyírábrány & 1986 & Siroki Zoltán & DE-siroki-05190.jpg \\
\hline 104 & Salix cinerea L. & Nyírábrány & 1986 & Siroki Zoltán & DE-siroki-05191.jpg \\
\hline 104 & Salix cinerea L. & Nyírábrány & 1986 & Siroki Zoltán & DE-siroki-05192.jpg \\
\hline 104 & Salix cinerea L. & Tarpa & 1955 & Siroki Zoltán & DE-siroki-05179.jpg \\
\hline 105 & Salix aurita L. & Csaroda & 1954 & Siroki Zoltán & DE-siroki-05208.jpg \\
\hline 105 & Salix aurita L. & Csaroda & 1954 & Siroki Zoltán & DE-siroki-05198.jpg \\
\hline 105 & Salix aurita L. & Csaroda & 1960 & Siroki Zoltán & DE-siroki-05197.jpg \\
\hline 105 & Salix aurita L. & Csaroda & 1960 & Siroki Zoltán & DE-siroki-05199.jpg \\
\hline 105 & Salix aurita L. & Csaroda & 1960 & Siroki Zoltán & DE-siroki-05200.jpg \\
\hline 105 & Salix aurita L. & Csaroda & 1960 & Siroki Zoltán & DE-siroki-05202.jpg \\
\hline 105 & Salix aurita L. & Csaroda & 1960 & Siroki Zoltán & DE-siroki-05203.jpg \\
\hline 105 & Salix aurita L. & Csaroda & 1960 & Siroki Zoltán & DE-siroki-05204.jpg \\
\hline 105 & Salix aurita L. & Csaroda & 1960 & Siroki Zoltán & DE-siroki-05206.jpg \\
\hline $99 \times 101$ & Salix purpurea L. $\times$ Salix viminalis L. & Debrecen & 1950 & Siroki Zoltán & DE-siroki-05161.jpg \\
\hline $104 \times 105$ & $\begin{array}{l}\text { Salix } \times \text { multinervis Döll } \\
(\text { S. cinerea } \times \text { aurita })\end{array}$ & Csaroda & - & Simon Tiborné & DE-siroki-05201.jpg \\
\hline 107 & Populus tremula L. & Debrecen & 1947 & Siroki Zoltán & DE-siroki-05167.jpg \\
\hline 107 & Populus tremula L. & Debrecen & 1947 & Siroki Zoltán & DE-siroki-05017.jpg \\
\hline 107 & Populus tremula L. & Kimle & 1962 & Siroki Zoltán & DE-siroki-05021.jpg \\
\hline 107 & Populus tremula L. & Kimle & 1962 & Siroki Zoltán & DE-siroki-05022.jpg \\
\hline 107 & Populus tremula L. & Szigetszentmiklós & 1951 & Siroki Zoltán & DE-siroki-05023.jpg \\
\hline 107 & Populus tremula L. & Szigetszentmiklós & 1951 & Siroki Zoltán & DE-siroki-05024.jpg \\
\hline 107 & Populus tremula L. & Szigetszentmiklós & 1951 & Siroki Zoltán & DE-siroki-05025.jpg \\
\hline
\end{tabular}




\begin{tabular}{|c|c|c|c|c|c|}
\hline $\begin{array}{l}\text { Sorszám / } \\
\text { Number }\end{array}$ & Taxon-név / Taxon-name & $\begin{array}{l}\text { Település / } \\
\text { Settlement }\end{array}$ & $\begin{array}{l}\text { Év / } \\
\text { Year }\end{array}$ & $\begin{array}{l}\text { Gyűjtő / } \\
\text { Collector }\end{array}$ & Fájlnév / File-name \\
\hline 108 & Populus simonii Carrière & Debrecen & 1970 & Siroki Zoltán & DE-siroki-05029.jpg \\
\hline 108 & Populus simonii Carrière & Debrecen & 1970 & Siroki Zoltán & DE-siroki-05030.jpg \\
\hline 114 & Betula pubescens Ehrh. & Bátorliget & 1957 & Siroki Zoltán & DE-siroki-05280.jpg \\
\hline 114 & Betula pubescens Ehrh. & Bátorliget & 1957 & Siroki Zoltán & DE-siroki-05282.jpg \\
\hline 114 & Betula pubescens Ehrh. & Bátorliget & 1957 & Siroki Zoltán & DE-siroki-05283.jpg \\
\hline 114 & Betula pubescens Ehrh. & Bátorliget & 1957 & Siroki Zoltán & DE-siroki-05284.jpg \\
\hline 114 & Betula pubescens Ehrh. & Csaroda & 1954 & Simon Tiborné & DE-siroki-05273.jpg \\
\hline 114 & Betula pubescens Ehrh. & Csaroda & 1954 & Siroki Zoltán & DE-siroki-05285.jpg \\
\hline 114 & Betula pubescens Ehrh. & Csaroda & 1960 & Siroki Zoltán & DE-siroki-05278.jpg \\
\hline 114 & Betula pubescens Ehrh. & Csaroda & 1960 & Siroki Zoltán & DE-siroki-05279.jpg \\
\hline 114 & Betula pubescens Ehrh. & Csaroda & 1960 & Siroki Zoltán & DE-siroki-05281.jpg \\
\hline 116 & Alnus glutinosa (L.) Gaertn. & Gödöllő & 1951 & Siroki Zoltán & DE-siroki-05308.jpg \\
\hline 116 & Alnus glutinosa (L.) Gaertn. & Kállósemjén & 1959 & Siroki Zoltán & DE-siroki-05309.jpg \\
\hline 116 & Alnus glutinosa (L.) Gaertn. & Kállósemjén & 1959 & Siroki Zoltán & DE-siroki-05310.jpg \\
\hline 116 & Alnus glutinosa (L.) Gaertn. & Kállósemjén & 1959 & Siroki Zoltán & DE-siroki-05311.jpg \\
\hline 116 & Alnus glutinosa (L.) Gaertn. & Kállósemjén & 1959 & Siroki Zoltán & DE-siroki-05312.jpg \\
\hline 116 & Alnus glutinosa (L.) Gaertn. & Nagyhuta & 1962 & Siroki Zoltán & DE-siroki-05314.jpg \\
\hline 116 & Alnus glutinosa (L.) Gaertn. & Nagyhuta & 1962 & Siroki Zoltán & DE-siroki-05315.jpg \\
\hline 116 & Alnus glutinosa (L.) Gaertn. & Nagyhuta & 1962 & Siroki Zoltán & DE-siroki-05299.jpg \\
\hline 116 & Alnus glutinosa (L.) Gaertn. & Nagyhuta & 1962 & Siroki Zoltán & DE-siroki-05300.jpg \\
\hline 116 & Alnus glutinosa (L.) Gaertn. & Nagyhuta & 1962 & Siroki Zoltán & DE-siroki-05301.jpg \\
\hline 116 & Alnus glutinosa (L.) Gaertn. & Nagyhuta & 1962 & Siroki Zoltán & DE-siroki-05302.jpg \\
\hline 116 & Alnus glutinosa (L.) Gaertn. & Nagyhuta & 1962 & Siroki Zoltán & DE-siroki-05303.jpg \\
\hline 116 & Alnus glutinosa (L.) Gaertn. & Nagyhuta & 1962 & Siroki Zoltán & DE-siroki-05304.jpg \\
\hline 116 & Alnus glutinosa (L.) Gaertn. & Tiszafüred & 1949 & Siroki Zoltán & DE-siroki-05305.jpg \\
\hline 116 & Alnus glutinosa (L.) Gaertn. & Tiszafüred & 1949 & Siroki Zoltán & DE-siroki-05306.jpg \\
\hline 116 & Alnus glutinosa (L.) Gaertn. & Tiszafüred & 1949 & Siroki Zoltán & DE-siroki-05316.jpg \\
\hline 117 & Alnus incana (L.) Moench & Gödöllő & 1951 & Siroki Zoltán & DE-siroki-05291.jpg \\
\hline 117 & Alnus incana (L.) Moench & Gödöllő & 1951 & Siroki Zoltán & DE-siroki-05292.jpg \\
\hline 117 & Alnus incana (L.) Moench & Gödöllő & 1951 & Siroki Zoltán & DE-siroki-05293.jpg \\
\hline 117 & Alnus incana (L.) Moench & Gödöllő & 1951 & Siroki Zoltán & DE-siroki-05289.jpg \\
\hline 117 & Alnus incana (L.) Moench & Gödöllő & 1951 & Siroki Zoltán & DE-siroki-05290.jpg \\
\hline 117 & Alnus incana (L.) Moench & Gödöllő & 1952 & Siroki Zoltán & DE-siroki-05294.jpg \\
\hline 117 & Alnus incana (L.) Moench & Gödöllő & 1952 & Siroki Zoltán & DE-siroki-05296.jpg \\
\hline 118 & Carpinus betulus L. & "Pilis" & 1951 & Siroki Zoltán & DE-siroki-05257.jpg \\
\hline 118 & Carpinus betulus L. & Budapest & 1960 & Siroki Zoltán & DE-siroki-05256.jpg \\
\hline 118 & Carpinus betulus L. & Háromhuta & 1967 & Siroki Zoltán & DE-siroki-05255.jpg \\
\hline 118 & Carpinus betulus L. & Háromhuta & 1976 & Siroki Zoltán & DE-siroki-05253.jpg \\
\hline 118 & Carpinus betulus L. & Pécs & 1958 & Siroki Zoltán & DE-siroki-05252.jpg \\
\hline 118 & Carpinus betulus L. & Pécs & 1958 & Siroki Zoltán & DE-siroki-05259.jpg \\
\hline 118 & Carpinus betulus L. & Recsk & 1964 & Siroki Zoltán & DE-siroki-05254.jpg \\
\hline 123 & Fagus sylvatica L. & "Nagymező" & 1968 & Siroki Zoltán & DE-siroki-05322.jpg \\
\hline 123 & Fagus sylvatica L. & "Nagymező" & 1968 & Siroki Zoltán & DE-siroki-05323.jpg \\
\hline 123 & Fagus sylvatica L. & "Nagymező" & 1968 & Siroki Zoltán & DE-siroki-05324.jpg \\
\hline 123 & Fagus sylvatica L. & Komlóska & 1973 & Siroki Zoltán & DE-siroki-05320.jpg \\
\hline 123 & Fagus sylvatica L. & Komlóska & 1973 & Siroki Zoltán & DE-siroki-05321.jpg \\
\hline
\end{tabular}




\begin{tabular}{|c|c|c|c|c|c|}
\hline $\begin{array}{l}\text { Sorszám / } \\
\text { Number }\end{array}$ & Taxon-név / Taxon-name & $\begin{array}{l}\text { Település / } \\
\text { Settlement }\end{array}$ & $\begin{array}{l}\text { Év / } \\
\text { Year }\end{array}$ & $\begin{array}{l}\text { Gyűjtő / } \\
\text { Collector }\end{array}$ & Fájlnév / File-name \\
\hline 123 & Fagus sylvatica L. & Szilvásvárad & 1954 & Siroki Zoltán & DE-siroki-05325.jpg \\
\hline 123 & Fagus sylvatica L. & Szilvásvárad & 1954 & Siroki Zoltán & DE-siroki-05326.jpg \\
\hline 123 & Fagus sylvatica L. & Szilvásvárad & 1954 & Siroki Zoltán & DE-siroki-05327.jpg \\
\hline 123 & Fagus sylvatica L. & Szilvásvárad & 1954 & Siroki Zoltán & DE-siroki-05329.jpg \\
\hline 123 & Fagus sylvatica L. & Szilvásvárad & 1954 & Siroki Zoltán & DE-siroki-05330.jpg \\
\hline 123 & Fagus sylvatica L. & Szilvásvárad & 1954 & Siroki Zoltán & DE-siroki-05331.jpg \\
\hline 123 & Fagus sylvatica L. & Szilvásvárad & 1954 & Siroki Zoltán & DE-siroki-05332.jpg \\
\hline 124 & Castanea sativa Mill. & "Szent-György-hegy" & 1955 & Siroki Zoltán & DE-siroki-05343.jpg \\
\hline 124 & Castanea sativa Mill. & "Szent-György-hegy" & 1955 & Siroki Zoltán & DE-siroki-05344.jpg \\
\hline 124 & Castanea sativa Mill. & Budapest & 1967 & Siroki Zoltán & DE-siroki-05338.jpg \\
\hline 124 & Castanea sativa Mill. & Budapest & 1967 & Siroki Zoltán & DE-siroki-05339.jpg \\
\hline 124 & Castanea sativa Mill. & Budapest & 1967 & Siroki Zoltán & DE-siroki-05340.jpg \\
\hline 124 & Castanea sativa Mill. & Budapest & 1967 & Siroki Zoltán & DE-siroki-05341.jpg \\
\hline 124 & Castanea sativa Mill. & Budapest & 1967 & Siroki Zoltán & DE-siroki-05342.jpg \\
\hline 124 & Castanea sativa Mill. & Debrecen & 1979 & Siroki Zoltán & DE-siroki-05336.jpg \\
\hline 124 & Castanea sativa Mill. & Debrecen & 1979 & Siroki Zoltán & DE-siroki-05337.jpg \\
\hline 124 & Castanea sativa Mill. & Nagymaros & 1950 & Kárpáti Zoltán & DE-siroki-05346.jpg \\
\hline 124 & Castanea sativa Mill. & Pécs & 1954 & Siroki Zoltán & DE-siroki-05334.jpg \\
\hline 124 & Castanea sativa Mill. & Pécs & 1954 & Siroki Zoltán & DE-siroki-05335.jpg \\
\hline 124 & Castanea sativa Mill. & Pécs & 1954 & Siroki Zoltán & DE-siroki-05347.jpg \\
\hline 124 & Castanea sativa Mill. & Pécs & 1954 & Siroki Zoltán & DE-siroki-05348.jpg \\
\hline 124 & Castanea sativa Mill. & Pomáz & 1952 & Siroki Zoltán & DE-siroki-05345.jpg \\
\hline 125 & Quercus cerris L. & "Vértes" & 1957 & Siroki Zoltán & DE-siroki-05372.jpg \\
\hline 125 & Quercus cerris L. & Budaörs & 1985 & Siroki Zoltán & DE-siroki-05365.jpg \\
\hline 125 & Quercus cerris L. & Budaörs & 1985 & Siroki Zoltán & DE-siroki-05366.jpg \\
\hline 125 & Quercus cerris L. & Budaörs & 1985 & Siroki Zoltán & DE-siroki-05367.jpg \\
\hline 125 & Quercus cerris L. & Budapest & 1948 & Siroki Zoltán & DE-siroki-05363.jpg \\
\hline 125 & Quercus cerris L. & Budapest & 1948 & Siroki Zoltán & DE-siroki-05369.jpg \\
\hline 125 & Quercus cerris L. & Budapest & 1950 & Siroki Zoltán & DE-siroki-05368.jpg \\
\hline 125 & Quercus cerris L. & Budapest & 1960 & Siroki Zoltán & DE-siroki-05364.jpg \\
\hline 125 & Quercus cerris L. & Budapest & 1960 & Siroki Zoltán & DE-siroki-05374.jpg \\
\hline 125 & Quercus cerris L. & Budapest & 1960 & Siroki Zoltán & DE-siroki-05375.jpg \\
\hline 125 & Quercus cerris L. & Budapest & 1964 & Siroki Zoltán & DE-siroki-05359.jpg \\
\hline 125 & Quercus cerris L. & Budapest & 1983 & Siroki Zoltán & DE-siroki-05361.jpg \\
\hline 125 & Quercus cerris L. & Debrecen & 1948 & Siroki Zoltán & DE-siroki-05362.jpg \\
\hline 125 & Quercus cerris L. & Debrecen & 1948 & Siroki Zoltán & DE-siroki-05373.jpg \\
\hline 125 & Quercus cerris L. & Egerbakta & 1968 & Siroki Zoltán & DE-siroki-05356.jpg \\
\hline 125 & Quercus cerris L. & Egerbakta & 1968 & Siroki Zoltán & DE-siroki-05357.jpg \\
\hline 125 & Quercus cerris L. & Egerbakta & 1968 & Siroki Zoltán & DE-siroki-05358.jpg \\
\hline 125 & Quercus cerris L. & Egerbakta & 1968 & Siroki Zoltán & DE-siroki-05360.jpg \\
\hline 125 & Quercus cerris L. & Pilisszentlászló & 1913 & Degen Árpád & DE-siroki-05355.jpg \\
\hline 125 & Quercus cerris L. & Uzsa & 1970 & Siroki Zoltán & DE-siroki-05370.jpg \\
\hline 125 & Quercus cerris L. & Uzsa & 1970 & Siroki Zoltán & DE-siroki-05376.jpg \\
\hline 125 & Quercus cerris L. & Uzsa & 1970 & Siroki Zoltán & DE-siroki-05377.jpg \\
\hline 126 & Quercus rubra L. & Háromhuta & 1960 & Siroki Zoltán & DE-siroki-05441.jpg \\
\hline 126 & Quercus rubra L. & Háromhuta & 1960 & Siroki Zoltán & DE-siroki-05444.jpg \\
\hline
\end{tabular}




\begin{tabular}{|c|c|c|c|c|c|}
\hline $\begin{array}{l}\text { Sorszám / } \\
\text { Number }\end{array}$ & Taxon-név / Taxon-name & $\begin{array}{l}\text { Település / } \\
\text { Settlement }\end{array}$ & $\begin{array}{l}\text { Év / } \\
\text { Year }\end{array}$ & $\begin{array}{l}\text { Gyűjtő / } \\
\text { Collector }\end{array}$ & Fájlnév / File-name \\
\hline 126 & Quercus rubra L. & Háromhuta & 1960 & Siroki Zoltán & DE-siroki-05445.jpg \\
\hline 126 & Quercus rubra L. & Pécs & 1954 & Siroki Zoltán & DE-siroki-05442.jpg \\
\hline 126 & Quercus rubra L. & Pécs & 1954 & Siroki Zoltán & DE-siroki-05443.jpg \\
\hline 126 & Quercus rubra L. & Pécs & - & Siroki Zoltán & DE-siroki-05446.jpg \\
\hline 128 & Quercus robur L. & Csaroda & 1960 & Siroki Zoltán & DE-siroki-05431.jpg \\
\hline 128 & Quercus robur L. & Csaroda & 1960 & Siroki Zoltán & DE-siroki-05436.jpg \\
\hline 128 & Quercus robur L. & Debrecen & 1947 & Siroki Zoltán & DE-siroki-05430.jpg \\
\hline 128 & Quercus robur L. & Debrecen & 1950 & Siroki Zoltán & DE-siroki-05429.jpg \\
\hline 128 & Quercus robur L. & Debrecen & 1950 & Siroki Zoltán & DE-siroki-05435.jpg \\
\hline 128 & Quercus robur L. & Debrecen & 1950 & Siroki Zoltán & DE-siroki-05438.jpg \\
\hline 128 & Quercus robur L. & Gödöllő & 1951 & Siroki Zoltán & DE-siroki-05433.jpg \\
\hline 128 & Quercus robur L. & Gödöllő & 1951 & Siroki Zoltán & DE-siroki-05434.jpg \\
\hline 128 & Quercus robur L. & Gödöllő & 1952 & Siroki Zoltán & DE-siroki-05437.jpg \\
\hline 128 & Quercus robur L. & Recsk & 1964 & Siroki Zoltán & DE-siroki-05432.jpg \\
\hline 129 & Quercus petraea agg. & Aggtelek & 1972 & Siroki Zoltán & DE-siroki-05409.jpg \\
\hline 129 & Quercus petraea agg. & Budapest & 1912 & Bocskay Ottó & DE-siroki-05424.jpg \\
\hline 129 & Quercus petraea agg. & Budapest & 1964 & Siroki Zoltán & DE-siroki-05415.jpg \\
\hline 129 & Quercus petraea agg. & Budapest & 1964 & Siroki Zoltán & DE-siroki-05416.jpg \\
\hline 129 & Quercus petraea agg. & Budapest & 1964 & Siroki Zoltán & DE-siroki-05417.jpg \\
\hline 129 & Quercus petraea agg. & Budapest & 1964 & Siroki Zoltán & DE-siroki-05418.jpg \\
\hline 129 & Quercus petraea agg. & Budapest & 1964 & Siroki Zoltán & DE-siroki-05419.jpg \\
\hline 129 & Quercus petraea agg. & Budapest & 1964 & Siroki Zoltán & DE-siroki-05420.jpg \\
\hline 129 & Quercus petraea agg. & Budapest & 1985 & Siroki Zoltán & DE-siroki-05423.jpg \\
\hline 129 & Quercus petraea agg. & Egerbakta & 1968 & Siroki Zoltán & DE-siroki-05421.jpg \\
\hline 129 & Quercus petraea agg. & Egerbakta & 1968 & Siroki Zoltán & DE-siroki-05422.jpg \\
\hline 129 & Quercus petraea agg. & Háromhuta & 1967 & Siroki Zoltán & DE-siroki-05410.jpg \\
\hline 129 & Quercus petraea agg. & Háromhuta & 1967 & Siroki Zoltán & DE-siroki-05411.jpg \\
\hline 129 & Quercus petraea agg. & Háromhuta & 1967 & Siroki Zoltán & DE-siroki-05412.jpg \\
\hline 129 & Quercus petraea agg. & Háromhuta & 1967 & Siroki Zoltán & DE-siroki-05413.jpg \\
\hline 129 & Quercus petraea agg. & Háromhuta & 1967 & Siroki Zoltán & DE-siroki-05414.jpg \\
\hline 129 & Quercus petraea agg. & Szilvásvárad & 1959 & Siroki Zoltán & DE-siroki-05406.jpg \\
\hline 129 & Quercus petraea agg. & Szilvásvárad & 1959 & Siroki Zoltán & DE-siroki-05408.jpg \\
\hline 129 & Quercus petraea agg. & Szilvásvárad & 1959 & Siroki Zoltán & DE-siroki-05425.jpg \\
\hline 129 & Quercus petraea agg. & Szilvásvárad & 1959 & Siroki Zoltán & DE-siroki-05426.jpg \\
\hline 131 & Quercus pubescens agg. & "Vértes" & 1957 & Siroki Zoltán & DE-siroki-05386.jpg \\
\hline 131 & Quercus pubescens agg. & "Vértes" & 1957 & Siroki Zoltán & DE-siroki-05387.jpg \\
\hline 131 & Quercus pubescens agg. & "Vértes" & 1957 & Siroki Zoltán & DE-siroki-05397.jpg \\
\hline 131 & Quercus pubescens agg. & "Vértes" & 1957 & Siroki Zoltán & DE-siroki-05399.jpg \\
\hline 131 & Quercus pubescens agg. & "Vértes" & 1957 & Siroki Zoltán & DE-siroki-05400.jpg \\
\hline 131 & Quercus pubescens agg. & Budaörs & 1985 & Siroki Zoltán & DE-siroki-05391.jpg \\
\hline 131 & Quercus pubescens agg. & Budaörs & 1985 & Siroki Zoltán & DE-siroki-05395.jpg \\
\hline 131 & Quercus pubescens agg. & Budapest & 1950 & Siroki Zoltán & DE-siroki-05404.jpg \\
\hline 131 & Quercus pubescens agg. & Budapest & 1950 & Siroki Zoltán & DE-siroki-05402.jpg \\
\hline 131 & Quercus pubescens agg. & Budapest & 1960 & Siroki Zoltán & DE-siroki-05392.jpg \\
\hline 131 & Quercus pubescens agg. & Budapest & 1964 & Siroki Zoltán & DE-siroki-05388.jpg \\
\hline 131 & Quercus pubescens agg. & Budapest & 1964 & Siroki Zoltán & DE-siroki-05389.jpg \\
\hline
\end{tabular}




\begin{tabular}{|c|c|c|c|c|c|}
\hline $\begin{array}{l}\text { Sorszám / } \\
\text { Number }\end{array}$ & Taxon-név / Taxon-name & $\begin{array}{l}\text { Település / } \\
\text { Settlement }\end{array}$ & $\begin{array}{l}\text { Év / } \\
\text { Year }\end{array}$ & $\begin{array}{l}\text { Gyűjtő / } \\
\text { Collector }\end{array}$ & Fájlnév / File-name \\
\hline 131 & Quercus pubescens agg. & Budapest & 1970 & Siroki Zoltán & DE-siroki-05401.jpg \\
\hline 131 & Quercus pubescens agg. & Egerbakta & 1968 & Siroki Zoltán & DE-siroki-05396.jpg \\
\hline 131 & Quercus pubescens agg. & Keszthely & 1955 & Siroki Zoltán & DE-siroki-05390.jpg \\
\hline 132 & Ulmus laevis Pall. & Debrecen & 1947 & Siroki Zoltán & DE-siroki-05468.jpg \\
\hline 132 & Ulmus laevis Pall. & Debrecen & 1950 & Siroki Zoltán & DE-siroki-05457.jpg \\
\hline 132 & Ulmus laevis Pall. & Debrecen & 1950 & Siroki Zoltán & DE-siroki-05458.jpg \\
\hline 132 & Ulmus laevis Pall. & Debrecen & 1950 & Siroki Zoltán & DE-siroki-05459.jpg \\
\hline 132 & Ulmus laevis Pall. & Debrecen & 1950 & Siroki Zoltán & DE-siroki-05460.jpg \\
\hline 132 & Ulmus laevis Pall. & Debrecen & 1950 & Siroki Zoltán & DE-siroki-05461.jpg \\
\hline 132 & Ulmus laevis Pall. & Debrecen & 1950 & Siroki Zoltán & DE-siroki-05462.jpg \\
\hline 132 & Ulmus laevis Pall. & Debrecen & 1950 & Siroki Zoltán & DE-siroki-05464.jpg \\
\hline 132 & Ulmus laevis Pall. & Debrecen & 1950 & Siroki Zoltán & DE-siroki-05465.jpg \\
\hline 132 & Ulmus laevis Pall. & Debrecen & 1950 & Siroki Zoltán & DE-siroki-05466.jpg \\
\hline 132 & Ulmus laevis Pall. & Pásztó & 1952 & Siroki Zoltán & DE-siroki-05463.jpg \\
\hline 132 & Ulmus laevis Pall. & Recsk & 1964 & Siroki Zoltán & DE-siroki-05454.jpg \\
\hline 132 & Ulmus laevis Pall. & Recsk & 1964 & Siroki Zoltán & DE-siroki-05455.jpg \\
\hline 132 & Ulmus laevis Pall. & Recsk & 1964 & Siroki Zoltán & DE-siroki-05456.jpg \\
\hline 133 & Ulmus glabra Huds. & Debrecen & 1950 & Siroki Zoltán & DE-siroki-05469.jpg \\
\hline 133 & Ulmus glabra Huds. & Egyek & 1975 & Siroki Zoltán & DE-siroki-05472.jpg \\
\hline 133 & Ulmus glabra Huds. & Martonvásár & 1954 & Gondola István & DE-siroki-05470.jpg \\
\hline 133 & Ulmus glabra Huds. & Martonvásár & 1954 & Gondola István & DE-siroki-05471.jpg \\
\hline 136 & Celtis australis L. & Debrecen & 1977 & Siroki Zoltán & DE-siroki-05474.jpg \\
\hline 139 & Morus alba L. & Debrecen & 1947 & Siroki Zoltán & DE-siroki-05475.jpg \\
\hline 139 & Morus alba L. & Debrecen & 1947 & Siroki Zoltán & DE-siroki-05476.jpg \\
\hline 142 & Ficus carica L. & Sárbogárd & 1952 & Gondola István & DE-siroki-05479.jpg \\
\hline 143 & Humulus lupulus L. & Mosonmagyaróvár & 1939 & Siroki Zoltán & DE-siroki-05478.jpg \\
\hline 144 & Humulus scandens (Lour.) Merr. & Debrecen & 1972 & Siroki Zoltán & DE-siroki-05480.jpg \\
\hline 144 & Humulus scandens (Lour.) Merr. & Debrecen & 1972 & Siroki Zoltán & DE-siroki-05481.jpg \\
\hline 144 & Humulus scandens (Lour.) Merr. & Debrecen & 1972 & Siroki Zoltán & DE-siroki-05482.jpg \\
\hline 145 & Cannabis sativa L. & Debrecen & 1947 & Siroki Zoltán & DE-siroki-05484.jpg \\
\hline 148 & Urtica kioviensis Rogow. & Csaroda & 1959 & Siroki Zoltán & DE-siroki-05489.jpg \\
\hline 148 & Urtica kioviensis Rogow. & Csaroda & 1959 & Siroki Zoltán & DE-siroki-05490.jpg \\
\hline 148 & Urtica kioviensis Rogow. & Csaroda & 1959 & Siroki Zoltán & DE-siroki-05491.jpg \\
\hline 148 & Urtica kioviensis Rogow. & Csaroda & 1959 & Siroki Zoltán & DE-siroki-05492.jpg \\
\hline 148 & Urtica kioviensis Rogow. & Csaroda & 1959 & Siroki Zoltán & DE-siroki-05493.jpg \\
\hline 148 & Urtica kioviensis Rogow. & Csaroda & 1959 & Siroki Zoltán & DE-siroki-05494.jpg \\
\hline 148 & Urtica kioviensis Rogow. & Csaroda & 1959 & Siroki Zoltán & DE-siroki-05495.jpg \\
\hline 148 & Urtica kioviensis Rogow. & Csaroda & 1959 & Siroki Zoltán & DE-siroki-05496.jpg \\
\hline 148 & Urtica kioviensis Rogow. & Csaroda & 1960 & Siroki Zoltán & DE-siroki-05497.jpg \\
\hline 148 & Urtica kioviensis Rogow. & Csaroda & 1960 & Siroki Zoltán & DE-siroki-05498.jpg \\
\hline 148 & Urtica kioviensis Rogow. & Csaroda & 1960 & Siroki Zoltán & DE-siroki-05499.jpg \\
\hline 148 & Urtica kioviensis Rogow. & Csaroda & 1960 & Siroki Zoltán & DE-siroki-05500.jpg \\
\hline 148 & Urtica kioviensis Rogow. & Csaroda & 1960 & Siroki Zoltán & DE-siroki-05501.jpg \\
\hline 148 & Urtica kioviensis Rogow. & Csaroda & 1960 & Siroki Zoltán & DE-siroki-05502.jpg \\
\hline 148 & Urtica kioviensis Rogow. & Csaroda & 1960 & Siroki Zoltán & DE-siroki-05503.jpg \\
\hline 149 & Parietaria officinalis L. & Budapest & 1944 & Siroki Zoltán & DE-siroki-05511.jpg \\
\hline
\end{tabular}




\begin{tabular}{|c|c|c|c|c|c|}
\hline $\begin{array}{l}\text { Sorszám / } \\
\text { Number }\end{array}$ & Taxon-név / Taxon-name & $\begin{array}{l}\text { Település / } \\
\text { Settlement }\end{array}$ & $\begin{array}{l}\text { Év / } \\
\text { Year }\end{array}$ & $\begin{array}{l}\text { Gyűjtő / } \\
\text { Collector }\end{array}$ & Fájlnév / File-name \\
\hline 149 & Parietaria officinalis L. & Mosonmagyaróvár & 1939 & Siroki Zoltán & DE-siroki-05510.jpg \\
\hline 149 & Parietaria officinalis L. & Nagyvisnyó & 1966 & Siroki Zoltán & DE-siroki-05509.jpg \\
\hline 151 & Thesium ramosum Hayne & Abaújszántó & 1944 & Siroki Zoltán & DE-siroki-05561.jpg \\
\hline 151 & Thesium ramosum Hayne & Budapest & 1904 & $\begin{array}{l}\text { Thaisz Lajos - } \\
\text { Baán Lajos }\end{array}$ & DE-siroki-05560.jpg \\
\hline 151 & Thesium ramosum Hayne & Budapest & 1905 & Thaisz Lajos & DE-siroki-05559.jpg \\
\hline 151 & Thesium ramosum Hayne & Budapest & 1951 & Siroki Zoltán & DE-siroki-05553.jpg \\
\hline 151 & Thesium ramosum Hayne & Debrecen & 1950 & Siroki Zoltán & DE-siroki-05548.jpg \\
\hline 151 & Thesium ramosum Hayne & Debrecen & 1950 & Siroki Zoltán & DE-siroki-05552.jpg \\
\hline 151 & Thesium ramosum Hayne & Debrecen & 1980 & Siroki Zoltán & DE-siroki-05556.jpg \\
\hline 151 & Thesium ramosum Hayne & Debrecen & 1980 & Siroki Zoltán & DE-siroki-05557.jpg \\
\hline 151 & Thesium ramosum Hayne & Debrecen & 1980 & Siroki Zoltán & DE-siroki-05558.jpg \\
\hline 151 & Thesium ramosum Hayne & Egyek & 1948 & Siroki Zoltán & DE-siroki-05562.jpg \\
\hline 151 & Thesium ramosum Hayne & Egyek & 1948 & Siroki Zoltán & DE-siroki-05551.jpg \\
\hline 151 & Thesium ramosum Hayne & Egyek & 1948 & Siroki Zoltán & DE-siroki-05550.jpg \\
\hline 151 & Thesium ramosum Hayne & Gödöllő & 1952 & Siroki Zoltán & DE-siroki-05549.jpg \\
\hline 151 & Thesium ramosum Hayne & Kecskemét & 1969 & Siroki Zoltán & DE-siroki-05555.jpg \\
\hline 153 & Thesium linophyllon L. & "Háromkő" & 1958 & Siroki Zoltán & DE-siroki-05537.jpg \\
\hline 153 & Thesium linophyllon L. & "Háromkő" & 1958 & Siroki Zoltán & DE-siroki-05540.jpg \\
\hline 153 & Thesium linophyllon L. & "Nagymező" & 1959 & Siroki Zoltán & DE-siroki-05533.jpg \\
\hline 153 & Thesium linophyllon L. & "Nagymező" & 1959 & Siroki Zoltán & DE-siroki-05534.jpg \\
\hline 153 & Thesium linophyllon L. & "Nagymező" & 1959 & Siroki Zoltán & DE-siroki-05544.jpg \\
\hline 153 & Thesium linophyllon L. & Budapest & 1904 & Kocsis István & DE-siroki-05535.jpg \\
\hline 153 & Thesium linophyllon L. & Háromhuta & 1965 & Siroki Zoltán & DE-siroki-05542.jpg \\
\hline 153 & Thesium linophyllon L. & Háromhuta & 1965 & Siroki Zoltán & DE-siroki-05543.jpg \\
\hline 153 & Thesium linophyllon L. & Háromhuta & 1965 & Siroki Zoltán & DE-siroki-05554.jpg \\
\hline 153 & Thesium linophyllon L. & Szalafő & 1955 & Kovács Margit & DE-siroki-05541.jpg \\
\hline 153 & Thesium linophyllon L. & Üröm & 1911 & Kocsis István & DE-siroki-05536.jpg \\
\hline 154 & Thesium bavarum Schrank & Sopron & 1950 & Kárpáti Zoltán & DE-siroki-05532.jpg \\
\hline 155 & Loranthus europaeus Jacq. & Debrecen & 1947 & Siroki Zoltán & DE-siroki-05515.jpg \\
\hline 155 & Loranthus europaeus Jacq. & Pécs & 1958 & Siroki Zoltán & DE-siroki-05514.jpg \\
\hline 156 & Viscum album L. & Vásárosnamény & 1982 & Siroki Zoltán & DE-siroki-05516.jpg \\
\hline 156 & Viscum album L. & Vásárosnamény & 1982 & Siroki Zoltán & DE-siroki-05517.jpg \\
\hline 156 & Viscum album L. & Vásárosnamény & 1982 & Siroki Zoltán & DE-siroki-05518.jpg \\
\hline 157 & Asarum europaeum L. & "Fáni-völgy" & 1955 & Siroki Zoltán & DE-siroki-05568.jpg \\
\hline 157 & Asarum europaeum L. & Bátorliget & 1954 & Siroki Zoltán & DE-siroki-05567.jpg \\
\hline 157 & Asarum europaeum L. & Bátorliget & 1954 & Siroki Zoltán & DE-siroki-05577.jpg \\
\hline 157 & Asarum europaeum L. & Füzérradvány & 1973 & Siroki Zoltán & DE-siroki-05575.jpg \\
\hline 157 & Asarum europaeum L. & Füzérradvány & 1973 & Siroki Zoltán & DE-siroki-05576.jpg \\
\hline 157 & Asarum europaeum L. & Miskolc & 1966 & Siroki Zoltán & DE-siroki-05569.jpg \\
\hline 157 & Asarum europaeum L. & Miskolc & 1966 & Siroki Zoltán & DE-siroki-05570.jpg \\
\hline 157 & Asarum europaeum L. & Miskolc & 1966 & Siroki Zoltán & DE-siroki-05571.jpg \\
\hline 157 & Asarum europaeum L. & Miskolc & 1966 & Siroki Zoltán & DE-siroki-05572.jpg \\
\hline 157 & Asarum europaeum L. & Miskolc & 1966 & Siroki Zoltán & DE-siroki-05573.jpg \\
\hline 157 & Asarum europaeum L. & Miskolc & 1966 & Siroki Zoltán & DE-siroki-05574.jpg \\
\hline 158 & Aristolochia clematitis L. & Debrecen & 1947 & Siroki Zoltán & DE-siroki-05580.jpg \\
\hline 158 & Aristolochia clematitis L. & Debrecen & 1947 & Siroki Zoltán & DE-siroki-05581.jpg \\
\hline
\end{tabular}




\begin{tabular}{|c|c|c|c|c|c|}
\hline $\begin{array}{l}\text { Sorszám / } \\
\text { Number }\end{array}$ & Taxon-név / Taxon-name & $\begin{array}{l}\text { Település / } \\
\text { Settlement }\end{array}$ & $\begin{array}{l}\text { Év / } \\
\text { Year }\end{array}$ & $\begin{array}{l}\text { Gyűjtő / } \\
\text { Collector }\end{array}$ & Fájlnév / File-name \\
\hline 159 & Persicaria amphibia (L.) Delarbre & Hortobágy & 1948 & Siroki Zoltán & DE-siroki-05774.jpg \\
\hline 159 & Persicaria amphibia (L.) Delarbre & Mikepércs & 1965 & Siroki Zoltán & DE-siroki-05777.jpg \\
\hline 159 & Persicaria amphibia (L.) Delarbre & Újszentmargita & 1963 & Siroki Zoltán & DE-siroki-05776.jpg \\
\hline 160 & Persicaria bistorta (L.) Samp. & Rakaca & 1982 & Siroki Zoltán & DE-siroki-05759.jpg \\
\hline 160 & Persicaria bistorta (L.) Samp. & Rakaca & 1982 & Siroki Zoltán & DE-siroki-05760.jpg \\
\hline 160 & Persicaria bistorta (L.) Samp. & Rakaca & 1982 & Siroki Zoltán & DE-siroki-05761.jpg \\
\hline 160 & Persicaria bistorta (L.) Samp. & Rakaca & 1982 & Siroki Zoltán & DE-siroki-05762.jpg \\
\hline 160 & Persicaria bistorta (L.) Samp. & Rakaca & 1982 & Siroki Zoltán & DE-siroki-05763.jpg \\
\hline 160 & Persicaria bistorta (L.) Samp. & Rakaca & 1985 & Siroki Zoltán & DE-siroki-05753.jpg \\
\hline 160 & Persicaria bistorta (L.) Samp. & Rakaca & 1985 & Siroki Zoltán & DE-siroki-05754.jpg \\
\hline 161 & Persicaria lapathifolia (L.) Delarbre & Debrecen & 1949 & Siroki Zoltán & DE-siroki-05780.jpg \\
\hline 161 & Persicaria lapathifolia (L.) Delarbre & Debrecen & 1957 & Siroki Zoltán & DE-siroki-05781.jpg \\
\hline 161 & Persicaria lapathifolia (L.) Delarbre & Debrecen & 1968 & Siroki Zoltán & DE-siroki-05782.jpg \\
\hline 161 & Persicaria lapathifolia (L.) Delarbre & Debrecen & 1968 & Siroki Zoltán & DE-siroki-05783.jpg \\
\hline 161 & Persicaria lapathifolia (L.) Delarbre & Debrecen & 1968 & Siroki Zoltán & DE-siroki-05784.jpg \\
\hline 161 & Persicaria lapathifolia (L.) Delarbre & Debrecen & 1968 & Siroki Zoltán & DE-siroki-05785.jpg \\
\hline 161 & Persicaria lapathifolia (L.) Delarbre & Debrecen & 1968 & Siroki Zoltán & DE-siroki-05786.jpg \\
\hline 161 & Persicaria lapathifolia (L.) Delarbre & Debrecen & 1978 & Siroki Zoltán & DE-siroki-05779.jpg \\
\hline 161 & Persicaria lapathifolia (L.) Delarbre & Hortobágy & 1948 & Siroki Zoltán & DE-siroki-05778.jpg \\
\hline 161 & Persicaria lapathifolia (L.) Delarbre & Mosonmagyaróvár & 1939 & Siroki Zoltán & DE-siroki-05792.jpg \\
\hline 161 & Persicaria lapathifolia (L.) Delarbre & Mosonmagyaróvár & 1939 & Siroki Zoltán & DE-siroki-05787.jpg \\
\hline 161 & Persicaria lapathifolia (L.) Delarbre & Mosonmagyaróvár & 1939 & Siroki Zoltán & DE-siroki-05791.jpg \\
\hline 162 & Persicaria maculosa Gray & Debrecen & 1949 & Siroki Zoltán & DE-siroki-05793.jpg \\
\hline 162 & Persicaria maculosa Gray & Mosonmagyaróvár & 1939 & Siroki Zoltán & DE-siroki-05797.jpg \\
\hline 164 & Persicaria hydropiper (L.) Delarbre & Debrecen & 1947 & Siroki Zoltán & DE-siroki-05808.jpg \\
\hline 164 & Persicaria hydropiper (L.) Delarbre & Debrecen & 1948 & Siroki Zoltán & DE-siroki-05809.jpg \\
\hline 164 & Persicaria hydropiper (L.) Delarbre & Miskolc & 1959 & Siroki Zoltán & DE-siroki-05815.jpg \\
\hline 164 & Persicaria hydropiper (L.) Delarbre & Mosonmagyaróvár & 1939 & Siroki Zoltán & DE-siroki-05816.jpg \\
\hline 164 & Persicaria hydropiper (L.) Delarbre & Tiszacsege & 1963 & Siroki Zoltán & DE-siroki-05812.jpg \\
\hline 164 & Persicaria hydropiper (L.) Delarbre & Tiszacsege & 1963 & Siroki Zoltán & DE-siroki-05814.jpg \\
\hline 164 & Persicaria hydropiper (L.) Delarbre & Tiszacsege & - & Siroki Zoltán & DE-siroki-05813.jpg \\
\hline 165 & Persicaria dubia (Stein) Fourr. & Gyula & 1974 & Siroki Zoltán & DE-siroki-05805.jpg \\
\hline 165 & Persicaria dubia (Stein) Fourr. & Gyula & 1974 & Siroki Zoltán & DE-siroki-05806.jpg \\
\hline 165 & Persicaria dubia (Stein) Fourr. & Gyula & 1974 & Siroki Zoltán & DE-siroki-05807.jpg \\
\hline 165 & Persicaria dubia (Stein) Fourr. & Mosonmagyaróvár & 1939 & Siroki Zoltán & DE-siroki-05803.jpg \\
\hline 166 & Persicaria minor (Huds.) Opiz & Debrecen & 1950 & Siroki Zoltán & DE-siroki-05801.jpg \\
\hline 166 & Persicaria minor (Huds.) Opiz & Debrecen & 1978 & Siroki Zoltán & DE-siroki-05798.jpg \\
\hline 166 & Persicaria minor (Huds.) Opiz & Debrecen & 1978 & Siroki Zoltán & DE-siroki-05799.jpg \\
\hline 166 & Persicaria minor (Huds.) Opiz & Hortobágy & 1976 & Siroki Zoltán & DE-siroki-05800.jpg \\
\hline 167 & Polygonum arenarium Waldst. et Kit. & Ágasegyháza & 1969 & Siroki Zoltán & DE-siroki-05827.jpg \\
\hline 167 & Polygonum arenarium Waldst. et Kit. & Ágasegyháza & 1969 & Siroki Zoltán & DE-siroki-05828.jpg \\
\hline 167 & Polygonum arenarium Waldst. et Kit. & Ágasegyháza & 1969 & Siroki Zoltán & DE-siroki-05829.jpg \\
\hline 167 & Polygonum arenarium Waldst. et Kit. & Budapest & 1941 & Siroki Zoltán & DE-siroki-05830.jpg \\
\hline 167 & Polygonum arenarium Waldst. et Kit. & Debrecen & 1946 & Siroki Zoltán & DE-siroki-05824.jpg \\
\hline 167 & Polygonum arenarium Waldst. et Kit. & Debrecen & 1947 & Siroki Zoltán & DE-siroki-05831.jpg \\
\hline 167 & Polygonum arenarium Waldst. et Kit. & Debrecen & 1953 & Siroki Zoltán & DE-siroki-05822.jpg \\
\hline
\end{tabular}




\begin{tabular}{|c|c|c|c|c|c|}
\hline $\begin{array}{l}\text { Sorszám / } \\
\text { Number }\end{array}$ & Taxon-név / Taxon-name & $\begin{array}{l}\text { Település / } \\
\text { Settlement }\end{array}$ & $\begin{array}{l}\text { Év / } \\
\text { Year }\end{array}$ & $\begin{array}{l}\text { Gyűjtő / } \\
\text { Collector }\end{array}$ & Fájlnév / File-name \\
\hline 167 & Polygonum arenarium Waldst. et Kit. & Debrecen & 1953 & Siroki Zoltán & DE-siroki-05823.jpg \\
\hline 167 & Polygonum arenarium Waldst. et Kit. & Pilisszentiván & 1950 & Siroki Zoltán & DE-siroki-05832.jpg \\
\hline 167 & Polygonum arenarium Waldst. et Kit. & Vámospércs & 1984 & Siroki Zoltán & DE-siroki-05825.jpg \\
\hline 167 & Polygonum arenarium Waldst. et Kit. & Vámospércs & 1984 & Siroki Zoltán & DE-siroki-05826.jpg \\
\hline 167 & Polygonum arenarium Waldst. et Kit. & Vámospércs & 1985 & Siroki Zoltán & DE-siroki-05820.jpg \\
\hline 167 & Polygonum arenarium Waldst. et Kit. & Vámospércs & 1985 & Siroki Zoltán & DE-siroki-05821.jpg \\
\hline 168 & Polygonum bellardii All. & Budapest & 1951 & Siroki Zoltán & DE-siroki-05835.jpg \\
\hline 168 & Polygonum bellardii All. & Budapest & 1951 & Siroki Zoltán & DE-siroki-05836.jpg \\
\hline 168 & Polygonum bellardii All. & Budapest & 1951 & Siroki Zoltán & DE-siroki-05837.jpg \\
\hline 168 & Polygonum bellardii All. & Budapest & 1951 & Siroki Zoltán & DE-siroki-05834.jpg \\
\hline 168 & Polygonum bellardii All. & Kecskemét & 1913 & Degen Árpád & DE-siroki-05833.jpg \\
\hline 169 & Polygonum graminifolium Wierzb. & Budapest & 1917 & Zsák Zoltán & DE-siroki-05839.jpg \\
\hline 172 & Polygonum aviculare L. & Budapest & 1951 & Siroki Zoltán & DE-siroki-05851.jpg \\
\hline 172 & Polygonum aviculare L. & Budapest & 1951 & Siroki Zoltán & DE-siroki-05852.jpg \\
\hline 172 & Polygonum aviculare L. & Budapest & 1951 & Siroki Zoltán & DE-siroki-05840.jpg \\
\hline 172 & Polygonum aviculare L. & Budapest & 1951 & Siroki Zoltán & DE-siroki-05849.jpg \\
\hline 172 & Polygonum aviculare L. & Hortobágy & 1947 & Siroki Zoltán & DE-siroki-05847.jpg \\
\hline 172 & Polygonum aviculare L. & Hortobágy & 1947 & Siroki Zoltán & DE-siroki-05848.jpg \\
\hline 172 & Polygonum aviculare L. & Hortobágy & 1947 & Siroki Zoltán & DE-siroki-05850.jpg \\
\hline 172 & Polygonum aviculare L. & Hortobágy & 1975 & Siroki Zoltán & DE-siroki-05846.jpg \\
\hline 172 & Polygonum aviculare L. & Hortobágy & 1975 & Siroki Zoltán & DE-siroki-05853.jpg \\
\hline 172 & Polygonum aviculare L. & Hortobágy & 1975 & Siroki Zoltán & DE-siroki-05854.jpg \\
\hline 172 & Polygonum aviculare L. & Hortobágy & 1975 & Siroki Zoltán & DE-siroki-05855.jpg \\
\hline 172 & Polygonum aviculare L. & Hortobágy & 1975 & Siroki Zoltán & DE-siroki-05856.jpg \\
\hline 172 & Polygonum aviculare L. & Mosonmagyaróvár & 1939 & Siroki Zoltán & DE-siroki-05844.jpg \\
\hline 179 & Fallopia convolvulus (L.) A. Löve & Mosonmagyaróvár & 1939 & Siroki Zoltán & DE-siroki-05858.jpg \\
\hline 180 & Fagopyrum esculentum Moench & Budapest & 1904 & Kocsis István & DE-siroki-05860.jpg \\
\hline 185 & Rumex acetosella L. & Debrecen & 1948 & Siroki Zoltán & DE-siroki-05724.jpg \\
\hline 185 & Rumex acetosella L. & Debrecen & 1948 & Siroki Zoltán & DE-siroki-05725.jpg \\
\hline 185 & Rumex acetosella L. & Debrecen & 1948 & Siroki Zoltán & DE-siroki-05726.jpg \\
\hline 185 & Rumex acetosella L. & Nagykőrös & 1913 & Degen Árpád & DE-siroki-05727.jpg \\
\hline 185 & Rumex acetosella L. & Vámospércs & 1985 & Siroki Zoltán & DE-siroki-05728.jpg \\
\hline 187 & Rumex acetosa L. & Debrecen & 1947 & Siroki Zoltán & DE-siroki-05735.jpg \\
\hline 187 & Rumex acetosa L. & Debrecen & 1947 & Siroki Zoltán & DE-siroki-05736.jpg \\
\hline 187 & Rumex acetosa L. & Debrecen & 1947 & Siroki Zoltán & DE-siroki-05737.jpg \\
\hline 187 & Rumex acetosa L. & Tiszafüred & 1970 & Siroki Zoltán & DE-siroki-05740.jpg \\
\hline 192 & Rumex maritimus L. & Keszthely & 1955 & Siroki Zoltán & DE-siroki-05596.jpg \\
\hline 192 & Rumex maritimus L. & Keszthely & 1955 & Siroki Zoltán & DE-siroki-05597.jpg \\
\hline 193 & Rumex palustris Sm. & Biatorbágy & 1950 & Siroki Zoltán & DE-siroki-05600.jpg \\
\hline 193 & Rumex palustris Sm. & Biatorbágy & 1950 & Siroki Zoltán & DE-siroki-05603.jpg \\
\hline 193 & Rumex palustris Sm. & Biharugra & 1961 & Siroki Zoltán & DE-siroki-05607.jpg \\
\hline 193 & Rumex palustris Sm. & Debrecen & 1962 & Siroki Zoltán & DE-siroki-05599.jpg \\
\hline 193 & Rumex palustris Sm. & Debrecen & 1970 & Siroki Zoltán & DE-siroki-05602.jpg \\
\hline 193 & Rumex palustris Sm. & Debrecen & 1973 & Siroki Zoltán & DE-siroki-05766.jpg \\
\hline 193 & Rumex palustris Sm. & Debrecen & 1973 & Siroki Zoltán & DE-siroki-05767.jpg \\
\hline 193 & Rumex palustris Sm. & Debrecen & 1973 & Siroki Zoltán & DE-siroki-05768.jpg \\
\hline
\end{tabular}




\begin{tabular}{|c|c|c|c|c|c|}
\hline $\begin{array}{l}\text { Sorszám / } \\
\text { Number }\end{array}$ & Taxon-név / Taxon-name & $\begin{array}{l}\text { Település / } \\
\text { Settlement }\end{array}$ & $\begin{array}{l}\text { Év / } \\
\text { Year }\end{array}$ & $\begin{array}{l}\text { Gyüjtő / } \\
\text { Collector }\end{array}$ & Fájlnév / File-name \\
\hline 193 & Rumex palustris Sm. & Hortobágy & 1947 & Siroki Zoltán & DE-siroki-05608.jpg \\
\hline 193 & Rumex palustris Sm. & Hortobágy & 1947 & Siroki Zoltán & DE-siroki-05609.jpg \\
\hline 193 & Rumex palustris Sm. & Mikepércs & 1962 & Siroki Zoltán & DE-siroki-05604.jpg \\
\hline 193 & Rumex palustris Sm. & Mikepércs & 1962 & Siroki Zoltán & DE-siroki-05606.jpg \\
\hline 193 & Rumex palustris Sm. & Mikepércs & 1962 & Siroki Zoltán & DE-siroki-05598.jpg \\
\hline 193 & Rumex palustris Sm. & Mikepércs & - & Siroki Zoltán & DE-siroki-05605.jpg \\
\hline 194 & Rumex pulcher L. & Debrecen & 1985 & Siroki Zoltán & DE-siroki-05588.jpg \\
\hline 194 & Rumex pulcher L. & Debrecen & 1985 & Siroki Zoltán & DE-siroki-05589.jpg \\
\hline 194 & Rumex pulcher L. & Debrecen & 1985 & Siroki Zoltán & DE-siroki-05590.jpg \\
\hline 194 & Rumex pulcher L. & Debrecen & 1985 & Siroki Zoltán & DE-siroki-05595.jpg \\
\hline 194 & Rumex pulcher L. & Vámospércs & 1985 & Siroki Zoltán & DE-siroki-05587.jpg \\
\hline 196 & Rumex obtusifolius L. & Debrecen & 1976 & Siroki Zoltán & DE-siroki-05656.jpg \\
\hline 196 & Rumex obtusifolius L. & Debrecen & 1976 & Siroki Zoltán & DE-siroki-05657.jpg \\
\hline 196 & Rumex obtusifolius L. & Debrecen & 1976 & Siroki Zoltán & DE-siroki-05658.jpg \\
\hline 196 & Rumex obtusifolius L. & Debrecen & 1976 & Siroki Zoltán & DE-siroki-05650.jpg \\
\hline 196 & Rumex obtusifolius L. & Debrecen & 1976 & Siroki Zoltán & DE-siroki-05651.jpg \\
\hline 196 & Rumex obtusifolius L. & Debrecen & 1976 & Siroki Zoltán & DE-siroki-05649.jpg \\
\hline 196 & Rumex obtusifolius L. & Debrecen & 1977 & Siroki Zoltán & DE-siroki-05654.jpg \\
\hline 196 & Rumex obtusifolius L. & Debrecen & 1977 & Siroki Zoltán & DE-siroki-05655.jpg \\
\hline 196 & Rumex obtusifolius L. & Hencida & 1983 & Siroki Zoltán & DE-siroki-05652.jpg \\
\hline 197 & Rumex confertus Willd. & Debrecen & 1955 & Siroki Zoltán & DE-siroki-05633.jpg \\
\hline 197 & Rumex confertus Willd. & Debrecen & 1955 & Siroki Zoltán & DE-siroki-05634.jpg \\
\hline 197 & Rumex confertus Willd. & Debrecen & 1959 & Siroki Zoltán & DE-siroki-05647.jpg \\
\hline 197 & Rumex confertus Willd. & Debrecen & 1959 & Siroki Zoltán & DE-siroki-05648.jpg \\
\hline 197 & Rumex confertus Willd. & Debrecen & 1959 & Siroki Zoltán & DE-siroki-05635.jpg \\
\hline 197 & Rumex confertus Willd. & Debrecen & 1959 & Siroki Zoltán & DE-siroki-05636.jpg \\
\hline 197 & Rumex confertus Willd. & Debrecen & 1959 & Siroki Zoltán & DE-siroki-05637.jpg \\
\hline 197 & Rumex confertus Willd. & Debrecen & 1959 & Siroki Zoltán & DE-siroki-05638.jpg \\
\hline 197 & Rumex confertus Willd. & Debrecen & 1976 & Siroki Zoltán & DE-siroki-05642.jpg \\
\hline 197 & Rumex confertus Willd. & Debrecen & 1976 & Siroki Zoltán & DE-siroki-05643.jpg \\
\hline 197 & Rumex confertus Willd. & Debrecen & 1976 & Siroki Zoltán & DE-siroki-05644.jpg \\
\hline 197 & Rumex confertus Willd. & Egyek & 1947 & Siroki Zoltán & DE-siroki-05645.jpg \\
\hline 197 & Rumex confertus Willd. & Egyek & 1947 & Siroki Zoltán & DE-siroki-05646.jpg \\
\hline 197 & Rumex confertus Willd. & Szilvásvárad & 1962 & Siroki Zoltán & DE-siroki-05639.jpg \\
\hline 197 & Rumex confertus Willd. & Szilvásvárad & 1962 & Siroki Zoltán & DE-siroki-05640.jpg \\
\hline 197 & Rumex confertus Willd. & Szilvásvárad & 1962 & Siroki Zoltán & DE-siroki-05641.jpg \\
\hline 197 & Rumex confertus Willd. & Tiszafüred & 1955 & $\begin{array}{l}\text { Siroki Zoltán - } \\
\text { Farkas Attila }\end{array}$ & DE-siroki-05631.jpg \\
\hline 197 & Rumex confertus Willd. & Tiszafüred & 1955 & $\begin{array}{l}\text { Siroki Zoltán - } \\
\text { Farkas Attila }\end{array}$ & DE-siroki-05632.jpg \\
\hline 198 & Rumex conglomeratus Murray & Debrecen & 1947 & Siroki Zoltán & DE-siroki-05617.jpg \\
\hline 198 & Rumex conglomeratus Murray & Debrecen & 1947 & Siroki Zoltán & DE-siroki-05610.jpg \\
\hline 198 & Rumex conglomeratus Murray & Debrecen & 1947 & Siroki Zoltán & DE-siroki-05611.jpg \\
\hline 199 & Rumex sanguineus L. & "Bükk-hg." & 1966 & Siroki Zoltán & DE-siroki-05618.jpg \\
\hline 199 & Rumex sanguineus L. & "Bükk-hg." & 1966 & Siroki Zoltán & DE-siroki-05619.jpg \\
\hline 199 & Rumex sanguineus L. & "Bükk-hg." & 1966 & Siroki Zoltán & DE-siroki-05620.jpg \\
\hline 199 & Rumex sanguineus L. & Debrecen & 1949 & Siroki Zoltán & DE-siroki-05621.jpg \\
\hline
\end{tabular}




\begin{tabular}{|c|c|c|c|c|c|}
\hline $\begin{array}{l}\text { Sorszám / } \\
\text { Number }\end{array}$ & Taxon-név / Taxon-name & $\begin{array}{l}\text { Település / } \\
\text { Settlement }\end{array}$ & $\begin{array}{l}\text { Év / } \\
\text { Year }\end{array}$ & $\begin{array}{l}\text { Gyűjtő / } \\
\text { Collector }\end{array}$ & Fájlnév / File-name \\
\hline 199 & Rumex sanguineus L. & Debrecen & 1949 & Siroki Zoltán & DE-siroki-05623.jpg \\
\hline 199 & Rumex sanguineus L. & Debrecen & 1949 & Siroki Zoltán & DE-siroki-05628.jpg \\
\hline 199 & Rumex sanguineus L. & Debrecen & 1950 & Siroki Zoltán & DE-siroki-05627.jpg \\
\hline 199 & Rumex sanguineus L. & Debrecen & 1976 & Siroki Zoltán & DE-siroki-05624.jpg \\
\hline 199 & Rumex sanguineus L. & Debrecen & 1976 & Siroki Zoltán & DE-siroki-05625.jpg \\
\hline 199 & Rumex sanguineus L. & Hosszúhetény & 1954 & Siroki Zoltán & DE-siroki-05626.jpg \\
\hline 199 & Rumex sanguineus L. & Mosonmagyaróvár & 1939 & Siroki Zoltán & DE-siroki-05622.jpg \\
\hline 200 & Rumex hydrolapathum Huds. & Debrecen & 1947 & Siroki Zoltán & DE-siroki-05679.jpg \\
\hline 200 & Rumex hydrolapathum Huds. & Debrecen & 1947 & Siroki Zoltán & DE-siroki-05687.jpg \\
\hline 200 & Rumex hydrolapathum Huds. & Debrecen & 1947 & Siroki Zoltán & DE-siroki-05688.jpg \\
\hline 200 & Rumex hydrolapathum Huds. & Debrecen & 1947 & Siroki Zoltán & DE-siroki-05689.jpg \\
\hline 200 & Rumex hydrolapathum Huds. & Debrecen & 1947 & Siroki Zoltán & DE-siroki-05678.jpg \\
\hline 200 & Rumex hydrolapathum Huds. & Debrecen & 1947 & Siroki Zoltán & DE-siroki-05683.jpg \\
\hline 200 & Rumex hydrolapathum Huds. & Debrecen & 1947 & Siroki Zoltán & DE-siroki-05680.jpg \\
\hline 200 & Rumex hydrolapathum Huds. & Debrecen & 1947 & Siroki Zoltán & DE-siroki-05681.jpg \\
\hline 200 & Rumex hydrolapathum Huds. & Debrecen & 1947 & Siroki Zoltán & DE-siroki-05684.jpg \\
\hline 200 & Rumex hydrolapathum Huds. & Debrecen & 1947 & Siroki Zoltán & DE-siroki-05685.jpg \\
\hline 200 & Rumex hydrolapathum Huds. & Debrecen & 1947 & Siroki Zoltán & DE-siroki-05686.jpg \\
\hline 200 & Rumex hydrolapathum Huds. & Keszthely & 1955 & Siroki Zoltán & DE-siroki-05682.jpg \\
\hline 201 & Rumex stenophyllus Ledeb. & Debrecen & 1947 & Siroki Zoltán & DE-siroki-05676.jpg \\
\hline 201 & Rumex stenophyllus Ledeb. & Debrecen & 1947 & Siroki Zoltán & DE-siroki-05677.jpg \\
\hline 201 & Rumex stenophyllus Ledeb. & Debrecen & 1947 & Siroki Zoltán & DE-siroki-05668.jpg \\
\hline 201 & Rumex stenophyllus Ledeb. & Debrecen & 1947 & Siroki Zoltán & DE-siroki-05669.jpg \\
\hline 201 & Rumex stenophyllus Ledeb. & Debrecen & 1947 & Siroki Zoltán & DE-siroki-05671.jpg \\
\hline 201 & Rumex stenophyllus Ledeb. & Debrecen & 1947 & Siroki Zoltán & DE-siroki-05672.jpg \\
\hline 201 & Rumex stenophyllus Ledeb. & Debrecen & 1947 & Siroki Zoltán & DE-siroki-05673.jpg \\
\hline 201 & Rumex stenophyllus Ledeb. & Debrecen & 1947 & Siroki Zoltán & DE-siroki-05667.jpg \\
\hline 201 & Rumex stenophyllus Ledeb. & Debrecen & 1947 & Siroki Zoltán & DE-siroki-05674.jpg \\
\hline 201 & Rumex stenophyllus Ledeb. & Debrecen & 1947 & Siroki Zoltán & DE-siroki-05675.jpg \\
\hline 201 & Rumex stenophyllus Ledeb. & Hortobágy & 1947 & Siroki Zoltán & DE-siroki-05666.jpg \\
\hline 201 & Rumex stenophyllus Ledeb. & Mikepércs & 1962 & Siroki Zoltán & DE-siroki-05665.jpg \\
\hline 201 & Rumex stenophyllus Ledeb. & Mikepércs & 1962 & Siroki Zoltán & DE-siroki-05670.jpg \\
\hline 202 & Rumex crispus L. & Debrecen & 1947 & Siroki Zoltán & DE-siroki-05691.jpg \\
\hline 202 & Rumex crispus L. & Debrecen & 1947 & Siroki Zoltán & DE-siroki-05693.jpg \\
\hline 202 & Rumex crispus L. & Debrecen & 1976 & Siroki Zoltán & DE-siroki-05694.jpg \\
\hline 202 & Rumex crispus L. & Debrecen & 1976 & Siroki Zoltán & DE-siroki-05690.jpg \\
\hline 202 & Rumex crispus L. & Gödöllő & 1952 & Máthé Imre & DE-siroki-05692.jpg \\
\hline 202 & Rumex crispus L. & Mosonmagyaróvár & 1939 & Siroki Zoltán & DE-siroki-05695.jpg \\
\hline 203 & Rumex patientia L. & Debrecen & 1947 & Siroki Zoltán & DE-siroki-05697.jpg \\
\hline 203 & Rumex patientia L. & Debrecen & 1947 & Siroki Zoltán & DE-siroki-05699.jpg \\
\hline 203 & Rumex patientia L. & Debrecen & 1947 & Siroki Zoltán & DE-siroki-05700.jpg \\
\hline 203 & Rumex patientia L. & Debrecen & 1947 & Siroki Zoltán & DE-siroki-05701.jpg \\
\hline 203 & Rumex patientia L. & Debrecen & 1947 & Siroki Zoltán & DE-siroki-05702.jpg \\
\hline 203 & Rumex patientia L. & Debrecen & 1970 & Siroki Zoltán & DE-siroki-05706.jpg \\
\hline 203 & Rumex patientia L. & Debrecen & 1970 & Siroki Zoltán & DE-siroki-05707.jpg \\
\hline 203 & Rumex patientia L. & Debrecen & 1970 & Siroki Zoltán & DE-siroki-05708.jpg \\
\hline
\end{tabular}




\begin{tabular}{|c|c|c|c|c|c|}
\hline $\begin{array}{l}\text { Sorszám / } \\
\text { Number }\end{array}$ & Taxon-név / Taxon-name & $\begin{array}{l}\text { Település / } \\
\text { Settlement }\end{array}$ & $\begin{array}{l}\text { Év / } \\
\text { Year }\end{array}$ & $\begin{array}{l}\text { Gyűjtő / } \\
\text { Collector }\end{array}$ & Fájlnév / File-name \\
\hline 203 & Rumex patientia L. & Debrecen & 1970 & Siroki Zoltán & DE-siroki-05709.jpg \\
\hline 203 & Rumex patientia L. & Debrecen & 1970 & Siroki Zoltán & DE-siroki-05710.jpg \\
\hline 203 & Rumex patientia L. & Debrecen & 1976 & Siroki Zoltán & DE-siroki-05711.jpg \\
\hline 203 & Rumex patientia L. & Debrecen & 1976 & Siroki Zoltán & DE-siroki-05712.jpg \\
\hline 203 & Rumex patientia L. & Debrecen & 1976 & Siroki Zoltán & DE-siroki-05713.jpg \\
\hline 203 & Rumex patientia L. & Tiszafüred & 1955 & $\begin{array}{l}\text { Siroki Zoltán - } \\
\text { Farkas Attila }\end{array}$ & DE-siroki-05698.jpg \\
\hline 204 & Rumex kerneri Borbás & Egyek & 1959 & Siroki Zoltán & DE-siroki-05764.jpg \\
\hline 204 & Rumex kerneri Borbás & Egyek & 1959 & Siroki Zoltán & DE-siroki-05765.jpg \\
\hline 205 & Polycnemum heuffelii Láng & Lácacséke & 1913 & Margittai Antal & DE-siroki-05865.jpg \\
\hline 205 & Polycnemum heuffelii Láng & Vásárosnamény & 1966 & Gondola István & DE-siroki-05867.jpg \\
\hline 205 & Polycnemum heuffelii Láng & Vásárosnamény & 1966 & Gondola István & DE-siroki-05868.jpg \\
\hline 205 & Polycnemum heuffelii Láng & Vásárosnamény & 1966 & Gondola István & DE-siroki-05869.jpg \\
\hline 205 & Polycnemum heuffelii Láng & Vásárosnamény & 1966 & Gondola István & DE-siroki-05870.jpg \\
\hline 206 & Polycnemum majus A. Braun & Debrecen & 1947 & Siroki Zoltán & DE-siroki-05873.jpg \\
\hline 206 & Polycnemum majus A. Braun & Debrecen & 1947 & Siroki Zoltán & DE-siroki-05889.jpg \\
\hline 206 & Polycnemum majus A. Braun & Sátoraljaújhely & 1944 & Siroki Zoltán & DE-siroki-05874.jpg \\
\hline 207 & Polycnemum arvense L. & Budapest & 1887 & Czakó Kálmán & DE-siroki-05877.jpg \\
\hline 207 & Polycnemum arvense L. & Budapest & 1950 & Siroki Zoltán & DE-siroki-05884.jpg \\
\hline 207 & Polycnemum arvense L. & Debrecen & 1947 & Siroki Zoltán & DE-siroki-05886.jpg \\
\hline 207 & Polycnemum arvense L. & Debrecen & 1947 & Siroki Zoltán & DE-siroki-05876.jpg \\
\hline 207 & Polycnemum arvense L. & Debrecen & 1947 & Siroki Zoltán & DE-siroki-05885.jpg \\
\hline 207 & Polycnemum arvense L. & Debrecen & 1947 & Siroki Zoltán & DE-siroki-05891.jpg \\
\hline 207 & Polycnemum arvense L. & Debrecen & 1966 & Siroki Zoltán & DE-siroki-05879.jpg \\
\hline 207 & Polycnemum arvense L. & Debrecen & 1966 & Siroki Zoltán & DE-siroki-05880.jpg \\
\hline 207 & Polycnemum arvense L. & Debrecen & 1966 & Siroki Zoltán & DE-siroki-05881.jpg \\
\hline 207 & Polycnemum arvense L. & Hortobágy & 1948 & Siroki Zoltán & DE-siroki-05875.jpg \\
\hline 207 & Polycnemum arvense L. & Hortobágy & 1948 & Siroki Zoltán & DE-siroki-05890.jpg \\
\hline 207 & Polycnemum arvense L. & Hortobágy & 1955 & Siroki Zoltán & DE-siroki-05888.jpg \\
\hline 207 & Polycnemum arvense L. & Hortobágy & 1955 & Siroki Zoltán & DE-siroki-05887.jpg \\
\hline 207 & Polycnemum arvense L. & Hortobágy & 1955 & Siroki Zoltán & DE-siroki-05883.jpg \\
\hline 207 & Polycnemum arvense L. & Hortobágy & 1965 & Siroki Zoltán & DE-siroki-05882.jpg \\
\hline 210 & Chenopodium aristatum L. & Budapest & 1950 & Siroki Zoltán & DE-siroki-05896.jpg \\
\hline 210 & Chenopodium aristatum L. & Budapest & 1950 & Siroki Zoltán & DE-siroki-05900.jpg \\
\hline 210 & Chenopodium aristatum L. & Budapest & 1950 & Siroki Zoltán & DE-siroki-05897.jpg \\
\hline 210 & Chenopodium aristatum L. & Budapest & 1950 & Siroki Zoltán & DE-siroki-05898.jpg \\
\hline 210 & Chenopodium aristatum L. & Budapest & 1950 & Siroki Zoltán & DE-siroki-05901.jpg \\
\hline 210 & Chenopodium aristatum L. & Budapest & 1950 & Siroki Zoltán & DE-siroki-05893.jpg \\
\hline 210 & Chenopodium aristatum L. & Budapest & 1950 & Siroki Zoltán & DE-siroki-05894.jpg \\
\hline 210 & Chenopodium aristatum L. & Budapest & 1950 & Siroki Zoltán & DE-siroki-05895.jpg \\
\hline 210 & Chenopodium aristatum L. & Budapest & 1950 & Siroki Zoltán & DE-siroki-05902.jpg \\
\hline 211 & Chenopodium ambrosioides L. & Szigetszentmárton & 1951 & Siroki Zoltán & DE-siroki-05913.jpg \\
\hline 213 & Chenopodium botrys L. & Debrecen & 1947 & Siroki Zoltán & DE-siroki-05917.jpg \\
\hline 213 & Chenopodium botrys $\mathrm{L}$. & Debrecen & 1979 & Siroki Zoltán & DE-siroki-05915.jpg \\
\hline 213 & Chenopodium botrys L. & Debrecen & 1979 & Siroki Zoltán & DE-siroki-05916.jpg \\
\hline 213 & Chenopodium botrys L. & Debrecen & 1983 & Siroki Zoltán & DE-siroki-05918.jpg \\
\hline 214 & Chenopodium schraderianum Schult. & Mosonmagyaróvár & 1939 & Siroki Zoltán & DE-siroki-05923.jpg \\
\hline
\end{tabular}




\begin{tabular}{|c|c|c|c|c|c|}
\hline $\begin{array}{l}\text { Sorszám / } \\
\text { Number }\end{array}$ & Taxon-név / Taxon-name & $\begin{array}{l}\text { Település / } \\
\text { Settlement }\end{array}$ & $\begin{array}{l}\text { Év / } \\
\text { Year }\end{array}$ & $\begin{array}{l}\text { Gyűjtő / } \\
\text { Collector }\end{array}$ & Fájlnév / File-name \\
\hline 216 & Chenopodium bonus-henricus L. & "Bükk-hg." & 1966 & Siroki Zoltán & DE-siroki-05932.jpg \\
\hline 216 & Chenopodium bonus-henricus L. & Háromhuta & 1978 & Siroki Zoltán & DE-siroki-05928.jpg \\
\hline 216 & Chenopodium bonus-henricus L. & Háromhuta & 1978 & Siroki Zoltán & DE-siroki-05929.jpg \\
\hline 216 & Chenopodium bonus-henricus L. & Háromhuta & 1978 & Siroki Zoltán & DE-siroki-05930.jpg \\
\hline 216 & Chenopodium bonus-henricus L. & Nagyvisnyó & 1966 & Siroki Zoltán & DE-siroki-05933.jpg \\
\hline 216 & Chenopodium bonus-henricus L. & Sopron & 1950 & Kárpáti Zoltán & DE-siroki-05935.jpg \\
\hline 216 & Chenopodium bonus-henricus L. & Szilvásvárad & 1961 & Siroki Zoltán & DE-siroki-05931.jpg \\
\hline 217 & Chenopodium glaucum L. & Konyár & 1975 & Siroki Zoltán & DE-siroki-05991.jpg \\
\hline 217 & Chenopodium glaucum L. & Mosonmagyaróvár & 1939 & Siroki Zoltán & DE-siroki-05992.jpg \\
\hline 218 & Chenopodium rubrum L. & Biharugra & 1961 & Siroki Zoltán & DE-siroki-06007.jpg \\
\hline 218 & Chenopodium rubrum L. & Biharugra & 1961 & Siroki Zoltán & DE-siroki-06008.jpg \\
\hline 218 & Chenopodium rubrum L. & Debrecen & 1946 & Siroki Zoltán & DE-siroki-06002.jpg \\
\hline 218 & Chenopodium rubrum L. & Debrecen & 1946 & Siroki Zoltán & DE-siroki-06006.jpg \\
\hline 218 & Chenopodium rubrum L. & Debrecen & 1947 & Siroki Zoltán & DE-siroki-06009.jpg \\
\hline 218 & Chenopodium rubrum L. & Debrecen & 1967 & Siroki Zoltán & DE-siroki-06001.jpg \\
\hline 218 & Chenopodium rubrum L. & Debrecen & 1979 & Siroki Zoltán & DE-siroki-05994.jpg \\
\hline 218 & Chenopodium rubrum L. & Debrecen & 1979 & Siroki Zoltán & DE-siroki-06000.jpg \\
\hline 219 & $\begin{array}{l}\text { Chenopodium chenopodioides } \\
\text { (L.) Aellen }\end{array}$ & Debrecen & 1950 & Siroki Zoltán & DE-siroki-05998.jpg \\
\hline 219 & $\begin{array}{l}\text { Chenopodium chenopodioides } \\
\text { (L.) Aellen }\end{array}$ & Debrecen & 1950 & Siroki Zoltán & DE-siroki-05999.jpg \\
\hline 219 & $\begin{array}{l}\text { Chenopodium chenopodioides } \\
\text { (L.) Aellen }\end{array}$ & Debrecen & 1963 & Siroki Zoltán & DE-siroki-05995.jpg \\
\hline 219 & $\begin{array}{l}\text { Chenopodium chenopodioides } \\
\text { (L.) Aellen }\end{array}$ & Debrecen & 1963 & Siroki Zoltán & DE-siroki-05996.jpg \\
\hline 219 & $\begin{array}{l}\text { Chenopodium chenopodioides } \\
\text { (L.) Aellen }\end{array}$ & Debrecen & 1963 & Siroki Zoltán & DE-siroki-05997.jpg \\
\hline 220 & Chenopodium vulvaria L. & Budapest & 1941 & Siroki Zoltán & DE-siroki-05950.jpg \\
\hline 220 & Chenopodium vulvaria L. & Budapest & 1941 & Siroki Zoltán & DE-siroki-05949.jpg \\
\hline 220 & Chenopodium vulvaria L. & Debrecen & 1949 & Siroki Zoltán & DE-siroki-05948.jpg \\
\hline 220 & Chenopodium vulvaria L. & Debrecen & 1949 & Siroki Zoltán & DE-siroki-05946.jpg \\
\hline 220 & Chenopodium vulvaria L. & Debrecen & 1949 & Siroki Zoltán & DE-siroki-05947.jpg \\
\hline 220 & Chenopodium vulvaria L. & Debrecen & 1978 & Siroki Zoltán & DE-siroki-05943.jpg \\
\hline 220 & Chenopodium vulvaria L. & Debrecen & 1978 & Siroki Zoltán & DE-siroki-05944.jpg \\
\hline 220 & Chenopodium vulvaria L. & Debrecen & 1978 & Siroki Zoltán & DE-siroki-05945.jpg \\
\hline 221 & Chenopodium polyspermum L. & Debrecen & 1949 & Siroki Zoltán & DE-siroki-05942.jpg \\
\hline 221 & Chenopodium polyspermum L. & Egyek & 1982 & Siroki Zoltán & DE-siroki-05938.jpg \\
\hline 221 & Chenopodium polyspermum L. & Egyek & 1982 & Siroki Zoltán & DE-siroki-05939.jpg \\
\hline 221 & Chenopodium polyspermum L. & Egyek & 1982 & Siroki Zoltán & DE-siroki-05940.jpg \\
\hline 221 & Chenopodium polyspermum L. & Győrtelek & 1975 & Siroki Zoltán & DE-siroki-05937.jpg \\
\hline 221 & Chenopodium polyspermum L. & Hortobágy & 1977 & Siroki Zoltán & DE-siroki-05941.jpg \\
\hline 222 & Chenopodium hybridum L. & Debrecen & 1949 & Siroki Zoltán & DE-siroki-05952.jpg \\
\hline 222 & Chenopodium hybridum L. & Debrecen & 1957 & Siroki Zoltán & DE-siroki-05951.jpg \\
\hline 222 & Chenopodium hybridum L. & Debrecen & 1979 & Siroki Zoltán & DE-siroki-05953.jpg \\
\hline 222 & Chenopodium hybridum L. & Mosonmagyaróvár & 1939 & Siroki Zoltán & DE-siroki-05955.jpg \\
\hline 223 & Chenopodium murale L. & Budapest & 1951 & Siroki Zoltán & DE-siroki-05987.jpg \\
\hline 223 & Chenopodium murale L. & Dunaharaszti & 1951 & Siroki Zoltán & DE-siroki-05986.jpg \\
\hline 223 & Chenopodium murale L. & Dunaharaszti & 1951 & Siroki Zoltán & DE-siroki-05988.jpg \\
\hline 223 & Chenopodium murale L. & Mosonmagyaróvár & 1939 & Siroki Zoltán & DE-siroki-05990.jpg \\
\hline
\end{tabular}




\begin{tabular}{|c|c|c|c|c|c|}
\hline $\begin{array}{l}\text { Sorszám / } \\
\text { Number }\end{array}$ & Taxon-név / Taxon-name & $\begin{array}{l}\text { Település / } \\
\text { Settlement }\end{array}$ & $\begin{array}{l}\text { Év / } \\
\text { Year }\end{array}$ & $\begin{array}{l}\text { Gyűjtő / } \\
\text { Collector }\end{array}$ & Fájlnév / File-name \\
\hline 224 & Chenopodium urbicum L. & Balmazújváros & 1969 & Siroki Zoltán & DE-siroki-05984.jpg \\
\hline 224 & Chenopodium urbicum L. & Budapest & 1941 & Siroki Zoltán & DE-siroki-05981.jpg \\
\hline 224 & Chenopodium urbicum L. & Budapest & 1941 & Siroki Zoltán & DE-siroki-05980.jpg \\
\hline 224 & Chenopodium urbicum L. & Debrecen & 1946 & Siroki Zoltán & DE-siroki-05982.jpg \\
\hline 224 & Chenopodium urbicum L. & Garadna & 1943 & Siroki Zoltán & DE-siroki-05985.jpg \\
\hline 224 & Chenopodium urbicum L. & Hortobágy & 1948 & Siroki Zoltán & DE-siroki-05983.jpg \\
\hline 225 & Chenopodium ficifolium Sm. & Debrecen & 1970 & Siroki Zoltán & DE-siroki-05958.jpg \\
\hline 225 & Chenopodium ficifolium Sm. & Debrecen & 1970 & Siroki Zoltán & DE-siroki-05959.jpg \\
\hline 225 & Chenopodium ficifolium Sm. & Dunaharaszti & 1951 & Siroki Zoltán & DE-siroki-05956.jpg \\
\hline 225 & Chenopodium ficifolium Sm. & Dunaharaszti & 1951 & Siroki Zoltán & DE-siroki-05957.jpg \\
\hline 225 & Chenopodium ficifolium Sm. & Dunaharaszti & 1951 & Siroki Zoltán & DE-siroki-05962.jpg \\
\hline 225 & Chenopodium ficifolium Sm. & Újfehértó & 1967 & Gondola István & DE-siroki-05960.jpg \\
\hline 225 & Chenopodium ficifolium Sm. & Újfehértó & 1967 & Gondola István & DE-siroki-05961.jpg \\
\hline 226 & Chenopodium opulifolium Schrad. & Hortobágy & 1948 & Siroki Zoltán & DE-siroki-05963.jpg \\
\hline 227 & Chenopodium suecicum Murr & Dunaharaszti & 1951 & Siroki Zoltán & DE-siroki-05968.jpg \\
\hline 227 & Chenopodium suecicum Murr & Dunaharaszti & 1951 & Siroki Zoltán & DE-siroki-05969.jpg \\
\hline 228 & Chenopodium strictum Roth & Budapest & 1950 & Siroki Zoltán & DE-siroki-05979.jpg \\
\hline 229 & Chenopodium album L. & Debrecen & 1947 & Siroki Zoltán & DE-siroki-05978.jpg \\
\hline 229 & Chenopodium album L. & Debrecen & 1957 & Siroki Zoltán & DE-siroki-05976.jpg \\
\hline 229 & Chenopodium album L. & Hajdúböszörmény & 1966 & Siroki Zoltán & DE-siroki-05970.jpg \\
\hline 229 & Chenopodium album L. & Hajdúböszörmény & 1966 & Siroki Zoltán & DE-siroki-05971.jpg \\
\hline 229 & Chenopodium album L. & Hajdúböszörmény & 1966 & Siroki Zoltán & DE-siroki-05972.jpg \\
\hline 229 & Chenopodium album L. & Hajdúböszörmény & 1966 & Siroki Zoltán & DE-siroki-05973.jpg \\
\hline 229 & Chenopodium album L. & Hajdúböszörmény & 1966 & Siroki Zoltán & DE-siroki-05974.jpg \\
\hline 229 & Chenopodium album L. & Hajdúböszörmény & 1966 & Siroki Zoltán & DE-siroki-05975.jpg \\
\hline 229 & Chenopodium album L. & Hortobágy & 1948 & Siroki Zoltán & DE-siroki-05977.jpg \\
\hline 229 & Chenopodium album L. & Mosonmagyaróvár & - & Siroki Zoltán & DE-siroki-05967.jpg \\
\hline 232 & Atriplex tatarica L. & Debrecen & 1947 & Siroki Zoltán & DE-siroki-06027.jpg \\
\hline 233 & Atriplex rosea L. & Karcag & 1979 & Siroki Zoltán & DE-siroki-06032.jpg \\
\hline 234 & Atriplex littoralis L. & Balmazújváros & 1969 & Siroki Zoltán & DE-siroki-06020.jpg \\
\hline 234 & Atriplex littoralis L. & Balmazújváros & 1981 & Siroki Zoltán & DE-siroki-06021.jpg \\
\hline 234 & Atriplex littoralis L. & Budapest & 1941 & Siroki Zoltán & DE-siroki-06022.jpg \\
\hline 234 & Atriplex littoralis L. & Budapest & 1941 & Siroki Zoltán & DE-siroki-06023.jpg \\
\hline 234 & Atriplex littoralis L. & Dévaványa & 1962 & Siroki Zoltán & DE-siroki-06018.jpg \\
\hline 234 & Atriplex littoralis L. & Dévaványa & 1962 & Siroki Zoltán & DE-siroki-06019.jpg \\
\hline 234 & Atriplex littoralis L. & Egyek & 1947 & Siroki Zoltán & DE-siroki-06025.jpg \\
\hline 234 & Atriplex littoralis L. & Hortobágy & 1947 & Siroki Zoltán & DE-siroki-06026.jpg \\
\hline 234 & Atriplex littoralis L. & Hortobágy & 1947 & Siroki Zoltán & DE-siroki-06024.jpg \\
\hline 235 & Atriplex oblongifolia Waldst. et Kit. & Budapest & 1950 & Siroki Zoltán & DE-siroki-06051.jpg \\
\hline 235 & Atriplex oblongifolia Waldst. et Kit. & Debrecen & 1947 & Siroki Zoltán & DE-siroki-06050.jpg \\
\hline 235 & Atriplex oblongifolia Waldst. et Kit. & Debrecen & 1976 & Siroki Zoltán & DE-siroki-06044.jpg \\
\hline 235 & Atriplex oblongifolia Waldst. et Kit. & Debrecen & 1976 & Siroki Zoltán & DE-siroki-06045.jpg \\
\hline 235 & Atriplex oblongifolia Waldst. et Kit. & Debrecen & 1976 & Siroki Zoltán & DE-siroki-06046.jpg \\
\hline 235 & Atriplex oblongifolia Waldst. et Kit. & Debrecen & 1976 & Siroki Zoltán & DE-siroki-06047.jpg \\
\hline 235 & Atriplex oblongifolia Waldst. et Kit. & Debrecen & 1976 & Siroki Zoltán & DE-siroki-06048.jpg \\
\hline 235 & Atriplex oblongifolia Waldst. et Kit. & Debrecen & 1976 & Siroki Zoltán & DE-siroki-06049.jpg \\
\hline
\end{tabular}




\begin{tabular}{|c|c|c|c|c|c|}
\hline $\begin{array}{l}\text { Sorszám / } \\
\text { Number }\end{array}$ & Taxon-név / Taxon-name & $\begin{array}{l}\text { Település / } \\
\text { Settlement }\end{array}$ & $\begin{array}{l}\text { Év / } \\
\text { Year }\end{array}$ & $\begin{array}{l}\text { Gyűjtő / } \\
\text { Collector }\end{array}$ & Fájlnév / File-name \\
\hline 236 & Atriplex patula L. & Debrecen & 1976 & Siroki Zoltán & DE-siroki-06055.jpg \\
\hline 236 & Atriplex patula L. & Debrecen & 1976 & Siroki Zoltán & DE-siroki-06056.jpg \\
\hline 236 & Atriplex patula L. & Debrecen & 1976 & Siroki Zoltán & DE-siroki-06057.jpg \\
\hline 237 & Atriplex prostrata Boucher & Biharugra & 1961 & Siroki Zoltán & DE-siroki-06038.jpg \\
\hline 237 & Atriplex prostrata Boucher & Budaörs & 1941 & Siroki Zoltán & DE-siroki-06041.jpg \\
\hline 237 & Atriplex prostrata Boucher & Budaörs & 1941 & Siroki Zoltán & DE-siroki-06042.jpg \\
\hline 237 & Atriplex prostrata Boucher & Budaörs & 1941 & Siroki Zoltán & DE-siroki-06043.jpg \\
\hline 237 & Atriplex prostrata Boucher & Debrecen & 1946 & Siroki Zoltán & DE-siroki-06040.jpg \\
\hline 237 & Atriplex prostrata Boucher & Debrecen & 1947 & Siroki Zoltán & DE-siroki-06039.jpg \\
\hline 238 & Atriplex sagittata Borkh. & Biatorbágy & 1950 & Siroki Zoltán & DE-siroki-06015.jpg \\
\hline 238 & Atriplex sagittata Borkh. & Debrecen & 1947 & Siroki Zoltán & DE-siroki-06016.jpg \\
\hline 239 & Atriplex hortensis L. & Debrecen & 1982 & Siroki Zoltán & DE-siroki-06012.jpg \\
\hline 239 & Atriplex hortensis L. & Debrecen & 1982 & Siroki Zoltán & DE-siroki-06013.jpg \\
\hline 241 & Camphorosma annua Pall. & Debrecen & 1947 & Siroki Zoltán & DE-siroki-06066.jpg \\
\hline 241 & Camphorosma annua Pall. & Debrecen & 1947 & Siroki Zoltán & DE-siroki-06067.jpg \\
\hline 241 & Camphorosma annua Pall. & Debrecen & 1962 & Siroki Zoltán & DE-siroki-06065.jpg \\
\hline 241 & Camphorosma annua Pall. & Debrecen & 1965 & Siroki Zoltán & DE-siroki-06063.jpg \\
\hline 241 & Camphorosma annua Pall. & Debrecen & 1965 & Siroki Zoltán & DE-siroki-06064.jpg \\
\hline 241 & Camphorosma annua Pall. & Hortobágy & 1947 & Siroki Zoltán & DE-siroki-06061.jpg \\
\hline 241 & Camphorosma annua Pall. & Hortobágy & 1947 & Siroki Zoltán & DE-siroki-06062.jpg \\
\hline 241 & Camphorosma annua Pall. & Konyár & 1975 & Siroki Zoltán & DE-siroki-06060.jpg \\
\hline 242 & Kochia scoparia (L.) Schrad. & Budapest & 1983 & Siroki Zoltán & DE-siroki-06083.jpg \\
\hline 242 & Kochia scoparia (L.) Schrad. & Budapest & 1983 & Siroki Zoltán & DE-siroki-06084.jpg \\
\hline 243 & Kochia prostrata (L.) Schrad. & Egyek & 1947 & Siroki Zoltán & DE-siroki-06087.jpg \\
\hline 243 & Kochia prostrata (L.) Schrad. & Egyek & 1947 & Siroki Zoltán & DE-siroki-06088.jpg \\
\hline 243 & Kochia prostrata (L.) Schrad. & Egyek & 1947 & Siroki Zoltán & DE-siroki-06086.jpg \\
\hline 243 & Kochia prostrata (L.) Schrad. & Egyek & 1947 & Siroki Zoltán & DE-siroki-06094.jpg \\
\hline 243 & Kochia prostrata (L.) Schrad. & Egyek & 1947 & Siroki Zoltán & DE-siroki-06090.jpg \\
\hline 243 & Kochia prostrata (L.) Schrad. & Hortobágy & 1958 & Siroki Zoltán & DE-siroki-06089.jpg \\
\hline 243 & Kochia prostrata (L.) Schrad. & Hortobágy & 1962 & Siroki Zoltán & DE-siroki-06091.jpg \\
\hline 243 & Kochia prostrata (L.) Schrad. & Hortobágy & 1962 & Siroki Zoltán & DE-siroki-06092.jpg \\
\hline 243 & Kochia prostrata (L.) Schrad. & Hortobágy & 1962 & Siroki Zoltán & DE-siroki-06093.jpg \\
\hline 243 & Kochia prostrata (L.) Schrad. & Tokaj & 1951 & Kárpáti Zoltán & DE-siroki-06085.jpg \\
\hline 244 & Kochia laniflora (S.G. Gmel.) Borbás & Budapest & 1941 & Siroki Zoltán & DE-siroki-06096.jpg \\
\hline 244 & Kochia laniflora (S.G. Gmel.) Borbás & Budapest & 1941 & Siroki Zoltán & DE-siroki-06095.jpg \\
\hline 244 & Kochia laniflora (S.G. Gmel.) Borbás & Bugac & 1973 & Siroki Zoltán & DE-siroki-06102.jpg \\
\hline 244 & Kochia laniflora (S.G. Gmel.) Borbás & Debrecen & 1946 & Siroki Zoltán & DE-siroki-06100.jpg \\
\hline 244 & Kochia laniflora (S.G. Gmel.) Borbás & Debrecen & 1947 & Siroki Zoltán & DE-siroki-06099.jpg \\
\hline 244 & Kochia laniflora (S.G. Gmel.) Borbás & Debrecen & 1947 & Siroki Zoltán & DE-siroki-06101.jpg \\
\hline 244 & Kochia laniflora (S.G. Gmel.) Borbás & Vámospércs & 1984 & Siroki Zoltán & DE-siroki-06097.jpg \\
\hline 244 & Kochia laniflora (S.G. Gmel.) Borbás & Vámospércs & 1984 & Siroki Zoltán & DE-siroki-06098.jpg \\
\hline 245 & Bassia sedoides (Pall.) Asch. & Boldogkőváralja & 1944 & Siroki Zoltán & DE-siroki-06068.jpg \\
\hline 245 & Bassia sedoides (Pall.) Asch. & Dévaványa & 1961 & Siroki Zoltán & DE-siroki-06072.jpg \\
\hline 245 & Bassia sedoides (Pall.) Asch. & Dévaványa & 1961 & Siroki Zoltán & DE-siroki-06074.jpg \\
\hline 245 & Bassia sedoides (Pall.) Asch. & Dévaványa & 1961 & Siroki Zoltán & DE-siroki-06075.jpg \\
\hline 245 & Bassia sedoides (Pall.) Asch. & Dévaványa & 1961 & Siroki Zoltán & DE-siroki-06076.jpg \\
\hline
\end{tabular}




\begin{tabular}{|c|c|c|c|c|c|}
\hline $\begin{array}{l}\text { Sorszám / } \\
\text { Number }\end{array}$ & Taxon-név / Taxon-name & $\begin{array}{l}\text { Település / } \\
\text { Settlement }\end{array}$ & $\begin{array}{l}\text { Év / } \\
\text { Year }\end{array}$ & $\begin{array}{l}\text { Gyűjtő / } \\
\text { Collector }\end{array}$ & Fájlnév / File-name \\
\hline 245 & Bassia sedoides (Pall.) Asch. & Dévaványa & 1961 & Siroki Zoltán & DE-siroki-06077.jpg \\
\hline 245 & Bassia sedoides (Pall.) Asch. & Dévaványa & 1961 & Siroki Zoltán & DE-siroki-06078.jpg \\
\hline 245 & Bassia sedoides (Pall.) Asch. & Dévaványa & 1962 & Siroki Zoltán & DE-siroki-06073.jpg \\
\hline 245 & Bassia sedoides (Pall.) Asch. & Hortobágy & 1947 & Siroki Zoltán & DE-siroki-06069.jpg \\
\hline 245 & Bassia sedoides (Pall.) Asch. & Hortobágy & 1947 & Siroki Zoltán & DE-siroki-06070.jpg \\
\hline 245 & Bassia sedoides (Pall.) Asch. & Hortobágy & 1947 & Siroki Zoltán & DE-siroki-06071.jpg \\
\hline 245 & Bassia sedoides (Pall.) Asch. & Püspökladány & 1969 & Siroki Zoltán & DE-siroki-06079.jpg \\
\hline 245 & Bassia sedoides (Pall.) Asch. & Püspökladány & 1969 & Siroki Zoltán & DE-siroki-06080.jpg \\
\hline 246 & Corispermum nitidum Kit. & Ágasegyháza & 1969 & Siroki Zoltán & DE-siroki-06107.jpg \\
\hline 246 & Corispermum nitidum Kit. & Ágasegyháza & 1969 & Siroki Zoltán & DE-siroki-06108.jpg \\
\hline 246 & Corispermum nitidum Kit. & Ágasegyháza & 1969 & Siroki Zoltán & DE-siroki-06109.jpg \\
\hline 246 & Corispermum nitidum Kit. & Budapest & 1879 & Staub Móric & DE-siroki-06115.jpg \\
\hline 246 & Corispermum nitidum Kit. & Budapest & 1888 & Czakó Kálmán & DE-siroki-06114.jpg \\
\hline 246 & Corispermum nitidum Kit. & Budapest & 1888 & Thaisz Lajos & DE-siroki-06112.jpg \\
\hline 246 & Corispermum nitidum Kit. & Budapest & 1888 & Thaisz Lajos & DE-siroki-06113.jpg \\
\hline 246 & Corispermum nitidum Kit. & Budapest & 1941 & Siroki Zoltán & DE-siroki-06110.jpg \\
\hline 246 & Corispermum nitidum Kit. & Budapest & 1941 & Siroki Zoltán & DE-siroki-06111.jpg \\
\hline 246 & Corispermum nitidum Kit. & Budapest & 1950 & Siroki Zoltán & DE-siroki-06106.jpg \\
\hline 246 & Corispermum nitidum Kit. & Budapest & 1950 & Siroki Zoltán & DE-siroki-06105.jpg \\
\hline 246 & Corispermum nitidum Kit. & Bugac & 1954 & Siroki Zoltán & DE-siroki-06103.jpg \\
\hline 246 & Corispermum nitidum Kit. & Pilisszentiván & 1950 & Siroki Zoltán & DE-siroki-06104.jpg \\
\hline 248 & Corispermum canescens Kit. & Budapest & 1913 & Degen Árpád & DE-siroki-06116.jpg \\
\hline 248 & Corispermum canescens Kit. & Budapest & 1925 & Degen Árpád & DE-siroki-06117.jpg \\
\hline 248 & Corispermum canescens Kit. & Budapest & 1926 & Degen Árpád & DE-siroki-06118.jpg \\
\hline 248 & Corispermum canescens Kit. & Budapest & 1950 & Siroki Zoltán & DE-siroki-06121.jpg \\
\hline 248 & Corispermum canescens Kit. & Budapest & 1950 & Siroki Zoltán & DE-siroki-06120.jpg \\
\hline 248 & Corispermum canescens Kit. & Budapest & - & Siroki Zoltán & DE-siroki-06122.jpg \\
\hline 248 & Corispermum canescens Kit. & Szigetszentmiklós & 1951 & Siroki Zoltán & DE-siroki-06119.jpg \\
\hline 250 & Salicornia prostrata Pall. & Budapest & 1903 & Kocsis István & DE-siroki-06126.jpg \\
\hline 250 & Salicornia prostrata Pall. & Budapest & 1909 & Kocsis István & DE-siroki-06125.jpg \\
\hline 250 & Salicornia prostrata Pall. & Szeged & 1913 & Lányi B. & DE-siroki-06127.jpg \\
\hline $251-253$ & Suaeda & Balmazújváros & 1969 & Siroki Zoltán & DE-siroki-06140.jpg \\
\hline $251-253$ & Suaeda & Balmazújváros & 1969 & Siroki Zoltán & DE-siroki-06141.jpg \\
\hline $251-253$ & Suaeda & Balmazújváros & 1969 & Siroki Zoltán & DE-siroki-06142.jpg \\
\hline $251-253$ & Suaeda & Balmazújváros & 1969 & Siroki Zoltán & DE-siroki-06143.jpg \\
\hline $251-253$ & Suaeda & Balmazújváros & 1969 & Siroki Zoltán & DE-siroki-06144.jpg \\
\hline $251-253$ & Suaeda & Balmazújváros & 1969 & Siroki Zoltán & DE-siroki-06145.jpg \\
\hline $251-253$ & Suaeda & Balmazújváros & 1969 & Siroki Zoltán & DE-siroki-06146.jpg \\
\hline $251-253$ & Suaeda & Balmazújváros & 1969 & Siroki Zoltán & DE-siroki-06147.jpg \\
\hline $251-253$ & Suaeda & Debrecen & 1962 & Siroki Zoltán & DE-siroki-06129.jpg \\
\hline $251-253$ & Suaeda & Debrecen & 1962 & Siroki Zoltán & DE-siroki-06133.jpg \\
\hline $251-253$ & Suaeda & Debrecen & 1962 & Siroki Zoltán & DE-siroki-06134.jpg \\
\hline $251-253$ & Suaeda & Debrecen & 1962 & Siroki Zoltán & DE-siroki-06135.jpg \\
\hline $251-253$ & Suaeda & Debrecen & 1962 & Siroki Zoltán & DE-siroki-06132.jpg \\
\hline $251-253$ & Suaeda & Debrecen & 1965 & Siroki Zoltán & DE-siroki-06130.jpg \\
\hline $251-253$ & Suaeda & Debrecen & 1965 & Siroki Zoltán & DE-siroki-06131.jpg \\
\hline
\end{tabular}




\begin{tabular}{|c|c|c|c|c|c|}
\hline $\begin{array}{l}\text { Sorszám / } \\
\text { Number }\end{array}$ & Taxon-név / Taxon-name & $\begin{array}{l}\text { Település / } \\
\text { Settlement }\end{array}$ & $\begin{array}{l}\text { Év / } \\
\text { Year }\end{array}$ & $\begin{array}{l}\text { Gyűjtő / } \\
\text { Collector }\end{array}$ & Fájlnév / File-name \\
\hline $251-253$ & Suaeda & Hortobágy & 1955 & Siroki Zoltán & DE-siroki-06128.jpg \\
\hline $251-253$ & Suaeda & Hortobágy & 1955 & Siroki Zoltán & DE-siroki-06137.jpg \\
\hline $251-253$ & Suaeda & Hortobágy & 1955 & Siroki Zoltán & DE-siroki-06136.jpg \\
\hline $251-253$ & Suaeda & Hortobágy & 1955 & Siroki Zoltán & DE-siroki-06138.jpg \\
\hline $251-253$ & Suaeda & Hortobágy & 1955 & Siroki Zoltán & DE-siroki-06139.jpg \\
\hline 254 & Salsola soda L. & Dömsöd & 1952 & Siroki Zoltán & DE-siroki-06151.jpg \\
\hline 254 & Salsola soda L. & Dömsöd & 1952 & Siroki Zoltán & DE-siroki-06152.jpg \\
\hline 254 & Salsola soda L. & Dömsöd & 1952 & Siroki Zoltán & DE-siroki-06153.jpg \\
\hline 254 & Salsola soda L. & Hortobágy & 1958 & Siroki Zoltán & DE-siroki-06150.jpg \\
\hline 254 & Salsola soda L. & Konyár & 1975 & Siroki Zoltán & DE-siroki-06148.jpg \\
\hline 254 & Salsola soda L. & Konyár & 1975 & Siroki Zoltán & DE-siroki-06149.jpg \\
\hline 254 & Salsola soda L. & Mikepércs & 1972 & Siroki Zoltán & DE-siroki-06154.jpg \\
\hline 254 & Salsola soda L. & Mikepércs & 1972 & Siroki Zoltán & DE-siroki-06155.jpg \\
\hline 260 & Amaranthus retroflexus L. & Debrecen & 1949 & Siroki Zoltán & DE-siroki-06172.jpg \\
\hline 260 & Amaranthus retroflexus L. & Debrecen & 1949 & Siroki Zoltán & DE-siroki-06170.jpg \\
\hline 260 & Amaranthus retroflexus L. & Debrecen & 1949 & Siroki Zoltán & DE-siroki-06171.jpg \\
\hline 260 & Amaranthus retroflexus L. & Debrecen & 1949 & Siroki Zoltán & DE-siroki-06173.jpg \\
\hline 260 & Amaranthus retroflexus L. & Debrecen & 1957 & Siroki Zoltán & DE-siroki-06168.jpg \\
\hline 260 & Amaranthus retroflexus L. & Debrecen & 1957 & Siroki Zoltán & DE-siroki-06169.jpg \\
\hline 260 & Amaranthus retroflexus L. & Debrecen & 1973 & Siroki Zoltán & DE-siroki-06174.jpg \\
\hline 260 & Amaranthus retroflexus L. & Szigetszentmiklós & 1951 & Siroki Zoltán & DE-siroki-06167.jpg \\
\hline 260 & Amaranthus retroflexus L. & Szigetszentmiklós & 1951 & Siroki Zoltán & DE-siroki-06166.jpg \\
\hline 262 & Amaranthus powellii S. Watson & Debrecen & 1949 & Siroki Zoltán & DE-siroki-06179.jpg \\
\hline 262 & Amaranthus powellii S. Watson & Debrecen & 1949 & Siroki Zoltán & DE-siroki-06180.jpg \\
\hline 262 & Amaranthus powellii S. Watson & Debrecen & 1949 & Siroki Zoltán & DE-siroki-06181.jpg \\
\hline 262 & Amaranthus powellii S. Watson & Debrecen & 1971 & Siroki Zoltán & DE-siroki-06178.jpg \\
\hline 262 & Amaranthus powellii S. Watson & Debrecen & 1979 & Siroki Zoltán & DE-siroki-06176.jpg \\
\hline 262 & Amaranthus powellii S. Watson & Debrecen & 1979 & Siroki Zoltán & DE-siroki-06177.jpg \\
\hline 262 & Amaranthus powellii S. Watson & Debrecen & 1979 & Siroki Zoltán & DE-siroki-06175.jpg \\
\hline 263 & Amaranthus viridis L. & Budapest & 1898 & Thaisz Lajos & DE-siroki-06207.jpg \\
\hline 263 & Amaranthus viridis $\mathrm{L}$. & Budapest & 1911 & Kocsis István & DE-siroki-06206.jpg \\
\hline 264 & Amaranthus blitum L. & Debrecen & 1949 & Siroki Zoltán & DE-siroki-06204.jpg \\
\hline 264 & Amaranthus blitum L. & Debrecen & 1949 & Siroki Zoltán & DE-siroki-06202.jpg \\
\hline 264 & Amaranthus blitum L. & Debrecen & 1949 & Siroki Zoltán & DE-siroki-06205.jpg \\
\hline 264 & Amaranthus blitum L. & Debrecen & 1979 & Siroki Zoltán & DE-siroki-06201.jpg \\
\hline 264 & Amaranthus blitum L. & Debrecen & 1979 & Siroki Zoltán & DE-siroki-06203.jpg \\
\hline 264 & Amaranthus blitum L. & Mosonmagyaróvár & 1939 & Siroki Zoltán & DE-siroki-06209.jpg \\
\hline 265 & Amaranthus deflexus L. & Debrecen & 1946 & Siroki Zoltán & DE-siroki-06222.jpg \\
\hline 265 & Amaranthus deflexus L. & Debrecen & 1946 & Siroki Zoltán & DE-siroki-06219.jpg \\
\hline 265 & Amaranthus deflexus L. & Debrecen & 1949 & Siroki Zoltán & DE-siroki-06220.jpg \\
\hline 265 & Amaranthus deflexus L. & Debrecen & 1949 & Siroki Zoltán & DE-siroki-06221.jpg \\
\hline 265 & Amaranthus deflexus L. & Debrecen & 1949 & Siroki Zoltán & DE-siroki-06223.jpg \\
\hline 265 & Amaranthus deflexus L. & Debrecen & 1979 & Siroki Zoltán & DE-siroki-06224.jpg \\
\hline 266 & Amaranthus blitoides S. Watson & Budapest & 1941 & Siroki Zoltán & DE-siroki-06229.jpg \\
\hline 266 & Amaranthus blitoides S. Watson & Budapest & 1985 & Siroki Zoltán & DE-siroki-06226.jpg \\
\hline 266 & Amaranthus blitoides S. Watson & Budapest & 1985 & Siroki Zoltán & DE-siroki-06227.jpg \\
\hline
\end{tabular}




\begin{tabular}{|c|c|c|c|c|c|}
\hline $\begin{array}{l}\text { Sorszám / } \\
\text { Number }\end{array}$ & Taxon-név / Taxon-name & $\begin{array}{l}\text { Település / } \\
\text { Settlement }\end{array}$ & $\begin{array}{l}\text { Év / } \\
\text { Year }\end{array}$ & $\begin{array}{l}\text { Gyüjtő / } \\
\text { Collector }\end{array}$ & Fájlnév / File-name \\
\hline 266 & Amaranthus blitoides S. Watson & Budapest & 1985 & Siroki Zoltán & DE-siroki-06225.jpg \\
\hline 267 & $\begin{array}{l}\text { Amaranthus crispus } \\
\text { (Lesp. et Thévenau) N. Terracc. }\end{array}$ & Abaújkér & 1943 & Siroki Zoltán & DE-siroki-06216.jpg \\
\hline 267 & $\begin{array}{l}\text { Amaranthus crispus } \\
\text { (Lesp. et Thévenau) N. Terracc. }\end{array}$ & Budapest & 1941 & Siroki Zoltán & DE-siroki-06217.jpg \\
\hline 267 & $\begin{array}{l}\text { Amaranthus crispus } \\
\text { (Lesp. et Thévenau) N. Terracc. }\end{array}$ & Budapest & 1941 & Siroki Zoltán & DE-siroki-06218.jpg \\
\hline 267 & $\begin{array}{l}\text { Amaranthus crispus } \\
\text { (Lesp. et Thévenau) N. Terracc. }\end{array}$ & Debrecen & 1949 & Siroki Zoltán & DE-siroki-06215.jpg \\
\hline 267 & $\begin{array}{l}\text { Amaranthus crispus } \\
\text { (Lesp. et Thévenau) N. Terracc. }\end{array}$ & Debrecen & 1949 & Siroki Zoltán & DE-siroki-06214.jpg \\
\hline 269 & Amaranthus albus L. & Budapest & 1941 & Siroki Zoltán & DE-siroki-06190.jpg \\
\hline 269 & Amaranthus albus L. & Debrecen & 1949 & Siroki Zoltán & DE-siroki-06192.jpg \\
\hline 269 & Amaranthus albus L. & Debrecen & 1949 & Siroki Zoltán & DE-siroki-06193.jpg \\
\hline 269 & Amaranthus albus L. & Debrecen & 1949 & Siroki Zoltán & DE-siroki-06194.jpg \\
\hline 269 & Amaranthus albus L. & Debrecen & 1979 & Siroki Zoltán & DE-siroki-06187.jpg \\
\hline 270 & Amaranthus graecizans L. & Budapest & 1909 & Kocsis István & DE-siroki-06195.jpg \\
\hline 270 & Amaranthus graecizans L. & Budapest & 1950 & Siroki Zoltán & DE-siroki-06199.jpg \\
\hline 270 & Amaranthus graecizans L. & Budapest & 1950 & Siroki Zoltán & DE-siroki-06200.jpg \\
\hline 270 & Amaranthus graecizans L. & Budapest & 1950 & Siroki Zoltán & DE-siroki-06198.jpg \\
\hline 270 & Amaranthus graecizans L. & Budapest & 1950 & Siroki Zoltán & DE-siroki-06197.jpg \\
\hline 270 & Amaranthus graecizans L. & Budapest & 1950 & Siroki Zoltán & DE-siroki-06196.jpg \\
\hline $260 \times 262$ & $\begin{array}{l}\text { Amaranthus retroflexus L. } \times \\
\text { Amaranthus powellii S. Watson }\end{array}$ & Debrecen & 1951 & Siroki Zoltán & DE-siroki-06213.jpg \\
\hline $265 \times 267$ & $\begin{array}{l}\text { Amaranthus deflexus L. } \times \\
\text { Amaranthus crispus } \\
\text { (Lesp. et Thévenau) N. Terracc. }\end{array}$ & Pásztó & 1952 & Siroki Zoltán & DE-siroki-06211.jpg \\
\hline $265 \times 267$ & $\begin{array}{l}\text { Amaranthus deflexus L. } \times \\
\text { Amaranthus crispus } \\
\text { (Lesp. et Thévenau) N. Terracc. }\end{array}$ & Pásztó & 1952 & Siroki Zoltán & DE-siroki-06212.jpg \\
\hline---- & Amaranthus paniculatus L. & Budapest & 1951 & Siroki Zoltán & DE-siroki-06183.jpg \\
\hline---- & Amaranthus paniculatus L. & Budapest & 1951 & Siroki Zoltán & DE-siroki-06184.jpg \\
\hline--- & Amaranthus paniculatus L. & Budapest & 1951 & Siroki Zoltán & DE-siroki-06185.jpg \\
\hline---- & Amaranthus paniculatus L. & Debrecen & 1979 & Siroki Zoltán & DE-siroki-06186.jpg \\
\hline 272 & $\begin{array}{l}\text { Oxybaphus nyctagineus } \\
\text { (Michx.) Sweet }\end{array}$ & Mátraverebély & 1952 & Siroki Zoltán & DE-siroki-06464.jpg \\
\hline 273 & Phytolacca americana L. & Debrecen & 1985 & Siroki Zoltán & DE-siroki-06230.jpg \\
\hline 280 & Arenaria procera Spreng. & Abaújszántó & 1944 & Siroki Zoltán & DE-siroki-06511.jpg \\
\hline 281 & Arenaria serpyllifolia L. & "Fáni-völgy" & 1955 & $\begin{array}{l}\text { Siroki Zoltán - } \\
\text { Farkas Attila }\end{array}$ & DE-siroki-06520.jpg \\
\hline 281 & Arenaria serpyllifolia L. & Berekböszörmény & 1970 & Siroki Zoltán & DE-siroki-06513.jpg \\
\hline 281 & Arenaria serpyllifolia L. & Cegléd & 1969 & Siroki Zoltán & DE-siroki-06518.jpg \\
\hline 281 & Arenaria serpyllifolia L. & Debrecen & 1948 & Siroki Zoltán & DE-siroki-06514.jpg \\
\hline 281 & Arenaria serpyllifolia L. & Debrecen & 1955 & Siroki Zoltán & DE-siroki-06515.jpg \\
\hline 281 & Arenaria serpyllifolia L. & Debrecen & 1955 & Siroki Zoltán & DE-siroki-06517.jpg \\
\hline 281 & Arenaria serpyllifolia L. & Debrecen & 1980 & Siroki Zoltán & DE-siroki-06516.jpg \\
\hline 281 & Arenaria serpyllifolia L. & Újléta & 1967 & Siroki Zoltán & DE-siroki-06519.jpg \\
\hline 282 & Arenaria leptoclados (Rchb.) Guss. & Budapest & 1906 & Kocsis István & DE-siroki-06524.jpg \\
\hline 282 & Arenaria leptoclados (Rchb.) Guss. & Dabas & 1929 & Zsák Zoltán & DE-siroki-06523.jpg \\
\hline 283 & Moehringia trinervia (L.) Clairv. & "Mátra" & 1984 & Siroki Zoltán & DE-siroki-06529.jpg \\
\hline 283 & Moehringia trinervia (L.) Clairv. & "Mátra" & 1984 & Siroki Zoltán & DE-siroki-06530.jpg \\
\hline 283 & Moehringia trinervia (L.) Clairv. & "Mátra" & 1984 & Siroki Zoltán & DE-siroki-06531.jpg \\
\hline
\end{tabular}




\begin{tabular}{|c|c|c|c|c|c|}
\hline $\begin{array}{l}\text { Sorszám / } \\
\text { Number }\end{array}$ & Taxon-név / Taxon-name & $\begin{array}{l}\text { Település / } \\
\text { Settlement }\end{array}$ & $\begin{array}{l}\text { Év / } \\
\text { Year }\end{array}$ & $\begin{array}{l}\text { Gyújtő / } \\
\text { Collector }\end{array}$ & Fájlnév / File-name \\
\hline 283 & Moehringia trinervia (L.) Clairv. & Debrecen & 1950 & Siroki Zoltán & DE-siroki-06534.jpg \\
\hline 283 & Moehringia trinervia (L.) Clairv. & Háromhuta & 1960 & Siroki Zoltán & DE-siroki-06532.jpg \\
\hline 283 & Moehringia trinervia (L.) Clairv. & Pilismarót & 1957 & Siroki Zoltán & DE-siroki-06533.jpg \\
\hline 285 & Minuartia setacea (Thuill.) Hayek & Ágasegyháza & 1969 & Siroki Zoltán & DE-siroki-06468.jpg \\
\hline 285 & Minuartia setacea (Thuill.) Hayek & Ágasegyháza & 1969 & Siroki Zoltán & DE-siroki-06470.jpg \\
\hline 285 & Minuartia setacea (Thuill.) Hayek & Ágasegyháza & 1969 & Siroki Zoltán & DE-siroki-06471.jpg \\
\hline 285 & Minuartia setacea (Thuill.) Hayek & Ágasegyháza & 1971 & Siroki Zoltán & DE-siroki-06469.jpg \\
\hline 285 & Minuartia setacea (Thuill.) Hayek & Bélapátfalva & 1958 & Siroki Zoltán & DE-siroki-06465.jpg \\
\hline 285 & Minuartia setacea (Thuill.) Hayek & Budaörs & 1951 & Siroki Zoltán & DE-siroki-06477.jpg \\
\hline 285 & Minuartia setacea (Thuill.) Hayek & Budapest & 1948 & Siroki Zoltán & DE-siroki-06475.jpg \\
\hline 285 & Minuartia setacea (Thuill.) Hayek & Budapest & 1948 & Siroki Zoltán & DE-siroki-06476.jpg \\
\hline 285 & Minuartia setacea (Thuill.) Hayek & Gyenesdiás & 1955 & Siroki Zoltán & DE-siroki-06473.jpg \\
\hline 285 & Minuartia setacea (Thuill.) Hayek & Keszthely & 1955 & Siroki Zoltán & DE-siroki-06472.jpg \\
\hline 285 & Minuartia setacea (Thuill.) Hayek & Nagykovácsi & 1957 & Siroki Zoltán & DE-siroki-06474.jpg \\
\hline 286 & Minuartia fastigiata (Sm.) Rchb. & "Szent-György-hegy" & 1955 & Siroki Zoltán & DE-siroki-06453.jpg \\
\hline 286 & Minuartia fastigiata (Sm.) Rchb. & "Szent-György-hegy" & 1955 & Siroki Zoltán & DE-siroki-06454.jpg \\
\hline 286 & Minuartia fastigiata (Sm.) Rchb. & Budapest & 1932 & Degen Árpád & DE-siroki-06450.jpg \\
\hline 286 & Minuartia fastigiata (Sm.) Rchb. & Budapest & 1952 & Siroki Zoltán & DE-siroki-06452.jpg \\
\hline 286 & Minuartia fastigiata (Sm.) Rchb. & Budapest & 1952 & Siroki Zoltán & DE-siroki-06451.jpg \\
\hline 286 & Minuartia fastigiata (Sm.) Rchb. & Nagyharsány & 1912 & Gerhárdt Guido & DE-siroki-06449.jpg \\
\hline 287 & Minuartia glomerata (M. Bieb.) Degen & Budapest & 1949 & Siroki Zoltán & DE-siroki-06458.jpg \\
\hline 287 & Minuartia glomerata (M. Bieb.) Degen & Budapest & 1949 & Siroki Zoltán & DE-siroki-06456.jpg \\
\hline 287 & Minuartia glomerata (M. Bieb.) Degen & Budapest & 1949 & Siroki Zoltán & DE-siroki-06457.jpg \\
\hline 287 & Minuartia glomerata (M. Bieb.) Degen & Gödöllő & 1951 & Siroki Zoltán & DE-siroki-06455.jpg \\
\hline 287 & Minuartia glomerata (M. Bieb.) Degen & Kecskemét & 1969 & Siroki Zoltán & DE-siroki-06459.jpg \\
\hline 288 & $\begin{array}{l}\text { Minuartia viscosa } \\
\text { (Schreb.) Schinz et Thell. }\end{array}$ & Ágasegyháza & 1971 & Siroki Zoltán & DE-siroki-06447.jpg \\
\hline 288 & $\begin{array}{l}\text { Minuartia viscosa } \\
\text { (Schreb.) Schinz et Thell. }\end{array}$ & Debrecen & 1950 & Siroki Zoltán & DE-siroki-06439.jpg \\
\hline 288 & $\begin{array}{l}\text { Minuartia viscosa } \\
\text { (Schreb.) Schinz et Thell. }\end{array}$ & Debrecen & 1950 & Siroki Zoltán & DE-siroki-06443.jpg \\
\hline 288 & $\begin{array}{l}\text { Minuartia viscosa } \\
\text { (Schreb.) Schinz et Thell. }\end{array}$ & Debrecen & 1954 & Siroki Zoltán & DE-siroki-06440.jpg \\
\hline 288 & $\begin{array}{l}\text { Minuartia viscosa } \\
\text { (Schreb.) Schinz et Thell. }\end{array}$ & Debrecen & 1954 & Siroki Zoltán & DE-siroki-06438.jpg \\
\hline 288 & $\begin{array}{l}\text { Minuartia viscosa } \\
\text { (Schreb.) Schinz et Thell. }\end{array}$ & Debrecen & 1954 & Siroki Zoltán & DE-siroki-06442.jpg \\
\hline 288 & $\begin{array}{l}\text { Minuartia viscosa } \\
\text { (Schreb.) Schinz et Thell. }\end{array}$ & Debrecen & 1954 & Siroki Zoltán & DE-siroki-06441.jpg \\
\hline 288 & $\begin{array}{l}\text { Minuartia viscosa } \\
\text { (Schreb.) Schinz et Thell. }\end{array}$ & Debrecen & 1954 & Siroki Zoltán & DE-siroki-06444.jpg \\
\hline 288 & $\begin{array}{l}\text { Minuartia viscosa } \\
\text { (Schreb.) Schinz et Thell. }\end{array}$ & Debrecen & 1954 & Siroki Zoltán & DE-siroki-06445.jpg \\
\hline 288 & $\begin{array}{l}\text { Minuartia viscosa } \\
\text { (Schreb.) Schinz et Thell. }\end{array}$ & Debrecen & 1954 & Siroki Zoltán & DE-siroki-06446.jpg \\
\hline 288 & $\begin{array}{l}\text { Minuartia viscosa } \\
\text { (Schreb.) Schinz et Thell. }\end{array}$ & Hajdúbagos & 1985 & Siroki Zoltán & DE-siroki-06448.jpg \\
\hline 289 & Minuartia glaucina Dvořáková & Budaörs & 1955 & Siroki Zoltán & DE-siroki-06489.jpg \\
\hline 289 & Minuartia glaucina Dvořáková & Budapest & 1904 & Thaisz Lajos & DE-siroki-06486.jpg \\
\hline 289 & Minuartia glaucina Dvořáková & Budapest & 1911 & Kocsis István & DE-siroki-06487.jpg \\
\hline 289 & Minuartia glaucina Dvořáková & Budapest & 1912 & Bocskay Ottó & DE-siroki-06488.jpg \\
\hline 289 & Minuartia glaucina Dvořáková & Budapest & 1941 & Siroki Zoltán & DE-siroki-06493.jpg \\
\hline
\end{tabular}




\begin{tabular}{|c|c|c|c|c|c|}
\hline $\begin{array}{l}\text { Sorszám / } \\
\text { Number }\end{array}$ & Taxon-név / Taxon-name & $\begin{array}{l}\text { Település / } \\
\text { Settlement }\end{array}$ & $\begin{array}{l}\text { Év / } \\
\text { Year }\end{array}$ & $\begin{array}{l}\text { Gyűjtő / } \\
\text { Collector }\end{array}$ & Fájlnév / File-name \\
\hline 289 & Minuartia glaucina Dvořáková & Budapest & 1949 & Siroki Zoltán & DE-siroki-06492.jpg \\
\hline 289 & Minuartia glaucina Dvořáková & Budapest & 1951 & Siroki Zoltán & DE-siroki-06491.jpg \\
\hline 289 & Minuartia glaucina Dvořáková & Gödöllő & 1951 & Siroki Zoltán & DE-siroki-06490.jpg \\
\hline 290 & Minuartia frutescens (Kit.) Tuzson & Abaújszántó & 1944 & Siroki Zoltán & DE-siroki-06509.jpg \\
\hline 290 & Minuartia frutescens (Kit.) Tuzson & Abaújszántó & 1944 & Siroki Zoltán & DE-siroki-06510.jpg \\
\hline 290 & Minuartia frutescens (Kit.) Tuzson & Boldogkőváralja & 1944 & Siroki Zoltán & DE-siroki-06507.jpg \\
\hline 290 & Minuartia frutescens (Kit.) Tuzson & Boldogkőváralja & 1944 & Siroki Zoltán & DE-siroki-06508.jpg \\
\hline 290 & Minuartia frutescens (Kit.) Tuzson & Boldogkőváralja & 1944 & Siroki Zoltán & DE-siroki-06506.jpg \\
\hline 290 & Minuartia frutescens (Kit.) Tuzson & Boldogkőváralja & 1967 & Siroki Zoltán & DE-siroki-06505.jpg \\
\hline 290 & Minuartia frutescens (Kit.) Tuzson & Füzér & 1973 & Siroki Zoltán & DE-siroki-06494.jpg \\
\hline 290 & Minuartia frutescens (Kit.) Tuzson & Szarvaskő & 1957 & Siroki Zoltán & DE-siroki-06496.jpg \\
\hline 290 & Minuartia frutescens (Kit.) Tuzson & Szarvaskő & 1957 & Siroki Zoltán & DE-siroki-06501.jpg \\
\hline 290 & Minuartia frutescens (Kit.) Tuzson & Szarvaskő & 1957 & Siroki Zoltán & DE-siroki-06502.jpg \\
\hline 290 & Minuartia frutescens (Kit.) Tuzson & Szarvaskő & 1957 & Siroki Zoltán & DE-siroki-06503.jpg \\
\hline 290 & Minuartia frutescens (Kit.) Tuzson & Szarvaskő & 1957 & Siroki Zoltán & DE-siroki-06504.jpg \\
\hline 290 & Minuartia frutescens (Kit.) Tuzson & Szarvaskő & 1966 & Siroki Zoltán & DE-siroki-06495.jpg \\
\hline 290 & Minuartia frutescens (Kit.) Tuzson & Szarvaskő & 1966 & Siroki Zoltán & DE-siroki-06497.jpg \\
\hline 290 & Minuartia frutescens (Kit.) Tuzson & Szarvaskő & 1966 & Siroki Zoltán & DE-siroki-06498.jpg \\
\hline 290 & Minuartia frutescens (Kit.) Tuzson & Szarvaskő & 1966 & Siroki Zoltán & DE-siroki-06499.jpg \\
\hline 290 & Minuartia frutescens (Kit.) Tuzson & Szarvaskő & 1966 & Siroki Zoltán & DE-siroki-06500.jpg \\
\hline 294 & Stellaria media (L.) Vill. & Debrecen & 1949 & Siroki Zoltán & DE-siroki-06256.jpg \\
\hline 294 & Stellaria media (L.) Vill. & Debrecen & 1949 & Siroki Zoltán & DE-siroki-06255.jpg \\
\hline 294 & Stellaria media (L.) Vill. & Debrecen & 1956 & Siroki Zoltán & DE-siroki-06257.jpg \\
\hline 294 & Stellaria media (L.) Vill. & Debrecen & 1957 & Siroki Zoltán & DE-siroki-06258.jpg \\
\hline 295 & Stellaria holostea L. & Debrecen & 1953 & Siroki Zoltán & DE-siroki-06250.jpg \\
\hline 295 & Stellaria holostea L. & Debrecen & 1953 & Siroki Zoltán & DE-siroki-06251.jpg \\
\hline 295 & Stellaria holostea L. & Debrecen & 1953 & Siroki Zoltán & DE-siroki-06252.jpg \\
\hline 295 & Stellaria holostea L. & Debrecen & 1953 & Siroki Zoltán & DE-siroki-06253.jpg \\
\hline 295 & Stellaria holostea L. & Debrecen & 1953 & Siroki Zoltán & DE-siroki-06248.jpg \\
\hline 295 & Stellaria holostea L. & Debrecen & 1953 & Siroki Zoltán & DE-siroki-06249.jpg \\
\hline 295 & Stellaria holostea L. & Debrecen & 1953 & Siroki Zoltán & DE-siroki-06254.jpg \\
\hline 295 & Stellaria holostea L. & Nagykovácsi & 1959 & Siroki Zoltán & DE-siroki-06245.jpg \\
\hline 295 & Stellaria holostea L. & Nagykovácsi & 1959 & Siroki Zoltán & DE-siroki-06246.jpg \\
\hline 295 & Stellaria holostea L. & Szilvásvárad & 1966 & Siroki Zoltán & DE-siroki-06243.jpg \\
\hline 295 & Stellaria holostea L. & Szilvásvárad & 1966 & Siroki Zoltán & DE-siroki-06244.jpg \\
\hline 296 & Stellaria alsine Grimm & Nagyhuta & 1961 & Siroki Zoltán & DE-siroki-06266.jpg \\
\hline 296 & Stellaria alsine Grimm & Nagyhuta & 1961 & Siroki Zoltán & DE-siroki-06267.jpg \\
\hline 296 & Stellaria alsine Grimm & Nagyhuta & 1961 & Siroki Zoltán & DE-siroki-06268.jpg \\
\hline 296 & Stellaria alsine Grimm & Nagyhuta & 1961 & Siroki Zoltán & DE-siroki-06269.jpg \\
\hline 296 & Stellaria alsine Grimm & Nagyhuta & 1961 & Siroki Zoltán & DE-siroki-06271.jpg \\
\hline 296 & Stellaria alsine Grimm & Nagyhuta & 1961 & Siroki Zoltán & DE-siroki-06272.jpg \\
\hline 296 & Stellaria alsine Grimm & Nagyhuta & 1961 & Siroki Zoltán & DE-siroki-06273.jpg \\
\hline 296 & Stellaria alsine Grimm & Nagyhuta & 1961 & Siroki Zoltán & DE-siroki-06274.jpg \\
\hline 296 & Stellaria alsine Grimm & Nagyhuta & 1963 & Siroki Zoltán & DE-siroki-06270.jpg \\
\hline 296 & Stellaria alsine Grimm & Sopron & 1956 & Kovács Béla & DE-siroki-06261.jpg \\
\hline 296 & Stellaria alsine Grimm & Sopron & 1956 & Kovács Béla & DE-siroki-06262.jpg \\
\hline
\end{tabular}




\begin{tabular}{|c|c|c|c|c|c|}
\hline $\begin{array}{l}\text { Sorszám / } \\
\text { Number }\end{array}$ & Taxon-név / Taxon-name & $\begin{array}{l}\text { Település / } \\
\text { Settlement }\end{array}$ & $\begin{array}{l}\text { Év / } \\
\text { Year }\end{array}$ & $\begin{array}{l}\text { Gyűjtő / } \\
\text { Collector }\end{array}$ & Fájlnév / File-name \\
\hline 297 & Stellaria graminea L. & Debrecen & 1954 & Siroki Zoltán & DE-siroki-06280.jpg \\
\hline 297 & Stellaria graminea L. & Debrecen & 1954 & Siroki Zoltán & DE-siroki-06281.jpg \\
\hline 297 & Stellaria graminea L. & Nagyhuta & 1978 & Siroki Zoltán & DE-siroki-06276.jpg \\
\hline 297 & Stellaria graminea L. & Nagyhuta & 1978 & Siroki Zoltán & DE-siroki-06275.jpg \\
\hline 299 & Holosteum umbellatum L. & Debrecen & 1947 & Siroki Zoltán & DE-siroki-06412.jpg \\
\hline 299 & Holosteum umbellatum L. & Debrecen & 1947 & Siroki Zoltán & DE-siroki-06413.jpg \\
\hline 299 & Holosteum umbellatum L. & Debrecen & 1954 & Siroki Zoltán & DE-siroki-06415.jpg \\
\hline 299 & Holosteum umbellatum L. & Debrecen & 1954 & Siroki Zoltán & DE-siroki-06414.jpg \\
\hline 300 & Cerastium dubium (Bastard) Guépin & Abaújkér & 1942 & Siroki Zoltán & DE-siroki-06396.jpg \\
\hline 300 & Cerastium dubium (Bastard) Guépin & Biharugra & 1961 & Siroki Zoltán & DE-siroki-06405.jpg \\
\hline 300 & Cerastium dubium (Bastard) Guépin & Debrecen & 1947 & Siroki Zoltán & DE-siroki-06400.jpg \\
\hline 300 & Cerastium dubium (Bastard) Guépin & Debrecen & 1954 & Siroki Zoltán & DE-siroki-06403.jpg \\
\hline 300 & Cerastium dubium (Bastard) Guépin & Debrecen & 1954 & Siroki Zoltán & DE-siroki-06402.jpg \\
\hline 300 & Cerastium dubium (Bastard) Guépin & Debrecen & 1954 & Siroki Zoltán & DE-siroki-06404.jpg \\
\hline 300 & Cerastium dubium (Bastard) Guépin & Debrecen & 1958 & Siroki Zoltán & DE-siroki-06397.jpg \\
\hline 300 & Cerastium dubium (Bastard) Guépin & Debrecen & 1958 & Siroki Zoltán & DE-siroki-06398.jpg \\
\hline 300 & Cerastium dubium (Bastard) Guépin & Debrecen & 1958 & Siroki Zoltán & DE-siroki-06399.jpg \\
\hline 300 & Cerastium dubium (Bastard) Guépin & Debrecen & 1958 & Siroki Zoltán & DE-siroki-06401.jpg \\
\hline 300 & Cerastium dubium (Bastard) Guépin & Derecske & 1972 & Siroki Zoltán & DE-siroki-06406.jpg \\
\hline 300 & Cerastium dubium (Bastard) Guépin & Derecske & 1972 & Siroki Zoltán & DE-siroki-06407.jpg \\
\hline 300 & Cerastium dubium (Bastard) Guépin & Hortobágy & 1947 & Siroki Zoltán & DE-siroki-06394.jpg \\
\hline 300 & Cerastium dubium (Bastard) Guépin & Hortobágy & 1947 & Siroki Zoltán & DE-siroki-06395.jpg \\
\hline 301 & Cerastium glomeratum Thuill. & Budapest & 1951 & Siroki Zoltán & DE-siroki-06283.jpg \\
\hline 303 & Cerastium brachypetalum Desp. & Budapest & 1952 & Siroki Zoltán & DE-siroki-06287.jpg \\
\hline 303 & Cerastium brachypetalum Desp. & Debrecen & 1949 & Siroki Zoltán & DE-siroki-06290.jpg \\
\hline 303 & Cerastium brachypetalum Desp. & Debrecen & 1949 & Siroki Zoltán & DE-siroki-06291.jpg \\
\hline 303 & Cerastium brachypetalum Desp. & Debrecen & 1949 & Siroki Zoltán & DE-siroki-06292.jpg \\
\hline 303 & Cerastium brachypetalum Desp. & Debrecen & 1949 & Siroki Zoltán & DE-siroki-06293.jpg \\
\hline 303 & Cerastium brachypetalum Desp. & Debrecen & 1965 & Siroki Zoltán & DE-siroki-06294.jpg \\
\hline 303 & Cerastium brachypetalum Desp. & Debrecen & 1965 & Siroki Zoltán & DE-siroki-06295.jpg \\
\hline 303 & Cerastium brachypetalum Desp. & Gödöllő & 1951 & Siroki Zoltán & DE-siroki-06286.jpg \\
\hline 303 & Cerastium brachypetalum Desp. & Gödöllő & 1952 & Siroki Zoltán & DE-siroki-06285.jpg \\
\hline 303 & Cerastium brachypetalum Desp. & Hernádszurdok & 1944 & Siroki Zoltán & DE-siroki-06301.jpg \\
\hline 303 & Cerastium brachypetalum Desp. & Hernádszurdok & 1944 & Siroki Zoltán & DE-siroki-06300.jpg \\
\hline 303 & Cerastium brachypetalum Desp. & Nagykovácsi & 1959 & Siroki Zoltán & DE-siroki-06298.jpg \\
\hline 303 & Cerastium brachypetalum Desp. & Pilisszentiván & 1915 & Degen Árpád & DE-siroki-06296.jpg \\
\hline 303 & Cerastium brachypetalum Desp. & Szemenye & 1951 & Siroki Zoltán & DE-siroki-06297.jpg \\
\hline 303 & Cerastium brachypetalum Desp. & Tarpa & 1955 & Siroki Zoltán & DE-siroki-06288.jpg \\
\hline 305 & Cerastium semidecandrum L. & Budapest & 1904 & $\begin{array}{l}\text { Thaisz Lajos - } \\
\text { Baán Lajos }\end{array}$ & DE-siroki-06318.jpg \\
\hline 305 & Cerastium semidecandrum L. & Budapest & 1910 & Kocsis István & DE-siroki-06320.jpg \\
\hline 305 & Cerastium semidecandrum L. & Debrecen & 1946 & Siroki Zoltán & DE-siroki-06329.jpg \\
\hline 305 & Cerastium semidecandrum L. & Debrecen & 1946 & Siroki Zoltán & DE-siroki-06324.jpg \\
\hline 305 & Cerastium semidecandrum L. & Debrecen & 1947 & Siroki Zoltán & DE-siroki-06325.jpg \\
\hline 305 & Cerastium semidecandrum L. & Debrecen & 1950 & Siroki Zoltán & DE-siroki-06330.jpg \\
\hline 305 & Cerastium semidecandrum L. & Debrecen & 1950 & Siroki Zoltán & DE-siroki-06326.jpg \\
\hline 305 & Cerastium semidecandrum L. & Debrecen & 1954 & Siroki Zoltán & DE-siroki-06327.jpg \\
\hline
\end{tabular}




\begin{tabular}{|c|c|c|c|c|c|}
\hline $\begin{array}{l}\text { Sorszám / } \\
\text { Number }\end{array}$ & Taxon-név / Taxon-name & $\begin{array}{l}\text { Település / } \\
\text { Settlement }\end{array}$ & $\begin{array}{l}\text { Év / } \\
\text { Year }\end{array}$ & $\begin{array}{l}\text { Gyújitő / } \\
\text { Collector }\end{array}$ & Fájlnév / File-name \\
\hline 305 & Cerastium semidecandrum L. & Debrecen & 1954 & Siroki Zoltán & DE-siroki-06328.jpg \\
\hline 305 & Cerastium semidecandrum L. & Debrecen & 1965 & Siroki Zoltán & DE-siroki-06331.jpg \\
\hline 305 & Cerastium semidecandrum L. & Debrecen & 1965 & Siroki Zoltán & DE-siroki-06332.jpg \\
\hline 305 & Cerastium semidecandrum L. & Debrecen & 1965 & Siroki Zoltán & DE-siroki-06333.jpg \\
\hline 305 & Cerastium semidecandrum L. & Debrecen & 1965 & Siroki Zoltán & DE-siroki-06334.jpg \\
\hline 305 & Cerastium semidecandrum L. & Debrecen & 1971 & Siroki Zoltán & DE-siroki-06335.jpg \\
\hline 305 & Cerastium semidecandrum L. & Debrecen & 1972 & Siroki Zoltán & DE-siroki-06316.jpg \\
\hline 305 & Cerastium semidecandrum L. & Gödöllő & 1952 & Kocsis István & DE-siroki-06322.jpg \\
\hline 305 & Cerastium semidecandrum L. & Hortobágy & 1976 & Siroki Zoltán & DE-siroki-06317.jpg \\
\hline 305 & Cerastium semidecandrum L. & Pilisszentiván & 1910 & Kocsis István & DE-siroki-06321.jpg \\
\hline 306 & Cerastium pumilum Curtis & Berekböszörmény & 1970 & Siroki Zoltán & DE-siroki-06336.jpg \\
\hline 307 & Cerastium glutinosum Fr. & Budapest & 1911 & Kocsis István & DE-siroki-06343.jpg \\
\hline 307 & Cerastium glutinosum Fr. & Szentistván & 1980 & Siroki Zoltán & DE-siroki-06344.jpg \\
\hline 308 & Cerastium sylvaticum Waldst. et Kit. & Füzér & 1966 & Siroki Zoltán & DE-siroki-06371.jpg \\
\hline 308 & Cerastium sylvaticum Waldst. et Kit. & Háromhuta & 1960 & Siroki Zoltán & DE-siroki-06347.jpg \\
\hline 308 & Cerastium sylvaticum Waldst. et Kit. & Háromhuta & 1960 & Siroki Zoltán & DE-siroki-06348.jpg \\
\hline 308 & Cerastium sylvaticum Waldst. et Kit. & Háromhuta & 1960 & Siroki Zoltán & DE-siroki-06349.jpg \\
\hline 308 & Cerastium sylvaticum Waldst. et Kit. & Háromhuta & 1960 & Siroki Zoltán & DE-siroki-06351.jpg \\
\hline 308 & Cerastium sylvaticum Waldst. et Kit. & Háromhuta & 1960 & Siroki Zoltán & DE-siroki-06352.jpg \\
\hline 308 & Cerastium sylvaticum Waldst. et Kit. & Háromhuta & 1960 & Siroki Zoltán & DE-siroki-06355.jpg \\
\hline 308 & Cerastium sylvaticum Waldst. et Kit. & Háromhuta & 1960 & Siroki Zoltán & DE-siroki-06356.jpg \\
\hline 308 & Cerastium sylvaticum Waldst. et Kit. & Háromhuta & 1960 & Siroki Zoltán & DE-siroki-06357.jpg \\
\hline 308 & Cerastium sylvaticum Waldst. et Kit. & Háromhuta & 1977 & Siroki Zoltán & DE-siroki-06361.jpg \\
\hline 308 & Cerastium sylvaticum Waldst. et Kit. & Háromhuta & 1977 & Siroki Zoltán & DE-siroki-06363.jpg \\
\hline 308 & Cerastium sylvaticum Waldst. et Kit. & Háromhuta & 1977 & Siroki Zoltán & DE-siroki-06364.jpg \\
\hline 308 & Cerastium sylvaticum Waldst. et Kit. & Nagyhuta & 1961 & Siroki Zoltán & DE-siroki-06353.jpg \\
\hline 308 & Cerastium sylvaticum Waldst. et Kit. & Nagyhuta & 1961 & Siroki Zoltán & DE-siroki-06354.jpg \\
\hline 308 & Cerastium sylvaticum Waldst. et Kit. & Nagyhuta & 1961 & Siroki Zoltán & DE-siroki-06358.jpg \\
\hline 308 & Cerastium sylvaticum Waldst. et Kit. & Nagyhuta & 1961 & Siroki Zoltán & DE-siroki-06359.jpg \\
\hline 308 & Cerastium sylvaticum Waldst. et Kit. & Nagyhuta & 1961 & Siroki Zoltán & DE-siroki-06367.jpg \\
\hline 308 & Cerastium sylvaticum Waldst. et Kit. & Nagyhuta & 1961 & Siroki Zoltán & DE-siroki-06368.jpg \\
\hline 308 & Cerastium sylvaticum Waldst. et Kit. & Nagyhuta & 1961 & Siroki Zoltán & DE-siroki-06369.jpg \\
\hline 308 & Cerastium sylvaticum Waldst. et Kit. & Nagyhuta & 1961 & Siroki Zoltán & DE-siroki-06370.jpg \\
\hline 308 & Cerastium sylvaticum Waldst. et Kit. & Nagyhuta & 1978 & Siroki Zoltán & DE-siroki-06350.jpg \\
\hline 308 & Cerastium sylvaticum Waldst. et Kit. & Nagyhuta & 1978 & Siroki Zoltán & DE-siroki-06360.jpg \\
\hline 308 & Cerastium sylvaticum Waldst. et Kit. & Nagyhuta & 1978 & Siroki Zoltán & DE-siroki-06366.jpg \\
\hline 308 & Cerastium sylvaticum Waldst. et Kit. & Nagyhuta & 1978 & Siroki Zoltán & DE-siroki-06362.jpg \\
\hline 308 & Cerastium sylvaticum Waldst. et Kit. & Nagyhuta & 1978 & Siroki Zoltán & DE-siroki-06365.jpg \\
\hline $309-310$ & Cerastium fontanum Baumg. s.l. & Budapest & 1981 & Siroki Zoltán & DE-siroki-06310.jpg \\
\hline $309-310$ & Cerastium fontanum Baumg. s.l. & Debrecen & 1948 & Siroki Zoltán & DE-siroki-06307.jpg \\
\hline $309-310$ & Cerastium fontanum Baumg. s.l. & Debrecen & 1949 & Siroki Zoltán & DE-siroki-06308.jpg \\
\hline $309-310$ & Cerastium fontanum Baumg. s.l. & Debrecen & 1955 & Siroki Zoltán & DE-siroki-06306.jpg \\
\hline $309-310$ & Cerastium fontanum Baumg. s.l. & Debrecen & 1960 & Siroki Zoltán & DE-siroki-06309.jpg \\
\hline $309-310$ & Cerastium fontanum Baumg. s.l. & Gégény & 1965 & Siroki Zoltán & DE-siroki-06311.jpg \\
\hline $309-310$ & Cerastium fontanum Baumg. s.l. & Miskolc & 1965 & Siroki Zoltán & DE-siroki-06312.jpg \\
\hline $309-310$ & Cerastium fontanum Baumg. s.l. & Miskolc & 1965 & Siroki Zoltán & DE-siroki-06313.jpg \\
\hline
\end{tabular}




\begin{tabular}{|c|c|c|c|c|c|}
\hline $\begin{array}{l}\text { Sorszám / } \\
\text { Number }\end{array}$ & Taxon-név / Taxon-name & $\begin{array}{l}\text { Település / } \\
\text { Settlement }\end{array}$ & $\begin{array}{l}\text { Év / } \\
\text { Year }\end{array}$ & $\begin{array}{l}\text { Gyújtő / } \\
\text { Collector }\end{array}$ & Fájlnév / File-name \\
\hline 311 & Cerastium arvense $\mathrm{L}$. & Bélapátfalva & 1913 & Hulják János & DE-siroki-06392.jpg \\
\hline 311 & Cerastium arvense L. & Budapest & 1951 & Siroki Zoltán & DE-siroki-06384.jpg \\
\hline 311 & Cerastium arvense L. & Budapest & 1951 & Siroki Zoltán & DE-siroki-06389.jpg \\
\hline 311 & Cerastium arvense $\mathrm{L}$. & Budapest & 1981 & Siroki Zoltán & DE-siroki-06383.jpg \\
\hline 311 & Cerastium arvense $\mathrm{L}$. & Budapest & 1981 & Siroki Zoltán & DE-siroki-06382.jpg \\
\hline 313 & Moenchia mantica (L.) Bartl. & Budapest & 1951 & Siroki Zoltán & DE-siroki-06416.jpg \\
\hline 313 & Moenchia mantica (L.) Bartl. & Budapest & 1962 & Siroki Zoltán & DE-siroki-06417.jpg \\
\hline 313 & Moenchia mantica (L.) Bartl. & Budapest & 1962 & Siroki Zoltán & DE-siroki-06418.jpg \\
\hline 313 & Moenchia mantica (L.) Bartl. & Budapest & 1962 & Siroki Zoltán & DE-siroki-06419.jpg \\
\hline 313 & Moenchia mantica (L.) Bartl. & Budapest & 1962 & Siroki Zoltán & DE-siroki-06420.jpg \\
\hline 313 & Moenchia mantica (L.) Bartl. & Budapest & 1962 & Siroki Zoltán & DE-siroki-06421.jpg \\
\hline 314 & Myosoton aquaticum (L.) Moench & Debrecen & 1950 & Siroki Zoltán & DE-siroki-06233.jpg \\
\hline 314 & Myosoton aquaticum (L.) Moench & Debrecen & 1950 & Siroki Zoltán & DE-siroki-06232.jpg \\
\hline 314 & Myosoton aquaticum (L.) Moench & Debrecen & 1977 & Siroki Zoltán & DE-siroki-06234.jpg \\
\hline 314 & Myosoton aquaticum (L.) Moench & Debrecen & 1977 & Siroki Zoltán & DE-siroki-06235.jpg \\
\hline 315 & Sagina procumbens L. & "Nagymező" & 1959 & Siroki Zoltán & DE-siroki-06425.jpg \\
\hline 315 & Sagina procumbens L. & Debrecen & 1948 & Siroki Zoltán & DE-siroki-06435.jpg \\
\hline 315 & Sagina procumbens L. & Debrecen & 1950 & Siroki Zoltán & DE-siroki-06430.jpg \\
\hline 315 & Sagina procumbens L. & Debrecen & 1950 & Siroki Zoltán & DE-siroki-06431.jpg \\
\hline 315 & Sagina procumbens L. & Debrecen & 1958 & Siroki Zoltán & DE-siroki-06436.jpg \\
\hline 315 & Sagina procumbens L. & Debrecen & 1968 & Siroki Zoltán & DE-siroki-06434.jpg \\
\hline 315 & Sagina procumbens L. & Debrecen & 1968 & Siroki Zoltán & DE-siroki-06432.jpg \\
\hline 315 & Sagina procumbens L. & Debrecen & 1968 & Siroki Zoltán & DE-siroki-06433.jpg \\
\hline 315 & Sagina procumbens L. & Nagyhuta & 1961 & Siroki Zoltán & DE-siroki-06426.jpg \\
\hline 315 & Sagina procumbens L. & Nyírbéltek & 1967 & Gondola István & DE-siroki-06428.jpg \\
\hline 315 & Sagina procumbens L. & Nyírbéltek & 1967 & Gondola István & DE-siroki-06429.jpg \\
\hline 315 & Sagina procumbens L. & Újkenéz & 1966 & Gondola István & DE-siroki-06427.jpg \\
\hline 318 & Sagina subulata (Sw.) C. Presl & Parád & 1871 & Vrabélyi Márton & DE-siroki-06437.jpg \\
\hline 323 & Scleranthus annuus L. & Budapest & 1951 & Siroki Zoltán & DE-siroki-06617.jpg \\
\hline 323 & Scleranthus annuus L. & Nagyhuta & 1978 & Siroki Zoltán & DE-siroki-06616.jpg \\
\hline 323 & Scleranthus annuus L. & Vámospércs & 1984 & Siroki Zoltán & DE-siroki-06615.jpg \\
\hline 323 & Scleranthus annuus L. & Vámospércs & 1985 & Siroki Zoltán & DE-siroki-06614.jpg \\
\hline 324 & $\begin{array}{l}\text { Paronychia cephalotes } \\
\text { (M. Bieb.) Besser }\end{array}$ & Budaörs & 1951 & Siroki Zoltán & DE-siroki-06599.jpg \\
\hline 324 & $\begin{array}{l}\text { Paronychia cephalotes } \\
\text { (M. Bieb.) Besser }\end{array}$ & Budaörs & 1952 & Siroki Zoltán & DE-siroki-06600.jpg \\
\hline 324 & $\begin{array}{l}\text { Paronychia cephalotes } \\
\text { (M. Bieb.) Besser }\end{array}$ & Budaörs & 1965 & Siroki Zoltán & DE-siroki-06597.jpg \\
\hline 324 & $\begin{array}{l}\text { Paronychia cephalotes } \\
\text { (M. Bieb.) Besser }\end{array}$ & Budaörs & 1965 & Siroki Zoltán & DE-siroki-06598.jpg \\
\hline 324 & $\begin{array}{l}\text { Paronychia cephalotes } \\
\text { (M. Bieb.) Besser }\end{array}$ & Nagykovácsi & 1957 & Siroki Zoltán & DE-siroki-06601.jpg \\
\hline 325 & Herniaria glabra L. & Debrecen & 1954 & Siroki Zoltán & DE-siroki-06602.jpg \\
\hline 325 & Herniaria glabra L. & Debrecen & 1957 & Siroki Zoltán & DE-siroki-06603.jpg \\
\hline 325 & Herniaria glabra L. & Debrecen & 1968 & Siroki Zoltán & DE-siroki-06604.jpg \\
\hline 326 & Herniaria hirsuta L. & "Szent-György-hegy" & 1955 & Siroki Zoltán & DE-siroki-06606.jpg \\
\hline 327 & Herniaria incana Lam. & Budaörs & 1952 & Siroki Zoltán & DE-siroki-06611.jpg \\
\hline 327 & Herniaria incana Lam. & Budaörs & 1955 & Siroki Zoltán & DE-siroki-06612.jpg \\
\hline 327 & Herniaria incana Lam. & Budaörs & - & Siroki Zoltán & DE-siroki-06610.jpg \\
\hline
\end{tabular}




\begin{tabular}{|c|c|c|c|c|c|}
\hline $\begin{array}{l}\text { Sorszám / } \\
\text { Number }\end{array}$ & Taxon-név / Taxon-name & $\begin{array}{l}\text { Település / } \\
\text { Settlement }\end{array}$ & $\begin{array}{l}\text { Év / } \\
\text { Year }\end{array}$ & $\begin{array}{l}\text { Gyűjtő / } \\
\text { Collector }\end{array}$ & Fájlnév / File-name \\
\hline 327 & Herniaria incana Lam. & Budapest & 1909 & Kocsis István & DE-siroki-06607.jpg \\
\hline 327 & Herniaria incana Lam. & Gödöllő & 1952 & Siroki Zoltán & DE-siroki-06609.jpg \\
\hline 327 & Herniaria incana Lam. & Nagykovácsi & 1951 & $\begin{array}{l}\text { Priszter } \\
\text { Szaniszló }\end{array}$ & DE-siroki-06608.jpg \\
\hline 329 & Spergula arvensis L. & Kántorjánosi & 1967 & Gondola István & DE-siroki-06551.jpg \\
\hline 329 & Spergula arvensis L. & Mátészalka & 1966 & Gondola István & DE-siroki-06552.jpg \\
\hline 329 & Spergula arvensis L. & Nyírmeggyes & 1966 & Gondola István & DE-siroki-06546.jpg \\
\hline 329 & Spergula arvensis L. & Nyírmeggyes & 1966 & Gondola István & DE-siroki-06547.jpg \\
\hline 329 & Spergula arvensis L. & Nyírmeggyes & 1966 & Gondola István & DE-siroki-06548.jpg \\
\hline 329 & Spergula arvensis L. & Nyírmeggyes & 1966 & Gondola István & DE-siroki-06549.jpg \\
\hline 329 & Spergula arvensis L. & Nyírmeggyes & 1966 & Gondola István & DE-siroki-06550.jpg \\
\hline 329 & Spergula arvensis L. & Nyírmihálydi & 1966 & Gondola István & DE-siroki-06539.jpg \\
\hline 329 & Spergula arvensis L. & Nyírmihálydi & 1966 & Gondola István & DE-siroki-06540.jpg \\
\hline 329 & Spergula arvensis L. & Nyírmihálydi & 1966 & Gondola István & DE-siroki-06541.jpg \\
\hline 330 & Spergula pentandra L. & Debrecen & 1946 & Siroki Zoltán & DE-siroki-06568.jpg \\
\hline 330 & Spergula pentandra L. & Debrecen & 1954 & Siroki Zoltán & DE-siroki-06561.jpg \\
\hline 330 & Spergula pentandra L. & Debrecen & 1954 & Siroki Zoltán & DE-siroki-06562.jpg \\
\hline 330 & Spergula pentandra L. & Debrecen & 1954 & Siroki Zoltán & DE-siroki-06563.jpg \\
\hline 330 & Spergula pentandra L. & Debrecen & 1954 & Siroki Zoltán & DE-siroki-06564.jpg \\
\hline 330 & Spergula pentandra L. & Debrecen & 1954 & Siroki Zoltán & DE-siroki-06569.jpg \\
\hline 330 & Spergula pentandra L. & Nyíradony & 1967 & Gondola István & DE-siroki-06559.jpg \\
\hline 330 & Spergula pentandra L. & Nyíradony & 1967 & Gondola István & DE-siroki-06560.jpg \\
\hline 331 & Spergularia maritima (All.) Chiov. & Budaörs & 1941 & Siroki Zoltán & DE-siroki-06579.jpg \\
\hline 331 & Spergularia maritima (All.) Chiov. & Budaörs & 1941 & Siroki Zoltán & DE-siroki-06578.jpg \\
\hline 331 & Spergularia maritima (All.) Chiov. & Bugyi & 1952 & Gondola István & DE-siroki-06570.jpg \\
\hline 331 & Spergularia maritima (All.) Chiov. & Dömsöd & 1952 & Siroki Zoltán & DE-siroki-06577.jpg \\
\hline 331 & Spergularia maritima (All.) Chiov. & Dömsöd & 1952 & Siroki Zoltán & DE-siroki-06572.jpg \\
\hline 331 & Spergularia maritima (All.) Chiov. & Hortobágy & 1970 & Siroki Zoltán & DE-siroki-06573.jpg \\
\hline 331 & Spergularia maritima (All.) Chiov. & Hortobágy & 1970 & Siroki Zoltán & DE-siroki-06574.jpg \\
\hline 331 & Spergularia maritima (All.) Chiov. & Hortobágy & 1970 & Siroki Zoltán & DE-siroki-06575.jpg \\
\hline 331 & Spergularia maritima (All.) Chiov. & Hortobágy & 1970 & Siroki Zoltán & DE-siroki-06576.jpg \\
\hline 331 & Spergularia maritima (All.) Chiov. & Kecskemét & 1969 & Siroki Zoltán & DE-siroki-06571.jpg \\
\hline 332 & $\begin{array}{l}\text { Spergularia rubra } \\
\text { (L.) J. Presl et C. Presl }\end{array}$ & Budapest & 1951 & Siroki Zoltán & DE-siroki-06584.jpg \\
\hline 332 & $\begin{array}{l}\text { Spergularia rubra } \\
\text { (L.) J. Presl et C. Presl }\end{array}$ & Budapest & 1951 & Siroki Zoltán & DE-siroki-06585.jpg \\
\hline 332 & $\begin{array}{l}\text { Spergularia rubra } \\
\text { (L.) J. Presl et C. Presl }\end{array}$ & Egyek & 1947 & Siroki Zoltán & DE-siroki-06583.jpg \\
\hline 332 & $\begin{array}{l}\text { Spergularia rubra } \\
\text { (L.) J. Presl et C. Presl }\end{array}$ & Hortobágy & 1954 & Siroki Zoltán & DE-siroki-06582.jpg \\
\hline 332 & $\begin{array}{l}\text { Spergularia rubra } \\
\text { (L.) J. Presl et C. Presl }\end{array}$ & Hortobágy & 1955 & Siroki Zoltán & DE-siroki-06581.jpg \\
\hline 332 & $\begin{array}{l}\text { Spergularia rubra } \\
\text { (L.) J. Presl et C. Presl }\end{array}$ & Hortobágy & 1975 & Siroki Zoltán & DE-siroki-06580.jpg \\
\hline 333 & Spergularia salina J. Presl et C. Presl & Hortobágy & 1954 & Siroki Zoltán & DE-siroki-06588.jpg \\
\hline 333 & Spergularia salina J. Presl et C. Presl & Hortobágy & 1954 & Siroki Zoltán & DE-siroki-06593.jpg \\
\hline 333 & Spergularia salina J. Presl et C. Presl & Hortobágy & 1955 & Siroki Zoltán & DE-siroki-06589.jpg \\
\hline 333 & Spergularia salina J. Presl et C. Presl & Hortobágy & 1955 & Siroki Zoltán & DE-siroki-06590.jpg \\
\hline 333 & Spergularia salina J. Presl et C. Presl & Hortobágy & 1955 & Siroki Zoltán & DE-siroki-06591.jpg \\
\hline 333 & Spergularia salina J. Presl et C. Presl & Hortobágy & 1955 & Siroki Zoltán & DE-siroki-06592.jpg \\
\hline
\end{tabular}




\begin{tabular}{|c|c|c|c|c|c|}
\hline $\begin{array}{l}\text { Sorszám / } \\
\text { Number }\end{array}$ & Taxon-név / Taxon-name & $\begin{array}{l}\text { Település / } \\
\text { Settlement }\end{array}$ & $\begin{array}{l}\text { Év / } \\
\text { Year }\end{array}$ & $\begin{array}{l}\text { Gyűjtő / } \\
\text { Collector }\end{array}$ & Fájlnév / File-name \\
\hline 333 & Spergularia salina J. Presl et C. Presl & Mikepércs & 1962 & Siroki Zoltán & DE-siroki-06587.jpg \\
\hline 334 & Lychnis flos-cuculi L. & Debrecen & 1948 & Siroki Zoltán & DE-siroki-06761.jpg \\
\hline 334 & Lychnis flos-cuculi L. & Mosonmagyaróvár & 1939 & Siroki Zoltán & DE-siroki-06763.jpg \\
\hline 335 & Lychnis coronaria (L.) Desr. & Debrecen & 1946 & Siroki Zoltán & DE-siroki-06760.jpg \\
\hline 335 & Lychnis coronaria (L.) Desr. & Debrecen & 1946 & Siroki Zoltán & DE-siroki-06757.jpg \\
\hline 335 & Lychnis coronaria (L.) Desr. & Debrecen & 1950 & Siroki Zoltán & DE-siroki-06756.jpg \\
\hline 335 & Lychnis coronaria (L.) Desr. & Debrecen & 1950 & Siroki Zoltán & DE-siroki-06758.jpg \\
\hline 335 & Lychnis coronaria (L.) Desr. & Debrecen & 1950 & Siroki Zoltán & DE-siroki-06759.jpg \\
\hline 335 & Lychnis coronaria (L.) Desr. & Mátraszentimre & 1959 & Gondola István & DE-siroki-06752.jpg \\
\hline 335 & Lychnis coronaria (L.) Desr. & Mátraszentimre & 1959 & Gondola István & DE-siroki-06753.jpg \\
\hline 335 & Lychnis coronaria (L.) Desr. & Mátraszentimre & 1959 & Gondola István & DE-siroki-06754.jpg \\
\hline 335 & Lychnis coronaria (L.) Desr. & Mátraszentimre & 1959 & Gondola István & DE-siroki-06755.jpg \\
\hline 336 & Lychnis viscaria L. & "Nagymező" & 1959 & Halász Tibor & DE-siroki-06634.jpg \\
\hline 336 & Lychnis viscaria L. & Debrecen & 1954 & Siroki Zoltán & DE-siroki-06633.jpg \\
\hline 336 & Lychnis viscaria L. & Egyek & 1949 & Siroki Zoltán & DE-siroki-06627.jpg \\
\hline 336 & Lychnis viscaria L. & Egyek & 1949 & Siroki Zoltán & DE-siroki-06628.jpg \\
\hline 336 & Lychnis viscaria L. & Egyek & 1949 & Siroki Zoltán & DE-siroki-06629.jpg \\
\hline 338 & Silene vulgaris (Moench) Garcke & Budapest & 1887 & Czakó Kálmán & DE-siroki-06643.jpg \\
\hline 338 & Silene vulgaris (Moench) Garcke & Debrecen & 1947 & Siroki Zoltán & DE-siroki-06644.jpg \\
\hline 338 & Silene vulgaris (Moench) Garcke & Debrecen & 1947 & Siroki Zoltán & DE-siroki-06645.jpg \\
\hline 338 & Silene vulgaris (Moench) Garcke & Mosonmagyaróvár & 1939 & Siroki Zoltán & DE-siroki-06647.jpg \\
\hline 338 & Silene vulgaris (Moench) Garcke & Mosonmagyaróvár & 1939 & Siroki Zoltán & DE-siroki-06646.jpg \\
\hline 339 & Silene otites (L.) Wibel & Debrecen & 1946 & Siroki Zoltán & DE-siroki-06657.jpg \\
\hline 339 & Silene otites (L.) Wibel & Gyenesdiás & 1953 & Siroki Zoltán & DE-siroki-06651.jpg \\
\hline 339 & Silene otites (L.) Wibel & Hortobágy & 1947 & Siroki Zoltán & DE-siroki-06656.jpg \\
\hline 339 & Silene otites (L.) Wibel & Szilvásvárad & 1959 & Siroki Zoltán & DE-siroki-06655.jpg \\
\hline 339 & Silene otites (L.) Wibel & Tokaj & 1971 & Siroki Zoltán & DE-siroki-06654.jpg \\
\hline 340 & Silene borysthenica (Gruner) Walters & Budapest & 1878 & Richter Lajos & DE-siroki-06650.jpg \\
\hline 340 & Silene borysthenica (Gruner) Walters & Budapest & 1905 & Kocsis István & DE-siroki-06649.jpg \\
\hline 341 & Silene alba (Mill.) E.H.L. Krause & Debrecen & 1947 & Siroki Zoltán & DE-siroki-06780.jpg \\
\hline 341 & Silene alba (Mill.) E.H.L. Krause & Debrecen & 1947 & Siroki Zoltán & DE-siroki-06779.jpg \\
\hline 341 & Silene alba (Mill.) E.H.L. Krause & Mosonmagyaróvár & 1939 & Siroki Zoltán & DE-siroki-06781.jpg \\
\hline 343 & Silene conica L. & Debrecen & 1948 & Siroki Zoltán & DE-siroki-06658.jpg \\
\hline 343 & Silene conica L. & Debrecen & 1948 & Siroki Zoltán & DE-siroki-06659.jpg \\
\hline 343 & Silene conica L. & Debrecen & 1948 & Siroki Zoltán & DE-siroki-06660.jpg \\
\hline 343 & Silene conica L. & Debrecen & 1948 & Siroki Zoltán & DE-siroki-06661.jpg \\
\hline 346 & Silene dichotoma Ehrh. & Budapest & 1949 & Siroki Zoltán & DE-siroki-06674.jpg \\
\hline 346 & Silene dichotoma Ehrh. & Budapest & 1951 & Siroki Zoltán & DE-siroki-06675.jpg \\
\hline 346 & Silene dichotoma Ehrh. & Budapest & 1951 & Siroki Zoltán & DE-siroki-06670.jpg \\
\hline 346 & Silene dichotoma Ehrh. & Budapest & 1951 & Siroki Zoltán & DE-siroki-06676.jpg \\
\hline 346 & Silene dichotoma Ehrh. & Budapest & 1966 & Siroki Zoltán & DE-siroki-06671.jpg \\
\hline 346 & Silene dichotoma Ehrh. & Budapest & 1966 & Siroki Zoltán & DE-siroki-06672.jpg \\
\hline 346 & Silene dichotoma Ehrh. & Budapest & 1966 & Siroki Zoltán & DE-siroki-06673.jpg \\
\hline 348 & Silene bupleuroides L. & Aggtelek & 1972 & Siroki Zoltán & DE-siroki-06697.jpg \\
\hline 348 & Silene bupleuroides L. & Aggtelek & 1972 & Siroki Zoltán & DE-siroki-06698.jpg \\
\hline 348 & Silene bupleuroides L. & Biatorbágy & 1950 & Siroki Zoltán & DE-siroki-06705.jpg \\
\hline
\end{tabular}




\begin{tabular}{|c|c|c|c|c|c|}
\hline $\begin{array}{l}\text { Sorszám / } \\
\text { Number }\end{array}$ & Taxon-név / Taxon-name & $\begin{array}{l}\text { Település / } \\
\text { Settlement }\end{array}$ & $\begin{array}{l}\text { Év / } \\
\text { Year }\end{array}$ & $\begin{array}{l}\text { Gyűjtő / } \\
\text { Collector }\end{array}$ & Fájlnév / File-name \\
\hline 348 & Silene bupleuroides L. & Budapest & 1941 & Siroki Zoltán & DE-siroki-06702.jpg \\
\hline 348 & Silene bupleuroides L. & Budapest & 1941 & Siroki Zoltán & DE-siroki-06703.jpg \\
\hline 348 & Silene bupleuroides L. & Budapest & 1941 & Siroki Zoltán & DE-siroki-06704.jpg \\
\hline 348 & Silene bupleuroides L. & Budapest & 1948 & Siroki Zoltán & DE-siroki-06699.jpg \\
\hline 348 & Silene bupleuroides L. & Budapest & 1962 & Siroki Zoltán & DE-siroki-06700.jpg \\
\hline 348 & Silene bupleuroides L. & Budapest & 1962 & Siroki Zoltán & DE-siroki-06701.jpg \\
\hline 349 & Silene multiflora (Waldst. et Kit.) Pers. & Budapest & 1909 & Kocsis István & DE-siroki-06689.jpg \\
\hline 349 & Silene multiflora (Waldst. et Kit.) Pers. & Budapest & 1909 & Kocsis István & DE-siroki-06688.jpg \\
\hline 349 & Silene multiflora (Waldst. et Kit.) Pers. & Budapest & 1950 & Siroki Zoltán & DE-siroki-06682.jpg \\
\hline 349 & Silene multiflora (Waldst. et Kit.) Pers. & Budapest & 1950 & Siroki Zoltán & DE-siroki-06683.jpg \\
\hline 349 & Silene multiflora (Waldst. et Kit.) Pers. & Budapest & 1950 & Siroki Zoltán & DE-siroki-06684.jpg \\
\hline 349 & Silene multiflora (Waldst. et Kit.) Pers. & Budapest & 1950 & Siroki Zoltán & DE-siroki-06685.jpg \\
\hline 349 & Silene multiflora (Waldst. et Kit.) Pers. & Budapest & 1950 & Siroki Zoltán & DE-siroki-06686.jpg \\
\hline 349 & Silene multiflora (Waldst. et Kit.) Pers. & Budapest & 1952 & Siroki Zoltán & DE-siroki-06687.jpg \\
\hline 349 & Silene multiflora (Waldst. et Kit.) Pers. & Bugyi & 1952 & Siroki Zoltán & DE-siroki-06690.jpg \\
\hline 349 & Silene multiflora (Waldst. et Kit.) Pers. & Nagykálló & 1974 & Siroki Zoltán & DE-siroki-06693.jpg \\
\hline 349 & Silene multiflora (Waldst. et Kit.) Pers. & Nagykálló & 1974 & Siroki Zoltán & DE-siroki-06694.jpg \\
\hline 349 & Silene multiflora (Waldst. et Kit.) Pers. & Nagykálló & 1974 & Siroki Zoltán & DE-siroki-06695.jpg \\
\hline 349 & Silene multiflora (Waldst. et Kit.) Pers. & Nagykálló & 1974 & Siroki Zoltán & DE-siroki-06696.jpg \\
\hline 349 & Silene multiflora (Waldst. et Kit.) Pers. & Sándorfalva & 1973 & Csombál József & DE-siroki-06692.jpg \\
\hline 350 & Silene viscosa (L.) Pers. & Biharugra & 1961 & Siroki Zoltán & DE-siroki-06777.jpg \\
\hline 350 & Silene viscosa (L.) Pers. & Debrecen & 1946 & Siroki Zoltán & DE-siroki-06774.jpg \\
\hline 350 & Silene viscosa (L.) Pers. & Debrecen & 1946 & Siroki Zoltán & DE-siroki-06776.jpg \\
\hline 350 & Silene viscosa (L.) Pers. & Debrecen & 1949 & Siroki Zoltán & DE-siroki-06775.jpg \\
\hline 350 & Silene viscosa (L.) Pers. & Debrecen & 1949 & Siroki Zoltán & DE-siroki-06773.jpg \\
\hline 350 & Silene viscosa (L.) Pers. & Gödöllő & 1952 & Siroki Zoltán & DE-siroki-06778.jpg \\
\hline 351 & Silene nemoralis Waldst. et Kit. & "Nagymező" & 1962 & Siroki Zoltán & DE-siroki-06711.jpg \\
\hline 351 & Silene nemoralis Waldst. et Kit. & "Nagymező" & 1962 & Siroki Zoltán & DE-siroki-06712.jpg \\
\hline 351 & Silene nemoralis Waldst. et Kit. & "Nagymező" & 1962 & Siroki Zoltán & DE-siroki-06713.jpg \\
\hline 351 & Silene nemoralis Waldst. et Kit. & "Nagymező" & 1962 & Siroki Zoltán & DE-siroki-06710.jpg \\
\hline 351 & Silene nemoralis Waldst. et Kit. & Szilvásvárad & 1960 & Siroki Zoltán & DE-siroki-06709.jpg \\
\hline 352 & Silene noctiflora L. & Budapest & 1950 & Siroki Zoltán & DE-siroki-06772.jpg \\
\hline 353 & Silene nutans L. & "Bükk-hg." & 1962 & Siroki Zoltán & DE-siroki-06739.jpg \\
\hline 353 & Silene nutans $\mathrm{L}$. & Budapest & 1981 & Siroki Zoltán & DE-siroki-06738.jpg \\
\hline 353 & Silene nutans L. & Debrecen & 1947 & Siroki Zoltán & DE-siroki-06744.jpg \\
\hline 353 & Silene nutans L. & Debrecen & 1947 & Siroki Zoltán & DE-siroki-06745.jpg \\
\hline 353 & Silene nutans $\mathrm{L}$. & Debrecen & 1954 & Siroki Zoltán & DE-siroki-06743.jpg \\
\hline 353 & Silene nutans L. & Pécs & 1958 & Siroki Zoltán & DE-siroki-06746.jpg \\
\hline 353 & Silene nutans L. & Újléta & 1967 & Siroki Zoltán & DE-siroki-06740.jpg \\
\hline 353 & Silene nutans L. & Újléta & 1967 & Siroki Zoltán & DE-siroki-06741.jpg \\
\hline 353 & Silene nutans L. & Újléta & 1967 & Siroki Zoltán & DE-siroki-06742.jpg \\
\hline 354 & Silene viridiflora L. & "Mátra" & 1984 & Siroki Zoltán & DE-siroki-06732.jpg \\
\hline 354 & Silene viridiflora L. & "Mátra" & 1984 & Siroki Zoltán & DE-siroki-06733.jpg \\
\hline 354 & Silene viridiflora L. & "Mátra" & 1984 & Siroki Zoltán & DE-siroki-06730.jpg \\
\hline 354 & Silene viridiflora L. & "Mátra" & 1984 & Siroki Zoltán & DE-siroki-06731.jpg \\
\hline 354 & Silene viridiflora L. & "Mátra" & 1984 & Siroki Zoltán & DE-siroki-06734.jpg \\
\hline
\end{tabular}




\begin{tabular}{|c|c|c|c|c|c|}
\hline $\begin{array}{l}\text { Sorszám / } \\
\text { Number }\end{array}$ & Taxon-név / Taxon-name & $\begin{array}{l}\text { Település / } \\
\text { Settlement }\end{array}$ & $\begin{array}{l}\text { Év / } \\
\text { Year }\end{array}$ & $\begin{array}{l}\text { Gyújtő / } \\
\text { Collector }\end{array}$ & Fájlnév / File-name \\
\hline 354 & Silene viridiflora $L$. & "Mátra" & 1984 & Siroki Zoltán & DE-siroki-06735.jpg \\
\hline 354 & Silene viridiflora $\mathrm{L}$. & Pásztó & 1952 & Siroki Zoltán & DE-siroki-06722.jpg \\
\hline 354 & Silene viridiflora L. & Pásztó & 1952 & Siroki Zoltán & DE-siroki-06723.jpg \\
\hline 354 & Silene viridiflora L. & Pásztó & 1952 & Siroki Zoltán & DE-siroki-06724.jpg \\
\hline 354 & Silene viridiflora L. & Pécs & 1954 & Siroki Zoltán & DE-siroki-06719.jpg \\
\hline 354 & Silene viridiflora L. & Pécs & 1954 & Siroki Zoltán & DE-siroki-06720.jpg \\
\hline 354 & Silene viridiflora L. & Pécs & 1954 & Siroki Zoltán & DE-siroki-06721.jpg \\
\hline 354 & Silene viridiflora L. & Szentendre & 1917 & Degen Árpád & DE-siroki-06726.jpg \\
\hline 354 & Silene viridiflora L. & Szilvásvárad & 1959 & Siroki Zoltán & DE-siroki-06736.jpg \\
\hline 354 & Silene viridiflora L. & Szilvásvárad & 1959 & Siroki Zoltán & DE-siroki-06737.jpg \\
\hline 354 & Silene viridiflora L. & Tahitótfalu & 1950 & Kárpáti Zoltán & DE-siroki-06725.jpg \\
\hline 354 & Silene viridiflora L. & Vác & 1916 & Degen Árpád & DE-siroki-06728.jpg \\
\hline 354 & Silene viridiflora L. & Vác & 1916 & Degen Árpád & DE-siroki-06729.jpg \\
\hline 355 & Cucubalus baccifer L. & Debrecen & 1947 & Siroki Zoltán & DE-siroki-06798.jpg \\
\hline 355 & Cucubalus baccifer L. & Debrecen & 1981 & Siroki Zoltán & DE-siroki-06795.jpg \\
\hline 355 & Cucubalus baccifer L. & Debrecen & 1981 & Siroki Zoltán & DE-siroki-06796.jpg \\
\hline 355 & Cucubalus baccifer L. & Debrecen & 1981 & Siroki Zoltán & DE-siroki-06797.jpg \\
\hline 355 & Cucubalus baccifer L. & Mátraszentimre & 1962 & Halász Tibor & DE-siroki-06793.jpg \\
\hline 355 & Cucubalus baccifer L. & Mátraszentimre & 1962 & Halász Tibor & DE-siroki-06794.jpg \\
\hline 356 & Gypsophila muralis L. & Háromhuta & 1984 & Siroki Zoltán & DE-siroki-06802.jpg \\
\hline 356 & Gypsophila muralis L. & Hortobágy & 1955 & Siroki Zoltán & DE-siroki-06803.jpg \\
\hline 359 & Gypsophila arenaria Waldst. et Kit. & Budaörs & 1941 & Siroki Zoltán & DE-siroki-06808.jpg \\
\hline 359 & Gypsophila arenaria Waldst. et Kit. & Pilisszentiván & 1950 & Siroki Zoltán & DE-siroki-06809.jpg \\
\hline 359 & Gypsophila arenaria Waldst. et Kit. & Szigetszentmiklós & 1951 & Siroki Zoltán & DE-siroki-06807.jpg \\
\hline 360 & Gypsophila paniculata L. & Budapest & 1891 & Borbás Vince & DE-siroki-06812.jpg \\
\hline 360 & Gypsophila paniculata L. & Bugac & 1973 & Siroki Zoltán & DE-siroki-06810.jpg \\
\hline 360 & Gypsophila paniculata L. & Bugac & 1973 & Siroki Zoltán & DE-siroki-06811.jpg \\
\hline 360 & Gypsophila paniculata L. & Debrecen & 1949 & Siroki Zoltán & DE-siroki-06815.jpg \\
\hline 360 & Gypsophila paniculata L. & Debrecen & 1949 & Siroki Zoltán & DE-siroki-06814.jpg \\
\hline 361 & Saponaria officinalis L. & Debrecen & 1948 & Siroki Zoltán & DE-siroki-06986.jpg \\
\hline 361 & Saponaria officinalis L. & Debrecen & 1948 & Siroki Zoltán & DE-siroki-06987.jpg \\
\hline 361 & Saponaria officinalis L. & Debrecen & 1948 & Siroki Zoltán & DE-siroki-06988.jpg \\
\hline 362 & Vaccaria hispanica (Mill.) Rauschert & Debrecen & 1948 & Siroki Zoltán & DE-siroki-06831.jpg \\
\hline 362 & Vaccaria hispanica (Mill.) Rauschert & Debrecen & 1948 & Siroki Zoltán & DE-siroki-06832.jpg \\
\hline 362 & Vaccaria hispanica (Mill.) Rauschert & Debrecen & 1948 & Siroki Zoltán & DE-siroki-06833.jpg \\
\hline 362 & Vaccaria hispanica (Mill.) Rauschert & Debrecen & 1948 & Siroki Zoltán & DE-siroki-06835.jpg \\
\hline 363 & Petrorhagia saxifraga (L.) Link & Balatongyörök & 1950 & Kárpáti Zoltán & DE-siroki-06822.jpg \\
\hline 363 & Petrorhagia saxifraga (L.) Link & Keszthely & 1955 & Siroki Zoltán & DE-siroki-06817.jpg \\
\hline 363 & Petrorhagia saxifraga (L.) Link & Pécs & 1954 & Siroki Zoltán & DE-siroki-06820.jpg \\
\hline 363 & Petrorhagia saxifraga (L.) Link & Pécs & 1954 & Siroki Zoltán & DE-siroki-06821.jpg \\
\hline 363 & Petrorhagia saxifraga (L.) Link & Pécs & 1954 & Siroki Zoltán & DE-siroki-06818.jpg \\
\hline 363 & Petrorhagia saxifraga (L.) Link & Pécs & 1954 & Siroki Zoltán & DE-siroki-06819.jpg \\
\hline 364 & $\begin{array}{l}\text { Petrorhagia prolifera } \\
\text { (L.) P.W. Ball et Heywood }\end{array}$ & Abaújszántó & 1943 & Siroki Zoltán & DE-siroki-06830.jpg \\
\hline 364 & $\begin{array}{l}\text { Petrorhagia prolifera } \\
\text { (L.) P.W. Ball et Heywood }\end{array}$ & Budapest & 1941 & Siroki Zoltán & DE-siroki-06829.jpg \\
\hline 364 & $\begin{array}{l}\text { Petrorhagia prolifera } \\
\text { (L.) P.W. Ball et Heywood }\end{array}$ & Budapest & 1941 & Siroki Zoltán & DE-siroki-06828.jpg \\
\hline
\end{tabular}




\begin{tabular}{|c|c|c|c|c|c|}
\hline $\begin{array}{l}\text { Sorszám / } \\
\text { Number }\end{array}$ & Taxon-név / Taxon-name & $\begin{array}{l}\text { Település / } \\
\text { Settlement }\end{array}$ & $\begin{array}{l}\text { Év / } \\
\text { Year }\end{array}$ & $\begin{array}{l}\text { Gyújtő / } \\
\text { Collector }\end{array}$ & Fájlnév / File-name \\
\hline 364 & $\begin{array}{l}\text { Petrorhagia prolifera } \\
\text { (L.) P.W. Ball et Heywood }\end{array}$ & Budapest & 1941 & Siroki Zoltán & DE-siroki-06827.jpg \\
\hline 364 & $\begin{array}{l}\text { Petrorhagia prolifera } \\
\text { (L.) P.W. Ball et Heywood }\end{array}$ & Debrecen & 1948 & Siroki Zoltán & DE-siroki-06826.jpg \\
\hline 364 & $\begin{array}{l}\text { Petrorhagia prolifera } \\
\text { (L.) P.W. Ball et Heywood }\end{array}$ & Debrecen & 1948 & Siroki Zoltán & DE-siroki-06825.jpg \\
\hline 364 & $\begin{array}{l}\text { Petrorhagia prolifera } \\
\text { (L.) P.W. Ball et Heywood }\end{array}$ & Debrecen & 1948 & Siroki Zoltán & DE-siroki-06824.jpg \\
\hline 366 & Dianthus superbus L. & Kiskőrös & 1954 & Siroki Zoltán & DE-siroki-06937.jpg \\
\hline 366 & Dianthus superbus L. & Nagykálló & 1974 & Siroki Zoltán & DE-siroki-06941.jpg \\
\hline 366 & Dianthus superbus L. & Nagykálló & 1974 & Siroki Zoltán & DE-siroki-06942.jpg \\
\hline 366 & Dianthus superbus L. & Nagykálló & 1974 & Siroki Zoltán & DE-siroki-06943.jpg \\
\hline 367 & Dianthus plumarius L. & Budaörs & 1966 & Siroki Zoltán & DE-siroki-06946.jpg \\
\hline 367 & Dianthus plumarius L. & Budaörs & 1966 & Siroki Zoltán & DE-siroki-06947.jpg \\
\hline 369 & Dianthus serotinus Waldst. et Kit. & Ágasegyháza & 1956 & Siroki Zoltán & DE-siroki-06953.jpg \\
\hline 369 & Dianthus serotinus Waldst. et Kit. & Ágasegyháza & 1956 & Siroki Zoltán & DE-siroki-06954.jpg \\
\hline 369 & Dianthus serotinus Waldst. et Kit. & Ágasegyháza & 1956 & Siroki Zoltán & DE-siroki-06955.jpg \\
\hline 369 & Dianthus serotinus Waldst. et Kit. & Ágasegyháza & 1969 & Siroki Zoltán & DE-siroki-06948.jpg \\
\hline 369 & Dianthus serotinus Waldst. et Kit. & Ágasegyháza & 1969 & Siroki Zoltán & DE-siroki-06949.jpg \\
\hline 369 & Dianthus serotinus Waldst. et Kit. & Ágasegyháza & 1969 & Siroki Zoltán & DE-siroki-06950.jpg \\
\hline 369 & Dianthus serotinus Waldst. et Kit. & Ágasegyháza & 1969 & Siroki Zoltán & DE-siroki-06951.jpg \\
\hline 369 & Dianthus serotinus Waldst. et Kit. & Ágasegyháza & 1969 & Siroki Zoltán & DE-siroki-06952.jpg \\
\hline 369 & Dianthus serotinus Waldst. et Kit. & Budapest & 1948 & Siroki Zoltán & DE-siroki-06957.jpg \\
\hline 369 & Dianthus serotinus Waldst. et Kit. & Budapest & 1948 & Siroki Zoltán & DE-siroki-06958.jpg \\
\hline 369 & Dianthus serotinus Waldst. et Kit. & Budapest & 1948 & Siroki Zoltán & DE-siroki-06959.jpg \\
\hline 369 & Dianthus serotinus Waldst. et Kit. & Budapest & 1948 & Siroki Zoltán & DE-siroki-06960.jpg \\
\hline 369 & Dianthus serotinus Waldst. et Kit. & Budapest & 1948 & Siroki Zoltán & DE-siroki-06961.jpg \\
\hline 369 & Dianthus serotinus Waldst. et Kit. & Budapest & 1948 & Siroki Zoltán & DE-siroki-06962.jpg \\
\hline 369 & Dianthus serotinus Waldst. et Kit. & Budapest & 1948 & Siroki Zoltán & DE-siroki-06963.jpg \\
\hline 369 & Dianthus serotinus Waldst. et Kit. & Budapest & 1950 & Siroki Zoltán & DE-siroki-06956.jpg \\
\hline 369 & Dianthus serotinus Waldst. et Kit. & Bugac & 1954 & Siroki Zoltán & DE-siroki-06944.jpg \\
\hline 369 & Dianthus serotinus Waldst. et Kit. & Bugac & 1973 & Siroki Zoltán & DE-siroki-06945.jpg \\
\hline 369 & Dianthus serotinus Waldst. et Kit. & Pilisszentiván & 1952 & Siroki Zoltán & DE-siroki-06964.jpg \\
\hline 370 & Dianthus deltoides L. & "Nagymező" & 1959 & Halász Tibor & DE-siroki-06921.jpg \\
\hline 370 & Dianthus deltoides L. & "Nagymező" & 1959 & Siroki Zoltán & DE-siroki-06917.jpg \\
\hline 370 & Dianthus deltoides L. & "Nagymező" & 1959 & Siroki Zoltán & DE-siroki-06918.jpg \\
\hline 370 & Dianthus deltoides L. & "Nagymező" & 1959 & Siroki Zoltán & DE-siroki-06919.jpg \\
\hline 370 & Dianthus deltoides L. & "Nagymező" & 1968 & Siroki Zoltán & DE-siroki-06915.jpg \\
\hline 370 & Dianthus deltoides L. & "Nagymező" & 1968 & Siroki Zoltán & DE-siroki-06916.jpg \\
\hline 370 & Dianthus deltoides L. & Gödöllő & 1952 & Siroki Zoltán & DE-siroki-06925.jpg \\
\hline 370 & Dianthus deltoides L. & Hollóháza & 1940 & Siroki Zoltán & DE-siroki-06926.jpg \\
\hline 370 & Dianthus deltoides L. & Hollóháza & 1940 & Siroki Zoltán & DE-siroki-06927.jpg \\
\hline 370 & Dianthus deltoides L. & Répáshuta & 1956 & Halász Tibor & DE-siroki-06920.jpg \\
\hline 371 & Dianthus diutinus Kit. & Monor & 1906 & Thaisz Lajos & DE-siroki-06838.jpg \\
\hline 371 & Dianthus diutinus Kit. & Nagykőrös & 1913 & Degen Árpád & DE-siroki-06837.jpg \\
\hline 371 & Dianthus diutinus Kit. & Pótharaszti & 1894 & Borbás Vince & DE-siroki-06839.jpg \\
\hline 372 & Dianthus carthusianorum L. & Háromhuta & 1960 & Siroki Zoltán & DE-siroki-06849.jpg \\
\hline 372 & Dianthus carthusianorum L. & Háromhuta & 1960 & Siroki Zoltán & DE-siroki-06850.jpg \\
\hline 372 & Dianthus carthusianorum L. & Háromhuta & 1960 & Siroki Zoltán & DE-siroki-06844.jpg \\
\hline
\end{tabular}




\begin{tabular}{|c|c|c|c|c|c|}
\hline $\begin{array}{l}\text { Sorszám / } \\
\text { Number }\end{array}$ & Taxon-név / Taxon-name & $\begin{array}{l}\text { Település / } \\
\text { Settlement }\end{array}$ & $\begin{array}{l}\text { Év / } \\
\text { Year }\end{array}$ & $\begin{array}{l}\text { Gyújitő / } \\
\text { Collector }\end{array}$ & Fájlnév / File-name \\
\hline 372 & Dianthus carthusianorum L. & Háromhuta & 1961 & Siroki Zoltán & DE-siroki-06845.jpg \\
\hline 372 & Dianthus carthusianorum L. & Háromhuta & 1961 & Siroki Zoltán & DE-siroki-06846.jpg \\
\hline 372 & Dianthus carthusianorum L. & Háromhuta & 1961 & Siroki Zoltán & DE-siroki-06847.jpg \\
\hline 372 & Dianthus carthusianorum L. & Háromhuta & 1961 & Siroki Zoltán & DE-siroki-06848.jpg \\
\hline 372 & Dianthus carthusianorum L. & Sopron & 1950 & Kárpáti Zoltán & DE-siroki-06857.jpg \\
\hline 373 & Dianthus pontederae A. Kern. & $\begin{array}{l}\text { "Bükk-hg, } \\
\text { Kiskerekhegy" }\end{array}$ & 1959 & Halász Tibor & DE-siroki-06870.jpg \\
\hline 373 & Dianthus pontederae A. Kern. & $\begin{array}{l}\text { "Bükk-hg, } \\
\text { Kiskerekhegy" }\end{array}$ & 1959 & Halász Tibor & DE-siroki-06871.jpg \\
\hline 373 & Dianthus pontederae A. Kern. & "Szent-György-hegy" & 1955 & Siroki Zoltán & DE-siroki-06879.jpg \\
\hline 373 & Dianthus pontederae A. Kern. & Abaújszántó & 1944 & Siroki Zoltán & DE-siroki-06868.jpg \\
\hline 373 & Dianthus pontederae A. Kern. & Abaújszántó & 1944 & Siroki Zoltán & DE-siroki-06869.jpg \\
\hline 373 & Dianthus pontederae A. Kern. & Boldogkőváralja & 1944 & Siroki Zoltán & DE-siroki-06883.jpg \\
\hline 373 & Dianthus pontederae A. Kern. & Budaörs & 1955 & Siroki Zoltán & DE-siroki-06873.jpg \\
\hline 373 & Dianthus pontederae A. Kern. & Budapest & 1944 & Siroki Zoltán & DE-siroki-06881.jpg \\
\hline 373 & Dianthus pontederae A. Kern. & Budapest & 1944 & Siroki Zoltán & DE-siroki-06882.jpg \\
\hline 373 & Dianthus pontederae A. Kern. & Cserszegtomaj & 1955 & Siroki Zoltán & DE-siroki-06880.jpg \\
\hline 373 & Dianthus pontederae A. Kern. & Debrecen & 1946 & Siroki Zoltán & DE-siroki-06878.jpg \\
\hline 373 & Dianthus pontederae A. Kern. & Debrecen & 1946 & Siroki Zoltán & DE-siroki-06877.jpg \\
\hline 373 & Dianthus pontederae A. Kern. & Debrecen & 1947 & Siroki Zoltán & DE-siroki-06876.jpg \\
\hline 373 & Dianthus pontederae A. Kern. & Debrecen & 1947 & Siroki Zoltán & DE-siroki-06875.jpg \\
\hline 373 & Dianthus pontederae A. Kern. & Debrecen & 1951 & Siroki Zoltán & DE-siroki-06874.jpg \\
\hline 373 & Dianthus pontederae A. Kern. & Gyenesdiás & 1972 & Siroki Zoltán & DE-siroki-06872.jpg \\
\hline 373 & Dianthus pontederae A. Kern. & Háromhuta & 1961 & Siroki Zoltán & DE-siroki-06867.jpg \\
\hline 373 & Dianthus pontederae A. Kern. & Hortobágy & 1947 & Siroki Zoltán & DE-siroki-06864.jpg \\
\hline 373 & Dianthus pontederae A. Kern. & Hortobágy & 1959 & Siroki Zoltán & DE-siroki-06865.jpg \\
\hline 373 & Dianthus pontederae A. Kern. & Hortobágy & 1959 & Siroki Zoltán & DE-siroki-06866.jpg \\
\hline 375 & Dianthus armeria L. & "Dobogókő" & 1957 & Siroki Zoltán & DE-siroki-06890.jpg \\
\hline 375 & Dianthus armeria L. & "Mátra" & 1958 & Pethő Menyhért & DE-siroki-06894.jpg \\
\hline 375 & Dianthus armeria L. & "Mátra" & 1984 & Siroki Zoltán & DE-siroki-06900.jpg \\
\hline 375 & Dianthus armeria L. & Budapest & 1966 & Siroki Zoltán & DE-siroki-06895.jpg \\
\hline 375 & Dianthus armeria L. & Hosszúhetény & 1954 & Siroki Zoltán & DE-siroki-06888.jpg \\
\hline 375 & Dianthus armeria L. & Pécs & 1954 & Siroki Zoltán & DE-siroki-06889.jpg \\
\hline 375 & Dianthus armeria L. & Pomáz & 1954 & Siroki Zoltán & DE-siroki-06892.jpg \\
\hline 375 & Dianthus armeria L. & Pomáz & 1957 & Siroki Zoltán & DE-siroki-06891.jpg \\
\hline 375 & Dianthus armeria L. & Sátoraljaújhely & 1944 & Siroki Zoltán & DE-siroki-06897.jpg \\
\hline 375 & Dianthus armeria L. & Sátoraljaújhely & 1944 & Siroki Zoltán & DE-siroki-06893.jpg \\
\hline 375 & Dianthus armeria L. & Tokaj & 1966 & Siroki Zoltán & DE-siroki-06896.jpg \\
\hline 375 & Dianthus armeria L. & Vámospércs & 1984 & Siroki Zoltán & DE-siroki-06899.jpg \\
\hline 376 & Dianthus collinus Waldst. et Kit. & Aszaló & 1944 & Siroki Zoltán & DE-siroki-06905.jpg \\
\hline 376 & Dianthus collinus Waldst. et Kit. & Aszaló & 1944 & Siroki Zoltán & DE-siroki-06906.jpg \\
\hline 376 & Dianthus collinus Waldst. et Kit. & Aszaló & 1944 & Siroki Zoltán & DE-siroki-06907.jpg \\
\hline 376 & Dianthus collinus Waldst. et Kit. & Háromhuta & 1960 & Siroki Zoltán & DE-siroki-06908.jpg \\
\hline 376 & Dianthus collinus Waldst. et Kit. & Háromhuta & 1960 & Siroki Zoltán & DE-siroki-06909.jpg \\
\hline 376 & Dianthus collinus Waldst. et Kit. & Sátoraljaújhely & 1944 & Siroki Zoltán & DE-siroki-06904.jpg \\
\hline 376 & Dianthus collinus Waldst. et Kit. & Tokaj & 1966 & Siroki Zoltán & DE-siroki-06911.jpg \\
\hline 376 & Dianthus collinus Waldst. et Kit. & Tokaj & 1966 & Siroki Zoltán & DE-siroki-06912.jpg \\
\hline
\end{tabular}




\begin{tabular}{|c|c|c|c|c|c|}
\hline $\begin{array}{l}\text { Sorszám / } \\
\text { Number }\end{array}$ & Taxon-név / Taxon-name & $\begin{array}{l}\text { Település / } \\
\text { Settlement }\end{array}$ & $\begin{array}{l}\text { Év / } \\
\text { Year }\end{array}$ & $\begin{array}{l}\text { Gyűjtő / } \\
\text { Collector }\end{array}$ & Fájlnév / File-name \\
\hline 376 & Dianthus collinus Waldst. et Kit. & Tokaj & 1971 & Siroki Zoltán & DE-siroki-06910.jpg \\
\hline 376 & Dianthus collinus Waldst. et Kit. & Tokaj & 1971 & Siroki Zoltán & DE-siroki-06913.jpg \\
\hline 379 & Nymphaea rubra Roxb. & Hévíz & 1955 & Siroki Zoltán & DE-siroki-07004.jpg \\
\hline 379 & Nymphaea rubra Roxb. & Hévíz & 1955 & Siroki Zoltán & DE-siroki-07005.jpg \\
\hline 381 & Nymphaea alba L. & Egyek & 1947 & Siroki Zoltán & DE-siroki-06992.jpg \\
\hline 381 & Nymphaea alba L. & Egyek & 1949 & Siroki Zoltán & DE-siroki-06991.jpg \\
\hline 381 & Nymphaea alba L. & Egyek & 1949 & Siroki Zoltán & DE-siroki-06993.jpg \\
\hline 381 & Nymphaea alba L. & Hortobágy & 1954 & Siroki Zoltán & DE-siroki-07003.jpg \\
\hline 381 & Nymphaea alba L. & Kállósemjén & 1955 & Kovács Béla & DE-siroki-06997.jpg \\
\hline 381 & Nymphaea alba L. & Kállósemjén & 1955 & Siroki Zoltán & DE-siroki-06995.jpg \\
\hline 381 & Nymphaea alba L. & Kállósemjén & 1955 & Siroki Zoltán & DE-siroki-06996.jpg \\
\hline 381 & Nymphaea alba L. & Tiszafüred & 1955 & Siroki Zoltán & DE-siroki-06994.jpg \\
\hline 381 & Nymphaea alba L. & Veresegyház & 1954 & Siroki Zoltán & DE-siroki-06998.jpg \\
\hline 381 & Nymphaea alba L. & Veresegyház & 1954 & Siroki Zoltán & DE-siroki-06999.jpg \\
\hline 381 & Nymphaea alba L. & Veresegyház & 1954 & Siroki Zoltán & DE-siroki-07000.jpg \\
\hline 381 & Nymphaea alba L. & Veresegyház & 1954 & Siroki Zoltán & DE-siroki-07001.jpg \\
\hline 381 & Nymphaea alba L. & Veresegyház & 1954 & Siroki Zoltán & DE-siroki-07002.jpg \\
\hline 382 & Nuphar lutea (L.) Sm. & Hortobágy & 1954 & Siroki Zoltán & DE-siroki-07011.jpg \\
\hline 382 & Nuphar lutea (L.) Sm. & Hortobágy & 1954 & Siroki Zoltán & DE-siroki-07012.jpg \\
\hline 382 & Nuphar lutea (L.) Sm. & Tiszafüred & 1949 & Siroki Zoltán & DE-siroki-07006.jpg \\
\hline 382 & Nuphar lutea (L.) Sm. & Tiszafüred & 1949 & Siroki Zoltán & DE-siroki-07008.jpg \\
\hline 382 & Nuphar lutea (L.) Sm. & Tiszafüred & 1955 & Siroki Zoltán & DE-siroki-07007.jpg \\
\hline 382 & Nuphar lutea (L.) Sm. & Tiszafüred & 1955 & Siroki Zoltán & DE-siroki-07009.jpg \\
\hline 382 & Nuphar lutea (L.) Sm. & Tiszafüred & 1955 & Siroki Zoltán & DE-siroki-07010.jpg \\
\hline 384 & Ceratophyllum submersum L. & Biatorbágy & 1950 & Siroki Zoltán & DE-siroki-07014.jpg \\
\hline 384 & Ceratophyllum submersum L. & Biatorbágy & 1950 & Siroki Zoltán & DE-siroki-07013.jpg \\
\hline 384 & Ceratophyllum submersum L. & Hortobágy & 1947 & Siroki Zoltán & DE-siroki-07015.jpg \\
\hline 385 & Ceratophyllum demersum L. & Abaújvár & 1943 & Siroki Zoltán & DE-siroki-07020.jpg \\
\hline 385 & Ceratophyllum demersum L. & Biharugra & 1961 & Siroki Zoltán & DE-siroki-07081.jpg \\
\hline 385 & Ceratophyllum demersum L. & Kalocsa & 1881 & Haynald Lajos & DE-siroki-07021.jpg \\
\hline 385 & Ceratophyllum demersum L. & Keszthely & 1955 & Siroki Zoltán & DE-siroki-07017.jpg \\
\hline 385 & Ceratophyllum demersum L. & Keszthely & 1955 & Siroki Zoltán & DE-siroki-07018.jpg \\
\hline 385 & Ceratophyllum demersum L. & Keszthely & 1955 & Siroki Zoltán & DE-siroki-07019.jpg \\
\hline 386 & $\begin{array}{l}\text { Helleborus purpurascens } \\
\text { Waldst. et Kit. }\end{array}$ & "Bükk-hg." & 1985 & Siroki Zoltán & DE-siroki-07076.jpg \\
\hline 386 & $\begin{array}{l}\text { Helleborus purpurascens } \\
\text { Waldst. et Kit. }\end{array}$ & "Pilis" & 1957 & Siroki Zoltán & DE-siroki-07079.jpg \\
\hline 386 & $\begin{array}{l}\text { Helleborus purpurascens } \\
\text { Waldst. et Kit. }\end{array}$ & Szentendre & 1951 & Siroki Zoltán & DE-siroki-07077.jpg \\
\hline 386 & $\begin{array}{l}\text { Helleborus purpurascens } \\
\text { Waldst. et Kit. }\end{array}$ & Szentendre & 1951 & Siroki Zoltán & DE-siroki-07078.jpg \\
\hline 386 & $\begin{array}{l}\text { Helleborus purpurascens } \\
\text { Waldst. et Kit. }\end{array}$ & Szentendre & 1951 & Siroki Zoltán & DE-siroki-07080.jpg \\
\hline 387 & Helleborus dumetorum Waldst. et Kit. & "Fáni-völgy" & 1955 & $\begin{array}{l}\text { Siroki Zoltán - } \\
\text { Farkas Attila }\end{array}$ & DE-siroki-07055.jpg \\
\hline 387 & Helleborus dumetorum Waldst. et Kit. & "Fáni-völgy" & 1955 & $\begin{array}{l}\text { Siroki Zoltán - } \\
\text { Farkas Attila }\end{array}$ & DE-siroki-07056.jpg \\
\hline 387 & Helleborus dumetorum Waldst. et Kit. & "Fáni-völgy" & 1955 & $\begin{array}{l}\text { Siroki Zoltán - } \\
\text { Farkas Attila }\end{array}$ & DE-siroki-07057.jpg \\
\hline 387 & Helleborus dumetorum Waldst. et Kit. & Budakeszi & 1951 & Siroki Zoltán & DE-siroki-07061.jpg \\
\hline 387 & Helleborus dumetorum Waldst. et Kit. & Budapest & 1951 & Siroki Zoltán & DE-siroki-07062.jpg \\
\hline
\end{tabular}




\begin{tabular}{|c|c|c|c|c|c|}
\hline $\begin{array}{l}\text { Sorszám / } \\
\text { Number }\end{array}$ & Taxon-név / Taxon-name & $\begin{array}{l}\text { Település / } \\
\text { Settlement }\end{array}$ & $\begin{array}{l}\text { Év / } \\
\text { Year }\end{array}$ & $\begin{array}{l}\text { Gyüjtő / } \\
\text { Collector }\end{array}$ & Fájlnév / File-name \\
\hline 387 & Helleborus dumetorum Waldst. et Kit. & Budapest & 1951 & Siroki Zoltán & DE-siroki-07058.jpg \\
\hline 387 & Helleborus dumetorum Waldst. et Kit. & Budapest & 1951 & Siroki Zoltán & DE-siroki-07059.jpg \\
\hline 387 & Helleborus dumetorum Waldst. et Kit. & Hosszúhetény & 1958 & Koppányi Tibor & DE-siroki-07063.jpg \\
\hline 387 & Helleborus dumetorum Waldst. et Kit. & Törökbálint & 1951 & Siroki Zoltán & DE-siroki-07060.jpg \\
\hline 388 & Helleborus odorus Waldst. et Kit. & Pécs & 1951 & Kárpáti Zoltán & DE-siroki-07075.jpg \\
\hline 388 & Helleborus odorus Waldst. et Kit. & Pécs & 1954 & Siroki Zoltán & DE-siroki-07067.jpg \\
\hline 388 & Helleborus odorus Waldst. et Kit. & Pécs & 1954 & Siroki Zoltán & DE-siroki-07064.jpg \\
\hline 388 & Helleborus odorus Waldst. et Kit. & Pécs & 1954 & Siroki Zoltán & DE-siroki-07065.jpg \\
\hline 388 & Helleborus odorus Waldst. et Kit. & Pécs & 1954 & Siroki Zoltán & DE-siroki-07066.jpg \\
\hline 388 & Helleborus odorus Waldst. et Kit. & Pécs & 1954 & Siroki Zoltán & DE-siroki-07068.jpg \\
\hline 388 & Helleborus odorus Waldst. et Kit. & Pécs & 1954 & Siroki Zoltán & DE-siroki-07069.jpg \\
\hline 388 & Helleborus odorus Waldst. et Kit. & Pécs & 1954 & Siroki Zoltán & DE-siroki-07070.jpg \\
\hline 388 & Helleborus odorus Waldst. et Kit. & Pécs & 1958 & Halász Tibor & DE-siroki-07073.jpg \\
\hline 388 & Helleborus odorus Waldst. et Kit. & Pécs & 1958 & Koppányi Tibor & DE-siroki-07072.jpg \\
\hline 388 & Helleborus odorus Waldst. et Kit. & Pécs & 1973 & Fazekas János & DE-siroki-07074.jpg \\
\hline 388 & Helleborus odorus Waldst. et Kit. & Pécs & - & Siroki Zoltán & DE-siroki-07071.jpg \\
\hline 389 & Eranthis hyemalis (L.) Salisb. & Budapest & 1951 & Siroki Zoltán & DE-siroki-07083.jpg \\
\hline 389 & Eranthis hyemalis (L.) Salisb. & Budapest & 1951 & Siroki Zoltán & DE-siroki-07082.jpg \\
\hline 389 & Eranthis hyemalis (L.) Salisb. & Keszthely & 1951 & Kovács Béla & DE-siroki-07084.jpg \\
\hline 391 & Nigella arvensis L. & Mosonmagyaróvár & 1939 & Siroki Zoltán & DE-siroki-07087.jpg \\
\hline 393 & Trollius europaeus L. & Bátorliget & 1954 & Siroki Zoltán & DE-siroki-07052.jpg \\
\hline 393 & Trollius europaeus L. & Bátorliget & 1954 & Siroki Zoltán & DE-siroki-07050.jpg \\
\hline 393 & Trollius europaeus L. & Bátorliget & 1954 & Siroki Zoltán & DE-siroki-07051.jpg \\
\hline 394 & Isopyrum thalictroides L. & "Dobogókő" & 1957 & Siroki Zoltán & DE-siroki-07089.jpg \\
\hline 394 & Isopyrum thalictroides L. & Háromhuta & 1955 & Siroki Zoltán & DE-siroki-07090.jpg \\
\hline 395 & Actaea spicata L. & "Háromkő" & 1956 & Halász Tibor & DE-siroki-07098.jpg \\
\hline 395 & Actaea spicata L. & "Nagymező" & 1959 & Halász Tibor & DE-siroki-07092.jpg \\
\hline 395 & Actaea spicata L. & "Szent-György-hegy" & 1955 & Siroki Zoltán & DE-siroki-07096.jpg \\
\hline 395 & Actaea spicata L. & "Szent-György-hegy" & 1955 & Siroki Zoltán & DE-siroki-07097.jpg \\
\hline 395 & Actaea spicata L. & Szilvásvárad & 1954 & Siroki Zoltán & DE-siroki-07093.jpg \\
\hline 395 & Actaea spicata L. & Szilvásvárad & 1954 & Siroki Zoltán & DE-siroki-07094.jpg \\
\hline 395 & Actaea spicata L. & Szilvásvárad & 1954 & Siroki Zoltán & DE-siroki-07095.jpg \\
\hline 396 & Cimicifuga europaea Schipcz. & Nagyvisnyó & 1959 & Siroki Zoltán & DE-siroki-07106.jpg \\
\hline 396 & Cimicifuga europaea Schipcz. & Nagyvisnyó & 1959 & Siroki Zoltán & DE-siroki-07107.jpg \\
\hline 396 & Cimicifuga europaea Schipcz. & Nagyvisnyó & 1959 & Siroki Zoltán & DE-siroki-07108.jpg \\
\hline 396 & Cimicifuga europaea Schipcz. & Nagyvisnyó & 1959 & Siroki Zoltán & DE-siroki-07109.jpg \\
\hline 396 & Cimicifuga europaea Schipcz. & Nagyvisnyó & 1959 & Siroki Zoltán & DE-siroki-07110.jpg \\
\hline 396 & Cimicifuga europaea Schipcz. & Nagyvisnyó & 1959 & Siroki Zoltán & DE-siroki-07111.jpg \\
\hline 396 & Cimicifuga europaea Schipcz. & Nagyvisnyó & 1959 & Siroki Zoltán & DE-siroki-07112.jpg \\
\hline 396 & Cimicifuga europaea Schipcz. & Nagyvisnyó & 1959 & Siroki Zoltán & DE-siroki-07113.jpg \\
\hline 396 & Cimicifuga europaea Schipcz. & Nagyvisnyó & 1959 & Siroki Zoltán & DE-siroki-07114.jpg \\
\hline 396 & Cimicifuga europaea Schipcz. & Nagyvisnyó & 1959 & Siroki Zoltán & DE-siroki-07115.jpg \\
\hline 396 & Cimicifuga europaea Schipcz. & Nagyvisnyó & 1959 & Siroki Zoltán & DE-siroki-07116.jpg \\
\hline 396 & Cimicifuga europaea Schipcz. & Nagyvisnyó & 1959 & Siroki Zoltán & DE-siroki-07117.jpg \\
\hline 397 & Caltha palustris L. & Debrecen & 1947 & Siroki Zoltán & DE-siroki-07036.jpg \\
\hline 397 & Caltha palustris L. & Debrecen & 1947 & Siroki Zoltán & DE-siroki-07039.jpg \\
\hline
\end{tabular}




\begin{tabular}{|c|c|c|c|c|c|}
\hline $\begin{array}{l}\text { Sorszám / } \\
\text { Number }\end{array}$ & Taxon-név / Taxon-name & $\begin{array}{l}\text { Település / } \\
\text { Settlement }\end{array}$ & $\begin{array}{l}\text { Év / } \\
\text { Year }\end{array}$ & $\begin{array}{l}\text { Gyűjtő / } \\
\text { Collector }\end{array}$ & Fájlnév / File-name \\
\hline 397 & Caltha palustris L. & Debrecen & 1949 & Siroki Zoltán & DE-siroki-07037.jpg \\
\hline 397 & Caltha palustris L. & Debrecen & 1949 & Siroki Zoltán & DE-siroki-07038.jpg \\
\hline 398 & Aconitum anthora L. & "Hármaskő" & 1957 & Siroki Zoltán & DE-siroki-07173.jpg \\
\hline 398 & Aconitum anthora L. & "Hármaskő" & 1957 & Siroki Zoltán & DE-siroki-07174.jpg \\
\hline 398 & Aconitum anthora L. & "Tarkő" & 1958 & Siroki Zoltán & DE-siroki-07171.jpg \\
\hline 398 & Aconitum anthora L. & "Tarkő" & 1958 & Siroki Zoltán & DE-siroki-07172.jpg \\
\hline 398 & Aconitum anthora L. & Szilvásvárad & 1959 & Siroki Zoltán & DE-siroki-07167.jpg \\
\hline 398 & Aconitum anthora L. & Szilvásvárad & 1959 & Siroki Zoltán & DE-siroki-07168.jpg \\
\hline 398 & Aconitum anthora L. & Szilvásvárad & 1959 & Siroki Zoltán & DE-siroki-07169.jpg \\
\hline 398 & Aconitum anthora L. & Szilvásvárad & 1959 & Siroki Zoltán & DE-siroki-07170.jpg \\
\hline 399 & Aconitum vulparia Rchb. & "Nagymező" & 1960 & Siroki Zoltán & DE-siroki-07152.jpg \\
\hline 399 & Aconitum vulparia Rchb. & Budapest & 1941 & Siroki Zoltán & DE-siroki-07155.jpg \\
\hline 399 & Aconitum vulparia Rchb. & Budapest & 1941 & Siroki Zoltán & DE-siroki-07156.jpg \\
\hline 399 & Aconitum vulparia Rchb. & Budapest & 1950 & Siroki Zoltán & DE-siroki-07157.jpg \\
\hline 399 & Aconitum vulparia Rchb. & Budapest & 1960 & Siroki Zoltán & DE-siroki-07153.jpg \\
\hline 399 & Aconitum vulparia Rchb. & Budapest & 1960 & Siroki Zoltán & DE-siroki-07154.jpg \\
\hline 399 & Aconitum vulparia Rchb. & Hosszúhetény & 1954 & Siroki Zoltán & DE-siroki-07161.jpg \\
\hline 399 & Aconitum vulparia Rchb. & Hosszúhetény & 1954 & Siroki Zoltán & DE-siroki-07162.jpg \\
\hline 399 & Aconitum vulparia Rchb. & Nagykovácsi & 1913 & Bocskay Ottó & DE-siroki-07159.jpg \\
\hline 399 & Aconitum vulparia Rchb. & Pécs & 1954 & Siroki Zoltán & DE-siroki-07160.jpg \\
\hline 400 & Aconitum variegatum L. & "Nagymező" & 1958 & Siroki Zoltán & DE-siroki-07184.jpg \\
\hline 400 & Aconitum variegatum L. & "Nagymező" & 1958 & Siroki Zoltán & DE-siroki-07185.jpg \\
\hline 400 & Aconitum variegatum L. & "Nagymező" & 1960 & Siroki Zoltán & DE-siroki-07186.jpg \\
\hline 400 & Aconitum variegatum L. & "Nagymező" & 1960 & Siroki Zoltán & DE-siroki-07187.jpg \\
\hline 400 & Aconitum variegatum L. & "Nagymező" & 1960 & Siroki Zoltán & DE-siroki-07188.jpg \\
\hline 400 & Aconitum variegatum L. & "Nagymező" & 1960 & Siroki Zoltán & DE-siroki-07189.jpg \\
\hline 400 & Aconitum variegatum L. & "Nagymező" & 1960 & Siroki Zoltán & DE-siroki-07190.jpg \\
\hline 400 & Aconitum variegatum L. & "Tarkő" & 1958 & Siroki Zoltán & DE-siroki-07191.jpg \\
\hline 400 & Aconitum variegatum L. & "Tarkő" & 1958 & Siroki Zoltán & DE-siroki-07192.jpg \\
\hline 400 & Aconitum variegatum L. & "Tarkő" & 1958 & Siroki Zoltán & DE-siroki-07193.jpg \\
\hline 400 & Aconitum variegatum L. & "Tarkő" & 1958 & Siroki Zoltán & DE-siroki-07194.jpg \\
\hline 400 & Aconitum variegatum L. & "Tarkő" & 1958 & Siroki Zoltán & DE-siroki-07195.jpg \\
\hline 400 & Aconitum variegatum L. & "Tarkő" & 1958 & Siroki Zoltán & DE-siroki-07196.jpg \\
\hline 400 & Aconitum variegatum $\mathrm{L}$. & "Tarkő" & 1958 & Siroki Zoltán & DE-siroki-07198.jpg \\
\hline 400 & Aconitum variegatum L. & Füzér & 1966 & Gondola István & DE-siroki-07197.jpg \\
\hline 400 & Aconitum variegatum $\mathrm{L}$. & Füzér & 1966 & Gondola István & DE-siroki-07199.jpg \\
\hline 401 & Aconitum moldavicum Hacq. & "Nagymező" & 1958 & Siroki Zoltán & DE-siroki-07141.jpg \\
\hline 401 & Aconitum moldavicum Hacq. & "Nagymező" & 1958 & Siroki Zoltán & DE-siroki-07142.jpg \\
\hline 401 & Aconitum moldavicum Hacq. & "Nagymező" & 1958 & Siroki Zoltán & DE-siroki-07140.jpg \\
\hline 401 & Aconitum moldavicum Hacq. & "Nagymező" & 1958 & Siroki Zoltán & DE-siroki-07143.jpg \\
\hline 401 & Aconitum moldavicum Hacq. & "Nagymező" & 1958 & Siroki Zoltán & DE-siroki-07144.jpg \\
\hline 401 & Aconitum moldavicum Hacq. & "Nagymező" & 1958 & Siroki Zoltán & DE-siroki-07145.jpg \\
\hline 401 & Aconitum moldavicum Hacq. & "Nagymező" & 1958 & Siroki Zoltán & DE-siroki-07146.jpg \\
\hline 401 & Aconitum moldavicum Hacq. & "Nagymező" & 1958 & Siroki Zoltán & DE-siroki-07147.jpg \\
\hline 403 & Consolida regalis Gray & Debrecen & 1947 & Siroki Zoltán & DE-siroki-07122.jpg \\
\hline 403 & Consolida regalis Gray & Debrecen & 1947 & Siroki Zoltán & DE-siroki-07123.jpg \\
\hline
\end{tabular}




\begin{tabular}{|c|c|c|c|c|c|}
\hline $\begin{array}{l}\text { Sorszám / } \\
\text { Number }\end{array}$ & Taxon-név / Taxon-name & $\begin{array}{l}\text { Település / } \\
\text { Settlement }\end{array}$ & $\begin{array}{l}\text { Év / } \\
\text { Year }\end{array}$ & $\begin{array}{l}\text { Gyújtő / } \\
\text { Collector }\end{array}$ & Fájlnév / File-name \\
\hline 404 & $\begin{array}{l}\text { Consolida orientalis } \\
\text { (J. Gay) Schrödinger }\end{array}$ & Debrecen & 1947 & Siroki Zoltán & DE-siroki-07130.jpg \\
\hline 404 & $\begin{array}{l}\text { Consolida orientalis } \\
\text { (J. Gay) Schrödinger }\end{array}$ & Dombrád & 1966 & Gondola István & DE-siroki-07125.jpg \\
\hline 404 & $\begin{array}{l}\text { Consolida orientalis } \\
\text { (J. Gay) Schrödinger }\end{array}$ & Dombrád & 1966 & Gondola István & DE-siroki-07126.jpg \\
\hline 404 & $\begin{array}{l}\text { Consolida orientalis } \\
\text { (J. Gay) Schrödinger }\end{array}$ & Dombrád & 1966 & Gondola István & DE-siroki-07127.jpg \\
\hline 404 & $\begin{array}{l}\text { Consolida orientalis } \\
\text { (J. Gay) Schrödinger }\end{array}$ & Dombrád & 1966 & Gondola István & DE-siroki-07128.jpg \\
\hline 408 & Anemone ranunculoides L. & Debrecen & 1940 & Siroki Zoltán & DE-siroki-07265.jpg \\
\hline 409 & Anemone sylvestris L. & "Nagymező" & 1957 & Siroki Zoltán & DE-siroki-07262.jpg \\
\hline 409 & Anemone sylvestris L. & "Nagymező" & 1957 & Siroki Zoltán & DE-siroki-07263.jpg \\
\hline 409 & Anemone sylvestris L. & "Nagymező" & 1959 & Halász Tibor & DE-siroki-07259.jpg \\
\hline 409 & Anemone sylvestris L. & "Nagymező" & 1959 & Halász Tibor & DE-siroki-07260.jpg \\
\hline 409 & Anemone sylvestris L. & "Nagymező" & 1959 & Halász Tibor & DE-siroki-07261.jpg \\
\hline 411 & Anemone nemorosa L. & Háromhuta & 1955 & Simon Tiborné & DE-siroki-07269.jpg \\
\hline 411 & Anemone nemorosa L. & Nagyhuta & 1954 & Simon Tiborné & DE-siroki-07271.jpg \\
\hline 411 & Anemone nemorosa L. & Nagyhuta & 1954 & Simon Tiborné & DE-siroki-07272.jpg \\
\hline 411 & Anemone nemorosa L. & Nagyhuta & 1955 & Simon Tiborné & DE-siroki-07270.jpg \\
\hline 411 & Anemone nemorosa L. & Tarpa & 1971 & Siroki Zoltán & DE-siroki-07267.jpg \\
\hline 411 & Anemone nemorosa L. & Tarpa & 1971 & Siroki Zoltán & DE-siroki-07268.jpg \\
\hline 412 & Hepatica nobilis Schreb. & Hosszúhetény & 1958 & Siroki Zoltán & DE-siroki-07281.jpg \\
\hline 412 & Hepatica nobilis Schreb. & Pécs & 1954 & Siroki Zoltán & DE-siroki-07279.jpg \\
\hline 412 & Hepatica nobilis Schreb. & Pécs & 1954 & Siroki Zoltán & DE-siroki-07282.jpg \\
\hline 412 & Hepatica nobilis Schreb. & Pécs & 1958 & Halász Tibor & DE-siroki-07276.jpg \\
\hline 412 & Hepatica nobilis Schreb. & Pécs & 1958 & Koppányi Tibor & DE-siroki-07277.jpg \\
\hline 412 & Hepatica nobilis Schreb. & Pécs & 1958 & Koppányi Tibor & DE-siroki-07278.jpg \\
\hline 412 & Hepatica nobilis Schreb. & Pécs & 1958 & Siroki Zoltán & DE-siroki-07280.jpg \\
\hline 412 & Hepatica nobilis Schreb. & Szentendre & 1951 & Siroki Zoltán & DE-siroki-07283.jpg \\
\hline 412 & Hepatica nobilis Schreb. & Szentendre & 1951 & Siroki Zoltán & DE-siroki-07284.jpg \\
\hline 413 & Pulsatilla patens (L.) Mill. & Bátorliget & 1954 & Simon Tiborné & DE-siroki-07238.jpg \\
\hline 413 & Pulsatilla patens (L.) Mill. & Bátorliget & 1954 & Simon Tiborné & DE-siroki-07239.jpg \\
\hline 413 & Pulsatilla patens (L.) Mill. & Bátorliget & 1954 & Simon Tiborné & DE-siroki-07237.jpg \\
\hline 413 & Pulsatilla patens (L.) Mill. & Bátorliget & 1959 & Siroki Zoltán & DE-siroki-07240.jpg \\
\hline 413 & Pulsatilla patens (L.) Mill. & Bátorliget & 1959 & Siroki Zoltán & DE-siroki-07241.jpg \\
\hline 414 & Pulsatilla grandis Wender. & Bátorliget & 1954 & Simon Tiborné & DE-siroki-07244.jpg \\
\hline 414 & Pulsatilla grandis Wender. & Bátorliget & 1954 & Simon Tiborné & DE-siroki-07245.jpg \\
\hline 414 & Pulsatilla grandis Wender. & Bátorliget & 1954 & Simon Tiborné & DE-siroki-07246.jpg \\
\hline 414 & Pulsatilla grandis Wender. & Bátorliget & 1959 & Siroki Zoltán & DE-siroki-07249.jpg \\
\hline 414 & Pulsatilla grandis Wender. & Bátorliget & 1959 & Siroki Zoltán & DE-siroki-07250.jpg \\
\hline 414 & Pulsatilla grandis Wender. & Bátorliget & 1959 & Siroki Zoltán & DE-siroki-07247.jpg \\
\hline 414 & Pulsatilla grandis Wender. & Bátorliget & 1959 & Siroki Zoltán & DE-siroki-07248.jpg \\
\hline 414 & Pulsatilla grandis Wender. & Budapest & 1952 & Siroki Zoltán & DE-siroki-07243.jpg \\
\hline 415 & Pulsatilla flavescens (Hazsl.) Borbás & Bátorliget & 1954 & Simon Tiborné & DE-siroki-07230.jpg \\
\hline 415 & Pulsatilla flavescens (Hazsl.) Borbás & Bátorliget & 1954 & Simon Tiborné & DE-siroki-07216.jpg \\
\hline 415 & Pulsatilla flavescens (Hazsl.) Borbás & Bátorliget & 1954 & Simon Tiborné & DE-siroki-07217.jpg \\
\hline 415 & Pulsatilla flavescens (Hazsl.) Borbás & Bátorliget & 1954 & Siroki Zoltán & DE-siroki-07209.jpg \\
\hline 415 & Pulsatilla flavescens (Hazsl.) Borbás & Bátorliget & 1954 & Siroki Zoltán & DE-siroki-07210.jpg \\
\hline
\end{tabular}




\begin{tabular}{|c|c|c|c|c|c|}
\hline $\begin{array}{l}\text { Sorszám / } \\
\text { Number }\end{array}$ & Taxon-név / Taxon-name & $\begin{array}{l}\text { Település / } \\
\text { Settlement }\end{array}$ & $\begin{array}{l}\text { Év / } \\
\text { Year }\end{array}$ & $\begin{array}{l}\text { Gyújtő / } \\
\text { Collector }\end{array}$ & Fájlnév / File-name \\
\hline 415 & Pulsatilla flavescens (Hazsl.) Borbás & Bátorliget & 1954 & Siroki Zoltán & DE-siroki-07215.jpg \\
\hline 415 & Pulsatilla flavescens (Hazsl.) Borbás & Bátorliget & 1959 & Siroki Zoltán & DE-siroki-07219.jpg \\
\hline 415 & Pulsatilla flavescens (Hazsl.) Borbás & Bátorliget & 1959 & Siroki Zoltán & DE-siroki-07220.jpg \\
\hline 415 & Pulsatilla flavescens (Hazsl.) Borbás & Bátorliget & 1959 & Siroki Zoltán & DE-siroki-07221.jpg \\
\hline 415 & Pulsatilla flavescens (Hazsl.) Borbás & Bátorliget & 1959 & Siroki Zoltán & DE-siroki-07222.jpg \\
\hline 415 & Pulsatilla flavescens (Hazsl.) Borbás & Bátorliget & 1959 & Siroki Zoltán & DE-siroki-07225.jpg \\
\hline 415 & Pulsatilla flavescens (Hazsl.) Borbás & Bátorliget & 1959 & Siroki Zoltán & DE-siroki-07226.jpg \\
\hline 415 & Pulsatilla flavescens (Hazsl.) Borbás & Bátorliget & 1959 & Siroki Zoltán & DE-siroki-07227.jpg \\
\hline 415 & Pulsatilla flavescens (Hazsl.) Borbás & Bátorliget & 1959 & Siroki Zoltán & DE-siroki-07228.jpg \\
\hline 415 & Pulsatilla flavescens (Hazsl.) Borbás & Debrecen & 1949 & Siroki Zoltán & DE-siroki-07218.jpg \\
\hline 415 & Pulsatilla flavescens (Hazsl.) Borbás & Debrecen & 1949 & Siroki Zoltán & DE-siroki-07229.jpg \\
\hline 415 & Pulsatilla flavescens (Hazsl.) Borbás & Debrecen & 1950 & Siroki Zoltán & DE-siroki-07223.jpg \\
\hline 415 & Pulsatilla flavescens (Hazsl.) Borbás & Debrecen & 1950 & Siroki Zoltán & DE-siroki-07231.jpg \\
\hline 415 & Pulsatilla flavescens (Hazsl.) Borbás & Debrecen & 1950 & Siroki Zoltán & DE-siroki-07232.jpg \\
\hline 416 & Pulsatilla nigricans Störck & Budaörs & 1951 & Siroki Zoltán & DE-siroki-07206.jpg \\
\hline 416 & Pulsatilla nigricans Störck & Budaörs & 1952 & Siroki Zoltán & DE-siroki-07207.jpg \\
\hline 416 & Pulsatilla nigricans Störck & Budaörs & 1952 & Siroki Zoltán & DE-siroki-07208.jpg \\
\hline 416 & Pulsatilla nigricans Störck & Gödöllő & 1952 & Siroki Zoltán & DE-siroki-07212.jpg \\
\hline 416 & Pulsatilla nigricans Störck & Gödöllő & 1952 & Siroki Zoltán & DE-siroki-07211.jpg \\
\hline 416 & Pulsatilla nigricans Störck & Gyenesdiás & 1953 & Siroki Zoltán & DE-siroki-07213.jpg \\
\hline 416 & Pulsatilla nigricans Störck & Gyenesdiás & 1953 & Siroki Zoltán & DE-siroki-07214.jpg \\
\hline $414 \times 416$ & $\begin{array}{l}\text { Pulsatilla grandis Wender. × Pulsatilla } \\
\text { nigricans Störck }\end{array}$ & Esztergom & 1951 & Kárpáti Zoltán & DE-siroki-07236.jpg \\
\hline 418 & Clematis integrifolia L. & Abaújvár & 1943 & Siroki Zoltán & DE-siroki-07296.jpg \\
\hline 418 & Clematis integrifolia L. & Egyek & 1947 & Siroki Zoltán & DE-siroki-07295.jpg \\
\hline 418 & Clematis integrifolia L. & Mosonmagyaróvár & 1939 & Siroki Zoltán & DE-siroki-07294.jpg \\
\hline 424 & Adonis vernalis L. & Budapest & 1941 & Siroki Zoltán & DE-siroki-07573.jpg \\
\hline 424 & Adonis vernalis L. & Budapest & 1970 & Siroki Zoltán & DE-siroki-07572.jpg \\
\hline 426 & Adonis flammea Jacq. & Baracska & 1951 & Siroki Zoltán & DE-siroki-07577.jpg \\
\hline 426 & Adonis flammea Jacq. & Baracska & 1951 & Siroki Zoltán & DE-siroki-07578.jpg \\
\hline 426 & Adonis flammea Jacq. & Budapest & 1951 & Siroki Zoltán & DE-siroki-07580.jpg \\
\hline 426 & Adonis flammea Jacq. & Budapest & 1951 & Siroki Zoltán & DE-siroki-07581.jpg \\
\hline 426 & Adonis flammea Jacq. & Budapest & 1951 & Siroki Zoltán & DE-siroki-07582.jpg \\
\hline 426 & Adonis flammea Jacq. & Budapest & 1951 & Siroki Zoltán & DE-siroki-07583.jpg \\
\hline 426 & Adonis flammea Jacq. & Budapest & 1951 & Siroki Zoltán & DE-siroki-07576.jpg \\
\hline 426 & Adonis flammea Jacq. & Budapest & 1951 & Siroki Zoltán & DE-siroki-07579.jpg \\
\hline 426 & Adonis flammea Jacq. & Dorog & 1901 & Thaisz Lajos & DE-siroki-07585.jpg \\
\hline 426 & Adonis flammea Jacq. & Dömsöd & 1952 & Siroki Zoltán & DE-siroki-07586.jpg \\
\hline 426 & Adonis flammea Jacq. & Gödöllő & 1952 & Máthé Imre & DE-siroki-07584.jpg \\
\hline 427 & Adonis aestivalis L. & Debrecen & 1947 & Siroki Zoltán & DE-siroki-07590.jpg \\
\hline 427 & Adonis aestivalis L. & Debrecen & 1947 & Siroki Zoltán & DE-siroki-07592.jpg \\
\hline 427 & Adonis aestivalis L. & Debrecen & 1947 & Siroki Zoltán & DE-siroki-07589.jpg \\
\hline 427 & Adonis aestivalis L. & Debrecen & 1954 & Siroki Zoltán & DE-siroki-07591.jpg \\
\hline 430 & Ranunculus aquatilis L. & Biharugra & 1961 & Siroki Zoltán & DE-siroki-07319.jpg \\
\hline 430 & Ranunculus aquatilis L. & Hortobágy & 1947 & Siroki Zoltán & DE-siroki-07321.jpg \\
\hline 430 & Ranunculus aquatilis L. & Hortobágy & 1947 & Siroki Zoltán & DE-siroki-07320.jpg \\
\hline 430 & Ranunculus aquatilis L. & Mezőpeterd & 1959 & Siroki Zoltán & DE-siroki-07322.jpg \\
\hline
\end{tabular}




\begin{tabular}{|c|c|c|c|c|c|}
\hline $\begin{array}{l}\text { Sorszám / } \\
\text { Number }\end{array}$ & Taxon-név / Taxon-name & $\begin{array}{l}\text { Település / } \\
\text { Settlement }\end{array}$ & $\begin{array}{l}\text { Év / } \\
\text { Year }\end{array}$ & $\begin{array}{l}\text { Gyűjtő / } \\
\text { Collector }\end{array}$ & Fájlnév / File-name \\
\hline 430 & Ranunculus aquatilis L. & Mezőpeterd & 1959 & Siroki Zoltán & DE-siroki-07323.jpg \\
\hline 434 & Ranunculus trichophyllus Chaix & Debrecen & 1947 & Siroki Zoltán & DE-siroki-07329.jpg \\
\hline 434 & Ranunculus trichophyllus Chaix & Debrecen & 1947 & Siroki Zoltán & DE-siroki-07328.jpg \\
\hline 434 & Ranunculus trichophyllus Chaix & Debrecen & 1957 & Siroki Zoltán & DE-siroki-07327.jpg \\
\hline 434 & Ranunculus trichophyllus Chaix & Mikepércs & 1965 & Siroki Zoltán & DE-siroki-07325.jpg \\
\hline 434 & Ranunculus trichophyllus Chaix & Mikepércs & 1965 & Siroki Zoltán & DE-siroki-07326.jpg \\
\hline 434 & Ranunculus trichophyllus Chaix & Pilisszentiván & 1952 & Siroki Zoltán & DE-siroki-07330.jpg \\
\hline 435 & Ranunculus ficaria L. & Debrecen & 1949 & Siroki Zoltán & DE-siroki-07341.jpg \\
\hline 435 & Ranunculus ficaria L. & Debrecen & 1949 & Siroki Zoltán & DE-siroki-07342.jpg \\
\hline 436 & Ranunculus pedatus Waldst. et Kit. & Abaújkér & 1942 & Siroki Zoltán & DE-siroki-07349.jpg \\
\hline 436 & Ranunculus pedatus Waldst. et Kit. & Budapest & 1952 & Siroki Zoltán & DE-siroki-07348.jpg \\
\hline 436 & Ranunculus pedatus Waldst. et Kit. & Debrecen & 1947 & Siroki Zoltán & DE-siroki-07347.jpg \\
\hline 436 & Ranunculus pedatus Waldst. et Kit. & Debrecen & 1947 & Siroki Zoltán & DE-siroki-07346.jpg \\
\hline 437 & Ranunculus illyricus L. & Debrecen & 1947 & Siroki Zoltán & DE-siroki-07352.jpg \\
\hline 437 & Ranunculus illyricus L. & Debrecen & 1950 & Siroki Zoltán & DE-siroki-07353.jpg \\
\hline 437 & Ranunculus illyricus L. & Hernádszurdok & 1944 & Siroki Zoltán & DE-siroki-07350.jpg \\
\hline 439 & Ranunculus lateriflorus DC. & Egyek & 1947 & Siroki Zoltán & DE-siroki-07367.jpg \\
\hline 439 & Ranunculus lateriflorus DC. & Hortobágy & 1947 & Siroki Zoltán & DE-siroki-07368.jpg \\
\hline 439 & Ranunculus lateriflorus DC. & Hortobágy & 1947 & Siroki Zoltán & DE-siroki-07369.jpg \\
\hline 439 & Ranunculus lateriflorus DC. & Hortobágy & 1947 & Siroki Zoltán & DE-siroki-07366.jpg \\
\hline 439 & Ranunculus lateriflorus DC. & Hortobágy & 1959 & Siroki Zoltán & DE-siroki-07357.jpg \\
\hline 439 & Ranunculus lateriflorus DC. & Hortobágy & 1959 & Siroki Zoltán & DE-siroki-07358.jpg \\
\hline 439 & Ranunculus lateriflorus DC. & Hortobágy & 1959 & Siroki Zoltán & DE-siroki-07359.jpg \\
\hline 439 & Ranunculus lateriflorus DC. & Hortobágy & 1961 & Siroki Zoltán & DE-siroki-07356.jpg \\
\hline 439 & Ranunculus lateriflorus DC. & Hortobágy & 1961 & Siroki Zoltán & DE-siroki-07360.jpg \\
\hline 439 & Ranunculus lateriflorus DC. & Hortobágy & 1961 & Siroki Zoltán & DE-siroki-07361.jpg \\
\hline 439 & Ranunculus lateriflorus DC. & Hortobágy & 1961 & Siroki Zoltán & DE-siroki-07362.jpg \\
\hline 439 & Ranunculus lateriflorus DC. & Hortobágy & 1961 & Siroki Zoltán & DE-siroki-07363.jpg \\
\hline 439 & Ranunculus lateriflorus DC. & Hortobágy & 1961 & Siroki Zoltán & DE-siroki-07364.jpg \\
\hline 439 & Ranunculus lateriflorus DC. & Hortobágy & 1961 & Siroki Zoltán & DE-siroki-07365.jpg \\
\hline 439 & Ranunculus lateriflorus DC. & Hortobágy & 1986 & Siroki Zoltán & DE-siroki-07354.jpg \\
\hline 439 & Ranunculus lateriflorus DC. & Hortobágy & 1986 & Siroki Zoltán & DE-siroki-07355.jpg \\
\hline 441 & Ranunculus cymbalaria Pursh & Debrecen & 1947 & Siroki Zoltán & DE-siroki-07500.jpg \\
\hline 441 & Ranunculus cymbalaria Pursh & Debrecen & 1950 & Siroki Zoltán & DE-siroki-07501.jpg \\
\hline 441 & Ranunculus cymbalaria Pursh & Debrecen & 1950 & Siroki Zoltán & DE-siroki-07502.jpg \\
\hline 442 & Ranunculus flammula L. & Csaroda & 1960 & Siroki Zoltán & DE-siroki-07374.jpg \\
\hline 442 & Ranunculus flammula L. & Csaroda & 1960 & Siroki Zoltán & DE-siroki-07375.jpg \\
\hline 442 & Ranunculus flammula L. & Csaroda & 1960 & Siroki Zoltán & DE-siroki-07376.jpg \\
\hline 442 & Ranunculus flammula L. & Csaroda & 1960 & Siroki Zoltán & DE-siroki-07377.jpg \\
\hline 442 & Ranunculus flammula L. & Csaroda & 1960 & Siroki Zoltán & DE-siroki-07378.jpg \\
\hline 442 & Ranunculus flammula L. & Csaroda & 1960 & Siroki Zoltán & DE-siroki-07379.jpg \\
\hline 442 & Ranunculus flammula L. & Csaroda & 1960 & Siroki Zoltán & DE-siroki-07380.jpg \\
\hline 442 & Ranunculus flammula L. & Csaroda & 1960 & Siroki Zoltán & DE-siroki-07381.jpg \\
\hline 442 & Ranunculus flammula L. & Nagyhuta & 1961 & Siroki Zoltán & DE-siroki-07370.jpg \\
\hline 442 & Ranunculus flammula L. & Nagyhuta & 1961 & Siroki Zoltán & DE-siroki-07371.jpg \\
\hline 442 & Ranunculus flammula L. & Nagyhuta & 1961 & Siroki Zoltán & DE-siroki-07372.jpg \\
\hline
\end{tabular}




\begin{tabular}{|c|c|c|c|c|c|}
\hline $\begin{array}{l}\text { Sorszám / } \\
\text { Number }\end{array}$ & Taxon-név / Taxon-name & $\begin{array}{l}\text { Település / } \\
\text { Settlement }\end{array}$ & $\begin{array}{l}\text { Év / } \\
\text { Year }\end{array}$ & $\begin{array}{l}\text { Gyűjtő / } \\
\text { Collector }\end{array}$ & Fájlnév / File-name \\
\hline 442 & Ranunculus flammula L. & Nagyhuta & 1961 & Siroki Zoltán & DE-siroki-07373.jpg \\
\hline 443 & Ranunculus lingua L. & Debrecen & 1949 & Siroki Zoltán & DE-siroki-07388.jpg \\
\hline 443 & Ranunculus lingua L. & Debrecen & 1949 & Siroki Zoltán & DE-siroki-07389.jpg \\
\hline 443 & Ranunculus lingua L. & Debrecen & 1949 & Siroki Zoltán & DE-siroki-07390.jpg \\
\hline 443 & Ranunculus lingua L. & Debrecen & 1949 & Siroki Zoltán & DE-siroki-07386.jpg \\
\hline 443 & Ranunculus lingua L. & Debrecen & 1949 & Siroki Zoltán & DE-siroki-07387.jpg \\
\hline 443 & Ranunculus lingua $\mathrm{L}$. & Debrecen & 1954 & Siroki Zoltán & DE-siroki-07384.jpg \\
\hline 443 & Ranunculus lingua L. & Debrecen & 1954 & Siroki Zoltán & DE-siroki-07385.jpg \\
\hline 444 & Ranunculus sceleratus L. & Abaújkér & 1942 & Siroki Zoltán & DE-siroki-07393.jpg \\
\hline 444 & Ranunculus sceleratus L. & Abaújkér & 1942 & Siroki Zoltán & DE-siroki-07394.jpg \\
\hline 444 & Ranunculus sceleratus L. & Debrecen & 1947 & Siroki Zoltán & DE-siroki-07395.jpg \\
\hline 444 & Ranunculus sceleratus L. & Debrecen & 1962 & Pethő Menyhért & DE-siroki-07392.jpg \\
\hline 444 & Ranunculus sceleratus L. & Mosonmagyaróvár & 1939 & Siroki Zoltán & DE-siroki-07396.jpg \\
\hline 445 & Ranunculus bulbosus L. & Gyenesdiás & 1953 & Siroki Zoltán & DE-siroki-07400.jpg \\
\hline 445 & Ranunculus bulbosus L. & Gyenesdiás & 1953 & Siroki Zoltán & DE-siroki-07401.jpg \\
\hline 445 & Ranunculus bulbosus L. & Gyenesdiás & 1953 & Siroki Zoltán & DE-siroki-07402.jpg \\
\hline 445 & Ranunculus bulbosus L. & Gyenesdiás & 1953 & Siroki Zoltán & DE-siroki-07403.jpg \\
\hline 445 & Ranunculus bulbosus L. & Hosszúhetény & 1958 & Siroki Zoltán & DE-siroki-07398.jpg \\
\hline 445 & Ranunculus bulbosus L. & Hosszúhetény & 1958 & Siroki Zoltán & DE-siroki-07399.jpg \\
\hline 446 & Ranunculus sardous Crantz & Berekböszörmény & 1970 & Siroki Zoltán & DE-siroki-07406.jpg \\
\hline 446 & Ranunculus sardous Crantz & Berekböszörmény & 1970 & Siroki Zoltán & DE-siroki-07407.jpg \\
\hline 446 & Ranunculus sardous Crantz & Csenger & 1975 & Siroki Zoltán & DE-siroki-07410.jpg \\
\hline 446 & Ranunculus sardous Crantz & Csenger & 1975 & Siroki Zoltán & DE-siroki-07411.jpg \\
\hline 446 & Ranunculus sardous Crantz & Debrecen & 1947 & Siroki Zoltán & DE-siroki-07416.jpg \\
\hline 446 & Ranunculus sardous Crantz & Debrecen & 1950 & Siroki Zoltán & DE-siroki-07412.jpg \\
\hline 446 & Ranunculus sardous Crantz & Debrecen & 1950 & Siroki Zoltán & DE-siroki-07414.jpg \\
\hline 446 & Ranunculus sardous Crantz & Debrecen & 1960 & Siroki Zoltán & DE-siroki-07413.jpg \\
\hline 446 & Ranunculus sardous Crantz & Debrecen & 1960 & Siroki Zoltán & DE-siroki-07415.jpg \\
\hline 446 & Ranunculus sardous Crantz & Egyek & 1947 & Siroki Zoltán & DE-siroki-07408.jpg \\
\hline 446 & Ranunculus sardous Crantz & Hortobágy & 1958 & Siroki Zoltán & DE-siroki-07409.jpg \\
\hline 446 & Ranunculus sardous Crantz & Hortobágy & 1985 & Siroki Zoltán & DE-siroki-07405.jpg \\
\hline 446 & Ranunculus sardous Crantz & Máriakálnok & 1939 & Siroki Zoltán & DE-siroki-07421.jpg \\
\hline 446 & Ranunculus sardous Crantz & Mosonmagyaróvár & 1939 & Siroki Zoltán & DE-siroki-07420.jpg \\
\hline 446 & Ranunculus sardous Crantz & Mosonmagyaróvár & 1939 & Siroki Zoltán & DE-siroki-07419.jpg \\
\hline 447 & Ranunculus repens L. & Bükkszentkereszt & 1959 & Halász Tibor & DE-siroki-07425.jpg \\
\hline 447 & Ranunculus repens L. & Bükkszentkereszt & 1959 & Halász Tibor & DE-siroki-07426.jpg \\
\hline 447 & Ranunculus repens L. & Bükkszentkereszt & 1959 & Halász Tibor & DE-siroki-07427.jpg \\
\hline 447 & Ranunculus repens L. & Bükkszentkereszt & 1959 & Siroki Zoltán & DE-siroki-07424.jpg \\
\hline 447 & Ranunculus repens L. & Debrecen & 1947 & Siroki Zoltán & DE-siroki-07422.jpg \\
\hline 447 & Ranunculus repens L. & Hortobágy & 1961 & Siroki Zoltán & DE-siroki-07423.jpg \\
\hline 447 & Ranunculus repens L. & Tarpa & 1955 & Farkas Attila & DE-siroki-07428.jpg \\
\hline 448 & Ranunculus arvensis L. & Berekböszörmény & 1970 & Siroki Zoltán & DE-siroki-07430.jpg \\
\hline 448 & Ranunculus arvensis L. & Cegléd & 1969 & Siroki Zoltán & DE-siroki-07431.jpg \\
\hline 448 & Ranunculus arvensis L. & Egyek & 1948 & Siroki Zoltán & DE-siroki-07432.jpg \\
\hline 448 & Ranunculus arvensis L. & Mosonmagyaróvár & 1939 & Siroki Zoltán & DE-siroki-07435.jpg \\
\hline 450 & Ranunculus auricomus agg. & Budapest & 1964 & Siroki Zoltán & DE-siroki-07438.jpg \\
\hline
\end{tabular}




\begin{tabular}{|c|c|c|c|c|c|}
\hline $\begin{array}{l}\text { Sorszám / } \\
\text { Number }\end{array}$ & Taxon-név / Taxon-name & $\begin{array}{l}\text { Település / } \\
\text { Settlement }\end{array}$ & $\begin{array}{l}\text { Év / } \\
\text { Year }\end{array}$ & $\begin{array}{l}\text { Gyűjtő / } \\
\text { Collector }\end{array}$ & Fájlnév / File-name \\
\hline 450 & Ranunculus auricomus agg. & Budapest & 1964 & Siroki Zoltán & DE-siroki-07439.jpg \\
\hline 450 & Ranunculus auricomus agg. & Budapest & 1964 & Siroki Zoltán & DE-siroki-07440.jpg \\
\hline 451 & Ranunculus polyanthemos L. & Budapest & 1951 & Siroki Zoltán & DE-siroki-07475.jpg \\
\hline 451 & Ranunculus polyanthemos L. & Budapest & 1964 & Siroki Zoltán & DE-siroki-07476.jpg \\
\hline 451 & Ranunculus polyanthemos L. & Budapest & 1964 & Siroki Zoltán & DE-siroki-07477.jpg \\
\hline 451 & Ranunculus polyanthemos L. & Budapest & 1964 & Siroki Zoltán & DE-siroki-07478.jpg \\
\hline 451 & Ranunculus polyanthemos L. & Budapest & 1964 & Siroki Zoltán & DE-siroki-07479.jpg \\
\hline 451 & Ranunculus polyanthemos L. & Budapest & 1964 & Siroki Zoltán & DE-siroki-07480.jpg \\
\hline 451 & Ranunculus polyanthemos L. & Debrecen & 1947 & Siroki Zoltán & DE-siroki-07470.jpg \\
\hline 451 & Ranunculus polyanthemos L. & Debrecen & 1947 & Siroki Zoltán & DE-siroki-07473.jpg \\
\hline 451 & Ranunculus polyanthemos L. & Debrecen & 1947 & Siroki Zoltán & DE-siroki-07471.jpg \\
\hline 451 & Ranunculus polyanthemos L. & Debrecen & 1947 & Siroki Zoltán & DE-siroki-07472.jpg \\
\hline 451 & Ranunculus polyanthemos L. & Debrecen & 1947 & Siroki Zoltán & DE-siroki-07474.jpg \\
\hline 451 & Ranunculus polyanthemos L. & Pomáz & 1954 & Siroki Zoltán & DE-siroki-07485.jpg \\
\hline 451 & Ranunculus polyanthemos L. & Pomáz & 1954 & Siroki Zoltán & DE-siroki-07486.jpg \\
\hline 454 & Ranunculus lanuginosus L. & "Nagymező" & 1957 & Siroki Zoltán & DE-siroki-07448.jpg \\
\hline 454 & Ranunculus lanuginosus L. & "Nagymező" & 1957 & Siroki Zoltán & DE-siroki-07449.jpg \\
\hline 454 & Ranunculus lanuginosus L. & Bükkszentkereszt & 1959 & Halász Tibor & DE-siroki-07442.jpg \\
\hline 454 & Ranunculus lanuginosus L. & Bükkszentkereszt & 1959 & Halász Tibor & DE-siroki-07443.jpg \\
\hline 454 & Ranunculus lanuginosus L. & Bükkszentkereszt & 1959 & Halász Tibor & DE-siroki-07444.jpg \\
\hline 454 & Ranunculus lanuginosus L. & Bükkszentkereszt & 1959 & Halász Tibor & DE-siroki-07445.jpg \\
\hline 454 & Ranunculus lanuginosus L. & Bükkszentkereszt & 1959 & Halász Tibor & DE-siroki-07446.jpg \\
\hline 454 & Ranunculus lanuginosus L. & Nagyhuta & 1961 & Siroki Zoltán & DE-siroki-07451.jpg \\
\hline 454 & Ranunculus lanuginosus L. & Nagyhuta & 1961 & Siroki Zoltán & DE-siroki-07452.jpg \\
\hline 454 & Ranunculus lanuginosus L. & Nagyhuta & 1961 & Siroki Zoltán & DE-siroki-07450.jpg \\
\hline 454 & Ranunculus lanuginosus L. & Nagyhuta & 1961 & Siroki Zoltán & DE-siroki-07453.jpg \\
\hline 454 & Ranunculus lanuginosus L. & Pásztó & 1953 & Siroki Zoltán & DE-siroki-07456.jpg \\
\hline 454 & Ranunculus lanuginosus L. & Pásztó & 1953 & Siroki Zoltán & DE-siroki-07457.jpg \\
\hline 454 & Ranunculus lanuginosus L. & Pécs & 1958 & Siroki Zoltán & DE-siroki-07454.jpg \\
\hline 454 & Ranunculus lanuginosus L. & Pécs & 1958 & Siroki Zoltán & DE-siroki-07455.jpg \\
\hline 454 & Ranunculus lanuginosus L. & Szarvaskő & 1966 & Siroki Zoltán & DE-siroki-07447.jpg \\
\hline 455 & Ranunculus acris L. & Debrecen & 1947 & Siroki Zoltán & DE-siroki-07462.jpg \\
\hline 455 & Ranunculus acris L. & Mosonmagyaróvár & 1939 & Siroki Zoltán & DE-siroki-07459.jpg \\
\hline 455 & Ranunculus acris L. & Mosonmagyaróvár & 1939 & Siroki Zoltán & DE-siroki-07460.jpg \\
\hline 455 & Ranunculus acris L. & Mosonmagyaróvár & 1939 & Siroki Zoltán & DE-siroki-07461.jpg \\
\hline 455 & Ranunculus acris L. & Tarpa & 1955 & Siroki Zoltán & DE-siroki-07463.jpg \\
\hline 457 & $\begin{array}{l}\text { Ceratocephala testiculata } \\
\text { (Crantz) Roth }\end{array}$ & Budapest & 1888 & Czakó Kálmán & DE-siroki-07314.jpg \\
\hline 457 & $\begin{array}{l}\text { Ceratocephala testiculata } \\
\text { (Crantz) Roth }\end{array}$ & Budapest & 1913 & Visky & DE-siroki-07313.jpg \\
\hline 457 & $\begin{array}{l}\text { Ceratocephala testiculata } \\
\text { (Crantz) Roth }\end{array}$ & Herceghalom & 1951 & Siroki Zoltán & DE-siroki-07315.jpg \\
\hline 457 & $\begin{array}{l}\text { Ceratocephala testiculata } \\
\text { (Crantz) Roth }\end{array}$ & Herceghalom & 1951 & Siroki Zoltán & DE-siroki-07317.jpg \\
\hline 457 & $\begin{array}{l}\text { Ceratocephala testiculata } \\
\text { (Crantz) Roth }\end{array}$ & Herceghalom & 1951 & Siroki Zoltán & DE-siroki-07316.jpg \\
\hline 457 & $\begin{array}{l}\text { Ceratocephala testiculata } \\
\text { (Crantz) Roth }\end{array}$ & Herceghalom & 1951 & Szegedi B.-né & DE-siroki-07318.jpg \\
\hline 459 & Myosurus minimus L. & Debrecen & 1947 & Siroki Zoltán & DE-siroki-07308.jpg \\
\hline 459 & Myosurus minimus L. & Debrecen & 1948 & Siroki Zoltán & DE-siroki-07312.jpg \\
\hline
\end{tabular}




\begin{tabular}{|c|c|c|c|c|c|}
\hline $\begin{array}{l}\text { Sorszám / } \\
\text { Number }\end{array}$ & Taxon-név / Taxon-name & $\begin{array}{l}\text { Település / } \\
\text { Settlement }\end{array}$ & $\begin{array}{l}\text { Év / } \\
\text { Year }\end{array}$ & $\begin{array}{l}\text { Gyűjtő / } \\
\text { Collector }\end{array}$ & Fájlnév / File-name \\
\hline 459 & Myosurus minimus L. & Debrecen & 1955 & Siroki Zoltán & DE-siroki-07307.jpg \\
\hline 459 & Myosurus minimus L. & Debrecen & 1955 & Siroki Zoltán & DE-siroki-07305.jpg \\
\hline 459 & Myosurus minimus L. & Debrecen & 1955 & Siroki Zoltán & DE-siroki-07306.jpg \\
\hline 459 & Myosurus minimus L. & Derecske & 1972 & Siroki Zoltán & DE-siroki-07304.jpg \\
\hline 459 & Myosurus minimus L. & Hortobágy & 1947 & Siroki Zoltán & DE-siroki-07309.jpg \\
\hline 459 & Myosurus minimus L. & Hortobágy & 1947 & Siroki Zoltán & DE-siroki-07310.jpg \\
\hline 459 & Myosurus minimus L. & Tarpa & 1955 & $\begin{array}{l}\text { Siroki Zoltán - } \\
\text { Farkas Attila }\end{array}$ & DE-siroki-07311.jpg \\
\hline 460 & Thalictrum aquilegiifolium $\mathrm{L}$. & Debrecen & 1948 & Siroki Zoltán & DE-siroki-07507.jpg \\
\hline 460 & Thalictrum aquilegiifolium L. & Debrecen & 1948 & Siroki Zoltán & DE-siroki-07508.jpg \\
\hline 460 & Thalictrum aquilegiifolium L. & Debrecen & 1949 & Siroki Zoltán & DE-siroki-07506.jpg \\
\hline 462 & Thalictrum minus L. & Budapest & 1905 & Kocsis István & DE-siroki-07520.jpg \\
\hline 462 & Thalictrum minus L. & Budapest & 1909 & Kocsis István & DE-siroki-07522.jpg \\
\hline 462 & Thalictrum minus L. & Budapest & 1909 & Kocsis István & DE-siroki-07521.jpg \\
\hline 462 & Thalictrum minus L. & Budapest & 1951 & Siroki Zoltán & DE-siroki-07519.jpg \\
\hline 462 & Thalictrum minus L. & Debrecen & 1949 & Siroki Zoltán & DE-siroki-07514.jpg \\
\hline 462 & Thalictrum minus L. & Debrecen & 1949 & Siroki Zoltán & DE-siroki-07515.jpg \\
\hline 463 & Thalictrum pseudominus Borbás & Budaörs & 1952 & Siroki Zoltán & DE-siroki-07509.jpg \\
\hline 463 & Thalictrum pseudominus Borbás & Budaörs & 1952 & Siroki Zoltán & DE-siroki-07510.jpg \\
\hline 463 & Thalictrum pseudominus Borbás & Gyenesdiás & 1955 & Siroki Zoltán & DE-siroki-07511.jpg \\
\hline 463 & Thalictrum pseudominus Borbás & Pilisszentiván & 1952 & Siroki Zoltán & DE-siroki-07512.jpg \\
\hline 463 & Thalictrum pseudominus Borbás & Pilisszentiván & 1952 & Siroki Zoltán & DE-siroki-07513.jpg \\
\hline 464 & Thalictrum simplex L. & "Bükk-hg." & 1983 & Siroki Zoltán & DE-siroki-07525.jpg \\
\hline 464 & Thalictrum simplex L. & "Nagymező" & 1959 & Siroki Zoltán & DE-siroki-07526.jpg \\
\hline 464 & Thalictrum simplex L. & "Nagymező" & 1959 & Siroki Zoltán & DE-siroki-07527.jpg \\
\hline 464 & Thalictrum simplex L. & "Nagymező" & 1959 & Siroki Zoltán & DE-siroki-07528.jpg \\
\hline 464 & Thalictrum simplex L. & "Nagymező" & 1959 & Siroki Zoltán & DE-siroki-07529.jpg \\
\hline 464 & Thalictrum simplex L. & Budapest & 1952 & Siroki Zoltán & DE-siroki-07530.jpg \\
\hline 464 & Thalictrum simplex L. & Gyenesdiás & 1955 & Siroki Zoltán & DE-siroki-07532.jpg \\
\hline 464 & Thalictrum simplex L. & Gyenesdiás & 1955 & Siroki Zoltán & DE-siroki-07533.jpg \\
\hline 464 & Thalictrum simplex L. & Gyenesdiás & 1955 & Siroki Zoltán & DE-siroki-07535.jpg \\
\hline 464 & Thalictrum simplex L. & Gyenesdiás & 1955 & Siroki Zoltán & DE-siroki-07531.jpg \\
\hline 464 & Thalictrum simplex L. & Nagykőrös & 1954 & Siroki Zoltán & DE-siroki-07534.jpg \\
\hline 464 & Thalictrum simplex L. & Tiszafüred & 1973 & Siroki Zoltán & DE-siroki-07524.jpg \\
\hline 465 & Thalictrum flavum L. & Szentes & 1952 & Siroki Zoltán & DE-siroki-07548.jpg \\
\hline 465 & Thalictrum flavum L. & Szentes & 1952 & Siroki Zoltán & DE-siroki-07549.jpg \\
\hline 465 & Thalictrum flavum L. & Szentes & 1952 & Siroki Zoltán & DE-siroki-07550.jpg \\
\hline 465 & Thalictrum flavum L. & Tiszafüred & 1949 & Siroki Zoltán & DE-siroki-07546.jpg \\
\hline 465 & Thalictrum flavum L. & Tiszafüred & 1949 & Siroki Zoltán & DE-siroki-07547.jpg \\
\hline 465 & Thalictrum flavum L. & Tiszafüred & 1968 & Siroki Zoltán & DE-siroki-07545.jpg \\
\hline 465 & Thalictrum flavum L. & Tiszafüred & 1968 & Siroki Zoltán & DE-siroki-07543.jpg \\
\hline 465 & Thalictrum flavum L. & Tiszafüred & 1968 & Siroki Zoltán & DE-siroki-07544.jpg \\
\hline 465 & Thalictrum flavum L. & Tiszafüred & 1970 & Siroki Zoltán & DE-siroki-07538.jpg \\
\hline 465 & Thalictrum flavum L. & Tiszafüred & 1970 & Siroki Zoltán & DE-siroki-07539.jpg \\
\hline 465 & Thalictrum flavum L. & Tiszafüred & 1970 & Siroki Zoltán & DE-siroki-07540.jpg \\
\hline 465 & Thalictrum flavum L. & Tiszafüred & 1970 & Siroki Zoltán & DE-siroki-07541.jpg \\
\hline 465 & Thalictrum flavum L. & Tiszafüred & 1970 & Siroki Zoltán & DE-siroki-07542.jpg \\
\hline
\end{tabular}




\begin{tabular}{|c|c|c|c|c|c|}
\hline $\begin{array}{l}\text { Sorszám / } \\
\text { Number }\end{array}$ & Taxon-név / Taxon-name & $\begin{array}{l}\text { Település / } \\
\text { Settlement }\end{array}$ & $\begin{array}{l}\text { Év / } \\
\text { Year }\end{array}$ & $\begin{array}{l}\text { Gyújtő / } \\
\text { Collector }\end{array}$ & Fájlnév / File-name \\
\hline 466 & Thalictrum lucidum L. & "Bükk-hg." & 1983 & Siroki Zoltán & DE-siroki-07557.jpg \\
\hline 466 & Thalictrum lucidum L. & Bodrogkeresztúr & 1965 & Siroki Zoltán & DE-siroki-07565.jpg \\
\hline 466 & Thalictrum lucidum L. & Bodrogkeresztúr & 1965 & Siroki Zoltán & DE-siroki-07566.jpg \\
\hline 466 & Thalictrum lucidum L. & Bodrogkeresztúr & 1965 & Siroki Zoltán & DE-siroki-07567.jpg \\
\hline 466 & Thalictrum lucidum L. & Bodrogkeresztúr & 1967 & Siroki Zoltán & DE-siroki-07568.jpg \\
\hline 466 & Thalictrum lucidum L. & Bodrogkeresztúr & 1967 & Siroki Zoltán & DE-siroki-07569.jpg \\
\hline 466 & Thalictrum lucidum L. & Debrecen & 1954 & Siroki Zoltán & DE-siroki-07570.jpg \\
\hline 466 & Thalictrum lucidum L. & Debrecen & 1954 & Siroki Zoltán & DE-siroki-07571.jpg \\
\hline 466 & Thalictrum lucidum L. & Egyek & 1947 & Siroki Zoltán & DE-siroki-07554.jpg \\
\hline 466 & Thalictrum lucidum L. & Egyek & 1947 & Siroki Zoltán & DE-siroki-07555.jpg \\
\hline 466 & Thalictrum lucidum L. & Egyek & 1947 & Siroki Zoltán & DE-siroki-07556.jpg \\
\hline 466 & Thalictrum lucidum L. & Egyek & 1949 & Siroki Zoltán & DE-siroki-07553.jpg \\
\hline 466 & Thalictrum lucidum L. & Háromhuta & 1960 & Siroki Zoltán & DE-siroki-07562.jpg \\
\hline 466 & Thalictrum lucidum L. & Háromhuta & 1960 & Siroki Zoltán & DE-siroki-07563.jpg \\
\hline 466 & Thalictrum lucidum L. & Háromhuta & 1978 & Siroki Zoltán & DE-siroki-07564.jpg \\
\hline 466 & Thalictrum lucidum L. & Nagykőrös & 1954 & Siroki Zoltán & DE-siroki-07552.jpg \\
\hline 466 & Thalictrum lucidum L. & Vámospércs & 1984 & Siroki Zoltán & DE-siroki-07560.jpg \\
\hline 466 & Thalictrum lucidum L. & Vámospércs & 1984 & Siroki Zoltán & DE-siroki-07561.jpg \\
\hline 466 & Thalictrum lucidum L. & Vámospércs & 1985 & Siroki Zoltán & DE-siroki-07558.jpg \\
\hline 466 & Thalictrum lucidum L. & Vámospércs & 1985 & Siroki Zoltán & DE-siroki-07559.jpg \\
\hline 467 & Paeonia officinalis L. & Hosszúhetény & 1954 & Siroki Zoltán & DE-siroki-07027.jpg \\
\hline 467 & Paeonia officinalis L. & Hosszúhetény & 1954 & Siroki Zoltán & DE-siroki-07028.jpg \\
\hline 467 & Paeonia officinalis L. & Hosszúhetény & 1954 & Siroki Zoltán & DE-siroki-07030.jpg \\
\hline 467 & Paeonia officinalis L. & Hosszúhetény & 1954 & Siroki Zoltán & DE-siroki-07031.jpg \\
\hline 467 & Paeonia officinalis L. & Hosszúhetény & 1958 & Siroki Zoltán & DE-siroki-07026.jpg \\
\hline 467 & Paeonia officinalis L. & Hosszúhetény & 1958 & Siroki Zoltán & DE-siroki-07029.jpg \\
\hline 467 & Paeonia officinalis L. & Hosszúhetény & 1958 & Siroki Zoltán & DE-siroki-07032.jpg \\
\hline 467 & Paeonia officinalis L. & Pécsvárad & 1951 & Kárpáti Zoltán & DE-siroki-07033.jpg \\
\hline 470 & Berberis vulgaris L. & Debrecen & 1977 & Siroki Zoltán & DE-siroki-07593.jpg \\
\hline 471 & Mahonia aquifolium (Pursh) Nutt. & Debrecen & 1984 & Siroki Zoltán & DE-siroki-07596.jpg \\
\hline 477 & Papaver argemone L. & Aszód & 1952 & Juhász József & DE-siroki-07636.jpg \\
\hline 477 & Papaver argemone L. & Pilisszentiván & 1950 & Kárpáti Zoltán & DE-siroki-07635.jpg \\
\hline 477 & Papaver argemone L. & Tiszafüred & 1955 & Siroki Zoltán & DE-siroki-07629.jpg \\
\hline 477 & Papaver argemone L. & Tiszafüred & 1955 & Siroki Zoltán & DE-siroki-07630.jpg \\
\hline 477 & Papaver argemone L. & Tiszafüred & 1955 & $\begin{array}{l}\text { Siroki Zoltán - } \\
\text { Farkas Attila }\end{array}$ & DE-siroki-07631.jpg \\
\hline 477 & Papaver argemone L. & Tiszafüred & 1955 & $\begin{array}{l}\text { Siroki Zoltán - } \\
\text { Farkas Attila }\end{array}$ & DE-siroki-07632.jpg \\
\hline 477 & Papaver argemone L. & Tiszafüred & 1955 & $\begin{array}{l}\text { Siroki Zoltán - } \\
\text { Farkas Attila }\end{array}$ & DE-siroki-07633.jpg \\
\hline 477 & Papaver argemone L. & Tiszafüred & 1955 & $\begin{array}{l}\text { Siroki Zoltán - } \\
\text { Farkas Attila }\end{array}$ & DE-siroki-07634.jpg \\
\hline 479 & Papaver rhoeas L. & Mosonmagyaróvár & 1939 & Siroki Zoltán & DE-siroki-07645.jpg \\
\hline 480 & Papaver dubium L. & Debrecen & 1947 & Siroki Zoltán & DE-siroki-07637.jpg \\
\hline 480 & Papaver dubium L. & Debrecen & 1947 & Siroki Zoltán & DE-siroki-07638.jpg \\
\hline 480 & Papaver dubium L. & Debrecen & 1947 & Siroki Zoltán & DE-siroki-07639.jpg \\
\hline 480 & Papaver dubium L. & Sátoraljaújhely & 1943 & Siroki Zoltán & DE-siroki-07643.jpg \\
\hline 482 & Glaucium corniculatum (L.) Rudolph & Debrecen & 1978 & Siroki Zoltán & DE-siroki-07614.jpg \\
\hline 482 & Glaucium corniculatum (L.) Rudolph & Debrecen & 1978 & Siroki Zoltán & DE-siroki-07615.jpg \\
\hline
\end{tabular}




\begin{tabular}{|c|c|c|c|c|c|}
\hline $\begin{array}{l}\text { Sorszám / } \\
\text { Number }\end{array}$ & Taxon-név / Taxon-name & $\begin{array}{l}\text { Település / } \\
\text { Settlement }\end{array}$ & $\begin{array}{l}\text { Év / } \\
\text { Year }\end{array}$ & $\begin{array}{l}\text { Gyűjtő / } \\
\text { Collector }\end{array}$ & Fájlnév / File-name \\
\hline 482 & Glaucium corniculatum (L.) Rudolph & Hajdúböszörmény & 1963 & Siroki Zoltán & DE-siroki-07617.jpg \\
\hline 482 & Glaucium corniculatum (L.) Rudolph & Hajdúböszörmény & 1966 & Gondola István & DE-siroki-07609.jpg \\
\hline 482 & Glaucium corniculatum (L.) Rudolph & Hajdúböszörmény & 1966 & Gondola István & DE-siroki-07610.jpg \\
\hline 482 & Glaucium corniculatum (L.) Rudolph & Hajdúböszörmény & 1966 & Gondola István & DE-siroki-07611.jpg \\
\hline 482 & Glaucium corniculatum (L.) Rudolph & Hajdúböszörmény & 1966 & Gondola István & DE-siroki-07612.jpg \\
\hline 482 & Glaucium corniculatum (L.) Rudolph & Hajdúböszörmény & 1966 & Gondola István & DE-siroki-07613.jpg \\
\hline 482 & Glaucium corniculatum (L.) Rudolph & Hajdúböszörmény & 1966 & Gondola István & DE-siroki-07618.jpg \\
\hline 482 & Glaucium corniculatum (L.) Rudolph & Hajdúböszörmény & 1966 & Gondola István & DE-siroki-07619.jpg \\
\hline 482 & Glaucium corniculatum (L.) Rudolph & Hortobágy & 1948 & Siroki Zoltán & DE-siroki-07626.jpg \\
\hline 482 & Glaucium corniculatum (L.) Rudolph & Hortobágy & 1948 & Siroki Zoltán & DE-siroki-07627.jpg \\
\hline 482 & Glaucium corniculatum (L.) Rudolph & Hortobágy & 1948 & Siroki Zoltán & DE-siroki-07623.jpg \\
\hline 482 & Glaucium corniculatum (L.) Rudolph & Hortobágy & 1948 & Siroki Zoltán & DE-siroki-07624.jpg \\
\hline 482 & Glaucium corniculatum (L.) Rudolph & Hortobágy & 1949 & Siroki Zoltán & DE-siroki-07616.jpg \\
\hline 482 & Glaucium corniculatum (L.) Rudolph & Hortobágy & 1949 & Siroki Zoltán & DE-siroki-07625.jpg \\
\hline 482 & Glaucium corniculatum (L.) Rudolph & Hortobágy & 1949 & Siroki Zoltán & DE-siroki-07620.jpg \\
\hline 482 & Glaucium corniculatum (L.) Rudolph & Hortobágy & 1949 & Siroki Zoltán & DE-siroki-07621.jpg \\
\hline 482 & Glaucium corniculatum (L.) Rudolph & Hortobágy & 1949 & Siroki Zoltán & DE-siroki-07622.jpg \\
\hline 483 & Chelidonium majus L. & Debrecen & 1947 & Siroki Zoltán & DE-siroki-07606.jpg \\
\hline 485 & Corydalis cava L. & Budapest & 1941 & Siroki Zoltán & DE-siroki-07659.jpg \\
\hline 485 & Corydalis cava L. & Budapest & 1941 & Siroki Zoltán & DE-siroki-07660.jpg \\
\hline 485 & Corydalis cava L. & Budapest & 1941 & Siroki Zoltán & DE-siroki-07661.jpg \\
\hline 485 & Corydalis cava L. & Debrecen & 1950 & Siroki Zoltán & DE-siroki-07657.jpg \\
\hline 485 & Corydalis cava L. & Debrecen & 1950 & Siroki Zoltán & DE-siroki-07658.jpg \\
\hline 485 & Corydalis cava L. & Debrecen & 1954 & Siroki Zoltán & DE-siroki-07655.jpg \\
\hline 485 & Corydalis cava L. & Debrecen & 1954 & Siroki Zoltán & DE-siroki-07656.jpg \\
\hline 485 & Corydalis cava L. & Debrecen & 1955 & Siroki Zoltán & DE-siroki-07653.jpg \\
\hline 485 & Corydalis cava L. & Debrecen & 1955 & Siroki Zoltán & DE-siroki-07654.jpg \\
\hline 485 & Corydalis cava L. & Debrecen & 1955 & Siroki Zoltán & DE-siroki-07652.jpg \\
\hline 487 & Corydalis pumila Rchb. & Sukoró & 1931 & Degen Árpád & DE-siroki-07663.jpg \\
\hline 488 & Corydalis solida L. & Bélapátfalva & 1985 & Siroki Zoltán & DE-siroki-07670.jpg \\
\hline 488 & Corydalis solida L. & Budapest & 1951 & Siroki Zoltán & DE-siroki-07668.jpg \\
\hline 488 & Corydalis solida L. & Háromhuta & 1955 & Simon Tiborné & DE-siroki-07669.jpg \\
\hline 488 & Corydalis solida L. & Miskolc & 1957 & Pethő Menyhért & DE-siroki-07667.jpg \\
\hline 488 & Corydalis solida L. & Tarpa & 1971 & Siroki Zoltán & DE-siroki-07651.jpg \\
\hline 490 & Fumaria rostellata Knaf & Debrecen & 1978 & Siroki Zoltán & DE-siroki-07673.jpg \\
\hline 490 & Fumaria rostellata Knaf & Debrecen & 1978 & Siroki Zoltán & DE-siroki-07674.jpg \\
\hline 491 & Fumaria officinalis L. & Budapest & 1951 & Siroki Zoltán & DE-siroki-07671.jpg \\
\hline 492 & Fumaria schleicheri Soy.-Will. & Debrecen & 1947 & Siroki Zoltán & DE-siroki-07680.jpg \\
\hline 492 & Fumaria schleicheri Soy.-Will. & Debrecen & 1950 & Siroki Zoltán & DE-siroki-07684.jpg \\
\hline 492 & Fumaria schleicheri Soy.-Will. & Debrecen & 1950 & Siroki Zoltán & DE-siroki-07685.jpg \\
\hline 492 & Fumaria schleicheri Soy.-Will. & Debrecen & 1954 & Siroki Zoltán & DE-siroki-07679.jpg \\
\hline 492 & Fumaria schleicheri Soy.-Will. & Debrecen & 1980 & Siroki Zoltán & DE-siroki-07681.jpg \\
\hline 492 & Fumaria schleicheri Soy.-Will. & Újléta & 1967 & Siroki Zoltán & DE-siroki-07682.jpg \\
\hline 492 & Fumaria schleicheri Soy.-Will. & Újléta & 1967 & Siroki Zoltán & DE-siroki-07683.jpg \\
\hline 493 & Fumaria vaillantii Loisel. & Budapest & 1944 & Siroki Zoltán & DE-siroki-07690.jpg \\
\hline 493 & Fumaria vaillantii Loisel. & Budapest & 1962 & Siroki Zoltán & DE-siroki-07686.jpg \\
\hline
\end{tabular}




\begin{tabular}{|c|c|c|c|c|c|}
\hline $\begin{array}{l}\text { Sorszám / } \\
\text { Number }\end{array}$ & Taxon-név / Taxon-name & $\begin{array}{l}\text { Település / } \\
\text { Settlement }\end{array}$ & $\begin{array}{l}\text { Év / } \\
\text { Year }\end{array}$ & $\begin{array}{l}\text { Gyűjtő / } \\
\text { Collector }\end{array}$ & Fájlnév / File-name \\
\hline 493 & Fumaria vaillantii Loisel. & Budapest & 1962 & Siroki Zoltán & DE-siroki-07687.jpg \\
\hline 493 & Fumaria vaillantii Loisel. & Debrecen & 1949 & Siroki Zoltán & DE-siroki-07691.jpg \\
\hline 493 & Fumaria vaillantii Loisel. & Egyek & 1947 & Siroki Zoltán & DE-siroki-07692.jpg \\
\hline 493 & Fumaria vaillantii Loisel. & Hernádszurdok & 1944 & Siroki Zoltán & DE-siroki-07688.jpg \\
\hline 493 & Fumaria vaillantii Loisel. & Hernádszurdok & 1944 & Siroki Zoltán & DE-siroki-07689.jpg \\
\hline 493 & Fumaria vaillantii Loisel. & Mosonmagyaróvár & 1939 & Siroki Zoltán & DE-siroki-07694.jpg \\
\hline 495 & Sisymbrium officinale (L.) Scop. & Debrecen & 1947 & Siroki Zoltán & DE-siroki-07815.jpg \\
\hline 495 & Sisymbrium officinale (L.) Scop. & Mosonmagyaróvár & 1939 & Siroki Zoltán & DE-siroki-07817.jpg \\
\hline 496 & Sisymbrium strictissimum L. & "Bükk-hg." & 1983 & Siroki Zoltán & DE-siroki-07836.jpg \\
\hline 496 & Sisymbrium strictissimum L. & Budapest & 1941 & Siroki Zoltán & DE-siroki-07833.jpg \\
\hline 496 & Sisymbrium strictissimum L. & Budapest & 1949 & Siroki Zoltán & DE-siroki-07831.jpg \\
\hline 496 & Sisymbrium strictissimum L. & Budapest & 1949 & Siroki Zoltán & DE-siroki-07832.jpg \\
\hline 496 & Sisymbrium strictissimum L. & Budapest & 1949 & Siroki Zoltán & DE-siroki-07834.jpg \\
\hline 496 & Sisymbrium strictissimum L. & Budapest & 1949 & Siroki Zoltán & DE-siroki-07835.jpg \\
\hline 496 & Sisymbrium strictissimum L. & Hajdúbagos & 1982 & Siroki Zoltán & DE-siroki-07828.jpg \\
\hline 497 & Sisymbrium altissimum L. & Debrecen & 1946 & Siroki Zoltán & DE-siroki-07841.jpg \\
\hline 497 & Sisymbrium altissimum L. & Debrecen & 1948 & Siroki Zoltán & DE-siroki-07840.jpg \\
\hline 497 & Sisymbrium altissimum L. & Debrecen & 1948 & Siroki Zoltán & DE-siroki-07842.jpg \\
\hline 497 & Sisymbrium altissimum L. & Debrecen & 1949 & Siroki Zoltán & DE-siroki-07843.jpg \\
\hline 497 & Sisymbrium altissimum L. & Debrecen & 1949 & Siroki Zoltán & DE-siroki-07844.jpg \\
\hline 497 & Sisymbrium altissimum L. & Hajdúbagos & 1985 & Siroki Zoltán & DE-siroki-07838.jpg \\
\hline 497 & Sisymbrium altissimum L. & Hortobágy & 1947 & Siroki Zoltán & DE-siroki-07839.jpg \\
\hline 498 & Sisymbrium orientale L. & Budapest & 1944 & Siroki Zoltán & DE-siroki-07851.jpg \\
\hline 498 & Sisymbrium orientale L. & Debrecen & 1947 & Siroki Zoltán & DE-siroki-07850.jpg \\
\hline 498 & Sisymbrium orientale L. & Debrecen & 1983 & Siroki Zoltán & DE-siroki-07845.jpg \\
\hline 498 & Sisymbrium orientale L. & Debrecen & 1983 & Siroki Zoltán & DE-siroki-07846.jpg \\
\hline 498 & Sisymbrium orientale L. & Debrecen & 1983 & Siroki Zoltán & DE-siroki-07847.jpg \\
\hline 498 & Sisymbrium orientale L. & Debrecen & 1983 & Siroki Zoltán & DE-siroki-07848.jpg \\
\hline 498 & Sisymbrium orientale L. & Debrecen & 1983 & Siroki Zoltán & DE-siroki-07849.jpg \\
\hline 499 & $\begin{array}{l}\text { Sisymbrium polymorphum } \\
\text { (Murray) Roth }\end{array}$ & Abaújszántó & 1943 & Siroki Zoltán & DE-siroki-07825.jpg \\
\hline 499 & $\begin{array}{l}\text { Sisymbrium polymorphum } \\
\text { (Murray) Roth }\end{array}$ & Abaújszántó & 1943 & Siroki Zoltán & DE-siroki-07827.jpg \\
\hline 499 & $\begin{array}{l}\text { Sisymbrium polymorphum } \\
\text { (Murray) Roth }\end{array}$ & Abaújszántó & 1944 & Siroki Zoltán & DE-siroki-07826.jpg \\
\hline 499 & $\begin{array}{l}\text { Sisymbrium polymorphum } \\
\text { (Murray) Roth }\end{array}$ & Budaörs & 1955 & $\begin{array}{l}\text { Siroki Zoltán - } \\
\text { Farkas Attila }\end{array}$ & DE-siroki-07824.jpg \\
\hline 500 & Sisymbrium loeselii L. & Boldogkőváralja & 1944 & Siroki Zoltán & DE-siroki-07860.jpg \\
\hline 500 & Sisymbrium loeselii L. & Debrecen & 1948 & Siroki Zoltán & DE-siroki-07856.jpg \\
\hline 500 & Sisymbrium loeselii L. & Debrecen & 1981 & Siroki Zoltán & DE-siroki-07852.jpg \\
\hline 500 & Sisymbrium loeselii L. & Debrecen & 1981 & Siroki Zoltán & DE-siroki-07853.jpg \\
\hline 500 & Sisymbrium loeselii L. & Debrecen & 1981 & Siroki Zoltán & DE-siroki-07854.jpg \\
\hline 500 & Sisymbrium loeselii L. & Debrecen & 1981 & Siroki Zoltán & DE-siroki-07855.jpg \\
\hline 500 & Sisymbrium loeselii L. & Hortobágy & 1959 & Siroki Zoltán & DE-siroki-07857.jpg \\
\hline 500 & Sisymbrium loeselii L. & Hortobágy & 1959 & Siroki Zoltán & DE-siroki-07858.jpg \\
\hline 500 & Sisymbrium loeselii L. & Sátoraljaújhely & 1944 & Siroki Zoltán & DE-siroki-07859.jpg \\
\hline 501 & Descurainia sophia (L.) Webb & Debrecen & 1947 & Siroki Zoltán & DE-siroki-07818.jpg \\
\hline 501 & Descurainia sophia (L.) Webb & Debrecen & 1948 & Siroki Zoltán & DE-siroki-07819.jpg \\
\hline 501 & Descurainia sophia (L.) Webb & Mosonmagyaróvár & 1939 & Siroki Zoltán & DE-siroki-07821.jpg \\
\hline
\end{tabular}




\begin{tabular}{|c|c|c|c|c|c|}
\hline $\begin{array}{l}\text { Sorszám / } \\
\text { Number }\end{array}$ & Taxon-név / Taxon-name & $\begin{array}{l}\text { Település / } \\
\text { Settlement }\end{array}$ & $\begin{array}{l}\text { Év / } \\
\text { Year }\end{array}$ & $\begin{array}{l}\text { Gyűjtő / } \\
\text { Collector }\end{array}$ & Fájlnév / File-name \\
\hline 501 & Descurainia sophia (L.) Webb & Mosonmagyaróvár & 1939 & Siroki Zoltán & DE-siroki-07822.jpg \\
\hline 502 & $\begin{array}{l}\text { Alliaria petiolata } \\
\text { (M. Bieb.) Cavara et Grande }\end{array}$ & Debrecen & 1948 & Siroki Zoltán & DE-siroki-07813.jpg \\
\hline 503 & Arabidopsis thaliana (L.) Heynh. & Debrecen & 1949 & Siroki Zoltán & DE-siroki-08307.jpg \\
\hline 503 & Arabidopsis thaliana (L.) Heynh. & Debrecen & 1965 & Siroki Zoltán & DE-siroki-08305.jpg \\
\hline 503 & Arabidopsis thaliana (L.) Heynh. & Debrecen & 1972 & Siroki Zoltán & DE-siroki-08306.jpg \\
\hline 503 & Arabidopsis thaliana (L.) Heynh. & Debrecen & 1978 & Siroki Zoltán & DE-siroki-08303.jpg \\
\hline 503 & Arabidopsis thaliana (L.) Heynh. & Debrecen & 1978 & Siroki Zoltán & DE-siroki-08304.jpg \\
\hline 504 & Myagrum perfoliatum L. & Berekböszörmény & 1970 & Siroki Zoltán & DE-siroki-07861.jpg \\
\hline 504 & Myagrum perfoliatum L. & Budapest & 1952 & Siroki Zoltán & DE-siroki-07872.jpg \\
\hline 504 & Myagrum perfoliatum L. & Debrecen & 1947 & Siroki Zoltán & DE-siroki-07863.jpg \\
\hline 504 & Myagrum perfoliatum L. & Debrecen & 1955 & Siroki Zoltán & DE-siroki-07862.jpg \\
\hline 504 & Myagrum perfoliatum L. & Debrecen & 1978 & Siroki Zoltán & DE-siroki-07864.jpg \\
\hline 504 & Myagrum perfoliatum L. & Debrecen & 1978 & Siroki Zoltán & DE-siroki-07865.jpg \\
\hline 504 & Myagrum perfoliatum L. & Debrecen & 1978 & Siroki Zoltán & DE-siroki-07879.jpg \\
\hline 504 & Myagrum perfoliatum L. & Debrecen & 1978 & Siroki Zoltán & DE-siroki-07880.jpg \\
\hline 504 & Myagrum perfoliatum L. & Debrecen & 1978 & Siroki Zoltán & DE-siroki-07881.jpg \\
\hline 504 & Myagrum perfoliatum L. & Nyírábrány & 1966 & Gondola István & DE-siroki-07868.jpg \\
\hline 504 & Myagrum perfoliatum L. & Nyírábrány & 1966 & Gondola István & DE-siroki-07869.jpg \\
\hline 504 & Myagrum perfoliatum L. & Nyírábrány & 1966 & Gondola István & DE-siroki-07870.jpg \\
\hline 504 & Myagrum perfoliatum L. & Nyírábrány & 1966 & Gondola István & DE-siroki-07871.jpg \\
\hline 504 & Myagrum perfoliatum L. & Újléta & 1967 & Siroki Zoltán & DE-siroki-07866.jpg \\
\hline 504 & Myagrum perfoliatum L. & Újléta & 1967 & Siroki Zoltán & DE-siroki-07867.jpg \\
\hline 505 & Isatis tinctoria L. & Szarvaskő & 1966 & Siroki Zoltán & DE-siroki-07882.jpg \\
\hline 505 & Isatis tinctoria L. & Szarvaskő & 1966 & Siroki Zoltán & DE-siroki-07883.jpg \\
\hline 506 & Bunias orientalis L. & Debrecen & 1972 & Siroki Zoltán & DE-siroki-08612.jpg \\
\hline 506 & Bunias orientalis L. & Debrecen & 1972 & Siroki Zoltán & DE-siroki-08613.jpg \\
\hline 506 & Bunias orientalis L. & Debrecen & 1972 & Siroki Zoltán & DE-siroki-08614.jpg \\
\hline 506 & Bunias orientalis L. & Debrecen & 1972 & Siroki Zoltán & DE-siroki-08615.jpg \\
\hline 506 & Bunias orientalis L. & Debrecen & 1972 & Siroki Zoltán & DE-siroki-08616.jpg \\
\hline 506 & Bunias orientalis L. & Hernádnémeti & 1944 & Siroki Zoltán & DE-siroki-08618.jpg \\
\hline 508 & Erysimum cheiranthoides L. & Csaroda & 1959 & Siroki Zoltán & DE-siroki-08394.jpg \\
\hline 508 & Erysimum cheiranthoides L. & Csaroda & 1959 & Siroki Zoltán & DE-siroki-08395.jpg \\
\hline 508 & Erysimum cheiranthoides L. & Debrecen & 1970 & Siroki Zoltán & DE-siroki-08402.jpg \\
\hline 508 & Erysimum cheiranthoides L. & Debrecen & 1970 & Siroki Zoltán & DE-siroki-08403.jpg \\
\hline 508 & Erysimum cheiranthoides L. & Debrecen & 1970 & Siroki Zoltán & DE-siroki-08404.jpg \\
\hline 508 & Erysimum cheiranthoides L. & Debrecen & 1970 & Siroki Zoltán & DE-siroki-08405.jpg \\
\hline 508 & Erysimum cheiranthoides L. & Debrecen & 1970 & Siroki Zoltán & DE-siroki-08406.jpg \\
\hline 508 & Erysimum cheiranthoides L. & Hortobágy & 1948 & Siroki Zoltán & DE-siroki-08396.jpg \\
\hline 508 & Erysimum cheiranthoides L. & Hortobágy & 1948 & Siroki Zoltán & DE-siroki-08397.jpg \\
\hline 508 & Erysimum cheiranthoides L. & Mosonmagyaróvár & 1939 & Siroki Zoltán & DE-siroki-08398.jpg \\
\hline 509 & Erysimum repandum L. & Debrecen & 1947 & Siroki Zoltán & DE-siroki-08411.jpg \\
\hline 509 & Erysimum repandum L. & Vámospércs & 1984 & Siroki Zoltán & DE-siroki-08449.jpg \\
\hline 509 & Erysimum repandum L. & Vámospércs & 1985 & Siroki Zoltán & DE-siroki-08447.jpg \\
\hline 509 & Erysimum repandum L. & Vámospércs & 1985 & Siroki Zoltán & DE-siroki-08448.jpg \\
\hline 510 & Erysimum diffusum Ehrh. & Budapest & 1941 & Siroki Zoltán & DE-siroki-08457.jpg \\
\hline 510 & Erysimum diffusum Ehrh. & Budapest & 1941 & Siroki Zoltán & DE-siroki-08459.jpg \\
\hline
\end{tabular}




\begin{tabular}{|c|c|c|c|c|c|}
\hline $\begin{array}{l}\text { Sorszám / } \\
\text { Number }\end{array}$ & Taxon-név / Taxon-name & $\begin{array}{l}\text { Település / } \\
\text { Settlement }\end{array}$ & $\begin{array}{l}\text { Év / } \\
\text { Year }\end{array}$ & $\begin{array}{l}\text { Gyűjtő / } \\
\text { Collector }\end{array}$ & Fájlnév / File-name \\
\hline 510 & Erysimum diffusum Ehrh. & Budapest & 1941 & Siroki Zoltán & DE-siroki-08460.jpg \\
\hline 510 & Erysimum diffusum Ehrh. & Budapest & 1941 & Siroki Zoltán & DE-siroki-08458.jpg \\
\hline 510 & Erysimum diffusum Ehrh. & Bugac & 1973 & Siroki Zoltán & DE-siroki-08461.jpg \\
\hline 510 & Erysimum diffusum Ehrh. & Debrecen & 1947 & Siroki Zoltán & DE-siroki-08453.jpg \\
\hline 510 & Erysimum diffusum Ehrh. & Debrecen & 1948 & Siroki Zoltán & DE-siroki-08455.jpg \\
\hline 510 & Erysimum diffusum Ehrh. & Debrecen & 1948 & Siroki Zoltán & DE-siroki-08454.jpg \\
\hline 510 & Erysimum diffusum Ehrh. & Debrecen & 1948 & Siroki Zoltán & DE-siroki-08456.jpg \\
\hline 510 & Erysimum diffusum Ehrh. & Debrecen & 1986 & Siroki Zoltán & DE-siroki-08451.jpg \\
\hline 510 & Erysimum diffusum Ehrh. & Debrecen & 1986 & Siroki Zoltán & DE-siroki-08452.jpg \\
\hline 510 & Erysimum diffusum Ehrh. & Hajdúbagos & 1981 & Siroki Zoltán & DE-siroki-08450.jpg \\
\hline 514 & Erysimum odoratum Ehrh. & "Bükk-hg." & 1982 & Siroki Zoltán & DE-siroki-08445.jpg \\
\hline 514 & Erysimum odoratum Ehrh. & "Bükk-hg." & 1982 & Siroki Zoltán & DE-siroki-08446.jpg \\
\hline 514 & Erysimum odoratum Ehrh. & "Háromkő" & 1956 & Halász Tibor & DE-siroki-08441.jpg \\
\hline 514 & Erysimum odoratum Ehrh. & Budapest & 1940 & Siroki Zoltán & DE-siroki-08424.jpg \\
\hline 514 & Erysimum odoratum Ehrh. & Budapest & 1940 & Siroki Zoltán & DE-siroki-08425.jpg \\
\hline 514 & Erysimum odoratum Ehrh. & Budapest & 1949 & Siroki Zoltán & DE-siroki-08427.jpg \\
\hline 514 & Erysimum odoratum Ehrh. & Budapest & 1951 & Siroki Zoltán & DE-siroki-08426.jpg \\
\hline 514 & Erysimum odoratum Ehrh. & Budapest & 1983 & Siroki Zoltán & DE-siroki-08429.jpg \\
\hline 514 & Erysimum odoratum Ehrh. & Budapest & 1984 & Siroki Zoltán & DE-siroki-08416.jpg \\
\hline 514 & Erysimum odoratum Ehrh. & Budapest & 1984 & Siroki Zoltán & DE-siroki-08418.jpg \\
\hline 514 & Erysimum odoratum Ehrh. & Budapest & 1984 & Siroki Zoltán & DE-siroki-08417.jpg \\
\hline 514 & Erysimum odoratum Ehrh. & Budapest & 1984 & Siroki Zoltán & DE-siroki-08419.jpg \\
\hline 514 & Erysimum odoratum Ehrh. & Budapest & 1984 & Siroki Zoltán & DE-siroki-08420.jpg \\
\hline 514 & Erysimum odoratum Ehrh. & Budapest & 1984 & Siroki Zoltán & DE-siroki-08423.jpg \\
\hline 514 & Erysimum odoratum Ehrh. & Budapest & 1985 & Siroki Zoltán & DE-siroki-08421.jpg \\
\hline 514 & Erysimum odoratum Ehrh. & Budapest & 1985 & Siroki Zoltán & DE-siroki-08428.jpg \\
\hline 514 & Erysimum odoratum Ehrh. & Budapest & - & Siroki Zoltán & DE-siroki-08422.jpg \\
\hline 514 & Erysimum odoratum Ehrh. & Gyenesdiás & 1955 & Siroki Zoltán & DE-siroki-08430.jpg \\
\hline 514 & Erysimum odoratum Ehrh. & Lábatlan & 1986 & Siroki Zoltán & DE-siroki-08435.jpg \\
\hline 514 & Erysimum odoratum Ehrh. & Lábatlan & 1986 & Siroki Zoltán & DE-siroki-08436.jpg \\
\hline 514 & Erysimum odoratum Ehrh. & Lábatlan & 1986 & Siroki Zoltán & DE-siroki-08433.jpg \\
\hline 514 & Erysimum odoratum Ehrh. & Lábatlan & 1986 & Siroki Zoltán & DE-siroki-08434.jpg \\
\hline 514 & Erysimum odoratum Ehrh. & Szilvásvárad & 1960 & Siroki Zoltán & DE-siroki-08437.jpg \\
\hline 514 & Erysimum odoratum Ehrh. & Szilvásvárad & 1960 & Siroki Zoltán & DE-siroki-08438.jpg \\
\hline 514 & Erysimum odoratum Ehrh. & Szilvásvárad & 1960 & Siroki Zoltán & DE-siroki-08439.jpg \\
\hline 515 & Syrenia cana (Piller et Mitterp.) Neilr. & Ágasegyháza & 1956 & Siroki Zoltán & DE-siroki-08468.jpg \\
\hline 515 & Syrenia cana (Piller et Mitterp.) Neilr. & Ágasegyháza & 1956 & Siroki Zoltán & DE-siroki-08469.jpg \\
\hline 515 & Syrenia cana (Piller et Mitterp.) Neilr. & Ágasegyháza & 1956 & Siroki Zoltán & DE-siroki-08470.jpg \\
\hline 515 & Syrenia cana (Piller et Mitterp.) Neilr. & Ágasegyháza & 1969 & Siroki Zoltán & DE-siroki-08462.jpg \\
\hline 515 & Syrenia cana (Piller et Mitterp.) Neilr. & Ágasegyháza & 1969 & Siroki Zoltán & DE-siroki-08463.jpg \\
\hline 515 & Syrenia cana (Piller et Mitterp.) Neilr. & Ágasegyháza & 1969 & Siroki Zoltán & DE-siroki-08464.jpg \\
\hline 515 & Syrenia cana (Piller et Mitterp.) Neilr. & Ágasegyháza & 1969 & Siroki Zoltán & DE-siroki-08465.jpg \\
\hline 515 & Syrenia cana (Piller et Mitterp.) Neilr. & Ágasegyháza & 1969 & Siroki Zoltán & DE-siroki-08466.jpg \\
\hline 515 & Syrenia cana (Piller et Mitterp.) Neilr. & Ágasegyháza & 1969 & Siroki Zoltán & DE-siroki-08467.jpg \\
\hline 515 & Syrenia cana (Piller et Mitterp.) Neilr. & Dunakeszi & 1951 & Kárpáti Zoltán & DE-siroki-08480.jpg \\
\hline 515 & Syrenia cana (Piller et Mitterp.) Neilr. & Fót & 1954 & $\begin{array}{l}\text { Máthé Imre - } \\
\text { Kovács Margit }\end{array}$ & DE-siroki-08471.jpg \\
\hline
\end{tabular}




\begin{tabular}{|c|c|c|c|c|c|}
\hline $\begin{array}{l}\text { Sorszám / } \\
\text { Number }\end{array}$ & Taxon-név / Taxon-name & $\begin{array}{l}\text { Település / } \\
\text { Settlement }\end{array}$ & $\begin{array}{l}\text { Év / } \\
\text { Year }\end{array}$ & $\begin{array}{l}\text { Gyűjtő / } \\
\text { Collector }\end{array}$ & Fájlnév / File-name \\
\hline 515 & Syrenia cana (Piller et Mitterp.) Neilr. & Gödöllő & 1952 & Siroki Zoltán & DE-siroki-08473.jpg \\
\hline 515 & Syrenia cana (Piller et Mitterp.) Neilr. & Nyáregyháza & 1954 & Siroki Zoltán & DE-siroki-08472.jpg \\
\hline 515 & Syrenia cana (Piller et Mitterp.) Neilr. & Veresegyház & 1954 & Siroki Zoltán & DE-siroki-08474.jpg \\
\hline 515 & Syrenia cana (Piller et Mitterp.) Neilr. & Veresegyház & 1954 & Siroki Zoltán & DE-siroki-08475.jpg \\
\hline 515 & Syrenia cana (Piller et Mitterp.) Neilr. & Veresegyház & 1954 & Siroki Zoltán & DE-siroki-08477.jpg \\
\hline 515 & Syrenia cana (Piller et Mitterp.) Neilr. & Veresegyház & 1954 & Siroki Zoltán & DE-siroki-08476.jpg \\
\hline 515 & Syrenia cana (Piller et Mitterp.) Neilr. & Veresegyház & 1954 & Siroki Zoltán & DE-siroki-08478.jpg \\
\hline 515 & Syrenia cana (Piller et Mitterp.) Neilr. & Veresegyház & 1954 & Siroki Zoltán & DE-siroki-08479.jpg \\
\hline 516 & Hesperis tristis L. & Abaújszántó & 1944 & Siroki Zoltán & DE-siroki-08579.jpg \\
\hline 516 & Hesperis tristis L. & Abaújszántó & 1944 & Siroki Zoltán & DE-siroki-08578.jpg \\
\hline 516 & Hesperis tristis L. & Budapest & 1951 & Siroki Zoltán & DE-siroki-08575.jpg \\
\hline 516 & Hesperis tristis L. & Budapest & 1951 & Siroki Zoltán & DE-siroki-08576.jpg \\
\hline 516 & Hesperis tristis L. & Budapest & 1954 & Gondola István & DE-siroki-08577.jpg \\
\hline 516 & Hesperis tristis L. & Nagykovácsi & 1957 & Siroki Zoltán & DE-siroki-08574.jpg \\
\hline 516 & Hesperis tristis L. & Nagykovácsi & 1959 & Siroki Zoltán & DE-siroki-08573.jpg \\
\hline 516 & Hesperis tristis L. & Nagykovácsi & 1960 & Siroki Zoltán & DE-siroki-08570.jpg \\
\hline 516 & Hesperis tristis L. & Nagykovácsi & 1960 & Siroki Zoltán & DE-siroki-08571.jpg \\
\hline 516 & Hesperis tristis L. & Nagykovácsi & 1960 & Siroki Zoltán & DE-siroki-08572.jpg \\
\hline 517.1 & $\begin{array}{l}\text { Hesperis matronalis L. } \\
\text { subsp. candida Kit. }\end{array}$ & "Hármaskő" & 1957 & Siroki Zoltán & DE-siroki-08606.jpg \\
\hline 517.1 & $\begin{array}{l}\text { Hesperis matronalis L. } \\
\text { subsp. candida Kit. }\end{array}$ & "Hármaskő" & 1957 & Siroki Zoltán & DE-siroki-08607.jpg \\
\hline 517.1 & $\begin{array}{l}\text { Hesperis matronalis L. } \\
\text { subsp. candida Kit. }\end{array}$ & "Háromkő" & 1957 & Siroki Zoltán & DE-siroki-08604.jpg \\
\hline 517.1 & $\begin{array}{l}\text { Hesperis matronalis L. } \\
\text { subsp. candida Kit. }\end{array}$ & "Háromkő" & 1957 & Siroki Zoltán & DE-siroki-08605.jpg \\
\hline 517.1 & $\begin{array}{l}\text { Hesperis matronalis L. } \\
\text { subsp. candida Kit. }\end{array}$ & "Nagymező" & 1960 & Siroki Zoltán & DE-siroki-08596.jpg \\
\hline 517.1 & $\begin{array}{l}\text { Hesperis matronalis L. } \\
\text { subsp. candida Kit. }\end{array}$ & "Nagymező" & 1960 & Siroki Zoltán & DE-siroki-08597.jpg \\
\hline 517.1 & $\begin{array}{l}\text { Hesperis matronalis L. } \\
\text { subsp. candida Kit. }\end{array}$ & "Nagymező" & 1960 & Siroki Zoltán & DE-siroki-08598.jpg \\
\hline 517.1 & $\begin{array}{l}\text { Hesperis matronalis L. } \\
\text { subsp. candida Kit. }\end{array}$ & "Nagymező" & 1960 & Siroki Zoltán & DE-siroki-08599.jpg \\
\hline 517.1 & $\begin{array}{l}\text { Hesperis matronalis L. } \\
\text { subsp. candida Kit. }\end{array}$ & "Nagymező" & 1960 & Siroki Zoltán & DE-siroki-08595.jpg \\
\hline 517.4 & $\begin{array}{l}\text { Hesperis matronalis L. subsp. } \\
\text { vrabelyiana (Schur) Soó }\end{array}$ & "Háromkő" & 1956 & Halász Tibor & DE-siroki-08608.jpg \\
\hline 517.4 & $\begin{array}{l}\text { Hesperis matronalis L. subsp. } \\
\text { vrabelyiana (Schur) Soó }\end{array}$ & "Háromkő" & 1959 & Siroki Zoltán & DE-siroki-08600.jpg \\
\hline 517.4 & $\begin{array}{l}\text { Hesperis matronalis L. subsp. } \\
\text { vrabelyiana (Schur) Soó }\end{array}$ & "Háromkő" & 1959 & Siroki Zoltán & DE-siroki-08601.jpg \\
\hline 517.4 & $\begin{array}{l}\text { Hesperis matronalis L. subsp. } \\
\text { vrabelyiana (Schur) Soó }\end{array}$ & "Háromkő" & 1959 & Siroki Zoltán & DE-siroki-08602.jpg \\
\hline 517.4 & $\begin{array}{l}\text { Hesperis matronalis L. subsp. } \\
\text { vrabelyiana (Schur) Soó }\end{array}$ & "Háromkő" & 1959 & Siroki Zoltán & DE-siroki-08603.jpg \\
\hline 518 & Hesperis sylvestris Crantz & Budapest & 1966 & Siroki Zoltán & DE-siroki-08580.jpg \\
\hline 518 & Hesperis sylvestris Crantz & Budapest & 1966 & Siroki Zoltán & DE-siroki-08581.jpg \\
\hline 518 & Hesperis sylvestris Crantz & Kazincbarcika & 1944 & Siroki Zoltán & DE-siroki-08582.jpg \\
\hline 518 & Hesperis sylvestris Crantz & Kazincbarcika & 1944 & Siroki Zoltán & DE-siroki-08583.jpg \\
\hline 519 & Malcolmia africana (L.) R. Br. & Budaörs & 1876 & Wilh??? & DE-siroki-08554.jpg \\
\hline 519 & Malcolmia africana (L.) R. Br. & Budapest & 1890 & Borbás Vince & DE-siroki-08552.jpg \\
\hline 519 & Malcolmia africana (L.) R. Br. & Csolnok & 1876 & Grundl Ignác & DE-siroki-08553.jpg \\
\hline 519 & Malcolmia africana (L.) R. Br. & Debrecen & 1953 & Siroki Zoltán & DE-siroki-08557.jpg \\
\hline
\end{tabular}




\begin{tabular}{|c|c|c|c|c|c|}
\hline $\begin{array}{l}\text { Sorszám / } \\
\text { Number }\end{array}$ & Taxon-név / Taxon-name & $\begin{array}{l}\text { Település / } \\
\text { Settlement }\end{array}$ & $\begin{array}{l}\text { Év / } \\
\text { Year }\end{array}$ & $\begin{array}{l}\text { Gyűjtő / } \\
\text { Collector }\end{array}$ & Fájlnév / File-name \\
\hline 519 & Malcolmia africana (L.) R. Br. & Debrecen & 1953 & Siroki Zoltán & DE-siroki-08558.jpg \\
\hline 519 & Malcolmia africana (L.) R. Br. & Ercsi & 1873 & Tauscher Gyula & DE-siroki-08555.jpg \\
\hline 519 & Malcolmia africana (L.) R. Br. & Ercsi & 1873 & Tauscher Gyula & DE-siroki-08556.jpg \\
\hline 523 & Euclidium syriacum (L.) R. Br. & Boldogkőújfalu & 1942 & Siroki Zoltán & DE-siroki-08569.jpg \\
\hline 523 & Euclidium syriacum (L.) R. Br. & Debrecen & 1947 & Siroki Zoltán & DE-siroki-08568.jpg \\
\hline 523 & Euclidium syriacum (L.) R. Br. & Debrecen & 1947 & Siroki Zoltán & DE-siroki-08567.jpg \\
\hline 523 & Euclidium syriacum (L.) R. Br. & Mezőhegyes & 1954 & Siroki Zoltán & DE-siroki-08564.jpg \\
\hline 523 & Euclidium syriacum (L.) R. Br. & Mezőhegyes & 1954 & Siroki Zoltán & DE-siroki-08565.jpg \\
\hline 523 & Euclidium syriacum (L.) R. Br. & Mezőhegyes & 1954 & Siroki Zoltán & DE-siroki-08566.jpg \\
\hline 523 & Euclidium syriacum (L.) R. Br. & Mikepércs & 1966 & Siroki Zoltán & DE-siroki-08560.jpg \\
\hline 523 & Euclidium syriacum (L.) R. Br. & Mikepércs & 1966 & Siroki Zoltán & DE-siroki-08562.jpg \\
\hline 523 & Euclidium syriacum (L.) R. Br. & Mikepércs & 1966 & Siroki Zoltán & DE-siroki-08561.jpg \\
\hline 523 & Euclidium syriacum (L.) R. Br. & Polgár & 1980 & Siroki Zoltán & DE-siroki-08559.jpg \\
\hline 523 & Euclidium syriacum (L.) R. Br. & Szolnok & 1971 & Siroki Zoltán & DE-siroki-08563.jpg \\
\hline 525 & Barbarea stricta Andrz. & Egyek & 1947 & Siroki Zoltán & DE-siroki-08022.jpg \\
\hline 525 & Barbarea stricta Andrz. & Egyek & 1947 & Siroki Zoltán & DE-siroki-08023.jpg \\
\hline 525 & Barbarea stricta Andrz. & Egyek & 1947 & Siroki Zoltán & DE-siroki-08024.jpg \\
\hline 525 & Barbarea stricta Andrz. & Tiszafüred & 1955 & Siroki Zoltán & DE-siroki-08012.jpg \\
\hline 525 & Barbarea stricta Andrz. & Tiszafüred & 1955 & Siroki Zoltán & DE-siroki-08013.jpg \\
\hline 525 & Barbarea stricta Andrz. & Tiszafüred & 1955 & Siroki Zoltán & DE-siroki-08014.jpg \\
\hline 525 & Barbarea stricta Andrz. & Tiszafüred & 1955 & Siroki Zoltán & DE-siroki-08015.jpg \\
\hline 525 & Barbarea stricta Andrz. & Tiszafüred & 1955 & Siroki Zoltán & DE-siroki-08016.jpg \\
\hline 525 & Barbarea stricta Andrz. & Tiszafüred & 1955 & Siroki Zoltán & DE-siroki-08019.jpg \\
\hline 525 & Barbarea stricta Andrz. & Tiszafüred & 1955 & $\begin{array}{l}\text { Siroki Zoltán - } \\
\text { Farkas Attila }\end{array}$ & DE-siroki-08020.jpg \\
\hline 525 & Barbarea stricta Andrz. & Tiszafüred & 1955 & $\begin{array}{l}\text { Siroki Zoltán - } \\
\text { Farkas Attila }\end{array}$ & DE-siroki-08021.jpg \\
\hline 525 & Barbarea stricta Andrz. & Tiszafüred & 1955 & $\begin{array}{l}\text { Siroki Zoltán - } \\
\text { Farkas Attila }\end{array}$ & DE-siroki-08017.jpg \\
\hline 525 & Barbarea stricta Andrz. & Tiszafüred & 1955 & $\begin{array}{l}\text { Siroki Zoltán - } \\
\text { Farkas Attila }\end{array}$ & DE-siroki-08018.jpg \\
\hline 526 & Barbarea vulgaris R. Br. & Debrecen & 1948 & Siroki Zoltán & DE-siroki-08030.jpg \\
\hline 526 & Barbarea vulgaris R. Br. & Debrecen & 1949 & Siroki Zoltán & DE-siroki-08033.jpg \\
\hline 526 & Barbarea vulgaris R. Br. & Debrecen & 1949 & Siroki Zoltán & DE-siroki-08031.jpg \\
\hline 526 & Barbarea vulgaris R. Br. & Debrecen & 1949 & Siroki Zoltán & DE-siroki-08032.jpg \\
\hline 526 & Barbarea vulgaris R. Br. & Hollóháza & 1940 & Siroki Zoltán & DE-siroki-08035.jpg \\
\hline 526 & Barbarea vulgaris R. Br. & Nagykovácsi & 1959 & Siroki Zoltán & DE-siroki-08025.jpg \\
\hline 526 & Barbarea vulgaris R. Br. & Nagykovácsi & 1959 & Siroki Zoltán & DE-siroki-08026.jpg \\
\hline 526 & Barbarea vulgaris R. Br. & Nagykovácsi & 1959 & Siroki Zoltán & DE-siroki-08027.jpg \\
\hline 526 & Barbarea vulgaris R. Br. & Nagykovácsi & 1959 & Siroki Zoltán & DE-siroki-08028.jpg \\
\hline 526 & Barbarea vulgaris R. Br. & Tarpa & 1955 & $\begin{array}{l}\text { Siroki Zoltán - } \\
\text { Farkas Attila }\end{array}$ & DE-siroki-08029.jpg \\
\hline 527 & Rapistrum perenne (L.) All. & Boldogkőváralja & 1944 & Siroki Zoltán & DE-siroki-08010.jpg \\
\hline 527 & Rapistrum perenne (L.) All. & Budapest & 1967 & Siroki Zoltán & DE-siroki-08009.jpg \\
\hline 527 & Rapistrum perenne (L.) All. & Debrecen & 1947 & Siroki Zoltán & DE-siroki-08006.jpg \\
\hline 527 & Rapistrum perenne (L.) All. & Debrecen & 1947 & Siroki Zoltán & DE-siroki-08007.jpg \\
\hline 527 & Rapistrum perenne (L.) All. & Debrecen & 1947 & Siroki Zoltán & DE-siroki-08008.jpg \\
\hline 529 & Nasturtium officinale R. Br. & Kishuta & 1954 & Simon Tiborné & DE-siroki-08041.jpg \\
\hline 529 & Nasturtium officinale R. Br. & Kishuta & 1954 & Simon Tiborné & DE-siroki-08042.jpg \\
\hline
\end{tabular}




\begin{tabular}{|c|c|c|c|c|c|}
\hline $\begin{array}{l}\text { Sorszám / } \\
\text { Number }\end{array}$ & Taxon-név / Taxon-name & $\begin{array}{l}\text { Település / } \\
\text { Settlement }\end{array}$ & $\begin{array}{l}\text { Év / } \\
\text { Year }\end{array}$ & $\begin{array}{l}\text { Gyűjtő / } \\
\text { Collector }\end{array}$ & Fájlnév / File-name \\
\hline 529 & Nasturtium officinale R. Br. & Nagyhuta & 1954 & Simon Tiborné & DE-siroki-08039.jpg \\
\hline 529 & Nasturtium officinale R. Br. & Nagyhuta & 1954 & Simon Tiborné & DE-siroki-08040.jpg \\
\hline 529 & Nasturtium officinale R. Br. & Tapolca & 1950 & $\begin{array}{l}\text { Priszter } \\
\text { Szaniszló }\end{array}$ & DE-siroki-08038.jpg \\
\hline 531 & $\begin{array}{l}\text { Armoracia macrocarpa } \\
\text { (Waldst. et Kit.) Kit. ex Baumg. }\end{array}$ & Egyek & 1947 & Siroki Zoltán & DE-siroki-08127.jpg \\
\hline 531 & $\begin{array}{l}\text { Armoracia macrocarpa } \\
\text { (Waldst. et Kit.) Kit. ex Baumg. }\end{array}$ & Egyek & 1947 & Siroki Zoltán & DE-siroki-08128.jpg \\
\hline 531 & $\begin{array}{l}\text { Armoracia macrocarpa } \\
\text { (Waldst. et Kit.) Kit. ex Baumg. }\end{array}$ & Egyek & 1947 & Siroki Zoltán & DE-siroki-08129.jpg \\
\hline 531 & $\begin{array}{l}\text { Armoracia macrocarpa } \\
\text { (Waldst. et Kit.) Kit. ex Baumg. }\end{array}$ & Egyek & 1947 & Siroki Zoltán & DE-siroki-08130.jpg \\
\hline 531 & $\begin{array}{l}\text { Armoracia macrocarpa } \\
\text { (Waldst. et Kit.) Kit. ex Baumg. }\end{array}$ & Tiszafüred & 1955 & $\begin{array}{l}\text { Siroki Zoltán - } \\
\text { Farkas Attila }\end{array}$ & DE-siroki-08125.jpg \\
\hline 531 & $\begin{array}{l}\text { Armoracia macrocarpa } \\
\text { (Waldst. et Kit.) Kit. ex Baumg. }\end{array}$ & Tiszafüred & 1955 & $\begin{array}{l}\text { Siroki Zoltán - } \\
\text { Farkas Attila }\end{array}$ & DE-siroki-08126.jpg \\
\hline 531 & $\begin{array}{l}\text { Armoracia macrocarpa } \\
\text { (Waldst. et Kit.) Kit. ex Baumg. }\end{array}$ & Tiszafüred & 1970 & Siroki Zoltán & DE-siroki-08123.jpg \\
\hline 531 & $\begin{array}{l}\text { Armoracia macrocarpa } \\
\text { (Waldst. et Kit.) Kit. ex Baumg. }\end{array}$ & Tiszafüred & 1970 & Siroki Zoltán & DE-siroki-08124.jpg \\
\hline 532 & Cardamine impatiens L. & "Hármaskő" & 1957 & Siroki Zoltán & DE-siroki-08165.jpg \\
\hline 532 & Cardamine impatiens L. & Miskolc & 1960 & Siroki Zoltán & DE-siroki-08163.jpg \\
\hline 532 & Cardamine impatiens L. & Nagyhuta & 1961 & Siroki Zoltán & DE-siroki-08161.jpg \\
\hline 532 & Cardamine impatiens L. & Nagyhuta & 1961 & Siroki Zoltán & DE-siroki-08162.jpg \\
\hline 532 & Cardamine impatiens L. & Nagyvisnyó & 1959 & Siroki Zoltán & DE-siroki-08164.jpg \\
\hline 532 & Cardamine impatiens L. & Szilvásvárad & 1954 & Siroki Zoltán & DE-siroki-08166.jpg \\
\hline 532 & Cardamine impatiens L. & Szilvásvárad & 1954 & Siroki Zoltán & DE-siroki-08167.jpg \\
\hline 535 & Cardamine enneaphyllos (L.) Crantz & Budapest & 1952 & Siroki Zoltán & DE-siroki-08148.jpg \\
\hline 535 & Cardamine enneaphyllos (L.) Crantz & Budapest & 1952 & Siroki Zoltán & DE-siroki-08146.jpg \\
\hline 535 & Cardamine enneaphyllos (L.) Crantz & Budapest & 1952 & Siroki Zoltán & DE-siroki-08147.jpg \\
\hline 535 & Cardamine enneaphyllos (L.) Crantz & Budapest & 1955 & Siroki Zoltán & DE-siroki-08143.jpg \\
\hline 535 & Cardamine enneaphyllos (L.) Crantz & Budapest & 1955 & Siroki Zoltán & DE-siroki-08144.jpg \\
\hline 535 & Cardamine enneaphyllos (L.) Crantz & Budapest & 1955 & Siroki Zoltán & DE-siroki-08140.jpg \\
\hline 535 & Cardamine enneaphyllos (L.) Crantz & Budapest & 1955 & Siroki Zoltán & DE-siroki-08141.jpg \\
\hline 535 & Cardamine enneaphyllos (L.) Crantz & Budapest & 1955 & Siroki Zoltán & DE-siroki-08142.jpg \\
\hline 535 & Cardamine enneaphyllos (L.) Crantz & Budapest & 1955 & Siroki Zoltán & DE-siroki-08145.jpg \\
\hline 535 & Cardamine enneaphyllos (L.) Crantz & Pécs & 1958 & Siroki Zoltán & DE-siroki-08138.jpg \\
\hline 535 & Cardamine enneaphyllos (L.) Crantz & Pécs & 1958 & Siroki Zoltán & DE-siroki-08139.jpg \\
\hline 536 & Cardamine glanduligera O. Schwarz & Háromhuta & 1955 & Simon Tiborné & DE-siroki-08157.jpg \\
\hline 536 & Cardamine glanduligera O. Schwarz & Háromhuta & 1955 & Simon Tiborné & DE-siroki-08152.jpg \\
\hline 536 & Cardamine glanduligera O. Schwarz & Háromhuta & 1955 & Simon Tiborné & DE-siroki-08151.jpg \\
\hline 536 & Cardamine glanduligera O. Schwarz & Háromhuta & 1963 & Siroki Zoltán & DE-siroki-08159.jpg \\
\hline 536 & Cardamine glanduligera O. Schwarz & Háromhuta & 1974 & Siroki Zoltán & DE-siroki-08158.jpg \\
\hline 536 & Cardamine glanduligera O. Schwarz & Nagyhuta & 1954 & Simon Tiborné & DE-siroki-08153.jpg \\
\hline 536 & Cardamine glanduligera O. Schwarz & Nagyhuta & 1954 & Simon Tiborné & DE-siroki-08154.jpg \\
\hline 536 & Cardamine glanduligera O. Schwarz & Nagyhuta & 1954 & Simon Tiborné & DE-siroki-08155.jpg \\
\hline 536 & Cardamine glanduligera O. Schwarz & Nagyhuta & 1955 & Simon Tiborné & DE-siroki-08156.jpg \\
\hline 537 & Cardamine bulbifera (L.) Crantz & "Fáni-völgy" & 1955 & $\begin{array}{l}\text { Siroki Zoltán - } \\
\text { Farkas Attila }\end{array}$ & DE-siroki-08135.jpg \\
\hline 537 & Cardamine bulbifera (L.) Crantz & "Mátra" & 1957 & Siroki Zoltán & DE-siroki-08134.jpg \\
\hline 537 & Cardamine bulbifera (L.) Crantz & Nagykovácsi & 1959 & Siroki Zoltán & DE-siroki-08131.jpg \\
\hline 537 & Cardamine bulbifera (L.) Crantz & Nagykovácsi & 1959 & Siroki Zoltán & DE-siroki-08132.jpg \\
\hline
\end{tabular}




\begin{tabular}{|c|c|c|c|c|c|}
\hline $\begin{array}{l}\text { Sorszám / } \\
\text { Number }\end{array}$ & Taxon-név / Taxon-name & $\begin{array}{l}\text { Település / } \\
\text { Settlement }\end{array}$ & $\begin{array}{l}\text { Év / } \\
\text { Year }\end{array}$ & $\begin{array}{l}\text { Gyűjtő / } \\
\text { Collector }\end{array}$ & Fájlnév / File-name \\
\hline 537 & Cardamine bulbifera (L.) Crantz & Nagykovácsi & 1959 & Siroki Zoltán & DE-siroki-08133.jpg \\
\hline 538 & Cardamine parviflora L. & Hortobágy & 1975 & Siroki Zoltán & DE-siroki-08178.jpg \\
\hline 538 & Cardamine parviflora L. & Tiszacsege & 1968 & Siroki Zoltán & DE-siroki-08180.jpg \\
\hline 538 & Cardamine parviflora L. & Tiszacsege & 1968 & Siroki Zoltán & DE-siroki-08177.jpg \\
\hline 538 & Cardamine parviflora L. & Tiszacsege & 1968 & Siroki Zoltán & DE-siroki-08179.jpg \\
\hline 539 & Cardamine hirsuta L. & Misefa & 1928 & Kováts Ferenc & DE-siroki-08175.jpg \\
\hline 539 & Cardamine hirsuta L. & Pilisszentiván & 1951 & Kárpáti Zoltán & DE-siroki-08176.jpg \\
\hline 539 & Cardamine hirsuta L. & Szemenye & 1951 & Jeanplong József & DE-siroki-08173.jpg \\
\hline 541 & Cardamine amara L. & Miskolc & 1966 & Siroki Zoltán & DE-siroki-08184.jpg \\
\hline 541 & Cardamine amara L. & Miskolc & 1966 & Siroki Zoltán & DE-siroki-08185.jpg \\
\hline 541 & Cardamine amara L. & Miskolc & 1966 & Siroki Zoltán & DE-siroki-08186.jpg \\
\hline 541 & Cardamine amara L. & Miskolc & 1966 & Siroki Zoltán & DE-siroki-08187.jpg \\
\hline 541 & Cardamine amara L. & Szilvásvárad & 1966 & Siroki Zoltán & DE-siroki-08188.jpg \\
\hline 541 & Cardamine amara L. & Szilvásvárad & 1966 & Siroki Zoltán & DE-siroki-08189.jpg \\
\hline 541 & Cardamine amara L. & Szilvásvárad & 1966 & Siroki Zoltán & DE-siroki-08190.jpg \\
\hline 541 & Cardamine amara L. & Szilvásvárad & 1966 & Siroki Zoltán & DE-siroki-08191.jpg \\
\hline 541 & Cardamine amara L. & Szilvásvárad & 1966 & Siroki Zoltán & DE-siroki-08192.jpg \\
\hline 542 & Cardamine pratensis L. & Bátorliget & 1954 & Simon Tiborné & DE-siroki-08209.jpg \\
\hline 542 & Cardamine pratensis L. & Bátorliget & 1954 & Siroki Zoltán & DE-siroki-08205.jpg \\
\hline 542 & Cardamine pratensis L. & Bátorliget & 1954 & Siroki Zoltán & DE-siroki-08206.jpg \\
\hline 542 & Cardamine pratensis L. & Bátorliget & 1954 & Siroki Zoltán & DE-siroki-08207.jpg \\
\hline 542 & Cardamine pratensis L. & Bátorliget & 1954 & Siroki Zoltán & DE-siroki-08208.jpg \\
\hline 542 & Cardamine pratensis L. & Budapest & 1885 & Szépligeti Győző & DE-siroki-08197.jpg \\
\hline 542 & Cardamine pratensis L. & Debrecen & 1948 & Siroki Zoltán & DE-siroki-08203.jpg \\
\hline 542 & Cardamine pratensis L. & Debrecen & 1948 & Siroki Zoltán & DE-siroki-08202.jpg \\
\hline 542 & Cardamine pratensis L. & Debrecen & 1957 & Siroki Zoltán & DE-siroki-08199.jpg \\
\hline 542 & Cardamine pratensis L. & Debrecen & 1957 & Siroki Zoltán & DE-siroki-08200.jpg \\
\hline 542 & Cardamine pratensis L. & Debrecen & 1957 & Siroki Zoltán & DE-siroki-08201.jpg \\
\hline 542 & Cardamine pratensis L. & Gödöllő & 1952 & Siroki Zoltán & DE-siroki-08204.jpg \\
\hline 542 & Cardamine pratensis L. & Háromhuta & 1965 & Siroki Zoltán & DE-siroki-08198.jpg \\
\hline 542 & Cardamine pratensis L. & Tarpa & 1955 & $\begin{array}{l}\text { Siroki Zoltán - } \\
\text { Farkas Attila }\end{array}$ & DE-siroki-08210.jpg \\
\hline 544 & Cardaminopsis petraea (L.) Hiitonen & Gyenesdiás & 1955 & Siroki Zoltán & DE-siroki-08362.jpg \\
\hline 544 & Cardaminopsis petraea (L.) Hiitonen & Gyenesdiás & 1955 & Siroki Zoltán & DE-siroki-08364.jpg \\
\hline 544 & Cardaminopsis petraea (L.) Hiitonen & Vonyarcvashegy & 1927 & Jávorka Sándor & DE-siroki-08363.jpg \\
\hline 545 & Cardaminopsis arenosa (L.) Hayek & Budapest & 1905 & K??? Géza & DE-siroki-08361.jpg \\
\hline 545 & Cardaminopsis arenosa (L.) Hayek & Budapest & 1941 & Siroki Zoltán & DE-siroki-08375.jpg \\
\hline 545 & Cardaminopsis arenosa (L.) Hayek & Budapest & 1960 & Siroki Zoltán & DE-siroki-08378.jpg \\
\hline 545 & Cardaminopsis arenosa (L.) Hayek & Budapest & 1960 & Siroki Zoltán & DE-siroki-08379.jpg \\
\hline 545 & Cardaminopsis arenosa (L.) Hayek & Budapest & 1960 & Siroki Zoltán & DE-siroki-08380.jpg \\
\hline 545 & Cardaminopsis arenosa (L.) Hayek & Budapest & 1970 & Siroki Zoltán & DE-siroki-08376.jpg \\
\hline 545 & Cardaminopsis arenosa (L.) Hayek & Budapest & 1970 & Siroki Zoltán & DE-siroki-08377.jpg \\
\hline 545 & Cardaminopsis arenosa (L.) Hayek & Budapest & 1984 & Siroki Zoltán & DE-siroki-08381.jpg \\
\hline 545 & Cardaminopsis arenosa (L.) Hayek & Nagyhuta & 1978 & Siroki Zoltán & DE-siroki-08382.jpg \\
\hline 545 & Cardaminopsis arenosa (L.) Hayek & Nagyhuta & 1978 & Siroki Zoltán & DE-siroki-08383.jpg \\
\hline 545 & Cardaminopsis arenosa (L.) Hayek & Szarvaskő & 1958 & Siroki Zoltán & DE-siroki-08374.jpg \\
\hline 545 & Cardaminopsis arenosa (L.) Hayek & Szarvaskő & 1958 & Siroki Zoltán & DE-siroki-08371.jpg \\
\hline
\end{tabular}




\begin{tabular}{|c|c|c|c|c|c|}
\hline $\begin{array}{l}\text { Sorszám / } \\
\text { Number }\end{array}$ & Taxon-név / Taxon-name & $\begin{array}{l}\text { Település / } \\
\text { Settlement }\end{array}$ & $\begin{array}{l}\text { Év / } \\
\text { Year }\end{array}$ & $\begin{array}{l}\text { Gyújtő / } \\
\text { Collector }\end{array}$ & Fájlnév / File-name \\
\hline 545 & Cardaminopsis arenosa (L.) Hayek & Szarvaskő & 1966 & Siroki Zoltán & DE-siroki-08372.jpg \\
\hline 545 & Cardaminopsis arenosa (L.) Hayek & Szarvaskő & 1966 & Siroki Zoltán & DE-siroki-08373.jpg \\
\hline 546 & Arabis turrita L. & "Fáni-völgy" & 1955 & $\begin{array}{l}\text { Siroki Zoltán - } \\
\text { Farkas Attila }\end{array}$ & DE-siroki-08324.jpg \\
\hline 546 & Arabis turrita L. & Budapest & 1890 & Czakó Kálmán & DE-siroki-08322.jpg \\
\hline 546 & Arabis turrita L. & Budapest & 1912 & Bocskay Ottó & DE-siroki-08321.jpg \\
\hline 546 & Arabis turrita L. & Pécs & 1958 & Siroki Zoltán & DE-siroki-08325.jpg \\
\hline 546 & Arabis turrita L. & Törökbálint & 1951 & Siroki Zoltán & DE-siroki-08323.jpg \\
\hline 547 & Arabis glabra (L.) Bernh. & "Dobogókő" & 1965 & Siroki Zoltán & DE-siroki-08312.jpg \\
\hline 547 & Arabis glabra (L.) Bernh. & "Dobogókő" & 1965 & Siroki Zoltán & DE-siroki-08313.jpg \\
\hline 547 & Arabis glabra (L.) Bernh. & "Nagymező" & 1959 & Halász Tibor & DE-siroki-08314.jpg \\
\hline 547 & Arabis glabra (L.) Bernh. & Budapest & 1952 & Siroki Zoltán & DE-siroki-08315.jpg \\
\hline 547 & Arabis glabra (L.) Bernh. & Debrecen & 1949 & Siroki Zoltán & DE-siroki-08317.jpg \\
\hline 547 & Arabis glabra (L.) Bernh. & Debrecen & 1954 & Siroki Zoltán & DE-siroki-08316.jpg \\
\hline 547 & Arabis glabra (L.) Bernh. & Debrecen & 1954 & Siroki Zoltán & DE-siroki-08318.jpg \\
\hline 547 & Arabis glabra (L.) Bernh. & Rakaca & 1982 & Siroki Zoltán & DE-siroki-08311.jpg \\
\hline 548 & Arabis alpina $\mathrm{L}$. & Nagyvisnyó & 1959 & Siroki Zoltán & DE-siroki-08331.jpg \\
\hline 548 & Arabis alpina L. & Nagyvisnyó & 1966 & Siroki Zoltán & DE-siroki-08329.jpg \\
\hline 548 & Arabis alpina L. & Nagyvisnyó & 1966 & Siroki Zoltán & DE-siroki-08330.jpg \\
\hline 549 & Arabis recta Vill. & Budapest & 1890 & F. et Sch. & DE-siroki-08337.jpg \\
\hline 549 & Arabis recta Vill. & Budapest & 1912 & Thaisz Lajos & DE-siroki-08338.jpg \\
\hline 549 & Arabis recta Vill. & Budapest & 1941 & Siroki Zoltán & DE-siroki-08347.jpg \\
\hline 549 & Arabis recta Vill. & Budapest & 1951 & Siroki Zoltán & DE-siroki-08340.jpg \\
\hline 549 & Arabis recta Vill. & Kimle & 1962 & Siroki Zoltán & DE-siroki-08335.jpg \\
\hline 549 & Arabis recta Vill. & Kimle & 1962 & Siroki Zoltán & DE-siroki-08336.jpg \\
\hline 549 & Arabis recta Vill. & Nagykovácsi & 1959 & Siroki Zoltán & DE-siroki-08341.jpg \\
\hline 549 & Arabis recta Vill. & Nagykovácsi & 1959 & Siroki Zoltán & DE-siroki-08342.jpg \\
\hline 549 & Arabis recta Vill. & Nagykovácsi & 1959 & Siroki Zoltán & DE-siroki-08343.jpg \\
\hline 549 & Arabis recta Vill. & Nagykovácsi & 1959 & Siroki Zoltán & DE-siroki-08344.jpg \\
\hline 552 & Arabis hirsuta (L.) Scop. & "Nagymező" & 1959 & Halász Tibor & DE-siroki-08349.jpg \\
\hline 552 & Arabis hirsuta (L.) Scop. & "Nagymező" & 1959 & Halász Tibor & DE-siroki-08348.jpg \\
\hline 552 & Arabis hirsuta (L.) Scop. & Budaörs & 1955 & $\begin{array}{l}\text { Siroki Zoltán - } \\
\text { Farkas Attila }\end{array}$ & DE-siroki-08354.jpg \\
\hline 552 & Arabis hirsuta (L.) Scop. & Debrecen & 1970 & Siroki Zoltán & DE-siroki-08350.jpg \\
\hline 552 & Arabis hirsuta (L.) Scop. & Debrecen & 1970 & Siroki Zoltán & DE-siroki-08351.jpg \\
\hline 552 & Arabis hirsuta (L.) Scop. & Debrecen & 1970 & Siroki Zoltán & DE-siroki-08352.jpg \\
\hline 552 & Arabis hirsuta (L.) Scop. & Debrecen & 1970 & Siroki Zoltán & DE-siroki-08353.jpg \\
\hline 553 & Lunaria rediviva L. & "Hármaskő" & 1957 & Siroki Zoltán & DE-siroki-08225.jpg \\
\hline 553 & Lunaria rediviva L. & "Hármaskő" & 1957 & Siroki Zoltán & DE-siroki-08226.jpg \\
\hline 553 & Lunaria rediviva L. & Mátraszentimre & 1958 & Pethő Menyhért & DE-siroki-08228.jpg \\
\hline 553 & Lunaria rediviva L. & Mátraszentimre & 1958 & Pethő Menyhért & DE-siroki-08229.jpg \\
\hline 553 & Lunaria rediviva L. & Mátraszentimre & 1958 & Pethő Menyhért & DE-siroki-08230.jpg \\
\hline 553 & Lunaria rediviva L. & Mátraszentimre & 1958 & Pethő Menyhért & DE-siroki-08227.jpg \\
\hline 553 & Lunaria rediviva L. & Szilvásvárad & 1954 & Siroki Zoltán & DE-siroki-08214.jpg \\
\hline 553 & Lunaria rediviva L. & Szilvásvárad & 1954 & Siroki Zoltán & DE-siroki-08215.jpg \\
\hline 553 & Lunaria rediviva L. & Szilvásvárad & 1954 & Siroki Zoltán & DE-siroki-08216.jpg \\
\hline 553 & Lunaria rediviva L. & Szilvásvárad & 1954 & Siroki Zoltán & DE-siroki-08217.jpg \\
\hline
\end{tabular}




\begin{tabular}{|c|c|c|c|c|c|}
\hline $\begin{array}{l}\text { Sorszám / } \\
\text { Number }\end{array}$ & Taxon-név / Taxon-name & $\begin{array}{l}\text { Település / } \\
\text { Settlement }\end{array}$ & $\begin{array}{l}\text { Év / } \\
\text { Year }\end{array}$ & $\begin{array}{l}\text { Gyűjtő / } \\
\text { Collector }\end{array}$ & Fájlnév / File-name \\
\hline 553 & Lunaria rediviva L. & Szilvásvárad & 1954 & Siroki Zoltán & DE-siroki-08218.jpg \\
\hline 553 & Lunaria rediviva L. & Szilvásvárad & 1954 & Siroki Zoltán & DE-siroki-08219.jpg \\
\hline 553 & Lunaria rediviva L. & Szilvásvárad & 1966 & Siroki Zoltán & DE-siroki-08220.jpg \\
\hline 553 & Lunaria rediviva L. & Szilvásvárad & 1966 & Siroki Zoltán & DE-siroki-08221.jpg \\
\hline 553 & Lunaria rediviva $\mathrm{L}$. & Szilvásvárad & 1966 & Siroki Zoltán & DE-siroki-08222.jpg \\
\hline 553 & Lunaria rediviva L. & Szilvásvárad & 1966 & Siroki Zoltán & DE-siroki-08223.jpg \\
\hline 553 & Lunaria rediviva L. & Szilvásvárad & 1968 & Siroki Zoltán & DE-siroki-08224.jpg \\
\hline 554 & Lunaria annua L. & Budapest & 1981 & Siroki Zoltán & DE-siroki-08234.jpg \\
\hline 556 & Alyssum alyssoides L. & "Nagymező" & 1959 & Halász Tibor & DE-siroki-08483.jpg \\
\hline 556 & Alyssum alyssoides L. & Debrecen & 1947 & Siroki Zoltán & DE-siroki-08484.jpg \\
\hline 556 & Alyssum alyssoides L. & Debrecen & 1949 & Siroki Zoltán & DE-siroki-08485.jpg \\
\hline 556 & Alyssum alyssoides L. & Hortobágy & 1975 & Siroki Zoltán & DE-siroki-08482.jpg \\
\hline 556 & Alyssum alyssoides L. & Lábatlan & 1986 & Siroki Zoltán & DE-siroki-08481.jpg \\
\hline 557 & Alyssum desertorum Stapf & Baracska & 1951 & Siroki Zoltán & DE-siroki-08490.jpg \\
\hline 557 & Alyssum desertorum Stapf & Budapest & 1872 & Tauscher Gyula & DE-siroki-08492.jpg \\
\hline 557 & Alyssum desertorum Stapf & Budapest & 1874 & Szépligeti Győző & DE-siroki-08491.jpg \\
\hline 557 & Alyssum desertorum Stapf & Debrecen & 1947 & Siroki Zoltán & DE-siroki-08488.jpg \\
\hline 557 & Alyssum desertorum Stapf & Debrecen & 1947 & Siroki Zoltán & DE-siroki-08489.jpg \\
\hline 557 & Alyssum desertorum Stapf & Debrecen & 1948 & Siroki Zoltán & DE-siroki-08487.jpg \\
\hline 558 & Alyssum montanum L. & Budaörs & 1955 & Siroki Zoltán & DE-siroki-08510.jpg \\
\hline 558 & Alyssum montanum L. & Budaörs & 1955 & $\begin{array}{l}\text { Siroki Zoltán - } \\
\text { Farkas Attila }\end{array}$ & DE-siroki-08512.jpg \\
\hline 558 & Alyssum montanum L. & Budaörs & 1964 & Siroki Zoltán & DE-siroki-08511.jpg \\
\hline 558 & Alyssum montanum L. & Budapest & 1941 & Siroki Zoltán & DE-siroki-08507.jpg \\
\hline 558 & Alyssum montanum L. & Budapest & 1955 & Siroki Zoltán & DE-siroki-08508.jpg \\
\hline 558 & Alyssum montanum L. & Budapest & 1970 & Siroki Zoltán & DE-siroki-08509.jpg \\
\hline 558 & Alyssum montanum L. & Debrecen & 1949 & Siroki Zoltán & DE-siroki-08499.jpg \\
\hline 558 & Alyssum montanum L. & Debrecen & 1949 & Siroki Zoltán & DE-siroki-08500.jpg \\
\hline 558 & Alyssum montanum L. & Debrecen & 1949 & Siroki Zoltán & DE-siroki-08506.jpg \\
\hline 558 & Alyssum montanum L. & Debrecen & 1950 & Siroki Zoltán & DE-siroki-08504.jpg \\
\hline 558 & Alyssum montanum L. & Debrecen & 1954 & Siroki Zoltán & DE-siroki-08503.jpg \\
\hline 558 & Alyssum montanum L. & Debrecen & 1954 & Siroki Zoltán & DE-siroki-08501.jpg \\
\hline 558 & Alyssum montanum L. & Debrecen & 1954 & Siroki Zoltán & DE-siroki-08502.jpg \\
\hline 558 & Alyssum montanum L. & Debrecen & 1954 & Siroki Zoltán & DE-siroki-08505.jpg \\
\hline 558 & Alyssum montanum L. & Gyenesdiás & 1972 & Siroki Zoltán & DE-siroki-08498.jpg \\
\hline 558 & Alyssum montanum L. & Nagykovácsi & 1959 & Siroki Zoltán & DE-siroki-08513.jpg \\
\hline 558 & Alyssum montanum L. & Nagykovácsi & 1959 & Siroki Zoltán & DE-siroki-08514.jpg \\
\hline 558 & Alyssum montanum L. & Nagykovácsi & 1959 & Siroki Zoltán & DE-siroki-08515.jpg \\
\hline 558 & Alyssum montanum L. & Nagykovácsi & 1959 & Siroki Zoltán & DE-siroki-08516.jpg \\
\hline 559 & Alyssum tortuosum Willd. & Budaörs & 1952 & Siroki Zoltán & DE-siroki-08535.jpg \\
\hline 559 & Alyssum tortuosum Willd. & Budaörs & 1964 & Siroki Zoltán & DE-siroki-08532.jpg \\
\hline 559 & Alyssum tortuosum Willd. & Budaörs & 1964 & Siroki Zoltán & DE-siroki-08533.jpg \\
\hline 559 & Alyssum tortuosum Willd. & Budaörs & 1964 & Siroki Zoltán & DE-siroki-08534.jpg \\
\hline 559 & Alyssum tortuosum Willd. & Budaörs & 1965 & Siroki Zoltán & DE-siroki-08523.jpg \\
\hline 559 & Alyssum tortuosum Willd. & Bugac & 1973 & Siroki Zoltán & DE-siroki-08524.jpg \\
\hline 559 & Alyssum tortuosum Willd. & Gödöllő & 1951 & Siroki Zoltán & DE-siroki-08527.jpg \\
\hline 559 & Alyssum tortuosum Willd. & Gödöllő & 1951 & Siroki Zoltán & DE-siroki-08530.jpg \\
\hline
\end{tabular}




\begin{tabular}{|c|c|c|c|c|c|}
\hline $\begin{array}{l}\text { Sorszám / } \\
\text { Number }\end{array}$ & Taxon-név / Taxon-name & $\begin{array}{l}\text { Település / } \\
\text { Settlement }\end{array}$ & $\begin{array}{l}\text { Év / } \\
\text { Year }\end{array}$ & $\begin{array}{l}\text { Gyűjtő / } \\
\text { Collector }\end{array}$ & Fájlnév / File-name \\
\hline 559 & Alyssum tortuosum Willd. & Gödöllő & 1951 & Siroki Zoltán & DE-siroki-08529.jpg \\
\hline 559 & Alyssum tortuosum Willd. & Gödöllő & 1951 & Siroki Zoltán & DE-siroki-08528.jpg \\
\hline 559 & Alyssum tortuosum Willd. & Kecskemét & 1969 & Siroki Zoltán & DE-siroki-08531.jpg \\
\hline 559 & Alyssum tortuosum Willd. & Veresegyház & 1960 & Siroki Zoltán & DE-siroki-08525.jpg \\
\hline 559 & Alyssum tortuosum Willd. & Veresegyház & 1960 & Siroki Zoltán & DE-siroki-08526.jpg \\
\hline 560 & Berteroa incana (L.) DC. & Debrecen & 1947 & Siroki Zoltán & DE-siroki-08549.jpg \\
\hline 561 & Aurinia saxatilis (L.) Desv. & Füzér & 1953 & Jeney Endre & DE-siroki-08545.jpg \\
\hline 561 & Aurinia saxatilis (L.) Desv. & Füzér & 1955 & Simon Tiborné & DE-siroki-08544.jpg \\
\hline 561 & Aurinia saxatilis (L.) Desv. & Füzér & 1973 & Siroki Zoltán & DE-siroki-08543.jpg \\
\hline 562 & Rorippa austriaca (Crantz) Besser & Debrecen & 1955 & Siroki Zoltán & DE-siroki-08070.jpg \\
\hline 563 & $\begin{array}{l}\text { Rorippa } \times \text { armoracioides } \\
\text { (Tausch) Fuss }\end{array}$ & Debrecen & 1947 & Siroki Zoltán & DE-siroki-08109.jpg \\
\hline 563 & $\begin{array}{l}\text { Rorippa } \times \text { armoracioides } \\
\text { (Tausch) Fuss }\end{array}$ & Tiszafüred & 1955 & Siroki Zoltán & DE-siroki-08105.jpg \\
\hline 563 & $\begin{array}{l}\text { Rorippa } \times \text { armoracioides } \\
\text { (Tausch) Fuss }\end{array}$ & Tiszafüred & 1955 & Siroki Zoltán & DE-siroki-08106.jpg \\
\hline 563 & $\begin{array}{l}\text { Rorippa } \times \text { armoracioides } \\
\text { (Tausch) Fuss }\end{array}$ & Tiszafüred & 1955 & Siroki Zoltán & DE-siroki-08107.jpg \\
\hline 563 & $\begin{array}{l}\text { Rorippa } \times \text { armoracioides } \\
\text { (Tausch) Fuss }\end{array}$ & Tiszafüred & 1955 & Siroki Zoltán & DE-siroki-08108.jpg \\
\hline 564 & Rorippa amphibia (L.) Besser & Debrecen & 1947 & Siroki Zoltán & DE-siroki-08060.jpg \\
\hline 564 & Rorippa amphibia (L.) Besser & Debrecen & 1947 & Siroki Zoltán & DE-siroki-08061.jpg \\
\hline 564 & Rorippa amphibia (L.) Besser & Debrecen & 1947 & Siroki Zoltán & DE-siroki-08062.jpg \\
\hline 564 & Rorippa amphibia (L.) Besser & Debrecen & 1947 & Siroki Zoltán & DE-siroki-08063.jpg \\
\hline 564 & Rorippa amphibia (L.) Besser & Debrecen & 1947 & Siroki Zoltán & DE-siroki-08064.jpg \\
\hline 564 & Rorippa amphibia (L.) Besser & Debrecen & 1947 & Siroki Zoltán & DE-siroki-08065.jpg \\
\hline 564 & Rorippa amphibia (L.) Besser & Debrecen & 1947 & Siroki Zoltán & DE-siroki-08057.jpg \\
\hline 564 & Rorippa amphibia (L.) Besser & Debrecen & 1947 & Siroki Zoltán & DE-siroki-08058.jpg \\
\hline 564 & Rorippa amphibia (L.) Besser & Debrecen & 1947 & Siroki Zoltán & DE-siroki-08059.jpg \\
\hline 564 & Rorippa amphibia (L.) Besser & Gödöllő & 1951 & Siroki Zoltán & DE-siroki-08066.jpg \\
\hline 566 & Rorippa $\times$ anceps (Wahlenb.) Rchb. & Gelej & 1980 & Siroki Zoltán & DE-siroki-08067.jpg \\
\hline 566 & Rorippa $\times$ anceps (Wahlenb.) Rchb. & Gelej & 1980 & Siroki Zoltán & DE-siroki-08068.jpg \\
\hline 566 & Rorippa $\times$ anceps (Wahlenb.) Rchb. & Gelej & 1980 & Siroki Zoltán & DE-siroki-08069.jpg \\
\hline 566 & Rorippa $\times$ anceps (Wahlenb.) Rchb. & Tornyospálca & 1967 & Gondola István & DE-siroki-08117.jpg \\
\hline 566 & Rorippa $\times$ anceps (Wahlenb.) Rchb. & Tornyospálca & 1967 & Gondola István & DE-siroki-08118.jpg \\
\hline 566 & Rorippa $\times$ anceps (Wahlenb.) Rchb. & Tornyospálca & 1967 & Gondola István & DE-siroki-08119.jpg \\
\hline 566 & Rorippa $\times$ anceps (Wahlenb.) Rchb. & Tuzsér & 1966 & Gondola István & DE-siroki-08114.jpg \\
\hline 566 & Rorippa $\times$ anceps (Wahlenb.) Rchb. & Tuzsér & 1966 & Gondola István & DE-siroki-08115.jpg \\
\hline 566 & Rorippa $\times$ anceps (Wahlenb.) Rchb. & Tuzsér & 1966 & Gondola István & DE-siroki-08116.jpg \\
\hline 567 & Rorippa sylvestris (L.) Besser & Abaújkér & 1942 & Siroki Zoltán & DE-siroki-08073.jpg \\
\hline 567 & Rorippa sylvestris (L.) Besser & Budapest & 1940 & Siroki Zoltán & DE-siroki-08103.jpg \\
\hline 567 & Rorippa sylvestris (L.) Besser & Debrecen & 1947 & Siroki Zoltán & DE-siroki-08086.jpg \\
\hline 567 & Rorippa sylvestris (L.) Besser & Debrecen & 1947 & Siroki Zoltán & DE-siroki-08089.jpg \\
\hline 567 & Rorippa sylvestris (L.) Besser & Debrecen & 1947 & Siroki Zoltán & DE-siroki-08087.jpg \\
\hline 567 & Rorippa sylvestris (L.) Besser & Debrecen & 1947 & Siroki Zoltán & DE-siroki-08088.jpg \\
\hline 567 & Rorippa sylvestris (L.) Besser & Debrecen & 1947 & Siroki Zoltán & DE-siroki-08079.jpg \\
\hline 567 & Rorippa sylvestris (L.) Besser & Debrecen & 1947 & Siroki Zoltán & DE-siroki-08080.jpg \\
\hline 567 & Rorippa sylvestris (L.) Besser & Debrecen & 1947 & Siroki Zoltán & DE-siroki-08077.jpg \\
\hline 567 & Rorippa sylvestris (L.) Besser & Debrecen & 1947 & Siroki Zoltán & DE-siroki-08078.jpg \\
\hline
\end{tabular}




\begin{tabular}{|c|c|c|c|c|c|}
\hline $\begin{array}{l}\text { Sorszám / } \\
\text { Number }\end{array}$ & Taxon-név / Taxon-name & $\begin{array}{l}\text { Település / } \\
\text { Settlement }\end{array}$ & $\begin{array}{l}\text { Év / } \\
\text { Year }\end{array}$ & $\begin{array}{l}\text { Gyüjtő / } \\
\text { Collector }\end{array}$ & Fájlnév / File-name \\
\hline 567 & Rorippa sylvestris (L.) Besser & Debrecen & 1969 & Siroki Zoltán & DE-siroki-08052.jpg \\
\hline 567 & Rorippa sylvestris (L.) Besser & Debrecen & 1970 & Siroki Zoltán & DE-siroki-08051.jpg \\
\hline 567 & Rorippa sylvestris (L.) Besser & Debrecen & 1970 & Siroki Zoltán & DE-siroki-08053.jpg \\
\hline 567 & Rorippa sylvestris (L.) Besser & Debrecen & 1970 & Siroki Zoltán & DE-siroki-08054.jpg \\
\hline 567 & Rorippa sylvestris (L.) Besser & Debrecen & 1970 & Siroki Zoltán & DE-siroki-08090.jpg \\
\hline 567 & Rorippa sylvestris (L.) Besser & Debrecen & 1970 & Siroki Zoltán & DE-siroki-08091.jpg \\
\hline 567 & Rorippa sylvestris (L.) Besser & Debrecen & 1970 & Siroki Zoltán & DE-siroki-08092.jpg \\
\hline 567 & Rorippa sylvestris (L.) Besser & Debrecen & 1970 & Siroki Zoltán & DE-siroki-08093.jpg \\
\hline 567 & Rorippa sylvestris (L.) Besser & Debrecen & 1970 & Siroki Zoltán & DE-siroki-08094.jpg \\
\hline 567 & Rorippa sylvestris (L.) Besser & Debrecen & 1970 & Siroki Zoltán & DE-siroki-08095.jpg \\
\hline 567 & Rorippa sylvestris (L.) Besser & Debrecen & 1970 & Siroki Zoltán & DE-siroki-08096.jpg \\
\hline 567 & Rorippa sylvestris (L.) Besser & Debrecen & 1986 & Siroki Zoltán & DE-siroki-08043.jpg \\
\hline 567 & Rorippa sylvestris (L.) Besser & Debrecen & 1986 & Siroki Zoltán & DE-siroki-08044.jpg \\
\hline 567 & Rorippa sylvestris (L.) Besser & Gelej & 1980 & Siroki Zoltán & DE-siroki-08045.jpg \\
\hline 567 & Rorippa sylvestris (L.) Besser & Gelej & 1980 & Siroki Zoltán & DE-siroki-08046.jpg \\
\hline 567 & Rorippa sylvestris (L.) Besser & Gelej & 1980 & Siroki Zoltán & DE-siroki-08047.jpg \\
\hline 567 & Rorippa sylvestris (L.) Besser & Gyula & 1974 & Siroki Zoltán & DE-siroki-08081.jpg \\
\hline 567 & Rorippa sylvestris (L.) Besser & Gyula & 1974 & Siroki Zoltán & DE-siroki-08082.jpg \\
\hline 567 & Rorippa sylvestris (L.) Besser & Gyula & 1974 & Siroki Zoltán & DE-siroki-08083.jpg \\
\hline 567 & Rorippa sylvestris (L.) Besser & Keszthely & 1955 & Siroki Zoltán & DE-siroki-08048.jpg \\
\hline 567 & Rorippa sylvestris (L.) Besser & Keszthely & 1955 & Siroki Zoltán & DE-siroki-08050.jpg \\
\hline 567 & Rorippa sylvestris (L.) Besser & Keszthely & 1955 & Siroki Zoltán & DE-siroki-08049.jpg \\
\hline 567 & Rorippa sylvestris (L.) Besser & Mikepércs & 1966 & Siroki Zoltán & DE-siroki-08074.jpg \\
\hline 567 & Rorippa sylvestris (L.) Besser & Mikepércs & 1966 & Siroki Zoltán & DE-siroki-08075.jpg \\
\hline 567 & Rorippa sylvestris (L.) Besser & Mikepércs & 1966 & Siroki Zoltán & DE-siroki-08076.jpg \\
\hline 567 & Rorippa sylvestris (L.) Besser & Mosonmagyaróvár & 1939 & Siroki Zoltán & DE-siroki-08099.jpg \\
\hline 567 & Rorippa sylvestris (L.) Besser & Mosonmagyaróvár & 1939 & Siroki Zoltán & DE-siroki-08100.jpg \\
\hline 567 & Rorippa sylvestris (L.) Besser & Mosonmagyaróvár & 1939 & Siroki Zoltán & DE-siroki-08097.jpg \\
\hline 567 & Rorippa sylvestris (L.) Besser & Mosonmagyaróvár & 1939 & Siroki Zoltán & DE-siroki-08098.jpg \\
\hline 567 & Rorippa sylvestris (L.) Besser & Mosonmagyaróvár & 1939 & Siroki Zoltán & DE-siroki-08055.jpg \\
\hline 567 & Rorippa sylvestris (L.) Besser & Mosonmagyaróvár & 1939 & Siroki Zoltán & DE-siroki-08056.jpg \\
\hline 567 & Rorippa sylvestris (L.) Besser & Mosonmagyaróvár & 1939 & Siroki Zoltán & DE-siroki-08101.jpg \\
\hline 567 & Rorippa sylvestris (L.) Besser & Mosonmagyaróvár & 1939 & Siroki Zoltán & DE-siroki-08102.jpg \\
\hline $562 \times 567$ & $\begin{array}{l}\text { Rorippa austriaca (Crantz) Besser } \times \\
\text { Rorippa sylvestris (L.) Besser }\end{array}$ & Debrecen & 1946 & Siroki Zoltán & DE-siroki-08110.jpg \\
\hline $562 \times 567$ & $\begin{array}{l}\text { Rorippa austriaca (Crantz) Besser } \times \\
\text { Rorippa sylvestris (L.) Besser }\end{array}$ & Debrecen & 1947 & Siroki Zoltán & DE-siroki-08112.jpg \\
\hline $562 \times 567$ & $\begin{array}{l}\text { Rorippa austriaca (Crantz) Besser } \times \\
\text { Rorippa sylvestris (L.) Besser }\end{array}$ & Debrecen & 1947 & Siroki Zoltán & DE-siroki-08111.jpg \\
\hline $562 \times 567$ & $\begin{array}{l}\text { Rorippa austriaca (Crantz) Besser } \times \\
\text { Rorippa sylvestris (L.) Besser }\end{array}$ & Debrecen & 1947 & Siroki Zoltán & DE-siroki-08113.jpg \\
\hline 568 & Draba lasiocarpa Rochel & Budapest & 1909 & Kocsis István & DE-siroki-08295.jpg \\
\hline 568 & Draba lasiocarpa Rochel & Budapest & 1941 & Siroki Zoltán & DE-siroki-08300.jpg \\
\hline 568 & Draba lasiocarpa Rochel & Miskolc & 1957 & Siroki Zoltán & DE-siroki-08299.jpg \\
\hline 568 & Draba lasiocarpa Rochel & Miskolc & 1961 & Siroki Zoltán & DE-siroki-08297.jpg \\
\hline 568 & Draba lasiocarpa Rochel & Miskolc & 1961 & Siroki Zoltán & DE-siroki-08298.jpg \\
\hline 569 & Draba nemorosa L. & Debrecen & 1947 & Siroki Zoltán & DE-siroki-08288.jpg \\
\hline 569 & Draba nemorosa L. & Debrecen & 1958 & Halász Tibor & DE-siroki-08285.jpg \\
\hline 569 & Draba nemorosa L. & Debrecen & 1958 & Halász Tibor & DE-siroki-08286.jpg \\
\hline
\end{tabular}




\begin{tabular}{|c|c|c|c|c|c|}
\hline $\begin{array}{l}\text { Sorszám / } \\
\text { Number }\end{array}$ & Taxon-név / Taxon-name & $\begin{array}{l}\text { Település / } \\
\text { Settlement }\end{array}$ & $\begin{array}{l}\text { Év / } \\
\text { Year }\end{array}$ & $\begin{array}{l}\text { Gyűjtő / } \\
\text { Collector }\end{array}$ & Fájlnév / File-name \\
\hline 569 & Draba nemorosa L. & Debrecen & 1958 & Halász Tibor & DE-siroki-08287.jpg \\
\hline 570 & Draba muralis L. & Pécsvárad & 1961 & Kárpáti Zoltán & DE-siroki-08290.jpg \\
\hline 570 & Draba muralis L. & Pomáz & 1926 & Degen Árpád & DE-siroki-08291.jpg \\
\hline 571 & Erophila verna (L.) Chevall. & Debrecen & 1947 & Siroki Zoltán & DE-siroki-08283.jpg \\
\hline 571 & Erophila verna (L.) Chevall. & Debrecen & 1955 & Siroki Zoltán & DE-siroki-08282.jpg \\
\hline 571 & Erophila verna (L.) Chevall. & Kőszeg & - & $\begin{array}{l}\text { Waisbecker } \\
\text { Antal }\end{array}$ & DE-siroki-08281.jpg \\
\hline 574 & Camelina microcarpa Andrz. ex DC. & Berekböszörmény & 1970 & Siroki Zoltán & DE-siroki-08258.jpg \\
\hline 574 & Camelina microcarpa Andrz. ex DC. & Debrecen & 1947 & Siroki Zoltán & DE-siroki-08261.jpg \\
\hline 574 & Camelina microcarpa Andrz. ex DC. & Debrecen & 1950 & Siroki Zoltán & DE-siroki-08260.jpg \\
\hline 574 & Camelina microcarpa Andrz. ex DC. & Debrecen & 1977 & Siroki Zoltán & DE-siroki-08259.jpg \\
\hline 578 & Neslia paniculata (L.) Desv. & Debrecen & 1947 & Siroki Zoltán & DE-siroki-08267.jpg \\
\hline 578 & Neslia paniculata (L.) Desv. & Debrecen & 1967 & Gondola István & DE-siroki-08276.jpg \\
\hline 578 & Neslia paniculata (L.) Desv. & Debrecen & 1977 & Siroki Zoltán & DE-siroki-08268.jpg \\
\hline 578 & Neslia paniculata (L.) Desv. & Debrecen & 1977 & Siroki Zoltán & DE-siroki-08269.jpg \\
\hline 578 & Neslia paniculata (L.) Desv. & Debrecen & 1977 & Siroki Zoltán & DE-siroki-08270.jpg \\
\hline 578 & Neslia paniculata (L.) Desv. & Dombrád & 1965 & Gondola István & DE-siroki-08271.jpg \\
\hline 578 & Neslia paniculata (L.) Desv. & Dombrád & 1965 & Gondola István & DE-siroki-08272.jpg \\
\hline 578 & Neslia paniculata (L.) Desv. & Mosonmagyaróvár & 1939 & Siroki Zoltán & DE-siroki-08279.jpg \\
\hline 578 & Neslia paniculata (L.) Desv. & Mosonmagyaróvár & 1939 & Siroki Zoltán & DE-siroki-08280.jpg \\
\hline 578 & Neslia paniculata (L.) Desv. & Tiszatelek & 1966 & Gondola István & DE-siroki-08273.jpg \\
\hline 578 & Neslia paniculata (L.) Desv. & Tiszatelek & 1966 & Gondola István & DE-siroki-08274.jpg \\
\hline 578 & Neslia paniculata (L.) Desv. & Tiszatelek & 1966 & Gondola István & DE-siroki-08275.jpg \\
\hline 579 & Capsella bursa-pastoris (L.) Medik. & Debrecen & 1948 & Siroki Zoltán & DE-siroki-08245.jpg \\
\hline 579 & Capsella bursa-pastoris (L.) Medik. & Debrecen & 1955 & Siroki Zoltán & DE-siroki-08246.jpg \\
\hline 579 & Capsella bursa-pastoris (L.) Medik. & Debrecen & 1955 & Siroki Zoltán & DE-siroki-08247.jpg \\
\hline 579 & Capsella bursa-pastoris (L.) Medik. & Debrecen & 1957 & Siroki Zoltán & DE-siroki-08241.jpg \\
\hline 579 & Capsella bursa-pastoris (L.) Medik. & Debrecen & 1957 & Siroki Zoltán & DE-siroki-08242.jpg \\
\hline 579 & Capsella bursa-pastoris (L.) Medik. & Debrecen & 1957 & Siroki Zoltán & DE-siroki-08244.jpg \\
\hline 579 & Capsella bursa-pastoris (L.) Medik. & Debrecen & 1960 & Siroki Zoltán & DE-siroki-08243.jpg \\
\hline 581 & Hornungia petraea (L.) Rchb. & Budaörs & 1951 & Siroki Zoltán & DE-siroki-08235.jpg \\
\hline 581 & Hornungia petraea (L.) Rchb. & Budapest & 1951 & Siroki Zoltán & DE-siroki-08236.jpg \\
\hline 581 & Hornungia petraea (L.) Rchb. & Budapest & 1951 & Siroki Zoltán & DE-siroki-08237.jpg \\
\hline 583 & Thlaspi perfoliatum L. & Debrecen & 1947 & Siroki Zoltán & DE-siroki-07777.jpg \\
\hline 583 & Thlaspi perfoliatum L. & Debrecen & 1951 & Siroki Zoltán & DE-siroki-07776.jpg \\
\hline 585 & Thlaspi arvense L. & Debrecen & 1948 & Siroki Zoltán & DE-siroki-07781.jpg \\
\hline 585 & Thlaspi arvense L. & Debrecen & 1957 & Siroki Zoltán & DE-siroki-07782.jpg \\
\hline 585 & Thlaspi arvense L. & Debrecen & 1957 & Siroki Zoltán & DE-siroki-07783.jpg \\
\hline 585 & Thlaspi arvense L. & Debrecen & 1957 & Siroki Zoltán & DE-siroki-07784.jpg \\
\hline 589 & Thlaspi jankae A. Kern. & "Bükk-hg." & 1966 & Siroki Zoltán & DE-siroki-07799.jpg \\
\hline 589 & Thlaspi jankae A. Kern. & "Nagymező" & 1957 & Siroki Zoltán & DE-siroki-07798.jpg \\
\hline 589 & Thlaspi jankae A. Kern. & "Nagymező" & 1957 & Siroki Zoltán & DE-siroki-07800.jpg \\
\hline 589 & Thlaspi jankae A. Kern. & "Nagymező" & 1957 & Siroki Zoltán & DE-siroki-07801.jpg \\
\hline 589 & Thlaspi jankae A. Kern. & Budapest & 1888 & Czakó Kálmán & DE-siroki-07795.jpg \\
\hline 589 & Thlaspi jankae A. Kern. & Gödöllő & 1951 & Siroki Zoltán & DE-siroki-07805.jpg \\
\hline 589 & Thlaspi jankae A. Kern. & Gödöllő & 1951 & Siroki Zoltán & DE-siroki-07804.jpg \\
\hline 589 & Thlaspi jankae A. Kern. & Gödöllő & 1952 & Siroki Zoltán & DE-siroki-07803.jpg \\
\hline
\end{tabular}




\begin{tabular}{|c|c|c|c|c|c|}
\hline $\begin{array}{l}\text { Sorszám / } \\
\text { Number }\end{array}$ & Taxon-név / Taxon-name & $\begin{array}{l}\text { Település / } \\
\text { Settlement }\end{array}$ & $\begin{array}{l}\text { Év / } \\
\text { Year }\end{array}$ & $\begin{array}{l}\text { Gyüjtő / } \\
\text { Collector }\end{array}$ & Fájlnév / File-name \\
\hline 589 & Thlaspi jankae A. Kern. & Gödöllő & 1952 & Siroki Zoltán & DE-siroki-07802.jpg \\
\hline 589 & Thlaspi jankae A. Kern. & Szarvaskő & 1958 & Siroki Zoltán & DE-siroki-07797.jpg \\
\hline 589 & Thlaspi jankae A. Kern. & Szarvaskő & 1958 & Siroki Zoltán & DE-siroki-07796.jpg \\
\hline 591 & Aethionema saxatile (L.) R. Br. & "Fáni-völgy" & 1955 & $\begin{array}{l}\text { Siroki Zoltán - } \\
\text { Farkas Attila }\end{array}$ & DE-siroki-07773.jpg \\
\hline 591 & Aethionema saxatile (L.) R. Br. & "Fáni-völgy" & 1955 & $\begin{array}{l}\text { Siroki Zoltán - } \\
\text { Farkas Attila }\end{array}$ & DE-siroki-07774.jpg \\
\hline 591 & Aethionema saxatile (L.) R. Br. & "Fáni-völgy" & 1955 & $\begin{array}{l}\text { Siroki Zoltán - } \\
\text { Farkas Attila }\end{array}$ & DE-siroki-07775.jpg \\
\hline 593 & Biscutella laevigata L. & "Fáni-völgy" & 1955 & Farkas Attila & DE-siroki-07766.jpg \\
\hline 593 & Biscutella laevigata L. & Budapest & 1984 & Siroki Zoltán & DE-siroki-07763.jpg \\
\hline 593 & Biscutella laevigata L. & Gyenesdiás & 1972 & Siroki Zoltán & DE-siroki-07761.jpg \\
\hline 593 & Biscutella laevigata L. & Gyenesdiás & 1972 & Siroki Zoltán & DE-siroki-07760.jpg \\
\hline 593 & Biscutella laevigata L. & Gyenesdiás & 1972 & Siroki Zoltán & DE-siroki-07762.jpg \\
\hline 593 & Biscutella laevigata L. & Nagykovácsi & 1959 & Siroki Zoltán & DE-siroki-07767.jpg \\
\hline 593 & Biscutella laevigata L. & Nagykovácsi & 1959 & Siroki Zoltán & DE-siroki-07768.jpg \\
\hline 593 & Biscutella laevigata L. & Nagykovácsi & 1959 & Siroki Zoltán & DE-siroki-07769.jpg \\
\hline 593 & Biscutella laevigata L. & Nagykovácsi & 1959 & Siroki Zoltán & DE-siroki-07770.jpg \\
\hline 594 & $\begin{array}{l}\text { Lepidium cartilagineum } \\
\text { (J.C. Mayer) Thell. }\end{array}$ & Dömsöd & 1952 & Siroki Zoltán & DE-siroki-07719.jpg \\
\hline 594 & $\begin{array}{l}\text { Lepidium cartilagineum } \\
\text { (J.C. Mayer) Thell. }\end{array}$ & Dömsöd & 1952 & Siroki Zoltán & DE-siroki-07720.jpg \\
\hline 594 & $\begin{array}{l}\text { Lepidium cartilagineum } \\
\text { (J.C. Mayer) Thell. }\end{array}$ & Dömsöd & 1952 & Siroki Zoltán & DE-siroki-07721.jpg \\
\hline 594 & $\begin{array}{l}\text { Lepidium cartilagineum } \\
\text { (J.C. Mayer) Thell. }\end{array}$ & Dömsöd & 1952 & Siroki Zoltán & DE-siroki-07722.jpg \\
\hline 594 & $\begin{array}{l}\text { Lepidium cartilagineum } \\
\text { (J.C. Mayer) Thell. }\end{array}$ & Kecskemét & 1967 & Siroki Zoltán & DE-siroki-07713.jpg \\
\hline 594 & $\begin{array}{l}\text { Lepidium cartilagineum } \\
\text { (J.C. Mayer) Thell. }\end{array}$ & Kecskemét & 1967 & Siroki Zoltán & DE-siroki-07714.jpg \\
\hline 594 & $\begin{array}{l}\text { Lepidium cartilagineum } \\
\text { (J.C. Mayer) Thell. }\end{array}$ & Kecskemét & 1967 & Siroki Zoltán & DE-siroki-07715.jpg \\
\hline 594 & $\begin{array}{l}\text { Lepidium cartilagineum } \\
\text { (J.C. Mayer) Thell. }\end{array}$ & Kecskemét & 1967 & Siroki Zoltán & DE-siroki-07716.jpg \\
\hline 594 & $\begin{array}{l}\text { Lepidium cartilagineum } \\
\text { (J.C. Mayer) Thell. }\end{array}$ & Kecskemét & 1967 & Siroki Zoltán & DE-siroki-07717.jpg \\
\hline 594 & $\begin{array}{l}\text { Lepidium cartilagineum } \\
\text { (J.C. Mayer) Thell. }\end{array}$ & Kecskemét & 1969 & Siroki Zoltán & DE-siroki-07718.jpg \\
\hline 595 & Lepidium perfoliatum L. & Debrecen & 1947 & Siroki Zoltán & DE-siroki-07699.jpg \\
\hline 595 & Lepidium perfoliatum L. & Debrecen & 1947 & Siroki Zoltán & DE-siroki-07700.jpg \\
\hline 595 & Lepidium perfoliatum $\mathrm{L}$. & Debrecen & 1947 & Siroki Zoltán & DE-siroki-07702.jpg \\
\hline 595 & Lepidium perfoliatum L. & Debrecen & 1947 & Siroki Zoltán & DE-siroki-07698.jpg \\
\hline 596 & Lepidium campestre (L.) R. Br. & Debrecen & 1947 & Siroki Zoltán & DE-siroki-07705.jpg \\
\hline 596 & Lepidium campestre (L.) R. Br. & Debrecen & 1947 & Siroki Zoltán & DE-siroki-07707.jpg \\
\hline 596 & Lepidium campestre (L.) R. Br. & Nagykovácsi & 1959 & Siroki Zoltán & DE-siroki-07704.jpg \\
\hline 596 & Lepidium campestre (L.) R. Br. & Nagykovácsi & 1959 & Siroki Zoltán & DE-siroki-07706.jpg \\
\hline 598 & Lepidium graminifolium L. & Balatongyörök & 1950 & Kárpáti Zoltán & DE-siroki-07734.jpg \\
\hline 598 & Lepidium graminifolium L. & Balatongyörök & 1950 & $\begin{array}{l}\text { Priszter } \\
\text { Szaniszló }\end{array}$ & DE-siroki-07736.jpg \\
\hline 599 & Lepidium virginicum $\mathrm{L}$. & Debrecen & 1949 & Siroki Zoltán & DE-siroki-07749.jpg \\
\hline 599 & Lepidium virginicum $L$. & Debrecen & 1949 & Siroki Zoltán & DE-siroki-07750.jpg \\
\hline 599 & Lepidium virginicum L. & Debrecen & 1949 & Siroki Zoltán & DE-siroki-07744.jpg \\
\hline 599 & Lepidium virginicum L. & Debrecen & 1949 & Siroki Zoltán & DE-siroki-07745.jpg \\
\hline 599 & Lepidium virginicum $\mathrm{L}$. & Debrecen & 1950 & Siroki Zoltán & DE-siroki-07751.jpg \\
\hline
\end{tabular}




\begin{tabular}{|c|c|c|c|c|c|}
\hline $\begin{array}{l}\text { Sorszám / } \\
\text { Number }\end{array}$ & Taxon-név / Taxon-name & $\begin{array}{l}\text { Település / } \\
\text { Settlement }\end{array}$ & $\begin{array}{l}\text { Év / } \\
\text { Year }\end{array}$ & $\begin{array}{l}\text { Gyűjtő / } \\
\text { Collector }\end{array}$ & Fájlnév / File-name \\
\hline 599 & Lepidium virginicum $L$. & Debrecen & 1953 & Siroki Zoltán & DE-siroki-07746.jpg \\
\hline 599 & Lepidium virginicum L. & Debrecen & 1953 & Siroki Zoltán & DE-siroki-07747.jpg \\
\hline 599 & Lepidium virginicum L. & Debrecen & 1953 & Siroki Zoltán & DE-siroki-07748.jpg \\
\hline 599 & Lepidium virginicum $\mathrm{L}$. & Debrecen & 1953 & Siroki Zoltán & DE-siroki-07743.jpg \\
\hline 599 & Lepidium virginicum L. & Debrecen & 1954 & Siroki Zoltán & DE-siroki-07742.jpg \\
\hline 599 & Lepidium virginicum $\mathrm{L}$. & Debrecen & 1954 & Siroki Zoltán & DE-siroki-07754.jpg \\
\hline 599 & Lepidium virginicum L. & Debrecen & 1978 & Siroki Zoltán & DE-siroki-07752.jpg \\
\hline 599 & Lepidium virginicum L. & Debrecen & 1978 & Siroki Zoltán & DE-siroki-07753.jpg \\
\hline 599 & Lepidium virginicum L. & Debrecen & 1981 & Siroki Zoltán & DE-siroki-07740.jpg \\
\hline 599 & Lepidium virginicum L. & Debrecen & 1981 & Siroki Zoltán & DE-siroki-07741.jpg \\
\hline 599 & Lepidium virginicum L. & Debrecen & 1981 & Siroki Zoltán & DE-siroki-07737.jpg \\
\hline 599 & Lepidium virginicum L. & Debrecen & 1981 & Siroki Zoltán & DE-siroki-07738.jpg \\
\hline 599 & Lepidium virginicum L. & Hortobágy & 1949 & Siroki Zoltán & DE-siroki-07739.jpg \\
\hline 600 & Lepidium ruderale L. & Debrecen & 1947 & Siroki Zoltán & DE-siroki-07726.jpg \\
\hline 600 & Lepidium ruderale L. & Debrecen & 1950 & Siroki Zoltán & DE-siroki-07727.jpg \\
\hline 600 & Lepidium ruderale L. & Debrecen & 1950 & Siroki Zoltán & DE-siroki-07729.jpg \\
\hline 600 & Lepidium ruderale L. & Debrecen & 1978 & Siroki Zoltán & DE-siroki-07728.jpg \\
\hline 600 & Lepidium ruderale L. & Hortobágy & 1947 & Siroki Zoltán & DE-siroki-07730.jpg \\
\hline 600 & Lepidium ruderale L. & Mosonmagyaróvár & 1939 & Siroki Zoltán & DE-siroki-07731.jpg \\
\hline 601 & Lepidium densiflorum Schrad. & Budapest & 1951 & Siroki Zoltán & DE-siroki-07755.jpg \\
\hline 601 & Lepidium densiflorum Schrad. & Budapest & 1951 & Siroki Zoltán & DE-siroki-07756.jpg \\
\hline 601 & Lepidium densiflorum Schrad. & Debrecen & 1949 & Siroki Zoltán & DE-siroki-07757.jpg \\
\hline 602 & Cardaria draba (L.) Desv. & Debrecen & 1947 & Siroki Zoltán & DE-siroki-07712.jpg \\
\hline 605 & Conringia orientalis (L.) Dumort. & Pásztó & 1952 & Siroki Zoltán & DE-siroki-08624.jpg \\
\hline 605 & Conringia orientalis (L.) Dumort. & Pásztó & 1952 & Siroki Zoltán & DE-siroki-08622.jpg \\
\hline 605 & Conringia orientalis (L.) Dumort. & Pásztó & 1953 & Siroki Zoltán & DE-siroki-08623.jpg \\
\hline 606 & Conringia austriaca (Jacq.) Sweet & Budapest & 1910 & Kocsis István & DE-siroki-08625.jpg \\
\hline 606 & Conringia austriaca (Jacq.) Sweet & Budapest & 1910 & Kocsis István & DE-siroki-08626.jpg \\
\hline 606 & Conringia austriaca (Jacq.) Sweet & Budapest & 1951 & Siroki Zoltán & DE-siroki-08628.jpg \\
\hline 606 & Conringia austriaca (Jacq.) Sweet & Budapest & 1951 & Siroki Zoltán & DE-siroki-08627.jpg \\
\hline 606 & Conringia austriaca (Jacq.) Sweet & Budapest & 1951 & Siroki Zoltán & DE-siroki-08629.jpg \\
\hline 606 & Conringia austriaca (Jacq.) Sweet & Budapest & 1951 & Siroki Zoltán & DE-siroki-08630.jpg \\
\hline 608 & Diplotaxis muralis (L.) DC. & Budapest & 1951 & Siroki Zoltán & DE-siroki-07907.jpg \\
\hline 608 & Diplotaxis muralis (L.) DC. & Debrecen & 1963 & Siroki Zoltán & DE-siroki-07903.jpg \\
\hline 608 & Diplotaxis muralis (L.) DC. & Debrecen & 1963 & Siroki Zoltán & DE-siroki-07904.jpg \\
\hline 608 & Diplotaxis muralis (L.) DC. & Debrecen & 1963 & Siroki Zoltán & DE-siroki-07905.jpg \\
\hline 608 & Diplotaxis muralis (L.) DC. & Debrecen & 1963 & Siroki Zoltán & DE-siroki-07906.jpg \\
\hline 608 & Diplotaxis muralis (L.) DC. & Debrecen & 1983 & Siroki Zoltán & DE-siroki-07901.jpg \\
\hline 608 & Diplotaxis muralis (L.) DC. & Debrecen & 1983 & Siroki Zoltán & DE-siroki-07902.jpg \\
\hline 608 & Diplotaxis muralis (L.) DC. & Debrecen & 1983 & Siroki Zoltán & DE-siroki-07898.jpg \\
\hline 608 & Diplotaxis muralis (L.) DC. & Debrecen & 1983 & Siroki Zoltán & DE-siroki-07899.jpg \\
\hline 608 & Diplotaxis muralis (L.) DC. & Debrecen & 1983 & Siroki Zoltán & DE-siroki-07900.jpg \\
\hline 608 & Diplotaxis muralis (L.) DC. & Méra & 1943 & Siroki Zoltán & DE-siroki-07909.jpg \\
\hline 608 & Diplotaxis muralis (L.) DC. & Törökbálint & 1951 & Siroki Zoltán & DE-siroki-07908.jpg \\
\hline 609 & Diplotaxis tenuifolia (L.) DC. & Abaújkér & 1943 & Siroki Zoltán & DE-siroki-07921.jpg \\
\hline 609 & Diplotaxis tenuifolia (L.) DC. & Ágasegyháza & 1969 & Siroki Zoltán & DE-siroki-07910.jpg \\
\hline
\end{tabular}




\begin{tabular}{|c|c|c|c|c|c|}
\hline $\begin{array}{l}\text { Sorszám / } \\
\text { Number }\end{array}$ & Taxon-név / Taxon-name & $\begin{array}{l}\text { Település / } \\
\text { Settlement }\end{array}$ & $\begin{array}{l}\text { Év / } \\
\text { Year }\end{array}$ & $\begin{array}{l}\text { Gyűjtő / } \\
\text { Collector }\end{array}$ & Fájlnév / File-name \\
\hline 609 & Diplotaxis tenuifolia (L.) DC. & Boldogkőváralja & 1943 & Siroki Zoltán & DE-siroki-07918.jpg \\
\hline 609 & Diplotaxis tenuifolia (L.) DC. & Budapest & 1941 & Siroki Zoltán & DE-siroki-07915.jpg \\
\hline 609 & Diplotaxis tenuifolia (L.) DC. & Budapest & 1941 & Siroki Zoltán & DE-siroki-07914.jpg \\
\hline 609 & Diplotaxis tenuifolia (L.) DC. & Debrecen & 1947 & Siroki Zoltán & DE-siroki-07913.jpg \\
\hline 609 & Diplotaxis tenuifolia (L.) DC. & Debrecen & 1967 & Siroki Zoltán & DE-siroki-07911.jpg \\
\hline 609 & Diplotaxis tenuifolia (L.) DC. & Debrecen & 1967 & Siroki Zoltán & DE-siroki-07912.jpg \\
\hline 609 & Diplotaxis tenuifolia (L.) DC. & Mosonmagyaróvár & 1939 & Siroki Zoltán & DE-siroki-07917.jpg \\
\hline 609 & Diplotaxis tenuifolia (L.) DC. & Mosonmagyaróvár & 1939 & Siroki Zoltán & DE-siroki-07916.jpg \\
\hline 610 & Brassica elongata Ehrh. & Biatorbágy & 1950 & Siroki Zoltán & DE-siroki-07949.jpg \\
\hline 610 & Brassica elongata Ehrh. & Biatorbágy & 1950 & Siroki Zoltán & DE-siroki-07950.jpg \\
\hline 610 & Brassica elongata Ehrh. & Budaörs & 1941 & Siroki Zoltán & DE-siroki-07953.jpg \\
\hline 610 & Brassica elongata Ehrh. & Budaörs & 1941 & Siroki Zoltán & DE-siroki-07954.jpg \\
\hline 610 & Brassica elongata Ehrh. & Budapest & 1941 & Siroki Zoltán & DE-siroki-07952.jpg \\
\hline 610 & Brassica elongata Ehrh. & Budapest & 1941 & Siroki Zoltán & DE-siroki-07955.jpg \\
\hline 610 & Brassica elongata Ehrh. & Budapest & 1985 & Siroki Zoltán & DE-siroki-07942.jpg \\
\hline 610 & Brassica elongata Ehrh. & Budapest & 1985 & Siroki Zoltán & DE-siroki-07946.jpg \\
\hline 610 & Brassica elongata Ehrh. & Budapest & 1985 & Siroki Zoltán & DE-siroki-07943.jpg \\
\hline 610 & Brassica elongata Ehrh. & Budapest & 1985 & Siroki Zoltán & DE-siroki-07944.jpg \\
\hline 610 & Brassica elongata Ehrh. & Budapest & 1985 & Siroki Zoltán & DE-siroki-07945.jpg \\
\hline 610 & Brassica elongata Ehrh. & Budapest & 1985 & Siroki Zoltán & DE-siroki-07941.jpg \\
\hline 610 & Brassica elongata Ehrh. & Budapest & 1985 & Siroki Zoltán & DE-siroki-07947.jpg \\
\hline 610 & Brassica elongata Ehrh. & Budapest & 1985 & Siroki Zoltán & DE-siroki-07948.jpg \\
\hline 612 & Brassica × juncea (L.) Czern. & Debrecen & 1972 & Siroki Zoltán & DE-siroki-07967.jpg \\
\hline 612 & Brassica × juncea (L.) Czern. & Debrecen & 1972 & Siroki Zoltán & DE-siroki-07968.jpg \\
\hline 612 & Brassica × juncea (L.) Czern. & Debrecen & 1972 & Siroki Zoltán & DE-siroki-07969.jpg \\
\hline 612 & Brassica × juncea (L.) Czern. & Debrecen & 1972 & Siroki Zoltán & DE-siroki-07970.jpg \\
\hline 612 & Brassica × juncea (L.) Czern. & Debrecen & 1972 & Siroki Zoltán & DE-siroki-07971.jpg \\
\hline 612 & Brassica $\times$ juncea (L.) Czern. & Debrecen & 1972 & Siroki Zoltán & DE-siroki-07972.jpg \\
\hline 612 & Brassica × juncea (L.) Czern. & Debrecen & 1972 & Siroki Zoltán & DE-siroki-07973.jpg \\
\hline 612 & Brassica × juncea (L.) Czern. & Debrecen & 1978 & Siroki Zoltán & DE-siroki-07957.jpg \\
\hline 612 & Brassica $\times$ juncea (L.) Czern. & Debrecen & 1978 & Siroki Zoltán & DE-siroki-07958.jpg \\
\hline 612 & Brassica × juncea (L.) Czern. & Debrecen & 1978 & Siroki Zoltán & DE-siroki-07959.jpg \\
\hline 612 & Brassica × juncea (L.) Czern. & Debrecen & 1978 & Siroki Zoltán & DE-siroki-07960.jpg \\
\hline 612 & Brassica $\times$ juncea (L.) Czern. & Debrecen & 1978 & Siroki Zoltán & DE-siroki-07961.jpg \\
\hline 612 & Brassica × juncea (L.) Czern. & Debrecen & 1978 & Siroki Zoltán & DE-siroki-07962.jpg \\
\hline 612 & Brassica × juncea (L.) Czern. & Debrecen & 1978 & Siroki Zoltán & DE-siroki-07963.jpg \\
\hline 612 & Brassica $\times$ juncea (L.) Czern. & Debrecen & 1978 & Siroki Zoltán & DE-siroki-07964.jpg \\
\hline 612 & Brassica × juncea (L.) Czern. & Debrecen & 1978 & Siroki Zoltán & DE-siroki-07965.jpg \\
\hline 612 & Brassica × juncea (L.) Czern. & Debrecen & 1978 & Siroki Zoltán & DE-siroki-07966.jpg \\
\hline 612 & Brassica × juncea (L.) Czern. & Debrecen & 1978 & Siroki Zoltán & DE-siroki-07975.jpg \\
\hline 612 & Brassica × juncea (L.) Czern. & Debrecen & 1978 & Siroki Zoltán & DE-siroki-07976.jpg \\
\hline 614 & Brassica rapa L. & Debrecen & 1950 & Siroki Zoltán & DE-siroki-07979.jpg \\
\hline 614 & Brassica rapa L. & Debrecen & 1964 & Siroki Zoltán & DE-siroki-07977.jpg \\
\hline 614 & Brassica rapa L. & Debrecen & 1964 & Siroki Zoltán & DE-siroki-07978.jpg \\
\hline 614 & Brassica rapa L. & Debrecen & 1978 & Siroki Zoltán & DE-siroki-07981.jpg \\
\hline 614 & Brassica rapa L. & Debrecen & 1978 & Siroki Zoltán & DE-siroki-07982.jpg \\
\hline
\end{tabular}




\begin{tabular}{|c|c|c|c|c|c|}
\hline $\begin{array}{l}\text { Sorszám / } \\
\text { Number }\end{array}$ & Taxon-név / Taxon-name & $\begin{array}{l}\text { Település / } \\
\text { Settlement }\end{array}$ & $\begin{array}{l}\text { Év / } \\
\text { Year }\end{array}$ & $\begin{array}{l}\text { Gyűjtő / } \\
\text { Collector }\end{array}$ & Fájlnév / File-name \\
\hline 614 & Brassica rapa L. & Debrecen & 1978 & Siroki Zoltán & DE-siroki-07983.jpg \\
\hline 614 & Brassica rapa L. & Debrecen & 1978 & Siroki Zoltán & DE-siroki-07984.jpg \\
\hline 614 & Brassica rapa L. & Debrecen & 1978 & Siroki Zoltán & DE-siroki-07985.jpg \\
\hline 614 & Brassica rapa L. & Nyírvasvári & 1967 & Gondola István & DE-siroki-07986.jpg \\
\hline 614 & Brassica rapa L. & Nyírvasvári & 1967 & Gondola István & DE-siroki-07987.jpg \\
\hline 615 & Brassica $\times$ napus L. & Baracska & 1951 & Siroki Zoltán & DE-siroki-07990.jpg \\
\hline 616 & Sinapis arvensis L. & Debrecen & 1947 & Siroki Zoltán & DE-siroki-07890.jpg \\
\hline 616 & Sinapis arvensis $\mathrm{L}$. & Debrecen & 1958 & Siroki Zoltán & DE-siroki-07891.jpg \\
\hline 616 & Sinapis arvensis $\mathrm{L}$. & Debrecen & 1958 & Siroki Zoltán & DE-siroki-07892.jpg \\
\hline 616 & Sinapis arvensis $\mathrm{L}$. & Debrecen & 1978 & Siroki Zoltán & DE-siroki-07889.jpg \\
\hline 616 & Sinapis arvensis L. & Mosonmagyaróvár & 1939 & Siroki Zoltán & DE-siroki-07893.jpg \\
\hline 619 & $\begin{array}{l}\text { Erucastrum gallicum } \\
\text { (Willd.) O.E. Schulz }\end{array}$ & Budapest & 1975 & Siroki Zoltán & DE-siroki-07923.jpg \\
\hline 619 & $\begin{array}{l}\text { Erucastrum gallicum } \\
\text { (Willd.) O.E. Schulz }\end{array}$ & Budapest & 1983 & Siroki Zoltán & DE-siroki-07924.jpg \\
\hline 619 & $\begin{array}{l}\text { Erucastrum gallicum } \\
\text { (Willd.) O.E. Schulz }\end{array}$ & Budapest & 1985 & Siroki Zoltán & DE-siroki-07922.jpg \\
\hline 619 & $\begin{array}{l}\text { Erucastrum gallicum } \\
\text { (Willd.) O.E. Schulz }\end{array}$ & Máriakálnok & 1939 & Siroki Zoltán & DE-siroki-07930.jpg \\
\hline 619 & $\begin{array}{l}\text { Erucastrum gallicum } \\
\text { (Willd.) O.E. Schulz }\end{array}$ & Máriakálnok & 1939 & Siroki Zoltán & DE-siroki-07931.jpg \\
\hline 619 & $\begin{array}{l}\text { Erucastrum gallicum } \\
\text { (Willd.) O.E. Schulz }\end{array}$ & Máriakálnok & 1939 & Siroki Zoltán & DE-siroki-07932.jpg \\
\hline 619 & $\begin{array}{l}\text { Erucastrum gallicum } \\
\text { (Willd.) O.E. Schulz }\end{array}$ & Mosonmagyaróvár & 1939 & Siroki Zoltán & DE-siroki-07933.jpg \\
\hline 619 & $\begin{array}{l}\text { Erucastrum gallicum } \\
\text { (Willd.) O.E. Schulz }\end{array}$ & Polgár & 1975 & Siroki Zoltán & DE-siroki-07925.jpg \\
\hline 619 & $\begin{array}{l}\text { Erucastrum gallicum } \\
\text { (Willd.) O.E. Schulz }\end{array}$ & Polgár & 1975 & Siroki Zoltán & DE-siroki-07926.jpg \\
\hline 619 & $\begin{array}{l}\text { Erucastrum gallicum } \\
\text { (Willd.) O.E. Schulz }\end{array}$ & Polgár & 1975 & Siroki Zoltán & DE-siroki-07927.jpg \\
\hline 619 & $\begin{array}{l}\text { Erucastrum gallicum } \\
\text { (Willd.) O.E. Schulz }\end{array}$ & Polgár & 1975 & Siroki Zoltán & DE-siroki-07928.jpg \\
\hline 620 & $\begin{array}{l}\text { Erucastrum nasturtiifolium } \\
\text { (Poir.) O.E. Schulz }\end{array}$ & Budapest & 1948 & Siroki Zoltán & DE-siroki-07938.jpg \\
\hline 620 & $\begin{array}{l}\text { Erucastrum nasturtiifolium } \\
\text { (Poir.) O.E. Schulz }\end{array}$ & Budapest & 1948 & Siroki Zoltán & DE-siroki-07939.jpg \\
\hline 620 & $\begin{array}{l}\text { Erucastrum nasturtiifolium } \\
\text { (Poir.) O.E. Schulz }\end{array}$ & Budapest & 1948 & Siroki Zoltán & DE-siroki-07935.jpg \\
\hline 620 & $\begin{array}{l}\text { Erucastrum nasturtiifolium } \\
\text { (Poir.) O.E. Schulz }\end{array}$ & Budapest & 1948 & Siroki Zoltán & DE-siroki-07936.jpg \\
\hline 620 & $\begin{array}{l}\text { Erucastrum nasturtiifolium } \\
\text { (Poir.) O.E. Schulz }\end{array}$ & Budapest & 1948 & Siroki Zoltán & DE-siroki-07937.jpg \\
\hline 620 & $\begin{array}{l}\text { Erucastrum nasturtiifolium } \\
\text { (Poir.) O.E. Schulz }\end{array}$ & Debrecen & 1978 & Siroki Zoltán & DE-siroki-07934.jpg \\
\hline 620 & $\begin{array}{l}\text { Erucastrum nasturtiifolium } \\
\text { (Poir.) O.E. Schulz }\end{array}$ & Mosonmagyaróvár & 1939 & Siroki Zoltán & DE-siroki-07940.jpg \\
\hline 622 & Calepina irregularis (Asso) Thell. & Baracska & 1951 & Siroki Zoltán & DE-siroki-07876.jpg \\
\hline 622 & Calepina irregularis (Asso) Thell. & Baracska & 1951 & Siroki Zoltán & DE-siroki-07877.jpg \\
\hline 622 & Calepina irregularis (Asso) Thell. & Budapest & 1952 & Siroki Zoltán & DE-siroki-07878.jpg \\
\hline 622 & Calepina irregularis (Asso) Thell. & Gödöllő & 1951 & Siroki Zoltán & DE-siroki-07875.jpg \\
\hline 622 & Calepina irregularis (Asso) Thell. & Gödöllő & 1951 & Siroki Zoltán & DE-siroki-07874.jpg \\
\hline 623 & Raphanus raphanistrum L. & Debrecen & 1947 & Siroki Zoltán & DE-siroki-07997.jpg \\
\hline 623 & Raphanus raphanistrum L. & Debrecen & 1947 & Siroki Zoltán & DE-siroki-07993.jpg \\
\hline 623 & Raphanus raphanistrum L. & Debrecen & 1947 & Siroki Zoltán & DE-siroki-07999.jpg \\
\hline 623 & Raphanus raphanistrum L. & Debrecen & 1947 & Siroki Zoltán & DE-siroki-07998.jpg \\
\hline
\end{tabular}




\begin{tabular}{|c|c|c|c|c|c|}
\hline $\begin{array}{l}\text { Sorszám / } \\
\text { Number }\end{array}$ & Taxon-név / Taxon-name & $\begin{array}{l}\text { Település / } \\
\text { Settlement }\end{array}$ & $\begin{array}{l}\text { Év / } \\
\text { Year }\end{array}$ & $\begin{array}{l}\text { Gyűjtő / } \\
\text { Collector }\end{array}$ & Fájlnév / File-name \\
\hline 623 & Raphanus raphanistrum L. & Debrecen & 1969 & Siroki Zoltán & DE-siroki-07992.jpg \\
\hline 623 & Raphanus raphanistrum L. & Debrecen & 1969 & Siroki Zoltán & DE-siroki-07994.jpg \\
\hline 623 & Raphanus raphanistrum L. & Debrecen & 1969 & Siroki Zoltán & DE-siroki-07995.jpg \\
\hline 623 & Raphanus raphanistrum L. & Debrecen & 1969 & Siroki Zoltán & DE-siroki-07996.jpg \\
\hline 623 & Raphanus raphanistrum L. & Gödöllő & 1951 & Siroki Zoltán & DE-siroki-08003.jpg \\
\hline 623 & Raphanus raphanistrum L. & Mosonmagyaróvár & 1939 & Siroki Zoltán & DE-siroki-08000.jpg \\
\hline 625 & Reseda luteola L. & Budaörs & 1985 & Siroki Zoltán & DE-siroki-08631.jpg \\
\hline 625 & Reseda luteola L. & Budapest & 1951 & Siroki Zoltán & DE-siroki-08634.jpg \\
\hline 625 & Reseda luteola L. & Budapest & 1951 & Siroki Zoltán & DE-siroki-08633.jpg \\
\hline 625 & Reseda luteola L. & Keszthely & 1955 & Siroki Zoltán & DE-siroki-08632.jpg \\
\hline 627 & Reseda inodora Rchb. & Budapest & 1952 & Siroki Zoltán & DE-siroki-08643.jpg \\
\hline 627 & Reseda inodora Rchb. & Budapest & 1952 & Siroki Zoltán & DE-siroki-08639.jpg \\
\hline 627 & Reseda inodora Rchb. & Budapest & 1952 & Siroki Zoltán & DE-siroki-08640.jpg \\
\hline 627 & Reseda inodora Rchb. & Budapest & 1952 & Siroki Zoltán & DE-siroki-08641.jpg \\
\hline 627 & Reseda inodora Rchb. & Budapest & 1952 & Siroki Zoltán & DE-siroki-08642.jpg \\
\hline 627 & Reseda inodora Rchb. & Budapest & 1952 & Siroki Zoltán & DE-siroki-08644.jpg \\
\hline 628 & Reseda phyteuma L. & Budaörs & 1964 & Siroki Zoltán & DE-siroki-08646.jpg \\
\hline 628 & Reseda phyteuma L. & Budaörs & 1965 & Siroki Zoltán & DE-siroki-08645.jpg \\
\hline 628 & Reseda phyteuma L. & Budapest & 1951 & Siroki Zoltán & DE-siroki-08648.jpg \\
\hline 628 & Reseda phyteuma L. & Budapest & 1951 & Siroki Zoltán & DE-siroki-08649.jpg \\
\hline 628 & Reseda phyteuma L. & Budapest & 1951 & Siroki Zoltán & DE-siroki-08647.jpg \\
\hline 628 & Reseda phyteuma L. & Budapest & 1952 & Siroki Zoltán & DE-siroki-08650.jpg \\
\hline 630 & Drosera rotundifolia L. & Csaroda & 1954 & Simon Tiborné & DE-siroki-08653.jpg \\
\hline 630 & Drosera rotundifolia L. & Csaroda & 1954 & Simon Tiborné & DE-siroki-08655.jpg \\
\hline 630 & Drosera rotundifolia L. & Csaroda & 1954 & Siroki Zoltán & DE-siroki-08656.jpg \\
\hline 630 & Drosera rotundifolia L. & Csaroda & 1956 & Siroki Zoltán & DE-siroki-08654.jpg \\
\hline 632 & Sempervivum tectorum L. & Bér & - & Siroki Zoltán & DE-siroki-08715.jpg \\
\hline 633 & Sempervivum marmoreum Griseb. & Szarvaskő & 1958 & Siroki Zoltán & DE-siroki-08712.jpg \\
\hline 634 & Jovibarba globifera (L.) J. Parn. & "Vértes" & 1957 & Siroki Zoltán & DE-siroki-08717.jpg \\
\hline 634 & Jovibarba globifera (L.) J. Parn. & Nagykovácsi & 1950 & Siroki Zoltán & DE-siroki-08718.jpg \\
\hline 638 & Sedum hispanicum Jusl. & Debrecen & 1949 & Siroki Zoltán & DE-siroki-08678.jpg \\
\hline 638 & Sedum hispanicum Jusl. & Debrecen & 1949 & Siroki Zoltán & DE-siroki-08676.jpg \\
\hline 638 & Sedum hispanicum Jusl. & Debrecen & 1949 & Siroki Zoltán & DE-siroki-08677.jpg \\
\hline 639 & Sedum album L. & "Bükk-hg." & 1966 & Siroki Zoltán & DE-siroki-08683.jpg \\
\hline 639 & Sedum album L. & "Háromkő" & 1959 & Siroki Zoltán & DE-siroki-08684.jpg \\
\hline 639 & Sedum album L. & Budapest & 1951 & Siroki Zoltán & DE-siroki-08686.jpg \\
\hline 639 & Sedum album L. & Cserszegtomaj & 1955 & Siroki Zoltán & DE-siroki-08685.jpg \\
\hline 639 & Sedum album L. & Nagykovácsi & 1957 & Siroki Zoltán & DE-siroki-08687.jpg \\
\hline 639 & Sedum album L. & Nagykovácsi & 1957 & Siroki Zoltán & DE-siroki-08688.jpg \\
\hline 639 & Sedum album L. & Nagykovácsi & 1957 & Siroki Zoltán & DE-siroki-08689.jpg \\
\hline 639 & Sedum album L. & Szilvásvárad & 1954 & Siroki Zoltán & DE-siroki-08682.jpg \\
\hline 640 & Sedum rupestre L. & Budapest & 1951 & Siroki Zoltán & DE-siroki-08709.jpg \\
\hline 640 & Sedum rupestre L. & Budapest & 1951 & Siroki Zoltán & DE-siroki-08708.jpg \\
\hline 642 & Sedum sexangulare L. & Budapest & 1944 & Siroki Zoltán & DE-siroki-08699.jpg \\
\hline 642 & Sedum sexangulare L. & Budapest & 1951 & Siroki Zoltán & DE-siroki-08700.jpg \\
\hline 642 & Sedum sexangulare L. & Budapest & 1967 & Siroki Zoltán & DE-siroki-08701.jpg \\
\hline
\end{tabular}




\begin{tabular}{|c|c|c|c|c|c|}
\hline $\begin{array}{l}\text { Sorszám / } \\
\text { Number }\end{array}$ & Taxon-név / Taxon-name & $\begin{array}{l}\text { Település / } \\
\text { Settlement }\end{array}$ & $\begin{array}{l}\text { Év / } \\
\text { Year }\end{array}$ & $\begin{array}{l}\text { Gyűjtő / } \\
\text { Collector }\end{array}$ & Fájlnév / File-name \\
\hline 642 & Sedum sexangulare L. & Budapest & 1967 & Siroki Zoltán & DE-siroki-08702.jpg \\
\hline 642 & Sedum sexangulare L. & Budapest & 1967 & Siroki Zoltán & DE-siroki-08703.jpg \\
\hline 642 & Sedum sexangulare L. & Háromhuta & 1977 & Siroki Zoltán & DE-siroki-08698.jpg \\
\hline 642 & Sedum sexangulare L. & Nagykovácsi & 1957 & Siroki Zoltán & DE-siroki-08704.jpg \\
\hline 643 & Sedum acre L. & "Háromkő" & 1959 & Siroki Zoltán & DE-siroki-08694.jpg \\
\hline 643 & Sedum acre L. & Debrecen & 1950 & Siroki Zoltán & DE-siroki-08695.jpg \\
\hline 643 & Sedum acre L. & Debrecen & 1950 & Siroki Zoltán & DE-siroki-08696.jpg \\
\hline 644 & Saxifraga paniculata Mill. & Szarvaskő & 1957 & Siroki Zoltán & DE-siroki-08722.jpg \\
\hline 644 & Saxifraga paniculata Mill. & Szarvaskő & 1957 & Siroki Zoltán & DE-siroki-08723.jpg \\
\hline 644 & Saxifraga paniculata Mill. & Szarvaskő & 1957 & Siroki Zoltán & DE-siroki-08724.jpg \\
\hline 645 & Saxifraga bulbifera L. & Abaújszántó & 1944 & Siroki Zoltán & DE-siroki-08788.jpg \\
\hline 645 & Saxifraga bulbifera L. & Budapest & 1962 & Siroki Zoltán & DE-siroki-08783.jpg \\
\hline 645 & Saxifraga bulbifera L. & Debrecen & 1954 & Kovács Béla & DE-siroki-08784.jpg \\
\hline 645 & Saxifraga bulbifera L. & Egyek & 1949 & Siroki Zoltán & DE-siroki-08785.jpg \\
\hline 645 & Saxifraga bulbifera L. & Egyek & 1949 & Siroki Zoltán & DE-siroki-08786.jpg \\
\hline 645 & Saxifraga bulbifera L. & Egyek & - & Siroki Zoltán & DE-siroki-08787.jpg \\
\hline 647 & Saxifraga tridactylites L. & Budapest & 1951 & Siroki Zoltán & DE-siroki-08761.jpg \\
\hline 647 & Saxifraga tridactylites L. & Budapest & 1951 & Siroki Zoltán & DE-siroki-08763.jpg \\
\hline 647 & Saxifraga tridactylites L. & Gödöllő & 1951 & Siroki Zoltán & DE-siroki-08762.jpg \\
\hline 647 & Saxifraga tridactylites L. & Hajdúsámson & 1967 & Gondola István & DE-siroki-08759.jpg \\
\hline 647 & Saxifraga tridactylites L. & Hajdúsámson & 1967 & Gondola István & DE-siroki-08760.jpg \\
\hline 648 & Saxifraga adscendens L. & Szarvaskő & 1966 & Siroki Zoltán & DE-siroki-08766.jpg \\
\hline 648 & Saxifraga adscendens L. & Szarvaskő & 1966 & Siroki Zoltán & DE-siroki-08767.jpg \\
\hline 648 & Saxifraga adscendens L. & Szarvaskő & 1966 & Siroki Zoltán & DE-siroki-08768.jpg \\
\hline 648 & Saxifraga adscendens L. & Szarvaskő & 1966 & Siroki Zoltán & DE-siroki-08769.jpg \\
\hline 648 & Saxifraga adscendens L. & Szarvaskő & 1966 & Siroki Zoltán & DE-siroki-08770.jpg \\
\hline 648 & Saxifraga adscendens L. & Szarvaskő & 1966 & Siroki Zoltán & DE-siroki-08771.jpg \\
\hline 648 & Saxifraga adscendens L. & Szarvaskő & 1966 & Siroki Zoltán & DE-siroki-08772.jpg \\
\hline 650 & Chrysosplenium alternifolium L. & Bükkszentkereszt & 1959 & Siroki Zoltán & DE-siroki-08793.jpg \\
\hline 650 & Chrysosplenium alternifolium L. & Háromhuta & 1955 & Simon Tiborné & DE-siroki-08797.jpg \\
\hline 650 & Chrysosplenium alternifolium L. & Pilismarót & 1957 & Siroki Zoltán & DE-siroki-08794.jpg \\
\hline 650 & Chrysosplenium alternifolium L. & Pilismarót & 1957 & Siroki Zoltán & DE-siroki-08795.jpg \\
\hline 650 & Chrysosplenium alternifolium L. & Pilismarót & 1957 & Siroki Zoltán & DE-siroki-08796.jpg \\
\hline 650 & Chrysosplenium alternifolium L. & Szilvásvárad & 1966 & Siroki Zoltán & DE-siroki-08790.jpg \\
\hline 650 & Chrysosplenium alternifolium L. & Szilvásvárad & 1966 & Siroki Zoltán & DE-siroki-08791.jpg \\
\hline 650 & Chrysosplenium alternifolium L. & Szilvásvárad & 1966 & Siroki Zoltán & DE-siroki-08792.jpg \\
\hline 653 & Parnassia palustris L. & Ágasegyháza & 1956 & Siroki Zoltán & DE-siroki-08805.jpg \\
\hline 653 & Parnassia palustris L. & Ágasegyháza & 1956 & Siroki Zoltán & DE-siroki-08806.jpg \\
\hline 653 & Parnassia palustris L. & Ágasegyháza & 1956 & Siroki Zoltán & DE-siroki-08803.jpg \\
\hline 653 & Parnassia palustris L. & Ágasegyháza & 1956 & Siroki Zoltán & DE-siroki-08804.jpg \\
\hline 653 & Parnassia palustris L. & Nagyhuta & 1962 & Siroki Zoltán & DE-siroki-08801.jpg \\
\hline 653 & Parnassia palustris L. & Nagyhuta & 1962 & Siroki Zoltán & DE-siroki-08802.jpg \\
\hline 653 & Parnassia palustris L. & Veresegyház & 1954 & Kovács Margit & DE-siroki-08800.jpg \\
\hline 654 & Ribes uva-crispa L. & "Dobogókő" & 1957 & Siroki Zoltán & DE-siroki-08809.jpg \\
\hline 654 & Ribes uva-crispa L. & "Dobogókő" & 1957 & Siroki Zoltán & DE-siroki-08810.jpg \\
\hline 654 & Ribes uva-crispa L. & "Nagymező" & 1973 & Siroki Zoltán & DE-siroki-08846.jpg \\
\hline
\end{tabular}




\begin{tabular}{|c|c|c|c|c|c|}
\hline $\begin{array}{l}\text { Sorszám / } \\
\text { Number }\end{array}$ & Taxon-név / Taxon-name & $\begin{array}{l}\text { Település / } \\
\text { Settlement }\end{array}$ & $\begin{array}{l}\text { Év / } \\
\text { Year }\end{array}$ & $\begin{array}{l}\text { Gyűjtő / } \\
\text { Collector }\end{array}$ & Fájlnév / File-name \\
\hline 657 & Ribes alpinum L. & "Nagymező" & 1968 & Siroki Zoltán & DE-siroki-08815.jpg \\
\hline 657 & Ribes alpinum L. & "Nagymező" & 1968 & Siroki Zoltán & DE-siroki-08816.jpg \\
\hline 657 & Ribes alpinum L. & "Nagymező" & 1968 & Siroki Zoltán & DE-siroki-08817.jpg \\
\hline 657 & Ribes alpinum L. & "Nagymező" & 1968 & Siroki Zoltán & DE-siroki-08818.jpg \\
\hline 657 & Ribes alpinum L. & Telkibánya & 1953 & Jeney Endre & DE-siroki-08819.jpg \\
\hline 663 & Spiraea media Schmidt & "Tarkő" & 1956 & Siroki Zoltán & DE-siroki-08836.jpg \\
\hline 663 & Spiraea media Schmidt & Felsőtárkány & 1957 & Siroki Zoltán & DE-siroki-08834.jpg \\
\hline 663 & Spiraea media Schmidt & Felsőtárkány & 1957 & Siroki Zoltán & DE-siroki-08835.jpg \\
\hline 663 & Spiraea media Schmidt & Pásztó & 1952 & Siroki Zoltán & DE-siroki-08837.jpg \\
\hline 663 & Spiraea media Schmidt & Szarvaskő & 1957 & Siroki Zoltán & DE-siroki-08832.jpg \\
\hline 663 & Spiraea media Schmidt & Szarvaskő & 1966 & Siroki Zoltán & DE-siroki-08833.jpg \\
\hline 664 & Spiraea crenata L. & Érd & 1879 & Tauscher Gyula & DE-siroki-08829.jpg \\
\hline 666 & Aruncus dioicus (Walter) Fernald & Háromhuta & 1961 & Siroki Zoltán & DE-siroki-08847.jpg \\
\hline 666 & Aruncus dioicus (Walter) Fernald & Háromhuta & 1961 & Siroki Zoltán & DE-siroki-08848.jpg \\
\hline 666 & Aruncus dioicus (Walter) Fernald & Háromhuta & 1961 & Siroki Zoltán & DE-siroki-08849.jpg \\
\hline 666 & Aruncus dioicus (Walter) Fernald & Háromhuta & 1961 & Siroki Zoltán & DE-siroki-08850.jpg \\
\hline 666 & Aruncus dioicus (Walter) Fernald & Háromhuta & 1961 & Siroki Zoltán & DE-siroki-08851.jpg \\
\hline 666 & Aruncus dioicus (Walter) Fernald & Háromhuta & 1961 & Siroki Zoltán & DE-siroki-08852.jpg \\
\hline 667 & Filipendula ulmaria (L.) Maxim. & Máriakálnok & 1939 & Siroki Zoltán & DE-siroki-09448.jpg \\
\hline 667 & Filipendula ulmaria (L.) Maxim. & Veresegyház & 1960 & Siroki Zoltán & DE-siroki-09443.jpg \\
\hline 667 & Filipendula ulmaria (L.) Maxim. & Veresegyház & 1960 & Siroki Zoltán & DE-siroki-09444.jpg \\
\hline 667 & Filipendula ulmaria (L.) Maxim. & Veresegyház & 1960 & Siroki Zoltán & DE-siroki-09445.jpg \\
\hline 667 & Filipendula ulmaria (L.) Maxim. & Veresegyház & 1960 & Siroki Zoltán & DE-siroki-09446.jpg \\
\hline 668 & Filipendula vulgaris Moench & "Dobogókő" & 1965 & Siroki Zoltán & DE-siroki-09451.jpg \\
\hline 668 & Filipendula vulgaris Moench & "Nagymező" & 1956 & Halász Tibor & DE-siroki-09457.jpg \\
\hline 668 & Filipendula vulgaris Moench & Cegléd & 1969 & Siroki Zoltán & DE-siroki-09454.jpg \\
\hline 668 & Filipendula vulgaris Moench & Debrecen & 1950 & Siroki Zoltán & DE-siroki-09455.jpg \\
\hline 668 & Filipendula vulgaris Moench & Debrecen & 1950 & Siroki Zoltán & DE-siroki-09456.jpg \\
\hline 668 & Filipendula vulgaris Moench & Egyek & 1948 & Siroki Zoltán & DE-siroki-09458.jpg \\
\hline 668 & Filipendula vulgaris Moench & Mátraszentimre & 1959 & Gondola István & DE-siroki-09450.jpg \\
\hline 668 & Filipendula vulgaris Moench & Mátraszentimre & 1959 & Gondola István & DE-siroki-09449.jpg \\
\hline 668 & Filipendula vulgaris Moench & Újléta & 1967 & Siroki Zoltán & DE-siroki-09452.jpg \\
\hline 668 & Filipendula vulgaris Moench & Újléta & 1967 & Siroki Zoltán & DE-siroki-09453.jpg \\
\hline 672 & Rubus fruticosus agg. & "Szent-György-hegy" & 1955 & Siroki Zoltán & DE-siroki-09023.jpg \\
\hline 672 & Rubus fruticosus agg. & "Szent-György-hegy" & 1955 & Siroki Zoltán & DE-siroki-09024.jpg \\
\hline 672 & Rubus fruticosus agg. & "Szent-György-hegy" & 1955 & Siroki Zoltán & DE-siroki-09025.jpg \\
\hline 672 & Rubus fruticosus agg. & "Szent-György-hegy" & 1955 & Siroki Zoltán & DE-siroki-09026.jpg \\
\hline 672 & Rubus fruticosus agg. & Balatonszepezd & 1918 & Degen Árpád & DE-siroki-09050.jpg \\
\hline 672 & Rubus fruticosus agg. & Budapest & 1911 & Kocsis István & DE-siroki-09039.jpg \\
\hline 672 & Rubus fruticosus agg. & Budapest & 1912 & Degen Árpád & DE-siroki-09038.jpg \\
\hline 672 & Rubus fruticosus agg. & Budapest & 1912 & Degen Árpád & DE-siroki-09075.jpg \\
\hline 672 & Rubus fruticosus agg. & Budapest & 1912 & Degen Árpád & DE-siroki-09087.jpg \\
\hline 672 & Rubus fruticosus agg. & Budapest & 1925 & Degen Árpád & DE-siroki-09036.jpg \\
\hline 672 & Rubus fruticosus agg. & Budapest & 1951 & Siroki Zoltán & DE-siroki-09047.jpg \\
\hline 672 & Rubus fruticosus agg. & Budapest & 1951 & Siroki Zoltán & DE-siroki-09048.jpg \\
\hline 672 & Rubus fruticosus agg. & Budapest & 1951 & Siroki Zoltán & DE-siroki-09049.jpg \\
\hline
\end{tabular}




\begin{tabular}{|c|c|c|c|c|c|}
\hline $\begin{array}{l}\text { Sorszám / } \\
\text { Number }\end{array}$ & Taxon-név / Taxon-name & $\begin{array}{l}\text { Település / } \\
\text { Settlement }\end{array}$ & $\begin{array}{l}\text { Év / } \\
\text { Year }\end{array}$ & $\begin{array}{l}\text { Gyűjtő / } \\
\text { Collector }\end{array}$ & Fájlnév / File-name \\
\hline 672 & Rubus fruticosus agg. & Budapest & 1951 & Siroki Zoltán & DE-siroki-09027.jpg \\
\hline 672 & Rubus fruticosus agg. & Budapest & 1951 & Siroki Zoltán & DE-siroki-09028.jpg \\
\hline 672 & Rubus fruticosus agg. & Budapest & 1951 & Siroki Zoltán & DE-siroki-09029.jpg \\
\hline 672 & Rubus fruticosus agg. & Budapest & 1951 & Siroki Zoltán & DE-siroki-09030.jpg \\
\hline 672 & Rubus fruticosus agg. & Budapest & 1951 & Siroki Zoltán & DE-siroki-09031.jpg \\
\hline 672 & Rubus fruticosus agg. & Budapest & 1951 & Siroki Zoltán & DE-siroki-09032.jpg \\
\hline 672 & Rubus fruticosus agg. & Budapest & 1951 & Siroki Zoltán & DE-siroki-09107.jpg \\
\hline 672 & Rubus fruticosus agg. & Budapest & 1951 & Siroki Zoltán & DE-siroki-09108.jpg \\
\hline 672 & Rubus fruticosus agg. & Háromhuta & 1960 & Siroki Zoltán & DE-siroki-09121.jpg \\
\hline 672 & Rubus fruticosus agg. & Háromhuta & 1960 & Siroki Zoltán & DE-siroki-09122.jpg \\
\hline 672 & Rubus fruticosus agg. & Háromhuta & 1960 & Siroki Zoltán & DE-siroki-09131.jpg \\
\hline 672 & Rubus fruticosus agg. & Háromhuta & 1960 & Siroki Zoltán & DE-siroki-09132.jpg \\
\hline 672 & Rubus fruticosus agg. & Háromhuta & 1960 & Siroki Zoltán & DE-siroki-09133.jpg \\
\hline 672 & Rubus fruticosus agg. & Háromhuta & 1960 & Siroki Zoltán & DE-siroki-09134.jpg \\
\hline 672 & Rubus fruticosus agg. & Hegymagas & 1930 & Rigler József & DE-siroki-09035.jpg \\
\hline 672 & Rubus fruticosus agg. & Hosszúhetény & 1954 & Siroki Zoltán & DE-siroki-09115.jpg \\
\hline 672 & Rubus fruticosus agg. & Hosszúhetény & 1954 & Siroki Zoltán & DE-siroki-09116.jpg \\
\hline 672 & Rubus fruticosus agg. & Keszthely & 1928 & Rigler József & DE-siroki-09096.jpg \\
\hline 672 & Rubus fruticosus agg. & Keszthely & 1930 & Rigler József & DE-siroki-09071.jpg \\
\hline 672 & Rubus fruticosus agg. & Keszthely & 1930 & Rigler József & DE-siroki-09089.jpg \\
\hline 672 & Rubus fruticosus agg. & Keszthely & 1930 & Rigler József & DE-siroki-09095.jpg \\
\hline 672 & Rubus fruticosus agg. & Leányfalu & 1917 & Degen Árpád & DE-siroki-09088.jpg \\
\hline 672 & Rubus fruticosus agg. & Mátraverebély & 1952 & Siroki Zoltán & DE-siroki-09043.jpg \\
\hline 672 & Rubus fruticosus agg. & Mátraverebély & 1952 & Siroki Zoltán & DE-siroki-09044.jpg \\
\hline 672 & Rubus fruticosus agg. & Mátraverebély & 1952 & Siroki Zoltán & DE-siroki-09083.jpg \\
\hline 672 & Rubus fruticosus agg. & Mátraverebély & 1952 & Siroki Zoltán & DE-siroki-09084.jpg \\
\hline 672 & Rubus fruticosus agg. & Mátraverebély & 1952 & Siroki Zoltán & DE-siroki-09085.jpg \\
\hline 672 & Rubus fruticosus agg. & Mátraverebély & 1952 & Siroki Zoltán & DE-siroki-09086.jpg \\
\hline 672 & Rubus fruticosus agg. & Mátraverebély & 1952 & Siroki Zoltán & DE-siroki-09099.jpg \\
\hline 672 & Rubus fruticosus agg. & Mátraverebély & 1952 & Siroki Zoltán & DE-siroki-09100.jpg \\
\hline 672 & Rubus fruticosus agg. & Mátraverebély & 1952 & Siroki Zoltán & DE-siroki-09101.jpg \\
\hline 672 & Rubus fruticosus agg. & Mátraverebély & 1952 & Siroki Zoltán & DE-siroki-09077.jpg \\
\hline 672 & Rubus fruticosus agg. & Mátraverebély & 1952 & Siroki Zoltán & DE-siroki-09078.jpg \\
\hline 672 & Rubus fruticosus agg. & Mátraverebély & 1952 & Siroki Zoltán & DE-siroki-09079.jpg \\
\hline 672 & Rubus fruticosus agg. & Mátraverebély & 1952 & Siroki Zoltán & DE-siroki-09080.jpg \\
\hline 672 & Rubus fruticosus agg. & Pásztó & 1952 & Siroki Zoltán & DE-siroki-09142.jpg \\
\hline 672 & Rubus fruticosus agg. & Pásztó & 1952 & Siroki Zoltán & DE-siroki-09143.jpg \\
\hline 672 & Rubus fruticosus agg. & Pásztó & 1952 & Siroki Zoltán & DE-siroki-09056.jpg \\
\hline 672 & Rubus fruticosus agg. & Pásztó & 1952 & Siroki Zoltán & DE-siroki-09057.jpg \\
\hline 672 & Rubus fruticosus agg. & Pásztó & 1952 & Siroki Zoltán & DE-siroki-09058.jpg \\
\hline 672 & Rubus fruticosus agg. & Piliscsév & 1925 & Degen Árpád & DE-siroki-09144.jpg \\
\hline 672 & Rubus fruticosus agg. & Pilisszentiván & 1917 & Degen Árpád & DE-siroki-09060.jpg \\
\hline 672 & Rubus fruticosus agg. & Pilisszentiván & 1917 & Degen Árpád & DE-siroki-09097.jpg \\
\hline 672 & Rubus fruticosus agg. & Pilisszentiván & 1917 & Degen Árpád & DE-siroki-09081.jpg \\
\hline 672 & Rubus fruticosus agg. & Pilisszentiván & 1925 & Degen Árpád & DE-siroki-09051.jpg \\
\hline 672 & Rubus fruticosus agg. & Pilisszentiván & 1925 & Degen Árpád & DE-siroki-09053.jpg \\
\hline
\end{tabular}




\begin{tabular}{|c|c|c|c|c|c|}
\hline $\begin{array}{l}\text { Sorszám / } \\
\text { Number }\end{array}$ & Taxon-név / Taxon-name & $\begin{array}{l}\text { Település / } \\
\text { Settlement }\end{array}$ & $\begin{array}{l}\text { Év / } \\
\text { Year }\end{array}$ & $\begin{array}{l}\text { Gyűjtő / } \\
\text { Collector }\end{array}$ & Fájlnév / File-name \\
\hline 672 & Rubus fruticosus agg. & Pilisszentiván & 1925 & Degen Árpád & DE-siroki-09074.jpg \\
\hline 672 & Rubus fruticosus agg. & Pilisszentiván & 1925 & Degen Árpád & DE-siroki-09052.jpg \\
\hline 672 & Rubus fruticosus agg. & Pilisszentlászló & 1917 & Degen Árpád & DE-siroki-09055.jpg \\
\hline 672 & Rubus fruticosus agg. & Pilisszentlászló & 1917 & Degen Árpád & DE-siroki-09054.jpg \\
\hline 672 & Rubus fruticosus agg. & Pomáz & 1910 & Degen Árpád & DE-siroki-09037.jpg \\
\hline 672 & Rubus fruticosus agg. & Sátoraljaújhely & 1944 & Siroki Zoltán & DE-siroki-09091.jpg \\
\hline 672 & Rubus fruticosus agg. & Sátoraljaújhely & 1944 & Siroki Zoltán & DE-siroki-09092.jpg \\
\hline 672 & Rubus fruticosus agg. & Sátoraljaújhely & 1944 & Siroki Zoltán & DE-siroki-09093.jpg \\
\hline 672 & Rubus fruticosus agg. & Sátoraljaújhely & 1944 & Siroki Zoltán & DE-siroki-09102.jpg \\
\hline 672 & Rubus fruticosus agg. & Sátoraljaújhely & 1944 & Siroki Zoltán & DE-siroki-09103.jpg \\
\hline 672 & Rubus fruticosus agg. & Sátoraljaújhely & 1944 & Siroki Zoltán & DE-siroki-09104.jpg \\
\hline 672 & Rubus fruticosus agg. & Szarvaskő & 1966 & Siroki Zoltán & DE-siroki-09126.jpg \\
\hline 672 & Rubus fruticosus agg. & Szarvaskő & 1966 & Siroki Zoltán & DE-siroki-09127.jpg \\
\hline 672 & Rubus fruticosus agg. & Szarvaskő & 1966 & Siroki Zoltán & DE-siroki-09128.jpg \\
\hline 672 & Rubus fruticosus agg. & Szarvaskő & 1966 & Siroki Zoltán & DE-siroki-09129.jpg \\
\hline 672 & Rubus fruticosus agg. & Szarvaskő & 1966 & Siroki Zoltán & DE-siroki-09130.jpg \\
\hline 672 & Rubus fruticosus agg. & Szentendre & 1918 & Degen Árpád & DE-siroki-09045.jpg \\
\hline 672 & Rubus fruticosus agg. & Szentendre & 1918 & Degen Árpád & DE-siroki-09046.jpg \\
\hline 672 & Rubus fruticosus agg. & Szilvásvárad & 1954 & Siroki Zoltán & DE-siroki-09062.jpg \\
\hline 672 & Rubus fruticosus agg. & Szilvásvárad & 1954 & Siroki Zoltán & DE-siroki-09063.jpg \\
\hline 672 & Rubus fruticosus agg. & Szilvásvárad & 1954 & Siroki Zoltán & DE-siroki-09064.jpg \\
\hline 672 & Rubus fruticosus agg. & Visegrád & 1916 & Degen Árpád & DE-siroki-09072.jpg \\
\hline 672 & Rubus fruticosus agg. & Visegrád & 1916 & Degen Árpád & DE-siroki-09076.jpg \\
\hline 673 & Rubus caesius L. & Egyek & 1947 & Siroki Zoltán & DE-siroki-09020.jpg \\
\hline 673 & Rubus caesius L. & Mátraszentimre & 1959 & Gondola István & DE-siroki-09019.jpg \\
\hline 673 & Rubus caesius L. & Szilvásvárad & 1954 & Siroki Zoltán & DE-siroki-09021.jpg \\
\hline 673 & Rubus caesius L. & Tiszafüred & 1970 & Siroki Zoltán & DE-siroki-09022.jpg \\
\hline 678 & Rosa spinosissima L. & Abaújszántó & 1943 & Siroki Zoltán & DE-siroki-09611.jpg \\
\hline 678 & Rosa spinosissima L. & Abaújszántó & 1943 & Siroki Zoltán & DE-siroki-09610.jpg \\
\hline 678 & Rosa spinosissima L. & Abaújszántó & 1944 & Siroki Zoltán & DE-siroki-09608.jpg \\
\hline 678 & Rosa spinosissima L. & Abaújszántó & 1944 & Siroki Zoltán & DE-siroki-09609.jpg \\
\hline 678 & Rosa spinosissima L. & Budapest & 1951 & Siroki Zoltán & DE-siroki-09612.jpg \\
\hline 678 & Rosa spinosissima L. & Budapest & 1964 & Siroki Zoltán & DE-siroki-09603.jpg \\
\hline 678 & Rosa spinosissima L. & Budapest & 1981 & Siroki Zoltán & DE-siroki-09602.jpg \\
\hline 678 & Rosa spinosissima L. & Szarvaskő & 1957 & Siroki Zoltán & DE-siroki-09606.jpg \\
\hline 678 & Rosa spinosissima L. & Szarvaskő & 1957 & Siroki Zoltán & DE-siroki-09607.jpg \\
\hline 678 & Rosa spinosissima L. & Szilvásvárad & 1960 & Siroki Zoltán & DE-siroki-09604.jpg \\
\hline 678 & Rosa spinosissima L. & Szilvásvárad & 1960 & Siroki Zoltán & DE-siroki-09605.jpg \\
\hline 681 & Rosa pendulina L. & "Nagymező" & 1957 & Siroki Zoltán & DE-siroki-09756.jpg \\
\hline 681 & Rosa pendulina L. & "Nagymező" & 1959 & Siroki Zoltán & DE-siroki-09757.jpg \\
\hline 681 & Rosa pendulina L. & Felsőtárkány & 1957 & Siroki Zoltán & DE-siroki-09758.jpg \\
\hline 681 & Rosa pendulina L. & Felsőtárkány & 1957 & Siroki Zoltán & DE-siroki-09759.jpg \\
\hline 685 & Rosa gallica L. & "Nagymező" & 1978 & Halász Tibor & DE-siroki-09539.jpg \\
\hline 685 & Rosa gallica L. & Aggtelek & 1974 & Siroki Zoltán & DE-siroki-09548.jpg \\
\hline 685 & Rosa gallica L. & Budapest & 1951 & Siroki Zoltán & DE-siroki-09543.jpg \\
\hline 685 & Rosa gallica L. & Gödöllő & 1952 & Siroki Zoltán & DE-siroki-09537.jpg \\
\hline
\end{tabular}




\begin{tabular}{|c|c|c|c|c|c|}
\hline $\begin{array}{l}\text { Sorszám / } \\
\text { Number }\end{array}$ & Taxon-név / Taxon-name & $\begin{array}{l}\text { Település / } \\
\text { Settlement }\end{array}$ & $\begin{array}{l}\text { Év / } \\
\text { Year }\end{array}$ & $\begin{array}{l}\text { Gyűjtő / } \\
\text { Collector }\end{array}$ & Fájlnév / File-name \\
\hline 685 & Rosa gallica L. & Gödöllő & 1952 & Siroki Zoltán & DE-siroki-09540.jpg \\
\hline 685 & Rosa gallica L. & Gödöllő & 1952 & Siroki Zoltán & DE-siroki-09541.jpg \\
\hline 685 & Rosa gallica L. & Gödöllő & 1952 & Siroki Zoltán & DE-siroki-09542.jpg \\
\hline 685 & Rosa gallica L. & Gödöllő & 1952 & Siroki Zoltán & DE-siroki-09538.jpg \\
\hline 685 & Rosa gallica L. & Háromhuta & 1961 & Siroki Zoltán & DE-siroki-09549.jpg \\
\hline 685 & Rosa gallica L. & Háromhuta & 1961 & Siroki Zoltán & DE-siroki-09550.jpg \\
\hline 685 & Rosa gallica L. & Hortobágy & 1948 & Siroki Zoltán & DE-siroki-09551.jpg \\
\hline 691 & Rosa micrantha Borrer ex Sm. & Budapest & 1952 & Siroki Zoltán & DE-siroki-09556.jpg \\
\hline 700 & Rosa canina L. & "Dobogókő" & 1965 & Siroki Zoltán & DE-siroki-09584.jpg \\
\hline 700 & Rosa canina L. & "Dobogókő" & 1965 & Siroki Zoltán & DE-siroki-09585.jpg \\
\hline 700 & Rosa canina L. & Salgótarján & 1954 & Máthé Imre & DE-siroki-09586.jpg \\
\hline 700 & Rosa canina L. & Salgótarján & 1954 & Máthé Imre & DE-siroki-09587.jpg \\
\hline 701 & Rosa dumalis Bechst. & "Szent-György-hegy" & 1930 & Rigler József & DE-siroki-09597.jpg \\
\hline 701 & Rosa dumalis Bechst. & "Szent-György-hegy" & 1930 & Rigler József & DE-siroki-09598.jpg \\
\hline 701 & Rosa dumalis Bechst. & "Szent-György-hegy" & 1930 & Rigler József & DE-siroki-09599.jpg \\
\hline 701 & Rosa dumalis Bechst. & Budapest & 1951 & Siroki Zoltán & DE-siroki-09594.jpg \\
\hline 701 & Rosa dumalis Bechst. & Budapest & 1951 & Siroki Zoltán & DE-siroki-09596.jpg \\
\hline 701 & Rosa dumalis Bechst. & Miskolc & 1960 & Siroki Zoltán & DE-siroki-09588.jpg \\
\hline 701 & Rosa dumalis Bechst. & Miskolc & 1960 & Siroki Zoltán & DE-siroki-09589.jpg \\
\hline 701 & Rosa dumalis Bechst. & Miskolc & 1960 & Siroki Zoltán & DE-siroki-09590.jpg \\
\hline 701 & Rosa dumalis Bechst. & Szilvásvárad & 1960 & Siroki Zoltán & DE-siroki-09591.jpg \\
\hline 701 & Rosa dumalis Bechst. & Szilvásvárad & 1960 & Siroki Zoltán & DE-siroki-09592.jpg \\
\hline 701 & Rosa dumalis Bechst. & Szilvásvárad & 1960 & Siroki Zoltán & DE-siroki-09593.jpg \\
\hline 701 & Rosa dumalis Bechst. & Vonyarcvashegy & - & Rigler József & DE-siroki-09600.jpg \\
\hline 703 & Rosa tomentella Léman & "Nagymező" & 1959 & Siroki Zoltán & DE-siroki-09561.jpg \\
\hline 703 & Rosa tomentella Léman & "Nagymező" & 1959 & Siroki Zoltán & DE-siroki-09562.jpg \\
\hline 703 & Rosa tomentella Léman & "Nagymező" & 1962 & Siroki Zoltán & DE-siroki-09558.jpg \\
\hline 703 & Rosa tomentella Léman & "Nagymező" & 1962 & Siroki Zoltán & DE-siroki-09559.jpg \\
\hline 703 & Rosa tomentella Léman & "Nagymező" & 1962 & Siroki Zoltán & DE-siroki-09560.jpg \\
\hline 703 & Rosa tomentella Léman & Szerencs & 1951 & Siroki Zoltán & DE-siroki-09563.jpg \\
\hline 703 & Rosa tomentella Léman & Szerencs & 1951 & Siroki Zoltán & DE-siroki-09564.jpg \\
\hline 703 & Rosa tomentella Léman & Szerencs & 1951 & Siroki Zoltán & DE-siroki-09565.jpg \\
\hline 703 & Rosa tomentella Léman & Szerencs & 1951 & Siroki Zoltán & DE-siroki-09566.jpg \\
\hline 704 & Rosa corymbifera Borkh. & "Szent-György-hegy" & 1930 & Rigler József & DE-siroki-09573.jpg \\
\hline 704 & Rosa corymbifera Borkh. & Gödöllő & 1952 & Siroki Zoltán & DE-siroki-09575.jpg \\
\hline 704 & Rosa corymbifera Borkh. & Gödöllő & 1952 & Siroki Zoltán & DE-siroki-09577.jpg \\
\hline 704 & Rosa corymbifera Borkh. & Gödöllő & 1952 & Siroki Zoltán & DE-siroki-09576.jpg \\
\hline 704 & Rosa corymbifera Borkh. & Szentendre & 1920 & Degen Árpád & DE-siroki-09571.jpg \\
\hline 704 & Rosa corymbifera Borkh. & Szentendre & 1920 & Degen Árpád & DE-siroki-09570.jpg \\
\hline 704 & Rosa corymbifera Borkh. & Szentendre & 1920 & Degen Árpád & DE-siroki-09572.jpg \\
\hline 704 & Rosa corymbifera Borkh. & Szilvásvárad & 1960 & Siroki Zoltán & DE-siroki-09574.jpg \\
\hline 704 & Rosa corymbifera Borkh. & Vonyarcvashegy & 1930 & Rigler József & DE-siroki-09568.jpg \\
\hline 704 & Rosa corymbifera Borkh. & Vonyarcvashegy & 1930 & Rigler József & DE-siroki-09569.jpg \\
\hline 708 & Agrimonia eupatoria L. & Debrecen & 1947 & Siroki Zoltán & DE-siroki-09525.jpg \\
\hline 708 & Agrimonia eupatoria L. & Debrecen & 1958 & Pethő Menyhért & DE-siroki-09524.jpg \\
\hline 708 & Agrimonia eupatoria L. & Hortobágy & 1949 & Siroki Zoltán & DE-siroki-09526.jpg \\
\hline
\end{tabular}




\begin{tabular}{|c|c|c|c|c|c|}
\hline $\begin{array}{l}\text { Sorszám / } \\
\text { Number }\end{array}$ & Taxon-név / Taxon-name & $\begin{array}{l}\text { Település / } \\
\text { Settlement }\end{array}$ & $\begin{array}{l}\text { Év / } \\
\text { Year }\end{array}$ & $\begin{array}{l}\text { Gyűjtő / } \\
\text { Collector }\end{array}$ & Fájlnév / File-name \\
\hline 708 & Agrimonia eupatoria L. & Hortobágy & 1949 & Siroki Zoltán & DE-siroki-09527.jpg \\
\hline 708 & Agrimonia eupatoria L. & Mosonmagyaróvár & 1939 & Siroki Zoltán & DE-siroki-09528.jpg \\
\hline 711 & Sanguisorba officinalis L. & Mosonmagyaróvár & 1939 & Siroki Zoltán & DE-siroki-09532.jpg \\
\hline 712 & Sanguisorba minor Scop. & Debrecen & 1950 & Siroki Zoltán & DE-siroki-09534.jpg \\
\hline 714 & Geum urbanum L. & Debrecen & 1947 & Siroki Zoltán & DE-siroki-09416.jpg \\
\hline 714 & Geum urbanum L. & Mosonmagyaróvár & 1939 & Siroki Zoltán & DE-siroki-09417.jpg \\
\hline 716 & Waldsteinia geoides Willd. & Budapest & 1951 & Siroki Zoltán & DE-siroki-09402.jpg \\
\hline 716 & Waldsteinia geoides Willd. & Budapest & 1951 & Siroki Zoltán & DE-siroki-09403.jpg \\
\hline 716 & Waldsteinia geoides Willd. & Budapest & 1960 & Siroki Zoltán & DE-siroki-09406.jpg \\
\hline 716 & Waldsteinia geoides Willd. & Budapest & 1960 & Siroki Zoltán & DE-siroki-09407.jpg \\
\hline 716 & Waldsteinia geoides Willd. & Budapest & 1960 & Siroki Zoltán & DE-siroki-09408.jpg \\
\hline 716 & Waldsteinia geoides Willd. & Budapest & 1960 & Siroki Zoltán & DE-siroki-09409.jpg \\
\hline 716 & Waldsteinia geoides Willd. & Miskolc & 1963 & Siroki Zoltán & DE-siroki-09396.jpg \\
\hline 716 & Waldsteinia geoides Willd. & Szarvaskő & 1958 & Siroki Zoltán & DE-siroki-09397.jpg \\
\hline 716 & Waldsteinia geoides Willd. & Szarvaskő & 1966 & Siroki Zoltán & DE-siroki-09395.jpg \\
\hline 718 & Potentilla palustris (L.) Scop. & Csaroda & 1954 & Siroki Zoltán & DE-siroki-09213.jpg \\
\hline 718 & Potentilla palustris (L.) Scop. & Csaroda & 1954 & Siroki Zoltán & DE-siroki-09216.jpg \\
\hline 718 & Potentilla palustris (L.) Scop. & Csaroda & 1954 & Siroki Zoltán & DE-siroki-09217.jpg \\
\hline 718 & Potentilla palustris (L.) Scop. & Csaroda & 1954 & Siroki Zoltán & DE-siroki-09220.jpg \\
\hline 718 & Potentilla palustris (L.) Scop. & Csaroda & 1954 & Siroki Zoltán & DE-siroki-09221.jpg \\
\hline 718 & Potentilla palustris (L.) Scop. & Csaroda & 1954 & Siroki Zoltán & DE-siroki-09222.jpg \\
\hline 718 & Potentilla palustris (L.) Scop. & Csaroda & 1954 & Siroki Zoltán & DE-siroki-09214.jpg \\
\hline 718 & Potentilla palustris (L.) Scop. & Csaroda & 1954 & Siroki Zoltán & DE-siroki-09215.jpg \\
\hline 718 & Potentilla palustris (L.) Scop. & Csaroda & 1960 & Siroki Zoltán & DE-siroki-09212.jpg \\
\hline 718 & Potentilla palustris (L.) Scop. & Csaroda & 1960 & Siroki Zoltán & DE-siroki-09219.jpg \\
\hline 718 & Potentilla palustris (L.) Scop. & Csaroda & - & Siroki Zoltán & DE-siroki-09218.jpg \\
\hline 719 & Potentilla rupestris L. & Háromhuta & 1962 & Siroki Zoltán & DE-siroki-09231.jpg \\
\hline 719 & Potentilla rupestris L. & Kishuta & 1961 & Siroki Zoltán & DE-siroki-09225.jpg \\
\hline 719 & Potentilla rupestris L. & Kishuta & 1961 & Siroki Zoltán & DE-siroki-09223.jpg \\
\hline 719 & Potentilla rupestris L. & Kishuta & 1961 & Siroki Zoltán & DE-siroki-09224.jpg \\
\hline 719 & Potentilla rupestris L. & Kishuta & 1961 & Siroki Zoltán & DE-siroki-09229.jpg \\
\hline 719 & Potentilla rupestris L. & Kishuta & 1961 & Siroki Zoltán & DE-siroki-09232.jpg \\
\hline 719 & Potentilla rupestris L. & Kishuta & 1961 & Siroki Zoltán & DE-siroki-09233.jpg \\
\hline 719 & Potentilla rupestris L. & Kishuta & 1961 & Siroki Zoltán & DE-siroki-09234.jpg \\
\hline 719 & Potentilla rupestris L. & Kishuta & 1961 & Siroki Zoltán & DE-siroki-09235.jpg \\
\hline 719 & Potentilla rupestris L. & Nagyhuta & 1961 & Siroki Zoltán & DE-siroki-09227.jpg \\
\hline 719 & Potentilla rupestris L. & Nagyhuta & 1961 & Siroki Zoltán & DE-siroki-09228.jpg \\
\hline 719 & Potentilla rupestris L. & Nagyhuta & 1961 & Siroki Zoltán & DE-siroki-09226.jpg \\
\hline 719 & Potentilla rupestris L. & Nagyhuta & 1961 & Siroki Zoltán & DE-siroki-09230.jpg \\
\hline 719 & Potentilla rupestris L. & Pécs & 1954 & Siroki Zoltán & DE-siroki-09238.jpg \\
\hline 719 & Potentilla rupestris L. & Sopron & 1951 & Kárpáti Zoltán & DE-siroki-09236.jpg \\
\hline 720 & Potentilla alba L. & "Bükk-hg." & 1966 & Siroki Zoltán & DE-siroki-09250.jpg \\
\hline 720 & Potentilla alba L. & Budapest & 1951 & Siroki Zoltán & DE-siroki-09246.jpg \\
\hline 720 & Potentilla alba L. & Budapest & 1951 & Siroki Zoltán & DE-siroki-09247.jpg \\
\hline 720 & Potentilla alba L. & Budapest & 1951 & Siroki Zoltán & DE-siroki-09248.jpg \\
\hline 720 & Potentilla alba L. & Budapest & 1962 & Siroki Zoltán & DE-siroki-09242.jpg \\
\hline
\end{tabular}




\begin{tabular}{|c|c|c|c|c|c|}
\hline $\begin{array}{l}\text { Sorszám / } \\
\text { Number }\end{array}$ & Taxon-név / Taxon-name & $\begin{array}{l}\text { Település / } \\
\text { Settlement }\end{array}$ & $\begin{array}{l}\text { Év / } \\
\text { Year }\end{array}$ & $\begin{array}{l}\text { Gyűjtő / } \\
\text { Collector }\end{array}$ & Fájlnév / File-name \\
\hline 720 & Potentilla alba L. & Budapest & 1962 & Siroki Zoltán & DE-siroki-09241.jpg \\
\hline 720 & Potentilla alba L. & Budapest & 1962 & Siroki Zoltán & DE-siroki-09243.jpg \\
\hline 720 & Potentilla alba L. & Budapest & 1962 & Siroki Zoltán & DE-siroki-09244.jpg \\
\hline 720 & Potentilla alba L. & Budapest & 1962 & Siroki Zoltán & DE-siroki-09245.jpg \\
\hline 720 & Potentilla alba L. & Gödöllő & 1952 & Siroki Zoltán & DE-siroki-09249.jpg \\
\hline 720 & Potentilla alba L. & Gyenesdiás & 1953 & Siroki Zoltán & DE-siroki-09251.jpg \\
\hline 721 & Potentilla micrantha Ramond ex DC. & Pécs & 1954 & Siroki Zoltán & DE-siroki-09253.jpg \\
\hline 721 & Potentilla micrantha Ramond ex DC. & Pécs & 1954 & Siroki Zoltán & DE-siroki-09254.jpg \\
\hline 721 & Potentilla micrantha Ramond ex DC. & Pécs & 1954 & Siroki Zoltán & DE-siroki-09255.jpg \\
\hline 721 & Potentilla micrantha Ramond ex DC. & Pécs & 1954 & Siroki Zoltán & DE-siroki-09256.jpg \\
\hline 721 & Potentilla micrantha Ramond ex DC. & Pécs & 1958 & Siroki Zoltán & DE-siroki-09257.jpg \\
\hline 721 & Potentilla micrantha Ramond ex DC. & Pécsvárad & 1951 & Kárpáti Zoltán & DE-siroki-09260.jpg \\
\hline 721 & Potentilla micrantha Ramond ex DC. & Szentendre & 1951 & Siroki Zoltán & DE-siroki-09258.jpg \\
\hline 721 & Potentilla micrantha Ramond ex DC. & Szentendre & 1951 & Siroki Zoltán & DE-siroki-09259.jpg \\
\hline 722 & Potentilla anserina L. & Debrecen & 1947 & Siroki Zoltán & DE-siroki-09271.jpg \\
\hline 722 & Potentilla anserina L. & Debrecen & 1947 & Siroki Zoltán & DE-siroki-09272.jpg \\
\hline 723 & Potentilla supina L. & Egyek & 1948 & Siroki Zoltán & DE-siroki-09263.jpg \\
\hline 723 & Potentilla supina L. & Gyula & 1974 & Siroki Zoltán & DE-siroki-09261.jpg \\
\hline 723 & Potentilla supina L. & Hortobágy & 1985 & Siroki Zoltán & DE-siroki-09262.jpg \\
\hline 723 & Potentilla supina L. & Mosonmagyaróvár & 1939 & Siroki Zoltán & DE-siroki-09266.jpg \\
\hline 723 & Potentilla supina L. & Mosonmagyaróvár & 1939 & Siroki Zoltán & DE-siroki-09267.jpg \\
\hline 723 & Potentilla supina L. & Tiszacsege & 1948 & Siroki Zoltán & DE-siroki-09268.jpg \\
\hline 723 & Potentilla supina L. & Tiszafüred & 1949 & Siroki Zoltán & DE-siroki-09264.jpg \\
\hline 724 & Potentilla erecta (L.) Rausch & "Nagymező" & 1959 & Siroki Zoltán & DE-siroki-09275.jpg \\
\hline 724 & Potentilla erecta (L.) Rausch & "Nagymező" & 1959 & Siroki Zoltán & DE-siroki-09276.jpg \\
\hline 724 & Potentilla erecta (L.) Rausch & Debrecen & 1954 & Siroki Zoltán & DE-siroki-09274.jpg \\
\hline 724 & Potentilla erecta (L.) Rausch & Gödöllő & 1951 & Siroki Zoltán & DE-siroki-09279.jpg \\
\hline 724 & Potentilla erecta (L.) Rausch & Hollóháza & 1940 & Siroki Zoltán & DE-siroki-09280.jpg \\
\hline 724 & Potentilla erecta (L.) Rausch & Nagyhuta & 1961 & Siroki Zoltán & DE-siroki-09277.jpg \\
\hline 724 & Potentilla erecta (L.) Rausch & Nagyhuta & 1961 & Siroki Zoltán & DE-siroki-09278.jpg \\
\hline 725 & Potentilla reptans L. & Debrecen & 1947 & Siroki Zoltán & DE-siroki-09286.jpg \\
\hline 725 & Potentilla reptans L. & Debrecen & 1948 & Siroki Zoltán & DE-siroki-09284.jpg \\
\hline 725 & Potentilla reptans L. & Debrecen & 1948 & Siroki Zoltán & DE-siroki-09285.jpg \\
\hline 725 & Potentilla reptans L. & Debrecen & 1984 & Siroki Zoltán & DE-siroki-09283.jpg \\
\hline 725 & Potentilla reptans L. & Mosonmagyaróvár & 1939 & Siroki Zoltán & DE-siroki-09287.jpg \\
\hline 726 & Potentilla collina agg. & "Nagymező" & 1959 & Halász Tibor & DE-siroki-09394.jpg \\
\hline 726 & Potentilla leucopolitana P.J. Müll. & Debrecen & 1947 & Siroki Zoltán & DE-siroki-09310.jpg \\
\hline 726 & Potentilla leucopolitana P.J. Müll. & Debrecen & 1955 & Siroki Zoltán & DE-siroki-09311.jpg \\
\hline 726 & Potentilla leucopolitana P.J. Müll. & Debrecen & 1955 & Siroki Zoltán & DE-siroki-09313.jpg \\
\hline 726 & Potentilla leucopolitana P.J. Müll. & Debrecen & - & Siroki Zoltán & DE-siroki-09312.jpg \\
\hline 727 & Potentilla inclinata Vill. & "Nagymező" & 1959 & Siroki Zoltán & DE-siroki-09295.jpg \\
\hline 727 & Potentilla inclinata Vill. & Debrecen & 1962 & Siroki Zoltán & DE-siroki-09289.jpg \\
\hline 727 & Potentilla inclinata Vill. & Debrecen & 1962 & Siroki Zoltán & DE-siroki-09290.jpg \\
\hline 727 & Potentilla inclinata Vill. & Debrecen & 1962 & Siroki Zoltán & DE-siroki-09291.jpg \\
\hline 727 & Potentilla inclinata Vill. & Debrecen & 1962 & Siroki Zoltán & DE-siroki-09292.jpg \\
\hline 727 & Potentilla inclinata Vill. & Debrecen & 1962 & Siroki Zoltán & DE-siroki-09293.jpg \\
\hline
\end{tabular}




\begin{tabular}{|c|c|c|c|c|c|}
\hline $\begin{array}{l}\text { Sorszám / } \\
\text { Number }\end{array}$ & Taxon-név / Taxon-name & $\begin{array}{l}\text { Település / } \\
\text { Settlement }\end{array}$ & $\begin{array}{l}\text { Év / } \\
\text { Year }\end{array}$ & $\begin{array}{l}\text { Gyújitő / } \\
\text { Collector }\end{array}$ & Fájlnév / File-name \\
\hline 727 & Potentilla inclinata Vill. & Háromhuta & 1960 & Siroki Zoltán & DE-siroki-09296.jpg \\
\hline 727 & Potentilla inclinata Vill. & Szilvásvárad & 1963 & Siroki Zoltán & DE-siroki-09294.jpg \\
\hline 728 & Potentilla argentea L. & Debrecen & 1947 & Siroki Zoltán & DE-siroki-09300.jpg \\
\hline 728 & Potentilla argentea L. & Hajdúböszörmény & 1981 & Siroki Zoltán & DE-siroki-09301.jpg \\
\hline 728 & Potentilla argentea L. & Mosonmagyaróvár & 1939 & Siroki Zoltán & DE-siroki-09304.jpg \\
\hline 728 & Potentilla argentea L. & Vámospércs & 1965 & Siroki Zoltán & DE-siroki-09393.jpg \\
\hline 728 & Potentilla argentea L. & Záhony & 1965 & Gondola István & DE-siroki-09302.jpg \\
\hline 728 & Potentilla argentea L. & Záhony & 1965 & Gondola István & DE-siroki-09303.jpg \\
\hline 730 & Potentilla recta L. & "Sátor-hg." & 1943 & Siroki Zoltán & DE-siroki-09337.jpg \\
\hline 730 & Potentilla recta L. & "Szent-György-hegy" & 1955 & Siroki Zoltán & DE-siroki-09321.jpg \\
\hline 730 & Potentilla recta L. & Aszaló & 1944 & Siroki Zoltán & DE-siroki-09329.jpg \\
\hline 730 & Potentilla recta L. & Budaörs & 1966 & Siroki Zoltán & DE-siroki-09316.jpg \\
\hline 730 & Potentilla recta L. & Budapest & 1944 & Siroki Zoltán & DE-siroki-09328.jpg \\
\hline 730 & Potentilla recta L. & Budapest & 1966 & Siroki Zoltán & DE-siroki-09318.jpg \\
\hline 730 & Potentilla recta L. & Budapest & 1966 & Siroki Zoltán & DE-siroki-09319.jpg \\
\hline 730 & Potentilla recta L. & Budapest & 1966 & Siroki Zoltán & DE-siroki-09317.jpg \\
\hline 730 & Potentilla recta L. & Budapest & 1966 & Siroki Zoltán & DE-siroki-09320.jpg \\
\hline 730 & Potentilla recta L. & Debrecen & 1947 & Siroki Zoltán & DE-siroki-09326.jpg \\
\hline 730 & Potentilla recta L. & Pomáz & 1957 & Siroki Zoltán & DE-siroki-09324.jpg \\
\hline 730 & Potentilla recta L. & Pomáz & 1957 & Siroki Zoltán & DE-siroki-09325.jpg \\
\hline 730 & Potentilla recta L. & Szilvásvárad & 1959 & Siroki Zoltán & DE-siroki-09322.jpg \\
\hline 730 & Potentilla recta L. & Szilvásvárad & 1959 & Siroki Zoltán & DE-siroki-09323.jpg \\
\hline 730 & Potentilla recta L. & Tokaj & 1966 & Siroki Zoltán & DE-siroki-09314.jpg \\
\hline 730 & Potentilla recta L. & Tokaj & 1971 & Siroki Zoltán & DE-siroki-09315.jpg \\
\hline 731 & Potentilla heptaphylla L. & "Bükk-hg." & 1966 & Siroki Zoltán & DE-siroki-09367.jpg \\
\hline 731 & Potentilla heptaphylla L. & "Bükk-hg." & 1966 & Siroki Zoltán & DE-siroki-09368.jpg \\
\hline 731 & Potentilla heptaphylla L. & "Dobogókő" & 1957 & Siroki Zoltán & DE-siroki-09356.jpg \\
\hline 731 & Potentilla heptaphylla L. & "Mátra" & 1957 & Siroki Zoltán & DE-siroki-09355.jpg \\
\hline 731 & Potentilla heptaphylla L. & "Nagymező" & 1957 & Siroki Zoltán & DE-siroki-09363.jpg \\
\hline 731 & Potentilla heptaphylla L. & "Nagymező" & 1957 & Siroki Zoltán & DE-siroki-09364.jpg \\
\hline 731 & Potentilla heptaphylla L. & "Nagymező" & 1957 & Siroki Zoltán & DE-siroki-09365.jpg \\
\hline 731 & Potentilla heptaphylla L. & "Nagymező" & 1957 & Siroki Zoltán & DE-siroki-09366.jpg \\
\hline 731 & Potentilla heptaphylla L. & "Nagymező" & 1957 & Siroki Zoltán & DE-siroki-09369.jpg \\
\hline 731 & Potentilla heptaphylla L. & "Nagymező" & 1959 & Siroki Zoltán & DE-siroki-09370.jpg \\
\hline 731 & Potentilla heptaphylla L. & Budapest & 1951 & Siroki Zoltán & DE-siroki-09357.jpg \\
\hline 731 & Potentilla heptaphylla L. & Budapest & 1951 & Siroki Zoltán & DE-siroki-09358.jpg \\
\hline 731 & Potentilla heptaphylla L. & Budapest & 1951 & Siroki Zoltán & DE-siroki-09359.jpg \\
\hline 731 & Potentilla heptaphylla L. & Budapest & 1951 & Siroki Zoltán & DE-siroki-09360.jpg \\
\hline 731 & Potentilla heptaphylla L. & Debrecen & 1954 & Siroki Zoltán & DE-siroki-09371.jpg \\
\hline 731 & Potentilla heptaphylla L. & Debrecen & 1954 & Siroki Zoltán & DE-siroki-09372.jpg \\
\hline 731 & Potentilla heptaphylla L. & Debrecen & 1954 & Siroki Zoltán & DE-siroki-09373.jpg \\
\hline 731 & Potentilla heptaphylla L. & Debrecen & 1964 & Siroki Zoltán & DE-siroki-09374.jpg \\
\hline 731 & Potentilla heptaphylla L. & Debrecen & 1964 & Siroki Zoltán & DE-siroki-09375.jpg \\
\hline 731 & Potentilla heptaphylla L. & Debrecen & 1964 & Siroki Zoltán & DE-siroki-09376.jpg \\
\hline 731 & Potentilla heptaphylla L. & Debrecen & 1964 & Siroki Zoltán & DE-siroki-09377.jpg \\
\hline 731 & Potentilla heptaphylla L. & Gyenesdiás & 1972 & Siroki Zoltán & DE-siroki-09378.jpg \\
\hline
\end{tabular}




\begin{tabular}{|c|c|c|c|c|c|}
\hline $\begin{array}{l}\text { Sorszám / } \\
\text { Number }\end{array}$ & Taxon-név / Taxon-name & $\begin{array}{l}\text { Település / } \\
\text { Settlement }\end{array}$ & $\begin{array}{l}\text { Év / } \\
\text { Year }\end{array}$ & $\begin{array}{l}\text { Gyújitő / } \\
\text { Collector }\end{array}$ & Fájlnév / File-name \\
\hline 731 & Potentilla heptaphylla L. & Háromhuta & 1961 & Siroki Zoltán & DE-siroki-09353.jpg \\
\hline 731 & Potentilla heptaphylla L. & Kishuta & 1961 & Siroki Zoltán & DE-siroki-09354.jpg \\
\hline 732 & Potentilla patula Waldst. et Kit. & Abaújszántó & 1944 & Siroki Zoltán & DE-siroki-09381.jpg \\
\hline 732 & Potentilla patula Waldst. et Kit. & Abaújszántó & 1944 & Siroki Zoltán & DE-siroki-09380.jpg \\
\hline 732 & Potentilla patula Waldst. et Kit. & Debrecen & 1947 & Siroki Zoltán & DE-siroki-09382.jpg \\
\hline 732 & Potentilla patula Waldst. et Kit. & Egyek & 1949 & Siroki Zoltán & DE-siroki-09384.jpg \\
\hline 732 & Potentilla patula Waldst. et Kit. & Egyek & 1949 & Siroki Zoltán & DE-siroki-09383.jpg \\
\hline 732 & Potentilla patula Waldst. et Kit. & Hortobágy & 1949 & Siroki Zoltán & DE-siroki-09385.jpg \\
\hline 732 & Potentilla patula Waldst. et Kit. & Hortobágy & 1949 & Siroki Zoltán & DE-siroki-09387.jpg \\
\hline 732 & Potentilla patula Waldst. et Kit. & Hortobágy & 1949 & Siroki Zoltán & DE-siroki-09386.jpg \\
\hline 734 & Potentilla arenaria Borkh. & Debrecen & 1947 & Siroki Zoltán & DE-siroki-09388.jpg \\
\hline 734 & Potentilla arenaria Borkh. & Debrecen & 1950 & Siroki Zoltán & DE-siroki-09389.jpg \\
\hline 734 & Potentilla arenaria Borkh. & Debrecen & 1950 & Siroki Zoltán & DE-siroki-09390.jpg \\
\hline 734 & Potentilla arenaria Borkh. & Füzér & 1955 & Simon Tiborné & DE-siroki-09391.jpg \\
\hline 736 & Fragaria viridis Duchesne & Hortobágy & 1954 & Siroki Zoltán & DE-siroki-09201.jpg \\
\hline 736 & Fragaria viridis Duchesne & Hortobágy & 1954 & Siroki Zoltán & DE-siroki-09202.jpg \\
\hline 736 & Fragaria viridis Duchesne & Mosonmagyaróvár & 1939 & Siroki Zoltán & DE-siroki-09198.jpg \\
\hline 736 & Fragaria viridis Duchesne & Pilisszentiván & 1952 & Siroki Zoltán & DE-siroki-09195.jpg \\
\hline 736 & Fragaria viridis Duchesne & Pilisszentiván & 1952 & Siroki Zoltán & DE-siroki-09196.jpg \\
\hline 736 & Fragaria viridis Duchesne & Pilisszentiván & 1952 & Siroki Zoltán & DE-siroki-09197.jpg \\
\hline 736 & Fragaria viridis Duchesne & Sajólád/Sajópetri & 1951 & Siroki Zoltán & DE-siroki-09199.jpg \\
\hline 736 & Fragaria viridis Duchesne & Sajólád/Sajópetri & 1951 & Siroki Zoltán & DE-siroki-09200.jpg \\
\hline 736 & Fragaria viridis Duchesne & Tarpa & 1955 & Siroki Zoltán & DE-siroki-09203.jpg \\
\hline 737 & Fragaria moschata Duchesne & Budapest & 1951 & Siroki Zoltán & DE-siroki-09168.jpg \\
\hline 737 & Fragaria moschata Duchesne & Budapest & 1952 & Siroki Zoltán & DE-siroki-09169.jpg \\
\hline 737 & Fragaria moschata Duchesne & Budapest & 1952 & Siroki Zoltán & DE-siroki-09170.jpg \\
\hline 737 & Fragaria moschata Duchesne & Budapest & 1964 & Siroki Zoltán & DE-siroki-09171.jpg \\
\hline 737 & Fragaria moschata Duchesne & Budapest & 1981 & Siroki Zoltán & DE-siroki-09172.jpg \\
\hline 737 & Fragaria moschata Duchesne & Debrecen & 1950 & Siroki Zoltán & DE-siroki-09182.jpg \\
\hline 737 & Fragaria moschata Duchesne & Debrecen & 1950 & Siroki Zoltán & DE-siroki-09175.jpg \\
\hline 737 & Fragaria moschata Duchesne & Debrecen & 1950 & Siroki Zoltán & DE-siroki-09176.jpg \\
\hline 737 & Fragaria moschata Duchesne & Debrecen & 1950 & Siroki Zoltán & DE-siroki-09179.jpg \\
\hline 737 & Fragaria moschata Duchesne & Debrecen & 1950 & Siroki Zoltán & DE-siroki-09180.jpg \\
\hline 737 & Fragaria moschata Duchesne & Debrecen & 1950 & Siroki Zoltán & DE-siroki-09177.jpg \\
\hline 737 & Fragaria moschata Duchesne & Debrecen & 1950 & Siroki Zoltán & DE-siroki-09178.jpg \\
\hline 737 & Fragaria moschata Duchesne & Debrecen & 1964 & Siroki Zoltán & DE-siroki-09173.jpg \\
\hline 737 & Fragaria moschata Duchesne & Debrecen & 1964 & Siroki Zoltán & DE-siroki-09174.jpg \\
\hline 737 & Fragaria moschata Duchesne & Hosszúhetény & 1958 & Siroki Zoltán & DE-siroki-09183.jpg \\
\hline 737 & Fragaria moschata Duchesne & Hosszúhetény & 1958 & Siroki Zoltán & DE-siroki-09184.jpg \\
\hline 738 & Fragaria vesca L. & "Mátra" & 1957 & Siroki Zoltán & DE-siroki-09191.jpg \\
\hline 738 & Fragaria vesca L. & Debrecen & 1950 & Siroki Zoltán & DE-siroki-09186.jpg \\
\hline 738 & Fragaria vesca L. & Debrecen & 1950 & Siroki Zoltán & DE-siroki-09188.jpg \\
\hline 738 & Fragaria vesca L. & Debrecen & 1950 & Siroki Zoltán & DE-siroki-09187.jpg \\
\hline 738 & Fragaria vesca L. & Debrecen & 1950 & Siroki Zoltán & DE-siroki-09190.jpg \\
\hline 738 & Fragaria vesca L. & Debrecen & 1964 & Siroki Zoltán & DE-siroki-09189.jpg \\
\hline $739-748$ & Alchemilla & "Bükk-hg." & 1960 & Siroki Zoltán & DE-siroki-09515.jpg \\
\hline
\end{tabular}




\begin{tabular}{|c|c|c|c|c|c|}
\hline $\begin{array}{l}\text { Sorszám / } \\
\text { Number }\end{array}$ & Taxon-név / Taxon-name & $\begin{array}{l}\text { Település / } \\
\text { Settlement }\end{array}$ & $\begin{array}{l}\text { Év / } \\
\text { Year }\end{array}$ & $\begin{array}{l}\text { Gyújtő / } \\
\text { Collector }\end{array}$ & Fájlnév / File-name \\
\hline $739-748$ & Alchemilla & "Bükk-hg." & 1960 & Siroki Zoltán & DE-siroki-09516.jpg \\
\hline $739-748$ & Alchemilla & "Hármaskő" & 1957 & Siroki Zoltán & DE-siroki-09513.jpg \\
\hline $739-748$ & Alchemilla & "Hármaskő" & 1957 & Siroki Zoltán & DE-siroki-09514.jpg \\
\hline $739-748$ & Alchemilla & "Háromkő" & 1957 & Siroki Zoltán & DE-siroki-09509.jpg \\
\hline $739-748$ & Alchemilla & "Háromkő" & 1957 & Siroki Zoltán & DE-siroki-09510.jpg \\
\hline $739-748$ & Alchemilla & "Háromkő" & 1957 & Siroki Zoltán & DE-siroki-09511.jpg \\
\hline $739-748$ & Alchemilla & "Háromkő" & 1957 & Siroki Zoltán & DE-siroki-09512.jpg \\
\hline $739-748$ & Alchemilla & "Nagymező" & 1957 & Siroki Zoltán & DE-siroki-09508.jpg \\
\hline $739-748$ & Alchemilla & "Nagymező" & 1957 & Siroki Zoltán & DE-siroki-09506.jpg \\
\hline $739-748$ & Alchemilla & "Nagymező" & 1957 & Siroki Zoltán & DE-siroki-09507.jpg \\
\hline $739-748$ & Alchemilla & "Nagymező" & 1959 & Halász Tibor & DE-siroki-09503.jpg \\
\hline $739-748$ & Alchemilla & "Nagymező" & 1968 & Siroki Zoltán & DE-siroki-09504.jpg \\
\hline $739-748$ & Alchemilla & "Nagymező" & 1968 & Siroki Zoltán & DE-siroki-09505.jpg \\
\hline $739-748$ & Alchemilla & "Sátor-hg." & 1967 & Siroki Zoltán & DE-siroki-09499.jpg \\
\hline $739-748$ & Alchemilla & Bükkszentkereszt & 1959 & Siroki Zoltán & DE-siroki-09517.jpg \\
\hline $739-748$ & Alchemilla & Bükkszentkereszt & 1959 & Siroki Zoltán & DE-siroki-09518.jpg \\
\hline $739-748$ & Alchemilla & Füzérradvány & 1973 & Siroki Zoltán & DE-siroki-09494.jpg \\
\hline 739-748 & Alchemilla & Füzérradvány & 1973 & Siroki Zoltán & DE-siroki-09495.jpg \\
\hline $739-748$ & Alchemilla & Füzérradvány & 1973 & Siroki Zoltán & DE-siroki-09496.jpg \\
\hline $739-748$ & Alchemilla & Füzérradvány & 1973 & Siroki Zoltán & DE-siroki-09497.jpg \\
\hline $739-748$ & Alchemilla & Háromhuta & 1977 & Siroki Zoltán & DE-siroki-09498.jpg \\
\hline $739-748$ & Alchemilla & Háromhuta & 1977 & Siroki Zoltán & DE-siroki-09502.jpg \\
\hline $739-748$ & Alchemilla & Nagyhuta & 1961 & Siroki Zoltán & DE-siroki-09501.jpg \\
\hline $739-748$ & Alchemilla & Nagyhuta & 1961 & Siroki Zoltán & DE-siroki-09500.jpg \\
\hline $739-748$ & Alchemilla & Sopron & 1950 & Kárpáti Zoltán & DE-siroki-09492.jpg \\
\hline 749 & Aphanes arvensis L. & Fényeslitke & 1965 & Siroki Zoltán & DE-siroki-09462.jpg \\
\hline 749 & Aphanes arvensis L. & Győröcske & 1965 & Gondola István & DE-siroki-09468.jpg \\
\hline 749 & Aphanes arvensis L. & Komoró & 1966 & Gondola István & DE-siroki-09461.jpg \\
\hline 749 & Aphanes arvensis L. & Vásárosnamény & 1966 & Gondola István & DE-siroki-09463.jpg \\
\hline 749 & Aphanes arvensis L. & Vásárosnamény & 1966 & Gondola István & DE-siroki-09464.jpg \\
\hline 749 & Aphanes arvensis L. & Vásárosnamény & 1966 & Gondola István & DE-siroki-09465.jpg \\
\hline 749 & Aphanes arvensis L. & Vásárosnamény & 1966 & Gondola István & DE-siroki-09466.jpg \\
\hline 749 & Aphanes arvensis L. & Záhony & 1965 & Gondola István & DE-siroki-09467.jpg \\
\hline 749 & Aphanes arvensis L. & Záhony & 1965 & Gondola István & DE-siroki-09469.jpg \\
\hline 749 & Aphanes arvensis L. & Záhony & 1965 & Gondola István & DE-siroki-09470.jpg \\
\hline 749 & Aphanes arvensis L. & Záhony & 1965 & Gondola István & DE-siroki-09471.jpg \\
\hline 749 & Aphanes arvensis L. & Záhony & 1965 & Gondola István & DE-siroki-09472.jpg \\
\hline 749 & Aphanes arvensis L. & Záhony & 1965 & Gondola István & DE-siroki-09473.jpg \\
\hline 749 & Aphanes arvensis L. & Záhony & 1965 & Gondola István & DE-siroki-09474.jpg \\
\hline 749 & Aphanes arvensis L. & Záhony & 1965 & Gondola István & DE-siroki-09475.jpg \\
\hline 749 & Aphanes arvensis L. & Záhony & 1965 & Gondola István & DE-siroki-09476.jpg \\
\hline 749 & Aphanes arvensis L. & Záhony & 1965 & Gondola István & DE-siroki-09477.jpg \\
\hline 749 & Aphanes arvensis L. & Záhony & 1965 & Gondola István & DE-siroki-09478.jpg \\
\hline 749 & Aphanes arvensis L. & Záhony & 1965 & Gondola István & DE-siroki-09479.jpg \\
\hline 749 & Aphanes arvensis L. & Záhony & 1965 & Gondola István & DE-siroki-09480.jpg \\
\hline 755 & Pyrus nivalis Jacq. & Budapest & 1873 & Simonkai Lajos & DE-siroki-08897.jpg \\
\hline
\end{tabular}




\begin{tabular}{|c|c|c|c|c|c|}
\hline $\begin{array}{l}\text { Sorszám / } \\
\text { Number }\end{array}$ & Taxon-név / Taxon-name & $\begin{array}{l}\text { Település / } \\
\text { Settlement }\end{array}$ & $\begin{array}{l}\text { Év / } \\
\text { Year }\end{array}$ & $\begin{array}{l}\text { Gyújitő / } \\
\text { Collector }\end{array}$ & Fájlnév / File-name \\
\hline 758 & Malus sylvestris (L.) Mill. & Budapest & 1952 & Siroki Zoltán & DE-siroki-08902.jpg \\
\hline 761 & Sorbus domestica L. & Budapest & 1886 & Czakó Kálmán & DE-siroki-08905.jpg \\
\hline 761 & Sorbus domestica L. & Budapest & 1950 & Siroki Zoltán & DE-siroki-08906.jpg \\
\hline 761 & Sorbus domestica L. & Budapest & 1950 & Siroki Zoltán & DE-siroki-08908.jpg \\
\hline 761 & Sorbus domestica L. & Budapest & 1954 & Siroki Zoltán & DE-siroki-08907.jpg \\
\hline 762 & Sorbus aucuparia L. & "Nagymező" & 1958 & Siroki Zoltán & DE-siroki-08909.jpg \\
\hline 762 & Sorbus aucuparia L. & "Nagymező" & 1958 & Siroki Zoltán & DE-siroki-08910.jpg \\
\hline 762 & Sorbus aucuparia L. & "Nagymező" & 1958 & Siroki Zoltán & DE-siroki-08911.jpg \\
\hline 762 & Sorbus aucuparia L. & Solymár & 1918 & Degen Árpád & DE-siroki-08904.jpg \\
\hline 763 & Sorbus aria (L.) Crantz & "Nagymező" & 1973 & Siroki Zoltán & DE-siroki-08937.jpg \\
\hline 763 & Sorbus aria (L.) Crantz & "Nagymező" & 1973 & Siroki Zoltán & DE-siroki-08938.jpg \\
\hline 763 & Sorbus aria (L.) Crantz & "Nagymező" & 1973 & Siroki Zoltán & DE-siroki-08939.jpg \\
\hline 763 & Sorbus aria (L.) Crantz & Budapest & 1904 & Kocsis István & DE-siroki-08936.jpg \\
\hline 764 & Sorbus graeca (Spach) Kotschy & "Háromkő" & - & Siroki Zoltán & DE-siroki-08964.jpg \\
\hline 764 & Sorbus graeca (Spach) Kotschy & Bélapátfalva & 1958 & Siroki Zoltán & DE-siroki-08965.jpg \\
\hline 768 & Sorbus danubialis (Jáv.) Kárpáti & "Nagymező" & - & Siroki Zoltán & DE-siroki-08963.jpg \\
\hline 768 & Sorbus danubialis (Jáv.) Kárpáti & "Szent-György-hegy" & 1955 & Siroki Zoltán & DE-siroki-08954.jpg \\
\hline 768 & Sorbus danubialis (Jáv.) Kárpáti & "Szent-György-hegy" & 1955 & Siroki Zoltán & DE-siroki-08953.jpg \\
\hline 768 & Sorbus danubialis (Jáv.) Kárpáti & Budapest & 1941 & Siroki Zoltán & DE-siroki-08969.jpg \\
\hline 768 & Sorbus danubialis (Jáv.) Kárpáti & Budapest & 1950 & Siroki Zoltán & DE-siroki-08970.jpg \\
\hline 768 & Sorbus danubialis (Jáv.) Kárpáti & Budapest & 1950 & Siroki Zoltán & DE-siroki-08974.jpg \\
\hline 768 & Sorbus danubialis (Jáv.) Kárpáti & Budapest & 1950 & Siroki Zoltán & DE-siroki-08976.jpg \\
\hline 768 & Sorbus danubialis (Jáv.) Kárpáti & Budapest & 1950 & Siroki Zoltán & DE-siroki-08967.jpg \\
\hline 768 & Sorbus danubialis (Jáv.) Kárpáti & Budapest & 1950 & Siroki Zoltán & DE-siroki-08968.jpg \\
\hline 768 & Sorbus danubialis (Jáv.) Kárpáti & Budapest & 1950 & Siroki Zoltán & DE-siroki-08972.jpg \\
\hline 768 & Sorbus danubialis (Jáv.) Kárpáti & Budapest & 1950 & Siroki Zoltán & DE-siroki-08973.jpg \\
\hline 768 & Sorbus danubialis (Jáv.) Kárpáti & Budapest & 1951 & Siroki Zoltán & DE-siroki-08966.jpg \\
\hline 768 & Sorbus danubialis (Jáv.) Kárpáti & Budapest & 1957 & Siroki Zoltán & DE-siroki-08955.jpg \\
\hline 768 & Sorbus danubialis (Jáv.) Kárpáti & Budapest & 1957 & Siroki Zoltán & DE-siroki-08971.jpg \\
\hline 768 & Sorbus danubialis (Jáv.) Kárpáti & Budapest & 1957 & Siroki Zoltán & DE-siroki-08975.jpg \\
\hline 768 & Sorbus danubialis (Jáv.) Kárpáti & Budapest & 1957 & Siroki Zoltán & DE-siroki-08977.jpg \\
\hline 768 & Sorbus danubialis (Jáv.) Kárpáti & Budapest & 1983 & Siroki Zoltán & DE-siroki-08956.jpg \\
\hline 768 & Sorbus danubialis (Jáv.) Kárpáti & Budapest & 1984 & Siroki Zoltán & DE-siroki-08957.jpg \\
\hline 768 & Sorbus danubialis (Jáv.) Kárpáti & Gyenesdiás & 1953 & Siroki Zoltán & DE-siroki-08978.jpg \\
\hline 768 & Sorbus danubialis (Jáv.) Kárpáti & Gyenesdiás & 1955 & Siroki Zoltán & DE-siroki-08979.jpg \\
\hline 768 & Sorbus danubialis (Jáv.) Kárpáti & Gyenesdiás & 1955 & Siroki Zoltán & DE-siroki-08980.jpg \\
\hline 768 & Sorbus danubialis (Jáv.) Kárpáti & Tatabánya & 1928 & Rigler József & DE-siroki-08952.jpg \\
\hline 768 & Sorbus danubialis (Jáv.) Kárpáti & Tatabánya & 1928 & Rigler József & DE-siroki-08950.jpg \\
\hline 768 & Sorbus danubialis (Jáv.) Kárpáti & Tatabánya & 1928 & Rigler József & DE-siroki-08951.jpg \\
\hline 772 & Sorbus torminalis (L.) Crantz & "Vértes" & 1957 & Siroki Zoltán & DE-siroki-08925.jpg \\
\hline 772 & Sorbus torminalis (L.) Crantz & "Vértes" & 1957 & Siroki Zoltán & DE-siroki-08926.jpg \\
\hline 772 & Sorbus torminalis (L.) Crantz & Budapest & 1904 & Kocsis István & DE-siroki-08924.jpg \\
\hline 772 & Sorbus torminalis (L.) Crantz & Budapest & 1912 & Bocskay Ottó & DE-siroki-08923.jpg \\
\hline 772 & Sorbus torminalis (L.) Crantz & Budapest & 1950 & Siroki Zoltán & DE-siroki-08914.jpg \\
\hline 772 & Sorbus torminalis (L.) Crantz & Budapest & 1950 & Siroki Zoltán & DE-siroki-08922.jpg \\
\hline 772 & Sorbus torminalis (L.) Crantz & Budapest & 1950 & Siroki Zoltán & DE-siroki-08919.jpg \\
\hline
\end{tabular}




\begin{tabular}{|c|c|c|c|c|c|}
\hline $\begin{array}{l}\text { Sorszám / } \\
\text { Number }\end{array}$ & Taxon-név / Taxon-name & $\begin{array}{l}\text { Település / } \\
\text { Settlement }\end{array}$ & $\begin{array}{l}\text { Év / } \\
\text { Year }\end{array}$ & $\begin{array}{l}\text { Gyüjtő / } \\
\text { Collector }\end{array}$ & Fájlnév / File-name \\
\hline 772 & Sorbus torminalis (L.) Crantz & Budapest & 1950 & Siroki Zoltán & DE-siroki-08918.jpg \\
\hline 772 & Sorbus torminalis (L.) Crantz & Budapest & 1950 & Siroki Zoltán & DE-siroki-08915.jpg \\
\hline 772 & Sorbus torminalis (L.) Crantz & Budapest & 1950 & Siroki Zoltán & DE-siroki-08916.jpg \\
\hline 772 & Sorbus torminalis (L.) Crantz & Budapest & 1950 & Siroki Zoltán & DE-siroki-08917.jpg \\
\hline 772 & Sorbus torminalis (L.) Crantz & Budapest & 1964 & Siroki Zoltán & DE-siroki-08920.jpg \\
\hline 772 & Sorbus torminalis (L.) Crantz & Budapest & 1964 & Siroki Zoltán & DE-siroki-08921.jpg \\
\hline 785 & Sorbus balatonica Kárpáti & Cserszegtomaj & 1930 & Rigler József & DE-siroki-08947.jpg \\
\hline 785 & Sorbus balatonica Kárpáti & Cserszegtomaj & 1930 & Rigler József & DE-siroki-08948.jpg \\
\hline 785 & Sorbus balatonica Kárpáti & Gyenesdiás & 1953 & Siroki Zoltán & DE-siroki-08960.jpg \\
\hline 785 & Sorbus balatonica Kárpáti & Gyenesdiás & 1955 & Siroki Zoltán & DE-siroki-08959.jpg \\
\hline 785 & Sorbus balatonica Kárpáti & Gyenesdiás & 1955 & Siroki Zoltán & DE-siroki-08961.jpg \\
\hline 785 & Sorbus balatonica Kárpáti & Gyenesdiás & 1955 & Siroki Zoltán & DE-siroki-08962.jpg \\
\hline 785 & Sorbus balatonica Kárpáti & Vonyarcvashegy & 1927 & Jávorka Sándor & DE-siroki-08949.jpg \\
\hline 793 & Sorbus bakonyensis (Jáv.) Kárpáti & "Szent-György-hegy" & 1955 & Siroki Zoltán & DE-siroki-08942.jpg \\
\hline 793 & Sorbus bakonyensis (Jáv.) Kárpáti & "Szent-György-hegy" & 1955 & Siroki Zoltán & DE-siroki-08944.jpg \\
\hline 793 & Sorbus bakonyensis (Jáv.) Kárpáti & "Szent-György-hegy" & 1955 & Siroki Zoltán & DE-siroki-08945.jpg \\
\hline 793 & Sorbus bakonyensis (Jáv.) Kárpáti & "Szent-György-hegy" & 1955 & Siroki Zoltán & DE-siroki-08946.jpg \\
\hline 793 & Sorbus bakonyensis (Jáv.) Kárpáti & Gyenesdiás & 1953 & Siroki Zoltán & DE-siroki-08943.jpg \\
\hline 801 & Sorbus semiincisa Borbás & Budapest & 1887 & Czakó Kálmán & DE-siroki-08935.jpg \\
\hline 801 & Sorbus semiincisa Borbás & Budapest & 1909 & $\begin{array}{l}\text { Kümmerle J. } \\
\text { Béla }\end{array}$ & DE-siroki-08927.jpg \\
\hline 801 & Sorbus semiincisa Borbás & Budapest & 1950 & Siroki Zoltán & DE-siroki-08932.jpg \\
\hline 801 & Sorbus semiincisa Borbás & Budapest & 1950 & Siroki Zoltán & DE-siroki-08933.jpg \\
\hline 801 & Sorbus semiincisa Borbás & Budapest & 1950 & Siroki Zoltán & DE-siroki-08934.jpg \\
\hline 801 & Sorbus semiincisa Borbás & Budapest & 1950 & Siroki Zoltán & DE-siroki-08931.jpg \\
\hline 801 & Sorbus semiincisa Borbás & Budapest & 1984 & Siroki Zoltán & DE-siroki-08929.jpg \\
\hline 801 & Sorbus semiincisa Borbás & Budapest & 1984 & Siroki Zoltán & DE-siroki-08930.jpg \\
\hline 801 & Sorbus semiincisa Borbás & Budapest & 1984 & Siroki Zoltán & DE-siroki-08928.jpg \\
\hline---- & $\begin{array}{l}\text { Sorbus } \times \text { semipinnata (Roth) Hedl. } \\
\text { (S. aria s. str. } \times \text { aucuparia) }\end{array}$ & Mályinka & 1951 & Kárpáti Zoltán & DE-siroki-08981.jpg \\
\hline--- & Sorbus $\times$ rotundifolia $\mathrm{cv}$ & Miskolc & 1951 & Kárpáti Zoltán & DE-siroki-08982.jpg \\
\hline 808 & Amelanchier ovalis Medik. & Bakonykúti & 1950 & Kárpáti Zoltán & DE-siroki-08984.jpg \\
\hline 808 & Amelanchier ovalis Medik. & Gánt & 1950 & Kárpáti Zoltán & DE-siroki-08985.jpg \\
\hline 809 & Cotoneaster tomentosus (Aiton) Lindl. & "Fáni-völgy" & 1955 & $\begin{array}{l}\text { Siroki Zoltán - } \\
\text { Farkas Attila }\end{array}$ & DE-siroki-08856.jpg \\
\hline 809 & Cotoneaster tomentosus (Aiton) Lindl. & "Szent-György-hegy" & 1955 & Siroki Zoltán & DE-siroki-08861.jpg \\
\hline 809 & Cotoneaster tomentosus (Aiton) Lindl. & Gyenesdiás & 1953 & Siroki Zoltán & DE-siroki-08859.jpg \\
\hline 809 & Cotoneaster tomentosus (Aiton) Lindl. & Gyenesdiás & 1953 & Siroki Zoltán & DE-siroki-08854.jpg \\
\hline 809 & Cotoneaster tomentosus (Aiton) Lindl. & Gyenesdiás & 1953 & Siroki Zoltán & DE-siroki-08855.jpg \\
\hline 809 & Cotoneaster tomentosus (Aiton) Lindl. & Gyenesdiás & 1953 & Siroki Zoltán & DE-siroki-08857.jpg \\
\hline 809 & Cotoneaster tomentosus (Aiton) Lindl. & Gyenesdiás & 1953 & Siroki Zoltán & DE-siroki-08858.jpg \\
\hline 809 & Cotoneaster tomentosus (Aiton) Lindl. & Gyenesdiás & 1955 & Siroki Zoltán & DE-siroki-08860.jpg \\
\hline 809 & Cotoneaster tomentosus (Aiton) Lindl. & Keszthely & 1950 & Kárpáti Zoltán & DE-siroki-08862.jpg \\
\hline 811 & Cotoneaster integerrimus Medik. & "Dobogókő" & 1965 & Siroki Zoltán & DE-siroki-08874.jpg \\
\hline 811 & Cotoneaster integerrimus Medik. & "Dobogókő" & 1965 & Siroki Zoltán & DE-siroki-08875.jpg \\
\hline 811 & Cotoneaster integerrimus Medik. & "Dobogókő" & 1965 & Siroki Zoltán & DE-siroki-08876.jpg \\
\hline 811 & Cotoneaster integerrimus Medik. & "Szent-György-hegy" & 1955 & Siroki Zoltán & DE-siroki-08883.jpg \\
\hline 811 & Cotoneaster integerrimus Medik. & "Szent-György-hegy" & 1955 & Siroki Zoltán & DE-siroki-08886.jpg \\
\hline
\end{tabular}




\begin{tabular}{|c|c|c|c|c|c|}
\hline $\begin{array}{l}\text { Sorszám / } \\
\text { Number }\end{array}$ & Taxon-név / Taxon-name & $\begin{array}{l}\text { Település / } \\
\text { Settlement }\end{array}$ & $\begin{array}{l}\text { Év / } \\
\text { Year }\end{array}$ & $\begin{array}{l}\text { Gyüjtő / } \\
\text { Collector }\end{array}$ & Fájlnév / File-name \\
\hline 811 & Cotoneaster integerrimus Medik. & "Szent-György-hegy" & 1955 & Siroki Zoltán & DE-siroki-08880.jpg \\
\hline 811 & Cotoneaster integerrimus Medik. & "Szent-György-hegy" & 1955 & Siroki Zoltán & DE-siroki-08881.jpg \\
\hline 811 & Cotoneaster integerrimus Medik. & "Szent-György-hegy" & 1955 & Siroki Zoltán & DE-siroki-08882.jpg \\
\hline 811 & Cotoneaster integerrimus Medik. & "Szent-György-hegy" & 1955 & Siroki Zoltán & DE-siroki-08885.jpg \\
\hline 811 & Cotoneaster integerrimus Medik. & Bakonykúti & 1950 & Kárpáti Zoltán & DE-siroki-08884.jpg \\
\hline 811 & Cotoneaster integerrimus Medik. & Gyenesdiás & 1953 & Siroki Zoltán & DE-siroki-08873.jpg \\
\hline 811 & Cotoneaster integerrimus Medik. & Gyenesdiás & 1953 & Siroki Zoltán & DE-siroki-08870.jpg \\
\hline 811 & Cotoneaster integerrimus Medik. & Gyenesdiás & 1953 & Siroki Zoltán & DE-siroki-08871.jpg \\
\hline 811 & Cotoneaster integerrimus Medik. & Gyenesdiás & 1953 & Siroki Zoltán & DE-siroki-08872.jpg \\
\hline 811 & Cotoneaster integerrimus Medik. & Gyenesdiás & 1953 & Siroki Zoltán & DE-siroki-08867.jpg \\
\hline 811 & Cotoneaster integerrimus Medik. & Gyenesdiás & 1953 & Siroki Zoltán & DE-siroki-08868.jpg \\
\hline 811 & Cotoneaster integerrimus Medik. & Gyenesdiás & 1953 & Siroki Zoltán & DE-siroki-08869.jpg \\
\hline 811 & Cotoneaster integerrimus Medik. & Szilvásvárad & 1965 & Siroki Zoltán & DE-siroki-08877.jpg \\
\hline 811 & Cotoneaster integerrimus Medik. & Szilvásvárad & 1965 & Siroki Zoltán & DE-siroki-08878.jpg \\
\hline 811 & Cotoneaster integerrimus Medik. & Szilvásvárad & 1965 & Siroki Zoltán & DE-siroki-08879.jpg \\
\hline 813 & Crataegus nigra Waldst. et Kit. & Dunaújváros & 1950 & Kárpáti Zoltán & DE-siroki-09005.jpg \\
\hline 813 & Crataegus nigra Waldst. et Kit. & Szarvaskő & 1957 & Siroki Zoltán & DE-siroki-08891.jpg \\
\hline 813 & Crataegus nigra Waldst. et Kit. & Szarvaskő & 1957 & Siroki Zoltán & DE-siroki-08890.jpg \\
\hline 813 & Crataegus nigra Waldst. et Kit. & Szarvaskő & 1966 & Siroki Zoltán & DE-siroki-08887.jpg \\
\hline 813 & Crataegus nigra Waldst. et Kit. & Szarvaskő & 1966 & Siroki Zoltán & DE-siroki-08888.jpg \\
\hline 813 & Crataegus nigra Waldst. et Kit. & Szarvaskő & 1966 & Siroki Zoltán & DE-siroki-08889.jpg \\
\hline 813 & Crataegus nigra Waldst. et Kit. & Szigetszentmárton & 1951 & Siroki Zoltán & DE-siroki-09002.jpg \\
\hline 813 & Crataegus nigra Waldst. et Kit. & Szigetszentmárton & 1951 & Siroki Zoltán & DE-siroki-09001.jpg \\
\hline 813 & Crataegus nigra Waldst. et Kit. & Szigetújfalu & 1871 & Tauscher Gyula & DE-siroki-09003.jpg \\
\hline 813 & Crataegus nigra Waldst. et Kit. & Szigetújfalu & 1928 & Rigler József & DE-siroki-09004.jpg \\
\hline 813 & Crataegus nigra Waldst. et Kit. & Tar & 1951 & Kárpáti Zoltán & DE-siroki-08893.jpg \\
\hline 813 & Crataegus nigra Waldst. et Kit. & Tar & 1951 & Kárpáti Zoltán & DE-siroki-08892.jpg \\
\hline 814 & Crataegus laevigata (Poir.) DC. & Budapest & 1952 & Siroki Zoltán & DE-siroki-08990.jpg \\
\hline 814 & Crataegus laevigata (Poir.) DC. & Budapest & 1952 & Siroki Zoltán & DE-siroki-08995.jpg \\
\hline 814 & Crataegus laevigata (Poir.) DC. & Budapest & 1952 & Siroki Zoltán & DE-siroki-08994.jpg \\
\hline 814 & Crataegus laevigata (Poir.) DC. & Sopron & 1956 & Kovács Béla & DE-siroki-08993.jpg \\
\hline 814 & Crataegus laevigata (Poir.) DC. & Szanda & 1955 & Máthé Imre & DE-siroki-08992.jpg \\
\hline 815 & Crataegus monogyna Jacq. & Debrecen & 1947 & Siroki Zoltán & DE-siroki-08996.jpg \\
\hline 815 & Crataegus monogyna Jacq. & Debrecen & 1947 & Siroki Zoltán & DE-siroki-08997.jpg \\
\hline $814 \times 815$ & $\begin{array}{l}\text { Crataegus } \times \text { media Bechst. } \\
(\text { C. laevigata } \times \text { monogyna) }\end{array}$ & Sopron & 1951 & Kárpáti Zoltán & DE-siroki-09006.jpg \\
\hline---- & $\begin{array}{l}\text { Crataegus pentagyna } \\
\text { Waldst. et Kit. ex Willd. }\end{array}$ & Dunaújváros & 1950 & Kárpáti Zoltán & DE-siroki-09000.jpg \\
\hline 817 & Padus avium Mill. & Gyenesdiás & 1955 & Siroki Zoltán & DE-siroki-09704.jpg \\
\hline 819 & Cerasus mahaleb (L.) Mill. & Budapest & 1952 & Siroki Zoltán & DE-siroki-09710.jpg \\
\hline 819 & Cerasus mahaleb (L.) Mill. & Szarvaskő & 1966 & Siroki Zoltán & DE-siroki-09709.jpg \\
\hline 821 & Cerasus fruticosa (Pall.) Woronow & Abaújszántó & 1943 & Siroki Zoltán & DE-siroki-09730.jpg \\
\hline 821 & Cerasus fruticosa (Pall.) Woronow & Biatorbágy & 1950 & Siroki Zoltán & DE-siroki-09722.jpg \\
\hline 821 & Cerasus fruticosa (Pall.) Woronow & Budapest & 1964 & Siroki Zoltán & DE-siroki-09711.jpg \\
\hline 821 & Cerasus fruticosa (Pall.) Woronow & Budapest & 1964 & Siroki Zoltán & DE-siroki-09712.jpg \\
\hline 821 & Cerasus fruticosa (Pall.) Woronow & Budapest & 1964 & Siroki Zoltán & DE-siroki-09713.jpg \\
\hline 821 & Cerasus fruticosa (Pall.) Woronow & Budapest & 1964 & Siroki Zoltán & DE-siroki-09714.jpg \\
\hline
\end{tabular}




\begin{tabular}{|c|c|c|c|c|c|}
\hline $\begin{array}{l}\text { Sorszám / } \\
\text { Number }\end{array}$ & Taxon-név / Taxon-name & $\begin{array}{l}\text { Település / } \\
\text { Settlement }\end{array}$ & $\begin{array}{l}\text { Év / } \\
\text { Year }\end{array}$ & $\begin{array}{l}\text { Gyűjtő / } \\
\text { Collector }\end{array}$ & Fájlnév / File-name \\
\hline 821 & Cerasus fruticosa (Pall.) Woronow & Budapest & 1964 & Siroki Zoltán & DE-siroki-09715.jpg \\
\hline 821 & Cerasus fruticosa (Pall.) Woronow & Cserszegtomaj & 1955 & Siroki Zoltán & DE-siroki-09727.jpg \\
\hline 821 & Cerasus fruticosa (Pall.) Woronow & Cserszegtomaj & 1955 & Siroki Zoltán & DE-siroki-09728.jpg \\
\hline 821 & Cerasus fruticosa (Pall.) Woronow & Cserszegtomaj & 1955 & Siroki Zoltán & DE-siroki-09729.jpg \\
\hline 821 & Cerasus fruticosa (Pall.) Woronow & Szilvásvárad & 1959 & Siroki Zoltán & DE-siroki-09720.jpg \\
\hline 821 & Cerasus fruticosa (Pall.) Woronow & Szilvásvárad & 1959 & Siroki Zoltán & DE-siroki-09721.jpg \\
\hline 821 & Cerasus fruticosa (Pall.) Woronow & Szilvásvárad & 1962 & Siroki Zoltán & DE-siroki-09716.jpg \\
\hline 821 & Cerasus fruticosa (Pall.) Woronow & Szilvásvárad & 1962 & Siroki Zoltán & DE-siroki-09717.jpg \\
\hline 821 & Cerasus fruticosa (Pall.) Woronow & Szilvásvárad & 1962 & Siroki Zoltán & DE-siroki-09718.jpg \\
\hline 821 & Cerasus fruticosa (Pall.) Woronow & Szilvásvárad & 1962 & Siroki Zoltán & DE-siroki-09719.jpg \\
\hline 824 & Amygdalus nana L. & Abaújszántó & 1943 & Siroki Zoltán & DE-siroki-09738.jpg \\
\hline 824 & Amygdalus nana L. & Abaújszántó & 1944 & Siroki Zoltán & DE-siroki-09739.jpg \\
\hline 824 & Amygdalus nana L. & Budapest & 1951 & Siroki Zoltán & DE-siroki-09736.jpg \\
\hline 824 & Amygdalus nana L. & Egyek & 1958 & Siroki Zoltán & DE-siroki-09735.jpg \\
\hline 824 & Amygdalus nana L. & Tokaj & 1966 & Siroki Zoltán & DE-siroki-09737.jpg \\
\hline 828 & Prunus cerasifera Ehrh. & Debrecen & 1985 & Siroki Zoltán & DE-siroki-09741.jpg \\
\hline 835 & Lembotropis nigricans (L.) Griseb. & Budapest & 1985 & Siroki Zoltán & DE-siroki-09614.jpg \\
\hline 835 & Lembotropis nigricans (L.) Griseb. & Budapest & 1985 & Siroki Zoltán & DE-siroki-09615.jpg \\
\hline 835 & Lembotropis nigricans (L.) Griseb. & Szilvásvárad & 1954 & Siroki Zoltán & DE-siroki-09616.jpg \\
\hline 835 & Lembotropis nigricans (L.) Griseb. & Szilvásvárad & 1954 & Siroki Zoltán & DE-siroki-09617.jpg \\
\hline 836 & $\begin{array}{l}\text { Sarothamnus scoparius } \\
\text { (L.) Wimm. ex W.D.J. Koch }\end{array}$ & Aszaló & 1944 & Siroki Zoltán & DE-siroki-09630.jpg \\
\hline 836 & $\begin{array}{l}\text { Sarothamnus scoparius } \\
\text { (L.) Wimm. ex W.D.J. Koch }\end{array}$ & Aszaló & 1944 & Siroki Zoltán & DE-siroki-09631.jpg \\
\hline 836 & $\begin{array}{l}\text { Sarothamnus scoparius } \\
\text { (L.) Wimm. ex W.D.J. Koch }\end{array}$ & Debrecen & 1948 & Siroki Zoltán & DE-siroki-09628.jpg \\
\hline 836 & $\begin{array}{l}\text { Sarothamnus scoparius } \\
\text { (L.) Wimm. ex W.D.J. Koch }\end{array}$ & Debrecen & 1949 & Siroki Zoltán & DE-siroki-09626.jpg \\
\hline 836 & $\begin{array}{l}\text { Sarothamnus scoparius } \\
\text { (L.) Wimm. ex W.D.J. Koch }\end{array}$ & Debrecen & 1949 & Siroki Zoltán & DE-siroki-09627.jpg \\
\hline 836 & $\begin{array}{l}\text { Sarothamnus scoparius } \\
\text { (L.) Wimm. ex W.D.J. Koch }\end{array}$ & Debrecen & 1949 & Siroki Zoltán & DE-siroki-09629.jpg \\
\hline 836 & $\begin{array}{l}\text { Sarothamnus scoparius } \\
\text { (L.) Wimm. ex W.D.J. Koch }\end{array}$ & Téglás & 1967 & Siroki Zoltán & DE-siroki-09624.jpg \\
\hline 836 & $\begin{array}{l}\text { Sarothamnus scoparius } \\
\text { (L.) Wimm. ex W.D.J. Koch }\end{array}$ & Téglás & - & Siroki Zoltán & DE-siroki-09625.jpg \\
\hline 837 & $\begin{array}{l}\text { Corothamnus procumbens } \\
\text { (Waldst. et Kit.) C. Presl }\end{array}$ & Aggtelek & 1941 & Siroki Zoltán & DE-siroki-09623.jpg \\
\hline 837 & $\begin{array}{l}\text { Corothamnus procumbens } \\
\text { (Waldst. et Kit.) C. Presl }\end{array}$ & Budapest & 1951 & Siroki Zoltán & DE-siroki-09619.jpg \\
\hline 838 & Chamaecytisus supinus (L.) Link & Budapest & 1888 & Czakó Kálmán & DE-siroki-09781.jpg \\
\hline 838.2 & $\begin{array}{l}\text { Chamaecytisus supinus (L.) Link } \\
\text { subsp. aggregatus (Schur) A et D Löve }\end{array}$ & "Dobogókő" & 1957 & Siroki Zoltán & DE-siroki-09765.jpg \\
\hline 838.2 & $\begin{array}{l}\text { Chamaecytisus supinus (L.) Link } \\
\text { subsp. aggregatus (Schur) A et D Löve }\end{array}$ & "Dobogókő" & 1957 & Siroki Zoltán & DE-siroki-09771.jpg \\
\hline 838.2 & $\begin{array}{l}\text { Chamaecytisus supinus (L.) Link } \\
\text { subsp. aggregatus (Schur) A et D Löve }\end{array}$ & "Dobogókő" & 1965 & Siroki Zoltán & DE-siroki-09766.jpg \\
\hline 838.2 & $\begin{array}{l}\text { Chamaecytisus supinus (L.) Link } \\
\text { subsp. aggregatus (Schur) A et D Löve }\end{array}$ & "Dobogókő" & 1965 & Siroki Zoltán & DE-siroki-09767.jpg \\
\hline 838.2 & $\begin{array}{l}\text { Chamaecytisus supinus (L.) Link } \\
\text { subsp. aggregatus (Schur) A et D Löve }\end{array}$ & "Dobogókő" & 1965 & Siroki Zoltán & DE-siroki-09768.jpg \\
\hline 838.2 & $\begin{array}{l}\text { Chamaecytisus supinus (L.) Link } \\
\text { subsp. aggregatus (Schur) A et D Löve }\end{array}$ & "Dobogókő" & 1965 & Siroki Zoltán & DE-siroki-09769.jpg \\
\hline 838.2 & $\begin{array}{l}\text { Chamaecytisus supinus (L.) Link } \\
\text { subsp. aggregatus (Schur) A et D Löve }\end{array}$ & "Dobogókő" & 1965 & Siroki Zoltán & DE-siroki-09770.jpg \\
\hline
\end{tabular}




\begin{tabular}{|c|c|c|c|c|c|}
\hline $\begin{array}{l}\text { Sorszám / } \\
\text { Number }\end{array}$ & Taxon-név / Taxon-name & $\begin{array}{l}\text { Település / } \\
\text { Settlement }\end{array}$ & $\begin{array}{l}\text { Év / } \\
\text { Year }\end{array}$ & $\begin{array}{l}\text { Gyújtő / } \\
\text { Collector }\end{array}$ & Fájlnév / File-name \\
\hline 838.2 & $\begin{array}{l}\text { Chamaecytisus supinus (L.) Link } \\
\text { subsp. aggregatus (Schur) A et D Löve }\end{array}$ & Budapest & 1907 & Butujás Gyula & DE-siroki-09780.jpg \\
\hline 838.2 & $\begin{array}{l}\text { Chamaecytisus supinus (L.) Link } \\
\text { subsp. aggregatus (Schur) A et D Löve }\end{array}$ & Budapest & 1909 & Kocsis István & DE-siroki-09779.jpg \\
\hline 838.2 & $\begin{array}{l}\text { Chamaecytisus supinus (L.) Link } \\
\text { subsp. aggregatus (Schur) A et D Löve }\end{array}$ & Budapest & 1941 & Siroki Zoltán & DE-siroki-09776.jpg \\
\hline 838.2 & $\begin{array}{l}\text { Chamaecytisus supinus (L.) Link } \\
\text { subsp. aggregatus (Schur) A et D Löve }\end{array}$ & Budapest & 1948 & Siroki Zoltán & DE-siroki-09778.jpg \\
\hline 838.2 & $\begin{array}{l}\text { Chamaecytisus supinus (L.) Link } \\
\text { subsp. aggregatus (Schur) A et D Löve }\end{array}$ & Budapest & 1951 & Siroki Zoltán & DE-siroki-09777.jpg \\
\hline 838.2 & $\begin{array}{l}\text { Chamaecytisus supinus (L.) Link } \\
\text { subsp. aggregatus (Schur) A et D Löve }\end{array}$ & Budapest & 1983 & Siroki Zoltán & DE-siroki-09773.jpg \\
\hline 838.2 & $\begin{array}{l}\text { Chamaecytisus supinus (L.) Link } \\
\text { subsp. aggregatus (Schur) A et D Löve }\end{array}$ & Budapest & 1983 & Siroki Zoltán & DE-siroki-09774.jpg \\
\hline 838.2 & $\begin{array}{l}\text { Chamaecytisus supinus (L.) Link } \\
\text { subsp. aggregatus (Schur) A et D Löve }\end{array}$ & Budapest & 1983 & Siroki Zoltán & DE-siroki-09775.jpg \\
\hline 838.2 & $\begin{array}{l}\text { Chamaecytisus supinus (L.) Link } \\
\text { subsp. aggregatus (Schur) A et D Löve }\end{array}$ & Budapest & 1984 & Siroki Zoltán & DE-siroki-09772.jpg \\
\hline 838.2 & $\begin{array}{l}\text { Chamaecytisus supinus (L.) Link } \\
\text { subsp. aggregatus (Schur) A et D Löve }\end{array}$ & Lábatlan & 1986 & Siroki Zoltán & DE-siroki-09782.jpg \\
\hline 839 & $\begin{array}{l}\text { Chamaecytisus virescens } \\
\text { (Kováts ex Neilr.) Dostál }\end{array}$ & Budapest & 1941 & Siroki Zoltán & DE-siroki-09818.jpg \\
\hline 839 & $\begin{array}{l}\text { Chamaecytisus virescens } \\
\text { (Kováts ex Neilr.) Dostál }\end{array}$ & Pásztó & 1952 & Siroki Zoltán & DE-siroki-09819.jpg \\
\hline 840 & $\begin{array}{l}\text { Chamaecytisus rochelii } \\
\text { (Wierzb.) Rothm. }\end{array}$ & Debrecen & 1917 & $\begin{array}{l}\text { Rapaics } \\
\text { Rajmund }\end{array}$ & DE-siroki-09859.jpg \\
\hline 840 & $\begin{array}{l}\text { Chamaecytisus rochelii } \\
\text { (Wierzb.) Rothm. }\end{array}$ & Tokaj & 1966 & Siroki Zoltán & DE-siroki-09797.jpg \\
\hline 840 & $\begin{array}{l}\text { Chamaecytisus rochelii } \\
\text { (Wierzb.) Rothm. }\end{array}$ & Tokaj & 1966 & Siroki Zoltán & DE-siroki-09798.jpg \\
\hline 840 & $\begin{array}{l}\text { Chamaecytisus rochelii } \\
\text { (Wierzb.) Rothm. }\end{array}$ & Tokaj & 1966 & Siroki Zoltán & DE-siroki-09799.jpg \\
\hline 840 & $\begin{array}{l}\text { Chamaecytisus rochelii } \\
\text { (Wierzb.) Rothm. }\end{array}$ & Tokaj & 1966 & Siroki Zoltán & DE-siroki-09800.jpg \\
\hline 840 & $\begin{array}{l}\text { Chamaecytisus rochelii } \\
\text { (Wierzb.) Rothm. }\end{array}$ & Tokaj & 1966 & Siroki Zoltán & DE-siroki-09801.jpg \\
\hline 841 & Chamaecytisus albus (Hacq.) Rothm. & Háromhuta & 1960 & Siroki Zoltán & DE-siroki-09790.jpg \\
\hline 841 & Chamaecytisus albus (Hacq.) Rothm. & Háromhuta & 1960 & Siroki Zoltán & DE-siroki-09791.jpg \\
\hline 841 & Chamaecytisus albus (Hacq.) Rothm. & Háromhuta & 1961 & Siroki Zoltán & DE-siroki-09792.jpg \\
\hline 841 & Chamaecytisus albus (Hacq.) Rothm. & Háromhuta & 1961 & Siroki Zoltán & DE-siroki-09793.jpg \\
\hline 841 & Chamaecytisus albus (Hacq.) Rothm. & Háromhuta & 1961 & Siroki Zoltán & DE-siroki-09794.jpg \\
\hline 841 & Chamaecytisus albus (Hacq.) Rothm. & Háromhuta & 1961 & Siroki Zoltán & DE-siroki-09795.jpg \\
\hline 841 & Chamaecytisus albus (Hacq.) Rothm. & Háromhuta & 1962 & Siroki Zoltán & DE-siroki-09789.jpg \\
\hline 841 & Chamaecytisus albus (Hacq.) Rothm. & Háromhuta & 1968 & Siroki Zoltán & DE-siroki-09787.jpg \\
\hline 841 & Chamaecytisus albus (Hacq.) Rothm. & Háromhuta & 1968 & Siroki Zoltán & DE-siroki-09788.jpg \\
\hline 841 & Chamaecytisus albus (Hacq.) Rothm. & Háromhuta & 1968 & Siroki Zoltán & DE-siroki-09783.jpg \\
\hline 841 & Chamaecytisus albus (Hacq.) Rothm. & Háromhuta & 1968 & Siroki Zoltán & DE-siroki-09784.jpg \\
\hline 841 & Chamaecytisus albus (Hacq.) Rothm. & Háromhuta & 1968 & Siroki Zoltán & DE-siroki-09785.jpg \\
\hline 841 & Chamaecytisus albus (Hacq.) Rothm. & Háromhuta & 1968 & Siroki Zoltán & DE-siroki-09786.jpg \\
\hline 842 & Chamaecytisus austriacus (L.) Link & Abaújszántó & 1943 & Siroki Zoltán & DE-siroki-09817.jpg \\
\hline 842 & Chamaecytisus austriacus (L.) Link & Abaújszántó & 1944 & Siroki Zoltán & DE-siroki-09815.jpg \\
\hline 842 & Chamaecytisus austriacus (L.) Link & Abaújszántó & 1944 & Siroki Zoltán & DE-siroki-09816.jpg \\
\hline 842 & Chamaecytisus austriacus (L.) Link & Boldogkőváralja & 1943 & Siroki Zoltán & DE-siroki-09814.jpg \\
\hline 842 & Chamaecytisus austriacus (L.) Link & Boldogkőváralja & 1944 & Siroki Zoltán & DE-siroki-09811.jpg \\
\hline 842 & Chamaecytisus austriacus (L.) Link & Boldogkőváralja & 1944 & Siroki Zoltán & DE-siroki-09812.jpg \\
\hline 842 & Chamaecytisus austriacus (L.) Link & Boldogkőváralja & 1944 & Siroki Zoltán & DE-siroki-09813.jpg \\
\hline
\end{tabular}




\begin{tabular}{|c|c|c|c|c|c|}
\hline $\begin{array}{l}\text { Sorszám / } \\
\text { Number }\end{array}$ & Taxon-név / Taxon-name & $\begin{array}{l}\text { Település / } \\
\text { Settlement }\end{array}$ & $\begin{array}{l}\text { Év / } \\
\text { Year }\end{array}$ & $\begin{array}{l}\text { Gyüjtő / } \\
\text { Collector }\end{array}$ & Fájlnév / File-name \\
\hline 842 & Chamaecytisus austriacus (L.) Link & Boldogkőváralja & 1967 & Siroki Zoltán & DE-siroki-09810.jpg \\
\hline 842 & Chamaecytisus austriacus (L.) Link & Budapest & 1941 & Siroki Zoltán & DE-siroki-09803.jpg \\
\hline 842 & Chamaecytisus austriacus (L.) Link & Budapest & 1949 & Siroki Zoltán & DE-siroki-09802.jpg \\
\hline 842 & Chamaecytisus austriacus (L.) Link & Budapest & 1984 & Siroki Zoltán & DE-siroki-09807.jpg \\
\hline 842 & Chamaecytisus austriacus (L.) Link & Budapest & 1984 & Siroki Zoltán & DE-siroki-09808.jpg \\
\hline 842 & Chamaecytisus austriacus (L.) Link & Debrecen & 1961 & Siroki Zoltán & DE-siroki-09809.jpg \\
\hline 842 & Chamaecytisus austriacus (L.) Link & Fót & 1954 & $\begin{array}{l}\text { Máthé Imre - } \\
\text { Kovács Margit }\end{array}$ & DE-siroki-09806.jpg \\
\hline 842 & Chamaecytisus austriacus (L.) Link & Háromhuta & 1961 & Siroki Zoltán & DE-siroki-09820.jpg \\
\hline 842 & Chamaecytisus austriacus (L.) Link & Pomáz & 1957 & Siroki Zoltán & DE-siroki-09804.jpg \\
\hline 842 & Chamaecytisus austriacus (L.) Link & Pomáz & 1957 & Siroki Zoltán & DE-siroki-09805.jpg \\
\hline 844 & $\begin{array}{l}\text { Chamaecytisus ratisbonensis } \\
\text { (Schaeff.) Rothm. }\end{array}$ & Debrecen & 1947 & Siroki Zoltán & DE-siroki-09851.jpg \\
\hline 844 & $\begin{array}{l}\text { Chamaecytisus ratisbonensis } \\
\text { (Schaeff.) Rothm. }\end{array}$ & Debrecen & 1947 & Siroki Zoltán & DE-siroki-09852.jpg \\
\hline 844 & $\begin{array}{l}\text { Chamaecytisus ratisbonensis } \\
\text { (Schaeff.) Rothm. }\end{array}$ & Debrecen & 1950 & Siroki Zoltán & DE-siroki-09850.jpg \\
\hline 844 & $\begin{array}{l}\text { Chamaecytisus ratisbonensis } \\
\text { (Schaeff.) Rothm. }\end{array}$ & Komlóska & 1973 & Siroki Zoltán & DE-siroki-09847.jpg \\
\hline 844 & $\begin{array}{l}\text { Chamaecytisus ratisbonensis } \\
\text { (Schaeff.) Rothm. }\end{array}$ & Komlóska & 1973 & Siroki Zoltán & DE-siroki-09848.jpg \\
\hline 844 & $\begin{array}{l}\text { Chamaecytisus ratisbonensis } \\
\text { (Schaeff.) Rothm. }\end{array}$ & Komlóska & 1973 & Siroki Zoltán & DE-siroki-09849.jpg \\
\hline 845 & $\begin{array}{l}\text { Chamaecytisus ciliatus } \\
\text { (Wahlenb.) Rothm. }\end{array}$ & Budapest & 1984 & Siroki Zoltán & DE-siroki-09821.jpg \\
\hline 845 & $\begin{array}{l}\text { Chamaecytisus ciliatus } \\
\text { (Wahlenb.) Rothm. }\end{array}$ & Nagykovácsi & 1959 & Siroki Zoltán & DE-siroki-09826.jpg \\
\hline 846 & $\begin{array}{l}\text { Chamaecytisus triflorus } \\
\text { (Lam.) Skalická }\end{array}$ & Budaörs & 1955 & $\begin{array}{l}\text { Siroki Zoltán - } \\
\text { Farkas Attila }\end{array}$ & DE-siroki-09839.jpg \\
\hline 846 & $\begin{array}{l}\text { Chamaecytisus triflorus } \\
\text { (Lam.) Skalická }\end{array}$ & Budapest & 1888 & Czakó Kálmán & DE-siroki-09840.jpg \\
\hline 846 & $\begin{array}{l}\text { Chamaecytisus triflorus } \\
\text { (Lam.) Skalická }\end{array}$ & Budapest & 1909 & Kocsis István & DE-siroki-09829.jpg \\
\hline 846 & $\begin{array}{l}\text { Chamaecytisus triflorus } \\
\text { (Lam.) Skalická }\end{array}$ & Budapest & 1916 & Degen Árpád & DE-siroki-09828.jpg \\
\hline 846 & $\begin{array}{l}\text { Chamaecytisus triflorus } \\
\text { (Lam.) Skalická }\end{array}$ & Budapest & 1951 & Siroki Zoltán & DE-siroki-09833.jpg \\
\hline 846 & $\begin{array}{l}\text { Chamaecytisus triflorus } \\
\text { (Lam.) Skalická }\end{array}$ & Budapest & 1951 & Siroki Zoltán & DE-siroki-09831.jpg \\
\hline 846 & $\begin{array}{l}\text { Chamaecytisus triflorus } \\
\text { (Lam.) Skalická }\end{array}$ & Budapest & 1951 & Siroki Zoltán & DE-siroki-09832.jpg \\
\hline 846 & $\begin{array}{l}\text { Chamaecytisus triflorus } \\
\text { (Lam.) Skalická }\end{array}$ & Budapest & 1952 & Siroki Zoltán & DE-siroki-09837.jpg \\
\hline 846 & $\begin{array}{l}\text { Chamaecytisus triflorus } \\
\text { (Lam.) Skalická }\end{array}$ & Budapest & 1964 & Siroki Zoltán & DE-siroki-09834.jpg \\
\hline 846 & $\begin{array}{l}\text { Chamaecytisus triflorus } \\
\text { (Lam.) Skalická }\end{array}$ & Budapest & 1964 & Siroki Zoltán & DE-siroki-09835.jpg \\
\hline 846 & $\begin{array}{l}\text { Chamaecytisus triflorus } \\
\text { (Lam.) Skalická }\end{array}$ & Budapest & 1964 & Siroki Zoltán & DE-siroki-09838.jpg \\
\hline 846 & $\begin{array}{l}\text { Chamaecytisus triflorus } \\
\text { (Lam.) Skalická }\end{array}$ & Budapest & 1970 & Siroki Zoltán & DE-siroki-09836.jpg \\
\hline 846 & $\begin{array}{l}\text { Chamaecytisus triflorus } \\
\text { (Lam.) Skalická }\end{array}$ & Gödöllő & 1952 & Siroki Zoltán & DE-siroki-09843.jpg \\
\hline 846 & $\begin{array}{l}\text { Chamaecytisus triflorus } \\
\text { (Lam.) Skalická }\end{array}$ & Gödöllő & 1954 & Gondola István & DE-siroki-09827.jpg \\
\hline 846 & $\begin{array}{l}\text { Chamaecytisus triflorus } \\
\text { (Lam.) Skalická }\end{array}$ & Pilisszentiván & 1913 & $\begin{array}{l}\text { Filarszky } \\
\text { Nándor }\end{array}$ & DE-siroki-09841.jpg \\
\hline 847 & Genistella sagittalis (L.) Gams & Körmend & 1952 & $\begin{array}{l}\text { Priszter } \\
\text { Szaniszló }\end{array}$ & DE-siroki-09669.jpg \\
\hline 847 & Genistella sagittalis (L.) Gams & Sopron & 1950 & Kárpáti Zoltán & DE-siroki-09670.jpg \\
\hline
\end{tabular}




\begin{tabular}{|c|c|c|c|c|c|}
\hline $\begin{array}{l}\text { Sorszám / } \\
\text { Number }\end{array}$ & Taxon-név / Taxon-name & $\begin{array}{l}\text { Település / } \\
\text { Settlement }\end{array}$ & $\begin{array}{l}\text { Év / } \\
\text { Year }\end{array}$ & $\begin{array}{l}\text { Gyűjtő / } \\
\text { Collector }\end{array}$ & Fájlnév / File-name \\
\hline 848 & Genista germanica L. & Háromhuta & 1973 & Siroki Zoltán & DE-siroki-09676.jpg \\
\hline 848 & Genista germanica L. & Hollóháza & 1940 & Siroki Zoltán & DE-siroki-09686.jpg \\
\hline 848 & Genista germanica L. & Hollóháza & 1940 & Siroki Zoltán & DE-siroki-09687.jpg \\
\hline 848 & Genista germanica L. & Nagyhuta & 1961 & Siroki Zoltán & DE-siroki-09675.jpg \\
\hline 848 & Genista germanica L. & Nagyhuta & 1961 & Siroki Zoltán & DE-siroki-09677.jpg \\
\hline 848 & Genista germanica L. & Nagyhuta & 1961 & Siroki Zoltán & DE-siroki-09678.jpg \\
\hline 848 & Genista germanica L. & Pécs & 1958 & Siroki Zoltán & DE-siroki-09682.jpg \\
\hline 848 & Genista germanica L. & Pécs & 1958 & Siroki Zoltán & DE-siroki-09679.jpg \\
\hline 848 & Genista germanica L. & Pécs & 1958 & Siroki Zoltán & DE-siroki-09680.jpg \\
\hline 848 & Genista germanica L. & Pécs & 1958 & Siroki Zoltán & DE-siroki-09681.jpg \\
\hline 848 & Genista germanica L. & Sopron & 1950 & Kárpáti Zoltán & DE-siroki-09684.jpg \\
\hline 849 & Genista pilosa L. & Abaújszántó & 1944 & Siroki Zoltán & DE-siroki-09664.jpg \\
\hline 849 & Genista pilosa L. & Abaújszántó & 1944 & Siroki Zoltán & DE-siroki-09662.jpg \\
\hline 849 & Genista pilosa L. & Abaújszántó & 1944 & Siroki Zoltán & DE-siroki-09663.jpg \\
\hline 849 & Genista pilosa L. & Budaörs & 1955 & Siroki Zoltán & DE-siroki-09665.jpg \\
\hline 849 & Genista pilosa L. & Budaörs & 1965 & Siroki Zoltán & DE-siroki-09657.jpg \\
\hline 849 & Genista pilosa L. & Budaörs & 1965 & Siroki Zoltán & DE-siroki-09658.jpg \\
\hline 849 & Genista pilosa L. & Budapest & 1984 & Siroki Zoltán & DE-siroki-09654.jpg \\
\hline 849 & Genista pilosa L. & Budapest & 1984 & Siroki Zoltán & DE-siroki-09655.jpg \\
\hline 849 & Genista pilosa L. & Budapest & 1984 & Siroki Zoltán & DE-siroki-09656.jpg \\
\hline 849 & Genista pilosa L. & Kishuta & 1961 & Siroki Zoltán & DE-siroki-09666.jpg \\
\hline 849 & Genista pilosa L. & Kishuta & 1961 & Siroki Zoltán & DE-siroki-09667.jpg \\
\hline 849 & Genista pilosa L. & Kishuta & 1961 & Siroki Zoltán & DE-siroki-09668.jpg \\
\hline 850 & Genista ovata Waldst. et Kit. & Pécs & 1954 & Siroki Zoltán & DE-siroki-09650.jpg \\
\hline 850 & Genista ovata Waldst. et Kit. & Pécs & 1954 & Siroki Zoltán & DE-siroki-09651.jpg \\
\hline 850 & Genista ovata Waldst. et Kit. & Pécs & 1954 & Siroki Zoltán & DE-siroki-09652.jpg \\
\hline 850 & Genista ovata Waldst. et Kit. & Pécs & 1954 & Siroki Zoltán & DE-siroki-09653.jpg \\
\hline 851 & Genista tinctoria $\mathrm{L}$. & "Dobogókő" & 1965 & Siroki Zoltán & DE-siroki-09644.jpg \\
\hline 851 & Genista tinctoria L. & "Mátra" & 1983 & Siroki Zoltán & DE-siroki-09648.jpg \\
\hline 851 & Genista tinctoria L. & "Nagymező" & 1959 & Siroki Zoltán & DE-siroki-09642.jpg \\
\hline 851 & Genista tinctoria $\mathrm{L}$. & "Nagymező" & 1959 & Siroki Zoltán & DE-siroki-09643.jpg \\
\hline 851 & Genista tinctoria L. & Abaújszántó & 1943 & Siroki Zoltán & DE-siroki-09649.jpg \\
\hline 851 & Genista tinctoria L. & Budaörs & 1985 & Siroki Zoltán & DE-siroki-09647.jpg \\
\hline 851 & Genista tinctoria L. & Budapest & 1951 & Siroki Zoltán & DE-siroki-09637.jpg \\
\hline 851 & Genista tinctoria L. & Budapest & 1951 & Siroki Zoltán & DE-siroki-09638.jpg \\
\hline 851 & Genista tinctoria L. & Budapest & 1951 & Siroki Zoltán & DE-siroki-09639.jpg \\
\hline 851 & Genista tinctoria L. & Budapest & 1951 & Siroki Zoltán & DE-siroki-09640.jpg \\
\hline 851 & Genista tinctoria L. & Debrecen & 1947 & Siroki Zoltán & DE-siroki-09633.jpg \\
\hline 851 & Genista tinctoria L. & Debrecen & 1950 & Siroki Zoltán & DE-siroki-09634.jpg \\
\hline 851 & Genista tinctoria L. & Debrecen & 1950 & Siroki Zoltán & DE-siroki-09641.jpg \\
\hline 851 & Genista tinctoria L. & Hencida & 1983 & Siroki Zoltán & DE-siroki-09646.jpg \\
\hline 851 & Genista tinctoria L. & Mátraszentimre & 1959 & Gondola István & DE-siroki-09645.jpg \\
\hline 860 & Galega officinalis L. & Berettyóújfalu & 1959 & Siroki Zoltán & DE-siroki-10293.jpg \\
\hline 860 & Galega officinalis L. & Debrecen & 1950 & Siroki Zoltán & DE-siroki-10294.jpg \\
\hline 860 & Galega officinalis L. & Debrecen & 1950 & Siroki Zoltán & DE-siroki-10295.jpg \\
\hline 860 & Galega officinalis L. & Debrecen & 1950 & Siroki Zoltán & DE-siroki-10296.jpg \\
\hline
\end{tabular}




\begin{tabular}{|c|c|c|c|c|c|}
\hline $\begin{array}{l}\text { Sorszám / } \\
\text { Number }\end{array}$ & Taxon-név / Taxon-name & $\begin{array}{l}\text { Település / } \\
\text { Settlement }\end{array}$ & $\begin{array}{l}\text { Év / } \\
\text { Year }\end{array}$ & $\begin{array}{l}\text { Gyújtő / } \\
\text { Collector }\end{array}$ & Fájlnév / File-name \\
\hline 860 & Galega officinalis L. & Egyek & 1947 & Siroki Zoltán & DE-siroki-10297.jpg \\
\hline 860 & Galega officinalis L. & Egyek & 1947 & Siroki Zoltán & DE-siroki-10298.jpg \\
\hline 860 & Galega officinalis L. & Garadna & 1943 & Siroki Zoltán & DE-siroki-10299.jpg \\
\hline 860 & Galega officinalis L. & Garadna & 1943 & Siroki Zoltán & DE-siroki-10300.jpg \\
\hline 860 & Galega officinalis L. & Kispalád & 1971 & Siroki Zoltán & DE-siroki-10292.jpg \\
\hline 861 & Colutea arborescens L. & Budapest & 1941 & Siroki Zoltán & DE-siroki-10307.jpg \\
\hline 861 & Colutea arborescens L. & Budapest & 1984 & Siroki Zoltán & DE-siroki-10302.jpg \\
\hline 861 & Colutea arborescens L. & Budapest & 1984 & Siroki Zoltán & DE-siroki-10306.jpg \\
\hline 861 & Colutea arborescens L. & Nagykovácsi & 1957 & Siroki Zoltán & DE-siroki-10305.jpg \\
\hline 861 & Colutea arborescens L. & Pomáz & 1954 & Siroki Zoltán & DE-siroki-10303.jpg \\
\hline 866 & Astragalus exscapus L. & Budapest & 1950 & Siroki Zoltán & DE-siroki-10311.jpg \\
\hline 866 & Astragalus exscapus L. & Budapest & 1950 & Siroki Zoltán & DE-siroki-10312.jpg \\
\hline 866 & Astragalus exscapus L. & Budapest & 1951 & Siroki Zoltán & DE-siroki-10313.jpg \\
\hline 866 & Astragalus exscapus L. & Budapest & 1951 & Siroki Zoltán & DE-siroki-10314.jpg \\
\hline 867 & Astragalus dasyanthus Pall. & Debrecen & 1914 & $\begin{array}{l}\text { Rapaics } \\
\text { Rajmund }\end{array}$ & DE-siroki-10317.jpg \\
\hline 867 & Astragalus dasyanthus Pall. & Debrecen & 1948 & Siroki Zoltán & DE-siroki-10315.jpg \\
\hline 867 & Astragalus dasyanthus Pall. & Debrecen & 1948 & Siroki Zoltán & DE-siroki-10316.jpg \\
\hline 867 & Astragalus dasyanthus Pall. & Tarcal & 1927 & Boros Ádám & DE-siroki-10320.jpg \\
\hline 869 & Astragalus glycyphyllos L. & Budapest & 1966 & Siroki Zoltán & DE-siroki-10322.jpg \\
\hline 869 & Astragalus glycyphyllos L. & Gödöllő & 1952 & Máthé Imre & DE-siroki-10323.jpg \\
\hline 869 & Astragalus glycyphyllos L. & Szilvásvárad & 1954 & Siroki Zoltán & DE-siroki-10324.jpg \\
\hline 870 & Astragalus cicer L. & Debrecen & 1947 & Siroki Zoltán & DE-siroki-10328.jpg \\
\hline 870 & Astragalus cicer L. & Debrecen & 1976 & Siroki Zoltán & DE-siroki-10327.jpg \\
\hline 870 & Astragalus cicer L. & Encs & 1944 & Siroki Zoltán & DE-siroki-10331.jpg \\
\hline 870 & Astragalus cicer L. & Encs & 1944 & Siroki Zoltán & DE-siroki-10332.jpg \\
\hline 870 & Astragalus cicer L. & Mosonmagyaróvár & 1939 & Siroki Zoltán & DE-siroki-10329.jpg \\
\hline 870 & Astragalus cicer L. & Mosonmagyaróvár & 1939 & Siroki Zoltán & DE-siroki-10330.jpg \\
\hline 871 & Astragalus asper Wulfen & Budapest & 1910 & Kocsis István & DE-siroki-10366.jpg \\
\hline 871 & Astragalus asper Wulfen & Budapest & 1951 & Siroki Zoltán & DE-siroki-10359.jpg \\
\hline 871 & Astragalus asper Wulfen & Budapest & 1951 & Siroki Zoltán & DE-siroki-10360.jpg \\
\hline 871 & Astragalus asper Wulfen & Budapest & 1951 & Siroki Zoltán & DE-siroki-10363.jpg \\
\hline 871 & Astragalus asper Wulfen & Budapest & 1951 & Siroki Zoltán & DE-siroki-10364.jpg \\
\hline 871 & Astragalus asper Wulfen & Budapest & 1951 & Siroki Zoltán & DE-siroki-10362.jpg \\
\hline 871 & Astragalus asper Wulfen & Budapest & 1955 & Siroki Zoltán & DE-siroki-10361.jpg \\
\hline 872 & Astragalus austriacus Jacq. & Ágasegyháza & 1956 & Siroki Zoltán & DE-siroki-10352.jpg \\
\hline 872 & Astragalus austriacus Jacq. & Budapest & 1952 & Siroki Zoltán & DE-siroki-10356.jpg \\
\hline 872 & Astragalus austriacus Jacq. & Budapest & 1952 & Siroki Zoltán & DE-siroki-10357.jpg \\
\hline 872 & Astragalus austriacus Jacq. & Budapest & 1952 & Siroki Zoltán & DE-siroki-10354.jpg \\
\hline 872 & Astragalus austriacus Jacq. & Budapest & - & Siroki Zoltán & DE-siroki-10353.jpg \\
\hline 872 & Astragalus austriacus Jacq. & Fertőrákos & 1950 & Kárpáti Zoltán & DE-siroki-10355.jpg \\
\hline 872 & Astragalus austriacus Jacq. & Kecskemét & 1969 & Siroki Zoltán & DE-siroki-10348.jpg \\
\hline 872 & Astragalus austriacus Jacq. & Kecskemét & 1969 & Siroki Zoltán & DE-siroki-10349.jpg \\
\hline 872 & Astragalus austriacus Jacq. & Kecskemét & 1969 & Siroki Zoltán & DE-siroki-10350.jpg \\
\hline 872 & Astragalus austriacus Jacq. & Kecskemét & 1969 & Siroki Zoltán & DE-siroki-10351.jpg \\
\hline 873 & Astragalus vesicarius L. & Budaörs & 1955 & Siroki Zoltán & DE-siroki-10370.jpg \\
\hline
\end{tabular}




\begin{tabular}{|c|c|c|c|c|c|}
\hline $\begin{array}{l}\text { Sorszám / } \\
\text { Number }\end{array}$ & Taxon-név / Taxon-name & $\begin{array}{l}\text { Település / } \\
\text { Settlement }\end{array}$ & $\begin{array}{l}\text { Év / } \\
\text { Year }\end{array}$ & $\begin{array}{l}\text { Gyűjtő / } \\
\text { Collector }\end{array}$ & Fájlnév / File-name \\
\hline 873 & Astragalus vesicarius L. & Budaörs & 1955 & $\begin{array}{l}\text { Siroki Zoltán - } \\
\text { Farkas Attila }\end{array}$ & DE-siroki-10369.jpg \\
\hline 873 & Astragalus vesicarius L. & Budaörs & 1955 & $\begin{array}{l}\text { Siroki Zoltán - } \\
\text { Farkas Attila }\end{array}$ & DE-siroki-10372.jpg \\
\hline 873 & Astragalus vesicarius L. & Budaörs & 1964 & Siroki Zoltán & DE-siroki-10367.jpg \\
\hline 873 & Astragalus vesicarius L. & Budaörs & 1964 & Siroki Zoltán & DE-siroki-10368.jpg \\
\hline 873 & Astragalus vesicarius L. & Budaörs & 1964 & Siroki Zoltán & DE-siroki-10371.jpg \\
\hline 873 & Astragalus vesicarius L. & Budapest & 1951 & Siroki Zoltán & DE-siroki-10373.jpg \\
\hline 873 & Astragalus vesicarius L. & Budapest & 1951 & Siroki Zoltán & DE-siroki-10374.jpg \\
\hline 873 & Astragalus vesicarius L. & Budapest & 1951 & Siroki Zoltán & DE-siroki-10375.jpg \\
\hline 873 & Astragalus vesicarius L. & Budapest & 1951 & Siroki Zoltán & DE-siroki-10376.jpg \\
\hline 874 & Astragalus onobrychis L. & Boldogkőváralja & 1943 & Siroki Zoltán & DE-siroki-10385.jpg \\
\hline 874 & Astragalus onobrychis L. & Boldogkőváralja & 1967 & Siroki Zoltán & DE-siroki-10386.jpg \\
\hline 874 & Astragalus onobrychis L. & Budaörs & 1966 & Siroki Zoltán & DE-siroki-10387.jpg \\
\hline 874 & Astragalus onobrychis L. & Budapest & 1941 & Siroki Zoltán & DE-siroki-10384.jpg \\
\hline 874 & Astragalus onobrychis L. & Budapest & 1941 & Siroki Zoltán & DE-siroki-10380.jpg \\
\hline 874 & Astragalus onobrychis L. & Budapest & 1944 & Siroki Zoltán & DE-siroki-10379.jpg \\
\hline 874 & Astragalus onobrychis L. & Budapest & 1944 & Siroki Zoltán & DE-siroki-10382.jpg \\
\hline 874 & Astragalus onobrychis L. & Budapest & 1944 & Siroki Zoltán & DE-siroki-10383.jpg \\
\hline 874 & Astragalus onobrychis L. & Budapest & 1948 & Siroki Zoltán & DE-siroki-10381.jpg \\
\hline 874 & Astragalus onobrychis L. & Budapest & 1983 & Siroki Zoltán & DE-siroki-10378.jpg \\
\hline 874 & Astragalus onobrychis L. & Fót & 1954 & $\begin{array}{l}\text { Máthé Imre - } \\
\text { Kovács Margit }\end{array}$ & DE-siroki-10388.jpg \\
\hline 875 & Astragalus varius S.G. Gmel. & Bugac & 1973 & Siroki Zoltán & DE-siroki-10389.jpg \\
\hline 875 & Astragalus varius S.G. Gmel. & Bugac & 1973 & Siroki Zoltán & DE-siroki-10392.jpg \\
\hline 875 & Astragalus varius S.G. Gmel. & Bugac & 1973 & Siroki Zoltán & DE-siroki-10393.jpg \\
\hline 875 & Astragalus varius S.G. Gmel. & Bugac & 1973 & Siroki Zoltán & DE-siroki-10391.jpg \\
\hline 875 & Astragalus varius S.G. Gmel. & Bugac & 1973 & Siroki Zoltán & DE-siroki-10394.jpg \\
\hline 875 & Astragalus varius S.G. Gmel. & Bugac & 1973 & Siroki Zoltán & DE-siroki-10395.jpg \\
\hline 875 & Astragalus varius S.G. Gmel. & Bugac & 1973 & Siroki Zoltán & DE-siroki-10396.jpg \\
\hline 875 & Astragalus varius S.G. Gmel. & Kecskemét & 1969 & Siroki Zoltán & DE-siroki-10390.jpg \\
\hline 875 & Astragalus varius S.G. Gmel. & Kecskemét & 1969 & Siroki Zoltán & DE-siroki-10397.jpg \\
\hline 876 & Oxytropis pilosa (L.) DC. & Tokaj & 1974 & Siroki Zoltán & DE-siroki-10399.jpg \\
\hline 876 & Oxytropis pilosa (L.) DC. & Tokaj & 1974 & Siroki Zoltán & DE-siroki-10400.jpg \\
\hline 876 & Oxytropis pilosa (L.) DC. & Tokaj & 1974 & Siroki Zoltán & DE-siroki-10401.jpg \\
\hline 877 & Glycyrrhiza echinata L. & Egyek & 1947 & Siroki Zoltán & DE-siroki-10408.jpg \\
\hline 877 & Glycyrrhiza echinata L. & Egyek & 1947 & Siroki Zoltán & DE-siroki-10409.jpg \\
\hline 877 & Glycyrrhiza echinata L. & Hortobágy & 1947 & Siroki Zoltán & DE-siroki-10411.jpg \\
\hline 877 & Glycyrrhiza echinata L. & Hortobágy & 1947 & Siroki Zoltán & DE-siroki-10412.jpg \\
\hline 877 & Glycyrrhiza echinata L. & Hortobágy & 1947 & Siroki Zoltán & DE-siroki-10410.jpg \\
\hline 879 & Amorpha fruticosa L. & Budaörs & 1941 & Siroki Zoltán & DE-siroki-10291.jpg \\
\hline 879 & Amorpha fruticosa L. & Debrecen & 1977 & Siroki Zoltán & DE-siroki-10289.jpg \\
\hline 879 & Amorpha fruticosa L. & Egyek & 1947 & Siroki Zoltán & DE-siroki-10290.jpg \\
\hline 887 & Vicia hirsuta (L.) Gray & Budapest & 1966 & Siroki Zoltán & DE-siroki-10482.jpg \\
\hline 887 & Vicia hirsuta (L.) Gray & Egyek & 1948 & Siroki Zoltán & DE-siroki-10477.jpg \\
\hline 887 & Vicia hirsuta (L.) Gray & Hortobágy & 1949 & Siroki Zoltán & DE-siroki-10479.jpg \\
\hline 887 & Vicia hirsuta (L.) Gray & Hortobágy & 1949 & Siroki Zoltán & DE-siroki-10478.jpg \\
\hline 887 & Vicia hirsuta (L.) Gray & Mátraszentimre & 1959 & Gondola István & DE-siroki-10480.jpg \\
\hline
\end{tabular}




\begin{tabular}{|c|c|c|c|c|c|}
\hline $\begin{array}{l}\text { Sorszám / } \\
\text { Number }\end{array}$ & Taxon-név / Taxon-name & $\begin{array}{l}\text { Település / } \\
\text { Settlement }\end{array}$ & $\begin{array}{l}\text { Év / } \\
\text { Year }\end{array}$ & $\begin{array}{l}\text { Gyújtő / } \\
\text { Collector }\end{array}$ & Fájlnév / File-name \\
\hline 887 & Vicia hirsuta (L.) Gray & Mátraszentimre & 1959 & Gondola István & DE-siroki-10481.jpg \\
\hline 888 & Vicia tetrasperma (L.) Schreb. & Budapest & 1951 & Siroki Zoltán & DE-siroki-10490.jpg \\
\hline 888 & Vicia tetrasperma (L.) Schreb. & Budapest & 1951 & Siroki Zoltán & DE-siroki-10489.jpg \\
\hline 888 & Vicia tetrasperma (L.) Schreb. & Kardoskút & 1945 & Siroki Zoltán & DE-siroki-10496.jpg \\
\hline 888 & Vicia tetrasperma (L.) Schreb. & Kardoskút & 1945 & Siroki Zoltán & DE-siroki-10497.jpg \\
\hline 888 & Vicia tetrasperma (L.) Schreb. & Kardoskút & 1945 & Siroki Zoltán & DE-siroki-10498.jpg \\
\hline 888 & Vicia tetrasperma (L.) Schreb. & Kardoskút & 1945 & Siroki Zoltán & DE-siroki-10499.jpg \\
\hline 888 & Vicia tetrasperma (L.) Schreb. & Kardoskút & 1975 & Siroki Zoltán & DE-siroki-10500.jpg \\
\hline 888 & Vicia tetrasperma (L.) Schreb. & Kékcse & 1967 & Gondola István & DE-siroki-10492.jpg \\
\hline 888 & Vicia tetrasperma (L.) Schreb. & Kékcse & 1967 & Gondola István & DE-siroki-10493.jpg \\
\hline 888 & Vicia tetrasperma (L.) Schreb. & Kékcse & 1967 & Gondola István & DE-siroki-10494.jpg \\
\hline 888 & Vicia tetrasperma (L.) Schreb. & Kékcse & 1967 & Gondola István & DE-siroki-10495.jpg \\
\hline 888 & Vicia tetrasperma (L.) Schreb. & Vámospércs & 1965 & Siroki Zoltán & DE-siroki-10483.jpg \\
\hline 888 & Vicia tetrasperma (L.) Schreb. & Vámospércs & 1965 & Siroki Zoltán & DE-siroki-10484.jpg \\
\hline 888 & Vicia tetrasperma (L.) Schreb. & Vámospércs & 1965 & Siroki Zoltán & DE-siroki-10485.jpg \\
\hline 888 & Vicia tetrasperma (L.) Schreb. & Vámospércs & 1965 & Siroki Zoltán & DE-siroki-10486.jpg \\
\hline 888 & Vicia tetrasperma (L.) Schreb. & Vámospércs & 1965 & Siroki Zoltán & DE-siroki-10487.jpg \\
\hline 888 & Vicia tetrasperma (L.) Schreb. & Vámospércs & 1965 & Siroki Zoltán & DE-siroki-10488.jpg \\
\hline 890 & Vicia sylvatica L. & Füzér & 1966 & Siroki Zoltán & DE-siroki-10502.jpg \\
\hline 890 & Vicia sylvatica L. & Hollóháza & 1940 & Siroki Zoltán & DE-siroki-10505.jpg \\
\hline 891 & Vicia pisiformis L. & "Bükk-hg." & 1983 & Siroki Zoltán & DE-siroki-10507.jpg \\
\hline 891 & Vicia pisiformis L. & Aszaló & 1944 & Siroki Zoltán & DE-siroki-10517.jpg \\
\hline 891 & Vicia pisiformis L. & Aszaló & 1944 & Siroki Zoltán & DE-siroki-10518.jpg \\
\hline 891 & Vicia pisiformis L. & Budaörs & 1966 & Siroki Zoltán & DE-siroki-10511.jpg \\
\hline 891 & Vicia pisiformis L. & Debrecen & 1948 & Siroki Zoltán & DE-siroki-10515.jpg \\
\hline 891 & Vicia pisiformis L. & Debrecen & 1948 & Siroki Zoltán & DE-siroki-10516.jpg \\
\hline 891 & Vicia pisiformis L. & Debrecen & 1950 & Siroki Zoltán & DE-siroki-10514.jpg \\
\hline 891 & Vicia pisiformis L. & Háromhuta & 1960 & Siroki Zoltán & DE-siroki-10512.jpg \\
\hline 891 & Vicia pisiformis L. & Szilvásvárad & 1959 & Siroki Zoltán & DE-siroki-10513.jpg \\
\hline 891 & Vicia pisiformis L. & Tokaj & 1966 & Siroki Zoltán & DE-siroki-10508.jpg \\
\hline 891 & Vicia pisiformis L. & Tokaj & 1966 & Siroki Zoltán & DE-siroki-10509.jpg \\
\hline 891 & Vicia pisiformis L. & Tokaj & 1966 & Siroki Zoltán & DE-siroki-10510.jpg \\
\hline 892 & Vicia dumetorum L. & "Dobogókő" & 1956 & Siroki Zoltán & DE-siroki-10523.jpg \\
\hline 892 & Vicia dumetorum L. & "Dobogókő" & 1956 & Siroki Zoltán & DE-siroki-10531.jpg \\
\hline 892 & Vicia dumetorum L. & Debrecen & 1954 & Siroki Zoltán & DE-siroki-10524.jpg \\
\hline 892 & Vicia dumetorum L. & Debrecen & 1954 & Siroki Zoltán & DE-siroki-10525.jpg \\
\hline 892 & Vicia dumetorum L. & Debrecen & 1954 & Siroki Zoltán & DE-siroki-10526.jpg \\
\hline 892 & Vicia dumetorum L. & Debrecen & 1954 & Siroki Zoltán & DE-siroki-10527.jpg \\
\hline 892 & Vicia dumetorum L. & Debrecen & 1954 & Siroki Zoltán & DE-siroki-10528.jpg \\
\hline 892 & Vicia dumetorum L. & Debrecen & 1954 & Siroki Zoltán & DE-siroki-10529.jpg \\
\hline 892 & Vicia dumetorum L. & Háromhuta & 1960 & Siroki Zoltán & DE-siroki-10522.jpg \\
\hline 892 & Vicia dumetorum L. & Pásztó & 1952 & Siroki Zoltán & DE-siroki-10533.jpg \\
\hline 892 & Vicia dumetorum L. & Pásztó & 1952 & Siroki Zoltán & DE-siroki-10532.jpg \\
\hline 892 & Vicia dumetorum L. & Pásztó & 1952 & Siroki Zoltán & DE-siroki-10530.jpg \\
\hline 892 & Vicia dumetorum L. & Szilvásvárad & 1954 & Siroki Zoltán & DE-siroki-10534.jpg \\
\hline 892 & Vicia dumetorum L. & Tokaj & 1966 & Siroki Zoltán & DE-siroki-10519.jpg \\
\hline
\end{tabular}




\begin{tabular}{|c|c|c|c|c|c|}
\hline $\begin{array}{l}\text { Sorszám / } \\
\text { Number }\end{array}$ & Taxon-név / Taxon-name & $\begin{array}{l}\text { Település / } \\
\text { Settlement }\end{array}$ & $\begin{array}{l}\text { Év / } \\
\text { Year }\end{array}$ & $\begin{array}{l}\text { Gyűjtő / } \\
\text { Collector }\end{array}$ & Fájlnév / File-name \\
\hline 892 & Vicia dumetorum L. & Tokaj & 1966 & Siroki Zoltán & DE-siroki-10520.jpg \\
\hline 892 & Vicia dumetorum L. & Tokaj & 1966 & Siroki Zoltán & DE-siroki-10521.jpg \\
\hline 893 & Vicia sparsiflora Ten. & Budapest & 1951 & Siroki Zoltán & DE-siroki-10535.jpg \\
\hline 893 & Vicia sparsiflora Ten. & Budapest & 1951 & Siroki Zoltán & DE-siroki-10536.jpg \\
\hline 893 & Vicia sparsiflora Ten. & Budapest & 1951 & Siroki Zoltán & DE-siroki-10537.jpg \\
\hline 894 & Vicia cassubica L. & "Bükk-hg." & 1983 & Siroki Zoltán & DE-siroki-10538.jpg \\
\hline 894 & Vicia cassubica L. & "Bükk-hg." & 1983 & Siroki Zoltán & DE-siroki-10539.jpg \\
\hline 894 & Vicia cassubica L. & "Mátra" & 1984 & Siroki Zoltán & DE-siroki-10540.jpg \\
\hline 894 & Vicia cassubica L. & Budapest & 1951 & Siroki Zoltán & DE-siroki-10548.jpg \\
\hline 894 & Vicia cassubica L. & Budapest & 1955 & Siroki Zoltán & DE-siroki-10545.jpg \\
\hline 894 & Vicia cassubica L. & Hajdúböszörmény & 1981 & Siroki Zoltán & DE-siroki-10541.jpg \\
\hline 894 & Vicia cassubica L. & Hajdúböszörmény & 1981 & Siroki Zoltán & DE-siroki-10542.jpg \\
\hline 894 & Vicia cassubica L. & Háromhuta & 1967 & Siroki Zoltán & DE-siroki-10543.jpg \\
\hline 894 & Vicia cassubica L. & Háromhuta & 1967 & Siroki Zoltán & DE-siroki-10544.jpg \\
\hline 895 & Vicia biennis L. & Debrecen & 1966 & - & DE-siroki-10550.jpg \\
\hline 896 & Vicia villosa Roth & Debrecen & 1947 & Siroki Zoltán & DE-siroki-10583.jpg \\
\hline 896 & Vicia villosa Roth & Debrecen & 1948 & Siroki Zoltán & DE-siroki-10587.jpg \\
\hline 896 & Vicia villosa Roth & Debrecen & 1948 & Siroki Zoltán & DE-siroki-10588.jpg \\
\hline 896 & Vicia villosa Roth & Debrecen & 1948 & Siroki Zoltán & DE-siroki-10584.jpg \\
\hline 896 & Vicia villosa Roth & Debrecen & 1957 & Siroki Zoltán & DE-siroki-10585.jpg \\
\hline 896 & Vicia villosa Roth & Hortobágy & 1983 & Siroki Zoltán & DE-siroki-10586.jpg \\
\hline 896 & Vicia villosa Roth & Mosonmagyaróvár & 1939 & Siroki Zoltán & DE-siroki-10592.jpg \\
\hline 897 & Vicia tenuifolia Roth & Abaújkér & 1942 & Siroki Zoltán & DE-siroki-10565.jpg \\
\hline 897 & Vicia tenuifolia Roth & Bélapátfalva & 1956 & Halász Tibor & DE-siroki-10563.jpg \\
\hline 897 & Vicia tenuifolia Roth & Boldogkőújfalu & 1942 & Siroki Zoltán & DE-siroki-10566.jpg \\
\hline 897 & Vicia tenuifolia Roth & Budapest & 1951 & Siroki Zoltán & DE-siroki-10562.jpg \\
\hline 897 & Vicia tenuifolia Roth & Debrecen & 1947 & Siroki Zoltán & DE-siroki-10564.jpg \\
\hline 897 & Vicia tenuifolia Roth & Hortobágy & 1980 & Siroki Zoltán & DE-siroki-10571.jpg \\
\hline 897 & Vicia tenuifolia Roth & Hortobágy & 1980 & Siroki Zoltán & DE-siroki-10572.jpg \\
\hline 897 & Vicia tenuifolia Roth & Hortobágy & 1980 & Siroki Zoltán & DE-siroki-10573.jpg \\
\hline 897 & Vicia tenuifolia Roth & Hortobágy & 1980 & Siroki Zoltán & DE-siroki-10574.jpg \\
\hline 897 & Vicia tenuifolia Roth & Kardoskút & 1975 & Siroki Zoltán & DE-siroki-10568.jpg \\
\hline 897.2 & $\begin{array}{l}\text { Vicia tenuifolia Roth } \\
\text { subsp. dalmatica (A. Kern.) Greuter }\end{array}$ & Pomáz & 1952 & Siroki Zoltán & DE-siroki-10552.jpg \\
\hline 897.2 & $\begin{array}{l}\text { Vicia tenuifolia Roth } \\
\text { subsp. dalmatica (A. Kern.) Greuter }\end{array}$ & Pomáz & 1952 & Siroki Zoltán & DE-siroki-10551.jpg \\
\hline 898 & Vicia cracca L. & Berekböszörmény & 1970 & Siroki Zoltán & DE-siroki-10577.jpg \\
\hline 898 & Vicia cracca L. & Cserháthaláp & 1954 & Máthé Imre & DE-siroki-10555.jpg \\
\hline 898 & Vicia cracca L. & Cserháthaláp & 1954 & Máthé Imre & DE-siroki-10556.jpg \\
\hline 898 & Vicia cracca L. & Debrecen & 1977 & Siroki Zoltán & DE-siroki-10578.jpg \\
\hline 898 & Vicia cracca L. & Debrecen & 1977 & Siroki Zoltán & DE-siroki-10579.jpg \\
\hline 898 & Vicia cracca L. & Háromhuta & 1961 & Siroki Zoltán & DE-siroki-10557.jpg \\
\hline 898 & Vicia cracca L. & Háromhuta & 1961 & Siroki Zoltán & DE-siroki-10558.jpg \\
\hline 898 & Vicia cracca L. & Háromhuta & 1961 & Siroki Zoltán & DE-siroki-10559.jpg \\
\hline 898 & Vicia cracca L. & Tiszafüred & 1973 & Siroki Zoltán & DE-siroki-10580.jpg \\
\hline 898 & Vicia cracca L. & Tiszafüred & 1973 & Siroki Zoltán & DE-siroki-10581.jpg \\
\hline 898 & Vicia cracca L. & Vámospércs & 1965 & Siroki Zoltán & DE-siroki-10553.jpg \\
\hline
\end{tabular}




\begin{tabular}{|c|c|c|c|c|c|}
\hline $\begin{array}{l}\text { Sorszám / } \\
\text { Number }\end{array}$ & Taxon-név / Taxon-name & $\begin{array}{l}\text { Település / } \\
\text { Settlement }\end{array}$ & $\begin{array}{l}\text { Év / } \\
\text { Year }\end{array}$ & $\begin{array}{l}\text { Gyüjtő / } \\
\text { Collector }\end{array}$ & Fájlnév / File-name \\
\hline 898 & Vicia cracca L. & Vámospércs & 1965 & Siroki Zoltán & DE-siroki-10554.jpg \\
\hline 898 & Vicia cracca L. & Vámospércs & 1965 & Siroki Zoltán & DE-siroki-10569.jpg \\
\hline 898 & Vicia cracca L. & Vámospércs & 1965 & Siroki Zoltán & DE-siroki-10570.jpg \\
\hline 898 & Vicia cracca L. & Vámospércs & 1985 & Siroki Zoltán & DE-siroki-10575.jpg \\
\hline 898 & Vicia cracca L. & Vámospércs & 1985 & Siroki Zoltán & DE-siroki-10576.jpg \\
\hline 900 & Vicia lathyroides L. & Debrecen & 1950 & Siroki Zoltán & DE-siroki-10598.jpg \\
\hline 900 & Vicia lathyroides L. & Debrecen & 1954 & Siroki Zoltán & DE-siroki-10596.jpg \\
\hline 900 & Vicia lathyroides L. & Debrecen & 1954 & Siroki Zoltán & DE-siroki-10597.jpg \\
\hline 901.1 & $\begin{array}{l}\text { Vicia pannonica Crantz } \\
\text { subsp. pannonica }\end{array}$ & Debrecen & 1948 & Siroki Zoltán & DE-siroki-10606.jpg \\
\hline 901.1 & $\begin{array}{l}\text { Vicia pannonica Crantz } \\
\text { subsp. pannonica }\end{array}$ & Debrecen & 1948 & Siroki Zoltán & DE-siroki-10605.jpg \\
\hline 901.1 & $\begin{array}{l}\text { Vicia pannonica Crantz } \\
\text { subsp. pannonica }\end{array}$ & Debrecen & 1948 & Siroki Zoltán & DE-siroki-10607.jpg \\
\hline 901.1 & $\begin{array}{l}\text { Vicia pannonica Crantz } \\
\text { subsp. pannonica }\end{array}$ & Mosonmagyaróvár & 1939 & Siroki Zoltán & DE-siroki-10609.jpg \\
\hline 901.2 & $\begin{array}{l}\text { Vicia pannonica Crantz } \\
\text { subsp. striata (M. Bieb.) Nyman }\end{array}$ & Debrecen & 1947 & Siroki Zoltán & DE-siroki-10614.jpg \\
\hline 901.2 & $\begin{array}{l}\text { Vicia pannonica Crantz } \\
\text { subsp. striata (M. Bieb.) Nyman }\end{array}$ & Debrecen & 1947 & Siroki Zoltán & DE-siroki-10615.jpg \\
\hline 901.2 & $\begin{array}{l}\text { Vicia pannonica Crantz } \\
\text { subsp. striata (M. Bieb.) Nyman }\end{array}$ & Debrecen & 1948 & Siroki Zoltán & DE-siroki-10616.jpg \\
\hline 901.2 & $\begin{array}{l}\text { Vicia pannonica Crantz } \\
\text { subsp. striata (M. Bieb.) Nyman }\end{array}$ & Hortobágy & 1980 & Siroki Zoltán & DE-siroki-10617.jpg \\
\hline 901.2 & $\begin{array}{l}\text { Vicia pannonica Crantz } \\
\text { subsp. striata (M. Bieb.) Nyman }\end{array}$ & Hortobágy & 1980 & Siroki Zoltán & DE-siroki-10618.jpg \\
\hline 901.2 & $\begin{array}{l}\text { Vicia pannonica Crantz } \\
\text { subsp. striata (M. Bieb.) Nyman }\end{array}$ & Hortobágy & 1980 & Siroki Zoltán & DE-siroki-10619.jpg \\
\hline 903 & Vicia grandiflora Scop. & Debrecen & 1948 & Siroki Zoltán & DE-siroki-10631.jpg \\
\hline 903 & Vicia grandiflora Scop. & Debrecen & 1950 & Siroki Zoltán & DE-siroki-10632.jpg \\
\hline 903 & Vicia grandiflora Scop. & Debrecen & 1960 & Siroki Zoltán & DE-siroki-10634.jpg \\
\hline 903 & Vicia grandiflora Scop. & Garadna & 1944 & Siroki Zoltán & DE-siroki-10633.jpg \\
\hline 905 & Vicia sepium L. & "Fáni-völgy" & 1955 & Siroki Zoltán & DE-siroki-10623.jpg \\
\hline 905 & Vicia sepium L. & "Nagymező" & 1959 & Halász Tibor & DE-siroki-10620.jpg \\
\hline 905 & Vicia sepium L. & Bélapátfalva & 1956 & Halász Tibor & DE-siroki-10621.jpg \\
\hline 905 & Vicia sepium L. & Debrecen & 1950 & Siroki Zoltán & DE-siroki-10622.jpg \\
\hline 905 & Vicia sepium L. & Füzérradvány & 1973 & Siroki Zoltán & DE-siroki-10626.jpg \\
\hline 905 & Vicia sepium L. & Nagyhuta & 1978 & Siroki Zoltán & DE-siroki-10627.jpg \\
\hline 905 & Vicia sepium L. & Nagyhuta & 1978 & Siroki Zoltán & DE-siroki-10628.jpg \\
\hline 908 & Vicia angustifolia L. & Debrecen & 1947 & Siroki Zoltán & DE-siroki-10640.jpg \\
\hline 908 & Vicia angustifolia L. & Garadna & 1944 & Siroki Zoltán & DE-siroki-10638.jpg \\
\hline 908 & Vicia angustifolia L. & Garadna & 1944 & Siroki Zoltán & DE-siroki-10639.jpg \\
\hline 908 & Vicia angustifolia L. & Kardoskút & 1975 & Siroki Zoltán & DE-siroki-10637.jpg \\
\hline 910 & Lathyrus aphaca L. & Biharugra & 1961 & Siroki Zoltán & DE-siroki-10649.jpg \\
\hline 910 & Lathyrus aphaca L. & Biharugra & 1961 & Siroki Zoltán & DE-siroki-10650.jpg \\
\hline 910 & Lathyrus aphaca L. & Biharugra & 1961 & Siroki Zoltán & DE-siroki-10651.jpg \\
\hline 910 & Lathyrus aphaca L. & Biharugra & 1961 & Siroki Zoltán & DE-siroki-10653.jpg \\
\hline 910 & Lathyrus aphaca L. & Biharugra & 1961 & Siroki Zoltán & DE-siroki-10654.jpg \\
\hline 910 & Lathyrus aphaca L. & Biharugra & 1961 & Siroki Zoltán & DE-siroki-10655.jpg \\
\hline 910 & Lathyrus aphaca L. & Biharugra & 1961 & Siroki Zoltán & DE-siroki-10656.jpg \\
\hline 910 & Lathyrus aphaca L. & Biharugra & 1961 & Siroki Zoltán & DE-siroki-10659.jpg \\
\hline 910 & Lathyrus aphaca L. & Biharugra & 1961 & Siroki Zoltán & DE-siroki-10657.jpg \\
\hline
\end{tabular}




\begin{tabular}{|c|c|c|c|c|c|}
\hline $\begin{array}{l}\text { Sorszám / } \\
\text { Number }\end{array}$ & Taxon-név / Taxon-name & $\begin{array}{l}\text { Település / } \\
\text { Settlement }\end{array}$ & $\begin{array}{l}\text { Év / } \\
\text { Year }\end{array}$ & $\begin{array}{l}\text { Gyűjtő / } \\
\text { Collector }\end{array}$ & Fájlnév / File-name \\
\hline 910 & Lathyrus aphaca L. & Biharugra & 1961 & Siroki Zoltán & DE-siroki-10658.jpg \\
\hline 910 & Lathyrus aphaca L. & Biharugra & 1961 & Siroki Zoltán & DE-siroki-10652.jpg \\
\hline 911 & Lathyrus nissolia L. & "Bükk-hg." & 1959 & Halász Tibor & DE-siroki-10661.jpg \\
\hline 911 & Lathyrus nissolia L. & "Bükk-hg." & 1959 & Halász Tibor & DE-siroki-10662.jpg \\
\hline 911 & Lathyrus nissolia L. & "Bükk-hg." & 1959 & Halász Tibor & DE-siroki-10663.jpg \\
\hline 911 & Lathyrus nissolia L. & "Nagymező" & 1959 & Halász Tibor & DE-siroki-10660.jpg \\
\hline 911 & Lathyrus nissolia L. & Budapest & 1951 & Siroki Zoltán & DE-siroki-10666.jpg \\
\hline 911 & Lathyrus nissolia L. & Budapest & 1951 & Siroki Zoltán & DE-siroki-10667.jpg \\
\hline 911 & Lathyrus nissolia L. & Mátraszentimre & 1959 & Gondola István & DE-siroki-10665.jpg \\
\hline 911 & Lathyrus nissolia L. & Pomáz & 1952 & $\begin{array}{l}\text { Priszter } \\
\text { Szaniszló }\end{array}$ & DE-siroki-10664.jpg \\
\hline 911 & Lathyrus nissolia L. & Szentendre & 1916 & Degen Árpád & DE-siroki-10668.jpg \\
\hline 912 & Lathyrus pratensis L. & Egyek & 1947 & Siroki Zoltán & DE-siroki-10710.jpg \\
\hline 912 & Lathyrus pratensis L. & Egyek & 1947 & Siroki Zoltán & DE-siroki-10711.jpg \\
\hline 912 & Lathyrus pratensis L. & Hollóháza & 1940 & Siroki Zoltán & DE-siroki-10712.jpg \\
\hline 912 & Lathyrus pratensis L. & Mátraszentimre & 1959 & Gondola István & DE-siroki-10707.jpg \\
\hline 912 & Lathyrus pratensis L. & Mátraszentimre & 1959 & Gondola István & DE-siroki-10708.jpg \\
\hline 912 & Lathyrus pratensis L. & Tiszafüred & 1970 & Siroki Zoltán & DE-siroki-10705.jpg \\
\hline 912 & Lathyrus pratensis L. & Tiszafüred & 1970 & Siroki Zoltán & DE-siroki-10706.jpg \\
\hline 912 & Lathyrus pratensis L. & Újléta & 1965 & Siroki Zoltán & DE-siroki-10709.jpg \\
\hline 913 & Lathyrus sphaericus Retz. & Budapest & 1887 & Czakó Kálmán & DE-siroki-10687.jpg \\
\hline 914 & Lathyrus tuberosus L. & Berekböszörmény & 1970 & Siroki Zoltán & DE-siroki-10697.jpg \\
\hline 914 & Lathyrus tuberosus L. & Berettyóújfalu & 1959 & Siroki Zoltán & DE-siroki-10700.jpg \\
\hline 914 & Lathyrus tuberosus L. & Csaroda & 1960 & Siroki Zoltán & DE-siroki-10698.jpg \\
\hline 914 & Lathyrus tuberosus L. & Csaroda & 1960 & Siroki Zoltán & DE-siroki-10699.jpg \\
\hline 914 & Lathyrus tuberosus L. & Hortobágy & 1947 & Siroki Zoltán & DE-siroki-10701.jpg \\
\hline 914 & Lathyrus tuberosus L. & Hortobágy & 1947 & Siroki Zoltán & DE-siroki-10702.jpg \\
\hline 914 & Lathyrus tuberosus L. & Máriakálnok & 1939 & Siroki Zoltán & DE-siroki-10703.jpg \\
\hline 916 & Lathyrus hirsutus L. & Budapest & 1966 & Siroki Zoltán & DE-siroki-10680.jpg \\
\hline 916 & Lathyrus hirsutus L. & Budapest & 1966 & Siroki Zoltán & DE-siroki-10681.jpg \\
\hline 916 & Lathyrus hirsutus L. & Budapest & 1966 & Siroki Zoltán & DE-siroki-10682.jpg \\
\hline 916 & Lathyrus hirsutus L. & Hódmezővásárhely & 1975 & Siroki Zoltán & DE-siroki-10669.jpg \\
\hline 916 & Lathyrus hirsutus L. & Hódmezővásárhely & 1975 & Siroki Zoltán & DE-siroki-10670.jpg \\
\hline 916 & Lathyrus hirsutus L. & Hortobágy & 1947 & Siroki Zoltán & DE-siroki-10672.jpg \\
\hline 916 & Lathyrus hirsutus L. & Hortobágy & 1947 & Siroki Zoltán & DE-siroki-10674.jpg \\
\hline 916 & Lathyrus hirsutus L. & Hortobágy & 1954 & Siroki Zoltán & DE-siroki-10673.jpg \\
\hline 916 & Lathyrus hirsutus L. & Hortobágy & 1954 & Siroki Zoltán & DE-siroki-10675.jpg \\
\hline 916 & Lathyrus hirsutus L. & Hortobágy & 1954 & Siroki Zoltán & DE-siroki-10676.jpg \\
\hline 916 & Lathyrus hirsutus L. & Hortobágy & 1954 & Siroki Zoltán & DE-siroki-10677.jpg \\
\hline 916 & Lathyrus hirsutus L. & Kispalád & 1971 & Siroki Zoltán & DE-siroki-10671.jpg \\
\hline 916 & Lathyrus hirsutus L. & Pásztó & 1952 & Siroki Zoltán & DE-siroki-10683.jpg \\
\hline 916 & Lathyrus hirsutus L. & Pásztó & 1952 & Siroki Zoltán & DE-siroki-10684.jpg \\
\hline 916 & Lathyrus hirsutus L. & Pomáz & 1952 & Siroki Zoltán & DE-siroki-10678.jpg \\
\hline 916 & Lathyrus hirsutus L. & Pomáz & 1952 & Siroki Zoltán & DE-siroki-10679.jpg \\
\hline 919 & Lathyrus palustris L. & Budapest & 1889 & Czakó Kálmán & DE-siroki-10691.jpg \\
\hline 919 & Lathyrus palustris L. & Budapest & 1909 & Kocsis István & DE-siroki-10692.jpg \\
\hline 919 & Lathyrus palustris L. & Debrecen & 1949 & Siroki Zoltán & DE-siroki-10694.jpg \\
\hline
\end{tabular}




\begin{tabular}{|c|c|c|c|c|c|}
\hline $\begin{array}{l}\text { Sorszám / } \\
\text { Number }\end{array}$ & Taxon-név / Taxon-name & $\begin{array}{l}\text { Település / } \\
\text { Settlement }\end{array}$ & $\begin{array}{l}\text { Év / } \\
\text { Year }\end{array}$ & $\begin{array}{l}\text { Gyűjtő / } \\
\text { Collector }\end{array}$ & Fájlnév / File-name \\
\hline 919 & Lathyrus palustris L. & Egyek & 1949 & Siroki Zoltán & DE-siroki-10696.jpg \\
\hline 919 & Lathyrus palustris L. & Lesenceistvánd & 1930 & Rigler József & DE-siroki-10693.jpg \\
\hline 919 & Lathyrus palustris L. & Sátoraljaújhely & 1944 & Siroki Zoltán & DE-siroki-10695.jpg \\
\hline 919 & Lathyrus palustris L. & Tiszafüred & 1949 & Siroki Zoltán & DE-siroki-10688.jpg \\
\hline 919 & Lathyrus palustris L. & Tiszafüred & 1968 & Siroki Zoltán & DE-siroki-10689.jpg \\
\hline 919 & Lathyrus palustris L. & Tiszafüred & 1968 & Siroki Zoltán & DE-siroki-10690.jpg \\
\hline 921 & Lathyrus sylvestris L. & Berettyóújfalu & 1959 & Siroki Zoltán & DE-siroki-10715.jpg \\
\hline 921 & Lathyrus sylvestris L. & Berettyóújfalu & 1959 & Siroki Zoltán & DE-siroki-10716.jpg \\
\hline 921 & Lathyrus sylvestris L. & Egyek & 1947 & Siroki Zoltán & DE-siroki-10717.jpg \\
\hline 921 & Lathyrus sylvestris L. & Egyek & 1947 & Siroki Zoltán & DE-siroki-10718.jpg \\
\hline 922 & Lathyrus latifolius L. & "Bükk-hg." & 1983 & Siroki Zoltán & DE-siroki-10729.jpg \\
\hline 922 & Lathyrus latifolius L. & Aszaló & 1944 & Siroki Zoltán & DE-siroki-10725.jpg \\
\hline 922 & Lathyrus latifolius L. & Budapest & 1941 & Siroki Zoltán & DE-siroki-10723.jpg \\
\hline 922 & Lathyrus latifolius L. & Budapest & 1941 & Siroki Zoltán & DE-siroki-10724.jpg \\
\hline 922 & Lathyrus latifolius L. & Budapest & 1950 & Siroki Zoltán & DE-siroki-10722.jpg \\
\hline 922 & Lathyrus latifolius L. & Pomáz & 1957 & Siroki Zoltán & DE-siroki-10726.jpg \\
\hline 922 & Lathyrus latifolius L. & Szilvásvárad & 1954 & Siroki Zoltán & DE-siroki-10727.jpg \\
\hline 922 & Lathyrus latifolius L. & Szilvásvárad & 1954 & Siroki Zoltán & DE-siroki-10728.jpg \\
\hline 924 & $\begin{array}{l}\text { Lathyrus transsylvanicus } \\
\text { (Spreng.) Fritsch }\end{array}$ & "Bükk-hg." & 1927 & Kováts Ferenc & DE-siroki-10778.jpg \\
\hline 925 & Lathyrus pallescens (M. Bieb.) K. Koch & Budapest & 1951 & Siroki Zoltán & DE-siroki-10732.jpg \\
\hline 925 & Lathyrus pallescens (M. Bieb.) K. Koch & Budapest & 1951 & Siroki Zoltán & DE-siroki-10730.jpg \\
\hline 925 & Lathyrus pallescens (M. Bieb.) K. Koch & Budapest & 1951 & Siroki Zoltán & DE-siroki-10731.jpg \\
\hline 926 & Lathyrus lacteus (M. Bieb.) Wissjul. & Budapest & 1951 & Siroki Zoltán & DE-siroki-10738.jpg \\
\hline 926 & Lathyrus lacteus (M. Bieb.) Wissjul. & Budapest & 1951 & Siroki Zoltán & DE-siroki-10739.jpg \\
\hline 926 & Lathyrus lacteus (M. Bieb.) Wissjul. & Budapest & 1951 & Siroki Zoltán & DE-siroki-10740.jpg \\
\hline 926 & Lathyrus lacteus (M. Bieb.) Wissjul. & Budapest & 1964 & Siroki Zoltán & DE-siroki-10744.jpg \\
\hline 926 & Lathyrus lacteus (M. Bieb.) Wissjul. & Budapest & 1964 & Siroki Zoltán & DE-siroki-10745.jpg \\
\hline 926 & Lathyrus lacteus (M. Bieb.) Wissjul. & Budapest & 1970 & Siroki Zoltán & DE-siroki-10743.jpg \\
\hline 926 & Lathyrus lacteus (M. Bieb.) Wissjul. & Egerbakta & 1968 & Siroki Zoltán & DE-siroki-10742.jpg \\
\hline 926 & Lathyrus lacteus (M. Bieb.) Wissjul. & Pécs & 1958 & Siroki Zoltán & DE-siroki-10741.jpg \\
\hline 928 & Lathyrus niger (L.) Bernh. & Hollóháza & 1940 & Siroki Zoltán & DE-siroki-10747.jpg \\
\hline 929 & Lathyrus vernus (L.) Bernh. & "Bükk-hg." & 1966 & Siroki Zoltán & DE-siroki-10759.jpg \\
\hline 929 & Lathyrus vernus (L.) Bernh. & "Dobogókő" & 1957 & Siroki Zoltán & DE-siroki-10760.jpg \\
\hline 929 & Lathyrus vernus (L.) Bernh. & "Nagymező" & 1959 & Halász Tibor & DE-siroki-10754.jpg \\
\hline 929 & Lathyrus vernus (L.) Bernh. & "Nagymező" & 1959 & Halász Tibor & DE-siroki-10755.jpg \\
\hline 929 & Lathyrus vernus (L.) Bernh. & Budapest & 1960 & Siroki Zoltán & DE-siroki-10756.jpg \\
\hline 929 & Lathyrus vernus (L.) Bernh. & Budapest & 1970 & Siroki Zoltán & DE-siroki-10757.jpg \\
\hline 929 & Lathyrus vernus (L.) Bernh. & Budapest & 1970 & Siroki Zoltán & DE-siroki-10758.jpg \\
\hline 929 & Lathyrus vernus (L.) Bernh. & Hosszúhetény & 1958 & Siroki Zoltán & DE-siroki-10761.jpg \\
\hline 929 & Lathyrus vernus (L.) Bernh. & Hosszúhetény & 1958 & Siroki Zoltán & DE-siroki-10762.jpg \\
\hline 929 & Lathyrus vernus (L.) Bernh. & Hosszúhetény & 1958 & Siroki Zoltán & DE-siroki-10763.jpg \\
\hline 929 & Lathyrus vernus (L.) Bernh. & Pécs & 1956 & Jeney Endre & DE-siroki-10751.jpg \\
\hline 929 & Lathyrus vernus (L.) Bernh. & Pécs & 1958 & Siroki Zoltán & DE-siroki-10764.jpg \\
\hline 929 & Lathyrus vernus (L.) Bernh. & Sárospatak & 1955 & Simon Tiborné & DE-siroki-10753.jpg \\
\hline 929 & Lathyrus vernus (L.) Bernh. & Szarvaskő & 1958 & Siroki Zoltán & DE-siroki-10750.jpg \\
\hline 929 & Lathyrus vernus (L.) Bernh. & Tarpa & 1955 & Farkas Attila & DE-siroki-10752.jpg \\
\hline
\end{tabular}




\begin{tabular}{|c|c|c|c|c|c|}
\hline $\begin{array}{l}\text { Sorszám / } \\
\text { Number }\end{array}$ & Taxon-név / Taxon-name & $\begin{array}{l}\text { Település / } \\
\text { Settlement }\end{array}$ & $\begin{array}{l}\text { Év / } \\
\text { Year }\end{array}$ & $\begin{array}{l}\text { Gyűjtő / } \\
\text { Collector }\end{array}$ & Fájlnév / File-name \\
\hline 930 & Lathyrus venetus (Mill.) Wohlf. & Pécs & 1958 & Siroki Zoltán & DE-siroki-10765.jpg \\
\hline 930 & Lathyrus venetus (Mill.) Wohlf. & Pécs & 1958 & Siroki Zoltán & DE-siroki-10766.jpg \\
\hline 930 & Lathyrus venetus (Mill.) Wohlf. & Pécs & 1958 & Siroki Zoltán & DE-siroki-10767.jpg \\
\hline 930 & Lathyrus venetus (Mill.) Wohlf. & Pécs & 1958 & Siroki Zoltán & DE-siroki-10768.jpg \\
\hline 930 & Lathyrus venetus (Mill.) Wohlf. & Pécs & 1958 & Siroki Zoltán & DE-siroki-10769.jpg \\
\hline 933 & Ononis pusilla L. & "Cserhát" & 1958 & - & DE-siroki-09860.jpg \\
\hline 933 & Ononis pusilla L. & "Cserhát" & 1958 & - & DE-siroki-09861.jpg \\
\hline 933 & Ononis pusilla L. & "Cserhát" & 1958 & - & DE-siroki-09862.jpg \\
\hline 933 & Ononis pusilla L. & Balatonederics & 1955 & Siroki Zoltán & DE-siroki-09867.jpg \\
\hline 933 & Ononis pusilla L. & Nagykovácsi & 1950 & Siroki Zoltán & DE-siroki-09863.jpg \\
\hline 933 & Ononis pusilla L. & Nagykovácsi & 1950 & Siroki Zoltán & DE-siroki-09865.jpg \\
\hline 933 & Ononis pusilla L. & Nagykovácsi & 1950 & Siroki Zoltán & DE-siroki-09866.jpg \\
\hline 933 & Ononis pusilla L. & Nagykovácsi & 1957 & Siroki Zoltán & DE-siroki-09864.jpg \\
\hline 934 & Ononis spinosa L. & Budapest & 1941 & Siroki Zoltán & DE-siroki-09882.jpg \\
\hline 934 & Ononis spinosa L. & Keszthely & 1955 & Siroki Zoltán & DE-siroki-09879.jpg \\
\hline 934 & Ononis spinosa L. & Máriakálnok & 1939 & Siroki Zoltán & DE-siroki-09883.jpg \\
\hline 934 & Ononis spinosa L. & Méra & 1943 & Siroki Zoltán & DE-siroki-09881.jpg \\
\hline 934 & Ononis spinosa L. & Szikszó & 1944 & Siroki Zoltán & DE-siroki-09880.jpg \\
\hline 935 & Ononis arvensis L. & Csaroda & 1962 & Siroki Zoltán & DE-siroki-09868.jpg \\
\hline 935 & Ononis arvensis L. & Debrecen & 1947 & Siroki Zoltán & DE-siroki-09869.jpg \\
\hline 935 & Ononis arvensis L. & Szilvásvárad & 1954 & Siroki Zoltán & DE-siroki-09870.jpg \\
\hline 936 & Ononis spinosiformis Simonk. & Debrecen & 1948 & Siroki Zoltán & DE-siroki-09877.jpg \\
\hline 936 & Ononis spinosiformis Simonk. & Debrecen & 1948 & Siroki Zoltán & DE-siroki-09878.jpg \\
\hline 936 & Ononis spinosiformis Simonk. & Debrecen & 1948 & Siroki Zoltán & DE-siroki-09876.jpg \\
\hline 936 & Ononis spinosiformis Simonk. & Penyige & 1971 & Siroki Zoltán & DE-siroki-09874.jpg \\
\hline 936 & Ononis spinosiformis Simonk. & Penyige & 1971 & Siroki Zoltán & DE-siroki-09875.jpg \\
\hline 936 & Ononis spinosiformis Simonk. & Vésztő & 1894 & Borbás Vince & DE-siroki-09872.jpg \\
\hline 937 & Melilotus albus Desr. & Debrecen & 1947 & Siroki Zoltán & DE-siroki-09947.jpg \\
\hline 938 & $\begin{array}{l}\text { Melilotus dentatus } \\
\text { (Waldst. et Kit.) Pers. }\end{array}$ & Debrecen & 1947 & Siroki Zoltán & DE-siroki-09938.jpg \\
\hline 938 & $\begin{array}{l}\text { Melilotus dentatus } \\
\text { (Waldst. et Kit.) Pers. }\end{array}$ & Debrecen & 1947 & Siroki Zoltán & DE-siroki-09939.jpg \\
\hline 938 & $\begin{array}{l}\text { Melilotus dentatus } \\
\text { (Waldst. et Kit.) Pers. }\end{array}$ & Debrecen & 1947 & Siroki Zoltán & DE-siroki-09940.jpg \\
\hline 938 & $\begin{array}{l}\text { Melilotus dentatus } \\
\text { (Waldst. et Kit.) Pers. }\end{array}$ & Debrecen & 1947 & Siroki Zoltán & DE-siroki-09941.jpg \\
\hline 938 & $\begin{array}{l}\text { Melilotus dentatus } \\
\text { (Waldst. et Kit.) Pers. }\end{array}$ & Debrecen & 1947 & Siroki Zoltán & DE-siroki-09942.jpg \\
\hline 938 & $\begin{array}{l}\text { Melilotus dentatus } \\
\text { (Waldst. et Kit.) Pers. }\end{array}$ & Hortobágy & 1947 & Siroki Zoltán & DE-siroki-09943.jpg \\
\hline 939 & Melilotus altissimus Thuill. & Szentendre & 1913 & Degen Árpád & DE-siroki-09944.jpg \\
\hline 939 & Melilotus altissimus Thuill. & Szentendre & 1914 & Degen Árpád & DE-siroki-09945.jpg \\
\hline 940 & Melilotus officinalis (L.) Pall. & Debrecen & 1947 & Siroki Zoltán & DE-siroki-09946.jpg \\
\hline 941 & Trigonella caerulea (L.) Ser. & Budapest & 1951 & Siroki Zoltán & DE-siroki-09891.jpg \\
\hline 942 & Trigonella procumbens (Besser) Rchb. & Budapest & 1951 & Siroki Zoltán & DE-siroki-09890.jpg \\
\hline 942 & Trigonella procumbens (Besser) Rchb. & Kardoskút & 1975 & Siroki Zoltán & DE-siroki-09888.jpg \\
\hline 942 & Trigonella procumbens (Besser) Rchb. & Kardoskút & 1975 & Siroki Zoltán & DE-siroki-09889.jpg \\
\hline 942 & Trigonella procumbens (Besser) Rchb. & Kardoskút & 1985 & Siroki Zoltán & DE-siroki-09885.jpg \\
\hline 942 & Trigonella procumbens (Besser) Rchb. & Kardoskút & 1985 & Siroki Zoltán & DE-siroki-09886.jpg \\
\hline 942 & Trigonella procumbens (Besser) Rchb. & Kardoskút & - & Siroki Zoltán & DE-siroki-09887.jpg \\
\hline
\end{tabular}




\begin{tabular}{|c|c|c|c|c|c|}
\hline $\begin{array}{l}\text { Sorszám / } \\
\text { Number }\end{array}$ & Taxon-név / Taxon-name & $\begin{array}{l}\text { Település / } \\
\text { Settlement }\end{array}$ & $\begin{array}{l}\text { Év / } \\
\text { Year }\end{array}$ & $\begin{array}{l}\text { Gyűjtő / } \\
\text { Collector }\end{array}$ & Fájlnév / File-name \\
\hline 946 & Medicago $\times$ varia Martyn & Garadna & 1943 & Siroki Zoltán & DE-siroki-09936.jpg \\
\hline 946 & Medicago $\times$ varia Martyn & Mosonmagyaróvár & 1939 & Siroki Zoltán & DE-siroki-09934.jpg \\
\hline 946 & Medicago $\times$ varia Martyn & Mosonmagyaróvár & 1939 & Siroki Zoltán & DE-siroki-09935.jpg \\
\hline 946 & Medicago $\times$ varia Martyn & Mosonmagyaróvár & 1939 & Siroki Zoltán & DE-siroki-09937.jpg \\
\hline 947 & Medicago falcata L. & Debrecen & 1947 & Siroki Zoltán & DE-siroki-09909.jpg \\
\hline 947 & Medicago falcata L. & Máriakálnok & 1939 & Siroki Zoltán & DE-siroki-09910.jpg \\
\hline 947 & Medicago falcata L. & Mosonmagyaróvár & 1939 & Siroki Zoltán & DE-siroki-09912.jpg \\
\hline 948 & Medicago lupulina L. & Debrecen & 1947 & Siroki Zoltán & DE-siroki-09902.jpg \\
\hline 948 & Medicago lupulina L. & Debrecen & 1948 & Siroki Zoltán & DE-siroki-09901.jpg \\
\hline 948 & Medicago lupulina L. & Debrecen & 1949 & Siroki Zoltán & DE-siroki-09904.jpg \\
\hline 948 & Medicago lupulina L. & Debrecen & 1949 & Siroki Zoltán & DE-siroki-09903.jpg \\
\hline 948 & Medicago lupulina L. & Debrecen & 1967 & Gondola István & DE-siroki-09905.jpg \\
\hline 948 & Medicago lupulina L. & Mosonmagyaróvár & 1939 & Siroki Zoltán & DE-siroki-09907.jpg \\
\hline 949 & Medicago monspeliaca (L.) Trautv. & Budapest & 1905 & Thaisz Lajos & DE-siroki-09893.jpg \\
\hline 949 & Medicago monspeliaca (L.) Trautv. & Dömsöd & 1952 & Siroki Zoltán & DE-siroki-09894.jpg \\
\hline 949 & Medicago monspeliaca (L.) Trautv. & Dömsöd & 1952 & Siroki Zoltán & DE-siroki-09895.jpg \\
\hline 949 & Medicago monspeliaca (L.) Trautv. & Dömsöd & 1952 & Siroki Zoltán & DE-siroki-09896.jpg \\
\hline 949 & Medicago monspeliaca (L.) Trautv. & Pilisvörösvár & 1920 & Degen Árpád & DE-siroki-09892.jpg \\
\hline 950 & Medicago prostrata Jacq. & "Vértes" & 1957 & Siroki Zoltán & DE-siroki-09915.jpg \\
\hline 950 & Medicago prostrata Jacq. & Budapest & 1941 & Siroki Zoltán & DE-siroki-09918.jpg \\
\hline 950 & Medicago prostrata Jacq. & Budapest & 1948 & Siroki Zoltán & DE-siroki-09917.jpg \\
\hline 950 & Medicago prostrata Jacq. & Budapest & 1948 & Siroki Zoltán & DE-siroki-09916.jpg \\
\hline 950 & Medicago prostrata Jacq. & Budapest & 1962 & Siroki Zoltán & DE-siroki-09913.jpg \\
\hline 950 & Medicago prostrata Jacq. & Budapest & 1962 & Siroki Zoltán & DE-siroki-09914.jpg \\
\hline 950 & Medicago prostrata Jacq. & Sátoraljaújhely & 1944 & Siroki Zoltán & DE-siroki-09919.jpg \\
\hline 953 & Medicago minima (L.) L. & Boldogkőváralja & 1944 & Siroki Zoltán & DE-siroki-09932.jpg \\
\hline 953 & Medicago minima (L.) L. & Budapest & 1944 & Siroki Zoltán & DE-siroki-09931.jpg \\
\hline 953 & Medicago minima (L.) L. & Kardoskút & 1975 & Siroki Zoltán & DE-siroki-09926.jpg \\
\hline 953 & Medicago minima (L.) L. & Kardoskút & 1975 & Siroki Zoltán & DE-siroki-09927.jpg \\
\hline 956 & Trifolium subterraneum L. & Biharugra & 1961 & Siroki Zoltán & DE-siroki-09949.jpg \\
\hline 958 & Trifolium hybridum L. & Hortobágy & 1966 & $\begin{array}{l}\text { Pankucsi } \\
\text { Lászlóné }\end{array}$ & DE-siroki-10062.jpg \\
\hline 958 & Trifolium hybridum L. & Tiszafüred & 1949 & Siroki Zoltán & DE-siroki-10063.jpg \\
\hline 958 & Trifolium hybridum L. & Tiszafüred & 1949 & Siroki Zoltán & DE-siroki-10065.jpg \\
\hline 958 & Trifolium hybridum L. & Tiszafüred & 1949 & Siroki Zoltán & DE-siroki-10064.jpg \\
\hline 959 & Trifolium micranthum Viv. & Biharugra & 1961 & Siroki Zoltán & DE-siroki-10011.jpg \\
\hline 959 & Trifolium micranthum Viv. & Biharugra & 1961 & Siroki Zoltán & DE-siroki-10012.jpg \\
\hline 959 & Trifolium micranthum Viv. & Biharugra & 1961 & Siroki Zoltán & DE-siroki-10010.jpg \\
\hline 959 & Trifolium micranthum Viv. & Biharugra & 1961 & Siroki Zoltán & DE-siroki-10013.jpg \\
\hline 959 & Trifolium micranthum Viv. & Biharugra & 1961 & Siroki Zoltán & DE-siroki-10014.jpg \\
\hline 961 & Trifolium aureum Pollich & $\begin{array}{l}\text { "Bükk-hg, } \\
\text { Kiskerekhegy" }\end{array}$ & 1959 & Siroki Zoltán & DE-siroki-09996.jpg \\
\hline 961 & Trifolium aureum Pollich & "Bükk-hg." & 1983 & Siroki Zoltán & DE-siroki-09994.jpg \\
\hline 961 & Trifolium aureum Pollich & "Nagymező" & 1959 & Siroki Zoltán & DE-siroki-09987.jpg \\
\hline 961 & Trifolium aureum Pollich & "Nagymező" & 1959 & Siroki Zoltán & DE-siroki-09988.jpg \\
\hline 961 & Trifolium aureum Pollich & Egyek & 1947 & Siroki Zoltán & DE-siroki-10000.jpg \\
\hline 961 & Trifolium aureum Pollich & Gödöllő & 1952 & Siroki Zoltán & DE-siroki-09999.jpg \\
\hline
\end{tabular}




\begin{tabular}{|c|c|c|c|c|c|}
\hline $\begin{array}{l}\text { Sorszám / } \\
\text { Number }\end{array}$ & Taxon-név / Taxon-name & $\begin{array}{l}\text { Település / } \\
\text { Settlement }\end{array}$ & $\begin{array}{l}\text { Év / } \\
\text { Year }\end{array}$ & $\begin{array}{l}\text { Gyűjtő / } \\
\text { Collector }\end{array}$ & Fájlnév / File-name \\
\hline 961 & Trifolium aureum Pollich & Háromhuta & 1961 & Siroki Zoltán & DE-siroki-09984.jpg \\
\hline 961 & Trifolium aureum Pollich & Háromhuta & 1961 & Siroki Zoltán & DE-siroki-09985.jpg \\
\hline 961 & Trifolium aureum Pollich & Háromhuta & 1961 & Siroki Zoltán & DE-siroki-09986.jpg \\
\hline 961 & Trifolium aureum Pollich & Hollóháza & 1940 & Siroki Zoltán & DE-siroki-10001.jpg \\
\hline 961 & Trifolium aureum Pollich & Pomáz & 1909 & Kocsis István & DE-siroki-09992.jpg \\
\hline 961 & Trifolium aureum Pollich & Pomáz & 1909 & Kocsis István & DE-siroki-09995.jpg \\
\hline 961 & Trifolium aureum Pollich & Pomáz & 1952 & Siroki Zoltán & DE-siroki-09998.jpg \\
\hline 961 & Trifolium aureum Pollich & Pomáz & 1952 & Siroki Zoltán & DE-siroki-09997.jpg \\
\hline 961 & Trifolium aureum Pollich & Regéc & 1967 & Siroki Zoltán & DE-siroki-09983.jpg \\
\hline 961 & Trifolium aureum Pollich & Szilvásvárad & 1954 & Siroki Zoltán & DE-siroki-09990.jpg \\
\hline 961 & Trifolium aureum Pollich & Szilvásvárad & 1954 & Siroki Zoltán & DE-siroki-09989.jpg \\
\hline 962 & Trifolium dubium Sibth. & Biharugra & 1961 & Siroki Zoltán & DE-siroki-10008.jpg \\
\hline 962 & Trifolium dubium Sibth. & Biharugra & 1961 & Siroki Zoltán & DE-siroki-10009.jpg \\
\hline 962 & Trifolium dubium Sibth. & Biharugra & 1961 & Siroki Zoltán & DE-siroki-10015.jpg \\
\hline 962 & Trifolium dubium Sibth. & Biharugra & 1961 & Siroki Zoltán & DE-siroki-10016.jpg \\
\hline 962 & Trifolium dubium Sibth. & Debrecen & 1950 & Siroki Zoltán & DE-siroki-10006.jpg \\
\hline 962 & Trifolium dubium Sibth. & Debrecen & 1954 & Siroki Zoltán & DE-siroki-10007.jpg \\
\hline 962 & Trifolium dubium Sibth. & Gödöllő & 1951 & Siroki Zoltán & DE-siroki-10004.jpg \\
\hline 963 & Trifolium campestre Schreb. & Boldogkőváralja & 1944 & Siroki Zoltán & DE-siroki-09975.jpg \\
\hline 963 & Trifolium campestre Schreb. & Boldogkőváralja & 1944 & Siroki Zoltán & DE-siroki-09974.jpg \\
\hline 963 & Trifolium campestre Schreb. & Budapest & 1940 & Siroki Zoltán & DE-siroki-09972.jpg \\
\hline 963 & Trifolium campestre Schreb. & Debrecen & 1947 & Siroki Zoltán & DE-siroki-09977.jpg \\
\hline 963 & Trifolium campestre Schreb. & Debrecen & 1950 & Siroki Zoltán & DE-siroki-09978.jpg \\
\hline 963 & Trifolium campestre Schreb. & Gödöllő & 1952 & Siroki Zoltán & DE-siroki-09979.jpg \\
\hline 963 & Trifolium campestre Schreb. & Hortobágy & 1959 & Siroki Zoltán & DE-siroki-09969.jpg \\
\hline 963 & Trifolium campestre Schreb. & Hortobágy & 1959 & Siroki Zoltán & DE-siroki-09970.jpg \\
\hline 963 & Trifolium campestre Schreb. & Hortobágy & 1959 & Siroki Zoltán & DE-siroki-09971.jpg \\
\hline 963 & Trifolium campestre Schreb. & Tokaj & 1971 & Siroki Zoltán & DE-siroki-09981.jpg \\
\hline 963 & Trifolium campestre Schreb. & Tokaj & 1971 & Siroki Zoltán & DE-siroki-09982.jpg \\
\hline 963 & Trifolium campestre Schreb. & Újléta & 1967 & Siroki Zoltán & DE-siroki-09980.jpg \\
\hline 964 & Trifolium strictum L. & Biharugra & 1961 & Siroki Zoltán & DE-siroki-10035.jpg \\
\hline 964 & Trifolium strictum L. & Biharugra & 1961 & Siroki Zoltán & DE-siroki-10037.jpg \\
\hline 964 & Trifolium strictum L. & Biharugra & 1961 & Siroki Zoltán & DE-siroki-10036.jpg \\
\hline 964 & Trifolium strictum L. & Hortobágy & 1959 & Siroki Zoltán & DE-siroki-10030.jpg \\
\hline 964 & Trifolium strictum L. & Hortobágy & 1959 & Siroki Zoltán & DE-siroki-10031.jpg \\
\hline 964 & Trifolium strictum L. & Hortobágy & 1959 & Siroki Zoltán & DE-siroki-10032.jpg \\
\hline 964 & Trifolium strictum L. & Hortobágy & 1959 & Siroki Zoltán & DE-siroki-10034.jpg \\
\hline 964 & Trifolium strictum L. & Hortobágy & 1960 & Siroki Zoltán & DE-siroki-10033.jpg \\
\hline 964 & Trifolium strictum L. & Hortobágy & 1975 & Siroki Zoltán & DE-siroki-10027.jpg \\
\hline 964 & Trifolium strictum L. & Hortobágy & 1975 & Siroki Zoltán & DE-siroki-10028.jpg \\
\hline 964 & Trifolium strictum L. & Hortobágy & 1975 & Siroki Zoltán & DE-siroki-10029.jpg \\
\hline 964 & Trifolium strictum L. & Kardoskút & 1975 & Siroki Zoltán & DE-siroki-10038.jpg \\
\hline 965 & Trifolium repens L. & Debrecen & 1948 & Siroki Zoltán & DE-siroki-10067.jpg \\
\hline 965 & Trifolium repens L. & Debrecen & 1948 & Siroki Zoltán & DE-siroki-10068.jpg \\
\hline 965 & Trifolium repens L. & Debrecen & 1948 & Siroki Zoltán & DE-siroki-10069.jpg \\
\hline 965 & Trifolium repens L. & Debrecen & 1948 & Siroki Zoltán & DE-siroki-10070.jpg \\
\hline
\end{tabular}




\begin{tabular}{|c|c|c|c|c|c|}
\hline $\begin{array}{l}\text { Sorszám / } \\
\text { Number }\end{array}$ & Taxon-név / Taxon-name & $\begin{array}{l}\text { Település / } \\
\text { Settlement }\end{array}$ & $\begin{array}{l}\text { Év / } \\
\text { Year }\end{array}$ & $\begin{array}{l}\text { Gyűjtő / } \\
\text { Collector }\end{array}$ & Fájlnév / File-name \\
\hline 966 & Trifolium angulatum Waldst. et Kit. & Debrecen & 1955 & Siroki Zoltán & DE-siroki-10060.jpg \\
\hline 966 & Trifolium angulatum Waldst. et Kit. & Debrecen & 1955 & Siroki Zoltán & DE-siroki-10061.jpg \\
\hline 966 & Trifolium angulatum Waldst. et Kit. & Hortobágy & 1954 & Siroki Zoltán & DE-siroki-10056.jpg \\
\hline 966 & Trifolium angulatum Waldst. et Kit. & Hortobágy & 1954 & Siroki Zoltán & DE-siroki-10052.jpg \\
\hline 966 & Trifolium angulatum Waldst. et Kit. & Hortobágy & 1954 & Siroki Zoltán & DE-siroki-10053.jpg \\
\hline 966 & Trifolium angulatum Waldst. et Kit. & Hortobágy & 1955 & Siroki Zoltán & DE-siroki-10058.jpg \\
\hline 966 & Trifolium angulatum Waldst. et Kit. & Hortobágy & 1959 & Siroki Zoltán & DE-siroki-10051.jpg \\
\hline 966 & Trifolium angulatum Waldst. et Kit. & Hortobágy & 1959 & Siroki Zoltán & DE-siroki-10054.jpg \\
\hline 966 & Trifolium angulatum Waldst. et Kit. & Hortobágy & 1959 & Siroki Zoltán & DE-siroki-10055.jpg \\
\hline 966 & Trifolium angulatum Waldst. et Kit. & Hortobágy & 1959 & Siroki Zoltán & DE-siroki-10057.jpg \\
\hline 966 & Trifolium angulatum Waldst. et Kit. & Hortobágy & 1959 & Siroki Zoltán & DE-siroki-10059.jpg \\
\hline 966 & Trifolium angulatum Waldst. et Kit. & Hortobágy & - & Siroki Zoltán & DE-siroki-10050.jpg \\
\hline 967 & Trifolium montanum L. & "Dobogókő" & 1957 & Siroki Zoltán & DE-siroki-10018.jpg \\
\hline 967 & Trifolium montanum L. & "Nagymező" & 1959 & Siroki Zoltán & DE-siroki-10019.jpg \\
\hline 967 & Trifolium montanum L. & "Nagymező" & 1959 & Siroki Zoltán & DE-siroki-10020.jpg \\
\hline 967 & Trifolium montanum L. & "Nagymező" & 1959 & Siroki Zoltán & DE-siroki-10021.jpg \\
\hline 967 & Trifolium montanum L. & "Nagymező" & 1959 & Siroki Zoltán & DE-siroki-10022.jpg \\
\hline 967 & Trifolium montanum L. & Debrecen & 1950 & Siroki Zoltán & DE-siroki-10023.jpg \\
\hline 967 & Trifolium montanum L. & Hollóháza & 1940 & Siroki Zoltán & DE-siroki-10024.jpg \\
\hline 967 & Trifolium montanum L. & Püski & 1939 & Siroki Zoltán & DE-siroki-10026.jpg \\
\hline 967 & Trifolium montanum L. & Tokaj & 1971 & Siroki Zoltán & DE-siroki-10017.jpg \\
\hline 968 & Trifolium retusum L. & Budapest & 1951 & Siroki Zoltán & DE-siroki-10044.jpg \\
\hline 968 & Trifolium retusum L. & Budapest & 1951 & Siroki Zoltán & DE-siroki-10045.jpg \\
\hline 968 & Trifolium retusum L. & Budapest & 1951 & Siroki Zoltán & DE-siroki-10047.jpg \\
\hline 968 & Trifolium retusum L. & Budapest & 1952 & Siroki Zoltán & DE-siroki-10046.jpg \\
\hline 968 & Trifolium retusum L. & Debrecen & 1950 & Siroki Zoltán & DE-siroki-10039.jpg \\
\hline 968 & Trifolium retusum L. & Debrecen & 1955 & Siroki Zoltán & DE-siroki-10040.jpg \\
\hline 968 & Trifolium retusum $\mathrm{L}$. & Debrecen & 1955 & Siroki Zoltán & DE-siroki-10042.jpg \\
\hline 968 & Trifolium retusum L. & Debrecen & 1970 & Siroki Zoltán & DE-siroki-10041.jpg \\
\hline 968 & Trifolium retusum L. & Hortobágy & 1954 & Siroki Zoltán & DE-siroki-10048.jpg \\
\hline 968 & Trifolium retusum L. & Hortobágy & 1959 & Siroki Zoltán & DE-siroki-10049.jpg \\
\hline 969 & Trifolium vesiculosum Savi & Debrecen & 1950 & Siroki Zoltán & DE-siroki-09953.jpg \\
\hline 969 & Trifolium vesiculosum Savi & Egyek & 1959 & Siroki Zoltán & DE-siroki-09952.jpg \\
\hline 970 & Trifolium fragiferum L. & Debrecen & 1948 & Siroki Zoltán & DE-siroki-09959.jpg \\
\hline 970 & Trifolium fragiferum L. & Debrecen & 1948 & Siroki Zoltán & DE-siroki-09960.jpg \\
\hline 970 & Trifolium fragiferum L. & Debrecen & 1948 & Siroki Zoltán & DE-siroki-09955.jpg \\
\hline 970 & Trifolium fragiferum $\mathrm{L}$. & Debrecen & 1948 & Siroki Zoltán & DE-siroki-09956.jpg \\
\hline 970 & Trifolium fragiferum L. & Debrecen & 1948 & Siroki Zoltán & DE-siroki-09958.jpg \\
\hline 970 & Trifolium fragiferum $L$. & Debrecen & 1958 & Pethő Menyhért & DE-siroki-09954.jpg \\
\hline 970 & Trifolium fragiferum $\mathrm{L}$. & Debrecen & 1962 & Siroki Zoltán & DE-siroki-09957.jpg \\
\hline 970 & Trifolium fragiferum $L$. & Méra & 1943 & Siroki Zoltán & DE-siroki-09961.jpg \\
\hline 970 & Trifolium fragiferum $L$. & Mosonmagyaróvár & 1939 & Siroki Zoltán & DE-siroki-09962.jpg \\
\hline 971 & Trifolium resupinatum L. & Budapest & 1911 & Kocsis István & DE-siroki-09964.jpg \\
\hline 971 & Trifolium resupinatum L. & Budapest & 1912 & Degen Árpád & DE-siroki-09963.jpg \\
\hline 972 & Trifolium rubens L. & "Dobogókő" & 1957 & Siroki Zoltán & DE-siroki-10082.jpg \\
\hline 972 & Trifolium rubens L. & "Dobogókő" & 1957 & Siroki Zoltán & DE-siroki-10083.jpg \\
\hline
\end{tabular}




\begin{tabular}{|c|c|c|c|c|c|}
\hline $\begin{array}{l}\text { Sorszám / } \\
\text { Number }\end{array}$ & Taxon-név / Taxon-name & $\begin{array}{l}\text { Település / } \\
\text { Settlement }\end{array}$ & $\begin{array}{l}\text { Év / } \\
\text { Year }\end{array}$ & $\begin{array}{l}\text { Gyújitő / } \\
\text { Collector }\end{array}$ & Fájlnév / File-name \\
\hline 972 & Trifolium rubens L. & Aszaló & 1944 & Siroki Zoltán & DE-siroki-10075.jpg \\
\hline 972 & Trifolium rubens L. & Aszaló & 1944 & Siroki Zoltán & DE-siroki-10076.jpg \\
\hline 972 & Trifolium rubens L. & Budaörs & 1966 & Siroki Zoltán & DE-siroki-10077.jpg \\
\hline 972 & Trifolium rubens L. & Budaörs & 1966 & Siroki Zoltán & DE-siroki-10078.jpg \\
\hline 972 & Trifolium rubens L. & Budapest & 1941 & Siroki Zoltán & DE-siroki-10074.jpg \\
\hline 972 & Trifolium rubens L. & Pomáz & 1954 & Siroki Zoltán & DE-siroki-10079.jpg \\
\hline 972 & Trifolium rubens L. & Pomáz & 1954 & Siroki Zoltán & DE-siroki-10080.jpg \\
\hline 972 & Trifolium rubens L. & Pomáz & 1954 & Siroki Zoltán & DE-siroki-10081.jpg \\
\hline 972 & Trifolium rubens L. & Szinpetri & 1974 & Siroki Zoltán & DE-siroki-10073.jpg \\
\hline 973 & Trifolium alpestre L. & "Dobogókő" & 1965 & Siroki Zoltán & DE-siroki-10084.jpg \\
\hline 973 & Trifolium alpestre L. & Bélapátfalva & 1956 & Halász Tibor & DE-siroki-10089.jpg \\
\hline 973 & Trifolium alpestre L. & Debrecen & 1950 & Siroki Zoltán & DE-siroki-10086.jpg \\
\hline 973 & Trifolium alpestre L. & Debrecen & 1950 & Siroki Zoltán & DE-siroki-10088.jpg \\
\hline 973 & Trifolium alpestre L. & Debrecen & - & Siroki Zoltán & DE-siroki-10087.jpg \\
\hline 975 & Trifolium ochroleucon Huds. & "Mátra" & 1984 & Siroki Zoltán & DE-siroki-10092.jpg \\
\hline 975 & Trifolium ochroleucon Huds. & "Nagymező" & 1959 & Siroki Zoltán & DE-siroki-10100.jpg \\
\hline 975 & Trifolium ochroleucon Huds. & "Nagymező" & 1959 & Siroki Zoltán & DE-siroki-10101.jpg \\
\hline 975 & Trifolium ochroleucon Huds. & "Nagymező" & 1959 & Siroki Zoltán & DE-siroki-10102.jpg \\
\hline 975 & Trifolium ochroleucon Huds. & "Nagymező" & 1959 & Siroki Zoltán & DE-siroki-10103.jpg \\
\hline 975 & Trifolium ochroleucon Huds. & "Nagymező" & 1959 & Siroki Zoltán & DE-siroki-10104.jpg \\
\hline 975 & Trifolium ochroleucon Huds. & "Nagymező" & 1959 & Siroki Zoltán & DE-siroki-10105.jpg \\
\hline 975 & Trifolium ochroleucon Huds. & "Nagymező" & 1959 & Siroki Zoltán & DE-siroki-10106.jpg \\
\hline 975 & Trifolium ochroleucon Huds. & Budapest & 1951 & Siroki Zoltán & DE-siroki-10112.jpg \\
\hline 975 & Trifolium ochroleucon Huds. & Csaroda & 1960 & Siroki Zoltán & DE-siroki-10093.jpg \\
\hline 975 & Trifolium ochroleucon Huds. & Csaroda & 1960 & Siroki Zoltán & DE-siroki-10094.jpg \\
\hline 975 & Trifolium ochroleucon Huds. & Csaroda & 1960 & Siroki Zoltán & DE-siroki-10095.jpg \\
\hline 975 & Trifolium ochroleucon Huds. & Csaroda & 1960 & Siroki Zoltán & DE-siroki-10096.jpg \\
\hline 975 & Trifolium ochroleucon Huds. & Csaroda & 1960 & Siroki Zoltán & DE-siroki-10097.jpg \\
\hline 975 & Trifolium ochroleucon Huds. & Csaroda & 1960 & Siroki Zoltán & DE-siroki-10098.jpg \\
\hline 975 & Trifolium ochroleucon Huds. & Csaroda & 1960 & Siroki Zoltán & DE-siroki-10099.jpg \\
\hline 975 & Trifolium ochroleucon Huds. & Háromhuta & 1967 & Siroki Zoltán & DE-siroki-10109.jpg \\
\hline 975 & Trifolium ochroleucon Huds. & Háromhuta & 1967 & Siroki Zoltán & DE-siroki-10110.jpg \\
\hline 976 & Trifolium pannonicum Jacq. & "Dobogókő" & 1957 & Siroki Zoltán & DE-siroki-10123.jpg \\
\hline 976 & Trifolium pannonicum Jacq. & "Dobogókő" & 1957 & Siroki Zoltán & DE-siroki-10124.jpg \\
\hline 976 & Trifolium pannonicum Jacq. & "Dobogókő" & 1957 & Siroki Zoltán & DE-siroki-10125.jpg \\
\hline 976 & Trifolium pannonicum Jacq. & Háromhuta & 1960 & Siroki Zoltán & DE-siroki-10113.jpg \\
\hline 976 & Trifolium pannonicum Jacq. & Háromhuta & 1960 & Siroki Zoltán & DE-siroki-10114.jpg \\
\hline 976 & Trifolium pannonicum Jacq. & Háromhuta & 1961 & Siroki Zoltán & DE-siroki-10115.jpg \\
\hline 976 & Trifolium pannonicum Jacq. & Háromhuta & 1984 & Siroki Zoltán & DE-siroki-10116.jpg \\
\hline 976 & Trifolium pannonicum Jacq. & Háromhuta & 1984 & Siroki Zoltán & DE-siroki-10117.jpg \\
\hline 976 & Trifolium pannonicum Jacq. & Tokaj & 1966 & Siroki Zoltán & DE-siroki-10119.jpg \\
\hline 976 & Trifolium pannonicum Jacq. & Tokaj & 1966 & Siroki Zoltán & DE-siroki-10120.jpg \\
\hline 976 & Trifolium pannonicum Jacq. & Tokaj & 1966 & Siroki Zoltán & DE-siroki-10121.jpg \\
\hline 976 & Trifolium pannonicum Jacq. & Tokaj & 1966 & Siroki Zoltán & DE-siroki-10122.jpg \\
\hline 976 & Trifolium pannonicum Jacq. & Tokaj & 1971 & Siroki Zoltán & DE-siroki-10118.jpg \\
\hline 977 & Trifolium medium L. & $\begin{array}{l}\text { "Bükk-hg, } \\
\text { Kiskerekhegy" }\end{array}$ & 1959 & Halász Tibor & DE-siroki-10131.jpg \\
\hline
\end{tabular}




\begin{tabular}{|c|c|c|c|c|c|}
\hline $\begin{array}{l}\text { Sorszám / } \\
\text { Number }\end{array}$ & Taxon-név / Taxon-name & $\begin{array}{l}\text { Település / } \\
\text { Settlement }\end{array}$ & $\begin{array}{l}\text { Év / } \\
\text { Year }\end{array}$ & $\begin{array}{l}\text { Gyüjtő / } \\
\text { Collector }\end{array}$ & Fájlnév / File-name \\
\hline 977 & Trifolium medium L. & $\begin{array}{l}\text { "Bükk-hg, } \\
\text { Kiskerekhegy" }\end{array}$ & 1959 & Halász Tibor & DE-siroki-10132.jpg \\
\hline 977 & Trifolium medium L. & Debrecen & 1948 & Siroki Zoltán & DE-siroki-10133.jpg \\
\hline 977 & Trifolium medium L. & Szilvásvárad & 1954 & Siroki Zoltán & DE-siroki-10134.jpg \\
\hline 977 & Trifolium medium L. & Szilvásvárad & 1954 & Siroki Zoltán & DE-siroki-10135.jpg \\
\hline 977 & Trifolium medium L. & Tokaj & 1971 & Siroki Zoltán & DE-siroki-10128.jpg \\
\hline 977 & Trifolium medium L. & Tokaj & 1971 & Siroki Zoltán & DE-siroki-10129.jpg \\
\hline 977 & Trifolium medium L. & Tokaj & 1971 & Siroki Zoltán & DE-siroki-10130.jpg \\
\hline 978 & Trifolium pratense L. & Debrecen & 1947 & Siroki Zoltán & DE-siroki-10142.jpg \\
\hline 978 & Trifolium pratense L. & Debrecen & 1948 & Siroki Zoltán & DE-siroki-10140.jpg \\
\hline 978 & Trifolium pratense L. & Debrecen & 1948 & Siroki Zoltán & DE-siroki-10141.jpg \\
\hline 978 & Trifolium pratense L. & Debrecen & 1954 & Siroki Zoltán & DE-siroki-10139.jpg \\
\hline 978 & Trifolium pratense L. & Mikepércs & 1965 & $\begin{array}{l}\text { Pankucsi } \\
\text { Lászlóné }\end{array}$ & DE-siroki-10143.jpg \\
\hline 980 & Trifolium striatum L. & Budapest & 1951 & Siroki Zoltán & DE-siroki-10146.jpg \\
\hline 980 & Trifolium striatum L. & Budapest & 1951 & Siroki Zoltán & DE-siroki-10147.jpg \\
\hline 980 & Trifolium striatum L. & Budapest & 1951 & Siroki Zoltán & DE-siroki-10148.jpg \\
\hline 980 & Trifolium striatum L. & Budapest & 1951 & Siroki Zoltán & DE-siroki-10149.jpg \\
\hline 980 & Trifolium striatum L. & Budapest & 1951 & Siroki Zoltán & DE-siroki-10151.jpg \\
\hline 980 & Trifolium striatum L. & Budapest & 1951 & Siroki Zoltán & DE-siroki-10152.jpg \\
\hline 980 & Trifolium striatum L. & Budapest & 1952 & Siroki Zoltán & DE-siroki-10150.jpg \\
\hline 980 & Trifolium striatum L. & Hortobágy & 1959 & Siroki Zoltán & DE-siroki-10153.jpg \\
\hline 980 & Trifolium striatum L. & Hortobágy & 1959 & Siroki Zoltán & DE-siroki-10155.jpg \\
\hline 980 & Trifolium striatum L. & Hortobágy & 1961 & Siroki Zoltán & DE-siroki-10154.jpg \\
\hline 980 & Trifolium striatum L. & Hortobágy & 1961 & Siroki Zoltán & DE-siroki-10156.jpg \\
\hline 980 & Trifolium striatum L. & Kardoskút & 1975 & Siroki Zoltán & DE-siroki-10144.jpg \\
\hline 980 & Trifolium striatum L. & Kardoskút & 1975 & Siroki Zoltán & DE-siroki-10145.jpg \\
\hline 981 & Trifolium diffusum Ehrh. & Debrecen & 1954 & Siroki Zoltán & DE-siroki-10160.jpg \\
\hline 981 & Trifolium diffusum Ehrh. & Debrecen & 1954 & Siroki Zoltán & DE-siroki-10161.jpg \\
\hline 981 & Trifolium diffusum Ehrh. & Debrecen & 1954 & Siroki Zoltán & DE-siroki-10162.jpg \\
\hline 981 & Trifolium diffusum Ehrh. & Debrecen & 1954 & Siroki Zoltán & DE-siroki-10163.jpg \\
\hline 981 & Trifolium diffusum Ehrh. & Debrecen & 1954 & Siroki Zoltán & DE-siroki-10164.jpg \\
\hline 981 & Trifolium diffusum Ehrh. & Debrecen & 1954 & Siroki Zoltán & DE-siroki-10165.jpg \\
\hline 981 & Trifolium diffusum Ehrh. & Debrecen & 1954 & Siroki Zoltán & DE-siroki-10167.jpg \\
\hline 981 & Trifolium diffusum Ehrh. & Debrecen & 1954 & Siroki Zoltán & DE-siroki-10168.jpg \\
\hline 981 & Trifolium diffusum Ehrh. & Debrecen & 1969 & Siroki Zoltán & DE-siroki-10169.jpg \\
\hline 981 & Trifolium diffusum Ehrh. & Debrecen & 1969 & Siroki Zoltán & DE-siroki-10170.jpg \\
\hline 981 & Trifolium diffusum Ehrh. & Debrecen & 1969 & Siroki Zoltán & DE-siroki-10171.jpg \\
\hline 981 & Trifolium diffusum Ehrh. & Debrecen & 1969 & Siroki Zoltán & DE-siroki-10174.jpg \\
\hline 981 & Trifolium diffusum Ehrh. & Debrecen & 1969 & Siroki Zoltán & DE-siroki-10175.jpg \\
\hline 981 & Trifolium diffusum Ehrh. & Debrecen & 1969 & Siroki Zoltán & DE-siroki-10176.jpg \\
\hline 981 & Trifolium diffusum Ehrh. & Debrecen & 1969 & Siroki Zoltán & DE-siroki-10172.jpg \\
\hline 981 & Trifolium diffusum Ehrh. & Debrecen & 1969 & Siroki Zoltán & DE-siroki-10173.jpg \\
\hline 981 & Trifolium diffusum Ehrh. & Debrecen & 1975 & Siroki Zoltán & DE-siroki-10158.jpg \\
\hline 981 & Trifolium diffusum Ehrh. & Debrecen & 1975 & Siroki Zoltán & DE-siroki-10159.jpg \\
\hline 981 & Trifolium diffusum Ehrh. & Debrecen & 1982 & Siroki Zoltán & DE-siroki-10157.jpg \\
\hline 981 & Trifolium diffusum Ehrh. & Debrecen & - & Siroki Zoltán & DE-siroki-10166.jpg \\
\hline
\end{tabular}




\begin{tabular}{|c|c|c|c|c|c|}
\hline $\begin{array}{l}\text { Sorszám / } \\
\text { Number }\end{array}$ & Taxon-név / Taxon-name & $\begin{array}{l}\text { Település / } \\
\text { Settlement }\end{array}$ & $\begin{array}{l}\text { Év / } \\
\text { Year }\end{array}$ & $\begin{array}{l}\text { Gyűjtő / } \\
\text { Collector }\end{array}$ & Fájlnév / File-name \\
\hline 981 & Trifolium diffusum Ehrh. & Egyek & 1959 & Siroki Zoltán & DE-siroki-10177.jpg \\
\hline 981 & Trifolium diffusum Ehrh. & Egyek & 1959 & Siroki Zoltán & DE-siroki-10178.jpg \\
\hline 981 & Trifolium diffusum Ehrh. & Egyek & 1959 & Siroki Zoltán & DE-siroki-10179.jpg \\
\hline 981 & Trifolium diffusum Ehrh. & Egyek & 1959 & Siroki Zoltán & DE-siroki-10180.jpg \\
\hline 981 & Trifolium diffusum Ehrh. & Egyek & 1959 & Siroki Zoltán & DE-siroki-10181.jpg \\
\hline 981 & Trifolium diffusum Ehrh. & Egyek & 1959 & Siroki Zoltán & DE-siroki-10182.jpg \\
\hline 981 & Trifolium diffusum Ehrh. & Egyek & 1959 & Siroki Zoltán & DE-siroki-10183.jpg \\
\hline 981 & Trifolium diffusum Ehrh. & Egyek & 1959 & Siroki Zoltán & DE-siroki-10184.jpg \\
\hline 981 & Trifolium diffusum Ehrh. & Egyek & 1959 & Siroki Zoltán & DE-siroki-10185.jpg \\
\hline 982 & Trifolium incarnatum L. & Debrecen & 1950 & Siroki Zoltán & DE-siroki-10188.jpg \\
\hline 983 & Trifolium arvense L. & Budapest & 1940 & Siroki Zoltán & DE-siroki-10190.jpg \\
\hline 983 & Trifolium arvense L. & Debrecen & 1948 & Siroki Zoltán & DE-siroki-10189.jpg \\
\hline 984 & Dorycnium herbaceum Vill. & Háromhuta & 1960 & Halász Tibor & DE-siroki-10244.jpg \\
\hline 984 & Dorycnium herbaceum Vill. & Háromhuta & 1960 & Halász Tibor & DE-siroki-10245.jpg \\
\hline 984 & Dorycnium herbaceum Vill. & Tahitótfalu & 1950 & Kárpáti Zoltán & DE-siroki-10246.jpg \\
\hline 985 & Dorycnium germanicum (Gremli) Rikli & Aggtelek & 1972 & Siroki Zoltán & DE-siroki-10229.jpg \\
\hline 985 & Dorycnium germanicum (Gremli) Rikli & Budaörs & 1966 & Siroki Zoltán & DE-siroki-10232.jpg \\
\hline 985 & Dorycnium germanicum (Gremli) Rikli & Budapest & 1941 & Siroki Zoltán & DE-siroki-10241.jpg \\
\hline 985 & Dorycnium germanicum (Gremli) Rikli & Budapest & 1944 & Siroki Zoltán & DE-siroki-10236.jpg \\
\hline 985 & Dorycnium germanicum (Gremli) Rikli & Budapest & 1944 & Siroki Zoltán & DE-siroki-10239.jpg \\
\hline 985 & Dorycnium germanicum (Gremli) Rikli & Budapest & 1948 & Siroki Zoltán & DE-siroki-10234.jpg \\
\hline 985 & Dorycnium germanicum (Gremli) Rikli & Budapest & 1962 & Siroki Zoltán & DE-siroki-10235.jpg \\
\hline 985 & Dorycnium germanicum (Gremli) Rikli & Budapest & 1962 & Siroki Zoltán & DE-siroki-10237.jpg \\
\hline 985 & Dorycnium germanicum (Gremli) Rikli & Budapest & 1962 & Siroki Zoltán & DE-siroki-10238.jpg \\
\hline 985 & Dorycnium germanicum (Gremli) Rikli & Budapest & 1962 & Siroki Zoltán & DE-siroki-10240.jpg \\
\hline 985 & Dorycnium germanicum (Gremli) Rikli & Budapest & 1983 & Siroki Zoltán & DE-siroki-10228.jpg \\
\hline 985 & Dorycnium germanicum (Gremli) Rikli & Budapest & 1984 & Siroki Zoltán & DE-siroki-10231.jpg \\
\hline 985 & Dorycnium germanicum (Gremli) Rikli & Egyek & 1947 & Siroki Zoltán & DE-siroki-10233.jpg \\
\hline 985 & Dorycnium germanicum (Gremli) Rikli & Háromhuta & 1961 & Siroki Zoltán & DE-siroki-10243.jpg \\
\hline 985 & Dorycnium germanicum (Gremli) Rikli & Komlóska & 1984 & Siroki Zoltán & DE-siroki-10230.jpg \\
\hline 985 & Dorycnium germanicum (Gremli) Rikli & Lábatlan & 1986 & Siroki Zoltán & DE-siroki-10226.jpg \\
\hline 985 & Dorycnium germanicum (Gremli) Rikli & Lábatlan & 1986 & Siroki Zoltán & DE-siroki-10227.jpg \\
\hline 986 & Lotus angustissimus L. & Biharugra & 1961 & Siroki Zoltán & DE-siroki-10262.jpg \\
\hline 986 & Lotus angustissimus L. & Biharugra & 1961 & Siroki Zoltán & DE-siroki-10263.jpg \\
\hline 986 & Lotus angustissimus L. & Biharugra & 1961 & Siroki Zoltán & DE-siroki-10264.jpg \\
\hline 986 & Lotus angustissimus L. & Biharugra & 1961 & Siroki Zoltán & DE-siroki-10265.jpg \\
\hline 986 & Lotus angustissimus $\mathrm{L}$. & Biharugra & 1961 & Siroki Zoltán & DE-siroki-10266.jpg \\
\hline 986 & Lotus angustissimus L. & Hortobágy & 1959 & Siroki Zoltán & DE-siroki-10255.jpg \\
\hline 986 & Lotus angustissimus L. & Hortobágy & 1959 & Siroki Zoltán & DE-siroki-10256.jpg \\
\hline 986 & Lotus angustissimus $\mathrm{L}$. & Hortobágy & 1959 & Siroki Zoltán & DE-siroki-10257.jpg \\
\hline 986 & Lotus angustissimus L. & Hortobágy & 1960 & Siroki Zoltán & DE-siroki-10258.jpg \\
\hline 986 & Lotus angustissimus L. & Hortobágy & 1960 & Siroki Zoltán & DE-siroki-10259.jpg \\
\hline 986 & Lotus angustissimus L. & Hortobágy & 1960 & Siroki Zoltán & DE-siroki-10260.jpg \\
\hline 986 & Lotus angustissimus L. & Hortobágy & 1960 & Siroki Zoltán & DE-siroki-10261.jpg \\
\hline 988 & Lotus tenuis Waldst. et Kit. & Debrecen & 1947 & Siroki Zoltán & DE-siroki-10282.jpg \\
\hline 988 & Lotus tenuis Waldst. et Kit. & Debrecen & 1947 & Siroki Zoltán & DE-siroki-10284.jpg \\
\hline
\end{tabular}




\begin{tabular}{|c|c|c|c|c|c|}
\hline $\begin{array}{l}\text { Sorszám / } \\
\text { Number }\end{array}$ & Taxon-név / Taxon-name & $\begin{array}{l}\text { Település / } \\
\text { Settlement }\end{array}$ & $\begin{array}{l}\text { Év / } \\
\text { Year }\end{array}$ & $\begin{array}{l}\text { Gyűjtő / } \\
\text { Collector }\end{array}$ & Fájlnév / File-name \\
\hline 988 & Lotus tenuis Waldst. et Kit. & Hortobágy & 1955 & Siroki Zoltán & DE-siroki-10273.jpg \\
\hline 988 & Lotus tenuis Waldst. et Kit. & Hortobágy & 1955 & Siroki Zoltán & DE-siroki-10274.jpg \\
\hline 988 & Lotus tenuis Waldst. et Kit. & Hortobágy & 1975 & Siroki Zoltán & DE-siroki-10272.jpg \\
\hline 989 & Lotus borbasii Ujhelyi & Budaörs & 1966 & Siroki Zoltán & DE-siroki-10275.jpg \\
\hline 989 & Lotus borbasii Ujhelyi & Budaörs & 1966 & Siroki Zoltán & DE-siroki-10276.jpg \\
\hline 989 & Lotus borbasii Ujhelyi & Budapest & 1904 & $\begin{array}{l}\text { Thaisz Lajos - } \\
\text { Baán Lajos }\end{array}$ & DE-siroki-10268.jpg \\
\hline 989 & Lotus borbasii Ujhelyi & Budapest & 1951 & Siroki Zoltán & DE-siroki-10277.jpg \\
\hline 989 & Lotus borbasii Ujhelyi & Pomáz & 1952 & Siroki Zoltán & DE-siroki-10271.jpg \\
\hline 990 & Lotus corniculatus L. & Budapest & 1952 & Siroki Zoltán & DE-siroki-10269.jpg \\
\hline 990 & Lotus corniculatus L. & Budapest & 1962 & Siroki Zoltán & DE-siroki-11377.jpg \\
\hline 990 & Lotus corniculatus L. & Debrecen & 1947 & Siroki Zoltán & DE-siroki-10283.jpg \\
\hline 990 & Lotus corniculatus L. & Debrecen & 1948 & Siroki Zoltán & DE-siroki-10281.jpg \\
\hline 990 & Lotus corniculatus L. & Debrecen & 1958 & Pethő Menyhért & DE-siroki-10278.jpg \\
\hline 990 & Lotus corniculatus L. & Debrecen & 1958 & Pethő Menyhért & DE-siroki-10279.jpg \\
\hline 990 & Lotus corniculatus L. & Debrecen & 1958 & Pethő Menyhért & DE-siroki-10280.jpg \\
\hline 990 & Lotus corniculatus L. & Szilvásvárad & 1960 & Siroki Zoltán & DE-siroki-11378.jpg \\
\hline 991 & Tetragonolobus maritimus (L.) Roth & Aszaló & 1944 & Siroki Zoltán & DE-siroki-10250.jpg \\
\hline 991 & Tetragonolobus maritimus (L.) Roth & Aszaló & 1944 & Siroki Zoltán & DE-siroki-10251.jpg \\
\hline 991 & Tetragonolobus maritimus (L.) Roth & Budaörs & 1941 & Siroki Zoltán & DE-siroki-10252.jpg \\
\hline 991 & Tetragonolobus maritimus (L.) Roth & Debrecen & 1947 & Siroki Zoltán & DE-siroki-10248.jpg \\
\hline 991 & Tetragonolobus maritimus (L.) Roth & Debrecen & 1950 & Siroki Zoltán & DE-siroki-10249.jpg \\
\hline 991 & Tetragonolobus maritimus (L.) Roth & Mosonmagyaróvár & 1939 & Siroki Zoltán & DE-siroki-10253.jpg \\
\hline 992 & Securigera varia (L.) Lassen & Debrecen & 1947 & Siroki Zoltán & DE-siroki-10430.jpg \\
\hline 994 & Anthyllis vulneraria L. & "Hármaskő" & 1957 & Siroki Zoltán & DE-siroki-10194.jpg \\
\hline 994 & Anthyllis vulneraria L. & "Hármaskő" & 1957 & Siroki Zoltán & DE-siroki-10195.jpg \\
\hline 994 & Anthyllis vulneraria L. & "Hármaskő" & 1957 & Siroki Zoltán & DE-siroki-10196.jpg \\
\hline 994 & Anthyllis vulneraria L. & "Nagymező" & 1959 & Halász Tibor & DE-siroki-10193.jpg \\
\hline 994 & Anthyllis vulneraria L. & Budaörs & 1964 & Siroki Zoltán & DE-siroki-10200.jpg \\
\hline 994 & Anthyllis vulneraria L. & Budaörs & 1964 & Siroki Zoltán & DE-siroki-10201.jpg \\
\hline 994 & Anthyllis vulneraria L. & Budaörs & 1964 & Siroki Zoltán & DE-siroki-10202.jpg \\
\hline 994 & Anthyllis vulneraria L. & Budapest & 1948 & Siroki Zoltán & DE-siroki-10198.jpg \\
\hline 994 & Anthyllis vulneraria L. & Cserszegtomaj & 1955 & Siroki Zoltán & DE-siroki-10197.jpg \\
\hline 994 & Anthyllis vulneraria L. & Háromhuta & 1961 & Siroki Zoltán & DE-siroki-10199.jpg \\
\hline 994 & Anthyllis vulneraria L. & Mosonmagyaróvár & 1939 & Siroki Zoltán & DE-siroki-10207.jpg \\
\hline 994 & Anthyllis vulneraria L. & Nagykovácsi & 1959 & Siroki Zoltán & DE-siroki-10210.jpg \\
\hline 994 & Anthyllis vulneraria L. & Nagykovácsi & 1959 & Siroki Zoltán & DE-siroki-10213.jpg \\
\hline 994 & Anthyllis vulneraria L. & Nagykovácsi & 1959 & Siroki Zoltán & DE-siroki-10216.jpg \\
\hline 994 & Anthyllis vulneraria L. & Pilisszentiván & 1952 & Siroki Zoltán & DE-siroki-10208.jpg \\
\hline 994 & Anthyllis vulneraria L. & Pilisszentiván & 1952 & Siroki Zoltán & DE-siroki-10214.jpg \\
\hline 994 & Anthyllis vulneraria L. & Pilisszentiván & 1952 & Siroki Zoltán & DE-siroki-10215.jpg \\
\hline 994 & Anthyllis vulneraria L. & Pilisszentiván & 1952 & Siroki Zoltán & DE-siroki-10205.jpg \\
\hline 994 & Anthyllis vulneraria L. & Pilisszentiván & 1952 & Siroki Zoltán & DE-siroki-10206.jpg \\
\hline 996 & Coronilla coronata L. & Budaörs & 1966 & Siroki Zoltán & DE-siroki-10436.jpg \\
\hline 996 & Coronilla coronata L. & Budapest & 1951 & Siroki Zoltán & DE-siroki-10435.jpg \\
\hline 996 & Coronilla coronata L. & Budapest & 1951 & Siroki Zoltán & DE-siroki-10434.jpg \\
\hline 996 & Coronilla coronata L. & Budapest & 1957 & Siroki Zoltán & DE-siroki-10433.jpg \\
\hline
\end{tabular}




\begin{tabular}{|c|c|c|c|c|c|}
\hline $\begin{array}{l}\text { Sorszám / } \\
\text { Number }\end{array}$ & Taxon-név / Taxon-name & $\begin{array}{l}\text { Település / } \\
\text { Settlement }\end{array}$ & $\begin{array}{l}\text { Év / } \\
\text { Year }\end{array}$ & $\begin{array}{l}\text { Gyújtő / } \\
\text { Collector }\end{array}$ & Fájlnév / File-name \\
\hline 996 & Coronilla coronata L. & Cserszegtomaj & 1955 & Siroki Zoltán & DE-siroki-10437.jpg \\
\hline 997 & Coronilla vaginalis Lam. & "Fáni-völgy" & 1955 & Siroki Zoltán & DE-siroki-10438.jpg \\
\hline 997 & Coronilla vaginalis Lam. & "Fáni-völgy" & 1955 & $\begin{array}{l}\text { Siroki Zoltán - } \\
\text { Farkas Attila }\end{array}$ & DE-siroki-10439.jpg \\
\hline 997 & Coronilla vaginalis Lam. & "Fáni-völgy" & 1955 & $\begin{array}{l}\text { Siroki Zoltán - } \\
\text { Farkas Attila }\end{array}$ & DE-siroki-10440.jpg \\
\hline 997 & Coronilla vaginalis Lam. & Pilisszentiván & 1950 & Kárpáti Zoltán & DE-siroki-10445.jpg \\
\hline 997 & Coronilla vaginalis Lam. & Pilisszentiván & 1952 & Siroki Zoltán & DE-siroki-10443.jpg \\
\hline 997 & Coronilla vaginalis Lam. & Pilisszentiván & 1952 & Siroki Zoltán & DE-siroki-10441.jpg \\
\hline 997 & Coronilla vaginalis Lam. & Pilisszentiván & 1952 & Siroki Zoltán & DE-siroki-10442.jpg \\
\hline 997 & Coronilla vaginalis Lam. & Pilisszentiván & 1952 & Siroki Zoltán & DE-siroki-10444.jpg \\
\hline 998 & Hippocrepis emerus (L.) Lassen & Gyenesdiás & 1972 & Siroki Zoltán & DE-siroki-10423.jpg \\
\hline 998 & Hippocrepis emerus (L.) Lassen & Gyenesdiás & 1972 & Siroki Zoltán & DE-siroki-10424.jpg \\
\hline 998 & Hippocrepis emerus (L.) Lassen & Gyenesdiás & 1972 & Siroki Zoltán & DE-siroki-10425.jpg \\
\hline 998 & Hippocrepis emerus (L.) Lassen & Gyenesdiás & 1972 & Siroki Zoltán & DE-siroki-10426.jpg \\
\hline 998 & Hippocrepis emerus (L.) Lassen & Gyenesdiás & 1972 & Siroki Zoltán & DE-siroki-10427.jpg \\
\hline 998 & Hippocrepis emerus (L.) Lassen & Gyenesdiás & 1972 & Siroki Zoltán & DE-siroki-10428.jpg \\
\hline 998 & Hippocrepis emerus (L.) Lassen & Gyenesdiás & 1972 & Siroki Zoltán & DE-siroki-10429.jpg \\
\hline 999 & Hippocrepis comosa L. & Aggtelek & 1941 & Siroki Zoltán & DE-siroki-10449.jpg \\
\hline 999 & Hippocrepis comosa L. & Budapest & 1951 & Siroki Zoltán & DE-siroki-10446.jpg \\
\hline 999 & Hippocrepis comosa L. & Budapest & 1964 & Siroki Zoltán & DE-siroki-10447.jpg \\
\hline 999 & Hippocrepis comosa L. & Gyenesdiás & 1955 & Siroki Zoltán & DE-siroki-10448.jpg \\
\hline 1000 & Onobrychis arenaria (Kit.) DC. & Tokaj & 1971 & Siroki Zoltán & DE-siroki-10462.jpg \\
\hline 1000 & Onobrychis arenaria (Kit.) DC. & Tokaj & 1971 & Siroki Zoltán & DE-siroki-10463.jpg \\
\hline 1000 & Onobrychis arenaria (Kit.) DC. & Tokaj & 1971 & Siroki Zoltán & DE-siroki-10464.jpg \\
\hline 1000 & Onobrychis arenaria (Kit.) DC. & Tokaj & 1971 & Siroki Zoltán & DE-siroki-10465.jpg \\
\hline 1000 & Onobrychis arenaria (Kit.) DC. & Tokaj & 1971 & Siroki Zoltán & DE-siroki-10466.jpg \\
\hline 1000 & Onobrychis arenaria (Kit.) DC. & Veresegyház & 1960 & Siroki Zoltán & DE-siroki-10467.jpg \\
\hline 1000 & Onobrychis arenaria (Kit.) DC. & Veresegyház & 1960 & Siroki Zoltán & DE-siroki-10468.jpg \\
\hline 1000 & Onobrychis arenaria (Kit.) DC. & Veresegyház & 1960 & Siroki Zoltán & DE-siroki-10469.jpg \\
\hline 1000 & Onobrychis arenaria (Kit.) DC. & Veresegyház & 1960 & Siroki Zoltán & DE-siroki-10470.jpg \\
\hline 1000 & Onobrychis arenaria (Kit.) DC. & Veresegyház & 1960 & Siroki Zoltán & DE-siroki-10471.jpg \\
\hline 1000 & Onobrychis arenaria (Kit.) DC. & Veresegyház & 1960 & Siroki Zoltán & DE-siroki-10472.jpg \\
\hline 1000 & Onobrychis arenaria (Kit.) DC. & Veresegyház & 1960 & Siroki Zoltán & DE-siroki-10473.jpg \\
\hline 1001 & Onobrychis viciifolia Scop. & Debrecen & 1976 & Siroki Zoltán & DE-siroki-10458.jpg \\
\hline 1001 & Onobrychis viciifolia Scop. & Hortobágy & 1948 & Siroki Zoltán & DE-siroki-10459.jpg \\
\hline 1001 & Onobrychis viciifolia Scop. & Hortobágy & 1948 & Siroki Zoltán & DE-siroki-10460.jpg \\
\hline 1001 & Onobrychis viciifolia Scop. & Hortobágy & 1948 & Siroki Zoltán & DE-siroki-10461.jpg \\
\hline 1002 & Oxalis acetosella $\mathrm{L}$. & Pilismarót & 1957 & Siroki Zoltán & DE-siroki-10917.jpg \\
\hline 1002 & Oxalis acetosella L. & Pilismarót & 1957 & Siroki Zoltán & DE-siroki-10918.jpg \\
\hline 1002 & Oxalis acetosella L. & Szilvásvárad & 1966 & Siroki Zoltán & DE-siroki-10919.jpg \\
\hline 1003 & Oxalis stricta L. & Mosonmagyaróvár & 1939 & Siroki Zoltán & DE-siroki-10920.jpg \\
\hline 1004 & Oxalis corniculata L. & Debrecen & 1955 & Siroki Zoltán & DE-siroki-10929.jpg \\
\hline 1004 & Oxalis corniculata L. & Debrecen & 1961 & Siroki Zoltán & DE-siroki-10925.jpg \\
\hline 1004 & Oxalis corniculata L. & Debrecen & 1961 & Siroki Zoltán & DE-siroki-10926.jpg \\
\hline 1004 & Oxalis corniculata L. & Debrecen & 1961 & Siroki Zoltán & DE-siroki-10927.jpg \\
\hline 1004 & Oxalis corniculata L. & Debrecen & 1961 & Siroki Zoltán & DE-siroki-10928.jpg \\
\hline
\end{tabular}




\begin{tabular}{|c|c|c|c|c|c|}
\hline $\begin{array}{l}\text { Sorszám / } \\
\text { Number }\end{array}$ & Taxon-név / Taxon-name & $\begin{array}{l}\text { Település / } \\
\text { Settlement }\end{array}$ & $\begin{array}{l}\text { Év / } \\
\text { Year }\end{array}$ & $\begin{array}{l}\text { Gyűjtő / } \\
\text { Collector }\end{array}$ & Fájlnév / File-name \\
\hline 1004 & Oxalis corniculata L. & Debrecen & 1972 & Siroki Zoltán & DE-siroki-10922.jpg \\
\hline 1004 & Oxalis corniculata L. & Debrecen & 1972 & Siroki Zoltán & DE-siroki-10923.jpg \\
\hline 1004 & Oxalis corniculata L. & Debrecen & 1972 & Siroki Zoltán & DE-siroki-10924.jpg \\
\hline 1007 & Geranium robertianum L. & Debrecen & 1954 & Siroki Zoltán & DE-siroki-10791.jpg \\
\hline 1007 & Geranium robertianum L. & Debrecen & 1954 & Siroki Zoltán & DE-siroki-10792.jpg \\
\hline 1007 & Geranium robertianum L. & Debrecen & 1964 & Siroki Zoltán & DE-siroki-10790.jpg \\
\hline 1007 & Geranium robertianum L. & Hollóháza & 1940 & Siroki Zoltán & DE-siroki-10795.jpg \\
\hline 1007 & Geranium robertianum L. & Mosonmagyaróvár & 1939 & Siroki Zoltán & DE-siroki-10794.jpg \\
\hline 1008 & Geranium phaeum L. & "Nagymező" & 1959 & Halász Tibor & DE-siroki-10783.jpg \\
\hline 1008 & Geranium phaeum L. & Debrecen & 1954 & Siroki Zoltán & DE-siroki-10787.jpg \\
\hline 1008 & Geranium phaeum L. & Debrecen & 1954 & Siroki Zoltán & DE-siroki-10785.jpg \\
\hline 1008 & Geranium phaeum L. & Debrecen & 1954 & Siroki Zoltán & DE-siroki-10786.jpg \\
\hline 1008 & Geranium phaeum L. & Debrecen & 1954 & Siroki Zoltán & DE-siroki-10784.jpg \\
\hline 1009 & Geranium sanguineum L. & Budapest & 1956 & Gondola István & DE-siroki-10863.jpg \\
\hline 1009 & Geranium sanguineum L. & Debrecen & 1948 & Siroki Zoltán & DE-siroki-10864.jpg \\
\hline 1009 & Geranium sanguineum L. & Debrecen & 1948 & Siroki Zoltán & DE-siroki-10865.jpg \\
\hline 1010 & Geranium palustre E. Torner & "Nagymező" & 1958 & Siroki Zoltán & DE-siroki-10869.jpg \\
\hline 1010 & Geranium palustre E. Torner & Debrecen & 1950 & Siroki Zoltán & DE-siroki-10868.jpg \\
\hline 1010 & Geranium palustre E. Torner & Debrecen & 1954 & Siroki Zoltán & DE-siroki-10867.jpg \\
\hline 1011 & Geranium pratense L. & Debrecen & 1946 & Siroki Zoltán & DE-siroki-10897.jpg \\
\hline 1011 & Geranium pratense L. & Debrecen & 1947 & Siroki Zoltán & DE-siroki-10898.jpg \\
\hline 1011 & Geranium pratense L. & Debrecen & 1960 & Siroki Zoltán & DE-siroki-10879.jpg \\
\hline 1011 & Geranium pratense L. & Debrecen & 1960 & Siroki Zoltán & DE-siroki-10880.jpg \\
\hline 1011 & Geranium pratense L. & Debrecen & 1960 & Siroki Zoltán & DE-siroki-10881.jpg \\
\hline 1011 & Geranium pratense L. & Debrecen & 1960 & Siroki Zoltán & DE-siroki-10882.jpg \\
\hline 1011 & Geranium pratense L. & Debrecen & 1960 & Siroki Zoltán & DE-siroki-10883.jpg \\
\hline 1011 & Geranium pratense L. & Debrecen & 1960 & Siroki Zoltán & DE-siroki-10884.jpg \\
\hline 1011 & Geranium pratense L. & Debrecen & 1960 & Siroki Zoltán & DE-siroki-10885.jpg \\
\hline 1011 & Geranium pratense L. & Debrecen & 1960 & Siroki Zoltán & DE-siroki-10886.jpg \\
\hline 1011 & Geranium pratense L. & Debrecen & 1960 & Siroki Zoltán & DE-siroki-10887.jpg \\
\hline 1011 & Geranium pratense L. & Debrecen & 1960 & Siroki Zoltán & DE-siroki-10888.jpg \\
\hline 1011 & Geranium pratense L. & Debrecen & 1960 & Siroki Zoltán & DE-siroki-10889.jpg \\
\hline 1011 & Geranium pratense L. & Debrecen & 1960 & Siroki Zoltán & DE-siroki-10890.jpg \\
\hline 1011 & Geranium pratense L. & Debrecen & 1960 & Siroki Zoltán & DE-siroki-10891.jpg \\
\hline 1011 & Geranium pratense L. & Debrecen & 1960 & Siroki Zoltán & DE-siroki-10892.jpg \\
\hline 1011 & Geranium pratense L. & Debrecen & 1960 & Siroki Zoltán & DE-siroki-10893.jpg \\
\hline 1013 & Geranium lucidum L. & "Fáni-völgy" & 1955 & $\begin{array}{l}\text { Siroki Zoltán - } \\
\text { Farkas Attila }\end{array}$ & DE-siroki-10798.jpg \\
\hline 1013 & Geranium lucidum L. & "Fáni-völgy" & 1955 & $\begin{array}{l}\text { Siroki Zoltán - } \\
\text { Farkas Attila }\end{array}$ & DE-siroki-10799.jpg \\
\hline 1013 & Geranium lucidum L. & Budapest & 1952 & Siroki Zoltán & DE-siroki-10801.jpg \\
\hline 1013 & Geranium lucidum L. & Budapest & 1952 & Siroki Zoltán & DE-siroki-10802.jpg \\
\hline 1013 & Geranium lucidum L. & Lábatlan & 1986 & Siroki Zoltán & DE-siroki-10800.jpg \\
\hline 1013 & Geranium lucidum L. & Szendehely & 1926 & Degen Árpád & DE-siroki-10796.jpg \\
\hline 1014 & Geranium columbinum L. & Debrecen & 1950 & Siroki Zoltán & DE-siroki-10824.jpg \\
\hline 1014 & Geranium columbinum L. & Debrecen & 1950 & Siroki Zoltán & DE-siroki-10823.jpg \\
\hline 1014 & Geranium columbinum L. & Debrecen & 1950 & Siroki Zoltán & DE-siroki-10821.jpg \\
\hline
\end{tabular}




\begin{tabular}{|c|c|c|c|c|c|}
\hline $\begin{array}{l}\text { Sorszám / } \\
\text { Number }\end{array}$ & Taxon-név / Taxon-name & $\begin{array}{l}\text { Település / } \\
\text { Settlement }\end{array}$ & $\begin{array}{l}\text { Év / } \\
\text { Year }\end{array}$ & $\begin{array}{l}\text { Gyűjtő / } \\
\text { Collector }\end{array}$ & Fájlnév / File-name \\
\hline 1014 & Geranium columbinum L. & Debrecen & 1950 & Siroki Zoltán & DE-siroki-10822.jpg \\
\hline 1015 & Geranium dissectum Jusl. & Debrecen & 1956 & Siroki Zoltán & DE-siroki-10827.jpg \\
\hline 1015 & Geranium dissectum Jusl. & Debrecen & 1977 & Siroki Zoltán & DE-siroki-10828.jpg \\
\hline 1015 & Geranium dissectum Jusl. & Debrecen & 1977 & Siroki Zoltán & DE-siroki-10829.jpg \\
\hline 1015 & Geranium dissectum Jusl. & Debrecen & 1977 & Siroki Zoltán & DE-siroki-10830.jpg \\
\hline 1015 & Geranium dissectum Jusl. & Debrecen & 1977 & Siroki Zoltán & DE-siroki-10831.jpg \\
\hline 1015 & Geranium dissectum Jusl. & Gyenesdiás & - & Siroki Zoltán & DE-siroki-10840.jpg \\
\hline 1015 & Geranium dissectum Jusl. & Kardoskút & 1945 & Siroki Zoltán & DE-siroki-10833.jpg \\
\hline 1015 & Geranium dissectum Jusl. & Kardoskút & 1975 & Siroki Zoltán & DE-siroki-10832.jpg \\
\hline 1015 & Geranium dissectum Jusl. & Kardoskút & 1975 & Siroki Zoltán & DE-siroki-10834.jpg \\
\hline 1015 & Geranium dissectum Jusl. & Kardoskút & 1975 & Siroki Zoltán & DE-siroki-10835.jpg \\
\hline 1015 & Geranium dissectum Jusl. & Szentendre & 1918 & Degen Árpád & DE-siroki-10838.jpg \\
\hline 1015 & Geranium dissectum Jusl. & Zebegény & 1918 & Degen Árpád & DE-siroki-10837.jpg \\
\hline 1018 & Geranium divaricatum Ehrh. & Debrecen & 1947 & Siroki Zoltán & DE-siroki-10806.jpg \\
\hline 1018 & Geranium divaricatum Ehrh. & Debrecen & 1955 & $\begin{array}{l}\text { Siroki Zoltán - } \\
\text { Farkas Attila }\end{array}$ & DE-siroki-10815.jpg \\
\hline 1018 & Geranium divaricatum Ehrh. & Debrecen & 1955 & $\begin{array}{l}\text { Siroki Zoltán - } \\
\text { Farkas Attila }\end{array}$ & DE-siroki-10816.jpg \\
\hline 1018 & Geranium divaricatum Ehrh. & Debrecen & 1978 & Siroki Zoltán & DE-siroki-10807.jpg \\
\hline 1018 & Geranium divaricatum Ehrh. & Debrecen & 1978 & Siroki Zoltán & DE-siroki-10808.jpg \\
\hline 1018 & Geranium divaricatum Ehrh. & Debrecen & 1978 & Siroki Zoltán & DE-siroki-13380.jpg \\
\hline 1018 & Geranium divaricatum Ehrh. & Debrecen & 1978 & Siroki Zoltán & DE-siroki-13381.jpg \\
\hline 1020 & Geranium molle L. & Gödöllő & 1952 & Siroki Zoltán & DE-siroki-10820.jpg \\
\hline 1020 & Geranium molle L. & Gyenesdiás & 1953 & Siroki Zoltán & DE-siroki-10818.jpg \\
\hline 1020 & Geranium molle L. & Gyenesdiás & 1953 & Siroki Zoltán & DE-siroki-10819.jpg \\
\hline 1020 & Geranium molle L. & Vonyarcvashegy & 1930 & Rigler József & DE-siroki-10817.jpg \\
\hline 1021 & Geranium pusillum Burm. f. & Debrecen & 1956 & Siroki Zoltán & DE-siroki-10844.jpg \\
\hline 1021 & Geranium pusillum Burm. f. & Debrecen & 1978 & Siroki Zoltán & DE-siroki-10846.jpg \\
\hline 1021 & Geranium pusillum Burm. f. & Debrecen & 1984 & Siroki Zoltán & DE-siroki-10845.jpg \\
\hline 1021 & Geranium pusillum Burm. f. & Debrecen & 1984 & Siroki Zoltán & DE-siroki-10847.jpg \\
\hline 1021 & Geranium pusillum Burm. f. & Debrecen & 1984 & Siroki Zoltán & DE-siroki-10848.jpg \\
\hline 1021 & Geranium pusillum Burm. f. & Debrecen & 1984 & Siroki Zoltán & DE-siroki-10849.jpg \\
\hline 1021 & Geranium pusillum Burm. f. & Debrecen & 1984 & Siroki Zoltán & DE-siroki-10850.jpg \\
\hline 1021 & Geranium pusillum Burm. f. & Debrecen & 1984 & Siroki Zoltán & DE-siroki-10851.jpg \\
\hline 1022 & Geranium rotundifolium L. & "Szent-György-hegy" & 1955 & Siroki Zoltán & DE-siroki-10842.jpg \\
\hline 1022 & Geranium rotundifolium L. & "Szent-György-hegy" & 1955 & Siroki Zoltán & DE-siroki-10843.jpg \\
\hline 1023 & Erodium cicutarium (L.) L'Hér. & Debrecen & 1947 & Siroki Zoltán & DE-siroki-10913.jpg \\
\hline 1024 & Erodium hoefftianum C.A. Mey. & Gödöllő & 1951 & Siroki Zoltán & DE-siroki-10906.jpg \\
\hline 1024 & Erodium hoefftianum C.A. Mey. & Gödöllő & 1951 & Siroki Zoltán & DE-siroki-10907.jpg \\
\hline 1024 & Erodium hoefftianum C.A. Mey. & Gödöllő & 1951 & Siroki Zoltán & DE-siroki-10905.jpg \\
\hline 1024 & Erodium hoefftianum C.A. Mey. & Gödöllő & 1951 & Siroki Zoltán & DE-siroki-10910.jpg \\
\hline 1024 & Erodium hoefftianum C.A. Mey. & Gödöllő & 1951 & Siroki Zoltán & DE-siroki-10911.jpg \\
\hline 1024 & Erodium hoefftianum C.A. Mey. & Gödöllő & 1951 & Siroki Zoltán & DE-siroki-10904.jpg \\
\hline 1024 & Erodium hoefftianum C.A. Mey. & Gödöllő & 1951 & Siroki Zoltán & DE-siroki-10908.jpg \\
\hline 1024 & Erodium hoefftianum C.A. Mey. & Gödöllő & 1951 & Siroki Zoltán & DE-siroki-10909.jpg \\
\hline 1024 & Erodium hoefftianum C.A. Mey. & Gödöllő & 1951 & Siroki Zoltán & DE-siroki-10912.jpg \\
\hline 1025 & Erodium ciconium (Jusl.) L’Hér. & Budapest & 1951 & Siroki Zoltán & DE-siroki-10900.jpg \\
\hline
\end{tabular}




\begin{tabular}{|c|c|c|c|c|c|}
\hline $\begin{array}{l}\text { Sorszám / } \\
\text { Number }\end{array}$ & Taxon-név / Taxon-name & $\begin{array}{l}\text { Település / } \\
\text { Settlement }\end{array}$ & $\begin{array}{l}\text { Év / } \\
\text { Year }\end{array}$ & $\begin{array}{l}\text { Gyűjtő / } \\
\text { Collector }\end{array}$ & Fájlnév / File-name \\
\hline 1025 & Erodium ciconium (Jusl.) L'Hér. & Budapest & 1951 & Siroki Zoltán & DE-siroki-10899.jpg \\
\hline 1025 & Erodium ciconium (Jusl.) L'Hér. & Budapest & 1951 & Siroki Zoltán & DE-siroki-10901.jpg \\
\hline 1025 & Erodium ciconium (Jusl.) L’Hér. & Budapest & 1951 & Siroki Zoltán & DE-siroki-10902.jpg \\
\hline 1025 & Erodium ciconium (Jusl.) L'Hér. & Budapest & 1951 & Siroki Zoltán & DE-siroki-10903.jpg \\
\hline 1026 & Tribulus terrestris L. & Ágasegyháza & 1969 & Siroki Zoltán & DE-siroki-10982.jpg \\
\hline 1026 & Tribulus terrestris L. & Budapest & 1941 & Siroki Zoltán & DE-siroki-10986.jpg \\
\hline 1026 & Tribulus terrestris L. & Debrecen & 1947 & Siroki Zoltán & DE-siroki-10984.jpg \\
\hline 1026 & Tribulus terrestris L. & Debrecen & 1947 & Siroki Zoltán & DE-siroki-10985.jpg \\
\hline 1026 & Tribulus terrestris L. & Debrecen & 1950 & Siroki Zoltán & DE-siroki-10983.jpg \\
\hline 1027 & Linum catharticum L. & "Nagymező" & 1959 & Siroki Zoltán & DE-siroki-10930.jpg \\
\hline 1027 & Linum catharticum L. & Debrecen & 1958 & Siroki Zoltán & DE-siroki-10931.jpg \\
\hline 1027 & Linum catharticum L. & Debrecen & 1958 & Siroki Zoltán & DE-siroki-10932.jpg \\
\hline 1027 & Linum catharticum L. & Gyenesdiás & - & Siroki Zoltán & DE-siroki-10933.jpg \\
\hline 1029 & Linum dolomiticum Borbás & Pilisszentiván & 1950 & Kárpáti Zoltán & DE-siroki-10938.jpg \\
\hline 1029 & Linum dolomiticum Borbás & Pilisszentiván & 1952 & Siroki Zoltán & DE-siroki-10935.jpg \\
\hline 1029 & Linum dolomiticum Borbás & Pilisszentiván & 1952 & Siroki Zoltán & DE-siroki-10936.jpg \\
\hline 1029 & Linum dolomiticum Borbás & Pilisszentiván & 1952 & Siroki Zoltán & DE-siroki-10937.jpg \\
\hline 1030 & Linum flavum L. & Abaújszántó & 1943 & Siroki Zoltán & DE-siroki-10944.jpg \\
\hline 1030 & Linum flavum $\mathrm{L}$. & Budapest & 1948 & Siroki Zoltán & DE-siroki-10943.jpg \\
\hline 1030 & Linum flavum L. & Budapest & 1951 & Siroki Zoltán & DE-siroki-10941.jpg \\
\hline 1030 & Linum flavum L. & Budapest & 1951 & Siroki Zoltán & DE-siroki-10942.jpg \\
\hline 1030 & Linum flavum $\mathrm{L}$. & Szinpetri & 1974 & Siroki Zoltán & DE-siroki-10939.jpg \\
\hline 1030 & Linum flavum $\mathrm{L}$. & Szinpetri & 1974 & Siroki Zoltán & DE-siroki-10940.jpg \\
\hline 1031 & Linum tenuifolium L. & Budapest & 1944 & Siroki Zoltán & DE-siroki-10960.jpg \\
\hline 1031 & Linum tenuifolium $\mathrm{L}$. & Budapest & 1944 & Siroki Zoltán & DE-siroki-10961.jpg \\
\hline 1031 & Linum tenuifolium L. & Budapest & 1944 & Siroki Zoltán & DE-siroki-10962.jpg \\
\hline 1031 & Linum tenuifolium L. & Gyenesdiás & 1955 & Siroki Zoltán & DE-siroki-10965.jpg \\
\hline 1031 & Linum tenuifolium L. & Nagykovácsi & 1957 & Siroki Zoltán & DE-siroki-10964.jpg \\
\hline 1031 & Linum tenuifolium L. & Tokaj & 1971 & Siroki Zoltán & DE-siroki-10963.jpg \\
\hline 1032 & Linum hirsutum L. & Budapest & 1951 & Siroki Zoltán & DE-siroki-10951.jpg \\
\hline 1032 & Linum hirsutum L. & Budapest & 1951 & Siroki Zoltán & DE-siroki-10952.jpg \\
\hline 1032 & Linum hirsutum L. & Bugac & 1973 & Siroki Zoltán & DE-siroki-10953.jpg \\
\hline 1032 & Linum hirsutum L. & Ózd & 1958 & Pethő Menyhért & DE-siroki-10950.jpg \\
\hline 1032 & Linum hirsutum L. & Tokaj & 1971 & Siroki Zoltán & DE-siroki-10948.jpg \\
\hline 1032 & Linum hirsutum L. & Tokaj & 1971 & Siroki Zoltán & DE-siroki-10949.jpg \\
\hline 1034 & Linum austriacum L. & "Zemplén" & 1963 & Siroki Zoltán & DE-siroki-10971.jpg \\
\hline 1034 & Linum austriacum L. & Budapest & 1941 & Siroki Zoltán & DE-siroki-10968.jpg \\
\hline 1034 & Linum austriacum L. & Budapest & 1948 & Siroki Zoltán & DE-siroki-10969.jpg \\
\hline 1034 & Linum austriacum L. & Budapest & 1951 & Siroki Zoltán & DE-siroki-10970.jpg \\
\hline 1034 & Linum austriacum L. & Bugyi & 1952 & Siroki Zoltán & DE-siroki-10976.jpg \\
\hline 1034 & Linum austriacum L. & Hajdúböszörmény & 1963 & Siroki Zoltán & DE-siroki-10972.jpg \\
\hline 1034 & Linum austriacum L. & Hajdúböszörmény & 1963 & Siroki Zoltán & DE-siroki-10973.jpg \\
\hline 1034 & Linum austriacum L. & Hajdúböszörmény & 1963 & Siroki Zoltán & DE-siroki-10974.jpg \\
\hline 1037 & Mercurialis annua L. & Mosonmagyaróvár & 1939 & Siroki Zoltán & DE-siroki-11059.jpg \\
\hline 1037 & Mercurialis annua L. & Mosonmagyaróvár & 1939 & Siroki Zoltán & DE-siroki-11060.jpg \\
\hline 1038 & Mercurialis perennis L. & "Dobogókő" & 1957 & Siroki Zoltán & DE-siroki-11061.jpg \\
\hline
\end{tabular}




\begin{tabular}{|c|c|c|c|c|c|}
\hline $\begin{array}{l}\text { Sorszám / } \\
\text { Number }\end{array}$ & Taxon-név / Taxon-name & $\begin{array}{l}\text { Település / } \\
\text { Settlement }\end{array}$ & $\begin{array}{l}\text { Év / } \\
\text { Year }\end{array}$ & $\begin{array}{l}\text { Gyűjtő / } \\
\text { Collector }\end{array}$ & Fájlnév / File-name \\
\hline 1038 & Mercurialis perennis L. & "Dobogókő" & 1957 & Siroki Zoltán & DE-siroki-11062.jpg \\
\hline 1038 & Mercurialis perennis L. & Budapest & 1941 & Siroki Zoltán & DE-siroki-11063.jpg \\
\hline 1038 & Mercurialis perennis L. & Budapest & 1955 & Siroki Zoltán & DE-siroki-11064.jpg \\
\hline 1038 & Mercurialis perennis L. & Budapest & 1955 & Siroki Zoltán & DE-siroki-11065.jpg \\
\hline 1039 & Mercurialis ovata Sternb. et Hoppe & Balatongyörök & 1950 & Kárpáti Zoltán & DE-siroki-11073.jpg \\
\hline 1039 & Mercurialis ovata Sternb. et Hoppe & Gyenesdiás & 1953 & Siroki Zoltán & DE-siroki-11068.jpg \\
\hline 1039 & Mercurialis ovata Sternb. et Hoppe & Gyenesdiás & 1953 & Siroki Zoltán & DE-siroki-11069.jpg \\
\hline 1039 & Mercurialis ovata Sternb. et Hoppe & Gyenesdiás & 1953 & Siroki Zoltán & DE-siroki-11070.jpg \\
\hline 1039 & Mercurialis ovata Sternb. et Hoppe & Gyenesdiás & 1972 & Siroki Zoltán & DE-siroki-11071.jpg \\
\hline 1039 & Mercurialis ovata Sternb. et Hoppe & Pécs & 1958 & Siroki Zoltán & DE-siroki-11072.jpg \\
\hline 1039 & Mercurialis ovata Sternb. et Hoppe & Sopron & 1951 & Kárpáti Zoltán & DE-siroki-11074.jpg \\
\hline 1042 & Euphorbia maculata L. & Debrecen & 1946 & Siroki Zoltán & DE-siroki-11079.jpg \\
\hline 1042 & Euphorbia maculata L. & Debrecen & 1946 & Siroki Zoltán & DE-siroki-11082.jpg \\
\hline 1042 & Euphorbia maculata L. & Debrecen & 1946 & Siroki Zoltán & DE-siroki-11083.jpg \\
\hline 1042 & Euphorbia maculata L. & Debrecen & 1946 & Siroki Zoltán & DE-siroki-11080.jpg \\
\hline 1042 & Euphorbia maculata L. & Debrecen & 1946 & Siroki Zoltán & DE-siroki-11081.jpg \\
\hline 1044 & Euphorbia helioscopia L. & Debrecen & 1949 & Siroki Zoltán & DE-siroki-11136.jpg \\
\hline 1044 & Euphorbia helioscopia L. & Mosonmagyaróvár & 1939 & Siroki Zoltán & DE-siroki-11134.jpg \\
\hline 1045 & Euphorbia platyphyllos L. & Debrecen & 1954 & Siroki Zoltán & DE-siroki-11091.jpg \\
\hline 1045 & Euphorbia platyphyllos L. & Debrecen & 1954 & Siroki Zoltán & DE-siroki-11092.jpg \\
\hline 1045 & Euphorbia platyphyllos L. & Debrecen & 1954 & Siroki Zoltán & DE-siroki-11093.jpg \\
\hline 1045 & Euphorbia platyphyllos L. & Fényeslitke & 1966 & Siroki Zoltán & DE-siroki-11084.jpg \\
\hline 1045 & Euphorbia platyphyllos L. & Fényeslitke & 1966 & Siroki Zoltán & DE-siroki-11085.jpg \\
\hline 1045 & Euphorbia platyphyllos L. & Fényeslitke & 1966 & Siroki Zoltán & DE-siroki-11086.jpg \\
\hline 1045 & Euphorbia platyphyllos L. & Hortobágy & 1949 & Siroki Zoltán & DE-siroki-11088.jpg \\
\hline 1045 & Euphorbia platyphyllos L. & Kispalád & 1971 & Siroki Zoltán & DE-siroki-11087.jpg \\
\hline 1045 & Euphorbia platyphyllos L. & Mosonmagyaróvár & 1939 & Siroki Zoltán & DE-siroki-11097.jpg \\
\hline 1045 & Euphorbia platyphyllos L. & Mosonmagyaróvár & 1939 & Siroki Zoltán & DE-siroki-11096.jpg \\
\hline 1046 & Euphorbia stricta L. & Budapest & 1911 & Bocskay Ottó & DE-siroki-11098.jpg \\
\hline 1047 & Euphorbia villosa Waldst. et Kit. & "Nagymező" & 1960 & Siroki Zoltán & DE-siroki-11147.jpg \\
\hline 1047 & Euphorbia villosa Waldst. et Kit. & "Nagymező" & 1960 & Siroki Zoltán & DE-siroki-11148.jpg \\
\hline 1047 & Euphorbia villosa Waldst. et Kit. & Bátorliget & 1957 & Siroki Zoltán & DE-siroki-11145.jpg \\
\hline 1047 & Euphorbia villosa Waldst. et Kit. & Bátorliget & 1957 & Siroki Zoltán & DE-siroki-11146.jpg \\
\hline 1047 & Euphorbia villosa Waldst. et Kit. & Budapest & 1887 & Czakó Kálmán & DE-siroki-11138.jpg \\
\hline 1047 & Euphorbia villosa Waldst. et Kit. & Debrecen & 1948 & Siroki Zoltán & DE-siroki-11144.jpg \\
\hline 1047 & Euphorbia villosa Waldst. et Kit. & Debrecen & 1954 & Siroki Zoltán & DE-siroki-11143.jpg \\
\hline 1047 & Euphorbia villosa Waldst. et Kit. & Debrecen & 1955 & $\begin{array}{l}\text { Siroki Zoltán - } \\
\text { Farkas Attila }\end{array}$ & DE-siroki-11155.jpg \\
\hline 1047 & Euphorbia villosa Waldst. et Kit. & Debrecen & 1955 & $\begin{array}{l}\text { Siroki Zoltán - } \\
\text { Farkas Attila }\end{array}$ & DE-siroki-11156.jpg \\
\hline 1047 & Euphorbia villosa Waldst. et Kit. & Debrecen & 1961 & Siroki Zoltán & DE-siroki-11149.jpg \\
\hline 1047 & Euphorbia villosa Waldst. et Kit. & Debrecen & 1961 & Siroki Zoltán & DE-siroki-11150.jpg \\
\hline 1047 & Euphorbia villosa Waldst. et Kit. & Debrecen & 1961 & Siroki Zoltán & DE-siroki-11151.jpg \\
\hline 1047 & Euphorbia villosa Waldst. et Kit. & Felsőtárkány & 1957 & Siroki Zoltán & DE-siroki-11154.jpg \\
\hline 1047 & Euphorbia villosa Waldst. et Kit. & Gödöllő & 1952 & Siroki Zoltán & DE-siroki-11142.jpg \\
\hline 1047 & Euphorbia villosa Waldst. et Kit. & Újléta & 1967 & Siroki Zoltán & DE-siroki-11152.jpg \\
\hline 1047 & Euphorbia villosa Waldst. et Kit. & Újléta & 1967 & Siroki Zoltán & DE-siroki-11153.jpg \\
\hline
\end{tabular}




\begin{tabular}{|c|c|c|c|c|c|}
\hline $\begin{array}{l}\text { Sorszám / } \\
\text { Number }\end{array}$ & Taxon-név / Taxon-name & $\begin{array}{l}\text { Település / } \\
\text { Settlement }\end{array}$ & $\begin{array}{l}\text { Év / } \\
\text { Year }\end{array}$ & $\begin{array}{l}\text { Gyűjtő / } \\
\text { Collector }\end{array}$ & Fájlnév / File-name \\
\hline 1048 & Euphorbia seguieriana Neck. & Budaörs & 1955 & Siroki Zoltán & DE-siroki-11172.jpg \\
\hline 1048 & Euphorbia seguieriana Neck. & Budapest & 1941 & Siroki Zoltán & DE-siroki-11157.jpg \\
\hline 1048 & Euphorbia seguieriana Neck. & Budapest & 1941 & Siroki Zoltán & DE-siroki-11158.jpg \\
\hline 1048 & Euphorbia seguieriana Neck. & Budapest & 1941 & Siroki Zoltán & DE-siroki-11159.jpg \\
\hline 1048 & Euphorbia seguieriana Neck. & Budapest & 1944 & Siroki Zoltán & DE-siroki-11161.jpg \\
\hline 1048 & Euphorbia seguieriana Neck. & Budapest & 1949 & Siroki Zoltán & DE-siroki-11160.jpg \\
\hline 1048 & Euphorbia seguieriana Neck. & Budapest & 1984 & Siroki Zoltán & DE-siroki-11162.jpg \\
\hline 1048 & Euphorbia seguieriana Neck. & Budapest & 1984 & Siroki Zoltán & DE-siroki-11163.jpg \\
\hline 1048 & Euphorbia seguieriana Neck. & Érpatak & 1968 & Siroki Zoltán & DE-siroki-11164.jpg \\
\hline 1048 & Euphorbia seguieriana Neck. & Érpatak & 1968 & Siroki Zoltán & DE-siroki-11165.jpg \\
\hline 1048 & Euphorbia seguieriana Neck. & Érpatak & 1970 & Siroki Zoltán & DE-siroki-11166.jpg \\
\hline 1048 & Euphorbia seguieriana Neck. & Gödöllő & 1951 & Siroki Zoltán & DE-siroki-11173.jpg \\
\hline 1048 & Euphorbia seguieriana Neck. & Kecskemét & 1969 & Siroki Zoltán & DE-siroki-11167.jpg \\
\hline 1048 & Euphorbia seguieriana Neck. & Nagykovácsi & 1957 & Siroki Zoltán & DE-siroki-11168.jpg \\
\hline 1048 & Euphorbia seguieriana Neck. & Nagykovácsi & 1959 & Siroki Zoltán & DE-siroki-11169.jpg \\
\hline 1048 & Euphorbia seguieriana Neck. & Nagykovácsi & 1959 & Siroki Zoltán & DE-siroki-11170.jpg \\
\hline 1048 & Euphorbia seguieriana Neck. & Veresegyház & 1960 & Siroki Zoltán & DE-siroki-11171.jpg \\
\hline 1049 & Euphorbia glareosa Pall. & Budapest & 1941 & Siroki Zoltán & DE-siroki-11180.jpg \\
\hline 1049 & Euphorbia glareosa Pall. & Budapest & 1941 & Siroki Zoltán & DE-siroki-11178.jpg \\
\hline 1049 & Euphorbia glareosa Pall. & Budapest & 1941 & Siroki Zoltán & DE-siroki-11179.jpg \\
\hline 1049 & Euphorbia glareosa Pall. & Budapest & 1944 & Siroki Zoltán & DE-siroki-11176.jpg \\
\hline 1049 & Euphorbia glareosa Pall. & Budapest & 1944 & Siroki Zoltán & DE-siroki-11177.jpg \\
\hline 1049 & Euphorbia glareosa Pall. & Budapest & 1957 & Siroki Zoltán & DE-siroki-11174.jpg \\
\hline 1049 & Euphorbia glareosa Pall. & Budapest & 1957 & Siroki Zoltán & DE-siroki-11175.jpg \\
\hline 1050 & Euphorbia palustris L. & Debrecen & 1954 & Siroki Zoltán & DE-siroki-11126.jpg \\
\hline 1050 & Euphorbia palustris L. & Debrecen & 1954 & Siroki Zoltán & DE-siroki-11127.jpg \\
\hline 1050 & Euphorbia palustris L. & Debrecen & 1954 & Siroki Zoltán & DE-siroki-11128.jpg \\
\hline 1050 & Euphorbia palustris L. & Egyek & 1948 & Siroki Zoltán & DE-siroki-11131.jpg \\
\hline 1050 & Euphorbia palustris L. & Egyek & 1948 & Siroki Zoltán & DE-siroki-11132.jpg \\
\hline 1050 & Euphorbia palustris L. & Egyek & 1948 & Siroki Zoltán & DE-siroki-11129.jpg \\
\hline 1050 & Euphorbia palustris L. & Egyek & 1948 & Siroki Zoltán & DE-siroki-11130.jpg \\
\hline 1050 & Euphorbia palustris L. & Fehérgyarmat & 1975 & Siroki Zoltán & DE-siroki-11123.jpg \\
\hline 1050 & Euphorbia palustris L. & Fehérgyarmat & 1975 & Siroki Zoltán & DE-siroki-11124.jpg \\
\hline 1050 & Euphorbia palustris L. & Tarpa & 1955 & Siroki Zoltán & DE-siroki-11133.jpg \\
\hline 1050 & Euphorbia palustris L. & Tiszafüred & 1970 & Siroki Zoltán & DE-siroki-11122.jpg \\
\hline 1050 & Euphorbia palustris L. & Tiszafüred & 1973 & Siroki Zoltán & DE-siroki-11125.jpg \\
\hline 1052 & Euphorbia epithymoides L. & Budapest & 1951 & Siroki Zoltán & DE-siroki-11107.jpg \\
\hline 1052 & Euphorbia epithymoides L. & Budapest & 1960 & Siroki Zoltán & DE-siroki-11104.jpg \\
\hline 1052 & Euphorbia epithymoides L. & Budapest & 1964 & Siroki Zoltán & DE-siroki-11105.jpg \\
\hline 1052 & Euphorbia epithymoides L. & Budapest & 1970 & Siroki Zoltán & DE-siroki-11106.jpg \\
\hline 1052 & Euphorbia epithymoides L. & Hosszúhetény & 1958 & Siroki Zoltán & DE-siroki-11099.jpg \\
\hline 1052 & Euphorbia epithymoides L. & Nagykovácsi & 1959 & Siroki Zoltán & DE-siroki-11103.jpg \\
\hline 1053 & Euphorbia verrucosa L. & Sopron & 1950 & Kárpáti Zoltán & DE-siroki-11120.jpg \\
\hline 1053 & Euphorbia verrucosa L. & Sopron & 1951 & Kárpáti Zoltán & DE-siroki-11121.jpg \\
\hline 1054 & Euphorbia angulata Jacq. & "Cuha-völgy" & 1928 & Degen Árpád & DE-siroki-11111.jpg \\
\hline 1054 & Euphorbia angulata Jacq. & Gyenesdiás & 1953 & Siroki Zoltán & DE-siroki-11114.jpg \\
\hline
\end{tabular}




\begin{tabular}{|c|c|c|c|c|c|}
\hline $\begin{array}{l}\text { Sorszám / } \\
\text { Number }\end{array}$ & Taxon-név / Taxon-name & $\begin{array}{l}\text { Település / } \\
\text { Settlement }\end{array}$ & $\begin{array}{l}\text { Év / } \\
\text { Year }\end{array}$ & $\begin{array}{l}\text { Gyűjtő / } \\
\text { Collector }\end{array}$ & Fájlnév / File-name \\
\hline 1054 & Euphorbia angulata Jacq. & Gyenesdiás & 1953 & Siroki Zoltán & DE-siroki-11115.jpg \\
\hline 1054 & Euphorbia angulata Jacq. & Gyenesdiás & 1953 & Siroki Zoltán & DE-siroki-11116.jpg \\
\hline 1054 & Euphorbia angulata Jacq. & Sopron & 1950 & Kárpáti Zoltán & DE-siroki-11118.jpg \\
\hline 1054 & Euphorbia angulata Jacq. & Sopron & 1951 & Kárpáti Zoltán & DE-siroki-11117.jpg \\
\hline 1057 & Euphorbia amygdaloides L. & "Fáni-völgy" & 1955 & $\begin{array}{l}\text { Siroki Zoltán - } \\
\text { Farkas Attila }\end{array}$ & DE-siroki-11244.jpg \\
\hline 1057 & Euphorbia amygdaloides L. & "Fáni-völgy" & 1955 & $\begin{array}{l}\text { Siroki Zoltán - } \\
\text { Farkas Attila }\end{array}$ & DE-siroki-11245.jpg \\
\hline 1057 & Euphorbia amygdaloides L. & Bátorliget & 1954 & Simon Tiborné & DE-siroki-11248.jpg \\
\hline 1057 & Euphorbia amygdaloides L. & Bátorliget & 1954 & Siroki Zoltán & DE-siroki-11246.jpg \\
\hline 1057 & Euphorbia amygdaloides L. & Bátorliget & 1954 & Siroki Zoltán & DE-siroki-11247.jpg \\
\hline 1057 & Euphorbia amygdaloides L. & Budapest & 1960 & Siroki Zoltán & DE-siroki-11241.jpg \\
\hline 1057 & Euphorbia amygdaloides L. & Budapest & 1964 & Siroki Zoltán & DE-siroki-11242.jpg \\
\hline 1057 & Euphorbia amygdaloides L. & Budapest & 1971 & Siroki Zoltán & DE-siroki-11243.jpg \\
\hline 1057 & Euphorbia amygdaloides L. & Gyenesdiás & 1972 & Siroki Zoltán & DE-siroki-11240.jpg \\
\hline 1058 & Euphorbia salicifolia Host & "Bükk-hg." & 1983 & Siroki Zoltán & DE-siroki-11198.jpg \\
\hline 1058 & Euphorbia salicifolia Host & Abaújszántó & 1944 & Siroki Zoltán & DE-siroki-11191.jpg \\
\hline 1058 & Euphorbia salicifolia Host & Berekböszörmény & 1970 & Siroki Zoltán & DE-siroki-11185.jpg \\
\hline 1058 & Euphorbia salicifolia Host & Berekböszörmény & 1970 & Siroki Zoltán & DE-siroki-11181.jpg \\
\hline 1058 & Euphorbia salicifolia Host & Berekböszörmény & 1970 & Siroki Zoltán & DE-siroki-11182.jpg \\
\hline 1058 & Euphorbia salicifolia Host & Berekböszörmény & 1970 & Siroki Zoltán & DE-siroki-11183.jpg \\
\hline 1058 & Euphorbia salicifolia Host & Berekböszörmény & 1970 & Siroki Zoltán & DE-siroki-11184.jpg \\
\hline 1058 & Euphorbia salicifolia Host & Budaörs & 1984 & Siroki Zoltán & DE-siroki-11196.jpg \\
\hline 1058 & Euphorbia salicifolia Host & Budaörs & 1984 & Siroki Zoltán & DE-siroki-11197.jpg \\
\hline 1058 & Euphorbia salicifolia Host & Debrecen & 1946 & Siroki Zoltán & DE-siroki-11190.jpg \\
\hline 1058 & Euphorbia salicifolia Host & Debrecen & 1955 & Siroki Zoltán & DE-siroki-11188.jpg \\
\hline 1058 & Euphorbia salicifolia Host & Egyek & 1948 & Siroki Zoltán & DE-siroki-11189.jpg \\
\hline 1058 & Euphorbia salicifolia Host & Fehérgyarmat & 1975 & Siroki Zoltán & DE-siroki-11192.jpg \\
\hline 1058 & Euphorbia salicifolia Host & Hajdúböszörmény & 1980 & Siroki Zoltán & DE-siroki-11194.jpg \\
\hline 1058 & Euphorbia salicifolia Host & Hajdúböszörmény & 1980 & Siroki Zoltán & DE-siroki-11195.jpg \\
\hline 1058 & Euphorbia salicifolia Host & Hajdúböszörmény & 1981 & Siroki Zoltán & DE-siroki-11193.jpg \\
\hline 1058 & Euphorbia salicifolia Host & Kecskemét & 1969 & Siroki Zoltán & DE-siroki-11186.jpg \\
\hline 1058 & Euphorbia salicifolia Host & Kecskemét & 1969 & Siroki Zoltán & DE-siroki-11187.jpg \\
\hline 1060 & Euphorbia cyparissias L. & Debrecen & 1947 & Siroki Zoltán & DE-siroki-11201.jpg \\
\hline 1061 & Euphorbia esula L. & Budapest & 1960 & Siroki Zoltán & DE-siroki-11205.jpg \\
\hline 1061 & Euphorbia esula L. & Debrecen & 1974 & Siroki Zoltán & DE-siroki-11209.jpg \\
\hline 1061 & Euphorbia esula L. & Hortobágy & 1947 & Siroki Zoltán & DE-siroki-11208.jpg \\
\hline 1062 & Euphorbia virgata Waldst. et Kit. & Abaújkér & 1942 & Siroki Zoltán & DE-siroki-11224.jpg \\
\hline 1062 & Euphorbia virgata Waldst. et Kit. & Budapest & 1966 & Siroki Zoltán & DE-siroki-11222.jpg \\
\hline 1062 & Euphorbia virgata Waldst. et Kit. & Budapest & 1984 & Siroki Zoltán & DE-siroki-11213.jpg \\
\hline 1062 & Euphorbia virgata Waldst. et Kit. & Budapest & 1985 & Siroki Zoltán & DE-siroki-11214.jpg \\
\hline 1062 & Euphorbia virgata Waldst. et Kit. & Budapest & 1985 & Siroki Zoltán & DE-siroki-11215.jpg \\
\hline 1062 & Euphorbia virgata Waldst. et Kit. & Debrecen & 1947 & Siroki Zoltán & DE-siroki-11221.jpg \\
\hline 1062 & Euphorbia virgata Waldst. et Kit. & Hajdúböszörmény & 1980 & Siroki Zoltán & DE-siroki-11216.jpg \\
\hline 1062 & Euphorbia virgata Waldst. et Kit. & Hajdúböszörmény & 1980 & Siroki Zoltán & DE-siroki-11217.jpg \\
\hline 1062 & Euphorbia virgata Waldst. et Kit. & Püspökladány & 1966 & Siroki Zoltán & DE-siroki-11218.jpg \\
\hline 1062 & Euphorbia virgata Waldst. et Kit. & Püspökladány & 1966 & Siroki Zoltán & DE-siroki-11219.jpg \\
\hline
\end{tabular}




\begin{tabular}{|c|c|c|c|c|c|}
\hline $\begin{array}{l}\text { Sorszám / } \\
\text { Number }\end{array}$ & Taxon-név / Taxon-name & $\begin{array}{l}\text { Település / } \\
\text { Settlement }\end{array}$ & $\begin{array}{l}\text { Év / } \\
\text { Year }\end{array}$ & $\begin{array}{l}\text { Gyűjtő / } \\
\text { Collector }\end{array}$ & Fájlnév / File-name \\
\hline 1062 & Euphorbia virgata Waldst. et Kit. & Püspökladány & 1966 & Siroki Zoltán & DE-siroki-11220.jpg \\
\hline 1063 & Euphorbia lucida Waldst. et Kit. & Debrecen & 1985 & Siroki Zoltán & DE-siroki-11231.jpg \\
\hline 1063 & Euphorbia lucida Waldst. et Kit. & Debrecen & 1985 & Siroki Zoltán & DE-siroki-11232.jpg \\
\hline 1063 & Euphorbia lucida Waldst. et Kit. & Debrecen & 1986 & Siroki Zoltán & DE-siroki-11235.jpg \\
\hline 1063 & Euphorbia lucida Waldst. et Kit. & Nyírábrány & 1984 & Siroki Zoltán & DE-siroki-11229.jpg \\
\hline 1063 & Euphorbia lucida Waldst. et Kit. & Tiszafüred & 1970 & Siroki Zoltán & DE-siroki-11227.jpg \\
\hline 1063 & Euphorbia lucida Waldst. et Kit. & Tiszafüred & 1970 & Siroki Zoltán & DE-siroki-11228.jpg \\
\hline 1063 & Euphorbia lucida Waldst. et Kit. & Tiszafüred & 1970 & Siroki Zoltán & DE-siroki-11234.jpg \\
\hline 1063 & Euphorbia lucida Waldst. et Kit. & Újléta & 1967 & Siroki Zoltán & DE-siroki-11236.jpg \\
\hline 1063 & Euphorbia lucida Waldst. et Kit. & Vámospércs & 1985 & Siroki Zoltán & DE-siroki-11225.jpg \\
\hline 1063 & Euphorbia lucida Waldst. et Kit. & Vámospércs & 1985 & Siroki Zoltán & DE-siroki-11226.jpg \\
\hline 1063 & Euphorbia lucida Waldst. et Kit. & Vámospércs & 1985 & Siroki Zoltán & DE-siroki-11230.jpg \\
\hline 1064 & Euphorbia peplus L. & Debrecen & 1949 & Siroki Zoltán & DE-siroki-11262.jpg \\
\hline 1064 & Euphorbia peplus L. & Debrecen & 1949 & Siroki Zoltán & DE-siroki-11261.jpg \\
\hline 1064 & Euphorbia peplus L. & Debrecen & 1977 & Siroki Zoltán & DE-siroki-11260.jpg \\
\hline 1064 & Euphorbia peplus L. & Debrecen & 1978 & Siroki Zoltán & DE-siroki-11259.jpg \\
\hline 1065 & Euphorbia exigua L. & Budapest & 1948 & Siroki Zoltán & DE-siroki-11255.jpg \\
\hline 1065 & Euphorbia exigua L. & Budapest & - & Siroki Zoltán & DE-siroki-11256.jpg \\
\hline 1065 & Euphorbia exigua L. & Máriakálnok & 1939 & Siroki Zoltán & DE-siroki-11258.jpg \\
\hline 1065 & Euphorbia exigua L. & Mogyoróska & 1966 & Gondola István & DE-siroki-11250.jpg \\
\hline 1065 & Euphorbia exigua L. & Nagydobos & 1966 & Gondola István & DE-siroki-11251.jpg \\
\hline 1065 & Euphorbia exigua L. & Nagydobos & 1966 & Gondola István & DE-siroki-11252.jpg \\
\hline 1065 & Euphorbia exigua L. & Nagydobos & 1966 & Gondola István & DE-siroki-11253.jpg \\
\hline 1065 & Euphorbia exigua L. & Nagydobos & 1966 & Gondola István & DE-siroki-11254.jpg \\
\hline 1067 & Euphorbia taurinensis All. & Budapest & 1884 & Czakó Kálmán & DE-siroki-11285.jpg \\
\hline 1067 & Euphorbia taurinensis All. & Budapest & 1949 & Siroki Zoltán & DE-siroki-11284.jpg \\
\hline 1067 & Euphorbia taurinensis All. & Budapest & 1950 & Siroki Zoltán & DE-siroki-11278.jpg \\
\hline 1067 & Euphorbia taurinensis All. & Budapest & 1960 & Siroki Zoltán & DE-siroki-11279.jpg \\
\hline 1067 & Euphorbia taurinensis All. & Budapest & 1960 & Siroki Zoltán & DE-siroki-11280.jpg \\
\hline 1067 & Euphorbia taurinensis All. & Budapest & 1960 & Siroki Zoltán & DE-siroki-11282.jpg \\
\hline 1067 & Euphorbia taurinensis All. & Budapest & 1960 & Siroki Zoltán & DE-siroki-11283.jpg \\
\hline 1067 & Euphorbia taurinensis All. & Budapest & 1961 & Siroki Zoltán & DE-siroki-11281.jpg \\
\hline 1067 & Euphorbia taurinensis All. & Budapest & 1983 & Siroki Zoltán & DE-siroki-11274.jpg \\
\hline 1067 & Euphorbia taurinensis All. & Budapest & 1983 & Siroki Zoltán & DE-siroki-11275.jpg \\
\hline 1067 & Euphorbia taurinensis All. & Budapest & 1983 & Siroki Zoltán & DE-siroki-11276.jpg \\
\hline 1067 & Euphorbia taurinensis All. & Budapest & 1983 & Siroki Zoltán & DE-siroki-11277.jpg \\
\hline 1068 & Euphorbia falcata L. & Budapest & 1952 & Siroki Zoltán & DE-siroki-11270.jpg \\
\hline 1068 & Euphorbia falcata L. & Budapest & 1985 & Siroki Zoltán & DE-siroki-11265.jpg \\
\hline 1068 & Euphorbia falcata L. & Budapest & 1985 & Siroki Zoltán & DE-siroki-11266.jpg \\
\hline 1068 & Euphorbia falcata L. & Debrecen & 1962 & Siroki Zoltán & DE-siroki-11267.jpg \\
\hline 1068 & Euphorbia falcata L. & Debrecen & 1962 & Siroki Zoltán & DE-siroki-11268.jpg \\
\hline 1068 & Euphorbia falcata L. & Debrecen & 1962 & Siroki Zoltán & DE-siroki-11269.jpg \\
\hline 1068 & Euphorbia falcata L. & Máriakálnok & 1939 & Siroki Zoltán & DE-siroki-11271.jpg \\
\hline 1069 & Ruta graveolens L. & Budapest & 1951 & Siroki Zoltán & DE-siroki-10990.jpg \\
\hline 1070 & Dictamnus albus L. & Aszaló & 1944 & Siroki Zoltán & DE-siroki-11000.jpg \\
\hline 1070 & Dictamnus albus L. & Aszaló & 1944 & Siroki Zoltán & DE-siroki-11001.jpg \\
\hline
\end{tabular}




\begin{tabular}{|c|c|c|c|c|c|}
\hline $\begin{array}{l}\text { Sorszám / } \\
\text { Number }\end{array}$ & Taxon-név / Taxon-name & $\begin{array}{l}\text { Település / } \\
\text { Settlement }\end{array}$ & $\begin{array}{l}\text { Év / } \\
\text { Year }\end{array}$ & $\begin{array}{l}\text { Gyűjtő / } \\
\text { Collector }\end{array}$ & Fájlnév / File-name \\
\hline 1070 & Dictamnus albus L. & Budapest & 1983 & Siroki Zoltán & DE-siroki-10991.jpg \\
\hline 1070 & Dictamnus albus L. & Debrecen & 1946 & Siroki Zoltán & DE-siroki-10997.jpg \\
\hline 1070 & Dictamnus albus L. & Debrecen & 1946 & Siroki Zoltán & DE-siroki-10999.jpg \\
\hline 1070 & Dictamnus albus L. & Debrecen & 1946 & Siroki Zoltán & DE-siroki-10996.jpg \\
\hline 1070 & Dictamnus albus L. & Debrecen & 1949 & Siroki Zoltán & DE-siroki-10998.jpg \\
\hline 1070 & Dictamnus albus L. & Rakaca & 1982 & Siroki Zoltán & DE-siroki-10992.jpg \\
\hline 1070 & Dictamnus albus L. & Rakaca & 1982 & Siroki Zoltán & DE-siroki-10993.jpg \\
\hline 1070 & Dictamnus albus L. & Rakaca & 1982 & Siroki Zoltán & DE-siroki-10994.jpg \\
\hline 1070 & Dictamnus albus L. & Szarvaskő & 1957 & Siroki Zoltán & DE-siroki-10995.jpg \\
\hline 1074 & Polygala major Jacq. & Budaörs & 1966 & Siroki Zoltán & DE-siroki-11011.jpg \\
\hline 1074 & Polygala major Jacq. & Budapest & 1964 & Siroki Zoltán & DE-siroki-11010.jpg \\
\hline 1074 & Polygala major Jacq. & Budapest & 1981 & Siroki Zoltán & DE-siroki-11009.jpg \\
\hline 1074 & Polygala major Jacq. & Háromhuta & 1962 & Siroki Zoltán & DE-siroki-11012.jpg \\
\hline 1074 & Polygala major Jacq. & Háromhuta & 1962 & Siroki Zoltán & DE-siroki-11013.jpg \\
\hline 1074 & Polygala major Jacq. & Háromhuta & 1962 & Siroki Zoltán & DE-siroki-11014.jpg \\
\hline 1074 & Polygala major Jacq. & Szinpetri & 1974 & Siroki Zoltán & DE-siroki-11008.jpg \\
\hline 1075 & Polygala vulgaris L. & Ágasegyháza & 1956 & Siroki Zoltán & DE-siroki-11042.jpg \\
\hline 1075 & Polygala vulgaris L. & Ágasegyháza & 1956 & Siroki Zoltán & DE-siroki-11043.jpg \\
\hline 1075 & Polygala vulgaris L. & Bugac & 1954 & Siroki Zoltán & DE-siroki-11045.jpg \\
\hline 1075 & Polygala vulgaris L. & Háromhuta & 1961 & Siroki Zoltán & DE-siroki-11034.jpg \\
\hline 1075 & Polygala vulgaris L. & Háromhuta & 1961 & Siroki Zoltán & DE-siroki-11035.jpg \\
\hline 1075 & Polygala vulgaris L. & Háromhuta & 1961 & Siroki Zoltán & DE-siroki-11036.jpg \\
\hline 1075 & Polygala vulgaris L. & Nagyhuta & 1961 & Siroki Zoltán & DE-siroki-11037.jpg \\
\hline 1075 & Polygala vulgaris L. & Rakaca & 1982 & Siroki Zoltán & DE-siroki-11040.jpg \\
\hline 1075 & Polygala vulgaris L. & Rakaca & 1982 & Siroki Zoltán & DE-siroki-11041.jpg \\
\hline 1075 & Polygala vulgaris L. & Répáshuta & 1956 & Halász Tibor & DE-siroki-11044.jpg \\
\hline 1076 & Polygala comosa Schkuhr & Debrecen & 1948 & Siroki Zoltán & DE-siroki-11021.jpg \\
\hline 1076 & Polygala comosa Schkuhr & Debrecen & 1948 & Siroki Zoltán & DE-siroki-11020.jpg \\
\hline 1076 & Polygala comosa Schkuhr & Debrecen & 1950 & Siroki Zoltán & DE-siroki-11022.jpg \\
\hline 1076 & Polygala comosa Schkuhr & Debrecen & 1950 & Siroki Zoltán & DE-siroki-11019.jpg \\
\hline 1076 & Polygala comosa Schkuhr & Füzérradvány & 1973 & Siroki Zoltán & DE-siroki-11017.jpg \\
\hline 1076 & Polygala comosa Schkuhr & Füzérradvány & 1973 & Siroki Zoltán & DE-siroki-11018.jpg \\
\hline 1076 & Polygala comosa Schkuhr & Gödöllő & 1952 & Siroki Zoltán & DE-siroki-11027.jpg \\
\hline 1076 & Polygala comosa Schkuhr & Gyenesdiás & 1953 & Siroki Zoltán & DE-siroki-11024.jpg \\
\hline 1076 & Polygala comosa Schkuhr & Gyenesdiás & 1953 & Siroki Zoltán & DE-siroki-11033.jpg \\
\hline 1076 & Polygala comosa Schkuhr & Pásztó & 1952 & Siroki Zoltán & DE-siroki-11023.jpg \\
\hline 1076 & Polygala comosa Schkuhr & Sáránd & 1984 & Siroki Zoltán & DE-siroki-11026.jpg \\
\hline 1076 & Polygala comosa Schkuhr & Újléta & 1967 & Siroki Zoltán & DE-siroki-11025.jpg \\
\hline 1079 & Polygala amara L. & "Fáni-völgy" & 1955 & $\begin{array}{l}\text { Siroki Zoltán - } \\
\text { Farkas Attila }\end{array}$ & DE-siroki-11057.jpg \\
\hline 1079 & Polygala amara L. & "Fáni-völgy" & 1955 & $\begin{array}{l}\text { Siroki Zoltán - } \\
\text { Farkas Attila }\end{array}$ & DE-siroki-11056.jpg \\
\hline 1079 & Polygala amara L. & Gánt & 1951 & Kárpáti Zoltán & DE-siroki-11052.jpg \\
\hline 1079 & Polygala amara L. & Gyenesdiás & 1953 & Siroki Zoltán & DE-siroki-11048.jpg \\
\hline 1079 & Polygala amara L. & Gyenesdiás & 1953 & Siroki Zoltán & DE-siroki-11049.jpg \\
\hline 1079 & Polygala amara L. & Gyenesdiás & 1953 & Siroki Zoltán & DE-siroki-11047.jpg \\
\hline 1079 & Polygala amara L. & Gyenesdiás & 1972 & Siroki Zoltán & DE-siroki-11050.jpg \\
\hline
\end{tabular}




\begin{tabular}{|c|c|c|c|c|c|}
\hline $\begin{array}{l}\text { Sorszám / } \\
\text { Number }\end{array}$ & Taxon-név / Taxon-name & $\begin{array}{l}\text { Település / } \\
\text { Settlement }\end{array}$ & $\begin{array}{l}\text { Év / } \\
\text { Year }\end{array}$ & $\begin{array}{l}\text { Gyújtő / } \\
\text { Collector }\end{array}$ & Fájlnév / File-name \\
\hline 1079 & Polygala amara L. & Gyenesdiás & 1972 & Siroki Zoltán & DE-siroki-11051.jpg \\
\hline 1079 & Polygala amara L. & Nagykovácsi & 1959 & Siroki Zoltán & DE-siroki-11054.jpg \\
\hline 1079 & Polygala amara L. & Nagykovácsi & 1959 & Siroki Zoltán & DE-siroki-11055.jpg \\
\hline 1079 & Polygala amara L. & Pilisszentiván & 1952 & Siroki Zoltán & DE-siroki-11053.jpg \\
\hline 1081 & Cotinus coggygria Scop. & Budapest & 1950 & Siroki Zoltán & DE-siroki-11307.jpg \\
\hline 1081 & Cotinus coggygria Scop. & Budapest & 1951 & Siroki Zoltán & DE-siroki-11311.jpg \\
\hline 1081 & Cotinus coggygria Scop. & Budapest & 1952 & Siroki Zoltán & DE-siroki-11308.jpg \\
\hline 1081 & Cotinus coggygria Scop. & Budapest & 1976 & Siroki Zoltán & DE-siroki-11309.jpg \\
\hline 1081 & Cotinus coggygria Scop. & Budapest & 1976 & Siroki Zoltán & DE-siroki-11310.jpg \\
\hline 1081 & Cotinus coggygria Scop. & Cserszegtomaj & 1955 & Siroki Zoltán & DE-siroki-11312.jpg \\
\hline 1083 & Acer tataricum L. & Bátorliget & 1956 & Siroki Zoltán & DE-siroki-11347.jpg \\
\hline 1083 & Acer tataricum L. & Bátorliget & 1957 & Siroki Zoltán & DE-siroki-11348.jpg \\
\hline 1083 & Acer tataricum L. & Bátorliget & 1957 & Siroki Zoltán & DE-siroki-11345.jpg \\
\hline 1083 & Acer tataricum L. & Bátorliget & 1957 & Siroki Zoltán & DE-siroki-11346.jpg \\
\hline 1083 & Acer tataricum L. & Budapest & 1951 & Siroki Zoltán & DE-siroki-11332.jpg \\
\hline 1083 & Acer tataricum L. & Hortobágy & 1974 & Siroki Zoltán & DE-siroki-11333.jpg \\
\hline 1083 & Acer tataricum L. & Hortobágy & 1974 & Siroki Zoltán & DE-siroki-11334.jpg \\
\hline 1083 & Acer tataricum L. & Hortobágy & 1974 & Siroki Zoltán & DE-siroki-11335.jpg \\
\hline 1083 & Acer tataricum L. & Hortobágy & 1974 & Siroki Zoltán & DE-siroki-11336.jpg \\
\hline 1083 & Acer tataricum L. & Hortobágy & 1974 & Siroki Zoltán & DE-siroki-11337.jpg \\
\hline 1083 & Acer tataricum L. & Pécs & 1958 & Siroki Zoltán & DE-siroki-11349.jpg \\
\hline 1083 & Acer tataricum L. & Pécs & 1958 & Siroki Zoltán & DE-siroki-11350.jpg \\
\hline 1083 & Acer tataricum L. & Recsk & 1964 & Siroki Zoltán & DE-siroki-11338.jpg \\
\hline 1083 & Acer tataricum L. & Recsk & 1964 & Siroki Zoltán & DE-siroki-11339.jpg \\
\hline 1083 & Acer tataricum L. & Recsk & 1964 & Siroki Zoltán & DE-siroki-11340.jpg \\
\hline 1083 & Acer tataricum L. & Szarvaskő & 1957 & Siroki Zoltán & DE-siroki-11341.jpg \\
\hline 1083 & Acer tataricum L. & Szarvaskő & 1957 & Siroki Zoltán & DE-siroki-11344.jpg \\
\hline 1083 & Acer tataricum L. & Szarvaskő & 1957 & Siroki Zoltán & DE-siroki-11342.jpg \\
\hline 1083 & Acer tataricum L. & Szarvaskő & 1957 & Siroki Zoltán & DE-siroki-11343.jpg \\
\hline 1085 & Acer campestre L. & Budapest & 1950 & Siroki Zoltán & DE-siroki-11364.jpg \\
\hline 1085 & Acer campestre L. & Budapest & 1960 & Siroki Zoltán & DE-siroki-11362.jpg \\
\hline 1085 & Acer campestre L. & Budapest & 1960 & Siroki Zoltán & DE-siroki-11363.jpg \\
\hline 1085 & Acer campestre L. & Hencida & 1983 & Siroki Zoltán & DE-siroki-11361.jpg \\
\hline 1086 & Acer pseudoplatanus L. & Recsk & 1964 & Siroki Zoltán & DE-siroki-11357.jpg \\
\hline 1086 & Acer pseudoplatanus L. & Recsk & 1964 & Siroki Zoltán & DE-siroki-11358.jpg \\
\hline 1088 & Koelreuteria paniculata Laxm. & Debrecen & 1950 & Siroki Zoltán & DE-siroki-11372.jpg \\
\hline 1088 & Koelreuteria paniculata Laxm. & Debrecen & 1976 & Siroki Zoltán & DE-siroki-11370.jpg \\
\hline 1088 & Koelreuteria paniculata Laxm. & Debrecen & 1976 & Siroki Zoltán & DE-siroki-11371.jpg \\
\hline 1089 & Impatiens noli-tangere L. & Nagyvisnyó & 1959 & Siroki Zoltán & DE-siroki-11379.jpg \\
\hline 1089 & Impatiens noli-tangere L. & Szilvásvárad & 1954 & Siroki Zoltán & DE-siroki-11380.jpg \\
\hline 1089 & Impatiens noli-tangere L. & Szilvásvárad & 1954 & Siroki Zoltán & DE-siroki-11381.jpg \\
\hline 1090 & Impatiens parviflora DC. & Budapest & 1940 & Siroki Zoltán & DE-siroki-11387.jpg \\
\hline 1090 & Impatiens parviflora DC. & Budapest & 1940 & Siroki Zoltán & DE-siroki-11388.jpg \\
\hline 1090 & Impatiens parviflora DC. & Debrecen & 1947 & Siroki Zoltán & DE-siroki-11386.jpg \\
\hline 1090 & Impatiens parviflora DC. & Mosonmagyaróvár & 1963 & Siroki Zoltán & DE-siroki-11383.jpg \\
\hline 1090 & Impatiens parviflora DC. & Mosonmagyaróvár & 1963 & Siroki Zoltán & DE-siroki-11384.jpg \\
\hline
\end{tabular}




\begin{tabular}{|c|c|c|c|c|c|}
\hline $\begin{array}{l}\text { Sorszám / } \\
\text { Number }\end{array}$ & Taxon-név / Taxon-name & $\begin{array}{l}\text { Település / } \\
\text { Settlement }\end{array}$ & $\begin{array}{l}\text { Év / } \\
\text { Year }\end{array}$ & $\begin{array}{l}\text { Gyújtő / } \\
\text { Collector }\end{array}$ & Fájlnév / File-name \\
\hline 1090 & Impatiens parviflora DC. & Mosonmagyaróvár & 1963 & Siroki Zoltán & DE-siroki-11385.jpg \\
\hline 1091 & Impatiens glandulifera Royle & Mosonmagyaróvár & 1952 & Gondola István & DE-siroki-11391.jpg \\
\hline 1091 & Impatiens glandulifera Royle & Mosonmagyaróvár & 1962 & Gondola István & DE-siroki-11399.jpg \\
\hline 1091 & Impatiens glandulifera Royle & Mosonmagyaróvár & 1962 & Gondola István & DE-siroki-11400.jpg \\
\hline 1091 & Impatiens glandulifera Royle & Mosonmagyaróvár & 1962 & Gondola István & DE-siroki-11401.jpg \\
\hline 1091 & Impatiens glandulifera Royle & Mosonmagyaróvár & 1962 & Gondola István & DE-siroki-11390.jpg \\
\hline 1091 & Impatiens glandulifera Royle & Mosonmagyaróvár & 1962 & Gondola István & DE-siroki-11392.jpg \\
\hline 1091 & Impatiens glandulifera Royle & Mosonmagyaróvár & 1962 & Gondola István & DE-siroki-11393.jpg \\
\hline 1091 & Impatiens glandulifera Royle & Mosonmagyaróvár & 1962 & Gondola István & DE-siroki-11395.jpg \\
\hline 1091 & Impatiens glandulifera Royle & Mosonmagyaróvár & 1962 & Gondola István & DE-siroki-11396.jpg \\
\hline 1091 & Impatiens glandulifera Royle & Mosonmagyaróvár & 1962 & Gondola István & DE-siroki-11397.jpg \\
\hline 1091 & Impatiens glandulifera Royle & Mosonmagyaróvár & 1963 & Gondola István & DE-siroki-11394.jpg \\
\hline 1091 & Impatiens glandulifera Royle & Mosonmagyaróvár & 1963 & Gondola István & DE-siroki-11389.jpg \\
\hline 1091 & Impatiens glandulifera Royle & Mosonmagyaróvár & 1963 & Gondola István & DE-siroki-11398.jpg \\
\hline 1096 & Euonymus europaeus L. & Debrecen & 1949 & Siroki Zoltán & DE-siroki-11322.jpg \\
\hline 1097 & Euonymus verrucosus Scop. & Debrecen & 1949 & Siroki Zoltán & DE-siroki-11316.jpg \\
\hline 1097 & Euonymus verrucosus Scop. & Gödöllő & 1954 & Gondola István & DE-siroki-11317.jpg \\
\hline 1097 & Euonymus verrucosus Scop. & Miskolc & 1951 & Kárpáti Zoltán & DE-siroki-11320.jpg \\
\hline 1098 & Staphylea pinnata L. & Budapest & 1952 & Siroki Zoltán & DE-siroki-11324.jpg \\
\hline 1098 & Staphylea pinnata L. & Budapest & 1964 & Siroki Zoltán & DE-siroki-11323.jpg \\
\hline 1098 & Staphylea pinnata L. & Budapest & 1964 & Siroki Zoltán & DE-siroki-11326.jpg \\
\hline 1098 & Staphylea pinnata L. & Budapest & 1964 & Siroki Zoltán & DE-siroki-11325.jpg \\
\hline 1100 & Rhamnus catharticus L. & Debrecen & 1947 & Siroki Zoltán & DE-siroki-11403.jpg \\
\hline 1100 & Rhamnus catharticus L. & Debrecen & 1947 & Siroki Zoltán & DE-siroki-11405.jpg \\
\hline 1100 & Rhamnus catharticus L. & Debrecen & 1947 & Siroki Zoltán & DE-siroki-11404.jpg \\
\hline 1100 & Rhamnus catharticus L. & Debrecen & 1955 & Siroki Zoltán & DE-siroki-11408.jpg \\
\hline 1101 & Rhamnus saxatilis Jacq. & Sopron & 1951 & Kárpáti Zoltán & DE-siroki-11409.jpg \\
\hline $\begin{array}{c}1100 \times \\
1101\end{array}$ & $\begin{array}{l}\text { Rhamnus } \times \text { gayeri Kárp. } \\
\text { (Rh. catharticus } \times \text { saxatilis) }\end{array}$ & Sopron & 1951 & Kárpáti Zoltán & DE-siroki-11410.jpg \\
\hline 1102 & Frangula alnus Mill. & Debrecen & 1947 & Siroki Zoltán & DE-siroki-11418.jpg \\
\hline 1102 & Frangula alnus Mill. & Hajdúbagos & 1981 & Siroki Zoltán & DE-siroki-11414.jpg \\
\hline 1102 & Frangula alnus Mill. & Hajdúbagos & 1981 & Siroki Zoltán & DE-siroki-11415.jpg \\
\hline 1102 & Frangula alnus Mill. & Nyírábrány & 1984 & Siroki Zoltán & DE-siroki-11411.jpg \\
\hline 1102 & Frangula alnus Mill. & Nyírábrány & 1984 & Siroki Zoltán & DE-siroki-11412.jpg \\
\hline 1102 & Frangula alnus Mill. & Nyírábrány & 1984 & Siroki Zoltán & DE-siroki-11413.jpg \\
\hline 1105 & Vitis vulpina L. & Kecskemét & 1954 & Siroki Zoltán & DE-siroki-11373.jpg \\
\hline 1105 & Vitis vulpina L. & Kecskemét & 1954 & Siroki Zoltán & DE-siroki-11374.jpg \\
\hline 1105 & Vitis vulpina $\mathrm{L}$. & Kecskemét & 1954 & Siroki Zoltán & DE-siroki-11375.jpg \\
\hline 1105 & Vitis vulpina L. & Kecskemét & 1954 & Siroki Zoltán & DE-siroki-11376.jpg \\
\hline 1105 & Vitis vulpina L. & Kecskemét & 1954 & Siroki Zoltán & DE-siroki-11402.jpg \\
\hline 1111 & Tilia tomentosa Moench & Pécs & 1954 & Siroki Zoltán & DE-siroki-11419.jpg \\
\hline 1111 & Tilia tomentosa Moench & Pécs & 1954 & Siroki Zoltán & DE-siroki-11420.jpg \\
\hline 1112 & Tilia platyphyllos Scop. & "Szent-György-hegy" & 1955 & Siroki Zoltán & DE-siroki-11434.jpg \\
\hline 1112 & Tilia platyphyllos Scop. & Budapest & 1964 & Siroki Zoltán & DE-siroki-11431.jpg \\
\hline 1112 & Tilia platyphyllos Scop. & Budapest & 1964 & Siroki Zoltán & DE-siroki-11432.jpg \\
\hline 1112 & Tilia platyphyllos Scop. & Budapest & 1964 & Siroki Zoltán & DE-siroki-11433.jpg \\
\hline 1112 & Tilia platyphyllos Scop. & Szilvásvárad & 1960 & Siroki Zoltán & DE-siroki-11429.jpg \\
\hline
\end{tabular}




\begin{tabular}{|c|c|c|c|c|c|}
\hline $\begin{array}{l}\text { Sorszám / } \\
\text { Number }\end{array}$ & Taxon-név / Taxon-name & $\begin{array}{l}\text { Település / } \\
\text { Settlement }\end{array}$ & $\begin{array}{l}\text { Év / } \\
\text { Year }\end{array}$ & $\begin{array}{l}\text { Gyűjtő / } \\
\text { Collector }\end{array}$ & Fájlnév / File-name \\
\hline 1112 & Tilia platyphyllos Scop. & Szilvásvárad & 1960 & Siroki Zoltán & DE-siroki-11430.jpg \\
\hline 1113 & Tilia cordata Mill. & Budapest & 1951 & Siroki Zoltán & DE-siroki-11424.jpg \\
\hline ---- & Tilia americana L. & Fehérvárcsurgó & 1887 & Czakó Kálmán & DE-siroki-11436.jpg \\
\hline 1117 & Malva sylvestris L. & Debrecen & 1948 & Siroki Zoltán & DE-siroki-11479.jpg \\
\hline 1117 & Malva sylvestris L. & Debrecen & 1948 & Siroki Zoltán & DE-siroki-11480.jpg \\
\hline 1117 & Malva sylvestris L. & Mosonmagyaróvár & 1939 & Siroki Zoltán & DE-siroki-11481.jpg \\
\hline 1117 & Malva sylvestris L. & Mosonmagyaróvár & 1939 & Siroki Zoltán & DE-siroki-11482.jpg \\
\hline 1118 & Malva verticillata $L$. & Debrecen & 1949 & Siroki Zoltán & DE-siroki-11490.jpg \\
\hline 1118 & Malva verticillata L. & Debrecen & 1949 & Siroki Zoltán & DE-siroki-11491.jpg \\
\hline 1118 & Malva verticillata L. & Debrecen & 1949 & Siroki Zoltán & DE-siroki-11492.jpg \\
\hline 1118 & Malva verticillata L. & Debrecen & 1949 & Siroki Zoltán & DE-siroki-11493.jpg \\
\hline 1119 & Malva neglecta Wallr. & Debrecen & 1949 & Siroki Zoltán & DE-siroki-11486.jpg \\
\hline 1119 & Malva neglecta Wallr. & Debrecen & 1949 & Siroki Zoltán & DE-siroki-11487.jpg \\
\hline 1119 & Malva neglecta Wallr. & Debrecen & 1979 & Siroki Zoltán & DE-siroki-11485.jpg \\
\hline 1120 & Malva pusilla Sm. & Debrecen & 1949 & Siroki Zoltán & DE-siroki-11489.jpg \\
\hline 1121 & Lavatera thuringiaca $\mathrm{L}$. & Debrecen & 1947 & Siroki Zoltán & DE-siroki-11448.jpg \\
\hline 1121 & Lavatera thuringiaca L. & Debrecen & 1947 & Siroki Zoltán & DE-siroki-11449.jpg \\
\hline 1121 & Lavatera thuringiaca L. & Hencida & 1983 & Siroki Zoltán & DE-siroki-11446.jpg \\
\hline 1123 & Althaea hirsuta L. & Budapest & 1952 & Siroki Zoltán & DE-siroki-11452.jpg \\
\hline 1123 & Althaea hirsuta L. & Budapest & 1952 & Siroki Zoltán & DE-siroki-11451.jpg \\
\hline 1123 & Althaea hirsuta L. & Budapest & 1952 & Siroki Zoltán & DE-siroki-11450.jpg \\
\hline 1124 & Althaea cannabina L. & Budapest & 1889 & $\begin{array}{l}\text { Schilberszky } \\
\text { Károly }\end{array}$ & DE-siroki-11454.jpg \\
\hline 1124 & Althaea cannabina L. & Budapest & 1948 & Siroki Zoltán & DE-siroki-11455.jpg \\
\hline 1124 & Althaea cannabina L. & Budapest & 1948 & Siroki Zoltán & DE-siroki-11456.jpg \\
\hline 1124 & Althaea cannabina L. & Budapest & 1948 & Siroki Zoltán & DE-siroki-11457.jpg \\
\hline 1124 & Althaea cannabina L. & Budapest & 1949 & Siroki Zoltán & DE-siroki-11458.jpg \\
\hline 1124 & Althaea cannabina L. & Budapest & 1949 & Siroki Zoltán & DE-siroki-11459.jpg \\
\hline 1124 & Althaea cannabina L. & Tokaj & 1933 & Hulják János & DE-siroki-11453.jpg \\
\hline 1125 & Althaea officinalis L. & Debrecen & 1947 & Siroki Zoltán & DE-siroki-11476.jpg \\
\hline 1125 & Althaea officinalis L. & Szikszó & 1944 & Siroki Zoltán & DE-siroki-11477.jpg \\
\hline 1127 & Alcea biennis Winterl & Budaörs & 1941 & Siroki Zoltán & DE-siroki-11472.jpg \\
\hline 1127 & Alcea biennis Winterl & Mátraverebély & 1952 & Siroki Zoltán & DE-siroki-11471.jpg \\
\hline 1127 & Alcea biennis Winterl & Mezőtúr & 1965 & Siroki Zoltán & DE-siroki-11462.jpg \\
\hline 1127 & Alcea biennis Winterl & Mezőtúr & 1965 & Siroki Zoltán & DE-siroki-11463.jpg \\
\hline 1127 & Alcea biennis Winterl & Mezőtúr & 1965 & Siroki Zoltán & DE-siroki-11464.jpg \\
\hline 1127 & Alcea biennis Winterl & Mezőtúr & 1965 & Siroki Zoltán & DE-siroki-11461.jpg \\
\hline 1127 & Alcea biennis Winterl & Mezőtúr & 1965 & Siroki Zoltán & DE-siroki-11465.jpg \\
\hline 1127 & Alcea biennis Winterl & Mezőtúr & 1965 & Siroki Zoltán & DE-siroki-11466.jpg \\
\hline 1127 & Alcea biennis Winterl & Mezőtúr & 1965 & Siroki Zoltán & DE-siroki-11467.jpg \\
\hline 1127 & Alcea biennis Winterl & Mezőtúr & 1965 & Siroki Zoltán & DE-siroki-11468.jpg \\
\hline 1127 & Alcea biennis Winterl & Mezőtúr & 1965 & Siroki Zoltán & DE-siroki-11469.jpg \\
\hline 1127 & Alcea biennis Winterl & Pásztó & 1952 & Siroki Zoltán & DE-siroki-11470.jpg \\
\hline 1127 & Alcea biennis Winterl & Sárbogárd & 1952 & Gondola István & DE-siroki-11460.jpg \\
\hline 1129 & Abutilon theophrasti Medik. & Debrecen & 1967 & Siroki Zoltán & DE-siroki-11443.jpg \\
\hline 1129 & Abutilon theophrasti Medik. & Nagyiván & 1975 & Siroki Zoltán & DE-siroki-11441.jpg \\
\hline 1129 & Abutilon theophrasti Medik. & Nagyiván & 1975 & Siroki Zoltán & DE-siroki-11442.jpg \\
\hline
\end{tabular}




\begin{tabular}{|c|c|c|c|c|c|}
\hline $\begin{array}{l}\text { Sorszám / } \\
\text { Number }\end{array}$ & Taxon-név / Taxon-name & $\begin{array}{l}\text { Település / } \\
\text { Settlement }\end{array}$ & $\begin{array}{l}\text { Év / } \\
\text { Year }\end{array}$ & $\begin{array}{l}\text { Gyújtő / } \\
\text { Collector }\end{array}$ & Fájlnév / File-name \\
\hline 1130 & Hibiscus trionum L. & Abaújkér & 1943 & Siroki Zoltán & DE-siroki-11495.jpg \\
\hline 1130 & Hibiscus trionum L. & Budaörs & 1941 & Siroki Zoltán & DE-siroki-11496.jpg \\
\hline 1130 & Hibiscus trionum L. & Budaörs & 1941 & Siroki Zoltán & DE-siroki-11497.jpg \\
\hline 1130 & Hibiscus trionum L. & Debrecen & 1947 & Siroki Zoltán & DE-siroki-11494.jpg \\
\hline 1132 & Daphne cneorum L. & Budaörs & 1912 & Jávorka Sándor & DE-siroki-12602.jpg \\
\hline 1132 & Daphne cneorum L. & Budaörs & 1952 & Siroki Zoltán & DE-siroki-12609.jpg \\
\hline 1132 & Daphne cneorum L. & Budaörs & 1952 & Siroki Zoltán & DE-siroki-12606.jpg \\
\hline 1132 & Daphne cneorum L. & Budaörs & 1952 & Siroki Zoltán & DE-siroki-12607.jpg \\
\hline 1132 & Daphne cneorum L. & Budaörs & 1952 & Siroki Zoltán & DE-siroki-12608.jpg \\
\hline 1132 & Daphne cneorum L. & Budaörs & 1955 & Siroki Zoltán & DE-siroki-12601.jpg \\
\hline 1132 & Daphne cneorum L. & Budaörs & 1955 & $\begin{array}{l}\text { Siroki Zoltán - } \\
\text { Farkas Attila }\end{array}$ & DE-siroki-12605.jpg \\
\hline 1132 & Daphne cneorum L. & Gánt & 1951 & Kárpáti Zoltán & DE-siroki-12610.jpg \\
\hline 1132 & Daphne cneorum L. & Gyenesdiás & 1953 & Siroki Zoltán & DE-siroki-12611.jpg \\
\hline 1133 & Daphne laureola L. & "Fáni-völgy" & 1955 & Siroki Zoltán & DE-siroki-12635.jpg \\
\hline 1133 & Daphne laureola L. & "Fáni-völgy" & 1955 & Siroki Zoltán & DE-siroki-12631.jpg \\
\hline 1133 & Daphne laureola L. & "Fáni-völgy" & 1955 & $\begin{array}{l}\text { Siroki Zoltán - } \\
\text { Farkas Attila }\end{array}$ & DE-siroki-12632.jpg \\
\hline 1133 & Daphne laureola L. & "Fáni-völgy" & 1955 & $\begin{array}{l}\text { Siroki Zoltán - } \\
\text { Farkas Attila }\end{array}$ & DE-siroki-12633.jpg \\
\hline 1133 & Daphne laureola L. & "Fáni-völgy" & 1955 & $\begin{array}{l}\text { Siroki Zoltán - } \\
\text { Farkas Attila }\end{array}$ & DE-siroki-12634.jpg \\
\hline 1134 & Daphne mezereum L. & "Bükk-hg." & 1961 & Siroki Zoltán & DE-siroki-12624.jpg \\
\hline 1134 & Daphne mezereum L. & "Bükk-hg." & 1961 & Siroki Zoltán & DE-siroki-12625.jpg \\
\hline 1134 & Daphne mezereum L. & "Nagymező" & 1958 & Siroki Zoltán & DE-siroki-12630.jpg \\
\hline 1134 & Daphne mezereum L. & "Nagymező" & 1959 & Siroki Zoltán & DE-siroki-12626.jpg \\
\hline 1134 & Daphne mezereum L. & "Nagymező" & 1959 & Siroki Zoltán & DE-siroki-12627.jpg \\
\hline 1134 & Daphne mezereum L. & "Nagymező" & 1959 & Siroki Zoltán & DE-siroki-12628.jpg \\
\hline 1134 & Daphne mezereum L. & "Nagymező" & 1973 & Siroki Zoltán & DE-siroki-12622.jpg \\
\hline 1134 & Daphne mezereum L. & "Nagymező" & 1973 & Siroki Zoltán & DE-siroki-12623.jpg \\
\hline 1134 & Daphne mezereum L. & "Nagymező" & 1973 & Siroki Zoltán & DE-siroki-12621.jpg \\
\hline 1134 & Daphne mezereum L. & "Tarkő" & 1958 & Siroki Zoltán & DE-siroki-12620.jpg \\
\hline 1135 & $\begin{array}{l}\text { Thymelaea passerina (L.) Coss. et } \\
\text { Germ. }\end{array}$ & Budapest & 1951 & Siroki Zoltán & DE-siroki-12599.jpg \\
\hline 1136 & Hippophaë rhamnoides L. & Budapest & 1941 & Siroki Zoltán & DE-siroki-12638.jpg \\
\hline 1137 & Elaeagnus angustifolia L. & Debrecen & 1972 & Siroki Zoltán & DE-siroki-12640.jpg \\
\hline 1137 & Elaeagnus angustifolia L. & Debrecen & 1972 & Siroki Zoltán & DE-siroki-12641.jpg \\
\hline 1137 & Elaeagnus angustifolia L. & Debrecen & 1972 & Siroki Zoltán & DE-siroki-12639.jpg \\
\hline 1139 & Hypericum humifusum L. & Győröcske & 1965 & Gondola István & DE-siroki-11503.jpg \\
\hline 1139 & Hypericum humifusum L. & Győröcske & 1965 & Gondola István & DE-siroki-11504.jpg \\
\hline 1139 & Hypericum humifusum L. & Lenti & 1929 & Rigler József & DE-siroki-11506.jpg \\
\hline 1139 & Hypericum humifusum L. & Mátraszentimre & 1984 & Siroki Zoltán & DE-siroki-11505.jpg \\
\hline 1139 & Hypericum humifusum L. & Sopron & 1950 & Kárpáti Zoltán & DE-siroki-11502.jpg \\
\hline 1141 & Hypericum perforatum L. & "Bükk-hg." & 1956 & Halász Tibor & DE-siroki-11520.jpg \\
\hline 1141 & Hypericum perforatum L. & Budaörs & 1966 & Siroki Zoltán & DE-siroki-11518.jpg \\
\hline 1141 & Hypericum perforatum L. & Budaörs & 1966 & Siroki Zoltán & DE-siroki-11519.jpg \\
\hline 1142 & Hypericum tetrapterum Fr. & Debrecen & 1950 & Siroki Zoltán & DE-siroki-11514.jpg \\
\hline 1142 & Hypericum tetrapterum Fr. & Debrecen & 1950 & Siroki Zoltán & DE-siroki-11516.jpg \\
\hline 1142 & Hypericum tetrapterum Fr. & Debrecen & 1951 & Siroki Zoltán & DE-siroki-11513.jpg \\
\hline
\end{tabular}




\begin{tabular}{|c|c|c|c|c|c|}
\hline $\begin{array}{l}\text { Sorszám / } \\
\text { Number }\end{array}$ & Taxon-név / Taxon-name & $\begin{array}{l}\text { Település / } \\
\text { Settlement }\end{array}$ & $\begin{array}{l}\text { Év / } \\
\text { Year }\end{array}$ & $\begin{array}{l}\text { Gyűjtő / } \\
\text { Collector }\end{array}$ & Fájlnév / File-name \\
\hline 1142 & Hypericum tetrapterum Fr. & Gödöllő & 1951 & Siroki Zoltán & DE-siroki-11512.jpg \\
\hline 1142 & Hypericum tetrapterum Fr. & Háromhuta & 1978 & Siroki Zoltán & DE-siroki-11510.jpg \\
\hline 1142 & Hypericum tetrapterum Fr. & Háromhuta & 1978 & Siroki Zoltán & DE-siroki-11511.jpg \\
\hline 1142 & Hypericum tetrapterum Fr. & Keszthely & 1955 & Siroki Zoltán & DE-siroki-11509.jpg \\
\hline 1142 & Hypericum tetrapterum Fr. & Veresegyház & 1951 & Siroki Zoltán & DE-siroki-11508.jpg \\
\hline 1145 & Hypericum hirsutum L. & "Bükk-hg." & 1983 & Siroki Zoltán & DE-siroki-11542.jpg \\
\hline 1145 & Hypericum hirsutum L. & "Bükk-hg." & 1983 & Siroki Zoltán & DE-siroki-11543.jpg \\
\hline 1145 & Hypericum hirsutum L. & "Bükk-hg." & 1983 & Siroki Zoltán & DE-siroki-11544.jpg \\
\hline 1145 & Hypericum hirsutum L. & "Dobogókő" & 1957 & Siroki Zoltán & DE-siroki-11536.jpg \\
\hline 1145 & Hypericum hirsutum L. & "Háromkő" & 1956 & Halász Tibor & DE-siroki-11537.jpg \\
\hline 1145 & Hypericum hirsutum L. & "Háromkő" & 1956 & Halász Tibor & DE-siroki-11538.jpg \\
\hline 1145 & Hypericum hirsutum L. & "Háromkő" & 1959 & Siroki Zoltán & DE-siroki-11539.jpg \\
\hline 1145 & Hypericum hirsutum L. & "Háromkő" & 1959 & Siroki Zoltán & DE-siroki-11540.jpg \\
\hline 1145 & Hypericum hirsutum L. & "Háromkő" & 1959 & Siroki Zoltán & DE-siroki-11541.jpg \\
\hline 1145 & Hypericum hirsutum L. & Pásztó & 1952 & Siroki Zoltán & DE-siroki-11533.jpg \\
\hline 1145 & Hypericum hirsutum L. & Szilvásvárad & 1954 & Siroki Zoltán & DE-siroki-11528.jpg \\
\hline 1145 & Hypericum hirsutum L. & Szilvásvárad & 1954 & Siroki Zoltán & DE-siroki-11529.jpg \\
\hline 1145 & Hypericum hirsutum L. & Szilvásvárad & 1954 & Siroki Zoltán & DE-siroki-11532.jpg \\
\hline 1145 & Hypericum hirsutum L. & Szilvásvárad & 1954 & Siroki Zoltán & DE-siroki-11530.jpg \\
\hline 1145 & Hypericum hirsutum L. & Szilvásvárad & 1954 & Siroki Zoltán & DE-siroki-11531.jpg \\
\hline 1147 & Hypericum montanum L. & "Dobogókő" & 1956 & Siroki Zoltán & DE-siroki-11546.jpg \\
\hline 1147 & Hypericum montanum L. & Gyenesdiás & 1955 & Siroki Zoltán & DE-siroki-11548.jpg \\
\hline 1147 & Hypericum montanum L. & Sopron & 1956 & Kovács Béla & DE-siroki-11547.jpg \\
\hline 1148 & Hypericum elegans Stephan ex Willd. & Abaújszántó & 1943 & Siroki Zoltán & DE-siroki-11553.jpg \\
\hline 1150 & Viola tricolor L. & Berekböszörmény & 1970 & Siroki Zoltán & DE-siroki-12577.jpg \\
\hline 1150 & Viola tricolor L. & Debrecen & 1947 & Siroki Zoltán & DE-siroki-12583.jpg \\
\hline 1150 & Viola tricolor L. & Debrecen & 1950 & Siroki Zoltán & DE-siroki-12584.jpg \\
\hline 1150 & Viola tricolor L. & Hortobágy & 1985 & Siroki Zoltán & DE-siroki-12582.jpg \\
\hline 1151 & Viola arvensis Murray & Budapest & 1951 & Siroki Zoltán & DE-siroki-12592.jpg \\
\hline 1151 & Viola arvensis Murray & Budapest & 1951 & Siroki Zoltán & DE-siroki-12594.jpg \\
\hline 1151 & Viola arvensis Murray & Debrecen & 1947 & Siroki Zoltán & DE-siroki-12590.jpg \\
\hline 1151 & Viola arvensis Murray & Debrecen & 1950 & Siroki Zoltán & DE-siroki-12591.jpg \\
\hline 1151 & Viola arvensis Murray & Debrecen & 1951 & Siroki Zoltán & DE-siroki-12593.jpg \\
\hline 1151 & Viola arvensis Murray & Mosonmagyaróvár & 1939 & Siroki Zoltán & DE-siroki-12596.jpg \\
\hline 1151 & Viola arvensis Murray & Mosonmagyaróvár & 1939 & Siroki Zoltán & DE-siroki-12597.jpg \\
\hline 1152 & Viola kitaibeliana Roem. et Schult. & Debrecen & 1947 & Siroki Zoltán & DE-siroki-12598.jpg \\
\hline 1153 & Viola alba Besser & Háromhuta & 1975 & Siroki Zoltán & DE-siroki-11768.jpg \\
\hline 1153 & Viola alba Besser & Háromhuta & 1975 & Siroki Zoltán & DE-siroki-11769.jpg \\
\hline 1153 & Viola alba Besser & Háromhuta & 1975 & Siroki Zoltán & DE-siroki-11770.jpg \\
\hline 1153 & Viola alba Besser & Makkoshotyka & 1955 & Siroki Zoltán & DE-siroki-11771.jpg \\
\hline 1153 & Viola alba Besser & Pomáz & 1951 & Siroki Zoltán & DE-siroki-11774.jpg \\
\hline 1153 & Viola alba Besser & Pomáz & 1951 & Siroki Zoltán & DE-siroki-11775.jpg \\
\hline 1153 & Viola alba Besser & Szentendre & 1951 & Siroki Zoltán & DE-siroki-11772.jpg \\
\hline 1153 & Viola alba Besser & Szentendre & 1951 & Siroki Zoltán & DE-siroki-11773.jpg \\
\hline 1154 & Viola suavis M. Bieb. & Budapest & 1941 & Siroki Zoltán & DE-siroki-11795.jpg \\
\hline 1154 & Viola suavis M. Bieb. & Budapest & 1951 & Siroki Zoltán & DE-siroki-11794.jpg \\
\hline
\end{tabular}




\begin{tabular}{|c|c|c|c|c|c|}
\hline $\begin{array}{l}\text { Sorszám / } \\
\text { Number }\end{array}$ & Taxon-név / Taxon-name & $\begin{array}{l}\text { Település / } \\
\text { Settlement }\end{array}$ & $\begin{array}{l}\text { Év / } \\
\text { Year }\end{array}$ & $\begin{array}{l}\text { Gyújtő / } \\
\text { Collector }\end{array}$ & Fájlnév / File-name \\
\hline 1154 & Viola suavis M. Bieb. & Budapest & 1951 & Siroki Zoltán & DE-siroki-11794.jpg \\
\hline 1154 & Viola suavis M. Bieb. & Debrecen & 1947 & Siroki Zoltán & DE-siroki-11785.jpg \\
\hline 1154 & Viola suavis M. Bieb. & Debrecen & 1949 & Siroki Zoltán & DE-siroki-11782.jpg \\
\hline 1154 & Viola suavis M. Bieb. & Debrecen & 1949 & Siroki Zoltán & DE-siroki-11783.jpg \\
\hline 1154 & Viola suavis M. Bieb. & Debrecen & 1950 & Siroki Zoltán & DE-siroki-11784.jpg \\
\hline 1154 & Viola suavis M. Bieb. & Debrecen & 1950 & Siroki Zoltán & DE-siroki-11788.jpg \\
\hline 1154 & Viola suavis M. Bieb. & Debrecen & 1950 & Siroki Zoltán & DE-siroki-11786.jpg \\
\hline 1154 & Viola suavis M. Bieb. & Debrecen & 1950 & Siroki Zoltán & DE-siroki-11787.jpg \\
\hline 1154 & Viola suavis M. Bieb. & Debrecen & 1950 & Siroki Zoltán & DE-siroki-11793.jpg \\
\hline 1154 & Viola suavis M. Bieb. & Debrecen & 1950 & Siroki Zoltán & DE-siroki-11781.jpg \\
\hline 1154 & Viola suavis M. Bieb. & Debrecen & 1950 & Siroki Zoltán & DE-siroki-11789.jpg \\
\hline 1154 & Viola suavis M. Bieb. & Debrecen & 1950 & Siroki Zoltán & DE-siroki-11790.jpg \\
\hline 1154 & Viola suavis M. Bieb. & Debrecen & 1950 & Siroki Zoltán & DE-siroki-11791.jpg \\
\hline 1154 & Viola suavis M. Bieb. & Debrecen & 1950 & Siroki Zoltán & DE-siroki-11792.jpg \\
\hline 1154 & Viola suavis M. Bieb. & Pomáz & 1951 & Siroki Zoltán & DE-siroki-11797.jpg \\
\hline 1154 & Viola suavis M. Bieb. & Pomáz & 1951 & Siroki Zoltán & DE-siroki-11798.jpg \\
\hline 1154 & Viola suavis M. Bieb. & Pomáz & 1951 & Siroki Zoltán & DE-siroki-11799.jpg \\
\hline 1155 & Viola odorata L. & Budapest & 1941 & Siroki Zoltán & DE-siroki-11761.jpg \\
\hline 1155 & Viola odorata L. & Budapest & 1951 & Siroki Zoltán & DE-siroki-11760.jpg \\
\hline 1155 & Viola odorata L. & Budapest & 1951 & Siroki Zoltán & DE-siroki-11763.jpg \\
\hline 1155 & Viola odorata L. & Budapest & 1951 & Siroki Zoltán & DE-siroki-11762.jpg \\
\hline 1155 & Viola odorata L. & Debrecen & 1949 & Siroki Zoltán & DE-siroki-11757.jpg \\
\hline 1155 & Viola odorata L. & Debrecen & 1949 & Siroki Zoltán & DE-siroki-11758.jpg \\
\hline 1155 & Viola odorata L. & Debrecen & 1954 & Siroki Zoltán & DE-siroki-11756.jpg \\
\hline 1155 & Viola odorata L. & Debrecen & 1954 & Siroki Zoltán & DE-siroki-11759.jpg \\
\hline 1156 & Viola mirabilis L. & Budapest & 1941 & Siroki Zoltán & DE-siroki-11833.jpg \\
\hline 1156 & Viola mirabilis L. & Budapest & 1941 & Siroki Zoltán & DE-siroki-11834.jpg \\
\hline 1156 & Viola mirabilis L. & Budapest & 1951 & Siroki Zoltán & DE-siroki-11832.jpg \\
\hline 1156 & Viola mirabilis L. & Budapest & 1951 & Siroki Zoltán & DE-siroki-11831.jpg \\
\hline 1156 & Viola mirabilis L. & Debrecen & 1950 & Siroki Zoltán & DE-siroki-11825.jpg \\
\hline 1156 & Viola mirabilis L. & Debrecen & 1950 & Siroki Zoltán & DE-siroki-11826.jpg \\
\hline 1156 & Viola mirabilis L. & Debrecen & 1950 & Siroki Zoltán & DE-siroki-11827.jpg \\
\hline 1156 & Viola mirabilis L. & Debrecen & 1954 & Siroki Zoltán & DE-siroki-11828.jpg \\
\hline 1156 & Viola mirabilis L. & Debrecen & 1954 & Siroki Zoltán & DE-siroki-11829.jpg \\
\hline 1156 & Viola mirabilis L. & Debrecen & 1954 & Siroki Zoltán & DE-siroki-11830.jpg \\
\hline 1158 & Viola hirta L. & "Bükk-hg." & 1966 & Siroki Zoltán & DE-siroki-11805.jpg \\
\hline 1158 & Viola hirta L. & "Bükk-hg." & 1966 & Siroki Zoltán & DE-siroki-11806.jpg \\
\hline 1158 & Viola hirta L. & Budapest & 1941 & Siroki Zoltán & DE-siroki-11811.jpg \\
\hline 1158 & Viola hirta L. & Budapest & 1951 & Siroki Zoltán & DE-siroki-11808.jpg \\
\hline 1158 & Viola hirta L. & Budapest & 1951 & Siroki Zoltán & DE-siroki-11809.jpg \\
\hline 1158 & Viola hirta L. & Budapest & 1951 & Siroki Zoltán & DE-siroki-11810.jpg \\
\hline 1158 & Viola hirta L. & Budapest & 1951 & Siroki Zoltán & DE-siroki-11812.jpg \\
\hline 1158 & Viola hirta L. & Gödöllő & 1952 & Siroki Zoltán & DE-siroki-11813.jpg \\
\hline 1158 & Viola hirta L. & Gyenesdiás & 1972 & Siroki Zoltán & DE-siroki-11803.jpg \\
\hline 1158 & Viola hirta L. & Szarvaskő & 1958 & Siroki Zoltán & DE-siroki-11807.jpg \\
\hline 1158 & Viola hirta L. & Szarvaskő & 1958 & Siroki Zoltán & DE-siroki-11804.jpg \\
\hline
\end{tabular}




\begin{tabular}{|c|c|c|c|c|c|}
\hline $\begin{array}{l}\text { Sorszám / } \\
\text { Number }\end{array}$ & Taxon-név / Taxon-name & $\begin{array}{l}\text { Település / } \\
\text { Settlement }\end{array}$ & $\begin{array}{l}\text { Év / } \\
\text { Year }\end{array}$ & $\begin{array}{l}\text { Gyűjtő / } \\
\text { Collector }\end{array}$ & Fájlnév / File-name \\
\hline 1159 & Viola ambigua Waldst. et Kit. & Budaörs & 1952 & Siroki Zoltán & DE-siroki-11819.jpg \\
\hline 1159 & Viola ambigua Waldst. et Kit. & Budapest & 1951 & Siroki Zoltán & DE-siroki-11820.jpg \\
\hline 1159 & Viola ambigua Waldst. et Kit. & Budapest & 1951 & Siroki Zoltán & DE-siroki-11821.jpg \\
\hline 1160 & Viola rupestris F.W. Schmidt & Budaörs & 1952 & Siroki Zoltán & DE-siroki-11839.jpg \\
\hline 1160 & Viola rupestris F.W. Schmidt & Budapest & 1941 & Siroki Zoltán & DE-siroki-11840.jpg \\
\hline 1160 & Viola rupestris F.W. Schmidt & Nagykőrös & 1954 & Siroki Zoltán & DE-siroki-11838.jpg \\
\hline 1160 & Viola rupestris F.W. Schmidt & Pilisszentiván & 1952 & Siroki Zoltán & DE-siroki-11836.jpg \\
\hline 1160 & Viola rupestris F.W. Schmidt & Pilisszentiván & 1952 & Siroki Zoltán & DE-siroki-11837.jpg \\
\hline 1161 & Viola reichenbachiana Jord. & "Bánkút" & 1966 & Siroki Zoltán & DE-siroki-11842.jpg \\
\hline 1161 & Viola reichenbachiana Jord. & "Bánkút" & 1966 & Siroki Zoltán & DE-siroki-12485.jpg \\
\hline 1161 & Viola reichenbachiana Jord. & "Bánkút" & 1966 & Siroki Zoltán & DE-siroki-12486.jpg \\
\hline 1161 & Viola reichenbachiana Jord. & "Bánkút" & 1966 & Siroki Zoltán & DE-siroki-12487.jpg \\
\hline 1161 & Viola reichenbachiana Jord. & "Bánkút" & 1966 & Siroki Zoltán & DE-siroki-12488.jpg \\
\hline 1161 & Viola reichenbachiana Jord. & "Fáni-völgy" & 1955 & $\begin{array}{l}\text { Farkas Attila - } \\
\text { Siroki Zoltán }\end{array}$ & DE-siroki-12489.jpg \\
\hline 1161 & Viola reichenbachiana Jord. & "Fáni-völgy" & 1955 & $\begin{array}{l}\text { Farkas Attila - } \\
\text { Siroki Zoltán }\end{array}$ & DE-siroki-12490.jpg \\
\hline 1161 & Viola reichenbachiana Jord. & "Fáni-völgy" & 1955 & $\begin{array}{l}\text { Farkas Attila - } \\
\text { Siroki Zoltán }\end{array}$ & DE-siroki-12491.jpg \\
\hline 1161 & Viola reichenbachiana Jord. & "Fáni-völgy" & 1955 & $\begin{array}{l}\text { Farkas Attila - } \\
\text { Siroki Zoltán }\end{array}$ & DE-siroki-12494.jpg \\
\hline 1161 & Viola reichenbachiana Jord. & "Nagymező" & 1959 & Halász Tibor & DE-siroki-12492.jpg \\
\hline 1161 & Viola reichenbachiana Jord. & Budapest & 1951 & Siroki Zoltán & DE-siroki-12498.jpg \\
\hline 1161 & Viola reichenbachiana Jord. & Pásztó & 1952 & Siroki Zoltán & DE-siroki-12497.jpg \\
\hline 1161 & Viola reichenbachiana Jord. & Pásztó & 1952 & Siroki Zoltán & DE-siroki-12499.jpg \\
\hline 1161 & Viola reichenbachiana Jord. & Pilismarót & 1957 & Siroki Zoltán & DE-siroki-11841.jpg \\
\hline 1161 & Viola reichenbachiana Jord. & Szarvaskő & 1958 & Siroki Zoltán & DE-siroki-12493.jpg \\
\hline 1161 & Viola reichenbachiana Jord. & Szarvaskő & 1958 & Siroki Zoltán & DE-siroki-12496.jpg \\
\hline 1161 & Viola reichenbachiana Jord. & Szilvásvárad & 1954 & Siroki Zoltán & DE-siroki-12495.jpg \\
\hline 1162 & Viola riviniana Rchb. & "Bánkút" & 1966 & Siroki Zoltán & DE-siroki-12502.jpg \\
\hline 1162 & Viola riviniana Rchb. & "Mátra" & 1957 & Siroki Zoltán & DE-siroki-12503.jpg \\
\hline 1162 & Viola riviniana Rchb. & Budapest & 1951 & Siroki Zoltán & DE-siroki-12511.jpg \\
\hline 1162 & Viola riviniana Rchb. & Budapest & 1951 & Siroki Zoltán & DE-siroki-12519.jpg \\
\hline 1162 & Viola riviniana Rchb. & Budapest & 1951 & Siroki Zoltán & DE-siroki-12518.jpg \\
\hline 1162 & Viola riviniana Rchb. & Budapest & 1952 & Siroki Zoltán & DE-siroki-12516.jpg \\
\hline 1162 & Viola riviniana Rchb. & Háromhuta & 1961 & Siroki Zoltán & DE-siroki-12501.jpg \\
\hline 1162 & Viola riviniana Rchb. & Nagyhuta & 1961 & Siroki Zoltán & DE-siroki-12507.jpg \\
\hline 1162 & Viola riviniana Rchb. & Nagyhuta & 1961 & Siroki Zoltán & DE-siroki-12508.jpg \\
\hline 1162 & Viola riviniana Rchb. & Nagyhuta & 1961 & Siroki Zoltán & DE-siroki-12509.jpg \\
\hline 1162 & Viola riviniana Rchb. & Nagyhuta & 1961 & Siroki Zoltán & DE-siroki-12505.jpg \\
\hline 1162 & Viola riviniana Rchb. & Nagyhuta & 1961 & Siroki Zoltán & DE-siroki-12506.jpg \\
\hline 1162 & Viola riviniana Rchb. & Nagykovácsi & 1959 & Siroki Zoltán & DE-siroki-12504.jpg \\
\hline 1162 & Viola riviniana Rchb. & Pilismarót & 1957 & Siroki Zoltán & DE-siroki-12510.jpg \\
\hline 1163 & Viola elatior Fr. & Debrecen & 1949 & Siroki Zoltán & DE-siroki-12549.jpg \\
\hline 1163 & Viola elatior Fr. & Szigetcsép & 1951 & Siroki Zoltán & DE-siroki-12548.jpg \\
\hline 1163 & Viola elatior Fr. & Szigetcsép & 1951 & Siroki Zoltán & DE-siroki-12550.jpg \\
\hline 1163 & Viola elatior Fr. & Szigetcsép & 1951 & Siroki Zoltán & DE-siroki-12551.jpg \\
\hline 1163 & Viola elatior Fr. & Szigetcsép & 1951 & Siroki Zoltán & DE-siroki-12552.jpg \\
\hline 1163 & Viola elatior Fr. & Szigetcsép & 1951 & Siroki Zoltán & DE-siroki-12553.jpg \\
\hline
\end{tabular}




\begin{tabular}{|c|c|c|c|c|c|}
\hline $\begin{array}{l}\text { Sorszám / } \\
\text { Number }\end{array}$ & Taxon-név / Taxon-name & $\begin{array}{l}\text { Település / } \\
\text { Settlement }\end{array}$ & $\begin{array}{l}\text { Év / } \\
\text { Year }\end{array}$ & $\begin{array}{l}\text { Gyújtő / } \\
\text { Collector }\end{array}$ & Fájlnév / File-name \\
\hline 1164 & Viola canina L. & "Bükk-hg." & 1966 & Siroki Zoltán & DE-siroki-12534.jpg \\
\hline 1164 & Viola canina L. & "Nagymező" & 1959 & Halász Tibor & DE-siroki-12522.jpg \\
\hline 1164 & Viola canina L. & Abaújszántó & 1944 & Siroki Zoltán & DE-siroki-12546.jpg \\
\hline 1164 & Viola canina L. & Abaújszántó & 1944 & Siroki Zoltán & DE-siroki-12542.jpg \\
\hline 1164 & Viola canina L. & Debrecen & 1954 & Siroki Zoltán & DE-siroki-12535.jpg \\
\hline 1164 & Viola canina L. & Debrecen & 1954 & Siroki Zoltán & DE-siroki-12536.jpg \\
\hline 1164 & Viola canina L. & Debrecen & 1954 & Siroki Zoltán & DE-siroki-12540.jpg \\
\hline 1164 & Viola canina L. & Debrecen & 1954 & Siroki Zoltán & DE-siroki-12541.jpg \\
\hline 1164 & Viola canina L. & Debrecen & 1964 & Siroki Zoltán & DE-siroki-12527.jpg \\
\hline 1164 & Viola canina L. & Debrecen & 1964 & Siroki Zoltán & DE-siroki-12528.jpg \\
\hline 1164 & Viola canina L. & Debrecen & 1964 & Siroki Zoltán & DE-siroki-12529.jpg \\
\hline 1164 & Viola canina L. & Háromhuta & 1961 & Siroki Zoltán & DE-siroki-12521.jpg \\
\hline 1164 & Viola canina L. & Háromhuta & 1961 & Siroki Zoltán & DE-siroki-12530.jpg \\
\hline 1164 & Viola canina L. & Háromhuta & 1961 & Siroki Zoltán & DE-siroki-12532.jpg \\
\hline 1164 & Viola canina L. & Háromhuta & 1961 & Siroki Zoltán & DE-siroki-12533.jpg \\
\hline 1164 & Viola canina L. & Háromhuta & 1961 & Siroki Zoltán & DE-siroki-12537.jpg \\
\hline 1164 & Viola canina L. & Nagyhuta & 1961 & Siroki Zoltán & DE-siroki-12531.jpg \\
\hline 1164 & Viola canina L. & Nagyhuta & 1961 & Siroki Zoltán & DE-siroki-12538.jpg \\
\hline 1165 & Viola pumila Chaix & Debrecen & 1949 & Siroki Zoltán & DE-siroki-12568.jpg \\
\hline 1165 & Viola pumila Chaix & Debrecen & 1949 & Siroki Zoltán & DE-siroki-12569.jpg \\
\hline 1165 & Viola pumila Chaix & Debrecen & 1949 & Siroki Zoltán & DE-siroki-12565.jpg \\
\hline 1165 & Viola pumila Chaix & Debrecen & 1949 & Siroki Zoltán & DE-siroki-12567.jpg \\
\hline 1165 & Viola pumila Chaix & Debrecen & 1949 & Siroki Zoltán & DE-siroki-12566.jpg \\
\hline 1165 & Viola pumila Chaix & Debrecen & 1949 & Siroki Zoltán & DE-siroki-12562.jpg \\
\hline 1165 & Viola pumila Chaix & Egyek & 1969 & Siroki Zoltán & DE-siroki-12554.jpg \\
\hline 1165 & Viola pumila Chaix & Egyek & 1969 & Siroki Zoltán & DE-siroki-12555.jpg \\
\hline 1165 & Viola pumila Chaix & Egyek & 1969 & Siroki Zoltán & DE-siroki-12556.jpg \\
\hline 1165 & Viola pumila Chaix & Egyek & 1969 & Siroki Zoltán & DE-siroki-12561.jpg \\
\hline 1165 & Viola pumila Chaix & Szarvasgede & 1954 & Máthé Imre & DE-siroki-12557.jpg \\
\hline 1165 & Viola pumila Chaix & Szarvasgede & 1954 & Máthé Imre & DE-siroki-12558.jpg \\
\hline 1165 & Viola pumila Chaix & Szarvasgede & 1954 & Máthé Imre & DE-siroki-12559.jpg \\
\hline 1165 & Viola pumila Chaix & Szarvasgede & 1954 & Máthé Imre & DE-siroki-12560.jpg \\
\hline 1165 & Viola pumila Chaix & Tarpa & 1955 & $\begin{array}{l}\text { Siroki Zoltán - } \\
\text { Farkas Attila }\end{array}$ & DE-siroki-12564.jpg \\
\hline 1165 & Viola pumila Chaix & Tiszafüred & 1955 & $\begin{array}{l}\text { Siroki Zoltán - } \\
\text { Farkas Attila }\end{array}$ & DE-siroki-12563.jpg \\
\hline 1166 & Viola stagnina Kit. & Debrecen & 1954 & Siroki Zoltán & DE-siroki-12570.jpg \\
\hline 1166 & Viola stagnina Kit. & Debrecen & 1954 & Siroki Zoltán & DE-siroki-12571.jpg \\
\hline 1166 & Viola stagnina Kit. & Debrecen & 1954 & Siroki Zoltán & DE-siroki-12572.jpg \\
\hline $1149-1166$ & Viola & Budapest & 1890 & Czakó Kálmán & DE-siroki-12589.jpg \\
\hline $1149-1166$ & Viola & Budapest & 1890 & Czakó Kálmán & DE-siroki-12588.jpg \\
\hline 1167 & Helianthemum canum (L.) Hornem. & Budaörs & 1955 & $\begin{array}{l}\text { Siroki Zoltán - } \\
\text { Farkas Attila }\end{array}$ & DE-siroki-11585.jpg \\
\hline 1168 & Helianthemum nummularium (L.) Mill. & Gyenesdiás & 1955 & Siroki Zoltán & DE-siroki-11583.jpg \\
\hline 1169 & $\begin{array}{l}\text { Helianthemum ovatum } \\
\text { (Viv.) Dunal in DC. }\end{array}$ & "Vértes" & 1957 & Siroki Zoltán & DE-siroki-11572.jpg \\
\hline 1169 & $\begin{array}{l}\text { Helianthemum ovatum } \\
\text { (Viv.) Dunal in DC. }\end{array}$ & "Vértes" & 1957 & Siroki Zoltán & DE-siroki-11574.jpg \\
\hline 1169 & $\begin{array}{l}\text { Helianthemum ovatum } \\
\text { (Viv.) Dunal in DC. }\end{array}$ & Budaörs & 1955 & $\begin{array}{l}\text { Siroki Zoltán - } \\
\text { Farkas Attila }\end{array}$ & DE-siroki-11570.jpg \\
\hline
\end{tabular}




\begin{tabular}{|c|c|c|c|c|c|}
\hline $\begin{array}{l}\text { Sorszám / } \\
\text { Number }\end{array}$ & Taxon-név / Taxon-name & $\begin{array}{l}\text { Település / } \\
\text { Settlement }\end{array}$ & $\begin{array}{l}\text { Év / } \\
\text { Year }\end{array}$ & $\begin{array}{l}\text { Gyújitő / } \\
\text { Collector }\end{array}$ & Fájlnév / File-name \\
\hline 1169 & $\begin{array}{l}\text { Helianthemum ovatum } \\
\text { (Viv.) Dunal in DC. }\end{array}$ & Budaörs & 1955 & $\begin{array}{l}\text { Siroki Zoltán - } \\
\text { Farkas Attila }\end{array}$ & DE-siroki-11571.jpg \\
\hline 1169 & $\begin{array}{l}\text { Helianthemum ovatum } \\
\text { (Viv.) Dunal in DC. }\end{array}$ & Háromhuta & 1961 & Siroki Zoltán & DE-siroki-11575.jpg \\
\hline 1169 & $\begin{array}{l}\text { Helianthemum ovatum } \\
\text { (Viv.) Dunal in DC. }\end{array}$ & Nagykovácsi & 1957 & Siroki Zoltán & DE-siroki-11573.jpg \\
\hline 1170 & $\begin{array}{l}\text { Fumana procumbens } \\
\text { (Dunal) Gren. et Godr. }\end{array}$ & Ágasegyháza & 1956 & Siroki Zoltán & DE-siroki-11589.jpg \\
\hline 1170 & $\begin{array}{l}\text { Fumana procumbens } \\
\text { (Dunal) Gren. et Godr. }\end{array}$ & Budapest & 1948 & Siroki Zoltán & DE-siroki-11591.jpg \\
\hline 1170 & $\begin{array}{l}\text { Fumana procumbens } \\
\text { (Dunal) Gren. et Godr. }\end{array}$ & Budapest & 1948 & Siroki Zoltán & DE-siroki-11590.jpg \\
\hline 1175 & Elatine alsinastrum L. & Csaroda & 1965 & Siroki Zoltán & DE-siroki-11563.jpg \\
\hline 1175 & Elatine alsinastrum L. & Csaroda & 1965 & Siroki Zoltán & DE-siroki-11564.jpg \\
\hline 1175 & Elatine alsinastrum L. & Dombrád & 1967 & Gondola István & DE-siroki-11565.jpg \\
\hline 1175 & Elatine alsinastrum L. & Dombrád & 1967 & Gondola István & DE-siroki-11566.jpg \\
\hline 1175 & Elatine alsinastrum L. & Egyek & 1947 & Siroki Zoltán & DE-siroki-11560.jpg \\
\hline 1175 & Elatine alsinastrum L. & Egyek & 1947 & Siroki Zoltán & DE-siroki-11567.jpg \\
\hline 1175 & Elatine alsinastrum L. & Hortobágy & 1955 & Siroki Zoltán & DE-siroki-11561.jpg \\
\hline 1175 & Elatine alsinastrum L. & Hortobágy & 1955 & Siroki Zoltán & DE-siroki-11562.jpg \\
\hline 1178 & Elatine triandra Schkuhr & Hortobágy & 1955 & Siroki Zoltán & DE-siroki-11557.jpg \\
\hline 1178 & Elatine triandra Schkuhr & Hortobágy & 1955 & Siroki Zoltán & DE-siroki-11559.jpg \\
\hline 1178 & Elatine triandra Schkuhr & Hortobágy & 1955 & Siroki Zoltán & DE-siroki-11558.jpg \\
\hline 1180 & Thladiantha dubia Bunge & Debrecen & 1982 & Siroki Zoltán & DE-siroki-15956.jpg \\
\hline 1180 & Thladiantha dubia Bunge & Debrecen & 1982 & Siroki Zoltán & DE-siroki-15957.jpg \\
\hline 1182 & Bryonia alba L. & Debrecen & 1986 & Siroki Zoltán & DE-siroki-15960.jpg \\
\hline 1182 & Bryonia alba L. & Debrecen & 1986 & Siroki Zoltán & DE-siroki-15961.jpg \\
\hline 1189 & $\begin{array}{l}\text { Echinocystis lobata } \\
\text { (Michx.) Torr. et A. Gray }\end{array}$ & "Cserhát" & 1952 & Siroki Zoltán & DE-siroki-15978.jpg \\
\hline 1189 & $\begin{array}{l}\text { Echinocystis lobata } \\
\text { (Michx.) Torr. et A. Gray }\end{array}$ & Debrecen & 1949 & Siroki Zoltán & DE-siroki-15981.jpg \\
\hline 1189 & $\begin{array}{l}\text { Echinocystis lobata } \\
\text { (Michx.) Torr. et A. Gray }\end{array}$ & Debrecen & 1980 & Siroki Zoltán & DE-siroki-15983.jpg \\
\hline 1189 & $\begin{array}{l}\text { Echinocystis lobata } \\
\text { (Michx.) Torr. et A. Gray }\end{array}$ & Szerencs & 1951 & Siroki Zoltán & DE-siroki-15980.jpg \\
\hline 1189 & $\begin{array}{l}\text { Echinocystis lobata } \\
\text { (Michx.) Torr. et A. Gray }\end{array}$ & Szerencs & 1951 & Siroki Zoltán & DE-siroki-15982.jpg \\
\hline 1194 & Peplis portula L. & Csaroda & 1962 & Siroki Zoltán & DE-siroki-12648.jpg \\
\hline 1194 & Peplis portula L. & Csaroda & 1962 & Siroki Zoltán & DE-siroki-12649.jpg \\
\hline 1194 & Peplis portula L. & Debrecen & 1955 & Siroki Zoltán & DE-siroki-12652.jpg \\
\hline 1194 & Peplis portula L. & Debrecen & 1955 & Siroki Zoltán & DE-siroki-12650.jpg \\
\hline 1194 & Peplis portula L. & Debrecen & 1955 & Siroki Zoltán & DE-siroki-12651.jpg \\
\hline 1194 & Peplis portula L. & Debrecen & 1975 & Siroki Zoltán & DE-siroki-12643.jpg \\
\hline 1194 & Peplis portula L. & Egyek & 1947 & Siroki Zoltán & DE-siroki-12653.jpg \\
\hline 1194 & Peplis portula L. & Egyek & 1982 & Siroki Zoltán & DE-siroki-12644.jpg \\
\hline 1194 & Peplis portula L. & Egyek & 1982 & Siroki Zoltán & DE-siroki-12645.jpg \\
\hline 1194 & Peplis portula L. & Tarcal & 1966 & Siroki Zoltán & DE-siroki-12646.jpg \\
\hline 1194 & Peplis portula L. & Tarcal & 1966 & Siroki Zoltán & DE-siroki-12647.jpg \\
\hline 1196 & Lythrum salicaria L. & "Dobogókő" & 1956 & Siroki Zoltán & DE-siroki-12665.jpg \\
\hline 1196 & Lythrum salicaria L. & "Dobogókő" & 1956 & Siroki Zoltán & DE-siroki-12666.jpg \\
\hline 1196 & Lythrum salicaria L. & Budaörs & 1941 & Siroki Zoltán & DE-siroki-12673.jpg \\
\hline 1196 & Lythrum salicaria L. & Budaörs & 1941 & Siroki Zoltán & DE-siroki-12672.jpg \\
\hline
\end{tabular}




\begin{tabular}{|c|c|c|c|c|c|}
\hline $\begin{array}{l}\text { Sorszám / } \\
\text { Number }\end{array}$ & Taxon-név / Taxon-name & $\begin{array}{l}\text { Település / } \\
\text { Settlement }\end{array}$ & $\begin{array}{l}\text { Év / } \\
\text { Year }\end{array}$ & $\begin{array}{l}\text { Gyűjtő / } \\
\text { Collector }\end{array}$ & Fájlnév / File-name \\
\hline 1196 & Lythrum salicaria L. & Debrecen & 1950 & Siroki Zoltán & DE-siroki-12667.jpg \\
\hline 1196 & Lythrum salicaria L. & Füzesabony & 1970 & Siroki Zoltán & DE-siroki-12664.jpg \\
\hline 1196 & Lythrum salicaria L. & Mosonmagyaróvár & 1939 & Siroki Zoltán & DE-siroki-12674.jpg \\
\hline 1196 & Lythrum salicaria L. & Mosonmagyaróvár & 1959 & Siroki Zoltán & DE-siroki-12668.jpg \\
\hline 1196 & Lythrum salicaria L. & Szikszó & 1944 & Siroki Zoltán & DE-siroki-12671.jpg \\
\hline 1196 & Lythrum salicaria L. & Tiszafüred & 1970 & Siroki Zoltán & DE-siroki-12670.jpg \\
\hline 1196 & Lythrum salicaria L. & Tiszafüred & 1970 & Siroki Zoltán & DE-siroki-12663.jpg \\
\hline 1196 & Lythrum salicaria L. & Vámospércs & 1985 & Siroki Zoltán & DE-siroki-12662.jpg \\
\hline 1197 & Lythrum hyssopifolia L. & Berekböszörmény & 1970 & Siroki Zoltán & DE-siroki-12654.jpg \\
\hline 1197 & Lythrum hyssopifolia L. & Csaroda & 1962 & Siroki Zoltán & DE-siroki-12656.jpg \\
\hline 1197 & Lythrum hyssopifolia L. & Debrecen & 1955 & Siroki Zoltán & DE-siroki-12657.jpg \\
\hline 1197 & Lythrum hyssopifolia L. & Debrecen & 1955 & Siroki Zoltán & DE-siroki-12658.jpg \\
\hline 1197 & Lythrum hyssopifolia L. & Debrecen & 1962 & Siroki Zoltán & DE-siroki-12655.jpg \\
\hline 1198 & $\begin{array}{l}\text { Lythrum tribracteatum } \\
\text { Salzm. in Spreng. }\end{array}$ & Ercsi & 1874 & Tauscher Gyula & DE-siroki-12661.jpg \\
\hline 1203 & Trapa natans L. & Biharugra & 1961 & Siroki Zoltán & DE-siroki-11901.jpg \\
\hline 1203 & Trapa natans L. & Hortobágy & 1948 & Siroki Zoltán & DE-siroki-11902.jpg \\
\hline 1203 & Trapa natans L. & Hortobágy & 1948 & Siroki Zoltán & DE-siroki-11903.jpg \\
\hline 1203 & Trapa natans L. & Hortobágy & 1948 & Siroki Zoltán & DE-siroki-11904.jpg \\
\hline 1203 & Trapa natans L. & Hortobágy & 1948 & Siroki Zoltán & DE-siroki-11905.jpg \\
\hline 1204 & Circaea lutetiana L. & Csaroda & 1954 & Siroki Zoltán & DE-siroki-11892.jpg \\
\hline 1204 & Circaea lutetiana L. & Csaroda & 1954 & Siroki Zoltán & DE-siroki-11893.jpg \\
\hline 1204 & Circaea lutetiana L. & Csaroda & 1954 & Siroki Zoltán & DE-siroki-11891.jpg \\
\hline 1204 & Circaea lutetiana L. & Debrecen & 1947 & Siroki Zoltán & DE-siroki-11894.jpg \\
\hline 1204 & Circaea lutetiana L. & Debrecen & 1947 & Siroki Zoltán & DE-siroki-11895.jpg \\
\hline 1204 & Circaea lutetiana L. & Mosonmagyaróvár & 1939 & Siroki Zoltán & DE-siroki-11896.jpg \\
\hline 1204 & Circaea lutetiana L. & Mosonmagyaróvár & 1939 & Siroki Zoltán & DE-siroki-11897.jpg \\
\hline 1215 & Ludwigia palustris (L.) Elliott & Alsóújlak & 1956 & Jeanplong József & DE-siroki-12678.jpg \\
\hline 1215 & Ludwigia palustris (L.) Elliott & Barcs & 1929 & Boros Ádám & DE-siroki-12677.jpg \\
\hline 1217 & Chamaenerion angustifolium (L.) Scop. & Budapest & 1951 & Siroki Zoltán & DE-siroki-11878.jpg \\
\hline 1217 & Chamaenerion angustifolium (L.) Scop. & Szilvásvárad & 1954 & Siroki Zoltán & DE-siroki-11879.jpg \\
\hline 1217 & Chamaenerion angustifolium (L.) Scop. & Tokaj & 1966 & Siroki Zoltán & DE-siroki-11877.jpg \\
\hline 1218 & Chamaenerion dodonaei (Vill.) Holub & Budaörs & 1958 & Siroki Zoltán & DE-siroki-11883.jpg \\
\hline 1218 & Chamaenerion dodonaei (Vill.) Holub & Budaörs & 1958 & Siroki Zoltán & DE-siroki-11884.jpg \\
\hline 1218 & Chamaenerion dodonaei (Vill.) Holub & Budaörs & 1958 & Siroki Zoltán & DE-siroki-11885.jpg \\
\hline 1218 & Chamaenerion dodonaei (Vill.) Holub & Budaörs & 1958 & Siroki Zoltán & DE-siroki-11886.jpg \\
\hline 1219 & Epilobium hirsutum L. & Debrecen & 1950 & Siroki Zoltán & DE-siroki-12683.jpg \\
\hline 1219 & Epilobium hirsutum L. & Debrecen & 1950 & Siroki Zoltán & DE-siroki-12684.jpg \\
\hline 1219 & Epilobium hirsutum L. & Debrecen & 1981 & Siroki Zoltán & DE-siroki-12679.jpg \\
\hline 1219 & Epilobium hirsutum L. & Mosonmagyaróvár & 1939 & Siroki Zoltán & DE-siroki-12682.jpg \\
\hline 1219 & Epilobium hirsutum L. & Mosonmagyaróvár & 1939 & Siroki Zoltán & DE-siroki-12686.jpg \\
\hline 1219 & Epilobium hirsutum L. & Nagyvisnyó & 1966 & Siroki Zoltán & DE-siroki-12680.jpg \\
\hline 1220 & Epilobium parviflorum Schreb. & Debrecen & 1947 & Siroki Zoltán & DE-siroki-12691.jpg \\
\hline 1220 & Epilobium parviflorum Schreb. & Debrecen & 1950 & Siroki Zoltán & DE-siroki-12692.jpg \\
\hline 1220 & Epilobium parviflorum Schreb. & Debrecen & 1950 & Siroki Zoltán & DE-siroki-12693.jpg \\
\hline 1220 & Epilobium parviflorum Schreb. & Debrecen & 1960 & Siroki Zoltán & DE-siroki-12695.jpg \\
\hline 1220 & Epilobium parviflorum Schreb. & Debrecen & 1960 & Siroki Zoltán & DE-siroki-12696.jpg \\
\hline
\end{tabular}




\begin{tabular}{|c|c|c|c|c|c|}
\hline $\begin{array}{l}\text { Sorszám / } \\
\text { Number }\end{array}$ & Taxon-név / Taxon-name & $\begin{array}{l}\text { Település / } \\
\text { Settlement }\end{array}$ & $\begin{array}{l}\text { Év / } \\
\text { Year }\end{array}$ & $\begin{array}{l}\text { Gyűjtő / } \\
\text { Collector }\end{array}$ & Fájlnév / File-name \\
\hline 1220 & Epilobium parviflorum Schreb. & Debrecen & 1960 & Siroki Zoltán & DE-siroki-12697.jpg \\
\hline 1220 & Epilobium parviflorum Schreb. & Debrecen & 1960 & Siroki Zoltán & DE-siroki-12698.jpg \\
\hline 1220 & Epilobium parviflorum Schreb. & Debrecen & 1985 & Siroki Zoltán & DE-siroki-12687.jpg \\
\hline 1220 & Epilobium parviflorum Schreb. & Gödöllő & 1951 & Siroki Zoltán & DE-siroki-12694.jpg \\
\hline 1220 & Epilobium parviflorum Schreb. & Gödöllő & 1951 & Siroki Zoltán & DE-siroki-12699.jpg \\
\hline 1220 & Epilobium parviflorum Schreb. & Gödöllő & 1951 & Siroki Zoltán & DE-siroki-12700.jpg \\
\hline 1220 & Epilobium parviflorum Schreb. & Gödöllő & 1951 & Siroki Zoltán & DE-siroki-12702.jpg \\
\hline 1220 & Epilobium parviflorum Schreb. & Gödöllő & 1951 & Siroki Zoltán & DE-siroki-12703.jpg \\
\hline 1220 & Epilobium parviflorum Schreb. & Hajdúbagos & 1981 & Siroki Zoltán & DE-siroki-12688.jpg \\
\hline 1220 & Epilobium parviflorum Schreb. & Háromhuta & 1984 & Siroki Zoltán & DE-siroki-12689.jpg \\
\hline 1220 & Epilobium parviflorum Schreb. & Háromhuta & 1984 & Siroki Zoltán & DE-siroki-12690.jpg \\
\hline 1220 & Epilobium parviflorum Schreb. & Szilvásvárad & 1954 & Siroki Zoltán & DE-siroki-12701.jpg \\
\hline 1221 & $\begin{array}{l}\text { Epilobium lanceolatum } \\
\text { Sebast. et Mauri }\end{array}$ & Budapest & 1951 & Siroki Zoltán & DE-siroki-12705.jpg \\
\hline 1221 & $\begin{array}{l}\text { Epilobium lanceolatum } \\
\text { Sebast. et Mauri }\end{array}$ & Budapest & 1951 & Siroki Zoltán & DE-siroki-12706.jpg \\
\hline 1222 & Epilobium montanum L. & "Vértes" & 1957 & Siroki Zoltán & DE-siroki-12717.jpg \\
\hline 1222 & Epilobium montanum L. & "Vértes" & 1957 & Siroki Zoltán & DE-siroki-12718.jpg \\
\hline 1222 & Epilobium montanum L. & Debrecen & 1954 & Siroki Zoltán & DE-siroki-12722.jpg \\
\hline 1222 & Epilobium montanum L. & Debrecen & 1954 & Siroki Zoltán & DE-siroki-12723.jpg \\
\hline 1222 & Epilobium montanum L. & Debrecen & 1954 & Siroki Zoltán & DE-siroki-12724.jpg \\
\hline 1222 & Epilobium montanum L. & Háromhuta & 1978 & Siroki Zoltán & DE-siroki-12711.jpg \\
\hline 1222 & Epilobium montanum L. & Háromhuta & 1978 & Siroki Zoltán & DE-siroki-12712.jpg \\
\hline 1222 & Epilobium montanum L. & Hollóháza & 1940 & Siroki Zoltán & DE-siroki-12719.jpg \\
\hline 1222 & Epilobium montanum L. & Lábatlan & 1986 & Siroki Zoltán & DE-siroki-12709.jpg \\
\hline 1222 & Epilobium montanum L. & Szilvásvárad & 1954 & Siroki Zoltán & DE-siroki-12714.jpg \\
\hline 1222 & Epilobium montanum L. & Szilvásvárad & 1954 & Siroki Zoltán & DE-siroki-12715.jpg \\
\hline 1222 & Epilobium montanum L. & Szilvásvárad & 1954 & Siroki Zoltán & DE-siroki-12716.jpg \\
\hline 1222 & Epilobium montanum L. & Szilvásvárad & 1954 & Siroki Zoltán & DE-siroki-12721.jpg \\
\hline 1223 & Epilobium collinum C.C. Gmel. & "Szent-György-hegy" & 1955 & Siroki Zoltán & DE-siroki-12727.jpg \\
\hline 1223 & Epilobium collinum C.C. Gmel. & "Szent-György-hegy" & 1955 & Siroki Zoltán & DE-siroki-12728.jpg \\
\hline 1223 & Epilobium collinum C.C. Gmel. & "Szent-György-hegy" & 1955 & Siroki Zoltán & DE-siroki-12729.jpg \\
\hline 1224 & Epilobium palustre L. & Debrecen & 1950 & Siroki Zoltán & DE-siroki-11865.jpg \\
\hline 1224 & Epilobium palustre L. & Debrecen & 1950 & Siroki Zoltán & DE-siroki-11866.jpg \\
\hline 1224 & Epilobium palustre L. & Debrecen & 1958 & Siroki Zoltán & DE-siroki-11867.jpg \\
\hline 1224 & Epilobium palustre L. & Debrecen & 1958 & Siroki Zoltán & DE-siroki-11868.jpg \\
\hline 1224 & Epilobium palustre L. & Debrecen & 1958 & Siroki Zoltán & DE-siroki-11869.jpg \\
\hline 1225 & Epilobium roseum Schreb. & Háromhuta & 1977 & Siroki Zoltán & DE-siroki-12731.jpg \\
\hline 1225 & Epilobium roseum Schreb. & Háromhuta & 1977 & Siroki Zoltán & DE-siroki-12733.jpg \\
\hline 1225 & Epilobium roseum Schreb. & Pásztó & 1952 & Siroki Zoltán & DE-siroki-11844.jpg \\
\hline 1225 & Epilobium roseum Schreb. & Pásztó & 1952 & Siroki Zoltán & DE-siroki-11845.jpg \\
\hline 1225 & Epilobium roseum Schreb. & Pilisszentlászló & 1890 & $\begin{array}{l}\text { Schilberszky } \\
\text { Károly }\end{array}$ & DE-siroki-12732.jpg \\
\hline 1227 & Epilobium obscurum Schreb. & "Dobogókő" & 1965 & Siroki Zoltán & DE-siroki-11857.jpg \\
\hline 1227 & Epilobium obscurum Schreb. & Debrecen & 1981 & Siroki Zoltán & DE-siroki-11859.jpg \\
\hline 1227 & Epilobium obscurum Schreb. & Debrecen & 1981 & Siroki Zoltán & DE-siroki-11860.jpg \\
\hline 1227 & Epilobium obscurum Schreb. & Debrecen & 1981 & Siroki Zoltán & DE-siroki-11861.jpg \\
\hline 1227 & Epilobium obscurum Schreb. & Debrecen & 1981 & Siroki Zoltán & DE-siroki-11862.jpg \\
\hline
\end{tabular}




\begin{tabular}{|c|c|c|c|c|c|}
\hline $\begin{array}{l}\text { Sorszám / } \\
\text { Number }\end{array}$ & Taxon-név / Taxon-name & $\begin{array}{l}\text { Település / } \\
\text { Settlement }\end{array}$ & $\begin{array}{l}\text { Év / } \\
\text { Year }\end{array}$ & $\begin{array}{l}\text { Gyűjtő / } \\
\text { Collector }\end{array}$ & Fájlnév / File-name \\
\hline 1227 & Epilobium obscurum Schreb. & Debrecen & 1981 & Siroki Zoltán & DE-siroki-11863.jpg \\
\hline 1227 & Epilobium obscurum Schreb. & Debrecen & 1981 & Siroki Zoltán & DE-siroki-11864.jpg \\
\hline 1227 & Epilobium obscurum Schreb. & Debrecen & 1982 & Siroki Zoltán & DE-siroki-11856.jpg \\
\hline 1228 & Epilobium tetragonum L. & Budapest & 1941 & Siroki Zoltán & DE-siroki-11847.jpg \\
\hline 1228 & Epilobium tetragonum L. & Budapest & 1941 & Siroki Zoltán & DE-siroki-11853.jpg \\
\hline 1228 & Epilobium tetragonum L. & Gödöllő & 1951 & Siroki Zoltán & DE-siroki-11850.jpg \\
\hline 1228 & Epilobium tetragonum L. & Gödöllő & 1951 & Siroki Zoltán & DE-siroki-11851.jpg \\
\hline 1228 & Epilobium tetragonum L. & Gödöllő & 1951 & Siroki Zoltán & DE-siroki-11852.jpg \\
\hline 1228 & Epilobium tetragonum L. & Sátoraljaújhely & 1944 & Siroki Zoltán & DE-siroki-11848.jpg \\
\hline 1228 & Epilobium tetragonum L. & Sátoraljaújhely & 1944 & Siroki Zoltán & DE-siroki-11849.jpg \\
\hline 1228 & Epilobium tetragonum L. & Sátoraljaújhely & 1944 & Siroki Zoltán & DE-siroki-11855.jpg \\
\hline 1229 & Myriophyllum spicatum L. & Budapest & 1909 & Kocsis István & DE-siroki-11911.jpg \\
\hline 1229 & Myriophyllum spicatum L. & Budapest & 1913 & Bocskay Ottó & DE-siroki-11916.jpg \\
\hline 1229 & Myriophyllum spicatum L. & Keszthely & 1955 & Siroki Zoltán & DE-siroki-11918.jpg \\
\hline 1229 & Myriophyllum spicatum L. & Keszthely & 1955 & Siroki Zoltán & DE-siroki-11919.jpg \\
\hline 1229 & Myriophyllum spicatum L. & Veresegyház & 1954 & Siroki Zoltán & DE-siroki-11917.jpg \\
\hline 1229 & Myriophyllum spicatum L. & Veresegyház & 1954 & Siroki Zoltán & DE-siroki-11920.jpg \\
\hline 1229 & Myriophyllum spicatum L. & Veresegyház & 1954 & Siroki Zoltán & DE-siroki-11921.jpg \\
\hline 1229 & Myriophyllum spicatum L. & Veresegyház & 1954 & Siroki Zoltán & DE-siroki-11922.jpg \\
\hline 1229 & Myriophyllum spicatum L. & Veresegyház & 1954 & Siroki Zoltán & DE-siroki-11923.jpg \\
\hline 1231 & Myriophyllum verticillatum L. & Biharugra & 1961 & Siroki Zoltán & DE-siroki-11906.jpg \\
\hline 1231 & Myriophyllum verticillatum L. & Biharugra & 1961 & Siroki Zoltán & DE-siroki-11907.jpg \\
\hline 1231 & Myriophyllum verticillatum L. & Biharugra & 1961 & Siroki Zoltán & DE-siroki-11908.jpg \\
\hline 1231 & Myriophyllum verticillatum L. & Biharugra & 1961 & Siroki Zoltán & DE-siroki-11909.jpg \\
\hline 1231 & Myriophyllum verticillatum L. & Tiszafüred & 1949 & Siroki Zoltán & DE-siroki-11910.jpg \\
\hline 1233 & Cornus mas L. & "Vértes" & 1957 & Siroki Zoltán & DE-siroki-12817.jpg \\
\hline 1233 & Cornus mas L. & "Vértes" & 1957 & Siroki Zoltán & DE-siroki-12818.jpg \\
\hline 1236 & Cornus alba L. & Budapest & 1951 & Siroki Zoltán & DE-siroki-12812.jpg \\
\hline 1236 & Cornus alba L. & Budapest & 1951 & Siroki Zoltán & DE-siroki-12813.jpg \\
\hline 1237 & Hippuris vulgaris L. & Budapest & 1951 & Kárpáti Zoltán & DE-siroki-11927.jpg \\
\hline 1238 & Hedera helix L. & "Szent-György-hegy" & 1955 & Siroki Zoltán & DE-siroki-11929.jpg \\
\hline 1238 & Hedera helix L. & "Szent-György-hegy" & 1955 & Siroki Zoltán & DE-siroki-11930.jpg \\
\hline 1238 & Hedera helix L. & Budapest & 1951 & Siroki Zoltán & DE-siroki-11931.jpg \\
\hline 1238 & Hedera helix L. & Budapest & 1951 & Siroki Zoltán & DE-siroki-11932.jpg \\
\hline 1241 & Sanicula europaea L. & "Bükk-hg." & 1956 & Halász Tibor & DE-siroki-11935.jpg \\
\hline 1241 & Sanicula europaea L. & "Dobogókő" & 1956 & Siroki Zoltán & DE-siroki-11938.jpg \\
\hline 1241 & Sanicula europaea L. & Budapest & 1951 & Siroki Zoltán & DE-siroki-11936.jpg \\
\hline 1241 & Sanicula europaea L. & Budapest & 1951 & Siroki Zoltán & DE-siroki-11942.jpg \\
\hline 1241 & Sanicula europaea L. & Debrecen & 1954 & Siroki Zoltán & DE-siroki-11941.jpg \\
\hline 1241 & Sanicula europaea L. & Háromhuta & 1967 & Siroki Zoltán & DE-siroki-11939.jpg \\
\hline 1241 & Sanicula europaea L. & Háromhuta & 1967 & Siroki Zoltán & DE-siroki-11940.jpg \\
\hline 1241 & Sanicula europaea L. & Szilvásvárad & 1956 & Halász Tibor & DE-siroki-11937.jpg \\
\hline 1242 & Astrantia major L. & "Háromkő" & 1957 & Siroki Zoltán & DE-siroki-11951.jpg \\
\hline 1242 & Astrantia major L. & "Nagymező" & 1957 & Siroki Zoltán & DE-siroki-11952.jpg \\
\hline 1242 & Astrantia major L. & "Nagymező" & 1958 & Siroki Zoltán & DE-siroki-11954.jpg \\
\hline 1242 & Astrantia major L. & "Nagymező" & 1958 & Siroki Zoltán & DE-siroki-11955.jpg \\
\hline
\end{tabular}




\begin{tabular}{|c|c|c|c|c|c|}
\hline $\begin{array}{l}\text { Sorszám / } \\
\text { Number }\end{array}$ & Taxon-név / Taxon-name & $\begin{array}{l}\text { Település / } \\
\text { Settlement }\end{array}$ & $\begin{array}{l}\text { Év / } \\
\text { Year }\end{array}$ & $\begin{array}{l}\text { Gyűjtő / } \\
\text { Collector }\end{array}$ & Fájlnév / File-name \\
\hline 1242 & Astrantia major L. & "Nagymező" & 1958 & Siroki Zoltán & DE-siroki-11956.jpg \\
\hline 1242 & Astrantia major L. & Háromhuta & 1967 & Siroki Zoltán & DE-siroki-11949.jpg \\
\hline 1242 & Astrantia major L. & Nagyvisnyó & 1966 & Siroki Zoltán & DE-siroki-11948.jpg \\
\hline 1242 & Astrantia major L. & Nagyvisnyó & 1966 & Siroki Zoltán & DE-siroki-11950.jpg \\
\hline 1242 & Astrantia major L. & Répáshuta & 1956 & Halász Tibor & DE-siroki-11953.jpg \\
\hline 1243 & Eryngium campestre L. & Debrecen & 1947 & Siroki Zoltán & DE-siroki-11960.jpg \\
\hline 1243 & Eryngium campestre L. & Debrecen & 1957 & Siroki Zoltán & DE-siroki-11959.jpg \\
\hline 1243 & Eryngium campestre L. & Debrecen & 1957 & Siroki Zoltán & DE-siroki-11961.jpg \\
\hline 1244 & Eryngium planum L. & Budapest & 1951 & Siroki Zoltán & DE-siroki-11971.jpg \\
\hline 1244 & Eryngium planum L. & Budapest & 1951 & Siroki Zoltán & DE-siroki-11972.jpg \\
\hline 1244 & Eryngium planum L. & Mosonmagyaróvár & 1939 & Siroki Zoltán & DE-siroki-11973.jpg \\
\hline 1244 & Eryngium planum L. & Sárospatak & 1951 & Siroki Zoltán & DE-siroki-11970.jpg \\
\hline 1244 & Eryngium planum L. & Tiszacsege & 1963 & Siroki Zoltán & DE-siroki-11967.jpg \\
\hline 1244 & Eryngium planum L. & Tiszacsege & 1963 & Siroki Zoltán & DE-siroki-11968.jpg \\
\hline 1244 & Eryngium planum L. & Tiszacsege & 1963 & Siroki Zoltán & DE-siroki-11969.jpg \\
\hline 1245 & Physocaulis nodosus (L.) W.D.J. Koch & Budapest & 1874 & Szépligeti Győző & DE-siroki-11976.jpg \\
\hline 1245 & Physocaulis nodosus (L.) W.D.J. Koch & Budapest & 1887 & Czakó Kálmán & DE-siroki-11978.jpg \\
\hline 1245 & Physocaulis nodosus (L.) W.D.J. Koch & Komárom & 1909 & Kocsis István & DE-siroki-11977.jpg \\
\hline 1245 & Physocaulis nodosus (L.) W.D.J. Koch & Lábatlan & 1951 & Kárpáti Zoltán & DE-siroki-11980.jpg \\
\hline 1249 & Chaerophyllum bulbosum L. & Debrecen & 1954 & Siroki Zoltán & DE-siroki-12003.jpg \\
\hline 1249 & Chaerophyllum bulbosum L. & Debrecen & 1954 & Siroki Zoltán & DE-siroki-12004.jpg \\
\hline 1249 & Chaerophyllum bulbosum L. & Debrecen & 1954 & Siroki Zoltán & DE-siroki-12005.jpg \\
\hline 1250 & Chaerophyllum temulum L. & Debrecen & 1947 & Siroki Zoltán & DE-siroki-11996.jpg \\
\hline 1250 & Chaerophyllum temulum L. & Debrecen & 1948 & Siroki Zoltán & DE-siroki-11998.jpg \\
\hline 1250 & Chaerophyllum temulum L. & Debrecen & 1958 & Pethő Menyhért & DE-siroki-11995.jpg \\
\hline 1250 & Chaerophyllum temulum L. & Mosonmagyaróvár & 1939 & Siroki Zoltán & DE-siroki-11997.jpg \\
\hline 1250 & Chaerophyllum temulum L. & Sátoraljaújhely & 1943 & Siroki Zoltán & DE-siroki-11999.jpg \\
\hline 1250 & Chaerophyllum temulum L. & Szilvásvárad & 1954 & Siroki Zoltán & DE-siroki-11994.jpg \\
\hline 1251 & Anthriscus caucalis M. Bieb. & Budapest & 1904 & $\begin{array}{l}\text { Thaisz Lajos - } \\
\text { Baán Lajos }\end{array}$ & DE-siroki-12032.jpg \\
\hline 1251 & Anthriscus caucalis M. Bieb. & Budapest & 1954 & Siroki Zoltán & DE-siroki-12035.jpg \\
\hline 1251 & Anthriscus caucalis M. Bieb. & Debrecen & 1954 & Siroki Zoltán & DE-siroki-12027.jpg \\
\hline 1251 & Anthriscus caucalis M. Bieb. & Debrecen & 1954 & Siroki Zoltán & DE-siroki-12028.jpg \\
\hline 1251 & Anthriscus caucalis M. Bieb. & Debrecen & 1955 & Siroki Zoltán & DE-siroki-12034.jpg \\
\hline 1251 & Anthriscus caucalis M. Bieb. & Debrecen & 1955 & Siroki Zoltán & DE-siroki-12029.jpg \\
\hline 1251 & Anthriscus caucalis M. Bieb. & Debrecen & 1955 & Siroki Zoltán & DE-siroki-12030.jpg \\
\hline 1251 & Anthriscus caucalis M. Bieb. & Debrecen & 1969 & Siroki Zoltán & DE-siroki-12012.jpg \\
\hline 1251 & Anthriscus caucalis M. Bieb. & Debrecen & 1969 & Siroki Zoltán & DE-siroki-12013.jpg \\
\hline 1251 & Anthriscus caucalis M. Bieb. & Debrecen & 1969 & Siroki Zoltán & DE-siroki-12014.jpg \\
\hline 1251 & Anthriscus caucalis M. Bieb. & Debrecen & 1969 & Siroki Zoltán & DE-siroki-12015.jpg \\
\hline 1251 & Anthriscus caucalis M. Bieb. & Mezőhegyes & 1954 & Siroki Zoltán & DE-siroki-12025.jpg \\
\hline 1251 & Anthriscus caucalis M. Bieb. & Mezőhegyes & 1954 & Siroki Zoltán & DE-siroki-12026.jpg \\
\hline 1251 & Anthriscus caucalis M. Bieb. & Mezőhegyes & 1954 & Siroki Zoltán & DE-siroki-12031.jpg \\
\hline 1251 & Anthriscus caucalis M. Bieb. & Mezőhegyes & 1954 & Siroki Zoltán & DE-siroki-12033.jpg \\
\hline 1251 & Anthriscus caucalis M. Bieb. & Paks & 1967 & Siroki Zoltán & DE-siroki-12016.jpg \\
\hline 1251 & Anthriscus caucalis M. Bieb. & Paks & 1967 & Siroki Zoltán & DE-siroki-12017.jpg \\
\hline 1251 & Anthriscus caucalis M. Bieb. & Paks & 1967 & Siroki Zoltán & DE-siroki-12018.jpg \\
\hline
\end{tabular}




\begin{tabular}{|c|c|c|c|c|c|}
\hline $\begin{array}{l}\text { Sorszám / } \\
\text { Number }\end{array}$ & Taxon-név / Taxon-name & $\begin{array}{l}\text { Település / } \\
\text { Settlement }\end{array}$ & $\begin{array}{l}\text { Év / } \\
\text { Year }\end{array}$ & $\begin{array}{l}\text { Gyüjtő / } \\
\text { Collector }\end{array}$ & Fájlnév / File-name \\
\hline 1251 & Anthriscus caucalis M. Bieb. & Paks & 1967 & Siroki Zoltán & DE-siroki-12019.jpg \\
\hline 1251 & Anthriscus caucalis M. Bieb. & Paks & 1967 & Siroki Zoltán & DE-siroki-12020.jpg \\
\hline 1251 & Anthriscus caucalis M. Bieb. & Paks & 1967 & Siroki Zoltán & DE-siroki-12021.jpg \\
\hline 1251 & Anthriscus caucalis M. Bieb. & Paks & 1967 & Siroki Zoltán & DE-siroki-12022.jpg \\
\hline 1251 & Anthriscus caucalis M. Bieb. & Paks & 1967 & Siroki Zoltán & DE-siroki-12023.jpg \\
\hline 1251 & Anthriscus caucalis M. Bieb. & Paks & 1967 & Siroki Zoltán & DE-siroki-12024.jpg \\
\hline 1252 & Anthriscus cerefolium (L.) Hoffm. & Debrecen & 1947 & Siroki Zoltán & DE-siroki-12036.jpg \\
\hline 1252 & Anthriscus cerefolium (L.) Hoffm. & Debrecen & 1947 & Siroki Zoltán & DE-siroki-12037.jpg \\
\hline 1253 & Anthriscus sylvestris (L.) Hoffm. & "Nagymező" & 1960 & Siroki Zoltán & DE-siroki-12042.jpg \\
\hline 1253 & Anthriscus sylvestris (L.) Hoffm. & "Nagymező" & 1960 & Siroki Zoltán & DE-siroki-12043.jpg \\
\hline 1253 & Anthriscus sylvestris (L.) Hoffm. & "Nagymező" & 1960 & Siroki Zoltán & DE-siroki-12044.jpg \\
\hline 1253 & Anthriscus sylvestris (L.) Hoffm. & Mátraverebély & 1952 & Siroki Zoltán & DE-siroki-12051.jpg \\
\hline 1253 & Anthriscus sylvestris (L.) Hoffm. & Mátraverebély & 1952 & Siroki Zoltán & DE-siroki-12052.jpg \\
\hline 1253 & Anthriscus sylvestris (L.) Hoffm. & Mátraverebély & 1952 & Siroki Zoltán & DE-siroki-12053.jpg \\
\hline 1253 & Anthriscus sylvestris (L.) Hoffm. & Mosonmagyaróvár & 1939 & Siroki Zoltán & DE-siroki-12050.jpg \\
\hline 1253 & Anthriscus sylvestris (L.) Hoffm. & Pásztó & 1952 & Siroki Zoltán & DE-siroki-12045.jpg \\
\hline 1253 & Anthriscus sylvestris (L.) Hoffm. & Pásztó & 1952 & Siroki Zoltán & DE-siroki-12046.jpg \\
\hline 1253 & Anthriscus sylvestris (L.) Hoffm. & Pásztó & 1952 & Siroki Zoltán & DE-siroki-12047.jpg \\
\hline 1254 & Anthriscus nitidus (Wahlenb.) Hazsl. & Miskolc & 1960 & Siroki Zoltán & DE-siroki-12054.jpg \\
\hline 1254 & Anthriscus nitidus (Wahlenb.) Hazsl. & Miskolc & 1960 & Siroki Zoltán & DE-siroki-12055.jpg \\
\hline 1254 & Anthriscus nitidus (Wahlenb.) Hazsl. & Miskolc & 1960 & Siroki Zoltán & DE-siroki-12056.jpg \\
\hline 1254 & Anthriscus nitidus (Wahlenb.) Hazsl. & Miskolc & 1960 & Siroki Zoltán & DE-siroki-12057.jpg \\
\hline 1254 & Anthriscus nitidus (Wahlenb.) Hazsl. & Nagyvisnyó & 1959 & Siroki Zoltán & DE-siroki-12058.jpg \\
\hline 1254 & Anthriscus nitidus (Wahlenb.) Hazsl. & Nagyvisnyó & 1959 & Siroki Zoltán & DE-siroki-12059.jpg \\
\hline 1254 & Anthriscus nitidus (Wahlenb.) Hazsl. & Nagyvisnyó & 1959 & Siroki Zoltán & DE-siroki-12060.jpg \\
\hline 1254 & Anthriscus nitidus (Wahlenb.) Hazsl. & Nagyvisnyó & 1959 & Siroki Zoltán & DE-siroki-12061.jpg \\
\hline 1254 & Anthriscus nitidus (Wahlenb.) Hazsl. & Nagyvisnyó & 1959 & Siroki Zoltán & DE-siroki-12062.jpg \\
\hline 1254 & Anthriscus nitidus (Wahlenb.) Hazsl. & Nagyvisnyó & 1959 & Siroki Zoltán & DE-siroki-12063.jpg \\
\hline 1254 & Anthriscus nitidus (Wahlenb.) Hazsl. & Nagyvisnyó & 1959 & Siroki Zoltán & DE-siroki-12064.jpg \\
\hline 1255 & Scandix pecten-veneris L. & Debrecen & 1955 & Dely Magdolna & DE-siroki-12070.jpg \\
\hline 1257 & Bifora radians M. Bieb. & Budapest & 1952 & Siroki Zoltán & DE-siroki-11655.jpg \\
\hline 1257 & Bifora radians M. Bieb. & Debrecen & 1947 & Siroki Zoltán & DE-siroki-11654.jpg \\
\hline 1257 & Bifora radians M. Bieb. & Dombrád & 1967 & Gondola István & DE-siroki-11650.jpg \\
\hline 1257 & Bifora radians M. Bieb. & Dombrád & 1967 & Siroki Zoltán & DE-siroki-11649.jpg \\
\hline 1257 & Bifora radians M. Bieb. & Egyek & 1947 & Siroki Zoltán & DE-siroki-11653.jpg \\
\hline 1257 & Bifora radians M. Bieb. & Egyek & 1947 & Siroki Zoltán & DE-siroki-11656.jpg \\
\hline 1257 & Bifora radians M. Bieb. & Tiszafüred & 1955 & Siroki Zoltán & DE-siroki-11648.jpg \\
\hline 1257 & Bifora radians M. Bieb. & Tiszafüred & 1955 & $\begin{array}{l}\text { Siroki Zoltán - } \\
\text { Farkas Attila }\end{array}$ & DE-siroki-11651.jpg \\
\hline 1257 & Bifora radians M. Bieb. & Tiszafüred & 1955 & $\begin{array}{l}\text { Siroki Zoltán - } \\
\text { Farkas Attila }\end{array}$ & DE-siroki-11652.jpg \\
\hline 1258 & Smyrnium perfoliatum L. & "Fáni-völgy" & 1955 & $\begin{array}{l}\text { Siroki Zoltán - } \\
\text { Farkas Attila }\end{array}$ & DE-siroki-11658.jpg \\
\hline 1258 & Smyrnium perfoliatum L. & "Fáni-völgy" & 1955 & $\begin{array}{l}\text { Siroki Zoltán - } \\
\text { Farkas Attila }\end{array}$ & DE-siroki-11659.jpg \\
\hline 1258 & Smyrnium perfoliatum L. & "Fáni-völgy" & 1955 & $\begin{array}{l}\text { Siroki Zoltán - } \\
\text { Farkas Attila }\end{array}$ & DE-siroki-11660.jpg \\
\hline 1258 & Smyrnium perfoliatum L. & "Fáni-völgy" & 1955 & $\begin{array}{l}\text { Siroki Zoltán - } \\
\text { Farkas Attila }\end{array}$ & DE-siroki-11661.jpg \\
\hline
\end{tabular}




\begin{tabular}{|c|c|c|c|c|c|}
\hline $\begin{array}{l}\text { Sorszám / } \\
\text { Number }\end{array}$ & Taxon-név / Taxon-name & $\begin{array}{l}\text { Település / } \\
\text { Settlement }\end{array}$ & $\begin{array}{l}\text { Év / } \\
\text { Year }\end{array}$ & $\begin{array}{l}\text { Gyújitő / } \\
\text { Collector }\end{array}$ & Fájlnév / File-name \\
\hline 1258 & Smyrnium perfoliatum L. & "Fáni-völgy" & 1955 & $\begin{array}{l}\text { Siroki Zoltán - } \\
\text { Farkas Attila }\end{array}$ & DE-siroki-11662.jpg \\
\hline 1258 & Smyrnium perfoliatum L. & "Fáni-völgy" & 1955 & $\begin{array}{l}\text { Siroki Zoltán - } \\
\text { Farkas Attila }\end{array}$ & DE-siroki-11663.jpg \\
\hline 1258 & Smyrnium perfoliatum L. & "Fáni-völgy" & 1955 & $\begin{array}{l}\text { Siroki Zoltán - } \\
\text { Farkas Attila }\end{array}$ & DE-siroki-11664.jpg \\
\hline 1259 & Pimpinella anisum L. & Mosonmagyaróvár & 1939 & Siroki Zoltán & DE-siroki-12221.jpg \\
\hline 1260 & Pimpinella major (L.) Huds. & "Dobogókő" & 1965 & Siroki Zoltán & DE-siroki-12185.jpg \\
\hline 1260 & Pimpinella major (L.) Huds. & Miskolc & 1965 & Siroki Zoltán & DE-siroki-12181.jpg \\
\hline 1260 & Pimpinella major (L.) Huds. & Miskolc & 1965 & Siroki Zoltán & DE-siroki-12182.jpg \\
\hline 1260 & Pimpinella major (L.) Huds. & Miskolc & 1965 & Siroki Zoltán & DE-siroki-12183.jpg \\
\hline 1260 & Pimpinella major (L.) Huds. & Miskolc & 1965 & Siroki Zoltán & DE-siroki-12184.jpg \\
\hline 1260 & Pimpinella major (L.) Huds. & Miskolc & 1965 & Siroki Zoltán & DE-siroki-12186.jpg \\
\hline 1260 & Pimpinella major (L.) Huds. & Miskolc & 1965 & Siroki Zoltán & DE-siroki-12180.jpg \\
\hline 1260 & Pimpinella major (L.) Huds. & Miskolc & 1965 & Siroki Zoltán & DE-siroki-12187.jpg \\
\hline 1260 & Pimpinella major (L.) Huds. & Miskolc & 1965 & Siroki Zoltán & DE-siroki-12188.jpg \\
\hline 1260 & Pimpinella major (L.) Huds. & Miskolc & 1965 & Siroki Zoltán & DE-siroki-12189.jpg \\
\hline 1260 & Pimpinella major (L.) Huds. & Miskolc & 1965 & Siroki Zoltán & DE-siroki-12190.jpg \\
\hline 1260 & Pimpinella major (L.) Huds. & Miskolc & 1965 & Siroki Zoltán & DE-siroki-12191.jpg \\
\hline 1260 & Pimpinella major (L.) Huds. & Miskolc & 1967 & Siroki Zoltán & DE-siroki-12192.jpg \\
\hline 1260 & Pimpinella major (L.) Huds. & Miskolc & 1967 & Siroki Zoltán & DE-siroki-12193.jpg \\
\hline 1260 & Pimpinella major (L.) Huds. & Mosonmagyaróvár & 1947 & Siroki Zoltán & DE-siroki-12178.jpg \\
\hline 1260 & Pimpinella major (L.) Huds. & Mosonmagyaróvár & 1949 & Siroki Zoltán & DE-siroki-12179.jpg \\
\hline 1260 & Pimpinella major (L.) Huds. & Pásztó & 1952 & Siroki Zoltán & DE-siroki-12196.jpg \\
\hline 1260 & Pimpinella major (L.) Huds. & Pásztó & 1952 & Siroki Zoltán & DE-siroki-12197.jpg \\
\hline 1260 & Pimpinella major (L.) Huds. & Pásztó & 1952 & Siroki Zoltán & DE-siroki-12198.jpg \\
\hline 1260 & Pimpinella major (L.) Huds. & Pásztó & 1952 & Siroki Zoltán & DE-siroki-12199.jpg \\
\hline 1261 & Pimpinella saxifraga L. & Budaörs & 1985 & Siroki Zoltán & DE-siroki-12200.jpg \\
\hline 1261 & Pimpinella saxifraga L. & Debrecen & 1947 & Siroki Zoltán & DE-siroki-12204.jpg \\
\hline 1261 & Pimpinella saxifraga L. & Debrecen & 1947 & Siroki Zoltán & DE-siroki-12209.jpg \\
\hline 1261 & Pimpinella saxifraga L. & Debrecen & 1947 & Siroki Zoltán & DE-siroki-12205.jpg \\
\hline 1261 & Pimpinella saxifraga L. & Háromhuta & 1961 & Siroki Zoltán & DE-siroki-12201.jpg \\
\hline 1261 & Pimpinella saxifraga $\mathrm{L}$. & Háromhuta & 1961 & Siroki Zoltán & DE-siroki-12202.jpg \\
\hline 1261 & Pimpinella saxifraga L. & Háromhuta & 1961 & Siroki Zoltán & DE-siroki-12203.jpg \\
\hline 1261 & Pimpinella saxifraga L. & Háromhuta & 1961 & Siroki Zoltán & DE-siroki-12206.jpg \\
\hline 1261 & Pimpinella saxifraga $\mathrm{L}$. & Háromhuta & 1961 & Siroki Zoltán & DE-siroki-12207.jpg \\
\hline 1261 & Pimpinella saxifraga $\mathrm{L}$. & Háromhuta & 1961 & Siroki Zoltán & DE-siroki-12210.jpg \\
\hline 1261 & Pimpinella saxifraga L. & Mosonmagyaróvár & 1939 & Siroki Zoltán & DE-siroki-12214.jpg \\
\hline 1261 & Pimpinella saxifraga $\mathrm{L}$. & Mosonmagyaróvár & 1939 & Siroki Zoltán & DE-siroki-12215.jpg \\
\hline 1261 & Pimpinella saxifraga L. & Mosonmagyaróvár & 1939 & Siroki Zoltán & DE-siroki-12216.jpg \\
\hline 1261 & Pimpinella saxifraga L. & Mosonmagyaróvár & 1939 & Siroki Zoltán & DE-siroki-12208.jpg \\
\hline 1262 & Aegopodium podagraria L. & Budapest & 1951 & Siroki Zoltán & DE-siroki-12228.jpg \\
\hline 1262 & Aegopodium podagraria L. & Mátraszentimre & 1958 & Pethő Menyhért & DE-siroki-12225.jpg \\
\hline 1262 & Aegopodium podagraria L. & Mátraszentimre & 1958 & Pethő Menyhért & DE-siroki-12226.jpg \\
\hline 1262 & Aegopodium podagraria L. & Mátraszentimre & 1958 & Pethő Menyhért & DE-siroki-12227.jpg \\
\hline 1262 & Aegopodium podagraria L. & Mosonmagyaróvár & 1939 & Siroki Zoltán & DE-siroki-12233.jpg \\
\hline 1262 & Aegopodium podagraria L. & Pásztó & 1952 & Siroki Zoltán & DE-siroki-12229.jpg \\
\hline 1262 & Aegopodium podagraria L. & Pásztó & 1952 & Siroki Zoltán & DE-siroki-12230.jpg \\
\hline
\end{tabular}




\begin{tabular}{|c|c|c|c|c|c|}
\hline $\begin{array}{l}\text { Sorszám / } \\
\text { Number }\end{array}$ & Taxon-név / Taxon-name & $\begin{array}{l}\text { Település / } \\
\text { Settlement }\end{array}$ & $\begin{array}{l}\text { Év / } \\
\text { Year }\end{array}$ & $\begin{array}{l}\text { Gyűjtő / } \\
\text { Collector }\end{array}$ & Fájlnév / File-name \\
\hline 1262 & Aegopodium podagraria L. & Pásztó & 1952 & Siroki Zoltán & DE-siroki-12231.jpg \\
\hline 1262 & Aegopodium podagraria L. & Szilvásvárad & 1954 & Siroki Zoltán & DE-siroki-12232.jpg \\
\hline 1263 & Sium latifolium L. & Budapest & 1940 & Siroki Zoltán & DE-siroki-12250.jpg \\
\hline 1263 & Sium latifolium L. & Debrecen & 1947 & Siroki Zoltán & DE-siroki-12251.jpg \\
\hline 1263 & Sium latifolium L. & Debrecen & 1947 & Siroki Zoltán & DE-siroki-12253.jpg \\
\hline 1263 & Sium latifolium L. & Debrecen & 1949 & Siroki Zoltán & DE-siroki-12248.jpg \\
\hline 1263 & Sium latifolium L. & Debrecen & 1949 & Siroki Zoltán & DE-siroki-12249.jpg \\
\hline 1263 & Sium latifolium L. & Debrecen & 1949 & Siroki Zoltán & DE-siroki-12246.jpg \\
\hline 1263 & Sium latifolium L. & Debrecen & 1949 & Siroki Zoltán & DE-siroki-12258.jpg \\
\hline 1263 & Sium latifolium L. & Debrecen & 1949 & Siroki Zoltán & DE-siroki-12259.jpg \\
\hline 1263 & Sium latifolium L. & Debrecen & 1949 & Siroki Zoltán & DE-siroki-12260.jpg \\
\hline 1263 & Sium latifolium L. & Debrecen & 1950 & Siroki Zoltán & DE-siroki-12257.jpg \\
\hline 1263 & Sium latifolium L. & Egyek & 1947 & Siroki Zoltán & DE-siroki-12252.jpg \\
\hline 1263 & Sium latifolium L. & Egyek & 1947 & Siroki Zoltán & DE-siroki-12254.jpg \\
\hline 1263 & Sium latifolium L. & Egyek & 1949 & Siroki Zoltán & DE-siroki-12255.jpg \\
\hline 1263 & Sium latifolium L. & Mezőpeterd & 1959 & Siroki Zoltán & DE-siroki-12261.jpg \\
\hline 1263 & Sium latifolium L. & Mezőpeterd & 1959 & Siroki Zoltán & DE-siroki-12262.jpg \\
\hline 1263 & Sium latifolium L. & Mezőpeterd & 1959 & Siroki Zoltán & DE-siroki-12263.jpg \\
\hline 1263 & Sium latifolium L. & Mezőpeterd & 1959 & Siroki Zoltán & DE-siroki-12264.jpg \\
\hline 1263 & Sium latifolium L. & Mezőpeterd & 1959 & Siroki Zoltán & DE-siroki-12265.jpg \\
\hline 1263 & Sium latifolium L. & Mosonmagyaróvár & 1939 & Siroki Zoltán & DE-siroki-12256.jpg \\
\hline 1263 & Sium latifolium L. & Tiszakeszi & 1952 & Gondola István & DE-siroki-12247.jpg \\
\hline 1264 & Sium sisarum L. & Debrecen & 1947 & Siroki Zoltán & DE-siroki-12275.jpg \\
\hline 1264 & Sium sisarum L. & Debrecen & 1947 & Siroki Zoltán & DE-siroki-12276.jpg \\
\hline 1264 & Sium sisarum L. & Debrecen & 1947 & Siroki Zoltán & DE-siroki-12277.jpg \\
\hline 1264 & Sium sisarum L. & Debrecen & 1947 & Siroki Zoltán & DE-siroki-12279.jpg \\
\hline 1264 & Sium sisarum L. & Debrecen & 1947 & Siroki Zoltán & DE-siroki-12280.jpg \\
\hline 1264 & Sium sisarum L. & Debrecen & 1947 & Siroki Zoltán & DE-siroki-12281.jpg \\
\hline 1264 & Sium sisarum L. & Debrecen & 1947 & Siroki Zoltán & DE-siroki-12282.jpg \\
\hline 1264 & Sium sisarum L. & Debrecen & 1947 & Siroki Zoltán & DE-siroki-12283.jpg \\
\hline 1264 & Sium sisarum L. & Debrecen & 1950 & Siroki Zoltán & DE-siroki-12272.jpg \\
\hline 1264 & Sium sisarum L. & Debrecen & 1950 & Siroki Zoltán & DE-siroki-12273.jpg \\
\hline 1264 & Sium sisarum L. & Debrecen & 1951 & Siroki Zoltán & DE-siroki-12278.jpg \\
\hline 1264 & Sium sisarum L. & Debrecen & 1951 & Siroki Zoltán & DE-siroki-12274.jpg \\
\hline 1264 & Sium sisarum L. & Debrecen & 1954 & Siroki Zoltán & DE-siroki-12266.jpg \\
\hline 1264 & Sium sisarum L. & Debrecen & 1954 & Siroki Zoltán & DE-siroki-12267.jpg \\
\hline 1264 & Sium sisarum L. & Debrecen & 1954 & Siroki Zoltán & DE-siroki-12268.jpg \\
\hline 1264 & Sium sisarum L. & Debrecen & 1960 & Siroki Zoltán & DE-siroki-12269.jpg \\
\hline 1264 & Sium sisarum L. & Debrecen & 1960 & Siroki Zoltán & DE-siroki-12270.jpg \\
\hline 1264 & Sium sisarum L. & Debrecen & 1960 & Siroki Zoltán & DE-siroki-12271.jpg \\
\hline 1265 & Berula erecta (Huds.) Coville & Debrecen & 1946 & Siroki Zoltán & DE-siroki-12245.jpg \\
\hline 1265 & Berula erecta (Huds.) Coville & Debrecen & 1946 & Siroki Zoltán & DE-siroki-12240.jpg \\
\hline 1265 & Berula erecta (Huds.) Coville & Debrecen & 1947 & Siroki Zoltán & DE-siroki-12244.jpg \\
\hline 1265 & Berula erecta (Huds.) Coville & Debrecen & 1950 & Siroki Zoltán & DE-siroki-12238.jpg \\
\hline 1265 & Berula erecta (Huds.) Coville & Debrecen & 1950 & Siroki Zoltán & DE-siroki-12239.jpg \\
\hline 1265 & Berula erecta (Huds.) Coville & Debrecen & 1950 & Siroki Zoltán & DE-siroki-12241.jpg \\
\hline
\end{tabular}




\begin{tabular}{|c|c|c|c|c|c|}
\hline $\begin{array}{l}\text { Sorszám / } \\
\text { Number }\end{array}$ & Taxon-név / Taxon-name & $\begin{array}{l}\text { Település / } \\
\text { Settlement }\end{array}$ & $\begin{array}{l}\text { Év / } \\
\text { Year }\end{array}$ & $\begin{array}{l}\text { Gyűjtő / } \\
\text { Collector }\end{array}$ & Fájlnév / File-name \\
\hline 1265 & Berula erecta (Huds.) Coville & Debrecen & 1950 & Siroki Zoltán & DE-siroki-12242.jpg \\
\hline 1265 & Berula erecta (Huds.) Coville & Debrecen & 1950 & Siroki Zoltán & DE-siroki-12243.jpg \\
\hline 1266 & Libanotis pyrenaica (L.) Bourg. & "Nagymező" & 1958 & Siroki Zoltán & DE-siroki-12384.jpg \\
\hline 1266 & Libanotis pyrenaica (L.) Bourg. & "Nagymező" & 1958 & Siroki Zoltán & DE-siroki-12385.jpg \\
\hline 1266 & Libanotis pyrenaica (L.) Bourg. & "Nagymező" & 1958 & Siroki Zoltán & DE-siroki-12386.jpg \\
\hline 1266 & Libanotis pyrenaica (L.) Bourg. & Mátraverebély & 1952 & Siroki Zoltán & DE-siroki-12388.jpg \\
\hline 1267 & $\begin{array}{l}\text { Seseli peucedanoides } \\
\text { (M. Bieb.) Koso-Pol. }\end{array}$ & "Háromkő" & 1959 & Siroki Zoltán & DE-siroki-12475.jpg \\
\hline 1267 & $\begin{array}{l}\text { Seseli peucedanoides } \\
\text { (M. Bieb.) Koso-Pol. }\end{array}$ & "Háromkő" & 1959 & Siroki Zoltán & DE-siroki-12476.jpg \\
\hline 1267 & $\begin{array}{l}\text { Seseli peucedanoides } \\
\text { (M. Bieb.) Koso-Pol. }\end{array}$ & "Háromkő" & 1959 & Siroki Zoltán & DE-siroki-12460.jpg \\
\hline 1267 & $\begin{array}{l}\text { Seseli peucedanoides } \\
\text { (M. Bieb.) Koso-Pol. }\end{array}$ & "Háromkő" & 1959 & Siroki Zoltán & DE-siroki-12461.jpg \\
\hline 1267 & $\begin{array}{l}\text { Seseli peucedanoides } \\
\text { (M. Bieb.) Koso-Pol. }\end{array}$ & "Háromkő" & 1959 & Siroki Zoltán & DE-siroki-12462.jpg \\
\hline 1267 & $\begin{array}{l}\text { Seseli peucedanoides } \\
\text { (M. Bieb.) Koso-Pol. }\end{array}$ & "Háromkő" & 1959 & Siroki Zoltán & DE-siroki-12463.jpg \\
\hline 1267 & $\begin{array}{l}\text { Seseli peucedanoides } \\
\text { (M. Bieb.) Koso-Pol. }\end{array}$ & "Háromkő" & 1959 & Siroki Zoltán & DE-siroki-12464.jpg \\
\hline 1267 & $\begin{array}{l}\text { Seseli peucedanoides } \\
\text { (M. Bieb.) Koso-Pol. }\end{array}$ & "Háromkő" & 1959 & Siroki Zoltán & DE-siroki-12465.jpg \\
\hline 1267 & $\begin{array}{l}\text { Seseli peucedanoides } \\
\text { (M. Bieb.) Koso-Pol. }\end{array}$ & "Háromkő" & 1959 & Siroki Zoltán & DE-siroki-12469.jpg \\
\hline 1267 & $\begin{array}{l}\text { Seseli peucedanoides } \\
\text { (M. Bieb.) Koso-Pol. }\end{array}$ & "Háromkő" & 1960 & Siroki Zoltán & DE-siroki-12466.jpg \\
\hline 1267 & $\begin{array}{l}\text { Seseli peucedanoides } \\
\text { (M. Bieb.) Koso-Pol. }\end{array}$ & "Háromkő" & 1960 & Siroki Zoltán & DE-siroki-12467.jpg \\
\hline 1267 & $\begin{array}{l}\text { Seseli peucedanoides } \\
\text { (M. Bieb.) Koso-Pol. }\end{array}$ & "Tarkő" & 1958 & Siroki Zoltán & DE-siroki-12471.jpg \\
\hline 1267 & $\begin{array}{l}\text { Seseli peucedanoides } \\
\text { (M. Bieb.) Koso-Pol. }\end{array}$ & "Tarkő" & 1958 & Siroki Zoltán & DE-siroki-12472.jpg \\
\hline 1267 & $\begin{array}{l}\text { Seseli peucedanoides } \\
\text { (M. Bieb.) Koso-Pol. }\end{array}$ & "Tarkő" & 1958 & Siroki Zoltán & DE-siroki-12473.jpg \\
\hline 1267 & $\begin{array}{l}\text { Seseli peucedanoides } \\
\text { (M. Bieb.) Koso-Pol. }\end{array}$ & "Tarkő" & 1958 & Siroki Zoltán & DE-siroki-12474.jpg \\
\hline 1267 & $\begin{array}{l}\text { Seseli peucedanoides } \\
\text { (M. Bieb.) Koso-Pol. }\end{array}$ & "Tarkő" & 1958 & Siroki Zoltán & DE-siroki-12478.jpg \\
\hline 1267 & $\begin{array}{l}\text { Seseli peucedanoides } \\
\text { (M. Bieb.) Koso-Pol. }\end{array}$ & "Tarkő" & 1958 & Siroki Zoltán & DE-siroki-12479.jpg \\
\hline 1267 & $\begin{array}{l}\text { Seseli peucedanoides } \\
\text { (M. Bieb.) Koso-Pol. }\end{array}$ & "Tarkő" & 1958 & Siroki Zoltán & DE-siroki-12480.jpg \\
\hline 1267 & $\begin{array}{l}\text { Seseli peucedanoides } \\
\text { (M. Bieb.) Koso-Pol. }\end{array}$ & "Tarkő" & 1958 & Siroki Zoltán & DE-siroki-12468.jpg \\
\hline 1267 & $\begin{array}{l}\text { Seseli peucedanoides } \\
\text { (M. Bieb.) Koso-Pol. }\end{array}$ & "Tarkő" & 1958 & Siroki Zoltán & DE-siroki-12470.jpg \\
\hline 1267 & $\begin{array}{l}\text { Seseli peucedanoides } \\
\text { (M. Bieb.) Koso-Pol. }\end{array}$ & "Tarkő" & 1959 & Siroki Zoltán & DE-siroki-12477.jpg \\
\hline 1267 & $\begin{array}{l}\text { Seseli peucedanoides } \\
\text { (M. Bieb.) Koso-Pol. }\end{array}$ & Tokaj & 1966 & Siroki Zoltán & DE-siroki-12458.jpg \\
\hline 1267 & $\begin{array}{l}\text { Seseli peucedanoides } \\
\text { (M. Bieb.) Koso-Pol. }\end{array}$ & Tokaj & 1966 & Siroki Zoltán & DE-siroki-12459.jpg \\
\hline 1267 & $\begin{array}{l}\text { Seseli peucedanoides } \\
\text { (M. Bieb.) Koso-Pol. }\end{array}$ & Tokaj & 1966 & Siroki Zoltán & DE-siroki-12456.jpg \\
\hline 1267 & $\begin{array}{l}\text { Seseli peucedanoides } \\
\text { (M. Bieb.) Koso-Pol. }\end{array}$ & Tokaj & 1971 & Siroki Zoltán & DE-siroki-12457.jpg \\
\hline 1268 & Seseli hippomarathrum Jacq. & Balatonederics & 1955 & Siroki Zoltán & DE-siroki-12288.jpg \\
\hline 1268 & Seseli hippomarathrum Jacq. & Biatorbágy & 1950 & Siroki Zoltán & DE-siroki-12287.jpg \\
\hline 1268 & Seseli hippomarathrum Jacq. & Budapest & 1941 & Siroki Zoltán & DE-siroki-12284.jpg \\
\hline 1268 & Seseli hippomarathrum Jacq. & Budapest & 1941 & Siroki Zoltán & DE-siroki-12291.jpg \\
\hline
\end{tabular}




\begin{tabular}{|c|c|c|c|c|c|}
\hline $\begin{array}{l}\text { Sorszám / } \\
\text { Number }\end{array}$ & Taxon-név / Taxon-name & $\begin{array}{l}\text { Település / } \\
\text { Settlement }\end{array}$ & $\begin{array}{l}\text { Év / } \\
\text { Year }\end{array}$ & $\begin{array}{l}\text { Gyűjtő / } \\
\text { Collector }\end{array}$ & Fájlnév / File-name \\
\hline 1268 & Seseli hippomarathrum Jacq. & Budapest & 1941 & Siroki Zoltán & DE-siroki-12292.jpg \\
\hline 1268 & Seseli hippomarathrum Jacq. & Budapest & 1941 & Siroki Zoltán & DE-siroki-12290.jpg \\
\hline 1268 & Seseli hippomarathrum Jacq. & Budapest & 1948 & Siroki Zoltán & DE-siroki-12289.jpg \\
\hline 1268 & Seseli hippomarathrum Jacq. & Budapest & 1957 & Siroki Zoltán & DE-siroki-12285.jpg \\
\hline 1268 & Seseli hippomarathrum Jacq. & Budapest & 1957 & Siroki Zoltán & DE-siroki-12286.jpg \\
\hline 1269 & Seseli annuum L. & Budapest & 1909 & Kocsis István & DE-siroki-12315.jpg \\
\hline 1269 & Seseli annuum L. & Budapest & 1948 & Siroki Zoltán & DE-siroki-12309.jpg \\
\hline 1269 & Seseli annuum L. & Budapest & 1985 & Siroki Zoltán & DE-siroki-12305.jpg \\
\hline 1269 & Seseli annuum L. & Debrecen & 1947 & Siroki Zoltán & DE-siroki-12310.jpg \\
\hline 1269 & Seseli annuum L. & Debrecen & 1947 & Siroki Zoltán & DE-siroki-12322.jpg \\
\hline 1269 & Seseli annuum L. & Debrecen & 1966 & Gondola István & DE-siroki-12323.jpg \\
\hline 1269 & Seseli annuum L. & Debrecen & 1966 & Gondola István & DE-siroki-12324.jpg \\
\hline 1269 & Seseli annuum L. & Gödöllő & 1954 & Jeanplong József & DE-siroki-12306.jpg \\
\hline 1269 & Seseli annuum L. & Hencida & 1983 & Siroki Zoltán & DE-siroki-12321.jpg \\
\hline 1269 & Seseli annuum L. & Mikepércs & 1962 & Siroki Zoltán & DE-siroki-12307.jpg \\
\hline 1269 & Seseli annuum L. & Mikepércs & 1962 & Siroki Zoltán & DE-siroki-12325.jpg \\
\hline 1269 & Seseli annuum L. & Sajólád/Sajópetri & 1951 & Siroki Zoltán & DE-siroki-12308.jpg \\
\hline 1269 & Seseli annuum L. & Szigetszentmiklós & 1911 & Kocsis István & DE-siroki-12314.jpg \\
\hline 1269 & Seseli annuum L. & Szigetújfalu & 1909 & Kocsis István & DE-siroki-12313.jpg \\
\hline 1269 & Seseli annuum L. & Tiszacsege & 1978 & Siroki Zoltán & DE-siroki-12311.jpg \\
\hline 1269 & Seseli annuum L. & Vác & 1909 & Kocsis István & DE-siroki-12312.jpg \\
\hline 1270 & Seseli leucospermum Waldst. et Kit. & Budaörs & 1976 & Siroki Zoltán & DE-siroki-12293.jpg \\
\hline 1270 & Seseli leucospermum Waldst. et Kit. & Budapest & 1941 & Siroki Zoltán & DE-siroki-12296.jpg \\
\hline 1270 & Seseli leucospermum Waldst. et Kit. & Budapest & 1941 & Siroki Zoltán & DE-siroki-12297.jpg \\
\hline 1270 & Seseli leucospermum Waldst. et Kit. & Budapest & 1948 & Siroki Zoltán & DE-siroki-12301.jpg \\
\hline 1270 & Seseli leucospermum Waldst. et Kit. & Budapest & 1948 & Siroki Zoltán & DE-siroki-12294.jpg \\
\hline 1270 & Seseli leucospermum Waldst. et Kit. & Budapest & 1948 & Siroki Zoltán & DE-siroki-12295.jpg \\
\hline 1270 & Seseli leucospermum Waldst. et Kit. & Budapest & 1948 & Siroki Zoltán & DE-siroki-12302.jpg \\
\hline 1270 & Seseli leucospermum Waldst. et Kit. & Budapest & 1957 & Siroki Zoltán & DE-siroki-12299.jpg \\
\hline 1270 & Seseli leucospermum Waldst. et Kit. & Budapest & 1957 & Siroki Zoltán & DE-siroki-12300.jpg \\
\hline 1270 & Seseli leucospermum Waldst. et Kit. & Nagykovácsi & 1950 & Siroki Zoltán & DE-siroki-12298.jpg \\
\hline 1271 & Seseli varium Trevir. & Abaújszántó & 1943 & Siroki Zoltán & DE-siroki-12352.jpg \\
\hline 1271 & Seseli varium Trevir. & Abaújszántó & 1943 & Siroki Zoltán & DE-siroki-12355.jpg \\
\hline 1271 & Seseli varium Trevir. & Budaörs & 1909 & Kocsis István & DE-siroki-12360.jpg \\
\hline 1271 & Seseli varium Trevir. & Egyek & 1947 & Siroki Zoltán & DE-siroki-12336.jpg \\
\hline 1271 & Seseli varium Trevir. & Egyek & 1947 & Siroki Zoltán & DE-siroki-12353.jpg \\
\hline 1271 & Seseli varium Trevir. & Egyek & 1947 & Siroki Zoltán & DE-siroki-12354.jpg \\
\hline 1271 & Seseli varium Trevir. & Kecskemét & 1913 & Degen Árpád & DE-siroki-12361.jpg \\
\hline 1271 & Seseli varium Trevir. & Mikepércs & 1962 & Siroki Zoltán & DE-siroki-12340.jpg \\
\hline 1271 & Seseli varium Trevir. & Mikepércs & 1962 & Siroki Zoltán & DE-siroki-12341.jpg \\
\hline 1271 & Seseli varium Trevir. & Mikepércs & 1962 & Siroki Zoltán & DE-siroki-12342.jpg \\
\hline 1271 & Seseli varium Trevir. & Mikepércs & 1962 & Siroki Zoltán & DE-siroki-12343.jpg \\
\hline 1271 & Seseli varium Trevir. & Mikepércs & 1962 & Siroki Zoltán & DE-siroki-12344.jpg \\
\hline 1271 & Seseli varium Trevir. & Mikepércs & 1962 & Siroki Zoltán & DE-siroki-12345.jpg \\
\hline 1271 & Seseli varium Trevir. & Mikepércs & 1962 & Siroki Zoltán & DE-siroki-12339.jpg \\
\hline 1271 & Seseli varium Trevir. & Mikepércs & 1962 & Siroki Zoltán & DE-siroki-12346.jpg \\
\hline
\end{tabular}




\begin{tabular}{|c|c|c|c|c|c|}
\hline $\begin{array}{l}\text { Sorszám / } \\
\text { Number }\end{array}$ & Taxon-név / Taxon-name & $\begin{array}{l}\text { Település / } \\
\text { Settlement }\end{array}$ & $\begin{array}{l}\text { Év / } \\
\text { Year }\end{array}$ & $\begin{array}{l}\text { Gyűjtő / } \\
\text { Collector }\end{array}$ & Fájlnév / File-name \\
\hline 1271 & Seseli varium Trevir. & Mikepércs & 1962 & Siroki Zoltán & DE-siroki-12347.jpg \\
\hline 1271 & Seseli varium Trevir. & Mikepércs & 1969 & Siroki Zoltán & DE-siroki-12359.jpg \\
\hline 1271 & Seseli varium Trevir. & Mikepércs & 1972 & Siroki Zoltán & DE-siroki-12362.jpg \\
\hline 1271 & Seseli varium Trevir. & Mikepércs & 1972 & Siroki Zoltán & DE-siroki-12363.jpg \\
\hline 1271 & Seseli varium Trevir. & Mikepércs & 1972 & Siroki Zoltán & DE-siroki-12364.jpg \\
\hline 1271 & Seseli varium Trevir. & Mikepércs & 1972 & Siroki Zoltán & DE-siroki-12365.jpg \\
\hline 1271 & Seseli varium Trevir. & Nagykőrös & 1954 & Siroki Zoltán & DE-siroki-12348.jpg \\
\hline 1271 & Seseli varium Trevir. & Nagykőrös & 1954 & Siroki Zoltán & DE-siroki-12349.jpg \\
\hline 1271 & Seseli varium Trevir. & Sajólád/Sajópetri & 1951 & Siroki Zoltán & DE-siroki-12338.jpg \\
\hline 1271 & Seseli varium Trevir. & Sajólád/Sajópetri & 1951 & Siroki Zoltán & DE-siroki-12350.jpg \\
\hline 1271 & Seseli varium Trevir. & Sajólád/Sajópetri & 1951 & Siroki Zoltán & DE-siroki-12351.jpg \\
\hline 1271 & Seseli varium Trevir. & Tokaj & 1966 & Siroki Zoltán & DE-siroki-12356.jpg \\
\hline 1271 & Seseli varium Trevir. & Tokaj & 1966 & Siroki Zoltán & DE-siroki-12357.jpg \\
\hline 1271 & Seseli varium Trevir. & Tokaj & 1966 & Siroki Zoltán & DE-siroki-12358.jpg \\
\hline 1272 & Seseli osseum Crantz em. Simonk. & "Háromkő" & - & Halász Tibor & DE-siroki-12375.jpg \\
\hline 1272 & Seseli osseum Crantz em. Simonk. & "Szent-György-hegy" & 1955 & Siroki Zoltán & DE-siroki-12374.jpg \\
\hline 1272 & Seseli osseum Crantz em. Simonk. & Aszaló & 1944 & Siroki Zoltán & DE-siroki-12366.jpg \\
\hline 1272 & Seseli osseum Crantz em. Simonk. & Budapest & 1941 & Siroki Zoltán & DE-siroki-12372.jpg \\
\hline 1272 & Seseli osseum Crantz em. Simonk. & Budapest & 1950 & Siroki Zoltán & DE-siroki-12370.jpg \\
\hline 1272 & Seseli osseum Crantz em. Simonk. & Gödöllő & 1952 & Siroki Zoltán & DE-siroki-12368.jpg \\
\hline 1272 & Seseli osseum Crantz em. Simonk. & Gödöllő & 1954 & Siroki Zoltán & DE-siroki-12371.jpg \\
\hline 1272 & Seseli osseum Crantz em. Simonk. & Nagykovácsi & 1957 & Siroki Zoltán & DE-siroki-12376.jpg \\
\hline 1272 & Seseli osseum Crantz em. Simonk. & Szilvásvárad & 1954 & Siroki Zoltán & DE-siroki-12369.jpg \\
\hline 1272 & Seseli osseum Crantz em. Simonk. & Szilvásvárad & 1954 & Siroki Zoltán & DE-siroki-12373.jpg \\
\hline 1273 & Oenanthe aquatica (L.) Poir. & Debrecen & 1947 & Siroki Zoltán & DE-siroki-12390.jpg \\
\hline 1273 & Oenanthe aquatica (L.) Poir. & Debrecen & 1954 & Siroki Zoltán & DE-siroki-12391.jpg \\
\hline 1273 & Oenanthe aquatica (L.) Poir. & Kazincbarcika & 1944 & Siroki Zoltán & DE-siroki-12393.jpg \\
\hline 1273 & Oenanthe aquatica (L.) Poir. & Kazincbarcika & 1944 & Siroki Zoltán & DE-siroki-12394.jpg \\
\hline 1273 & Oenanthe aquatica (L.) Poir. & Mosonmagyaróvár & 1939 & Siroki Zoltán & DE-siroki-12395.jpg \\
\hline 1274 & Oenanthe fistulosa $\mathrm{L}$. & Budapest & 1940 & Siroki Zoltán & DE-siroki-12397.jpg \\
\hline 1274 & Oenanthe fistulosa L. & Pomáz & 1957 & Siroki Zoltán & DE-siroki-12396.jpg \\
\hline 1274 & Oenanthe fistulosa L. & Szigliget & 1955 & Siroki Zoltán & DE-siroki-12398.jpg \\
\hline 1275 & Oenanthe silaifolia M. Bieb. & Biharugra & 1961 & Siroki Zoltán & DE-siroki-12407.jpg \\
\hline 1275 & Oenanthe silaifolia M. Bieb. & Debrecen & 1947 & Siroki Zoltán & DE-siroki-12414.jpg \\
\hline 1275 & Oenanthe silaifolia M. Bieb. & Debrecen & 1947 & Siroki Zoltán & DE-siroki-12415.jpg \\
\hline 1275 & Oenanthe silaifolia M. Bieb. & Debrecen & 1947 & Siroki Zoltán & DE-siroki-12404.jpg \\
\hline 1275 & Oenanthe silaifolia M. Bieb. & Debrecen & 1947 & Siroki Zoltán & DE-siroki-12402.jpg \\
\hline 1275 & Oenanthe silaifolia M. Bieb. & Debrecen & 1947 & Siroki Zoltán & DE-siroki-12403.jpg \\
\hline 1275 & Oenanthe silaifolia M. Bieb. & Debrecen & 1947 & Siroki Zoltán & DE-siroki-12416.jpg \\
\hline 1275 & Oenanthe silaifolia M. Bieb. & Debrecen & 1954 & Siroki Zoltán & DE-siroki-12405.jpg \\
\hline 1275 & Oenanthe silaifolia M. Bieb. & Debrecen & 1954 & Siroki Zoltán & DE-siroki-12406.jpg \\
\hline 1275 & Oenanthe silaifolia M. Bieb. & Debrecen & 1964 & Siroki Zoltán & DE-siroki-12413.jpg \\
\hline 1275 & Oenanthe silaifolia M. Bieb. & Debrecen & 1966 & Siroki Zoltán & DE-siroki-12408.jpg \\
\hline 1275 & Oenanthe silaifolia M. Bieb. & Debrecen & 1966 & Siroki Zoltán & DE-siroki-12409.jpg \\
\hline 1275 & Oenanthe silaifolia M. Bieb. & Debrecen & 1966 & Siroki Zoltán & DE-siroki-12410.jpg \\
\hline 1275 & Oenanthe silaifolia M. Bieb. & Debrecen & 1966 & Siroki Zoltán & DE-siroki-12411.jpg \\
\hline
\end{tabular}




\begin{tabular}{|c|c|c|c|c|c|}
\hline $\begin{array}{l}\text { Sorszám / } \\
\text { Number }\end{array}$ & Taxon-név / Taxon-name & $\begin{array}{l}\text { Település / } \\
\text { Settlement }\end{array}$ & $\begin{array}{l}\text { Év / } \\
\text { Year }\end{array}$ & $\begin{array}{l}\text { Gyűjtő / } \\
\text { Collector }\end{array}$ & Fájlnév / File-name \\
\hline 1275 & Oenanthe silaifolia M. Bieb. & Debrecen & 1966 & Siroki Zoltán & DE-siroki-12412.jpg \\
\hline 1276 & Oenanthe banatica Heuff. & Debrecen & 1876 & Simonkai Lajos & DE-siroki-12422.jpg \\
\hline 1276 & Oenanthe banatica Heuff. & Debrecen & 1955 & Siroki Zoltán & DE-siroki-12420.jpg \\
\hline 1276 & Oenanthe banatica Heuff. & Debrecen & 1955 & Siroki Zoltán & DE-siroki-12421.jpg \\
\hline 1276 & Oenanthe banatica Heuff. & Tarpa & 1955 & Siroki Zoltán & DE-siroki-12419.jpg \\
\hline 1276 & Oenanthe banatica Heuff. & Tarpa & 1955 & Siroki Zoltán & DE-siroki-12418.jpg \\
\hline 1276 & Oenanthe banatica Heuff. & Tarpa & 1955 & $\begin{array}{l}\text { Siroki Zoltán - } \\
\text { Farkas Attila }\end{array}$ & DE-siroki-12417.jpg \\
\hline 1277 & Aethusa cynapium L. & Biatorbágy & 1950 & Siroki Zoltán & DE-siroki-12431.jpg \\
\hline 1277 & Aethusa cynapium L. & Biatorbágy & 1950 & Siroki Zoltán & DE-siroki-12432.jpg \\
\hline 1277 & Aethusa cynapium L. & Biatorbágy & 1950 & Siroki Zoltán & DE-siroki-12433.jpg \\
\hline 1277 & Aethusa cynapium L. & Budapest & 1985 & Siroki Zoltán & DE-siroki-12424.jpg \\
\hline 1277 & Aethusa cynapium L. & Dombrád & 1966 & Gondola István & DE-siroki-12427.jpg \\
\hline 1277 & Aethusa cynapium L. & Dombrád & 1966 & Gondola István & DE-siroki-12428.jpg \\
\hline 1277 & Aethusa cynapium L. & Háromhuta & 1978 & Siroki Zoltán & DE-siroki-12425.jpg \\
\hline 1277 & Aethusa cynapium L. & Háromhuta & 1978 & Siroki Zoltán & DE-siroki-12426.jpg \\
\hline 1277 & Aethusa cynapium L. & Mátraverebély & 1952 & Siroki Zoltán & DE-siroki-12429.jpg \\
\hline 1277 & Aethusa cynapium L. & Mátraverebély & 1952 & Siroki Zoltán & DE-siroki-12430.jpg \\
\hline 1277 & Aethusa cynapium L. & Mosonmagyaróvár & 1939 & Siroki Zoltán & DE-siroki-12434.jpg \\
\hline 1280 & Silaum silaus (L.) Schinz et Thell. & Miskolc & 1965 & Siroki Zoltán & DE-siroki-12449.jpg \\
\hline 1280 & Silaum silaus (L.) Schinz et Thell. & Miskolc & 1965 & Siroki Zoltán & DE-siroki-12450.jpg \\
\hline 1280 & Silaum silaus (L.) Schinz et Thell. & Miskolc & 1965 & Siroki Zoltán & DE-siroki-12451.jpg \\
\hline 1280 & Silaum silaus (L.) Schinz et Thell. & Miskolc & 1965 & Siroki Zoltán & DE-siroki-12452.jpg \\
\hline 1280 & Silaum silaus (L.) Schinz et Thell. & Miskolc & 1965 & Siroki Zoltán & DE-siroki-12453.jpg \\
\hline 1280 & Silaum silaus (L.) Schinz et Thell. & Miskolc & 1965 & Siroki Zoltán & DE-siroki-12454.jpg \\
\hline 1280 & Silaum silaus (L.) Schinz et Thell. & Miskolc & 1965 & Siroki Zoltán & DE-siroki-12455.jpg \\
\hline 1280 & Silaum silaus (L.) Schinz et Thell. & Miskolc & 1965 & Siroki Zoltán & DE-siroki-12445.jpg \\
\hline 1280 & Silaum silaus (L.) Schinz et Thell. & Miskolc & 1965 & Siroki Zoltán & DE-siroki-12446.jpg \\
\hline 1280 & Silaum silaus (L.) Schinz et Thell. & Miskolc & 1965 & Siroki Zoltán & DE-siroki-12447.jpg \\
\hline 1280 & Silaum silaus (L.) Schinz et Thell. & Miskolc & 1965 & Siroki Zoltán & DE-siroki-12448.jpg \\
\hline 1281 & Physospermum cornubiense (L.) DC. & "Dobogókő" & 1956 & Siroki Zoltán & DE-siroki-11666.jpg \\
\hline 1281 & Physospermum cornubiense (L.) DC. & "Dobogókő" & 1956 & Siroki Zoltán & DE-siroki-11667.jpg \\
\hline 1281 & Physospermum cornubiense (L.) DC. & "Dobogókő" & 1956 & Siroki Zoltán & DE-siroki-11669.jpg \\
\hline 1281 & Physospermum cornubiense (L.) DC. & "Dobogókő" & 1956 & Siroki Zoltán & DE-siroki-11670.jpg \\
\hline 1281 & Physospermum cornubiense (L.) DC. & "Dobogókő" & 1956 & Siroki Zoltán & DE-siroki-11678.jpg \\
\hline 1281 & Physospermum cornubiense (L.) DC. & "Dobogókő" & 1956 & Siroki Zoltán & DE-siroki-11679.jpg \\
\hline 1281 & Physospermum cornubiense (L.) DC. & "Dobogókő" & 1956 & Siroki Zoltán & DE-siroki-11680.jpg \\
\hline 1281 & Physospermum cornubiense (L.) DC. & "Dobogókő" & 1956 & Siroki Zoltán & DE-siroki-11681.jpg \\
\hline 1281 & Physospermum cornubiense (L.) DC. & "Dobogókő" & 1957 & Siroki Zoltán & DE-siroki-11668.jpg \\
\hline 1281 & Physospermum cornubiense (L.) DC. & "Dobogókő" & 1957 & Siroki Zoltán & DE-siroki-11682.jpg \\
\hline 1281 & Physospermum cornubiense (L.) DC. & "Dobogókő" & 1957 & Siroki Zoltán & DE-siroki-11683.jpg \\
\hline 1281 & Physospermum cornubiense (L.) DC. & "Dobogókő" & 1965 & Siroki Zoltán & DE-siroki-11665.jpg \\
\hline 1281 & Physospermum cornubiense (L.) DC. & "Dobogókő" & 1965 & Siroki Zoltán & DE-siroki-11671.jpg \\
\hline 1281 & Physospermum cornubiense (L.) DC. & "Dobogókő" & 1965 & Siroki Zoltán & DE-siroki-11672.jpg \\
\hline 1281 & Physospermum cornubiense (L.) DC. & "Dobogókő" & 1965 & Siroki Zoltán & DE-siroki-11673.jpg \\
\hline 1281 & Physospermum cornubiense (L.) DC. & "Dobogókő" & 1965 & Siroki Zoltán & DE-siroki-11674.jpg \\
\hline 1281 & Physospermum cornubiense (L.) DC. & "Dobogókő" & 1965 & Siroki Zoltán & DE-siroki-11677.jpg \\
\hline
\end{tabular}




\begin{tabular}{|c|c|c|c|c|c|}
\hline $\begin{array}{l}\text { Sorszám / } \\
\text { Number }\end{array}$ & Taxon-név / Taxon-name & $\begin{array}{l}\text { Település / } \\
\text { Settlement }\end{array}$ & $\begin{array}{l}\text { Év / } \\
\text { Year }\end{array}$ & $\begin{array}{l}\text { Gyűjtő / } \\
\text { Collector }\end{array}$ & Fájlnév / File-name \\
\hline 1281 & Physospermum cornubiense (L.) DC. & Pilismarót & 1963 & Siroki Zoltán & DE-siroki-11675.jpg \\
\hline 1281 & Physospermum cornubiense (L.) DC. & Pilismarót & 1963 & Siroki Zoltán & DE-siroki-11676.jpg \\
\hline 1282 & Conium maculatum L. & Debrecen & 1947 & Siroki Zoltán & DE-siroki-11684.jpg \\
\hline 1283 & $\begin{array}{l}\text { Pleurospermum austriacum } \\
\text { (L.) Hoffm. }\end{array}$ & "Bánkút" & 1927 & Hulják János & DE-siroki-11688.jpg \\
\hline 1284 & Bupleurum rotundifolium L. & "Háromkő" & 1956 & Halász Tibor & DE-siroki-11692.jpg \\
\hline 1284 & Bupleurum rotundifolium L. & Budapest & 1948 & Siroki Zoltán & DE-siroki-11691.jpg \\
\hline 1284 & Bupleurum rotundifolium L. & Budapest & 1948 & Siroki Zoltán & DE-siroki-11696.jpg \\
\hline 1284 & Bupleurum rotundifolium L. & Budapest & 1948 & Siroki Zoltán & DE-siroki-11697.jpg \\
\hline 1284 & Bupleurum rotundifolium L. & Buják & 1954 & Siroki Zoltán & DE-siroki-11693.jpg \\
\hline 1284 & Bupleurum rotundifolium L. & Buják & 1954 & Siroki Zoltán & DE-siroki-11694.jpg \\
\hline 1284 & Bupleurum rotundifolium L. & Buják & 1954 & Siroki Zoltán & DE-siroki-11695.jpg \\
\hline 1286 & Bupleurum longifolium L. & "Bükk-hg." & 1956 & Halász Tibor & DE-siroki-11702.jpg \\
\hline 1286 & Bupleurum longifolium L. & "Háromkő" & 1958 & Siroki Zoltán & DE-siroki-11700.jpg \\
\hline 1286 & Bupleurum longifolium L. & "Nagymező" & 1958 & Siroki Zoltán & DE-siroki-11698.jpg \\
\hline 1286 & Bupleurum longifolium L. & "Nagymező" & 1958 & Siroki Zoltán & DE-siroki-11699.jpg \\
\hline 1286 & Bupleurum longifolium L. & "Nagymező" & 1959 & Halász Tibor & DE-siroki-11707.jpg \\
\hline 1286 & Bupleurum longifolium L. & "Nagymező" & 1959 & Siroki Zoltán & DE-siroki-11704.jpg \\
\hline 1286 & Bupleurum longifolium L. & "Nagymező" & 1959 & Siroki Zoltán & DE-siroki-11708.jpg \\
\hline 1286 & Bupleurum longifolium L. & "Nagymező" & 1959 & Siroki Zoltán & DE-siroki-11709.jpg \\
\hline 1286 & Bupleurum longifolium L. & "Nagymező" & 1959 & Siroki Zoltán & DE-siroki-11710.jpg \\
\hline 1286 & Bupleurum longifolium L. & "Nagymező" & 1959 & Siroki Zoltán & DE-siroki-11711.jpg \\
\hline 1286 & Bupleurum longifolium L. & "Nagymező" & 1959 & Siroki Zoltán & DE-siroki-11712.jpg \\
\hline 1286 & Bupleurum longifolium L. & "Nagymező" & 1959 & Siroki Zoltán & DE-siroki-11703.jpg \\
\hline 1286 & Bupleurum longifolium L. & "Nagymező" & 1959 & Siroki Zoltán & DE-siroki-11705.jpg \\
\hline 1286 & Bupleurum longifolium L. & "Nagymező" & 1959 & Siroki Zoltán & DE-siroki-11706.jpg \\
\hline 1286 & Bupleurum longifolium L. & "Tarkő" & 1958 & Siroki Zoltán & DE-siroki-11701.jpg \\
\hline 1287 & Bupleurum tenuissimum L. & Egyek & 1947 & Siroki Zoltán & DE-siroki-11713.jpg \\
\hline 1287 & Bupleurum tenuissimum L. & Hortobágy & 1947 & Siroki Zoltán & DE-siroki-11714.jpg \\
\hline 1287 & Bupleurum tenuissimum L. & Hortobágy & 1947 & Siroki Zoltán & DE-siroki-11715.jpg \\
\hline 1287 & Bupleurum tenuissimum L. & Hortobágy & 1947 & Siroki Zoltán & DE-siroki-11717.jpg \\
\hline 1287 & Bupleurum tenuissimum L. & Hortobágy & 1947 & Siroki Zoltán & DE-siroki-11716.jpg \\
\hline 1288 & Bupleurum falcatum L. & Budaörs & 1941 & Siroki Zoltán & DE-siroki-12084.jpg \\
\hline 1288 & Bupleurum falcatum L. & Budapest & 1941 & Siroki Zoltán & DE-siroki-12085.jpg \\
\hline 1288 & Bupleurum falcatum L. & Budapest & 1948 & Siroki Zoltán & DE-siroki-12092.jpg \\
\hline 1288 & Bupleurum falcatum L. & Felsőtárkány & 1963 & Siroki Zoltán & DE-siroki-12089.jpg \\
\hline 1288 & Bupleurum falcatum L. & Felsőtárkány & 1963 & Siroki Zoltán & DE-siroki-12090.jpg \\
\hline 1288 & Bupleurum falcatum L. & Felsőtárkány & 1963 & Siroki Zoltán & DE-siroki-12091.jpg \\
\hline 1289 & Bupleurum praealtum L. & "Háromkő" & 1958 & Siroki Zoltán & DE-siroki-11720.jpg \\
\hline 1289 & Bupleurum praealtum L. & "Háromkő" & 1958 & Siroki Zoltán & DE-siroki-11725.jpg \\
\hline 1289 & Bupleurum praealtum L. & "Háromkő" & 1958 & Siroki Zoltán & DE-siroki-11726.jpg \\
\hline 1289 & Bupleurum praealtum L. & "Háromkő" & 1958 & Siroki Zoltán & DE-siroki-11727.jpg \\
\hline 1289 & Bupleurum praealtum L. & "Háromkő" & 1958 & Siroki Zoltán & DE-siroki-11728.jpg \\
\hline 1289 & Bupleurum praealtum L. & Bélapátfalva & 1958 & Siroki Zoltán & DE-siroki-11721.jpg \\
\hline 1289 & Bupleurum praealtum L. & Bélapátfalva & 1958 & Siroki Zoltán & DE-siroki-11722.jpg \\
\hline 1289 & Bupleurum praealtum L. & Budapest & 1888 & $\begin{array}{l}\text { Schilberszky } \\
\text { Károly }\end{array}$ & DE-siroki-11724.jpg \\
\hline
\end{tabular}




\begin{tabular}{|c|c|c|c|c|c|}
\hline $\begin{array}{l}\text { Sorszám / } \\
\text { Number }\end{array}$ & Taxon-név / Taxon-name & $\begin{array}{l}\text { Település / } \\
\text { Settlement }\end{array}$ & $\begin{array}{l}\text { Év / } \\
\text { Year }\end{array}$ & $\begin{array}{l}\text { Gyújtő / } \\
\text { Collector }\end{array}$ & Fájlnév / File-name \\
\hline 1289 & Bupleurum praealtum L. & Budapest & 1962 & Siroki Zoltán & DE-siroki-11723.jpg \\
\hline 1289 & Bupleurum praealtum L. & Budapest & 1962 & Siroki Zoltán & DE-siroki-11729.jpg \\
\hline 1289 & Bupleurum praealtum L. & Budapest & 1962 & Siroki Zoltán & DE-siroki-11730.jpg \\
\hline 1289 & Bupleurum praealtum L. & Budapest & 1962 & Siroki Zoltán & DE-siroki-11731.jpg \\
\hline 1289 & Bupleurum praealtum L. & Budapest & 1962 & Siroki Zoltán & DE-siroki-11733.jpg \\
\hline 1289 & Bupleurum praealtum L. & Pilismarót & 1963 & Siroki Zoltán & DE-siroki-11732.jpg \\
\hline 1291 & Bupleurum affine Sadler & Budaörs & 1951 & Siroki Zoltán & DE-siroki-12079.jpg \\
\hline 1291 & Bupleurum affine Sadler & Budaörs & 1954 & Siroki Zoltán & DE-siroki-12080.jpg \\
\hline 1291 & Bupleurum affine Sadler & Budaörs & 1954 & Siroki Zoltán & DE-siroki-12081.jpg \\
\hline 1291 & Bupleurum affine Sadler & Budaörs & 1951 & Siroki Zoltán & DE-siroki-12074.jpg \\
\hline 1291 & Bupleurum affine Sadler & Budapest & 1913 & Jávorka Sándor & DE-siroki-12077.jpg \\
\hline 1291 & Bupleurum affine Sadler & Budapest & 1950 & Siroki Zoltán & DE-siroki-12082.jpg \\
\hline 1291 & Bupleurum affine Sadler & Budapest & - & Kováts J. & DE-siroki-12076.jpg \\
\hline 1291 & Bupleurum affine Sadler & Pomáz & 1918 & Degen Árpád & DE-siroki-12075.jpg \\
\hline 1291 & Bupleurum affine Sadler & Szentendre & - & Degen Árpád & DE-siroki-12078.jpg \\
\hline 1292 & Bupleurum pachnospermum Pančić & Budapest & 1948 & Siroki Zoltán & DE-siroki-11736.jpg \\
\hline 1292 & Bupleurum pachnospermum Pančić & Budapest & 1948 & Siroki Zoltán & DE-siroki-11738.jpg \\
\hline 1292 & Bupleurum pachnospermum Pančić & Sátoraljaújhely & 1944 & Siroki Zoltán & DE-siroki-11741.jpg \\
\hline 1292 & Bupleurum pachnospermum Pančić & Sátoraljaújhely & 1944 & Siroki Zoltán & DE-siroki-11737.jpg \\
\hline 1292 & Bupleurum pachnospermum Pančić & Sátoraljaújhely & 1944 & Siroki Zoltán & DE-siroki-11734.jpg \\
\hline 1292 & Bupleurum pachnospermum Pančić & Sátoraljaújhely & 1944 & Siroki Zoltán & DE-siroki-11735.jpg \\
\hline 1292 & Bupleurum pachnospermum Pančić & Szentendre & 1895 & Borbás Vince & DE-siroki-11740.jpg \\
\hline 1292 & Bupleurum pachnospermum Pančić & Szentendre & - & Borbás Vince & DE-siroki-11739.jpg \\
\hline 1293 & Trinia glauca (L.) Dumort. & Abaújszántó & 1944 & Siroki Zoltán & DE-siroki-12107.jpg \\
\hline 1293 & Trinia glauca (L.) Dumort. & Budaörs & 1955 & $\begin{array}{l}\text { Siroki Zoltán - } \\
\text { Farkas Attila }\end{array}$ & DE-siroki-12105.jpg \\
\hline 1293 & Trinia glauca (L.) Dumort. & Budapest & 1951 & Siroki Zoltán & DE-siroki-12102.jpg \\
\hline 1293 & Trinia glauca (L.) Dumort. & Budapest & 1951 & Siroki Zoltán & DE-siroki-12103.jpg \\
\hline 1293 & Trinia glauca (L.) Dumort. & Budapest & 1981 & Siroki Zoltán & DE-siroki-12095.jpg \\
\hline 1293 & Trinia glauca (L.) Dumort. & Budapest & 1981 & Siroki Zoltán & DE-siroki-12096.jpg \\
\hline 1293 & Trinia glauca (L.) Dumort. & Budapest & 1981 & Siroki Zoltán & DE-siroki-12097.jpg \\
\hline 1293 & Trinia glauca (L.) Dumort. & Gödöllő & 1952 & Siroki Zoltán & DE-siroki-12106.jpg \\
\hline 1293 & Trinia glauca (L.) Dumort. & Nagykovácsi & 1959 & Siroki Zoltán & DE-siroki-12099.jpg \\
\hline 1293 & Trinia glauca (L.) Dumort. & Nagykovácsi & 1959 & Siroki Zoltán & DE-siroki-12100.jpg \\
\hline 1293 & Trinia glauca (L.) Dumort. & Pomáz & 1954 & Siroki Zoltán & DE-siroki-12101.jpg \\
\hline 1294 & $\begin{array}{l}\text { Trinia ramosissima } \\
\text { (Fisch.) W.D.J. Koch }\end{array}$ & Mátraverebély & 1952 & Siroki Zoltán & DE-siroki-12110.jpg \\
\hline 1294 & $\begin{array}{l}\text { Trinia ramosissima } \\
\text { (Fisch.) W.D.J. Koch }\end{array}$ & Mátraverebély & 1952 & Siroki Zoltán & DE-siroki-12111.jpg \\
\hline 1294 & $\begin{array}{l}\text { Trinia ramosissima } \\
\text { (Fisch.) W.D.J. Koch }\end{array}$ & Mátraverebély & 1953 & Siroki Zoltán & DE-siroki-12109.jpg \\
\hline 1294 & $\begin{array}{l}\text { Trinia ramosissima } \\
\text { (Fisch.) W.D.J. Koch }\end{array}$ & Mátraverebély & 1953 & Siroki Zoltán & DE-siroki-12108.jpg \\
\hline 1295 & Apium repens (Jacq.) Lag. & Debrecen & 1970 & Siroki Zoltán & DE-siroki-12112.jpg \\
\hline 1295 & Apium repens (Jacq.) Lag. & Debrecen & 1970 & Siroki Zoltán & DE-siroki-12113.jpg \\
\hline 1295 & Apium repens (Jacq.) Lag. & Debrecen & 1970 & Siroki Zoltán & DE-siroki-12114.jpg \\
\hline 1295 & Apium repens (Jacq.) Lag. & Debrecen & 1970 & Siroki Zoltán & DE-siroki-12115.jpg \\
\hline 1295 & Apium repens (Jacq.) Lag. & Debrecen & 1970 & Siroki Zoltán & DE-siroki-12116.jpg \\
\hline 1295 & Apium repens (Jacq.) Lag. & Dunaharaszti & 1951 & Siroki Zoltán & DE-siroki-12117.jpg \\
\hline
\end{tabular}




\begin{tabular}{|c|c|c|c|c|c|}
\hline $\begin{array}{l}\text { Sorszám / } \\
\text { Number }\end{array}$ & Taxon-név / Taxon-name & $\begin{array}{l}\text { Település / } \\
\text { Settlement }\end{array}$ & $\begin{array}{l}\text { Év / } \\
\text { Year }\end{array}$ & $\begin{array}{l}\text { Gyüjtő / } \\
\text { Collector }\end{array}$ & Fájlnév / File-name \\
\hline 1295 & Apium repens (Jacq.) Lag. & Dunaharaszti & 1954 & Siroki Zoltán & DE-siroki-12118.jpg \\
\hline 1295 & Apium repens (Jacq.) Lag. & Dunaharaszti & 1954 & Siroki Zoltán & DE-siroki-12119.jpg \\
\hline 1298 & Cicuta virosa $\mathrm{L}$. & Csaroda & 1960 & Siroki Zoltán & DE-siroki-12135.jpg \\
\hline 1298 & Cicuta virosa $\mathrm{L}$. & Egerbakta & 1968 & Siroki Zoltán & DE-siroki-12123.jpg \\
\hline 1298 & Cicuta virosa $\mathrm{L}$. & Egerbakta & 1968 & Siroki Zoltán & DE-siroki-12124.jpg \\
\hline 1298 & Cicuta virosa $\mathrm{L}$. & Egerbakta & 1968 & Siroki Zoltán & DE-siroki-12128.jpg \\
\hline 1298 & Cicuta virosa L. & Egerbakta & 1968 & Siroki Zoltán & DE-siroki-12131.jpg \\
\hline 1298 & Cicuta virosa L. & Egerbakta & 1968 & Siroki Zoltán & DE-siroki-12144.jpg \\
\hline 1298 & Cicuta virosa L. & Veresegyház & 1954 & Petrányi L. & DE-siroki-12129.jpg \\
\hline 1298 & Cicuta virosa $\mathrm{L}$. & Veresegyház & 1954 & Petrányi L. & DE-siroki-12130.jpg \\
\hline 1298 & Cicuta virosa L. & Veresegyház & 1954 & Siroki Zoltán & DE-siroki-12125.jpg \\
\hline 1298 & Cicuta virosa L. & Veresegyház & 1954 & Siroki Zoltán & DE-siroki-12126.jpg \\
\hline 1298 & Cicuta virosa $\mathrm{L}$. & Veresegyház & 1954 & Siroki Zoltán & DE-siroki-12127.jpg \\
\hline 1298 & Cicuta virosa L. & Veresegyház & 1954 & Siroki Zoltán & DE-siroki-12132.jpg \\
\hline 1298 & Cicuta virosa L. & Veresegyház & 1954 & Siroki Zoltán & DE-siroki-12133.jpg \\
\hline 1298 & Cicuta virosa $\mathrm{L}$. & Veresegyház & 1954 & Siroki Zoltán & DE-siroki-12134.jpg \\
\hline 1298 & Cicuta virosa L. & Veresegyház & 1954 & Siroki Zoltán & DE-siroki-12136.jpg \\
\hline 1298 & Cicuta virosa L. & Veresegyház & 1954 & Siroki Zoltán & DE-siroki-12137.jpg \\
\hline 1298 & Cicuta virosa $\mathrm{L}$. & Veresegyház & 1954 & Siroki Zoltán & DE-siroki-12140.jpg \\
\hline 1298 & Cicuta virosa L. & Veresegyház & 1954 & Siroki Zoltán & DE-siroki-12141.jpg \\
\hline 1298 & Cicuta virosa L. & Veresegyház & 1954 & Siroki Zoltán & DE-siroki-12142.jpg \\
\hline 1298 & Cicuta virosa $\mathrm{L}$. & Veresegyház & 1955 & Siroki Zoltán & DE-siroki-12138.jpg \\
\hline 1298 & Cicuta virosa L. & Veresegyház & 1955 & Siroki Zoltán & DE-siroki-12139.jpg \\
\hline 1298 & Cicuta virosa L. & Veresegyház & 1955 & Siroki Zoltán & DE-siroki-12143.jpg \\
\hline 1299 & Falcaria vulgaris Bernh. & Mosonmagyaróvár & 1939 & Siroki Zoltán & DE-siroki-12146.jpg \\
\hline 1300 & Carum carvi L. & "Háromkő" & 1957 & Siroki Zoltán & DE-siroki-12152.jpg \\
\hline 1300 & Carum carvi L. & "Nagymező" & 1968 & Siroki Zoltán & DE-siroki-12165.jpg \\
\hline 1300 & Carum carvi L. & "Nagymező" & 1973 & Siroki Zoltán & DE-siroki-12147.jpg \\
\hline 1300 & Carum carvi L. & "Nagymező" & 1973 & Siroki Zoltán & DE-siroki-12148.jpg \\
\hline 1300 & Carum carvi L. & "Nagymező" & 1973 & Siroki Zoltán & DE-siroki-12149.jpg \\
\hline 1300 & Carum carvi L. & Debrecen & 1955 & Siroki Zoltán & DE-siroki-12163.jpg \\
\hline 1300 & Carum carvi L. & Debrecen & 1955 & Siroki Zoltán & DE-siroki-12166.jpg \\
\hline 1300 & Carum carvi L. & Debrecen & 1955 & Siroki Zoltán & DE-siroki-12153.jpg \\
\hline 1300 & Carum carvi L. & Debrecen & 1955 & $\begin{array}{l}\text { Siroki Zoltán - } \\
\text { Farkas Attila }\end{array}$ & DE-siroki-12151.jpg \\
\hline 1300 & Carum carvi L. & Debrecen & 1955 & $\begin{array}{l}\text { Siroki Zoltán - } \\
\text { Farkas Attila }\end{array}$ & DE-siroki-12154.jpg \\
\hline 1300 & Carum carvi L. & Debrecen & 1955 & $\begin{array}{l}\text { Siroki Zoltán - } \\
\text { Farkas Attila }\end{array}$ & DE-siroki-12155.jpg \\
\hline 1300 & Carum carvi L. & Debrecen & 1955 & $\begin{array}{l}\text { Siroki Zoltán - } \\
\text { Farkas Attila }\end{array}$ & DE-siroki-12164.jpg \\
\hline 1300 & Carum carvi L. & Debrecen & 1976 & Siroki Zoltán & DE-siroki-12173.jpg \\
\hline 1300 & Carum carvi L. & Debrecen & 1976 & Siroki Zoltán & DE-siroki-12174.jpg \\
\hline 1300 & Carum carvi L. & Debrecen & 1978 & Siroki Zoltán & DE-siroki-12175.jpg \\
\hline 1300 & Carum carvi L. & Debrecen & 1978 & Siroki Zoltán & DE-siroki-12176.jpg \\
\hline 1300 & Carum carvi L. & Fehérgyarmat & 1975 & Siroki Zoltán & DE-siroki-12162.jpg \\
\hline 1300 & Carum carvi L. & Füzérradvány & 1973 & Siroki Zoltán & DE-siroki-12170.jpg \\
\hline 1300 & Carum carvi L. & Füzérradvány & 1973 & Siroki Zoltán & DE-siroki-12172.jpg \\
\hline 1300 & Carum carvi L. & Komlóska & 1973 & Siroki Zoltán & DE-siroki-12167.jpg \\
\hline
\end{tabular}




\begin{tabular}{|c|c|c|c|c|c|}
\hline $\begin{array}{l}\text { Sorszám / } \\
\text { Number }\end{array}$ & Taxon-név / Taxon-name & $\begin{array}{l}\text { Település / } \\
\text { Settlement }\end{array}$ & $\begin{array}{l}\text { Év / } \\
\text { Year }\end{array}$ & $\begin{array}{l}\text { Gyújtő / } \\
\text { Collector }\end{array}$ & Fájlnév / File-name \\
\hline 1300 & Carum carvi L. & Komlóska & 1973 & Siroki Zoltán & DE-siroki-12168.jpg \\
\hline 1300 & Carum carvi L. & Komlóska & 1973 & Siroki Zoltán & DE-siroki-12169.jpg \\
\hline 1300 & Carum carvi L. & Komlóska & 1973 & Siroki Zoltán & DE-siroki-12171.jpg \\
\hline 1301 & Cnidium dubium (Schkuhr) Thell. & Tatárszentgyörgy & 1950 & Kárpáti Zoltán & DE-siroki-13047.jpg \\
\hline 1301 & Cnidium dubium (Schkuhr) Thell. & Tiszafüred & 1970 & Siroki Zoltán & DE-siroki-13041.jpg \\
\hline 1301 & Cnidium dubium (Schkuhr) Thell. & Tiszafüred & 1970 & Siroki Zoltán & DE-siroki-13042.jpg \\
\hline 1301 & Cnidium dubium (Schkuhr) Thell. & Tiszafüred & 1970 & Siroki Zoltán & DE-siroki-13043.jpg \\
\hline 1301 & Cnidium dubium (Schkuhr) Thell. & Tiszafüred & 1970 & Siroki Zoltán & DE-siroki-13044.jpg \\
\hline 1301 & Cnidium dubium (Schkuhr) Thell. & Tiszafüred & 1970 & Siroki Zoltán & DE-siroki-13045.jpg \\
\hline 1301 & Cnidium dubium (Schkuhr) Thell. & Tiszafüred & 1970 & Siroki Zoltán & DE-siroki-13046.jpg \\
\hline 1301 & Cnidium dubium (Schkuhr) Thell. & Tiszafüred & 1970 & Siroki Zoltán & DE-siroki-13038.jpg \\
\hline 1301 & Cnidium dubium (Schkuhr) Thell. & Tiszafüred & 1973 & Siroki Zoltán & DE-siroki-13036.jpg \\
\hline 1301 & Cnidium dubium (Schkuhr) Thell. & Tiszafüred & 1973 & Siroki Zoltán & DE-siroki-13037.jpg \\
\hline 1301 & Cnidium dubium (Schkuhr) Thell. & Tiszafüred & 1973 & Siroki Zoltán & DE-siroki-13039.jpg \\
\hline 1301 & Cnidium dubium (Schkuhr) Thell. & Tiszafüred & 1973 & Siroki Zoltán & DE-siroki-13040.jpg \\
\hline 1302 & Selinum carvifolia L. & Csaroda & 1954 & Siroki Zoltán & DE-siroki-13019.jpg \\
\hline 1302 & Selinum carvifolia L. & Csaroda & 1954 & Siroki Zoltán & DE-siroki-13020.jpg \\
\hline 1302 & Selinum carvifolia L. & Csaroda & 1954 & Siroki Zoltán & DE-siroki-13021.jpg \\
\hline 1302 & Selinum carvifolia L. & Csaroda & 1954 & Siroki Zoltán & DE-siroki-13023.jpg \\
\hline 1302 & Selinum carvifolia L. & Csaroda & 1954 & Siroki Zoltán & DE-siroki-13032.jpg \\
\hline 1302 & Selinum carvifolia L. & Debrecen & 1951 & Siroki Zoltán & DE-siroki-13030.jpg \\
\hline 1302 & Selinum carvifolia L. & Debrecen & 1951 & Siroki Zoltán & DE-siroki-13031.jpg \\
\hline 1302 & Selinum carvifolia L. & Fehérgyarmat & 1975 & Siroki Zoltán & DE-siroki-13027.jpg \\
\hline 1302 & Selinum carvifolia L. & Fehérgyarmat & 1975 & Siroki Zoltán & DE-siroki-13028.jpg \\
\hline 1302 & Selinum carvifolia L. & Gödöllő & 1951 & Siroki Zoltán & DE-siroki-13022.jpg \\
\hline 1302 & Selinum carvifolia L. & Háromhuta & 1960 & Siroki Zoltán & DE-siroki-13024.jpg \\
\hline 1302 & Selinum carvifolia L. & Háromhuta & 1960 & Siroki Zoltán & DE-siroki-13025.jpg \\
\hline 1302 & Selinum carvifolia L. & Háromhuta & 1960 & Siroki Zoltán & DE-siroki-13026.jpg \\
\hline 1302 & Selinum carvifolia L. & Háromhuta & 1960 & Siroki Zoltán & DE-siroki-13033.jpg \\
\hline 1302 & Selinum carvifolia L. & Túristvándi & 1975 & Siroki Zoltán & DE-siroki-13029.jpg \\
\hline 1303 & Angelica palustris (Besser) Hoffm. & Debrecen & 1951 & Siroki Zoltán & DE-siroki-13009.jpg \\
\hline 1303 & Angelica palustris (Besser) Hoffm. & Debrecen & 1951 & Siroki Zoltán & DE-siroki-13012.jpg \\
\hline 1303 & Angelica palustris (Besser) Hoffm. & Debrecen & 1951 & Siroki Zoltán & DE-siroki-13013.jpg \\
\hline 1303 & Angelica palustris (Besser) Hoffm. & Debrecen & 1951 & Siroki Zoltán & DE-siroki-13004.jpg \\
\hline 1303 & Angelica palustris (Besser) Hoffm. & Debrecen & 1951 & Siroki Zoltán & DE-siroki-13005.jpg \\
\hline 1303 & Angelica palustris (Besser) Hoffm. & Debrecen & 1951 & Siroki Zoltán & DE-siroki-13006.jpg \\
\hline 1303 & Angelica palustris (Besser) Hoffm. & Debrecen & 1951 & Siroki Zoltán & DE-siroki-13007.jpg \\
\hline 1303 & Angelica palustris (Besser) Hoffm. & Debrecen & 1951 & Siroki Zoltán & DE-siroki-13008.jpg \\
\hline 1303 & Angelica palustris (Besser) Hoffm. & Debrecen & 1951 & Siroki Zoltán & DE-siroki-13010.jpg \\
\hline 1303 & Angelica palustris (Besser) Hoffm. & Debrecen & 1951 & Siroki Zoltán & DE-siroki-13011.jpg \\
\hline 1304 & Angelica sylvestris L. & Debrecen & 1947 & Siroki Zoltán & DE-siroki-12998.jpg \\
\hline 1304 & Angelica sylvestris L. & Debrecen & 1947 & Siroki Zoltán & DE-siroki-13000.jpg \\
\hline 1304 & Angelica sylvestris L. & Debrecen & 1950 & Siroki Zoltán & DE-siroki-12990.jpg \\
\hline 1304 & Angelica sylvestris L. & Dunaharaszti & 1951 & Siroki Zoltán & DE-siroki-13002.jpg \\
\hline 1304 & Angelica sylvestris L. & Dunaharaszti & 1951 & Siroki Zoltán & DE-siroki-13003.jpg \\
\hline 1304 & Angelica sylvestris L. & Gödöllő & 1951 & Siroki Zoltán & DE-siroki-12996.jpg \\
\hline
\end{tabular}




\begin{tabular}{|c|c|c|c|c|c|}
\hline $\begin{array}{l}\text { Sorszám / } \\
\text { Number }\end{array}$ & Taxon-név / Taxon-name & $\begin{array}{l}\text { Település / } \\
\text { Settlement }\end{array}$ & $\begin{array}{l}\text { Év / } \\
\text { Year }\end{array}$ & $\begin{array}{l}\text { Gyújitő / } \\
\text { Collector }\end{array}$ & Fájlnév / File-name \\
\hline 1304 & Angelica sylvestris L. & Gödöllő & 1951 & Siroki Zoltán & DE-siroki-12997.jpg \\
\hline 1304 & Angelica sylvestris L. & Gödöllő & 1951 & Siroki Zoltán & DE-siroki-12999.jpg \\
\hline 1304 & Angelica sylvestris L. & Gödöllő & 1951 & Siroki Zoltán & DE-siroki-13001.jpg \\
\hline 1304 & Angelica sylvestris L. & Mosonmagyaróvár & 1939 & Siroki Zoltán & DE-siroki-12983.jpg \\
\hline 1304 & Angelica sylvestris L. & Mosonmagyaróvár & 1939 & Siroki Zoltán & DE-siroki-12984.jpg \\
\hline 1304 & Angelica sylvestris L. & Nyírábrány & 1985 & Siroki Zoltán & DE-siroki-12991.jpg \\
\hline 1304 & Angelica sylvestris L. & Nyírábrány & 1985 & Siroki Zoltán & DE-siroki-12992.jpg \\
\hline 1304 & Angelica sylvestris L. & Nyírábrány & 1985 & Siroki Zoltán & DE-siroki-12993.jpg \\
\hline 1304 & Angelica sylvestris L. & Nyírábrány & 1985 & Siroki Zoltán & DE-siroki-12994.jpg \\
\hline 1304 & Angelica sylvestris L. & Nyírábrány & 1985 & Siroki Zoltán & DE-siroki-12995.jpg \\
\hline 1307 & Ferula sadleriana Ledeb. & "Gerecse" & 1986 & Csapody István & DE-siroki-12974.jpg \\
\hline 1307 & Ferula sadleriana Ledeb. & Lábatlan & 1986 & Csapody István & DE-siroki-12976.jpg \\
\hline 1307 & Ferula sadleriana Ledeb. & Lábatlan & 1986 & Csapody István & DE-siroki-12975.jpg \\
\hline 1309 & Peucedanum carvifolia Vill. & Budapest & 1948 & Siroki Zoltán & DE-siroki-12961.jpg \\
\hline 1309 & Peucedanum carvifolia Vill. & Budapest & 1948 & Siroki Zoltán & DE-siroki-12962.jpg \\
\hline 1309 & Peucedanum carvifolia Vill. & Budapest & 1948 & Siroki Zoltán & DE-siroki-12963.jpg \\
\hline 1309 & Peucedanum carvifolia Vill. & Budapest & 1948 & Siroki Zoltán & DE-siroki-12964.jpg \\
\hline 1309 & Peucedanum carvifolia Vill. & Budapest & 1948 & Siroki Zoltán & DE-siroki-12965.jpg \\
\hline 1309 & Peucedanum carvifolia Vill. & Regéc & 1962 & Siroki Zoltán & DE-siroki-12968.jpg \\
\hline 1309 & Peucedanum carvifolia Vill. & Regéc & 1962 & Siroki Zoltán & DE-siroki-12969.jpg \\
\hline 1309 & Peucedanum carvifolia Vill. & Regéc & 1963 & Siroki Zoltán & DE-siroki-12966.jpg \\
\hline 1309 & Peucedanum carvifolia Vill. & Regéc & 1963 & Siroki Zoltán & DE-siroki-12967.jpg \\
\hline 1310 & Peucedanum arenarium Waldst. et Kit. & "Csepel-sziget" & 1904 & Kocsis István & DE-siroki-12949.jpg \\
\hline 1310 & Peucedanum arenarium Waldst. et Kit. & Budapest & 1897 & Degen Árpád & DE-siroki-12954.jpg \\
\hline 1310 & Peucedanum arenarium Waldst. et Kit. & Budapest & 1897 & Degen Árpád & DE-siroki-12953.jpg \\
\hline 1310 & Peucedanum arenarium Waldst. et Kit. & Budapest & 1904 & Kocsis István & DE-siroki-12950.jpg \\
\hline 1310 & Peucedanum arenarium Waldst. et Kit. & Gödöllő & 1951 & Siroki Zoltán & DE-siroki-12955.jpg \\
\hline 1310 & Peucedanum arenarium Waldst. et Kit. & Nagykovácsi & 1950 & Siroki Zoltán & DE-siroki-12947.jpg \\
\hline 1310 & Peucedanum arenarium Waldst. et Kit. & Nagykovácsi & 1950 & Siroki Zoltán & DE-siroki-12948.jpg \\
\hline 1310 & Peucedanum arenarium Waldst. et Kit. & Nagykovácsi & 1950 & Siroki Zoltán & DE-siroki-12956.jpg \\
\hline 1310 & Peucedanum arenarium Waldst. et Kit. & Nagykovácsi & 1950 & Siroki Zoltán & DE-siroki-12958.jpg \\
\hline 1310 & Peucedanum arenarium Waldst. et Kit. & Nagykőrös & 1954 & Siroki Zoltán & DE-siroki-12957.jpg \\
\hline 1311 & Peucedanum officinale L. & Debrecen & 1947 & Siroki Zoltán & DE-siroki-12933.jpg \\
\hline 1311 & Peucedanum officinale L. & Debrecen & 1947 & Siroki Zoltán & DE-siroki-12938.jpg \\
\hline 1311 & Peucedanum officinale L. & Debrecen & 1947 & Siroki Zoltán & DE-siroki-12939.jpg \\
\hline 1311 & Peucedanum officinale L. & Debrecen & 1947 & Siroki Zoltán & DE-siroki-12941.jpg \\
\hline 1311 & Peucedanum officinale L. & Debrecen & 1947 & Siroki Zoltán & DE-siroki-12944.jpg \\
\hline 1311 & Peucedanum officinale L. & Egyek & 1947 & Siroki Zoltán & DE-siroki-12940.jpg \\
\hline 1311 & Peucedanum officinale L. & Egyek & 1947 & Siroki Zoltán & DE-siroki-12945.jpg \\
\hline 1311 & Peucedanum officinale L. & Egyek & 1947 & Siroki Zoltán & DE-siroki-12934.jpg \\
\hline 1311 & Peucedanum officinale L. & Egyek & 1947 & Siroki Zoltán & DE-siroki-12935.jpg \\
\hline 1311 & Peucedanum officinale L. & Egyek & 1947 & Siroki Zoltán & DE-siroki-12936.jpg \\
\hline 1311 & Peucedanum officinale L. & Egyek & 1947 & Siroki Zoltán & DE-siroki-12937.jpg \\
\hline 1311 & Peucedanum officinale L. & Mátészalka & 1975 & Siroki Zoltán & DE-siroki-12942.jpg \\
\hline 1311 & Peucedanum officinale L. & Mátészalka & 1975 & Siroki Zoltán & DE-siroki-12943.jpg \\
\hline 1312 & Peucedanum alsaticum L. & Budaörs & 1985 & Siroki Zoltán & DE-siroki-12928.jpg \\
\hline
\end{tabular}




\begin{tabular}{|c|c|c|c|c|c|}
\hline $\begin{array}{l}\text { Sorszám / } \\
\text { Number }\end{array}$ & Taxon-név / Taxon-name & $\begin{array}{l}\text { Település / } \\
\text { Settlement }\end{array}$ & $\begin{array}{l}\text { Év / } \\
\text { Year }\end{array}$ & $\begin{array}{l}\text { Gyűjtő / } \\
\text { Collector }\end{array}$ & Fájlnév / File-name \\
\hline 1312 & Peucedanum alsaticum L. & Budapest & 1941 & Siroki Zoltán & DE-siroki-12920.jpg \\
\hline 1312 & Peucedanum alsaticum L. & Budapest & 1985 & Siroki Zoltán & DE-siroki-12924.jpg \\
\hline 1312 & Peucedanum alsaticum L. & Budapest & 1985 & Siroki Zoltán & DE-siroki-12925.jpg \\
\hline 1312 & Peucedanum alsaticum L. & Budapest & 1985 & Siroki Zoltán & DE-siroki-12926.jpg \\
\hline 1312 & Peucedanum alsaticum L. & Budapest & 1985 & Siroki Zoltán & DE-siroki-12927.jpg \\
\hline 1312 & Peucedanum alsaticum L. & Egyek & 1947 & Siroki Zoltán & DE-siroki-12922.jpg \\
\hline 1312 & Peucedanum alsaticum L. & Egyek & 1947 & Siroki Zoltán & DE-siroki-12916.jpg \\
\hline 1312 & Peucedanum alsaticum L. & Egyek & 1947 & Siroki Zoltán & DE-siroki-12917.jpg \\
\hline 1312 & Peucedanum alsaticum L. & Egyek & 1947 & Siroki Zoltán & DE-siroki-12918.jpg \\
\hline 1312 & Peucedanum alsaticum L. & Egyek & 1947 & Siroki Zoltán & DE-siroki-12921.jpg \\
\hline 1312 & Peucedanum alsaticum L. & Egyek & 1947 & Siroki Zoltán & DE-siroki-12923.jpg \\
\hline 1312 & Peucedanum alsaticum L. & Egyek & 1947 & Siroki Zoltán & DE-siroki-12929.jpg \\
\hline 1313 & Peucedanum palustre (L.) Moench & Debrecen & 1958 & Siroki Zoltán & DE-siroki-12902.jpg \\
\hline 1313 & Peucedanum palustre (L.) Moench & Debrecen & 1958 & Siroki Zoltán & DE-siroki-12898.jpg \\
\hline 1313 & Peucedanum palustre (L.) Moench & Debrecen & 1958 & Siroki Zoltán & DE-siroki-12899.jpg \\
\hline 1313 & Peucedanum palustre (L.) Moench & Debrecen & 1958 & Siroki Zoltán & DE-siroki-12900.jpg \\
\hline 1313 & Peucedanum palustre (L.) Moench & Debrecen & 1958 & Siroki Zoltán & DE-siroki-12901.jpg \\
\hline 1313 & Peucedanum palustre (L.) Moench & Háromhuta & 1984 & Siroki Zoltán & DE-siroki-12911.jpg \\
\hline 1313 & Peucedanum palustre (L.) Moench & Háromhuta & 1984 & Siroki Zoltán & DE-siroki-12912.jpg \\
\hline 1313 & Peucedanum palustre (L.) Moench & Veresegyház & 1954 & Siroki Zoltán & DE-siroki-12904.jpg \\
\hline 1313 & Peucedanum palustre (L.) Moench & Veresegyház & 1954 & Siroki Zoltán & DE-siroki-12905.jpg \\
\hline 1313 & Peucedanum palustre (L.) Moench & Veresegyház & 1954 & Siroki Zoltán & DE-siroki-12906.jpg \\
\hline 1313 & Peucedanum palustre (L.) Moench & Veresegyház & 1954 & Siroki Zoltán & DE-siroki-12907.jpg \\
\hline 1313 & Peucedanum palustre (L.) Moench & Veresegyház & 1954 & Siroki Zoltán & DE-siroki-12908.jpg \\
\hline 1313 & Peucedanum palustre (L.) Moench & Veresegyház & 1954 & Siroki Zoltán & DE-siroki-12909.jpg \\
\hline 1313 & Peucedanum palustre (L.) Moench & Veresegyház & 1954 & Siroki Zoltán & DE-siroki-12910.jpg \\
\hline 1314 & Peucedanum cervaria (L.) Lapeyr. & "Vértes" & 1957 & Siroki Zoltán & DE-siroki-12892.jpg \\
\hline 1314 & Peucedanum cervaria (L.) Lapeyr. & Budapest & 1948 & Siroki Zoltán & DE-siroki-12887.jpg \\
\hline 1314 & Peucedanum cervaria (L.) Lapeyr. & Budapest & 1948 & Siroki Zoltán & DE-siroki-12888.jpg \\
\hline 1314 & Peucedanum cervaria (L.) Lapeyr. & Budapest & 1948 & Siroki Zoltán & DE-siroki-12889.jpg \\
\hline 1314 & Peucedanum cervaria (L.) Lapeyr. & Budapest & 1954 & Siroki Zoltán & DE-siroki-12890.jpg \\
\hline 1314 & Peucedanum cervaria (L.) Lapeyr. & Budapest & 1954 & Siroki Zoltán & DE-siroki-12891.jpg \\
\hline 1315 & Peucedanum oreoselinum (L.) Moench & "Vértes" & 1957 & Siroki Zoltán & DE-siroki-12883.jpg \\
\hline 1315 & Peucedanum oreoselinum (L.) Moench & Debrecen & 1947 & Siroki Zoltán & DE-siroki-12881.jpg \\
\hline 1315 & Peucedanum oreoselinum (L.) Moench & Debrecen & 1947 & Siroki Zoltán & DE-siroki-12882.jpg \\
\hline 1315 & Peucedanum oreoselinum (L.) Moench & Debrecen & 1947 & Siroki Zoltán & DE-siroki-12878.jpg \\
\hline 1315 & Peucedanum oreoselinum (L.) Moench & Debrecen & 1947 & Siroki Zoltán & DE-siroki-12879.jpg \\
\hline 1315 & Peucedanum oreoselinum (L.) Moench & Debrecen & 1947 & Siroki Zoltán & DE-siroki-12880.jpg \\
\hline 1316 & Pastinaca sativa L. & Debrecen & 1948 & Siroki Zoltán & DE-siroki-12874.jpg \\
\hline 1316 & Pastinaca sativa L. & Debrecen & 1948 & Siroki Zoltán & DE-siroki-12875.jpg \\
\hline 1316 & Pastinaca sativa L. & Debrecen & 1957 & Siroki Zoltán & DE-siroki-12877.jpg \\
\hline 1316 & Pastinaca sativa L. & Debrecen & 1957 & Siroki Zoltán & DE-siroki-12876.jpg \\
\hline 1316 & Pastinaca sativa L. & Máriakálnok & 1939 & Siroki Zoltán & DE-siroki-12872.jpg \\
\hline 1316 & Pastinaca sativa L. & Mosonmagyaróvár & 1939 & Siroki Zoltán & DE-siroki-12870.jpg \\
\hline 1316 & Pastinaca sativa L. & Mosonmagyaróvár & 1939 & Siroki Zoltán & DE-siroki-12871.jpg \\
\hline 1317 & Heracleum sphondylium L. & Budapest & 1909 & Kocsis István & DE-siroki-12867.jpg \\
\hline
\end{tabular}




\begin{tabular}{|c|c|c|c|c|c|}
\hline $\begin{array}{l}\text { Sorszám / } \\
\text { Number }\end{array}$ & Taxon-név / Taxon-name & $\begin{array}{l}\text { Település / } \\
\text { Settlement }\end{array}$ & $\begin{array}{l}\text { Év / } \\
\text { Year }\end{array}$ & $\begin{array}{l}\text { Gyűjtő / } \\
\text { Collector }\end{array}$ & Fájlnév / File-name \\
\hline 1317 & Heracleum sphondylium L. & Mosonmagyaróvár & 1939 & Siroki Zoltán & DE-siroki-12864.jpg \\
\hline 1317 & Heracleum sphondylium L. & Mosonmagyaróvár & 1939 & Siroki Zoltán & DE-siroki-12865.jpg \\
\hline 1320 & Tordylium maximum L. & Budapest & 1951 & Siroki Zoltán & DE-siroki-12855.jpg \\
\hline 1320 & Tordylium maximum L. & Mosonmagyaróvár & 1939 & Siroki Zoltán & DE-siroki-12863.jpg \\
\hline 1320 & Tordylium maximum L. & Pomáz & 1954 & Siroki Zoltán & DE-siroki-12856.jpg \\
\hline 1320 & Tordylium maximum L. & Pomáz & 1954 & Siroki Zoltán & DE-siroki-12861.jpg \\
\hline 1320 & Tordylium maximum L. & Sátoraljaújhely & 1944 & Siroki Zoltán & DE-siroki-12857.jpg \\
\hline 1320 & Tordylium maximum L. & Sátoraljaújhely & 1944 & Siroki Zoltán & DE-siroki-12858.jpg \\
\hline 1320 & Tordylium maximum L. & Sátoraljaújhely & 1944 & Siroki Zoltán & DE-siroki-12859.jpg \\
\hline 1320 & Tordylium maximum L. & Sátoraljaújhely & 1944 & Siroki Zoltán & DE-siroki-12860.jpg \\
\hline 1320 & Tordylium maximum L. & Sátoraljaújhely & 1944 & Siroki Zoltán & DE-siroki-12862.jpg \\
\hline 1321 & Laser trilobum (L.) Borkh. & Budapest & 1911 & Kocsis István & DE-siroki-12853.jpg \\
\hline 1321 & Laser trilobum (L.) Borkh. & Budapest & 1911 & Kocsis István & DE-siroki-12854.jpg \\
\hline 1321 & Laser trilobum (L.) Borkh. & Cserszegtomaj & 1955 & Siroki Zoltán & DE-siroki-12846.jpg \\
\hline 1321 & Laser trilobum (L.) Borkh. & Cserszegtomaj & 1955 & Siroki Zoltán & DE-siroki-12847.jpg \\
\hline 1321 & Laser trilobum (L.) Borkh. & Cserszegtomaj & 1955 & Siroki Zoltán & DE-siroki-12848.jpg \\
\hline 1321 & Laser trilobum (L.) Borkh. & Cserszegtomaj & 1955 & Siroki Zoltán & DE-siroki-12849.jpg \\
\hline 1321 & Laser trilobum (L.) Borkh. & Pécs & 1958 & Siroki Zoltán & DE-siroki-12850.jpg \\
\hline 1321 & Laser trilobum (L.) Borkh. & Pécs & 1958 & Siroki Zoltán & DE-siroki-12851.jpg \\
\hline 1322 & Laserpitium prutenicum L. & Miskolc & 1916 & Hulják János & DE-siroki-12845.jpg \\
\hline 1323 & Laserpitium latifolium L. & Budaörs & 1916 & Degen Árpád & DE-siroki-12831.jpg \\
\hline 1323 & Laserpitium latifolium L. & Budaörs & 1916 & Degen Árpád & DE-siroki-12832.jpg \\
\hline 1323 & Laserpitium latifolium L. & Budapest & 1951 & Siroki Zoltán & DE-siroki-12828.jpg \\
\hline 1323 & Laserpitium latifolium L. & Budapest & 1951 & Siroki Zoltán & DE-siroki-12829.jpg \\
\hline 1323 & Laserpitium latifolium L. & Gyenesdiás & 1955 & Siroki Zoltán & DE-siroki-12839.jpg \\
\hline 1323 & Laserpitium latifolium L. & Gyenesdiás & 1955 & Siroki Zoltán & DE-siroki-12840.jpg \\
\hline 1323 & Laserpitium latifolium L. & Hosszúhetény & 1954 & Siroki Zoltán & DE-siroki-12841.jpg \\
\hline 1323 & Laserpitium latifolium L. & Miskolc & 1965 & Siroki Zoltán & DE-siroki-12837.jpg \\
\hline 1323 & Laserpitium latifolium L. & Miskolc & 1965 & Siroki Zoltán & DE-siroki-12836.jpg \\
\hline 1323 & Laserpitium latifolium L. & Miskolc & 1965 & Siroki Zoltán & DE-siroki-12838.jpg \\
\hline 1324 & Torilis arvensis (Huds.) Link & Abaújszántó & 1943 & Siroki Zoltán & DE-siroki-11596.jpg \\
\hline 1324 & Torilis arvensis (Huds.) Link & Debrecen & 1947 & Siroki Zoltán & DE-siroki-11592.jpg \\
\hline 1324 & Torilis arvensis (Huds.) Link & Debrecen & 1947 & Siroki Zoltán & DE-siroki-11593.jpg \\
\hline 1324 & Torilis arvensis (Huds.) Link & Debrecen & 1947 & Siroki Zoltán & DE-siroki-11594.jpg \\
\hline 1325 & Torilis japonica (Houtt.) DC. & Debrecen & 1947 & Siroki Zoltán & DE-siroki-11604.jpg \\
\hline 1325 & Torilis japonica (Houtt.) DC. & Debrecen & 1947 & Siroki Zoltán & DE-siroki-11606.jpg \\
\hline 1325 & Torilis japonica (Houtt.) DC. & Hencida & 1983 & Siroki Zoltán & DE-siroki-11607.jpg \\
\hline 1325 & Torilis japonica (Houtt.) DC. & Hencida & 1983 & Siroki Zoltán & DE-siroki-11608.jpg \\
\hline 1325 & Torilis japonica (Houtt.) DC. & Hencida & 1983 & Siroki Zoltán & DE-siroki-11609.jpg \\
\hline 1325 & Torilis japonica (Houtt.) DC. & Hortobágy & 1947 & Siroki Zoltán & DE-siroki-11605.jpg \\
\hline 1325 & Torilis japonica (Houtt.) DC. & Mosonmagyaróvár & 1939 & Siroki Zoltán & DE-siroki-11598.jpg \\
\hline 1325 & Torilis japonica (Houtt.) DC. & Tokaj & 1966 & Siroki Zoltán & DE-siroki-11599.jpg \\
\hline 1325 & Torilis japonica (Houtt.) DC. & Tokaj & 1966 & Siroki Zoltán & DE-siroki-11600.jpg \\
\hline 1325 & Torilis japonica (Houtt.) DC. & Tokaj & 1966 & Siroki Zoltán & DE-siroki-11601.jpg \\
\hline 1325 & Torilis japonica (Houtt.) DC. & Tokaj & 1966 & Siroki Zoltán & DE-siroki-11602.jpg \\
\hline 1325 & Torilis japonica (Houtt.) DC. & Tokaj & 1966 & Siroki Zoltán & DE-siroki-11603.jpg \\
\hline
\end{tabular}




\begin{tabular}{|c|c|c|c|c|c|}
\hline $\begin{array}{l}\text { Sorszám / } \\
\text { Number }\end{array}$ & Taxon-név / Taxon-name & $\begin{array}{l}\text { Település / } \\
\text { Settlement }\end{array}$ & $\begin{array}{l}\text { Év / } \\
\text { Year }\end{array}$ & $\begin{array}{l}\text { Gyűjtő / } \\
\text { Collector }\end{array}$ & Fájlnév / File-name \\
\hline 1327 & Caucalis platycarpos L. & Berekböszörmény & 1970 & Siroki Zoltán & DE-siroki-11616.jpg \\
\hline 1327 & Caucalis platycarpos L. & Berettyóújfalu & 1959 & Siroki Zoltán & DE-siroki-11625.jpg \\
\hline 1327 & Caucalis platycarpos L. & Berettyóújfalu & 1959 & Siroki Zoltán & DE-siroki-11626.jpg \\
\hline 1327 & Caucalis platycarpos L. & Budapest & 1951 & Siroki Zoltán & DE-siroki-11631.jpg \\
\hline 1327 & Caucalis platycarpos L. & Budapest & 1962 & Siroki Zoltán & DE-siroki-11617.jpg \\
\hline 1327 & Caucalis platycarpos L. & Budapest & 1962 & Siroki Zoltán & DE-siroki-11633.jpg \\
\hline 1327 & Caucalis platycarpos L. & Budapest & 1962 & Siroki Zoltán & DE-siroki-11634.jpg \\
\hline 1327 & Caucalis platycarpos L. & Budapest & 1962 & Siroki Zoltán & DE-siroki-11635.jpg \\
\hline 1327 & Caucalis platycarpos L. & Debrecen & 1947 & Siroki Zoltán & DE-siroki-11623.jpg \\
\hline 1327 & Caucalis platycarpos L. & Debrecen & 1947 & Siroki Zoltán & DE-siroki-11624.jpg \\
\hline 1327 & Caucalis platycarpos L. & Debrecen & 1947 & Siroki Zoltán & DE-siroki-11629.jpg \\
\hline 1327 & Caucalis platycarpos L. & Egyek & 1947 & Siroki Zoltán & DE-siroki-11630.jpg \\
\hline 1327 & Caucalis platycarpos L. & Hajdúvid & 1966 & Gondola István & DE-siroki-11620.jpg \\
\hline 1327 & Caucalis platycarpos L. & Hajdúvid & 1966 & Gondola István & DE-siroki-11622.jpg \\
\hline 1327 & Caucalis platycarpos L. & Nyírábrány & 1966 & - & DE-siroki-11627.jpg \\
\hline 1327 & Caucalis platycarpos L. & Nyírábrány & 1966 & Gondola István & DE-siroki-11621.jpg \\
\hline 1327 & Caucalis platycarpos L. & Nyírábrány & 1966 & Gondola István & DE-siroki-11618.jpg \\
\hline 1327 & Caucalis platycarpos L. & Nyírábrány & 1966 & Gondola István & DE-siroki-11619.jpg \\
\hline 1328 & Turgenia latifolia (L.) Hoffm. & Debrecen & 1945 & Siroki Zoltán & DE-siroki-11615.jpg \\
\hline 1328 & Turgenia latifolia (L.) Hoffm. & Debrecen & 1947 & Siroki Zoltán & DE-siroki-11610.jpg \\
\hline 1328 & Turgenia latifolia (L.) Hoffm. & Debrecen & 1947 & Siroki Zoltán & DE-siroki-11613.jpg \\
\hline 1328 & Turgenia latifolia (L.) Hoffm. & Egyek & 1947 & Siroki Zoltán & DE-siroki-11614.jpg \\
\hline 1328 & Turgenia latifolia (L.) Hoffm. & Egyek & 1948 & Siroki Zoltán & DE-siroki-11612.jpg \\
\hline 1328 & Turgenia latifolia (L.) Hoffm. & Püspökladány & 1966 & Siroki Zoltán & DE-siroki-11611.jpg \\
\hline 1329 & Orlaya grandiflora (L.) Hoffm. & Budapest & 1940 & Siroki Zoltán & DE-siroki-11640.jpg \\
\hline 1329 & Orlaya grandiflora (L.) Hoffm. & Budapest & 1940 & Siroki Zoltán & DE-siroki-11641.jpg \\
\hline 1329 & Orlaya grandiflora (L.) Hoffm. & Budapest & 1944 & Siroki Zoltán & DE-siroki-11643.jpg \\
\hline 1329 & Orlaya grandiflora (L.) Hoffm. & Budapest & 1944 & Siroki Zoltán & DE-siroki-11642.jpg \\
\hline 1329 & Orlaya grandiflora (L.) Hoffm. & Budapest & 1944 & Siroki Zoltán & DE-siroki-11644.jpg \\
\hline 1329 & Orlaya grandiflora (L.) Hoffm. & Budapest & 1966 & Siroki Zoltán & DE-siroki-11637.jpg \\
\hline 1329 & Orlaya grandiflora (L.) Hoffm. & Budapest & 1966 & Siroki Zoltán & DE-siroki-11638.jpg \\
\hline 1329 & Orlaya grandiflora (L.) Hoffm. & Budapest & 1966 & Siroki Zoltán & DE-siroki-11639.jpg \\
\hline 1330 & Daucus carota L. & Debrecen & 1947 & Siroki Zoltán & DE-siroki-12822.jpg \\
\hline 1330 & Daucus carota L. & Debrecen & 1957 & Siroki Zoltán & DE-siroki-12821.jpg \\
\hline 1330 & Daucus carota L. & Nyírábrány & 1985 & Siroki Zoltán & DE-siroki-12823.jpg \\
\hline 1330 & Daucus carota L. & Nyírábrány & 1985 & Siroki Zoltán & DE-siroki-12824.jpg \\
\hline 1331 & Pyrola minor L. & "Nagymező" & 1959 & Siroki Zoltán & DE-siroki-12780.jpg \\
\hline 1331 & Pyrola minor L. & Háromhuta & 1955 & Simon Tiborné & DE-siroki-12787.jpg \\
\hline 1331 & Pyrola minor L. & Háromhuta & 1960 & Siroki Zoltán & DE-siroki-12789.jpg \\
\hline 1331 & Pyrola minor L. & Háromhuta & 1960 & Siroki Zoltán & DE-siroki-12781.jpg \\
\hline 1331 & Pyrola minor L. & Háromhuta & 1960 & Siroki Zoltán & DE-siroki-12782.jpg \\
\hline 1331 & Pyrola minor L. & Háromhuta & 1960 & Siroki Zoltán & DE-siroki-12783.jpg \\
\hline 1331 & Pyrola minor L. & Háromhuta & 1960 & Siroki Zoltán & DE-siroki-12788.jpg \\
\hline 1331 & Pyrola minor L. & Háromhuta & 1961 & Siroki Zoltán & DE-siroki-12784.jpg \\
\hline 1331 & Pyrola minor L. & Háromhuta & 1961 & Siroki Zoltán & DE-siroki-12785.jpg \\
\hline 1331 & Pyrola minor L. & Háromhuta & 1961 & Siroki Zoltán & DE-siroki-12786.jpg \\
\hline
\end{tabular}




\begin{tabular}{|c|c|c|c|c|c|}
\hline $\begin{array}{l}\text { Sorszám / } \\
\text { Number }\end{array}$ & Taxon-név / Taxon-name & $\begin{array}{l}\text { Település / } \\
\text { Settlement }\end{array}$ & $\begin{array}{l}\text { Év / } \\
\text { Year }\end{array}$ & $\begin{array}{l}\text { Gyüjtő / } \\
\text { Collector }\end{array}$ & Fájlnév / File-name \\
\hline 1333 & Pyrola rotundifolia L. & Miskolc & 1959 & Siroki Zoltán & DE-siroki-12795.jpg \\
\hline 1335 & Orthilia secunda (L.) House & Háromhuta & 1955 & Simon Tiborné & DE-siroki-12801.jpg \\
\hline 1335 & Orthilia secunda (L.) House & Háromhuta & 1960 & Siroki Zoltán & DE-siroki-12803.jpg \\
\hline 1335 & Orthilia secunda (L.) House & Miskolc & 1959 & Siroki Zoltán & DE-siroki-12800.jpg \\
\hline 1335 & Orthilia secunda (L.) House & Pálháza & 1951 & Kárpáti Zoltán & DE-siroki-12798.jpg \\
\hline 1335 & Orthilia secunda (L.) House & Pásztó & 1952 & Siroki Zoltán & DE-siroki-12802.jpg \\
\hline 1335 & Orthilia secunda (L.) House & Pásztó & 1952 & Siroki Zoltán & DE-siroki-12797.jpg \\
\hline 1335 & Orthilia secunda (L.) House & Pásztó & 1952 & Siroki Zoltán & DE-siroki-12799.jpg \\
\hline 1336 & Moneses uniflora (L.) A. Gray & Háromhuta & 1960 & Siroki Zoltán & DE-siroki-12805.jpg \\
\hline 1336 & Moneses uniflora (L.) A. Gray & Háromhuta & 1960 & Siroki Zoltán & DE-siroki-12806.jpg \\
\hline 1336 & Moneses uniflora (L.) A. Gray & Háromhuta & 1960 & Siroki Zoltán & DE-siroki-12807.jpg \\
\hline 1338 & Monotropa hypopitys L. & "Bükk-hg." & 1960 & Siroki Zoltán & DE-siroki-12775.jpg \\
\hline 1338 & Monotropa hypopitys L. & "Bükk-hg." & 1960 & Siroki Zoltán & DE-siroki-12776.jpg \\
\hline 1338 & Monotropa hypopitys L. & "Bükk-hg." & 1960 & Siroki Zoltán & DE-siroki-12777.jpg \\
\hline 1340 & Calluna vulgaris (L.) Hull & Kishuta & 1954 & Siroki Zoltán & DE-siroki-13090.jpg \\
\hline 1340 & Calluna vulgaris (L.) Hull & Nagyhuta & 1954 & Simon Tiborné & DE-siroki-13086.jpg \\
\hline 1340 & Calluna vulgaris (L.) Hull & Nagyhuta & 1954 & Simon Tiborné & DE-siroki-13087.jpg \\
\hline 1340 & Calluna vulgaris (L.) Hull & Nagyhuta & 1962 & Siroki Zoltán & DE-siroki-13095.jpg \\
\hline 1340 & Calluna vulgaris (L.) Hull & Pécs & 1958 & Koppányi Tibor & DE-siroki-13105.jpg \\
\hline 1340 & Calluna vulgaris (L.) Hull & Sopron & 1956 & Kovács Béla & DE-siroki-13089.jpg \\
\hline 1340 & Calluna vulgaris (L.) Hull & Sopron & 1956 & Siroki Zoltán & DE-siroki-13085.jpg \\
\hline 1340 & Calluna vulgaris (L.) Hull & Uzsa & 1955 & Kovács Béla & DE-siroki-13092.jpg \\
\hline 1340 & Calluna vulgaris (L.) Hull & Uzsa & 1955 & Kovács Béla & DE-siroki-13076.jpg \\
\hline 1340 & Calluna vulgaris (L.) Hull & Uzsa & 1955 & Kovács Béla & DE-siroki-13077.jpg \\
\hline 1340 & Calluna vulgaris (L.) Hull & Uzsa & 1955 & Kovács Béla & DE-siroki-13078.jpg \\
\hline 1340 & Calluna vulgaris (L.) Hull & Uzsa & 1955 & Kovács Béla & DE-siroki-13079.jpg \\
\hline 1340 & Calluna vulgaris (L.) Hull & Uzsa & 1955 & Kovács Béla & DE-siroki-13080.jpg \\
\hline 1340 & Calluna vulgaris (L.) Hull & Uzsa & 1955 & Kovács Béla & DE-siroki-13081.jpg \\
\hline 1340 & Calluna vulgaris (L.) Hull & Uzsa & 1955 & Kovács Béla & DE-siroki-13082.jpg \\
\hline 1340 & Calluna vulgaris (L.) Hull & Uzsa & 1955 & Kovács Béla & DE-siroki-13083.jpg \\
\hline 1340 & Calluna vulgaris (L.) Hull & Uzsa & 1955 & Kovács Béla & DE-siroki-13084.jpg \\
\hline 1340 & Calluna vulgaris (L.) Hull & Uzsa & 1955 & Kovács Béla & DE-siroki-13088.jpg \\
\hline 1340 & Calluna vulgaris (L.) Hull & Uzsa & 1971 & Siroki Zoltán & DE-siroki-13093.jpg \\
\hline 1340 & Calluna vulgaris (L.) Hull & Uzsa & 1971 & Siroki Zoltán & DE-siroki-13094.jpg \\
\hline 1342 & Vaccinium oxycoccos L. & Csaroda & 1954 & Simon Tiborné & DE-siroki-13074.jpg \\
\hline 1342 & Vaccinium oxycoccos L. & Csaroda & 1954 & Simon Tiborné & DE-siroki-13075.jpg \\
\hline 1342 & Vaccinium oxycoccos L. & Csaroda & 1954 & Simon Tiborné & DE-siroki-13060.jpg \\
\hline 1342 & Vaccinium oxycoccos L. & Csaroda & 1954 & Simon Tiborné & DE-siroki-13061.jpg \\
\hline 1342 & Vaccinium oxycoccos L. & Csaroda & 1954 & Siroki Zoltán & DE-siroki-13057.jpg \\
\hline 1342 & Vaccinium oxycoccos L. & Csaroda & 1954 & Siroki Zoltán & DE-siroki-13058.jpg \\
\hline 1342 & Vaccinium oxycoccos L. & Csaroda & 1954 & Siroki Zoltán & DE-siroki-13059.jpg \\
\hline 1342 & Vaccinium oxycoccos L. & Csaroda & 1959 & Siroki Zoltán & DE-siroki-13062.jpg \\
\hline 1342 & Vaccinium oxycoccos L. & Csaroda & 1959 & Siroki Zoltán & DE-siroki-13063.jpg \\
\hline 1342 & Vaccinium oxycoccos L. & Csaroda & 1959 & Siroki Zoltán & DE-siroki-13064.jpg \\
\hline 1342 & Vaccinium oxycoccos L. & Csaroda & 1959 & Siroki Zoltán & DE-siroki-13065.jpg \\
\hline 1342 & Vaccinium oxycoccos L. & Csaroda & 1959 & Siroki Zoltán & DE-siroki-13066.jpg \\
\hline
\end{tabular}




\begin{tabular}{|c|c|c|c|c|c|}
\hline $\begin{array}{l}\text { Sorszám / } \\
\text { Number }\end{array}$ & Taxon-név / Taxon-name & $\begin{array}{l}\text { Település / } \\
\text { Settlement }\end{array}$ & $\begin{array}{l}\text { Év / } \\
\text { Year }\end{array}$ & $\begin{array}{l}\text { Gyűjtő / } \\
\text { Collector }\end{array}$ & Fájlnév / File-name \\
\hline 1342 & Vaccinium oxycoccos L. & Csaroda & 1959 & Siroki Zoltán & DE-siroki-13067.jpg \\
\hline 1342 & Vaccinium oxycoccos L. & Csaroda & 1959 & Siroki Zoltán & DE-siroki-13068.jpg \\
\hline 1342 & Vaccinium oxycoccos L. & Csaroda & 1959 & Siroki Zoltán & DE-siroki-13069.jpg \\
\hline 1342 & Vaccinium oxycoccos L. & Csaroda & 1960 & Siroki Zoltán & DE-siroki-13070.jpg \\
\hline 1342 & Vaccinium oxycoccos L. & Csaroda & 1960 & Siroki Zoltán & DE-siroki-13071.jpg \\
\hline 1342 & Vaccinium oxycoccos L. & Csaroda & 1960 & Siroki Zoltán & DE-siroki-13072.jpg \\
\hline 1342 & Vaccinium oxycoccos L. & Csaroda & 1960 & Siroki Zoltán & DE-siroki-13073.jpg \\
\hline 1343 & Vaccinium vitis-idaea L. & Háromhuta & 1955 & Siroki Zoltán & DE-siroki-12751.jpg \\
\hline 1343 & Vaccinium vitis-idaea L. & Háromhuta & 1955 & Siroki Zoltán & DE-siroki-12749.jpg \\
\hline 1343 & Vaccinium vitis-idaea L. & Háromhuta & 1960 & Siroki Zoltán & DE-siroki-12747.jpg \\
\hline 1343 & Vaccinium vitis-idaea L. & Háromhuta & 1960 & Siroki Zoltán & DE-siroki-12745.jpg \\
\hline 1343 & Vaccinium vitis-idaea L. & Háromhuta & 1960 & Siroki Zoltán & DE-siroki-12746.jpg \\
\hline 1343 & Vaccinium vitis-idaea L. & Háromhuta & 1960 & Siroki Zoltán & DE-siroki-12753.jpg \\
\hline 1343 & Vaccinium vitis-idaea L. & Háromhuta & 1960 & Siroki Zoltán & DE-siroki-12754.jpg \\
\hline 1343 & Vaccinium vitis-idaea L. & Háromhuta & 1984 & Siroki Zoltán & DE-siroki-12755.jpg \\
\hline 1343 & Vaccinium vitis-idaea L. & Kishuta & 1954 & Simon Tiborné & DE-siroki-12744.jpg \\
\hline 1343 & Vaccinium vitis-idaea L. & Nagyhuta & 1954 & Simon Tiborné & DE-siroki-12750.jpg \\
\hline 1344 & Vaccinium myrtillus L. & Háromhuta & 1960 & Siroki Zoltán & DE-siroki-12736.jpg \\
\hline 1344 & Vaccinium myrtillus L. & Háromhuta & 1960 & Siroki Zoltán & DE-siroki-12737.jpg \\
\hline 1344 & Vaccinium myrtillus L. & Háromhuta & 1960 & Siroki Zoltán & DE-siroki-12738.jpg \\
\hline 1344 & Vaccinium myrtillus L. & Háromhuta & 1960 & Siroki Zoltán & DE-siroki-12739.jpg \\
\hline 1344 & Vaccinium myrtillus L. & Háromhuta & 1960 & Siroki Zoltán & DE-siroki-12740.jpg \\
\hline 1344 & Vaccinium myrtillus L. & Háromhuta & 1984 & Siroki Zoltán & DE-siroki-12741.jpg \\
\hline 1344 & Vaccinium myrtillus L. & Kishuta & 1954 & Siroki Zoltán & DE-siroki-13051.jpg \\
\hline 1344 & Vaccinium myrtillus L. & Nagyhuta & 1954 & Simon Tiborné & DE-siroki-13049.jpg \\
\hline 1344 & Vaccinium myrtillus L. & Sopron & 1956 & Kovács Béla & DE-siroki-12735.jpg \\
\hline 1344 & Vaccinium myrtillus L. & Sopron & 1956 & Kovács Béla & DE-siroki-13050.jpg \\
\hline 1347 & Primula vulgaris Huds. & "Zalavár" & 1951 & Kovács Béla & DE-siroki-13106.jpg \\
\hline 1347 & Primula vulgaris Huds. & Gyenesdiás & 1972 & Siroki Zoltán & DE-siroki-13107.jpg \\
\hline 1348 & Primula veris L. & "Dobogókő" & 1957 & Siroki Zoltán & DE-siroki-13113.jpg \\
\hline 1348 & Primula veris L. & "Dobogókő" & 1957 & Siroki Zoltán & DE-siroki-13114.jpg \\
\hline 1348 & Primula veris L. & "Fáni-völgy" & 1955 & $\begin{array}{l}\text { Siroki Zoltán - } \\
\text { Farkas Attila }\end{array}$ & DE-siroki-13111.jpg \\
\hline 1348 & Primula veris L. & "Fáni-völgy" & 1955 & $\begin{array}{l}\text { Siroki Zoltán - } \\
\text { Farkas Attila }\end{array}$ & DE-siroki-13112.jpg \\
\hline 1348 & Primula veris L. & "Nagymező" & 1965 & Siroki Zoltán & DE-siroki-13116.jpg \\
\hline 1348 & Primula veris L. & Budapest & 1909 & Kocsis István & DE-siroki-13118.jpg \\
\hline 1348 & Primula veris L. & Debrecen & 1949 & Siroki Zoltán & DE-siroki-13108.jpg \\
\hline 1348 & Primula veris $\mathrm{L}$. & Debrecen & 1964 & Siroki Zoltán & DE-siroki-13119.jpg \\
\hline 1348 & Primula veris L. & Debrecen & 1964 & Siroki Zoltán & DE-siroki-13120.jpg \\
\hline 1348 & Primula veris L. & Debrecen & 1964 & Siroki Zoltán & DE-siroki-13121.jpg \\
\hline 1348 & Primula veris L. & Miskolc & 1964 & Siroki Zoltán & DE-siroki-13115.jpg \\
\hline 1348 & Primula veris L. & Miskolc & 1964 & Siroki Zoltán & DE-siroki-13117.jpg \\
\hline 1348 & Primula veris $\mathrm{L}$. & Szarvaskő & 1958 & Siroki Zoltán & DE-siroki-13110.jpg \\
\hline 1349 & Primula elatior (L.) Hill & "Bánkút" & 1966 & Siroki Zoltán & DE-siroki-13128.jpg \\
\hline 1349 & Primula elatior (L.) Hill & "Bánkút" & 1966 & Siroki Zoltán & DE-siroki-13129.jpg \\
\hline 1349 & Primula elatior (L.) Hill & Miskolc & 1966 & Siroki Zoltán & DE-siroki-13127.jpg \\
\hline
\end{tabular}




\begin{tabular}{|c|c|c|c|c|c|}
\hline $\begin{array}{l}\text { Sorszám / } \\
\text { Number }\end{array}$ & Taxon-név / Taxon-name & $\begin{array}{l}\text { Település / } \\
\text { Settlement }\end{array}$ & $\begin{array}{l}\text { Év / } \\
\text { Year }\end{array}$ & $\begin{array}{l}\text { Gyújtő / } \\
\text { Collector }\end{array}$ & Fájlnév / File-name \\
\hline $\begin{array}{c}1347 \times \\
1348\end{array}$ & $\begin{array}{l}\text { Primula } \times \text { brevistyla DC. } \\
(\text { P. vulgaris } \times \text { veris })\end{array}$ & Gyenesdiás & 1972 & Siroki Zoltán & DE-siroki-13122.jpg \\
\hline $\begin{array}{c}1347 \times \\
1348\end{array}$ & $\begin{array}{l}\text { Primula } \times \text { brevistyla DC. } \\
\text { (P. vulgaris } \times \text { veris) }\end{array}$ & Gyenesdiás & 1972 & Siroki Zoltán & DE-siroki-13123.jpg \\
\hline $\begin{array}{c}1347 \times \\
1348\end{array}$ & $\begin{array}{l}\text { Primula } \times \text { brevistyla DC. } \\
\text { (P. vulgaris } \times \text { veris })\end{array}$ & Gyenesdiás & 1972 & Siroki Zoltán & DE-siroki-13140.jpg \\
\hline $\begin{array}{c}1347 \times \\
1348\end{array}$ & $\begin{array}{l}\text { Primula } \times \text { brevistyla DC. } \\
\text { (P. vulgaris } \times \text { veris })\end{array}$ & Gyenesdiás & 1972 & Siroki Zoltán & DE-siroki-13141.jpg \\
\hline $\begin{array}{c}1347 \times \\
1348\end{array}$ & $\begin{array}{l}\text { Primula } \times \text { brevistyla DC. } \\
\text { (P. vulgaris } \times \text { veris) }\end{array}$ & Gyenesdiás & 1972 & Siroki Zoltán & DE-siroki-13142.jpg \\
\hline 1350 & Androsace maxima L. & Baracska & 1951 & Siroki Zoltán & DE-siroki-13148.jpg \\
\hline 1350 & Androsace maxima L. & Budapest & 1880 & Richter Lajos & DE-siroki-13170.jpg \\
\hline 1350 & Androsace maxima L. & Budapest & 1906 & Kocsis István & DE-siroki-13144.jpg \\
\hline 1350 & Androsace maxima L. & Budapest & 1928 & Rigler József & DE-siroki-13145.jpg \\
\hline 1350 & Androsace maxima L. & Budapest & 1951 & Siroki Zoltán & DE-siroki-13150.jpg \\
\hline 1350 & Androsace maxima L. & Budapest & 1951 & Siroki Zoltán & DE-siroki-13143.jpg \\
\hline 1350 & Androsace maxima L. & Budapest & 1951 & Siroki Zoltán & DE-siroki-13147.jpg \\
\hline 1350 & Androsace maxima L. & Budapest & 1951 & Siroki Zoltán & DE-siroki-13149.jpg \\
\hline 1350 & Androsace maxima L. & Budapest & 1951 & Siroki Zoltán & DE-siroki-13146.jpg \\
\hline 1351 & Androsace elongata L. & Debrecen & 1951 & Siroki Zoltán & DE-siroki-13157.jpg \\
\hline 1351 & Androsace elongata L. & Debrecen & 1958 & Halász Tibor & DE-siroki-13155.jpg \\
\hline 1351 & Androsace elongata L. & Debrecen & 1958 & Halász Tibor & DE-siroki-13156.jpg \\
\hline 1351 & Androsace elongata L. & Hajdúböszörmény & 1966 & Gondola István & DE-siroki-13152.jpg \\
\hline 1351 & Androsace elongata L. & Hajdúböszörmény & 1966 & Gondola István & DE-siroki-13153.jpg \\
\hline 1351 & Androsace elongata L. & Hajdúböszörmény & 1966 & Gondola István & DE-siroki-13151.jpg \\
\hline 1351 & Androsace elongata L. & Hajdúböszörmény & 1967 & Gondola István & DE-siroki-13154.jpg \\
\hline 1351 & Androsace elongata L. & Pomáz & 1951 & Siroki Zoltán & DE-siroki-13159.jpg \\
\hline 1351 & Androsace elongata L. & Pomáz & 1951 & Siroki Zoltán & DE-siroki-13158.jpg \\
\hline 1352 & Hottonia palustris L. & Debrecen & 1954 & Kovács Béla & DE-siroki-13189.jpg \\
\hline 1352 & Hottonia palustris L. & Debrecen & 1954 & Siroki Zoltán & DE-siroki-13195.jpg \\
\hline 1352 & Hottonia palustris L. & Debrecen & 1954 & Siroki Zoltán & DE-siroki-13196.jpg \\
\hline 1352 & Hottonia palustris L. & Debrecen & 1954 & Siroki Zoltán & DE-siroki-13191.jpg \\
\hline 1352 & Hottonia palustris L. & Debrecen & 1954 & Siroki Zoltán & DE-siroki-13192.jpg \\
\hline 1352 & Hottonia palustris L. & Debrecen & 1954 & Siroki Zoltán & DE-siroki-13193.jpg \\
\hline 1352 & Hottonia palustris L. & Debrecen & 1954 & Siroki Zoltán & DE-siroki-13194.jpg \\
\hline 1352 & Hottonia palustris L. & Debrecen & 1954 & Siroki Zoltán & DE-siroki-13197.jpg \\
\hline 1352 & Hottonia palustris L. & Debrecen & 1954 & Siroki Zoltán & DE-siroki-13188.jpg \\
\hline 1352 & Hottonia palustris L. & Debrecen & 1955 & $\begin{array}{l}\text { Siroki Zoltán - } \\
\text { Farkas Attila }\end{array}$ & DE-siroki-13190.jpg \\
\hline 1352 & Hottonia palustris L. & Debrecen & 1972 & Siroki Zoltán & DE-siroki-13187.jpg \\
\hline 1353 & Cyclamen purpurascens Mill. & Sopron & 1949 & Farkas József & DE-siroki-13260.jpg \\
\hline 1354 & Lysimachia nummularia L. & Gyula & 1974 & Siroki Zoltán & DE-siroki-13206.jpg \\
\hline 1357 & Lysimachia punctata L. & "Dobogókő" & 1957 & Siroki Zoltán & DE-siroki-13223.jpg \\
\hline 1357 & Lysimachia punctata L. & "Dobogókő" & 1965 & Siroki Zoltán & DE-siroki-13222.jpg \\
\hline 1357 & Lysimachia punctata L. & Balatonederics & 1955 & Siroki Zoltán & DE-siroki-13230.jpg \\
\hline 1357 & Lysimachia punctata L. & Pécs & 1954 & Siroki Zoltán & DE-siroki-13229.jpg \\
\hline 1357 & Lysimachia punctata L. & Pécs & 1954 & Siroki Zoltán & DE-siroki-13235.jpg \\
\hline 1357 & Lysimachia punctata L. & Pécs & 1954 & Siroki Zoltán & DE-siroki-13234.jpg \\
\hline 1357 & Lysimachia punctata L. & Pécs & 1954 & Siroki Zoltán & DE-siroki-13233.jpg \\
\hline 1357 & Lysimachia punctata L. & Pécs & 1954 & Siroki Zoltán & DE-siroki-13227.jpg \\
\hline
\end{tabular}




\begin{tabular}{|c|c|c|c|c|c|}
\hline $\begin{array}{l}\text { Sorszám / } \\
\text { Number }\end{array}$ & Taxon-név / Taxon-name & $\begin{array}{l}\text { Település / } \\
\text { Settlement }\end{array}$ & $\begin{array}{l}\text { Év / } \\
\text { Year }\end{array}$ & $\begin{array}{l}\text { Gyűjtő / } \\
\text { Collector }\end{array}$ & Fájlnév / File-name \\
\hline 1357 & Lysimachia punctata L. & Pécs & 1954 & Siroki Zoltán & DE-siroki-13228.jpg \\
\hline 1357 & Lysimachia punctata L. & Pécs & 1954 & Siroki Zoltán & DE-siroki-13226.jpg \\
\hline 1357 & Lysimachia punctata L. & Pécs & 1954 & Siroki Zoltán & DE-siroki-13224.jpg \\
\hline 1357 & Lysimachia punctata L. & Pécs & 1954 & Siroki Zoltán & DE-siroki-13225.jpg \\
\hline 1357 & Lysimachia punctata L. & Rezi & 1955 & Siroki Zoltán & DE-siroki-13231.jpg \\
\hline 1357 & Lysimachia punctata L. & Rezi & 1955 & Siroki Zoltán & DE-siroki-13232.jpg \\
\hline 1358 & Lysimachia vulgaris L. & Debrecen & 1950 & Siroki Zoltán & DE-siroki-13218.jpg \\
\hline 1358 & Lysimachia vulgaris L. & Debrecen & 1959 & Siroki Zoltán & DE-siroki-13217.jpg \\
\hline 1358 & Lysimachia vulgaris L. & Felsőtárkány & 1963 & Halász Tibor & DE-siroki-13216.jpg \\
\hline 1358 & Lysimachia vulgaris L. & Mosonmagyaróvár & 1939 & Siroki Zoltán & DE-siroki-13219.jpg \\
\hline 1358 & Lysimachia vulgaris L. & Mosonmagyaróvár & 1939 & Siroki Zoltán & DE-siroki-13220.jpg \\
\hline 1358 & Lysimachia vulgaris L. & Mosonmagyaróvár & 1939 & Siroki Zoltán & DE-siroki-13221.jpg \\
\hline 1358 & Lysimachia vulgaris L. & Vámospércs & 1984 & Siroki Zoltán & DE-siroki-13213.jpg \\
\hline 1358 & Lysimachia vulgaris L. & Vámospércs & 1984 & Siroki Zoltán & DE-siroki-13214.jpg \\
\hline 1358 & Lysimachia vulgaris L. & Vámospércs & 1984 & Siroki Zoltán & DE-siroki-13215.jpg \\
\hline 1360 & Centunculus minimus L. & Tornyospálca & 1967 & Gondola István & DE-siroki-13247.jpg \\
\hline 1360 & Centunculus minimus L. & Tornyospálca & 1967 & Gondola István & DE-siroki-13248.jpg \\
\hline 1360 & Centunculus minimus L. & Tuzsér & 1965 & Gondola István & DE-siroki-13250.jpg \\
\hline 1360 & Centunculus minimus L. & Tuzsér & 1965 & Gondola István & DE-siroki-13251.jpg \\
\hline 1360 & Centunculus minimus L. & Tuzsér & 1965 & Gondola István & DE-siroki-13252.jpg \\
\hline 1360 & Centunculus minimus L. & Tuzsér & 1965 & Gondola István & DE-siroki-13253.jpg \\
\hline 1360 & Centunculus minimus L. & Tuzsér & 1965 & Gondola István & DE-siroki-13254.jpg \\
\hline 1360 & Centunculus minimus L. & Tuzsér & 1965 & Gondola István & DE-siroki-13255.jpg \\
\hline 1360 & Centunculus minimus L. & Tuzsér & 1965 & Gondola István & DE-siroki-13256.jpg \\
\hline 1360 & Centunculus minimus L. & Tuzsér & 1965 & Gondola István & DE-siroki-13257.jpg \\
\hline 1360 & Centunculus minimus L. & Tuzsér & 1965 & Gondola István & DE-siroki-13258.jpg \\
\hline 1360 & Centunculus minimus L. & Tuzsér & 1965 & Gondola István & DE-siroki-13259.jpg \\
\hline 1360 & Centunculus minimus L. & Tuzsér & 1967 & Gondola István & DE-siroki-13245.jpg \\
\hline 1360 & Centunculus minimus L. & Tuzsér & 1967 & Gondola István & DE-siroki-13246.jpg \\
\hline 1361 & Anagallis arvensis L. & Debrecen & 1947 & Siroki Zoltán & DE-siroki-13240.jpg \\
\hline 1361 & Anagallis arvensis L. & Mosonmagyaróvár & 1939 & Siroki Zoltán & DE-siroki-13242.jpg \\
\hline 1362 & Anagallis foemina Mill. & Mosonmagyaróvár & 1939 & Siroki Zoltán & DE-siroki-13243.jpg \\
\hline 1362 & Anagallis foemina Mill. & Mosonmagyaróvár & 1939 & Siroki Zoltán & DE-siroki-13244.jpg \\
\hline 1363 & Samolus valerandi L. & Budapest & 1917 & Degen Árpád & DE-siroki-13201.jpg \\
\hline 1363 & Samolus valerandi L. & Csehi & 1954 & - & DE-siroki-13198.jpg \\
\hline 1363 & Samolus valerandi $\mathrm{L}$. & Csehi & 1954 & - & DE-siroki-13199.jpg \\
\hline 1363 & Samolus valerandi $\mathrm{L}$. & Keszthely & 1928 & Rigler József & DE-siroki-13200.jpg \\
\hline 1363 & Samolus valerandi L. & Keszthely & 1955 & Siroki Zoltán & DE-siroki-13205.jpg \\
\hline 1363 & Samolus valerandi $\mathrm{L}$. & Keszthely & 1955 & Siroki Zoltán & DE-siroki-13202.jpg \\
\hline 1363 & Samolus valerandi L. & Keszthely & 1955 & Siroki Zoltán & DE-siroki-13203.jpg \\
\hline 1363 & Samolus valerandi L. & Keszthely & 1955 & Siroki Zoltán & DE-siroki-13204.jpg \\
\hline 1366 & Limonium gmelinii (Willd.) Kuntze & Budaörs & 1941 & Siroki Zoltán & DE-siroki-13264.jpg \\
\hline 1366 & Limonium gmelinii (Willd.) Kuntze & Budaörs & 1941 & Siroki Zoltán & DE-siroki-13265.jpg \\
\hline 1366 & Limonium gmelinii (Willd.) Kuntze & Budaörs & 1941 & Siroki Zoltán & DE-siroki-13266.jpg \\
\hline 1366 & Limonium gmelinii (Willd.) Kuntze & Dévaványa & 1962 & Siroki Zoltán & DE-siroki-13267.jpg \\
\hline 1366 & Limonium gmelinii (Willd.) Kuntze & Dévaványa & 1962 & Siroki Zoltán & DE-siroki-13268.jpg \\
\hline
\end{tabular}




\begin{tabular}{|c|c|c|c|c|c|}
\hline $\begin{array}{l}\text { Sorszám / } \\
\text { Number }\end{array}$ & Taxon-név / Taxon-name & $\begin{array}{l}\text { Település / } \\
\text { Settlement }\end{array}$ & $\begin{array}{l}\text { Év / } \\
\text { Year }\end{array}$ & $\begin{array}{l}\text { Gyüjtő / } \\
\text { Collector }\end{array}$ & Fájlnév / File-name \\
\hline 1366 & Limonium gmelinii (Willd.) Kuntze & Hortobágy & 1947 & Siroki Zoltán & DE-siroki-13270.jpg \\
\hline 1366 & Limonium gmelinii (Willd.) Kuntze & Hortobágy & 1947 & Siroki Zoltán & DE-siroki-13269.jpg \\
\hline 1366 & Limonium gmelinii (Willd.) Kuntze & Hortobágy & 1947 & Siroki Zoltán & DE-siroki-13263.jpg \\
\hline 1372 & Fraxinus ornus L. & "Fáni-völgy" & 1955 & Siroki Zoltán & DE-siroki-13282.jpg \\
\hline 1372 & Fraxinus ornus L. & "Fáni-völgy" & 1955 & $\begin{array}{l}\text { Siroki Zoltán - } \\
\text { Farkas Attila }\end{array}$ & DE-siroki-13279.jpg \\
\hline 1372 & Fraxinus ornus L. & "Fáni-völgy" & 1955 & $\begin{array}{l}\text { Siroki Zoltán - } \\
\text { Farkas Attila }\end{array}$ & DE-siroki-13280.jpg \\
\hline 1372 & Fraxinus ornus L. & Budapest & 1950 & Siroki Zoltán & DE-siroki-13278.jpg \\
\hline 1372 & Fraxinus ornus L. & Gyenesdiás & 1953 & Siroki Zoltán & DE-siroki-13281.jpg \\
\hline 1372 & Fraxinus ornus L. & Gyenesdiás & 1953 & Siroki Zoltán & DE-siroki-13283.jpg \\
\hline 1372 & Fraxinus ornus L. & Pécs & 1958 & Siroki Zoltán & DE-siroki-13275.jpg \\
\hline 1372 & Fraxinus ornus L. & Pécs & 1958 & Siroki Zoltán & DE-siroki-13276.jpg \\
\hline 1372 & Fraxinus ornus L. & Pécs & 1958 & Siroki Zoltán & DE-siroki-13277.jpg \\
\hline 1373 & Fraxinus pennsylvanica Marshall & Debrecen & 1948 & Siroki Zoltán & DE-siroki-13306.jpg \\
\hline 1373 & Fraxinus pennsylvanica Marshall & Debrecen & 1950 & Siroki Zoltán & DE-siroki-13305.jpg \\
\hline 1373 & Fraxinus pennsylvanica Marshall & Debrecen & 1955 & Siroki Zoltán & DE-siroki-13302.jpg \\
\hline 1373 & Fraxinus pennsylvanica Marshall & Debrecen & 1955 & Siroki Zoltán & DE-siroki-13303.jpg \\
\hline 1373 & Fraxinus pennsylvanica Marshall & Egyek & 1947 & Siroki Zoltán & DE-siroki-13304.jpg \\
\hline 1373 & Fraxinus pennsylvanica Marshall & Hortobágy & - & Siroki Zoltán & DE-siroki-13298.jpg \\
\hline 1373 & Fraxinus pennsylvanica Marshall & Hortobágy & - & Siroki Zoltán & DE-siroki-13299.jpg \\
\hline 1373 & Fraxinus pennsylvanica Marshall & Hortobágy & - & Siroki Zoltán & DE-siroki-13301.jpg \\
\hline 1373 & Fraxinus pennsylvanica Marshall & Hortobágy & - & Siroki Zoltán & DE-siroki-13300.jpg \\
\hline 1375 & Fraxinus excelsior L. & "Vértes" & 1957 & Siroki Zoltán & DE-siroki-13287.jpg \\
\hline 1375 & Fraxinus excelsior L. & "Vértes" & 1957 & Siroki Zoltán & DE-siroki-13294.jpg \\
\hline 1375 & Fraxinus excelsior L. & Debrecen & 1948 & Siroki Zoltán & DE-siroki-13286.jpg \\
\hline 1375 & Fraxinus excelsior L. & Debrecen & 1974 & $\begin{array}{l}\text { Pankucsi } \\
\text { Lászlóné }\end{array}$ & DE-siroki-13285.jpg \\
\hline 1376 & Fraxinus angustifolia Vahl & Debrecen & 1976 & Siroki Zoltán & DE-siroki-13297.jpg \\
\hline 1376 & Fraxinus angustifolia Vahl & Újléta & 1967 & Siroki Zoltán & DE-siroki-13288.jpg \\
\hline 1376 & Fraxinus angustifolia Vahl & Újléta & 1967 & Siroki Zoltán & DE-siroki-13289.jpg \\
\hline 1376 & Fraxinus angustifolia Vahl & Újléta & 1967 & Siroki Zoltán & DE-siroki-13290.jpg \\
\hline 1376 & Fraxinus angustifolia Vahl & Újléta & 1967 & Siroki Zoltán & DE-siroki-13291.jpg \\
\hline 1376 & Fraxinus angustifolia Vahl & Újléta & 1967 & Siroki Zoltán & DE-siroki-13292.jpg \\
\hline 1376 & Fraxinus angustifolia Vahl & Újléta & 1967 & Siroki Zoltán & DE-siroki-13293.jpg \\
\hline 1378 & Ligustrum vulgare L. & Debrecen & 1950 & Siroki Zoltán & DE-siroki-13325.jpg \\
\hline 1378 & Ligustrum vulgare $\mathrm{L}$. & Debrecen & 1950 & Siroki Zoltán & DE-siroki-13320.jpg \\
\hline 1378 & Ligustrum vulgare $\mathrm{L}$. & Debrecen & 1986 & Siroki Zoltán & DE-siroki-13321.jpg \\
\hline 1378 & Ligustrum vulgare L. & Debrecen & 1986 & Siroki Zoltán & DE-siroki-13322.jpg \\
\hline 1378 & Ligustrum vulgare $\mathrm{L}$. & Debrecen & 1986 & Siroki Zoltán & DE-siroki-13323.jpg \\
\hline 1378 & Ligustrum vulgare L. & Mátraszentimre & 1959 & Gondola István & DE-siroki-13324.jpg \\
\hline 1380 & $\begin{array}{l}\text { Blackstonia acuminata } \\
\text { (W.D.J. Koch et Ziz) Domin }\end{array}$ & Szigetszentmiklós & 1951 & Siroki Zoltán & DE-siroki-13350.jpg \\
\hline 1381 & Centaurium littorale (Turner) Gilmour & Ágasegyháza & 1956 & Siroki Zoltán & DE-siroki-13331.jpg \\
\hline 1381 & Centaurium littorale (Turner) Gilmour & Ágasegyháza & 1956 & Siroki Zoltán & DE-siroki-13332.jpg \\
\hline 1381 & Centaurium littorale (Turner) Gilmour & Budapest & 1909 & Kocsis István & DE-siroki-13330.jpg \\
\hline 1381 & Centaurium littorale (Turner) Gilmour & Debrecen & 1978 & Siroki Zoltán & DE-siroki-13328.jpg \\
\hline 1381 & Centaurium littorale (Turner) Gilmour & Keszthely & 1955 & Siroki Zoltán & DE-siroki-13335.jpg \\
\hline 1381 & Centaurium littorale (Turner) Gilmour & Szigetszentmiklós & 1951 & Siroki Zoltán & DE-siroki-13333.jpg \\
\hline
\end{tabular}




\begin{tabular}{|c|c|c|c|c|c|}
\hline $\begin{array}{l}\text { Sorszám / } \\
\text { Number }\end{array}$ & Taxon-név / Taxon-name & $\begin{array}{l}\text { Település / } \\
\text { Settlement }\end{array}$ & $\begin{array}{l}\text { Év / } \\
\text { Year }\end{array}$ & $\begin{array}{l}\text { Gyüjtő / } \\
\text { Collector }\end{array}$ & Fájlnév / File-name \\
\hline 1381 & Centaurium littorale (Turner) Gilmour & Szigetszentmiklós & 1951 & Siroki Zoltán & DE-siroki-13334.jpg \\
\hline 1381 & Centaurium littorale (Turner) Gilmour & Vámospércs & 1984 & Siroki Zoltán & DE-siroki-13329.jpg \\
\hline 1382 & Centaurium pulchellum (Sw.) Druce & Debrecen & 1947 & Siroki Zoltán & DE-siroki-13346.jpg \\
\hline 1382 & Centaurium pulchellum (Sw.) Druce & Debrecen & 1981 & Siroki Zoltán & DE-siroki-13344.jpg \\
\hline 1382 & Centaurium pulchellum (Sw.) Druce & Hortobágy & 1948 & Siroki Zoltán & DE-siroki-13349.jpg \\
\hline 1382 & Centaurium pulchellum (Sw.) Druce & Hortobágy & 1948 & Siroki Zoltán & DE-siroki-13345.jpg \\
\hline 1382 & Centaurium pulchellum (Sw.) Druce & Sátoraljaújhely & 1944 & Siroki Zoltán & DE-siroki-13347.jpg \\
\hline 1383 & Centaurium erythraea Raf. & Budapest & 1941 & Siroki Zoltán & DE-siroki-13342.jpg \\
\hline 1383 & Centaurium erythraea Raf. & Hajdúbagos & 1982 & Siroki Zoltán & DE-siroki-13337.jpg \\
\hline 1383 & Centaurium erythraea Raf. & Hajdúbagos & 1982 & Siroki Zoltán & DE-siroki-13339.jpg \\
\hline 1383 & Centaurium erythraea Raf. & Mosonmagyaróvár & 1939 & Siroki Zoltán & DE-siroki-13343.jpg \\
\hline 1383 & Centaurium erythraea Raf. & Tokaj & 1966 & Siroki Zoltán & DE-siroki-13336.jpg \\
\hline 1383 & Centaurium erythraea Raf. & Tokaj & 1966 & Siroki Zoltán & DE-siroki-13338.jpg \\
\hline 1383 & Centaurium erythraea Raf. & Tokaj & 1966 & Siroki Zoltán & DE-siroki-13340.jpg \\
\hline 1383 & Centaurium erythraea Raf. & Tokaj & 1966 & Siroki Zoltán & DE-siroki-13341.jpg \\
\hline 1384 & Gentiana cruciata L. & "Nagymező" & 1958 & Siroki Zoltán & DE-siroki-13353.jpg \\
\hline 1384 & Gentiana cruciata L. & "Nagymező" & 1958 & Siroki Zoltán & DE-siroki-13367.jpg \\
\hline 1384 & Gentiana cruciata L. & Balatonederics & 1955 & Siroki Zoltán & DE-siroki-13361.jpg \\
\hline 1384 & Gentiana cruciata L. & Balatonederics & 1955 & Siroki Zoltán & DE-siroki-13363.jpg \\
\hline 1384 & Gentiana cruciata L. & Balatonederics & 1955 & Siroki Zoltán & DE-siroki-13364.jpg \\
\hline 1384 & Gentiana cruciata L. & Bükkzsérc & 1963 & Halász Tibor & DE-siroki-13354.jpg \\
\hline 1384 & Gentiana cruciata L. & Bükkzsérc & 1963 & Halász Tibor & DE-siroki-13355.jpg \\
\hline 1384 & Gentiana cruciata L. & Bükkzsérc & 1963 & Halász Tibor & DE-siroki-13356.jpg \\
\hline 1384 & Gentiana cruciata L. & Háromhuta & 1968 & Siroki Zoltán & DE-siroki-13359.jpg \\
\hline 1384 & Gentiana cruciata L. & Miskolc & 1965 & Siroki Zoltán & DE-siroki-13357.jpg \\
\hline 1384 & Gentiana cruciata L. & Miskolc & 1965 & Siroki Zoltán & DE-siroki-13358.jpg \\
\hline 1384 & Gentiana cruciata L. & Miskolc & 1965 & Siroki Zoltán & DE-siroki-13360.jpg \\
\hline 1384 & Gentiana cruciata L. & Miskolc & 1978 & $\begin{array}{l}\text { Pankucsi } \\
\text { Lászlóné }\end{array}$ & DE-siroki-13352.jpg \\
\hline 1384 & Gentiana cruciata L. & Nagykovácsi & 1957 & Siroki Zoltán & DE-siroki-13365.jpg \\
\hline 1384 & Gentiana cruciata L. & Nagykovácsi & 1957 & Siroki Zoltán & DE-siroki-13366.jpg \\
\hline 1384 & Gentiana cruciata L. & Pásztó & 1952 & Siroki Zoltán & DE-siroki-13368.jpg \\
\hline 1384 & Gentiana cruciata L. & Pásztó & 1952 & Siroki Zoltán & DE-siroki-13369.jpg \\
\hline 1384 & Gentiana cruciata L. & Pásztó & 1952 & Siroki Zoltán & DE-siroki-13362.jpg \\
\hline 1385 & Gentiana pneumonanthe L. & "Nagymező" & 1958 & Siroki Zoltán & DE-siroki-13375.jpg \\
\hline 1385 & Gentiana pneumonanthe L. & "Nagymező" & 1968 & Siroki Zoltán & DE-siroki-13376.jpg \\
\hline 1385 & Gentiana pneumonanthe L. & Debrecen & 1949 & Siroki Zoltán & DE-siroki-13378.jpg \\
\hline 1385 & Gentiana pneumonanthe L. & Debrecen & 1951 & Siroki Zoltán & DE-siroki-13377.jpg \\
\hline 1385 & Gentiana pneumonanthe L. & Háromhuta & 1984 & Siroki Zoltán & DE-siroki-13374.jpg \\
\hline 1387 & Gentianopsis ciliata (L.) Ma & "Bánkút" & 1959 & Siroki Zoltán & DE-siroki-13388.jpg \\
\hline 1387 & Gentianopsis ciliata (L.) Ma & "Bánkút" & 1959 & Siroki Zoltán & DE-siroki-13389.jpg \\
\hline 1387 & Gentianopsis ciliata (L.) Ma & Dédestapolcsány & 1955 & Jeney Endre & DE-siroki-13390.jpg \\
\hline 1388 & $\begin{array}{l}\text { Gentianella austriaca } \\
\text { (A. Kern. et J. Kern.) Holub }\end{array}$ & "Háromkő" & 1956 & Halász Tibor & DE-siroki-13403.jpg \\
\hline 1388 & $\begin{array}{l}\text { Gentianella austriaca } \\
\text { (A. Kern. et J. Kern.) Holub }\end{array}$ & "Nagymező" & 1927 & Hulják János & DE-siroki-13410.jpg \\
\hline 1388 & $\begin{array}{l}\text { Gentianella austriaca } \\
\text { (A. Kern. et J. Kern.) Holub }\end{array}$ & "Nagymező" & 1959 & Siroki Zoltán & DE-siroki-13406.jpg \\
\hline
\end{tabular}




\begin{tabular}{|c|c|c|c|c|c|}
\hline $\begin{array}{l}\text { Sorszám / } \\
\text { Number }\end{array}$ & Taxon-név / Taxon-name & $\begin{array}{l}\text { Település / } \\
\text { Settlement }\end{array}$ & $\begin{array}{l}\text { Év / } \\
\text { Year }\end{array}$ & $\begin{array}{l}\text { Gyújtő / } \\
\text { Collector }\end{array}$ & Fájlnév / File-name \\
\hline 1388 & $\begin{array}{l}\text { Gentianella austriaca } \\
\text { (A. Kern. et J. Kern.) Holub }\end{array}$ & "Nagymező" & 1959 & Siroki Zoltán & DE-siroki-13405.jpg \\
\hline 1388 & $\begin{array}{l}\text { Gentianella austriaca } \\
\text { (A. Kern. et J. Kern.) Holub }\end{array}$ & "Nagymező" & 1959 & Siroki Zoltán & DE-siroki-13411.jpg \\
\hline 1388 & $\begin{array}{l}\text { Gentianella austriaca } \\
\text { (A. Kern. et J. Kern.) Holub }\end{array}$ & "Nagymező" & 1960 & Siroki Zoltán & DE-siroki-13412.jpg \\
\hline 1388 & $\begin{array}{l}\text { Gentianella austriaca } \\
\text { (A. Kern. et J. Kern.) Holub }\end{array}$ & "Nagymező" & 1960 & Siroki Zoltán & DE-siroki-13413.jpg \\
\hline 1388 & $\begin{array}{l}\text { Gentianella austriaca } \\
\text { (A. Kern. et J. Kern.) Holub }\end{array}$ & "Nagymező" & 1960 & Siroki Zoltán & DE-siroki-13414.jpg \\
\hline 1388 & $\begin{array}{l}\text { Gentianella austriaca } \\
\text { (A. Kern. et J. Kern.) Holub }\end{array}$ & Háromhuta & 1976 & Siroki Zoltán & DE-siroki-13398.jpg \\
\hline 1388 & $\begin{array}{l}\text { Gentianella austriaca } \\
\text { (A. Kern. et J. Kern.) Holub }\end{array}$ & Lébény & 1924 & $\begin{array}{l}\text { Boros Ádám - } \\
\text { Polgár Sándor }\end{array}$ & DE-siroki-13409.jpg \\
\hline 1388 & $\begin{array}{l}\text { Gentianella austriaca } \\
\text { (A. Kern. et J. Kern.) Holub }\end{array}$ & Szilvásvárad & 1951 & Kárpáti Zoltán & DE-siroki-13399.jpg \\
\hline 1389 & Gentianella amarella (L.) Börner & "Háromkő" & 1956 & Halász Tibor & DE-siroki-13395.jpg \\
\hline 1389 & Gentianella amarella (L.) Börner & "Nagymező" & 1956 & Halász Tibor & DE-siroki-13396.jpg \\
\hline 1389 & Gentianella amarella (L.) Börner & Miskolc & 1917 & Hulják János & DE-siroki-13394.jpg \\
\hline 1390 & Menyanthes trifoliata L. & Csaroda & 1954 & Siroki Zoltán & DE-siroki-13419.jpg \\
\hline 1390 & Menyanthes trifoliata L. & Debrecen & 1947 & Siroki Zoltán & DE-siroki-13431.jpg \\
\hline 1390 & Menyanthes trifoliata L. & Debrecen & 1948 & Siroki Zoltán & DE-siroki-13428.jpg \\
\hline 1390 & Menyanthes trifoliata L. & Debrecen & 1948 & Siroki Zoltán & DE-siroki-13418.jpg \\
\hline 1390 & Menyanthes trifoliata L. & Debrecen & 1958 & Siroki Zoltán & DE-siroki-13421.jpg \\
\hline 1390 & Menyanthes trifoliata L. & Debrecen & 1958 & Siroki Zoltán & DE-siroki-13422.jpg \\
\hline 1390 & Menyanthes trifoliata L. & Debrecen & 1958 & Siroki Zoltán & DE-siroki-13423.jpg \\
\hline 1390 & Menyanthes trifoliata L. & Debrecen & 1958 & Siroki Zoltán & DE-siroki-13424.jpg \\
\hline 1390 & Menyanthes trifoliata L. & Debrecen & 1958 & Siroki Zoltán & DE-siroki-13426.jpg \\
\hline 1390 & Menyanthes trifoliata L. & Debrecen & 1958 & Siroki Zoltán & DE-siroki-13427.jpg \\
\hline 1390 & Menyanthes trifoliata L. & Debrecen & 1958 & Siroki Zoltán & DE-siroki-13429.jpg \\
\hline 1390 & Menyanthes trifoliata L. & Debrecen & 1958 & Siroki Zoltán & DE-siroki-13430.jpg \\
\hline 1390 & Menyanthes trifoliata L. & Egerbakta & 1968 & Siroki Zoltán & DE-siroki-13420.jpg \\
\hline 1390 & Menyanthes trifoliata L. & Nyíracsád & 1984 & Siroki Zoltán & DE-siroki-13425.jpg \\
\hline 1391 & $\begin{array}{l}\text { Nymphoides peltata } \\
\text { (S.G. Gmel.) Kuntze }\end{array}$ & Tiszafüred & 1949 & Siroki Zoltán & DE-siroki-13432.jpg \\
\hline 1391 & $\begin{array}{l}\text { Nymphoides peltata } \\
\text { (S.G. Gmel.) Kuntze }\end{array}$ & Tiszafüred & 1949 & Siroki Zoltán & DE-siroki-13437.jpg \\
\hline 1391 & $\begin{array}{l}\text { Nymphoides peltata } \\
\text { (S.G. Gmel.) Kuntze }\end{array}$ & Tiszafüred & 1949 & Siroki Zoltán & DE-siroki-13438.jpg \\
\hline 1391 & $\begin{array}{l}\text { Nymphoides peltata } \\
\text { (S.G. Gmel.) Kuntze }\end{array}$ & Újszentmargita & 1963 & Siroki Zoltán & DE-siroki-13433.jpg \\
\hline 1391 & $\begin{array}{l}\text { Nymphoides peltata } \\
\text { (S.G. Gmel.) Kuntze }\end{array}$ & Újszentmargita & 1963 & Siroki Zoltán & DE-siroki-13434.jpg \\
\hline 1391 & $\begin{array}{l}\text { Nymphoides peltata } \\
\text { (S.G. Gmel.) Kuntze }\end{array}$ & Újszentmargita & 1963 & Siroki Zoltán & DE-siroki-13435.jpg \\
\hline 1391 & $\begin{array}{l}\text { Nymphoides peltata } \\
\text { (S.G. Gmel.) Kuntze }\end{array}$ & Újszentmargita & 1963 & Siroki Zoltán & DE-siroki-13436.jpg \\
\hline 1392 & Vinca herbacea Waldst. et Kit. & Abaújszántó & 1944 & Siroki Zoltán & DE-siroki-13451.jpg \\
\hline 1392 & Vinca herbacea Waldst. et Kit. & Abaújszántó & 1944 & Siroki Zoltán & DE-siroki-13452.jpg \\
\hline 1392 & Vinca herbacea Waldst. et Kit. & Abaújszántó & 1944 & Siroki Zoltán & DE-siroki-13453.jpg \\
\hline 1392 & Vinca herbacea Waldst. et Kit. & Budapest & 1951 & Siroki Zoltán & DE-siroki-13450.jpg \\
\hline 1392 & Vinca herbacea Waldst. et Kit. & Budapest & 1964 & Siroki Zoltán & DE-siroki-13448.jpg \\
\hline 1392 & Vinca herbacea Waldst. et Kit. & Budapest & 1964 & Siroki Zoltán & DE-siroki-13449.jpg \\
\hline 1392 & Vinca herbacea Waldst. et Kit. & Budapest & 1970 & Siroki Zoltán & DE-siroki-13447.jpg \\
\hline
\end{tabular}




\begin{tabular}{|c|c|c|c|c|c|}
\hline $\begin{array}{l}\text { Sorszám / } \\
\text { Number }\end{array}$ & Taxon-név / Taxon-name & $\begin{array}{l}\text { Település / } \\
\text { Settlement }\end{array}$ & $\begin{array}{l}\text { Év / } \\
\text { Year }\end{array}$ & $\begin{array}{l}\text { Gyűjtő / } \\
\text { Collector }\end{array}$ & Fájlnév / File-name \\
\hline 1393 & Vinca minor L. & Pilismarót & 1957 & Siroki Zoltán & DE-siroki-13440.jpg \\
\hline 1393 & Vinca minor L. & Pilismarót & 1957 & Siroki Zoltán & DE-siroki-13441.jpg \\
\hline 1393 & Vinca minor L. & Pilismarót & 1957 & Siroki Zoltán & DE-siroki-13442.jpg \\
\hline 1393 & Vinca minor L. & Tarpa & 1971 & Siroki Zoltán & DE-siroki-13439.jpg \\
\hline 1395 & Asclepias syriaca L. & Debrecen & 1948 & Siroki Zoltán & DE-siroki-13455.jpg \\
\hline 1395 & Asclepias syriaca L. & Fényeslitke & 1966 & Gondola István & DE-siroki-13454.jpg \\
\hline 1396 & Vincetoxicum hirundinaria Medik. & Debrecen & 1948 & Siroki Zoltán & DE-siroki-13458.jpg \\
\hline 1396 & Vincetoxicum hirundinaria Medik. & Debrecen & 1954 & Siroki Zoltán & DE-siroki-13459.jpg \\
\hline 1396 & Vincetoxicum hirundinaria Medik. & Debrecen & 1954 & Siroki Zoltán & DE-siroki-13460.jpg \\
\hline 1396 & Vincetoxicum hirundinaria Medik. & Létavértes & 1984 & Siroki Zoltán & DE-siroki-13461.jpg \\
\hline 1396 & Vincetoxicum hirundinaria Medik. & Létavértes & 1984 & Siroki Zoltán & DE-siroki-13462.jpg \\
\hline 1399 & Convolvulus arvensis L. & Debrecen & 1950 & Siroki Zoltán & DE-siroki-13500.jpg \\
\hline 1400 & Convolvulus cantabrica L. & Budapest & 1941 & Siroki Zoltán & DE-siroki-13502.jpg \\
\hline 1400 & Convolvulus cantabrica L. & Budapest & 1941 & Siroki Zoltán & DE-siroki-13501.jpg \\
\hline 1400 & Convolvulus cantabrica L. & Budapest & 1941 & Siroki Zoltán & DE-siroki-13503.jpg \\
\hline 1400 & Convolvulus cantabrica L. & Budapest & 1948 & Siroki Zoltán & DE-siroki-13506.jpg \\
\hline 1400 & Convolvulus cantabrica L. & Budapest & 1948 & Siroki Zoltán & DE-siroki-13507.jpg \\
\hline 1400 & Convolvulus cantabrica L. & Budapest & 1967 & Siroki Zoltán & DE-siroki-13504.jpg \\
\hline 1400 & Convolvulus cantabrica L. & Budapest & 1967 & Siroki Zoltán & DE-siroki-13505.jpg \\
\hline 1403 & Cuscuta lupuliformis Krock. & Szentes & 1952 & Siroki Zoltán & DE-siroki-13464.jpg \\
\hline 1404 & Cuscuta campestris Yunck. & Debrecen & 1947 & Siroki Zoltán & DE-siroki-13475.jpg \\
\hline 1404 & Cuscuta campestris Yunck. & Debrecen & 1969 & $\begin{array}{l}\text { Pankucsi } \\
\text { Lászlóné }\end{array}$ & DE-siroki-13466.jpg \\
\hline 1404 & Cuscuta campestris Yunck. & Debrecen & 1969 & $\begin{array}{l}\text { Pankucsi } \\
\text { Lászlóné }\end{array}$ & DE-siroki-13467.jpg \\
\hline 1404 & Cuscuta campestris Yunck. & Debrecen & 1969 & $\begin{array}{l}\text { Pankucsi } \\
\text { Lászlóné }\end{array}$ & DE-siroki-13468.jpg \\
\hline 1404 & Cuscuta campestris Yunck. & Debrecen & 1969 & $\begin{array}{l}\text { Pankucsi } \\
\text { Lászlóné }\end{array}$ & DE-siroki-13469.jpg \\
\hline 1404 & Cuscuta campestris Yunck. & Debrecen & 1969 & $\begin{array}{l}\text { Pankucsi } \\
\text { Lászlóné }\end{array}$ & DE-siroki-13470.jpg \\
\hline 1404 & Cuscuta campestris Yunck. & Debrecen & 1969 & $\begin{array}{l}\text { Pankucsi } \\
\text { Lászlóné }\end{array}$ & DE-siroki-13471.jpg \\
\hline 1404 & Cuscuta campestris Yunck. & Tiszafüred & 1973 & Siroki Zoltán & DE-siroki-13474.jpg \\
\hline 1407 & Cuscuta epithymum (L.) Nath. & "Vértes" & 1957 & Siroki Zoltán & DE-siroki-13491.jpg \\
\hline 1407 & Cuscuta epithymum (L.) Nath. & "Vértes" & 1957 & Siroki Zoltán & DE-siroki-13492.jpg \\
\hline 1407 & Cuscuta epithymum (L.) Nath. & "Vértes" & 1957 & Siroki Zoltán & DE-siroki-13493.jpg \\
\hline 1407 & Cuscuta epithymum (L.) Nath. & Egyek & 1944 & Siroki Zoltán & DE-siroki-13494.jpg \\
\hline 1407 & Cuscuta epithymum (L.) Nath. & Tiszafüred & 1973 & Siroki Zoltán & DE-siroki-13490.jpg \\
\hline 1409 & Cuscuta europaea L. & Debrecen & 1947 & Siroki Zoltán & DE-siroki-13485.jpg \\
\hline 1409 & Cuscuta europaea L. & Debrecen & 1954 & Siroki Zoltán & DE-siroki-13481.jpg \\
\hline 1409 & Cuscuta europaea L. & Debrecen & 1954 & Siroki Zoltán & DE-siroki-13483.jpg \\
\hline 1409 & Cuscuta europaea L. & Debrecen & 1954 & Siroki Zoltán & DE-siroki-13484.jpg \\
\hline 1409 & Cuscuta europaea L. & Tiszafüred & 1973 & Siroki Zoltán & DE-siroki-13479.jpg \\
\hline 1410 & Heliotropium europaeum L. & Debrecen & 1948 & Siroki Zoltán & DE-siroki-13520.jpg \\
\hline 1410 & Heliotropium europaeum L. & Mosonmagyaróvár & 1939 & Siroki Zoltán & DE-siroki-13521.jpg \\
\hline 1410 & Heliotropium europaeum L. & Szarvas & 1974 & Siroki Zoltán & DE-siroki-13519.jpg \\
\hline 1411 & Heliotropium supinum L. & Hortobágy & 1962 & Siroki Zoltán & DE-siroki-13523.jpg \\
\hline 1411 & Heliotropium supinum L. & Hortobágy & 1962 & Siroki Zoltán & DE-siroki-13524.jpg \\
\hline 1411 & Heliotropium supinum L. & Hortobágy & 1962 & Siroki Zoltán & DE-siroki-13525.jpg \\
\hline
\end{tabular}




\begin{tabular}{|c|c|c|c|c|c|}
\hline $\begin{array}{l}\text { Sorszám / } \\
\text { Number }\end{array}$ & Taxon-név / Taxon-name & $\begin{array}{l}\text { Település / } \\
\text { Settlement }\end{array}$ & $\begin{array}{l}\text { Év / } \\
\text { Year }\end{array}$ & $\begin{array}{l}\text { Gyűjtő / } \\
\text { Collector }\end{array}$ & Fájlnév / File-name \\
\hline 1411 & Heliotropium supinum L. & Hortobágy & 1962 & Siroki Zoltán & DE-siroki-13526.jpg \\
\hline 1411 & Heliotropium supinum L. & Hortobágy & 1962 & Siroki Zoltán & DE-siroki-13527.jpg \\
\hline 1411 & Heliotropium supinum L. & Hortobágy & 1962 & Siroki Zoltán & DE-siroki-13528.jpg \\
\hline 1411 & Heliotropium supinum L. & Hortobágy & 1962 & Siroki Zoltán & DE-siroki-13529.jpg \\
\hline 1412 & Lithospermum officinale L. & Debrecen & 1950 & Siroki Zoltán & DE-siroki-13786.jpg \\
\hline 1412 & Lithospermum officinale L. & Debrecen & 1950 & Siroki Zoltán & DE-siroki-13787.jpg \\
\hline 1412 & Lithospermum officinale L. & Debrecen & 1950 & Siroki Zoltán & DE-siroki-13789.jpg \\
\hline 1412 & Lithospermum officinale L. & Debrecen & 1950 & Siroki Zoltán & DE-siroki-13788.jpg \\
\hline 1412 & Lithospermum officinale L. & Keszthely & 1955 & Siroki Zoltán & DE-siroki-13783.jpg \\
\hline 1412 & Lithospermum officinale L. & Keszthely & 1955 & Siroki Zoltán & DE-siroki-13784.jpg \\
\hline 1412 & Lithospermum officinale L. & Szilvásvárad & 1954 & Siroki Zoltán & DE-siroki-13785.jpg \\
\hline 1413 & $\begin{array}{l}\text { Buglossoides purpurocaerulea } \\
\text { (L.) I.M. Johnston }\end{array}$ & Budapest & 1962 & Siroki Zoltán & DE-siroki-13791.jpg \\
\hline 1413 & $\begin{array}{l}\text { Buglossoides purpurocaerulea } \\
\text { (L.) I.M. Johnston }\end{array}$ & Budapest & 1962 & Siroki Zoltán & DE-siroki-13792.jpg \\
\hline 1413 & $\begin{array}{l}\text { Buglossoides purpurocaerulea } \\
\text { (L.) I.M. Johnston }\end{array}$ & Budapest & 1962 & Siroki Zoltán & DE-siroki-13793.jpg \\
\hline 1413 & $\begin{array}{l}\text { Buglossoides purpurocaerulea } \\
\text { (L.) I.M. Johnston }\end{array}$ & Budapest & 1962 & Siroki Zoltán & DE-siroki-13794.jpg \\
\hline 1413 & $\begin{array}{l}\text { Buglossoides purpurocaerulea } \\
\text { (L.) I.M. Johnston }\end{array}$ & Budapest & 1962 & Siroki Zoltán & DE-siroki-13790.jpg \\
\hline 1413 & $\begin{array}{l}\text { Buglossoides purpurocaerulea } \\
\text { (L.) I.M. Johnston }\end{array}$ & Debrecen & 1950 & Siroki Zoltán & DE-siroki-13796.jpg \\
\hline 1413 & $\begin{array}{l}\text { Buglossoides purpurocaerulea } \\
\text { (L.) I.M. Johnston }\end{array}$ & Debrecen & 1950 & Siroki Zoltán & DE-siroki-13799.jpg \\
\hline 1413 & $\begin{array}{l}\text { Buglossoides purpurocaerulea } \\
\text { (L.) I.M. Johnston }\end{array}$ & Debrecen & 1950 & Siroki Zoltán & DE-siroki-13800.jpg \\
\hline 1413 & $\begin{array}{l}\text { Buglossoides purpurocaerulea } \\
\text { (L.) I.M. Johnston }\end{array}$ & Debrecen & 1954 & Siroki Zoltán & DE-siroki-13798.jpg \\
\hline 1413 & $\begin{array}{l}\text { Buglossoides purpurocaerulea } \\
\text { (L.) I.M. Johnston }\end{array}$ & Debrecen & 1954 & Siroki Zoltán & DE-siroki-13797.jpg \\
\hline 1413 & $\begin{array}{l}\text { Buglossoides purpurocaerulea } \\
\text { (L.) I.M. Johnston }\end{array}$ & Debrecen & 1964 & Siroki Zoltán & DE-siroki-13801.jpg \\
\hline 1413 & $\begin{array}{l}\text { Buglossoides purpurocaerulea } \\
\text { (L.) I.M. Johnston }\end{array}$ & Debrecen & 1964 & Siroki Zoltán & DE-siroki-13802.jpg \\
\hline 1413 & $\begin{array}{l}\text { Buglossoides purpurocaerulea } \\
\text { (L.) I.M. Johnston }\end{array}$ & Debrecen & 1964 & Siroki Zoltán & DE-siroki-13803.jpg \\
\hline 1415 & Onosma visianii Clementi & Budapest & 1951 & Siroki Zoltán & DE-siroki-13806.jpg \\
\hline 1416 & Onosma arenaria Waldst. et Kit. & Abaújszántó & 1943 & Siroki Zoltán & DE-siroki-13819.jpg \\
\hline 1416 & Onosma arenaria Waldst. et Kit. & Abaújszántó & 1943 & Siroki Zoltán & DE-siroki-13820.jpg \\
\hline 1416 & Onosma arenaria Waldst. et Kit. & Abaújszántó & 1944 & Siroki Zoltán & DE-siroki-13821.jpg \\
\hline 1416 & Onosma arenaria Waldst. et Kit. & Ágasegyháza & 1956 & Siroki Zoltán & DE-siroki-13828.jpg \\
\hline 1416 & Onosma arenaria Waldst. et Kit. & Bér & 1954 & Siroki Zoltán & DE-siroki-13825.jpg \\
\hline 1416 & Onosma arenaria Waldst. et Kit. & Bér & 1954 & Siroki Zoltán & DE-siroki-13826.jpg \\
\hline 1416 & Onosma arenaria Waldst. et Kit. & Budaörs & 1966 & Siroki Zoltán & DE-siroki-13815.jpg \\
\hline 1416 & Onosma arenaria Waldst. et Kit. & Budaörs & 1966 & Siroki Zoltán & DE-siroki-13816.jpg \\
\hline 1416 & Onosma arenaria Waldst. et Kit. & Debrecen & 1947 & Siroki Zoltán & DE-siroki-13824.jpg \\
\hline 1416 & Onosma arenaria Waldst. et Kit. & Debrecen & 1948 & Siroki Zoltán & DE-siroki-13817.jpg \\
\hline 1416 & Onosma arenaria Waldst. et Kit. & Debrecen & 1948 & Siroki Zoltán & DE-siroki-13818.jpg \\
\hline 1416 & Onosma arenaria Waldst. et Kit. & Debrecen & 1948 & Siroki Zoltán & DE-siroki-13813.jpg \\
\hline 1416 & Onosma arenaria Waldst. et Kit. & Debrecen & 1948 & Siroki Zoltán & DE-siroki-13823.jpg \\
\hline 1416 & Onosma arenaria Waldst. et Kit. & Debrecen & 1949 & Siroki Zoltán & DE-siroki-13822.jpg \\
\hline 1416 & Onosma arenaria Waldst. et Kit. & Gödöllő & 1951 & Siroki Zoltán & DE-siroki-13827.jpg \\
\hline
\end{tabular}




\begin{tabular}{|c|c|c|c|c|c|}
\hline $\begin{array}{l}\text { Sorszám / } \\
\text { Number }\end{array}$ & Taxon-név / Taxon-name & $\begin{array}{l}\text { Település / } \\
\text { Settlement }\end{array}$ & $\begin{array}{l}\text { Év / } \\
\text { Year }\end{array}$ & $\begin{array}{l}\text { Gyűjtő / } \\
\text { Collector }\end{array}$ & Fájlnév / File-name \\
\hline 1416 & Onosma arenaria Waldst. et Kit. & Nagykovácsi & 1957 & Siroki Zoltán & DE-siroki-13814.jpg \\
\hline 1416 & Onosma arenaria Waldst. et Kit. & Pomáz & 1954 & Siroki Zoltán & DE-siroki-13811.jpg \\
\hline 1416 & Onosma arenaria Waldst. et Kit. & Pomáz & 1954 & Siroki Zoltán & DE-siroki-13812.jpg \\
\hline 1418 & Cerinthe minor L. & Debrecen & 1947 & Siroki Zoltán & DE-siroki-13845.jpg \\
\hline 1418 & Cerinthe minor L. & Mosonmagyaróvár & 1939 & Siroki Zoltán & DE-siroki-13846.jpg \\
\hline 1419 & Alkanna tinctoria (L.) Tausch & Ágasegyháza & 1971 & Siroki Zoltán & DE-siroki-13659.jpg \\
\hline 1419 & Alkanna tinctoria (L.) Tausch & Ágasegyháza & 1971 & Siroki Zoltán & DE-siroki-13660.jpg \\
\hline 1419 & Alkanna tinctoria (L.) Tausch & Ágasegyháza & 1971 & Siroki Zoltán & DE-siroki-13661.jpg \\
\hline 1419 & Alkanna tinctoria (L.) Tausch & Budapest & 1909 & Kocsis István & DE-siroki-13662.jpg \\
\hline 1419 & Alkanna tinctoria (L.) Tausch & Kecskemét & 1969 & Siroki Zoltán & DE-siroki-13658.jpg \\
\hline 1419 & Alkanna tinctoria (L.) Tausch & Nagykőrös & 1954 & Siroki Zoltán & DE-siroki-13657.jpg \\
\hline 1419 & Alkanna tinctoria (L.) Tausch & Veresegyház & 1952 & Petrányi I. & DE-siroki-13653.jpg \\
\hline 1419 & Alkanna tinctoria (L.) Tausch & Veresegyház & 1952 & Petrányi I. & DE-siroki-13654.jpg \\
\hline 1419 & Alkanna tinctoria (L.) Tausch & Veresegyház & 1954 & Siroki Zoltán & DE-siroki-13655.jpg \\
\hline 1419 & Alkanna tinctoria (L.) Tausch & Veresegyház & 1954 & Siroki Zoltán & DE-siroki-13656.jpg \\
\hline 1419 & Alkanna tinctoria (L.) Tausch & Veresegyház & 1960 & Siroki Zoltán & DE-siroki-13663.jpg \\
\hline 1419 & Alkanna tinctoria (L.) Tausch & Veresegyház & 1960 & Siroki Zoltán & DE-siroki-13664.jpg \\
\hline 1419 & Alkanna tinctoria (L.) Tausch & Veresegyház & 1960 & Siroki Zoltán & DE-siroki-13665.jpg \\
\hline 1420 & Echium italicum L. & Bér & 1954 & Siroki Zoltán & DE-siroki-13850.jpg \\
\hline 1420 & Echium italicum L. & Bér & 1954 & Siroki Zoltán & DE-siroki-13851.jpg \\
\hline 1420 & Echium italicum L. & Bér & 1954 & Siroki Zoltán & DE-siroki-13852.jpg \\
\hline 1420 & Echium italicum L. & Bér & 1954 & Siroki Zoltán & DE-siroki-13853.jpg \\
\hline 1420 & Echium italicum L. & Máriakálnok & 1939 & Siroki Zoltán & DE-siroki-13854.jpg \\
\hline 1421 & Echium vulgare L. & Debrecen & 1947 & Siroki Zoltán & DE-siroki-13856.jpg \\
\hline 1421 & Echium vulgare L. & Debrecen & 1949 & Siroki Zoltán & DE-siroki-13857.jpg \\
\hline 1421 & Echium vulgare L. & Mosonmagyaróvár & 1939 & Siroki Zoltán & DE-siroki-13858.jpg \\
\hline 1421 & Echium vulgare L. & Szilvásvárad & 1954 & Siroki Zoltán & DE-siroki-13855.jpg \\
\hline 1422 & Echium maculatum L. & Budapest & 1951 & Siroki Zoltán & DE-siroki-13860.jpg \\
\hline 1422 & Echium maculatum L. & Budapest & 1951 & Siroki Zoltán & DE-siroki-13862.jpg \\
\hline 1422 & Echium maculatum L. & Budapest & 1952 & Siroki Zoltán & DE-siroki-13861.jpg \\
\hline 1422 & Echium maculatum L. & Budapest & 1952 & Siroki Zoltán & DE-siroki-13859.jpg \\
\hline 1424 & Pulmonaria officinalis L. & Bátorliget & 1954 & Siroki Zoltán & DE-siroki-13672.jpg \\
\hline 1424 & Pulmonaria officinalis L. & Bátorliget & 1954 & Siroki Zoltán & DE-siroki-13673.jpg \\
\hline 1424 & Pulmonaria officinalis L. & Budapest & 1955 & Siroki Zoltán & DE-siroki-13675.jpg \\
\hline 1424 & Pulmonaria officinalis L. & Budapest & 1955 & Siroki Zoltán & DE-siroki-13674.jpg \\
\hline 1424 & Pulmonaria officinalis L. & Gyenesdiás & 1972 & Siroki Zoltán & DE-siroki-13677.jpg \\
\hline 1424 & Pulmonaria officinalis L. & Szarvaskő & 1958 & Siroki Zoltán & DE-siroki-13671.jpg \\
\hline 1424 & Pulmonaria officinalis L. & Szarvaskő & 1958 & Siroki Zoltán & DE-siroki-13676.jpg \\
\hline 1424 & Pulmonaria officinalis L. & Tarpa & 1971 & Siroki Zoltán & DE-siroki-13666.jpg \\
\hline 1426 & Pulmonaria mollissima A. Kern. & "Dobogókő" & 1957 & Siroki Zoltán & DE-siroki-13681.jpg \\
\hline 1426 & Pulmonaria mollissima A. Kern. & Budapest & 1970 & Siroki Zoltán & DE-siroki-13682.jpg \\
\hline 1426 & Pulmonaria mollissima A. Kern. & debrecen & 1947 & Siroki Zoltán & DE-siroki-13678.jpg \\
\hline 1426 & Pulmonaria mollissima A. Kern. & debrecen & 1948 & Siroki Zoltán & DE-siroki-13679.jpg \\
\hline 1426 & Pulmonaria mollissima A. Kern. & Gyenesdiás & 1972 & Siroki Zoltán & DE-siroki-13683.jpg \\
\hline 1428 & Nonea pulla (L.) DC. & Mosonmagyaróvár & 1939 & Siroki Zoltán & DE-siroki-13651.jpg \\
\hline 1428 & Nonea pulla (L.) DC. & Mosonmagyaróvár & 1939 & Siroki Zoltán & DE-siroki-13652.jpg \\
\hline
\end{tabular}




\begin{tabular}{|c|c|c|c|c|c|}
\hline $\begin{array}{l}\text { Sorszám / } \\
\text { Number }\end{array}$ & Taxon-név / Taxon-name & $\begin{array}{l}\text { Település / } \\
\text { Settlement }\end{array}$ & $\begin{array}{l}\text { Év / } \\
\text { Year }\end{array}$ & $\begin{array}{l}\text { Gyújitő / } \\
\text { Collector }\end{array}$ & Fájlnév / File-name \\
\hline 1429 & Symphytum tuberosum L. & "Fáni-völgy" & 1955 & $\begin{array}{l}\text { Siroki Zoltán - } \\
\text { Farkas Attila }\end{array}$ & DE-siroki-13573.jpg \\
\hline 1429 & Symphytum tuberosum L. & "Nagymező" & 1959 & Siroki Zoltán & DE-siroki-13575.jpg \\
\hline 1429 & Symphytum tuberosum L. & Bátorliget & 1954 & Siroki Zoltán & DE-siroki-13574.jpg \\
\hline 1429 & Symphytum tuberosum L. & Gyenesdiás & 1972 & Siroki Zoltán & DE-siroki-13568.jpg \\
\hline 1429 & Symphytum tuberosum L. & Nagyhuta & 1961 & Siroki Zoltán & DE-siroki-13569.jpg \\
\hline 1429 & Symphytum tuberosum L. & Nagyhuta & 1961 & Siroki Zoltán & DE-siroki-13570.jpg \\
\hline 1429 & Symphytum tuberosum L. & Nagykovácsi & 1959 & Siroki Zoltán & DE-siroki-13571.jpg \\
\hline 1429 & Symphytum tuberosum L. & Nagykovácsi & 1959 & Siroki Zoltán & DE-siroki-13572.jpg \\
\hline 1430 & Symphytum officinale L. & Debrecen & 1947 & Siroki Zoltán & DE-siroki-13582.jpg \\
\hline 1430 & Symphytum officinale L. & Debrecen & 1957 & Siroki Zoltán & DE-siroki-13581.jpg \\
\hline 1430 & Symphytum officinale L. & Mosonmagyaróvár & 1939 & Siroki Zoltán & DE-siroki-13577.jpg \\
\hline 1430 & Symphytum officinale L. & Mosonmagyaróvár & 1939 & Siroki Zoltán & DE-siroki-13580.jpg \\
\hline 1430 & Symphytum officinale L. & Tarpa & 1955 & Siroki Zoltán & DE-siroki-13583.jpg \\
\hline 1434 & Lycopsis arvensis L. & Debrecen & 1973 & Siroki Zoltán & DE-siroki-13643.jpg \\
\hline 1434 & Lycopsis arvensis L. & Debrecen & 1973 & Siroki Zoltán & DE-siroki-13644.jpg \\
\hline 1434 & Lycopsis arvensis L. & Debrecen & 1973 & Siroki Zoltán & DE-siroki-13645.jpg \\
\hline 1434 & Lycopsis arvensis L. & Debrecen & 1973 & Siroki Zoltán & DE-siroki-13646.jpg \\
\hline 1434 & Lycopsis arvensis L. & Debrecen & 1973 & Siroki Zoltán & DE-siroki-13647.jpg \\
\hline 1434 & Lycopsis arvensis L. & Hortobágy & 1956 & Siroki Zoltán & DE-siroki-13619.jpg \\
\hline 1434 & Lycopsis arvensis L. & Hortobágy & 1956 & Siroki Zoltán & DE-siroki-13620.jpg \\
\hline 1434 & Lycopsis arvensis L. & Hortobágy & 1956 & Siroki Zoltán & DE-siroki-13621.jpg \\
\hline 1434 & Lycopsis arvensis L. & Hortobágy & 1956 & Siroki Zoltán & DE-siroki-13622.jpg \\
\hline 1434 & Lycopsis arvensis L. & Hortobágy & 1956 & Siroki Zoltán & DE-siroki-13648.jpg \\
\hline 1434 & Lycopsis arvensis L. & Hortobágy & 1956 & Siroki Zoltán & DE-siroki-13649.jpg \\
\hline 1434 & Lycopsis arvensis L. & Hortobágy & 1956 & Siroki Zoltán & DE-siroki-13650.jpg \\
\hline 1434 & Lycopsis arvensis L. & Hortobágy & 1959 & Siroki Zoltán & DE-siroki-13623.jpg \\
\hline 1434 & Lycopsis arvensis L. & Hortobágy & 1959 & Siroki Zoltán & DE-siroki-13624.jpg \\
\hline 1434 & Lycopsis arvensis L. & Hortobágy & 1959 & Siroki Zoltán & DE-siroki-13625.jpg \\
\hline 1434 & Lycopsis arvensis L. & Hortobágy & 1959 & Siroki Zoltán & DE-siroki-13626.jpg \\
\hline 1434 & Lycopsis arvensis L. & Hortobágy & 1959 & Siroki Zoltán & DE-siroki-13627.jpg \\
\hline 1434 & Lycopsis arvensis L. & Hortobágy & 1959 & Siroki Zoltán & DE-siroki-13628.jpg \\
\hline 1434 & Lycopsis arvensis L. & Hortobágy & 1959 & Siroki Zoltán & DE-siroki-13629.jpg \\
\hline 1434 & Lycopsis arvensis L. & Hortobágy & 1959 & Siroki Zoltán & DE-siroki-13630.jpg \\
\hline 1434 & Lycopsis arvensis L. & Kántorjánosi & 1967 & Gondola István & DE-siroki-13638.jpg \\
\hline 1434 & Lycopsis arvensis L. & Kántorjánosi & 1967 & Gondola István & DE-siroki-13642.jpg \\
\hline 1434 & Lycopsis arvensis L. & Újfehértó & 1967 & Gondola István & DE-siroki-13636.jpg \\
\hline 1434 & Lycopsis arvensis L. & Újfehértó & 1967 & Gondola István & DE-siroki-13637.jpg \\
\hline 1434 & Lycopsis arvensis L. & Újfehértó & 1967 & Gondola István & DE-siroki-13639.jpg \\
\hline 1434 & Lycopsis arvensis L. & Újfehértó & 1967 & Gondola István & DE-siroki-13640.jpg \\
\hline 1434 & Lycopsis arvensis L. & Újfehértó & 1967 & Gondola István & DE-siroki-13641.jpg \\
\hline 1435 & Anchusa barrelieri (All.) Vitman & Hajdúszoboszló & 1964 & Siroki Zoltán & DE-siroki-13593.jpg \\
\hline 1435 & Anchusa barrelieri (All.) Vitman & Hajdúszoboszló & 1964 & Siroki Zoltán & DE-siroki-13594.jpg \\
\hline 1435 & Anchusa barrelieri (All.) Vitman & Hajdúszoboszló & 1964 & Siroki Zoltán & DE-siroki-13596.jpg \\
\hline 1435 & Anchusa barrelieri (All.) Vitman & Hajdúszoboszló & 1964 & Siroki Zoltán & DE-siroki-13597.jpg \\
\hline 1435 & Anchusa barrelieri (All.) Vitman & Hajdúszoboszló & 1964 & Siroki Zoltán & DE-siroki-13598.jpg \\
\hline 1435 & Anchusa barrelieri (All.) Vitman & Hajdúszoboszló & 1964 & Siroki Zoltán & DE-siroki-13599.jpg \\
\hline
\end{tabular}




\begin{tabular}{|c|c|c|c|c|c|}
\hline $\begin{array}{l}\text { Sorszám / } \\
\text { Number }\end{array}$ & Taxon-név / Taxon-name & $\begin{array}{l}\text { Település / } \\
\text { Settlement }\end{array}$ & $\begin{array}{l}\text { Év / } \\
\text { Year }\end{array}$ & $\begin{array}{l}\text { Gyűjtő / } \\
\text { Collector }\end{array}$ & Fájlnév / File-name \\
\hline 1435 & Anchusa barrelieri (All.) Vitman & Hajdúszoboszló & 1964 & Siroki Zoltán & DE-siroki-13600.jpg \\
\hline 1435 & Anchusa barrelieri (All.) Vitman & Hajdúszoboszló & 1964 & Siroki Zoltán & DE-siroki-13601.jpg \\
\hline 1435 & Anchusa barrelieri (All.) Vitman & Hajdúszoboszló & 1964 & Siroki Zoltán & DE-siroki-13602.jpg \\
\hline 1435 & Anchusa barrelieri (All.) Vitman & Hortobágy & 1954 & Kovács Béla & DE-siroki-13587.jpg \\
\hline 1435 & Anchusa barrelieri (All.) Vitman & Hortobágy & 1954 & Kovács Béla & DE-siroki-13588.jpg \\
\hline 1435 & Anchusa barrelieri (All.) Vitman & Hortobágy & 1954 & Kovács Béla & DE-siroki-13589.jpg \\
\hline 1435 & Anchusa barrelieri (All.) Vitman & Hortobágy & 1954 & Kovács Béla & DE-siroki-13590.jpg \\
\hline 1435 & Anchusa barrelieri (All.) Vitman & Hortobágy & 1954 & Kovács Béla & DE-siroki-13591.jpg \\
\hline 1435 & Anchusa barrelieri (All.) Vitman & Hortobágy & 1954 & Kovács Béla & DE-siroki-13592.jpg \\
\hline 1435 & Anchusa barrelieri (All.) Vitman & Hortobágy & 1954 & Siroki Zoltán & DE-siroki-13604.jpg \\
\hline 1435 & Anchusa barrelieri (All.) Vitman & Hortobágy & 1954 & Siroki Zoltán & DE-siroki-13605.jpg \\
\hline 1435 & Anchusa barrelieri (All.) Vitman & Hosszúhetény & 1958 & Siroki Zoltán & DE-siroki-13603.jpg \\
\hline 1436 & Anchusa azurea Mill. & Budapest & 1951 & Siroki Zoltán & DE-siroki-13608.jpg \\
\hline 1436 & Anchusa azurea Mill. & Budapest & 1951 & Siroki Zoltán & DE-siroki-13609.jpg \\
\hline 1436 & Anchusa azurea Mill. & Budapest & 1951 & Siroki Zoltán & DE-siroki-13612.jpg \\
\hline 1436 & Anchusa azurea Mill. & Budapest & 1962 & Siroki Zoltán & DE-siroki-13610.jpg \\
\hline 1436 & Anchusa azurea Mill. & Budapest & 1962 & Siroki Zoltán & DE-siroki-13611.jpg \\
\hline 1436 & Anchusa azurea Mill. & Egyek & 1948 & Siroki Zoltán & DE-siroki-13613.jpg \\
\hline 1436 & Anchusa azurea Mill. & Egyek & 1948 & Siroki Zoltán & DE-siroki-13607.jpg \\
\hline 1437 & Anchusa officinalis L. & Debrecen & 1947 & Siroki Zoltán & DE-siroki-13614.jpg \\
\hline 1440 & Asperugo procumbens L. & Debrecen & 1947 & Siroki Zoltán & DE-siroki-13562.jpg \\
\hline 1442 & Myosotis caespitosa Schultz & Debrecen & 1950 & Siroki Zoltán & DE-siroki-13715.jpg \\
\hline 1442 & Myosotis caespitosa Schultz & Debrecen & 1951 & Siroki Zoltán & DE-siroki-13720.jpg \\
\hline 1442 & Myosotis caespitosa Schultz & Debrecen & 1951 & Siroki Zoltán & DE-siroki-13721.jpg \\
\hline 1442 & Myosotis caespitosa Schultz & Debrecen & 1951 & Siroki Zoltán & DE-siroki-13724.jpg \\
\hline 1442 & Myosotis caespitosa Schultz & Debrecen & 1951 & Siroki Zoltán & DE-siroki-13706.jpg \\
\hline 1442 & Myosotis caespitosa Schultz & Debrecen & 1951 & Siroki Zoltán & DE-siroki-13713.jpg \\
\hline 1442 & Myosotis caespitosa Schultz & Debrecen & 1954 & Siroki Zoltán & DE-siroki-13722.jpg \\
\hline 1442 & Myosotis caespitosa Schultz & Debrecen & 1954 & Siroki Zoltán & DE-siroki-13712.jpg \\
\hline 1442 & Myosotis caespitosa Schultz & Debrecen & 1954 & Siroki Zoltán & DE-siroki-13719.jpg \\
\hline 1442 & Myosotis caespitosa Schultz & Debrecen & 1954 & Siroki Zoltán & DE-siroki-13723.jpg \\
\hline 1442 & Myosotis caespitosa Schultz & Debrecen & 1956 & Siroki Zoltán & DE-siroki-13714.jpg \\
\hline 1442 & Myosotis caespitosa Schultz & Debrecen & 1958 & Siroki Zoltán & DE-siroki-13708.jpg \\
\hline 1442 & Myosotis caespitosa Schultz & Debrecen & 1958 & Siroki Zoltán & DE-siroki-13710.jpg \\
\hline 1442 & Myosotis caespitosa Schultz & Debrecen & 1958 & Siroki Zoltán & DE-siroki-13711.jpg \\
\hline 1442 & Myosotis caespitosa Schultz & Debrecen & 1958 & Siroki Zoltán & DE-siroki-13709.jpg \\
\hline 1442 & Myosotis caespitosa Schultz & Debrecen & 1958 & Siroki Zoltán & DE-siroki-13707.jpg \\
\hline 1442 & Myosotis caespitosa Schultz & Debrecen & 1960 & Siroki Zoltán & DE-siroki-13716.jpg \\
\hline 1442 & Myosotis caespitosa Schultz & Újléta & 1967 & Siroki Zoltán & DE-siroki-13717.jpg \\
\hline 1442 & Myosotis caespitosa Schultz & Újléta & 1967 & Siroki Zoltán & DE-siroki-13718.jpg \\
\hline 1444 & Myosotis scorpioides L. & "Nagymező" & 1959 & Halász Tibor & DE-siroki-13690.jpg \\
\hline 1444 & Myosotis scorpioides L. & Debrecen & 1964 & Siroki Zoltán & DE-siroki-13695.jpg \\
\hline 1444 & Myosotis scorpioides L. & Debrecen & 1964 & Siroki Zoltán & DE-siroki-13696.jpg \\
\hline 1444 & Myosotis scorpioides L. & Debrecen & 1964 & Siroki Zoltán & DE-siroki-13697.jpg \\
\hline 1444 & Myosotis scorpioides L. & Debrecen & 1964 & Siroki Zoltán & DE-siroki-13698.jpg \\
\hline 1444 & Myosotis scorpioides L. & Debrecen & 1964 & Siroki Zoltán & DE-siroki-13699.jpg \\
\hline
\end{tabular}




\begin{tabular}{|c|c|c|c|c|c|}
\hline $\begin{array}{l}\text { Sorszám / } \\
\text { Number }\end{array}$ & Taxon-név / Taxon-name & $\begin{array}{l}\text { Település / } \\
\text { Settlement }\end{array}$ & $\begin{array}{l}\text { Év / } \\
\text { Year }\end{array}$ & $\begin{array}{l}\text { Gyűjtő / } \\
\text { Collector }\end{array}$ & Fájlnév / File-name \\
\hline 1444 & Myosotis scorpioides L. & Debrecen & 1964 & Siroki Zoltán & DE-siroki-13700.jpg \\
\hline 1444 & Myosotis scorpioides L. & Debrecen & 1964 & Siroki Zoltán & DE-siroki-13701.jpg \\
\hline 1444 & Myosotis scorpioides L. & Hajdúbagos & 1982 & Siroki Zoltán & DE-siroki-13688.jpg \\
\hline 1444 & Myosotis scorpioides L. & Háromhuta & 1961 & Siroki Zoltán & DE-siroki-13692.jpg \\
\hline 1444 & Myosotis scorpioides L. & Háromhuta & 1961 & Siroki Zoltán & DE-siroki-13693.jpg \\
\hline 1444 & Myosotis scorpioides L. & Háromhuta & 1961 & Siroki Zoltán & DE-siroki-13694.jpg \\
\hline 1444 & Myosotis scorpioides L. & Nagyhuta & 1978 & Siroki Zoltán & DE-siroki-13702.jpg \\
\hline 1444 & Myosotis scorpioides L. & Tiszafüred & 1949 & Siroki Zoltán & DE-siroki-13691.jpg \\
\hline 1446 & Myosotis sylvatica (Ehrh.) Hoffm. & "Bánkút" & 1966 & Siroki Zoltán & DE-siroki-13770.jpg \\
\hline 1446 & Myosotis sylvatica (Ehrh.) Hoffm. & "Bánkút" & 1966 & Siroki Zoltán & DE-siroki-13771.jpg \\
\hline 1446 & Myosotis sylvatica (Ehrh.) Hoffm. & "Bánkút" & 1966 & Siroki Zoltán & DE-siroki-13772.jpg \\
\hline 1446 & Myosotis sylvatica (Ehrh.) Hoffm. & "Bánkút" & 1966 & Siroki Zoltán & DE-siroki-13773.jpg \\
\hline 1446 & Myosotis sylvatica (Ehrh.) Hoffm. & "Bánkút" & 1966 & Siroki Zoltán & DE-siroki-13774.jpg \\
\hline 1446 & Myosotis sylvatica (Ehrh.) Hoffm. & "Hármaskő" & 1957 & Siroki Zoltán & DE-siroki-13777.jpg \\
\hline 1446 & Myosotis sylvatica (Ehrh.) Hoffm. & "Háromkő" & 1957 & Siroki Zoltán & DE-siroki-13768.jpg \\
\hline 1446 & Myosotis sylvatica (Ehrh.) Hoffm. & "Háromkő" & 1957 & Siroki Zoltán & DE-siroki-13769.jpg \\
\hline 1446 & Myosotis sylvatica (Ehrh.) Hoffm. & "Nagymező" & 1959 & Halász Tibor & DE-siroki-13763.jpg \\
\hline 1446 & Myosotis sylvatica (Ehrh.) Hoffm. & "Nagymező" & 1959 & Halász Tibor & DE-siroki-13775.jpg \\
\hline 1446 & Myosotis sylvatica (Ehrh.) Hoffm. & "Nagymező" & 1960 & Siroki Zoltán & DE-siroki-13765.jpg \\
\hline 1446 & Myosotis sylvatica (Ehrh.) Hoffm. & "Nagymező" & 1960 & Siroki Zoltán & DE-siroki-13766.jpg \\
\hline 1446 & Myosotis sylvatica (Ehrh.) Hoffm. & "Nagymező" & 1960 & Siroki Zoltán & DE-siroki-13767.jpg \\
\hline 1446 & Myosotis sylvatica (Ehrh.) Hoffm. & "Nagymező" & 1960 & Siroki Zoltán & DE-siroki-13764.jpg \\
\hline 1446 & Myosotis sylvatica (Ehrh.) Hoffm. & Szilvásvárad & 1954 & Siroki Zoltán & DE-siroki-13776.jpg \\
\hline 1447 & Myosotis stricta Link & Budapest & 1941 & Siroki Zoltán & DE-siroki-13726.jpg \\
\hline 1447 & Myosotis stricta Link & Budapest & 1951 & Siroki Zoltán & DE-siroki-13730.jpg \\
\hline 1447 & Myosotis stricta Link & Debrecen & 1950 & Siroki Zoltán & DE-siroki-13734.jpg \\
\hline 1447 & Myosotis stricta Link & Debrecen & 1950 & Siroki Zoltán & DE-siroki-13727.jpg \\
\hline 1447 & Myosotis stricta Link & Debrecen & 1950 & Siroki Zoltán & DE-siroki-13731.jpg \\
\hline 1447 & Myosotis stricta Link & Debrecen & 1950 & Siroki Zoltán & DE-siroki-13729.jpg \\
\hline 1447 & Myosotis stricta Link & Debrecen & 1965 & Siroki Zoltán & DE-siroki-13732.jpg \\
\hline 1447 & Myosotis stricta Link & Debrecen & 1985 & Siroki Zoltán & DE-siroki-13728.jpg \\
\hline 1447 & Myosotis stricta Link & Kardoskút & 1945 & Siroki Zoltán & DE-siroki-13733.jpg \\
\hline 1449 & Myosotis sparsiflora J.G. Mikan & Debrecen & 1949 & Siroki Zoltán & DE-siroki-13737.jpg \\
\hline 1449 & Myosotis sparsiflora J.G. Mikan & Debrecen & 1950 & Siroki Zoltán & DE-siroki-13736.jpg \\
\hline 1449 & Myosotis sparsiflora J.G. Mikan & Debrecen & 1965 & Siroki Zoltán & DE-siroki-13740.jpg \\
\hline 1449 & Myosotis sparsiflora J.G. Mikan & Debrecen & 1965 & Siroki Zoltán & DE-siroki-13738.jpg \\
\hline 1449 & Myosotis sparsiflora J.G. Mikan & Debrecen & 1965 & Siroki Zoltán & DE-siroki-13739.jpg \\
\hline 1450 & Myosotis arvensis (L.) Hill & Budapest & 1951 & Siroki Zoltán & DE-siroki-13757.jpg \\
\hline 1450 & Myosotis arvensis (L.) Hill & Debrecen & 1948 & Siroki Zoltán & DE-siroki-13750.jpg \\
\hline 1450 & Myosotis arvensis (L.) Hill & Debrecen & 1948 & Siroki Zoltán & DE-siroki-13753.jpg \\
\hline 1450 & Myosotis arvensis (L.) Hill & Debrecen & 1948 & Siroki Zoltán & DE-siroki-13749.jpg \\
\hline 1450 & Myosotis arvensis (L.) Hill & Debrecen & 1948 & Siroki Zoltán & DE-siroki-13759.jpg \\
\hline 1450 & Myosotis arvensis (L.) Hill & Debrecen & 1955 & Siroki Zoltán & DE-siroki-13756.jpg \\
\hline 1450 & Myosotis arvensis (L.) Hill & Debrecen & 1955 & Siroki Zoltán & DE-siroki-13758.jpg \\
\hline 1450 & Myosotis arvensis (L.) Hill & Debrecen & 1965 & Siroki Zoltán & DE-siroki-13760.jpg \\
\hline 1450 & Myosotis arvensis (L.) Hill & Debrecen & 1965 & Siroki Zoltán & DE-siroki-13761.jpg \\
\hline
\end{tabular}




\begin{tabular}{|c|c|c|c|c|c|}
\hline $\begin{array}{l}\text { Sorszám / } \\
\text { Number }\end{array}$ & Taxon-név / Taxon-name & $\begin{array}{l}\text { Település / } \\
\text { Settlement }\end{array}$ & $\begin{array}{l}\text { Év / } \\
\text { Year }\end{array}$ & $\begin{array}{l}\text { Gyűjtő / } \\
\text { Collector }\end{array}$ & Fájlnév / File-name \\
\hline 1450 & Myosotis arvensis (L.) Hill & Debrecen & 1985 & Siroki Zoltán & DE-siroki-13748.jpg \\
\hline 1450 & Myosotis arvensis (L.) Hill & Háromhuta & 1961 & Siroki Zoltán & DE-siroki-13762.jpg \\
\hline 1450 & Myosotis arvensis (L.) Hill & Háromhuta & 1978 & Siroki Zoltán & DE-siroki-13755.jpg \\
\hline 1450 & Myosotis arvensis (L.) Hill & Nagyhuta & 1978 & Siroki Zoltán & DE-siroki-13754.jpg \\
\hline 1451 & Myosotis ramosissima Rochel & Biharugra & 1961 & Siroki Zoltán & DE-siroki-13744.jpg \\
\hline 1451 & Myosotis ramosissima Rochel & Budapest & 1904 & $\begin{array}{l}\text { Thaisz Lajos - } \\
\text { Baán Lajos }\end{array}$ & DE-siroki-13747.jpg \\
\hline 1451 & Myosotis ramosissima Rochel & Debrecen & 1947 & Siroki Zoltán & DE-siroki-13745.jpg \\
\hline 1455 & Lappula squarrosa (Retz.) Dumort. & Debrecen & 1947 & Siroki Zoltán & DE-siroki-13557.jpg \\
\hline 1455 & Lappula squarrosa (Retz.) Dumort. & Debrecen & 1948 & Siroki Zoltán & DE-siroki-13558.jpg \\
\hline 1455 & Lappula squarrosa (Retz.) Dumort. & Hortobágy & 1985 & Siroki Zoltán & DE-siroki-13554.jpg \\
\hline 1455 & Lappula squarrosa (Retz.) Dumort. & Hortobágy & 1985 & Siroki Zoltán & DE-siroki-13555.jpg \\
\hline 1455 & Lappula squarrosa (Retz.) Dumort. & Mikepércs & 1962 & Siroki Zoltán & DE-siroki-13556.jpg \\
\hline 1456 & Lappula heteracantha (Ledeb.) Borbás & Bajót & 1951 & Kárpáti Zoltán & DE-siroki-13561.jpg \\
\hline 1457 & $\begin{array}{l}\text { Omphalodes scorpioides } \\
\text { (Haenke) Schrank }\end{array}$ & "Fáni-völgy" & 1955 & $\begin{array}{l}\text { Siroki Zoltán - } \\
\text { Farkas Attila }\end{array}$ & DE-siroki-13532.jpg \\
\hline 1457 & $\begin{array}{l}\text { Omphalodes scorpioides } \\
\text { (Haenke) Schrank }\end{array}$ & "Fáni-völgy" & 1955 & $\begin{array}{l}\text { Siroki Zoltán - } \\
\text { Farkas Attila }\end{array}$ & DE-siroki-13533.jpg \\
\hline 1457 & $\begin{array}{l}\text { Omphalodes scorpioides } \\
\text { (Haenke) Schrank }\end{array}$ & Budapest & 1951 & Siroki Zoltán & DE-siroki-13530.jpg \\
\hline 1457 & $\begin{array}{l}\text { Omphalodes scorpioides } \\
\text { (Haenke) Schrank }\end{array}$ & Budapest & 1951 & Siroki Zoltán & DE-siroki-13531.jpg \\
\hline 1457 & $\begin{array}{l}\text { Omphalodes scorpioides } \\
\text { (Haenke) Schrank }\end{array}$ & Budapest & 1951 & $\begin{array}{l}\text { Siroki Zoltán - } \\
\text { Farkas Attila }\end{array}$ & DE-siroki-13534.jpg \\
\hline 1459 & Cynoglossum officinale L. & Debrecen & 1946 & Siroki Zoltán & DE-siroki-13550.jpg \\
\hline 1459 & Cynoglossum officinale L. & Hajdúbagos & 1985 & Siroki Zoltán & DE-siroki-13549.jpg \\
\hline 1459 & Cynoglossum officinale L. & Hajdúböszörmény & 1981 & Siroki Zoltán & DE-siroki-13547.jpg \\
\hline 1459 & Cynoglossum officinale L. & Vámospércs & 1965 & Siroki Zoltán & DE-siroki-13595.jpg \\
\hline 1459 & Cynoglossum officinale L. & Vámospércs & 1985 & Siroki Zoltán & DE-siroki-13548.jpg \\
\hline 1460 & Cynoglossum hungaricum Simonk. & Budapest & 1911 & Kocsis István & DE-siroki-13543.jpg \\
\hline 1460 & Cynoglossum hungaricum Simonk. & Debrecen & 1947 & Siroki Zoltán & DE-siroki-13546.jpg \\
\hline 1460 & Cynoglossum hungaricum Simonk. & Debrecen & 1947 & Siroki Zoltán & DE-siroki-13545.jpg \\
\hline 1460 & Cynoglossum hungaricum Simonk. & Debrecen & 1950 & Siroki Zoltán & DE-siroki-13544.jpg \\
\hline 1460 & Cynoglossum hungaricum Simonk. & Debrecen & 1977 & Siroki Zoltán & DE-siroki-13540.jpg \\
\hline 1460 & Cynoglossum hungaricum Simonk. & Debrecen & 1977 & Siroki Zoltán & DE-siroki-13541.jpg \\
\hline 1460 & Cynoglossum hungaricum Simonk. & Tatabánya & 1909 & Kocsis István & DE-siroki-13542.jpg \\
\hline 1463 & Verbena officinalis L. & Debrecen & 1947 & Siroki Zoltán & DE-siroki-13865.jpg \\
\hline 1463 & Verbena officinalis L. & Mosonmagyaróvár & 1939 & Siroki Zoltán & DE-siroki-13863.jpg \\
\hline 1464 & Verbena supina L. & Szerep & 1911 & Rácz B. & DE-siroki-13866.jpg \\
\hline 1464 & Verbena supina L. & Szerep & 1911 & Rácz B. & DE-siroki-13867.jpg \\
\hline 1466 & Callitriche cophocarpa Sendtn. & Debrecen & 1958 & Siroki Zoltán & DE-siroki-11292.jpg \\
\hline 1466 & Callitriche cophocarpa Sendtn. & Debrecen & 1958 & Siroki Zoltán & DE-siroki-11293.jpg \\
\hline 1466 & Callitriche cophocarpa Sendtn. & Debrecen & 1958 & Siroki Zoltán & DE-siroki-11294.jpg \\
\hline 1466 & Callitriche cophocarpa Sendtn. & Nagyhuta & 1963 & Siroki Zoltán & DE-siroki-11295.jpg \\
\hline 1466 & Callitriche cophocarpa Sendtn. & Nagyhuta & 1963 & Siroki Zoltán & DE-siroki-11296.jpg \\
\hline 1466 & Callitriche cophocarpa Sendtn. & Nagyhuta & 1963 & Siroki Zoltán & DE-siroki-11297.jpg \\
\hline 1467 & Callitriche palustris L. & Miskolc & 1959 & Siroki Zoltán & DE-siroki-11291.jpg \\
\hline 1470 & Ajuga chamaepitys (L.) Schreb. & Boldogkőváralja & 1943 & Siroki Zoltán & DE-siroki-13874.jpg \\
\hline 1470 & Ajuga chamaepitys (L.) Schreb. & Budapest & 1983 & Siroki Zoltán & DE-siroki-13870.jpg \\
\hline 1470 & Ajuga chamaepitys (L.) Schreb. & Budapest & 1983 & Siroki Zoltán & DE-siroki-13873.jpg \\
\hline
\end{tabular}




\begin{tabular}{|c|c|c|c|c|c|}
\hline $\begin{array}{l}\text { Sorszám / } \\
\text { Number }\end{array}$ & Taxon-név / Taxon-name & $\begin{array}{l}\text { Település / } \\
\text { Settlement }\end{array}$ & $\begin{array}{l}\text { Év / } \\
\text { Year }\end{array}$ & $\begin{array}{l}\text { Gyújtő / } \\
\text { Collector }\end{array}$ & Fájlnév / File-name \\
\hline 1470 & Ajuga chamaepitys (L.) Schreb. & Debrecen & 1947 & Siroki Zoltán & DE-siroki-13877.jpg \\
\hline 1470 & Ajuga chamaepitys (L.) Schreb. & Mosonmagyaróvár & 1939 & Siroki Zoltán & DE-siroki-13876.jpg \\
\hline 1471 & Ajuga laxmannii (L.) Benth. & Budapest & 1888 & Czakó Kálmán & DE-siroki-13881.jpg \\
\hline 1472 & Ajuga reptans L. & "Mátra" & 1957 & Siroki Zoltán & DE-siroki-13888.jpg \\
\hline 1472 & Ajuga reptans L. & Gödöllő & 1952 & Siroki Zoltán & DE-siroki-13885.jpg \\
\hline 1472 & Ajuga reptans L. & Nagyhuta & 1961 & Siroki Zoltán & DE-siroki-13887.jpg \\
\hline 1472 & Ajuga reptans L. & Nagyhuta & 1961 & Siroki Zoltán & DE-siroki-13889.jpg \\
\hline 1472 & Ajuga reptans L. & Nagyhuta & 1961 & Siroki Zoltán & DE-siroki-13890.jpg \\
\hline 1472 & Ajuga reptans L. & Tarpa & 1955 & $\begin{array}{l}\text { Siroki Zoltán - } \\
\text { Farkas Attila }\end{array}$ & DE-siroki-13886.jpg \\
\hline 1473 & Ajuga genevensis L. & "Nagymező" & - & Siroki Zoltán & DE-siroki-13893.jpg \\
\hline 1473 & Ajuga genevensis L. & Debrecen & 1948 & Siroki Zoltán & DE-siroki-13899.jpg \\
\hline 1473 & Ajuga genevensis L. & Debrecen & 1948 & Siroki Zoltán & DE-siroki-13898.jpg \\
\hline 1473 & Ajuga genevensis L. & Debrecen & 1949 & Siroki Zoltán & DE-siroki-13897.jpg \\
\hline 1473 & Ajuga genevensis L. & Debrecen & 1950 & Siroki Zoltán & DE-siroki-13894.jpg \\
\hline 1473 & Ajuga genevensis L. & Debrecen & 1954 & Siroki Zoltán & DE-siroki-13895.jpg \\
\hline 1473 & Ajuga genevensis L. & Debrecen & 1964 & Siroki Zoltán & DE-siroki-13891.jpg \\
\hline 1473 & Ajuga genevensis L. & Debrecen & 1964 & Siroki Zoltán & DE-siroki-13892.jpg \\
\hline 1473 & Ajuga genevensis L. & Mosonmagyaróvár & 1939 & Siroki Zoltán & DE-siroki-13900.jpg \\
\hline 1473 & Ajuga genevensis L. & Szilvásvárad & 1954 & Siroki Zoltán & DE-siroki-13896.jpg \\
\hline 1475 & Teucrium montanum L. & "Vértes" & 1957 & Siroki Zoltán & DE-siroki-13911.jpg \\
\hline 1475 & Teucrium montanum L. & "Vértes" & 1957 & Siroki Zoltán & DE-siroki-13909.jpg \\
\hline 1475 & Teucrium montanum L. & "Vértes" & 1957 & Siroki Zoltán & DE-siroki-13910.jpg \\
\hline 1475 & Teucrium montanum L. & Aggtelek & 1972 & Siroki Zoltán & DE-siroki-13915.jpg \\
\hline 1475 & Teucrium montanum L. & Aggtelek & 1972 & Siroki Zoltán & DE-siroki-13908.jpg \\
\hline 1475 & Teucrium montanum L. & Budapest & 1948 & Siroki Zoltán & DE-siroki-13913.jpg \\
\hline 1475 & Teucrium montanum L. & Budapest & 1950 & Siroki Zoltán & DE-siroki-13912.jpg \\
\hline 1476 & Teucrium scorodonia L. & Budapest & 1940 & Siroki Zoltán & DE-siroki-13923.jpg \\
\hline 1476 & Teucrium scorodonia L. & Budapest & 1940 & Siroki Zoltán & DE-siroki-13924.jpg \\
\hline 1476 & Teucrium scorodonia L. & Debrecen & 1946 & Siroki Zoltán & DE-siroki-13921.jpg \\
\hline 1476 & Teucrium scorodonia L. & Debrecen & 1947 & Siroki Zoltán & DE-siroki-13920.jpg \\
\hline 1476 & Teucrium scorodonia L. & Debrecen & 1958 & Siroki Zoltán & DE-siroki-13922.jpg \\
\hline 1476 & Teucrium scorodonia L. & Hajdúbagos & 1981 & Siroki Zoltán & DE-siroki-13919.jpg \\
\hline 1476 & Teucrium scorodonia L. & Hajdúbagos & 1981 & Siroki Zoltán & DE-siroki-13918.jpg \\
\hline 1477 & Teucrium chamaedrys L. & "Bükk-hg." & 1983 & Siroki Zoltán & DE-siroki-13925.jpg \\
\hline 1477 & Teucrium chamaedrys L. & Bélapátfalva & 1958 & Siroki Zoltán & DE-siroki-13926.jpg \\
\hline 1477 & Teucrium chamaedrys L. & Debrecen & 1947 & Siroki Zoltán & DE-siroki-13927.jpg \\
\hline 1477 & Teucrium chamaedrys L. & Nagykovácsi & 1957 & Siroki Zoltán & DE-siroki-13928.jpg \\
\hline 1477 & Teucrium chamaedrys L. & Tokaj & 1971 & Siroki Zoltán & DE-siroki-13929.jpg \\
\hline 1479 & Scutellaria hastifolia L. & Biharugra & 1961 & Siroki Zoltán & DE-siroki-13939.jpg \\
\hline 1479 & Scutellaria hastifolia L. & Biharugra & 1961 & Siroki Zoltán & DE-siroki-13940.jpg \\
\hline 1479 & Scutellaria hastifolia L. & Debrecen & 1948 & Siroki Zoltán & DE-siroki-13942.jpg \\
\hline 1479 & Scutellaria hastifolia L. & Egyek & 1947 & Siroki Zoltán & DE-siroki-13934.jpg \\
\hline 1479 & Scutellaria hastifolia L. & Háromhuta & 1967 & Siroki Zoltán & DE-siroki-13935.jpg \\
\hline 1479 & Scutellaria hastifolia L. & Háromhuta & 1967 & Siroki Zoltán & DE-siroki-13936.jpg \\
\hline 1479 & Scutellaria hastifolia L. & Tiszafüred & 1955 & Siroki Zoltán & DE-siroki-13937.jpg \\
\hline 1480 & Scutellaria galericulata L. & Debrecen & 1947 & Siroki Zoltán & DE-siroki-13947.jpg \\
\hline
\end{tabular}




\begin{tabular}{|c|c|c|c|c|c|}
\hline $\begin{array}{l}\text { Sorszám / } \\
\text { Number }\end{array}$ & Taxon-név / Taxon-name & $\begin{array}{l}\text { Település / } \\
\text { Settlement }\end{array}$ & $\begin{array}{l}\text { Év / } \\
\text { Year }\end{array}$ & $\begin{array}{l}\text { Gyújtő / } \\
\text { Collector }\end{array}$ & Fájlnév / File-name \\
\hline 1480 & Scutellaria galericulata L. & Debrecen & 1948 & Siroki Zoltán & DE-siroki-13943.jpg \\
\hline 1480 & Scutellaria galericulata L. & Debrecen & 1948 & Siroki Zoltán & DE-siroki-13944.jpg \\
\hline 1480 & Scutellaria galericulata L. & Kispalád & 1971 & Siroki Zoltán & DE-siroki-13946.jpg \\
\hline 1481 & Scutellaria columnae All. & Budapest & 1887 & Czakó Kálmán & DE-siroki-13951.jpg \\
\hline 1481 & Scutellaria columnae All. & Budapest & 1904 & Baán Lajos & DE-siroki-13950.jpg \\
\hline 1481 & Scutellaria columnae All. & Budapest & 1917 & Degen Árpád & DE-siroki-13949.jpg \\
\hline 1481 & Scutellaria columnae All. & Budapest & 1917 & Degen Árpád & DE-siroki-13952.jpg \\
\hline 1482 & Scutellaria altissima L. & Budapest & 1911 & Kocsis István & DE-siroki-13957.jpg \\
\hline 1482 & Scutellaria altissima L. & Budapest & 1917 & Rigler József & DE-siroki-13954.jpg \\
\hline 1482 & Scutellaria altissima L. & Budapest & 1917 & Rigler József & DE-siroki-13955.jpg \\
\hline 1483 & Marrubium vulgare L. & Debrecen & 1948 & Siroki Zoltán & DE-siroki-13972.jpg \\
\hline 1483 & Marrubium vulgare L. & Debrecen & 1948 & Siroki Zoltán & DE-siroki-13973.jpg \\
\hline 1483 & Marrubium vulgare L. & Debrecen & 1948 & Siroki Zoltán & DE-siroki-13970.jpg \\
\hline 1484 & Marrubium peregrinum L. & Abaújszántó & 1943 & Siroki Zoltán & DE-siroki-13975.jpg \\
\hline 1484 & Marrubium peregrinum L. & Budapest & 1941 & Siroki Zoltán & DE-siroki-13976.jpg \\
\hline 1484 & Marrubium peregrinum L. & Debrecen & 1947 & Siroki Zoltán & DE-siroki-13974.jpg \\
\hline 1485 & Marrubium × paniculatum Desr. & Bajót & 1951 & Kárpáti Zoltán & DE-siroki-13982.jpg \\
\hline 1485 & Marrubium × paniculatum Desr. & Szár & 1957 & Siroki Zoltán & DE-siroki-13978.jpg \\
\hline 1485 & Marrubium × paniculatum Desr. & Szár & 1957 & Siroki Zoltán & DE-siroki-13979.jpg \\
\hline 1485 & Marrubium × paniculatum Desr. & Szár & 1957 & Siroki Zoltán & DE-siroki-13980.jpg \\
\hline 1485 & Marrubium × paniculatum Desr. & Szár & 1957 & Siroki Zoltán & DE-siroki-13981.jpg \\
\hline 1485 & Marrubium × paniculatum Desr. & Szár & 1957 & Siroki Zoltán & DE-siroki-13977.jpg \\
\hline 1486 & Sideritis montana L. & Budapest & 1949 & Siroki Zoltán & DE-siroki-13985.jpg \\
\hline 1486 & Sideritis montana L. & Cegléd & 1969 & Siroki Zoltán & DE-siroki-13983.jpg \\
\hline 1486 & Sideritis montana L. & Cegléd & 1969 & Siroki Zoltán & DE-siroki-13984.jpg \\
\hline 1487 & Melittis melissophyllum L. & "Fáni-völgy" & 1955 & $\begin{array}{l}\text { Siroki Zoltán - } \\
\text { Farkas Attila }\end{array}$ & DE-siroki-14060.jpg \\
\hline 1487 & Melittis melissophyllum L. & Bátorliget & 1957 & Siroki Zoltán & DE-siroki-14061.jpg \\
\hline 1487 & Melittis melissophyllum L. & Budapest & 1951 & Siroki Zoltán & DE-siroki-14048.jpg \\
\hline 1487 & Melittis melissophyllum L. & Budapest & 1962 & Siroki Zoltán & DE-siroki-14049.jpg \\
\hline 1487 & Melittis melissophyllum L. & Budapest & 1962 & Siroki Zoltán & DE-siroki-14050.jpg \\
\hline 1487 & Melittis melissophyllum L. & Budapest & 1962 & Siroki Zoltán & DE-siroki-14051.jpg \\
\hline 1487 & Melittis melissophyllum L. & Budapest & 1981 & Siroki Zoltán & DE-siroki-14052.jpg \\
\hline 1487 & Melittis melissophyllum L. & Budapest & 1981 & Siroki Zoltán & DE-siroki-14053.jpg \\
\hline 1487 & Melittis melissophyllum L. & Budapest & 1981 & Siroki Zoltán & DE-siroki-14054.jpg \\
\hline 1487 & Melittis melissophyllum L. & Budapest & 1981 & Siroki Zoltán & DE-siroki-14055.jpg \\
\hline 1487 & Melittis melissophyllum L. & Budapest & 1981 & Siroki Zoltán & DE-siroki-14056.jpg \\
\hline 1487 & Melittis melissophyllum L. & Budapest & 1981 & Siroki Zoltán & DE-siroki-14057.jpg \\
\hline 1487 & Melittis melissophyllum L. & Háromhuta & 1967 & Siroki Zoltán & DE-siroki-14058.jpg \\
\hline 1487 & Melittis melissophyllum L. & Háromhuta & 1967 & Siroki Zoltán & DE-siroki-14059.jpg \\
\hline 1488 & Phlomis tuberosa L. & Budapest & 1944 & Siroki Zoltán & DE-siroki-14073.jpg \\
\hline 1488 & Phlomis tuberosa L. & Debrecen & 1957 & Siroki Zoltán & DE-siroki-14069.jpg \\
\hline 1488 & Phlomis tuberosa L. & Debrecen & 1957 & Siroki Zoltán & DE-siroki-14070.jpg \\
\hline 1488 & Phlomis tuberosa L. & Debrecen & 1957 & Siroki Zoltán & DE-siroki-14071.jpg \\
\hline 1488 & Phlomis tuberosa L. & Debrecen & 1957 & Siroki Zoltán & DE-siroki-14068.jpg \\
\hline 1488 & Phlomis tuberosa L. & Debrecen & 1959 & Siroki Zoltán & DE-siroki-14064.jpg \\
\hline 1488 & Phlomis tuberosa L. & Debrecen & 1959 & Siroki Zoltán & DE-siroki-14065.jpg \\
\hline
\end{tabular}




\begin{tabular}{|c|c|c|c|c|c|}
\hline $\begin{array}{l}\text { Sorszám / } \\
\text { Number }\end{array}$ & Taxon-név / Taxon-name & $\begin{array}{l}\text { Település / } \\
\text { Settlement }\end{array}$ & $\begin{array}{l}\text { Év / } \\
\text { Year }\end{array}$ & $\begin{array}{l}\text { Gyűjtő / } \\
\text { Collector }\end{array}$ & Fájlnév / File-name \\
\hline 1488 & Phlomis tuberosa L. & Debrecen & 1959 & Siroki Zoltán & DE-siroki-14066.jpg \\
\hline 1488 & Phlomis tuberosa L. & Debrecen & 1959 & Siroki Zoltán & DE-siroki-14067.jpg \\
\hline 1490 & Galeopsis ladanum L. & Kispalád & 1971 & Siroki Zoltán & DE-siroki-14074.jpg \\
\hline 1490 & Galeopsis ladanum L. & Kispalád & 1971 & Siroki Zoltán & DE-siroki-14079.jpg \\
\hline 1490 & Galeopsis ladanum L. & Kispalád & 1971 & Siroki Zoltán & DE-siroki-14080.jpg \\
\hline 1490 & Galeopsis ladanum L. & Kispalád & 1971 & Siroki Zoltán & DE-siroki-14081.jpg \\
\hline 1490 & Galeopsis ladanum L. & Nagyvisnyó & 1966 & Siroki Zoltán & DE-siroki-14075.jpg \\
\hline 1490 & Galeopsis ladanum L. & Szilvásvárad & 1954 & Siroki Zoltán & DE-siroki-14076.jpg \\
\hline 1490 & Galeopsis ladanum L. & Szilvásvárad & 1954 & Siroki Zoltán & DE-siroki-14077.jpg \\
\hline 1491 & Galeopsis angustifolia (Ehrh.) Hoffm. & Budapest & 1940 & Siroki Zoltán & DE-siroki-14084.jpg \\
\hline 1491 & Galeopsis angustifolia (Ehrh.) Hoffm. & Budapest & 1948 & Siroki Zoltán & DE-siroki-14082.jpg \\
\hline 1491 & Galeopsis angustifolia (Ehrh.) Hoffm. & Budapest & 1948 & Siroki Zoltán & DE-siroki-14083.jpg \\
\hline 1492 & Galeopsis pubescens Besser & "Vértes" & 1957 & Siroki Zoltán & DE-siroki-14110.jpg \\
\hline 1492 & Galeopsis pubescens Besser & Debrecen & 1948 & Siroki Zoltán & DE-siroki-14111.jpg \\
\hline 1492 & Galeopsis pubescens Besser & Debrecen & 1948 & Siroki Zoltán & DE-siroki-14112.jpg \\
\hline 1492 & Galeopsis pubescens Besser & Mosonmagyaróvár & 1939 & Siroki Zoltán & DE-siroki-14113.jpg \\
\hline 1492 & Galeopsis pubescens Besser & Mosonmagyaróvár & 1939 & Siroki Zoltán & DE-siroki-14114.jpg \\
\hline 1492 & Galeopsis pubescens Besser & Nagyhalász & 1966 & Gondola István & DE-siroki-14107.jpg \\
\hline 1492 & Galeopsis pubescens Besser & Nagyhalász & 1966 & Gondola István & DE-siroki-14108.jpg \\
\hline 1492 & Galeopsis pubescens Besser & Nagyhalász & 1966 & Gondola István & DE-siroki-14109.jpg \\
\hline 1493 & Galeopsis speciosa Mill. & Háromhuta & 1960 & Siroki Zoltán & DE-siroki-14104.jpg \\
\hline 1493 & Galeopsis speciosa Mill. & Háromhuta & 1960 & Siroki Zoltán & DE-siroki-14098.jpg \\
\hline 1493 & Galeopsis speciosa Mill. & Háromhuta & 1960 & Siroki Zoltán & DE-siroki-14099.jpg \\
\hline 1493 & Galeopsis speciosa Mill. & Háromhuta & 1960 & Siroki Zoltán & DE-siroki-14102.jpg \\
\hline 1493 & Galeopsis speciosa Mill. & Háromhuta & 1960 & Siroki Zoltán & DE-siroki-14103.jpg \\
\hline 1493 & Galeopsis speciosa Mill. & Háromhuta & 1960 & Siroki Zoltán & DE-siroki-14101.jpg \\
\hline 1493 & Galeopsis speciosa Mill. & Háromhuta & 1968 & Siroki Zoltán & DE-siroki-14100.jpg \\
\hline 1493 & Galeopsis speciosa Mill. & Mosonmagyaróvár & 1939 & Siroki Zoltán & DE-siroki-14105.jpg \\
\hline 1493 & Galeopsis speciosa Mill. & Mosonmagyaróvár & 1939 & Siroki Zoltán & DE-siroki-14106.jpg \\
\hline 1494 & Galeopsis tetrahit L. & Háromhuta & 1960 & Siroki Zoltán & DE-siroki-14090.jpg \\
\hline 1494 & Galeopsis tetrahit L. & Háromhuta & 1960 & Siroki Zoltán & DE-siroki-14092.jpg \\
\hline 1494 & Galeopsis tetrahit L. & Háromhuta & 1960 & Siroki Zoltán & DE-siroki-14093.jpg \\
\hline 1494 & Galeopsis tetrahit L. & Háromhuta & 1960 & Siroki Zoltán & DE-siroki-14094.jpg \\
\hline 1494 & Galeopsis tetrahit L. & Háromhuta & 1961 & Siroki Zoltán & DE-siroki-14091.jpg \\
\hline 1494 & Galeopsis tetrahit L. & Nagyhalász & 1966 & Gondola István & DE-siroki-14087.jpg \\
\hline 1494 & Galeopsis tetrahit L. & Nagyhalász & 1966 & Gondola István & DE-siroki-14088.jpg \\
\hline 1494 & Galeopsis tetrahit L. & Nagyhalász & 1966 & Gondola István & DE-siroki-14089.jpg \\
\hline 1494 & Galeopsis tetrahit L. & Tiszatelek & 1966 & Gondola István & DE-siroki-14085.jpg \\
\hline 1494 & Galeopsis tetrahit L. & Tiszatelek & 1966 & Gondola István & DE-siroki-14086.jpg \\
\hline 1495 & Galeopsis bifida Boenn. & Háromhuta & 1978 & Siroki Zoltán & DE-siroki-14096.jpg \\
\hline 1497 & Lamium album L. & "Nagymező" & 1959 & Halász Tibor & DE-siroki-14126.jpg \\
\hline 1497 & Lamium album L. & Bátorliget & 1954 & Siroki Zoltán & DE-siroki-14127.jpg \\
\hline 1497 & Lamium album L. & Debrecen & 1949 & Siroki Zoltán & DE-siroki-14128.jpg \\
\hline 1497 & Lamium album L. & Debrecen & 1949 & Siroki Zoltán & DE-siroki-14125.jpg \\
\hline 1497 & Lamium album L. & Debrecen & 1955 & Siroki Zoltán & DE-siroki-14124.jpg \\
\hline 1497 & Lamium album L. & Debrecen & 1977 & Siroki Zoltán & DE-siroki-14137.jpg \\
\hline
\end{tabular}




\begin{tabular}{|c|c|c|c|c|c|}
\hline $\begin{array}{l}\text { Sorszám / } \\
\text { Number }\end{array}$ & Taxon-név / Taxon-name & $\begin{array}{l}\text { Település / } \\
\text { Settlement }\end{array}$ & $\begin{array}{l}\text { Év / } \\
\text { Year }\end{array}$ & $\begin{array}{l}\text { Gyűjtő / } \\
\text { Collector }\end{array}$ & Fájlnév / File-name \\
\hline 1498 & Lamium maculatum L. & Budapest & 1960 & Siroki Zoltán & DE-siroki-14131.jpg \\
\hline 1498 & Lamium maculatum L. & Budapest & 1960 & Siroki Zoltán & DE-siroki-14132.jpg \\
\hline 1498 & Lamium maculatum L. & Budapest & 1960 & Siroki Zoltán & DE-siroki-14133.jpg \\
\hline 1498 & Lamium maculatum L. & Budapest & 1970 & Siroki Zoltán & DE-siroki-14129.jpg \\
\hline 1498 & Lamium maculatum L. & Budapest & 1970 & Siroki Zoltán & DE-siroki-14130.jpg \\
\hline 1499 & Lamium amplexicaule L. & Debrecen & 1947 & Siroki Zoltán & DE-siroki-14120.jpg \\
\hline 1500 & Lamium purpureum L. & Debrecen & 1947 & Siroki Zoltán & DE-siroki-14122.jpg \\
\hline 1500 & Lamium purpureum L. & Debrecen & 1958 & Halász Tibor & DE-siroki-14121.jpg \\
\hline 1502 & Galeobdolon luteum Huds. & Budapest & 1951 & Siroki Zoltán & DE-siroki-14116.jpg \\
\hline 1502 & Galeobdolon luteum Huds. & Nagyhuta & 1961 & Siroki Zoltán & DE-siroki-14115.jpg \\
\hline 1504 & Leonurus cardiaca L. & Encs & 1944 & Siroki Zoltán & DE-siroki-14138.jpg \\
\hline 1505 & Leonurus marrubiastrum L. & Debrecen & 1948 & Siroki Zoltán & DE-siroki-14150.jpg \\
\hline 1505 & Leonurus marrubiastrum L. & Debrecen & 1948 & Siroki Zoltán & DE-siroki-14141.jpg \\
\hline 1505 & Leonurus marrubiastrum L. & Debrecen & 1949 & Siroki Zoltán & DE-siroki-14148.jpg \\
\hline 1505 & Leonurus marrubiastrum L. & Debrecen & 1949 & Siroki Zoltán & DE-siroki-14151.jpg \\
\hline 1505 & Leonurus marrubiastrum L. & Dombrád & 1966 & Gondola István & DE-siroki-14142.jpg \\
\hline 1505 & Leonurus marrubiastrum L. & Dombrád & 1966 & Gondola István & DE-siroki-14143.jpg \\
\hline 1505 & Leonurus marrubiastrum L. & Egyek & 1947 & Siroki Zoltán & DE-siroki-14147.jpg \\
\hline 1505 & Leonurus marrubiastrum L. & Tiszatelek & 1966 & Gondola István & DE-siroki-14144.jpg \\
\hline 1505 & Leonurus marrubiastrum L. & Tiszatelek & 1966 & Gondola István & DE-siroki-14145.jpg \\
\hline 1505 & Leonurus marrubiastrum L. & Tiszatelek & 1966 & Gondola István & DE-siroki-14146.jpg \\
\hline 1506 & Ballota nigra L. & Debrecen & 1947 & Siroki Zoltán & DE-siroki-14153.jpg \\
\hline 1506 & Ballota nigra L. & Debrecen & 1948 & Siroki Zoltán & DE-siroki-14152.jpg \\
\hline 1506 & Ballota nigra L. & Mosonmagyaróvár & 1939 & Siroki Zoltán & DE-siroki-14154.jpg \\
\hline 1507 & Betonica officinalis L. & Egyek & 1947 & Siroki Zoltán & DE-siroki-14157.jpg \\
\hline 1507 & Betonica officinalis L. & Regéc & 1967 & Siroki Zoltán & DE-siroki-14156.jpg \\
\hline 1508 & Stachys annua L. & Abaújkér & 1943 & Siroki Zoltán & DE-siroki-14162.jpg \\
\hline 1508 & Stachys annua L. & Debrecen & 1947 & Siroki Zoltán & DE-siroki-14160.jpg \\
\hline 1509 & Stachys recta L. & Budapest & 1964 & Siroki Zoltán & DE-siroki-14163.jpg \\
\hline 1509 & Stachys recta L. & Debrecen & 1947 & Siroki Zoltán & DE-siroki-14164.jpg \\
\hline 1510 & Stachys sylvatica L. & Debrecen & 1947 & Siroki Zoltán & DE-siroki-14171.jpg \\
\hline 1510 & Stachys sylvatica L. & Debrecen & 1948 & Siroki Zoltán & DE-siroki-14173.jpg \\
\hline 1510 & Stachys sylvatica L. & Debrecen & 1948 & Siroki Zoltán & DE-siroki-14172.jpg \\
\hline 1510 & Stachys sylvatica L. & Háromhuta & 1977 & Siroki Zoltán & DE-siroki-14167.jpg \\
\hline 1510 & Stachys sylvatica L. & Hollóháza & 1940 & Siroki Zoltán & DE-siroki-14174.jpg \\
\hline 1510 & Stachys sylvatica L. & Mátraszentimre & 1958 & Pethő Menyhért & DE-siroki-14170.jpg \\
\hline 1510 & Stachys sylvatica L. & Pásztó & 1959 & Gondola István & DE-siroki-14169.jpg \\
\hline 1510 & Stachys sylvatica L. & Recsk & 1981 & Rácz Gy.-né & DE-siroki-14166.jpg \\
\hline 1511 & Stachys palustris L. & Debrecen & 1948 & Siroki Zoltán & DE-siroki-14183.jpg \\
\hline 1511 & Stachys palustris L. & Debrecen & 1959 & Siroki Zoltán & DE-siroki-14179.jpg \\
\hline 1511 & Stachys palustris L. & Debrecen & 1959 & Siroki Zoltán & DE-siroki-14180.jpg \\
\hline 1511 & Stachys palustris L. & Debrecen & 1959 & Siroki Zoltán & DE-siroki-14181.jpg \\
\hline 1511 & Stachys palustris L. & Egyek & 1947 & Siroki Zoltán & DE-siroki-14182.jpg \\
\hline 1511 & Stachys palustris L. & Kispalád & 1971 & Siroki Zoltán & DE-siroki-14177.jpg \\
\hline 1511 & Stachys palustris L. & Kispalád & 1971 & Siroki Zoltán & DE-siroki-14178.jpg \\
\hline 1511 & Stachys palustris L. & Mosonmagyaróvár & 1939 & Siroki Zoltán & DE-siroki-14184.jpg \\
\hline
\end{tabular}




\begin{tabular}{|c|c|c|c|c|c|}
\hline $\begin{array}{l}\text { Sorszám / } \\
\text { Number }\end{array}$ & Taxon-név / Taxon-name & $\begin{array}{l}\text { Település / } \\
\text { Settlement }\end{array}$ & $\begin{array}{l}\text { Év / } \\
\text { Year }\end{array}$ & $\begin{array}{l}\text { Gyűjtő / } \\
\text { Collector }\end{array}$ & Fájlnév / File-name \\
\hline 1511 & Stachys palustris L. & Mosonmagyaróvár & 1939 & Siroki Zoltán & DE-siroki-14185.jpg \\
\hline 1511 & Stachys palustris L. & Tiszafüred & 1970 & Siroki Zoltán & DE-siroki-14175.jpg \\
\hline 1512 & Stachys alpina L. & Hosszúhetény & 1954 & Siroki Zoltán & DE-siroki-14190.jpg \\
\hline 1512 & Stachys alpina L. & Hosszúhetény & 1954 & Siroki Zoltán & DE-siroki-14191.jpg \\
\hline 1512 & Stachys alpina L. & Hosszúhetény & 1954 & Siroki Zoltán & DE-siroki-14192.jpg \\
\hline 1512 & Stachys alpina L. & Hosszúhetény & 1954 & Siroki Zoltán & DE-siroki-14193.jpg \\
\hline 1512 & Stachys alpina L. & Hosszúhetény & 1954 & Siroki Zoltán & DE-siroki-14194.jpg \\
\hline 1512 & Stachys alpina L. & Hosszúhetény & 1954 & Siroki Zoltán & DE-siroki-14195.jpg \\
\hline 1512 & Stachys alpina L. & Hosszúhetény & 1954 & Siroki Zoltán & DE-siroki-14196.jpg \\
\hline 1513 & Stachys germanica L. & Debrecen & 1948 & Siroki Zoltán & DE-siroki-14200.jpg \\
\hline 1513 & Stachys germanica L. & Debrecen & 1948 & Siroki Zoltán & DE-siroki-14201.jpg \\
\hline 1516 & Nepeta pannonica L. & Debrecen & 1948 & Siroki Zoltán & DE-siroki-14004.jpg \\
\hline 1516 & Nepeta pannonica L. & Debrecen & 1948 & Siroki Zoltán & DE-siroki-14006.jpg \\
\hline 1516 & Nepeta pannonica L. & Keszthely & 1955 & Siroki Zoltán & DE-siroki-14005.jpg \\
\hline 1516 & Nepeta pannonica L. & Szilvásvárad & 1959 & Siroki Zoltán & DE-siroki-14003.jpg \\
\hline 1517 & Nepeta cataria L. & Dömsöd & 1952 & Siroki Zoltán & DE-siroki-13999.jpg \\
\hline 1517 & Nepeta cataria L. & Egyek & 1947 & Siroki Zoltán & DE-siroki-14000.jpg \\
\hline 1518 & Glechoma hederacea L. & Mosonmagyaróvár & 1939 & Siroki Zoltán & DE-siroki-13994.jpg \\
\hline 1518 & Glechoma hederacea L. & Mosonmagyaróvár & 1939 & Siroki Zoltán & DE-siroki-13993.jpg \\
\hline 1519 & Glechoma hirsuta Waldst. et Kit. & Debrecen & 1947 & Siroki Zoltán & DE-siroki-13989.jpg \\
\hline 1519 & Glechoma hirsuta Waldst. et Kit. & Debrecen & 1947 & Siroki Zoltán & DE-siroki-13990.jpg \\
\hline 1519 & Glechoma hirsuta Waldst. et Kit. & Debrecen & 1949 & Siroki Zoltán & DE-siroki-13991.jpg \\
\hline 1520 & Dracocephalum ruyschiana L. & "Nagymező" & 1960 & Siroki Zoltán & DE-siroki-14014.jpg \\
\hline 1520 & Dracocephalum ruyschiana L. & "Nagymező" & 1973 & Siroki Zoltán & DE-siroki-14012.jpg \\
\hline 1520 & Dracocephalum ruyschiana L. & "Nagymező" & 1973 & Siroki Zoltán & DE-siroki-14013.jpg \\
\hline 1522 & Prunella laciniata L. & Budapest & 1951 & Siroki Zoltán & DE-siroki-14040.jpg \\
\hline 1522 & Prunella laciniata L. & Budapest & 1951 & Siroki Zoltán & DE-siroki-14041.jpg \\
\hline 1522 & Prunella laciniata L. & Debrecen & 1954 & Siroki Zoltán & DE-siroki-14042.jpg \\
\hline 1522 & Prunella laciniata L. & Debrecen & 1954 & Siroki Zoltán & DE-siroki-14043.jpg \\
\hline 1522 & Prunella laciniata L. & Háromhuta & 1961 & Siroki Zoltán & DE-siroki-14038.jpg \\
\hline 1522 & Prunella laciniata L. & Háromhuta & 1961 & Siroki Zoltán & DE-siroki-14039.jpg \\
\hline 1523 & Prunella vulgaris L. & Debrecen & 1948 & Siroki Zoltán & DE-siroki-14031.jpg \\
\hline 1523 & Prunella vulgaris L. & Debrecen & 1948 & Siroki Zoltán & DE-siroki-14033.jpg \\
\hline 1523 & Prunella vulgaris L. & Egyek & 1947 & Siroki Zoltán & DE-siroki-14032.jpg \\
\hline 1523 & Prunella vulgaris L. & Mosonmagyaróvár & 1939 & Siroki Zoltán & DE-siroki-14035.jpg \\
\hline 1523 & Prunella vulgaris L. & Mosonmagyaróvár & 1939 & Siroki Zoltán & DE-siroki-14036.jpg \\
\hline 1524 & Prunella grandiflora (L.) Scholler & "Nagymező" & 1959 & Siroki Zoltán & DE-siroki-14020.jpg \\
\hline 1524 & Prunella grandiflora (L.) Scholler & "Nagymező" & 1959 & Siroki Zoltán & DE-siroki-14021.jpg \\
\hline 1524 & Prunella grandiflora (L.) Scholler & "Nagymező" & 1959 & Siroki Zoltán & DE-siroki-14022.jpg \\
\hline 1524 & Prunella grandiflora (L.) Scholler & Budapest & 1941 & Siroki Zoltán & DE-siroki-14024.jpg \\
\hline 1524 & Prunella grandiflora (L.) Scholler & Háromhuta & 1960 & Siroki Zoltán & DE-siroki-14015.jpg \\
\hline 1524 & Prunella grandiflora (L.) Scholler & Háromhuta & 1960 & Siroki Zoltán & DE-siroki-14016.jpg \\
\hline 1524 & Prunella grandiflora (L.) Scholler & Háromhuta & 1960 & Siroki Zoltán & DE-siroki-14017.jpg \\
\hline 1524 & Prunella grandiflora (L.) Scholler & Háromhuta & 1962 & Siroki Zoltán & DE-siroki-14018.jpg \\
\hline 1524 & Prunella grandiflora (L.) Scholler & Háromhuta & 1962 & Siroki Zoltán & DE-siroki-14019.jpg \\
\hline 1524 & Prunella grandiflora (L.) Scholler & Mátraverebély & 1952 & Siroki Zoltán & DE-siroki-14023.jpg \\
\hline
\end{tabular}




\begin{tabular}{|c|c|c|c|c|c|}
\hline $\begin{array}{l}\text { Sorszám / } \\
\text { Number }\end{array}$ & Taxon-név / Taxon-name & $\begin{array}{l}\text { Település / } \\
\text { Settlement }\end{array}$ & $\begin{array}{l}\text { Év / } \\
\text { Year }\end{array}$ & $\begin{array}{l}\text { Gyűjtő / } \\
\text { Collector }\end{array}$ & Fájlnév / File-name \\
\hline 1524 & Prunella grandiflora (L.) Scholler & Sátoraljaújhely & 1944 & Siroki Zoltán & DE-siroki-14025.jpg \\
\hline $\begin{array}{c}1522 \times \\
1523\end{array}$ & $\begin{array}{l}\text { Prunella } \times \text { intermedia Link } \\
(\text { P. laciniata } \times \text { vulgaris })\end{array}$ & Hosszúhetény & 1954 & Siroki Zoltán & DE-siroki-14044.jpg \\
\hline $\begin{array}{c}1522 \times \\
1523\end{array}$ & $\begin{array}{l}\text { Prunella } \times \text { intermedia Link } \\
(\text { P. laciniata } \times \text { vulgaris) }\end{array}$ & Hosszúhetény & 1954 & Siroki Zoltán & DE-siroki-14037.jpg \\
\hline 1525 & Melissa officinalis L. & Hosszúhetény & 1954 & Siroki Zoltán & DE-siroki-14247.jpg \\
\hline 1525 & Melissa officinalis L. & Hosszúhetény & 1954 & Siroki Zoltán & DE-siroki-14249.jpg \\
\hline 1525 & Melissa officinalis L. & Hosszúhetény & 1954 & Siroki Zoltán & DE-siroki-14250.jpg \\
\hline 1525 & Melissa officinalis L. & Pécs & 1954 & Siroki Zoltán & DE-siroki-14246.jpg \\
\hline 1525 & Melissa officinalis L. & Pécs & 1954 & Siroki Zoltán & DE-siroki-14244.jpg \\
\hline 1525 & Melissa officinalis L. & Pécs & 1954 & Siroki Zoltán & DE-siroki-14245.jpg \\
\hline 1525 & Melissa officinalis L. & Pécs & 1954 & Siroki Zoltán & DE-siroki-14248.jpg \\
\hline 1527 & Acinos arvensis (Lam.) Dandy & Budapest & 1906 & Kocsis István & DE-siroki-14255.jpg \\
\hline 1527 & Acinos arvensis (Lam.) Dandy & Budapest & 1906 & Kocsis István & DE-siroki-14254.jpg \\
\hline 1527 & Acinos arvensis (Lam.) Dandy & Debrecen & 1947 & Siroki Zoltán & DE-siroki-14259.jpg \\
\hline 1527 & Acinos arvensis (Lam.) Dandy & Debrecen & 1949 & Siroki Zoltán & DE-siroki-14258.jpg \\
\hline 1527 & Acinos arvensis (Lam.) Dandy & Vámospércs & 1965 & Siroki Zoltán & DE-siroki-14256.jpg \\
\hline 1527 & Acinos arvensis (Lam.) Dandy & Vámospércs & 1965 & Siroki Zoltán & DE-siroki-14257.jpg \\
\hline 1528 & Calamintha menthifolia Host & "Vértes" & 1957 & Siroki Zoltán & DE-siroki-14272.jpg \\
\hline 1528 & Calamintha menthifolia Host & "Vértes" & 1957 & Siroki Zoltán & DE-siroki-14273.jpg \\
\hline 1528 & Calamintha menthifolia Host & "Vértes" & 1957 & Siroki Zoltán & DE-siroki-14275.jpg \\
\hline 1528 & Calamintha menthifolia Host & "Vértes" & 1957 & Siroki Zoltán & DE-siroki-14279.jpg \\
\hline 1528 & Calamintha menthifolia Host & "Vértes" & 1957 & Siroki Zoltán & DE-siroki-14274.jpg \\
\hline 1528 & Calamintha menthifolia Host & "Vértes" & 1957 & Siroki Zoltán & DE-siroki-14280.jpg \\
\hline 1528 & Calamintha menthifolia Host & Balatonederics & 1955 & Siroki Zoltán & DE-siroki-14276.jpg \\
\hline 1528 & Calamintha menthifolia Host & Balatonederics & 1955 & Siroki Zoltán & DE-siroki-14277.jpg \\
\hline 1528 & Calamintha menthifolia Host & Sopron & 1950 & Kárpáti Zoltán & DE-siroki-14270.jpg \\
\hline 1530 & Clinopodium vulgare L. & Debrecen & 1948 & Siroki Zoltán & DE-siroki-14253.jpg \\
\hline 1530 & Clinopodium vulgare L. & Mosonmagyaróvár & 1939 & Siroki Zoltán & DE-siroki-14251.jpg \\
\hline 1530 & Clinopodium vulgare L. & Mosonmagyaróvár & 1939 & Siroki Zoltán & DE-siroki-14252.jpg \\
\hline 1532 & Hyssopus officinalis L. & Szár & 1957 & Siroki Zoltán & DE-siroki-14295.jpg \\
\hline 1532 & Hyssopus officinalis L. & Szár & 1957 & Siroki Zoltán & DE-siroki-14296.jpg \\
\hline 1532 & Hyssopus officinalis L. & Szár & 1957 & Siroki Zoltán & DE-siroki-14297.jpg \\
\hline 1532 & Hyssopus officinalis L. & Szár & 1957 & Siroki Zoltán & DE-siroki-14300.jpg \\
\hline 1532 & Hyssopus officinalis L. & Szár & 1957 & Siroki Zoltán & DE-siroki-14301.jpg \\
\hline 1534 & Origanum vulgare L. & "Háromkő" & 1956 & Halász Tibor & DE-siroki-14307.jpg \\
\hline 1534 & Origanum vulgare L. & Pomáz & 1954 & Siroki Zoltán & DE-siroki-14306.jpg \\
\hline 1536 & Thymus pulegioides L. & "Nagymező" & 1959 & Siroki Zoltán & DE-siroki-14448.jpg \\
\hline 1536 & Thymus pulegioides L. & "Nagymező" & 1959 & Siroki Zoltán & DE-siroki-14449.jpg \\
\hline 1536 & Thymus pulegioides L. & "Nagymező" & 1959 & Siroki Zoltán & DE-siroki-14450.jpg \\
\hline 1536 & Thymus pulegioides L. & "Nagymező" & 1959 & Siroki Zoltán & DE-siroki-14451.jpg \\
\hline 1536 & Thymus pulegioides L. & "Szent-György-hegy" & 1955 & Siroki Zoltán & DE-siroki-14461.jpg \\
\hline 1536 & Thymus pulegioides L. & Háromhuta & 1960 & Siroki Zoltán & DE-siroki-14452.jpg \\
\hline 1536 & Thymus pulegioides L. & Háromhuta & 1960 & Siroki Zoltán & DE-siroki-14453.jpg \\
\hline 1536 & Thymus pulegioides L. & Háromhuta & 1960 & Siroki Zoltán & DE-siroki-14454.jpg \\
\hline 1536 & Thymus pulegioides L. & Háromhuta & 1961 & Siroki Zoltán & DE-siroki-14458.jpg \\
\hline 1536 & Thymus pulegioides L. & Háromhuta & 1961 & Siroki Zoltán & DE-siroki-14459.jpg \\
\hline
\end{tabular}




\begin{tabular}{|c|c|c|c|c|c|}
\hline $\begin{array}{l}\text { Sorszám / } \\
\text { Number }\end{array}$ & Taxon-név / Taxon-name & $\begin{array}{l}\text { Település / } \\
\text { Settlement }\end{array}$ & $\begin{array}{l}\text { Év / } \\
\text { Year }\end{array}$ & $\begin{array}{l}\text { Gyűjtő / } \\
\text { Collector }\end{array}$ & Fájlnév / File-name \\
\hline 1536 & Thymus pulegioides L. & Háromhuta & 1962 & Siroki Zoltán & DE-siroki-14455.jpg \\
\hline 1536 & Thymus pulegioides L. & Háromhuta & 1962 & Siroki Zoltán & DE-siroki-14456.jpg \\
\hline 1536 & Thymus pulegioides L. & Háromhuta & 1962 & Siroki Zoltán & DE-siroki-14457.jpg \\
\hline 1536 & Thymus pulegioides L. & Háromhuta & 1965 & Gondola István & DE-siroki-14463.jpg \\
\hline 1536 & Thymus pulegioides L. & Háromhuta & 1965 & Gondola István & DE-siroki-14464.jpg \\
\hline 1536 & Thymus pulegioides L. & Háromhuta & 1965 & Siroki Zoltán & DE-siroki-14432.jpg \\
\hline 1536 & Thymus pulegioides L. & Háromhuta & 1965 & Siroki Zoltán & DE-siroki-14431.jpg \\
\hline 1536 & Thymus pulegioides L. & Háromhuta & 1977 & Siroki Zoltán & DE-siroki-14446.jpg \\
\hline 1536 & Thymus pulegioides L. & Háromhuta & 1977 & Siroki Zoltán & DE-siroki-14447.jpg \\
\hline 1536 & Thymus pulegioides L. & Hosszúhetény & 1954 & Siroki Zoltán & DE-siroki-14462.jpg \\
\hline 1536 & Thymus pulegioides L. & Hosszúhetény & 1954 & Siroki Zoltán & DE-siroki-14460.jpg \\
\hline 1536 & Thymus pulegioides L. & Pásztó & 1952 & Siroki Zoltán & DE-siroki-14441.jpg \\
\hline 1536 & Thymus pulegioides L. & Pécs & 1954 & Siroki Zoltán & DE-siroki-14433.jpg \\
\hline 1536 & Thymus pulegioides L. & Pécs & 1954 & Siroki Zoltán & DE-siroki-14438.jpg \\
\hline 1536 & Thymus pulegioides L. & Pécs & 1954 & Siroki Zoltán & DE-siroki-14439.jpg \\
\hline 1536 & Thymus pulegioides L. & Uzsa & 1971 & Siroki Zoltán & DE-siroki-14428.jpg \\
\hline 1536 & Thymus pulegioides L. & Uzsa & 1971 & Siroki Zoltán & DE-siroki-14429.jpg \\
\hline 1536 & Thymus pulegioides L. & Uzsa & 1971 & Siroki Zoltán & DE-siroki-14430.jpg \\
\hline 1537 & Thymus pannonicus All. & Boldogkőváralja & 1967 & Siroki Zoltán & DE-siroki-14319.jpg \\
\hline 1537 & Thymus pannonicus All. & Debrecen & 1946 & Siroki Zoltán & DE-siroki-14328.jpg \\
\hline 1537 & Thymus pannonicus All. & Debrecen & 1947 & Siroki Zoltán & DE-siroki-14327.jpg \\
\hline 1537 & Thymus pannonicus All. & Debrecen & 1948 & Siroki Zoltán & DE-siroki-14325.jpg \\
\hline 1537 & Thymus pannonicus All. & Debrecen & 1959 & Siroki Zoltán & DE-siroki-14315.jpg \\
\hline 1537 & Thymus pannonicus All. & Debrecen & 1959 & Siroki Zoltán & DE-siroki-14316.jpg \\
\hline 1537 & Thymus pannonicus All. & Debrecen & 1959 & Siroki Zoltán & DE-siroki-14317.jpg \\
\hline 1537 & Thymus pannonicus All. & Egyek & 1947 & Siroki Zoltán & DE-siroki-14326.jpg \\
\hline 1537 & Thymus pannonicus All. & Gödöllő & 1952 & Siroki Zoltán & DE-siroki-14313.jpg \\
\hline 1537 & Thymus pannonicus All. & Háromhuta & 1961 & Siroki Zoltán & DE-siroki-14314.jpg \\
\hline 1537 & Thymus pannonicus All. & Sirok & 1964 & Siroki Zoltán & DE-siroki-14321.jpg \\
\hline 1537 & Thymus pannonicus All. & Sirok & - & Siroki Zoltán & DE-siroki-14318.jpg \\
\hline 1537 & Thymus pannonicus All. & Szentistván & 1980 & Siroki Zoltán & DE-siroki-14320.jpg \\
\hline 1538 & Thymus glabrescens Willd. & "Háromkő" & 1957 & Siroki Zoltán & DE-siroki-14341.jpg \\
\hline 1538 & Thymus glabrescens Willd. & "Nagymező" & 1959 & Siroki Zoltán & DE-siroki-14349.jpg \\
\hline 1538 & Thymus glabrescens Willd. & "Nagymező" & 1959 & Siroki Zoltán & DE-siroki-14350.jpg \\
\hline 1538 & Thymus glabrescens Willd. & Boldogkőváralja & 1942 & Siroki Zoltán & DE-siroki-14334.jpg \\
\hline 1538 & Thymus glabrescens Willd. & Budapest & 1962 & Siroki Zoltán & DE-siroki-14337.jpg \\
\hline 1538 & Thymus glabrescens Willd. & Budapest & 1962 & Siroki Zoltán & DE-siroki-14338.jpg \\
\hline 1538 & Thymus glabrescens Willd. & Debrecen & 1946 & Siroki Zoltán & DE-siroki-14348.jpg \\
\hline 1538 & Thymus glabrescens Willd. & Debrecen & 1946 & Siroki Zoltán & DE-siroki-14377.jpg \\
\hline 1538 & Thymus glabrescens Willd. & Debrecen & 1946 & Siroki Zoltán & DE-siroki-14387.jpg \\
\hline 1538 & Thymus glabrescens Willd. & Debrecen & 1946 & Siroki Zoltán & DE-siroki-14366.jpg \\
\hline 1538 & Thymus glabrescens Willd. & Debrecen & 1946 & Siroki Zoltán & DE-siroki-14396.jpg \\
\hline 1538 & Thymus glabrescens Willd. & Debrecen & 1946 & Siroki Zoltán & DE-siroki-14394.jpg \\
\hline 1538 & Thymus glabrescens Willd. & Debrecen & 1946 & Siroki Zoltán & DE-siroki-14395.jpg \\
\hline 1538 & Thymus glabrescens Willd. & Debrecen & 1946 & Siroki Zoltán & DE-siroki-14375.jpg \\
\hline 1538 & Thymus glabrescens Willd. & Debrecen & 1946 & Siroki Zoltán & DE-siroki-14380.jpg \\
\hline
\end{tabular}




\begin{tabular}{|c|c|c|c|c|c|}
\hline $\begin{array}{l}\text { Sorszám / } \\
\text { Number }\end{array}$ & Taxon-név / Taxon-name & $\begin{array}{l}\text { Település / } \\
\text { Settlement }\end{array}$ & $\begin{array}{l}\text { Év / } \\
\text { Year }\end{array}$ & $\begin{array}{l}\text { Gyűjtő / } \\
\text { Collector }\end{array}$ & Fájlnév / File-name \\
\hline 1538 & Thymus glabrescens Willd. & Debrecen & 1947 & Siroki Zoltán & DE-siroki-14385.jpg \\
\hline 1538 & Thymus glabrescens Willd. & Debrecen & 1947 & Siroki Zoltán & DE-siroki-14367.jpg \\
\hline 1538 & Thymus glabrescens Willd. & Debrecen & 1947 & Siroki Zoltán & DE-siroki-14354.jpg \\
\hline 1538 & Thymus glabrescens Willd. & Debrecen & 1947 & Siroki Zoltán & DE-siroki-14382.jpg \\
\hline 1538 & Thymus glabrescens Willd. & Debrecen & 1947 & Siroki Zoltán & DE-siroki-14400.jpg \\
\hline 1538 & Thymus glabrescens Willd. & Debrecen & 1948 & Siroki Zoltán & DE-siroki-14365.jpg \\
\hline 1538 & Thymus glabrescens Willd. & Debrecen & 1948 & Siroki Zoltán & DE-siroki-14384.jpg \\
\hline 1538 & Thymus glabrescens Willd. & Debrecen & 1948 & Siroki Zoltán & DE-siroki-14386.jpg \\
\hline 1538 & Thymus glabrescens Willd. & Debrecen & 1948 & Siroki Zoltán & DE-siroki-14369.jpg \\
\hline 1538 & Thymus glabrescens Willd. & Debrecen & 1948 & Siroki Zoltán & DE-siroki-14398.jpg \\
\hline 1538 & Thymus glabrescens Willd. & Debrecen & 1948 & Siroki Zoltán & DE-siroki-14376.jpg \\
\hline 1538 & Thymus glabrescens Willd. & Debrecen & 1948 & Siroki Zoltán & DE-siroki-14378.jpg \\
\hline 1538 & Thymus glabrescens Willd. & Debrecen & 1954 & Siroki Zoltán & DE-siroki-14374.jpg \\
\hline 1538 & Thymus glabrescens Willd. & Debrecen & 1954 & Siroki Zoltán & DE-siroki-14381.jpg \\
\hline 1538 & Thymus glabrescens Willd. & Debrecen & 1954 & Siroki Zoltán & DE-siroki-14383.jpg \\
\hline 1538 & Thymus glabrescens Willd. & Debrecen & 1956 & Siroki Zoltán & DE-siroki-14353.jpg \\
\hline 1538 & Thymus glabrescens Willd. & Egyek & 1948 & Siroki Zoltán & DE-siroki-14370.jpg \\
\hline 1538 & Thymus glabrescens Willd. & Egyek & 1948 & Siroki Zoltán & DE-siroki-14371.jpg \\
\hline 1538 & Thymus glabrescens Willd. & Gödöllő & 1951 & Siroki Zoltán & DE-siroki-14360.jpg \\
\hline 1538 & Thymus glabrescens Willd. & Gödöllő & 1951 & Siroki Zoltán & DE-siroki-14361.jpg \\
\hline 1538 & Thymus glabrescens Willd. & Gödöllő & 1952 & Siroki Zoltán & DE-siroki-14359.jpg \\
\hline 1538 & Thymus glabrescens Willd. & Gödöllő & 1952 & Siroki Zoltán & DE-siroki-14362.jpg \\
\hline 1538 & Thymus glabrescens Willd. & Hajdúbagos & 1982 & Siroki Zoltán & DE-siroki-14336.jpg \\
\hline 1538 & Thymus glabrescens Willd. & Hajdúbagos & 1984 & Siroki Zoltán & DE-siroki-14331.jpg \\
\hline 1538 & Thymus glabrescens Willd. & Hajdúbagos & 1984 & Siroki Zoltán & DE-siroki-14330.jpg \\
\hline 1538 & Thymus glabrescens Willd. & Háromhuta & 1962 & Siroki Zoltán & DE-siroki-14347.jpg \\
\hline 1538 & Thymus glabrescens Willd. & Kecskemét & 1969 & Siroki Zoltán & DE-siroki-14342.jpg \\
\hline 1538 & Thymus glabrescens Willd. & Kecskemét & 1969 & Siroki Zoltán & DE-siroki-14343.jpg \\
\hline 1538 & Thymus glabrescens Willd. & Kecskemét & 1969 & Siroki Zoltán & DE-siroki-14344.jpg \\
\hline 1538 & Thymus glabrescens Willd. & Kecskemét & 1969 & Siroki Zoltán & DE-siroki-14345.jpg \\
\hline 1538 & Thymus glabrescens Willd. & Kecskemét & 1969 & Siroki Zoltán & DE-siroki-14355.jpg \\
\hline 1538 & Thymus glabrescens Willd. & Lábatlan & 1986 & Siroki Zoltán & DE-siroki-14373.jpg \\
\hline 1538 & Thymus glabrescens Willd. & Lábatlan & 1986 & Siroki Zoltán & DE-siroki-14335.jpg \\
\hline 1538 & Thymus glabrescens Willd. & Sátoraljaújhely & 1944 & Siroki Zoltán & DE-siroki-14379.jpg \\
\hline 1538 & Thymus glabrescens Willd. & Szilvásvárad & 1960 & Siroki Zoltán & DE-siroki-14363.jpg \\
\hline 1538 & Thymus glabrescens Willd. & Vámospércs & 1984 & Siroki Zoltán & DE-siroki-14364.jpg \\
\hline 1538 & Thymus glabrescens Willd. & Veresegyház & 1960 & Siroki Zoltán & DE-siroki-14339.jpg \\
\hline 1538 & Thymus glabrescens Willd. & Veresegyház & 1960 & Siroki Zoltán & DE-siroki-14340.jpg \\
\hline 1538 & Thymus glabrescens Willd. & Veresegyház & 1960 & Siroki Zoltán & DE-siroki-14346.jpg \\
\hline 1539 & Thymus serpyllum L. & Hajdúbagos & 1981 & Siroki Zoltán & DE-siroki-14329.jpg \\
\hline 1540 & Thymus praecox Opiz & Budaörs & 1952 & Siroki Zoltán & DE-siroki-14414.jpg \\
\hline 1540 & Thymus praecox Opiz & Budaörs & 1952 & Siroki Zoltán & DE-siroki-14415.jpg \\
\hline 1540 & Thymus praecox Opiz & Budaörs & 1952 & Siroki Zoltán & DE-siroki-14409.jpg \\
\hline 1540 & Thymus praecox Opiz & Budaörs & 1952 & Siroki Zoltán & DE-siroki-14406.jpg \\
\hline 1540 & Thymus praecox Opiz & Budaörs & 1952 & Siroki Zoltán & DE-siroki-14411.jpg \\
\hline 1540 & Thymus praecox Opiz & Budaörs & 1955 & Siroki Zoltán & DE-siroki-14416.jpg \\
\hline
\end{tabular}




\begin{tabular}{|c|c|c|c|c|c|}
\hline $\begin{array}{l}\text { Sorszám / } \\
\text { Number }\end{array}$ & Taxon-név / Taxon-name & $\begin{array}{l}\text { Település / } \\
\text { Settlement }\end{array}$ & $\begin{array}{l}\text { Év / } \\
\text { Year }\end{array}$ & $\begin{array}{l}\text { Gyưjitő / } \\
\text { Collector }\end{array}$ & Fájlnév / File-name \\
\hline 1540 & Thymus praecox Opiz & Budaörs & 1955 & $\begin{array}{l}\text { Siroki Zoltán - } \\
\text { Farkas Attila }\end{array}$ & DE-siroki-14413.jpg \\
\hline 1540 & Thymus praecox Opiz & Budaörs & 1964 & Siroki Zoltán & DE-siroki-14417.jpg \\
\hline 1540 & Thymus praecox Opiz & Budapest & 1951 & Siroki Zoltán & DE-siroki-14426.jpg \\
\hline 1540 & Thymus praecox Opiz & Budapest & 1954 & Siroki Zoltán & DE-siroki-14410.jpg \\
\hline 1540 & Thymus praecox Opiz & Füzér & 1973 & Siroki Zoltán & DE-siroki-14418.jpg \\
\hline 1540 & Thymus praecox Opiz & Füzér & 1973 & Siroki Zoltán & DE-siroki-14419.jpg \\
\hline 1540 & Thymus praecox Opiz & Pécs & 1958 & Siroki Zoltán & DE-siroki-14404.jpg \\
\hline 1540 & Thymus praecox Opiz & Pilisszentiván & 1952 & Siroki Zoltán & DE-siroki-14412.jpg \\
\hline 1540 & Thymus praecox Opiz & Pilisszentiván & 1952 & Siroki Zoltán & DE-siroki-14405.jpg \\
\hline 1540 & Thymus praecox Opiz & Pilisszentiván & 1952 & Siroki Zoltán & DE-siroki-14408.jpg \\
\hline 1540 & Thymus praecox Opiz & Pilisszentiván & 1952 & Siroki Zoltán & DE-siroki-14407.jpg \\
\hline 1541 & Lycopus europaeus L. & Debrecen & 1985 & Siroki Zoltán & DE-siroki-14469.jpg \\
\hline 1541 & Lycopus europaeus L. & Debrecen & 1985 & Siroki Zoltán & DE-siroki-14468.jpg \\
\hline 1541 & Lycopus europaeus L. & Debrecen & 1985 & Siroki Zoltán & DE-siroki-14470.jpg \\
\hline 1541 & Lycopus europaeus L. & Hajdúbagos & 1981 & Siroki Zoltán & DE-siroki-14476.jpg \\
\hline 1541 & Lycopus europaeus L. & Mosonmagyaróvár & 1939 & Siroki Zoltán & DE-siroki-14477.jpg \\
\hline 1541 & Lycopus europaeus L. & Mosonmagyaróvár & 1939 & Siroki Zoltán & DE-siroki-14479.jpg \\
\hline 1541 & Lycopus europaeus L. & Vámospércs & 1985 & Siroki Zoltán & DE-siroki-14473.jpg \\
\hline 1541 & Lycopus europaeus L. & Vámospércs & 1985 & Siroki Zoltán & DE-siroki-14474.jpg \\
\hline 1541 & Lycopus europaeus L. & Vámospércs & 1985 & Siroki Zoltán & DE-siroki-14471.jpg \\
\hline 1541 & Lycopus europaeus L. & Vámospércs & 1985 & Siroki Zoltán & DE-siroki-14472.jpg \\
\hline 1541 & Lycopus europaeus L. & Vámospércs & 1985 & Siroki Zoltán & DE-siroki-14475.jpg \\
\hline 1542 & Lycopus exaltatus L. f. & Debrecen & 1946 & Siroki Zoltán & DE-siroki-14482.jpg \\
\hline 1542 & Lycopus exaltatus L. f. & Debrecen & 1947 & Siroki Zoltán & DE-siroki-14480.jpg \\
\hline 1542 & Lycopus exaltatus L. f. & Debrecen & 1949 & Siroki Zoltán & DE-siroki-14481.jpg \\
\hline 1543 & Mentha pulegium L. & Debrecen & 1947 & Siroki Zoltán & DE-siroki-14486.jpg \\
\hline 1543 & Mentha pulegium L. & Debrecen & 1957 & Siroki Zoltán & DE-siroki-14490.jpg \\
\hline 1543 & Mentha pulegium L. & Debrecen & 1957 & Siroki Zoltán & DE-siroki-14491.jpg \\
\hline 1543 & Mentha pulegium L. & Méra & 1943 & Siroki Zoltán & DE-siroki-14488.jpg \\
\hline 1543 & Mentha pulegium L. & Pomáz & 1954 & Siroki Zoltán & DE-siroki-14489.jpg \\
\hline 1544 & Mentha longifolia (L.) Nath. & Debrecen & 1945 & Siroki Zoltán & DE-siroki-14510.jpg \\
\hline 1544 & Mentha longifolia (L.) Nath. & Debrecen & 1946 & Siroki Zoltán & DE-siroki-14517.jpg \\
\hline 1544 & Mentha longifolia (L.) Nath. & Debrecen & 1946 & Siroki Zoltán & DE-siroki-14519.jpg \\
\hline 1544 & Mentha longifolia (L.) Nath. & Debrecen & 1947 & Siroki Zoltán & DE-siroki-14522.jpg \\
\hline 1544 & Mentha longifolia (L.) Nath. & Debrecen & 1947 & Siroki Zoltán & DE-siroki-14520.jpg \\
\hline 1544 & Mentha longifolia (L.) Nath. & Debrecen & 1947 & Siroki Zoltán & DE-siroki-14511.jpg \\
\hline 1544 & Mentha longifolia (L.) Nath. & Debrecen & 1947 & Siroki Zoltán & DE-siroki-14512.jpg \\
\hline 1544 & Mentha longifolia (L.) Nath. & Debrecen & 1947 & Siroki Zoltán & DE-siroki-14516.jpg \\
\hline 1544 & Mentha longifolia (L.) Nath. & Debrecen & 1947 & Siroki Zoltán & DE-siroki-14513.jpg \\
\hline 1544 & Mentha longifolia (L.) Nath. & Debrecen & 1947 & Siroki Zoltán & DE-siroki-14514.jpg \\
\hline 1544 & Mentha longifolia (L.) Nath. & Debrecen & 1947 & Siroki Zoltán & DE-siroki-14515.jpg \\
\hline 1544 & Mentha longifolia (L.) Nath. & Debrecen & 1947 & Siroki Zoltán & DE-siroki-14518.jpg \\
\hline 1544 & Mentha longifolia (L.) Nath. & Debrecen & 1950 & Siroki Zoltán & DE-siroki-14509.jpg \\
\hline 1544 & Mentha longifolia (L.) Nath. & Debrecen & 1985 & Siroki Zoltán & DE-siroki-14492.jpg \\
\hline 1544 & Mentha longifolia (L.) Nath. & Debrecen & 1985 & Siroki Zoltán & DE-siroki-14493.jpg \\
\hline 1544 & Mentha longifolia (L.) Nath. & Érd & 1918 & Magyar Ant. & DE-siroki-14524.jpg \\
\hline
\end{tabular}




\begin{tabular}{|c|c|c|c|c|c|}
\hline $\begin{array}{l}\text { Sorszám / } \\
\text { Number }\end{array}$ & Taxon-név / Taxon-name & $\begin{array}{l}\text { Település / } \\
\text { Settlement }\end{array}$ & $\begin{array}{l}\text { Év / } \\
\text { Year }\end{array}$ & $\begin{array}{l}\text { Gyűjtő / } \\
\text { Collector }\end{array}$ & Fájlnév / File-name \\
\hline 1544 & Mentha longifolia (L.) Nath. & Érd & 1918 & Magyar Ant. & DE-siroki-14525.jpg \\
\hline 1544 & Mentha longifolia (L.) Nath. & Érd & 1918 & Magyar Ant. & DE-siroki-14526.jpg \\
\hline 1544 & Mentha longifolia (L.) Nath. & Gödöllő & 1954 & Siroki Zoltán & DE-siroki-14495.jpg \\
\hline 1544 & Mentha longifolia (L.) Nath. & Háromhuta & 1977 & Siroki Zoltán & DE-siroki-14528.jpg \\
\hline 1544 & Mentha longifolia (L.) Nath. & Mosonmagyaróvár & 1939 & Siroki Zoltán & DE-siroki-14506.jpg \\
\hline 1544 & Mentha longifolia (L.) Nath. & Nyíregyháza & 1951 & Siroki Zoltán & DE-siroki-14500.jpg \\
\hline 1544 & Mentha longifolia (L.) Nath. & Nyíregyháza & 1954 & Siroki Zoltán & DE-siroki-14499.jpg \\
\hline 1544 & Mentha longifolia (L.) Nath. & Szerencs & 1951 & Siroki Zoltán & DE-siroki-14501.jpg \\
\hline 1544 & Mentha longifolia (L.) Nath. & Szerencs & 1951 & Siroki Zoltán & DE-siroki-14502.jpg \\
\hline 1544 & Mentha longifolia (L.) Nath. & Szerencs & 1951 & Siroki Zoltán & DE-siroki-14503.jpg \\
\hline 1544 & Mentha longifolia (L.) Nath. & Vámospércs & 1985 & Siroki Zoltán & DE-siroki-14494.jpg \\
\hline 1544 & Mentha longifolia (L.) Nath. & Veresegyház & 1951 & Siroki Zoltán & DE-siroki-14521.jpg \\
\hline 1545 & Mentha spicata L. & Szentendre & 1909 & Kocsis István & DE-siroki-14680.jpg \\
\hline 1545 & Mentha spicata L. & Szentendre & 1909 & Kocsis István & DE-siroki-14683.jpg \\
\hline 1546 & Mentha aquatica L. & Debrecen & 1945 & Siroki Zoltán & DE-siroki-14564.jpg \\
\hline 1546 & Mentha aquatica L. & Debrecen & 1945 & Siroki Zoltán & DE-siroki-14560.jpg \\
\hline 1546 & Mentha aquatica L. & Debrecen & 1947 & Siroki Zoltán & DE-siroki-14557.jpg \\
\hline 1546 & Mentha aquatica L. & Debrecen & 1947 & Siroki Zoltán & DE-siroki-14558.jpg \\
\hline 1546 & Mentha aquatica L. & Debrecen & 1947 & Siroki Zoltán & DE-siroki-14550.jpg \\
\hline 1546 & Mentha aquatica L. & Debrecen & 1947 & Siroki Zoltán & DE-siroki-14559.jpg \\
\hline 1546 & Mentha aquatica L. & Debrecen & 1947 & Siroki Zoltán & DE-siroki-14561.jpg \\
\hline 1546 & Mentha aquatica L. & Debrecen & 1947 & Siroki Zoltán & DE-siroki-14556.jpg \\
\hline 1546 & Mentha aquatica L. & Debrecen & 1948 & Siroki Zoltán & DE-siroki-14555.jpg \\
\hline 1546 & Mentha aquatica L. & Debrecen & 1977 & Siroki Zoltán & DE-siroki-14551.jpg \\
\hline 1546 & Mentha aquatica L. & Hajdúbagos & 1981 & Siroki Zoltán & DE-siroki-14567.jpg \\
\hline 1546 & Mentha aquatica L. & Hajdúbagos & 1981 & Siroki Zoltán & DE-siroki-14568.jpg \\
\hline 1546 & Mentha aquatica L. & Hortobágy & 1948 & Siroki Zoltán & DE-siroki-14562.jpg \\
\hline 1546 & Mentha aquatica L. & Hortobágy & 1948 & Siroki Zoltán & DE-siroki-14563.jpg \\
\hline 1546 & Mentha aquatica L. & Mosonmagyaróvár & 1939 & Siroki Zoltán & DE-siroki-14549.jpg \\
\hline 1546 & Mentha aquatica L. & Mosonmagyaróvár & 1939 & Siroki Zoltán & DE-siroki-14553.jpg \\
\hline 1546 & Mentha aquatica L. & Mosonmagyaróvár & 1939 & Siroki Zoltán & DE-siroki-14554.jpg \\
\hline 1546 & Mentha aquatica L. & Szigetszentmiklós & 1951 & Siroki Zoltán & DE-siroki-14542.jpg \\
\hline 1546 & Mentha aquatica L. & Szigetszentmiklós & 1951 & Siroki Zoltán & DE-siroki-14547.jpg \\
\hline 1546 & Mentha aquatica L. & Szigetszentmiklós & 1951 & Siroki Zoltán & DE-siroki-14565.jpg \\
\hline 1546 & Mentha aquatica L. & Szigetszentmiklós & 1951 & Siroki Zoltán & DE-siroki-14566.jpg \\
\hline 1546 & Mentha aquatica L. & Vámospércs & 1985 & Siroki Zoltán & DE-siroki-14548.jpg \\
\hline 1546 & Mentha aquatica L. & Veresegyház & 1951 & Siroki Zoltán & DE-siroki-14552.jpg \\
\hline 1547 & Mentha × dumetorum Schult. & Debrecen & 1945 & Siroki Zoltán & DE-siroki-14538.jpg \\
\hline 1547 & Mentha $\times$ dumetorum Schult. & Debrecen & 1945 & Siroki Zoltán & DE-siroki-14535.jpg \\
\hline 1547 & Mentha $\times$ dumetorum Schult. & Debrecen & 1945 & Siroki Zoltán & DE-siroki-14536.jpg \\
\hline 1547 & Mentha $\times$ dumetorum Schult. & Debrecen & 1945 & Siroki Zoltán & DE-siroki-14537.jpg \\
\hline 1547 & Mentha $\times$ dumetorum Schult. & Debrecen & 1945 & Siroki Zoltán & DE-siroki-14539.jpg \\
\hline 1547 & Mentha $\times$ dumetorum Schult. & Debrecen & 1951 & Siroki Zoltán & DE-siroki-14545.jpg \\
\hline 1547 & Mentha $\times$ dumetorum Schult. & Debrecen & 1951 & Siroki Zoltán & DE-siroki-14546.jpg \\
\hline 1547 & Mentha $\times$ dumetorum Schult. & Dunaharaszti & 1915 & Degen Árpád & DE-siroki-14543.jpg \\
\hline 1547 & Mentha $\times$ dumetorum Schult. & Érd & 1918 & Magyar Ant. & DE-siroki-14544.jpg \\
\hline
\end{tabular}




\begin{tabular}{|c|c|c|c|c|c|}
\hline $\begin{array}{l}\text { Sorszám / } \\
\text { Number }\end{array}$ & Taxon-név / Taxon-name & $\begin{array}{l}\text { Település / } \\
\text { Settlement }\end{array}$ & $\begin{array}{l}\text { Év / } \\
\text { Year }\end{array}$ & $\begin{array}{l}\text { Gyüjtő / } \\
\text { Collector }\end{array}$ & Fájlnév / File-name \\
\hline 1547 & Mentha $\times$ dumetorum Schult. & Keszthely & 1955 & Siroki Zoltán & DE-siroki-14540.jpg \\
\hline 1547 & Mentha $\times$ dumetorum Schult. & Keszthely & 1955 & Siroki Zoltán & DE-siroki-14541.jpg \\
\hline 1549 & Mentha arvensis L. & "Bükk-hg." & 1974 & Siroki Zoltán & DE-siroki-14609.jpg \\
\hline 1549 & Mentha arvensis L. & "Bükk-hg." & 1974 & Siroki Zoltán & DE-siroki-14610.jpg \\
\hline 1549 & Mentha arvensis L. & "Vértes" & 1957 & Siroki Zoltán & DE-siroki-14598.jpg \\
\hline 1549 & Mentha arvensis L. & "Vértes" & 1957 & Siroki Zoltán & DE-siroki-14599.jpg \\
\hline 1549 & Mentha arvensis L. & "Vértes" & 1957 & Siroki Zoltán & DE-siroki-14600.jpg \\
\hline 1549 & Mentha arvensis L. & "Vértes" & 1957 & Siroki Zoltán & DE-siroki-14601.jpg \\
\hline 1549 & Mentha arvensis L. & "Vértes" & 1957 & Siroki Zoltán & DE-siroki-14602.jpg \\
\hline 1549 & Mentha arvensis L. & "Vértes" & 1957 & Siroki Zoltán & DE-siroki-14626.jpg \\
\hline 1549 & Mentha arvensis L. & "Vértes" & 1957 & Siroki Zoltán & DE-siroki-14627.jpg \\
\hline 1549 & Mentha arvensis L. & "Vértes" & 1957 & Siroki Zoltán & DE-siroki-14628.jpg \\
\hline 1549 & Mentha arvensis L. & Ágasegyháza & 1956 & Siroki Zoltán & DE-siroki-14589.jpg \\
\hline 1549 & Mentha arvensis L. & Ágasegyháza & 1956 & Siroki Zoltán & DE-siroki-14590.jpg \\
\hline 1549 & Mentha arvensis L. & Ágasegyháza & 1956 & Siroki Zoltán & DE-siroki-14591.jpg \\
\hline 1549 & Mentha arvensis L. & Ágasegyháza & 1956 & Siroki Zoltán & DE-siroki-14592.jpg \\
\hline 1549 & Mentha arvensis L. & Budaörs & 1941 & Siroki Zoltán & DE-siroki-14616.jpg \\
\hline 1549 & Mentha arvensis L. & Budapest & 1908 & Kocsis István & DE-siroki-14607.jpg \\
\hline 1549 & Mentha arvensis L. & Bükkszentkereszt & 1977 & Siroki Zoltán & DE-siroki-14611.jpg \\
\hline 1549 & Mentha arvensis L. & Bükkszentkereszt & 1977 & Siroki Zoltán & DE-siroki-14612.jpg \\
\hline 1549 & Mentha arvensis L. & Debrecen & 1947 & Siroki Zoltán & DE-siroki-14593.jpg \\
\hline 1549 & Mentha arvensis L. & Debrecen & 1947 & Siroki Zoltán & DE-siroki-14594.jpg \\
\hline 1549 & Mentha arvensis L. & Debrecen & 1947 & Siroki Zoltán & DE-siroki-14595.jpg \\
\hline 1549 & Mentha arvensis L. & Debrecen & 1960 & Siroki Zoltán & DE-siroki-14580.jpg \\
\hline 1549 & Mentha arvensis L. & Debrecen & 1960 & Siroki Zoltán & DE-siroki-14581.jpg \\
\hline 1549 & Mentha arvensis L. & Debrecen & 1960 & Siroki Zoltán & DE-siroki-14582.jpg \\
\hline 1549 & Mentha arvensis L. & Debrecen & 1960 & Siroki Zoltán & DE-siroki-14583.jpg \\
\hline 1549 & Mentha arvensis L. & Debrecen & 1960 & Siroki Zoltán & DE-siroki-14584.jpg \\
\hline 1549 & Mentha arvensis L. & Debrecen & 1960 & Siroki Zoltán & DE-siroki-14585.jpg \\
\hline 1549 & Mentha arvensis L. & Debrecen & 1960 & Siroki Zoltán & DE-siroki-14586.jpg \\
\hline 1549 & Mentha arvensis L. & Debrecen & 1974 & Siroki Zoltán & DE-siroki-14587.jpg \\
\hline 1549 & Mentha arvensis L. & Debrecen & 1974 & Siroki Zoltán & DE-siroki-14588.jpg \\
\hline 1549 & Mentha arvensis L. & Dunaharaszti & 1915 & Degen Árpád & DE-siroki-14606.jpg \\
\hline 1549 & Mentha arvensis L. & Gyula & 1974 & Siroki Zoltán & DE-siroki-14574.jpg \\
\hline 1549 & Mentha arvensis L. & Gyula & 1974 & Siroki Zoltán & DE-siroki-14575.jpg \\
\hline 1549 & Mentha arvensis L. & Gyula & 1974 & Siroki Zoltán & DE-siroki-14576.jpg \\
\hline 1549 & Mentha arvensis L. & Gyula & 1974 & Siroki Zoltán & DE-siroki-14577.jpg \\
\hline 1549 & Mentha arvensis L. & Hajdúbagos & 1981 & Siroki Zoltán & DE-siroki-14603.jpg \\
\hline 1549 & Mentha arvensis L. & Hajdúbagos & 1981 & Siroki Zoltán & DE-siroki-14604.jpg \\
\hline 1549 & Mentha arvensis L. & Háromhuta & 1960 & Siroki Zoltán & DE-siroki-14569.jpg \\
\hline 1549 & Mentha arvensis L. & Háromhuta & 1960 & Siroki Zoltán & DE-siroki-14570.jpg \\
\hline 1549 & Mentha arvensis L. & Háromhuta & 1960 & Siroki Zoltán & DE-siroki-14571.jpg \\
\hline 1549 & Mentha arvensis L. & Háromhuta & 1960 & Siroki Zoltán & DE-siroki-14572.jpg \\
\hline 1549 & Mentha arvensis L. & Köröstarcsa & 1928 & Rigler József & DE-siroki-14605.jpg \\
\hline 1549 & Mentha arvensis L. & Miskolc & 1965 & Siroki Zoltán & DE-siroki-14573.jpg \\
\hline 1549 & Mentha arvensis L. & Miskolc & 1965 & Siroki Zoltán & DE-siroki-14578.jpg \\
\hline
\end{tabular}




\begin{tabular}{|c|c|c|c|c|c|}
\hline $\begin{array}{l}\text { Sorszám / } \\
\text { Number }\end{array}$ & Taxon-név / Taxon-name & $\begin{array}{l}\text { Település / } \\
\text { Settlement }\end{array}$ & $\begin{array}{l}\text { Év / } \\
\text { Year }\end{array}$ & $\begin{array}{l}\text { Gyűjtő / } \\
\text { Collector }\end{array}$ & Fájlnév / File-name \\
\hline 1549 & Mentha arvensis L. & Miskolc & 1965 & Siroki Zoltán & DE-siroki-14579.jpg \\
\hline 1549 & Mentha arvensis L. & Mosonmagyaróvár & 1939 & Siroki Zoltán & DE-siroki-14619.jpg \\
\hline 1549 & Mentha arvensis L. & Mosonmagyaróvár & 1939 & Siroki Zoltán & DE-siroki-14620.jpg \\
\hline 1549 & Mentha arvensis L. & Szerencs & 1951 & Siroki Zoltán & DE-siroki-14621.jpg \\
\hline 1549 & Mentha arvensis L. & Szerencs & 1951 & Siroki Zoltán & DE-siroki-14622.jpg \\
\hline 1549 & Mentha arvensis L. & Szerencs & 1951 & Siroki Zoltán & DE-siroki-14623.jpg \\
\hline 1551 & Mentha $\times$ verticillata $\mathrm{L}$. & Budapest & 1940 & Siroki Zoltán & DE-siroki-14687.jpg \\
\hline 1551 & Mentha $\times$ verticillata $L$ & Debrecen & 1947 & Siroki Zoltán & DE-siroki-14649.jpg \\
\hline 1551 & Mentha $\times$ verticillata L. & Debrecen & 1947 & Siroki Zoltán & DE-siroki-14650.jpg \\
\hline 1551 & Mentha $\times$ verticillata L. & Debrecen & 1947 & Siroki Zoltán & DE-siroki-14644.jpg \\
\hline 1551 & Mentha $\times$ verticillata $\mathrm{L}$. & Debrecen & 1947 & Siroki Zoltán & DE-siroki-14654.jpg \\
\hline 1551 & Mentha $\times$ verticillata L. & Debrecen & 1947 & Siroki Zoltán & DE-siroki-14656.jpg \\
\hline 1551 & Mentha $\times$ verticillata $L$. & Debrecen & 1947 & Siroki Zoltán & DE-siroki-14657.jpg \\
\hline 1551 & Mentha $\times$ verticillata $\mathrm{L}$. & Debrecen & 1947 & Siroki Zoltán & DE-siroki-14658.jpg \\
\hline 1551 & Mentha $\times$ verticillata L. & Debrecen & 1947 & Siroki Zoltán & DE-siroki-14659.jpg \\
\hline 1551 & Mentha $\times$ verticillata $\mathrm{L}$. & Debrecen & 1947 & Siroki Zoltán & DE-siroki-14663.jpg \\
\hline 1551 & Mentha $\times$ verticillata L. & Debrecen & 1950 & Siroki Zoltán & DE-siroki-14660.jpg \\
\hline 1551 & Mentha $\times$ verticillata L. & Debrecen & 1950 & Siroki Zoltán & DE-siroki-14665.jpg \\
\hline 1551 & Mentha $\times$ verticillata $L$. & Debrecen & 1950 & Siroki Zoltán & DE-siroki-14666.jpg \\
\hline 1551 & Mentha $\times$ verticillata $\mathrm{L}$. & Debrecen & 1951 & Siroki Zoltán & DE-siroki-14639.jpg \\
\hline 1551 & Mentha $\times$ verticillata L. & Debrecen & 1951 & Siroki Zoltán & DE-siroki-14672.jpg \\
\hline 1551 & Mentha $\times$ verticillata $L$. & Debrecen & 1951 & Siroki Zoltán & DE-siroki-14673.jpg \\
\hline 1551 & Mentha $\times$ verticillata $\mathrm{L}$. & Debrecen & 1951 & Siroki Zoltán & DE-siroki-14674.jpg \\
\hline 1551 & Mentha $\times$ verticillata L. & Debrecen & 1960 & Siroki Zoltán & DE-siroki-14667.jpg \\
\hline 1551 & Mentha $\times$ verticillata $L$. & Debrecen & 1960 & Siroki Zoltán & DE-siroki-14668.jpg \\
\hline 1551 & Mentha $\times$ verticillata $L$ & Debrecen & 1960 & Siroki Zoltán & DE-siroki-14669.jpg \\
\hline 1551 & Mentha $\times$ verticillata L. & Debrecen & 1960 & Siroki Zoltán & DE-siroki-14670.jpg \\
\hline 1551 & Mentha $\times$ verticillata $L$. & Debrecen & 1960 & Siroki Zoltán & DE-siroki-14671.jpg \\
\hline 1551 & Mentha $\times$ verticillata $\mathrm{L}$. & Debrecen & 1960 & Siroki Zoltán & DE-siroki-14675.jpg \\
\hline 1551 & Mentha $\times$ verticillata L. & Debrecen & 1960 & Siroki Zoltán & DE-siroki-14676.jpg \\
\hline 1551 & Mentha $\times$ verticillata $L$ & Debrecen & 1960 & Siroki Zoltán & DE-siroki-14677.jpg \\
\hline 1551 & Mentha $\times$ verticillata $L$ & Egyek & 1947 & Siroki Zoltán & DE-siroki-14652.jpg \\
\hline 1551 & Mentha $\times$ verticillata L. & Egyek & 1947 & Siroki Zoltán & DE-siroki-14653.jpg \\
\hline 1551 & Mentha $\times$ verticillata $L$. & Egyek & 1947 & Siroki Zoltán & DE-siroki-14646.jpg \\
\hline 1551 & Mentha $\times$ verticillata $\mathrm{L}$. & Egyek & 1947 & Siroki Zoltán & DE-siroki-14655.jpg \\
\hline 1551 & Mentha $\times$ verticillata L. & Egyek & 1947 & Siroki Zoltán & DE-siroki-14661.jpg \\
\hline 1551 & Mentha $\times$ verticillata $L$. & Egyek & 1947 & Siroki Zoltán & DE-siroki-14662.jpg \\
\hline 1551 & Mentha $\times$ verticillata $\mathrm{L}$. & Egyek & 1947 & Siroki Zoltán & DE-siroki-14664.jpg \\
\hline 1551 & Mentha $\times$ verticillata L. & Hajdúbagos & 1981 & Siroki Zoltán & DE-siroki-14633.jpg \\
\hline 1551 & Mentha $\times$ verticillata $L$. & Hortobágy & 1948 & Siroki Zoltán & DE-siroki-14651.jpg \\
\hline 1551 & Mentha $\times$ verticillata $L$ & Hortobágy & 1948 & Siroki Zoltán & DE-siroki-14647.jpg \\
\hline 1551 & Mentha $\times$ verticillata L. & Miskolc & 1959 & Siroki Zoltán & DE-siroki-14645.jpg \\
\hline 1551 & Mentha $\times$ verticillata $L$. & Őrbottyán & 1916 & Degen Árpád & DE-siroki-14679.jpg \\
\hline 1551 & Mentha $\times$ verticillata L. & Szerencs & 1951 & Siroki Zoltán & DE-siroki-14640.jpg \\
\hline 1551 & Mentha $\times$ verticillata $L$ & Szerencs & 1951 & Siroki Zoltán & DE-siroki-14641.jpg \\
\hline 1551 & Mentha $\times$ verticillata $L$ & Szerencs & 1951 & Siroki Zoltán & DE-siroki-14642.jpg \\
\hline
\end{tabular}




\begin{tabular}{|c|c|c|c|c|c|}
\hline $\begin{array}{l}\text { Sorszám / } \\
\text { Number }\end{array}$ & Taxon-név / Taxon-name & $\begin{array}{l}\text { Település / } \\
\text { Settlement }\end{array}$ & $\begin{array}{l}\text { Év / } \\
\text { Year }\end{array}$ & $\begin{array}{l}\text { Gyűjtő / } \\
\text { Collector }\end{array}$ & Fájlnév / File-name \\
\hline 1551 & Mentha $\times$ verticillata $L$. & Szerencs & 1951 & Siroki Zoltán & DE-siroki-14643.jpg \\
\hline 1551 & Mentha $\times$ verticillata $L$. & Tiszafüred & 1973 & Siroki Zoltán & DE-siroki-14678.jpg \\
\hline 1551 & Mentha $\times$ verticillata $L$. & Vámospércs & 1985 & Siroki Zoltán & DE-siroki-14634.jpg \\
\hline 1551 & Mentha $\times$ verticillata $L$. & Vámospércs & 1985 & Siroki Zoltán & DE-siroki-14635.jpg \\
\hline 1551 & Mentha $\times$ verticillata $\mathrm{L}$. & Vámospércs & 1985 & Siroki Zoltán & DE-siroki-14636.jpg \\
\hline 1552 & Mentha $\times$ dalmatica Tausch & Bátonyterenye & 1889 & Borbás Vince & DE-siroki-14684.jpg \\
\hline 1552 & Mentha $\times$ dalmatica Tausch & Komádi & 1880 & Borbás Vince & DE-siroki-14533.jpg \\
\hline $1543-1553$ & Mentha & Vésztő & 1888 & Borbás Vince & DE-siroki-14529.jpg \\
\hline 1556 & Salvia verticillata L. & Debrecen & 1947 & Siroki Zoltán & DE-siroki-14209.jpg \\
\hline 1556 & Salvia verticillata L. & Debrecen & 1947 & Siroki Zoltán & DE-siroki-14210.jpg \\
\hline 1557 & Salvia glutinosa L. & Csaroda & 1954 & Siroki Zoltán & DE-siroki-14205.jpg \\
\hline 1557 & Salvia glutinosa L. & Csaroda & 1954 & Siroki Zoltán & DE-siroki-14204.jpg \\
\hline 1557 & Salvia glutinosa L. & Debrecen & 1947 & Siroki Zoltán & DE-siroki-14206.jpg \\
\hline 1557 & Salvia glutinosa L. & Debrecen & 1947 & Siroki Zoltán & DE-siroki-14207.jpg \\
\hline 1559 & Salvia aethiopis L. & Debrecen & 1947 & Siroki Zoltán & DE-siroki-14213.jpg \\
\hline 1559 & Salvia aethiopis L. & Debrecen & 1947 & Siroki Zoltán & DE-siroki-14214.jpg \\
\hline 1559 & Salvia aethiopis L. & Debrecen & 1947 & Siroki Zoltán & DE-siroki-14215.jpg \\
\hline 1559 & Salvia aethiopis L. & Debrecen & 1947 & Siroki Zoltán & DE-siroki-14219.jpg \\
\hline 1559 & Salvia aethiopis L. & Debrecen & 1947 & Siroki Zoltán & DE-siroki-14216.jpg \\
\hline 1559 & Salvia aethiopis L. & Debrecen & 1947 & Siroki Zoltán & DE-siroki-14217.jpg \\
\hline 1559 & Salvia aethiopis L. & Debrecen & 1947 & Siroki Zoltán & DE-siroki-14218.jpg \\
\hline 1560 & Salvia austriaca Jacq. & Debrecen & 1947 & Siroki Zoltán & DE-siroki-14223.jpg \\
\hline 1560 & Salvia austriaca Jacq. & Debrecen & 1947 & Siroki Zoltán & DE-siroki-14221.jpg \\
\hline 1560 & Salvia austriaca Jacq. & Hernádszurdok & 1944 & Siroki Zoltán & DE-siroki-14224.jpg \\
\hline 1560 & Salvia austriaca Jacq. & Mosonmagyaróvár & 1939 & Siroki Zoltán & DE-siroki-14225.jpg \\
\hline 1562 & Salvia nemorosa L. & Debrecen & 1947 & Siroki Zoltán & DE-siroki-14230.jpg \\
\hline 1562 & Salvia nemorosa L. & Mosonmagyaróvár & 1939 & Siroki Zoltán & DE-siroki-14232.jpg \\
\hline 1563 & Salvia pratensis L. & Debrecen & 1948 & Siroki Zoltán & DE-siroki-14242.jpg \\
\hline 1563 & Salvia pratensis L. & Debrecen & 1948 & Siroki Zoltán & DE-siroki-14243.jpg \\
\hline 1563 & Salvia pratensis L. & Debrecen & 1949 & Siroki Zoltán & DE-siroki-14241.jpg \\
\hline 1563 & Salvia pratensis L. & Mosonmagyaróvár & 1939 & Siroki Zoltán & DE-siroki-14239.jpg \\
\hline 1563 & Salvia pratensis L. & Mosonmagyaróvár & 1939 & Siroki Zoltán & DE-siroki-14240.jpg \\
\hline 1566 & Nicandra physalodes (L.) Gaertn. & Újfehértó & 1967 & Gondola István & DE-siroki-14700.jpg \\
\hline 1566 & Nicandra physalodes (L.) Gaertn. & Újfehértó & 1967 & Gondola István & DE-siroki-14701.jpg \\
\hline 1569 & Atropa belladonna L. & "Dobogókő" & 1965 & Siroki Zoltán & DE-siroki-14703.jpg \\
\hline 1569 & Atropa belladonna L. & "Dobogókő" & 1965 & Siroki Zoltán & DE-siroki-14704.jpg \\
\hline 1569 & Atropa belladonna L. & "Dobogókő" & 1965 & Siroki Zoltán & DE-siroki-14705.jpg \\
\hline 1570 & Scopolia carniolica Jacq. & Miskolc & 1960 & Siroki Zoltán & DE-siroki-14721.jpg \\
\hline 1570 & Scopolia carniolica Jacq. & Miskolc & 1960 & Siroki Zoltán & DE-siroki-14722.jpg \\
\hline 1570 & Scopolia carniolica Jacq. & Miskolc & 1960 & Siroki Zoltán & DE-siroki-14723.jpg \\
\hline 1570 & Scopolia carniolica Jacq. & Miskolc & 1960 & Siroki Zoltán & DE-siroki-14724.jpg \\
\hline 1570 & Scopolia carniolica Jacq. & Miskolc & 1966 & Siroki Zoltán & DE-siroki-14712.jpg \\
\hline 1570 & Scopolia carniolica Jacq. & Miskolc & 1966 & Siroki Zoltán & DE-siroki-14713.jpg \\
\hline 1570 & Scopolia carniolica Jacq. & Miskolc & 1966 & Siroki Zoltán & DE-siroki-14714.jpg \\
\hline 1570 & Scopolia carniolica Jacq. & Miskolc & 1966 & Siroki Zoltán & DE-siroki-14715.jpg \\
\hline 1570 & Scopolia carniolica Jacq. & Miskolc & 1966 & Siroki Zoltán & DE-siroki-14716.jpg \\
\hline
\end{tabular}




\begin{tabular}{|c|c|c|c|c|c|}
\hline $\begin{array}{l}\text { Sorszám / } \\
\text { Number }\end{array}$ & Taxon-név / Taxon-name & $\begin{array}{l}\text { Település / } \\
\text { Settlement }\end{array}$ & $\begin{array}{l}\text { Év / } \\
\text { Year }\end{array}$ & $\begin{array}{l}\text { Gyújtő / } \\
\text { Collector }\end{array}$ & Fájlnév / File-name \\
\hline 1570 & Scopolia carniolica Jacq. & Miskolc & 1966 & Siroki Zoltán & DE-siroki-14717.jpg \\
\hline 1570 & Scopolia carniolica Jacq. & Miskolc & 1966 & Siroki Zoltán & DE-siroki-14718.jpg \\
\hline 1570 & Scopolia carniolica Jacq. & Miskolc & 1966 & Siroki Zoltán & DE-siroki-14719.jpg \\
\hline 1570 & Scopolia carniolica Jacq. & Miskolc & 1966 & Siroki Zoltán & DE-siroki-14720.jpg \\
\hline 1570 & Scopolia carniolica Jacq. & Pécs & 1958 & Siroki Zoltán & DE-siroki-14708.jpg \\
\hline 1570 & Scopolia carniolica Jacq. & Pécs & 1958 & Siroki Zoltán & DE-siroki-14709.jpg \\
\hline 1570 & Scopolia carniolica Jacq. & Pécs & 1958 & Siroki Zoltán & DE-siroki-14710.jpg \\
\hline 1570 & Scopolia carniolica Jacq. & Pécs & 1958 & Siroki Zoltán & DE-siroki-14711.jpg \\
\hline 1571 & Hyoscyamus niger L. & Debrecen & 1948 & Siroki Zoltán & DE-siroki-14726.jpg \\
\hline 1571 & Hyoscyamus niger L. & Debrecen & 1976 & Siroki Zoltán & DE-siroki-14725.jpg \\
\hline 1572 & Physalis alkekengi L. & Budapest & 1950 & Siroki Zoltán & DE-siroki-14728.jpg \\
\hline 1572 & Physalis alkekengi $\mathrm{L}$. & Budapest & 1950 & Siroki Zoltán & DE-siroki-14730.jpg \\
\hline 1572 & Physalis alkekengi L. & Mosonmagyaróvár & 1939 & Siroki Zoltán & DE-siroki-14729.jpg \\
\hline 1579 & Solanum nigrum L. & Budapest & 1951 & Siroki Zoltán & DE-siroki-14742.jpg \\
\hline 1579 & Solanum nigrum L. & Mosonmagyaróvár & 1939 & Siroki Zoltán & DE-siroki-14741.jpg \\
\hline 1580 & Solanum alatum Moench & Debrecen & 1949 & Siroki Zoltán & DE-siroki-14738.jpg \\
\hline 1580 & Solanum alatum Moench & Debrecen & 1949 & Siroki Zoltán & DE-siroki-14739.jpg \\
\hline 1581 & Solanum villosum Mill. & Debrecen & 1956 & Siroki Zoltán & DE-siroki-14735.jpg \\
\hline 1581 & Solanum villosum Mill. & Debrecen & 1956 & Siroki Zoltán & DE-siroki-14736.jpg \\
\hline 1581 & Solanum villosum Mill. & Debrecen & 1956 & Siroki Zoltán & DE-siroki-14737.jpg \\
\hline 1590 & Gratiola officinalis L. & Biharugra & 1961 & Siroki Zoltán & DE-siroki-14894.jpg \\
\hline 1590 & Gratiola officinalis L. & Debrecen & 1977 & Siroki Zoltán & DE-siroki-14892.jpg \\
\hline 1590 & Gratiola officinalis L. & Encs & 1944 & Siroki Zoltán & DE-siroki-14900.jpg \\
\hline 1590 & Gratiola officinalis L. & Encs & 1944 & Siroki Zoltán & DE-siroki-14898.jpg \\
\hline 1590 & Gratiola officinalis L. & Háromhuta & 1967 & Siroki Zoltán & DE-siroki-14893.jpg \\
\hline 1590 & Gratiola officinalis L. & Hortobágy & 1947 & Siroki Zoltán & DE-siroki-14899.jpg \\
\hline 1590 & Gratiola officinalis L. & Hortobágy & 1954 & Siroki Zoltán & DE-siroki-14896.jpg \\
\hline 1590 & Gratiola officinalis L. & Hortobágy & 1954 & Siroki Zoltán & DE-siroki-14897.jpg \\
\hline 1590 & Gratiola officinalis L. & Sátoraljaújhely & 1944 & Siroki Zoltán & DE-siroki-14901.jpg \\
\hline 1590 & Gratiola officinalis L. & Tiszafüred & 1955 & $\begin{array}{l}\text { Siroki Zoltán - } \\
\text { Farkas Attila }\end{array}$ & DE-siroki-14895.jpg \\
\hline 1590 & Gratiola officinalis L. & Tiszafüred & 1970 & Siroki Zoltán & DE-siroki-14890.jpg \\
\hline 1590 & Gratiola officinalis L. & Tiszafüred & 1970 & Siroki Zoltán & DE-siroki-14891.jpg \\
\hline 1591 & Lindernia procumbens (Krock.) Philcox & Hortobágy & 1960 & Siroki Zoltán & DE-siroki-14913.jpg \\
\hline 1591 & Lindernia procumbens (Krock.) Philcox & Hortobágy & 1960 & Siroki Zoltán & DE-siroki-14914.jpg \\
\hline 1591 & Lindernia procumbens (Krock.) Philcox & Hortobágy & 1960 & Siroki Zoltán & DE-siroki-14916.jpg \\
\hline 1591 & Lindernia procumbens (Krock.) Philcox & Nyíregyháza & 1967 & Gondola István & DE-siroki-14908.jpg \\
\hline 1591 & Lindernia procumbens (Krock.) Philcox & Nyíregyháza & 1967 & Gondola István & DE-siroki-14909.jpg \\
\hline 1591 & Lindernia procumbens (Krock.) Philcox & Nyíregyháza & 1967 & Gondola István & DE-siroki-14910.jpg \\
\hline 1591 & Lindernia procumbens (Krock.) Philcox & Nyíregyháza & 1967 & Gondola István & DE-siroki-14911.jpg \\
\hline 1591 & Lindernia procumbens (Krock.) Philcox & Sárospatak & 1951 & Siroki Zoltán & DE-siroki-14915.jpg \\
\hline 1591 & Lindernia procumbens (Krock.) Philcox & Sárospatak & 1951 & Siroki Zoltán & DE-siroki-14912.jpg \\
\hline 1591 & Lindernia procumbens (Krock.) Philcox & Szarvas & 1974 & Siroki Zoltán & DE-siroki-14906.jpg \\
\hline 1591 & Lindernia procumbens (Krock.) Philcox & Szarvas & 1974 & Siroki Zoltán & DE-siroki-14907.jpg \\
\hline 1593 & Limosella aquatica $\mathrm{L}$. & Dunaújváros & 1950 & Kárpáti Zoltán & DE-siroki-14904.jpg \\
\hline 1593 & Limosella aquatica L. & Hortobágy & 1955 & Siroki Zoltán & DE-siroki-14905.jpg \\
\hline 1593 & Limosella aquatica L. & Hortobágy & 1975 & Siroki Zoltán & DE-siroki-14902.jpg \\
\hline
\end{tabular}




\begin{tabular}{|c|c|c|c|c|c|}
\hline $\begin{array}{l}\text { Sorszám / } \\
\text { Number }\end{array}$ & Taxon-név / Taxon-name & $\begin{array}{l}\text { Település / } \\
\text { Settlement }\end{array}$ & $\begin{array}{l}\text { Év / } \\
\text { Year }\end{array}$ & $\begin{array}{l}\text { Gyüjtő / } \\
\text { Collector }\end{array}$ & Fájlnév / File-name \\
\hline 1593 & Limosella aquatica L. & Sárospatak & 1951 & Siroki Zoltán & DE-siroki-14903.jpg \\
\hline 1595 & Verbascum phoeniceum L. & Abaújvár & 1943 & Siroki Zoltán & DE-siroki-14750.jpg \\
\hline 1595 & Verbascum phoeniceum L. & Boldogkőváralja & 1942 & Siroki Zoltán & DE-siroki-14751.jpg \\
\hline 1595 & Verbascum phoeniceum L. & Budaörs & 1966 & Siroki Zoltán & DE-siroki-14752.jpg \\
\hline 1595 & Verbascum phoeniceum L. & Hortobágy & 1949 & Siroki Zoltán & DE-siroki-14753.jpg \\
\hline 1595 & Verbascum phoeniceum L. & Hortobágy & 1949 & Siroki Zoltán & DE-siroki-14749.jpg \\
\hline 1596 & Verbascum blattaria L. & Hortobágy & 1948 & Siroki Zoltán & DE-siroki-14757.jpg \\
\hline 1596 & Verbascum blattaria L. & Hortobágy & 1949 & Siroki Zoltán & DE-siroki-14754.jpg \\
\hline 1596 & Verbascum blattaria L. & Hortobágy & 1949 & Siroki Zoltán & DE-siroki-14758.jpg \\
\hline 1596 & Verbascum blattaria L. & Mosonmagyaróvár & 1939 & Siroki Zoltán & DE-siroki-14756.jpg \\
\hline 1598 & Verbascum nigrum L. & Csaroda & 1954 & Siroki Zoltán & DE-siroki-14789.jpg \\
\hline 1598 & Verbascum nigrum L. & Csaroda & 1960 & Siroki Zoltán & DE-siroki-14790.jpg \\
\hline 1599 & Verbascum lychnitis L. & Budapest & 1941 & Siroki Zoltán & DE-siroki-14771.jpg \\
\hline 1599 & Verbascum lychnitis L. & Debrecen & 1946 & Siroki Zoltán & DE-siroki-14770.jpg \\
\hline 1601 & Verbascum speciosum Schrad. & "Nagymező" & 1962 & Siroki Zoltán & DE-siroki-14786.jpg \\
\hline 1601 & Verbascum speciosum Schrad. & Budapest & 1960 & Siroki Zoltán & DE-siroki-14784.jpg \\
\hline 1601 & Verbascum speciosum Schrad. & Budapest & 1960 & Siroki Zoltán & DE-siroki-14785.jpg \\
\hline 1601 & Verbascum speciosum Schrad. & Pomáz & 1954 & Siroki Zoltán & DE-siroki-14775.jpg \\
\hline 1601 & Verbascum speciosum Schrad. & Pomáz & 1954 & Siroki Zoltán & DE-siroki-14776.jpg \\
\hline 1601 & Verbascum speciosum Schrad. & Pomáz & 1954 & Siroki Zoltán & DE-siroki-14777.jpg \\
\hline 1601 & Verbascum speciosum Schrad. & Pomáz & 1954 & Siroki Zoltán & DE-siroki-14778.jpg \\
\hline 1604 & Verbascum phlomoides L. & Debrecen & 1947 & Siroki Zoltán & DE-siroki-14765.jpg \\
\hline 1604 & Verbascum phlomoides L. & Debrecen & 1986 & Siroki Zoltán & DE-siroki-14761.jpg \\
\hline $\begin{array}{c}1596 \times \\
1604\end{array}$ & $\begin{array}{l}\text { Verbascum blattaria L. } \times \\
\text { Verbascum phlomoides L. }\end{array}$ & Budapest & 1941 & Siroki Zoltán & DE-siroki-14759.jpg \\
\hline $\begin{array}{c}1597 \times \\
1598\end{array}$ & $\begin{array}{l}\text { Verbascum chaixii Vill. subsp. } \\
\text { austriacum (Schott) Hayek × } \\
\text { Verbascum nigrum L. }\end{array}$ & Sajólád/Sajópetri & 1951 & Siroki Zoltán & DE-siroki-14792.jpg \\
\hline $\begin{array}{c}1597 \times \\
1598\end{array}$ & $\begin{array}{l}\text { Verbascum chaixii Vill. subsp. } \\
\text { austriacum (Schott) Hayek × } \\
\text { Verbascum nigrum L. }\end{array}$ & Sajólád/Sajópetri & 1951 & Siroki Zoltán & DE-siroki-14793.jpg \\
\hline $\begin{array}{c}1597 \times \\
1598\end{array}$ & $\begin{array}{l}\text { Verbascum chaixii Vill. subsp. } \\
\text { austriacum (Schott) Hayek × } \\
\text { Verbascum nigrum L. }\end{array}$ & Sajólád/Sajópetri & 1951 & Siroki Zoltán & DE-siroki-14794.jpg \\
\hline 1605 & Scrophularia vernalis L. & "Dobogókő" & 1957 & Siroki Zoltán & DE-siroki-14866.jpg \\
\hline 1605 & Scrophularia vernalis L. & "Nagymező" & 1957 & Siroki Zoltán & DE-siroki-14867.jpg \\
\hline 1606 & Scrophularia umbrosa Dumort. & Gödöllő & 1951 & Siroki Zoltán & DE-siroki-14885.jpg \\
\hline 1606 & Scrophularia umbrosa Dumort. & Háromhuta & 1968 & Siroki Zoltán & DE-siroki-14883.jpg \\
\hline 1606 & Scrophularia umbrosa Dumort. & Háromhuta & 1968 & Siroki Zoltán & DE-siroki-14884.jpg \\
\hline 1606 & Scrophularia umbrosa Dumort. & Máriakálnok & 1939 & Siroki Zoltán & DE-siroki-14886.jpg \\
\hline 1606 & Scrophularia umbrosa Dumort. & Máriakálnok & 1939 & Siroki Zoltán & DE-siroki-14887.jpg \\
\hline 1607 & Scrophularia scopolii Hoppe & Dombrád & 1967 & Gondola István & DE-siroki-14872.jpg \\
\hline 1607 & Scrophularia scopolii Hoppe & Dombrád & 1967 & Gondola István & DE-siroki-14873.jpg \\
\hline 1607 & Scrophularia scopolii Hoppe & Nagyhalász & 1967 & Gondola István & DE-siroki-14874.jpg \\
\hline 1607 & Scrophularia scopolii Hoppe & Zsurk & 1966 & Gondola István & DE-siroki-14871.jpg \\
\hline 1608 & Scrophularia nodosa L. & Bátorliget & 1956 & Siroki Zoltán & DE-siroki-14879.jpg \\
\hline 1608 & Scrophularia nodosa L. & Bátorliget & 1956 & Siroki Zoltán & DE-siroki-14880.jpg \\
\hline 1608 & Scrophularia nodosa L. & Debrecen & 1974 & Siroki Zoltán & DE-siroki-14878.jpg \\
\hline 1608 & Scrophularia nodosa L. & Mosonmagyaróvár & 1939 & Siroki Zoltán & DE-siroki-14881.jpg \\
\hline
\end{tabular}




\begin{tabular}{|c|c|c|c|c|c|}
\hline $\begin{array}{l}\text { Sorszám / } \\
\text { Number }\end{array}$ & Taxon-név / Taxon-name & $\begin{array}{l}\text { Település / } \\
\text { Settlement }\end{array}$ & $\begin{array}{l}\text { Év / } \\
\text { Year }\end{array}$ & $\begin{array}{l}\text { Gyüjtő / } \\
\text { Collector }\end{array}$ & Fájlnév / File-name \\
\hline 1609 & Antirrhinum majus L. & Mosonmagyaróvár & 1939 & Siroki Zoltán & DE-siroki-14853.jpg \\
\hline 1609 & Antirrhinum majus L. & Szilvásvárad & 1954 & Siroki Zoltán & DE-siroki-14851.jpg \\
\hline 1609 & Antirrhinum majus L. & Zsurk & 1966 & Gondola István & DE-siroki-14846.jpg \\
\hline 1609 & Antirrhinum majus L. & Zsurk & 1966 & Gondola István & DE-siroki-14847.jpg \\
\hline 1609 & Antirrhinum majus L. & Zsurk & 1966 & Gondola István & DE-siroki-14848.jpg \\
\hline 1609 & Antirrhinum majus L. & Zsurk & 1966 & Gondola István & DE-siroki-14849.jpg \\
\hline 1609 & Antirrhinum majus L. & Zsurk & 1966 & Gondola István & DE-siroki-14850.jpg \\
\hline 1612 & Microrrhinum minus (L.) Fourr. & Bátorliget & 1966 & Gondola István & DE-siroki-14858.jpg \\
\hline 1612 & Microrrhinum minus (L.) Fourr. & Budapest & 1941 & Siroki Zoltán & DE-siroki-14861.jpg \\
\hline 1612 & Microrrhinum minus (L.) Fourr. & Budapest & 1985 & Siroki Zoltán & DE-siroki-15355.jpg \\
\hline 1612 & Microrrhinum minus (L.) Fourr. & Budapest & 1985 & Siroki Zoltán & DE-siroki-14855.jpg \\
\hline 1612 & Microrrhinum minus (L.) Fourr. & Budapest & 1985 & Siroki Zoltán & DE-siroki-14854.jpg \\
\hline 1612 & Microrrhinum minus (L.) Fourr. & Debrecen & 1983 & Siroki Zoltán & DE-siroki-14856.jpg \\
\hline 1612 & Microrrhinum minus (L.) Fourr. & Mosonmagyaróvár & 1939 & Siroki Zoltán & DE-siroki-14862.jpg \\
\hline 1612 & Microrrhinum minus (L.) Fourr. & Nagydobos & 1966 & Gondola István & DE-siroki-14859.jpg \\
\hline 1612 & Microrrhinum minus (L.) Fourr. & Pátroha & 1967 & Gondola István & DE-siroki-14857.jpg \\
\hline 1614 & Linaria genistifolia (L.) Mill. & "Mátra" & 1964 & Siroki Zoltán & DE-siroki-14837.jpg \\
\hline 1614 & Linaria genistifolia (L.) Mill. & "Mátra" & 1984 & Siroki Zoltán & DE-siroki-14836.jpg \\
\hline 1614 & Linaria genistifolia (L.) Mill. & "Mátra" & 1984 & Siroki Zoltán & DE-siroki-14838.jpg \\
\hline 1614 & Linaria genistifolia (L.) Mill. & "Vértes" & 1957 & Siroki Zoltán & DE-siroki-14840.jpg \\
\hline 1614 & Linaria genistifolia (L.) Mill. & "Vértes" & 1957 & Siroki Zoltán & DE-siroki-14841.jpg \\
\hline 1614 & Linaria genistifolia (L.) Mill. & Abaújszántó & 1943 & Siroki Zoltán & DE-siroki-14832.jpg \\
\hline 1614 & Linaria genistifolia (L.) Mill. & Ágasegyháza & 1969 & Siroki Zoltán & DE-siroki-14839.jpg \\
\hline 1614 & Linaria genistifolia (L.) Mill. & Boldogkőváralja & 1943 & Siroki Zoltán & DE-siroki-14833.jpg \\
\hline 1614 & Linaria genistifolia (L.) Mill. & Budapest & 1941 & Siroki Zoltán & DE-siroki-14834.jpg \\
\hline 1614 & Linaria genistifolia (L.) Mill. & Budapest & 1941 & Siroki Zoltán & DE-siroki-14835.jpg \\
\hline 1614 & Linaria genistifolia (L.) Mill. & Budapest & 1948 & Siroki Zoltán & DE-siroki-14842.jpg \\
\hline 1614 & Linaria genistifolia (L.) Mill. & Budapest & 1985 & Siroki Zoltán & DE-siroki-14831.jpg \\
\hline 1614 & Linaria genistifolia (L.) Mill. & Debrecen & 1947 & Siroki Zoltán & DE-siroki-14843.jpg \\
\hline 1615 & Linaria angustissima (Loisel.) Borbás & Budaörs & 1985 & Siroki Zoltán & DE-siroki-14826.jpg \\
\hline 1615 & Linaria angustissima (Loisel.) Borbás & Budaörs & 1985 & Siroki Zoltán & DE-siroki-14827.jpg \\
\hline 1615 & Linaria angustissima (Loisel.) Borbás & Lábatlan & 1986 & Siroki Zoltán & DE-siroki-14828.jpg \\
\hline 1615 & Linaria angustissima (Loisel.) Borbás & Szajol & 1905 & Thaisz Lajos & DE-siroki-14829.jpg \\
\hline 1616 & Linaria vulgaris Mill. & Debrecen & 1947 & Siroki Zoltán & DE-siroki-14823.jpg \\
\hline 1616 & Linaria vulgaris Mill. & Debrecen & 1948 & Siroki Zoltán & DE-siroki-14824.jpg \\
\hline 1616 & Linaria vulgaris Mill. & Debrecen & 1949 & Siroki Zoltán & DE-siroki-14825.jpg \\
\hline 1616 & Linaria vulgaris Mill. & Debrecen & 1957 & Siroki Zoltán & DE-siroki-14821.jpg \\
\hline 1616 & Linaria vulgaris Mill. & Hortobágy & 1948 & Siroki Zoltán & DE-siroki-14822.jpg \\
\hline 1618 & $\begin{array}{l}\text { Cymbalaria muralis } \\
\text { G. Gaertn., B. Mey. et Scherb. }\end{array}$ & Budapest & 1940 & Siroki Zoltán & DE-siroki-14808.jpg \\
\hline 1618 & $\begin{array}{l}\text { Cymbalaria muralis } \\
\text { G. Gaertn., B. Mey. et Scherb. }\end{array}$ & Budapest & 1944 & Siroki Zoltán & DE-siroki-14806.jpg \\
\hline 1618 & $\begin{array}{l}\text { Cymbalaria muralis } \\
\text { G. Gaertn., B. Mey. et Scherb. }\end{array}$ & Budapest & 1944 & Siroki Zoltán & DE-siroki-14807.jpg \\
\hline 1619 & Kickxia spuria (L.) Dumort. & Abaújkér & 1943 & Siroki Zoltán & DE-siroki-14818.jpg \\
\hline 1619 & Kickxia spuria (L.) Dumort. & Debrecen & 1967 & Gondola István & DE-siroki-14809.jpg \\
\hline 1619 & Kickxia spuria (L.) Dumort. & Debrecen & 1967 & Gondola István & DE-siroki-14810.jpg \\
\hline 1619 & Kickxia spuria (L.) Dumort. & Hajdúnánás & 1967 & Gondola István & DE-siroki-14811.jpg \\
\hline
\end{tabular}




\begin{tabular}{|c|c|c|c|c|c|}
\hline $\begin{array}{l}\text { Sorszám / } \\
\text { Number }\end{array}$ & Taxon-név / Taxon-name & $\begin{array}{l}\text { Település / } \\
\text { Settlement }\end{array}$ & $\begin{array}{l}\text { Év / } \\
\text { Year }\end{array}$ & $\begin{array}{l}\text { Gyújtő / } \\
\text { Collector }\end{array}$ & Fájlnév / File-name \\
\hline 1619 & Kickxia spuria (L.) Dumort. & Hajdúnánás & 1967 & Gondola István & DE-siroki-14812.jpg \\
\hline 1619 & Kickxia spuria (L.) Dumort. & Mosonmagyaróvár & 1939 & Siroki Zoltán & DE-siroki-14819.jpg \\
\hline 1619 & Kickxia spuria (L.) Dumort. & Szarvas & 1974 & Siroki Zoltán & DE-siroki-14815.jpg \\
\hline 1622 & Digitalis grandiflora Mill. & "Bükk-hg., Hárskút" & 1956 & Halász Tibor & DE-siroki-15071.jpg \\
\hline 1622 & Digitalis grandiflora Mill. & "Nagymező" & 1959 & Siroki Zoltán & DE-siroki-15072.jpg \\
\hline 1622 & Digitalis grandiflora Mill. & Hollóháza & 1940 & Siroki Zoltán & DE-siroki-15075.jpg \\
\hline 1622 & Digitalis grandiflora Mill. & Hollóháza & 1940 & Siroki Zoltán & DE-siroki-15076.jpg \\
\hline 1622 & Digitalis grandiflora Mill. & Szilvásvárad & 1954 & Siroki Zoltán & DE-siroki-15073.jpg \\
\hline 1623 & Digitalis lanata Ehrh. & Budapest & 1890 & Czakó Kálmán & DE-siroki-15077.jpg \\
\hline 1625 & Pseudolysimachion longifolium (L.) Opiz & Debrecen & 1949 & Siroki Zoltán & DE-siroki-14801.jpg \\
\hline 1625 & Pseudolysimachion longifolium (L.) Opiz & Debrecen & 1950 & Siroki Zoltán & DE-siroki-14798.jpg \\
\hline 1625 & Pseudolysimachion longifolium (L.) Opiz & Debrecen & 1950 & Siroki Zoltán & DE-siroki-14799.jpg \\
\hline 1625 & Pseudolysimachion longifolium (L.) Opiz & Debrecen & 1950 & Siroki Zoltán & DE-siroki-14804.jpg \\
\hline 1625 & Pseudolysimachion longifolium (L.) Opiz & Sajólád/Sajópetri & 1951 & Siroki Zoltán & DE-siroki-14805.jpg \\
\hline 1625 & Pseudolysimachion longifolium (L.) Opiz & Sátoraljaújhely & 1944 & Siroki Zoltán & DE-siroki-14802.jpg \\
\hline 1625 & Pseudolysimachion longifolium (L.) Opiz & Újszentmargita & 1963 & Siroki Zoltán & DE-siroki-14800.jpg \\
\hline 1628 & Pseudolysimachion spicatum (L.) Opiz & Biatorbágy & 1950 & Siroki Zoltán & DE-siroki-14995.jpg \\
\hline 1628 & Pseudolysimachion spicatum (L.) Opiz & Boldogkőváralja & 1944 & Siroki Zoltán & DE-siroki-14999.jpg \\
\hline 1628 & Pseudolysimachion spicatum (L.) Opiz & Budapest & 1940 & Siroki Zoltán & DE-siroki-14998.jpg \\
\hline 1628 & Pseudolysimachion spicatum (L.) Opiz & Egyek & 1947 & Siroki Zoltán & DE-siroki-14983.jpg \\
\hline 1628 & Pseudolysimachion spicatum (L.) Opiz & Háromhuta & 1960 & Siroki Zoltán & DE-siroki-14990.jpg \\
\hline 1628 & Pseudolysimachion spicatum (L.) Opiz & Háromhuta & 1960 & Siroki Zoltán & DE-siroki-14991.jpg \\
\hline 1628 & Pseudolysimachion spicatum (L.) Opiz & Háromhuta & 1960 & Siroki Zoltán & DE-siroki-14992.jpg \\
\hline 1628 & Pseudolysimachion spicatum (L.) Opiz & Háromhuta & 1960 & Siroki Zoltán & DE-siroki-14993.jpg \\
\hline 1628 & Pseudolysimachion spicatum (L.) Opiz & Háromhuta & 1960 & Siroki Zoltán & DE-siroki-14994.jpg \\
\hline 1628 & Pseudolysimachion spicatum (L.) Opiz & Pilismarót & 1963 & Siroki Zoltán & DE-siroki-15002.jpg \\
\hline 1628 & Pseudolysimachion spicatum (L.) Opiz & Pilismarót & 1963 & Siroki Zoltán & DE-siroki-15004.jpg \\
\hline 1628 & Pseudolysimachion spicatum (L.) Opiz & Pilismarót & 1963 & Siroki Zoltán & DE-siroki-14984.jpg \\
\hline 1628 & Pseudolysimachion spicatum (L.) Opiz & Pomáz & 1957 & Siroki Zoltán & DE-siroki-14996.jpg \\
\hline 1628 & Pseudolysimachion spicatum (L.) Opiz & Pomáz & 1957 & Siroki Zoltán & DE-siroki-14997.jpg \\
\hline 1628 & Pseudolysimachion spicatum (L.) Opiz & Tokaj & 1966 & Siroki Zoltán & DE-siroki-14989.jpg \\
\hline 1628 & Pseudolysimachion spicatum (L.) Opiz & Tokaj & 1966 & Siroki Zoltán & DE-siroki-14985.jpg \\
\hline 1628 & Pseudolysimachion spicatum (L.) Opiz & Tokaj & 1966 & Siroki Zoltán & DE-siroki-14986.jpg \\
\hline 1628 & Pseudolysimachion spicatum (L.) Opiz & Tokaj & 1966 & Siroki Zoltán & DE-siroki-14987.jpg \\
\hline 1628 & Pseudolysimachion spicatum (L.) Opiz & Tokaj & 1966 & Siroki Zoltán & DE-siroki-14988.jpg \\
\hline 1629 & $\begin{array}{l}\text { Pseudolysimachion orchideum } \\
\text { (Crantz) Wraber }\end{array}$ & Egerbakta & 1968 & Siroki Zoltán & DE-siroki-15005.jpg \\
\hline 1629 & $\begin{array}{l}\text { Pseudolysimachion orchideum } \\
\text { (Crantz) Wraber }\end{array}$ & Egerbakta & 1968 & Siroki Zoltán & DE-siroki-15006.jpg \\
\hline 1629 & $\begin{array}{l}\text { Pseudolysimachion orchideum } \\
\text { (Crantz) Wraber }\end{array}$ & Pilismarót & 1963 & Siroki Zoltán & DE-siroki-15009.jpg \\
\hline 1629 & $\begin{array}{l}\text { Pseudolysimachion orchideum } \\
\text { (Crantz) Wraber }\end{array}$ & Pomáz & 1954 & Siroki Zoltán & DE-siroki-15008.jpg \\
\hline 1630 & Veronica scutellata L. & Debrecen & 1950 & Siroki Zoltán & DE-siroki-14919.jpg \\
\hline 1630 & Veronica scutellata L. & Debrecen & 1950 & Siroki Zoltán & DE-siroki-14920.jpg \\
\hline 1630 & Veronica scutellata L. & Debrecen & 1950 & Siroki Zoltán & DE-siroki-14923.jpg \\
\hline 1630 & Veronica scutellata L. & Debrecen & 1950 & Siroki Zoltán & DE-siroki-15150.jpg \\
\hline 1630 & Veronica scutellata L. & Debrecen & 1950 & Siroki Zoltán & DE-siroki-15151.jpg \\
\hline 1630 & Veronica scutellata L. & Egyek & 1947 & Siroki Zoltán & DE-siroki-14918.jpg \\
\hline
\end{tabular}




\begin{tabular}{|c|c|c|c|c|c|}
\hline $\begin{array}{l}\text { Sorszám / } \\
\text { Number }\end{array}$ & Taxon-név / Taxon-name & $\begin{array}{l}\text { Település / } \\
\text { Settlement }\end{array}$ & $\begin{array}{l}\text { Év / } \\
\text { Year }\end{array}$ & $\begin{array}{l}\text { Gyűjtő / } \\
\text { Collector }\end{array}$ & Fájlnév / File-name \\
\hline 1630 & Veronica scutellata L. & Hortobágy & 1947 & Siroki Zoltán & DE-siroki-15152.jpg \\
\hline 1630 & Veronica scutellata L. & Hortobágy & 1947 & Siroki Zoltán & DE-siroki-14921.jpg \\
\hline 1630 & Veronica scutellata L. & Hortobágy & 1947 & Siroki Zoltán & DE-siroki-14922.jpg \\
\hline 1631 & Veronica beccabunga L. & Debrecen & 1964 & Siroki Zoltán & DE-siroki-15182.jpg \\
\hline 1631 & Veronica beccabunga L. & Háromhuta & 1961 & Siroki Zoltán & DE-siroki-15173.jpg \\
\hline 1631 & Veronica beccabunga L. & Háromhuta & 1961 & Siroki Zoltán & DE-siroki-15174.jpg \\
\hline 1631 & Veronica beccabunga L. & Háromhuta & 1961 & Siroki Zoltán & DE-siroki-15175.jpg \\
\hline 1631 & Veronica beccabunga L. & Szilvásvárad & 1954 & Siroki Zoltán & DE-siroki-15177.jpg \\
\hline 1631 & Veronica beccabunga L. & Szilvásvárad & 1954 & Siroki Zoltán & DE-siroki-15178.jpg \\
\hline 1633 & Veronica anagalloides Guss. & Debrecen & 1947 & Siroki Zoltán & DE-siroki-15161.jpg \\
\hline 1633 & Veronica anagalloides Guss. & Kazincbarcika & 1944 & Siroki Zoltán & DE-siroki-15160.jpg \\
\hline 1633 & Veronica anagalloides Guss. & Kazincbarcika & 1944 & Siroki Zoltán & DE-siroki-15162.jpg \\
\hline 1633 & Veronica anagalloides Guss. & Kazincbarcika & 1944 & Siroki Zoltán & DE-siroki-15163.jpg \\
\hline 1633 & Veronica anagalloides Guss. & Mikepércs & 1966 & Siroki Zoltán & DE-siroki-15155.jpg \\
\hline 1633 & Veronica anagalloides Guss. & Mikepércs & 1966 & Siroki Zoltán & DE-siroki-15156.jpg \\
\hline 1633 & Veronica anagalloides Guss. & Mikepércs & 1966 & Siroki Zoltán & DE-siroki-15157.jpg \\
\hline 1633 & Veronica anagalloides Guss. & Mikepércs & 1966 & Siroki Zoltán & DE-siroki-15158.jpg \\
\hline 1633 & Veronica anagalloides Guss. & Mikepércs & 1966 & Siroki Zoltán & DE-siroki-15159.jpg \\
\hline 1635 & Veronica anagallis-aquatica L. & Debrecen & 1950 & Siroki Zoltán & DE-siroki-15165.jpg \\
\hline 1635 & Veronica anagallis-aquatica L. & Debrecen & 1950 & Siroki Zoltán & DE-siroki-15167.jpg \\
\hline 1635 & Veronica anagallis-aquatica L. & Háromhuta & 1961 & Siroki Zoltán & DE-siroki-15166.jpg \\
\hline 1635 & Veronica anagallis-aquatica L. & Mosonmagyaróvár & 1939 & Siroki Zoltán & DE-siroki-15171.jpg \\
\hline 1635 & Veronica anagallis-aquatica L. & Veresegyház & 1960 & Siroki Zoltán & DE-siroki-15168.jpg \\
\hline 1635 & Veronica anagallis-aquatica L. & Veresegyház & 1960 & Siroki Zoltán & DE-siroki-15169.jpg \\
\hline 1635 & Veronica anagallis-aquatica L. & Veresegyház & 1960 & Siroki Zoltán & DE-siroki-15164.jpg \\
\hline 1637 & Veronica jacquinii Baumg. & Kunpeszér-Kunadacs & 1951 & Kárpáti Zoltán & DE-siroki-14946.jpg \\
\hline 1638 & Veronica austriaca L. & Abaújszántó & 1944 & Siroki Zoltán & DE-siroki-14957.jpg \\
\hline 1638 & Veronica austriaca L. & Budaörs & 1955 & Siroki Zoltán & DE-siroki-14952.jpg \\
\hline 1638 & Veronica austriaca L. & Budapest & 1951 & Siroki Zoltán & DE-siroki-14947.jpg \\
\hline 1638 & Veronica austriaca L. & Budapest & 1951 & Siroki Zoltán & DE-siroki-14955.jpg \\
\hline 1638 & Veronica austriaca L. & Budapest & 1964 & Siroki Zoltán & DE-siroki-14948.jpg \\
\hline 1638 & Veronica austriaca L. & Budapest & 1964 & Siroki Zoltán & DE-siroki-14949.jpg \\
\hline 1638 & Veronica austriaca L. & Budapest & 1964 & Siroki Zoltán & DE-siroki-14950.jpg \\
\hline 1638 & Veronica austriaca L. & Felsőtárkány & 1957 & Siroki Zoltán & DE-siroki-14953.jpg \\
\hline 1638 & Veronica austriaca L. & Felsőtárkány & 1957 & Siroki Zoltán & DE-siroki-14954.jpg \\
\hline 1638 & Veronica austriaca L. & Háromhuta & 1967 & Siroki Zoltán & DE-siroki-14951.jpg \\
\hline 1639 & Veronica teucrium L. & "Nagymező" & 1959 & Siroki Zoltán & DE-siroki-14969.jpg \\
\hline 1639 & Veronica teucrium L. & "Nagymező" & 1959 & Siroki Zoltán & DE-siroki-14970.jpg \\
\hline 1639 & Veronica teucrium L. & "Nagymező" & 1959 & Siroki Zoltán & DE-siroki-14971.jpg \\
\hline 1639 & Veronica teucrium L. & "Nagymező" & 1962 & Siroki Zoltán & DE-siroki-14968.jpg \\
\hline 1639 & Veronica teucrium L. & "Nagymező" & 1962 & Siroki Zoltán & DE-siroki-14977.jpg \\
\hline 1639 & Veronica teucrium L. & "Nagymező" & 1962 & Siroki Zoltán & DE-siroki-14978.jpg \\
\hline 1639 & Veronica teucrium L. & Bér & 1954 & Siroki Zoltán & DE-siroki-14963.jpg \\
\hline 1639 & Veronica teucrium L. & Budapest & 1951 & Siroki Zoltán & DE-siroki-14966.jpg \\
\hline 1639 & Veronica teucrium L. & Felsőtárkány & 1959 & Siroki Zoltán & DE-siroki-14964.jpg \\
\hline 1639 & Veronica teucrium L. & Hajdúböszörmény & 1963 & Siroki Zoltán & DE-siroki-14967.jpg \\
\hline
\end{tabular}




\begin{tabular}{|c|c|c|c|c|c|}
\hline $\begin{array}{l}\text { Sorszám / } \\
\text { Number }\end{array}$ & Taxon-név / Taxon-name & $\begin{array}{l}\text { Település / } \\
\text { Settlement }\end{array}$ & $\begin{array}{l}\text { Év / } \\
\text { Year }\end{array}$ & $\begin{array}{l}\text { Gyűjtő / } \\
\text { Collector }\end{array}$ & Fájlnév / File-name \\
\hline 1639 & Veronica teucrium L. & Hajdúböszörmény & 1963 & Siroki Zoltán & DE-siroki-14973.jpg \\
\hline 1639 & Veronica teucrium L. & Hajdúböszörmény & 1963 & Siroki Zoltán & DE-siroki-14974.jpg \\
\hline 1639 & Veronica teucrium L. & Hajdúböszörmény & 1963 & Siroki Zoltán & DE-siroki-14975.jpg \\
\hline 1639 & Veronica teucrium L. & Háromhuta & 1967 & Siroki Zoltán & DE-siroki-14976.jpg \\
\hline 1639 & Veronica teucrium L. & Háromhuta & 1967 & Siroki Zoltán & DE-siroki-14979.jpg \\
\hline 1639 & Veronica teucrium L. & Keszthely & 1955 & Siroki Zoltán & DE-siroki-14965.jpg \\
\hline 1641 & Veronica chamaedrys L. & Debrecen & 1950 & Siroki Zoltán & DE-siroki-15183.jpg \\
\hline 1642 & Veronica officinalis L. & $\begin{array}{l}\text { "Bükk-hg, } \\
\text { Kiskerekhegy" }\end{array}$ & 1959 & Halász Tibor & DE-siroki-15187.jpg \\
\hline 1642 & Veronica officinalis L. & Debrecen & 1951 & Siroki Zoltán & DE-siroki-15188.jpg \\
\hline 1642 & Veronica officinalis L. & Debrecen & 1954 & Siroki Zoltán & DE-siroki-15189.jpg \\
\hline 1642 & Veronica officinalis L. & Debrecen & 1954 & Siroki Zoltán & DE-siroki-15190.jpg \\
\hline 1642 & Veronica officinalis L. & Hollóháza & 1940 & Siroki Zoltán & DE-siroki-15192.jpg \\
\hline 1642 & Veronica officinalis L. & Hollóháza & 1940 & Siroki Zoltán & DE-siroki-15193.jpg \\
\hline 1643 & Veronica montana L. & "Dobogókő" & 1965 & Siroki Zoltán & DE-siroki-14927.jpg \\
\hline 1643 & Veronica montana L. & "Dobogókő" & 1965 & Siroki Zoltán & DE-siroki-14933.jpg \\
\hline 1643 & Veronica montana L. & "Dobogókő" & 1965 & Siroki Zoltán & DE-siroki-14924.jpg \\
\hline 1643 & Veronica montana L. & "Dobogókő" & 1965 & Siroki Zoltán & DE-siroki-14925.jpg \\
\hline 1643 & Veronica montana L. & "Dobogókő" & 1965 & Siroki Zoltán & DE-siroki-14926.jpg \\
\hline 1643 & Veronica montana L. & "Dobogókő" & 1965 & Siroki Zoltán & DE-siroki-14928.jpg \\
\hline 1643 & Veronica montana L. & "Dobogókő" & 1965 & Siroki Zoltán & DE-siroki-14929.jpg \\
\hline 1643 & Veronica montana L. & "Dobogókő" & 1965 & Siroki Zoltán & DE-siroki-14930.jpg \\
\hline 1643 & Veronica montana L. & "Dobogókő" & 1965 & Siroki Zoltán & DE-siroki-14931.jpg \\
\hline 1643 & Veronica montana L. & "Dobogókő" & 1965 & Siroki Zoltán & DE-siroki-14932.jpg \\
\hline 1643 & Veronica montana L. & "Dobogókő" & 1965 & Siroki Zoltán & DE-siroki-15195.jpg \\
\hline 1643 & Veronica montana L. & Budaörs & 1955 & Siroki Zoltán & DE-siroki-14943.jpg \\
\hline 1643 & Veronica montana L. & Debrecen & 1947 & Siroki Zoltán & DE-siroki-14942.jpg \\
\hline 1643 & Veronica montana L. & Nagykovácsi & 1959 & Siroki Zoltán & DE-siroki-14941.jpg \\
\hline 1644 & Veronica triphyllos L. & Debrecen & 1965 & Siroki Zoltán & DE-siroki-15010.jpg \\
\hline 1645 & Veronica verna L. & Debrecen & 1950 & Siroki Zoltán & DE-siroki-15013.jpg \\
\hline 1645 & Veronica verna L. & Hortobágy & 1960 & Siroki Zoltán & DE-siroki-15012.jpg \\
\hline 1645 & Veronica verna L. & Monor & 1887 & Czakó Kálmán & DE-siroki-15015.jpg \\
\hline 1646 & Veronica dillenii Crantz & Abaújszántó & 1944 & Siroki Zoltán & DE-siroki-15019.jpg \\
\hline 1646 & Veronica dillenii Crantz & Debrecen & 1950 & Siroki Zoltán & DE-siroki-15017.jpg \\
\hline 1646 & Veronica dillenii Crantz & Debrecen & 1950 & Siroki Zoltán & DE-siroki-15018.jpg \\
\hline 1646 & Veronica dillenii Crantz & Debrecen & 1954 & Siroki Zoltán & DE-siroki-15016.jpg \\
\hline 1646 & Veronica dillenii Crantz & Gödöllő & 1951 & Siroki Zoltán & DE-siroki-15021.jpg \\
\hline 1646 & Veronica dillenii Crantz & Gödöllő & 1951 & Siroki Zoltán & DE-siroki-15020.jpg \\
\hline 1647 & Veronica serpyllifolia L. & Debrecen & 1949 & Siroki Zoltán & DE-siroki-15037.jpg \\
\hline 1647 & Veronica serpyllifolia L. & Debrecen & 1950 & Siroki Zoltán & DE-siroki-15034.jpg \\
\hline 1647 & Veronica serpyllifolia L. & Debrecen & 1950 & Siroki Zoltán & DE-siroki-15035.jpg \\
\hline 1647 & Veronica serpyllifolia L. & Debrecen & 1954 & Siroki Zoltán & DE-siroki-15036.jpg \\
\hline 1647 & Veronica serpyllifolia L. & Hollóháza & 1940 & Siroki Zoltán & DE-siroki-15038.jpg \\
\hline 1648 & Veronica arvensis L. & Debrecen & 1950 & Siroki Zoltán & DE-siroki-15023.jpg \\
\hline 1648 & Veronica arvensis L. & Debrecen & 1955 & Siroki Zoltán & DE-siroki-15024.jpg \\
\hline 1648 & Veronica arvensis L. & Debrecen & 1980 & Siroki Zoltán & DE-siroki-15022.jpg \\
\hline 1650 & Veronica praecox All. & Baracska & 1951 & Siroki Zoltán & DE-siroki-15030.jpg \\
\hline
\end{tabular}




\begin{tabular}{|c|c|c|c|c|c|}
\hline $\begin{array}{l}\text { Sorszám / } \\
\text { Number }\end{array}$ & Taxon-név / Taxon-name & $\begin{array}{l}\text { Település / } \\
\text { Settlement }\end{array}$ & $\begin{array}{l}\text { Év / } \\
\text { Year }\end{array}$ & $\begin{array}{l}\text { Gyűjtő / } \\
\text { Collector }\end{array}$ & Fájlnév / File-name \\
\hline 1650 & Veronica praecox All. & Budapest & 1941 & Siroki Zoltán & DE-siroki-15033.jpg \\
\hline 1650 & Veronica praecox All. & Budapest & 1951 & Siroki Zoltán & DE-siroki-15031.jpg \\
\hline 1650 & Veronica praecox All. & Debrecen & 1971 & Siroki Zoltán & DE-siroki-15029.jpg \\
\hline 1653 & Veronica hederifolia L. & Debrecen & 1947 & Siroki Zoltán & DE-siroki-15048.jpg \\
\hline 1653 & Veronica hederifolia L. & Debrecen & 1949 & Siroki Zoltán & DE-siroki-15049.jpg \\
\hline 1653 & Veronica hederifolia L. & Debrecen & 1955 & Farkas Attila & DE-siroki-15047.jpg \\
\hline 1656 & Veronica persica Poir. & Debrecen & 1960 & Siroki Zoltán & DE-siroki-15053.jpg \\
\hline 1656 & Veronica persica Poir. & Debrecen & 1960 & Siroki Zoltán & DE-siroki-15054.jpg \\
\hline 1656 & Veronica persica Poir. & Debrecen & 1967 & Gondola István & DE-siroki-15057.jpg \\
\hline 1656 & Veronica persica Poir. & Debrecen & 1967 & Gondola István & DE-siroki-15058.jpg \\
\hline 1656 & Veronica persica Poir. & Dombrád & 1966 & Gondola István & DE-siroki-15055.jpg \\
\hline 1656 & Veronica persica Poir. & Dombrád & 1966 & Gondola István & DE-siroki-15056.jpg \\
\hline 1656 & Veronica persica Poir. & Dombrád & 1967 & Gondola István & DE-siroki-15059.jpg \\
\hline 1656 & Veronica persica Poir. & Mosonmagyaróvár & 1939 & Siroki Zoltán & DE-siroki-15063.jpg \\
\hline 1656 & Veronica persica Poir. & Tarpa & 1955 & Siroki Zoltán & DE-siroki-15052.jpg \\
\hline 1658 & Veronica polita Fr. & Debrecen & 1972 & Siroki Zoltán & DE-siroki-15064.jpg \\
\hline 1658 & Veronica polita Fr. & Mosonmagyaróvár & 1939 & Siroki Zoltán & DE-siroki-15068.jpg \\
\hline 1660 & Melampyrum cristatum L. & Abaújszántó & 1943 & Siroki Zoltán & DE-siroki-15088.jpg \\
\hline 1660 & Melampyrum cristatum L. & Egyek & 1947 & Siroki Zoltán & DE-siroki-15086.jpg \\
\hline 1660 & Melampyrum cristatum L. & Gyenesdiás & - & Siroki Zoltán & DE-siroki-15085.jpg \\
\hline 1660 & Melampyrum cristatum L. & Háromhuta & 1961 & Siroki Zoltán & DE-siroki-15082.jpg \\
\hline 1660 & Melampyrum cristatum L. & Pomáz & 1954 & Siroki Zoltán & DE-siroki-15083.jpg \\
\hline 1660 & Melampyrum cristatum L. & Pomáz & 1957 & Siroki Zoltán & DE-siroki-15084.jpg \\
\hline 1661 & Melampyrum arvense L. & Bér & 1954 & Siroki Zoltán & DE-siroki-15091.jpg \\
\hline 1661 & Melampyrum arvense L. & Budapest & 1948 & Siroki Zoltán & DE-siroki-15095.jpg \\
\hline 1661 & Melampyrum arvense L. & Budapest & 1948 & Siroki Zoltán & DE-siroki-15090.jpg \\
\hline 1661 & Melampyrum arvense L. & Budapest & 1984 & Siroki Zoltán & DE-siroki-15089.jpg \\
\hline 1661 & Melampyrum arvense L. & Háromhuta & 1957 & Siroki Zoltán & DE-siroki-15093.jpg \\
\hline 1661 & Melampyrum arvense L. & Regéc & 1959 & Halász Tibor & DE-siroki-15092.jpg \\
\hline 1662 & Melampyrum barbatum Waldst. et Kit. & Budapest & 1940 & Siroki Zoltán & DE-siroki-15100.jpg \\
\hline 1662 & Melampyrum barbatum Waldst. et Kit. & Budapest & 1941 & Siroki Zoltán & DE-siroki-15099.jpg \\
\hline 1662 & Melampyrum barbatum Waldst. et Kit. & Budapest & 1951 & Siroki Zoltán & DE-siroki-15098.jpg \\
\hline 1663 & Melampyrum pratense L. & Debrecen & 1986 & Siroki Zoltán & DE-siroki-15119.jpg \\
\hline 1663 & Melampyrum pratense L. & Debrecen & 1986 & Siroki Zoltán & DE-siroki-15120.jpg \\
\hline 1663 & Melampyrum pratense L. & Debrecen & 1986 & Siroki Zoltán & DE-siroki-15121.jpg \\
\hline 1663 & Melampyrum pratense L. & Háromhuta & 1960 & Siroki Zoltán & DE-siroki-15125.jpg \\
\hline 1663 & Melampyrum pratense L. & Háromhuta & 1960 & Siroki Zoltán & DE-siroki-15126.jpg \\
\hline 1663 & Melampyrum pratense L. & Kishuta & 1954 & Simon Tiborné & DE-siroki-15124.jpg \\
\hline 1663 & Melampyrum pratense L. & Pécs & 1954 & Siroki Zoltán & DE-siroki-15122.jpg \\
\hline 1663 & Melampyrum pratense L. & Pécs & 1954 & Siroki Zoltán & DE-siroki-15123.jpg \\
\hline 1663 & Melampyrum pratense L. & Pécs & 1954 & Siroki Zoltán & DE-siroki-15127.jpg \\
\hline 1665 & Melampyrum nemorosum L. & Budapest & 1948 & Siroki Zoltán & DE-siroki-15111.jpg \\
\hline 1665 & Melampyrum nemorosum L. & Budapest & 1984 & Siroki Zoltán & DE-siroki-15110.jpg \\
\hline 1665 & Melampyrum nemorosum L. & Csaroda & 1954 & Simon Tiborné & DE-siroki-15112.jpg \\
\hline 1665 & Melampyrum nemorosum L. & Csaroda & 1954 & Simon Tiborné & DE-siroki-15114.jpg \\
\hline 1665 & Melampyrum nemorosum L. & Debrecen & 1947 & Siroki Zoltán & DE-siroki-15109.jpg \\
\hline
\end{tabular}




\begin{tabular}{|c|c|c|c|c|c|}
\hline $\begin{array}{l}\text { Sorszám / } \\
\text { Number }\end{array}$ & Taxon-név / Taxon-name & $\begin{array}{l}\text { Település / } \\
\text { Settlement }\end{array}$ & $\begin{array}{l}\text { Év / } \\
\text { Year }\end{array}$ & $\begin{array}{l}\text { Gyűjtő / } \\
\text { Collector }\end{array}$ & Fájlnév / File-name \\
\hline 1665 & Melampyrum nemorosum L. & Debrecen & 1947 & Siroki Zoltán & DE-siroki-15116.jpg \\
\hline 1665 & Melampyrum nemorosum L. & Debrecen & 1947 & Siroki Zoltán & DE-siroki-15113.jpg \\
\hline 1665 & Melampyrum nemorosum L. & Debrecen & 1954 & Siroki Zoltán & DE-siroki-15107.jpg \\
\hline 1665 & Melampyrum nemorosum L. & Debrecen & 1954 & Siroki Zoltán & DE-siroki-15108.jpg \\
\hline 1665 & Melampyrum nemorosum L. & Háromhuta & 1948 & Siroki Zoltán & DE-siroki-15106.jpg \\
\hline 1665 & Melampyrum nemorosum L. & Hencida & 1983 & Siroki Zoltán & DE-siroki-15105.jpg \\
\hline 1665 & Melampyrum nemorosum L. & Mátraszentimre & 1959 & Gondola István & DE-siroki-15115.jpg \\
\hline 1666 & Euphrasia rostkoviana Hayne & "Bánkút" & 1959 & Siroki Zoltán & DE-siroki-15144.jpg \\
\hline 1666 & Euphrasia rostkoviana Hayne & "Bánkút" & 1959 & Siroki Zoltán & DE-siroki-15145.jpg \\
\hline 1666 & Euphrasia rostkoviana Hayne & "Nagymező" & 1958 & Siroki Zoltán & DE-siroki-15131.jpg \\
\hline 1666 & Euphrasia rostkoviana Hayne & "Nagymező" & 1958 & Siroki Zoltán & DE-siroki-15132.jpg \\
\hline 1666 & Euphrasia rostkoviana Hayne & "Nagymező" & 1960 & Siroki Zoltán & DE-siroki-15141.jpg \\
\hline 1666 & Euphrasia rostkoviana Hayne & "Nagymező" & 1960 & Siroki Zoltán & DE-siroki-15142.jpg \\
\hline 1666 & Euphrasia rostkoviana Hayne & "Nagymező" & 1960 & Siroki Zoltán & DE-siroki-15143.jpg \\
\hline 1666 & Euphrasia rostkoviana Hayne & Bükkszentkereszt & 1978 & Siroki Zoltán & DE-siroki-15133.jpg \\
\hline 1666 & Euphrasia rostkoviana Hayne & Gödöllő & 1952 & Siroki Zoltán & DE-siroki-15137.jpg \\
\hline 1666 & Euphrasia rostkoviana Hayne & Keszthely & 1955 & Siroki Zoltán & DE-siroki-15134.jpg \\
\hline 1666 & Euphrasia rostkoviana Hayne & Keszthely & 1955 & Siroki Zoltán & DE-siroki-15135.jpg \\
\hline 1666 & Euphrasia rostkoviana Hayne & Sátoraljaújhely & 1944 & Siroki Zoltán & DE-siroki-15136.jpg \\
\hline 1666 & Euphrasia rostkoviana Hayne & Sátoraljaújhely & 1944 & Siroki Zoltán & DE-siroki-15138.jpg \\
\hline 1666 & Euphrasia rostkoviana Hayne & Veresegyház & 1960 & Siroki Zoltán & DE-siroki-15139.jpg \\
\hline 1666 & Euphrasia rostkoviana Hayne & Veresegyház & 1960 & Siroki Zoltán & DE-siroki-15140.jpg \\
\hline 1667 & Euphrasia kerneri Wettst. & Háromhuta & 1984 & Siroki Zoltán & DE-siroki-15197.jpg \\
\hline 1667 & Euphrasia kerneri Wettst. & Háromhuta & 1984 & Siroki Zoltán & DE-siroki-15199.jpg \\
\hline 1668 & Euphrasia stricta Wolf & "Bükk-hg." & 1965 & Siroki Zoltán & DE-siroki-15211.jpg \\
\hline 1668 & Euphrasia stricta Wolf & "Szent-György-hegy" & 1955 & Siroki Zoltán & DE-siroki-15209.jpg \\
\hline 1668 & Euphrasia stricta Wolf & Háromhuta & 1961 & Siroki Zoltán & DE-siroki-15212.jpg \\
\hline 1668 & Euphrasia stricta Wolf & Sopron & 1956 & Kovács Béla & DE-siroki-15207.jpg \\
\hline 1668 & Euphrasia stricta Wolf & Szilvásvárad & 1954 & Siroki Zoltán & DE-siroki-15208.jpg \\
\hline 1668 & Euphrasia stricta Wolf & Szilvásvárad & 1954 & Siroki Zoltán & DE-siroki-15210.jpg \\
\hline 1668 & Euphrasia stricta Wolf & Szilvásvárad & 1954 & Siroki Zoltán & DE-siroki-15213.jpg \\
\hline 1668 & Euphrasia stricta Wolf & Szilvásvárad & 1954 & Siroki Zoltán & DE-siroki-15214.jpg \\
\hline 1668 & Euphrasia stricta Wolf & Szilvásvárad & 1954 & Siroki Zoltán & DE-siroki-15206.jpg \\
\hline 1670 & Odontites lutea (L.) Clairv. & Budapest & 1957 & Siroki Zoltán & DE-siroki-15219.jpg \\
\hline 1670 & Odontites lutea (L.) Clairv. & Budapest & 1983 & Siroki Zoltán & DE-siroki-15217.jpg \\
\hline 1670 & Odontites lutea (L.) Clairv. & Egyek & 1947 & Siroki Zoltán & DE-siroki-15218.jpg \\
\hline 1671 & Odontites vernus (Bellardi) Dumort. & "Vértes" & 1957 & Siroki Zoltán & DE-siroki-15222.jpg \\
\hline 1671 & Odontites vernus (Bellardi) Dumort. & Debrecen & 1947 & Siroki Zoltán & DE-siroki-15224.jpg \\
\hline 1671 & Odontites vernus (Bellardi) Dumort. & Debrecen & 1950 & Siroki Zoltán & DE-siroki-15223.jpg \\
\hline 1671 & Odontites vernus (Bellardi) Dumort. & Mosonmagyaróvár & 1939 & Siroki Zoltán & DE-siroki-15226.jpg \\
\hline 1671 & Odontites vernus (Bellardi) Dumort. & Sáránd & 1987 & Siroki Zoltán & DE-siroki-15221.jpg \\
\hline 1672 & Pedicularis palustris L. & Budapest & 1958 & Siroki Zoltán & DE-siroki-15311.jpg \\
\hline 1672 & Pedicularis palustris $\mathrm{L}$. & Budapest & 1958 & Siroki Zoltán & DE-siroki-15312.jpg \\
\hline 1672 & Pedicularis palustris L. & Budapest & 1958 & Siroki Zoltán & DE-siroki-15313.jpg \\
\hline 1672 & Pedicularis palustris L. & Budapest & 1958 & Siroki Zoltán & DE-siroki-15314.jpg \\
\hline 1672 & Pedicularis palustris L. & Budapest & 1958 & Siroki Zoltán & DE-siroki-15315.jpg \\
\hline
\end{tabular}




\begin{tabular}{|c|c|c|c|c|c|}
\hline $\begin{array}{l}\text { Sorszám / } \\
\text { Number }\end{array}$ & Taxon-név / Taxon-name & $\begin{array}{l}\text { Település / } \\
\text { Settlement }\end{array}$ & $\begin{array}{l}\text { Év / } \\
\text { Year }\end{array}$ & $\begin{array}{l}\text { Gyüjtő / } \\
\text { Collector }\end{array}$ & Fájlnév / File-name \\
\hline 1672 & Pedicularis palustris L. & Budapest & 1958 & Siroki Zoltán & DE-siroki-15316.jpg \\
\hline 1672 & Pedicularis palustris L. & Budapest & 1958 & Siroki Zoltán & DE-siroki-15322.jpg \\
\hline 1672 & Pedicularis palustris L. & Budapest & 1958 & Siroki Zoltán & DE-siroki-15323.jpg \\
\hline 1672 & Pedicularis palustris L. & Budapest & 1958 & Siroki Zoltán & DE-siroki-15324.jpg \\
\hline 1672 & Pedicularis palustris L. & Budapest & 1958 & Siroki Zoltán & DE-siroki-15325.jpg \\
\hline 1672 & Pedicularis palustris L. & Budapest & 1958 & Siroki Zoltán & DE-siroki-15326.jpg \\
\hline 1672 & Pedicularis palustris L. & Budapest & 1958 & Siroki Zoltán & DE-siroki-15317.jpg \\
\hline 1672 & Pedicularis palustris L. & Sopron & 1950 & Kárpáti Zoltán & DE-siroki-15327.jpg \\
\hline 1672 & Pedicularis palustris L. & Veresegyház & 1955 & Jeney Endre & DE-siroki-15321.jpg \\
\hline 1672 & Pedicularis palustris L. & Veresegyház & 1960 & Siroki Zoltán & DE-siroki-15318.jpg \\
\hline 1672 & Pedicularis palustris L. & Veresegyház & 1960 & Siroki Zoltán & DE-siroki-15319.jpg \\
\hline 1672 & Pedicularis palustris L. & Veresegyház & 1960 & Siroki Zoltán & DE-siroki-15320.jpg \\
\hline 1673 & Rhinanthus minor L. & Budapest & 1958 & Siroki Zoltán & DE-siroki-15243.jpg \\
\hline 1673 & Rhinanthus minor L. & Budapest & 1962 & Siroki Zoltán & DE-siroki-15234.jpg \\
\hline 1673 & Rhinanthus minor L. & Budapest & 1962 & Siroki Zoltán & DE-siroki-15235.jpg \\
\hline 1673 & Rhinanthus minor L. & Budapest & 1962 & Siroki Zoltán & DE-siroki-15236.jpg \\
\hline 1673 & Rhinanthus minor L. & Háromhuta & 1961 & Siroki Zoltán & DE-siroki-15242.jpg \\
\hline 1673 & Rhinanthus minor L. & Háromhuta & 1967 & Siroki Zoltán & DE-siroki-15231.jpg \\
\hline 1673 & Rhinanthus minor L. & Háromhuta & 1967 & Siroki Zoltán & DE-siroki-15232.jpg \\
\hline 1673 & Rhinanthus minor L. & Háromhuta & 1967 & Siroki Zoltán & DE-siroki-15233.jpg \\
\hline 1673 & Rhinanthus minor L. & Háromhuta & 1967 & Siroki Zoltán & DE-siroki-15237.jpg \\
\hline 1673 & Rhinanthus minor L. & Háromhuta & 1967 & Siroki Zoltán & DE-siroki-15238.jpg \\
\hline 1673 & Rhinanthus minor L. & Nagyhuta & 1961 & Siroki Zoltán & DE-siroki-15239.jpg \\
\hline 1673 & Rhinanthus minor L. & Nagyhuta & 1961 & Siroki Zoltán & DE-siroki-15240.jpg \\
\hline 1673 & Rhinanthus minor L. & Nagyhuta & 1961 & Siroki Zoltán & DE-siroki-15241.jpg \\
\hline 1673 & Rhinanthus minor L. & Tokaj & 1966 & Siroki Zoltán & DE-siroki-15230.jpg \\
\hline 1674 & $\begin{array}{l}\text { Rhinanthus serotinus } \\
\text { (Schönh.) Oborný }\end{array}$ & "Nagymező" & 1959 & Siroki Zoltán & DE-siroki-15267.jpg \\
\hline 1674 & $\begin{array}{l}\text { Rhinanthus serotinus } \\
\text { (Schönh.) Oborný }\end{array}$ & "Nagymező" & 1960 & Siroki Zoltán & DE-siroki-15266.jpg \\
\hline 1674 & $\begin{array}{l}\text { Rhinanthus serotinus } \\
\text { (Schönh.) Oborný }\end{array}$ & "Nagymező" & 1960 & Siroki Zoltán & DE-siroki-15268.jpg \\
\hline 1674 & $\begin{array}{l}\text { Rhinanthus serotinus } \\
\text { (Schönh.) Oborný }\end{array}$ & "Nagymező" & 1960 & Siroki Zoltán & DE-siroki-15269.jpg \\
\hline 1674 & $\begin{array}{l}\text { Rhinanthus serotinus } \\
\text { (Schönh.) Oborný }\end{array}$ & "Nagymező" & 1960 & Siroki Zoltán & DE-siroki-15278.jpg \\
\hline 1674 & $\begin{array}{l}\text { Rhinanthus serotinus } \\
\text { (Schönh.) Oborný }\end{array}$ & "Nagymező" & 1960 & Siroki Zoltán & DE-siroki-15279.jpg \\
\hline 1674 & $\begin{array}{l}\text { Rhinanthus serotinus } \\
\text { (Schönh.) Oborný }\end{array}$ & Abaújkér & 1942 & Siroki Zoltán & DE-siroki-15281.jpg \\
\hline 1674 & $\begin{array}{l}\text { Rhinanthus serotinus } \\
\text { (Schönh.) Oborný }\end{array}$ & Ágasegyháza & 1956 & Siroki Zoltán & DE-siroki-15270.jpg \\
\hline 1674 & $\begin{array}{l}\text { Rhinanthus serotinus } \\
\text { (Schönh.) Oborný }\end{array}$ & Ágasegyháza & 1956 & Siroki Zoltán & DE-siroki-15271.jpg \\
\hline 1674 & $\begin{array}{l}\text { Rhinanthus serotinus } \\
\text { (Schönh.) Oborný }\end{array}$ & Budapest & 1958 & Siroki Zoltán & DE-siroki-15246.jpg \\
\hline 1674 & $\begin{array}{l}\text { Rhinanthus serotinus } \\
\text { (Schönh.) Oborný }\end{array}$ & Budapest & 1958 & Siroki Zoltán & DE-siroki-15247.jpg \\
\hline 1674 & $\begin{array}{l}\text { Rhinanthus serotinus } \\
\text { (Schönh.) Oborný }\end{array}$ & Budapest & 1962 & Siroki Zoltán & DE-siroki-15249.jpg \\
\hline 1674 & $\begin{array}{l}\text { Rhinanthus serotinus } \\
\text { (Schönh.) Oborný }\end{array}$ & Budapest & 1962 & Siroki Zoltán & DE-siroki-15250.jpg \\
\hline 1674 & $\begin{array}{l}\text { Rhinanthus serotinus } \\
\text { (Schönh.) Oborný }\end{array}$ & Budapest & 1962 & Siroki Zoltán & DE-siroki-15260.jpg \\
\hline
\end{tabular}




\begin{tabular}{|c|c|c|c|c|c|}
\hline $\begin{array}{l}\text { Sorszám / } \\
\text { Number }\end{array}$ & Taxon-név / Taxon-name & $\begin{array}{l}\text { Település / } \\
\text { Settlement }\end{array}$ & $\begin{array}{l}\text { Év / } \\
\text { Year }\end{array}$ & $\begin{array}{l}\text { Gyüjtő / } \\
\text { Collector }\end{array}$ & Fájlnév / File-name \\
\hline 1674 & $\begin{array}{l}\text { Rhinanthus serotinus } \\
\text { (Schönh.) Oborný }\end{array}$ & Budapest & 1962 & Siroki Zoltán & DE-siroki-15261.jpg \\
\hline 1674 & $\begin{array}{l}\text { Rhinanthus serotinus } \\
\text { (Schönh.) Oborný }\end{array}$ & Cegléd & 1969 & Siroki Zoltán & DE-siroki-15248.jpg \\
\hline 1674 & $\begin{array}{l}\text { Rhinanthus serotinus } \\
\text { (Schönh.) Oborný }\end{array}$ & Cegléd & 1969 & Siroki Zoltán & DE-siroki-15255.jpg \\
\hline 1674 & $\begin{array}{l}\text { Rhinanthus serotinus } \\
\text { (Schönh.) Oborný }\end{array}$ & Csaroda & 1960 & Siroki Zoltán & DE-siroki-15263.jpg \\
\hline 1674 & $\begin{array}{l}\text { Rhinanthus serotinus } \\
\text { (Schönh.) Oborný }\end{array}$ & Csaroda & 1960 & Siroki Zoltán & DE-siroki-15264.jpg \\
\hline 1674 & $\begin{array}{l}\text { Rhinanthus serotinus } \\
\text { (Schönh.) Oborný }\end{array}$ & Csaroda & 1960 & Siroki Zoltán & DE-siroki-15265.jpg \\
\hline 1674 & $\begin{array}{l}\text { Rhinanthus serotinus } \\
\text { (Schönh.) Oborný }\end{array}$ & Debrecen & 1951 & Siroki Zoltán & DE-siroki-15272.jpg \\
\hline 1674 & $\begin{array}{l}\text { Rhinanthus serotinus } \\
\text { (Schönh.) Oborný }\end{array}$ & Háromhuta & 1961 & Siroki Zoltán & DE-siroki-15262.jpg \\
\hline 1674 & $\begin{array}{l}\text { Rhinanthus serotinus } \\
\text { (Schönh.) Oborný }\end{array}$ & Kecskemét & 1967 & Siroki Zoltán & DE-siroki-15252.jpg \\
\hline 1674 & $\begin{array}{l}\text { Rhinanthus serotinus } \\
\text { (Schönh.) Oborný }\end{array}$ & Kecskemét & 1967 & Siroki Zoltán & DE-siroki-15251.jpg \\
\hline 1674 & $\begin{array}{l}\text { Rhinanthus serotinus } \\
\text { (Schönh.) Oborný }\end{array}$ & Kecskemét & 1967 & Siroki Zoltán & DE-siroki-15253.jpg \\
\hline 1674 & $\begin{array}{l}\text { Rhinanthus serotinus } \\
\text { (Schönh.) Oborný }\end{array}$ & Kecskemét & 1967 & Siroki Zoltán & DE-siroki-15254.jpg \\
\hline 1674 & $\begin{array}{l}\text { Rhinanthus serotinus } \\
\text { (Schönh.) Oborný }\end{array}$ & Keszthely & 1955 & Siroki Zoltán & DE-siroki-15273.jpg \\
\hline 1674 & $\begin{array}{l}\text { Rhinanthus serotinus } \\
\text { (Schönh.) Oborný }\end{array}$ & Répáshuta & 1956 & Halász Tibor & DE-siroki-15274.jpg \\
\hline 1678 & Lathraea squamaria L. & "Dobogókő" & 1957 & Siroki Zoltán & DE-siroki-15386.jpg \\
\hline 1678 & Lathraea squamaria L. & "Dobogókő" & 1957 & Siroki Zoltán & DE-siroki-15384.jpg \\
\hline 1678 & Lathraea squamaria L. & Háromhuta & 1955 & Siroki Zoltán & DE-siroki-15385.jpg \\
\hline 1680 & Catalpa bignonioides Walter & Debrecen & 1948 & Siroki Zoltán & DE-siroki-15336.jpg \\
\hline 1680 & Catalpa bignonioides Walter & Debrecen & 1948 & Siroki Zoltán & DE-siroki-15335.jpg \\
\hline 1682 & Globularia punctata Lapeyr. & Budaörs & 1952 & Siroki Zoltán & DE-siroki-15411.jpg \\
\hline 1682 & Globularia punctata Lapeyr. & Budapest & 1949 & Siroki Zoltán & DE-siroki-15415.jpg \\
\hline 1682 & Globularia punctata Lapeyr. & Budapest & 1951 & Siroki Zoltán & DE-siroki-15413.jpg \\
\hline 1682 & Globularia punctata Lapeyr. & Budapest & 1951 & Siroki Zoltán & DE-siroki-15414.jpg \\
\hline 1682 & Globularia punctata Lapeyr. & Budapest & 1951 & Siroki Zoltán & DE-siroki-15410.jpg \\
\hline 1682 & Globularia punctata Lapeyr. & Budapest & 1970 & Siroki Zoltán & DE-siroki-15412.jpg \\
\hline 1685 & Orobanche ramosa L. & Debrecen & 1948 & Siroki Zoltán & DE-siroki-15338.jpg \\
\hline 1685 & Orobanche ramosa L. & Debrecen & 1948 & Siroki Zoltán & DE-siroki-15339.jpg \\
\hline 1685 & Orobanche ramosa L. & Debrecen & 1948 & Siroki Zoltán & DE-siroki-15340.jpg \\
\hline 1685 & Orobanche ramosa L. & Gégény & 1965 & Gondola István & DE-siroki-15337.jpg \\
\hline 1687 & Orobanche purpurea Jacq. & "Háromkő" & 1959 & Siroki Zoltán & DE-siroki-15342.jpg \\
\hline 1687 & Orobanche purpurea Jacq. & Pomáz & 1952 & Siroki Zoltán & DE-siroki-15344.jpg \\
\hline 1687 & Orobanche purpurea Jacq. & Tokaj & 1971 & Siroki Zoltán & DE-siroki-15343.jpg \\
\hline 1692 & Orobanche cumana Wallr. & Debrecen & 1947 & Siroki Zoltán & DE-siroki-15363.jpg \\
\hline 1692 & Orobanche cumana Wallr. & Debrecen & 1948 & Siroki Zoltán & DE-siroki-15368.jpg \\
\hline 1692 & Orobanche cumana Wallr. & Debrecen & 1948 & Siroki Zoltán & DE-siroki-15364.jpg \\
\hline 1692 & Orobanche cumana Wallr. & Debrecen & 1948 & Siroki Zoltán & DE-siroki-15365.jpg \\
\hline 1692 & Orobanche cumana Wallr. & Debrecen & 1948 & Siroki Zoltán & DE-siroki-15366.jpg \\
\hline 1692 & Orobanche cumana Wallr. & Debrecen & 1948 & Siroki Zoltán & DE-siroki-15360.jpg \\
\hline 1692 & Orobanche cumana Wallr. & Debrecen & 1948 & Siroki Zoltán & DE-siroki-15361.jpg \\
\hline 1692 & Orobanche cumana Wallr. & Kecskemét & 1954 & Siroki Zoltán & DE-siroki-15362.jpg \\
\hline
\end{tabular}




\begin{tabular}{|c|c|c|c|c|c|}
\hline $\begin{array}{l}\text { Sorszám / } \\
\text { Number }\end{array}$ & Taxon-név / Taxon-name & $\begin{array}{l}\text { Település / } \\
\text { Settlement }\end{array}$ & $\begin{array}{l}\text { Év / } \\
\text { Year }\end{array}$ & $\begin{array}{l}\text { Gyűjtő / } \\
\text { Collector }\end{array}$ & Fájlnév / File-name \\
\hline 1694 & Orobanche alba Stephan ex Willd. & "Tarkő" & 1956 & Halász Tibor & DE-siroki-15379.jpg \\
\hline 1694 & Orobanche alba Stephan ex Willd. & Boldogkőváralja & 1967 & Siroki Zoltán & DE-siroki-15345.jpg \\
\hline 1694 & Orobanche alba Stephan ex Willd. & Boldogkőváralja & 1967 & Siroki Zoltán & DE-siroki-15346.jpg \\
\hline 1694 & Orobanche alba Stephan ex Willd. & Boldogkőváralja & 1967 & Siroki Zoltán & DE-siroki-15347.jpg \\
\hline 1694 & Orobanche alba Stephan ex Willd. & Budapest & 1928 & Rigler József & DE-siroki-15352.jpg \\
\hline 1694 & Orobanche alba Stephan ex Willd. & Budapest & 1951 & Siroki Zoltán & DE-siroki-15381.jpg \\
\hline 1694 & Orobanche alba Stephan ex Willd. & Budapest & 1951 & Siroki Zoltán & DE-siroki-15353.jpg \\
\hline 1694 & Orobanche alba Stephan ex Willd. & Budapest & 1952 & Siroki Zoltán & DE-siroki-15375.jpg \\
\hline 1694 & Orobanche alba Stephan ex Willd. & Budapest & 1952 & Siroki Zoltán & DE-siroki-15376.jpg \\
\hline 1694 & Orobanche alba Stephan ex Willd. & Budapest & 1955 & Siroki Zoltán & DE-siroki-15380.jpg \\
\hline 1694 & Orobanche alba Stephan ex Willd. & Pásztó & 1952 & Siroki Zoltán & DE-siroki-15378.jpg \\
\hline 1694 & Orobanche alba Stephan ex Willd. & Pomáz & 1952 & Siroki Zoltán & DE-siroki-15371.jpg \\
\hline 1694 & Orobanche alba Stephan ex Willd. & Szarvaskő & 1957 & Siroki Zoltán & DE-siroki-15348.jpg \\
\hline $\begin{array}{c}1694+ \\
1701\end{array}$ & $\begin{array}{l}\text { Orobanche alba Stephan ex Willd. + } \\
\text { Orobanche caryophyllacea Sm. }\end{array}$ & Boldogkőváralja & 1967 & Siroki Zoltán & DE-siroki-15383.jpg \\
\hline 1701 & Orobanche caryophyllacea Sm. & Gyenesdiás & 1951 & Siroki Zoltán & DE-siroki-15358.jpg \\
\hline 1701 & Orobanche caryophyllacea Sm. & Pilisszentiván & 1952 & Siroki Zoltán & DE-siroki-15372.jpg \\
\hline 1708 & Pinguicula vulgaris L. & Csaroda & 1976 & Halász Tibor & DE-siroki-15395.jpg \\
\hline 1708 & Pinguicula vulgaris L. & Hortobágy & 1948 & Siroki Zoltán & DE-siroki-15401.jpg \\
\hline 1708 & Pinguicula vulgaris L. & Hortobágy & 1948 & Siroki Zoltán & DE-siroki-15402.jpg \\
\hline 1708 & Pinguicula vulgaris L. & Hortobágy & 1948 & Siroki Zoltán & DE-siroki-15400.jpg \\
\hline 1708 & Pinguicula vulgaris L. & Keszthely & 1955 & Siroki Zoltán & DE-siroki-15399.jpg \\
\hline 1708 & Pinguicula vulgaris L. & Keszthely & 1955 & Siroki Zoltán & DE-siroki-15403.jpg \\
\hline 1708 & Pinguicula vulgaris L. & Sopron & 1951 & Kárpáti Zoltán & DE-siroki-15388.jpg \\
\hline 1708 & Pinguicula vulgaris L. & Tiszaroff & - & Perlaky Gábor & DE-siroki-15398.jpg \\
\hline 1709 & Pinguicula alpina L. & Lesenceistvánd & 1930 & Rigler József & DE-siroki-15393.jpg \\
\hline 1712 & Utricularia bremii Heer & Budapest & - & $\begin{array}{l}\text { Filarszky } \\
\text { Nándor }\end{array}$ & DE-siroki-15405.jpg \\
\hline 1712 & Utricularia bremii Heer & Sopron & 1951 & Kárpáti Zoltán & DE-siroki-15407.jpg \\
\hline 1712 & Utricularia bremii Heer & Veresegyház & 1954 & Siroki Zoltán & DE-siroki-15406.jpg \\
\hline 1715 & Sherardia arvensis L. & Mátraverebély & 1952 & Siroki Zoltán & DE-siroki-15490.jpg \\
\hline 1715 & Sherardia arvensis L. & Mátraverebély & 1952 & Siroki Zoltán & DE-siroki-15492.jpg \\
\hline 1715 & Sherardia arvensis L. & Mosonmagyaróvár & 1939 & Siroki Zoltán & DE-siroki-15493.jpg \\
\hline 1716 & Asperula taurina L. & Hosszúhetény & 1954 & Siroki Zoltán & DE-siroki-15503.jpg \\
\hline 1716 & Asperula taurina L. & Hosszúhetény & 1954 & Siroki Zoltán & DE-siroki-15495.jpg \\
\hline 1716 & Asperula taurina L. & Hosszúhetény & 1954 & Siroki Zoltán & DE-siroki-15496.jpg \\
\hline 1716 & Asperula taurina L. & Hosszúhetény & 1954 & Siroki Zoltán & DE-siroki-15497.jpg \\
\hline 1716 & Asperula taurina L. & Hosszúhetény & 1954 & Siroki Zoltán & DE-siroki-15501.jpg \\
\hline 1716 & Asperula taurina L. & Hosszúhetény & 1954 & Siroki Zoltán & DE-siroki-15502.jpg \\
\hline 1716 & Asperula taurina L. & Hosszúhetény & 1954 & Siroki Zoltán & DE-siroki-15504.jpg \\
\hline 1716 & Asperula taurina L. & Hosszúhetény & 1958 & Siroki Zoltán & DE-siroki-15498.jpg \\
\hline 1716 & Asperula taurina L. & Hosszúhetény & 1958 & Siroki Zoltán & DE-siroki-15494.jpg \\
\hline 1716 & Asperula taurina L. & Hosszúhetény & 1958 & Siroki Zoltán & DE-siroki-15500.jpg \\
\hline 1717 & Asperula tinctoria L. & Gyenesdiás & 1955 & Siroki Zoltán & DE-siroki-15550.jpg \\
\hline 1717 & Asperula tinctoria L. & Gyenesdiás & 1955 & Siroki Zoltán & DE-siroki-15551.jpg \\
\hline 1717 & Asperula tinctoria L. & Gyenesdiás & 1955 & Siroki Zoltán & DE-siroki-15552.jpg \\
\hline 1717 & Asperula tinctoria L. & Gyenesdiás & 1955 & Siroki Zoltán & DE-siroki-15553.jpg \\
\hline
\end{tabular}




\begin{tabular}{|c|c|c|c|c|c|}
\hline $\begin{array}{l}\text { Sorszám / } \\
\text { Number }\end{array}$ & Taxon-név / Taxon-name & $\begin{array}{l}\text { Település / } \\
\text { Settlement }\end{array}$ & $\begin{array}{l}\text { Év / } \\
\text { Year }\end{array}$ & $\begin{array}{l}\text { Gyűjtő / } \\
\text { Collector }\end{array}$ & Fájlnév / File-name \\
\hline 1717 & Asperula tinctoria L. & Pilisszentiván & 1913 & $\begin{array}{l}\text { Filarszky } \\
\text { Nándor - } \\
\text { Jávorka Sándor }\end{array}$ & DE-siroki-15560.jpg \\
\hline 1717 & Asperula tinctoria L. & Szilvásvárad & 1960 & Siroki Zoltán & DE-siroki-15547.jpg \\
\hline 1717 & Asperula tinctoria L. & Szilvásvárad & 1962 & Siroki Zoltán & DE-siroki-15546.jpg \\
\hline 1717 & Asperula tinctoria L. & Szilvásvárad & 1962 & Siroki Zoltán & DE-siroki-15548.jpg \\
\hline 1717 & Asperula tinctoria L. & Szilvásvárad & 1962 & Siroki Zoltán & DE-siroki-15549.jpg \\
\hline 1717 & Asperula tinctoria L. & Szilvásvárad & 1962 & Siroki Zoltán & DE-siroki-15544.jpg \\
\hline 1717 & Asperula tinctoria L. & Szilvásvárad & 1962 & Siroki Zoltán & DE-siroki-15545.jpg \\
\hline 1717 & Asperula tinctoria L. & Szilvásvárad & 1962 & Siroki Zoltán & DE-siroki-15554.jpg \\
\hline 1717 & Asperula tinctoria L. & Szilvásvárad & 1962 & Siroki Zoltán & DE-siroki-15555.jpg \\
\hline 1717 & Asperula tinctoria L. & Szilvásvárad & 1962 & Siroki Zoltán & DE-siroki-15556.jpg \\
\hline 1717 & Asperula tinctoria L. & Szilvásvárad & 1962 & Siroki Zoltán & DE-siroki-15557.jpg \\
\hline 1717 & Asperula tinctoria L. & Szilvásvárad & 1962 & Siroki Zoltán & DE-siroki-15558.jpg \\
\hline 1717 & Asperula tinctoria L. & Szilvásvárad & 1962 & Siroki Zoltán & DE-siroki-15559.jpg \\
\hline 1718 & Asperula cynanchica L. & "Háromkő" & 1959 & Siroki Zoltán & DE-siroki-15570.jpg \\
\hline 1718 & Asperula cynanchica L. & Abaújszántó & 1943 & Siroki Zoltán & DE-siroki-15568.jpg \\
\hline 1718 & Asperula cynanchica L. & Debrecen & 1947 & Siroki Zoltán & DE-siroki-15571.jpg \\
\hline 1718 & Asperula cynanchica L. & Tokaj & 1971 & Siroki Zoltán & DE-siroki-15572.jpg \\
\hline 1718 & Asperula cynanchica L. & Tokaj & 1971 & Siroki Zoltán & DE-siroki-15573.jpg \\
\hline 1718 & Asperula cynanchica L. & Vámospércs & 1984 & Siroki Zoltán & DE-siroki-15574.jpg \\
\hline 1723 & Galium boreale L. & Egyek & 1949 & Siroki Zoltán & DE-siroki-15610.jpg \\
\hline 1723 & Galium boreale L. & Egyek & 1949 & Siroki Zoltán & DE-siroki-15611.jpg \\
\hline 1723 & Galium boreale L. & Gyenesdiás & 1955 & Siroki Zoltán & DE-siroki-15608.jpg \\
\hline 1723 & Galium boreale L. & Hajdúböszörmény & 1966 & Siroki Zoltán & DE-siroki-15606.jpg \\
\hline 1723 & Galium boreale L. & Tiszafüred & 1955 & $\begin{array}{l}\text { Siroki Zoltán - } \\
\text { Farkas Attila }\end{array}$ & DE-siroki-15609.jpg \\
\hline 1723 & Galium boreale L. & Tiszafüred & 1955 & $\begin{array}{l}\text { Siroki Zoltán - } \\
\text { Farkas Attila }\end{array}$ & DE-siroki-15607.jpg \\
\hline 1724 & Galium rubioides L. & Aszaló & 1944 & Siroki Zoltán & DE-siroki-15618.jpg \\
\hline 1724 & Galium rubioides L. & Bodrogkeresztúr & 1967 & Siroki Zoltán & DE-siroki-15615.jpg \\
\hline 1724 & Galium rubioides L. & Bodrogkeresztúr & 1967 & Siroki Zoltán & DE-siroki-15616.jpg \\
\hline 1724 & Galium rubioides L. & Dunakeszi & 1905 & Thaisz Lajos & DE-siroki-15614.jpg \\
\hline 1724 & Galium rubioides L. & Egyek & 1947 & Siroki Zoltán & DE-siroki-15617.jpg \\
\hline 1725 & Galium rivale (Sibth. et Sm.) Griseb. & Gödöllő & 1951 & Siroki Zoltán & DE-siroki-15508.jpg \\
\hline 1725 & Galium rivale (Sibth. et Sm.) Griseb. & Miskolc & 1965 & Siroki Zoltán & DE-siroki-15514.jpg \\
\hline 1725 & Galium rivale (Sibth. et Sm.) Griseb. & Miskolc & 1965 & Siroki Zoltán & DE-siroki-15515.jpg \\
\hline 1726 & Galium odoratum (L.) Scop. & "Fáni-völgy" & 1955 & $\begin{array}{l}\text { Farkas Attila - } \\
\text { Siroki Zoltán }\end{array}$ & DE-siroki-15505.jpg \\
\hline 1726 & Galium odoratum (L.) Scop. & "Fáni-völgy" & 1955 & $\begin{array}{l}\text { Siroki Zoltán - } \\
\text { Farkas Attila }\end{array}$ & DE-siroki-15506.jpg \\
\hline 1727 & Galium humifusum M. Bieb. & Szeged & 1951 & Jeanplong József & DE-siroki-15578.jpg \\
\hline 1728 & Galium glaucum L. & Abaújszántó & 1943 & Siroki Zoltán & DE-siroki-15525.jpg \\
\hline 1728 & Galium glaucum L. & Budaörs & 1955 & Siroki Zoltán & DE-siroki-15540.jpg \\
\hline 1728 & Galium glaucum L. & Budaörs & 1966 & Siroki Zoltán & DE-siroki-15528.jpg \\
\hline 1728 & Galium glaucum L. & Budaörs & 1966 & Siroki Zoltán & DE-siroki-15529.jpg \\
\hline 1728 & Galium glaucum L. & Budapest & 1966 & Siroki Zoltán & DE-siroki-15530.jpg \\
\hline 1728 & Galium glaucum L. & Budapest & 1966 & Siroki Zoltán & DE-siroki-15531.jpg \\
\hline 1728 & Galium glaucum L. & Debrecen & 1961 & Siroki Zoltán & DE-siroki-15533.jpg \\
\hline
\end{tabular}




\begin{tabular}{|c|c|c|c|c|c|}
\hline $\begin{array}{l}\text { Sorszám / } \\
\text { Number }\end{array}$ & Taxon-név / Taxon-name & $\begin{array}{l}\text { Település / } \\
\text { Settlement }\end{array}$ & $\begin{array}{l}\text { Év / } \\
\text { Year }\end{array}$ & $\begin{array}{l}\text { Gyújtő / } \\
\text { Collector }\end{array}$ & Fájlnév / File-name \\
\hline 1728 & Galium glaucum L. & Debrecen & 1961 & Siroki Zoltán & DE-siroki-15534.jpg \\
\hline 1728 & Galium glaucum L. & Debrecen & 1961 & Siroki Zoltán & DE-siroki-15535.jpg \\
\hline 1728 & Galium glaucum L. & Debrecen & 1961 & Siroki Zoltán & DE-siroki-15536.jpg \\
\hline 1728 & Galium glaucum L. & Debrecen & 1961 & Siroki Zoltán & DE-siroki-15524.jpg \\
\hline 1728 & Galium glaucum L. & Gyenesdiás & 1955 & Siroki Zoltán & DE-siroki-15541.jpg \\
\hline 1728 & Galium glaucum L. & Gyenesdiás & 1955 & Siroki Zoltán & DE-siroki-15542.jpg \\
\hline 1728 & Galium glaucum L. & Gyenesdiás & 1955 & Siroki Zoltán & DE-siroki-15543.jpg \\
\hline 1728 & Galium glaucum L. & Pomáz & 1957 & Siroki Zoltán & DE-siroki-15537.jpg \\
\hline 1728 & Galium glaucum L. & Pomáz & 1957 & Siroki Zoltán & DE-siroki-15538.jpg \\
\hline 1728 & Galium glaucum L. & Pomáz & 1957 & Siroki Zoltán & DE-siroki-15539.jpg \\
\hline 1728 & Galium glaucum L. & Rakaca & 1982 & Siroki Zoltán & DE-siroki-15523.jpg \\
\hline 1728 & Galium glaucum L. & Tokaj & 1966 & Siroki Zoltán & DE-siroki-15532.jpg \\
\hline 1729 & Galium palustre L. & Debrecen & 1950 & Siroki Zoltán & DE-siroki-15637.jpg \\
\hline 1729 & Galium palustre L. & Hollóháza & - & Siroki Zoltán & DE-siroki-15642.jpg \\
\hline 1729 & Galium palustre L. & Hortobágy & 1947 & Siroki Zoltán & DE-siroki-15641.jpg \\
\hline 1732 & Galium aparine L. & "Fáni-völgy" & 1955 & $\begin{array}{l}\text { Siroki Zoltán - } \\
\text { Farkas Attila }\end{array}$ & DE-siroki-15624.jpg \\
\hline 1732 & Galium aparine L. & Gödöllő & 1951 & Siroki Zoltán & DE-siroki-15509.jpg \\
\hline 1732 & Galium aparine L. & Gödöllő & 1951 & Siroki Zoltán & DE-siroki-15510.jpg \\
\hline 1732 & Galium aparine L. & Gödöllő & 1951 & Siroki Zoltán & DE-siroki-15511.jpg \\
\hline 1732 & Galium aparine L. & Gödöllő & 1951 & Siroki Zoltán & DE-siroki-15516.jpg \\
\hline 1732 & Galium aparine L. & Háromhuta & 1968 & Siroki Zoltán & DE-siroki-15512.jpg \\
\hline 1732 & Galium aparine L. & Háromhuta & 1968 & Siroki Zoltán & DE-siroki-15513.jpg \\
\hline 1733 & Galium spurium L. & Dömsöd & 1952 & Siroki Zoltán & DE-siroki-15620.jpg \\
\hline 1733 & Galium spurium L. & Hortobágy & 1975 & Siroki Zoltán & DE-siroki-15623.jpg \\
\hline 1733 & Galium spurium L. & Tiszafüred & 1970 & Siroki Zoltán & DE-siroki-15621.jpg \\
\hline 1734 & Galium uliginosum L. & Debrecen & 1950 & Siroki Zoltán & DE-siroki-15630.jpg \\
\hline 1734 & Galium uliginosum L. & Debrecen & 1950 & Siroki Zoltán & DE-siroki-15635.jpg \\
\hline 1734 & Galium uliginosum L. & Debrecen & 1950 & Siroki Zoltán & DE-siroki-15628.jpg \\
\hline 1734 & Galium uliginosum L. & Debrecen & 1950 & Siroki Zoltán & DE-siroki-15629.jpg \\
\hline 1734 & Galium uliginosum L. & Debrecen & 1950 & Siroki Zoltán & DE-siroki-15634.jpg \\
\hline 1734 & Galium uliginosum L. & Debrecen & 1958 & Siroki Zoltán & DE-siroki-15632.jpg \\
\hline 1734 & Galium uliginosum L. & Debrecen & 1975 & Siroki Zoltán & DE-siroki-15626.jpg \\
\hline 1734 & Galium uliginosum L. & Debrecen & 1975 & Siroki Zoltán & DE-siroki-15627.jpg \\
\hline 1734 & Galium uliginosum L. & Gödöllő & 1952 & Siroki Zoltán & DE-siroki-15631.jpg \\
\hline 1734 & Galium uliginosum L. & Gödöllő & 1952 & Siroki Zoltán & DE-siroki-15633.jpg \\
\hline 1734 & Galium uliginosum L. & Hajdúbagos & 1981 & Siroki Zoltán & DE-siroki-15625.jpg \\
\hline 1735 & Galium tenuissimum M. Bieb. & Vitnyéd & 1928 & Rigler József & DE-siroki-15636.jpg \\
\hline 1738 & Galium pumilum Murray & "Fáni-völgy" & 1955 & Siroki Zoltán & DE-siroki-15696.jpg \\
\hline 1738 & Galium pumilum Murray & Gyenesdiás & 1955 & Siroki Zoltán & DE-siroki-15698.jpg \\
\hline 1738 & Galium pumilum Murray & Gyenesdiás & 1955 & Siroki Zoltán & DE-siroki-15702.jpg \\
\hline 1738 & Galium pumilum Murray & Gyenesdiás & 1955 & Siroki Zoltán & DE-siroki-15703.jpg \\
\hline 1738 & Galium pumilum Murray & Gyenesdiás & 1955 & Siroki Zoltán & DE-siroki-15699.jpg \\
\hline 1738 & Galium pumilum Murray & Gyenesdiás & 1955 & Siroki Zoltán & DE-siroki-15694.jpg \\
\hline 1738 & Galium pumilum Murray & Gyenesdiás & 1955 & Siroki Zoltán & DE-siroki-15695.jpg \\
\hline 1738 & Galium pumilum Murray & Pilisszentiván & 1952 & Siroki Zoltán & DE-siroki-15700.jpg \\
\hline 1738 & Galium pumilum Murray & Pilisszentiván & 1952 & Siroki Zoltán & DE-siroki-15701.jpg \\
\hline
\end{tabular}




\begin{tabular}{|c|c|c|c|c|c|}
\hline $\begin{array}{l}\text { Sorszám / } \\
\text { Number }\end{array}$ & Taxon-név / Taxon-name & $\begin{array}{l}\text { Település / } \\
\text { Settlement }\end{array}$ & $\begin{array}{l}\text { Év / } \\
\text { Year }\end{array}$ & $\begin{array}{l}\text { Gyüjtő / } \\
\text { Collector }\end{array}$ & Fájlnév / File-name \\
\hline 1738 & Galium pumilum Murray & Pilisszentiván & 1952 & Siroki Zoltán & DE-siroki-15704.jpg \\
\hline 1738 & Galium pumilum Murray & Pilisszentiván & 1955 & Siroki Zoltán & DE-siroki-15697.jpg \\
\hline 1740 & Galium verum $L$. & Keszthely & 1955 & Siroki Zoltán & DE-siroki-15659.jpg \\
\hline 1740 & Galium verum $\mathrm{L}$. & Mosonmagyaróvár & 1939 & Siroki Zoltán & DE-siroki-15657.jpg \\
\hline 1740 & Galium verum L. & Mosonmagyaróvár & 1939 & Siroki Zoltán & DE-siroki-15658.jpg \\
\hline 1741 & Galium sylvaticum L. & "Dobogókő" & 1956 & Siroki Zoltán & DE-siroki-15649.jpg \\
\hline 1741 & Galium sylvaticum L. & "Dobogókő" & 1956 & Siroki Zoltán & DE-siroki-15650.jpg \\
\hline 1741 & Galium sylvaticum L. & "Dobogókő" & 1965 & Siroki Zoltán & DE-siroki-15648.jpg \\
\hline 1741 & Galium sylvaticum L. & Háromhuta & 1977 & Siroki Zoltán & DE-siroki-15647.jpg \\
\hline 1741 & Galium sylvaticum L. & Pécs & 1954 & Siroki Zoltán & DE-siroki-15652.jpg \\
\hline 1741 & Galium sylvaticum L. & Pécs & 1954 & Siroki Zoltán & DE-siroki-15653.jpg \\
\hline 1741 & Galium sylvaticum L. & Rezi & 1955 & Siroki Zoltán & DE-siroki-15651.jpg \\
\hline 1741 & Galium sylvaticum L. & Rezi & 1955 & Siroki Zoltán & DE-siroki-15654.jpg \\
\hline 1741 & Galium sylvaticum L. & Sopron & 1951 & Kárpáti Zoltán & DE-siroki-15655.jpg \\
\hline 1742 & Galium schultesii Vest & Budapest & 1950 & Siroki Zoltán & DE-siroki-15644.jpg \\
\hline 1743 & Galium abaujense Borbás & Kishuta & 1954 & Simon Tiborné & DE-siroki-15663.jpg \\
\hline 1743 & Galium abaujense Borbás & Kishuta & 1954 & Simon Tiborné & DE-siroki-15664.jpg \\
\hline 1743 & Galium abaujense Borbás & Kishuta & 1954 & Simon Tiborné & DE-siroki-15680.jpg \\
\hline 1743 & Galium abaujense Borbás & Nagyhuta & 1978 & Siroki Zoltán & DE-siroki-15668.jpg \\
\hline 1743 & Galium abaujense Borbás & Nagyvisnyó & 1959 & Siroki Zoltán & DE-siroki-15676.jpg \\
\hline 1743 & Galium abaujense Borbás & Nagyvisnyó & 1959 & Siroki Zoltán & DE-siroki-15677.jpg \\
\hline 1743 & Galium abaujense Borbás & Nagyvisnyó & 1959 & Siroki Zoltán & DE-siroki-15678.jpg \\
\hline 1743 & Galium abaujense Borbás & Nagyvisnyó & 1959 & Siroki Zoltán & DE-siroki-15679.jpg \\
\hline 1743 & Galium abaujense Borbás & Pásztó & 1952 & Siroki Zoltán & DE-siroki-15666.jpg \\
\hline 1743 & Galium abaujense Borbás & Pásztó & 1952 & Siroki Zoltán & DE-siroki-15665.jpg \\
\hline 1743 & Galium abaujense Borbás & Sátoraljaújhely & 1944 & Siroki Zoltán & DE-siroki-15681.jpg \\
\hline 1743 & Galium abaujense Borbás & Sátoraljaújhely & 1944 & Siroki Zoltán & DE-siroki-15662.jpg \\
\hline 1743 & Galium abaujense Borbás & Sátoraljaújhely & 1944 & Siroki Zoltán & DE-siroki-15667.jpg \\
\hline 1743 & Galium abaujense Borbás & Szilvásvárad & 1962 & Siroki Zoltán & DE-siroki-15669.jpg \\
\hline 1743 & Galium abaujense Borbás & Szilvásvárad & 1962 & Siroki Zoltán & DE-siroki-15670.jpg \\
\hline 1743 & Galium abaujense Borbás & Szilvásvárad & 1962 & Siroki Zoltán & DE-siroki-15671.jpg \\
\hline 1743 & Galium abaujense Borbás & Szilvásvárad & 1962 & Siroki Zoltán & DE-siroki-15672.jpg \\
\hline 1743 & Galium abaujense Borbás & Szilvásvárad & 1962 & Siroki Zoltán & DE-siroki-15673.jpg \\
\hline 1743 & Galium abaujense Borbás & Szilvásvárad & 1962 & Siroki Zoltán & DE-siroki-15674.jpg \\
\hline 1743 & Galium abaujense Borbás & Szilvásvárad & 1962 & Siroki Zoltán & DE-siroki-15675.jpg \\
\hline 1744 & Galium lucidum All. & Szilvásvárad & 1954 & Siroki Zoltán & DE-siroki-15693.jpg \\
\hline 1745 & Galium mollugo L. & "Bükk-hg." & 1983 & Siroki Zoltán & DE-siroki-15682.jpg \\
\hline 1745 & Galium mollugo L. & Budaörs & 1955 & Siroki Zoltán & DE-siroki-15685.jpg \\
\hline 1745 & Galium mollugo L. & Budaörs & 1955 & Siroki Zoltán & DE-siroki-15686.jpg \\
\hline 1745 & Galium mollugo L. & Mosonmagyaróvár & 1939 & Siroki Zoltán & DE-siroki-15691.jpg \\
\hline 1745 & Galium mollugo L. & Mosonmagyaróvár & 1939 & Siroki Zoltán & DE-siroki-15692.jpg \\
\hline 1745 & Galium mollugo L. & Pécs & 1954 & Siroki Zoltán & DE-siroki-15684.jpg \\
\hline 1745 & Galium mollugo L. & Pécs & 1954 & Siroki Zoltán & DE-siroki-15687.jpg \\
\hline 1745 & Galium mollugo L. & Pécs & 1954 & Siroki Zoltán & DE-siroki-15688.jpg \\
\hline 1745 & Galium mollugo L. & Szilvásvárad & 1962 & Siroki Zoltán & DE-siroki-15683.jpg \\
\hline $\begin{array}{c}1740 \times \\
1745\end{array}$ & $\begin{array}{l}\text { Galium } \times \text { pomeranicum Retz. } \\
\text { (G. album } \times \text { verum) }\end{array}$ & Encs & 1944 & Siroki Zoltán & DE-siroki-15706.jpg \\
\hline
\end{tabular}




\begin{tabular}{|c|c|c|c|c|c|}
\hline $\begin{array}{l}\text { Sorszám / } \\
\text { Number }\end{array}$ & Taxon-név / Taxon-name & $\begin{array}{l}\text { Település / } \\
\text { Settlement }\end{array}$ & $\begin{array}{l}\text { Év / } \\
\text { Year }\end{array}$ & $\begin{array}{l}\text { Gyűjtő / } \\
\text { Collector }\end{array}$ & Fájlnév / File-name \\
\hline $\begin{array}{c}1740 \times \\
1745\end{array}$ & $\begin{array}{l}\text { Galium } \times \text { pomeranicum Retz. } \\
\text { (G. album } \times \text { verum) }\end{array}$ & Encs & 1944 & Siroki Zoltán & DE-siroki-15707.jpg \\
\hline $\begin{array}{c}1740 \times \\
1745\end{array}$ & $\begin{array}{l}\text { Galium } \times \text { pomeranicum Retz } \\
\text { (G. album } \times \text { verum) }\end{array}$ & Encs & 1944 & Siroki Zoltán & DE-siroki-15705.jpg \\
\hline 1747 & $\begin{array}{l}\text { Cruciata pedemontana } \\
\text { (Bellardi) Ehrend. }\end{array}$ & Budapest & 1951 & Siroki Zoltán & DE-siroki-15584.jpg \\
\hline 1747 & $\begin{array}{l}\text { Cruciata pedemontana } \\
\text { (Bellardi) Ehrend. }\end{array}$ & Budapest & 1951 & Siroki Zoltán & DE-siroki-15585.jpg \\
\hline 1747 & $\begin{array}{l}\text { Cruciata pedemontana } \\
\text { (Bellardi) Ehrend. }\end{array}$ & Budapest & 1951 & Siroki Zoltán & DE-siroki-15587.jpg \\
\hline 1747 & $\begin{array}{l}\text { Cruciata pedemontana } \\
\text { (Bellardi) Ehrend. }\end{array}$ & Debrecen & 1959 & Siroki Zoltán & DE-siroki-15583.jpg \\
\hline 1747 & $\begin{array}{l}\text { Cruciata pedemontana } \\
\text { (Bellardi) Ehrend. }\end{array}$ & Debrecen & 1959 & Siroki Zoltán & DE-siroki-15586.jpg \\
\hline 1747 & $\begin{array}{l}\text { Cruciata pedemontana } \\
\text { (Bellardi) Ehrend. }\end{array}$ & Vámospércs & 1965 & Siroki Zoltán & DE-siroki-15579.jpg \\
\hline 1747 & $\begin{array}{l}\text { Cruciata pedemontana } \\
\text { (Bellardi) Ehrend. }\end{array}$ & Vámospércs & 1965 & Siroki Zoltán & DE-siroki-15580.jpg \\
\hline 1747 & $\begin{array}{l}\text { Cruciata pedemontana } \\
\text { (Bellardi) Ehrend. }\end{array}$ & Vámospércs & 1965 & Siroki Zoltán & DE-siroki-15581.jpg \\
\hline 1747 & $\begin{array}{l}\text { Cruciata pedemontana } \\
\text { (Bellardi) Ehrend. }\end{array}$ & Vámospércs & 1965 & Siroki Zoltán & DE-siroki-15582.jpg \\
\hline 1748 & Cruciata laevipes Opiz & Debrecen & 1947 & Siroki Zoltán & DE-siroki-15588.jpg \\
\hline 1748 & Cruciata laevipes Opiz & Mosonmagyaróvár & 1939 & Siroki Zoltán & DE-siroki-15590.jpg \\
\hline 1749 & Cruciata glabra (L.) Ehrend. & Debrecen & 1964 & Siroki Zoltán & DE-siroki-15592.jpg \\
\hline 1749 & Cruciata glabra (L.) Ehrend. & Debrecen & 1964 & Siroki Zoltán & DE-siroki-15594.jpg \\
\hline 1749 & Cruciata glabra (L.) Ehrend. & Debrecen & 1964 & Siroki Zoltán & DE-siroki-15595.jpg \\
\hline 1749 & Cruciata glabra (L.) Ehrend. & Debrecen & 1964 & Siroki Zoltán & DE-siroki-15596.jpg \\
\hline 1749 & Cruciata glabra (L.) Ehrend. & Debrecen & 1964 & Siroki Zoltán & DE-siroki-15597.jpg \\
\hline 1749 & Cruciata glabra (L.) Ehrend. & Debrecen & 1964 & Siroki Zoltán & DE-siroki-15598.jpg \\
\hline 1749 & Cruciata glabra (L.) Ehrend. & Felsőtárkány & 1957 & Siroki Zoltán & DE-siroki-15599.jpg \\
\hline 1749 & Cruciata glabra (L.) Ehrend. & Háromhuta & 1961 & Siroki Zoltán & DE-siroki-15593.jpg \\
\hline 1751 & Plantago indica L. & Budapest & 1941 & Siroki Zoltán & DE-siroki-15421.jpg \\
\hline 1751 & Plantago indica L. & Debrecen & 1946 & Siroki Zoltán & DE-siroki-15418.jpg \\
\hline 1751 & Plantago indica L. & Debrecen & 1946 & Siroki Zoltán & DE-siroki-15419.jpg \\
\hline 1751 & Plantago indica L. & Debrecen & 1947 & Siroki Zoltán & DE-siroki-15420.jpg \\
\hline 1751 & Plantago indica L. & Debrecen & 1977 & Siroki Zoltán & DE-siroki-15416.jpg \\
\hline 1751 & Plantago indica L. & Debrecen & 1977 & Siroki Zoltán & DE-siroki-15417.jpg \\
\hline 1752 & Plantago maritima L. & Budaörs & 1941 & Siroki Zoltán & DE-siroki-15429.jpg \\
\hline 1752 & Plantago maritima L. & Budaörs & 1941 & Siroki Zoltán & DE-siroki-15430.jpg \\
\hline 1752 & Plantago maritima L. & Budaörs & 1941 & Siroki Zoltán & DE-siroki-15432.jpg \\
\hline 1752 & Plantago maritima L. & Budapest & 1941 & Siroki Zoltán & DE-siroki-15431.jpg \\
\hline 1752 & Plantago maritima L. & Debrecen & 1947 & Siroki Zoltán & DE-siroki-15428.jpg \\
\hline 1752 & Plantago maritima L. & Debrecen & 1962 & Siroki Zoltán & DE-siroki-15427.jpg \\
\hline 1752 & Plantago maritima L. & Egyek & 1947 & Siroki Zoltán & DE-siroki-15426.jpg \\
\hline 1753 & Plantago tenuiflora Waldst. et Kit. & Debrecen & 1947 & Siroki Zoltán & DE-siroki-15442.jpg \\
\hline 1753 & Plantago tenuiflora Waldst. et Kit. & Dömsöd & 1952 & Siroki Zoltán & DE-siroki-15441.jpg \\
\hline 1753 & Plantago tenuiflora Waldst. et Kit. & Egyek & 1947 & Siroki Zoltán & DE-siroki-15439.jpg \\
\hline 1753 & Plantago tenuiflora Waldst. et Kit. & Hortobágy & 1947 & Siroki Zoltán & DE-siroki-15440.jpg \\
\hline 1753 & Plantago tenuiflora Waldst. et Kit. & Hortobágy & 1947 & Siroki Zoltán & DE-siroki-15443.jpg \\
\hline 1753 & Plantago tenuiflora Waldst. et Kit. & Hortobágy & 1954 & Siroki Zoltán & DE-siroki-15436.jpg \\
\hline 1753 & Plantago tenuiflora Waldst. et Kit. & Hortobágy & 1957 & Siroki Zoltán & DE-siroki-15437.jpg \\
\hline
\end{tabular}




\begin{tabular}{|c|c|c|c|c|c|}
\hline $\begin{array}{l}\text { Sorszám / } \\
\text { Number }\end{array}$ & Taxon-név / Taxon-name & $\begin{array}{l}\text { Település / } \\
\text { Settlement }\end{array}$ & $\begin{array}{l}\text { Év / } \\
\text { Year }\end{array}$ & $\begin{array}{l}\text { Gyújtő / } \\
\text { Collector }\end{array}$ & Fájlnév / File-name \\
\hline 1753 & Plantago tenuiflora Waldst. et Kit. & Mikepércs & 1966 & Siroki Zoltán & DE-siroki-15434.jpg \\
\hline 1753 & Plantago tenuiflora Waldst. et Kit. & Mikepércs & 1966 & Siroki Zoltán & DE-siroki-15435.jpg \\
\hline 1753 & Plantago tenuiflora Waldst. et Kit. & Szerencs & 1951 & Siroki Zoltán & DE-siroki-15438.jpg \\
\hline 1754 & Plantago schwarzenbergiana Schur & Berettyóújfalu & 1959 & Püspöki Pál & DE-siroki-15462.jpg \\
\hline 1754 & Plantago schwarzenbergiana Schur & Biharugra & 1961 & Siroki Zoltán & DE-siroki-15445.jpg \\
\hline 1754 & Plantago schwarzenbergiana Schur & Biharugra & 1961 & Siroki Zoltán & DE-siroki-15453.jpg \\
\hline 1754 & Plantago schwarzenbergiana Schur & Biharugra & 1961 & Siroki Zoltán & DE-siroki-15454.jpg \\
\hline 1754 & Plantago schwarzenbergiana Schur & Biharugra & 1961 & Siroki Zoltán & DE-siroki-15455.jpg \\
\hline 1754 & Plantago schwarzenbergiana Schur & Biharugra & 1961 & Siroki Zoltán & DE-siroki-15456.jpg \\
\hline 1754 & Plantago schwarzenbergiana Schur & Biharugra & 1961 & Siroki Zoltán & DE-siroki-15457.jpg \\
\hline 1754 & Plantago schwarzenbergiana Schur & Biharugra & 1961 & Siroki Zoltán & DE-siroki-15458.jpg \\
\hline 1754 & Plantago schwarzenbergiana Schur & Biharugra & 1961 & Siroki Zoltán & DE-siroki-15459.jpg \\
\hline 1754 & Plantago schwarzenbergiana Schur & Biharugra & 1961 & Siroki Zoltán & DE-siroki-15460.jpg \\
\hline 1754 & Plantago schwarzenbergiana Schur & Biharugra & 1961 & Siroki Zoltán & DE-siroki-15461.jpg \\
\hline 1754 & Plantago schwarzenbergiana Schur & Derecske & 1965 & Siroki Zoltán & DE-siroki-15449.jpg \\
\hline 1754 & Plantago schwarzenbergiana Schur & Derecske & 1965 & Siroki Zoltán & DE-siroki-15450.jpg \\
\hline 1754 & Plantago schwarzenbergiana Schur & Derecske & 1965 & Siroki Zoltán & DE-siroki-15451.jpg \\
\hline 1754 & Plantago schwarzenbergiana Schur & Hortobágy & 1975 & Siroki Zoltán & DE-siroki-15452.jpg \\
\hline 1754 & Plantago schwarzenbergiana Schur & Sárrétudvari & 1966 & Siroki Zoltán & DE-siroki-15446.jpg \\
\hline 1754 & Plantago schwarzenbergiana Schur & Sárrétudvari & 1966 & Siroki Zoltán & DE-siroki-15447.jpg \\
\hline 1754 & Plantago schwarzenbergiana Schur & Sárrétudvari & 1966 & Siroki Zoltán & DE-siroki-15448.jpg \\
\hline 1755 & Plantago argentea Chaix in Vill. & Pécs & 1958 & Siroki Zoltán & DE-siroki-15463.jpg \\
\hline 1755 & Plantago argentea Chaix in Vill. & Pécs & 1958 & Siroki Zoltán & DE-siroki-15464.jpg \\
\hline 1755 & Plantago argentea Chaix in Vill. & Pécs & 1958 & Siroki Zoltán & DE-siroki-15465.jpg \\
\hline 1755 & Plantago argentea Chaix in Vill. & Pécs & 1958 & Siroki Zoltán & DE-siroki-15466.jpg \\
\hline 1756 & Plantago lanceolata L. & Debrecen & 1947 & Siroki Zoltán & DE-siroki-15467.jpg \\
\hline 1756 & Plantago lanceolata L. & Hortobágy & 1947 & Siroki Zoltán & DE-siroki-15468.jpg \\
\hline 1756 & Plantago lanceolata L. & Hortobágy & 1948 & Siroki Zoltán & DE-siroki-15469.jpg \\
\hline 1756 & Plantago lanceolata L. & Mosonmagyaróvár & 1939 & Siroki Zoltán & DE-siroki-15471.jpg \\
\hline 1757 & Plantago altissima L. & Budapest & 1904 & $\begin{array}{l}\text { Thaisz Lajos - } \\
\text { Baán Lajos }\end{array}$ & DE-siroki-15473.jpg \\
\hline 1757 & Plantago altissima L. & Budapest & 1909 & Kocsis István & DE-siroki-15472.jpg \\
\hline 1757 & Plantago altissima L. & Dabas & 1951 & Kárpáti Zoltán & DE-siroki-15475.jpg \\
\hline 1758 & Plantago media L. & Debrecen & 1947 & Siroki Zoltán & DE-siroki-15483.jpg \\
\hline 1758 & Plantago media L. & Debrecen & 1959 & Siroki Zoltán & DE-siroki-15477.jpg \\
\hline 1758 & Plantago media L. & Debrecen & 1959 & Siroki Zoltán & DE-siroki-15478.jpg \\
\hline 1758 & Plantago media L. & Debrecen & 1970 & Siroki Zoltán & DE-siroki-15479.jpg \\
\hline 1758 & Plantago media L. & Debrecen & 1970 & Siroki Zoltán & DE-siroki-15480.jpg \\
\hline 1758 & Plantago media L. & Debrecen & 1970 & Siroki Zoltán & DE-siroki-15481.jpg \\
\hline 1758 & Plantago media L. & Debrecen & 1970 & Siroki Zoltán & DE-siroki-15482.jpg \\
\hline 1758 & Plantago media L. & Mosonmagyaróvár & 1939 & Siroki Zoltán & DE-siroki-15484.jpg \\
\hline 1759 & Plantago maxima Juss. ex Jacq. & Dabas & 1928 & Boros Ádám & DE-siroki-15487.jpg \\
\hline 1760 & Plantago major L. & Debrecen & 1957 & Siroki Zoltán & DE-siroki-15489.jpg \\
\hline 1760 & Plantago major L. & Szigetszentmiklós & 1951 & Siroki Zoltán & DE-siroki-15488.jpg \\
\hline 1762 & Sambucus nigra L. & Debrecen & 1985 & Siroki Zoltán & DE-siroki-15712.jpg \\
\hline 1763 & Sambucus racemosa L. & Pásztó & 1952 & Siroki Zoltán & DE-siroki-15714.jpg \\
\hline 1763 & Sambucus racemosa L. & Pásztó & 1952 & Siroki Zoltán & DE-siroki-15713.jpg \\
\hline
\end{tabular}




\begin{tabular}{|c|c|c|c|c|c|}
\hline $\begin{array}{l}\text { Sorszám / } \\
\text { Number }\end{array}$ & Taxon-név / Taxon-name & $\begin{array}{l}\text { Település / } \\
\text { Settlement }\end{array}$ & $\begin{array}{l}\text { Év / } \\
\text { Year }\end{array}$ & $\begin{array}{l}\text { Gyújtő / } \\
\text { Collector }\end{array}$ & Fájlnév / File-name \\
\hline 1764 & Viburnum opulus L. & Debrecen & 1954 & Siroki Zoltán & DE-siroki-15723.jpg \\
\hline 1764 & Viburnum opulus L. & Debrecen & 1955 & Siroki Zoltán & DE-siroki-15721.jpg \\
\hline 1764 & Viburnum opulus L. & Debrecen & 1955 & Siroki Zoltán & DE-siroki-15722.jpg \\
\hline 1764 & Viburnum opulus L. & Debrecen & 1985 & Siroki Zoltán & DE-siroki-15717.jpg \\
\hline 1764 & Viburnum opulus L. & Gödöllő & 1952 & Siroki Zoltán & DE-siroki-15724.jpg \\
\hline 1764 & Viburnum opulus L. & Háromhuta & 1973 & Siroki Zoltán & DE-siroki-15718.jpg \\
\hline 1764 & Viburnum opulus L. & Háromhuta & 1973 & Siroki Zoltán & DE-siroki-15719.jpg \\
\hline 1764 & Viburnum opulus L. & Miskolc & 1965 & Siroki Zoltán & DE-siroki-15720.jpg \\
\hline 1765 & Viburnum lantana L. & Budapest & 1964 & Siroki Zoltán & DE-siroki-15732.jpg \\
\hline 1765 & Viburnum lantana L. & Budapest & 1964 & Siroki Zoltán & DE-siroki-15733.jpg \\
\hline 1765 & Viburnum lantana L. & Nagykovácsi & 1959 & Siroki Zoltán & DE-siroki-15730.jpg \\
\hline 1765 & Viburnum lantana L. & Nagykovácsi & 1959 & Siroki Zoltán & DE-siroki-15731.jpg \\
\hline 1765 & Viburnum lantana L. & Nagykovácsi & 1959 & Siroki Zoltán & DE-siroki-15734.jpg \\
\hline 1768 & Lonicera caprifolium L. & Budapest & 1951 & Siroki Zoltán & DE-siroki-15745.jpg \\
\hline 1768 & Lonicera caprifolium L. & Pécs & 1958 & Siroki Zoltán & DE-siroki-15743.jpg \\
\hline 1770 & Lonicera xylosteum L. & "Nagymező" & 1959 & Halász Tibor & DE-siroki-15752.jpg \\
\hline 1770 & Lonicera xylosteum L. & Budapest & 1952 & Siroki Zoltán & DE-siroki-15753.jpg \\
\hline 1770 & Lonicera xylosteum L. & Budapest & 1984 & Siroki Zoltán & DE-siroki-15757.jpg \\
\hline 1770 & Lonicera xylosteum L. & Szilvásvárad & 1960 & Siroki Zoltán & DE-siroki-15754.jpg \\
\hline 1770 & Lonicera xylosteum L. & Szilvásvárad & 1960 & Siroki Zoltán & DE-siroki-15755.jpg \\
\hline 1770 & Lonicera xylosteum L. & Szilvásvárad & 1960 & Siroki Zoltán & DE-siroki-15756.jpg \\
\hline 1773 & Adoxa moschatellina L. & Budapest & 1951 & Siroki Zoltán & DE-siroki-15760.jpg \\
\hline 1773 & Adoxa moschatellina L. & Budapest & 1951 & Siroki Zoltán & DE-siroki-15761.jpg \\
\hline 1773 & Adoxa moschatellina L. & Budapest & 1951 & Siroki Zoltán & DE-siroki-15763.jpg \\
\hline 1773 & Adoxa moschatellina L. & Miskolc & 1961 & Siroki Zoltán & DE-siroki-15762.jpg \\
\hline 1774 & Valerianella coronata (L.) DC. & budapest & 1904 & $\begin{array}{l}\text { Thaisz Lajos - } \\
\text { Baán Lajos }\end{array}$ & DE-siroki-15774.jpg \\
\hline 1774 & Valerianella coronata (L.) DC. & Budapest & 1951 & Siroki Zoltán & DE-siroki-15764.jpg \\
\hline 1774 & Valerianella coronata (L.) DC. & Budapest & 1951 & Siroki Zoltán & DE-siroki-15765.jpg \\
\hline 1774 & Valerianella coronata (L.) DC. & Budapest & 1951 & Siroki Zoltán & DE-siroki-15766.jpg \\
\hline 1774 & Valerianella coronata (L.) DC. & Budapest & 1951 & Siroki Zoltán & DE-siroki-15767.jpg \\
\hline 1774 & Valerianella coronata (L.) DC. & Budapest & 1951 & Siroki Zoltán & DE-siroki-15768.jpg \\
\hline 1774 & Valerianella coronata (L.) DC. & Budapest & 1951 & Siroki Zoltán & DE-siroki-15769.jpg \\
\hline 1774 & Valerianella coronata (L.) DC. & Budapest & 1951 & Siroki Zoltán & DE-siroki-15770.jpg \\
\hline 1774 & Valerianella coronata (L.) DC. & Budapest & 1951 & Siroki Zoltán & DE-siroki-15771.jpg \\
\hline 1774 & Valerianella coronata (L.) DC. & Budapest & 1951 & Siroki Zoltán & DE-siroki-15772.jpg \\
\hline 1774 & Valerianella coronata (L.) DC. & Budapest & 1951 & Siroki Zoltán & DE-siroki-15773.jpg \\
\hline 1775 & Valerianella locusta (L.) Laterr. & Budapest & 1928 & Rigler József & DE-siroki-15799.jpg \\
\hline 1777 & Valerianella dentata (L.) Pollich & Berekböszörmény & 1970 & Siroki Zoltán & DE-siroki-15775.jpg \\
\hline 1777 & Valerianella dentata (L.) Pollich & Berekböszörmény & 1970 & Siroki Zoltán & DE-siroki-15776.jpg \\
\hline 1777 & Valerianella dentata (L.) Pollich & Berekböszörmény & 1970 & Siroki Zoltán & DE-siroki-15777.jpg \\
\hline 1777 & Valerianella dentata (L.) Pollich & Berekböszörmény & 1970 & Siroki Zoltán & DE-siroki-15778.jpg \\
\hline 1777 & Valerianella dentata (L.) Pollich & Berekböszörmény & 1970 & Siroki Zoltán & DE-siroki-15779.jpg \\
\hline 1777 & Valerianella dentata (L.) Pollich & Kardoskút & 1975 & Siroki Zoltán & DE-siroki-15780.jpg \\
\hline 1777 & Valerianella dentata (L.) Pollich & Kardoskút & 1975 & Siroki Zoltán & DE-siroki-15784.jpg \\
\hline 1777 & Valerianella dentata (L.) Pollich & Kardoskút & 1975 & Siroki Zoltán & DE-siroki-15785.jpg \\
\hline 1777 & Valerianella dentata (L.) Pollich & Kardoskút & 1975 & Siroki Zoltán & DE-siroki-15787.jpg \\
\hline
\end{tabular}




\begin{tabular}{|c|c|c|c|c|c|}
\hline $\begin{array}{l}\text { Sorszám / } \\
\text { Number }\end{array}$ & Taxon-név / Taxon-name & $\begin{array}{l}\text { Település / } \\
\text { Settlement }\end{array}$ & $\begin{array}{l}\text { Év / } \\
\text { Year }\end{array}$ & $\begin{array}{l}\text { Gyűjtő / } \\
\text { Collector }\end{array}$ & Fájlnév / File-name \\
\hline 1778 & Valerianella rimosa Bastard & Abaújszántó & 1944 & Siroki Zoltán & DE-siroki-15792.jpg \\
\hline 1778 & Valerianella rimosa Bastard & Budapest & 1952 & Siroki Zoltán & DE-siroki-15793.jpg \\
\hline 1778 & Valerianella rimosa Bastard & Cegléd & 1969 & Siroki Zoltán & DE-siroki-15789.jpg \\
\hline 1778 & Valerianella rimosa Bastard & Cegléd & 1969 & Siroki Zoltán & DE-siroki-15790.jpg \\
\hline 1778 & Valerianella rimosa Bastard & Cegléd & 1969 & Siroki Zoltán & DE-siroki-15791.jpg \\
\hline 1779 & Valerianella pumila (L.) DC. & Budapest & 1887 & Czakó Kálmán & DE-siroki-15794.jpg \\
\hline 1779 & Valerianella pumila (L.) DC. & Budapest & 1951 & Siroki Zoltán & DE-siroki-15796.jpg \\
\hline 1779 & Valerianella pumila (L.) DC. & Budapest & 1951 & Siroki Zoltán & DE-siroki-15797.jpg \\
\hline 1779 & Valerianella pumila (L.) DC. & Budapest & 1951 & Siroki Zoltán & DE-siroki-15798.jpg \\
\hline 1780 & Valeriana officinalis L. & Bükkszentkereszt & 1959 & Halász Tibor & DE-siroki-15816.jpg \\
\hline 1780 & Valeriana officinalis L. & Bükkszentkereszt & 1959 & Halász Tibor & DE-siroki-15815.jpg \\
\hline 1780 & Valeriana officinalis L. & Debrecen & 1947 & Siroki Zoltán & DE-siroki-15819.jpg \\
\hline 1780 & Valeriana officinalis L. & Debrecen & 1949 & Siroki Zoltán & DE-siroki-15817.jpg \\
\hline 1780 & Valeriana officinalis L. & Egyek & 1947 & Siroki Zoltán & DE-siroki-15818.jpg \\
\hline 1780 & Valeriana officinalis L. & Háromhuta & 1973 & Siroki Zoltán & DE-siroki-15810.jpg \\
\hline 1780 & Valeriana officinalis L. & Háromhuta & 1973 & Siroki Zoltán & DE-siroki-15811.jpg \\
\hline 1780 & Valeriana officinalis L. & Miskolc & 1965 & Siroki Zoltán & DE-siroki-15812.jpg \\
\hline 1780 & Valeriana officinalis L. & Vámospércs & 1984 & Siroki Zoltán & DE-siroki-15813.jpg \\
\hline 1780 & Valeriana officinalis L. & Vámospércs & 1984 & Siroki Zoltán & DE-siroki-15814.jpg \\
\hline 1781 & Valeriana tripteris L. & Nagyvisnyó & 1959 & Siroki Zoltán & DE-siroki-15842.jpg \\
\hline 1781 & Valeriana tripteris L. & Nagyvisnyó & 1959 & Siroki Zoltán & DE-siroki-15845.jpg \\
\hline 1781 & Valeriana tripteris L. & Nagyvisnyó & 1959 & Siroki Zoltán & DE-siroki-15847.jpg \\
\hline 1781 & Valeriana tripteris L. & Nagyvisnyó & 1959 & Siroki Zoltán & DE-siroki-15848.jpg \\
\hline 1781 & Valeriana tripteris L. & Nagyvisnyó & 1966 & Siroki Zoltán & DE-siroki-15843.jpg \\
\hline 1781 & Valeriana tripteris L. & Nagyvisnyó & 1966 & Siroki Zoltán & DE-siroki-15844.jpg \\
\hline 1781 & Valeriana tripteris L. & Nagyvisnyó & 1966 & Siroki Zoltán & DE-siroki-15846.jpg \\
\hline 1782 & Valeriana dioica L. & Budapest & 1909 & Kocsis István & DE-siroki-15837.jpg \\
\hline 1782 & Valeriana dioica L. & Budapest & 1909 & Kocsis István & DE-siroki-15836.jpg \\
\hline 1782 & Valeriana dioica L. & Budapest & 1958 & Siroki Zoltán & DE-siroki-15828.jpg \\
\hline 1782 & Valeriana dioica L. & Gödöllő & 1951 & Siroki Zoltán & DE-siroki-15829.jpg \\
\hline 1782 & Valeriana dioica L. & Gödöllő & 1951 & Siroki Zoltán & DE-siroki-15830.jpg \\
\hline 1782 & Valeriana dioica L. & Gödöllő & 1951 & Siroki Zoltán & DE-siroki-15831.jpg \\
\hline 1782 & Valeriana dioica L. & Gödöllő & 1951 & Siroki Zoltán & DE-siroki-15832.jpg \\
\hline 1782 & Valeriana dioica L. & Gödöllő & 1951 & Siroki Zoltán & DE-siroki-15833.jpg \\
\hline 1782 & Valeriana dioica L. & Gödöllő & 1951 & Siroki Zoltán & DE-siroki-15834.jpg \\
\hline 1782 & Valeriana dioica L. & Hévíz & 1928 & Rigler József & DE-siroki-15835.jpg \\
\hline 1784 & Cephalaria transsylvanica (L.) Schrad. & Budapest & 1941 & Siroki Zoltán & DE-siroki-15868.jpg \\
\hline 1784 & Cephalaria transsylvanica (L.) Schrad. & Budapest & 1950 & Siroki Zoltán & DE-siroki-15870.jpg \\
\hline 1784 & Cephalaria transsylvanica (L.) Schrad. & Budapest & 1985 & Siroki Zoltán & DE-siroki-15863.jpg \\
\hline 1784 & Cephalaria transsylvanica (L.) Schrad. & Budapest & 1985 & Siroki Zoltán & DE-siroki-15864.jpg \\
\hline 1784 & Cephalaria transsylvanica (L.) Schrad. & Budapest & 1985 & Siroki Zoltán & DE-siroki-15865.jpg \\
\hline 1784 & Cephalaria transsylvanica (L.) Schrad. & Debrecen & 1947 & Siroki Zoltán & DE-siroki-15869.jpg \\
\hline 1784 & Cephalaria transsylvanica (L.) Schrad. & Debrecen & 1947 & Siroki Zoltán & DE-siroki-15867.jpg \\
\hline 1784 & Cephalaria transsylvanica (L.) Schrad. & Debrecen & 1947 & Siroki Zoltán & DE-siroki-15866.jpg \\
\hline 1784 & Cephalaria transsylvanica (L.) Schrad. & Létavértes & 1966 & Gondola István & DE-siroki-15871.jpg \\
\hline 1785 & Dipsacus pilosus L. & Debrecen & 1947 & Siroki Zoltán & DE-siroki-15850.jpg \\
\hline
\end{tabular}




\begin{tabular}{|c|c|c|c|c|c|}
\hline $\begin{array}{l}\text { Sorszám / } \\
\text { Number }\end{array}$ & Taxon-név / Taxon-name & $\begin{array}{l}\text { Település / } \\
\text { Settlement }\end{array}$ & $\begin{array}{l}\text { Év / } \\
\text { Year }\end{array}$ & $\begin{array}{l}\text { Gyűjtő / } \\
\text { Collector }\end{array}$ & Fájlnév / File-name \\
\hline 1785 & Dipsacus pilosus L. & Debrecen & 1947 & Siroki Zoltán & DE-siroki-15852.jpg \\
\hline 1786 & Dipsacus laciniatus L. & Debrecen & 1947 & Siroki Zoltán & DE-siroki-15857.jpg \\
\hline 1786 & Dipsacus laciniatus L. & Debrecen & 1947 & Siroki Zoltán & DE-siroki-15858.jpg \\
\hline 1786 & Dipsacus laciniatus L. & Debrecen & 1947 & Siroki Zoltán & DE-siroki-15859.jpg \\
\hline 1787 & Dipsacus fullonum L. & Hortobágy & 1956 & Gondola István & DE-siroki-15860.jpg \\
\hline 1787 & Dipsacus fullonum L. & Mosonmagyaróvár & 1939 & Siroki Zoltán & DE-siroki-15862.jpg \\
\hline 1788 & Succisa pratensis Moench & Dunakeszi & 1954 & Kovács Margit & DE-siroki-15886.jpg \\
\hline 1788 & Succisa pratensis Moench & Gödöllő & 1951 & Siroki Zoltán & DE-siroki-15880.jpg \\
\hline 1788 & Succisa pratensis Moench & Gödöllő & 1951 & Siroki Zoltán & DE-siroki-15882.jpg \\
\hline 1788 & Succisa pratensis Moench & Gödöllő & 1952 & Siroki Zoltán & DE-siroki-15885.jpg \\
\hline 1788 & Succisa pratensis Moench & Gödöllő & 1952 & Siroki Zoltán & DE-siroki-15888.jpg \\
\hline 1788 & Succisa pratensis Moench & Gödöllő & 1952 & Siroki Zoltán & DE-siroki-15889.jpg \\
\hline 1788 & Succisa pratensis Moench & Gödöllő & 1952 & Siroki Zoltán & DE-siroki-15887.jpg \\
\hline 1788 & Succisa pratensis Moench & Gödöllő & 1952 & Siroki Zoltán & DE-siroki-15881.jpg \\
\hline 1788 & Succisa pratensis Moench & Háromhuta & 1978 & Siroki Zoltán & DE-siroki-15892.jpg \\
\hline 1788 & Succisa pratensis Moench & Háromhuta & 1978 & Siroki Zoltán & DE-siroki-15893.jpg \\
\hline 1788 & Succisa pratensis Moench & Nagyhuta & 1962 & Siroki Zoltán & DE-siroki-15883.jpg \\
\hline 1788 & Succisa pratensis Moench & Nagyhuta & 1962 & Siroki Zoltán & DE-siroki-15884.jpg \\
\hline 1788 & Succisa pratensis Moench & Nagyhuta & 1962 & Siroki Zoltán & DE-siroki-15890.jpg \\
\hline 1788 & Succisa pratensis Moench & Nagyhuta & 1962 & Siroki Zoltán & DE-siroki-15891.jpg \\
\hline 1790 & Knautia arvensis (L.) Coult. & Debrecen & 1947 & Siroki Zoltán & DE-siroki-15897.jpg \\
\hline 1790 & Knautia arvensis (L.) Coult. & Debrecen & 1947 & Siroki Zoltán & DE-siroki-15898.jpg \\
\hline 1790 & Knautia arvensis (L.) Coult. & Piliscsaba & 1909 & Kocsis István & DE-siroki-15900.jpg \\
\hline 1790 & Knautia arvensis (L.) Coult. & Piliscsaba & 1909 & Kocsis István & DE-siroki-15903.jpg \\
\hline 1790 & Knautia arvensis (L.) Coult. & Piliscsaba & 1909 & Kocsis István & DE-siroki-15904.jpg \\
\hline 1791 & Knautia drymeia Heuff. & "Vértes" & 1957 & Siroki Zoltán & DE-siroki-15914.jpg \\
\hline 1791 & Knautia drymeia Heuff. & "Vértes" & 1957 & Siroki Zoltán & DE-siroki-15915.jpg \\
\hline 1791 & Knautia drymeia Heuff. & "Vértes" & 1957 & Siroki Zoltán & DE-siroki-15916.jpg \\
\hline 1791 & Knautia drymeia Heuff. & "Vértes" & 1957 & Siroki Zoltán & DE-siroki-15917.jpg \\
\hline 1791 & Knautia drymeia Heuff. & Gyenesdiás & 1955 & Siroki Zoltán & DE-siroki-15919.jpg \\
\hline 1791 & Knautia drymeia Heuff. & Gyenesdiás & 1955 & Siroki Zoltán & DE-siroki-15920.jpg \\
\hline 1791 & Knautia drymeia Heuff. & Hosszúhetény & 1954 & Siroki Zoltán & DE-siroki-15925.jpg \\
\hline 1791 & Knautia drymeia Heuff. & Pécs & 1954 & Siroki Zoltán & DE-siroki-15922.jpg \\
\hline 1791 & Knautia drymeia Heuff. & Pécs & 1954 & Siroki Zoltán & DE-siroki-15923.jpg \\
\hline 1791 & Knautia drymeia Heuff. & Pécs & 1954 & Siroki Zoltán & DE-siroki-15924.jpg \\
\hline 1791 & Knautia drymeia Heuff. & Pécs & 1954 & Siroki Zoltán & DE-siroki-15918.jpg \\
\hline 1791 & Knautia drymeia Heuff. & Pécs & 1954 & Siroki Zoltán & DE-siroki-15921.jpg \\
\hline 1793 & Scabiosa canescens Waldst. et Kit. & Abaújszántó & 1943 & Siroki Zoltán & DE-siroki-15934.jpg \\
\hline 1793 & Scabiosa canescens Waldst. et Kit. & Boldogkőváralja & 1943 & Siroki Zoltán & DE-siroki-15935.jpg \\
\hline 1793 & Scabiosa canescens Waldst. et Kit. & Budaörs & 1941 & Siroki Zoltán & DE-siroki-15928.jpg \\
\hline 1793 & Scabiosa canescens Waldst. et Kit. & Budaörs & 1941 & Siroki Zoltán & DE-siroki-15933.jpg \\
\hline 1793 & Scabiosa canescens Waldst. et Kit. & Budapest & 1941 & Siroki Zoltán & DE-siroki-15931.jpg \\
\hline 1793 & Scabiosa canescens Waldst. et Kit. & Budapest & 1941 & Siroki Zoltán & DE-siroki-15932.jpg \\
\hline 1793 & Scabiosa canescens Waldst. et Kit. & Budapest & 1948 & Siroki Zoltán & DE-siroki-15930.jpg \\
\hline 1793 & Scabiosa canescens Waldst. et Kit. & Budapest & 1957 & Siroki Zoltán & DE-siroki-15929.jpg \\
\hline 1793 & Scabiosa canescens Waldst. et Kit. & Nagykovácsi & 1957 & Siroki Zoltán & DE-siroki-15927.jpg \\
\hline
\end{tabular}




\begin{tabular}{|c|c|c|c|c|c|}
\hline $\begin{array}{l}\text { Sorszám / } \\
\text { Number }\end{array}$ & Taxon-név / Taxon-name & $\begin{array}{l}\text { Település / } \\
\text { Settlement }\end{array}$ & $\begin{array}{l}\text { Év / } \\
\text { Year }\end{array}$ & $\begin{array}{l}\text { Gyújtő / } \\
\text { Collector }\end{array}$ & Fájlnév / File-name \\
\hline 1794 & Scabiosa ochroleuca L. & Budapest & 1957 & Siroki Zoltán & DE-siroki-15938.jpg \\
\hline 1794 & Scabiosa ochroleuca L. & Debrecen & 1963 & Siroki Zoltán & DE-siroki-15937.jpg \\
\hline 1794 & Scabiosa ochroleuca L. & Nagykovácsi & 1957 & Siroki Zoltán & DE-siroki-15939.jpg \\
\hline 1795 & Scabiosa columbaria L. & Nagyvisnyó & 1955 & Jeney Endre & DE-siroki-15942.jpg \\
\hline 1797 & Campanula glomerata L. & "Nagymező" & 1959 & Siroki Zoltán & DE-siroki-15994.jpg \\
\hline 1797 & Campanula glomerata L. & "Nagymező" & 1959 & Siroki Zoltán & DE-siroki-15995.jpg \\
\hline 1797 & Campanula glomerata L. & "Nagymező" & 1968 & Siroki Zoltán & DE-siroki-15993.jpg \\
\hline 1797 & Campanula glomerata L. & "Nagymező" & 1973 & Siroki Zoltán & DE-siroki-16003.jpg \\
\hline 1797 & Campanula glomerata L. & "Nagymező" & 1973 & Siroki Zoltán & DE-siroki-16005.jpg \\
\hline 1797 & Campanula glomerata L. & "Nagymező" & 1973 & Siroki Zoltán & DE-siroki-16006.jpg \\
\hline 1797 & Campanula glomerata L. & Budapest & 1941 & Siroki Zoltán & DE-siroki-15999.jpg \\
\hline 1797 & Campanula glomerata L. & Budapest & 1948 & Siroki Zoltán & DE-siroki-15989.jpg \\
\hline 1797 & Campanula glomerata L. & Budapest & 1948 & Siroki Zoltán & DE-siroki-15990.jpg \\
\hline 1797 & Campanula glomerata L. & Budapest & 1950 & Siroki Zoltán & DE-siroki-15987.jpg \\
\hline 1797 & Campanula glomerata L. & Budapest & 1983 & Siroki Zoltán & DE-siroki-15992.jpg \\
\hline 1797 & Campanula glomerata L. & Budapest & 1984 & Siroki Zoltán & DE-siroki-16002.jpg \\
\hline 1797 & Campanula glomerata L. & Debrecen & 1951 & Siroki Zoltán & DE-siroki-15988.jpg \\
\hline 1797 & Campanula glomerata L. & Nagykovácsi & 1957 & Siroki Zoltán & DE-siroki-15986.jpg \\
\hline 1797 & Campanula glomerata L. & $\begin{array}{l}\text { Pilisszentiván- } \\
\text { Nagykovácsi }\end{array}$ & 1957 & Siroki Zoltán & DE-siroki-16001.jpg \\
\hline 1797 & Campanula glomerata L. & Pomáz & 1954 & Siroki Zoltán & DE-siroki-15985.jpg \\
\hline 1797 & Campanula glomerata L. & Sátoraljaújhely & 1944 & Siroki Zoltán & DE-siroki-16000.jpg \\
\hline 1798 & Campanula macrostachya Kit. & Pomáz & 1909 & Kocsis István & DE-siroki-16025.jpg \\
\hline 1798 & Campanula macrostachya Kit. & Pomáz & 1909 & Kocsis István & DE-siroki-16024.jpg \\
\hline 1798 & Campanula macrostachya Kit. & Pomáz & 1924 & Degen Árpád & DE-siroki-16023.jpg \\
\hline 1798 & Campanula macrostachya Kit. & Pomáz & 1957 & Siroki Zoltán & DE-siroki-16026.jpg \\
\hline 1798 & Campanula macrostachya Kit. & Pomáz & 1957 & Siroki Zoltán & DE-siroki-16027.jpg \\
\hline 1798 & Campanula macrostachya Kit. & Pomáz & 1957 & Siroki Zoltán & DE-siroki-16028.jpg \\
\hline 1799 & Campanula cervicaria L. & "Bükk-hg." & 1983 & Siroki Zoltán & DE-siroki-16021.jpg \\
\hline 1799 & Campanula cervicaria L. & "Mátra" & 1984 & Siroki Zoltán & DE-siroki-16020.jpg \\
\hline 1799 & Campanula cervicaria L. & "Mátra" & 1984 & Siroki Zoltán & DE-siroki-16022.jpg \\
\hline 1799 & Campanula cervicaria L. & "Nagymező" & 1959 & Siroki Zoltán & DE-siroki-16011.jpg \\
\hline 1799 & Campanula cervicaria L. & Debrecen & 1950 & Siroki Zoltán & DE-siroki-16012.jpg \\
\hline 1799 & Campanula cervicaria L. & Debrecen & 1950 & Siroki Zoltán & DE-siroki-16013.jpg \\
\hline 1799 & Campanula cervicaria L. & Debrecen & 1950 & Siroki Zoltán & DE-siroki-16014.jpg \\
\hline 1799 & Campanula cervicaria L. & Debrecen & 1950 & Siroki Zoltán & DE-siroki-16015.jpg \\
\hline 1799 & Campanula cervicaria L. & Gödöllő & 1952 & Siroki Zoltán & DE-siroki-16010.jpg \\
\hline 1799 & Campanula cervicaria L. & Háromhuta & 1965 & Gondola István & DE-siroki-16008.jpg \\
\hline 1799 & Campanula cervicaria L. & Háromhuta & 1965 & Siroki Zoltán & DE-siroki-16017.jpg \\
\hline 1799 & Campanula cervicaria L. & Háromhuta & 1965 & Siroki Zoltán & DE-siroki-16018.jpg \\
\hline 1799 & Campanula cervicaria L. & Háromhuta & 1965 & Siroki Zoltán & DE-siroki-16019.jpg \\
\hline 1799 & Campanula cervicaria L. & Regéc & 1967 & Siroki Zoltán & DE-siroki-16016.jpg \\
\hline 1800 & Campanula sibirica L. & Budapest & 1951 & Siroki Zoltán & DE-siroki-16053.jpg \\
\hline 1800 & Campanula sibirica L. & Pilisszentiván & 1952 & Siroki Zoltán & DE-siroki-16047.jpg \\
\hline 1800 & Campanula sibirica L. & Rakaca & 1982 & Siroki Zoltán & DE-siroki-16044.jpg \\
\hline 1800 & Campanula sibirica L. & Rakaca & - & Siroki Zoltán & DE-siroki-16045.jpg \\
\hline 1800 & Campanula sibirica L. & Répáshuta & 1956 & Halász Tibor & DE-siroki-16049.jpg \\
\hline
\end{tabular}




\begin{tabular}{|c|c|c|c|c|c|}
\hline $\begin{array}{l}\text { Sorszám / } \\
\text { Number }\end{array}$ & Taxon-név / Taxon-name & $\begin{array}{l}\text { Település / } \\
\text { Settlement }\end{array}$ & $\begin{array}{l}\text { Év / } \\
\text { Year }\end{array}$ & $\begin{array}{l}\text { Gyűjtő / } \\
\text { Collector }\end{array}$ & Fájlnév / File-name \\
\hline 1800 & Campanula sibirica L. & Szarvaskő & 1957 & Siroki Zoltán & DE-siroki-16048.jpg \\
\hline 1800 & Campanula sibirica L. & Szarvaskő & 1957 & Siroki Zoltán & DE-siroki-16052.jpg \\
\hline 1800 & Campanula sibirica L. & Szilvásvárad & 1960 & Siroki Zoltán & DE-siroki-16043.jpg \\
\hline 1801 & Campanula bononiensis L. & Bér & 1954 & Siroki Zoltán & DE-siroki-16123.jpg \\
\hline 1801 & Campanula bononiensis L. & Bér & 1954 & Siroki Zoltán & DE-siroki-16124.jpg \\
\hline 1801 & Campanula bononiensis L. & Budaörs & 1966 & Siroki Zoltán & DE-siroki-16119.jpg \\
\hline 1801 & Campanula bononiensis L. & Budapest & 1941 & Siroki Zoltán & DE-siroki-16128.jpg \\
\hline 1801 & Campanula bononiensis L. & Budapest & 1983 & Siroki Zoltán & DE-siroki-16115.jpg \\
\hline 1801 & Campanula bononiensis L. & Budapest & 1983 & Siroki Zoltán & DE-siroki-16116.jpg \\
\hline 1801 & Campanula bononiensis L. & Budapest & 1984 & Siroki Zoltán & DE-siroki-16134.jpg \\
\hline 1801 & Campanula bononiensis L. & Egyek & 1947 & Siroki Zoltán & DE-siroki-16122.jpg \\
\hline 1801 & Campanula bononiensis L. & Pomáz & 1954 & Siroki Zoltán & DE-siroki-16118.jpg \\
\hline 1801 & Campanula bononiensis L. & Pomáz & 1954 & Siroki Zoltán & DE-siroki-16126.jpg \\
\hline 1801 & Campanula bononiensis L. & Sajólád/Sajópetri & 1951 & Siroki Zoltán & DE-siroki-16125.jpg \\
\hline 1801 & Campanula bononiensis L. & Sajólád/Sajópetri & 1951 & Siroki Zoltán & DE-siroki-16121.jpg \\
\hline 1801 & Campanula bononiensis L. & Tokaj & 1971 & Siroki Zoltán & DE-siroki-16117.jpg \\
\hline 1801 & Campanula bononiensis L. & Tokaj & 1971 & Siroki Zoltán & DE-siroki-16120.jpg \\
\hline 1801 & Campanula bononiensis L. & Tokaj & 1971 & Siroki Zoltán & DE-siroki-16130.jpg \\
\hline 1801 & Campanula bononiensis L. & Túristvándi & 1975 & Siroki Zoltán & DE-siroki-16131.jpg \\
\hline 1801 & Campanula bononiensis L. & Túristvándi & 1975 & Siroki Zoltán & DE-siroki-16132.jpg \\
\hline 1802 & Campanula rapunculoides L. & "Dobogókő" & 1965 & Siroki Zoltán & DE-siroki-16073.jpg \\
\hline 1802 & Campanula rapunculoides L. & "Dobogókő" & 1965 & Siroki Zoltán & DE-siroki-16074.jpg \\
\hline 1802 & Campanula rapunculoides L. & "Dobogókő" & 1965 & Siroki Zoltán & DE-siroki-16075.jpg \\
\hline 1802 & Campanula rapunculoides L. & "Dobogókő" & 1965 & Siroki Zoltán & DE-siroki-16076.jpg \\
\hline 1802 & Campanula rapunculoides L. & "Dobogókő" & 1965 & Siroki Zoltán & DE-siroki-16085.jpg \\
\hline 1802 & Campanula rapunculoides L. & "Dobogókő" & 1965 & Siroki Zoltán & DE-siroki-16088.jpg \\
\hline 1802 & Campanula rapunculoides L. & "Háromkő" & 1975 & Siroki Zoltán & DE-siroki-16067.jpg \\
\hline 1802 & Campanula rapunculoides L. & "Nagymező" & 1963 & Siroki Zoltán & DE-siroki-16093.jpg \\
\hline 1802 & Campanula rapunculoides L. & Budapest & 1951 & Siroki Zoltán & DE-siroki-16080.jpg \\
\hline 1802 & Campanula rapunculoides L. & Budapest & 1960 & Siroki Zoltán & DE-siroki-16072.jpg \\
\hline 1802 & Campanula rapunculoides L. & Háromhuta & 1960 & Siroki Zoltán & DE-siroki-16070.jpg \\
\hline 1802 & Campanula rapunculoides L. & Háromhuta & 1960 & Siroki Zoltán & DE-siroki-16071.jpg \\
\hline 1802 & Campanula rapunculoides L. & Háromhuta & 1960 & Siroki Zoltán & DE-siroki-16081.jpg \\
\hline 1802 & Campanula rapunculoides L. & Háromhuta & 1960 & Siroki Zoltán & DE-siroki-16082.jpg \\
\hline 1802 & Campanula rapunculoides L. & Miskolc & 1965 & Siroki Zoltán & DE-siroki-16091.jpg \\
\hline 1802 & Campanula rapunculoides L. & Miskolc & 1965 & Siroki Zoltán & DE-siroki-16092.jpg \\
\hline 1802 & Campanula rapunculoides L. & Miskolc & 1965 & Siroki Zoltán & DE-siroki-16083.jpg \\
\hline 1802 & Campanula rapunculoides L. & Miskolc & 1965 & Siroki Zoltán & DE-siroki-16084.jpg \\
\hline 1802 & Campanula rapunculoides L. & Miskolc & 1965 & Siroki Zoltán & DE-siroki-16087.jpg \\
\hline 1802 & Campanula rapunculoides L. & Mosonmagyaróvár & 1939 & Siroki Zoltán & DE-siroki-16069.jpg \\
\hline 1802 & Campanula rapunculoides L. & Pécs & 1954 & Siroki Zoltán & DE-siroki-16078.jpg \\
\hline 1802 & Campanula rapunculoides L. & Pécs & 1954 & Siroki Zoltán & DE-siroki-16079.jpg \\
\hline 1802 & Campanula rapunculoides L. & Regéc & 1967 & Siroki Zoltán & DE-siroki-16086.jpg \\
\hline 1802 & Campanula rapunculoides L. & Szilvásvárad & 1954 & Siroki Zoltán & DE-siroki-16077.jpg \\
\hline 1802 & Campanula rapunculoides L. & Tokaj & 1966 & Siroki Zoltán & DE-siroki-16089.jpg \\
\hline 1802 & Campanula rapunculoides L. & Tokaj & 1966 & Siroki Zoltán & DE-siroki-16090.jpg \\
\hline
\end{tabular}




\begin{tabular}{|c|c|c|c|c|c|}
\hline $\begin{array}{l}\text { Sorszám / } \\
\text { Number }\end{array}$ & Taxon-név / Taxon-name & $\begin{array}{l}\text { Település / } \\
\text { Settlement }\end{array}$ & $\begin{array}{l}\text { Év / } \\
\text { Year }\end{array}$ & $\begin{array}{l}\text { Gyűjtő / } \\
\text { Collector }\end{array}$ & Fájlnév / File-name \\
\hline 1804 & Campanula trachelium L. & Budaörs & 1966 & Siroki Zoltán & DE-siroki-16111.jpg \\
\hline 1804 & Campanula trachelium L. & Háromhuta & 1960 & Siroki Zoltán & DE-siroki-16099.jpg \\
\hline 1804 & Campanula trachelium L. & Háromhuta & 1968 & Siroki Zoltán & DE-siroki-16100.jpg \\
\hline 1804 & Campanula trachelium L. & Háromhuta & 1968 & Siroki Zoltán & DE-siroki-16114.jpg \\
\hline 1804 & Campanula trachelium L. & Háromhuta & 1977 & Siroki Zoltán & DE-siroki-16094.jpg \\
\hline 1804 & Campanula trachelium L. & Háromhuta & 1977 & Siroki Zoltán & DE-siroki-16095.jpg \\
\hline 1804 & Campanula trachelium L. & Háromhuta & 1977 & Siroki Zoltán & DE-siroki-16096.jpg \\
\hline 1804 & Campanula trachelium L. & Miskolc & 1965 & Siroki Zoltán & DE-siroki-16112.jpg \\
\hline 1804 & Campanula trachelium L. & Miskolc & 1965 & Siroki Zoltán & DE-siroki-16101.jpg \\
\hline 1804 & Campanula trachelium L. & Miskolc & 1965 & Siroki Zoltán & DE-siroki-16102.jpg \\
\hline 1804 & Campanula trachelium L. & Miskolc & 1965 & Siroki Zoltán & DE-siroki-16113.jpg \\
\hline 1804 & Campanula trachelium L. & Miskolc & 1965 & Siroki Zoltán & DE-siroki-16109.jpg \\
\hline 1804 & Campanula trachelium L. & Miskolc & 1965 & Siroki Zoltán & DE-siroki-16103.jpg \\
\hline 1804 & Campanula trachelium L. & Mosonmagyaróvár & 1939 & Siroki Zoltán & DE-siroki-16107.jpg \\
\hline 1804 & Campanula trachelium L. & Mosonmagyaróvár & 1939 & Siroki Zoltán & DE-siroki-16108.jpg \\
\hline 1804 & Campanula trachelium L. & Nagyvisnyó & 1966 & Siroki Zoltán & DE-siroki-16110.jpg \\
\hline 1804 & Campanula trachelium L. & Sajólád/Sajópetri & 1951 & Siroki Zoltán & DE-siroki-16097.jpg \\
\hline 1804 & Campanula trachelium L. & Szilvásvárad & 1954 & Siroki Zoltán & DE-siroki-16105.jpg \\
\hline 1804 & Campanula trachelium L. & Szilvásvárad & 1954 & Siroki Zoltán & DE-siroki-16098.jpg \\
\hline 1805 & Campanula persicifolia L. & "Nagymező" & 1956 & Halász Tibor & DE-siroki-16167.jpg \\
\hline 1805 & Campanula persicifolia L. & "Nagymező" & 1959 & Siroki Zoltán & DE-siroki-16168.jpg \\
\hline 1805 & Campanula persicifolia L. & Háromhuta & 1965 & Gondola István & DE-siroki-16172.jpg \\
\hline 1805 & Campanula persicifolia L. & Hollóháza & 1940 & Siroki Zoltán & DE-siroki-16174.jpg \\
\hline 1805 & Campanula persicifolia L. & Recsk & 1981 & Rácz Gy.-né & DE-siroki-16173.jpg \\
\hline 1806 & Campanula rapunculus L. & Budapest & 1951 & Siroki Zoltán & DE-siroki-16180.jpg \\
\hline 1806 & Campanula rapunculus L. & Budapest & 1951 & Siroki Zoltán & DE-siroki-16181.jpg \\
\hline 1806 & Campanula rapunculus L. & Budapest & 1953 & Siroki Zoltán & DE-siroki-16179.jpg \\
\hline 1806 & Campanula rapunculus L. & Debrecen & 1948 & Siroki Zoltán & DE-siroki-16183.jpg \\
\hline 1806 & Campanula rapunculus L. & Debrecen & 1948 & Siroki Zoltán & DE-siroki-16184.jpg \\
\hline 1806 & Campanula rapunculus L. & Debrecen & 1953 & Siroki Zoltán & DE-siroki-16178.jpg \\
\hline 1806 & Campanula rapunculus L. & Gödöllő & 1952 & Siroki Zoltán & DE-siroki-16182.jpg \\
\hline 1806 & Campanula rapunculus L. & Hajdúböszörmény & 1981 & Siroki Zoltán & DE-siroki-16175.jpg \\
\hline 1806 & Campanula rapunculus L. & Hajdúböszörmény & 1981 & Siroki Zoltán & DE-siroki-16176.jpg \\
\hline 1806 & Campanula rapunculus L. & Hajdúböszörmény & 1981 & Siroki Zoltán & DE-siroki-16177.jpg \\
\hline 1807 & Campanula patula L. & Csaroda & 1960 & Halász Tibor & DE-siroki-16191.jpg \\
\hline 1807 & Campanula patula L. & Háromhuta & 1960 & Siroki Zoltán & DE-siroki-16188.jpg \\
\hline 1807 & Campanula patula L. & Háromhuta & 1960 & Siroki Zoltán & DE-siroki-16189.jpg \\
\hline 1807 & Campanula patula L. & Háromhuta & 1961 & Siroki Zoltán & DE-siroki-16192.jpg \\
\hline 1807 & Campanula patula L. & Háromhuta & 1978 & Siroki Zoltán & DE-siroki-16186.jpg \\
\hline 1807 & Campanula patula L. & Háromhuta & 1978 & Siroki Zoltán & DE-siroki-16187.jpg \\
\hline 1807 & Campanula patula L. & Hollóháza & 1940 & Siroki Zoltán & DE-siroki-16193.jpg \\
\hline 1807 & Campanula patula L. & Nagyhuta & 1978 & Siroki Zoltán & DE-siroki-16185.jpg \\
\hline 1808 & Campanula rotundifolia L. & "Szent-György-hegy" & 1955 & Siroki Zoltán & DE-siroki-16156.jpg \\
\hline 1808 & Campanula rotundifolia L. & Budapest & 1984 & Siroki Zoltán & DE-siroki-16152.jpg \\
\hline 1808 & Campanula rotundifolia L. & Debrecen & 1950 & Siroki Zoltán & DE-siroki-16160.jpg \\
\hline 1808 & Campanula rotundifolia L. & Debrecen & 1950 & Siroki Zoltán & DE-siroki-16159.jpg \\
\hline
\end{tabular}




\begin{tabular}{|c|c|c|c|c|c|}
\hline $\begin{array}{l}\text { Sorszám / } \\
\text { Number }\end{array}$ & Taxon-név / Taxon-name & $\begin{array}{l}\text { Település / } \\
\text { Settlement }\end{array}$ & $\begin{array}{l}\text { Év / } \\
\text { Year }\end{array}$ & $\begin{array}{l}\text { Gyűjtő / } \\
\text { Collector }\end{array}$ & Fájlnév / File-name \\
\hline 1808 & Campanula rotundifolia L. & Debrecen & 1953 & Siroki Zoltán & DE-siroki-16157.jpg \\
\hline 1808 & Campanula rotundifolia L. & Háromhuta & 1984 & Siroki Zoltán & DE-siroki-16154.jpg \\
\hline 1808 & Campanula rotundifolia L. & Nagykovácsi & 1950 & Siroki Zoltán & DE-siroki-16161.jpg \\
\hline 1808 & Campanula rotundifolia $\mathrm{L}$. & Nagykovácsi & 1957 & Siroki Zoltán & DE-siroki-16158.jpg \\
\hline 1808 & Campanula rotundifolia L. & Szilvásvárad & 1954 & Siroki Zoltán & DE-siroki-16155.jpg \\
\hline 1811 & $\begin{array}{l}\text { Adenophora liliifolia } \\
\text { (L.) Ledeb. ex A. DC. }\end{array}$ & Kiskőrös & 1925 & Degen Árpád & DE-siroki-16199.jpg \\
\hline 1813 & $\begin{array}{l}\text { Asyneuma canescens } \\
\text { (Waldst. et Kit.) Griseb. et Schenk }\end{array}$ & Abaújszántó & 1943 & Siroki Zoltán & DE-siroki-16209.jpg \\
\hline 1813 & $\begin{array}{l}\text { Asyneuma canescens } \\
\text { (Waldst. et Kit.) Griseb. et Schenk }\end{array}$ & Aggtelek & 1972 & Siroki Zoltán & DE-siroki-16201.jpg \\
\hline 1813 & $\begin{array}{l}\text { Asyneuma canescens } \\
\text { (Waldst. et Kit.) Griseb. et Schenk }\end{array}$ & Aggtelek & 1972 & Siroki Zoltán & DE-siroki-16202.jpg \\
\hline 1813 & $\begin{array}{l}\text { Asyneuma canescens } \\
\text { (Waldst. et Kit.) Griseb. et Schenk }\end{array}$ & Budapest & 1941 & Siroki Zoltán & DE-siroki-16207.jpg \\
\hline 1813 & $\begin{array}{l}\text { Asyneuma canescens } \\
\text { (Waldst. et Kit.) Griseb. et Schenk }\end{array}$ & Budapest & 1941 & Siroki Zoltán & DE-siroki-16208.jpg \\
\hline 1813 & $\begin{array}{l}\text { Asyneuma canescens } \\
\text { (Waldst. et Kit.) Griseb. et Schenk }\end{array}$ & Budapest & 1948 & Siroki Zoltán & DE-siroki-16206.jpg \\
\hline 1813 & $\begin{array}{l}\text { Asyneuma canescens } \\
\text { (Waldst. et Kit.) Griseb. et Schenk }\end{array}$ & Budapest & 1954 & Siroki Zoltán & DE-siroki-16203.jpg \\
\hline 1813 & $\begin{array}{l}\text { Asyneuma canescens } \\
\text { (Waldst. et Kit.) Griseb. et Schenk }\end{array}$ & Budapest & 1954 & Siroki Zoltán & DE-siroki-16204.jpg \\
\hline 1813 & $\begin{array}{l}\text { Asyneuma canescens } \\
\text { (Waldst. et Kit.) Griseb. et Schenk }\end{array}$ & Budapest & 1954 & Siroki Zoltán & DE-siroki-16205.jpg \\
\hline 1814 & Phyteuma spicatum L. & Pásztó & 1952 & Siroki Zoltán & DE-siroki-16214.jpg \\
\hline 1814 & Phyteuma spicatum L. & Telkibánya & 1963 & Halász Tibor & DE-siroki-16213.jpg \\
\hline 1815 & Phyteuma orbiculare L. & Budapest & 1951 & Siroki Zoltán & DE-siroki-16221.jpg \\
\hline 1815 & Phyteuma orbiculare L. & Budapest & 1955 & Siroki Zoltán & DE-siroki-16222.jpg \\
\hline 1815 & Phyteuma orbiculare L. & Pilisszentiván & 1952 & Siroki Zoltán & DE-siroki-16223.jpg \\
\hline 1816 & Jasione montana L. & Budapest & 1951 & Siroki Zoltán & DE-siroki-16231.jpg \\
\hline 1816 & Jasione montana L. & Debrecen & 1949 & Siroki Zoltán & DE-siroki-16233.jpg \\
\hline 1816 & Jasione montana L. & Debrecen & 1949 & Siroki Zoltán & DE-siroki-16230.jpg \\
\hline 1816 & Jasione montana L. & Hajdúbagos & 1982 & Siroki Zoltán & DE-siroki-16228.jpg \\
\hline 1816 & Jasione montana L. & Vámospércs & 1984 & Siroki Zoltán & DE-siroki-16229.jpg \\
\hline 1817 & Eupatorium cannabinum L. & Debrecen & 1947 & Siroki Zoltán & DE-siroki-16236.jpg \\
\hline 1817 & Eupatorium cannabinum L. & Mosonmagyaróvár & 1939 & Siroki Zoltán & DE-siroki-16237.jpg \\
\hline 1817 & Eupatorium cannabinum L. & Vámospércs & 1984 & Siroki Zoltán & DE-siroki-16235.jpg \\
\hline 1821 & Solidago virgaurea L. & Budapest & 1948 & Siroki Zoltán & DE-siroki-16248.jpg \\
\hline 1821 & Solidago virgaurea L. & Budapest & 1948 & Siroki Zoltán & DE-siroki-16251.jpg \\
\hline 1821 & Solidago virgaurea L. & Debrecen & 1950 & Siroki Zoltán & DE-siroki-16247.jpg \\
\hline 1821 & Solidago virgaurea L. & Háromhuta & 1978 & Siroki Zoltán & DE-siroki-16249.jpg \\
\hline 1821 & Solidago virgaurea L. & Pilismarót & 1963 & Siroki Zoltán & DE-siroki-16255.jpg \\
\hline 1821 & Solidago virgaurea L. & Pilismarót & 1963 & Siroki Zoltán & DE-siroki-16257.jpg \\
\hline 1821 & Solidago virgaurea L. & Pilismarót & 1963 & Siroki Zoltán & DE-siroki-16258.jpg \\
\hline 1821 & Solidago virgaurea L. & Pilismarót & 1963 & Siroki Zoltán & DE-siroki-16259.jpg \\
\hline 1821 & Solidago virgaurea L. & Pilismarót & 1963 & Siroki Zoltán & DE-siroki-16260.jpg \\
\hline 1821 & Solidago virgaurea L. & Pilismarót & 1963 & Siroki Zoltán & DE-siroki-16261.jpg \\
\hline 1821 & Solidago virgaurea L. & Pilismarót & 1963 & Siroki Zoltán & DE-siroki-16262.jpg \\
\hline 1821 & Solidago virgaurea L. & Pilismarót & 1963 & Siroki Zoltán & DE-siroki-16256.jpg \\
\hline 1821 & Solidago virgaurea L. & Pilismarót & 1963 & Siroki Zoltán & DE-siroki-16263.jpg \\
\hline 1823 & Solidago gigantea Aiton & Keszthely & 1955 & Siroki Zoltán & DE-siroki-16239.jpg \\
\hline
\end{tabular}




\begin{tabular}{|c|c|c|c|c|c|}
\hline $\begin{array}{l}\text { Sorszám / } \\
\text { Number }\end{array}$ & Taxon-név / Taxon-name & $\begin{array}{l}\text { Település / } \\
\text { Settlement }\end{array}$ & $\begin{array}{l}\text { Év / } \\
\text { Year }\end{array}$ & $\begin{array}{l}\text { Gyüjtő / } \\
\text { Collector }\end{array}$ & Fájlnév / File-name \\
\hline 1823 & Solidago gigantea Aiton & Püski & 1939 & Siroki Zoltán & DE-siroki-16240.jpg \\
\hline 1823 & Solidago gigantea Aiton & Püski & 1939 & Siroki Zoltán & DE-siroki-16242.jpg \\
\hline 1824 & Solidago canadensis L. & Budapest & 1976 & Siroki Zoltán & DE-siroki-16244.jpg \\
\hline 1825 & Bellis perennis L. & Gödöllő & - & Siroki Zoltán & DE-siroki-16267.jpg \\
\hline 1825 & Bellis perennis L. & Mosonmagyaróvár & 1939 & Siroki Zoltán & DE-siroki-16269.jpg \\
\hline 1827 & Aster oleifolius (Lam.) Wagenitz & Tokaj & 1971 & Siroki Zoltán & DE-siroki-16270.jpg \\
\hline 1827 & Aster oleifolius (Lam.) Wagenitz & Tokaj & 1971 & Siroki Zoltán & DE-siroki-16271.jpg \\
\hline 1827 & Aster oleifolius (Lam.) Wagenitz & Tokaj & 1971 & Siroki Zoltán & DE-siroki-16272.jpg \\
\hline 1828 & Aster linosyris (L.) Bernh. & "Vértes" & 1957 & Siroki Zoltán & DE-siroki-16281.jpg \\
\hline 1828 & Aster linosyris (L.) Bernh. & Budapest & 1948 & Siroki Zoltán & DE-siroki-16284.jpg \\
\hline 1828 & Aster linosyris (L.) Bernh. & Budapest & 1950 & Siroki Zoltán & DE-siroki-16273.jpg \\
\hline 1828 & Aster linosyris (L.) Bernh. & Budapest & 1985 & Siroki Zoltán & DE-siroki-16279.jpg \\
\hline 1828 & Aster linosyris (L.) Bernh. & Egyek & 1947 & Siroki Zoltán & DE-siroki-16280.jpg \\
\hline 1828 & Aster linosyris (L.) Bernh. & Fót & 1954 & $\begin{array}{l}\text { Máthé Imre - } \\
\text { Kovács Margit }\end{array}$ & DE-siroki-16275.jpg \\
\hline 1828 & Aster linosyris (L.) Bernh. & Pilismarót & 1963 & Siroki Zoltán & DE-siroki-16274.jpg \\
\hline 1828 & Aster linosyris (L.) Bernh. & Sárospatak & 1954 & Siroki Zoltán & DE-siroki-16282.jpg \\
\hline 1828 & Aster linosyris (L.) Bernh. & Sárospatak & 1954 & Siroki Zoltán & DE-siroki-16283.jpg \\
\hline 1829 & Aster sedifolius L. & Budaörs & 1950 & Papp József & DE-siroki-16292.jpg \\
\hline 1829 & Aster sedifolius L. & Egyek & 1947 & Siroki Zoltán & DE-siroki-16293.jpg \\
\hline 1829 & Aster sedifolius L. & Egyek & 1947 & Siroki Zoltán & DE-siroki-16290.jpg \\
\hline 1829 & Aster sedifolius L. & Egyek & 1947 & Siroki Zoltán & DE-siroki-16291.jpg \\
\hline 1829 & Aster sedifolius L. & Hortobágy & 1947 & Siroki Zoltán & DE-siroki-16294.jpg \\
\hline 1829 & Aster sedifolius L. & Hortobágy & 1947 & Siroki Zoltán & DE-siroki-16295.jpg \\
\hline 1829 & Aster sedifolius L. & Sárospatak & 1954 & Simon Tiborné & DE-siroki-16288.jpg \\
\hline 1829 & Aster sedifolius L. & Sárospatak & 1954 & Simon Tiborné & DE-siroki-16289.jpg \\
\hline 1829 & Aster sedifolius L. & Sárospatak & 1954 & Siroki Zoltán & DE-siroki-16287.jpg \\
\hline 1830 & Aster tripolium L. & Abaújkér & 1943 & Siroki Zoltán & DE-siroki-16310.jpg \\
\hline 1830 & Aster tripolium L. & Budaörs & 1941 & Siroki Zoltán & DE-siroki-16312.jpg \\
\hline 1830 & Aster tripolium L. & Budaörs & 1941 & Siroki Zoltán & DE-siroki-16313.jpg \\
\hline 1830 & Aster tripolium L. & Budapest & 1954 & Siroki Zoltán & DE-siroki-16314.jpg \\
\hline 1830 & Aster tripolium L. & Debrecen & 1947 & Siroki Zoltán & DE-siroki-16308.jpg \\
\hline 1830 & Aster tripolium L. & Debrecen & 1947 & Siroki Zoltán & DE-siroki-16309.jpg \\
\hline 1830 & Aster tripolium L. & Debrecen & 1962 & Siroki Zoltán & DE-siroki-16311.jpg \\
\hline 1831 & Aster amellus L. & Budapest & 1948 & Siroki Zoltán & DE-siroki-16305.jpg \\
\hline 1831 & Aster amellus L. & Budapest & 1948 & Siroki Zoltán & DE-siroki-16306.jpg \\
\hline 1831 & Aster amellus L. & Budapest & 1948 & Siroki Zoltán & DE-siroki-16299.jpg \\
\hline 1831 & Aster amellus L. & Budapest & 1948 & Siroki Zoltán & DE-siroki-16301.jpg \\
\hline 1831 & Aster amellus L. & Budapest & 1948 & Siroki Zoltán & DE-siroki-16302.jpg \\
\hline 1831 & Aster amellus L. & Budapest & 1948 & Siroki Zoltán & DE-siroki-16303.jpg \\
\hline 1835 & Aster $\times$ salignus Willd & Budapest & - & Simonkai Lajos & DE-siroki-16319.jpg \\
\hline 1835 & Aster $\times$ salignus Willd. & Budapest & - & W. Steinitz & DE-siroki-16320.jpg \\
\hline 1837 & Aster tradescantii L. & Dunaújváros & 1950 & Kárpáti Zoltán & DE-siroki-16321.jpg \\
\hline $\begin{array}{c}1833 \times \\
1834\end{array}$ & $\begin{array}{l}\text { Aster } \times \text { versicolor Willd. } \\
(\text { A. novi-belgii } \times \text { laevis) }\end{array}$ & Mosonmagyaróvár & 1939 & Siroki Zoltán & DE-siroki-16317.jpg \\
\hline 1838 & Erigeron annuus (L.) Pers. & Berettyóújfalu & 1959 & Siroki Zoltán & DE-siroki-16325.jpg \\
\hline 1838 & Erigeron annuus (L.) Pers. & Berettyóújfalu & 1959 & Siroki Zoltán & DE-siroki-16326.jpg \\
\hline
\end{tabular}




\begin{tabular}{|c|c|c|c|c|c|}
\hline $\begin{array}{l}\text { Sorszám / } \\
\text { Number }\end{array}$ & Taxon-név / Taxon-name & $\begin{array}{l}\text { Település / } \\
\text { Settlement }\end{array}$ & $\begin{array}{l}\text { Év / } \\
\text { Year }\end{array}$ & $\begin{array}{l}\text { Gyűjtő / } \\
\text { Collector }\end{array}$ & Fájlnév / File-name \\
\hline 1838 & Erigeron annuus (L.) Pers. & Berettyóújfalu & 1959 & Siroki Zoltán & DE-siroki-16327.jpg \\
\hline 1838 & Erigeron annuus (L.) Pers. & Budapest & 1951 & Siroki Zoltán & DE-siroki-16329.jpg \\
\hline 1838 & Erigeron annuus (L.) Pers. & Budapest & 1954 & Siroki Zoltán & DE-siroki-16335.jpg \\
\hline 1838 & Erigeron annuus (L.) Pers. & Debrecen & 1948 & Siroki Zoltán & DE-siroki-16332.jpg \\
\hline 1838 & Erigeron annuus (L.) Pers. & Debrecen & 1950 & Siroki Zoltán & DE-siroki-16328.jpg \\
\hline 1838 & Erigeron annuus (L.) Pers. & Debrecen & 1950 & Siroki Zoltán & DE-siroki-16330.jpg \\
\hline 1838 & Erigeron annuus (L.) Pers. & Egyek & 1947 & Siroki Zoltán & DE-siroki-16331.jpg \\
\hline 1838 & Erigeron annuus (L.) Pers. & Mosonmagyaróvár & 1939 & Siroki Zoltán & DE-siroki-16333.jpg \\
\hline 1838 & Erigeron annuus (L.) Pers. & Tiszafüred & 1970 & Siroki Zoltán & DE-siroki-16323.jpg \\
\hline 1838 & Erigeron annuus (L.) Pers. & Tokaj & 1971 & Siroki Zoltán & DE-siroki-16324.jpg \\
\hline 1839 & Erigeron acris L. & "Nagymező" & 1959 & Siroki Zoltán & DE-siroki-16338.jpg \\
\hline 1839 & Erigeron acris L. & "Nagymező" & 1959 & Siroki Zoltán & DE-siroki-16347.jpg \\
\hline 1839 & Erigeron acris L. & "Nagymező" & 1959 & Siroki Zoltán & DE-siroki-16348.jpg \\
\hline 1839 & Erigeron acris L. & "Nagymező" & 1973 & Siroki Zoltán & DE-siroki-16344.jpg \\
\hline 1839 & Erigeron acris L. & Balatonederics & 1955 & Siroki Zoltán & DE-siroki-16339.jpg \\
\hline 1839 & Erigeron acris L. & Balatonederics & 1955 & Siroki Zoltán & DE-siroki-16340.jpg \\
\hline 1839 & Erigeron acris L. & Boldogkőváralja & 1967 & Siroki Zoltán & DE-siroki-16345.jpg \\
\hline 1839 & Erigeron acris L. & Boldogkőváralja & 1967 & Siroki Zoltán & DE-siroki-16346.jpg \\
\hline 1839 & Erigeron acris L. & Budapest & 1941 & Siroki Zoltán & DE-siroki-16341.jpg \\
\hline 1839 & Erigeron acris L. & Budapest & 1954 & Siroki Zoltán & DE-siroki-16342.jpg \\
\hline 1839 & Erigeron acris L. & Lesencetomaj & 1955 & Kovács Margit & DE-siroki-16337.jpg \\
\hline 1842 & Filago vulgaris L. & "Szent-György-hegy" & 1955 & Siroki Zoltán & DE-siroki-16376.jpg \\
\hline 1842 & Filago vulgaris L. & "Szent-György-hegy" & 1955 & Siroki Zoltán & DE-siroki-16373.jpg \\
\hline 1842 & Filago vulgaris L. & Háromhuta & 1960 & Siroki Zoltán & DE-siroki-16368.jpg \\
\hline 1842 & Filago vulgaris L. & Háromhuta & 1960 & Siroki Zoltán & DE-siroki-16369.jpg \\
\hline 1842 & Filago vulgaris L. & Háromhuta & 1960 & Siroki Zoltán & DE-siroki-16372.jpg \\
\hline 1842 & Filago vulgaris L. & Háromhuta & 1960 & Siroki Zoltán & DE-siroki-16374.jpg \\
\hline 1842 & Filago vulgaris L. & Háromhuta & 1960 & Siroki Zoltán & DE-siroki-16375.jpg \\
\hline 1842 & Filago vulgaris L. & Pécs & 1954 & Siroki Zoltán & DE-siroki-16370.jpg \\
\hline 1843 & Filago arvensis L. & Budapest & 1941 & Siroki Zoltán & DE-siroki-16380.jpg \\
\hline 1843 & Filago arvensis L. & Budapest & 1954 & Siroki Zoltán & DE-siroki-16393.jpg \\
\hline 1843 & Filago arvensis L. & Debrecen & 1946 & Siroki Zoltán & DE-siroki-16385.jpg \\
\hline 1843 & Filago arvensis L. & Debrecen & 1948 & Siroki Zoltán & DE-siroki-16382.jpg \\
\hline 1843 & Filago arvensis L. & Egyek & 1947 & Siroki Zoltán & DE-siroki-16381.jpg \\
\hline 1843 & Filago arvensis L. & Hortobágy & 1949 & Siroki Zoltán & DE-siroki-16386.jpg \\
\hline 1843 & Filago arvensis L. & Tokaj & 1971 & Siroki Zoltán & DE-siroki-16383.jpg \\
\hline 1843 & Filago arvensis L. & Tokaj & 1971 & Siroki Zoltán & DE-siroki-16384.jpg \\
\hline 1844 & Filago minima (Sm.) Pers. & Budapest & 1942 & Siroki Zoltán & DE-siroki-16390.jpg \\
\hline 1844 & Filago minima (Sm.) Pers. & Darány & 1955 & Kovács Margit & DE-siroki-16388.jpg \\
\hline 1844 & Filago minima (Sm.) Pers. & Háromhuta & 1960 & Siroki Zoltán & DE-siroki-16389.jpg \\
\hline 1844 & Filago minima (Sm.) Pers. & Háromhuta & 1960 & Siroki Zoltán & DE-siroki-16391.jpg \\
\hline 1844 & Filago minima (Sm.) Pers. & Háromhuta & 1960 & Siroki Zoltán & DE-siroki-16392.jpg \\
\hline 1845 & Micropus erectus L. & Bajót & 1951 & Kárpáti Zoltán & DE-siroki-16359.jpg \\
\hline 1845 & Micropus erectus L. & Budaörs & 1887 & Czakó Kálmán & DE-siroki-16360.jpg \\
\hline 1845 & Micropus erectus L. & Budapest & 1909 & Kocsis István & DE-siroki-16361.jpg \\
\hline 1845 & Micropus erectus L. & Budapest & 1931 & Rigler József & DE-siroki-16364.jpg \\
\hline
\end{tabular}




\begin{tabular}{|c|c|c|c|c|c|}
\hline $\begin{array}{l}\text { Sorszám / } \\
\text { Number }\end{array}$ & Taxon-név / Taxon-name & $\begin{array}{l}\text { Település / } \\
\text { Settlement }\end{array}$ & $\begin{array}{l}\text { Év / } \\
\text { Year }\end{array}$ & $\begin{array}{l}\text { Gyújtő / } \\
\text { Collector }\end{array}$ & Fájlnév / File-name \\
\hline 1845 & Micropus erectus L. & Budapest & 1952 & Siroki Zoltán & DE-siroki-16365.jpg \\
\hline 1845 & Micropus erectus L. & Budapest & 1952 & Siroki Zoltán & DE-siroki-16366.jpg \\
\hline 1845 & Micropus erectus L. & Budapest & 1952 & Siroki Zoltán & DE-siroki-16367.jpg \\
\hline 1845 & Micropus erectus L. & Dorog & 1878 & Grundl Ignác & DE-siroki-16358.jpg \\
\hline 1845 & Micropus erectus L. & Szentendre & 1916 & Degen Árpád & DE-siroki-16362.jpg \\
\hline 1845 & Micropus erectus L. & Verőce & 1923 & Degen Árpád & DE-siroki-16363.jpg \\
\hline 1846 & Gnaphalium sylvaticum L. & "Vértes" & 1957 & Siroki Zoltán & DE-siroki-16445.jpg \\
\hline 1846 & Gnaphalium sylvaticum L. & "Vértes" & 1957 & Siroki Zoltán & DE-siroki-16446.jpg \\
\hline 1846 & Gnaphalium sylvaticum L. & "Vértes" & 1957 & Siroki Zoltán & DE-siroki-16447.jpg \\
\hline 1846 & Gnaphalium sylvaticum L. & "Vértes" & 1957 & Siroki Zoltán & DE-siroki-16448.jpg \\
\hline 1846 & Gnaphalium sylvaticum L. & "Vértes" & 1957 & Siroki Zoltán & DE-siroki-16449.jpg \\
\hline 1846 & Gnaphalium sylvaticum L. & Háromhuta & 1960 & Siroki Zoltán & DE-siroki-16443.jpg \\
\hline 1846 & Gnaphalium sylvaticum L. & Háromhuta & 1960 & Siroki Zoltán & DE-siroki-16444.jpg \\
\hline 1846 & Gnaphalium sylvaticum L. & Háromhuta & 1978 & Siroki Zoltán & DE-siroki-16442.jpg \\
\hline 1847 & Gnaphalium uliginosum L. & Csaroda & 1962 & Siroki Zoltán & DE-siroki-16412.jpg \\
\hline 1847 & Gnaphalium uliginosum L. & Csaroda & 1962 & Siroki Zoltán & DE-siroki-16414.jpg \\
\hline 1847 & Gnaphalium uliginosum L. & Egyek & 1947 & Siroki Zoltán & DE-siroki-16421.jpg \\
\hline 1847 & Gnaphalium uliginosum L. & Egyek & - & Siroki Zoltán & DE-siroki-16415.jpg \\
\hline 1847 & Gnaphalium uliginosum L. & Gyula & 1974 & Siroki Zoltán & DE-siroki-16413.jpg \\
\hline 1847 & Gnaphalium uliginosum L. & Hortobágy & 1948 & Siroki Zoltán & DE-siroki-16422.jpg \\
\hline 1847 & Gnaphalium uliginosum L. & Hortobágy & 1962 & Siroki Zoltán & DE-siroki-16416.jpg \\
\hline 1847 & Gnaphalium uliginosum L. & Hortobágy & 1962 & Siroki Zoltán & DE-siroki-16417.jpg \\
\hline 1847 & Gnaphalium uliginosum L. & Hortobágy & 1962 & Siroki Zoltán & DE-siroki-16418.jpg \\
\hline 1847 & Gnaphalium uliginosum L. & Sárospatak & 1951 & Siroki Zoltán & DE-siroki-16419.jpg \\
\hline 1847 & Gnaphalium uliginosum L. & Sárospatak & 1951 & Siroki Zoltán & DE-siroki-16420.jpg \\
\hline 1848 & Gnaphalium luteoalbum L. & Debrecen & 1947 & Siroki Zoltán & DE-siroki-16427.jpg \\
\hline 1848 & Gnaphalium luteoalbum L. & Debrecen & 1947 & Siroki Zoltán & DE-siroki-16428.jpg \\
\hline 1848 & Gnaphalium luteoalbum L. & Debrecen & 1947 & Siroki Zoltán & DE-siroki-16429.jpg \\
\hline 1848 & Gnaphalium luteoalbum L. & Debrecen & 1949 & Siroki Zoltán & DE-siroki-16431.jpg \\
\hline 1848 & Gnaphalium luteoalbum L. & Debrecen & 1968 & Siroki Zoltán & DE-siroki-16426.jpg \\
\hline 1848 & Gnaphalium luteoalbum L. & Debrecen & 1968 & Siroki Zoltán & DE-siroki-16432.jpg \\
\hline 1848 & Gnaphalium luteoalbum L. & Debrecen & 1968 & Siroki Zoltán & DE-siroki-16433.jpg \\
\hline 1848 & Gnaphalium luteoalbum L. & Debrecen & 1968 & Siroki Zoltán & DE-siroki-16435.jpg \\
\hline 1848 & Gnaphalium luteoalbum L. & Debrecen & 1968 & Siroki Zoltán & DE-siroki-16436.jpg \\
\hline 1848 & Gnaphalium luteoalbum L. & Gégény & 1965 & Gondola István & DE-siroki-16434.jpg \\
\hline 1848 & Gnaphalium luteoalbum L. & Szigetszentmiklós & 1954 & Siroki Zoltán & DE-siroki-16430.jpg \\
\hline 1849 & Helichrysum arenarium (L.) Moench & Debrecen & 1947 & Siroki Zoltán & DE-siroki-16458.jpg \\
\hline 1849 & Helichrysum arenarium (L.) Moench & Debrecen & 1948 & Siroki Zoltán & DE-siroki-16457.jpg \\
\hline 1849 & Helichrysum arenarium (L.) Moench & Fót & 1954 & $\begin{array}{l}\text { Máthé Imre - } \\
\text { Kovács Margit }\end{array}$ & DE-siroki-16455.jpg \\
\hline 1849 & Helichrysum arenarium (L.) Moench & Hajdúbagos & 1982 & Siroki Zoltán & DE-siroki-16453.jpg \\
\hline 1849 & Helichrysum arenarium (L.) Moench & Hajdúbagos & 1982 & Siroki Zoltán & DE-siroki-16454.jpg \\
\hline 1849 & Helichrysum arenarium (L.) Moench & Rezi & 1955 & Siroki Zoltán & DE-siroki-16456.jpg \\
\hline 1850 & Antennaria dioica (L.) Gaertn. & "Nagymező" & 1959 & Halász Tibor & DE-siroki-16398.jpg \\
\hline 1850 & Antennaria dioica (L.) Gaertn. & "Nagymező" & 1959 & Siroki Zoltán & DE-siroki-16399.jpg \\
\hline 1850 & Antennaria dioica (L.) Gaertn. & "Nagymező" & 1960 & Siroki Zoltán & DE-siroki-16400.jpg \\
\hline 1850 & Antennaria dioica (L.) Gaertn. & Háromhuta & 1961 & Siroki Zoltán & DE-siroki-16401.jpg \\
\hline
\end{tabular}




\begin{tabular}{|c|c|c|c|c|c|}
\hline $\begin{array}{l}\text { Sorszám / } \\
\text { Number }\end{array}$ & Taxon-név / Taxon-name & $\begin{array}{l}\text { Település / } \\
\text { Settlement }\end{array}$ & $\begin{array}{l}\text { Év / } \\
\text { Year }\end{array}$ & $\begin{array}{l}\text { Gyűjtő / } \\
\text { Collector }\end{array}$ & Fájlnév / File-name \\
\hline 1850 & Antennaria dioica (L.) Gaertn. & Háromhuta & 1973 & Siroki Zoltán & DE-siroki-16394.jpg \\
\hline 1850 & Antennaria dioica (L.) Gaertn. & Hollóháza & 1940 & Siroki Zoltán & DE-siroki-16396.jpg \\
\hline 1852 & Inula conyza DC. & "Vértes" & 1957 & Siroki Zoltán & DE-siroki-16466.jpg \\
\hline 1852 & Inula conyza DC. & Budapest & 1948 & Siroki Zoltán & DE-siroki-16468.jpg \\
\hline 1852 & Inula conyza DC. & Budapest & 1948 & Siroki Zoltán & DE-siroki-16469.jpg \\
\hline 1852 & Inula conyza DC. & Budapest & 1954 & Siroki Zoltán & DE-siroki-16467.jpg \\
\hline 1852 & Inula conyza DC. & Budapest & 1983 & Siroki Zoltán & DE-siroki-16464.jpg \\
\hline 1852 & Inula conyza DC. & Budapest & 1983 & Siroki Zoltán & DE-siroki-16465.jpg \\
\hline 1852 & Inula conyza DC. & Nagykovácsi & 1985 & Siroki Zoltán & DE-siroki-16463.jpg \\
\hline 1853 & Inula hirta L. & "Dobogókő" & 1965 & Siroki Zoltán & DE-siroki-16506.jpg \\
\hline 1853 & Inula hirta L. & "Mátra" & 1982 & Siroki Zoltán & DE-siroki-16493.jpg \\
\hline 1853 & Inula hirta L. & "Mátra" & 1982 & Siroki Zoltán & DE-siroki-16494.jpg \\
\hline 1853 & Inula hirta L. & "Mátra" & 1982 & Siroki Zoltán & DE-siroki-16495.jpg \\
\hline 1853 & Inula hirta L. & "Mátra" & 1984 & Siroki Zoltán & DE-siroki-16505.jpg \\
\hline 1853 & Inula hirta L. & Budapest & 1954 & Siroki Zoltán & DE-siroki-16502.jpg \\
\hline 1853 & Inula hirta L. & Szarvaskő & 1957 & Siroki Zoltán & DE-siroki-16503.jpg \\
\hline 1853 & Inula hirta L. & Szarvaskő & 1957 & Siroki Zoltán & DE-siroki-16504.jpg \\
\hline 1853 & Inula hirta L. & Szilvásvárad & 1960 & Siroki Zoltán & DE-siroki-16507.jpg \\
\hline 1854 & Inula britannica L. & Budaörs & 1985 & Siroki Zoltán & DE-siroki-16516.jpg \\
\hline 1854 & Inula britannica L. & Budapest & 1985 & Siroki Zoltán & DE-siroki-16517.jpg \\
\hline 1854 & Inula britannica L. & Debrecen & 1947 & Siroki Zoltán & DE-siroki-16523.jpg \\
\hline 1854 & Inula britannica L. & Debrecen & 1948 & Siroki Zoltán & DE-siroki-16522.jpg \\
\hline 1854 & Inula britannica L. & Debrecen & 1957 & Siroki Zoltán & DE-siroki-16518.jpg \\
\hline 1854 & Inula britannica L. & Gödöllő & 1954 & $\begin{array}{l}\text { Jeanplong József } \\
\text { - L. Kormány } \\
\text { - M. Rösch }\end{array}$ & DE-siroki-16519.jpg \\
\hline 1854 & Inula britannica L. & Gödöllő & 1954 & $\begin{array}{l}\text { Jeanplong József } \\
\text { - L. Kormány } \\
\text { - M. Rösch }\end{array}$ & DE-siroki-16520.jpg \\
\hline 1854 & Inula britannica L. & Hortobágy & 1948 & Siroki Zoltán & DE-siroki-16521.jpg \\
\hline 1854 & Inula britannica L. & Hortobágy & 1948 & Siroki Zoltán & DE-siroki-16515.jpg \\
\hline 1854 & Inula britannica L. & Mosonmagyaróvár & 1939 & Siroki Zoltán & DE-siroki-16524.jpg \\
\hline 1855 & Inula oculus-christi L. & Budapest & 1944 & Siroki Zoltán & DE-siroki-16533.jpg \\
\hline 1855 & Inula oculus-christi L. & Budapest & 1944 & Siroki Zoltán & DE-siroki-16534.jpg \\
\hline 1855 & Inula oculus-christi L. & Budapest & 1944 & Siroki Zoltán & DE-siroki-16535.jpg \\
\hline 1855 & Inula oculus-christi L. & Budapest & 1944 & Siroki Zoltán & DE-siroki-16532.jpg \\
\hline 1855 & Inula oculus-christi L. & Budapest & 1948 & Siroki Zoltán & DE-siroki-16531.jpg \\
\hline 1855 & Inula oculus-christi L. & Mátraszentimre & 1962 & Siroki Zoltán & DE-siroki-16527.jpg \\
\hline 1855 & Inula oculus-christi L. & Pomáz & 1954 & Siroki Zoltán & DE-siroki-16528.jpg \\
\hline 1855 & Inula oculus-christi L. & Pomáz & 1954 & Siroki Zoltán & DE-siroki-16529.jpg \\
\hline 1855 & Inula oculus-christi L. & Pomáz & 1954 & Siroki Zoltán & DE-siroki-16530.jpg \\
\hline 1856 & Inula germanica L. & "Szent-György-hegy" & 1955 & Siroki Zoltán & DE-siroki-16509.jpg \\
\hline 1856 & Inula germanica L. & "Szent-György-hegy" & 1955 & Siroki Zoltán & DE-siroki-16510.jpg \\
\hline 1856 & Inula germanica L. & "Szent-György-hegy" & 1955 & Siroki Zoltán & DE-siroki-16511.jpg \\
\hline 1856 & Inula germanica L. & "Szent-György-hegy" & 1955 & Siroki Zoltán & DE-siroki-16512.jpg \\
\hline 1856 & Inula germanica L. & Abaújszántó & 1943 & Siroki Zoltán & DE-siroki-16513.jpg \\
\hline 1856 & Inula germanica L. & Abaújszántó & 1943 & Siroki Zoltán & DE-siroki-16514.jpg \\
\hline 1856 & Inula germanica L. & Hortobágy & 1975 & Siroki Zoltán & DE-siroki-16508.jpg \\
\hline
\end{tabular}




\begin{tabular}{|c|c|c|c|c|c|}
\hline $\begin{array}{l}\text { Sorszám / } \\
\text { Number }\end{array}$ & Taxon-név / Taxon-name & $\begin{array}{l}\text { Település / } \\
\text { Settlement }\end{array}$ & $\begin{array}{l}\text { Év / } \\
\text { Year }\end{array}$ & $\begin{array}{l}\text { Gyújtő / } \\
\text { Collector }\end{array}$ & Fájlnév / File-name \\
\hline 1857 & Inula salicina $\mathrm{L}$. & Budapest & 1983 & Siroki Zoltán & DE-siroki-16492.jpg \\
\hline 1857 & Inula salicina L. & Debrecen & 1950 & Siroki Zoltán & DE-siroki-16486.jpg \\
\hline 1857 & Inula salicina L. & Debrecen & 1950 & Siroki Zoltán & DE-siroki-16489.jpg \\
\hline 1857 & Inula salicina L. & Egyek & 1947 & Siroki Zoltán & DE-siroki-16488.jpg \\
\hline 1857 & Inula salicina L. & Háromhuta & 1960 & Siroki Zoltán & DE-siroki-16484.jpg \\
\hline 1857 & Inula salicina L. & Háromhuta & 1960 & Siroki Zoltán & DE-siroki-16485.jpg \\
\hline 1857 & Inula salicina L. & Tokaj & 1971 & Siroki Zoltán & DE-siroki-16482.jpg \\
\hline 1857 & Inula salicina L. & Tokaj & 1971 & Siroki Zoltán & DE-siroki-16483.jpg \\
\hline 1858 & Inula ensifolia L. & Budaörs & 1966 & Siroki Zoltán & DE-siroki-16476.jpg \\
\hline 1858 & Inula ensifolia L. & Budaörs & 1966 & Siroki Zoltán & DE-siroki-16477.jpg \\
\hline 1858 & Inula ensifolia L. & Budapest & 1948 & Siroki Zoltán & DE-siroki-16480.jpg \\
\hline 1858 & Inula ensifolia L. & Nagykovácsi & 1985 & Siroki Zoltán & DE-siroki-16472.jpg \\
\hline 1858 & Inula ensifolia L. & Pomáz & 1957 & Siroki Zoltán & DE-siroki-16478.jpg \\
\hline 1858 & Inula ensifolia L. & Tokaj & 1971 & Siroki Zoltán & DE-siroki-16473.jpg \\
\hline 1858 & Inula ensifolia L. & Tokaj & 1971 & Siroki Zoltán & DE-siroki-16474.jpg \\
\hline 1858 & Inula ensifolia L. & Tokaj & 1971 & Siroki Zoltán & DE-siroki-16475.jpg \\
\hline 1860 & Pulicaria vulgaris Gaertn. & Boldogkőváralja & 1943 & Siroki Zoltán & DE-siroki-16541.jpg \\
\hline 1860 & Pulicaria vulgaris Gaertn. & Budapest & 1941 & Siroki Zoltán & DE-siroki-16536.jpg \\
\hline 1860 & Pulicaria vulgaris Gaertn. & Budapest & 1941 & Siroki Zoltán & DE-siroki-16540.jpg \\
\hline 1860 & Pulicaria vulgaris Gaertn. & Egyek & 1947 & Siroki Zoltán & DE-siroki-16539.jpg \\
\hline 1860 & Pulicaria vulgaris Gaertn. & Hortobágy & 1948 & Siroki Zoltán & DE-siroki-16537.jpg \\
\hline 1860 & Pulicaria vulgaris Gaertn. & Hortobágy & 1948 & Siroki Zoltán & DE-siroki-16538.jpg \\
\hline 1861 & Pulicaria dysenterica (L.) Bernh. & Dunaharaszti & 1954 & Siroki Zoltán & DE-siroki-16545.jpg \\
\hline 1861 & Pulicaria dysenterica (L.) Bernh. & Hajdúbagos & 1981 & Siroki Zoltán & DE-siroki-16542.jpg \\
\hline 1861 & Pulicaria dysenterica (L.) Bernh. & Hajdúbagos & 1981 & Siroki Zoltán & DE-siroki-16543.jpg \\
\hline 1861 & Pulicaria dysenterica (L.) Bernh. & Keszthely & 1955 & Siroki Zoltán & DE-siroki-16544.jpg \\
\hline 1861 & Pulicaria dysenterica (L.) Bernh. & Mosonmagyaróvár & 1939 & Siroki Zoltán & DE-siroki-16546.jpg \\
\hline 1861 & Pulicaria dysenterica (L.) Bernh. & Mosonmagyaróvár & 1939 & Siroki Zoltán & DE-siroki-16547.jpg \\
\hline 1862 & Carpesium cernuum L. & Mosonmagyaróvár & 1958 & Gondola István & DE-siroki-16548.jpg \\
\hline 1867 & Bidens tripartita L. & Debrecen & 1947 & Siroki Zoltán & DE-siroki-16579.jpg \\
\hline 1867 & Bidens tripartita L. & Debrecen & 1949 & Siroki Zoltán & DE-siroki-16578.jpg \\
\hline 1867 & Bidens tripartita L. & Mosonmagyaróvár & 1939 & Siroki Zoltán & DE-siroki-16582.jpg \\
\hline 1867 & Bidens tripartita L. & Mosonmagyaróvár & 1939 & Siroki Zoltán & DE-siroki-16580.jpg \\
\hline 1875 & Iva xanthiifolia Nutt. & Fényeslitke & 1965 & Gondola István & DE-siroki-16561.jpg \\
\hline 1875 & Iva xanthiifolia Nutt. & Fényeslitke & 1965 & Gondola István & DE-siroki-16562.jpg \\
\hline 1875 & Iva xanthiifolia Nutt. & Fényeslitke & 1965 & Gondola István & DE-siroki-16563.jpg \\
\hline 1875 & Iva xanthiifolia Nutt. & Fényeslitke & 1965 & Gondola István & DE-siroki-16565.jpg \\
\hline 1875 & Iva xanthiifolia Nutt. & Fényeslitke & 1965 & Gondola István & DE-siroki-16566.jpg \\
\hline 1875 & Iva xanthiifolia Nutt. & Fényeslitke & 1965 & Gondola István & DE-siroki-16564.jpg \\
\hline 1875 & Iva xanthiifolia Nutt. & Fényeslitke & 1965 & Gondola István & DE-siroki-16567.jpg \\
\hline 1876 & Ambrosia artemisiifolia L. & Budapest & 1950 & Siroki Zoltán & DE-siroki-16552.jpg \\
\hline 1876 & Ambrosia artemisiifolia L. & Budapest & 1950 & Siroki Zoltán & DE-siroki-16555.jpg \\
\hline 1876 & Ambrosia artemisiifolia L. & Budapest & 1985 & Siroki Zoltán & DE-siroki-16558.jpg \\
\hline 1876 & Ambrosia artemisiifolia L. & Debrecen & 1949 & Siroki Zoltán & DE-siroki-16556.jpg \\
\hline 1876 & Ambrosia artemisiifolia L. & Debrecen & 1949 & Siroki Zoltán & DE-siroki-16554.jpg \\
\hline 1876 & Ambrosia artemisiifolia L. & Debrecen & 1985 & Siroki Zoltán & DE-siroki-16559.jpg \\
\hline
\end{tabular}




\begin{tabular}{|c|c|c|c|c|c|}
\hline $\begin{array}{l}\text { Sorszám / } \\
\text { Number }\end{array}$ & Taxon-név / Taxon-name & $\begin{array}{l}\text { Település / } \\
\text { Settlement }\end{array}$ & $\begin{array}{l}\text { Év / } \\
\text { Year }\end{array}$ & $\begin{array}{l}\text { Gyújitő / } \\
\text { Collector }\end{array}$ & Fájlnév / File-name \\
\hline 1876 & Ambrosia artemisiifolia L. & Debrecen & 1985 & Siroki Zoltán & DE-siroki-16560.jpg \\
\hline 1876 & Ambrosia artemisiifolia L. & Hidegkút & 1950 & Siroki Zoltán & DE-siroki-16553.jpg \\
\hline 1879 & Xanthium strumarium L. & Debrecen & 1957 & Siroki Zoltán & DE-siroki-16571.jpg \\
\hline 1879 & Xanthium strumarium L. & Mosonmagyaróvár & 1939 & Siroki Zoltán & DE-siroki-16573.jpg \\
\hline 1886 & Galinsoga parviflora Cav. & Debrecen & 1957 & Siroki Zoltán & DE-siroki-16586.jpg \\
\hline 1886 & Galinsoga parviflora Cav. & Debrecen & 1957 & Siroki Zoltán & DE-siroki-16587.jpg \\
\hline 1890 & Anthemis cotula L. & Boldogkőváralja & 1943 & Siroki Zoltán & DE-siroki-16597.jpg \\
\hline 1890 & Anthemis cotula L. & Debrecen & 1947 & Siroki Zoltán & DE-siroki-16596.jpg \\
\hline 1890 & Anthemis cotula L. & Debrecen & 1949 & Siroki Zoltán & DE-siroki-16592.jpg \\
\hline 1890 & Anthemis cotula L. & Debrecen & 1949 & Siroki Zoltán & DE-siroki-16593.jpg \\
\hline 1890 & Anthemis cotula L. & Debrecen & 1957 & Siroki Zoltán & DE-siroki-16590.jpg \\
\hline 1890 & Anthemis cotula L. & Debrecen & 1957 & Siroki Zoltán & DE-siroki-16591.jpg \\
\hline 1890 & Anthemis cotula L. & Mosonmagyaróvár & 1939 & Siroki Zoltán & DE-siroki-16598.jpg \\
\hline 1891 & Anthemis arvensis L. & Debrecen & 1947 & Siroki Zoltán & DE-siroki-16629.jpg \\
\hline 1891 & Anthemis arvensis L. & Hollóháza & 1940 & Siroki Zoltán & DE-siroki-16630.jpg \\
\hline 1892 & Anthemis ruthenica L. & Boldogkőváralja & 1944 & Siroki Zoltán & DE-siroki-16637.jpg \\
\hline 1892 & Anthemis ruthenica L. & Boldogkőváralja & 1944 & Siroki Zoltán & DE-siroki-16638.jpg \\
\hline 1892 & Anthemis ruthenica L. & Debrecen & 1946 & Siroki Zoltán & DE-siroki-16635.jpg \\
\hline 1892 & Anthemis ruthenica L. & Debrecen & 1947 & Siroki Zoltán & DE-siroki-16634.jpg \\
\hline 1892 & Anthemis ruthenica L. & Debrecen & 1954 & Siroki Zoltán & DE-siroki-16636.jpg \\
\hline 1892 & Anthemis ruthenica L. & Debrecen & 1984 & Siroki Zoltán & DE-siroki-16633.jpg \\
\hline 1893 & Anthemis austriaca Jacq. & Abaújszántó & 1944 & Siroki Zoltán & DE-siroki-16614.jpg \\
\hline 1893 & Anthemis austriaca Jacq. & Abaújszántó & 1944 & Siroki Zoltán & DE-siroki-16615.jpg \\
\hline 1893 & Anthemis austriaca Jacq. & Abaújszántó & 1944 & Siroki Zoltán & DE-siroki-16608.jpg \\
\hline 1893 & Anthemis austriaca Jacq. & Debrecen & 1961 & Siroki Zoltán & DE-siroki-16603.jpg \\
\hline 1893 & Anthemis austriaca Jacq. & Debrecen & 1961 & Siroki Zoltán & DE-siroki-16604.jpg \\
\hline 1893 & Anthemis austriaca Jacq. & Debrecen & 1961 & Siroki Zoltán & DE-siroki-16605.jpg \\
\hline 1893 & Anthemis austriaca Jacq. & Debrecen & 1961 & Siroki Zoltán & DE-siroki-16606.jpg \\
\hline 1893 & Anthemis austriaca Jacq. & Dévaványa & 1962 & Siroki Zoltán & DE-siroki-16607.jpg \\
\hline 1893 & Anthemis austriaca Jacq. & Egyek & 1948 & Siroki Zoltán & DE-siroki-16609.jpg \\
\hline 1893 & Anthemis austriaca Jacq. & Egyek & 1948 & Siroki Zoltán & DE-siroki-16610.jpg \\
\hline 1893 & Anthemis austriaca Jacq. & Egyek & 1948 & Siroki Zoltán & DE-siroki-16616.jpg \\
\hline 1893 & Anthemis austriaca Jacq. & Hódmezővásárhely & 1975 & Siroki Zoltán & DE-siroki-16611.jpg \\
\hline 1893 & Anthemis austriaca Jacq. & Mosonmagyaróvár & 1939 & Siroki Zoltán & DE-siroki-16613.jpg \\
\hline 1893 & Anthemis austriaca Jacq. & Polgár & 1980 & Siroki Zoltán & DE-siroki-16612.jpg \\
\hline 1893 & Anthemis austriaca Jacq. & Püspökladány & 1966 & Siroki Zoltán & DE-siroki-16599.jpg \\
\hline 1893 & Anthemis austriaca Jacq. & Püspökladány & 1966 & Siroki Zoltán & DE-siroki-16600.jpg \\
\hline 1893 & Anthemis austriaca Jacq. & Püspökladány & 1966 & Siroki Zoltán & DE-siroki-16601.jpg \\
\hline 1893 & Anthemis austriaca Jacq. & Püspökladány & 1966 & Siroki Zoltán & DE-siroki-16602.jpg \\
\hline 1894 & Anthemis tinctoria L. & "Bükk-hg." & 1959 & Halász Tibor & DE-siroki-16628.jpg \\
\hline 1894 & Anthemis tinctoria L. & Budaörs & 1966 & Siroki Zoltán & DE-siroki-16625.jpg \\
\hline 1894 & Anthemis tinctoria L. & Budaörs & 1966 & Siroki Zoltán & DE-siroki-16626.jpg \\
\hline 1894 & Anthemis tinctoria L. & Budapest & 1948 & Siroki Zoltán & DE-siroki-16617.jpg \\
\hline 1894 & Anthemis tinctoria L. & Pomáz & 1957 & Siroki Zoltán & DE-siroki-16618.jpg \\
\hline 1894 & Anthemis tinctoria L. & Pomáz & 1957 & Siroki Zoltán & DE-siroki-16619.jpg \\
\hline 1894 & Anthemis tinctoria L. & Szilvásvárad & 1954 & Siroki Zoltán & DE-siroki-16624.jpg \\
\hline
\end{tabular}




\begin{tabular}{|c|c|c|c|c|c|}
\hline $\begin{array}{l}\text { Sorszám / } \\
\text { Number }\end{array}$ & Taxon-név / Taxon-name & $\begin{array}{l}\text { Település / } \\
\text { Settlement }\end{array}$ & $\begin{array}{l}\text { Év / } \\
\text { Year }\end{array}$ & $\begin{array}{l}\text { Gyűjtő / } \\
\text { Collector }\end{array}$ & Fájlnév / File-name \\
\hline 1894 & Anthemis tinctoria L. & Szilvásvárad & 1954 & Siroki Zoltán & DE-siroki-16620.jpg \\
\hline 1894 & Anthemis tinctoria L. & Tokaj & 1966 & Siroki Zoltán & DE-siroki-16627.jpg \\
\hline 1896 & Achillea ochroleuca Ehrh. & Gödöllő & 1942 & Siroki Zoltán & DE-siroki-16661.jpg \\
\hline 1896 & Achillea ochroleuca Ehrh. & Gödöllő & 1952 & Siroki Zoltán & DE-siroki-16665.jpg \\
\hline 1896 & Achillea ochroleuca Ehrh. & Gödöllő & - & Siroki Zoltán & DE-siroki-16663.jpg \\
\hline 1896 & Achillea ochroleuca Ehrh. & Gödöllő & - & Siroki Zoltán & DE-siroki-16662.jpg \\
\hline 1896 & Achillea ochroleuca Ehrh. & Pilisszentiván & 1952 & Siroki Zoltán & DE-siroki-16664.jpg \\
\hline 1896 & Achillea ochroleuca Ehrh. & Veresegyház & 1960 & Siroki Zoltán & DE-siroki-16659.jpg \\
\hline 1896 & Achillea ochroleuca Ehrh. & Veresegyház & 1960 & Siroki Zoltán & DE-siroki-16660.jpg \\
\hline 1897 & Achillea crithmifolia Waldst. et Kit. & "Mátra" & 1928 & Kováts Ferenc & DE-siroki-16733.jpg \\
\hline 1897 & Achillea crithmifolia Waldst. et Kit. & Leányfalu & 1950 & Kárpáti Zoltán & DE-siroki-16737.jpg \\
\hline 1897 & Achillea crithmifolia Waldst. et Kit. & Nagymaros & 1950 & Kárpáti Zoltán & DE-siroki-16738.jpg \\
\hline 1899 & Achillea nobilis L. & "Háromkő" & 1959 & Siroki Zoltán & DE-siroki-16675.jpg \\
\hline 1899 & Achillea nobilis L. & "Mátra" & 1984 & Siroki Zoltán & DE-siroki-16685.jpg \\
\hline 1899 & Achillea nobilis L. & "Mátra" & 1984 & Siroki Zoltán & DE-siroki-16686.jpg \\
\hline 1899 & Achillea nobilis L. & "Mátra" & 1984 & Siroki Zoltán & DE-siroki-16687.jpg \\
\hline 1899 & Achillea nobilis L. & "Nagymező" & 1959 & Siroki Zoltán & DE-siroki-16674.jpg \\
\hline 1899 & Achillea nobilis L. & Abaújszántó & 1943 & Siroki Zoltán & DE-siroki-16684.jpg \\
\hline 1899 & Achillea nobilis L. & Aggtelek & 1972 & Siroki Zoltán & DE-siroki-16702.jpg \\
\hline 1899 & Achillea nobilis L. & Aggtelek & 1972 & Siroki Zoltán & DE-siroki-13379.jpg \\
\hline 1899 & Achillea nobilis L. & Háromhuta & 1967 & Siroki Zoltán & DE-siroki-16688.jpg \\
\hline 1899 & Achillea nobilis L. & Hortobágy & 1949 & Siroki Zoltán & DE-siroki-16680.jpg \\
\hline 1899 & Achillea nobilis L. & Hortobágy & 1949 & Siroki Zoltán & DE-siroki-16693.jpg \\
\hline 1899 & Achillea nobilis L. & Hortobágy & 1957 & Siroki Zoltán & DE-siroki-16671.jpg \\
\hline 1899 & Achillea nobilis L. & Hortobágy & 1957 & Siroki Zoltán & DE-siroki-16697.jpg \\
\hline 1899 & Achillea nobilis L. & Hortobágy & 1959 & Siroki Zoltán & DE-siroki-16676.jpg \\
\hline 1899 & Achillea nobilis L. & Hortobágy & 1959 & Siroki Zoltán & DE-siroki-16677.jpg \\
\hline 1899 & Achillea nobilis L. & Nagykovácsi & 1957 & Siroki Zoltán & DE-siroki-16695.jpg \\
\hline 1899 & Achillea nobilis L. & Nagykovácsi & 1957 & Siroki Zoltán & DE-siroki-16689.jpg \\
\hline 1899 & Achillea nobilis L. & Nagykovácsi & 1957 & Siroki Zoltán & DE-siroki-16690.jpg \\
\hline 1899 & Achillea nobilis L. & Nagykovácsi & 1957 & Siroki Zoltán & DE-siroki-16694.jpg \\
\hline 1899 & Achillea nobilis L. & Nagykovácsi & 1957 & Siroki Zoltán & DE-siroki-16696.jpg \\
\hline 1899 & Achillea nobilis L. & Nagykovácsi & 1957 & Siroki Zoltán & DE-siroki-16698.jpg \\
\hline 1899 & Achillea nobilis L. & Nagykovácsi & 1957 & Siroki Zoltán & DE-siroki-16699.jpg \\
\hline 1899 & Achillea nobilis L. & Nagykovácsi & 1957 & Siroki Zoltán & DE-siroki-16700.jpg \\
\hline 1899 & Achillea nobilis L. & Nagykovácsi & 1957 & Siroki Zoltán & DE-siroki-16701.jpg \\
\hline 1899 & Achillea nobilis L. & $\begin{array}{l}\text { Pilisszentiván- } \\
\text { Nagykovácsi }\end{array}$ & 1957 & Siroki Zoltán & DE-siroki-16670.jpg \\
\hline 1899 & Achillea nobilis L. & Pomáz & 1954 & Siroki Zoltán & DE-siroki-16673.jpg \\
\hline 1899 & Achillea nobilis L. & Pomáz & 1954 & Siroki Zoltán & DE-siroki-16691.jpg \\
\hline 1899 & Achillea nobilis L. & Pomáz & 1957 & Siroki Zoltán & DE-siroki-16672.jpg \\
\hline 1899 & Achillea nobilis L. & Szilvásvárad & 1954 & Siroki Zoltán & DE-siroki-16692.jpg \\
\hline 1901 & $\begin{array}{l}\text { Achillea distans } \\
\text { Waldst. et Kit. ex Willd. }\end{array}$ & "Dobogókő" & 1965 & Siroki Zoltán & DE-siroki-16710.jpg \\
\hline 1901 & $\begin{array}{l}\text { Achillea distans } \\
\text { Waldst. et Kit. ex Willd. }\end{array}$ & "Mátra" & 1984 & Siroki Zoltán & DE-siroki-16721.jpg \\
\hline 1901 & $\begin{array}{l}\text { Achillea distans } \\
\text { Waldst. et Kit. ex Willd. }\end{array}$ & "Mátra" & 1984 & Siroki Zoltán & DE-siroki-16708.jpg \\
\hline
\end{tabular}




\begin{tabular}{|c|c|c|c|c|c|}
\hline $\begin{array}{l}\text { Sorszám / } \\
\text { Number }\end{array}$ & Taxon-név / Taxon-name & $\begin{array}{l}\text { Település / } \\
\text { Settlement }\end{array}$ & $\begin{array}{l}\text { Év / } \\
\text { Year }\end{array}$ & $\begin{array}{l}\text { Gyűjtő / } \\
\text { Collector }\end{array}$ & Fájlnév / File-name \\
\hline 1901 & $\begin{array}{l}\text { Achillea distans } \\
\text { Waldst. et Kit. ex Willd. }\end{array}$ & "Mátra" & 1984 & Siroki Zoltán & DE-siroki-16720.jpg \\
\hline 1901 & $\begin{array}{l}\text { Achillea distans } \\
\text { Waldst. et Kit. ex Willd. }\end{array}$ & Budapest & 1940 & Siroki Zoltán & DE-siroki-16727.jpg \\
\hline 1901 & $\begin{array}{l}\text { Achillea distans } \\
\text { Waldst. et Kit. ex Willd. }\end{array}$ & Budapest & 1948 & Siroki Zoltán & DE-siroki-16717.jpg \\
\hline 1901 & $\begin{array}{l}\text { Achillea distans } \\
\text { Waldst. et Kit. ex Willd. }\end{array}$ & Budapest & 1948 & Siroki Zoltán & DE-siroki-16718.jpg \\
\hline 1901 & $\begin{array}{l}\text { Achillea distans } \\
\text { Waldst. et Kit. ex Willd. }\end{array}$ & Budapest & 1960 & Siroki Zoltán & DE-siroki-16709.jpg \\
\hline 1901 & $\begin{array}{l}\text { Achillea distans } \\
\text { Waldst. et Kit. ex Willd. }\end{array}$ & Budapest & 1960 & Siroki Zoltán & DE-siroki-16711.jpg \\
\hline 1901 & $\begin{array}{l}\text { Achillea distans } \\
\text { Waldst. et Kit. ex Willd. }\end{array}$ & Budapest & 1960 & Siroki Zoltán & DE-siroki-16712.jpg \\
\hline 1901 & $\begin{array}{l}\text { Achillea distans } \\
\text { Waldst. et Kit. ex Willd. }\end{array}$ & Pomáz & 1957 & Siroki Zoltán & DE-siroki-16716.jpg \\
\hline 1901 & $\begin{array}{l}\text { Achillea distans } \\
\text { Waldst. et Kit. ex Willd. }\end{array}$ & Pomáz & 1957 & Siroki Zoltán & DE-siroki-16713.jpg \\
\hline 1901 & $\begin{array}{l}\text { Achillea distans } \\
\text { Waldst. et Kit. ex Willd. }\end{array}$ & Pomáz & 1957 & Siroki Zoltán & DE-siroki-16714.jpg \\
\hline 1901 & $\begin{array}{l}\text { Achillea distans } \\
\text { Waldst. et Kit. ex Willd. }\end{array}$ & Pomáz & 1957 & Siroki Zoltán & DE-siroki-16715.jpg \\
\hline 1903 & Achillea setacea Waldst. et Kit. & Abaújkér & 1942 & Siroki Zoltán & DE-siroki-16752.jpg \\
\hline 1903 & Achillea setacea Waldst. et Kit. & Abaújszántó & 1944 & Siroki Zoltán & DE-siroki-16753.jpg \\
\hline 1903 & Achillea setacea Waldst. et Kit. & Abaújszántó & 1944 & Siroki Zoltán & DE-siroki-16755.jpg \\
\hline 1903 & Achillea setacea Waldst. et Kit. & Cegléd & 1969 & Siroki Zoltán & DE-siroki-16744.jpg \\
\hline 1903 & Achillea setacea Waldst. et Kit. & Cegléd & 1969 & Siroki Zoltán & DE-siroki-16745.jpg \\
\hline 1903 & Achillea setacea Waldst. et Kit. & Cegléd & 1969 & Siroki Zoltán & DE-siroki-16746.jpg \\
\hline 1903 & Achillea setacea Waldst. et Kit. & Debrecen & 1946 & Siroki Zoltán & DE-siroki-16743.jpg \\
\hline 1903 & Achillea setacea Waldst. et Kit. & Debrecen & 1948 & Siroki Zoltán & DE-siroki-16739.jpg \\
\hline 1903 & Achillea setacea Waldst. et Kit. & Debrecen & 1958 & Siroki Zoltán & DE-siroki-16751.jpg \\
\hline 1903 & Achillea setacea Waldst. et Kit. & Debrecen & 1958 & Siroki Zoltán & DE-siroki-16748.jpg \\
\hline 1903 & Achillea setacea Waldst. et Kit. & Debrecen & 1958 & Siroki Zoltán & DE-siroki-16749.jpg \\
\hline 1903 & Achillea setacea Waldst. et Kit. & Debrecen & 1980 & Siroki Zoltán & DE-siroki-16740.jpg \\
\hline 1903 & Achillea setacea Waldst. et Kit. & Debrecen & 1980 & Siroki Zoltán & DE-siroki-16741.jpg \\
\hline 1903 & Achillea setacea Waldst. et Kit. & Gelej & 1980 & Siroki Zoltán & DE-siroki-16747.jpg \\
\hline 1903 & Achillea setacea Waldst. et Kit. & Hortobágy & 1947 & Siroki Zoltán & DE-siroki-16754.jpg \\
\hline 1903 & Achillea setacea Waldst. et Kit. & Hortobágy & 1947 & Siroki Zoltán & DE-siroki-16750.jpg \\
\hline 1903 & Achillea setacea Waldst. et Kit. & Hortobágy & 1959 & Siroki Zoltán & DE-siroki-16742.jpg \\
\hline 1904 & Achillea asplenifolia Vent. & Ágasegyháza & 1956 & Siroki Zoltán & DE-siroki-16765.jpg \\
\hline 1904 & Achillea asplenifolia Vent. & Ágasegyháza & 1956 & Siroki Zoltán & DE-siroki-16766.jpg \\
\hline 1904 & Achillea asplenifolia Vent. & Debrecen & 1946 & Siroki Zoltán & DE-siroki-16758.jpg \\
\hline 1904 & Achillea asplenifolia Vent. & Debrecen & 1946 & Siroki Zoltán & DE-siroki-16759.jpg \\
\hline 1904 & Achillea asplenifolia Vent. & Debrecen & 1947 & Siroki Zoltán & DE-siroki-16767.jpg \\
\hline 1904 & Achillea asplenifolia Vent. & Debrecen & 1948 & Siroki Zoltán & DE-siroki-16757.jpg \\
\hline 1904 & Achillea asplenifolia Vent. & Hajdúbagos & 1981 & Siroki Zoltán & DE-siroki-16760.jpg \\
\hline 1904 & Achillea asplenifolia Vent. & Hajdúböszörmény & 1966 & Siroki Zoltán & DE-siroki-16761.jpg \\
\hline 1904 & Achillea asplenifolia Vent. & Hajdúböszörmény & 1966 & Siroki Zoltán & DE-siroki-16762.jpg \\
\hline 1904 & Achillea asplenifolia Vent. & Hajdúböszörmény & 1966 & Siroki Zoltán & DE-siroki-16763.jpg \\
\hline 1904 & Achillea asplenifolia Vent. & Hajdúböszörmény & 1966 & Siroki Zoltán & DE-siroki-16764.jpg \\
\hline 1905 & Achillea pannonica Scheele & Debrecen & 1947 & Siroki Zoltán & DE-siroki-16771.jpg \\
\hline 1905 & Achillea pannonica Scheele & Debrecen & 1947 & Siroki Zoltán & DE-siroki-16775.jpg \\
\hline
\end{tabular}




\begin{tabular}{|c|c|c|c|c|c|}
\hline $\begin{array}{l}\text { Sorszám / } \\
\text { Number }\end{array}$ & Taxon-név / Taxon-name & $\begin{array}{l}\text { Település / } \\
\text { Settlement }\end{array}$ & $\begin{array}{l}\text { Év / } \\
\text { Year }\end{array}$ & $\begin{array}{l}\text { Gyűjtő / } \\
\text { Collector }\end{array}$ & Fájlnév / File-name \\
\hline 1905 & Achillea pannonica Scheele & Debrecen & 1980 & Siroki Zoltán & DE-siroki-16768.jpg \\
\hline 1905 & Achillea pannonica Scheele & Debrecen & 1980 & Siroki Zoltán & DE-siroki-16769.jpg \\
\hline 1905 & Achillea pannonica Scheele & Debrecen & 1980 & Siroki Zoltán & DE-siroki-16770.jpg \\
\hline 1905 & Achillea pannonica Scheele & Debrecen & 1980 & Siroki Zoltán & DE-siroki-16772.jpg \\
\hline 1905 & Achillea pannonica Scheele & Debrecen & 1980 & Siroki Zoltán & DE-siroki-16773.jpg \\
\hline 1905 & Achillea pannonica Scheele & Debrecen & 1980 & Siroki Zoltán & DE-siroki-16774.jpg \\
\hline 1907 & Achillea millefolium L. & "Bükk-hg." & 1983 & Siroki Zoltán & DE-siroki-16783.jpg \\
\hline 1907 & Achillea millefolium L. & Aszaló & 1944 & Siroki Zoltán & DE-siroki-16793.jpg \\
\hline 1907 & Achillea millefolium L. & Boldogkőváralja & 1944 & Siroki Zoltán & DE-siroki-16796.jpg \\
\hline 1907 & Achillea millefolium L. & Budapest & 1887 & Czakó Kálmán & DE-siroki-16728.jpg \\
\hline 1907 & Achillea millefolium L. & Budapest & 1887 & Czakó Kálmán & DE-siroki-16729.jpg \\
\hline 1907 & Achillea millefolium L. & Budapest & 1889 & Czakó Kálmán & DE-siroki-16730.jpg \\
\hline 1907 & Achillea millefolium L. & Debrecen & 1947 & Siroki Zoltán & DE-siroki-16792.jpg \\
\hline 1907 & Achillea millefolium L. & Debrecen & 1947 & Siroki Zoltán & DE-siroki-16789.jpg \\
\hline 1907 & Achillea millefolium L. & Debrecen & 1948 & Siroki Zoltán & DE-siroki-16788.jpg \\
\hline 1907 & Achillea millefolium L. & Debrecen & 1957 & Siroki Zoltán & DE-siroki-16794.jpg \\
\hline 1907 & Achillea millefolium L. & Pomáz & 1957 & Siroki Zoltán & DE-siroki-16784.jpg \\
\hline 1907 & Achillea millefolium L. & Pomáz & 1957 & Siroki Zoltán & DE-siroki-16785.jpg \\
\hline 1907 & Achillea millefolium L. & Szinpetri & 1974 & Siroki Zoltán & DE-siroki-16780.jpg \\
\hline 1907 & Achillea millefolium L. & Szinpetri & 1974 & Siroki Zoltán & DE-siroki-16781.jpg \\
\hline 1907 & Achillea millefolium L. & Szinpetri & 1974 & Siroki Zoltán & DE-siroki-16782.jpg \\
\hline 1907 & Achillea millefolium L. & Tokaj & 1971 & Siroki Zoltán & DE-siroki-16786.jpg \\
\hline 1907 & Achillea millefolium L. & Tokaj & 1971 & Siroki Zoltán & DE-siroki-16787.jpg \\
\hline $1903+1907$ & $\begin{array}{l}\text { Achillea setacea Waldst. et Kit. - } \\
\text { Achillea millefolium L. }\end{array}$ & Abaújkér & 1942 & Siroki Zoltán & DE-siroki-16756.jpg \\
\hline 1911 & Matricaria recutita L. & Debrecen & 1947 & Siroki Zoltán & DE-siroki-16801.jpg \\
\hline 1911 & Matricaria recutita L. & Debrecen & 1947 & Siroki Zoltán & DE-siroki-16800.jpg \\
\hline 1911 & Matricaria recutita L. & Hortobágy & 1954 & Siroki Zoltán & DE-siroki-16806.jpg \\
\hline 1911 & Matricaria recutita $\mathrm{L}$. & Hortobágy & 1959 & Siroki Zoltán & DE-siroki-16803.jpg \\
\hline 1911 & Matricaria recutita L. & Hortobágy & 1959 & Siroki Zoltán & DE-siroki-16802.jpg \\
\hline 1911 & Matricaria recutita $\mathrm{L}$. & Hortobágy & 1959 & Siroki Zoltán & DE-siroki-16804.jpg \\
\hline 1911 & Matricaria recutita L. & Hortobágy & 1959 & Siroki Zoltán & DE-siroki-16805.jpg \\
\hline 1912 & Matricaria discoidea DC. & Debrecen & 1960 & Siroki Zoltán & DE-siroki-16797.jpg \\
\hline 1912 & Matricaria discoidea DC. & Mosonmagyaróvár & 1939 & Siroki Zoltán & DE-siroki-16798.jpg \\
\hline 1913 & Tanacetum vulgare L. & Egyek & 1947 & Siroki Zoltán & DE-siroki-16810.jpg \\
\hline 1913 & Tanacetum vulgare $\mathrm{L}$. & Mosonmagyaróvár & 1939 & Siroki Zoltán & DE-siroki-16811.jpg \\
\hline 1914 & Tanacetum corymbosum (L.) Sch. Bip. & "Dobogókő" & 1957 & Siroki Zoltán & DE-siroki-16823.jpg \\
\hline 1914 & Tanacetum corymbosum (L.) Sch. Bip. & "Dobogókő" & 1957 & Siroki Zoltán & DE-siroki-16824.jpg \\
\hline 1914 & Tanacetum corymbosum (L.) Sch. Bip. & "Nagymező" & 1959 & Siroki Zoltán & DE-siroki-16822.jpg \\
\hline 1914 & Tanacetum corymbosum (L.) Sch. Bip. & Gödöllő & 1952 & Siroki Zoltán & DE-siroki-16826.jpg \\
\hline 1914 & Tanacetum corymbosum (L.) Sch. Bip. & Szilvásvárad & 1954 & Siroki Zoltán & DE-siroki-16825.jpg \\
\hline 1914 & Tanacetum corymbosum (L.) Sch. Bip. & Szilvásvárad & 1960 & Siroki Zoltán & DE-siroki-16821.jpg \\
\hline 1916 & Leucanthemella serotina (L.) Tzvelev & Debrecen & 1953 & Siroki Zoltán & DE-siroki-16835.jpg \\
\hline 1916 & Leucanthemella serotina (L.) Tzvelev & Tiszacsege & 1963 & Siroki Zoltán & DE-siroki-16836.jpg \\
\hline 1916 & Leucanthemella serotina (L.) Tzvelev & Tiszacsege & 1963 & Siroki Zoltán & DE-siroki-16838.jpg \\
\hline 1916 & Leucanthemella serotina (L.) Tzvelev & Tiszacsege & 1963 & Siroki Zoltán & DE-siroki-16839.jpg \\
\hline 1916 & Leucanthemella serotina (L.) Tzvelev & Tiszacsege & 1963 & Siroki Zoltán & DE-siroki-16840.jpg \\
\hline
\end{tabular}




\begin{tabular}{|c|c|c|c|c|c|}
\hline $\begin{array}{l}\text { Sorszám / } \\
\text { Number }\end{array}$ & Taxon-név / Taxon-name & $\begin{array}{l}\text { Település / } \\
\text { Settlement }\end{array}$ & $\begin{array}{l}\text { Év / } \\
\text { Year }\end{array}$ & $\begin{array}{l}\text { Gyűjtő / } \\
\text { Collector }\end{array}$ & Fájlnév / File-name \\
\hline 1916 & Leucanthemella serotina (L.) Tzvelev & Tiszafüred & 1970 & Siroki Zoltán & DE-siroki-16834.jpg \\
\hline 1916 & Leucanthemella serotina (L.) Tzvelev & Tiszakeszi & 1963 & Siroki Zoltán & DE-siroki-16837.jpg \\
\hline 1916 & Leucanthemella serotina (L.) Tzvelev & Tiszakeszi & 1963 & Siroki Zoltán & DE-siroki-16841.jpg \\
\hline 1916 & Leucanthemella serotina (L.) Tzvelev & Tiszakeszi & 1963 & Siroki Zoltán & DE-siroki-16842.jpg \\
\hline 1916 & Leucanthemella serotina (L.) Tzvelev & Tiszakeszi & 1963 & Siroki Zoltán & DE-siroki-16843.jpg \\
\hline 1916 & Leucanthemella serotina (L.) Tzvelev & Tiszakeszi & 1963 & Siroki Zoltán & DE-siroki-16844.jpg \\
\hline 1916 & Leucanthemella serotina (L.) Tzvelev & Tiszakeszi & 1963 & Siroki Zoltán & DE-siroki-16845.jpg \\
\hline 1916 & Leucanthemella serotina (L.) Tzvelev & Tiszakeszi & 1963 & Siroki Zoltán & DE-siroki-16846.jpg \\
\hline 1916 & Leucanthemella serotina (L.) Tzvelev & Tiszakeszi & 1963 & Siroki Zoltán & DE-siroki-16847.jpg \\
\hline 1916 & Leucanthemella serotina (L.) Tzvelev & Tiszakeszi & 1963 & Siroki Zoltán & DE-siroki-16848.jpg \\
\hline 1916 & Leucanthemella serotina (L.) Tzvelev & Tiszakeszi & 1963 & Siroki Zoltán & DE-siroki-16849.jpg \\
\hline 1918 & Leucanthemum vulgare Lam. & $\begin{array}{l}\text { "Bükk-hg, } \\
\text { Kiskerekhegy" }\end{array}$ & 1959 & Halász Tibor & DE-siroki-16854.jpg \\
\hline 1918 & Leucanthemum vulgare Lam. & "Nagymező" & 1956 & Halász Tibor & DE-siroki-16860.jpg \\
\hline 1918 & Leucanthemum vulgare Lam. & "Nagymező" & 1959 & Siroki Zoltán & DE-siroki-16862.jpg \\
\hline 1918 & Leucanthemum vulgare Lam. & Debrecen & 1948 & Siroki Zoltán & DE-siroki-16859.jpg \\
\hline 1918 & Leucanthemum vulgare Lam. & Debrecen & 1954 & Siroki Zoltán & DE-siroki-16861.jpg \\
\hline 1918 & Leucanthemum vulgare Lam. & Egyek & 1949 & Siroki Zoltán & DE-siroki-16857.jpg \\
\hline 1918 & Leucanthemum vulgare Lam. & Egyek & 1949 & Siroki Zoltán & DE-siroki-16858.jpg \\
\hline 1918 & Leucanthemum vulgare Lam. & Háromhuta & 1967 & Siroki Zoltán & DE-siroki-16863.jpg \\
\hline 1918 & Leucanthemum vulgare Lam. & Mosonmagyaróvár & 1939 & Siroki Zoltán & DE-siroki-16856.jpg \\
\hline 1922 & Artemisia annua L. & Debrecen & 1954 & Siroki Zoltán & DE-siroki-16934.jpg \\
\hline 1922 & Artemisia annua L. & Debrecen & 1954 & Siroki Zoltán & DE-siroki-16935.jpg \\
\hline 1922 & Artemisia annua L. & Keszthely & 1955 & Siroki Zoltán & DE-siroki-16936.jpg \\
\hline 1922 & Artemisia annua L. & Keszthely & 1955 & Siroki Zoltán & DE-siroki-16937.jpg \\
\hline 1923 & Artemisia santonicum L. & Abaújkér & 1943 & Siroki Zoltán & DE-siroki-16877.jpg \\
\hline 1923 & Artemisia santonicum L. & Abaújkér & 1943 & Siroki Zoltán & DE-siroki-16878.jpg \\
\hline 1923 & Artemisia santonicum L. & Aszaló & 1944 & Siroki Zoltán & DE-siroki-16876.jpg \\
\hline 1923 & Artemisia santonicum L. & Aszaló & 1944 & Siroki Zoltán & DE-siroki-16879.jpg \\
\hline 1923 & Artemisia santonicum L. & Dévaványa & 1962 & Siroki Zoltán & DE-siroki-16868.jpg \\
\hline 1923 & Artemisia santonicum L. & Dévaványa & 1962 & Siroki Zoltán & DE-siroki-16869.jpg \\
\hline 1923 & Artemisia santonicum L. & Dévaványa & 1962 & Siroki Zoltán & DE-siroki-16870.jpg \\
\hline 1923 & Artemisia santonicum L. & Dévaványa & 1962 & Siroki Zoltán & DE-siroki-16871.jpg \\
\hline 1923 & Artemisia santonicum L. & Dévaványa & 1962 & Siroki Zoltán & DE-siroki-16872.jpg \\
\hline 1923 & Artemisia santonicum L. & Dévaványa & 1962 & Siroki Zoltán & DE-siroki-16873.jpg \\
\hline 1923 & Artemisia santonicum L. & Egyek & 1947 & Siroki Zoltán & DE-siroki-16865.jpg \\
\hline 1923 & Artemisia santonicum L. & Egyek & 1947 & Siroki Zoltán & DE-siroki-16866.jpg \\
\hline 1923 & Artemisia santonicum L. & Hortobágy & 1948 & Siroki Zoltán & DE-siroki-16867.jpg \\
\hline 1923 & Artemisia santonicum L. & Kecskemét & 1969 & Siroki Zoltán & DE-siroki-16874.jpg \\
\hline 1923 & Artemisia santonicum L. & Kecskemét & 1969 & Siroki Zoltán & DE-siroki-16875.jpg \\
\hline 1924 & Artemisia campestris L. & Ágasegyháza & 1969 & Siroki Zoltán & DE-siroki-16903.jpg \\
\hline 1924 & Artemisia campestris L. & Boldogkőváralja & 1944 & Siroki Zoltán & DE-siroki-16896.jpg \\
\hline 1924 & Artemisia campestris L. & Boldogkőváralja & 1944 & Siroki Zoltán & DE-siroki-16895.jpg \\
\hline 1924 & Artemisia campestris L. & Budapest & 1957 & Siroki Zoltán & DE-siroki-16901.jpg \\
\hline 1924 & Artemisia campestris L. & Budapest & 1957 & Siroki Zoltán & DE-siroki-16902.jpg \\
\hline 1924 & Artemisia campestris L. & Debrecen & 1947 & Siroki Zoltán & DE-siroki-16900.jpg \\
\hline 1924 & Artemisia campestris L. & Hajdúbagos & 1981 & Siroki Zoltán & DE-siroki-16894.jpg \\
\hline
\end{tabular}




\begin{tabular}{|c|c|c|c|c|c|}
\hline $\begin{array}{l}\text { Sorszám / } \\
\text { Number }\end{array}$ & Taxon-név / Taxon-name & $\begin{array}{l}\text { Település / } \\
\text { Settlement }\end{array}$ & $\begin{array}{l}\text { Év / } \\
\text { Year }\end{array}$ & $\begin{array}{l}\text { Gyűjtő / } \\
\text { Collector }\end{array}$ & Fájlnév / File-name \\
\hline 1924 & Artemisia campestris L. & Sáránd & 1987 & Siroki Zoltán & DE-siroki-16892.jpg \\
\hline 1924 & Artemisia campestris L. & Sáránd & 1987 & Siroki Zoltán & DE-siroki-16893.jpg \\
\hline 1924 & Artemisia campestris L. & Sátoraljaújhely & 1944 & Siroki Zoltán & DE-siroki-16897.jpg \\
\hline 1924 & Artemisia campestris L. & Sátoraljaújhely & 1944 & Siroki Zoltán & DE-siroki-16898.jpg \\
\hline 1927 & Artemisia vulgaris L. & Mosonmagyaróvár & 1939 & Siroki Zoltán & DE-siroki-16890.jpg \\
\hline 1928 & Artemisia alba Turra & Iszkaszentgyörgy & 1923 & $\begin{array}{l}\text { Moesz Gusztáv - } \\
\text { Timkó György }\end{array}$ & DE-siroki-16930.jpg \\
\hline 1928 & Artemisia alba Turra & Pécs & 1958 & Siroki Zoltán & DE-siroki-16927.jpg \\
\hline 1928 & Artemisia alba Turra & Pécs & 1958 & Siroki Zoltán & DE-siroki-16928.jpg \\
\hline 1928 & Artemisia alba Turra & Pécs & 1958 & Siroki Zoltán & DE-siroki-16929.jpg \\
\hline 1928 & Artemisia alba Turra & Pécs & 1958 & Siroki Zoltán & DE-siroki-16931.jpg \\
\hline 1929 & Artemisia pontica L. & Debrecen & 1947 & Siroki Zoltán & DE-siroki-16922.jpg \\
\hline 1929 & Artemisia pontica L. & Dévaványa & 1962 & Siroki Zoltán & DE-siroki-16917.jpg \\
\hline 1929 & Artemisia pontica L. & Dévaványa & 1962 & Siroki Zoltán & DE-siroki-16918.jpg \\
\hline 1929 & Artemisia pontica L. & Dévaványa & 1962 & Siroki Zoltán & DE-siroki-16919.jpg \\
\hline 1929 & Artemisia pontica L. & Egerbakta & 1968 & Siroki Zoltán & DE-siroki-16920.jpg \\
\hline 1929 & Artemisia pontica L. & Egerbakta & 1968 & Siroki Zoltán & DE-siroki-16921.jpg \\
\hline 1929 & Artemisia pontica L. & Hortobágy & 1948 & Siroki Zoltán & DE-siroki-16923.jpg \\
\hline 1929 & Artemisia pontica L. & Hortobágy & 1986 & Siroki Zoltán & DE-siroki-16915.jpg \\
\hline 1929 & Artemisia pontica L. & Hortobágy & 1986 & Siroki Zoltán & DE-siroki-16916.jpg \\
\hline 1929 & Artemisia pontica L. & Mosonmagyaróvár & 1939 & Siroki Zoltán & DE-siroki-16924.jpg \\
\hline 1929 & Artemisia pontica L. & Pomáz & 1909 & Kocsis István & DE-siroki-16914.jpg \\
\hline 1930 & Artemisia austriaca Jacq. & Debrecen & 1947 & Siroki Zoltán & DE-siroki-16912.jpg \\
\hline 1930 & Artemisia austriaca Jacq. & Debrecen & 1947 & Siroki Zoltán & DE-siroki-16913.jpg \\
\hline 1930 & Artemisia austriaca Jacq. & Debrecen & 1954 & Siroki Zoltán & DE-siroki-16904.jpg \\
\hline 1930 & Artemisia austriaca Jacq. & Debrecen & 1954 & Siroki Zoltán & DE-siroki-16905.jpg \\
\hline 1930 & Artemisia austriaca Jacq. & Nagykőrös & 1913 & Degen Árpád & DE-siroki-16908.jpg \\
\hline 1930 & Artemisia austriaca Jacq. & Nagykőrös & 1916 & Magyar & DE-siroki-16906.jpg \\
\hline 1930 & Artemisia austriaca Jacq. & Nagykőrös & 1916 & Magyar & DE-siroki-16910.jpg \\
\hline 1930 & Artemisia austriaca Jacq. & Nagykőrös & 1916 & Magyar & DE-siroki-16911.jpg \\
\hline 1930 & Artemisia austriaca Jacq. & Tihany & 1894 & Borbás Vince & DE-siroki-16909.jpg \\
\hline 1931 & Tussilago farfara L. & Budapest & 1955 & Siroki Zoltán & DE-siroki-16944.jpg \\
\hline 1931 & Tussilago farfara L. & Debrecen & 1944 & Siroki Zoltán & DE-siroki-16938.jpg \\
\hline 1931 & Tussilago farfara L. & Debrecen & 1950 & Siroki Zoltán & DE-siroki-16941.jpg \\
\hline 1931 & Tussilago farfara L. & Debrecen & 1950 & Siroki Zoltán & DE-siroki-16941.jpg \\
\hline 1931 & Tussilago farfara L. & Debrecen & 1950 & Siroki Zoltán & DE-siroki-16942.jpg \\
\hline 1931 & Tussilago farfara L. & Debrecen & 1950 & Siroki Zoltán & DE-siroki-16942.jpg \\
\hline 1931 & Tussilago farfara L. & Debrecen & 1954 & Siroki Zoltán & DE-siroki-16943.jpg \\
\hline 1931 & Tussilago farfara L. & Mosonmagyaróvár & 1939 & Siroki Zoltán & DE-siroki-16939.jpg \\
\hline 1931 & Tussilago farfara L. & Szilvásvárad & 1985 & Siroki Zoltán & DE-siroki-16945.jpg \\
\hline 1932 & Petasites albus (L.) Gaertn. & Nagyvisnyó & 1966 & Siroki Zoltán & DE-siroki-16959.jpg \\
\hline 1932 & Petasites albus (L.) Gaertn. & Nagyvisnyó & 1966 & Siroki Zoltán & DE-siroki-16960.jpg \\
\hline 1932 & Petasites albus (L.) Gaertn. & Nagyvisnyó & 1966 & Siroki Zoltán & DE-siroki-16961.jpg \\
\hline 1932 & Petasites albus (L.) Gaertn. & Nagyvisnyó & 1966 & Siroki Zoltán & DE-siroki-16962.jpg \\
\hline 1932 & Petasites albus (L.) Gaertn. & Nagyvisnyó & 1966 & Siroki Zoltán & DE-siroki-16963.jpg \\
\hline 1933 & $\begin{array}{l}\text { Petasites hybridus } \\
\text { (L.) G. Gaertn., B. Mey. et Scherb. }\end{array}$ & Miskolc & 1957 & Pethő Menyhért & DE-siroki-16950.jpg \\
\hline
\end{tabular}




\begin{tabular}{|c|c|c|c|c|c|}
\hline $\begin{array}{l}\text { Sorszám / } \\
\text { Number }\end{array}$ & Taxon-név / Taxon-name & $\begin{array}{l}\text { Település / } \\
\text { Settlement }\end{array}$ & $\begin{array}{l}\text { Év / } \\
\text { Year }\end{array}$ & $\begin{array}{l}\text { Gyüjtő / } \\
\text { Collector }\end{array}$ & Fájlnév / File-name \\
\hline 1933 & $\begin{array}{l}\text { Petasites hybridus } \\
\text { (L.) G. Gaertn., B. Mey. et Scherb. }\end{array}$ & Pilismarót & 1957 & Siroki Zoltán & DE-siroki-16949.jpg \\
\hline 1933 & $\begin{array}{l}\text { Petasites hybridus } \\
\text { (L.) G. Gaertn., B. Mey. et Scherb. }\end{array}$ & Pilismarót & 1957 & Siroki Zoltán & DE-siroki-16957.jpg \\
\hline 1933 & $\begin{array}{l}\text { Petasites hybridus } \\
\text { (L.) G. Gaertn., B. Mey. et Scherb. }\end{array}$ & Szilvásvárad & 1966 & Siroki Zoltán & DE-siroki-16946.jpg \\
\hline 1933 & $\begin{array}{l}\text { Petasites hybridus } \\
\text { (L.) G. Gaertn., B. Mey. et Scherb. }\end{array}$ & Szilvásvárad & 1966 & Siroki Zoltán & DE-siroki-16947.jpg \\
\hline 1933 & $\begin{array}{l}\text { Petasites hybridus } \\
\text { (L.) G. Gaertn., B. Mey. et Scherb. }\end{array}$ & Szilvásvárad & 1966 & Siroki Zoltán & DE-siroki-16948.jpg \\
\hline 1933 & $\begin{array}{l}\text { Petasites hybridus } \\
\text { (L.) G. Gaertn., B. Mey. et Scherb. }\end{array}$ & Veresegyház & 1952 & Petrányi I. & DE-siroki-16953.jpg \\
\hline 1934 & Arnica montana L. & Ágfalva & 1950 & Kárpáti Zoltán & DE-siroki-16984.jpg \\
\hline 1935 & Doronicum hungaricum (Sadler) Rchb. & "Fáni-völgy" & 1955 & $\begin{array}{l}\text { Siroki Zoltán - } \\
\text { Farkas Attila }\end{array}$ & DE-siroki-16997.jpg \\
\hline 1935 & Doronicum hungaricum (Sadler) Rchb. & "Fáni-völgy" & 1955 & $\begin{array}{l}\text { Siroki Zoltán - } \\
\text { Farkas Attila }\end{array}$ & DE-siroki-16998.jpg \\
\hline 1935 & Doronicum hungaricum (Sadler) Rchb. & "Fáni-völgy" & 1955 & $\begin{array}{l}\text { Siroki Zoltán - } \\
\text { Farkas Attila }\end{array}$ & DE-siroki-16999.jpg \\
\hline 1935 & Doronicum hungaricum (Sadler) Rchb. & Budapest & 1951 & Siroki Zoltán & DE-siroki-17000.jpg \\
\hline 1935 & Doronicum hungaricum (Sadler) Rchb. & Budapest & 1951 & Siroki Zoltán & DE-siroki-17001.jpg \\
\hline 1935 & Doronicum hungaricum (Sadler) Rchb. & Budapest & 1962 & Siroki Zoltán & DE-siroki-16996.jpg \\
\hline 1935 & Doronicum hungaricum (Sadler) Rchb. & Pécs & 1958 & Siroki Zoltán & DE-siroki-17003.jpg \\
\hline 1935 & Doronicum hungaricum (Sadler) Rchb. & Pécs & 1958 & Siroki Zoltán & DE-siroki-17002.jpg \\
\hline 1937 & Doronicum orientale Hoffm. & Pécs & 1951 & Kárpáti Zoltán & DE-siroki-17484.jpg \\
\hline 1938 & Erechtites hieracifolia (L.) Raf. ex DC. & Csaroda & 1954 & Siroki Zoltán & DE-siroki-16980.jpg \\
\hline 1938 & Erechtites hieracifolia (L.) Raf. ex DC. & Háromhuta & 1960 & Siroki Zoltán & DE-siroki-16977.jpg \\
\hline 1938 & Erechtites hieracifolia (L.) Raf. ex DC. & Kishuta & 1954 & Simon Tiborné & DE-siroki-16974.jpg \\
\hline 1938 & Erechtites hieracifolia (L.) Raf. ex DC. & Sopron & 1956 & Kovács Béla & DE-siroki-16978.jpg \\
\hline 1938 & Erechtites hieracifolia (L.) Raf. ex DC. & Sopron & 1956 & Siroki Zoltán & DE-siroki-16979.jpg \\
\hline 1941 & Tephroseris integrifolia (L.) Holub & "Nagymező" & 1959 & Halász Tibor & DE-siroki-17493.jpg \\
\hline 1941 & Tephroseris integrifolia (L.) Holub & Abaújszántó & 1944 & Siroki Zoltán & DE-siroki-17503.jpg \\
\hline 1941 & Tephroseris integrifolia (L.) Holub & Abaújszántó & 1944 & Siroki Zoltán & DE-siroki-17497.jpg \\
\hline 1941 & Tephroseris integrifolia (L.) Holub & Debrecen & 1950 & Kovács Béla & DE-siroki-17501.jpg \\
\hline 1941 & Tephroseris integrifolia (L.) Holub & Debrecen & 1950 & Siroki Zoltán & DE-siroki-17499.jpg \\
\hline 1941 & Tephroseris integrifolia (L.) Holub & Debrecen & 1950 & Siroki Zoltán & DE-siroki-17498.jpg \\
\hline 1941 & Tephroseris integrifolia (L.) Holub & Debrecen & 1954 & Kovács Béla & DE-siroki-17505.jpg \\
\hline 1941 & Tephroseris integrifolia (L.) Holub & Debrecen & 1954 & Siroki Zoltán & DE-siroki-17495.jpg \\
\hline 1941 & Tephroseris integrifolia (L.) Holub & Debrecen & 1954 & Siroki Zoltán & DE-siroki-17496.jpg \\
\hline 1941 & Tephroseris integrifolia (L.) Holub & Debrecen & 1954 & Siroki Zoltán & DE-siroki-17500.jpg \\
\hline 1941 & Tephroseris integrifolia (L.) Holub & Füzérradvány & 1973 & Siroki Zoltán & DE-siroki-17506.jpg \\
\hline 1941 & Tephroseris integrifolia (L.) Holub & Gödöllő & 1953 & Máthé Imre & DE-siroki-17507.jpg \\
\hline 1941 & Tephroseris integrifolia (L.) Holub & Nagykovácsi & 1959 & Siroki Zoltán & DE-siroki-17494.jpg \\
\hline 1941 & Tephroseris integrifolia (L.) Holub & Pécs & 1951 & Kárpáti Zoltán & DE-siroki-17492.jpg \\
\hline 1941 & Tephroseris integrifolia (L.) Holub & Pilisszentiván & 1952 & Siroki Zoltán & DE-siroki-17504.jpg \\
\hline 1942 & $\begin{array}{l}\text { Tephroseris aurantiaca } \\
\text { (Willd.) Griseb. et Schenk }\end{array}$ & Ágfalva & 1950 & Kárpáti Zoltán & DE-siroki-17509.jpg \\
\hline 1943 & Senecio vulgaris L. & Debrecen & 1957 & Siroki Zoltán & DE-siroki-17517.jpg \\
\hline 1943 & Senecio vulgaris L. & Debrecen & 1957 & Siroki Zoltán & DE-siroki-17518.jpg \\
\hline 1943 & Senecio vulgaris L. & Mosonmagyaróvár & 1949 & Siroki Zoltán & DE-siroki-17519.jpg \\
\hline 1944 & Senecio sylvaticus L. & Háromhuta & 1978 & Siroki Zoltán & DE-siroki-17521.jpg \\
\hline 1944 & Senecio sylvaticus L. & Háromhuta & 1978 & Siroki Zoltán & DE-siroki-17522.jpg \\
\hline
\end{tabular}




\begin{tabular}{|c|c|c|c|c|c|}
\hline $\begin{array}{l}\text { Sorszám / } \\
\text { Number }\end{array}$ & Taxon-név / Taxon-name & $\begin{array}{l}\text { Település / } \\
\text { Settlement }\end{array}$ & $\begin{array}{l}\text { Év / } \\
\text { Year }\end{array}$ & $\begin{array}{l}\text { Gyűjtő / } \\
\text { Collector }\end{array}$ & Fájlnév / File-name \\
\hline 1944 & Senecio sylvaticus L. & Háromhuta & 1978 & Siroki Zoltán & DE-siroki-17523.jpg \\
\hline 1944 & Senecio sylvaticus L. & Háromhuta & 1978 & Siroki Zoltán & DE-siroki-17004.jpg \\
\hline 1944 & Senecio sylvaticus L. & Pásztó & 1952 & Siroki Zoltán & DE-siroki-17005.jpg \\
\hline 1945 & Senecio viscosus L. & Budapest & 1951 & Siroki Zoltán & DE-siroki-17011.jpg \\
\hline 1945 & Senecio viscosus $\mathrm{L}$. & Budapest & 1951 & Siroki Zoltán & DE-siroki-17010.jpg \\
\hline 1945 & Senecio viscosus L. & Háromhuta & 1978 & Siroki Zoltán & DE-siroki-17007.jpg \\
\hline 1945 & Senecio viscosus L. & Háromhuta & 1978 & Siroki Zoltán & DE-siroki-17008.jpg \\
\hline 1945 & Senecio viscosus $\mathrm{L}$. & Háromhuta & 1978 & Siroki Zoltán & DE-siroki-17009.jpg \\
\hline 1945 & Senecio viscosus L. & Sopron & 1956 & Kovács Béla & DE-siroki-17012.jpg \\
\hline 1946 & Senecio vernalis Waldst. et Kit. & Debrecen & 1947 & Siroki Zoltán & DE-siroki-17027.jpg \\
\hline 1946 & Senecio vernalis Waldst. et Kit. & Debrecen & 1959 & Siroki Zoltán & DE-siroki-17028.jpg \\
\hline 1946 & Senecio vernalis Waldst. et Kit. & Debrecen & 1959 & Siroki Zoltán & DE-siroki-17030.jpg \\
\hline 1946 & Senecio vernalis Waldst. et Kit. & Debrecen & 1959 & Siroki Zoltán & DE-siroki-17031.jpg \\
\hline 1946 & Senecio vernalis Waldst. et Kit. & Debrecen & 1968 & Siroki Zoltán & DE-siroki-17023.jpg \\
\hline 1946 & Senecio vernalis Waldst. et Kit. & Debrecen & 1968 & Siroki Zoltán & DE-siroki-17024.jpg \\
\hline 1946 & Senecio vernalis Waldst. et Kit. & Debrecen & 1968 & Siroki Zoltán & DE-siroki-17025.jpg \\
\hline 1946 & Senecio vernalis Waldst. et Kit. & Debrecen & 1968 & Siroki Zoltán & DE-siroki-17026.jpg \\
\hline 1946 & Senecio vernalis Waldst. et Kit. & Debrecen & 1977 & Siroki Zoltán & DE-siroki-17032.jpg \\
\hline 1946 & Senecio vernalis Waldst. et Kit. & Debrecen & 1977 & Siroki Zoltán & DE-siroki-17033.jpg \\
\hline 1946 & Senecio vernalis Waldst. et Kit. & Debrecen & 1977 & Siroki Zoltán & DE-siroki-17034.jpg \\
\hline 1946 & Senecio vernalis Waldst. et Kit. & Debrecen & 1977 & Siroki Zoltán & DE-siroki-17035.jpg \\
\hline 1946 & Senecio vernalis Waldst. et Kit. & Kékcse & 1967 & Gondola István & DE-siroki-17029.jpg \\
\hline 1948 & Senecio erucifolius L. & Debrecen & 1946 & Siroki Zoltán & DE-siroki-17047.jpg \\
\hline 1948 & Senecio erucifolius L. & Debrecen & 1946 & Siroki Zoltán & DE-siroki-17048.jpg \\
\hline 1948 & Senecio erucifolius L. & Debrecen & 1946 & Siroki Zoltán & DE-siroki-17049.jpg \\
\hline 1948 & Senecio erucifolius L. & Debrecen & 1946 & Siroki Zoltán & DE-siroki-17045.jpg \\
\hline 1948 & Senecio erucifolius L. & Debrecen & 1946 & Siroki Zoltán & DE-siroki-17046.jpg \\
\hline 1948 & Senecio erucifolius L. & Debrecen & 1947 & Siroki Zoltán & DE-siroki-17044.jpg \\
\hline 1948 & Senecio erucifolius L. & Debrecen & 1977 & Siroki Zoltán & DE-siroki-17050.jpg \\
\hline 1948 & Senecio erucifolius L. & Hajdúböszörmény & 1966 & Siroki Zoltán & DE-siroki-17042.jpg \\
\hline 1948 & Senecio erucifolius L. & Hajdúböszörmény & 1966 & Siroki Zoltán & DE-siroki-17043.jpg \\
\hline 1948 & Senecio erucifolius L. & Mikepércs & 1962 & Siroki Zoltán & DE-siroki-17040.jpg \\
\hline 1948 & Senecio erucifolius L. & Mikepércs & 1962 & Siroki Zoltán & DE-siroki-17041.jpg \\
\hline 1948 & Senecio erucifolius L. & Mikepércs & 1972 & Siroki Zoltán & DE-siroki-17038.jpg \\
\hline 1948 & Senecio erucifolius L. & Tokaj & 1971 & Siroki Zoltán & DE-siroki-17039.jpg \\
\hline 1949 & Senecio jacobaea L. & Háromhuta & 1960 & Siroki Zoltán & DE-siroki-17059.jpg \\
\hline 1949 & Senecio jacobaea L. & Tokaj & 1966 & Siroki Zoltán & DE-siroki-17057.jpg \\
\hline 1949 & Senecio jacobaea L. & Tokaj & 1966 & Siroki Zoltán & DE-siroki-17058.jpg \\
\hline 1951 & Senecio erraticus Bertol. & Debrecen & 1947 & Siroki Zoltán & DE-siroki-17062.jpg \\
\hline 1951 & Senecio erraticus Bertol. & Hencida & 1983 & Siroki Zoltán & DE-siroki-17061.jpg \\
\hline 1951 & Senecio erraticus Bertol. & Mosonmagyaróvár & 1939 & Siroki Zoltán & DE-siroki-17063.jpg \\
\hline 1953 & Senecio paludosus L. & Kecskemét & 1954 & Siroki Zoltán & DE-siroki-17106.jpg \\
\hline 1953 & Senecio paludosus L. & Kecskemét & 1954 & Siroki Zoltán & DE-siroki-17107.jpg \\
\hline 1953 & Senecio paludosus L. & Tiszafüred & 1968 & Siroki Zoltán & DE-siroki-17109.jpg \\
\hline 1953 & Senecio paludosus L. & Tiszafüred & 1968 & Siroki Zoltán & DE-siroki-17110.jpg \\
\hline 1953 & Senecio paludosus L. & Tiszafüred & 1968 & Siroki Zoltán & DE-siroki-17111.jpg \\
\hline
\end{tabular}




\begin{tabular}{|c|c|c|c|c|c|}
\hline $\begin{array}{l}\text { Sorszám / } \\
\text { Number }\end{array}$ & Taxon-név / Taxon-name & $\begin{array}{l}\text { Település / } \\
\text { Settlement }\end{array}$ & $\begin{array}{l}\text { Év / } \\
\text { Year }\end{array}$ & $\begin{array}{l}\text { Gyűjtő / } \\
\text { Collector }\end{array}$ & Fájlnév / File-name \\
\hline 1953 & Senecio paludosus L. & Tiszafüred & 1968 & Siroki Zoltán & DE-siroki-17112.jpg \\
\hline 1953 & Senecio paludosus L. & Tiszafüred & 1968 & Siroki Zoltán & DE-siroki-17113.jpg \\
\hline 1953 & Senecio paludosus L. & Tiszafüred & 1968 & Siroki Zoltán & DE-siroki-17114.jpg \\
\hline 1953 & Senecio paludosus L. & Tiszafüred & 1968 & Siroki Zoltán & DE-siroki-17115.jpg \\
\hline 1953 & Senecio paludosus L. & Tiszafüred & 1968 & Siroki Zoltán & DE-siroki-17116.jpg \\
\hline 1953 & Senecio paludosus L. & Tiszafüred & 1968 & Siroki Zoltán & DE-siroki-17117.jpg \\
\hline 1953 & Senecio paludosus L. & Tiszafüred & 1968 & Siroki Zoltán & DE-siroki-17118.jpg \\
\hline 1953 & Senecio paludosus L. & Tiszafüred & 1968 & Siroki Zoltán & DE-siroki-17108.jpg \\
\hline 1953 & Senecio paludosus L. & Tiszafüred & 1970 & Siroki Zoltán & DE-siroki-17105.jpg \\
\hline 1954 & Senecio sarracenicus L. & Szigetcsép & 1951 & Siroki Zoltán & DE-siroki-17066.jpg \\
\hline 1954 & Senecio sarracenicus L. & Szigetcsép & 1951 & Siroki Zoltán & DE-siroki-17067.jpg \\
\hline 1954 & Senecio sarracenicus L. & Szigetszentmiklós & 1951 & Siroki Zoltán & DE-siroki-17065.jpg \\
\hline 1955 & Senecio germanicus Wallr. & Háromhuta & 1960 & Siroki Zoltán & DE-siroki-17078.jpg \\
\hline 1955 & Senecio germanicus Wallr. & Háromhuta & 1978 & Siroki Zoltán & DE-siroki-17070.jpg \\
\hline 1955 & Senecio germanicus Wallr. & Háromhuta & 1978 & Siroki Zoltán & DE-siroki-17071.jpg \\
\hline 1955 & Senecio germanicus Wallr. & Miskolc & 1965 & Siroki Zoltán & DE-siroki-17072.jpg \\
\hline 1955 & Senecio germanicus Wallr. & Sopron & 1956 & Kovács Béla & DE-siroki-17084.jpg \\
\hline 1955 & Senecio germanicus Wallr. & Sopron & 1956 & Siroki Zoltán & DE-siroki-17080.jpg \\
\hline 1955 & Senecio germanicus Wallr. & Sopron & 1956 & Siroki Zoltán & DE-siroki-17073.jpg \\
\hline 1955 & Senecio germanicus Wallr. & Szilvásvárad & 1954 & Siroki Zoltán & DE-siroki-17074.jpg \\
\hline 1955 & Senecio germanicus Wallr. & Szilvásvárad & 1954 & Siroki Zoltán & DE-siroki-17075.jpg \\
\hline 1955 & Senecio germanicus Wallr. & Szilvásvárad & 1954 & Siroki Zoltán & DE-siroki-17076.jpg \\
\hline 1955 & Senecio germanicus Wallr. & Szilvásvárad & 1954 & Siroki Zoltán & DE-siroki-17077.jpg \\
\hline 1955 & Senecio germanicus Wallr. & Szilvásvárad & 1954 & Siroki Zoltán & DE-siroki-17079.jpg \\
\hline 1957 & Senecio doria Nath. & Debrecen & 1947 & Siroki Zoltán & DE-siroki-17093.jpg \\
\hline 1957 & Senecio doria Nath. & Debrecen & 1947 & Siroki Zoltán & DE-siroki-17097.jpg \\
\hline 1957 & Senecio doria Nath. & Debrecen & 1947 & Siroki Zoltán & DE-siroki-17098.jpg \\
\hline 1957 & Senecio doria Nath. & Debrecen & 1947 & Siroki Zoltán & DE-siroki-17087.jpg \\
\hline 1957 & Senecio doria Nath. & Debrecen & 1947 & Siroki Zoltán & DE-siroki-17088.jpg \\
\hline 1957 & Senecio doria Nath. & Debrecen & 1947 & Siroki Zoltán & DE-siroki-17089.jpg \\
\hline 1957 & Senecio doria Nath. & Debrecen & 1947 & Siroki Zoltán & DE-siroki-17099.jpg \\
\hline 1957 & Senecio doria Nath. & Debrecen & 1947 & Siroki Zoltán & DE-siroki-17100.jpg \\
\hline 1957 & Senecio doria Nath. & Debrecen & 1957 & Siroki Zoltán & DE-siroki-17090.jpg \\
\hline 1957 & Senecio doria Nath. & Debrecen & 1957 & Siroki Zoltán & DE-siroki-17091.jpg \\
\hline 1957 & Senecio doria Nath. & Debrecen & 1978 & Siroki Zoltán & DE-siroki-17094.jpg \\
\hline 1957 & Senecio doria Nath. & Debrecen & 1978 & Siroki Zoltán & DE-siroki-17095.jpg \\
\hline 1957 & Senecio doria Nath. & Debrecen & 1978 & Siroki Zoltán & DE-siroki-17096.jpg \\
\hline 1961 & Carlina acaulis L. & "Nagymező" & 1958 & Siroki Zoltán & DE-siroki-17181.jpg \\
\hline 1961 & Carlina acaulis L. & Komlóska & 1978 & $\begin{array}{l}\text { Pankucsi } \\
\text { Lászlóné }\end{array}$ & DE-siroki-17182.jpg \\
\hline 1961 & Carlina acaulis L. & Komlóska & 1978 & $\begin{array}{l}\text { Pankucsi } \\
\text { Lászlóné }\end{array}$ & DE-siroki-17183.jpg \\
\hline 1962 & Carlina vulgaris L. & Budapest & 1950 & Siroki Zoltán & DE-siroki-17169.jpg \\
\hline 1962 & Carlina vulgaris L. & Budapest & 1950 & Siroki Zoltán & DE-siroki-17170.jpg \\
\hline 1962 & Carlina vulgaris L. & Budapest & 1950 & Siroki Zoltán & DE-siroki-17171.jpg \\
\hline 1962 & Carlina vulgaris L. & Budapest & 1950 & Siroki Zoltán & DE-siroki-17172.jpg \\
\hline 1962 & Carlina vulgaris L. & Budapest & 1954 & Siroki Zoltán & DE-siroki-17168.jpg \\
\hline
\end{tabular}




\begin{tabular}{|c|c|c|c|c|c|}
\hline $\begin{array}{l}\text { Sorszám / } \\
\text { Number }\end{array}$ & Taxon-név / Taxon-name & $\begin{array}{l}\text { Település / } \\
\text { Settlement }\end{array}$ & $\begin{array}{l}\text { Év / } \\
\text { Year }\end{array}$ & $\begin{array}{l}\text { Gyűjtő / } \\
\text { Collector }\end{array}$ & Fájlnév / File-name \\
\hline 1962 & Carlina vulgaris L. & Egyek & 1947 & Siroki Zoltán & DE-siroki-17161.jpg \\
\hline 1962 & Carlina vulgaris L. & Egyek & 1947 & Siroki Zoltán & DE-siroki-17166.jpg \\
\hline 1962 & Carlina vulgaris L. & Egyek & 1947 & Siroki Zoltán & DE-siroki-17167.jpg \\
\hline 1962 & Carlina vulgaris L. & Nagykovácsi & 1957 & Siroki Zoltán & DE-siroki-17173.jpg \\
\hline 1962 & Carlina vulgaris L. & Püski & 1939 & Siroki Zoltán & DE-siroki-17160.jpg \\
\hline 1962 & Carlina vulgaris L. & Tokaj & 1971 & Siroki Zoltán & DE-siroki-17174.jpg \\
\hline 1962 & Carlina vulgaris L. & Tokaj & 1971 & Siroki Zoltán & DE-siroki-17175.jpg \\
\hline 1962 & Carlina vulgaris L. & Tokaj & 1971 & Siroki Zoltán & DE-siroki-17176.jpg \\
\hline 1962 & Carlina vulgaris L. & Tokaj & 1971 & Siroki Zoltán & DE-siroki-17177.jpg \\
\hline 1962 & Carlina vulgaris L. & Vámospércs & 1984 & Siroki Zoltán & DE-siroki-17163.jpg \\
\hline 1962 & Carlina vulgaris L. & Vámospércs & 1984 & Siroki Zoltán & DE-siroki-17164.jpg \\
\hline 1962 & Carlina vulgaris L. & Vámospércs & 1984 & Siroki Zoltán & DE-siroki-17178.jpg \\
\hline 1963 & $\begin{array}{l}\text { Xeranthemum cylindraceum } \\
\text { Sibth. et Sm. }\end{array}$ & Mátraverebély & 1952 & Siroki Zoltán & DE-siroki-17154.jpg \\
\hline 1963 & $\begin{array}{l}\text { Xeranthemum cylindraceum } \\
\text { Sibth. et Sm. }\end{array}$ & Mátraverebély & 1952 & Siroki Zoltán & DE-siroki-17153.jpg \\
\hline 1963 & $\begin{array}{l}\text { Xeranthemum cylindraceum } \\
\text { Sibth. et Sm. }\end{array}$ & Mátraverebély & - & Siroki Zoltán & DE-siroki-17155.jpg \\
\hline 1963 & $\begin{array}{l}\text { Xeranthemum cylindraceum } \\
\text { Sibth. et Sm. }\end{array}$ & Mátraverebély & - & Siroki Zoltán & DE-siroki-17156.jpg \\
\hline 1963 & $\begin{array}{l}\text { Xeranthemum cylindraceum } \\
\text { Sibth. et Sm. }\end{array}$ & Pomáz & 1954 & Siroki Zoltán & DE-siroki-17157.jpg \\
\hline 1963 & $\begin{array}{l}\text { Xeranthemum cylindraceum } \\
\text { Sibth. et Sm. }\end{array}$ & Pomáz & 1954 & Siroki Zoltán & DE-siroki-17158.jpg \\
\hline 1963 & $\begin{array}{l}\text { Xeranthemum cylindraceum } \\
\text { Sibth. et Sm. }\end{array}$ & Pomáz & 1954 & Siroki Zoltán & DE-siroki-17159.jpg \\
\hline 1964 & Xeranthemum annuum L. & Boldogkőváralja & 1944 & Siroki Zoltán & DE-siroki-17145.jpg \\
\hline 1964 & Xeranthemum annuum L. & Budapest & 1941 & Siroki Zoltán & DE-siroki-17144.jpg \\
\hline 1964 & Xeranthemum annuum L. & Budapest & 1941 & Siroki Zoltán & DE-siroki-17143.jpg \\
\hline 1964 & Xeranthemum annuum L. & Budapest & 1948 & Siroki Zoltán & DE-siroki-17146.jpg \\
\hline 1964 & Xeranthemum annuum L. & Debrecen & 1962 & Siroki Zoltán & DE-siroki-17152.jpg \\
\hline 1964 & Xeranthemum annuum L. & Debrecen & 1962 & Siroki Zoltán & DE-siroki-17147.jpg \\
\hline 1964 & Xeranthemum annuum L. & Debrecen & 1962 & Siroki Zoltán & DE-siroki-17148.jpg \\
\hline 1964 & Xeranthemum annuum L. & Debrecen & 1962 & Siroki Zoltán & DE-siroki-17149.jpg \\
\hline 1964 & Xeranthemum annuum L. & Debrecen & 1962 & Siroki Zoltán & DE-siroki-17150.jpg \\
\hline 1964 & Xeranthemum annuum L. & Debrecen & 1962 & Siroki Zoltán & DE-siroki-17151.jpg \\
\hline 1965 & Echinops sphaerocephalus L. & Debrecen & 1947 & Siroki Zoltán & DE-siroki-17123.jpg \\
\hline 1965 & Echinops sphaerocephalus L. & Keszthely & 1955 & Siroki Zoltán & DE-siroki-17122.jpg \\
\hline 1966 & Echinops ruthenicus (Fisch.) M. Bieb. & Ágasegyháza & 1956 & Siroki Zoltán & DE-siroki-17138.jpg \\
\hline 1966 & Echinops ruthenicus (Fisch.) M. Bieb. & Ágasegyháza & 1956 & Siroki Zoltán & DE-siroki-17139.jpg \\
\hline 1966 & Echinops ruthenicus (Fisch.) M. Bieb. & Ágasegyháza & 1956 & Siroki Zoltán & DE-siroki-17140.jpg \\
\hline 1966 & Echinops ruthenicus (Fisch.) M. Bieb. & Budapest & 1948 & Siroki Zoltán & DE-siroki-17135.jpg \\
\hline 1966 & Echinops ruthenicus (Fisch.) M. Bieb. & Budapest & 1948 & Siroki Zoltán & DE-siroki-17137.jpg \\
\hline 1966 & Echinops ruthenicus (Fisch.) M. Bieb. & Budapest & 1948 & Siroki Zoltán & DE-siroki-17136.jpg \\
\hline 1966 & Echinops ruthenicus (Fisch.) M. Bieb. & Budapest & 1948 & Siroki Zoltán & DE-siroki-17141.jpg \\
\hline 1966 & Echinops ruthenicus (Fisch.) M. Bieb. & Budapest & 1948 & Siroki Zoltán & DE-siroki-17142.jpg \\
\hline 1966 & Echinops ruthenicus (Fisch.) M. Bieb. & Bugac & 1973 & Siroki Zoltán & DE-siroki-17132.jpg \\
\hline 1966 & Echinops ruthenicus (Fisch.) M. Bieb. & Bugac & 1973 & Siroki Zoltán & DE-siroki-17133.jpg \\
\hline 1966 & Echinops ruthenicus (Fisch.) M. Bieb. & Bugac & 1973 & Siroki Zoltán & DE-siroki-17134.jpg \\
\hline 1967 & Arctium tomentosum Mill. & Debrecen & 1948 & Siroki Zoltán & DE-siroki-17191.jpg \\
\hline
\end{tabular}




\begin{tabular}{|c|c|c|c|c|c|}
\hline $\begin{array}{l}\text { Sorszám / } \\
\text { Number }\end{array}$ & Taxon-név / Taxon-name & $\begin{array}{l}\text { Település / } \\
\text { Settlement }\end{array}$ & $\begin{array}{l}\text { Év / } \\
\text { Year }\end{array}$ & $\begin{array}{l}\text { Gyújtő / } \\
\text { Collector }\end{array}$ & Fájlnév / File-name \\
\hline 1968 & Arctium lappa L. & Buják & 1954 & Siroki Zoltán & DE-siroki-17187.jpg \\
\hline 1968 & Arctium lappa L. & Buják & 1954 & Siroki Zoltán & DE-siroki-17190.jpg \\
\hline 1968 & Arctium lappa L. & Debrecen & 1947 & Siroki Zoltán & DE-siroki-17188.jpg \\
\hline 1968 & Arctium lappa L. & Debrecen & 1949 & Siroki Zoltán & DE-siroki-17192.jpg \\
\hline 1968 & Arctium lappa L. & Debrecen & 1964 & Siroki Zoltán & DE-siroki-17186.jpg \\
\hline 1969 & Arctium minus (Hill) Bernh. & Budakeszi & 1954 & Siroki Zoltán & DE-siroki-17206.jpg \\
\hline 1969 & Arctium minus (Hill) Bernh. & Budapest & 1954 & Siroki Zoltán & DE-siroki-17203.jpg \\
\hline 1969 & Arctium minus (Hill) Bernh. & Budapest & 1954 & Siroki Zoltán & DE-siroki-17204.jpg \\
\hline 1969 & Arctium minus (Hill) Bernh. & Buják & 1954 & Siroki Zoltán & DE-siroki-17202.jpg \\
\hline 1969 & Arctium minus (Hill) Bernh. & Buják & 1954 & Siroki Zoltán & DE-siroki-17205.jpg \\
\hline 1969 & Arctium minus (Hill) Bernh. & Debrecen & 1947 & Siroki Zoltán & DE-siroki-17193.jpg \\
\hline 1969 & Arctium minus (Hill) Bernh. & Debrecen & 1957 & Siroki Zoltán & DE-siroki-17199.jpg \\
\hline 1969 & Arctium minus (Hill) Bernh. & Debrecen & 1957 & Siroki Zoltán & DE-siroki-17200.jpg \\
\hline 1969 & Arctium minus (Hill) Bernh. & Debrecen & 1957 & Siroki Zoltán & DE-siroki-17201.jpg \\
\hline $\begin{array}{c}1967 \times \\
1969\end{array}$ & $\begin{array}{l}\text { Arctium } \times \text { mixtum (Simonk.) Nyman } \\
\text { (A. tomentosum } \times \text { minus) }\end{array}$ & Buják & 1954 & Siroki Zoltán & DE-siroki-17208.jpg \\
\hline 1971 & Jurinea mollis (L.) Rchb. & Budapest & 1889 & Czakó Kálmán & DE-siroki-17228.jpg \\
\hline 1971 & Jurinea mollis (L.) Rchb. & Budapest & 1981 & Siroki Zoltán & DE-siroki-17222.jpg \\
\hline 1971 & Jurinea mollis (L.) Rchb. & Gyenesdiás & 1953 & Siroki Zoltán & DE-siroki-17226.jpg \\
\hline 1973 & Carduus nutans L. & Hortobágy & 1944 & Siroki Zoltán & DE-siroki-17232.jpg \\
\hline 1974 & Carduus acanthoides L. & Debrecen & 1947 & Siroki Zoltán & DE-siroki-17270.jpg \\
\hline 1974 & Carduus acanthoides L. & Debrecen & 1963 & Siroki Zoltán & DE-siroki-17269.jpg \\
\hline 1975 & Carduus crispus L. & Debrecen & 1948 & Siroki Zoltán & DE-siroki-17278.jpg \\
\hline 1975 & Carduus crispus L. & Hencida & 1983 & Siroki Zoltán & DE-siroki-17272.jpg \\
\hline 1975 & Carduus crispus L. & Hencida & 1983 & Siroki Zoltán & DE-siroki-17274.jpg \\
\hline 1975 & Carduus crispus L. & Hencida & 1983 & Siroki Zoltán & DE-siroki-17279.jpg \\
\hline 1975 & Carduus crispus L. & Hencida & 1983 & Siroki Zoltán & DE-siroki-17273.jpg \\
\hline 1975 & Carduus crispus L. & Mosonmagyaróvár & 1939 & Siroki Zoltán & DE-siroki-17280.jpg \\
\hline 1975 & Carduus crispus L. & Mosonmagyaróvár & 1939 & Siroki Zoltán & DE-siroki-17281.jpg \\
\hline 1975 & Carduus crispus L. & Szilvásvárad & 1954 & Siroki Zoltán & DE-siroki-17277.jpg \\
\hline 1975 & Carduus crispus L. & Tokaj & 1971 & Siroki Zoltán & DE-siroki-17275.jpg \\
\hline 1975 & Carduus crispus L. & Tokaj & 1971 & Siroki Zoltán & DE-siroki-17276.jpg \\
\hline 1976 & Carduus crassifolius Willd. & Nagykovácsi & 1957 & Siroki Zoltán & DE-siroki-17261.jpg \\
\hline 1976 & Carduus crassifolius Willd. & Piliscsaba & 1909 & Kocsis István & DE-siroki-17262.jpg \\
\hline 1977 & Carduus hamulosus Ehrh. & Budapest & 1941 & Siroki Zoltán & DE-siroki-17236.jpg \\
\hline 1977 & Carduus hamulosus Ehrh. & Budapest & 1949 & Siroki Zoltán & DE-siroki-17234.jpg \\
\hline 1977 & Carduus hamulosus Ehrh. & Budapest & 1949 & Siroki Zoltán & DE-siroki-17235.jpg \\
\hline 1977 & Carduus hamulosus Ehrh. & Budapest & 1949 & Siroki Zoltán & DE-siroki-17249.jpg \\
\hline 1977 & Carduus hamulosus Ehrh. & Debrecen & 1947 & Siroki Zoltán & DE-siroki-17233.jpg \\
\hline 1977 & Carduus hamulosus Ehrh. & Hortobágy & 1947 & Siroki Zoltán & DE-siroki-17245.jpg \\
\hline 1977 & Carduus hamulosus Ehrh. & Hortobágy & 1947 & Siroki Zoltán & DE-siroki-17250.jpg \\
\hline 1977 & Carduus hamulosus Ehrh. & Kaba & 1964 & Siroki Zoltán & DE-siroki-17237.jpg \\
\hline 1977 & Carduus hamulosus Ehrh. & Kaba & 1964 & Siroki Zoltán & DE-siroki-17238.jpg \\
\hline 1977 & Carduus hamulosus Ehrh. & Kaba & 1964 & Siroki Zoltán & DE-siroki-17239.jpg \\
\hline 1977 & Carduus hamulosus Ehrh. & Kaba & 1964 & Siroki Zoltán & DE-siroki-17240.jpg \\
\hline 1977 & Carduus hamulosus Ehrh. & Kaba & 1964 & Siroki Zoltán & DE-siroki-17241.jpg \\
\hline 1977 & Carduus hamulosus Ehrh. & Kaba & 1964 & Siroki Zoltán & DE-siroki-17242.jpg \\
\hline
\end{tabular}




\begin{tabular}{|c|c|c|c|c|c|}
\hline $\begin{array}{l}\text { Sorszám / } \\
\text { Number }\end{array}$ & Taxon-név / Taxon-name & $\begin{array}{l}\text { Település / } \\
\text { Settlement }\end{array}$ & $\begin{array}{l}\text { Év / } \\
\text { Year }\end{array}$ & $\begin{array}{l}\text { Gyújtő / } \\
\text { Collector }\end{array}$ & Fájlnév / File-name \\
\hline 1977 & Carduus hamulosus Ehrh. & Kaba & 1964 & Siroki Zoltán & DE-siroki-17243.jpg \\
\hline 1977 & Carduus hamulosus Ehrh. & Kaba & 1964 & Siroki Zoltán & DE-siroki-17244.jpg \\
\hline 1977 & Carduus hamulosus Ehrh. & Kaba & 1964 & Siroki Zoltán & DE-siroki-17246.jpg \\
\hline 1977 & Carduus hamulosus Ehrh. & Kaba & 1964 & Siroki Zoltán & DE-siroki-17247.jpg \\
\hline 1977 & Carduus hamulosus Ehrh. & Kaba & 1964 & Siroki Zoltán & DE-siroki-17248.jpg \\
\hline 1978 & Carduus collinus Waldst. et Kit. & Aggtelek & 1972 & Siroki Zoltán & DE-siroki-17252.jpg \\
\hline 1978 & Carduus collinus Waldst. et Kit. & Boldogkőváralja & 1944 & Siroki Zoltán & DE-siroki-17259.jpg \\
\hline 1978 & Carduus collinus Waldst. et Kit. & Szarvaskő & 1957 & Siroki Zoltán & DE-siroki-17257.jpg \\
\hline 1978 & Carduus collinus Waldst. et Kit. & Tokaj & 1966 & Siroki Zoltán & DE-siroki-17258.jpg \\
\hline $\begin{array}{c}1973 \times \\
1976\end{array}$ & $\begin{array}{l}\text { Carduus nutans L. } \times \text { Carduus } \\
\text { crassifolius Willd. } \\
\text { subsp. glaucus (Baumg.) Kazmi }\end{array}$ & Nagykovácsi & 1957 & Siroki Zoltán & DE-siroki-17285.jpg \\
\hline---- & Carduus & Visegrád & 1888 & Szépligeti Győző & DE-siroki-17251.jpg \\
\hline 1979 & Cirsium vulgare (Savi) Ten. & Debrecen & 1946 & Siroki Zoltán & DE-siroki-17287.jpg \\
\hline 1979 & Cirsium vulgare (Savi) Ten. & Mosonmagyaróvár & 1939 & Siroki Zoltán & DE-siroki-17288.jpg \\
\hline 1980 & Cirsium eriophorum (L.) Scop. & Budapest & 1950 & Siroki Zoltán & DE-siroki-17308.jpg \\
\hline 1980 & Cirsium eriophorum (L.) Scop. & Keszthely & 1955 & Siroki Zoltán & DE-siroki-17311.jpg \\
\hline 1980 & Cirsium eriophorum (L.) Scop. & Keszthely & 1955 & Siroki Zoltán & DE-siroki-17312.jpg \\
\hline 1980 & Cirsium eriophorum (L.) Scop. & Keszthely & 1955 & Siroki Zoltán & DE-siroki-17313.jpg \\
\hline 1980 & Cirsium eriophorum (L.) Scop. & Keszthely & 1955 & Siroki Zoltán & DE-siroki-17310.jpg \\
\hline 1980 & Cirsium eriophorum (L.) Scop. & Szigetcsép & 1951 & Siroki Zoltán & DE-siroki-17309.jpg \\
\hline 1981 & Cirsium furiens Griseb. et Schenk & Debrecen & 1946 & Siroki Zoltán & DE-siroki-17296.jpg \\
\hline 1981 & Cirsium furiens Griseb. et Schenk & Debrecen & 1946 & Siroki Zoltán & DE-siroki-17295.jpg \\
\hline 1981 & Cirsium furiens Griseb. et Schenk & Debrecen & 1946 & Siroki Zoltán & DE-siroki-17298.jpg \\
\hline 1981 & Cirsium furiens Griseb. et Schenk & Debrecen & 1946 & Siroki Zoltán & DE-siroki-17293.jpg \\
\hline 1981 & Cirsium furiens Griseb. et Schenk & Debrecen & 1946 & Siroki Zoltán & DE-siroki-17294.jpg \\
\hline 1981 & Cirsium furiens Griseb. et Schenk & Debrecen & 1947 & Siroki Zoltán & DE-siroki-17301.jpg \\
\hline 1981 & Cirsium furiens Griseb. et Schenk & Debrecen & 1947 & Siroki Zoltán & DE-siroki-17303.jpg \\
\hline 1981 & Cirsium furiens Griseb. et Schenk & Debrecen & 1948 & Siroki Zoltán & DE-siroki-17292.jpg \\
\hline 1981 & Cirsium furiens Griseb. et Schenk & Debrecen & 1948 & Siroki Zoltán & DE-siroki-17297.jpg \\
\hline 1981 & Cirsium furiens Griseb. et Schenk & Debrecen & 1948 & Siroki Zoltán & DE-siroki-17302.jpg \\
\hline 1981 & Cirsium furiens Griseb. et Schenk & Debrecen & 1975 & Siroki Zoltán & DE-siroki-17290.jpg \\
\hline 1981 & Cirsium furiens Griseb. et Schenk & Debrecen & 1975 & Siroki Zoltán & DE-siroki-17291.jpg \\
\hline 1981 & Cirsium furiens Griseb. et Schenk & Debrecen & 1980 & Siroki Zoltán & DE-siroki-17304.jpg \\
\hline 1981 & Cirsium furiens Griseb. et Schenk & Debrecen & 1980 & Siroki Zoltán & DE-siroki-17305.jpg \\
\hline 1981 & Cirsium furiens Griseb. et Schenk & Debrecen & 1980 & Siroki Zoltán & DE-siroki-17306.jpg \\
\hline 1981 & Cirsium furiens Griseb. et Schenk & Debrecen & 1980 & Siroki Zoltán & DE-siroki-17299.jpg \\
\hline 1981 & Cirsium furiens Griseb. et Schenk & Debrecen & 1980 & Siroki Zoltán & DE-siroki-17300.jpg \\
\hline 1983 & Cirsium arvense (L.) Scop. & Mosonmagyaróvár & 1939 & Siroki Zoltán & DE-siroki-17318.jpg \\
\hline 1984 & Cirsium brachycephalum Jur. & Cegléd & 1969 & Siroki Zoltán & DE-siroki-17335.jpg \\
\hline 1984 & Cirsium brachycephalum Jur. & Cegléd & 1969 & Siroki Zoltán & DE-siroki-17336.jpg \\
\hline 1984 & Cirsium brachycephalum Jur. & Debrecen & 1947 & Siroki Zoltán & DE-siroki-17322.jpg \\
\hline 1984 & Cirsium brachycephalum Jur. & Debrecen & 1947 & Siroki Zoltán & DE-siroki-17323.jpg \\
\hline 1984 & Cirsium brachycephalum Jur. & Debrecen & 1947 & Siroki Zoltán & DE-siroki-17324.jpg \\
\hline 1984 & Cirsium brachycephalum Jur. & Debrecen & 1947 & Siroki Zoltán & DE-siroki-17325.jpg \\
\hline 1984 & Cirsium brachycephalum Jur. & Debrecen & 1947 & Siroki Zoltán & DE-siroki-17326.jpg \\
\hline 1984 & Cirsium brachycephalum Jur. & Debrecen & 1947 & Siroki Zoltán & DE-siroki-17330.jpg \\
\hline
\end{tabular}




\begin{tabular}{|c|c|c|c|c|c|}
\hline $\begin{array}{l}\text { Sorszám / } \\
\text { Number }\end{array}$ & Taxon-név / Taxon-name & $\begin{array}{l}\text { Település / } \\
\text { Settlement }\end{array}$ & $\begin{array}{l}\text { Év / } \\
\text { Year }\end{array}$ & $\begin{array}{l}\text { Gyűjtő / } \\
\text { Collector }\end{array}$ & Fájlnév / File-name \\
\hline 1984 & Cirsium brachycephalum Jur. & Debrecen & 1947 & Siroki Zoltán & DE-siroki-17331.jpg \\
\hline 1984 & Cirsium brachycephalum Jur. & Debrecen & 1947 & Siroki Zoltán & DE-siroki-17319.jpg \\
\hline 1984 & Cirsium brachycephalum Jur. & Debrecen & 1947 & Siroki Zoltán & DE-siroki-17320.jpg \\
\hline 1984 & Cirsium brachycephalum Jur. & Debrecen & 1947 & Siroki Zoltán & DE-siroki-17321.jpg \\
\hline 1984 & Cirsium brachycephalum Jur. & Hortobágy & 1949 & Siroki Zoltán & DE-siroki-17328.jpg \\
\hline 1984 & Cirsium brachycephalum Jur. & Mezőpeterd & 1959 & Siroki Zoltán & DE-siroki-17327.jpg \\
\hline 1984 & Cirsium brachycephalum Jur. & Mezőpeterd & 1959 & Siroki Zoltán & DE-siroki-17329.jpg \\
\hline 1984 & Cirsium brachycephalum Jur. & Mezőpeterd & 1959 & Siroki Zoltán & DE-siroki-17332.jpg \\
\hline 1984 & Cirsium brachycephalum Jur. & Mezőpeterd & 1959 & Siroki Zoltán & DE-siroki-17333.jpg \\
\hline 1984 & Cirsium brachycephalum Jur. & Mikepércs & 1962 & Siroki Zoltán & DE-siroki-17334.jpg \\
\hline 1985 & Cirsium palustre (L.) Scop. & Háromhuta & 1979 & Siroki Zoltán & DE-siroki-17347.jpg \\
\hline 1985 & Cirsium palustre (L.) Scop. & Háromhuta & 1979 & Siroki Zoltán & DE-siroki-17348.jpg \\
\hline 1985 & Cirsium palustre (L.) Scop. & Miskolc & 1959 & Siroki Zoltán & DE-siroki-17339.jpg \\
\hline 1985 & Cirsium palustre (L.) Scop. & Miskolc & 1959 & Siroki Zoltán & DE-siroki-17340.jpg \\
\hline 1985 & Cirsium palustre (L.) Scop. & Miskolc & 1959 & Siroki Zoltán & DE-siroki-17341.jpg \\
\hline 1985 & Cirsium palustre (L.) Scop. & Miskolc & 1959 & Siroki Zoltán & DE-siroki-17342.jpg \\
\hline 1985 & Cirsium palustre (L.) Scop. & Miskolc & 1959 & Siroki Zoltán & DE-siroki-17343.jpg \\
\hline 1985 & Cirsium palustre (L.) Scop. & Miskolc & 1959 & Siroki Zoltán & DE-siroki-17344.jpg \\
\hline 1985 & Cirsium palustre (L.) Scop. & Miskolc & 1959 & Siroki Zoltán & DE-siroki-17345.jpg \\
\hline 1985 & Cirsium palustre (L.) Scop. & Miskolc & 1959 & Siroki Zoltán & DE-siroki-17346.jpg \\
\hline 1986 & Cirsium canum (L.) All. & Debrecen & 1947 & Siroki Zoltán & DE-siroki-17349.jpg \\
\hline 1986 & Cirsium canum (L.) All. & Mosonmagyaróvár & 1939 & Siroki Zoltán & DE-siroki-17351.jpg \\
\hline 1987 & Cirsium pannonicum (L. f.) Link & "Dobogókő" & 1957 & Siroki Zoltán & DE-siroki-17357.jpg \\
\hline 1987 & Cirsium pannonicum (L. f.) Link & "Dobogókő" & 1957 & Siroki Zoltán & DE-siroki-17358.jpg \\
\hline 1987 & Cirsium pannonicum (L. f.) Link & "Dobogókő" & 1957 & Siroki Zoltán & DE-siroki-17354.jpg \\
\hline 1987 & Cirsium pannonicum (L. f.) Link & "Dobogókő" & 1965 & Siroki Zoltán & DE-siroki-17361.jpg \\
\hline 1987 & Cirsium pannonicum (L. f.) Link & "Dobogókő" & 1965 & Siroki Zoltán & DE-siroki-17362.jpg \\
\hline 1987 & Cirsium pannonicum (L. f.) Link & "Nagymező" & 1959 & Siroki Zoltán & DE-siroki-17359.jpg \\
\hline 1987 & Cirsium pannonicum (L. f.) Link & "Nagymező" & 1959 & Siroki Zoltán & DE-siroki-17360.jpg \\
\hline 1987 & Cirsium pannonicum (L. f.) Link & "Tarkő" & - & Halász Tibor & DE-siroki-17352.jpg \\
\hline 1987 & Cirsium pannonicum (L. f.) Link & Budapest & 1888 & Czakó Kálmán & DE-siroki-17363.jpg \\
\hline 1987 & Cirsium pannonicum (L. f.) Link & Budapest & 1888 & Czakó Kálmán & DE-siroki-17365.jpg \\
\hline 1987 & Cirsium pannonicum (L. f.) Link & Budapest & 1951 & Siroki Zoltán & DE-siroki-17353.jpg \\
\hline 1987 & Cirsium pannonicum (L. f.) Link & Budapest & 1951 & Siroki Zoltán & DE-siroki-17355.jpg \\
\hline 1987 & Cirsium pannonicum (L. f.) Link & Piliscsaba & 1909 & Kocsis István & DE-siroki-17366.jpg \\
\hline 1987 & Cirsium pannonicum (L. f.) Link & Solymár & 1911 & Kocsis István & DE-siroki-17364.jpg \\
\hline 1988 & Cirsium rivulare (Jacq.) All. & Debrecen & 1948 & Siroki Zoltán & DE-siroki-17407.jpg \\
\hline 1988 & Cirsium rivulare (Jacq.) All. & Debrecen & 1950 & Siroki Zoltán & DE-siroki-17406.jpg \\
\hline 1988 & Cirsium rivulare (Jacq.) All. & Debrecen & 1950 & Siroki Zoltán & DE-siroki-17408.jpg \\
\hline 1988 & Cirsium rivulare (Jacq.) All. & Debrecen & 1951 & Siroki Zoltán & DE-siroki-17405.jpg \\
\hline 1988 & Cirsium rivulare (Jacq.) All. & Debrecen & 1951 & Siroki Zoltán & DE-siroki-17395.jpg \\
\hline 1988 & Cirsium rivulare (Jacq.) All. & Debrecen & 1954 & Siroki Zoltán & DE-siroki-17391.jpg \\
\hline 1988 & Cirsium rivulare (Jacq.) All. & Debrecen & 1954 & Siroki Zoltán & DE-siroki-17392.jpg \\
\hline 1988 & Cirsium rivulare (Jacq.) All. & Debrecen & 1954 & Siroki Zoltán & DE-siroki-17393.jpg \\
\hline 1988 & Cirsium rivulare (Jacq.) All. & Debrecen & 1954 & Siroki Zoltán & DE-siroki-17394.jpg \\
\hline 1988 & Cirsium rivulare (Jacq.) All. & Újléta & 1967 & Siroki Zoltán & DE-siroki-17396.jpg \\
\hline
\end{tabular}




\begin{tabular}{|c|c|c|c|c|c|}
\hline $\begin{array}{l}\text { Sorszám / } \\
\text { Number }\end{array}$ & Taxon-név / Taxon-name & $\begin{array}{l}\text { Település / } \\
\text { Settlement }\end{array}$ & $\begin{array}{l}\text { Év / } \\
\text { Year }\end{array}$ & $\begin{array}{l}\text { Gyújtő / } \\
\text { Collector }\end{array}$ & Fájlnév / File-name \\
\hline 1988 & Cirsium rivulare (Jacq.) All. & Újléta & 1967 & Siroki Zoltán & DE-siroki-17397.jpg \\
\hline 1988 & Cirsium rivulare (Jacq.) All. & Újléta & 1967 & Siroki Zoltán & DE-siroki-17398.jpg \\
\hline 1988 & Cirsium rivulare (Jacq.) All. & Újléta & 1967 & Siroki Zoltán & DE-siroki-17399.jpg \\
\hline 1988 & Cirsium rivulare (Jacq.) All. & Újléta & 1967 & Siroki Zoltán & DE-siroki-17400.jpg \\
\hline 1988 & Cirsium rivulare (Jacq.) All. & Újléta & 1967 & Siroki Zoltán & DE-siroki-17401.jpg \\
\hline 1988 & Cirsium rivulare (Jacq.) All. & Újléta & 1967 & Siroki Zoltán & DE-siroki-17402.jpg \\
\hline 1988 & Cirsium rivulare (Jacq.) All. & Újléta & 1967 & Siroki Zoltán & DE-siroki-17403.jpg \\
\hline 1988 & Cirsium rivulare (Jacq.) All. & Újléta & 1967 & Siroki Zoltán & DE-siroki-17404.jpg \\
\hline 1989 & Cirsium oleraceum (L.) Scop. & Gödöllő & 1951 & Siroki Zoltán & DE-siroki-17373.jpg \\
\hline 1989 & Cirsium oleraceum (L.) Scop. & Gödöllő & 1951 & Siroki Zoltán & DE-siroki-17371.jpg \\
\hline 1989 & Cirsium oleraceum (L.) Scop. & Gödöllő & 1951 & Siroki Zoltán & DE-siroki-17375.jpg \\
\hline 1989 & Cirsium oleraceum (L.) Scop. & Sopron & 1956 & Siroki Zoltán & DE-siroki-17372.jpg \\
\hline 1989 & Cirsium oleraceum (L.) Scop. & Szilvásvárad & 1954 & Siroki Zoltán & DE-siroki-17370.jpg \\
\hline 1990 & Cirsium erisithales (Jacq.) Scop. & Miskolc & 1960 & Siroki Zoltán & DE-siroki-17376.jpg \\
\hline 1990 & Cirsium erisithales (Jacq.) Scop. & Miskolc & 1960 & Siroki Zoltán & DE-siroki-17377.jpg \\
\hline 1990 & Cirsium erisithales (Jacq.) Scop. & Miskolc & 1960 & Siroki Zoltán & DE-siroki-17378.jpg \\
\hline 1990 & Cirsium erisithales (Jacq.) Scop. & Miskolc & 1960 & Siroki Zoltán & DE-siroki-17379.jpg \\
\hline 1990 & Cirsium erisithales (Jacq.) Scop. & Miskolc & 1960 & Siroki Zoltán & DE-siroki-17380.jpg \\
\hline 1990 & Cirsium erisithales (Jacq.) Scop. & Miskolc & 1960 & Siroki Zoltán & DE-siroki-17382.jpg \\
\hline 1990 & Cirsium erisithales (Jacq.) Scop. & Miskolc & 1960 & Siroki Zoltán & DE-siroki-17383.jpg \\
\hline 1990 & Cirsium erisithales (Jacq.) Scop. & Miskolc & 1960 & Siroki Zoltán & DE-siroki-17384.jpg \\
\hline 1990 & Cirsium erisithales (Jacq.) Scop. & Miskolc & 1960 & Siroki Zoltán & DE-siroki-17385.jpg \\
\hline 1990 & Cirsium erisithales (Jacq.) Scop. & Miskolc & 1960 & Siroki Zoltán & DE-siroki-17386.jpg \\
\hline 1990 & Cirsium erisithales (Jacq.) Scop. & Miskolc & 1960 & Siroki Zoltán & DE-siroki-17387.jpg \\
\hline 1990 & Cirsium erisithales (Jacq.) Scop. & Miskolc & 1960 & Siroki Zoltán & DE-siroki-17390.jpg \\
\hline 1990 & Cirsium erisithales (Jacq.) Scop. & Miskolc & 1960 & Siroki Zoltán & DE-siroki-17381.jpg \\
\hline 1990 & Cirsium erisithales (Jacq.) Scop. & Nagyvisnyó & 1966 & Siroki Zoltán & DE-siroki-17389.jpg \\
\hline 1990 & Cirsium erisithales (Jacq.) Scop. & Nagyvisnyó & 1966 & Siroki Zoltán & DE-siroki-17388.jpg \\
\hline 1991 & Onopordum acanthium L. & Debrecen & 1957 & Siroki Zoltán & DE-siroki-17409.jpg \\
\hline 1991 & Onopordum acanthium L. & Debrecen & 1957 & Siroki Zoltán & DE-siroki-17410.jpg \\
\hline 1993 & Serratula tinctoria L. & "Vértes" & 1957 & Siroki Zoltán & DE-siroki-17425.jpg \\
\hline 1993 & Serratula tinctoria L. & Debrecen & 1947 & Siroki Zoltán & DE-siroki-17422.jpg \\
\hline 1993 & Serratula tinctoria L. & Debrecen & 1948 & Siroki Zoltán & DE-siroki-17423.jpg \\
\hline 1993 & Serratula tinctoria $\mathrm{L}$. & Debrecen & 1948 & Siroki Zoltán & DE-siroki-17424.jpg \\
\hline 1993 & Serratula tinctoria L. & Háromhuta & 1984 & Siroki Zoltán & DE-siroki-17426.jpg \\
\hline 1993 & Serratula tinctoria L. & Háromhuta & 1984 & Siroki Zoltán & DE-siroki-17427.jpg \\
\hline 1993 & Serratula tinctoria $\mathrm{L}$. & Mosonmagyaróvár & 1939 & Siroki Zoltán & DE-siroki-17419.jpg \\
\hline 1993 & Serratula tinctoria L. & Mosonmagyaróvár & 1939 & Siroki Zoltán & DE-siroki-17420.jpg \\
\hline 1993 & Serratula tinctoria L. & Tiszacsege & 1978 & Siroki Zoltán & DE-siroki-17428.jpg \\
\hline 1994 & Serratula lycopifolia (Vill.) A. Kern. & Pécs & 1958 & Siroki Zoltán & DE-siroki-17430.jpg \\
\hline 1994 & Serratula lycopifolia (Vill.) A. Kern. & Pécs & 1958 & Siroki Zoltán & DE-siroki-17429.jpg \\
\hline 1995 & $\begin{array}{l}\text { Serratula radiata } \\
\text { (Waldst. et Kit.) M. Bieb. }\end{array}$ & Budapest & 1954 & Siroki Zoltán & DE-siroki-17435.jpg \\
\hline 1995 & $\begin{array}{l}\text { Serratula radiata } \\
\text { (Waldst. et Kit.) M. Bieb. }\end{array}$ & Budapest & 1954 & Siroki Zoltán & DE-siroki-17436.jpg \\
\hline 1995 & $\begin{array}{l}\text { Serratula radiata } \\
\text { (Waldst. et Kit.) M. Bieb. }\end{array}$ & Budapest & 1954 & Siroki Zoltán & DE-siroki-17437.jpg \\
\hline 1995 & $\begin{array}{l}\text { Serratula radiata } \\
\text { (Waldst. et Kit.) M. Bieb. }\end{array}$ & Budapest & 1954 & Siroki Zoltán & DE-siroki-17447.jpg \\
\hline
\end{tabular}




\begin{tabular}{|c|c|c|c|c|c|}
\hline $\begin{array}{l}\text { Sorszám / } \\
\text { Number }\end{array}$ & Taxon-név / Taxon-name & $\begin{array}{l}\text { Település / } \\
\text { Settlement }\end{array}$ & $\begin{array}{l}\text { Év / } \\
\text { Year }\end{array}$ & $\begin{array}{l}\text { Gyưjtő / } \\
\text { Collector }\end{array}$ & Fájlnév / File-name \\
\hline 1995 & $\begin{array}{l}\text { Serratula radiata } \\
\text { (Waldst. et Kit.) M. Bieb. }\end{array}$ & Budapest & 1954 & Siroki Zoltán & DE-siroki-17448.jpg \\
\hline 1995 & $\begin{array}{l}\text { Serratula radiata } \\
\text { (Waldst. et Kit.) M. Bieb. }\end{array}$ & Budapest & 1954 & Siroki Zoltán & DE-siroki-17449.jpg \\
\hline 1995 & $\begin{array}{l}\text { Serratula radiata } \\
\text { (Waldst. et Kit.) M. Bieb. }\end{array}$ & Budapest & 1962 & Siroki Zoltán & DE-siroki-17445.jpg \\
\hline 1995 & $\begin{array}{l}\text { Serratula radiata } \\
\text { (Waldst. et Kit.) M. Bieb. }\end{array}$ & Budapest & 1962 & Siroki Zoltán & DE-siroki-17446.jpg \\
\hline 1995 & $\begin{array}{l}\text { Serratula radiata } \\
\text { (Waldst. et Kit.) M. Bieb. }\end{array}$ & Budapest & 1962 & Siroki Zoltán & DE-siroki-17450.jpg \\
\hline 1995 & $\begin{array}{l}\text { Serratula radiata } \\
\text { (Waldst. et Kit.) M. Bieb. }\end{array}$ & Budapest & 1962 & Siroki Zoltán & DE-siroki-17451.jpg \\
\hline 1995 & $\begin{array}{l}\text { Serratula radiata } \\
\text { (Waldst. et Kit.) M. Bieb. }\end{array}$ & Budapest & 1962 & Siroki Zoltán & DE-siroki-17452.jpg \\
\hline 1995 & $\begin{array}{l}\text { Serratula radiata } \\
\text { (Waldst. et Kit.) M. Bieb. }\end{array}$ & Budapest & 1962 & Siroki Zoltán & DE-siroki-17438.jpg \\
\hline 1995 & $\begin{array}{l}\text { Serratula radiata } \\
\text { (Waldst. et Kit.) M. Bieb. }\end{array}$ & Budapest & 1962 & Siroki Zoltán & DE-siroki-17439.jpg \\
\hline 1995 & $\begin{array}{l}\text { Serratula radiata } \\
\text { (Waldst. et Kit.) M. Bieb. }\end{array}$ & Budapest & 1962 & Siroki Zoltán & DE-siroki-17440.jpg \\
\hline 1995 & $\begin{array}{l}\text { Serratula radiata } \\
\text { (Waldst. et Kit.) M. Bieb. }\end{array}$ & Budapest & 1962 & Siroki Zoltán & DE-siroki-17441.jpg \\
\hline 1995 & $\begin{array}{l}\text { Serratula radiata } \\
\text { (Waldst. et Kit.) M. Bieb. }\end{array}$ & Budapest & 1962 & Siroki Zoltán & DE-siroki-17442.jpg \\
\hline 1995 & $\begin{array}{l}\text { Serratula radiata } \\
\text { (Waldst. et Kit.) M. Bieb. }\end{array}$ & Budapest & 1962 & Siroki Zoltán & DE-siroki-17443.jpg \\
\hline 1995 & $\begin{array}{l}\text { Serratula radiata } \\
\text { (Waldst. et Kit.) M. Bieb. }\end{array}$ & Budapest & 1962 & Siroki Zoltán & DE-siroki-17444.jpg \\
\hline 1995 & $\begin{array}{l}\text { Serratula radiata } \\
\text { (Waldst. et Kit.) M. Bieb. }\end{array}$ & Budapest & 1962 & Siroki Zoltán & DE-siroki-17453.jpg \\
\hline 1996 & Centaurea solstitialis L. & Budapest & 1941 & Siroki Zoltán & DE-siroki-17455.jpg \\
\hline 1996 & Centaurea solstitialis L. & Budapest & 1941 & Siroki Zoltán & DE-siroki-17456.jpg \\
\hline 1996 & Centaurea solstitialis L. & Budapest & 1948 & Siroki Zoltán & DE-siroki-17457.jpg \\
\hline 1996 & Centaurea solstitialis L. & Budapest & 1948 & Siroki Zoltán & DE-siroki-17458.jpg \\
\hline 1996 & Centaurea solstitialis L. & Újszentmargita & 1952 & Gondola István & DE-siroki-17462.jpg \\
\hline 1996 & Centaurea solstitialis L. & Újszentmargita & 1952 & Gondola István & DE-siroki-17463.jpg \\
\hline 1998 & Centaurea nigrescens Willd. & Debrecen & 1948 & Siroki Zoltán & DE-siroki-17570.jpg \\
\hline 1998 & Centaurea nigrescens Willd. & Debrecen & 1948 & Siroki Zoltán & DE-siroki-17571.jpg \\
\hline 1998 & Centaurea nigrescens Willd. & Háromhuta & 1978 & Siroki Zoltán & DE-siroki-17567.jpg \\
\hline 1998 & Centaurea nigrescens Willd. & Murakeresztúr & 1886 & Czakó Kálmán & DE-siroki-17569.jpg \\
\hline 1999 & Centaurea jacea L. & "Nagymező" & 1959 & Siroki Zoltán & DE-siroki-17544.jpg \\
\hline 1999 & Centaurea jacea L. & Budapest & 1941 & Siroki Zoltán & DE-siroki-17537.jpg \\
\hline 1999 & Centaurea jacea L. & Budapest & 1985 & Siroki Zoltán & DE-siroki-17532.jpg \\
\hline 1999 & Centaurea jacea L. & Budapest & 1985 & Siroki Zoltán & DE-siroki-17527.jpg \\
\hline 1999 & Centaurea jacea L. & Budapest & 1985 & Siroki Zoltán & DE-siroki-17528.jpg \\
\hline 1999 & Centaurea jacea L. & Budapest & 1985 & Siroki Zoltán & DE-siroki-17529.jpg \\
\hline 1999 & Centaurea jacea L. & Budapest & 1985 & Siroki Zoltán & DE-siroki-17530.jpg \\
\hline 1999 & Centaurea jacea L. & Budapest & 1985 & Siroki Zoltán & DE-siroki-17531.jpg \\
\hline 1999 & Centaurea jacea L. & Debrecen & 1946 & Siroki Zoltán & DE-siroki-17525.jpg \\
\hline 1999 & Centaurea jacea L. & Debrecen & 1947 & Siroki Zoltán & DE-siroki-17549.jpg \\
\hline 1999 & Centaurea jacea L. & Debrecen & 1947 & Siroki Zoltán & DE-siroki-17619.jpg \\
\hline 1999 & Centaurea jacea L. & Debrecen & 1947 & Siroki Zoltán & DE-siroki-17642.jpg \\
\hline 1999 & Centaurea jacea L. & Debrecen & 1947 & Siroki Zoltán & DE-siroki-17542.jpg \\
\hline 1999 & Centaurea jacea L. & Debrecen & 1947 & Siroki Zoltán & DE-siroki-17547.jpg \\
\hline
\end{tabular}




\begin{tabular}{|c|c|c|c|c|c|}
\hline $\begin{array}{l}\text { Sorszám / } \\
\text { Number }\end{array}$ & Taxon-név / Taxon-name & $\begin{array}{l}\text { Település / } \\
\text { Settlement }\end{array}$ & $\begin{array}{l}\text { Év / } \\
\text { Year }\end{array}$ & $\begin{array}{l}\text { Gyújtő / } \\
\text { Collector }\end{array}$ & Fájlnév / File-name \\
\hline 1999 & Centaurea jacea L. & Debrecen & 1947 & Siroki Zoltán & DE-siroki-17548.jpg \\
\hline 1999 & Centaurea jacea L. & Debrecen & 1948 & Siroki Zoltán & DE-siroki-17479.jpg \\
\hline 1999 & Centaurea jacea L. & Debrecen & 1948 & Siroki Zoltán & DE-siroki-17535.jpg \\
\hline 1999 & Centaurea jacea L. & Debrecen & 1949 & Siroki Zoltán & DE-siroki-17476.jpg \\
\hline 1999 & Centaurea jacea L. & Debrecen & 1949 & Siroki Zoltán & DE-siroki-17477.jpg \\
\hline 1999 & Centaurea jacea L. & Debrecen & 1983 & Siroki Zoltán & DE-siroki-17470.jpg \\
\hline 1999 & Centaurea jacea L. & Debrecen & 1983 & Siroki Zoltán & DE-siroki-17471.jpg \\
\hline 1999 & Centaurea jacea L. & Háromhuta & 1978 & Siroki Zoltán & DE-siroki-17472.jpg \\
\hline 1999 & Centaurea jacea L. & Háromhuta & 1984 & Siroki Zoltán & DE-siroki-17466.jpg \\
\hline 1999 & Centaurea jacea L. & Háromhuta & 1984 & Siroki Zoltán & DE-siroki-17467.jpg \\
\hline 1999 & Centaurea jacea L. & Háromhuta & 1984 & Siroki Zoltán & DE-siroki-17468.jpg \\
\hline 1999 & Centaurea jacea L. & Háromhuta & 1984 & Siroki Zoltán & DE-siroki-17469.jpg \\
\hline 1999 & Centaurea jacea L. & Hortobágy & 1947 & Siroki Zoltán & DE-siroki-17554.jpg \\
\hline 1999 & Centaurea jacea L. & Hortobágy & 1947 & Siroki Zoltán & DE-siroki-17556.jpg \\
\hline 1999 & Centaurea jacea L. & Hortobágy & 1947 & Siroki Zoltán & DE-siroki-17557.jpg \\
\hline 1999 & Centaurea jacea L. & Hortobágy & 1947 & Siroki Zoltán & DE-siroki-17558.jpg \\
\hline 1999 & Centaurea jacea L. & Hortobágy & 1947 & Siroki Zoltán & DE-siroki-17559.jpg \\
\hline 1999 & Centaurea jacea L. & Hortobágy & 1948 & Siroki Zoltán & DE-siroki-17555.jpg \\
\hline 1999 & Centaurea jacea L. & Hortobágy & 1948 & Siroki Zoltán & DE-siroki-17550.jpg \\
\hline 1999 & Centaurea jacea L. & Hortobágy & 1948 & Siroki Zoltán & DE-siroki-17551.jpg \\
\hline 1999 & Centaurea jacea L. & Hortobágy & 1948 & Siroki Zoltán & DE-siroki-17552.jpg \\
\hline 1999 & Centaurea jacea L. & Hortobágy & 1948 & Siroki Zoltán & DE-siroki-17553.jpg \\
\hline 1999 & Centaurea jacea L. & Mátraszentimre & 1962 & Halász Tibor & DE-siroki-17543.jpg \\
\hline 1999 & Centaurea jacea L. & Mátraszentimre & 1962 & Halász Tibor & DE-siroki-17545.jpg \\
\hline 1999 & Centaurea jacea L. & Mátraszentimre & 1962 & Halász Tibor & DE-siroki-17546.jpg \\
\hline 1999 & Centaurea jacea L. & Mosonmagyaróvár & 1939 & Siroki Zoltán & DE-siroki-17539.jpg \\
\hline 1999 & Centaurea jacea L. & Mosonmagyaróvár & 1939 & Siroki Zoltán & DE-siroki-17465.jpg \\
\hline 1999 & Centaurea jacea L. & Mosonmagyaróvár & 1939 & Siroki Zoltán & DE-siroki-17540.jpg \\
\hline 1999 & Centaurea jacea L. & Szalonna & 1986 & Siroki Zoltán & DE-siroki-17630.jpg \\
\hline 1999 & Centaurea jacea L. & Szalonna & 1986 & Siroki Zoltán & DE-siroki-17631.jpg \\
\hline 1999 & Centaurea jacea L. & Szalonna & 1986 & Siroki Zoltán & DE-siroki-17632.jpg \\
\hline 1999 & Centaurea jacea L. & Szilvásvárad & 1954 & Siroki Zoltán & DE-siroki-17524.jpg \\
\hline 1999 & Centaurea jacea L. & Szilvásvárad & 1954 & Siroki Zoltán & DE-siroki-17526.jpg \\
\hline 1999 & Centaurea jacea L. & Szilvásvárad & 1954 & Siroki Zoltán & DE-siroki-17536.jpg \\
\hline 1999 & Centaurea jacea L. & Szilvásvárad & 1954 & Siroki Zoltán & DE-siroki-17641.jpg \\
\hline 1999 & Centaurea jacea L. & Szinpetri & 1974 & Siroki Zoltán & DE-siroki-17618.jpg \\
\hline 1999 & Centaurea jacea L. & Szinpetri & 1974 & Siroki Zoltán & DE-siroki-17620.jpg \\
\hline 1999 & Centaurea jacea L. & Szinpetri & 1974 & Siroki Zoltán & DE-siroki-17621.jpg \\
\hline 1999 & Centaurea jacea L. & Szinpetri & 1974 & Siroki Zoltán & DE-siroki-17622.jpg \\
\hline 1999 & Centaurea jacea L. & Szinpetri & 1974 & Siroki Zoltán & DE-siroki-17623.jpg \\
\hline 1999 & Centaurea jacea L. & Szinpetri & 1974 & Siroki Zoltán & DE-siroki-17624.jpg \\
\hline 1999 & Centaurea jacea L. & Szinpetri & 1974 & Siroki Zoltán & DE-siroki-17625.jpg \\
\hline 1999 & Centaurea jacea L. & Szinpetri & 1974 & Siroki Zoltán & DE-siroki-17626.jpg \\
\hline 1999 & Centaurea jacea L. & Szinpetri & 1974 & Siroki Zoltán & DE-siroki-17627.jpg \\
\hline 1999 & Centaurea jacea L. & Szinpetri & 1974 & Siroki Zoltán & DE-siroki-17636.jpg \\
\hline 1999 & Centaurea jacea L. & Szinpetri & 1974 & Siroki Zoltán & DE-siroki-17637.jpg \\
\hline
\end{tabular}




\begin{tabular}{|c|c|c|c|c|c|}
\hline $\begin{array}{l}\text { Sorszám / } \\
\text { Number }\end{array}$ & Taxon-név / Taxon-name & $\begin{array}{l}\text { Település / } \\
\text { Settlement }\end{array}$ & $\begin{array}{l}\text { Év / } \\
\text { Year }\end{array}$ & $\begin{array}{l}\text { Gyűjtő / } \\
\text { Collector }\end{array}$ & Fájlnév / File-name \\
\hline 1999 & Centaurea jacea L. & Szinpetri & 1974 & Siroki Zoltán & DE-siroki-17638.jpg \\
\hline 1999 & Centaurea jacea L. & Szinpetri & 1974 & Siroki Zoltán & DE-siroki-17639.jpg \\
\hline 1999 & Centaurea jacea L. & Szinpetri & 1974 & Siroki Zoltán & DE-siroki-17640.jpg \\
\hline 1999 & Centaurea jacea L. & Szinpetri & 1974 & Siroki Zoltán & DE-siroki-17643.jpg \\
\hline 1999 & Centaurea jacea L. & Szinpetri & 1974 & Siroki Zoltán & DE-siroki-17644.jpg \\
\hline 1999 & Centaurea jacea L. & Szinpetri & 1975 & Siroki Zoltán & DE-siroki-17628.jpg \\
\hline 1999 & Centaurea jacea L. & Szinpetri & 1975 & Siroki Zoltán & DE-siroki-17629.jpg \\
\hline 1999 & Centaurea jacea L. & Vámospércs & 1984 & Siroki Zoltán & DE-siroki-17560.jpg \\
\hline 2000 & Centaurea indurata Janka & Háromhuta & 1960 & Siroki Zoltán & DE-siroki-17596.jpg \\
\hline 2000 & Centaurea indurata Janka & Háromhuta & 1960 & Siroki Zoltán & DE-siroki-17589.jpg \\
\hline 2000 & Centaurea indurata Janka & Háromhuta & 1960 & Siroki Zoltán & DE-siroki-17590.jpg \\
\hline 2000 & Centaurea indurata Janka & Háromhuta & 1960 & Siroki Zoltán & DE-siroki-17591.jpg \\
\hline 2000 & Centaurea indurata Janka & Háromhuta & 1960 & Siroki Zoltán & DE-siroki-17592.jpg \\
\hline 2000 & Centaurea indurata Janka & Háromhuta & 1960 & Siroki Zoltán & DE-siroki-17593.jpg \\
\hline 2000 & Centaurea indurata Janka & Háromhuta & 1960 & Siroki Zoltán & DE-siroki-17594.jpg \\
\hline 2000 & Centaurea indurata Janka & Háromhuta & 1960 & Siroki Zoltán & DE-siroki-17595.jpg \\
\hline 2000 & Centaurea indurata Janka & Mátraszentimre & 1962 & Halász Tibor & DE-siroki-17597.jpg \\
\hline 2000 & Centaurea indurata Janka & Mátraszentimre & 1962 & Halász Tibor & DE-siroki-17598.jpg \\
\hline 2000 & Centaurea indurata Janka & Mátraszentimre & 1962 & Halász Tibor & DE-siroki-17599.jpg \\
\hline 2000 & Centaurea indurata Janka & Mátraszentimre & 1962 & Halász Tibor & DE-siroki-17600.jpg \\
\hline 2000 & Centaurea indurata Janka & Mátraszentimre & 1962 & Halász Tibor & DE-siroki-17601.jpg \\
\hline 2001 & Centaurea pseudophrygia C.A. Mey. & "Mátra" & 1984 & Siroki Zoltán & DE-siroki-17602.jpg \\
\hline 2001 & Centaurea pseudophrygia C.A. Mey. & "Mátra" & 1984 & Siroki Zoltán & DE-siroki-17603.jpg \\
\hline 2001 & Centaurea pseudophrygia C.A. Mey. & Budapest & 1940 & Siroki Zoltán & DE-siroki-17616.jpg \\
\hline 2001 & Centaurea pseudophrygia C.A. Mey. & Budapest & 1940 & Siroki Zoltán & DE-siroki-17617.jpg \\
\hline 2001 & Centaurea pseudophrygia C.A. Mey. & Budapest & 1948 & Siroki Zoltán & DE-siroki-17615.jpg \\
\hline 2001 & Centaurea pseudophrygia C.A. Mey. & Budapest & 1948 & Siroki Zoltán & DE-siroki-17612.jpg \\
\hline 2001 & Centaurea pseudophrygia C.A. Mey. & Budapest & 1948 & Siroki Zoltán & DE-siroki-17613.jpg \\
\hline 2001 & Centaurea pseudophrygia C.A. Mey. & Budapest & 1948 & Siroki Zoltán & DE-siroki-17614.jpg \\
\hline 2001 & Centaurea pseudophrygia C.A. Mey. & Budapest & 1985 & Siroki Zoltán & DE-siroki-17611.jpg \\
\hline 2002 & Centaurea stenolepis A. Kern. & Budapest & 1954 & Siroki Zoltán & DE-siroki-17605.jpg \\
\hline 2002 & Centaurea stenolepis A. Kern. & Budapest & 1954 & Siroki Zoltán & DE-siroki-17606.jpg \\
\hline 2002 & Centaurea stenolepis A. Kern. & Budapest & 1954 & Siroki Zoltán & DE-siroki-17607.jpg \\
\hline 2002 & Centaurea stenolepis A. Kern. & Budapest & 1985 & Siroki Zoltán & DE-siroki-17608.jpg \\
\hline 2002 & Centaurea stenolepis A. Kern. & Budapest & 1985 & Siroki Zoltán & DE-siroki-17609.jpg \\
\hline 2002 & Centaurea stenolepis A. Kern. & Budapest & 1985 & Siroki Zoltán & DE-siroki-17610.jpg \\
\hline 2003 & Centaurea cyanus L. & Debrecen & 1948 & Siroki Zoltán & DE-siroki-17726.jpg \\
\hline 2003 & Centaurea cyanus L. & Újléta & 1967 & Siroki Zoltán & DE-siroki-17723.jpg \\
\hline 2003 & Centaurea cyanus L. & Újléta & 1967 & Siroki Zoltán & DE-siroki-17724.jpg \\
\hline 2003 & Centaurea cyanus L. & Újléta & 1967 & Siroki Zoltán & DE-siroki-17725.jpg \\
\hline 2004 & Centaurea mollis Waldst. et Kit. & "Háromkő" & 1957 & Siroki Zoltán & DE-siroki-17649.jpg \\
\hline 2004 & Centaurea mollis Waldst. et Kit. & "Háromkő" & 1957 & Siroki Zoltán & DE-siroki-17650.jpg \\
\hline 2004 & Centaurea mollis Waldst. et Kit. & "Tarkő" & 1956 & Halász Tibor & DE-siroki-17648.jpg \\
\hline 2004 & Centaurea mollis Waldst. et Kit. & Szilvásvárad & 1960 & Siroki Zoltán & DE-siroki-17645.jpg \\
\hline 2004 & Centaurea mollis Waldst. et Kit. & Szilvásvárad & 1960 & Siroki Zoltán & DE-siroki-17646.jpg \\
\hline 2004 & Centaurea mollis Waldst. et Kit. & Szilvásvárad & 1960 & Siroki Zoltán & DE-siroki-17647.jpg \\
\hline
\end{tabular}




\begin{tabular}{|c|c|c|c|c|c|}
\hline $\begin{array}{l}\text { Sorszám / } \\
\text { Number }\end{array}$ & Taxon-név / Taxon-name & $\begin{array}{l}\text { Település / } \\
\text { Settlement }\end{array}$ & $\begin{array}{l}\text { Év / } \\
\text { Year }\end{array}$ & $\begin{array}{l}\text { Gyűjtő / } \\
\text { Collector }\end{array}$ & Fájlnév / File-name \\
\hline 2005 & Centaurea triumfettii All. & "Bükk-hg." & - & Halász Tibor & DE-siroki-17652.jpg \\
\hline 2005 & Centaurea triumfettii All. & "Bükk-hg." & - & Halász Tibor & DE-siroki-17653.jpg \\
\hline 2005 & Centaurea triumfettii All. & "Bükk-hg." & - & Halász Tibor & DE-siroki-17654.jpg \\
\hline 2005 & Centaurea triumfettii All. & "Háromkő" & 1956 & Halász Tibor & DE-siroki-17656.jpg \\
\hline 2005 & Centaurea triumfettii All. & "Háromkő" & 1956 & Halász Tibor & DE-siroki-17669.jpg \\
\hline 2005 & Centaurea triumfettii All. & Abaújszántó & 1943 & Siroki Zoltán & DE-siroki-17679.jpg \\
\hline 2005 & Centaurea triumfettii All. & Abaújszántó & 1943 & Siroki Zoltán & DE-siroki-17680.jpg \\
\hline 2005 & Centaurea triumfettii All. & Budaörs & 1966 & Siroki Zoltán & DE-siroki-17663.jpg \\
\hline 2005 & Centaurea triumfettii All. & Budaörs & 1966 & Siroki Zoltán & DE-siroki-17664.jpg \\
\hline 2005 & Centaurea triumfettii All. & Budaörs & 1966 & Siroki Zoltán & DE-siroki-17665.jpg \\
\hline 2005 & Centaurea triumfettii All. & Budaörs & 1966 & Siroki Zoltán & DE-siroki-17657.jpg \\
\hline 2005 & Centaurea triumfettii All. & Budaörs & 1966 & Siroki Zoltán & DE-siroki-17658.jpg \\
\hline 2005 & Centaurea triumfettii All. & Budaörs & 1966 & Siroki Zoltán & DE-siroki-17659.jpg \\
\hline 2005 & Centaurea triumfettii All. & Budaörs & 1966 & Siroki Zoltán & DE-siroki-17660.jpg \\
\hline 2005 & Centaurea triumfettii All. & Budaörs & 1966 & Siroki Zoltán & DE-siroki-17661.jpg \\
\hline 2005 & Centaurea triumfettii All. & Budaörs & 1966 & Siroki Zoltán & DE-siroki-17662.jpg \\
\hline 2005 & Centaurea triumfettii All. & Budapest & 1948 & Siroki Zoltán & DE-siroki-17674.jpg \\
\hline 2005 & Centaurea triumfettii All. & Budapest & 1948 & Siroki Zoltán & DE-siroki-17672.jpg \\
\hline 2005 & Centaurea triumfettii All. & Budapest & 1948 & Siroki Zoltán & DE-siroki-17673.jpg \\
\hline 2005 & Centaurea triumfettii All. & Budapest & 1951 & Siroki Zoltán & DE-siroki-17677.jpg \\
\hline 2005 & Centaurea triumfettii All. & Debrecen & 1953 & Siroki Zoltán & DE-siroki-17667.jpg \\
\hline 2005 & Centaurea triumfettii All. & Debrecen & 1954 & Siroki Zoltán & DE-siroki-17670.jpg \\
\hline 2005 & Centaurea triumfettii All. & Debrecen & 1954 & Siroki Zoltán & DE-siroki-17671.jpg \\
\hline 2005 & Centaurea triumfettii All. & Debrecen & 1954 & Siroki Zoltán & DE-siroki-17675.jpg \\
\hline 2005 & Centaurea triumfettii All. & Füzér & 1953 & Jeney Endre & DE-siroki-17668.jpg \\
\hline 2005 & Centaurea triumfettii All. & Háromhuta & 1967 & Siroki Zoltán & DE-siroki-17666.jpg \\
\hline 2005 & Centaurea triumfettii All. & Lábatlan & 1986 & Siroki Zoltán & DE-siroki-17655.jpg \\
\hline 2008.1 & $\begin{array}{l}\text { Centaurea scabiosa L. subsp. } \\
\text { sadleriana (Janka) Asch. et Graebn. }\end{array}$ & Budapest & 1944 & Siroki Zoltán & DE-siroki-17778.jpg \\
\hline 2008.1 & $\begin{array}{l}\text { Centaurea scabiosa L. subsp. } \\
\text { sadleriana (Janka) Asch. et Graebn. }\end{array}$ & Budapest & 1944 & Siroki Zoltán & DE-siroki-17779.jpg \\
\hline 2008.1 & $\begin{array}{l}\text { Centaurea scabiosa L. subsp. } \\
\text { sadleriana (Janka) Asch. et Graebn. }\end{array}$ & Budapest & 1948 & Siroki Zoltán & DE-siroki-17746.jpg \\
\hline 2008.1 & $\begin{array}{l}\text { Centaurea scabiosa L. subsp. } \\
\text { sadleriana (Janka) Asch. et Graebn. }\end{array}$ & Budapest & 1948 & Siroki Zoltán & DE-siroki-17747.jpg \\
\hline 2008.1 & $\begin{array}{l}\text { Centaurea scabiosa L. subsp. } \\
\text { sadleriana (Janka) Asch. et Graebn. }\end{array}$ & Budapest & 1948 & Siroki Zoltán & DE-siroki-17758.jpg \\
\hline 2008.1 & $\begin{array}{l}\text { Centaurea scabiosa L. subsp. } \\
\text { sadleriana (Janka) Asch. et Graebn. }\end{array}$ & Budapest & 1948 & Siroki Zoltán & DE-siroki-17759.jpg \\
\hline 2008.1 & $\begin{array}{l}\text { Centaurea scabiosa L. subsp. } \\
\text { sadleriana (Janka) Asch. et Graebn. }\end{array}$ & Budapest & 1948 & Siroki Zoltán & DE-siroki-17749.jpg \\
\hline 2008.1 & $\begin{array}{l}\text { Centaurea scabiosa L. subsp. } \\
\text { sadleriana (Janka) Asch. et Graebn. }\end{array}$ & Budapest & 1948 & Siroki Zoltán & DE-siroki-17750.jpg \\
\hline 2008.1 & $\begin{array}{l}\text { Centaurea scabiosa L. subsp. } \\
\text { sadleriana (Janka) Asch. et Graebn. }\end{array}$ & Budapest & 1949 & Siroki Zoltán & DE-siroki-17751.jpg \\
\hline 2008.1 & $\begin{array}{l}\text { Centaurea scabiosa L. subsp. } \\
\text { sadleriana (Janka) Asch. et Graebn. }\end{array}$ & Budapest & 1949 & Siroki Zoltán & DE-siroki-17752.jpg \\
\hline 2008.1 & $\begin{array}{l}\text { Centaurea scabiosa L. subsp. } \\
\text { sadleriana (Janka) Asch. et Graebn. }\end{array}$ & Budapest & 1949 & Siroki Zoltán & DE-siroki-17753.jpg \\
\hline 2008.1 & $\begin{array}{l}\text { Centaurea scabiosa L. subsp. } \\
\text { sadleriana (Janka) Asch. et Graebn. }\end{array}$ & Budapest & 1949 & Siroki Zoltán & DE-siroki-17754.jpg \\
\hline 2008.1 & $\begin{array}{l}\text { Centaurea scabiosa L. subsp. } \\
\text { sadleriana (Janka) Asch. et Graebn. }\end{array}$ & Budapest & 1949 & Siroki Zoltán & DE-siroki-17755.jpg \\
\hline
\end{tabular}




\begin{tabular}{|c|c|c|c|c|c|}
\hline $\begin{array}{l}\text { Sorszám / } \\
\text { Number }\end{array}$ & Taxon-név / Taxon-name & $\begin{array}{l}\text { Település / } \\
\text { Settlement }\end{array}$ & $\begin{array}{l}\text { Év / } \\
\text { Year }\end{array}$ & $\begin{array}{l}\text { Gyújtő / } \\
\text { Collector }\end{array}$ & Fájlnév / File-name \\
\hline 2008.1 & $\begin{array}{l}\text { Centaurea scabiosa L. subsp. } \\
\text { sadleriana (Janka) Asch. et Graebn. }\end{array}$ & Budapest & 1949 & Siroki Zoltán & DE-siroki-17756.jpg \\
\hline 2008.1 & $\begin{array}{l}\text { Centaurea scabiosa L. subsp. } \\
\text { sadleriana (Janka) Asch. et Graebn. }\end{array}$ & Budapest & 1949 & Siroki Zoltán & DE-siroki-17757.jpg \\
\hline 2008.1 & $\begin{array}{l}\text { Centaurea scabiosa L. subsp. } \\
\text { sadleriana (Janka) Asch. et Graebn. }\end{array}$ & Egyek & 1973 & Siroki Zoltán & DE-siroki-17776.jpg \\
\hline 2008.1 & $\begin{array}{l}\text { Centaurea scabiosa L. subsp. } \\
\text { sadleriana (Janka) Asch. et Graebn. }\end{array}$ & Egyek & 1973 & Siroki Zoltán & DE-siroki-17777.jpg \\
\hline 2008.1 & $\begin{array}{l}\text { Centaurea scabiosa L. subsp. } \\
\text { sadleriana (Janka) Asch. et Graebn. }\end{array}$ & Mosonmagyaróvár & 1939 & Siroki Zoltán & DE-siroki-17748.jpg \\
\hline 2008.2 & $\begin{array}{l}\text { Centaurea scabiosa L. } \\
\text { subsp. spinulosa (Rochel) Arcang. }\end{array}$ & Debrecen & 1947 & Siroki Zoltán & DE-siroki-17760.jpg \\
\hline 2008.2 & $\begin{array}{l}\text { Centaurea scabiosa L. } \\
\text { subsp. spinulosa (Rochel) Arcang. }\end{array}$ & Debrecen & 1947 & Siroki Zoltán & DE-siroki-17761.jpg \\
\hline 2008.2 & $\begin{array}{l}\text { Centaurea scabiosa L. } \\
\text { subsp. spinulosa (Rochel) Arcang. }\end{array}$ & Debrecen & 1947 & Siroki Zoltán & DE-siroki-17762.jpg \\
\hline 2008.2 & $\begin{array}{l}\text { Centaurea scabiosa L. } \\
\text { subsp. spinulosa (Rochel) Arcang. }\end{array}$ & Debrecen & 1947 & Siroki Zoltán & DE-siroki-17767.jpg \\
\hline 2008.2 & $\begin{array}{l}\text { Centaurea scabiosa L. } \\
\text { subsp. spinulosa (Rochel) Arcang. }\end{array}$ & Debrecen & 1947 & Siroki Zoltán & DE-siroki-17768.jpg \\
\hline 2008.2 & $\begin{array}{l}\text { Centaurea scabiosa L. } \\
\text { subsp. spinulosa (Rochel) Arcang. }\end{array}$ & Debrecen & 1947 & Siroki Zoltán & DE-siroki-17769.jpg \\
\hline 2008.2 & $\begin{array}{l}\text { Centaurea scabiosa L. } \\
\text { subsp. spinulosa (Rochel) Arcang. }\end{array}$ & Egyek & 1959 & Siroki Zoltán & DE-siroki-17766.jpg \\
\hline 2008.2 & $\begin{array}{l}\text { Centaurea scabiosa L. } \\
\text { subsp. spinulosa (Rochel) Arcang. }\end{array}$ & Egyek & 1959 & Siroki Zoltán & DE-siroki-17764.jpg \\
\hline 2008.2 & $\begin{array}{l}\text { Centaurea scabiosa L. } \\
\text { subsp. spinulosa (Rochel) Arcang. }\end{array}$ & Egyek & 1959 & Siroki Zoltán & DE-siroki-17765.jpg \\
\hline 2008.2 & $\begin{array}{l}\text { Centaurea scabiosa L. } \\
\text { subsp. spinulosa (Rochel) Arcang. }\end{array}$ & Pásztó & 1952 & Siroki Zoltán & DE-siroki-17771.jpg \\
\hline 2008.2 & $\begin{array}{l}\text { Centaurea scabiosa L. } \\
\text { subsp. spinulosa (Rochel) Arcang. }\end{array}$ & Pásztó & 1952 & Siroki Zoltán & DE-siroki-17770.jpg \\
\hline 2008.2 & $\begin{array}{l}\text { Centaurea scabiosa L. } \\
\text { subsp. spinulosa (Rochel) Arcang. }\end{array}$ & Tokaj & 1971 & Siroki Zoltán & DE-siroki-17773.jpg \\
\hline 2008.2 & $\begin{array}{l}\text { Centaurea scabiosa L. } \\
\text { subsp. spinulosa (Rochel) Arcang. }\end{array}$ & Tokaj & 1977 & Siroki Zoltán & DE-siroki-17772.jpg \\
\hline 2008.2 & $\begin{array}{l}\text { Centaurea scabiosa L. } \\
\text { subsp. spinulosa (Rochel) Arcang. }\end{array}$ & Vámospércs & 1985 & Siroki Zoltán & DE-siroki-17774.jpg \\
\hline 2008.2 & $\begin{array}{l}\text { Centaurea scabiosa L. } \\
\text { subsp. spinulosa (Rochel) Arcang. }\end{array}$ & Vámospércs & 1985 & Siroki Zoltán & DE-siroki-17775.jpg \\
\hline 2008.3 & Centaurea scabiosa L. subsp. scabiosa & "Nagymező" & 1959 & Siroki Zoltán & DE-siroki-17784.jpg \\
\hline 2008.3 & Centaurea scabiosa L. subsp. scabiosa & "Nagymező" & 1959 & Siroki Zoltán & DE-siroki-17785.jpg \\
\hline 2008.3 & Centaurea scabiosa L. subsp. scabiosa & "Nagymező" & 1959 & Siroki Zoltán & DE-siroki-17786.jpg \\
\hline 2008.3 & Centaurea scabiosa L. subsp. scabiosa & "Nagymező" & 1959 & Siroki Zoltán & DE-siroki-17787.jpg \\
\hline 2008.3 & Centaurea scabiosa L. subsp. scabiosa & "Nagymező" & 1959 & Siroki Zoltán & DE-siroki-17788.jpg \\
\hline 2008.3 & Centaurea scabiosa L. subsp. scabiosa & Budapest & 1985 & Siroki Zoltán & DE-siroki-17794.jpg \\
\hline 2008.3 & Centaurea scabiosa L. subsp. scabiosa & Szinpetri & 1974 & Siroki Zoltán & DE-siroki-17781.jpg \\
\hline 2008.3 & Centaurea scabiosa L. subsp. scabiosa & Tokaj & 1966 & Siroki Zoltán & DE-siroki-17789.jpg \\
\hline 2006 & Centaurea salonitana Vis. & Budapest & 1951 & Siroki Zoltán & DE-siroki-17728.jpg \\
\hline 2006 & Centaurea salonitana Vis. & Budapest & 1951 & Siroki Zoltán & DE-siroki-17730.jpg \\
\hline 2006 & Centaurea salonitana Vis. & Budapest & 1951 & Siroki Zoltán & DE-siroki-17731.jpg \\
\hline 2006 & Centaurea salonitana Vis. & Budapest & 1951 & Siroki Zoltán & DE-siroki-17732.jpg \\
\hline 2006 & Centaurea salonitana Vis. & Budapest & 1951 & Siroki Zoltán & DE-siroki-17733.jpg \\
\hline 2006 & Centaurea salonitana Vis. & Budapest & 1951 & Siroki Zoltán & DE-siroki-17734.jpg \\
\hline 2006 & Centaurea salonitana Vis. & Budapest & 1951 & Siroki Zoltán & DE-siroki-17735.jpg \\
\hline 2006 & Centaurea salonitana Vis. & Budapest & 1951 & Siroki Zoltán & DE-siroki-17736.jpg \\
\hline 2006 & Centaurea salonitana Vis. & Budapest & 1951 & Siroki Zoltán & DE-siroki-17737.jpg \\
\hline
\end{tabular}




\begin{tabular}{|c|c|c|c|c|c|}
\hline $\begin{array}{l}\text { Sorszám / } \\
\text { Number }\end{array}$ & Taxon-név / Taxon-name & $\begin{array}{l}\text { Település / } \\
\text { Settlement }\end{array}$ & $\begin{array}{l}\text { Év / } \\
\text { Year }\end{array}$ & $\begin{array}{l}\text { Gyújtő / } \\
\text { Collector }\end{array}$ & Fájlnév / File-name \\
\hline 2006 & Centaurea salonitana Vis. & Budapest & 1951 & Siroki Zoltán & DE-siroki-17739.jpg \\
\hline 2006 & Centaurea salonitana Vis. & Budapest & 1951 & Siroki Zoltán & DE-siroki-17740.jpg \\
\hline 2009 & Centaurea arenaria M. Bieb. ex Willd. & Ágasegyháza & 1969 & Siroki Zoltán & DE-siroki-17693.jpg \\
\hline 2009 & Centaurea arenaria M. Bieb. ex Willd. & Ágasegyháza & 1969 & Siroki Zoltán & DE-siroki-17694.jpg \\
\hline 2009 & Centaurea arenaria M. Bieb. ex Willd. & Ágasegyháza & 1969 & Siroki Zoltán & DE-siroki-17695.jpg \\
\hline 2009 & Centaurea arenaria M. Bieb. ex Willd. & Ágasegyháza & 1969 & Siroki Zoltán & DE-siroki-17696.jpg \\
\hline 2009 & Centaurea arenaria M. Bieb. ex Willd. & Bugac & 1973 & Siroki Zoltán & DE-siroki-17684.jpg \\
\hline 2009 & Centaurea arenaria M. Bieb. ex Willd. & Debrecen & 1946 & Siroki Zoltán & DE-siroki-17691.jpg \\
\hline 2009 & Centaurea arenaria M. Bieb. ex Willd. & Debrecen & 1947 & Siroki Zoltán & DE-siroki-17687.jpg \\
\hline 2009 & Centaurea arenaria M. Bieb. ex Willd. & Debrecen & 1947 & Siroki Zoltán & DE-siroki-17688.jpg \\
\hline 2009 & Centaurea arenaria M. Bieb. ex Willd. & Debrecen & 1947 & Siroki Zoltán & DE-siroki-17689.jpg \\
\hline 2009 & Centaurea arenaria M. Bieb. ex Willd. & Debrecen & 1947 & Siroki Zoltán & DE-siroki-17685.jpg \\
\hline 2009 & Centaurea arenaria M. Bieb. ex Willd. & Debrecen & 1947 & Siroki Zoltán & DE-siroki-17690.jpg \\
\hline 2009 & Centaurea arenaria M. Bieb. ex Willd. & Debrecen & 1947 & Siroki Zoltán & DE-siroki-17686.jpg \\
\hline 2009 & Centaurea arenaria M. Bieb. ex Willd. & Debrecen & 1957 & Siroki Zoltán & DE-siroki-17692.jpg \\
\hline 2009 & Centaurea arenaria M. Bieb. ex Willd. & Érpatak & 1968 & Siroki Zoltán & DE-siroki-17697.jpg \\
\hline 2009 & Centaurea arenaria M. Bieb. ex Willd. & Érpatak & 1968 & Siroki Zoltán & DE-siroki-17698.jpg \\
\hline 2009 & Centaurea arenaria M. Bieb. ex Willd. & Érpatak & 1968 & Siroki Zoltán & DE-siroki-17699.jpg \\
\hline 2009 & Centaurea arenaria M. Bieb. ex Willd. & Vámospércs & 1984 & Siroki Zoltán & DE-siroki-17682.jpg \\
\hline 2009 & Centaurea arenaria M. Bieb. ex Willd. & Vámospércs & 1984 & Siroki Zoltán & DE-siroki-17683.jpg \\
\hline 2009 & Centaurea arenaria M. Bieb. ex Willd. & Vámospércs & 1984 & Siroki Zoltán & DE-siroki-17681.jpg \\
\hline 2010 & Centaurea stoebe L. & Budaörs & 1985 & Siroki Zoltán & DE-siroki-17706.jpg \\
\hline 2010 & Centaurea stoebe L. & Budapest & 1948 & Siroki Zoltán & DE-siroki-17717.jpg \\
\hline 2010 & Centaurea stoebe L. & Budapest & 1951 & Siroki Zoltán & DE-siroki-17722.jpg \\
\hline 2010 & Centaurea stoebe L. & Budapest & 1951 & Siroki Zoltán & DE-siroki-17712.jpg \\
\hline 2010 & Centaurea stoebe L. & Budapest & 1951 & Siroki Zoltán & DE-siroki-17713.jpg \\
\hline 2010 & Centaurea stoebe L. & Budapest & 1985 & Siroki Zoltán & DE-siroki-17704.jpg \\
\hline 2010 & Centaurea stoebe L. & Budapest & 1985 & Siroki Zoltán & DE-siroki-17710.jpg \\
\hline 2010 & Centaurea stoebe L. & Budapest & 1985 & Siroki Zoltán & DE-siroki-17711.jpg \\
\hline 2010 & Centaurea stoebe L. & Budapest & 1985 & Siroki Zoltán & DE-siroki-17705.jpg \\
\hline 2010 & Centaurea stoebe L. & Debrecen & 1947 & Siroki Zoltán & DE-siroki-17719.jpg \\
\hline 2010 & Centaurea stoebe L. & Hajdúbagos & 1981 & Siroki Zoltán & DE-siroki-17700.jpg \\
\hline 2010 & Centaurea stoebe L. & Hortobágy & 1948 & Siroki Zoltán & DE-siroki-17720.jpg \\
\hline 2010 & Centaurea stoebe L. & Hortobágy & 1948 & Siroki Zoltán & DE-siroki-17701.jpg \\
\hline 2010 & Centaurea stoebe L. & Mosonmagyaróvár & 1939 & Siroki Zoltán & DE-siroki-17714.jpg \\
\hline 2010 & Centaurea stoebe L. & Mosonmagyaróvár & 1939 & Siroki Zoltán & DE-siroki-17715.jpg \\
\hline 2010 & Centaurea stoebe L. & Nagykovácsi & 1985 & Siroki Zoltán & DE-siroki-17707.jpg \\
\hline 2010 & Centaurea stoebe L. & Nagykovácsi & 1985 & Siroki Zoltán & DE-siroki-17708.jpg \\
\hline 2010 & Centaurea stoebe L. & Nagykovácsi & 1985 & Siroki Zoltán & DE-siroki-17709.jpg \\
\hline 2010 & Centaurea stoebe L. & Tokaj & 1977 & Siroki Zoltán & DE-siroki-17703.jpg \\
\hline $\begin{array}{c}1998 \times \\
1999\end{array}$ & $\begin{array}{l}\text { Centaurea nigrescens Willd. } \times \\
\text { Centaurea jacea L. }\end{array}$ & Mosonmagyaróvár & 1939 & Siroki Zoltán & DE-siroki-17568.jpg \\
\hline $\begin{array}{c}1999 \times \\
2010\end{array}$ & $\begin{array}{l}\text { Centaurea jacea L. } \times \\
\text { Centaurea stoebe L. }\end{array}$ & Hortobágy & 1948 & Siroki Zoltán & DE-siroki-17808.jpg \\
\hline 2011 & Crupina vulgaris Cass. & Budapest & 1944 & Siroki Zoltán & DE-siroki-17411.jpg \\
\hline 2011 & Crupina vulgaris Cass. & Budapest & 1944 & Siroki Zoltán & DE-siroki-17412.jpg \\
\hline 2011 & Crupina vulgaris Cass. & Budapest & 1944 & Siroki Zoltán & DE-siroki-17413.jpg \\
\hline
\end{tabular}




\begin{tabular}{|c|c|c|c|c|c|}
\hline $\begin{array}{l}\text { Sorszám / } \\
\text { Number }\end{array}$ & Taxon-név / Taxon-name & $\begin{array}{l}\text { Település / } \\
\text { Settlement }\end{array}$ & $\begin{array}{l}\text { Év / } \\
\text { Year }\end{array}$ & $\begin{array}{l}\text { Gyűjtő / } \\
\text { Collector }\end{array}$ & Fájlnév / File-name \\
\hline 2011 & Crupina vulgaris Cass. & Budapest & 1944 & Siroki Zoltán & DE-siroki-17414.jpg \\
\hline 2011 & Crupina vulgaris Cass. & Budapest & 1944 & Siroki Zoltán & DE-siroki-17415.jpg \\
\hline 2013 & Carthamus lanatus L. & Hortobágy & 1955 & Siroki Zoltán & DE-siroki-17811.jpg \\
\hline 2013 & Carthamus lanatus L. & Hortobágy & 1955 & Siroki Zoltán & DE-siroki-17812.jpg \\
\hline 2013 & Carthamus lanatus L. & Szerencs & 1951 & Siroki Zoltán & DE-siroki-17810.jpg \\
\hline 2015 & Cichorium intybus L. & Debrecen & 1947 & Siroki Zoltán & DE-siroki-17819.jpg \\
\hline 2015 & Cichorium intybus L. & Debrecen & 1957 & Siroki Zoltán & DE-siroki-17818.jpg \\
\hline 2016 & Hypochoeris maculata L. & "Nagymező" & 1959 & Siroki Zoltán & DE-siroki-17867.jpg \\
\hline 2016 & Hypochoeris maculata L. & Debrecen & 1949 & Siroki Zoltán & DE-siroki-17868.jpg \\
\hline 2016 & Hypochoeris maculata L. & Debrecen & 1949 & Siroki Zoltán & DE-siroki-17869.jpg \\
\hline 2016 & Hypochoeris maculata L. & Háromhuta & 1961 & Siroki Zoltán & DE-siroki-17865.jpg \\
\hline 2016 & Hypochoeris maculata L. & Háromhuta & 1961 & Siroki Zoltán & DE-siroki-17866.jpg \\
\hline 2017 & Hypochoeris radicata L. & Budapest & 1951 & Siroki Zoltán & DE-siroki-17852.jpg \\
\hline 2017 & Hypochoeris radicata L. & Debrecen & 1948 & Siroki Zoltán & DE-siroki-17843.jpg \\
\hline 2017 & Hypochoeris radicata L. & Debrecen & 1948 & Siroki Zoltán & DE-siroki-17849.jpg \\
\hline 2017 & Hypochoeris radicata L. & Debrecen & 1948 & Siroki Zoltán & DE-siroki-17848.jpg \\
\hline 2017 & Hypochoeris radicata L. & Debrecen & 1948 & Siroki Zoltán & DE-siroki-17842.jpg \\
\hline 2017 & Hypochoeris radicata L. & Debrecen & 1948 & Siroki Zoltán & DE-siroki-17847.jpg \\
\hline 2017 & Hypochoeris radicata L. & Debrecen & 1982 & Siroki Zoltán & DE-siroki-17841.jpg \\
\hline 2017 & Hypochoeris radicata L. & Újléta & 1966 & Siroki Zoltán & DE-siroki-17845.jpg \\
\hline 2017 & Hypochoeris radicata L. & Újléta & 1968 & Siroki Zoltán & DE-siroki-17844.jpg \\
\hline 2017 & Hypochoeris radicata L. & Újléta & 1968 & Siroki Zoltán & DE-siroki-17846.jpg \\
\hline 2017 & Hypochoeris radicata L. & Vámospércs & 1985 & Siroki Zoltán & DE-siroki-17853.jpg \\
\hline 2017 & Hypochoeris radicata L. & Vámospércs & 1985 & Siroki Zoltán & DE-siroki-17854.jpg \\
\hline 2018 & Thrincia nudicaulis (L.) Dostál & Ábrahámhegy & 1950 & Siroki Zoltán & DE-siroki-17876.jpg \\
\hline 2018 & Thrincia nudicaulis (L.) Dostál & Budapest & 1951 & Siroki Zoltán & DE-siroki-17877.jpg \\
\hline 2018 & Thrincia nudicaulis (L.) Dostál & Budapest & 1952 & Siroki Zoltán & DE-siroki-17878.jpg \\
\hline 2018 & Thrincia nudicaulis (L.) Dostál & Budapest & 1952 & Siroki Zoltán & DE-siroki-17879.jpg \\
\hline 2018 & Thrincia nudicaulis (L.) Dostál & Bugyi & 1952 & Gondola István & DE-siroki-17873.jpg \\
\hline 2018 & Thrincia nudicaulis (L.) Dostál & Bugyi & 1952 & Gondola István & DE-siroki-17874.jpg \\
\hline 2018 & Thrincia nudicaulis (L.) Dostál & Hévíz & 1955 & Siroki Zoltán & DE-siroki-17872.jpg \\
\hline 2018 & Thrincia nudicaulis (L.) Dostál & Hévíz & 1955 & Siroki Zoltán & DE-siroki-17875.jpg \\
\hline 2019 & Leontodon incanus (L.) Schrank & Gyenesdiás & 1953 & Siroki Zoltán & DE-siroki-17884.jpg \\
\hline 2019 & Leontodon incanus (L.) Schrank & Gyenesdiás & 1953 & Siroki Zoltán & DE-siroki-17885.jpg \\
\hline 2019 & Leontodon incanus (L.) Schrank & Gyenesdiás & 1953 & Siroki Zoltán & DE-siroki-17886.jpg \\
\hline 2019 & Leontodon incanus (L.) Schrank & Gyenesdiás & 1953 & Siroki Zoltán & DE-siroki-17881.jpg \\
\hline 2019 & Leontodon incanus (L.) Schrank & Gyenesdiás & 1953 & Siroki Zoltán & DE-siroki-17882.jpg \\
\hline 2019 & Leontodon incanus (L.) Schrank & Gyenesdiás & 1953 & Siroki Zoltán & DE-siroki-17883.jpg \\
\hline 2019 & Leontodon incanus (L.) Schrank & Gyenesdiás & 1955 & Siroki Zoltán & DE-siroki-17887.jpg \\
\hline 2019 & Leontodon incanus (L.) Schrank & Sopron & 1951 & Kárpáti Zoltán & DE-siroki-17880.jpg \\
\hline 2020 & Leontodon autumnalis L. & "Bánkút" & 1959 & Siroki Zoltán & DE-siroki-17917.jpg \\
\hline 2020 & Leontodon autumnalis L. & "Bánkút" & 1959 & Siroki Zoltán & DE-siroki-17918.jpg \\
\hline 2020 & Leontodon autumnalis L. & Csaroda & 1962 & Siroki Zoltán & DE-siroki-17923.jpg \\
\hline 2020 & Leontodon autumnalis L. & Csaroda & 1962 & Siroki Zoltán & DE-siroki-17925.jpg \\
\hline 2020 & Leontodon autumnalis L. & Debrecen & 1946 & Siroki Zoltán & DE-siroki-17919.jpg \\
\hline 2020 & Leontodon autumnalis L. & Debrecen & 1946 & Siroki Zoltán & DE-siroki-17924.jpg \\
\hline
\end{tabular}




\begin{tabular}{|c|c|c|c|c|c|}
\hline $\begin{array}{l}\text { Sorszám / } \\
\text { Number }\end{array}$ & Taxon-név / Taxon-name & $\begin{array}{l}\text { Település / } \\
\text { Settlement }\end{array}$ & $\begin{array}{l}\text { Év / } \\
\text { Year }\end{array}$ & $\begin{array}{l}\text { Gyűjtő / } \\
\text { Collector }\end{array}$ & Fájlnév / File-name \\
\hline 2020 & Leontodon autumnalis L. & Debrecen & 1946 & Siroki Zoltán & DE-siroki-17915.jpg \\
\hline 2020 & Leontodon autumnalis L. & Debrecen & 1946 & Siroki Zoltán & DE-siroki-17916.jpg \\
\hline 2020 & Leontodon autumnalis L. & Debrecen & 1947 & Siroki Zoltán & DE-siroki-17914.jpg \\
\hline 2020 & Leontodon autumnalis L. & Debrecen & 1957 & Siroki Zoltán & DE-siroki-17926.jpg \\
\hline 2020 & Leontodon autumnalis L. & Mosonmagyaróvár & 1939 & Siroki Zoltán & DE-siroki-17921.jpg \\
\hline 2020 & Leontodon autumnalis L. & Mosonmagyaróvár & 1939 & Siroki Zoltán & DE-siroki-17922.jpg \\
\hline 2021 & Leontodon hispidus L. & Budapest & 1909 & Kocsis István & DE-siroki-17912.jpg \\
\hline 2021 & Leontodon hispidus L. & Budapest & 1941 & Siroki Zoltán & DE-siroki-17897.jpg \\
\hline 2021 & Leontodon hispidus L. & Budapest & 1966 & Siroki Zoltán & DE-siroki-17904.jpg \\
\hline 2021 & Leontodon hispidus L. & Budapest & 1985 & Siroki Zoltán & DE-siroki-17893.jpg \\
\hline 2021 & Leontodon hispidus L. & Debrecen & 1947 & Siroki Zoltán & DE-siroki-17901.jpg \\
\hline 2021 & Leontodon hispidus L. & Debrecen & 1949 & Siroki Zoltán & DE-siroki-17898.jpg \\
\hline 2021 & Leontodon hispidus L. & Debrecen & 1949 & Siroki Zoltán & DE-siroki-17903.jpg \\
\hline 2021 & Leontodon hispidus L. & Hajdúbagos & 1981 & Siroki Zoltán & DE-siroki-17896.jpg \\
\hline 2021 & Leontodon hispidus L. & Mosonmagyaróvár & 1939 & Siroki Zoltán & DE-siroki-17900.jpg \\
\hline 2021 & Leontodon hispidus L. & Szigetszentmiklós & 1909 & Kocsis István & DE-siroki-17910.jpg \\
\hline 2021 & Leontodon hispidus L. & Vámospércs & 1985 & Siroki Zoltán & DE-siroki-17889.jpg \\
\hline 2021 & Leontodon hispidus L. & Vámospércs & 1985 & Siroki Zoltán & DE-siroki-17894.jpg \\
\hline 2021 & Leontodon hispidus L. & Vámospércs & 1985 & Siroki Zoltán & DE-siroki-17895.jpg \\
\hline 2023 & Picris hieracioides L. & Debrecen & 1947 & Siroki Zoltán & DE-siroki-17938.jpg \\
\hline 2023 & Picris hieracioides L. & Debrecen & 1947 & Siroki Zoltán & DE-siroki-17939.jpg \\
\hline 2023 & Picris hieracioides L. & Debrecen & 1985 & Siroki Zoltán & DE-siroki-17931.jpg \\
\hline 2023 & Picris hieracioides L. & Debrecen & 1985 & Siroki Zoltán & DE-siroki-17932.jpg \\
\hline 2023 & Picris hieracioides L. & Debrecen & 1985 & Siroki Zoltán & DE-siroki-17933.jpg \\
\hline 2023 & Picris hieracioides L. & Debrecen & 1985 & Siroki Zoltán & DE-siroki-17936.jpg \\
\hline 2023 & Picris hieracioides L. & Debrecen & 1985 & Siroki Zoltán & DE-siroki-17934.jpg \\
\hline 2023 & Picris hieracioides L. & Debrecen & 1985 & Siroki Zoltán & DE-siroki-17935.jpg \\
\hline 2023 & Picris hieracioides L. & Debrecen & 1985 & Siroki Zoltán & DE-siroki-17937.jpg \\
\hline 2023 & Picris hieracioides L. & Sátoraljaújhely & 1944 & Siroki Zoltán & DE-siroki-17944.jpg \\
\hline 2023 & Picris hieracioides L. & Sátoraljaújhely & 1944 & Siroki Zoltán & DE-siroki-17945.jpg \\
\hline 2024 & $\begin{array}{l}\text { Podospermum canum } \\
\text { (C.A. Mey.) Griseb. }\end{array}$ & Budaörs & 1941 & Siroki Zoltán & DE-siroki-18022.jpg \\
\hline 2024 & $\begin{array}{l}\text { Podospermum canum } \\
\text { (C.A. Mey.) Griseb. }\end{array}$ & Budapest & 1941 & Siroki Zoltán & DE-siroki-18023.jpg \\
\hline 2024 & $\begin{array}{l}\text { Podospermum canum } \\
\text { (C.A. Mey.) Griseb. }\end{array}$ & Budapest & 1951 & Siroki Zoltán & DE-siroki-18025.jpg \\
\hline 2024 & $\begin{array}{l}\text { Podospermum canum } \\
\text { (C.A. Mey.) Griseb. }\end{array}$ & Debrecen & 1947 & Siroki Zoltán & DE-siroki-18026.jpg \\
\hline 2024 & $\begin{array}{l}\text { Podospermum canum } \\
\text { (C.A. Mey.) Griseb. }\end{array}$ & Debrecen & 1947 & Siroki Zoltán & DE-siroki-18027.jpg \\
\hline 2024 & $\begin{array}{l}\text { Podospermum canum } \\
\text { (C.A. Mey.) Griseb. }\end{array}$ & Debrecen & 1976 & Siroki Zoltán & DE-siroki-18021.jpg \\
\hline 2024 & $\begin{array}{l}\text { Podospermum canum } \\
\text { (C.A. Mey.) Griseb. }\end{array}$ & Gibárt & 1942 & Siroki Zoltán & DE-siroki-18024.jpg \\
\hline 2025 & Podospermum laciniatum (L.) DC. & Debrecen & 1980 & Siroki Zoltán & DE-siroki-18028.jpg \\
\hline 2025 & Podospermum laciniatum (L.) DC. & Debrecen & 1980 & Siroki Zoltán & DE-siroki-18029.jpg \\
\hline 2025 & Podospermum laciniatum (L.) DC. & Debrecen & 1980 & Siroki Zoltán & DE-siroki-18030.jpg \\
\hline 2025 & Podospermum laciniatum (L.) DC. & Debrecen & 1980 & Siroki Zoltán & DE-siroki-18031.jpg \\
\hline 2025 & Podospermum laciniatum (L.) DC. & Debrecen & 1980 & Siroki Zoltán & DE-siroki-18032.jpg \\
\hline 2026 & Scorzonera purpurea L. & Abaújszántó & 1944 & Siroki Zoltán & DE-siroki-18017.jpg \\
\hline
\end{tabular}




\begin{tabular}{|c|c|c|c|c|c|}
\hline $\begin{array}{l}\text { Sorszám / } \\
\text { Number }\end{array}$ & Taxon-név / Taxon-name & $\begin{array}{l}\text { Település / } \\
\text { Settlement }\end{array}$ & $\begin{array}{l}\text { Év / } \\
\text { Year }\end{array}$ & $\begin{array}{l}\text { Gyűjtő / } \\
\text { Collector }\end{array}$ & Fájlnév / File-name \\
\hline 2026 & Scorzonera purpurea L. & Abaújszántó & 1944 & Siroki Zoltán & DE-siroki-18015.jpg \\
\hline 2026 & Scorzonera purpurea L. & Budapest & 1951 & Siroki Zoltán & DE-siroki-18019.jpg \\
\hline 2026 & Scorzonera purpurea L. & Gyenesdiás & 1953 & Siroki Zoltán & DE-siroki-18016.jpg \\
\hline 2026 & Scorzonera purpurea L. & Nagykovácsi & 1959 & Siroki Zoltán & DE-siroki-18014.jpg \\
\hline 2026 & Scorzonera purpurea L. & Nagykovácsi & 1959 & Siroki Zoltán & DE-siroki-18013.jpg \\
\hline 2027 & Scorzonera hispanica L. & Abaújszántó & 1944 & Siroki Zoltán & DE-siroki-17981.jpg \\
\hline 2027 & Scorzonera hispanica L. & Budapest & 1951 & Siroki Zoltán & DE-siroki-17975.jpg \\
\hline 2027 & Scorzonera hispanica L. & Budapest & 1962 & Siroki Zoltán & DE-siroki-17976.jpg \\
\hline 2027 & Scorzonera hispanica L. & Budapest & 1962 & Siroki Zoltán & DE-siroki-17977.jpg \\
\hline 2027 & Scorzonera hispanica L. & Budapest & 1962 & Siroki Zoltán & DE-siroki-17978.jpg \\
\hline 2027 & Scorzonera hispanica L. & Budapest & 1962 & Siroki Zoltán & DE-siroki-17979.jpg \\
\hline 2027 & Scorzonera hispanica L. & Pomáz & 1954 & Siroki Zoltán & DE-siroki-17973.jpg \\
\hline 2027 & Scorzonera hispanica L. & Pomáz & 1954 & Siroki Zoltán & DE-siroki-17974.jpg \\
\hline 2028 & Scorzonera austriaca L. & "Fáni-völgy" & 1955 & Siroki Zoltán & DE-siroki-17988.jpg \\
\hline 2028 & Scorzonera austriaca L. & "Fáni-völgy" & 1955 & Siroki Zoltán & DE-siroki-17989.jpg \\
\hline 2028 & Scorzonera austriaca L. & Budapest & 1951 & Siroki Zoltán & DE-siroki-17990.jpg \\
\hline 2028 & Scorzonera austriaca L. & Budapest & 1981 & Siroki Zoltán & DE-siroki-17983.jpg \\
\hline 2028 & Scorzonera austriaca L. & Budapest & 1981 & Siroki Zoltán & DE-siroki-17984.jpg \\
\hline 2028 & Scorzonera austriaca L. & Budapest & 1984 & Siroki Zoltán & DE-siroki-17985.jpg \\
\hline 2028 & Scorzonera austriaca L. & Budapest & 1984 & Siroki Zoltán & DE-siroki-17986.jpg \\
\hline 2028 & Scorzonera austriaca L. & Gyenesdiás & 1972 & Siroki Zoltán & DE-siroki-17982.jpg \\
\hline 2028 & Scorzonera austriaca L. & Nagykovácsi & 1959 & Siroki Zoltán & DE-siroki-17987.jpg \\
\hline 2030 & Scorzonera parviflora Jacq. & Budapest & 1952 & Siroki Zoltán & DE-siroki-17998.jpg \\
\hline 2030 & Scorzonera parviflora Jacq. & Budapest & 1952 & Siroki Zoltán & DE-siroki-17999.jpg \\
\hline 2030 & Scorzonera parviflora Jacq. & Budapest & 1952 & Siroki Zoltán & DE-siroki-18008.jpg \\
\hline 2030 & Scorzonera parviflora Jacq. & Budapest & 1952 & Siroki Zoltán & DE-siroki-18010.jpg \\
\hline 2030 & Scorzonera parviflora Jacq. & Bugyi & 1952 & Siroki Zoltán & DE-siroki-18012.jpg \\
\hline 2030 & Scorzonera parviflora Jacq. & Cegléd & 1969 & Siroki Zoltán & DE-siroki-18003.jpg \\
\hline 2030 & Scorzonera parviflora Jacq. & Cegléd & 1969 & Siroki Zoltán & DE-siroki-18004.jpg \\
\hline 2030 & Scorzonera parviflora Jacq. & Cegléd & 1969 & Siroki Zoltán & DE-siroki-18005.jpg \\
\hline 2030 & Scorzonera parviflora Jacq. & Dabas & 1951 & Kárpáti Zoltán & DE-siroki-18011.jpg \\
\hline 2030 & Scorzonera parviflora Jacq. & Debrecen & 1962 & Siroki Zoltán & DE-siroki-18000.jpg \\
\hline 2030 & Scorzonera parviflora Jacq. & Debrecen & 1962 & Siroki Zoltán & DE-siroki-18006.jpg \\
\hline 2030 & Scorzonera parviflora Jacq. & Debrecen & 1963 & Siroki Zoltán & DE-siroki-18007.jpg \\
\hline 2030 & Scorzonera parviflora Jacq. & Mikepércs & 1960 & Siroki Zoltán & DE-siroki-18002.jpg \\
\hline 2030 & Scorzonera parviflora Jacq. & Mikepércs & 1960 & Siroki Zoltán & DE-siroki-18009.jpg \\
\hline 2030 & Scorzonera parviflora Jacq. & Mikepércs & 1965 & Siroki Zoltán & DE-siroki-18001.jpg \\
\hline 2032 & Tragopogon dubius Scop. & "Fáni-völgy" & 1955 & Siroki Zoltán & DE-siroki-17946.jpg \\
\hline 2032 & Tragopogon dubius Scop. & Budaörs & 1955 & Siroki Zoltán & DE-siroki-17948.jpg \\
\hline 2032 & Tragopogon dubius Scop. & Budapest & 1941 & Siroki Zoltán & DE-siroki-17953.jpg \\
\hline 2032 & Tragopogon dubius Scop. & Debrecen & 1947 & Siroki Zoltán & DE-siroki-17947.jpg \\
\hline 2032 & Tragopogon dubius Scop. & Debrecen & 1960 & Siroki Zoltán & DE-siroki-17949.jpg \\
\hline 2032 & Tragopogon dubius Scop. & Debrecen & 1960 & Siroki Zoltán & DE-siroki-17950.jpg \\
\hline 2032 & Tragopogon dubius Scop. & Sátoraljaújhely & 1943 & Siroki Zoltán & DE-siroki-17951.jpg \\
\hline 2033 & Tragopogon orientalis L. & Budapest & 1941 & Siroki Zoltán & DE-siroki-17970.jpg \\
\hline 2033 & Tragopogon orientalis L. & Mosonmagyaróvár & 1939 & Siroki Zoltán & DE-siroki-17972.jpg \\
\hline
\end{tabular}




\begin{tabular}{|c|c|c|c|c|c|}
\hline $\begin{array}{l}\text { Sorszám / } \\
\text { Number }\end{array}$ & Taxon-név / Taxon-name & $\begin{array}{l}\text { Település / } \\
\text { Settlement }\end{array}$ & $\begin{array}{l}\text { Év / } \\
\text { Year }\end{array}$ & $\begin{array}{l}\text { Gyújtő / } \\
\text { Collector }\end{array}$ & Fájlnév / File-name \\
\hline 2034 & Tragopogon floccosus Waldst. et Kit. & Ágasegyháza & 1956 & Siroki Zoltán & DE-siroki-17956.jpg \\
\hline 2034 & Tragopogon floccosus Waldst. et Kit. & Ágasegyháza & 1956 & Siroki Zoltán & DE-siroki-17957.jpg \\
\hline 2034 & Tragopogon floccosus Waldst. et Kit. & Ágasegyháza & 1956 & Siroki Zoltán & DE-siroki-17958.jpg \\
\hline 2034 & Tragopogon floccosus Waldst. et Kit. & Ágasegyháza & 1956 & Siroki Zoltán & DE-siroki-17959.jpg \\
\hline 2034 & Tragopogon floccosus Waldst. et Kit. & Ágasegyháza & 1956 & Siroki Zoltán & DE-siroki-17960.jpg \\
\hline 2034 & Tragopogon floccosus Waldst. et Kit. & Ágasegyháza & 1956 & Siroki Zoltán & DE-siroki-17961.jpg \\
\hline 2034 & Tragopogon floccosus Waldst. et Kit. & Ágasegyháza & 1956 & Siroki Zoltán & DE-siroki-17962.jpg \\
\hline 2034 & Tragopogon floccosus Waldst. et Kit. & Ágasegyháza & 1956 & Siroki Zoltán & DE-siroki-17963.jpg \\
\hline 2034 & Tragopogon floccosus Waldst. et Kit. & Ágasegyháza & 1956 & Siroki Zoltán & DE-siroki-17964.jpg \\
\hline 2034 & Tragopogon floccosus Waldst. et Kit. & Ágasegyháza & 1969 & Siroki Zoltán & DE-siroki-17965.jpg \\
\hline 2034 & Tragopogon floccosus Waldst. et Kit. & Ágasegyháza & 1972 & Siroki Zoltán & DE-siroki-17966.jpg \\
\hline 2034 & Tragopogon floccosus Waldst. et Kit. & Ágasegyháza & 1972 & Siroki Zoltán & DE-siroki-17967.jpg \\
\hline 2034 & Tragopogon floccosus Waldst. et Kit. & Ágasegyháza & 1972 & Siroki Zoltán & DE-siroki-17969.jpg \\
\hline 2034 & Tragopogon floccosus Waldst. et Kit. & Bugac & 1973 & Siroki Zoltán & DE-siroki-17968.jpg \\
\hline 2035 & Sonchus asper (L.) Hill & Debrecen & 1947 & Siroki Zoltán & DE-siroki-18129.jpg \\
\hline 2035 & Sonchus asper (L.) Hill & Debrecen & 1949 & Siroki Zoltán & DE-siroki-18128.jpg \\
\hline 2035 & Sonchus asper (L.) Hill & Debrecen & 1985 & Siroki Zoltán & DE-siroki-18125.jpg \\
\hline 2035 & Sonchus asper (L.) Hill & Debrecen & 1985 & Siroki Zoltán & DE-siroki-18126.jpg \\
\hline 2035 & Sonchus asper (L.) Hill & Debrecen & 1985 & Siroki Zoltán & DE-siroki-18127.jpg \\
\hline 2035 & Sonchus asper (L.) Hill & Mosonmagyaróvár & 1939 & Siroki Zoltán & DE-siroki-18131.jpg \\
\hline 2036 & Sonchus oleraceus L. & Debrecen & 1955 & Siroki Zoltán & DE-siroki-18117.jpg \\
\hline 2036 & Sonchus oleraceus L. & Debrecen & 1955 & Siroki Zoltán & DE-siroki-18118.jpg \\
\hline 2036 & Sonchus oleraceus L. & Debrecen & 1969 & Siroki Zoltán & DE-siroki-18119.jpg \\
\hline 2036 & Sonchus oleraceus L. & Debrecen & 1969 & Siroki Zoltán & DE-siroki-18120.jpg \\
\hline 2036 & Sonchus oleraceus L. & Debrecen & 1980 & Siroki Zoltán & DE-siroki-18113.jpg \\
\hline 2036 & Sonchus oleraceus L. & Debrecen & 1980 & Siroki Zoltán & DE-siroki-18114.jpg \\
\hline 2036 & Sonchus oleraceus L. & Debrecen & 1980 & Siroki Zoltán & DE-siroki-18115.jpg \\
\hline 2036 & Sonchus oleraceus L. & Debrecen & 1980 & Siroki Zoltán & DE-siroki-18116.jpg \\
\hline 2036 & Sonchus oleraceus L. & Debrecen & 1985 & Siroki Zoltán & DE-siroki-18110.jpg \\
\hline 2036 & Sonchus oleraceus L. & Debrecen & 1985 & Siroki Zoltán & DE-siroki-18111.jpg \\
\hline 2036 & Sonchus oleraceus L. & Debrecen & 1985 & Siroki Zoltán & DE-siroki-18112.jpg \\
\hline 2036 & Sonchus oleraceus L. & Mosonmagyaróvár & 1939 & Siroki Zoltán & DE-siroki-18123.jpg \\
\hline 2036 & Sonchus oleraceus L. & Mosonmagyaróvár & 1939 & Siroki Zoltán & DE-siroki-18124.jpg \\
\hline 2038 & Sonchus arvensis L. & Budapest & - & Müller & DE-siroki-18097.jpg \\
\hline 2038 & Sonchus arvensis L. & Debrecen & 1947 & Siroki Zoltán & DE-siroki-18105.jpg \\
\hline 2038 & Sonchus arvensis L. & Debrecen & 1947 & Siroki Zoltán & DE-siroki-18104.jpg \\
\hline 2038 & Sonchus arvensis L. & Debrecen & 1985 & Siroki Zoltán & DE-siroki-18098.jpg \\
\hline 2038 & Sonchus arvensis L. & Debrecen & 1985 & Siroki Zoltán & DE-siroki-18099.jpg \\
\hline 2038 & Sonchus arvensis L. & Debrecen & 1985 & Siroki Zoltán & DE-siroki-18100.jpg \\
\hline 2038 & Sonchus arvensis L. & Debrecen & 1985 & Siroki Zoltán & DE-siroki-18101.jpg \\
\hline 2038 & Sonchus arvensis L. & Debrecen & 1985 & Siroki Zoltán & DE-siroki-18102.jpg \\
\hline 2038 & Sonchus arvensis L. & Debrecen & 1985 & Siroki Zoltán & DE-siroki-18103.jpg \\
\hline 2038 & Sonchus arvensis L. & Mosonmagyaróvár & 1939 & Siroki Zoltán & DE-siroki-18106.jpg \\
\hline 2038 & Sonchus arvensis L. & Sajólád/Sajópetri & 1951 & Siroki Zoltán & DE-siroki-18109.jpg \\
\hline 2039 & Lactuca perennis L. & $\begin{array}{l}\text { "Bükk-hg., } \\
\text { Nagytölgyes" }\end{array}$ & 1956 & Halász Tibor & DE-siroki-18138.jpg \\
\hline 2039 & Lactuca perennis L. & Budapest & 1951 & Siroki Zoltán & DE-siroki-18134.jpg \\
\hline
\end{tabular}




\begin{tabular}{|c|c|c|c|c|c|}
\hline $\begin{array}{l}\text { Sorszám / } \\
\text { Number }\end{array}$ & Taxon-név / Taxon-name & $\begin{array}{l}\text { Település / } \\
\text { Settlement }\end{array}$ & $\begin{array}{l}\text { Év / } \\
\text { Year }\end{array}$ & $\begin{array}{l}\text { Gyűjtő / } \\
\text { Collector }\end{array}$ & Fájlnév / File-name \\
\hline 2039 & Lactuca perennis L. & Szarvaskő & 1957 & Siroki Zoltán & DE-siroki-18135.jpg \\
\hline 2039 & Lactuca perennis L. & Szarvaskő & 1957 & Siroki Zoltán & DE-siroki-18136.jpg \\
\hline 2039 & Lactuca perennis L. & Szarvaskő & 1957 & Siroki Zoltán & DE-siroki-18137.jpg \\
\hline 2039 & Lactuca perennis L. & Szinpetri & 1974 & Siroki Zoltán & DE-siroki-18132.jpg \\
\hline 2039 & Lactuca perennis L. & Szinpetri & 1974 & Siroki Zoltán & DE-siroki-18133.jpg \\
\hline 2040 & Lactuca viminea (L.) J. Presl et C. Presl & Budapest & 1941 & Siroki Zoltán & DE-siroki-18144.jpg \\
\hline 2040 & Lactuca viminea (L.) J. Presl et C. Presl & Budapest & 1941 & Siroki Zoltán & DE-siroki-18145.jpg \\
\hline 2040 & Lactuca viminea (L.) J. Presl et C. Presl & Budapest & 1941 & Siroki Zoltán & DE-siroki-18146.jpg \\
\hline 2040 & Lactuca viminea (L.) J. Presl et C. Presl & Nagykovácsi & 1985 & Siroki Zoltán & DE-siroki-18141.jpg \\
\hline 2040 & Lactuca viminea (L.) J. Presl et C. Presl & Nagykovácsi & 1985 & Siroki Zoltán & DE-siroki-18142.jpg \\
\hline 2041 & Lactuca quercina $\mathrm{L}$. & Debrecen & 1947 & Siroki Zoltán & DE-siroki-18152.jpg \\
\hline 2041 & Lactuca quercina L. & Debrecen & 1948 & Siroki Zoltán & DE-siroki-18149.jpg \\
\hline 2041 & Lactuca quercina L. & Debrecen & 1948 & Siroki Zoltán & DE-siroki-18153.jpg \\
\hline 2041 & Lactuca quercina L. & Debrecen & 1948 & Siroki Zoltán & DE-siroki-18154.jpg \\
\hline 2041 & Lactuca quercina L. & Egyek & 1947 & Siroki Zoltán & DE-siroki-18151.jpg \\
\hline 2041 & Lactuca quercina L. & Egyek & 1947 & Siroki Zoltán & DE-siroki-18155.jpg \\
\hline 2041 & Lactuca quercina L. & Egyek & 1947 & Siroki Zoltán & DE-siroki-18156.jpg \\
\hline 2041 & Lactuca quercina L. & Egyek & - & Siroki Zoltán & DE-siroki-18148.jpg \\
\hline 2041 & Lactuca quercina L. & Hosszúhetény & 1954 & Siroki Zoltán & DE-siroki-18150.jpg \\
\hline 2041 & Lactuca quercina L. & Lábatlan & 1986 & Siroki Zoltán & DE-siroki-18147.jpg \\
\hline 2042 & Lactuca saligna L. & Debrecen & 1948 & Siroki Zoltán & DE-siroki-18157.jpg \\
\hline 2042 & Lactuca saligna L. & Hortobágy & 1948 & Siroki Zoltán & DE-siroki-18158.jpg \\
\hline 2043 & Lactuca serriola L. & Debrecen & 1947 & Siroki Zoltán & DE-siroki-18162.jpg \\
\hline 2043 & Lactuca serriola L. & Debrecen & 1985 & Siroki Zoltán & DE-siroki-18161.jpg \\
\hline 2043 & Lactuca serriola L. & Mosonmagyaróvár & 1939 & Siroki Zoltán & DE-siroki-18163.jpg \\
\hline 2045 & Prenanthes purpurea L. & Háromhuta & 1960 & Siroki Zoltán & DE-siroki-18310.jpg \\
\hline 2045 & Prenanthes purpurea L. & Sopron & 1956 & Siroki Zoltán & DE-siroki-18313.jpg \\
\hline 2045 & Prenanthes purpurea L. & Sopron & 1956 & Siroki Zoltán & DE-siroki-18314.jpg \\
\hline 2045 & Prenanthes purpurea L. & Szilvásvárad & 1954 & Siroki Zoltán & DE-siroki-18315.jpg \\
\hline 2045 & Prenanthes purpurea L. & Szilvásvárad & 1954 & Siroki Zoltán & DE-siroki-18316.jpg \\
\hline 2045 & Prenanthes purpurea L. & Szilvásvárad & 1954 & Siroki Zoltán & DE-siroki-18317.jpg \\
\hline 2045 & Prenanthes purpurea L. & Szilvásvárad & 1954 & Siroki Zoltán & DE-siroki-18318.jpg \\
\hline 2045 & Prenanthes purpurea L. & Szilvásvárad & 1954 & Siroki Zoltán & DE-siroki-18319.jpg \\
\hline 2045 & Prenanthes purpurea L. & Szilvásvárad & 1954 & Siroki Zoltán & DE-siroki-18311.jpg \\
\hline 2045 & Prenanthes purpurea L. & Szilvásvárad & 1954 & Siroki Zoltán & DE-siroki-18312.jpg \\
\hline 2046 & Mycelis muralis (L.) Dumort. & Csaroda & 1954 & Siroki Zoltán & DE-siroki-18084.jpg \\
\hline 2046 & Mycelis muralis (L.) Dumort. & Mosonmagyaróvár & 1939 & Siroki Zoltán & DE-siroki-18087.jpg \\
\hline 2046 & Mycelis muralis (L.) Dumort. & Mosonmagyaróvár & 1939 & Siroki Zoltán & DE-siroki-18088.jpg \\
\hline 2046 & Mycelis muralis (L.) Dumort. & Szilvásvárad & - & Siroki Zoltán & DE-siroki-18085.jpg \\
\hline 2047 & $\begin{array}{l}\text { Taraxacum bessarabicum } \\
\text { (Hornem.) Hand.-Mazz. }\end{array}$ & Abaújkér & 1943 & Siroki Zoltán & DE-siroki-18055.jpg \\
\hline 2047 & $\begin{array}{l}\text { Taraxacum bessarabicum } \\
\text { (Hornem.) Hand.-Mazz. }\end{array}$ & Balmazújváros & 1975 & Siroki Zoltán & DE-siroki-18046.jpg \\
\hline 2047 & $\begin{array}{l}\text { Taraxacum bessarabicum } \\
\text { (Hornem.) Hand.-Mazz. }\end{array}$ & Balmazújváros & 1981 & Siroki Zoltán & DE-siroki-18045.jpg \\
\hline 2047 & $\begin{array}{l}\text { Taraxacum bessarabicum } \\
\text { (Hornem.) Hand.-Mazz. }\end{array}$ & Debrecen & 1946 & Siroki Zoltán & DE-siroki-18052.jpg \\
\hline 2047 & $\begin{array}{l}\text { Taraxacum bessarabicum } \\
\text { (Hornem.) Hand.-Mazz. }\end{array}$ & Debrecen & 1948 & Siroki Zoltán & DE-siroki-18054.jpg \\
\hline
\end{tabular}




\begin{tabular}{|c|c|c|c|c|c|}
\hline $\begin{array}{l}\text { Sorszám / } \\
\text { Number }\end{array}$ & Taxon-név / Taxon-name & $\begin{array}{l}\text { Település / } \\
\text { Settlement }\end{array}$ & $\begin{array}{l}\text { Év / } \\
\text { Year }\end{array}$ & $\begin{array}{l}\text { Gyüjtő / } \\
\text { Collector }\end{array}$ & Fájlnév / File-name \\
\hline 2047 & $\begin{array}{l}\text { Taraxacum bessarabicum } \\
\text { (Hornem.) Hand.-Mazz. }\end{array}$ & Debrecen & 1948 & Siroki Zoltán & DE-siroki-18051.jpg \\
\hline 2047 & $\begin{array}{l}\text { Taraxacum bessarabicum } \\
\text { (Hornem.) Hand.-Mazz. }\end{array}$ & Debrecen & 1962 & Siroki Zoltán & DE-siroki-18048.jpg \\
\hline 2047 & $\begin{array}{l}\text { Taraxacum bessarabicum } \\
\text { (Hornem.) Hand.-Mazz. }\end{array}$ & Debrecen & 1962 & Siroki Zoltán & DE-siroki-18047.jpg \\
\hline 2047 & $\begin{array}{l}\text { Taraxacum bessarabicum } \\
\text { (Hornem.) Hand.-Mazz. }\end{array}$ & Dunaharaszti & 1951 & Siroki Zoltán & DE-siroki-18049.jpg \\
\hline 2047 & $\begin{array}{l}\text { Taraxacum bessarabicum } \\
\text { (Hornem.) Hand.-Mazz. }\end{array}$ & Dunaharaszti & 1951 & Siroki Zoltán & DE-siroki-18050.jpg \\
\hline 2047 & $\begin{array}{l}\text { Taraxacum bessarabicum } \\
\text { (Hornem.) Hand.-Mazz. }\end{array}$ & Ónod & 1949 & Siroki Zoltán & DE-siroki-18053.jpg \\
\hline 2048 & $\begin{array}{l}\text { Taraxacum serotinum } \\
\text { (Waldst. et Kit.) Poir. }\end{array}$ & Biatorbágy & 1951 & Siroki Zoltán & DE-siroki-18039.jpg \\
\hline 2048 & $\begin{array}{l}\text { Taraxacum serotinum } \\
\text { (Waldst. et Kit.) Poir. }\end{array}$ & Debrecen & 1946 & Siroki Zoltán & DE-siroki-18042.jpg \\
\hline 2048 & $\begin{array}{l}\text { Taraxacum serotinum } \\
\text { (Waldst. et Kit.) Poir. }\end{array}$ & Debrecen & 1946 & Siroki Zoltán & DE-siroki-18040.jpg \\
\hline 2048 & $\begin{array}{l}\text { Taraxacum serotinum } \\
\text { (Waldst. et Kit.) Poir. }\end{array}$ & Debrecen & 1946 & Siroki Zoltán & DE-siroki-18041.jpg \\
\hline 2048 & $\begin{array}{l}\text { Taraxacum serotinum } \\
\text { (Waldst. et Kit.) Poir. }\end{array}$ & Debrecen & 1947 & Siroki Zoltán & DE-siroki-18043.jpg \\
\hline 2048 & $\begin{array}{l}\text { Taraxacum serotinum } \\
\text { (Waldst. et Kit.) Poir. }\end{array}$ & Debrecen & 1957 & Siroki Zoltán & DE-siroki-18037.jpg \\
\hline 2048 & $\begin{array}{l}\text { Taraxacum serotinum } \\
\text { (Waldst. et Kit.) Poir. }\end{array}$ & Debrecen & 1957 & Siroki Zoltán & DE-siroki-18038.jpg \\
\hline 2048 & $\begin{array}{l}\text { Taraxacum serotinum } \\
\text { (Waldst. et Kit.) Poir. }\end{array}$ & Gödöllő & 1954 & Jeanplong József & DE-siroki-18044.jpg \\
\hline 2049 & Taraxacum laevigatum agg. & Bátorliget & 1959 & Siroki Zoltán & DE-siroki-18064.jpg \\
\hline 2049 & Taraxacum laevigatum agg. & Budapest & 1951 & Siroki Zoltán & DE-siroki-18058.jpg \\
\hline 2049 & Taraxacum laevigatum agg. & Budapest & 1952 & Siroki Zoltán & DE-siroki-18063.jpg \\
\hline 2049 & Taraxacum laevigatum agg. & Debrecen & 1948 & Siroki Zoltán & DE-siroki-18060.jpg \\
\hline 2049 & Taraxacum laevigatum agg. & Debrecen & 1954 & Siroki Zoltán & DE-siroki-18061.jpg \\
\hline 2049 & Taraxacum laevigatum agg. & Debrecen & 1954 & Siroki Zoltán & DE-siroki-18071.jpg \\
\hline 2049 & Taraxacum laevigatum agg. & Debrecen & 1964 & Siroki Zoltán & DE-siroki-18065.jpg \\
\hline 2049 & Taraxacum laevigatum agg. & Debrecen & 1968 & Siroki Zoltán & DE-siroki-18067.jpg \\
\hline 2049 & Taraxacum laevigatum agg. & Debrecen & 1968 & Siroki Zoltán & DE-siroki-18068.jpg \\
\hline 2049 & Taraxacum laevigatum agg. & Debrecen & 1968 & Siroki Zoltán & DE-siroki-18069.jpg \\
\hline 2049 & Taraxacum laevigatum agg. & Gödöllő & 1951 & Siroki Zoltán & DE-siroki-18062.jpg \\
\hline 2049 & Taraxacum laevigatum agg. & Miskolc & 1961 & Siroki Zoltán & DE-siroki-18066.jpg \\
\hline 2049 & Taraxacum laevigatum agg. & Pomáz & 1951 & Siroki Zoltán & DE-siroki-18057.jpg \\
\hline 2050 & Taraxacum officinale agg. & Baracska & 1951 & Siroki Zoltán & DE-siroki-18074.jpg \\
\hline 2050 & Taraxacum officinale agg. & Bátorliget & 1959 & Siroki Zoltán & DE-siroki-18075.jpg \\
\hline 2050 & Taraxacum officinale agg. & Debrecen & 1985 & Siroki Zoltán & DE-siroki-18077.jpg \\
\hline 2050 & Taraxacum officinale agg. & Debrecen & 1985 & Siroki Zoltán & DE-siroki-18072.jpg \\
\hline 2050 & Taraxacum officinale agg. & Debrecen & 1985 & Siroki Zoltán & DE-siroki-18073.jpg \\
\hline 2051 & Taraxacum palustre agg. & Baracska & 1951 & Siroki Zoltán & DE-siroki-18082.jpg \\
\hline 2051 & Taraxacum palustre agg. & Debrecen & 1950 & Siroki Zoltán & DE-siroki-18081.jpg \\
\hline 2053 & Lapsana communis L. & "Vértes" & 1957 & Siroki Zoltán & DE-siroki-17826.jpg \\
\hline 2053 & Lapsana communis L. & Debrecen & 1954 & Siroki Zoltán & DE-siroki-17824.jpg \\
\hline 2053 & Lapsana communis L. & Debrecen & 1954 & Siroki Zoltán & DE-siroki-17825.jpg \\
\hline 2053 & Lapsana communis L. & Mosonmagyaróvár & 1939 & Siroki Zoltán & DE-siroki-17821.jpg \\
\hline 2053 & Lapsana communis L. & Mosonmagyaróvár & 1939 & Siroki Zoltán & DE-siroki-17823.jpg \\
\hline 2054 & Crepis rhoeadifolia M. Bieb. & Ágasegyháza & 1969 & Siroki Zoltán & DE-siroki-18174.jpg \\
\hline
\end{tabular}




\begin{tabular}{|c|c|c|c|c|c|}
\hline $\begin{array}{l}\text { Sorszám / } \\
\text { Number }\end{array}$ & Taxon-név / Taxon-name & $\begin{array}{l}\text { Település / } \\
\text { Settlement }\end{array}$ & $\begin{array}{l}\text { Év / } \\
\text { Year }\end{array}$ & $\begin{array}{l}\text { Gyűjtő / } \\
\text { Collector }\end{array}$ & Fájlnév / File-name \\
\hline 2054 & Crepis rhoeadifolia M. Bieb. & Ágasegyháza & 1969 & Siroki Zoltán & DE-siroki-18175.jpg \\
\hline 2054 & Crepis rhoeadifolia M. Bieb. & Budapest & 1941 & Siroki Zoltán & DE-siroki-18182.jpg \\
\hline 2054 & Crepis rhoeadifolia M. Bieb. & Budapest & 1941 & Siroki Zoltán & DE-siroki-18183.jpg \\
\hline 2054 & Crepis rhoeadifolia M. Bieb. & Budapest & 1951 & Siroki Zoltán & DE-siroki-18176.jpg \\
\hline 2054 & Crepis rhoeadifolia M. Bieb. & Budapest & 1976 & Siroki Zoltán & DE-siroki-18171.jpg \\
\hline 2054 & Crepis rhoeadifolia M. Bieb. & Budapest & 1976 & Siroki Zoltán & DE-siroki-18172.jpg \\
\hline 2054 & Crepis rhoeadifolia M. Bieb. & Debrecen & 1946 & Siroki Zoltán & DE-siroki-18177.jpg \\
\hline 2054 & Crepis rhoeadifolia M. Bieb. & Debrecen & 1971 & Siroki Zoltán & DE-siroki-18173.jpg \\
\hline 2054 & Crepis rhoeadifolia M. Bieb. & Máriakálnok & 1939 & Siroki Zoltán & DE-siroki-18180.jpg \\
\hline 2054 & Crepis rhoeadifolia M. Bieb. & Máriakálnok & 1944 & Siroki Zoltán & DE-siroki-18181.jpg \\
\hline 2054 & Crepis rhoeadifolia M. Bieb. & Vámospércs & 1985 & Siroki Zoltán & DE-siroki-18166.jpg \\
\hline 2054 & Crepis rhoeadifolia M. Bieb. & Vámospércs & 1985 & Siroki Zoltán & DE-siroki-18167.jpg \\
\hline 2054 & Crepis rhoeadifolia M. Bieb. & Vámospércs & 1985 & Siroki Zoltán & DE-siroki-18168.jpg \\
\hline 2054 & Crepis rhoeadifolia M. Bieb. & Vámospércs & 1985 & Siroki Zoltán & DE-siroki-18169.jpg \\
\hline 2054 & Crepis rhoeadifolia M. Bieb. & Vámospércs & 1985 & Siroki Zoltán & DE-siroki-18170.jpg \\
\hline 2056 & Crepis setosa Haller & Aszaló & 1944 & Siroki Zoltán & DE-siroki-18197.jpg \\
\hline 2056 & Crepis setosa Haller & Aszaló & 1944 & Siroki Zoltán & DE-siroki-18199.jpg \\
\hline 2056 & Crepis setosa Haller & Berekböszörmény & 1970 & Siroki Zoltán & DE-siroki-18190.jpg \\
\hline 2056 & Crepis setosa Haller & Budapest & 1944 & Siroki Zoltán & DE-siroki-18201.jpg \\
\hline 2056 & Crepis setosa Haller & Budapest & 1951 & Siroki Zoltán & DE-siroki-18195.jpg \\
\hline 2056 & Crepis setosa Haller & Csenger & 1975 & Siroki Zoltán & DE-siroki-18192.jpg \\
\hline 2056 & Crepis setosa Haller & Debrecen & 1947 & Siroki Zoltán & DE-siroki-18198.jpg \\
\hline 2056 & Crepis setosa Haller & Debrecen & 1958 & Siroki Zoltán & DE-siroki-18193.jpg \\
\hline 2056 & Crepis setosa Haller & Debrecen & 1958 & Siroki Zoltán & DE-siroki-18194.jpg \\
\hline 2056 & Crepis setosa Haller & Debrecen & 1985 & Siroki Zoltán & DE-siroki-18188.jpg \\
\hline 2056 & Crepis setosa Haller & Debrecen & 1985 & Siroki Zoltán & DE-siroki-18191.jpg \\
\hline 2056 & Crepis setosa Haller & Hencida & 1983 & Siroki Zoltán & DE-siroki-18196.jpg \\
\hline 2056 & Crepis setosa Haller & Hortobágy & 1985 & Siroki Zoltán & DE-siroki-18185.jpg \\
\hline 2056 & Crepis setosa Haller & Hortobágy & 1985 & Siroki Zoltán & DE-siroki-18186.jpg \\
\hline 2056 & Crepis setosa Haller & Hortobágy & 1985 & Siroki Zoltán & DE-siroki-18187.jpg \\
\hline 2056 & Crepis setosa Haller & Hortobágy & 1985 & Siroki Zoltán & DE-siroki-18189.jpg \\
\hline 2056 & Crepis setosa Haller & Mosonmagyaróvár & 1939 & Siroki Zoltán & DE-siroki-18200.jpg \\
\hline 2057 & Crepis paludosa (L.) Moench & Hévíz & 1929 & Rigler József & DE-siroki-18293.jpg \\
\hline 2058 & Crepis praemorsa (L.) Walther & "Nagymező" & 1959 & Halász Tibor & DE-siroki-18267.jpg \\
\hline 2058 & Crepis praemorsa (L.) Walther & "Nagymező" & 1959 & Siroki Zoltán & DE-siroki-18274.jpg \\
\hline 2058 & Crepis praemorsa (L.) Walther & "Nagymező" & 1960 & Siroki Zoltán & DE-siroki-18268.jpg \\
\hline 2058 & Crepis praemorsa (L.) Walther & "Nagymező" & 1960 & Siroki Zoltán & DE-siroki-18278.jpg \\
\hline 2058 & Crepis praemorsa (L.) Walther & "Nagymező" & 1960 & Siroki Zoltán & DE-siroki-18279.jpg \\
\hline 2058 & Crepis praemorsa (L.) Walther & "Nagymező" & 1960 & Siroki Zoltán & DE-siroki-18272.jpg \\
\hline 2058 & Crepis praemorsa (L.) Walther & "Nagymező" & 1960 & Siroki Zoltán & DE-siroki-18273.jpg \\
\hline 2058 & Crepis praemorsa (L.) Walther & "Sátor-hg." & 1973 & Siroki Zoltán & DE-siroki-18275.jpg \\
\hline 2058 & Crepis praemorsa (L.) Walther & "Sátor-hg." & 1973 & Siroki Zoltán & DE-siroki-18276.jpg \\
\hline 2058 & Crepis praemorsa (L.) Walther & Debrecen & 1950 & Siroki Zoltán & DE-siroki-18277.jpg \\
\hline 2058 & Crepis praemorsa (L.) Walther & Háromhuta & 1967 & Siroki Zoltán & DE-siroki-18269.jpg \\
\hline 2058 & Crepis praemorsa (L.) Walther & Háromhuta & 1967 & Siroki Zoltán & DE-siroki-18270.jpg \\
\hline 2058 & Crepis praemorsa (L.) Walther & Háromhuta & 1967 & Siroki Zoltán & DE-siroki-18271.jpg \\
\hline
\end{tabular}




\begin{tabular}{|c|c|c|c|c|c|}
\hline $\begin{array}{l}\text { Sorszám / } \\
\text { Number }\end{array}$ & Taxon-név / Taxon-name & $\begin{array}{l}\text { Település / } \\
\text { Settlement }\end{array}$ & $\begin{array}{l}\text { Év / } \\
\text { Year }\end{array}$ & $\begin{array}{l}\text { Gyűjtő / } \\
\text { Collector }\end{array}$ & Fájlnév / File-name \\
\hline 2059 & Crepis pulchra L. & Budapest & 1951 & Siroki Zoltán & DE-siroki-18249.jpg \\
\hline 2059 & Crepis pulchra L. & Budapest & 1951 & Siroki Zoltán & DE-siroki-18254.jpg \\
\hline 2059 & Crepis pulchra L. & Budapest & 1951 & Siroki Zoltán & DE-siroki-18255.jpg \\
\hline 2059 & Crepis pulchra L. & Budapest & 1951 & Siroki Zoltán & DE-siroki-18252.jpg \\
\hline 2059 & Crepis pulchra L. & Buják & - & Siroki Zoltán & DE-siroki-18250.jpg \\
\hline 2059 & Crepis pulchra L. & Gödöllő & 1952 & Siroki Zoltán & DE-siroki-18247.jpg \\
\hline 2059 & Crepis pulchra L. & Gödöllő & 1952 & Siroki Zoltán & DE-siroki-18248.jpg \\
\hline 2059 & Crepis pulchra L. & Gödöllő & 1952 & Siroki Zoltán & DE-siroki-18253.jpg \\
\hline 2059 & Crepis pulchra L. & Gödöllő & 1952 & Siroki Zoltán & DE-siroki-18251.jpg \\
\hline 2060 & Crepis pannonica (Jacq.) K. Koch & Budapest & 1909 & Kocsis István & DE-siroki-18203.jpg \\
\hline 2060 & Crepis pannonica (Jacq.) K. Koch & Budapest & 1909 & Kocsis István & DE-siroki-18204.jpg \\
\hline 2060 & Crepis pannonica (Jacq.) K. Koch & Budapest & 1909 & Kocsis István & DE-siroki-18205.jpg \\
\hline 2060 & Crepis pannonica (Jacq.) K. Koch & Budapest & 1909 & Kocsis István & DE-siroki-18206.jpg \\
\hline 2060 & Crepis pannonica (Jacq.) K. Koch & Budapest & 1941 & Siroki Zoltán & DE-siroki-18213.jpg \\
\hline 2060 & Crepis pannonica (Jacq.) K. Koch & Budapest & 1941 & Siroki Zoltán & DE-siroki-18212.jpg \\
\hline 2060 & Crepis pannonica (Jacq.) K. Koch & Budapest & 1951 & Siroki Zoltán & DE-siroki-18202.jpg \\
\hline 2060 & Crepis pannonica (Jacq.) K. Koch & Tokaj & 1966 & Siroki Zoltán & DE-siroki-18208.jpg \\
\hline 2060 & Crepis pannonica (Jacq.) K. Koch & Tokaj & 1966 & Siroki Zoltán & DE-siroki-18210.jpg \\
\hline 2060 & Crepis pannonica (Jacq.) K. Koch & Tokaj & 1966 & Siroki Zoltán & DE-siroki-18211.jpg \\
\hline 2060 & Crepis pannonica (Jacq.) K. Koch & Tokaj & 1971 & Siroki Zoltán & DE-siroki-18207.jpg \\
\hline 2060 & Crepis pannonica (Jacq.) K. Koch & Tokaj & 1971 & Siroki Zoltán & DE-siroki-18209.jpg \\
\hline 2061 & Crepis tectorum L. & Debrecen & 1947 & Siroki Zoltán & DE-siroki-18218.jpg \\
\hline 2061 & Crepis tectorum L. & Debrecen & 1947 & Siroki Zoltán & DE-siroki-18219.jpg \\
\hline 2061 & Crepis tectorum L. & Debrecen & 1986 & Siroki Zoltán & DE-siroki-18214.jpg \\
\hline 2061 & Crepis tectorum L. & Debrecen & 1986 & Siroki Zoltán & DE-siroki-18215.jpg \\
\hline 2061 & Crepis tectorum L. & Debrecen & 1986 & Siroki Zoltán & DE-siroki-18216.jpg \\
\hline 2061 & Crepis tectorum L. & Téglás & 1967 & Siroki Zoltán & DE-siroki-18220.jpg \\
\hline 2061 & Crepis tectorum L. & Téglás & 1967 & Siroki Zoltán & DE-siroki-18221.jpg \\
\hline 2062 & Crepis biennis L. & "Sátor-hg." & 1977 & Siroki Zoltán & DE-siroki-18228.jpg \\
\hline 2062 & Crepis biennis L. & "Sátor-hg." & 1977 & Siroki Zoltán & DE-siroki-18229.jpg \\
\hline 2062 & Crepis biennis L. & "Sátor-hg." & 1977 & Siroki Zoltán & DE-siroki-18230.jpg \\
\hline 2062 & Crepis biennis L. & "Sátor-hg." & 1977 & Siroki Zoltán & DE-siroki-18231.jpg \\
\hline 2062 & Crepis biennis L. & Aszaló & 1944 & Siroki Zoltán & DE-siroki-18244.jpg \\
\hline 2062 & Crepis biennis L. & Debrecen & 1960 & Siroki Zoltán & DE-siroki-18232.jpg \\
\hline 2062 & Crepis biennis L. & Debrecen & 1960 & Siroki Zoltán & DE-siroki-18233.jpg \\
\hline 2062 & Crepis biennis L. & Debrecen & 1960 & Siroki Zoltán & DE-siroki-18234.jpg \\
\hline 2062 & Crepis biennis L. & Debrecen & 1960 & Siroki Zoltán & DE-siroki-18235.jpg \\
\hline 2062 & Crepis biennis L. & Debrecen & 1960 & Siroki Zoltán & DE-siroki-18238.jpg \\
\hline 2062 & Crepis biennis L. & Debrecen & 1960 & Siroki Zoltán & DE-siroki-18239.jpg \\
\hline 2062 & Crepis biennis L. & Debrecen & 1960 & Siroki Zoltán & DE-siroki-18240.jpg \\
\hline 2062 & Crepis biennis L. & Debrecen & 1960 & Siroki Zoltán & DE-siroki-18243.jpg \\
\hline 2062 & Crepis biennis L. & Debrecen & 1960 & Siroki Zoltán & DE-siroki-18236.jpg \\
\hline 2062 & Crepis biennis L. & Debrecen & 1960 & Siroki Zoltán & DE-siroki-18237.jpg \\
\hline 2062 & Crepis biennis L. & Debrecen & 1960 & Siroki Zoltán & DE-siroki-18241.jpg \\
\hline 2062 & Crepis biennis L. & Debrecen & 1960 & Siroki Zoltán & DE-siroki-18242.jpg \\
\hline 2062 & Crepis biennis L. & Mosonmagyaróvár & 1939 & Siroki Zoltán & DE-siroki-18222.jpg \\
\hline
\end{tabular}




\begin{tabular}{|c|c|c|c|c|c|}
\hline $\begin{array}{l}\text { Sorszám / } \\
\text { Number }\end{array}$ & Taxon-név / Taxon-name & $\begin{array}{l}\text { Település / } \\
\text { Settlement }\end{array}$ & $\begin{array}{l}\text { Év / } \\
\text { Year }\end{array}$ & $\begin{array}{l}\text { Gyújtő / } \\
\text { Collector }\end{array}$ & Fájlnév / File-name \\
\hline 2062 & Crepis biennis L. & Mosonmagyaróvár & 1939 & Siroki Zoltán & DE-siroki-18225.jpg \\
\hline 2062 & Crepis biennis L. & Mosonmagyaróvár & 1939 & Siroki Zoltán & DE-siroki-18227.jpg \\
\hline 2062 & Crepis biennis L. & Nyíri & 1942 & Siroki Zoltán & DE-siroki-18245.jpg \\
\hline 2062 & Crepis biennis L. & Szalonna & 1986 & Siroki Zoltán & DE-siroki-18223.jpg \\
\hline 2062 & Crepis biennis L. & Szalonna & 1986 & Siroki Zoltán & DE-siroki-18224.jpg \\
\hline 2065 & Hieracium pilosella L. & "Nagymező" & 1959 & Siroki Zoltán & DE-siroki-18374.jpg \\
\hline 2065 & Hieracium pilosella L. & "Nagymező" & 1959 & Siroki Zoltán & DE-siroki-18375.jpg \\
\hline 2065 & Hieracium pilosella L. & "Nagymező" & 1959 & Siroki Zoltán & DE-siroki-18358.jpg \\
\hline 2065 & Hieracium pilosella L. & "Nagymező" & 1959 & Siroki Zoltán & DE-siroki-18359.jpg \\
\hline 2065 & Hieracium pilosella L. & Budapest & 1951 & Siroki Zoltán & DE-siroki-18352.jpg \\
\hline 2065 & Hieracium pilosella L. & Budapest & 1962 & Siroki Zoltán & DE-siroki-18360.jpg \\
\hline 2065 & Hieracium pilosella L. & Budapest & 1981 & Siroki Zoltán & DE-siroki-18344.jpg \\
\hline 2065 & Hieracium pilosella L. & Budapest & 1981 & Siroki Zoltán & DE-siroki-18346.jpg \\
\hline 2065 & Hieracium pilosella L. & Budapest & 1981 & Siroki Zoltán & DE-siroki-18349.jpg \\
\hline 2065 & Hieracium pilosella L. & Cserszegtomaj & 1955 & Siroki Zoltán & DE-siroki-18355.jpg \\
\hline 2065 & Hieracium pilosella L. & Debrecen & 1949 & Siroki Zoltán & DE-siroki-18365.jpg \\
\hline 2065 & Hieracium pilosella L. & Debrecen & 1949 & Siroki Zoltán & DE-siroki-18351.jpg \\
\hline 2065 & Hieracium pilosella L. & Debrecen & 1949 & Siroki Zoltán & DE-siroki-18353.jpg \\
\hline 2065 & Hieracium pilosella L. & Debrecen & 1954 & Siroki Zoltán & DE-siroki-18357.jpg \\
\hline 2065 & Hieracium pilosella L. & Debrecen & 1984 & Siroki Zoltán & DE-siroki-18347.jpg \\
\hline 2065 & Hieracium pilosella L. & Debrecen & 1984 & Siroki Zoltán & DE-siroki-18348.jpg \\
\hline 2065 & Hieracium pilosella L. & Gödöllő & 1952 & Siroki Zoltán & DE-siroki-18363.jpg \\
\hline 2065 & Hieracium pilosella L. & Hajdúbagos & 1981 & Siroki Zoltán & DE-siroki-18371.jpg \\
\hline 2065 & Hieracium pilosella L. & Hajdúbagos & 1982 & Siroki Zoltán & DE-siroki-18345.jpg \\
\hline 2065 & Hieracium pilosella L. & Hajdúböszörmény & 1981 & Siroki Zoltán & DE-siroki-18376.jpg \\
\hline 2065 & Hieracium pilosella L. & Hajdúböszörmény & 1981 & Siroki Zoltán & DE-siroki-18377.jpg \\
\hline 2065 & Hieracium pilosella L. & Hernádszurdok & 1944 & Siroki Zoltán & DE-siroki-18364.jpg \\
\hline 2065 & Hieracium pilosella L. & Hollóháza & 1940 & Siroki Zoltán & DE-siroki-18369.jpg \\
\hline 2065 & Hieracium pilosella L. & Leányfalu & 1927 & Degen Árpád & DE-siroki-18381.jpg \\
\hline 2065 & Hieracium pilosella L. & Nyíregyháza & 1951 & Siroki Zoltán & DE-siroki-18350.jpg \\
\hline 2065 & Hieracium pilosella L. & Pécs & 1958 & Siroki Zoltán & DE-siroki-18372.jpg \\
\hline 2065 & Hieracium pilosella L. & Pécs & 1958 & Siroki Zoltán & DE-siroki-18373.jpg \\
\hline 2065 & Hieracium pilosella L. & Pomáz & 1926 & Degen Árpád & DE-siroki-18379.jpg \\
\hline 2065 & Hieracium pilosella L. & Pomáz & 1926 & Degen Árpád & DE-siroki-18380.jpg \\
\hline 2065 & Hieracium pilosella L. & Szentendre & 1925 & Degen Árpád & DE-siroki-18382.jpg \\
\hline 2065 & Hieracium pilosella L. & Szigetszentmiklós & 1910 & Kocsis István & DE-siroki-18378.jpg \\
\hline 2065 & Hieracium pilosella L. & Téglás & 1967 & Siroki Zoltán & DE-siroki-18361.jpg \\
\hline 2065 & Hieracium pilosella L. & Vámospércs & 1985 & Siroki Zoltán & DE-siroki-18343.jpg \\
\hline 2066 & Hieracium macranthum Ten. & "Nagymező" & 1963 & Siroki Zoltán & DE-siroki-18334.jpg \\
\hline 2066 & Hieracium macranthum Ten. & Bélapátfalva & 1958 & Siroki Zoltán & DE-siroki-18332.jpg \\
\hline 2066 & Hieracium macranthum Ten. & Budapest & 1941 & Siroki Zoltán & DE-siroki-18329.jpg \\
\hline 2066 & Hieracium macranthum Ten. & Budapest & 1951 & Siroki Zoltán & DE-siroki-18326.jpg \\
\hline 2066 & Hieracium macranthum Ten. & Budapest & 1951 & Siroki Zoltán & DE-siroki-18340.jpg \\
\hline 2066 & Hieracium macranthum Ten. & Budapest & 1951 & Siroki Zoltán & DE-siroki-18341.jpg \\
\hline 2066 & Hieracium macranthum Ten. & Budapest & 1951 & Siroki Zoltán & DE-siroki-18342.jpg \\
\hline 2066 & Hieracium macranthum Ten. & Debrecen & 1947 & Siroki Zoltán & DE-siroki-18324.jpg \\
\hline
\end{tabular}




\begin{tabular}{|c|c|c|c|c|c|}
\hline $\begin{array}{l}\text { Sorszám / } \\
\text { Number }\end{array}$ & Taxon-név / Taxon-name & $\begin{array}{l}\text { Település / } \\
\text { Settlement }\end{array}$ & $\begin{array}{l}\text { Év / } \\
\text { Year }\end{array}$ & $\begin{array}{l}\text { Gyújtő / } \\
\text { Collector }\end{array}$ & Fájlnév / File-name \\
\hline 2066 & Hieracium macranthum Ten. & Debrecen & 1948 & Siroki Zoltán & DE-siroki-18336.jpg \\
\hline 2066 & Hieracium macranthum Ten. & Egyek & 1947 & Siroki Zoltán & DE-siroki-18325.jpg \\
\hline 2066 & Hieracium macranthum Ten. & Gödöllő & 1952 & Siroki Zoltán & DE-siroki-18330.jpg \\
\hline 2066 & Hieracium macranthum Ten. & Gödöllő & 1952 & Siroki Zoltán & DE-siroki-18331.jpg \\
\hline 2066 & Hieracium macranthum Ten. & Gyenesdiás & 1955 & Siroki Zoltán & DE-siroki-18339.jpg \\
\hline 2066 & Hieracium macranthum Ten. & Háromhuta & 1978 & Siroki Zoltán & DE-siroki-18323.jpg \\
\hline 2066 & Hieracium macranthum Ten. & Nagykovácsi & 1957 & Siroki Zoltán & DE-siroki-18337.jpg \\
\hline 2066 & Hieracium macranthum Ten. & Pásztó & 1952 & Siroki Zoltán & DE-siroki-18338.jpg \\
\hline 2068 & Hieracium lactucella Wallr. & "Nagymező" & 1960 & Siroki Zoltán & DE-siroki-18416.jpg \\
\hline 2068 & Hieracium lactucella Wallr. & "Nagymező" & 1960 & Siroki Zoltán & DE-siroki-18417.jpg \\
\hline 2068 & Hieracium lactucella Wallr. & "Nagymező" & 1960 & Siroki Zoltán & DE-siroki-18418.jpg \\
\hline 2068 & Hieracium lactucella Wallr. & "Nagymező" & 1960 & Siroki Zoltán & DE-siroki-18419.jpg \\
\hline 2068 & Hieracium lactucella Wallr. & "Nagymező" & 1960 & Siroki Zoltán & DE-siroki-18420.jpg \\
\hline 2068 & Hieracium lactucella Wallr. & Hollóháza & 1940 & Siroki Zoltán & DE-siroki-18412.jpg \\
\hline 2068 & Hieracium lactucella Wallr. & Hollóháza & 1940 & Siroki Zoltán & DE-siroki-18413.jpg \\
\hline 2068 & Hieracium lactucella Wallr. & Kemenessömjén & 1930 & Rigler József & DE-siroki-18425.jpg \\
\hline 2068 & Hieracium lactucella Wallr. & Kemenessömjén & 1930 & Rigler József & DE-siroki-18426.jpg \\
\hline 2068 & Hieracium lactucella Wallr. & Pásztó & 1952 & Siroki Zoltán & DE-siroki-18405.jpg \\
\hline 2068 & Hieracium lactucella Wallr. & Pásztó & 1952 & Siroki Zoltán & DE-siroki-18406.jpg \\
\hline 2068 & Hieracium lactucella Wallr. & Regéc & 1967 & Siroki Zoltán & DE-siroki-18403.jpg \\
\hline 2069 & Hieracium echioides Lumn. & Boldogkőváralja & 1943 & Siroki Zoltán & DE-siroki-18694.jpg \\
\hline 2069 & Hieracium echioides Lumn. & Boldogkőváralja & 1944 & Siroki Zoltán & DE-siroki-18692.jpg \\
\hline 2069 & Hieracium echioides Lumn. & Boldogkőváralja & 1944 & Siroki Zoltán & DE-siroki-18693.jpg \\
\hline 2069 & Hieracium echioides Lumn. & Boldogkőváralja & 1944 & Siroki Zoltán & DE-siroki-18690.jpg \\
\hline 2069 & Hieracium echioides Lumn. & Boldogkőváralja & 1967 & Siroki Zoltán & DE-siroki-18686.jpg \\
\hline 2069 & Hieracium echioides Lumn. & Boldogkőváralja & 1967 & Siroki Zoltán & DE-siroki-18687.jpg \\
\hline 2069 & Hieracium echioides Lumn. & Boldogkőváralja & 1967 & Siroki Zoltán & DE-siroki-18688.jpg \\
\hline 2069 & Hieracium echioides Lumn. & Budapest & 1889 & Thaisz Lajos & DE-siroki-18682.jpg \\
\hline 2069 & Hieracium echioides Lumn. & Budapest & 1890 & Thaisz Lajos & DE-siroki-18681.jpg \\
\hline 2069 & Hieracium echioides Lumn. & Budapest & 1905 & Kocsis István & DE-siroki-18683.jpg \\
\hline 2069 & Hieracium echioides Lumn. & Gyenesdiás & 1953 & Siroki Zoltán & DE-siroki-18695.jpg \\
\hline 2069 & Hieracium echioides Lumn. & Lesenceistvánd & 1930 & Rigler József & DE-siroki-18684.jpg \\
\hline 2069 & Hieracium echioides Lumn. & Nagykovácsi & 1957 & Siroki Zoltán & DE-siroki-18691.jpg \\
\hline 2069 & Hieracium echioides Lumn. & Veresegyház & 1960 & Siroki Zoltán & DE-siroki-18689.jpg \\
\hline 2070 & Hieracium cymosum L. & "Nagymező" & 1960 & Siroki Zoltán & DE-siroki-18659.jpg \\
\hline 2070 & Hieracium cymosum L. & "Nagymező" & 1960 & Siroki Zoltán & DE-siroki-18660.jpg \\
\hline 2070 & Hieracium cymosum L. & "Nagymező" & 1960 & Siroki Zoltán & DE-siroki-18661.jpg \\
\hline 2070 & Hieracium cymosum L. & Budapest & 1888 & Czakó Kálmán & DE-siroki-18655.jpg \\
\hline 2070 & Hieracium cymosum L. & Budapest & 1888 & Czakó Kálmán & DE-siroki-18657.jpg \\
\hline 2070 & Hieracium cymosum L. & Budapest & 1888 & Czakó Kálmán & DE-siroki-18654.jpg \\
\hline 2070 & Hieracium cymosum L. & Budapest & 1951 & Siroki Zoltán & DE-siroki-18671.jpg \\
\hline 2070 & Hieracium cymosum L. & Csaroda & 1960 & Siroki Zoltán & DE-siroki-18662.jpg \\
\hline 2070 & Hieracium cymosum L. & Debrecen & 1954 & Siroki Zoltán & DE-siroki-18666.jpg \\
\hline 2070 & Hieracium cymosum L. & Debrecen & 1954 & Siroki Zoltán & DE-siroki-18667.jpg \\
\hline 2070 & Hieracium cymosum L. & Gyenesdiás & 1913 & Gondola István & DE-siroki-18653.jpg \\
\hline 2070 & Hieracium cymosum L. & Gyenesdiás & 1953 & Siroki Zoltán & DE-siroki-18668.jpg \\
\hline
\end{tabular}




\begin{tabular}{|c|c|c|c|c|c|}
\hline $\begin{array}{l}\text { Sorszám / } \\
\text { Number }\end{array}$ & Taxon-név / Taxon-name & $\begin{array}{l}\text { Település / } \\
\text { Settlement }\end{array}$ & $\begin{array}{l}\text { Év / } \\
\text { Year }\end{array}$ & $\begin{array}{l}\text { Gyújtő / } \\
\text { Collector }\end{array}$ & Fájlnév / File-name \\
\hline 2070 & Hieracium cymosum L. & Gyenesdiás & 1953 & Siroki Zoltán & DE-siroki-18669.jpg \\
\hline 2070 & Hieracium cymosum L. & Gyenesdiás & 1953 & Siroki Zoltán & DE-siroki-18663.jpg \\
\hline 2070 & Hieracium cymosum L. & Pécs & 1958 & Siroki Zoltán & DE-siroki-18665.jpg \\
\hline 2070 & Hieracium cymosum L. & Pilisszentiván & 1952 & Siroki Zoltán & DE-siroki-18670.jpg \\
\hline 2071 & Hieracium caespitosum Dumort. & "Nagymező" & 1960 & Siroki Zoltán & DE-siroki-18532.jpg \\
\hline 2071 & Hieracium caespitosum Dumort. & "Nagymező" & 1960 & Siroki Zoltán & DE-siroki-18533.jpg \\
\hline 2071 & Hieracium caespitosum Dumort. & "Nagymező" & 1960 & Siroki Zoltán & DE-siroki-18534.jpg \\
\hline 2071 & Hieracium caespitosum Dumort. & "Nagymező" & 1960 & Siroki Zoltán & DE-siroki-18535.jpg \\
\hline 2071 & Hieracium caespitosum Dumort. & "Nagymező" & 1960 & Siroki Zoltán & DE-siroki-18536.jpg \\
\hline 2071 & Hieracium caespitosum Dumort. & "Nagymező" & 1960 & Siroki Zoltán & DE-siroki-18537.jpg \\
\hline 2071 & Hieracium caespitosum Dumort. & Bátorliget & 1957 & Siroki Zoltán & DE-siroki-18527.jpg \\
\hline 2071 & Hieracium caespitosum Dumort. & Bátorliget & 1957 & Siroki Zoltán & DE-siroki-18528.jpg \\
\hline 2071 & Hieracium caespitosum Dumort. & Csaroda & 1960 & Siroki Zoltán & DE-siroki-18516.jpg \\
\hline 2071 & Hieracium caespitosum Dumort. & Csaroda & 1960 & Siroki Zoltán & DE-siroki-18517.jpg \\
\hline 2071 & Hieracium caespitosum Dumort. & Csaroda & 1960 & Siroki Zoltán & DE-siroki-18519.jpg \\
\hline 2071 & Hieracium caespitosum Dumort. & Csaroda & 1960 & Siroki Zoltán & DE-siroki-18541.jpg \\
\hline 2071 & Hieracium caespitosum Dumort. & Debrecen & 1948 & Siroki Zoltán & DE-siroki-18521.jpg \\
\hline 2071 & Hieracium caespitosum Dumort. & Debrecen & 1950 & Siroki Zoltán & DE-siroki-18523.jpg \\
\hline 2071 & Hieracium caespitosum Dumort. & Debrecen & 1950 & Siroki Zoltán & DE-siroki-18529.jpg \\
\hline 2071 & Hieracium caespitosum Dumort. & Debrecen & 1950 & Siroki Zoltán & DE-siroki-18530.jpg \\
\hline 2071 & Hieracium caespitosum Dumort. & Debrecen & 1950 & Siroki Zoltán & DE-siroki-18531.jpg \\
\hline 2071 & Hieracium caespitosum Dumort. & Debrecen & 1951 & Siroki Zoltán & DE-siroki-18522.jpg \\
\hline 2071 & Hieracium caespitosum Dumort. & Debrecen & 1951 & Siroki Zoltán & DE-siroki-18520.jpg \\
\hline 2071 & Hieracium caespitosum Dumort. & Debrecen & 1954 & Siroki Zoltán & DE-siroki-18514.jpg \\
\hline 2071 & Hieracium caespitosum Dumort. & Debrecen & 1954 & Siroki Zoltán & DE-siroki-18515.jpg \\
\hline 2071 & Hieracium caespitosum Dumort. & Nyírábrány & 1985 & Siroki Zoltán & DE-siroki-18539.jpg \\
\hline 2071 & Hieracium caespitosum Dumort. & Nyírábrány & 1985 & Siroki Zoltán & DE-siroki-18540.jpg \\
\hline 2073 & Hieracium bauhinii Schult. ex Besser & $\begin{array}{l}\text { "Bükk-hg, } \\
\text { Kiskerekhegy" }\end{array}$ & 1959 & Halász Tibor & DE-siroki-18602.jpg \\
\hline 2073 & Hieracium bauhinii Schult. ex Besser & Abaújkér & 1942 & Siroki Zoltán & DE-siroki-18625.jpg \\
\hline 2073 & Hieracium bauhinii Schult. ex Besser & Abaújkér & 1942 & Siroki Zoltán & DE-siroki-18626.jpg \\
\hline 2073 & Hieracium bauhinii Schult. ex Besser & Bátorliget & 1957 & Siroki Zoltán & DE-siroki-18606.jpg \\
\hline 2073 & Hieracium bauhinii Schult. ex Besser & Bátorliget & 1957 & Siroki Zoltán & DE-siroki-18607.jpg \\
\hline 2073 & Hieracium bauhinii Schult. ex Besser & Budapest & 1951 & Siroki Zoltán & DE-siroki-18609.jpg \\
\hline 2073 & Hieracium bauhinii Schult. ex Besser & Budapest & 1951 & Siroki Zoltán & DE-siroki-18610.jpg \\
\hline 2073 & Hieracium bauhinii Schult. ex Besser & Budapest & 1951 & Siroki Zoltán & DE-siroki-18649.jpg \\
\hline 2073 & Hieracium bauhinii Schult. ex Besser & Budapest & 1951 & Siroki Zoltán & DE-siroki-18650.jpg \\
\hline 2073 & Hieracium bauhinii Schult. ex Besser & Budapest & 1958 & Siroki Zoltán & DE-siroki-18646.jpg \\
\hline 2073 & Hieracium bauhinii Schult. ex Besser & Budapest & 1958 & Siroki Zoltán & DE-siroki-18647.jpg \\
\hline 2073 & Hieracium bauhinii Schult. ex Besser & Budapest & 1966 & Siroki Zoltán & DE-siroki-18633.jpg \\
\hline 2073 & Hieracium bauhinii Schult. ex Besser & Budapest & 1981 & Siroki Zoltán & DE-siroki-18643.jpg \\
\hline 2073 & Hieracium bauhinii Schult. ex Besser & Budapest & 1981 & Siroki Zoltán & DE-siroki-18644.jpg \\
\hline 2073 & Hieracium bauhinii Schult. ex Besser & Csaroda & 1960 & Siroki Zoltán & DE-siroki-18635.jpg \\
\hline 2073 & Hieracium bauhinii Schult. ex Besser & Csaroda & 1960 & Siroki Zoltán & DE-siroki-18636.jpg \\
\hline 2073 & Hieracium bauhinii Schult. ex Besser & Csaroda & 1960 & Siroki Zoltán & DE-siroki-18637.jpg \\
\hline 2073 & Hieracium bauhinii Schult. ex Besser & Debrecen & 1950 & Siroki Zoltán & DE-siroki-18605.jpg \\
\hline 2073 & Hieracium bauhinii Schult. ex Besser & Debrecen & 1950 & Siroki Zoltán & DE-siroki-18608.jpg \\
\hline
\end{tabular}




\begin{tabular}{|c|c|c|c|c|c|}
\hline $\begin{array}{l}\text { Sorszám / } \\
\text { Number }\end{array}$ & Taxon-név / Taxon-name & $\begin{array}{l}\text { Település / } \\
\text { Settlement }\end{array}$ & $\begin{array}{l}\text { Év / } \\
\text { Year }\end{array}$ & $\begin{array}{l}\text { Gyűjtő / } \\
\text { Collector }\end{array}$ & Fájlnév / File-name \\
\hline 2073 & Hieracium bauhinii Schult. ex Besser & Debrecen & 1950 & Siroki Zoltán & DE-siroki-18614.jpg \\
\hline 2073 & Hieracium bauhinii Schult. ex Besser & Debrecen & 1959 & Siroki Zoltán & DE-siroki-18638.jpg \\
\hline 2073 & Hieracium bauhinii Schult. ex Besser & Gödöllő & 1952 & Siroki Zoltán & DE-siroki-18611.jpg \\
\hline 2073 & Hieracium bauhinii Schult. ex Besser & Gödöllő & 1952 & Siroki Zoltán & DE-siroki-18621.jpg \\
\hline 2073 & Hieracium bauhinii Schult. ex Besser & Háromhuta & 1960 & Siroki Zoltán & DE-siroki-18601.jpg \\
\hline 2073 & Hieracium bauhinii Schult. ex Besser & Háromhuta & 1961 & Siroki Zoltán & DE-siroki-18603.jpg \\
\hline 2073 & Hieracium bauhinii Schult. ex Besser & Háromhuta & 1961 & Siroki Zoltán & DE-siroki-18604.jpg \\
\hline 2073 & Hieracium bauhinii Schult. ex Besser & Háromhuta & 1984 & Siroki Zoltán & DE-siroki-18599.jpg \\
\hline 2073 & Hieracium bauhinii Schult. ex Besser & Mátraverebély & 1952 & Siroki Zoltán & DE-siroki-18620.jpg \\
\hline 2073 & Hieracium bauhinii Schult. ex Besser & Nagyhuta & 1978 & Siroki Zoltán & DE-siroki-18641.jpg \\
\hline 2073 & Hieracium bauhinii Schult. ex Besser & Nagyhuta & 1978 & Siroki Zoltán & DE-siroki-18642.jpg \\
\hline 2073 & Hieracium bauhinii Schult. ex Besser & Noszvaj & 1958 & Siroki Zoltán & DE-siroki-18645.jpg \\
\hline 2073 & Hieracium bauhinii Schult. ex Besser & Noszvaj & 1958 & Siroki Zoltán & DE-siroki-18648.jpg \\
\hline 2073 & Hieracium bauhinii Schult. ex Besser & Pásztó & 1952 & Siroki Zoltán & DE-siroki-18612.jpg \\
\hline 2073 & Hieracium bauhinii Schult. ex Besser & Pásztó & 1952 & Siroki Zoltán & DE-siroki-18622.jpg \\
\hline 2073 & Hieracium bauhinii Schult. ex Besser & Pécs & 1958 & Siroki Zoltán & DE-siroki-18617.jpg \\
\hline 2073 & Hieracium bauhinii Schult. ex Besser & Pécs & 1958 & Siroki Zoltán & DE-siroki-18618.jpg \\
\hline 2073 & Hieracium bauhinii Schult. ex Besser & Pomáz & 1926 & Degen Árpád & DE-siroki-18600.jpg \\
\hline 2073 & Hieracium bauhinii Schult. ex Besser & Rakaca & 1982 & Siroki Zoltán & DE-siroki-18615.jpg \\
\hline 2073 & Hieracium bauhinii Schult. ex Besser & Rakaca & 1982 & Siroki Zoltán & DE-siroki-18616.jpg \\
\hline 2073 & Hieracium bauhinii Schult. ex Besser & Rakaca & 1982 & Siroki Zoltán & DE-siroki-18639.jpg \\
\hline 2073 & Hieracium bauhinii Schult. ex Besser & Rakaca & 1982 & Siroki Zoltán & DE-siroki-18640.jpg \\
\hline 2073 & Hieracium bauhinii Schult. ex Besser & Regéc & 1967 & Siroki Zoltán & DE-siroki-18629.jpg \\
\hline 2073 & Hieracium bauhinii Schult. ex Besser & Regéc & 1967 & Siroki Zoltán & DE-siroki-18630.jpg \\
\hline 2073 & Hieracium bauhinii Schult. ex Besser & Szilvásvárad & 1961 & Siroki Zoltán & DE-siroki-18634.jpg \\
\hline 2073 & Hieracium bauhinii Schult. ex Besser & Újléta & 1967 & Siroki Zoltán & DE-siroki-18631.jpg \\
\hline 2073 & Hieracium bauhinii Schult. ex Besser & Újléta & 1967 & Siroki Zoltán & DE-siroki-18632.jpg \\
\hline 2073 & Hieracium bauhinii Schult. ex Besser & Vámospércs & 1984 & Siroki Zoltán & DE-siroki-18619.jpg \\
\hline 2077 & Hieracium bifidum Kit. & Pilisszentiván & 1952 & Siroki Zoltán & DE-siroki-18739.jpg \\
\hline 2077 & Hieracium bifidum Kit. & Pilisszentiván & 1952 & Siroki Zoltán & DE-siroki-18740.jpg \\
\hline 2077 & Hieracium bifidum Kit. & Pilisszentiván & 1952 & Siroki Zoltán & DE-siroki-18741.jpg \\
\hline 2077 & Hieracium bifidum Kit. & Pilisszentiván & 1952 & Siroki Zoltán & DE-siroki-18742.jpg \\
\hline 2077 & Hieracium bifidum Kit. & Pilisszentiván & 1952 & Siroki Zoltán & DE-siroki-18762.jpg \\
\hline 2077 & Hieracium bifidum Kit. & Pilisszentiván & 1952 & Siroki Zoltán & DE-siroki-18763.jpg \\
\hline 2077 & Hieracium bifidum Kit. & Pilisszentiván & 1952 & Siroki Zoltán & DE-siroki-18764.jpg \\
\hline 2077 & Hieracium bifidum Kit. & Rezi & 1930 & Rigler József & DE-siroki-18746.jpg \\
\hline 2077 & Hieracium bifidum Kit. & Szilvásvárad & 1959 & Siroki Zoltán & DE-siroki-18737.jpg \\
\hline 2077 & Hieracium bifidum Kit. & Szilvásvárad & 1959 & Siroki Zoltán & DE-siroki-18738.jpg \\
\hline 2077 & Hieracium bifidum Kit. & Szilvásvárad & 1959 & Siroki Zoltán & DE-siroki-18759.jpg \\
\hline 2077 & Hieracium bifidum Kit. & Szilvásvárad & 1960 & Siroki Zoltán & DE-siroki-18766.jpg \\
\hline 2077 & Hieracium bifidum Kit. & Szilvásvárad & 1960 & Siroki Zoltán & DE-siroki-18767.jpg \\
\hline 2077 & Hieracium bifidum Kit. & Szilvásvárad & 1960 & Siroki Zoltán & DE-siroki-18768.jpg \\
\hline 2077 & Hieracium bifidum Kit. & Szilvásvárad & 1960 & Siroki Zoltán & DE-siroki-18782.jpg \\
\hline 2077 & Hieracium bifidum Kit. & Szilvásvárad & 1960 & Siroki Zoltán & DE-siroki-18765.jpg \\
\hline 2077 & Hieracium bifidum Kit. & Szilvásvárad & 1960 & Siroki Zoltán & DE-siroki-18747.jpg \\
\hline 2077 & Hieracium bifidum Kit. & Szilvásvárad & 1960 & Siroki Zoltán & DE-siroki-18748.jpg \\
\hline
\end{tabular}




\begin{tabular}{|c|c|c|c|c|c|}
\hline $\begin{array}{l}\text { Sorszám / } \\
\text { Number }\end{array}$ & Taxon-név / Taxon-name & $\begin{array}{l}\text { Település / } \\
\text { Settlement }\end{array}$ & $\begin{array}{l}\text { Év / } \\
\text { Year }\end{array}$ & $\begin{array}{l}\text { Gyújtő / } \\
\text { Collector }\end{array}$ & Fájlnév / File-name \\
\hline 2077 & Hieracium bifidum Kit. & Szilvásvárad & 1960 & Siroki Zoltán & DE-siroki-18753.jpg \\
\hline 2077 & Hieracium bifidum Kit. & Szilvásvárad & 1960 & Siroki Zoltán & DE-siroki-18754.jpg \\
\hline 2077 & Hieracium bifidum Kit. & Szilvásvárad & 1960 & Siroki Zoltán & DE-siroki-18755.jpg \\
\hline 2077 & Hieracium bifidum Kit. & Szilvásvárad & 1960 & Siroki Zoltán & DE-siroki-18756.jpg \\
\hline 2077 & Hieracium bifidum Kit. & Szilvásvárad & 1960 & Siroki Zoltán & DE-siroki-18757.jpg \\
\hline 2077 & Hieracium bifidum Kit. & Szilvásvárad & 1960 & Siroki Zoltán & DE-siroki-18758.jpg \\
\hline 2077 & Hieracium bifidum Kit. & Szilvásvárad & 1960 & Siroki Zoltán & DE-siroki-18751.jpg \\
\hline 2077 & Hieracium bifidum Kit. & Szilvásvárad & 1960 & Siroki Zoltán & DE-siroki-18752.jpg \\
\hline 2077 & Hieracium bifidum Kit. & Szilvásvárad & 1962 & Siroki Zoltán & DE-siroki-18749.jpg \\
\hline 2077 & Hieracium bifidum Kit. & Szilvásvárad & 1962 & Siroki Zoltán & DE-siroki-18750.jpg \\
\hline 2078 & Hieracium murorum L. & $\begin{array}{l}\text { "Bükk-hg, } \\
\text { Kiskerekhegy" }\end{array}$ & 1959 & Halász Tibor & DE-siroki-18855.jpg \\
\hline 2078 & Hieracium murorum L. & Balatonederics & 1955 & Siroki Zoltán & DE-siroki-18857.jpg \\
\hline 2078 & Hieracium murorum L. & Bélapátfalva & 1958 & Siroki Zoltán & DE-siroki-18841.jpg \\
\hline 2078 & Hieracium murorum L. & Bélapátfalva & 1958 & Siroki Zoltán & DE-siroki-18842.jpg \\
\hline 2078 & Hieracium murorum L. & Budapest & 1951 & Siroki Zoltán & DE-siroki-18836.jpg \\
\hline 2078 & Hieracium murorum L. & Budapest & 1951 & Siroki Zoltán & DE-siroki-18837.jpg \\
\hline 2078 & Hieracium murorum L. & Budapest & 1951 & Siroki Zoltán & DE-siroki-18858.jpg \\
\hline 2078 & Hieracium murorum L. & Budapest & 1951 & Siroki Zoltán & DE-siroki-18835.jpg \\
\hline 2078 & Hieracium murorum L. & Budapest & 1962 & Siroki Zoltán & DE-siroki-18851.jpg \\
\hline 2078 & Hieracium murorum L. & Budapest & 1962 & Siroki Zoltán & DE-siroki-18848.jpg \\
\hline 2078 & Hieracium murorum L. & Budapest & 1962 & Siroki Zoltán & DE-siroki-18847.jpg \\
\hline 2078 & Hieracium murorum L. & Füzérradvány & 1973 & Siroki Zoltán & DE-siroki-18832.jpg \\
\hline 2078 & Hieracium murorum L. & Füzérradvány & 1973 & Siroki Zoltán & DE-siroki-18830.jpg \\
\hline 2078 & Hieracium murorum L. & Füzérradvány & 1973 & Siroki Zoltán & DE-siroki-18831.jpg \\
\hline 2078 & Hieracium murorum L. & Gödöllő & 1952 & Siroki Zoltán & DE-siroki-18827.jpg \\
\hline 2078 & Hieracium murorum L. & Gödöllő & 1952 & Siroki Zoltán & DE-siroki-18864.jpg \\
\hline 2078 & Hieracium murorum L. & Gyenesdiás & 1955 & Siroki Zoltán & DE-siroki-18867.jpg \\
\hline 2078 & Hieracium murorum L. & Háromhuta & 1960 & Siroki Zoltán & DE-siroki-18853.jpg \\
\hline 2078 & Hieracium murorum L. & Háromhuta & 1960 & Siroki Zoltán & DE-siroki-18854.jpg \\
\hline 2078 & Hieracium murorum L. & Háromhuta & 1978 & Siroki Zoltán & DE-siroki-18833.jpg \\
\hline 2078 & Hieracium murorum L. & Pécs & 1958 & Siroki Zoltán & DE-siroki-18856.jpg \\
\hline 2078 & Hieracium murorum L. & Pécs & 1958 & Siroki Zoltán & DE-siroki-18843.jpg \\
\hline 2078 & Hieracium murorum L. & Pécs & 1958 & Siroki Zoltán & DE-siroki-18844.jpg \\
\hline 2078 & Hieracium murorum L. & Pécs & 1958 & Siroki Zoltán & DE-siroki-18845.jpg \\
\hline 2078 & Hieracium murorum L. & Pécs & 1958 & Siroki Zoltán & DE-siroki-18846.jpg \\
\hline 2078 & Hieracium murorum L. & Pomáz & 1952 & Siroki Zoltán & DE-siroki-18828.jpg \\
\hline 2078 & Hieracium murorum L. & Pomáz & 1952 & Siroki Zoltán & DE-siroki-18829.jpg \\
\hline 2078 & Hieracium murorum L. & Pomáz & 1952 & Siroki Zoltán & DE-siroki-18859.jpg \\
\hline 2078 & Hieracium murorum L. & Pomáz & 1952 & Siroki Zoltán & DE-siroki-18860.jpg \\
\hline 2078 & Hieracium murorum L. & Pomáz & 1952 & Siroki Zoltán & DE-siroki-18866.jpg \\
\hline 2078 & Hieracium murorum L. & Pomáz & 1952 & Siroki Zoltán & DE-siroki-18869.jpg \\
\hline 2078 & Hieracium murorum L. & Pomáz & 1952 & Siroki Zoltán & DE-siroki-18862.jpg \\
\hline 2078 & Hieracium murorum L. & Szada & 1952 & Siroki Zoltán & DE-siroki-18863.jpg \\
\hline 2078 & Hieracium murorum L. & Szada & 1952 & Siroki Zoltán & DE-siroki-18861.jpg \\
\hline 2078 & Hieracium murorum L. & Szada & 1952 & Siroki Zoltán & DE-siroki-18865.jpg \\
\hline 2078 & Hieracium murorum L. & Szada & 1952 & Siroki Zoltán & DE-siroki-18823.jpg \\
\hline
\end{tabular}




\begin{tabular}{|c|c|c|c|c|c|}
\hline $\begin{array}{l}\text { Sorszám / } \\
\text { Number }\end{array}$ & Taxon-név / Taxon-name & $\begin{array}{l}\text { Település / } \\
\text { Settlement }\end{array}$ & $\begin{array}{l}\text { Év / } \\
\text { Year }\end{array}$ & $\begin{array}{l}\text { Gyújitő / } \\
\text { Collector }\end{array}$ & Fájlnév / File-name \\
\hline 2078 & Hieracium murorum L. & Szada & 1952 & Siroki Zoltán & DE-siroki-18824.jpg \\
\hline 2078 & Hieracium murorum L. & Szada & 1952 & Siroki Zoltán & DE-siroki-18825.jpg \\
\hline 2078 & Hieracium murorum L. & Szada & 1952 & Siroki Zoltán & DE-siroki-18826.jpg \\
\hline 2078 & Hieracium murorum L. & Szilvásvárad & 1954 & Siroki Zoltán & DE-siroki-18834.jpg \\
\hline 2078 & Hieracium murorum L. & Szilvásvárad & 1954 & Siroki Zoltán & DE-siroki-18868.jpg \\
\hline 2078 & Hieracium murorum L. & Szilvásvárad & 1960 & Siroki Zoltán & DE-siroki-18849.jpg \\
\hline 2078 & Hieracium murorum L. & Szilvásvárad & 1960 & Siroki Zoltán & DE-siroki-18850.jpg \\
\hline 2078 & Hieracium murorum L. & Szilvásvárad & 1960 & Siroki Zoltán & DE-siroki-18852.jpg \\
\hline 2079 & Hieracium lachenalii C.C. Gmel. & "Dobogókő" & 1957 & Siroki Zoltán & DE-siroki-18935.jpg \\
\hline 2079 & Hieracium lachenalii C.C. Gmel. & Balatonederics & 1955 & Siroki Zoltán & DE-siroki-18938.jpg \\
\hline 2079 & Hieracium lachenalii C.C. Gmel. & Balatonederics & 1955 & Siroki Zoltán & DE-siroki-18939.jpg \\
\hline 2079 & Hieracium lachenalii C.C. Gmel. & Balatonederics & 1955 & Siroki Zoltán & DE-siroki-18940.jpg \\
\hline 2079 & Hieracium lachenalii C.C. Gmel. & Balatonederics & 1955 & Siroki Zoltán & DE-siroki-18941.jpg \\
\hline 2079 & Hieracium lachenalii C.C. Gmel. & Balatonederics & 1955 & Siroki Zoltán & DE-siroki-18942.jpg \\
\hline 2079 & Hieracium lachenalii C.C. Gmel. & Balatonederics & 1955 & Siroki Zoltán & DE-siroki-18943.jpg \\
\hline 2079 & Hieracium lachenalii C.C. Gmel. & Balatonederics & 1955 & Siroki Zoltán & DE-siroki-18944.jpg \\
\hline 2079 & Hieracium lachenalii C.C. Gmel. & Balatonederics & 1955 & Siroki Zoltán & DE-siroki-18946.jpg \\
\hline 2079 & Hieracium lachenalii C.C. Gmel. & Balatonederics & 1955 & Siroki Zoltán & DE-siroki-18947.jpg \\
\hline 2079 & Hieracium lachenalii C.C. Gmel. & Budapest & 1889 & Borbás Vince & DE-siroki-18911.jpg \\
\hline 2079 & Hieracium lachenalii C.C. Gmel. & Budapest & 1890 & Borbás Vince & DE-siroki-18916.jpg \\
\hline 2079 & Hieracium lachenalii C.C. Gmel. & Budapest & 1890 & Czakó Kálmán & DE-siroki-18917.jpg \\
\hline 2079 & Hieracium lachenalii C.C. Gmel. & Gödöllő & 1952 & Siroki Zoltán & DE-siroki-18879.jpg \\
\hline 2079 & Hieracium lachenalii C.C. Gmel. & Gyenesdiás & 1955 & Siroki Zoltán & DE-siroki-18948.jpg \\
\hline 2079 & Hieracium lachenalii C.C. Gmel. & Háromhuta & 1962 & Siroki Zoltán & DE-siroki-18904.jpg \\
\hline 2079 & Hieracium lachenalii C.C. Gmel. & Háromhuta & 1962 & Siroki Zoltán & DE-siroki-18905.jpg \\
\hline 2079 & Hieracium lachenalii C.C. Gmel. & Háromhuta & 1962 & Siroki Zoltán & DE-siroki-18926.jpg \\
\hline 2079 & Hieracium lachenalii C.C. Gmel. & Háromhuta & 1962 & Siroki Zoltán & DE-siroki-18927.jpg \\
\hline 2079 & Hieracium lachenalii C.C. Gmel. & Háromhuta & 1962 & Siroki Zoltán & DE-siroki-18928.jpg \\
\hline 2079 & Hieracium lachenalii C.C. Gmel. & Háromhuta & 1967 & Siroki Zoltán & DE-siroki-18900.jpg \\
\hline 2079 & Hieracium lachenalii C.C. Gmel. & Háromhuta & 1967 & Siroki Zoltán & DE-siroki-18901.jpg \\
\hline 2079 & Hieracium lachenalii C.C. Gmel. & Háromhuta & 1967 & Siroki Zoltán & DE-siroki-18902.jpg \\
\hline 2079 & Hieracium lachenalii C.C. Gmel. & Háromhuta & 1967 & Siroki Zoltán & DE-siroki-18903.jpg \\
\hline 2079 & Hieracium lachenalii C.C. Gmel. & Háromhuta & 1967 & Siroki Zoltán & DE-siroki-18906.jpg \\
\hline 2079 & Hieracium lachenalii C.C. Gmel. & Háromhuta & 1967 & Siroki Zoltán & DE-siroki-18907.jpg \\
\hline 2079 & Hieracium lachenalii C.C. Gmel. & Miskolc & 1959 & Siroki Zoltán & DE-siroki-18929.jpg \\
\hline 2079 & Hieracium lachenalii C.C. Gmel. & Nagyhuta & 1978 & Siroki Zoltán & DE-siroki-18894.jpg \\
\hline 2079 & Hieracium lachenalii C.C. Gmel. & Nagyhuta & - & Siroki Zoltán & DE-siroki-18893.jpg \\
\hline 2079 & Hieracium lachenalii C.C. Gmel. & Nagyvisnyó & 1959 & Siroki Zoltán & DE-siroki-18930.jpg \\
\hline 2079 & Hieracium lachenalii C.C. Gmel. & Nagyvisnyó & 1959 & Siroki Zoltán & DE-siroki-18931.jpg \\
\hline 2079 & Hieracium lachenalii C.C. Gmel. & Nagyvisnyó & 1959 & Siroki Zoltán & DE-siroki-18932.jpg \\
\hline 2079 & Hieracium lachenalii C.C. Gmel. & Nagyvisnyó & 1959 & Siroki Zoltán & DE-siroki-18933.jpg \\
\hline 2079 & Hieracium lachenalii C.C. Gmel. & Nagyvisnyó & 1959 & Siroki Zoltán & DE-siroki-18934.jpg \\
\hline 2079 & Hieracium lachenalii C.C. Gmel. & Noszvaj & 1958 & Siroki Zoltán & DE-siroki-18876.jpg \\
\hline 2079 & Hieracium lachenalii C.C. Gmel. & Noszvaj & 1958 & Siroki Zoltán & DE-siroki-18877.jpg \\
\hline 2079 & Hieracium lachenalii C.C. Gmel. & Noszvaj & 1958 & Siroki Zoltán & DE-siroki-18892.jpg \\
\hline 2079 & Hieracium lachenalii C.C. Gmel. & Pomáz & 1954 & Siroki Zoltán & DE-siroki-18937.jpg \\
\hline
\end{tabular}




\begin{tabular}{|c|c|c|c|c|c|}
\hline $\begin{array}{l}\text { Sorszám / } \\
\text { Number }\end{array}$ & Taxon-név / Taxon-name & $\begin{array}{l}\text { Település / } \\
\text { Settlement }\end{array}$ & $\begin{array}{l}\text { Év / } \\
\text { Year }\end{array}$ & $\begin{array}{l}\text { Gyűjtő / } \\
\text { Collector }\end{array}$ & Fájlnév / File-name \\
\hline 2079 & Hieracium lachenalii C.C. Gmel. & Pomáz & 1954 & Siroki Zoltán & DE-siroki-18949.jpg \\
\hline 2079 & Hieracium lachenalii C.C. Gmel. & Pomáz & 1954 & Siroki Zoltán & DE-siroki-18950.jpg \\
\hline 2079 & Hieracium lachenalii C.C. Gmel. & Rezi & 1955 & Siroki Zoltán & DE-siroki-18945.jpg \\
\hline 2079 & Hieracium lachenalii C.C. Gmel. & Szada & 1952 & Siroki Zoltán & DE-siroki-18951.jpg \\
\hline 2079 & Hieracium lachenalii C.C. Gmel. & Szada & 1952 & Siroki Zoltán & DE-siroki-18880.jpg \\
\hline 2079 & Hieracium lachenalii C.C. Gmel. & Szada & 1952 & Siroki Zoltán & DE-siroki-18881.jpg \\
\hline 2079 & Hieracium lachenalii C.C. Gmel. & Szada & 1952 & Siroki Zoltán & DE-siroki-18878.jpg \\
\hline 2079 & Hieracium lachenalii C.C. Gmel. & Szilvásvárad & 1954 & Siroki Zoltán & DE-siroki-18886.jpg \\
\hline 2079 & Hieracium lachenalii C.C. Gmel. & Szilvásvárad & 1954 & Siroki Zoltán & DE-siroki-18887.jpg \\
\hline 2079 & Hieracium lachenalii C.C. Gmel. & Szilvásvárad & 1954 & Siroki Zoltán & DE-siroki-18936.jpg \\
\hline 2081 & Hieracium umbellatum L. & Budapest & 1948 & Siroki Zoltán & DE-siroki-19076.jpg \\
\hline 2081 & Hieracium umbellatum L. & Budapest & 1948 & Siroki Zoltán & DE-siroki-19084.jpg \\
\hline 2081 & Hieracium umbellatum L. & Csaroda & 1954 & Siroki Zoltán & DE-siroki-19078.jpg \\
\hline 2081 & Hieracium umbellatum L. & Debrecen & 1947 & Siroki Zoltán & DE-siroki-19066.jpg \\
\hline 2081 & Hieracium umbellatum L. & Debrecen & 1947 & Siroki Zoltán & DE-siroki-19077.jpg \\
\hline 2081 & Hieracium umbellatum L. & Debrecen & 1977 & Siroki Zoltán & DE-siroki-19063.jpg \\
\hline 2081 & Hieracium umbellatum L. & Debrecen & 1977 & Siroki Zoltán & DE-siroki-19064.jpg \\
\hline 2081 & Hieracium umbellatum L. & Egyek & 1947 & Siroki Zoltán & DE-siroki-19067.jpg \\
\hline 2081 & Hieracium umbellatum L. & Egyek & 1975 & Siroki Zoltán & DE-siroki-19065.jpg \\
\hline 2081 & Hieracium umbellatum L. & Háromhuta & 1961 & Siroki Zoltán & DE-siroki-19082.jpg \\
\hline 2081 & Hieracium umbellatum L. & Háromhuta & 1961 & Siroki Zoltán & DE-siroki-19083.jpg \\
\hline 2081 & Hieracium umbellatum L. & Háromhuta & 1978 & Siroki Zoltán & DE-siroki-19070.jpg \\
\hline 2081 & Hieracium umbellatum L. & Háromhuta & 1978 & Siroki Zoltán & DE-siroki-19071.jpg \\
\hline 2081 & Hieracium umbellatum L. & Háromhuta & 1978 & Siroki Zoltán & DE-siroki-19072.jpg \\
\hline 2081 & Hieracium umbellatum L. & Háromhuta & - & Siroki Zoltán & DE-siroki-19079.jpg \\
\hline 2081 & Hieracium umbellatum L. & Tokaj & 1971 & Siroki Zoltán & DE-siroki-19080.jpg \\
\hline 2081 & Hieracium umbellatum L. & Tokaj & 1971 & Siroki Zoltán & DE-siroki-19081.jpg \\
\hline 2082 & Hieracium sabaudum L. & "Vértes" & 1957 & Siroki Zoltán & DE-siroki-19116.jpg \\
\hline 2082 & Hieracium sabaudum L. & Budapest & 1950 & Siroki Zoltán & DE-siroki-19126.jpg \\
\hline 2082 & Hieracium sabaudum L. & Budapest & 1950 & Siroki Zoltán & DE-siroki-19127.jpg \\
\hline 2082 & Hieracium sabaudum L. & Budapest & 1950 & Siroki Zoltán & DE-siroki-19124.jpg \\
\hline 2082 & Hieracium sabaudum L. & Budapest & 1950 & Siroki Zoltán & DE-siroki-19109.jpg \\
\hline 2082 & Hieracium sabaudum L. & Budapest & 1950 & Siroki Zoltán & DE-siroki-19110.jpg \\
\hline 2082 & Hieracium sabaudum L. & Budapest & 1950 & Siroki Zoltán & DE-siroki-19123.jpg \\
\hline 2082 & Hieracium sabaudum L. & Budapest & 1951 & Siroki Zoltán & DE-siroki-19104.jpg \\
\hline 2082 & Hieracium sabaudum L. & Budapest & 1954 & Siroki Zoltán & DE-siroki-19129.jpg \\
\hline 2082 & Hieracium sabaudum L. & Budapest & 1954 & Siroki Zoltán & DE-siroki-19130.jpg \\
\hline 2082 & Hieracium sabaudum L. & Budapest & 1954 & Siroki Zoltán & DE-siroki-19132.jpg \\
\hline 2082 & Hieracium sabaudum L. & Egyek & 1975 & Siroki Zoltán & DE-siroki-19117.jpg \\
\hline 2082 & Hieracium sabaudum L. & Gödöllő & 1952 & Siroki Zoltán & DE-siroki-19114.jpg \\
\hline 2082 & Hieracium sabaudum L. & Háromhuta & 1978 & Siroki Zoltán & DE-siroki-19136.jpg \\
\hline 2082 & Hieracium sabaudum L. & Háromhuta & 1978 & Siroki Zoltán & DE-siroki-19115.jpg \\
\hline 2082 & Hieracium sabaudum L. & Háromhuta & 1978 & Siroki Zoltán & DE-siroki-19118.jpg \\
\hline 2082 & Hieracium sabaudum L. & Háromhuta & 1978 & Siroki Zoltán & DE-siroki-19138.jpg \\
\hline 2082 & Hieracium sabaudum L. & Háromhuta & - & Siroki Zoltán & DE-siroki-19137.jpg \\
\hline 2082 & Hieracium sabaudum L. & Miskolc & 1959 & Siroki Zoltán & DE-siroki-19131.jpg \\
\hline
\end{tabular}




\begin{tabular}{|c|c|c|c|c|c|}
\hline $\begin{array}{l}\text { Sorszám / } \\
\text { Number }\end{array}$ & Taxon-név / Taxon-name & $\begin{array}{l}\text { Település / } \\
\text { Settlement }\end{array}$ & $\begin{array}{l}\text { Év / } \\
\text { Year }\end{array}$ & $\begin{array}{l}\text { Gyújtő / } \\
\text { Collector }\end{array}$ & Fájlnév / File-name \\
\hline 2082 & Hieracium sabaudum L. & Miskolc & 1959 & Siroki Zoltán & DE-siroki-19133.jpg \\
\hline 2082 & Hieracium sabaudum L. & Noszvaj & 1958 & Siroki Zoltán & DE-siroki-19113.jpg \\
\hline 2082 & Hieracium sabaudum L. & Sopron & 1956 & Kovács Béla & DE-siroki-19128.jpg \\
\hline 2087 & Hieracium $\times$ bifurcum M. Bieb. & Boldogkőváralja & 1967 & Siroki Zoltán & DE-siroki-18450.jpg \\
\hline 2089 & Hieracium $\times$ laschii Zahn & Boldogkőváralja & 1944 & Siroki Zoltán & DE-siroki-18451.jpg \\
\hline 2090 & Hieracium $\times$ brachiatum Bertol. ex DC. & "Nagymező" & 1959 & Siroki Zoltán & DE-siroki-18483.jpg \\
\hline 2090 & Hieracium $\times$ brachiatum Bertol. ex DC. & "Nagymező" & 1959 & Siroki Zoltán & DE-siroki-18484.jpg \\
\hline 2090 & Hieracium $\times$ brachiatum Bertol. ex DC. & "Nagymező" & 1959 & Siroki Zoltán & DE-siroki-18485.jpg \\
\hline 2090 & Hieracium $\times$ brachiatum Bertol. ex DC. & "Nagymező" & 1959 & Siroki Zoltán & DE-siroki-18490.jpg \\
\hline 2090 & Hieracium $\times$ brachiatum Bertol. ex DC. & "Nagymező" & 1959 & Siroki Zoltán & DE-siroki-18491.jpg \\
\hline 2090 & Hieracium $\times$ brachiatum Bertol. ex DC. & "Nagymező" & 1959 & Siroki Zoltán & DE-siroki-18492.jpg \\
\hline 2090 & Hieracium $\times$ brachiatum Bertol. ex DC. & Budapest & 1888 & Czakó Kálmán & DE-siroki-18457.jpg \\
\hline 2090 & Hieracium $\times$ brachiatum Bertol. ex DC. & Budapest & 1951 & Siroki Zoltán & DE-siroki-18480.jpg \\
\hline 2090 & Hieracium $\times$ brachiatum Bertol. ex DC. & Debrecen & 1946 & Siroki Zoltán & DE-siroki-18470.jpg \\
\hline 2090 & Hieracium $\times$ brachiatum Bertol. ex DC. & Debrecen & 1950 & Siroki Zoltán & DE-siroki-18478.jpg \\
\hline 2090 & Hieracium $\times$ brachiatum Bertol. ex DC. & Debrecen & 1955 & Siroki Zoltán & DE-siroki-18486.jpg \\
\hline 2090 & Hieracium $\times$ brachiatum Bertol. ex DC. & Debrecen & 1955 & Siroki Zoltán & DE-siroki-18487.jpg \\
\hline 2090 & Hieracium $\times$ brachiatum Bertol. ex DC. & Debrecen & 1955 & Siroki Zoltán & DE-siroki-18488.jpg \\
\hline 2090 & Hieracium $\times$ brachiatum Bertol. ex DC. & Debrecen & 1955 & Siroki Zoltán & DE-siroki-18489.jpg \\
\hline 2090 & Hieracium $\times$ brachiatum Bertol. ex DC. & Debrecen & 1955 & Siroki Zoltán & DE-siroki-18493.jpg \\
\hline 2090 & Hieracium $\times$ brachiatum Bertol. ex DC. & Debrecen & 1981 & Siroki Zoltán & DE-siroki-18501.jpg \\
\hline 2090 & Hieracium $\times$ brachiatum Bertol. ex DC. & Debrecen & 1981 & Siroki Zoltán & DE-siroki-18502.jpg \\
\hline 2090 & Hieracium $\times$ brachiatum Bertol. ex DC. & Debrecen & 1981 & Siroki Zoltán & DE-siroki-18503.jpg \\
\hline 2090 & Hieracium $\times$ brachiatum Bertol. ex DC. & Debrecen & 1981 & Siroki Zoltán & DE-siroki-18504.jpg \\
\hline 2090 & Hieracium $\times$ brachiatum Bertol. ex DC. & Debrecen & 1983 & Siroki Zoltán & DE-siroki-18468.jpg \\
\hline 2090 & Hieracium $\times$ brachiatum Bertol. ex DC. & Debrecen & 1983 & Siroki Zoltán & DE-siroki-18469.jpg \\
\hline 2090 & Hieracium $\times$ brachiatum Bertol. ex DC. & Debrecen & 1984 & Siroki Zoltán & DE-siroki-18494.jpg \\
\hline 2090 & Hieracium $\times$ brachiatum Bertol. ex DC. & Debrecen & 1984 & Siroki Zoltán & DE-siroki-18495.jpg \\
\hline 2090 & Hieracium $\times$ brachiatum Bertol. ex DC. & Debrecen & 1984 & Siroki Zoltán & DE-siroki-18498.jpg \\
\hline 2090 & Hieracium $\times$ brachiatum Bertol. ex DC. & Debrecen & 1984 & Siroki Zoltán & DE-siroki-18500.jpg \\
\hline 2090 & Hieracium $\times$ brachiatum Bertol. ex DC. & Gödöllő & 1952 & Siroki Zoltán & DE-siroki-18481.jpg \\
\hline 2090 & Hieracium $\times$ brachiatum Bertol. ex DC. & Gödöllő & 1952 & Siroki Zoltán & DE-siroki-18507.jpg \\
\hline 2090 & Hieracium $\times$ brachiatum Bertol. ex DC. & Gödöllő & 1952 & Siroki Zoltán & DE-siroki-18508.jpg \\
\hline 2090 & Hieracium $\times$ brachiatum Bertol. ex DC. & Gödöllő & 1952 & Siroki Zoltán & DE-siroki-18509.jpg \\
\hline 2090 & Hieracium $\times$ brachiatum Bertol. ex DC. & Hajdúbagos & 1981 & Siroki Zoltán & DE-siroki-18505.jpg \\
\hline 2090 & Hieracium $\times$ brachiatum Bertol. ex DC. & Hajdúbagos & 1981 & Siroki Zoltán & DE-siroki-18459.jpg \\
\hline 2090 & Hieracium $\times$ brachiatum Bertol. ex DC. & Hajdúbagos & 1981 & Siroki Zoltán & DE-siroki-18460.jpg \\
\hline 2090 & Hieracium $\times$ brachiatum Bertol. ex DC. & Hajdúbagos & 1981 & Siroki Zoltán & DE-siroki-18461.jpg \\
\hline 2090 & Hieracium $\times$ brachiatum Bertol. ex DC. & Hajdúbagos & 1981 & Siroki Zoltán & DE-siroki-18462.jpg \\
\hline 2090 & Hieracium $\times$ brachiatum Bertol. ex DC. & Hajdúbagos & 1982 & Siroki Zoltán & DE-siroki-18458.jpg \\
\hline 2090 & Hieracium $\times$ brachiatum Bertol. ex DC. & Hajdúbagos & 1984 & Siroki Zoltán & DE-siroki-18466.jpg \\
\hline 2090 & Hieracium $\times$ brachiatum Bertol. ex DC. & Hajdúbagos & 1984 & Siroki Zoltán & DE-siroki-18467.jpg \\
\hline 2090 & Hieracium $\times$ brachiatum Bertol. ex DC. & Háromhuta & 1978 & Siroki Zoltán & DE-siroki-18463.jpg \\
\hline 2090 & Hieracium $\times$ brachiatum Bertol. ex DC. & Háromhuta & 1978 & Siroki Zoltán & DE-siroki-18464.jpg \\
\hline 2090 & Hieracium $\times$ brachiatum Bertol. ex DC. & Háromhuta & 1978 & Siroki Zoltán & DE-siroki-18465.jpg \\
\hline 2090 & Hieracium $\times$ brachiatum Bertol. ex DC. & Miskolc & 1927 & Degen Árpád & DE-siroki-18455.jpg \\
\hline
\end{tabular}




\begin{tabular}{|c|c|c|c|c|c|}
\hline $\begin{array}{l}\text { Sorszám / } \\
\text { Number }\end{array}$ & Taxon-név / Taxon-name & $\begin{array}{l}\text { Település / } \\
\text { Settlement }\end{array}$ & $\begin{array}{l}\text { Év / } \\
\text { Year }\end{array}$ & $\begin{array}{l}\text { Gyújitő / } \\
\text { Collector }\end{array}$ & Fájlnév / File-name \\
\hline 2090 & Hieracium $\times$ brachiatum Bertol. ex DC. & Pásztó & 1952 & Siroki Zoltán & DE-siroki-18479.jpg \\
\hline 2090 & Hieracium $\times$ brachiatum Bertol. ex DC. & Pásztó & 1952 & Siroki Zoltán & DE-siroki-18510.jpg \\
\hline 2090 & Hieracium × brachiatum Bertol. ex DC. & Tatabánya & 1928 & Degen Árpád & DE-siroki-18456.jpg \\
\hline 2094 & Hieracium $\times$ flagellare Willd. & Debrecen & 1981 & Siroki Zoltán & DE-siroki-18432.jpg \\
\hline 2094 & Hieracium $\times$ flagellare Willd. & Debrecen & 1981 & Siroki Zoltán & DE-siroki-18433.jpg \\
\hline 2094 & Hieracium $\times$ flagellare Willd. & Debrecen & 1981 & Siroki Zoltán & DE-siroki-18434.jpg \\
\hline 2094 & Hieracium $\times$ flagellare Willd. & Debrecen & 1981 & Siroki Zoltán & DE-siroki-18435.jpg \\
\hline 2098 & Hieracium fallax Willd. & Pilisszentiván & 1925 & Degen Árpád & DE-siroki-18696.jpg \\
\hline 2099 & Hieracium auriculoides Láng & Budapest & 1888 & Czakó Kálmán & DE-siroki-18575.jpg \\
\hline 2099 & Hieracium auriculoides Láng & Budapest & 1888 & Czakó Kálmán & DE-siroki-18576.jpg \\
\hline 2099 & Hieracium auriculoides Láng & Budapest & 1888 & Czakó Kálmán & DE-siroki-18577.jpg \\
\hline 2099 & Hieracium auriculoides Láng & Budapest & 1888 & Czakó Kálmán & DE-siroki-18579.jpg \\
\hline 2099 & Hieracium auriculoides Láng & Budapest & 1888 & Czakó Kálmán & DE-siroki-18580.jpg \\
\hline 2099 & Hieracium auriculoides Láng & Budapest & 1888 & Czakó Kálmán & DE-siroki-18581.jpg \\
\hline 2099 & Hieracium auriculoides Láng & Budapest & 1888 & Czakó Kálmán & DE-siroki-18598.jpg \\
\hline 2099 & Hieracium auriculoides Láng & Budapest & 1889 & Czakó Kálmán & DE-siroki-18578.jpg \\
\hline 2099 & Hieracium auriculoides Láng & Budapest & 1924 & Degen Árpád & DE-siroki-18573.jpg \\
\hline 2099 & Hieracium auriculoides Láng & Budapest & 1951 & Siroki Zoltán & DE-siroki-18589.jpg \\
\hline 2099 & Hieracium auriculoides Láng & Budapest & 1951 & Siroki Zoltán & DE-siroki-18585.jpg \\
\hline 2099 & Hieracium auriculoides Láng & Budapest & 1952 & Siroki Zoltán & DE-siroki-18568.jpg \\
\hline 2099 & Hieracium auriculoides Láng & Budapest & 1966 & Siroki Zoltán & DE-siroki-18592.jpg \\
\hline 2099 & Hieracium auriculoides Láng & Budapest & 1966 & Siroki Zoltán & DE-siroki-18593.jpg \\
\hline 2099 & Hieracium auriculoides Láng & Budapest & 1966 & Siroki Zoltán & DE-siroki-18594.jpg \\
\hline 2099 & Hieracium auriculoides Láng & Budapest & 1966 & Siroki Zoltán & DE-siroki-18595.jpg \\
\hline 2099 & Hieracium auriculoides Láng & Budapest & 1966 & Siroki Zoltán & DE-siroki-18562.jpg \\
\hline 2099 & Hieracium auriculoides Láng & Budapest & 1966 & Siroki Zoltán & DE-siroki-18590.jpg \\
\hline 2099 & Hieracium auriculoides Láng & Cegléd & 1969 & Siroki Zoltán & DE-siroki-18559.jpg \\
\hline 2099 & Hieracium auriculoides Láng & Cegléd & 1969 & Siroki Zoltán & DE-siroki-18560.jpg \\
\hline 2099 & Hieracium auriculoides Láng & Cegléd & 1969 & Siroki Zoltán & DE-siroki-18561.jpg \\
\hline 2099 & Hieracium auriculoides Láng & Csaroda & 1960 & Siroki Zoltán & DE-siroki-18550.jpg \\
\hline 2099 & Hieracium auriculoides Láng & Csaroda & 1960 & Siroki Zoltán & DE-siroki-18551.jpg \\
\hline 2099 & Hieracium auriculoides Láng & Csaroda & 1960 & Siroki Zoltán & DE-siroki-18552.jpg \\
\hline 2099 & Hieracium auriculoides Láng & Csaroda & 1960 & Siroki Zoltán & DE-siroki-18553.jpg \\
\hline 2099 & Hieracium auriculoides Láng & Csaroda & 1960 & Siroki Zoltán & DE-siroki-18554.jpg \\
\hline 2099 & Hieracium auriculoides Láng & Csaroda & 1960 & Siroki Zoltán & DE-siroki-18555.jpg \\
\hline 2099 & Hieracium auriculoides Láng & Csaroda & 1960 & Siroki Zoltán & DE-siroki-18556.jpg \\
\hline 2099 & Hieracium auriculoides Láng & Csaroda & 1960 & Siroki Zoltán & DE-siroki-18557.jpg \\
\hline 2099 & Hieracium auriculoides Láng & Csaroda & 1960 & Siroki Zoltán & DE-siroki-18558.jpg \\
\hline 2099 & Hieracium auriculoides Láng & Csaroda & 1960 & Siroki Zoltán & DE-siroki-18591.jpg \\
\hline 2099 & Hieracium auriculoides Láng & Debrecen & 1949 & Siroki Zoltán & DE-siroki-18572.jpg \\
\hline 2099 & Hieracium auriculoides Láng & Debrecen & 1949 & Siroki Zoltán & DE-siroki-18565.jpg \\
\hline 2099 & Hieracium auriculoides Láng & Egyek & 1947 & Siroki Zoltán & DE-siroki-18571.jpg \\
\hline 2099 & Hieracium auriculoides Láng & Egyek & 1948 & Siroki Zoltán & DE-siroki-18584.jpg \\
\hline 2099 & Hieracium auriculoides Láng & Egyek & 1948 & Siroki Zoltán & DE-siroki-18583.jpg \\
\hline 2099 & Hieracium auriculoides Láng & Egyek & 1948 & Siroki Zoltán & DE-siroki-18563.jpg \\
\hline 2099 & Hieracium auriculoides Láng & Egyek & 1948 & Siroki Zoltán & DE-siroki-18564.jpg \\
\hline
\end{tabular}




\begin{tabular}{|c|c|c|c|c|c|}
\hline $\begin{array}{l}\text { Sorszám / } \\
\text { Number }\end{array}$ & Taxon-név / Taxon-name & $\begin{array}{l}\text { Település / } \\
\text { Settlement }\end{array}$ & $\begin{array}{l}\text { Év / } \\
\text { Year }\end{array}$ & $\begin{array}{l}\text { Gyűjtő / } \\
\text { Collector }\end{array}$ & Fájlnév / File-name \\
\hline 2099 & Hieracium auriculoides Láng & Gödöllő & 1952 & Siroki Zoltán & DE-siroki-18570.jpg \\
\hline 2099 & Hieracium auriculoides Láng & Hortobágy & 1960 & Siroki Zoltán & DE-siroki-18543.jpg \\
\hline 2099 & Hieracium auriculoides Láng & Hortobágy & 1960 & Siroki Zoltán & DE-siroki-18544.jpg \\
\hline 2099 & Hieracium auriculoides Láng & Hortobágy & 1960 & Siroki Zoltán & DE-siroki-18545.jpg \\
\hline 2099 & Hieracium auriculoides Láng & Hortobágy & 1960 & Siroki Zoltán & DE-siroki-18546.jpg \\
\hline 2099 & Hieracium auriculoides Láng & Hortobágy & 1960 & Siroki Zoltán & DE-siroki-18547.jpg \\
\hline 2099 & Hieracium auriculoides Láng & Hortobágy & 1960 & Siroki Zoltán & DE-siroki-18548.jpg \\
\hline 2099 & Hieracium auriculoides Láng & Hortobágy & 1960 & Siroki Zoltán & DE-siroki-18549.jpg \\
\hline 2099 & Hieracium auriculoides Láng & Hortobágy & 1960 & Siroki Zoltán & DE-siroki-18586.jpg \\
\hline 2099 & Hieracium auriculoides Láng & Hortobágy & 1960 & Siroki Zoltán & DE-siroki-18587.jpg \\
\hline 2099 & Hieracium auriculoides Láng & Méra & 1943 & Siroki Zoltán & DE-siroki-18582.jpg \\
\hline 2099 & Hieracium auriculoides Láng & Pilisszentiván & 1925 & Degen Árpád & DE-siroki-18566.jpg \\
\hline 2099 & Hieracium auriculoides Láng & Pilisszentiván & 1952 & Siroki Zoltán & DE-siroki-18569.jpg \\
\hline 2099 & Hieracium auriculoides Láng & Szigetszentmiklós & 1926 & Degen Árpád & DE-siroki-18574.jpg \\
\hline 2099 & Hieracium auriculoides Láng & Szigetszentmiklós & 1951 & Siroki Zoltán & DE-siroki-18588.jpg \\
\hline 2104 & Hieracium densiflorum Tausch & "Nagymező" & 1973 & Siroki Zoltán & DE-siroki-18677.jpg \\
\hline 2104 & Hieracium densiflorum Tausch & "Nagymező" & 1973 & Siroki Zoltán & DE-siroki-18678.jpg \\
\hline 2109 & Hieracium wiesbaurianum Uechtr. & "Szent-György-hegy" & 1955 & Siroki Zoltán & DE-siroki-18713.jpg \\
\hline 2109 & Hieracium wiesbaurianum Uechtr. & "Szent-György-hegy" & 1955 & Siroki Zoltán & DE-siroki-18714.jpg \\
\hline 2109 & Hieracium wiesbaurianum Uechtr. & "Szent-György-hegy" & 1955 & Siroki Zoltán & DE-siroki-18715.jpg \\
\hline 2109 & Hieracium wiesbaurianum Uechtr. & "Szent-György-hegy" & 1955 & Siroki Zoltán & DE-siroki-18716.jpg \\
\hline 2112 & Hieracium kossuthianum Soó & Budaörs & 1966 & Siroki Zoltán & DE-siroki-18704.jpg \\
\hline 2112 & Hieracium kossuthianum Soó & Budaörs & 1966 & Siroki Zoltán & DE-siroki-18705.jpg \\
\hline 2112 & Hieracium kossuthianum Soó & Budapest & 1951 & Siroki Zoltán & DE-siroki-18708.jpg \\
\hline 2112 & Hieracium kossuthianum Soó & Budapest & 1951 & Siroki Zoltán & DE-siroki-18706.jpg \\
\hline 2112 & Hieracium kossuthianum Soó & Budapest & 1951 & Siroki Zoltán & DE-siroki-18707.jpg \\
\hline 2113 & Hieracium maculatum Schrank & "Fáni-völgy" & 1955 & Siroki Zoltán & DE-siroki-18970.jpg \\
\hline 2113 & Hieracium maculatum Schrank & Gyenesdiás & 1955 & Siroki Zoltán & DE-siroki-18969.jpg \\
\hline 2113 & Hieracium maculatum Schrank & Pomáz & 1952 & Siroki Zoltán & DE-siroki-18968.jpg \\
\hline 2113 & Hieracium maculatum Schrank & Pomáz & 1952 & Siroki Zoltán & DE-siroki-18971.jpg \\
\hline 2113 & Hieracium maculatum Schrank & Pomáz & 1952 & Siroki Zoltán & DE-siroki-18972.jpg \\
\hline 2113 & Hieracium maculatum Schrank & Pomáz & 1952 & Siroki Zoltán & DE-siroki-18973.jpg \\
\hline 2113 & Hieracium maculatum Schrank & Pomáz & 1952 & Siroki Zoltán & DE-siroki-18974.jpg \\
\hline 2117 & Hieracium ramosum Waldst. et Kit. & "Vértes" & 1957 & Siroki Zoltán & DE-siroki-19145.jpg \\
\hline 2117 & Hieracium ramosum Waldst. et Kit. & Bélapátfalva & 1958 & Siroki Zoltán & DE-siroki-19150.jpg \\
\hline 2117 & Hieracium ramosum Waldst. et Kit. & Bélapátfalva & 1958 & Siroki Zoltán & DE-siroki-19151.jpg \\
\hline 2117 & Hieracium ramosum Waldst. et Kit. & Bélapátfalva & 1958 & Siroki Zoltán & DE-siroki-19152.jpg \\
\hline 2117 & Hieracium ramosum Waldst. et Kit. & Háromhuta & 1960 & Siroki Zoltán & DE-siroki-19143.jpg \\
\hline 2117 & Hieracium ramosum Waldst. et Kit. & Háromhuta & 1960 & Siroki Zoltán & DE-siroki-19144.jpg \\
\hline 2117 & Hieracium ramosum Waldst. et Kit. & Háromhuta & 1960 & Siroki Zoltán & DE-siroki-19146.jpg \\
\hline 2117 & Hieracium ramosum Waldst. et Kit. & Háromhuta & 1960 & Siroki Zoltán & DE-siroki-19147.jpg \\
\hline 2117 & Hieracium ramosum Waldst. et Kit. & Háromhuta & 1978 & Siroki Zoltán & DE-siroki-19139.jpg \\
\hline 2117 & Hieracium ramosum Waldst. et Kit. & Háromhuta & 1978 & Siroki Zoltán & DE-siroki-19140.jpg \\
\hline 2117 & Hieracium ramosum Waldst. et Kit. & Háromhuta & 1978 & Siroki Zoltán & DE-siroki-19141.jpg \\
\hline 2117 & Hieracium ramosum Waldst. et Kit. & Háromhuta & 1978 & Siroki Zoltán & DE-siroki-19142.jpg \\
\hline 2117 & Hieracium ramosum Waldst. et Kit. & Szilvásvárad & 1959 & Siroki Zoltán & DE-siroki-19148.jpg \\
\hline
\end{tabular}




\begin{tabular}{|c|c|c|c|c|c|}
\hline $\begin{array}{l}\text { Sorszám / } \\
\text { Number }\end{array}$ & Taxon-név / Taxon-name & $\begin{array}{l}\text { Település / } \\
\text { Settlement }\end{array}$ & $\begin{array}{l}\text { Év / } \\
\text { Year }\end{array}$ & $\begin{array}{l}\text { Gyűjtő / } \\
\text { Collector }\end{array}$ & Fájlnév / File-name \\
\hline 2117 & Hieracium ramosum Waldst. et Kit. & Szilvásvárad & 1959 & Siroki Zoltán & DE-siroki-19149.jpg \\
\hline 2118 & Hieracium laevicaule Jord. & Miskolc & 1959 & Siroki Zoltán & DE-siroki-18994.jpg \\
\hline 2118 & Hieracium laevicaule Jord. & Miskolc & 1959 & Siroki Zoltán & DE-siroki-18995.jpg \\
\hline 2118 & Hieracium laevicaule Jord. & Miskolc & 1959 & Siroki Zoltán & DE-siroki-19009.jpg \\
\hline 2118 & Hieracium laevicaule Jord. & Szilvásvárad & 1959 & Siroki Zoltán & DE-siroki-18997.jpg \\
\hline 2118 & Hieracium laevicaule Jord. & Szilvásvárad & 1959 & Siroki Zoltán & DE-siroki-18998.jpg \\
\hline 2118 & Hieracium laevicaule Jord. & Szilvásvárad & 1959 & Siroki Zoltán & DE-siroki-18996.jpg \\
\hline 2118 & Hieracium laevicaule Jord. & Szilvásvárad & 1959 & Siroki Zoltán & DE-siroki-19010.jpg \\
\hline 2118 & Hieracium laevicaule Jord. & Szilvásvárad & 1959 & Siroki Zoltán & DE-siroki-19011.jpg \\
\hline 2118 & Hieracium laevicaule Jord. & Szilvásvárad & 1959 & Siroki Zoltán & DE-siroki-19012.jpg \\
\hline 2118 & Hieracium laevicaule Jord. & Szilvásvárad & 1959 & Siroki Zoltán & DE-siroki-19013.jpg \\
\hline 2118 & Hieracium laevicaule Jord. & Szilvásvárad & 1959 & Siroki Zoltán & DE-siroki-19014.jpg \\
\hline 2118 & Hieracium laevicaule Jord. & Szilvásvárad & 1960 & Siroki Zoltán & DE-siroki-19015.jpg \\
\hline 2118 & Hieracium laevicaule Jord. & Szilvásvárad & 1960 & Siroki Zoltán & DE-siroki-19016.jpg \\
\hline 2118 & Hieracium laevicaule Jord. & Szilvásvárad & 1960 & Siroki Zoltán & DE-siroki-19017.jpg \\
\hline 2121 & Hieracium latifolium Spreng. & Bélapátfalva & 1958 & Siroki Zoltán & DE-siroki-19095.jpg \\
\hline 2121 & Hieracium latifolium Spreng. & Bélapátfalva & 1958 & Siroki Zoltán & DE-siroki-19096.jpg \\
\hline 2121 & Hieracium latifolium Spreng. & Bélapátfalva & 1958 & Siroki Zoltán & DE-siroki-19097.jpg \\
\hline 2121 & Hieracium latifolium Spreng. & Budapest & 1888 & Czakó Kálmán & DE-siroki-19087.jpg \\
\hline 2121 & Hieracium latifolium Spreng. & Budapest & 1889 & Czakó Kálmán & DE-siroki-19088.jpg \\
\hline 2121 & Hieracium latifolium Spreng. & Budapest & 1950 & Siroki Zoltán & DE-siroki-19094.jpg \\
\hline 2121 & Hieracium latifolium Spreng. & Uzsa & 1971 & Siroki Zoltán & DE-siroki-19091.jpg \\
\hline 2121 & Hieracium latifolium Spreng. & Uzsa & 1971 & Siroki Zoltán & DE-siroki-19092.jpg \\
\hline 2121 & Hieracium latifolium Spreng. & Uzsa & 1971 & Siroki Zoltán & DE-siroki-19093.jpg \\
\hline 2122 & Sagittaria sagittifolia L. & Biharugra & 1961 & Siroki Zoltán & DE-siroki-00673.jpg \\
\hline 2122 & Sagittaria sagittifolia L. & Biharugra & 1961 & Siroki Zoltán & DE-siroki-00674.jpg \\
\hline 2122 & Sagittaria sagittifolia L. & Egyek & 1947 & Siroki Zoltán & DE-siroki-00677.jpg \\
\hline 2122 & Sagittaria sagittifolia L. & Tiszafüred & 1949 & Siroki Zoltán & DE-siroki-00675.jpg \\
\hline 2122 & Sagittaria sagittifolia L. & Tiszafüred & 1949 & Siroki Zoltán & DE-siroki-00672.jpg \\
\hline 2122 & Sagittaria sagittifolia L. & Tiszafüred & 1949 & Siroki Zoltán & DE-siroki-00676.jpg \\
\hline 2124 & Alisma plantago-aquatica L. & Mosonmagyaróvár & 1939 & Siroki Zoltán & DE-siroki-00660.jpg \\
\hline 2124 & Alisma plantago-aquatica L. & Mosonmagyaróvár & 1939 & Siroki Zoltán & DE-siroki-00661.jpg \\
\hline 2124 & Alisma plantago-aquatica L. & Vitnyéd & 1928 & Rigler József & DE-siroki-00654.jpg \\
\hline 2125 & Alisma lanceolatum With. & Debrecen & 1958 & Pethő Menyhért & DE-siroki-00664.jpg \\
\hline 2125 & Alisma lanceolatum With. & Egyek & - & Siroki Zoltán & DE-siroki-00665.jpg \\
\hline 2125 & Alisma lanceolatum With. & Hajdúbagos & 1981 & Siroki Zoltán & DE-siroki-00662.jpg \\
\hline 2125 & Alisma lanceolatum With. & Hajdúbagos & 1981 & Siroki Zoltán & DE-siroki-00663.jpg \\
\hline 2125 & Alisma lanceolatum With. & Hajdúbagos & 1981 & Siroki Zoltán & DE-siroki-00666.jpg \\
\hline 2125 & Alisma lanceolatum With. & Hajdúbagos & 1981 & Siroki Zoltán & DE-siroki-00667.jpg \\
\hline 2127 & Butomus umbellatus L. & Budapest & 1909 & Kocsis István & DE-siroki-00681.jpg \\
\hline 2127 & Butomus umbellatus L. & Budapest & 1909 & Kocsis István & DE-siroki-00682.jpg \\
\hline 2127 & Butomus umbellatus L. & Debrecen & 1948 & Siroki Zoltán & DE-siroki-00685.jpg \\
\hline 2128 & Hydrocharis morsus-ranae L. & Hortobágy & 1947 & Siroki Zoltán & DE-siroki-00709.jpg \\
\hline 2128 & Hydrocharis morsus-ranae L. & Hortobágy & 1954 & Siroki Zoltán & DE-siroki-00710.jpg \\
\hline 2128 & Hydrocharis morsus-ranae L. & Hortobágy & 1954 & Siroki Zoltán & DE-siroki-00711.jpg \\
\hline 2129 & Stratiotes aloides L. & Újszentmargita & 1963 & Siroki Zoltán & DE-siroki-00695.jpg \\
\hline
\end{tabular}




\begin{tabular}{|c|c|c|c|c|c|}
\hline $\begin{array}{l}\text { Sorszám / } \\
\text { Number }\end{array}$ & Taxon-név / Taxon-name & $\begin{array}{l}\text { Település / } \\
\text { Settlement }\end{array}$ & $\begin{array}{l}\text { Év / } \\
\text { Year }\end{array}$ & $\begin{array}{l}\text { Gyűjtő / } \\
\text { Collector }\end{array}$ & Fájlnév / File-name \\
\hline 2129 & Stratiotes aloides L. & Újszentmargita & 1963 & Siroki Zoltán & DE-siroki-00696.jpg \\
\hline 2129 & Stratiotes aloides L. & Újszentmargita & 1963 & Siroki Zoltán & DE-siroki-00697.jpg \\
\hline 2129 & Stratiotes aloides L. & Újszentmargita & 1963 & Siroki Zoltán & DE-siroki-00698.jpg \\
\hline 2129 & Stratiotes aloides L. & Újszentmargita & 1963 & Siroki Zoltán & DE-siroki-00699.jpg \\
\hline 2129 & Stratiotes aloides L. & Újszentmargita & 1963 & Siroki Zoltán & DE-siroki-00700.jpg \\
\hline 2129 & Stratiotes aloides L. & Újszentmargita & 1963 & Siroki Zoltán & DE-siroki-00701.jpg \\
\hline 2129 & Stratiotes aloides L. & Újszentmargita & 1963 & Siroki Zoltán & DE-siroki-00702.jpg \\
\hline 2129 & Stratiotes aloides L. & Újszentmargita & 1963 & Siroki Zoltán & DE-siroki-00703.jpg \\
\hline 2129 & Stratiotes aloides L. & Újszentmargita & 1963 & Siroki Zoltán & DE-siroki-00704.jpg \\
\hline 2129 & Stratiotes aloides L. & Újszentmargita & 1963 & Siroki Zoltán & DE-siroki-00705.jpg \\
\hline 2129 & Stratiotes aloides L. & Újszentmargita & 1963 & Siroki Zoltán & DE-siroki-00706.jpg \\
\hline 2131 & Elodea canadensis Michx. & Budapest & 1891 & Simonkai Lajos & DE-siroki-00687.jpg \\
\hline 2131 & Elodea canadensis Michx. & Budapest & 1909 & Kocsis István & DE-siroki-00688.jpg \\
\hline 2131 & Elodea canadensis Michx. & Keszthely & 1955 & Siroki Zoltán & DE-siroki-00690.jpg \\
\hline 2136 & Vallisneria spiralis L. & Budapest & 1887 & Czakó Kálmán & DE-siroki-00692.jpg \\
\hline 2137 & Triglochin maritimum L. & Budapest & 1909 & Kocsis István & DE-siroki-00634.jpg \\
\hline 2137 & Triglochin maritimum L. & Kecskemét & 1971 & Siroki Zoltán & DE-siroki-00635.jpg \\
\hline 2137 & Triglochin maritimum L. & Kecskemét & 1971 & Siroki Zoltán & DE-siroki-00638.jpg \\
\hline 2137 & Triglochin maritimum L. & Kecskemét & 1971 & Siroki Zoltán & DE-siroki-00639.jpg \\
\hline 2137 & Triglochin maritimum L. & Kecskemét & 1971 & Siroki Zoltán & DE-siroki-00640.jpg \\
\hline 2137 & Triglochin maritimum L. & Kecskemét & 1971 & Siroki Zoltán & DE-siroki-00641.jpg \\
\hline 2138 & Triglochin palustre L. & Debrecen & 1946 & Siroki Zoltán & DE-siroki-00646.jpg \\
\hline 2138 & Triglochin palustre L. & Debrecen & 1946 & Siroki Zoltán & DE-siroki-00648.jpg \\
\hline 2138 & Triglochin palustre L. & Debrecen & 1951 & Siroki Zoltán & DE-siroki-00649.jpg \\
\hline 2138 & Triglochin palustre L. & Debrecen & 1960 & Siroki Zoltán & DE-siroki-00647.jpg \\
\hline 2138 & Triglochin palustre L. & Taksony & 1909 & Kocsis István & DE-siroki-00643.jpg \\
\hline 2140 & Veratrum nigrum L. & "Dobogókő" & 1965 & Siroki Zoltán & DE-siroki-04416.jpg \\
\hline 2140 & Veratrum nigrum L. & "Dobogókő" & 1965 & Siroki Zoltán & DE-siroki-04418.jpg \\
\hline 2140 & Veratrum nigrum L. & "Dobogókő" & 1965 & Siroki Zoltán & DE-siroki-04419.jpg \\
\hline 2140 & Veratrum nigrum L. & Gyenesdiás & 1955 & Siroki Zoltán & DE-siroki-04420.jpg \\
\hline 2140 & Veratrum nigrum L. & Gyenesdiás & 1955 & Siroki Zoltán & DE-siroki-04414.jpg \\
\hline 2140 & Veratrum nigrum L. & Gyenesdiás & 1955 & Siroki Zoltán & DE-siroki-04415.jpg \\
\hline 2140 & Veratrum nigrum L. & Gyenesdiás & 1955 & Siroki Zoltán & DE-siroki-04413.jpg \\
\hline 2140 & Veratrum nigrum L. & Gyenesdiás & 1955 & Siroki Zoltán & DE-siroki-04417.jpg \\
\hline 2140 & Veratrum nigrum L. & Pilismarót & 1887 & $\begin{array}{l}\text { Schilberszky } \\
\text { Károly }\end{array}$ & DE-siroki-04411.jpg \\
\hline 2140 & Veratrum nigrum L. & Rezi & 1955 & Siroki Zoltán & DE-siroki-04421.jpg \\
\hline 2140 & Veratrum nigrum L. & Rezi & 1955 & Siroki Zoltán & DE-siroki-04422.jpg \\
\hline 2140 & Veratrum nigrum L. & Rezi & 1955 & Siroki Zoltán & DE-siroki-04424.jpg \\
\hline 2140 & Veratrum nigrum L. & Rezi & 1955 & Siroki Zoltán & DE-siroki-04425.jpg \\
\hline 2140 & Veratrum nigrum L. & Rezi & 1955 & Siroki Zoltán & DE-siroki-04423.jpg \\
\hline 2141 & Veratrum album L. & Bátorliget & 1956 & Siroki Zoltán & DE-siroki-04430.jpg \\
\hline 2141 & Veratrum album L. & Nyíracsád & 1984 & Siroki Zoltán & DE-siroki-04428.jpg \\
\hline 2141 & Veratrum album L. & Nyíracsád & 1984 & Siroki Zoltán & DE-siroki-04429.jpg \\
\hline 2141 & Veratrum album L. & Nyíracsád & 1984 & Siroki Zoltán & DE-siroki-04431.jpg \\
\hline 2141 & Veratrum album L. & Nyíracsád & 1984 & Siroki Zoltán & DE-siroki-04432.jpg \\
\hline 2143 & Anthericum liliago L. & Budapest & 1951 & Siroki Zoltán & DE-siroki-04456.jpg \\
\hline
\end{tabular}




\begin{tabular}{|c|c|c|c|c|c|}
\hline $\begin{array}{l}\text { Sorszám / } \\
\text { Number }\end{array}$ & Taxon-név / Taxon-name & $\begin{array}{l}\text { Település / } \\
\text { Settlement }\end{array}$ & $\begin{array}{l}\text { Év / } \\
\text { Year }\end{array}$ & $\begin{array}{l}\text { Gyűjtő / } \\
\text { Collector }\end{array}$ & Fájlnév / File-name \\
\hline 2143 & Anthericum liliago L. & Budapest & 1951 & Siroki Zoltán & DE-siroki-04457.jpg \\
\hline 2143 & Anthericum liliago L. & Budapest & 1962 & Siroki Zoltán & DE-siroki-04455.jpg \\
\hline 2144 & Anthericum ramosum L. & "Bükk-hg." & 1960 & Siroki Zoltán & DE-siroki-18991.jpg \\
\hline 2144 & Anthericum ramosum L. & Budapest & 1909 & Kocsis István & DE-siroki-04459.jpg \\
\hline 2144 & Anthericum ramosum L. & Budapest & 1910 & Bocskay Ottó & DE-siroki-04458.jpg \\
\hline 2144 & Anthericum ramosum L. & Budapest & 1962 & Siroki Zoltán & DE-siroki-04463.jpg \\
\hline 2144 & Anthericum ramosum L. & Pásztó & 1942 & Siroki Zoltán & DE-siroki-18987.jpg \\
\hline 2144 & Anthericum ramosum L. & Pásztó & 1942 & Siroki Zoltán & DE-siroki-18988.jpg \\
\hline 2144 & Anthericum ramosum L. & Pásztó & 1942 & Siroki Zoltán & DE-siroki-18989.jpg \\
\hline 2144 & Anthericum ramosum L. & Pásztó & 1952 & Siroki Zoltán & DE-siroki-18985.jpg \\
\hline 2144 & Anthericum ramosum L. & Pásztó & 1952 & Siroki Zoltán & DE-siroki-18986.jpg \\
\hline 2144 & Anthericum ramosum L. & Pásztó & 1952 & Siroki Zoltán & DE-siroki-18990.jpg \\
\hline 2144 & Anthericum ramosum L. & Pásztó & 1952 & Siroki Zoltán & DE-siroki-18982.jpg \\
\hline 2144 & Anthericum ramosum L. & Szilvásvárad & 1954 & Siroki Zoltán & DE-siroki-04465.jpg \\
\hline 2144 & Anthericum ramosum L. & Szilvásvárad & 1954 & Siroki Zoltán & DE-siroki-04464.jpg \\
\hline 2144 & Anthericum ramosum L. & Szilvásvárad & 1954 & Siroki Zoltán & DE-siroki-04466.jpg \\
\hline 2144 & Anthericum ramosum L. & Szilvásvárad & 1961 & Siroki Zoltán & DE-siroki-18984.jpg \\
\hline 2148 & Colchicum arenarium Waldst. et Kit. & Budapest & 1872 & Tauscher Gyula & DE-siroki-04444.jpg \\
\hline 2148 & Colchicum arenarium Waldst. et Kit. & Budapest & 1872 & Tauscher Gyula & DE-siroki-04445.jpg \\
\hline 2148 & Colchicum arenarium Waldst. et Kit. & Budapest & 1909 & Kocsis István & DE-siroki-04443.jpg \\
\hline 2148 & Colchicum arenarium Waldst. et Kit. & Gödöllő & 1948 & Papp József & DE-siroki-04446.jpg \\
\hline 2150 & Bulbocodium vernum L. & Debrecen & 1954 & Siroki Zoltán & DE-siroki-04441.jpg \\
\hline 2150 & Bulbocodium vernum L. & Hosszúpályi & 1903 & Thaisz Lajos & DE-siroki-04437.jpg \\
\hline 2150 & Bulbocodium vernum L. & Hosszúpályi & 1930 & Vajda Ernő & DE-siroki-04438.jpg \\
\hline 2150 & Bulbocodium vernum $\mathrm{L}$. & Hosszúpályi & 1966 & Siroki Zoltán & DE-siroki-04439.jpg \\
\hline 2150 & Bulbocodium vernum L. & Hosszúpályi & 1966 & Siroki Zoltán & DE-siroki-04440.jpg \\
\hline 2153 & $\begin{array}{l}\text { Ornithogalum boucheanum } \\
\text { (Kunth) Asch. }\end{array}$ & Debrecen & 1950 & Siroki Zoltán & DE-siroki-04736.jpg \\
\hline 2153 & $\begin{array}{l}\text { Ornithogalum boucheanum } \\
\text { (Kunth) Asch. }\end{array}$ & Debrecen & 1950 & Siroki Zoltán & DE-siroki-04737.jpg \\
\hline 2155 & Ornithogalum brevistylum Wolfner & Mezőtúr & 1965 & Siroki Zoltán & DE-siroki-04710.jpg \\
\hline 2155 & Ornithogalum brevistylum Wolfner & Mezőtúr & 1965 & Siroki Zoltán & DE-siroki-04711.jpg \\
\hline 2155 & Ornithogalum brevistylum Wolfner & Mezőtúr & 1965 & Siroki Zoltán & DE-siroki-04712.jpg \\
\hline 2155 & Ornithogalum brevistylum Wolfner & Mezőtúr & 1965 & Siroki Zoltán & DE-siroki-04714.jpg \\
\hline 2155 & Ornithogalum brevistylum Wolfner & Mezőtúr & 1965 & Siroki Zoltán & DE-siroki-04715.jpg \\
\hline 2155 & Ornithogalum brevistylum Wolfner & Mezőtúr & 1965 & Siroki Zoltán & DE-siroki-04716.jpg \\
\hline 2155 & Ornithogalum brevistylum Wolfner & Mezőtúr & 1965 & Siroki Zoltán & DE-siroki-04717.jpg \\
\hline 2155 & Ornithogalum brevistylum Wolfner & Mezőtúr & 1965 & Siroki Zoltán & DE-siroki-04718.jpg \\
\hline 2155 & Ornithogalum brevistylum Wolfner & Mezőtúr & 1965 & Siroki Zoltán & DE-siroki-04707.jpg \\
\hline 2155 & Ornithogalum brevistylum Wolfner & Mezőtúr & 1965 & Siroki Zoltán & DE-siroki-04708.jpg \\
\hline 2155 & Ornithogalum brevistylum Wolfner & Mezőtúr & 1965 & Siroki Zoltán & DE-siroki-04709.jpg \\
\hline 2155 & Ornithogalum brevistylum Wolfner & Mezőtúr & 1965 & Siroki Zoltán & DE-siroki-04713.jpg \\
\hline 2156 & Ornithogalum pannonicum Chaix & "Nagymező" & 1962 & Siroki Zoltán & DE-siroki-04743.jpg \\
\hline 2156 & Ornithogalum pannonicum Chaix & Budapest & 1878 & Richter Lajos & DE-siroki-04722.jpg \\
\hline 2156 & Ornithogalum pannonicum Chaix & Budapest & 1904 & Thaisz Lajos & DE-siroki-04742.jpg \\
\hline 2156 & Ornithogalum pannonicum Chaix & Hajdúbagos & 1985 & Siroki Zoltán & DE-siroki-04744.jpg \\
\hline 2156 & Ornithogalum pannonicum Chaix & Sátoraljaújhely & 1943 & Siroki Zoltán & DE-siroki-04746.jpg \\
\hline
\end{tabular}




\begin{tabular}{|c|c|c|c|c|c|}
\hline $\begin{array}{l}\text { Sorszám / } \\
\text { Number }\end{array}$ & Taxon-név / Taxon-name & $\begin{array}{l}\text { Település / } \\
\text { Settlement }\end{array}$ & $\begin{array}{l}\text { Év / } \\
\text { Year }\end{array}$ & $\begin{array}{l}\text { Gyűjtő / } \\
\text { Collector }\end{array}$ & Fájlnév / File-name \\
\hline $2157-2159$ & Ornithogalum umbellatum agg. & Abaújvár & 1943 & Siroki Zoltán & DE-siroki-04732.jpg \\
\hline $2157-2159$ & Ornithogalum umbellatum agg. & Abaújvár & 1943 & Siroki Zoltán & DE-siroki-04733.jpg \\
\hline $2157-2159$ & Ornithogalum umbellatum agg. & Abaújvár & 1943 & Siroki Zoltán & DE-siroki-04734.jpg \\
\hline $2157-2159$ & Ornithogalum umbellatum agg. & Budapest & 1909 & Kocsis István & DE-siroki-04730.jpg \\
\hline $2157-2159$ & Ornithogalum umbellatum agg. & Debrecen & 1964 & Siroki Zoltán & DE-siroki-04735.jpg \\
\hline $2157-2159$ & Ornithogalum umbellatum agg. & Derecske & 1965 & Siroki Zoltán & DE-siroki-04724.jpg \\
\hline $2157-2159$ & Ornithogalum umbellatum agg. & Gyenesdiás & 1928 & Rigler József & DE-siroki-04753.jpg \\
\hline $2157-2159$ & Ornithogalum umbellatum agg. & Monorierdő & 1888 & Czakó Kálmán & DE-siroki-04720.jpg \\
\hline $2157-2159$ & Ornithogalum umbellatum agg. & Rezi & 1930 & Rigler József & DE-siroki-04727.jpg \\
\hline $2157-2159$ & Ornithogalum umbellatum agg. & Tatabánya & 1909 & Kocsis István & DE-siroki-04726.jpg \\
\hline $2162-2165$ & Scilla bifolia agg. & Debrecen & 1950 & Siroki Zoltán & DE-siroki-04694.jpg \\
\hline $2162-2165$ & Scilla bifolia agg. & Debrecen & 1950 & Siroki Zoltán & DE-siroki-04691.jpg \\
\hline $2162-2165$ & Scilla bifolia agg. & Debrecen & 1950 & Siroki Zoltán & DE-siroki-04692.jpg \\
\hline $2162-2165$ & Scilla bifolia agg. & Debrecen & 1950 & Siroki Zoltán & DE-siroki-04693.jpg \\
\hline $2162-2165$ & Scilla bifolia agg. & Miskolc & 1957 & Pethő Menyhért & DE-siroki-04695.jpg \\
\hline $2162-2165$ & Scilla bifolia agg. & Tarpa & 1971 & Siroki Zoltán & DE-siroki-04690.jpg \\
\hline 2169 & Muscari neglectum Guss. ex Ten. & Budaörs & 1952 & Siroki Zoltán & DE-siroki-04761.jpg \\
\hline 2169 & Muscari neglectum Guss. ex Ten. & Budapest & 1909 & Kocsis István & DE-siroki-04756.jpg \\
\hline 2169 & Muscari neglectum Guss. ex Ten. & Budapest & 1912 & Bocskay Ottó & DE-siroki-04754.jpg \\
\hline 2169 & Muscari neglectum Guss. ex Ten. & Budapest & 1951 & Siroki Zoltán & DE-siroki-04762.jpg \\
\hline 2170 & Muscari botryoides (L.) Mill. & Csehimindszent & 1951 & Jeanplong József & DE-siroki-04764.jpg \\
\hline 2171 & Allium vineale $\mathrm{L}$. & Balatonederics & 1955 & Siroki Zoltán & DE-siroki-04508.jpg \\
\hline 2171 & Allium vineale $\mathrm{L}$. & Budapest & 1951 & Siroki Zoltán & DE-siroki-04509.jpg \\
\hline 2171 & Allium vineale $\mathrm{L}$. & Budapest & 1951 & Siroki Zoltán & DE-siroki-04510.jpg \\
\hline 2171 & Allium vineale L. & Mezőpeterd & 1959 & Siroki Zoltán & DE-siroki-04507.jpg \\
\hline 2172 & Allium sphaerocephalon L. & "Szent-György-hegy" & 1955 & Siroki Zoltán & DE-siroki-04522.jpg \\
\hline 2172 & Allium sphaerocephalon L. & "Szent-György-hegy" & 1955 & Siroki Zoltán & DE-siroki-04523.jpg \\
\hline 2172 & Allium sphaerocephalon L. & "Szent-György-hegy" & 1955 & Siroki Zoltán & DE-siroki-04524.jpg \\
\hline 2172 & Allium sphaerocephalon L. & Balatonederics & 1955 & Siroki Zoltán & DE-siroki-04526.jpg \\
\hline 2172 & Allium sphaerocephalon L. & Budapest & 1909 & Kocsis István & DE-siroki-04514.jpg \\
\hline 2172 & Allium sphaerocephalon L. & Budapest & 1912 & Bocskay Ottó & DE-siroki-04525.jpg \\
\hline 2172 & Allium sphaerocephalon L. & Budapest & 1912 & Bocskay Ottó & DE-siroki-04528.jpg \\
\hline 2172 & Allium sphaerocephalon L. & Budapest & 1948 & Siroki Zoltán & DE-siroki-04521.jpg \\
\hline 2172 & Allium sphaerocephalon L. & Budapest & 1984 & Siroki Zoltán & DE-siroki-04520.jpg \\
\hline 2172 & Allium sphaerocephalon L. & Gyenesdiás & 1955 & Siroki Zoltán & DE-siroki-04530.jpg \\
\hline 2172 & Allium sphaerocephalon L. & Nagykőrös & 1954 & Siroki Zoltán & DE-siroki-04529.jpg \\
\hline 2172 & Allium sphaerocephalon L. & Nagykőrös & 1954 & Siroki Zoltán & DE-siroki-04531.jpg \\
\hline 2172 & Allium sphaerocephalon L. & Tokaj & 1977 & Siroki Zoltán & DE-siroki-04515.jpg \\
\hline 2172 & Allium sphaerocephalon L. & Tokaj & 1977 & Siroki Zoltán & DE-siroki-04516.jpg \\
\hline 2172 & Allium sphaerocephalon L. & Tokaj & 1977 & Siroki Zoltán & DE-siroki-04517.jpg \\
\hline 2172 & Allium sphaerocephalon L. & Tokaj & 1977 & Siroki Zoltán & DE-siroki-04518.jpg \\
\hline 2172 & Allium sphaerocephalon L. & Tokaj & 1977 & Siroki Zoltán & DE-siroki-04519.jpg \\
\hline 2172 & Allium sphaerocephalon L. & Tokaj & 1977 & Siroki Zoltán & DE-siroki-04533.jpg \\
\hline 2172 & Allium sphaerocephalon L. & Tokaj & 1977 & Siroki Zoltán & DE-siroki-04534.jpg \\
\hline 2172 & Allium sphaerocephalon L. & Tokaj & 1977 & Siroki Zoltán & DE-siroki-04532.jpg \\
\hline 2174 & Allium scorodoprasum L. & Budapest & 1909 & Kocsis István & DE-siroki-04535.jpg \\
\hline
\end{tabular}




\begin{tabular}{|c|c|c|c|c|c|}
\hline $\begin{array}{l}\text { Sorszám / } \\
\text { Number }\end{array}$ & Taxon-név / Taxon-name & $\begin{array}{l}\text { Település / } \\
\text { Settlement }\end{array}$ & $\begin{array}{l}\text { Év / } \\
\text { Year }\end{array}$ & $\begin{array}{l}\text { Gyűjtő / } \\
\text { Collector }\end{array}$ & Fájlnév / File-name \\
\hline 2174 & Allium scorodoprasum L. & Dunakeszi & 1905 & Thaisz Lajos & DE-siroki-04536.jpg \\
\hline 2174 & Allium scorodoprasum L. & Mosonmagyaróvár & 1939 & Siroki Zoltán & DE-siroki-04537.jpg \\
\hline 2176 & Allium atroviolaceum Boiss. & "Szent-György-hegy" & 1955 & Siroki Zoltán & DE-siroki-04541.jpg \\
\hline 2176 & Allium atroviolaceum Boiss. & "Szent-György-hegy" & 1955 & Siroki Zoltán & DE-siroki-04543.jpg \\
\hline 2176 & Allium atroviolaceum Boiss. & "Szent-György-hegy" & 1955 & Siroki Zoltán & DE-siroki-04544.jpg \\
\hline 2176 & Allium atroviolaceum Boiss. & Budapest & 1951 & Siroki Zoltán & DE-siroki-04542.jpg \\
\hline 2176 & Allium atroviolaceum Boiss. & Dömsöd & 1952 & Siroki Zoltán & DE-siroki-04545.jpg \\
\hline 2178 & Allium moschatum L. & Budapest & 1912 & Degen Árpád & DE-siroki-04547.jpg \\
\hline 2178 & Allium moschatum L. & Budapest & 1924 & Degen Árpád & DE-siroki-04548.jpg \\
\hline 2178 & Allium moschatum L. & Budapest & 1941 & Siroki Zoltán & DE-siroki-04557.jpg \\
\hline 2178 & Allium moschatum L. & Budapest & 1948 & Siroki Zoltán & DE-siroki-04549.jpg \\
\hline 2178 & Allium moschatum L. & Budapest & 1948 & Siroki Zoltán & DE-siroki-04556.jpg \\
\hline 2178 & Allium moschatum L. & Budapest & 1950 & Siroki Zoltán & DE-siroki-04550.jpg \\
\hline 2178 & Allium moschatum L. & Budapest & 1950 & Siroki Zoltán & DE-siroki-04551.jpg \\
\hline 2178 & Allium moschatum L. & Budapest & 1950 & Siroki Zoltán & DE-siroki-04552.jpg \\
\hline 2178 & Allium moschatum L. & Budapest & 1950 & Siroki Zoltán & DE-siroki-04553.jpg \\
\hline 2178 & Allium moschatum L. & Diósd & 1879 & Tauscher Gyula & DE-siroki-04546.jpg \\
\hline 2178 & Allium moschatum L. & Fót & 1954 & $\begin{array}{l}\text { Máthé Imre - } \\
\text { Kovács Margit }\end{array}$ & DE-siroki-04554.jpg \\
\hline 2178 & Allium moschatum L. & Fót & 1954 & $\begin{array}{l}\text { Máthé Imre - } \\
\text { Kovács Margit }\end{array}$ & DE-siroki-04555.jpg \\
\hline 2182 & Allium ursinum L. & Bátorliget & 1954 & Farkas Attila & DE-siroki-04567.jpg \\
\hline 2182 & Allium ursinum L. & Bátorliget & 1954 & Siroki Zoltán & DE-siroki-04565.jpg \\
\hline 2182 & Allium ursinum L. & Bátorliget & 1954 & Siroki Zoltán & DE-siroki-04566.jpg \\
\hline 2182 & Allium ursinum L. & Bátorliget & 1957 & Siroki Zoltán & DE-siroki-04568.jpg \\
\hline 2182 & Allium ursinum L. & Gyenesdiás & 1972 & Siroki Zoltán & DE-siroki-04564.jpg \\
\hline 2182 & Allium ursinum L. & Gyenesdiás & 1972 & Siroki Zoltán & DE-siroki-04569.jpg \\
\hline 2183 & Allium victorialis L. & Nagyvisnyó & 1954 & Jeney Endre & DE-siroki-04571.jpg \\
\hline 2184 & Allium atropurpureum Waldst. et Kit. & Kisújszállás & 1969 & Siroki Zoltán & DE-siroki-04573.jpg \\
\hline 2184 & Allium atropurpureum Waldst. et Kit. & Kisújszállás & 1969 & Siroki Zoltán & DE-siroki-04574.jpg \\
\hline 2184 & Allium atropurpureum Waldst. et Kit. & Kisújszállás & 1969 & Siroki Zoltán & DE-siroki-04575.jpg \\
\hline 2186 & Allium angulosum L. & Budapest & 1898 & Thaisz Lajos & DE-siroki-04587.jpg \\
\hline 2186 & Allium angulosum L. & Budapest & 1909 & Kocsis István & DE-siroki-04586.jpg \\
\hline 2186 & Allium angulosum L. & Debrecen & 1947 & Siroki Zoltán & DE-siroki-04597.jpg \\
\hline 2186 & Allium angulosum L. & Debrecen & 1947 & Siroki Zoltán & DE-siroki-04599.jpg \\
\hline 2186 & Allium angulosum L. & Debrecen & 1948 & Siroki Zoltán & DE-siroki-04598.jpg \\
\hline 2186 & Allium angulosum L. & Debrecen & 1950 & Siroki Zoltán & DE-siroki-04592.jpg \\
\hline 2186 & Allium angulosum L. & Dunakeszi & 1954 & Kovács Margit & DE-siroki-04594.jpg \\
\hline 2186 & Allium angulosum L. & Hajdúsámson & 1947 & Siroki Zoltán & DE-siroki-04595.jpg \\
\hline 2186 & Allium angulosum L. & Hajdúsámson & 1947 & Siroki Zoltán & DE-siroki-04601.jpg \\
\hline 2186 & Allium angulosum L. & Izsák & 1954 & Siroki Zoltán & DE-siroki-04600.jpg \\
\hline 2186 & Allium angulosum L. & Sátoraljaújhely & 1944 & Siroki Zoltán & DE-siroki-04593.jpg \\
\hline 2186 & Allium angulosum L. & Sátoraljaújhely & 1944 & Siroki Zoltán & DE-siroki-04596.jpg \\
\hline 2186 & Allium angulosum L. & Tiszafüred & 1973 & Siroki Zoltán & DE-siroki-04589.jpg \\
\hline 2186 & Allium angulosum L. & Tiszafüred & 1973 & Siroki Zoltán & DE-siroki-04590.jpg \\
\hline 2186 & Allium angulosum L. & Tiszafüred & 1973 & Siroki Zoltán & DE-siroki-04591.jpg \\
\hline 2187 & Allium lusitanicum Lam. & Budapest & 1941 & Siroki Zoltán & DE-siroki-04606.jpg \\
\hline
\end{tabular}




\begin{tabular}{|c|c|c|c|c|c|}
\hline $\begin{array}{l}\text { Sorszám / } \\
\text { Number }\end{array}$ & Taxon-név / Taxon-name & $\begin{array}{l}\text { Település / } \\
\text { Settlement }\end{array}$ & $\begin{array}{l}\text { Év / } \\
\text { Year }\end{array}$ & $\begin{array}{l}\text { Gyüjtő / } \\
\text { Collector }\end{array}$ & Fájlnév / File-name \\
\hline 2187 & Allium lusitanicum Lam. & Budapest & 1941 & Siroki Zoltán & DE-siroki-04607.jpg \\
\hline 2187 & Allium lusitanicum Lam. & Komlóska & 1984 & Siroki Zoltán & DE-siroki-04605.jpg \\
\hline 2187 & Allium lusitanicum Lam. & Piliscsaba & 1916 & $\begin{array}{l}\text { Filarszky } \\
\text { Nándor }\end{array}$ & DE-siroki-04603.jpg \\
\hline 2188 & Allium oleraceum L. & "Nagymező" & 1958 & Siroki Zoltán & DE-siroki-04609.jpg \\
\hline 2188 & Allium oleraceum L. & Balatonederics & 1955 & Siroki Zoltán & DE-siroki-04612.jpg \\
\hline 2188 & Allium oleraceum L. & Balatonederics & 1955 & Siroki Zoltán & DE-siroki-04613.jpg \\
\hline 2188 & Allium oleraceum L. & Nagykőrös & 1954 & Siroki Zoltán & DE-siroki-04610.jpg \\
\hline 2188 & Allium oleraceum L. & Nagykőrös & 1954 & Siroki Zoltán & DE-siroki-04611.jpg \\
\hline 2189 & Allium carinatum L. & Balatonederics & 1955 & Siroki Zoltán & DE-siroki-04620.jpg \\
\hline 2189 & Allium carinatum L. & Balatonederics & 1955 & Siroki Zoltán & DE-siroki-04621.jpg \\
\hline 2189 & Allium carinatum L. & Balatonederics & 1955 & Siroki Zoltán & DE-siroki-04622.jpg \\
\hline 2190 & Allium flavum L. & Aggtelek & 1972 & Siroki Zoltán & DE-siroki-04631.jpg \\
\hline 2190 & Allium flavum L. & Budapest & 1877 & Richter Lajos & DE-siroki-04625.jpg \\
\hline 2190 & Allium flavum L. & Budapest & 1877 & Richter Lajos & DE-siroki-04626.jpg \\
\hline 2190 & Allium flavum L. & Budapest & 1909 & Kocsis István & DE-siroki-04623.jpg \\
\hline 2190 & Allium flavum L. & Budapest & 1909 & Kocsis István & DE-siroki-04624.jpg \\
\hline 2190 & Allium flavum L. & Budapest & 1941 & Siroki Zoltán & DE-siroki-04629.jpg \\
\hline 2190 & Allium flavum L. & Budapest & 1948 & Siroki Zoltán & DE-siroki-04630.jpg \\
\hline 2190 & Allium flavum L. & Cserszegtomaj & 1930 & Rigler József & DE-siroki-04627.jpg \\
\hline 2190 & Allium flavum L. & Nagyharsány & 1912 & Gerhárdt Guido & DE-siroki-04628.jpg \\
\hline 2192 & Convallaria majalis L. & "Nagymező" & 1959 & Halász Tibor & DE-siroki-04862.jpg \\
\hline 2192 & Convallaria majalis L. & Debrecen & 1950 & Siroki Zoltán & DE-siroki-04863.jpg \\
\hline 2192 & Convallaria majalis L. & Hosszúhetény & 1958 & Siroki Zoltán & DE-siroki-04864.jpg \\
\hline 2193 & $\begin{array}{l}\text { Maianthemum bifolium } \\
\text { (L.) F.W. Schmidt }\end{array}$ & "Nagymező" & 1957 & Siroki Zoltán & DE-siroki-04815.jpg \\
\hline 2193 & $\begin{array}{l}\text { Maianthemum bifolium } \\
\text { (L.) F.W. Schmidt }\end{array}$ & "Nagymező" & 1957 & Siroki Zoltán & DE-siroki-04817.jpg \\
\hline 2193 & $\begin{array}{l}\text { Maianthemum bifolium } \\
\text { (L.) F.W. Schmidt }\end{array}$ & "Nagymező" & 1959 & Siroki Zoltán & DE-siroki-04813.jpg \\
\hline 2193 & $\begin{array}{l}\text { Maianthemum bifolium } \\
\text { (L.) F.W. Schmidt }\end{array}$ & "Nagymező" & 1959 & Siroki Zoltán & DE-siroki-04814.jpg \\
\hline 2193 & $\begin{array}{l}\text { Maianthemum bifolium } \\
\text { (L.) F.W. Schmidt }\end{array}$ & Bátorliget & 1956 & Siroki Zoltán & DE-siroki-04816.jpg \\
\hline 2193 & $\begin{array}{l}\text { Maianthemum bifolium } \\
\text { (L.) F.W. Schmidt }\end{array}$ & Debrecen & 1950 & Kovács Béla & DE-siroki-04818.jpg \\
\hline 2193 & $\begin{array}{l}\text { Maianthemum bifolium } \\
\text { (L.) F.W. Schmidt }\end{array}$ & Háromhuta & 1960 & Siroki Zoltán & DE-siroki-04811.jpg \\
\hline 2193 & $\begin{array}{l}\text { Maianthemum bifolium } \\
\text { (L.) F.W. Schmidt }\end{array}$ & Nagyhuta & 1960 & Siroki Zoltán & DE-siroki-04810.jpg \\
\hline 2193 & $\begin{array}{l}\text { Maianthemum bifolium } \\
\text { (L.) F.W. Schmidt }\end{array}$ & Nagyhuta & 1961 & Siroki Zoltán & DE-siroki-04812.jpg \\
\hline 2193 & $\begin{array}{l}\text { Maianthemum bifolium } \\
\text { (L.) F.W. Schmidt }\end{array}$ & Úrkút & 1930 & Rigler József & DE-siroki-04809.jpg \\
\hline 2194 & Polygonatum verticillatum (L.) All. & "Hármaskő" & 1957 & Siroki Zoltán & DE-siroki-04834.jpg \\
\hline 2194 & Polygonatum verticillatum (L.) All. & "Hármaskő" & 1957 & Siroki Zoltán & DE-siroki-04835.jpg \\
\hline 2194 & Polygonatum verticillatum (L.) All. & "Hármaskő" & 1957 & Siroki Zoltán & DE-siroki-04836.jpg \\
\hline 2194 & Polygonatum verticillatum (L.) All. & "Hármaskő" & 1957 & Siroki Zoltán & DE-siroki-04837.jpg \\
\hline 2194 & Polygonatum verticillatum (L.) All. & "Nagymező" & 1957 & Siroki Zoltán & DE-siroki-04833.jpg \\
\hline 2194 & Polygonatum verticillatum (L.) All. & "Nagymező" & 1968 & Siroki Zoltán & DE-siroki-04832.jpg \\
\hline 2195 & Polygonatum latifolium (Jacq.) Desf. & Debrecen & 1949 & Siroki Zoltán & DE-siroki-04847.jpg \\
\hline 2195 & Polygonatum latifolium (Jacq.) Desf. & Debrecen & 1950 & Siroki Zoltán & DE-siroki-04846.jpg \\
\hline
\end{tabular}




\begin{tabular}{|c|c|c|c|c|c|}
\hline $\begin{array}{c}\text { Sorszám / } \\
\text { Number }\end{array}$ & Taxon-név / Taxon-name & $\begin{array}{l}\text { Település / } \\
\text { Settlement }\end{array}$ & $\begin{array}{l}\text { Év / } \\
\text { Year }\end{array}$ & $\begin{array}{l}\text { Gyújtő / } \\
\text { Collector }\end{array}$ & Fájlnév / File-name \\
\hline 2195 & Polygonatum latifolium (Jacq.) Desf. & Debrecen & 1958 & Pethő Menyhért & DE-siroki-04850.jpg \\
\hline 2195 & Polygonatum latifolium (Jacq.) Desf. & Debrecen & - & Siroki Zoltán & DE-siroki-04845.jpg \\
\hline 2195 & Polygonatum latifolium (Jacq.) Desf. & Szigetszentmiklós & 1910 & Kocsis István & DE-siroki-04839.jpg \\
\hline 2195 & Polygonatum latifolium (Jacq.) Desf. & Szigetszentmiklós & 1910 & Kocsis István & DE-siroki-04840.jpg \\
\hline 2195 & Polygonatum latifolium (Jacq.) Desf. & Szigetszentmiklós & 1910 & Kocsis István & DE-siroki-04841.jpg \\
\hline 2195 & Polygonatum latifolium (Jacq.) Desf. & Tarcal & 1938 & Hulják János & DE-siroki-04844.jpg \\
\hline 2196 & Polygonatum odoratum (Mill.) Druce & Debrecen & 1950 & Siroki Zoltán & DE-siroki-04849.jpg \\
\hline 2196 & Polygonatum odoratum (Mill.) Druce & Debrecen & 1958 & Pethő Menyhért & DE-siroki-04851.jpg \\
\hline 2196 & Polygonatum odoratum (Mill.) Druce & Debrecen & 1958 & Pethő Menyhért & DE-siroki-04852.jpg \\
\hline 2196 & Polygonatum odoratum (Mill.) Druce & Gyenesdiás & 1930 & Rigler József & DE-siroki-04848.jpg \\
\hline 2197 & Polygonatum multiflorum (L.) All. & Bükkszentkereszt & 1959 & Halász Tibor & DE-siroki-04856.jpg \\
\hline 2198 & Asparagus officinalis L. & Budapest & 1941 & Siroki Zoltán & DE-siroki-04786.jpg \\
\hline 2198 & Asparagus officinalis L. & Debrecen & 1955 & Siroki Zoltán & DE-siroki-04782.jpg \\
\hline 2198 & Asparagus officinalis L. & Debrecen & 1955 & Siroki Zoltán & DE-siroki-04783.jpg \\
\hline 2198 & Asparagus officinalis L. & Debrecen & 1958 & Pethő Menyhért & DE-siroki-04784.jpg \\
\hline 2198 & Asparagus officinalis L. & Debrecen & 1958 & Pethő Menyhért & DE-siroki-04785.jpg \\
\hline 2198 & Asparagus officinalis L. & Hajdúbagos & 1947 & Siroki Zoltán & DE-siroki-04780.jpg \\
\hline 2198 & Asparagus officinalis L. & Mikepércs & 1969 & Siroki Zoltán & DE-siroki-04779.jpg \\
\hline 2199 & Paris quadrifolia L. & "Nagymező" & 1957 & Siroki Zoltán & DE-siroki-04870.jpg \\
\hline 2199 & Paris quadrifolia L. & "Nagymező" & 1959 & Halász Tibor & DE-siroki-04868.jpg \\
\hline 2199 & Paris quadrifolia L. & Bátorliget & 1954 & Simon Tiborné & DE-siroki-04871.jpg \\
\hline 2199 & Paris quadrifolia $\mathrm{L}$. & Bátorliget & 1956 & Siroki Zoltán & DE-siroki-04872.jpg \\
\hline 2199 & Paris quadrifolia L. & Nagyhuta & 1961 & Siroki Zoltán & DE-siroki-04869.jpg \\
\hline 2200 & Ruscus aculeatus L. & Balatonederics & 1955 & Siroki Zoltán & DE-siroki-04796.jpg \\
\hline 2200 & Ruscus aculeatus L. & Balatonederics & 1955 & Siroki Zoltán & DE-siroki-04799.jpg \\
\hline 2200 & Ruscus aculeatus L. & Balatonederics & 1955 & Siroki Zoltán & DE-siroki-04800.jpg \\
\hline 2200 & Ruscus aculeatus L. & Pécs & 1954 & Siroki Zoltán & DE-siroki-04803.jpg \\
\hline 2200 & Ruscus aculeatus L. & Pécs & 1954 & Siroki Zoltán & DE-siroki-04801.jpg \\
\hline 2200 & Ruscus aculeatus L. & Pécs & 1954 & Siroki Zoltán & DE-siroki-04802.jpg \\
\hline 2200 & Ruscus aculeatus L. & Pécs & 1954 & Siroki Zoltán & DE-siroki-04797.jpg \\
\hline 2200 & Ruscus aculeatus L. & Pécs & 1954 & Siroki Zoltán & DE-siroki-04798.jpg \\
\hline 2200 & Ruscus aculeatus L. & Pécsvárad & 1961 & Kárpáti Zoltán & DE-siroki-04804.jpg \\
\hline 2201 & Ruscus hypoglossum L. & Pécs & 1958 & Siroki Zoltán & DE-siroki-04789.jpg \\
\hline 2201 & Ruscus hypoglossum L. & Pécs & 1958 & Siroki Zoltán & DE-siroki-04791.jpg \\
\hline 2201 & Ruscus hypoglossum L. & Pécsvárad & 1956 & Jeney Endre & DE-siroki-04790.jpg \\
\hline 2202 & Potamogeton pectinatus L. & Balatonberény & 1930 & Papp László & DE-siroki-00569.jpg \\
\hline 2202 & Potamogeton pectinatus L. & Budapest & 1913 & Bocskay Ottó & DE-siroki-00575.jpg \\
\hline 2202 & Potamogeton pectinatus L. & Dunaharaszti & 1952 & Siroki Zoltán & DE-siroki-00576.jpg \\
\hline 2202 & Potamogeton pectinatus L. & Dunaharaszti & 1955 & Siroki Zoltán & DE-siroki-00573.jpg \\
\hline 2202 & Potamogeton pectinatus L. & Hortobágy & 1961 & Siroki Zoltán & DE-siroki-00570.jpg \\
\hline 2202 & Potamogeton pectinatus L. & Hortobágy & 1961 & Siroki Zoltán & DE-siroki-00571.jpg \\
\hline 2202 & Potamogeton pectinatus L. & Hortobágy & 1961 & Siroki Zoltán & DE-siroki-00572.jpg \\
\hline 2202 & Potamogeton pectinatus L. & Keszthely & 1955 & Kovács Béla & DE-siroki-00577.jpg \\
\hline 2202 & Potamogeton pectinatus L. & Keszthely & 1955 & Kovács Béla & DE-siroki-00578.jpg \\
\hline 2202 & Potamogeton pectinatus L. & Keszthely & 1955 & Kovács Béla & DE-siroki-00579.jpg \\
\hline 2202 & Potamogeton pectinatus L. & Keszthely & 1955 & Siroki Zoltán & DE-siroki-00574.jpg \\
\hline
\end{tabular}




\begin{tabular}{|c|c|c|c|c|c|}
\hline $\begin{array}{l}\text { Sorszám / } \\
\text { Number }\end{array}$ & Taxon-név / Taxon-name & $\begin{array}{l}\text { Település / } \\
\text { Settlement }\end{array}$ & $\begin{array}{l}\text { Év / } \\
\text { Year }\end{array}$ & $\begin{array}{l}\text { Gyűjtő / } \\
\text { Collector }\end{array}$ & Fájlnév / File-name \\
\hline 2207 & Potamogeton pusillus L. em. Fieber & Hortobágy & 1955 & Siroki Zoltán & DE-siroki-00598.jpg \\
\hline 2207 & Potamogeton pusillus L. em. Fieber & Hortobágy & 1955 & Siroki Zoltán & DE-siroki-00599.jpg \\
\hline 2207 & Potamogeton pusillus L. em. Fieber & Hortobágy & 1955 & Siroki Zoltán & DE-siroki-00600.jpg \\
\hline 2207 & Potamogeton pusillus L. em. Fieber & Hortobágy & 1955 & Siroki Zoltán & DE-siroki-00597.jpg \\
\hline 2207 & Potamogeton pusillus L. em. Fieber & Szigetszentmiklós & 1951 & Siroki Zoltán & DE-siroki-00594.jpg \\
\hline 2207 & Potamogeton pusillus L. em. Fieber & Szigetszentmiklós & 1951 & Siroki Zoltán & DE-siroki-00595.jpg \\
\hline 2207 & Potamogeton pusillus L. em. Fieber & Szigetszentmiklós & 1951 & Siroki Zoltán & DE-siroki-00596.jpg \\
\hline 2209 & Potamogeton crispus L. & Biharugra & 1961 & Siroki Zoltán & DE-siroki-00537.jpg \\
\hline 2209 & Potamogeton crispus L. & Biharugra & 1961 & Siroki Zoltán & DE-siroki-00538.jpg \\
\hline 2209 & Potamogeton crispus L. & Biharugra & 1961 & Siroki Zoltán & DE-siroki-00539.jpg \\
\hline 2209 & Potamogeton crispus L. & Budapest & 1882 & W. Steinitz & DE-siroki-00545.jpg \\
\hline 2209 & Potamogeton crispus L. & Gödöllő & 1951 & Siroki Zoltán & DE-siroki-00541.jpg \\
\hline 2209 & Potamogeton crispus L. & Hortobágy & 1947 & Siroki Zoltán & DE-siroki-00542.jpg \\
\hline 2209 & Potamogeton crispus L. & Hortobágy & 1947 & Siroki Zoltán & DE-siroki-00543.jpg \\
\hline 2209 & Potamogeton crispus L. & Kállósemjén & 1955 & Siroki Zoltán & DE-siroki-00540.jpg \\
\hline 2209 & Potamogeton crispus L. & Tiszafüred & 1955 & $\begin{array}{l}\text { Siroki Zoltán - } \\
\text { Farkas Attila }\end{array}$ & DE-siroki-00536.jpg \\
\hline 2210 & Potamogeton perfoliatus L. & Bugyi & 1952 & Siroki Zoltán & DE-siroki-00534.jpg \\
\hline 2210 & Potamogeton perfoliatus L. & Bugyi & 1952 & Siroki Zoltán & DE-siroki-00535.jpg \\
\hline 2210 & Potamogeton perfoliatus L. & Keszthely & 1955 & Siroki Zoltán & DE-siroki-00530.jpg \\
\hline 2210 & Potamogeton perfoliatus L. & Keszthely & 1955 & Siroki Zoltán & DE-siroki-00531.jpg \\
\hline 2210 & Potamogeton perfoliatus L. & Keszthely & 1955 & Siroki Zoltán & DE-siroki-00532.jpg \\
\hline 2210 & Potamogeton perfoliatus L. & Keszthely & 1955 & Siroki Zoltán & DE-siroki-00533.jpg \\
\hline 2212 & Potamogeton lucens L. & Tiszafüred & 1955 & Siroki Zoltán & DE-siroki-00562.jpg \\
\hline 2212 & Potamogeton lucens L. & Tiszafüred & 1955 & Siroki Zoltán & DE-siroki-00563.jpg \\
\hline 2212 & Potamogeton lucens L. & Tiszafüred & 1955 & Siroki Zoltán & DE-siroki-00564.jpg \\
\hline 2212 & Potamogeton lucens L. & Veresegyház & 1954 & Siroki Zoltán & DE-siroki-00559.jpg \\
\hline 2212 & Potamogeton lucens L. & Veresegyház & 1954 & Siroki Zoltán & DE-siroki-00560.jpg \\
\hline 2212 & Potamogeton lucens L. & Veresegyház & 1954 & Siroki Zoltán & DE-siroki-00550.jpg \\
\hline 2212 & Potamogeton lucens L. & Veresegyház & 1954 & Siroki Zoltán & DE-siroki-00551.jpg \\
\hline 2212 & Potamogeton lucens L. & Veresegyház & 1954 & Siroki Zoltán & DE-siroki-00552.jpg \\
\hline 2212 & Potamogeton lucens L. & Veresegyház & 1954 & Siroki Zoltán & DE-siroki-00553.jpg \\
\hline 2212 & Potamogeton lucens L. & Veresegyház & 1954 & Siroki Zoltán & DE-siroki-00554.jpg \\
\hline 2212 & Potamogeton lucens L. & Veresegyház & 1954 & Siroki Zoltán & DE-siroki-00555.jpg \\
\hline 2212 & Potamogeton lucens L. & Veresegyház & 1954 & Siroki Zoltán & DE-siroki-00556.jpg \\
\hline 2212 & Potamogeton lucens L. & Veresegyház & 1954 & Siroki Zoltán & DE-siroki-00557.jpg \\
\hline 2212 & Potamogeton lucens L. & Veresegyház & 1954 & Siroki Zoltán & DE-siroki-00558.jpg \\
\hline 2214 & Potamogeton natans L. & Abaújvár & 1943 & Siroki Zoltán & DE-siroki-00516.jpg \\
\hline 2214 & Potamogeton natans L. & Hortobágy & 1947 & Siroki Zoltán & DE-siroki-00515.jpg \\
\hline 2214 & Potamogeton natans L. & Hortobágy & 1947 & Siroki Zoltán & DE-siroki-00520.jpg \\
\hline 2214 & Potamogeton natans L. & Hortobágy & 1947 & Siroki Zoltán & DE-siroki-00521.jpg \\
\hline 2214 & Potamogeton natans L. & Hortobágy & 1955 & Siroki Zoltán & DE-siroki-00518.jpg \\
\hline 2214 & Potamogeton natans L. & Hortobágy & 1955 & Siroki Zoltán & DE-siroki-00519.jpg \\
\hline 2214 & Potamogeton natans L. & Hortobágy & 1955 & Siroki Zoltán & DE-siroki-00517.jpg \\
\hline 2214 & Potamogeton natans $\mathrm{L}$. & Tapolca & 1950 & $\begin{array}{l}\text { Priszter } \\
\text { Szaniszló }\end{array}$ & DE-siroki-00512.jpg \\
\hline 2215 & Potamogeton coloratus Hornem. & Budapest & 1913 & Bocskay Ottó & DE-siroki-00509.jpg \\
\hline
\end{tabular}




\begin{tabular}{|c|c|c|c|c|c|}
\hline $\begin{array}{l}\text { Sorszám / } \\
\text { Number }\end{array}$ & Taxon-név / Taxon-name & $\begin{array}{l}\text { Település / } \\
\text { Settlement }\end{array}$ & $\begin{array}{l}\text { Év / } \\
\text { Year }\end{array}$ & $\begin{array}{l}\text { Gyüjtő / } \\
\text { Collector }\end{array}$ & Fájlnév / File-name \\
\hline 2216 & Potamogeton nodosus Poir. & Budapest & - & W. Steinitz & DE-siroki-00523.jpg \\
\hline 2218 & Zannichellia palustris L. & Budapest & 1915 & Degen Árpád & DE-siroki-00613.jpg \\
\hline 2218 & Zannichellia palustris L. & Veresegyház & 1954 & Siroki Zoltán & DE-siroki-00620.jpg \\
\hline 2218 & Zannichellia palustris L. & Veresegyház & 1954 & Siroki Zoltán & DE-siroki-00618.jpg \\
\hline 2218 & Zannichellia palustris L. & Veresegyház & 1954 & Siroki Zoltán & DE-siroki-00619.jpg \\
\hline 2218 & Zannichellia palustris L. & Veresegyház & 1954 & Siroki Zoltán & DE-siroki-00616.jpg \\
\hline 2218 & Zannichellia palustris L. & Veresegyház & 1954 & Siroki Zoltán & DE-siroki-00617.jpg \\
\hline 2219 & Najas marina L. & Keszthely & 1955 & Siroki Zoltán & DE-siroki-00623.jpg \\
\hline 2219 & Najas marina L. & Keszthely & 1955 & Siroki Zoltán & DE-siroki-00624.jpg \\
\hline 2219 & Najas marina L. & Keszthely & 1955 & Siroki Zoltán & DE-siroki-00625.jpg \\
\hline 2220 & Najas minor All. & Hortobágy & 1972 & Kovács Béla & DE-siroki-00629.jpg \\
\hline 2220 & Najas minor All. & Hortobágy & 1972 & Kovács Béla & DE-siroki-00630.jpg \\
\hline 2222 & Gagea pratensis (Pers.) Dumort. & Debrecen & 1947 & Siroki Zoltán & DE-siroki-04473.jpg \\
\hline 2222 & Gagea pratensis (Pers.) Dumort. & Debrecen & 1955 & Siroki Zoltán & DE-siroki-04472.jpg \\
\hline 2222 & Gagea pratensis (Pers.) Dumort. & Kőszeg & - & $\begin{array}{l}\text { Waisbecker } \\
\text { Antal }\end{array}$ & DE-siroki-04470.jpg \\
\hline 2222 & Gagea pratensis (Pers.) Dumort. & Tarpa & 1971 & Siroki Zoltán & DE-siroki-04471.jpg \\
\hline 2223 & Gagea lutea (L.) Ker Gawl. & Budapest & 1905 & K??? Géza & DE-siroki-04476.jpg \\
\hline 2223 & Gagea lutea (L.) Ker Gawl. & Budapest & 1905 & Szartorisz Béla & DE-siroki-04475.jpg \\
\hline 2223 & Gagea lutea (L.) Ker Gawl. & Budapest & 1951 & Siroki Zoltán & DE-siroki-04483.jpg \\
\hline 2223 & Gagea lutea (L.) Ker Gawl. & Budapest & 1955 & Siroki Zoltán & DE-siroki-04485.jpg \\
\hline 2223 & Gagea lutea (L.) Ker Gawl. & Debrecen & 1950 & Siroki Zoltán & DE-siroki-04482.jpg \\
\hline 2223 & Gagea lutea (L.) Ker Gawl. & Miskolc & 1961 & Siroki Zoltán & DE-siroki-04484.jpg \\
\hline 2223 & Gagea lutea (L.) Ker Gawl. & Tarpa & 1971 & Siroki Zoltán & DE-siroki-04480.jpg \\
\hline 2224 & Gagea minima (L.) Ker Gawl. & Pomáz & 1951 & Siroki Zoltán & DE-siroki-04499.jpg \\
\hline 2225 & $\begin{array}{l}\text { Gagea pusilla } \\
\text { (F.W. Schmidt) Schult. et Schult. f. }\end{array}$ & Bénye & 1932 & Rigler József & DE-siroki-04489.jpg \\
\hline 2225 & $\begin{array}{l}\text { Gagea pusilla } \\
\text { (F.W. Schmidt) Schult. et Schult. f. }\end{array}$ & Budapest & 1874 & Staub Móric & DE-siroki-04486.jpg \\
\hline 2225 & $\begin{array}{l}\text { Gagea pusilla } \\
\text { (F.W. Schmidt) Schult. et Schult. f. }\end{array}$ & Budapest & 1951 & Siroki Zoltán & DE-siroki-04491.jpg \\
\hline 2225 & $\begin{array}{l}\text { Gagea pusilla } \\
\text { (F.W. Schmidt) Schult. et Schult. f. }\end{array}$ & Debrecen & 1947 & Siroki Zoltán & DE-siroki-04490.jpg \\
\hline 2227 & Gagea villosa (M. Bieb.) Duby & Budapest & 1951 & Siroki Zoltán & DE-siroki-04502.jpg \\
\hline 2227 & Gagea villosa (M. Bieb.) Duby & Budapest & - & Hermann & DE-siroki-04505.jpg \\
\hline 2228 & $\begin{array}{l}\text { Gagea bohemica } \\
\text { (Zauschn.) Schult. et Schult. f. }\end{array}$ & Szentendre & 1951 & Kárpáti Zoltán & DE-siroki-04504.jpg \\
\hline $\begin{array}{c}2225 \times \\
2227\end{array}$ & $\begin{array}{l}\text { Gagea pusilla (F.W. Schmidt) Schult. et } \\
\text { Schult. f. } \times \\
\text { Gagea villosa (M. Bieb.) Duby }\end{array}$ & Budapest & 1884 & Richter Lajos & DE-siroki-04506.jpg \\
\hline 2233 & Fritillaria meleagris L. & Tarpa & 1955 & Siroki Zoltán & DE-siroki-04655.jpg \\
\hline 2233 & Fritillaria meleagris L. & Tarpa & 1955 & Siroki Zoltán & DE-siroki-04656.jpg \\
\hline 2233 & Fritillaria meleagris L. & Tarpa & 1955 & $\begin{array}{l}\text { Siroki Zoltán - } \\
\text { Farkas Attila }\end{array}$ & DE-siroki-04659.jpg \\
\hline 2233 & Fritillaria meleagris L. & Tarpa & 1955 & $\begin{array}{l}\text { Siroki Zoltán - } \\
\text { Farkas Attila }\end{array}$ & DE-siroki-04657.jpg \\
\hline 2233 & Fritillaria meleagris L. & Tarpa & 1955 & $\begin{array}{l}\text { Siroki Zoltán - } \\
\text { Farkas Attila }\end{array}$ & DE-siroki-04658.jpg \\
\hline 2233 & Fritillaria meleagris L. & Tarpa & 1965 & Siroki Zoltán & DE-siroki-04660.jpg \\
\hline 2233 & Fritillaria meleagris L. & Tarpa & 1971 & Siroki Zoltán & DE-siroki-04661.jpg \\
\hline 2233 & Fritillaria meleagris L. & Tarpa & 1971 & Siroki Zoltán & DE-siroki-04662.jpg \\
\hline 2233 & Fritillaria meleagris L. & Tarpa & 1971 & Siroki Zoltán & DE-siroki-04663.jpg \\
\hline
\end{tabular}




\begin{tabular}{|c|c|c|c|c|c|}
\hline $\begin{array}{l}\text { Sorszám / } \\
\text { Number }\end{array}$ & Taxon-név / Taxon-name & $\begin{array}{l}\text { Település / } \\
\text { Settlement }\end{array}$ & $\begin{array}{l}\text { Év / } \\
\text { Year }\end{array}$ & $\begin{array}{l}\text { Gyüjtő / } \\
\text { Collector }\end{array}$ & Fájlnév / File-name \\
\hline 2233 & Fritillaria meleagris L. & Tarpa & 1971 & Siroki Zoltán & DE-siroki-04664.jpg \\
\hline 2235 & Lilium martagon L. & "Nagymező" & 1956 & Halász Tibor & DE-siroki-04644.jpg \\
\hline 2235 & Lilium martagon L. & "Nagymező" & 1959 & Siroki Zoltán & DE-siroki-04645.jpg \\
\hline 2235 & Lilium martagon L. & Bátorliget & 1956 & Siroki Zoltán & DE-siroki-04643.jpg \\
\hline 2235 & Lilium martagon L. & Budapest & 1952 & Gondola István & DE-siroki-04641.jpg \\
\hline 2235 & Lilium martagon L. & Létavértes & 1984 & Siroki Zoltán & DE-siroki-04647.jpg \\
\hline 2235 & Lilium martagon L. & Szilvásvárad & 1961 & Siroki Zoltán & DE-siroki-04646.jpg \\
\hline 2238 & $\begin{array}{l}\text { Sternbergia colchiciflora } \\
\text { Waldst. et Kit. }\end{array}$ & Budaörs & 1952 & Siroki Zoltán & DE-siroki-04896.jpg \\
\hline 2238 & $\begin{array}{l}\text { Sternbergia colchiciflora } \\
\text { Waldst. et Kit. }\end{array}$ & Budapest & 1887 & Czakó Kálmán & DE-siroki-04894.jpg \\
\hline 2238 & $\begin{array}{l}\text { Sternbergia colchiciflora } \\
\text { Waldst. et Kit. }\end{array}$ & Budapest & 1911 & $\begin{array}{l}\text { Filarszky } \\
\text { Nándor - } \\
\text { Jávorka Sándor } \\
\text { - Szurák János }\end{array}$ & DE-siroki-04893.jpg \\
\hline 2238 & $\begin{array}{l}\text { Sternbergia colchiciflora } \\
\text { Waldst. et Kit. }\end{array}$ & Budapest & 1951 & Siroki Zoltán & DE-siroki-04895.jpg \\
\hline 2240 & Leucojum aestivum L. & Bátorliget & 1954 & Siroki Zoltán & DE-siroki-04887.jpg \\
\hline 2240 & Leucojum aestivum L. & Bátorliget & 1954 & Siroki Zoltán & DE-siroki-04888.jpg \\
\hline 2240 & Leucojum aestivum L. & Bátorliget & 1954 & Siroki Zoltán & DE-siroki-04889.jpg \\
\hline 2240 & Leucojum aestivum L. & Bátorliget & 1954 & Siroki Zoltán & DE-siroki-04890.jpg \\
\hline 2240 & Leucojum aestivum L. & Bátorliget & 1954 & Siroki Zoltán & DE-siroki-04891.jpg \\
\hline 2240 & Leucojum aestivum L. & Egyek & 1947 & Siroki Zoltán & DE-siroki-04892.jpg \\
\hline 2240 & Leucojum aestivum L. & Kimle & 1962 & Siroki Zoltán & DE-siroki-04884.jpg \\
\hline 2240 & Leucojum aestivum L. & Kimle & 1962 & Siroki Zoltán & DE-siroki-04885.jpg \\
\hline 2240 & Leucojum aestivum L. & Kimle & 1962 & Siroki Zoltán & DE-siroki-04886.jpg \\
\hline 2241 & Galanthus nivalis L. & Szilvásvárad & 1958 & Pethő Menyhért & DE-siroki-04879.jpg \\
\hline 2246 & Tamus communis L. & Gyenesdiás & 1953 & Siroki Zoltán & DE-siroki-04922.jpg \\
\hline 2246 & Tamus communis L. & Gyenesdiás & 1953 & Siroki Zoltán & DE-siroki-04923.jpg \\
\hline 2246 & Tamus communis L. & Gyenesdiás & 1953 & Siroki Zoltán & DE-siroki-04924.jpg \\
\hline 2246 & Tamus communis L. & Hosszúhetény & 1954 & Siroki Zoltán & DE-siroki-04914.jpg \\
\hline 2246 & Tamus communis L. & Hosszúhetény & 1954 & Siroki Zoltán & DE-siroki-04915.jpg \\
\hline 2246 & Tamus communis L. & Hosszúhetény & 1954 & Siroki Zoltán & DE-siroki-04916.jpg \\
\hline 2246 & Tamus communis L. & Hosszúhetény & 1954 & Siroki Zoltán & DE-siroki-04917.jpg \\
\hline 2246 & Tamus communis L. & Hosszúhetény & 1958 & Siroki Zoltán & DE-siroki-04920.jpg \\
\hline 2246 & Tamus communis L. & Hosszúhetény & 1958 & Siroki Zoltán & DE-siroki-04921.jpg \\
\hline 2246 & Tamus communis L. & Hosszúhetény & 1958 & Siroki Zoltán & DE-siroki-04918.jpg \\
\hline 2246 & Tamus communis L. & Hosszúhetény & 1958 & Siroki Zoltán & DE-siroki-04919.jpg \\
\hline 2251 & Iris pseudacorus L. & Debrecen & 1948 & Siroki Zoltán & DE-siroki-04972.jpg \\
\hline 2251 & Iris pseudacorus L. & Mosonmagyaróvár & 1939 & Siroki Zoltán & DE-siroki-04973.jpg \\
\hline 2252 & Iris graminea L. & Felsőtárkány & 1957 & Siroki Zoltán & DE-siroki-04994.jpg \\
\hline 2252 & Iris graminea L. & Felsőtárkány & 1957 & Siroki Zoltán & DE-siroki-04995.jpg \\
\hline 2252 & Iris graminea L. & Felsőtárkány & 1957 & Siroki Zoltán & DE-siroki-04993.jpg \\
\hline 2252 & Iris graminea L. & Felsőtárkány & 1957 & Siroki Zoltán & DE-siroki-04992.jpg \\
\hline 2253 & Iris spuria L. & Mikepércs & 1962 & Siroki Zoltán & DE-siroki-04984.jpg \\
\hline 2253 & Iris spuria L. & Mikepércs & 1962 & Siroki Zoltán & DE-siroki-04985.jpg \\
\hline 2253 & Iris spuria L. & Mikepércs & 1962 & Siroki Zoltán & DE-siroki-04986.jpg \\
\hline 2253 & Iris spuria L. & Mikepércs & 1962 & Siroki Zoltán & DE-siroki-04987.jpg \\
\hline 2253 & Iris spuria L. & Mikepércs & 1962 & Siroki Zoltán & DE-siroki-04988.jpg \\
\hline
\end{tabular}




\begin{tabular}{|c|c|c|c|c|c|}
\hline $\begin{array}{l}\text { Sorszám / } \\
\text { Number }\end{array}$ & Taxon-név / Taxon-name & $\begin{array}{l}\text { Település / } \\
\text { Settlement }\end{array}$ & $\begin{array}{l}\text { Év / } \\
\text { Year }\end{array}$ & $\begin{array}{l}\text { Gyűjtő / } \\
\text { Collector }\end{array}$ & Fájlnév / File-name \\
\hline 2254 & Iris sibirica L. & "Nagymező" & 1960 & Siroki Zoltán & DE-siroki-04975.jpg \\
\hline 2254 & Iris sibirica L. & "Nagymező" & 1960 & Siroki Zoltán & DE-siroki-04976.jpg \\
\hline 2254 & Iris sibirica L. & "Nagymező" & 1960 & Siroki Zoltán & DE-siroki-04977.jpg \\
\hline 2254 & Iris sibirica L. & "Nagymező" & 1960 & Siroki Zoltán & DE-siroki-04978.jpg \\
\hline 2254 & Iris sibirica L. & "Nagymező" & 1960 & Siroki Zoltán & DE-siroki-04979.jpg \\
\hline 2254 & Iris sibirica L. & "Nagymező" & 1960 & Siroki Zoltán & DE-siroki-04980.jpg \\
\hline 2254 & Iris sibirica L. & "Nagymező" & 1960 & Siroki Zoltán & DE-siroki-04981.jpg \\
\hline 2254 & Iris sibirica L. & "Nagymező" & 1960 & Siroki Zoltán & DE-siroki-04982.jpg \\
\hline 2254 & Iris sibirica L. & Bátorliget & 1957 & Siroki Zoltán & DE-siroki-04983.jpg \\
\hline 2255 & Iris arenaria Waldst. et Kit. & Debrecen & 1950 & Siroki Zoltán & DE-siroki-04949.jpg \\
\hline 2255 & Iris arenaria Waldst. et Kit. & Debrecen & 1950 & Siroki Zoltán & DE-siroki-04951.jpg \\
\hline 2255 & Iris arenaria Waldst. et Kit. & Debrecen & 1950 & Siroki Zoltán & DE-siroki-04952.jpg \\
\hline 2255 & Iris arenaria Waldst. et Kit. & Debrecen & 1954 & Siroki Zoltán & DE-siroki-04950.jpg \\
\hline 2256 & Iris pumila L. & Budapest & 1951 & Siroki Zoltán & DE-siroki-04947.jpg \\
\hline 2256 & Iris pumila L. & Budapest & 1951 & Siroki Zoltán & DE-siroki-04948.jpg \\
\hline 2259 & Iris aphylla L. & Debrecen & 1950 & Siroki Zoltán & DE-siroki-04957.jpg \\
\hline 2259 & Iris aphylla L. & Debrecen & 1950 & Siroki Zoltán & DE-siroki-04958.jpg \\
\hline 2259 & Iris aphylla L. & Debrecen & 1950 & Siroki Zoltán & DE-siroki-04956.jpg \\
\hline 2259 & Iris aphylla L. & Debrecen & 1950 & Siroki Zoltán & DE-siroki-04959.jpg \\
\hline 2259 & Iris aphylla L. & Debrecen & 1950 & Siroki Zoltán & DE-siroki-04961.jpg \\
\hline 2259 & Iris aphylla L. & Debrecen & 1950 & Siroki Zoltán & DE-siroki-04960.jpg \\
\hline 2260 & Iris variegata L. & "Nagymező" & 1960 & Siroki Zoltán & DE-siroki-04971.jpg \\
\hline 2260 & Iris variegata L. & "Nagymező" & 1962 & Siroki Zoltán & DE-siroki-04965.jpg \\
\hline 2260 & Iris variegata L. & "Nagymező" & 1962 & Siroki Zoltán & DE-siroki-04966.jpg \\
\hline 2260 & Iris variegata $L$. & Gödöllő & 1952 & Siroki Zoltán & DE-siroki-04970.jpg \\
\hline 2260 & Iris variegata L. & Gödöllő & 1952 & Siroki Zoltán & DE-siroki-04969.jpg \\
\hline 2260 & Iris variegata L. & Mátraszentimre & 1959 & Gondola István & DE-siroki-04962.jpg \\
\hline 2260 & Iris variegata $L$. & Mátraszentimre & 1959 & Gondola István & DE-siroki-04963.jpg \\
\hline 2260 & Iris variegata L. & Mátraszentimre & 1959 & Gondola István & DE-siroki-04964.jpg \\
\hline 2260 & Iris variegata L. & Szarvaskő & 1957 & Siroki Zoltán & DE-siroki-04967.jpg \\
\hline 2260 & Iris variegata $\mathrm{L}$. & Szarvaskő & 1957 & Siroki Zoltán & DE-siroki-04968.jpg \\
\hline 2261 & Crocus reticulatus Steven & Debrecen & 1954 & Kovács Béla & DE-siroki-04943.jpg \\
\hline 2261 & Crocus reticulatus Steven & Debrecen & 1955 & Siroki Zoltán & DE-siroki-04942.jpg \\
\hline 2266 & Gladiolus imbricatus L. & "Nagymező" & 1959 & Siroki Zoltán & DE-siroki-05013.jpg \\
\hline 2266 & Gladiolus imbricatus L. & "Nagymező" & 1959 & Siroki Zoltán & DE-siroki-05011.jpg \\
\hline 2266 & Gladiolus imbricatus L. & "Nagymező" & 1959 & Siroki Zoltán & DE-siroki-05012.jpg \\
\hline 2266 & Gladiolus imbricatus L. & "Nagymező" & 1959 & Siroki Zoltán & DE-siroki-05014.jpg \\
\hline 2266 & Gladiolus imbricatus L. & "Nagymező" & 1959 & Siroki Zoltán & DE-siroki-05009.jpg \\
\hline 2266 & Gladiolus imbricatus L. & "Nagymező" & 1959 & Siroki Zoltán & DE-siroki-05010.jpg \\
\hline 2266 & Gladiolus imbricatus L. & "Nagymező" & 1959 & Siroki Zoltán & DE-siroki-05006.jpg \\
\hline 2266 & Gladiolus imbricatus L. & "Nagymező" & 1959 & Siroki Zoltán & DE-siroki-05007.jpg \\
\hline 2266 & Gladiolus imbricatus L. & "Nagymező" & 1959 & Siroki Zoltán & DE-siroki-05008.jpg \\
\hline 2266 & Gladiolus imbricatus L. & Háromhuta & 1961 & Siroki Zoltán & DE-siroki-05003.jpg \\
\hline 2266 & Gladiolus imbricatus L. & Háromhuta & 1962 & Siroki Zoltán & DE-siroki-05004.jpg \\
\hline 2266 & Gladiolus imbricatus L. & Háromhuta & 1965 & Siroki Zoltán & DE-siroki-05005.jpg \\
\hline 2269 & Juncus inflexus L. & Debrecen & 1947 & Siroki Zoltán & DE-siroki-04225.jpg \\
\hline
\end{tabular}




\begin{tabular}{|c|c|c|c|c|c|}
\hline $\begin{array}{c}\text { Sorszám / } \\
\text { Number }\end{array}$ & Taxon-név / Taxon-name & $\begin{array}{l}\text { Település / } \\
\text { Settlement }\end{array}$ & $\begin{array}{l}\text { Év / } \\
\text { Year }\end{array}$ & $\begin{array}{l}\text { Gyűjtő / } \\
\text { Collector }\end{array}$ & Fájlnév / File-name \\
\hline 2269 & Juncus inflexus L. & Debrecen & 1947 & Siroki Zoltán & DE-siroki-04218.jpg \\
\hline 2269 & Juncus inflexus L. & Debrecen & 1957 & Siroki Zoltán & DE-siroki-04219.jpg \\
\hline 2269 & Juncus inflexus L. & Debrecen & 1957 & Siroki Zoltán & DE-siroki-04220.jpg \\
\hline 2269 & Juncus inflexus L. & Hortobágy & 1949 & Siroki Zoltán & DE-siroki-04224.jpg \\
\hline 2269 & Juncus inflexus L. & Hortobágy & 1949 & Siroki Zoltán & DE-siroki-04223.jpg \\
\hline 2270 & Juncus effusus L. & Debrecen & 1954 & Siroki Zoltán & DE-siroki-04230.jpg \\
\hline 2270 & Juncus effusus L. & Debrecen & 1956 & Siroki Zoltán & DE-siroki-04231.jpg \\
\hline 2270 & Juncus effusus L. & Debrecen & 1956 & Siroki Zoltán & DE-siroki-04226.jpg \\
\hline 2271 & Juncus conglomeratus L. & Debrecen & 1951 & Siroki Zoltán & DE-siroki-04240.jpg \\
\hline 2271 & Juncus conglomeratus L. & Debrecen & 1951 & Siroki Zoltán & DE-siroki-04241.jpg \\
\hline 2271 & Juncus conglomeratus L. & Debrecen & 1951 & Siroki Zoltán & DE-siroki-04237.jpg \\
\hline 2271 & Juncus conglomeratus L. & Háromhuta & 1965 & Siroki Zoltán & DE-siroki-04234.jpg \\
\hline 2271 & Juncus conglomeratus L. & Háromhuta & 1965 & Siroki Zoltán & DE-siroki-04235.jpg \\
\hline 2271 & Juncus conglomeratus L. & Háromhuta & 1967 & Siroki Zoltán & DE-siroki-04232.jpg \\
\hline 2271 & Juncus conglomeratus L. & Háromhuta & 1967 & Siroki Zoltán & DE-siroki-04236.jpg \\
\hline 2271 & Juncus conglomeratus L. & Hortobágy & 1956 & Siroki Zoltán & DE-siroki-04242.jpg \\
\hline 2271 & Juncus conglomeratus L. & Regéc & 1967 & Siroki Zoltán & DE-siroki-04233.jpg \\
\hline 2273 & Juncus sphaerocarpus Nees & Budapest & 1909 & Kocsis István & DE-siroki-04314.jpg \\
\hline 2273 & Juncus sphaerocarpus Nees & Budapest & 1915 & Degen Árpád & DE-siroki-04313.jpg \\
\hline 2273 & Juncus sphaerocarpus Nees & Ercsi & - & Tauscher Gyula & DE-siroki-04315.jpg \\
\hline 2275 & Juncus bufonius L. & Berekböszörmény & 1970 & Siroki Zoltán & DE-siroki-04322.jpg \\
\hline 2275 & Juncus bufonius L. & Debrecen & 1954 & Siroki Zoltán & DE-siroki-04316.jpg \\
\hline 2275 & Juncus bufonius L. & Debrecen & 1954 & Siroki Zoltán & DE-siroki-04326.jpg \\
\hline 2275 & Juncus bufonius L. & Debrecen & 1954 & Siroki Zoltán & DE-siroki-04327.jpg \\
\hline 2275 & Juncus bufonius L. & Fényeslitke & 1965 & Gondola István & DE-siroki-04319.jpg \\
\hline 2275 & Juncus bufonius L. & Gyula & 1974 & Siroki Zoltán & DE-siroki-04318.jpg \\
\hline 2275 & Juncus bufonius L. & Keszthely & 1955 & Siroki Zoltán & DE-siroki-04320.jpg \\
\hline 2275 & Juncus bufonius L. & Keszthely & 1955 & Siroki Zoltán & DE-siroki-04321.jpg \\
\hline 2275 & Juncus bufonius L. & Tiszafüred & 1970 & Siroki Zoltán & DE-siroki-04323.jpg \\
\hline 2276 & Juncus tenuis Willd. & Debrecen & 1953 & Siroki Zoltán & DE-siroki-04264.jpg \\
\hline 2276 & Juncus tenuis Willd. & Debrecen & 1972 & Siroki Zoltán & DE-siroki-04261.jpg \\
\hline 2276 & Juncus tenuis Willd. & Debrecen & 1972 & Siroki Zoltán & DE-siroki-04262.jpg \\
\hline 2276 & Juncus tenuis Willd. & Debrecen & 1972 & Siroki Zoltán & DE-siroki-04259.jpg \\
\hline 2276 & Juncus tenuis Willd. & Debrecen & 1977 & Siroki Zoltán & DE-siroki-04258.jpg \\
\hline 2276 & Juncus tenuis Willd. & Debrecen & 1977 & Siroki Zoltán & DE-siroki-04260.jpg \\
\hline 2276 & Juncus tenuis Willd. & Háromhuta & 1960 & Siroki Zoltán & DE-siroki-04249.jpg \\
\hline 2276 & Juncus tenuis Willd. & Háromhuta & 1960 & Siroki Zoltán & DE-siroki-04250.jpg \\
\hline 2276 & Juncus tenuis Willd. & Háromhuta & 1960 & Siroki Zoltán & DE-siroki-04253.jpg \\
\hline 2276 & Juncus tenuis Willd. & Háromhuta & 1960 & Siroki Zoltán & DE-siroki-04254.jpg \\
\hline 2276 & Juncus tenuis Willd. & Háromhuta & 1960 & Siroki Zoltán & DE-siroki-04255.jpg \\
\hline 2276 & Juncus tenuis Willd. & Háromhuta & 1965 & Siroki Zoltán & DE-siroki-04248.jpg \\
\hline 2276 & Juncus tenuis Willd. & Háromhuta & 1977 & Siroki Zoltán & DE-siroki-04257.jpg \\
\hline 2276 & Juncus tenuis Willd. & Nagyhuta & 1962 & Siroki Zoltán & DE-siroki-04251.jpg \\
\hline 2276 & Juncus tenuis Willd. & Nagyhuta & 1962 & Siroki Zoltán & DE-siroki-04252.jpg \\
\hline 2277 & Juncus compressus Jacq. & Debrecen & 1947 & Siroki Zoltán & DE-siroki-04287.jpg \\
\hline 2277 & Juncus compressus Jacq. & Debrecen & 1962 & Siroki Zoltán & DE-siroki-04300.jpg \\
\hline
\end{tabular}




\begin{tabular}{|c|c|c|c|c|c|}
\hline $\begin{array}{c}\text { Sorszám / } \\
\text { Number }\end{array}$ & Taxon-név / Taxon-name & $\begin{array}{l}\text { Település / } \\
\text { Settlement }\end{array}$ & $\begin{array}{l}\text { Év / } \\
\text { Year }\end{array}$ & $\begin{array}{l}\text { Gyűjtő / } \\
\text { Collector }\end{array}$ & Fájlnév / File-name \\
\hline 2277 & Juncus compressus Jacq. & Egyek & 1947 & Siroki Zoltán & DE-siroki-04282.jpg \\
\hline 2277 & Juncus compressus Jacq. & Hévíz & 1953 & Siroki Zoltán & DE-siroki-04284.jpg \\
\hline 2277 & Juncus compressus Jacq. & Hortobágy & 1947 & Siroki Zoltán & DE-siroki-04291.jpg \\
\hline 2277 & Juncus compressus Jacq. & Hortobágy & 1947 & Siroki Zoltán & DE-siroki-04286.jpg \\
\hline 2277 & Juncus compressus Jacq. & Hortobágy & 1948 & Siroki Zoltán & DE-siroki-04274.jpg \\
\hline 2277 & Juncus compressus Jacq. & Kecskemét & 1967 & Siroki Zoltán & DE-siroki-04281.jpg \\
\hline 2277 & Juncus compressus Jacq. & Mikepércs & 1962 & Siroki Zoltán & DE-siroki-04306.jpg \\
\hline 2277 & Juncus compressus Jacq. & Mikepércs & 1963 & Siroki Zoltán & DE-siroki-04273.jpg \\
\hline 2277 & Juncus compressus Jacq. & Mosonmagyaróvár & 1939 & Siroki Zoltán & DE-siroki-04283.jpg \\
\hline 2277 & Juncus compressus Jacq. & Mosonmagyaróvár & 1939 & Siroki Zoltán & DE-siroki-04285.jpg \\
\hline 2278 & Juncus gerardii Lois. & Abaújkér & 1942 & Siroki Zoltán & DE-siroki-04295.jpg \\
\hline 2278 & Juncus gerardii Lois. & Berekböszörmény & 1970 & Siroki Zoltán & DE-siroki-04292.jpg \\
\hline 2278 & Juncus gerardii Lois. & Berekböszörmény & 1970 & Siroki Zoltán & DE-siroki-04293.jpg \\
\hline 2278 & Juncus gerardii Lois. & Debrecen & 1947 & Siroki Zoltán & DE-siroki-04275.jpg \\
\hline 2278 & Juncus gerardii Lois. & Debrecen & 1954 & Siroki Zoltán & DE-siroki-04296.jpg \\
\hline 2278 & Juncus gerardii Lois. & Debrecen & 1954 & Siroki Zoltán & DE-siroki-04297.jpg \\
\hline 2278 & Juncus gerardii Lois. & Debrecen & 1954 & Siroki Zoltán & DE-siroki-04298.jpg \\
\hline 2278 & Juncus gerardii Lois. & Debrecen & 1962 & Siroki Zoltán & DE-siroki-04301.jpg \\
\hline 2278 & Juncus gerardii Lois. & Debrecen & 1962 & Siroki Zoltán & DE-siroki-04304.jpg \\
\hline 2278 & Juncus gerardii Lois. & Debrecen & 1962 & Siroki Zoltán & DE-siroki-04309.jpg \\
\hline 2278 & Juncus gerardii Lois. & Debrecen & 1962 & Siroki Zoltán & DE-siroki-04310.jpg \\
\hline 2278 & Juncus gerardii Lois. & Debrecen & 1962 & Siroki Zoltán & DE-siroki-04311.jpg \\
\hline 2278 & Juncus gerardii Lois. & Hortobágy & 1947 & Siroki Zoltán & DE-siroki-04291.jpg \\
\hline 2278 & Juncus gerardii Lois. & Kecskemét & 1967 & Siroki Zoltán & DE-siroki-04277.jpg \\
\hline 2278 & Juncus gerardii Lois. & Kecskemét & 1967 & Siroki Zoltán & DE-siroki-04278.jpg \\
\hline 2278 & Juncus gerardii Lois. & Kecskemét & 1967 & Siroki Zoltán & DE-siroki-04279.jpg \\
\hline 2278 & Juncus gerardii Lois. & Kecskemét & 1967 & Siroki Zoltán & DE-siroki-04280.jpg \\
\hline 2278 & Juncus gerardii Lois. & Mikepércs & 1962 & Siroki Zoltán & DE-siroki-04299.jpg \\
\hline 2278 & Juncus gerardii Lois. & Mikepércs & 1962 & Siroki Zoltán & DE-siroki-04302.jpg \\
\hline 2278 & Juncus gerardii Lois. & Mikepércs & 1962 & Siroki Zoltán & DE-siroki-04303.jpg \\
\hline 2278 & Juncus gerardii Lois. & Mikepércs & 1962 & Siroki Zoltán & DE-siroki-04305.jpg \\
\hline 2278 & Juncus gerardii Lois. & Mikepércs & 1962 & Siroki Zoltán & DE-siroki-04306.jpg \\
\hline 2278 & Juncus gerardii Lois. & Mikepércs & 1962 & Siroki Zoltán & DE-siroki-04307.jpg \\
\hline 2278 & Juncus gerardii Lois. & Mikepércs & 1962 & Siroki Zoltán & DE-siroki-04308.jpg \\
\hline 2278 & Juncus gerardii Lois. & Mikepércs & 1966 & Siroki Zoltán & DE-siroki-04276.jpg \\
\hline 2280 & Juncus capitatus Weigel & Nyírkáta & 1967 & Gondola István & DE-siroki-04200.jpg \\
\hline 2280 & Juncus capitatus Weigel & Nyírkáta & 1967 & Gondola István & DE-siroki-04201.jpg \\
\hline 2280 & Juncus capitatus Weigel & Nyírkáta & 1967 & Gondola István & DE-siroki-04202.jpg \\
\hline 2280 & Juncus capitatus Weigel & Nyírkáta & 1967 & Gondola István & DE-siroki-04203.jpg \\
\hline 2280 & Juncus capitatus Weigel & Nyírkáta & 1967 & Gondola István & DE-siroki-04204.jpg \\
\hline 2282 & Juncus subnodulosus Schrank & Keszthely & 1955 & Siroki Zoltán & DE-siroki-04149.jpg \\
\hline 2282 & Juncus subnodulosus Schrank & Keszthely & 1955 & Siroki Zoltán & DE-siroki-04145.jpg \\
\hline 2282 & Juncus subnodulosus Schrank & Keszthely & 1955 & Siroki Zoltán & DE-siroki-04146.jpg \\
\hline 2282 & Juncus subnodulosus Schrank & Keszthely & 1955 & Siroki Zoltán & DE-siroki-04143.jpg \\
\hline 2282 & Juncus subnodulosus Schrank & Keszthely & 1955 & Siroki Zoltán & DE-siroki-04144.jpg \\
\hline 2282 & Juncus subnodulosus Schrank & Veresegyház & 1960 & Siroki Zoltán & DE-siroki-04147.jpg \\
\hline
\end{tabular}




\begin{tabular}{|c|c|c|c|c|c|}
\hline $\begin{array}{l}\text { Sorszám / } \\
\text { Number }\end{array}$ & Taxon-név / Taxon-name & $\begin{array}{l}\text { Település / } \\
\text { Settlement }\end{array}$ & $\begin{array}{l}\text { Év / } \\
\text { Year }\end{array}$ & $\begin{array}{l}\text { Gyűjtő / } \\
\text { Collector }\end{array}$ & Fájlnév / File-name \\
\hline 2282 & Juncus subnodulosus Schrank & Veresegyház & 1960 & Siroki Zoltán & DE-siroki-04148.jpg \\
\hline 2283 & Juncus atratus Krock. & Egyek & 1947 & Siroki Zoltán & DE-siroki-04151.jpg \\
\hline 2283 & Juncus atratus Krock. & Egyek & 1947 & Siroki Zoltán & DE-siroki-04156.jpg \\
\hline 2283 & Juncus atratus Krock. & Egyek & 1947 & Siroki Zoltán & DE-siroki-04164.jpg \\
\hline 2283 & Juncus atratus Krock. & Egyek & 1947 & Siroki Zoltán & DE-siroki-04165.jpg \\
\hline 2283 & Juncus atratus Krock. & Háromhuta & 1965 & Siroki Zoltán & DE-siroki-04157.jpg \\
\hline 2283 & Juncus atratus Krock. & Háromhuta & 1965 & Siroki Zoltán & DE-siroki-04168.jpg \\
\hline 2283 & Juncus atratus Krock. & Háromhuta & 1965 & Siroki Zoltán & DE-siroki-04169.jpg \\
\hline 2283 & Juncus atratus Krock. & Háromhuta & 1965 & Siroki Zoltán & DE-siroki-04170.jpg \\
\hline 2283 & Juncus atratus Krock. & Háromhuta & 1965 & Siroki Zoltán & DE-siroki-04150.jpg \\
\hline 2283 & Juncus atratus Krock. & Háromhuta & 1965 & Siroki Zoltán & DE-siroki-04158.jpg \\
\hline 2283 & Juncus atratus Krock. & Háromhuta & 1965 & Siroki Zoltán & DE-siroki-04171.jpg \\
\hline 2283 & Juncus atratus Krock. & Háromhuta & 1965 & Siroki Zoltán & DE-siroki-04172.jpg \\
\hline 2283 & Juncus atratus Krock. & Háromhuta & 1965 & Siroki Zoltán & DE-siroki-04159.jpg \\
\hline 2283 & Juncus atratus Krock. & Hortobágy & 1956 & Siroki Zoltán & DE-siroki-04166.jpg \\
\hline 2283 & Juncus atratus Krock. & Hortobágy & 1956 & Siroki Zoltán & DE-siroki-04167.jpg \\
\hline 2283 & Juncus atratus Krock. & Izsák & 1954 & Siroki Zoltán & DE-siroki-04161.jpg \\
\hline 2283 & Juncus atratus Krock. & Izsák & 1954 & Siroki Zoltán & DE-siroki-04163.jpg \\
\hline 2283 & Juncus atratus Krock. & Nagykőrös & 1954 & Siroki Zoltán & DE-siroki-04154.jpg \\
\hline 2283 & Juncus atratus Krock. & Nagykőrös & 1954 & Siroki Zoltán & DE-siroki-04155.jpg \\
\hline 2283 & Juncus atratus Krock. & Nagykőrös & 1954 & Siroki Zoltán & DE-siroki-04160.jpg \\
\hline 2283 & Juncus atratus Krock. & Nagykőrös & 1954 & Siroki Zoltán & DE-siroki-04162.jpg \\
\hline 2283 & Juncus atratus Krock. & Sátoraljaújhely & 1944 & Siroki Zoltán & DE-siroki-04152.jpg \\
\hline 2283 & Juncus atratus Krock. & Sátoraljaújhely & 1944 & Siroki Zoltán & DE-siroki-04153.jpg \\
\hline 2283 & Juncus atratus Krock. & Újléta & 1968 & Siroki Zoltán & DE-siroki-04173.jpg \\
\hline 2283 & Juncus atratus Krock. & Újléta & 1968 & Siroki Zoltán & DE-siroki-04174.jpg \\
\hline 2284 & Juncus articulatus L. & Budapest & 1913 & Zsák Zoltán & DE-siroki-04180.jpg \\
\hline 2284 & Juncus articulatus L. & Debrecen & 1946 & Siroki Zoltán & DE-siroki-04196.jpg \\
\hline 2284 & Juncus articulatus L. & Debrecen & 1947 & Siroki Zoltán & DE-siroki-04188.jpg \\
\hline 2284 & Juncus articulatus L. & Debrecen & 1948 & Siroki Zoltán & DE-siroki-04192.jpg \\
\hline 2284 & Juncus articulatus L. & Debrecen & 1948 & Siroki Zoltán & DE-siroki-04185.jpg \\
\hline 2284 & Juncus articulatus L. & Debrecen & 1948 & Siroki Zoltán & DE-siroki-04189.jpg \\
\hline 2284 & Juncus articulatus L. & Debrecen & 1948 & Siroki Zoltán & DE-siroki-04190.jpg \\
\hline 2284 & Juncus articulatus L. & Debrecen & 1948 & Siroki Zoltán & DE-siroki-04195.jpg \\
\hline 2284 & Juncus articulatus L. & Debrecen & 1951 & Siroki Zoltán & DE-siroki-04193.jpg \\
\hline 2284 & Juncus articulatus L. & Debrecen & 1951 & Siroki Zoltán & DE-siroki-04194.jpg \\
\hline 2284 & Juncus articulatus L. & Debrecen & 1957 & Siroki Zoltán & DE-siroki-04191.jpg \\
\hline 2284 & Juncus articulatus L. & Háromhuta & 1967 & Siroki Zoltán & DE-siroki-04184.jpg \\
\hline 2284 & Juncus articulatus L. & Mosonmagyaróvár & 1939 & Siroki Zoltán & DE-siroki-04198.jpg \\
\hline 2284 & Juncus articulatus L. & Sátoraljaújhely & 1944 & Siroki Zoltán & DE-siroki-04182.jpg \\
\hline 2284 & Juncus articulatus L. & Szár & 1955 & Kovács Margit & DE-siroki-04183.jpg \\
\hline 2284 & Juncus articulatus L. & Újléta & 1965 & Siroki Zoltán & DE-siroki-04178.jpg \\
\hline 2284 & Juncus articulatus L. & Újléta & 1965 & Siroki Zoltán & DE-siroki-04179.jpg \\
\hline 2284 & Juncus articulatus L. & Újléta & 1965 & Siroki Zoltán & DE-siroki-04186.jpg \\
\hline 2285 & Luzula forsteri (Sm.) DC. & Pécs & 1951 & Kárpáti Zoltán & DE-siroki-04331.jpg \\
\hline 2285 & Luzula forsteri (Sm.) DC. & Pécs & 1958 & Siroki Zoltán & DE-siroki-04330.jpg \\
\hline
\end{tabular}




\begin{tabular}{|c|c|c|c|c|c|}
\hline $\begin{array}{l}\text { Sorszám / } \\
\text { Number }\end{array}$ & Taxon-név / Taxon-name & $\begin{array}{l}\text { Település / } \\
\text { Settlement }\end{array}$ & $\begin{array}{l}\text { Év / } \\
\text { Year }\end{array}$ & $\begin{array}{l}\text { Gyűjtő / } \\
\text { Collector }\end{array}$ & Fájlnév / File-name \\
\hline 2285 & Luzula forsteri (Sm.) DC. & Pécs & 1958 & Siroki Zoltán & DE-siroki-04332.jpg \\
\hline 2285 & Luzula forsteri (Sm.) DC. & Pécs & 1958 & Siroki Zoltán & DE-siroki-04333.jpg \\
\hline 2285 & Luzula forsteri (Sm.) DC. & Pécs & 1958 & Siroki Zoltán & DE-siroki-04334.jpg \\
\hline 2285 & Luzula forsteri (Sm.) DC. & Pécs & 1958 & Siroki Zoltán & DE-siroki-04335.jpg \\
\hline 2285 & Luzula forsteri (Sm.) DC. & Pécs & 1958 & Siroki Zoltán & DE-siroki-04336.jpg \\
\hline 2286 & Luzula pilosa (L.) Willd. & Pilismarót & 1957 & Siroki Zoltán & DE-siroki-04337.jpg \\
\hline 2286 & Luzula pilosa (L.) Willd. & Pilismarót & 1957 & Siroki Zoltán & DE-siroki-04338.jpg \\
\hline 2286 & Luzula pilosa (L.) Willd. & Pilismarót & 1957 & Siroki Zoltán & DE-siroki-04339.jpg \\
\hline 2286 & Luzula pilosa (L.) Willd. & Pilismarót & 1957 & Siroki Zoltán & DE-siroki-04340.jpg \\
\hline 2286 & Luzula pilosa (L.) Willd. & Pilismarót & 1957 & Siroki Zoltán & DE-siroki-04341.jpg \\
\hline 2287 & $\begin{array}{l}\text { Luzula luzuloides } \\
\text { (Lam.) Dandy et Wilmott }\end{array}$ & "Háromkő" & 1957 & Siroki Zoltán & DE-siroki-04352.jpg \\
\hline 2287 & $\begin{array}{l}\text { Luzula luzuloides } \\
\text { (Lam.) Dandy et Wilmott }\end{array}$ & "Szent-György-hegy" & 1955 & Siroki Zoltán & DE-siroki-04351.jpg \\
\hline 2287 & $\begin{array}{l}\text { Luzula luzuloides } \\
\text { (Lam.) Dandy et Wilmott }\end{array}$ & Pécs & 1958 & Siroki Zoltán & DE-siroki-04350.jpg \\
\hline 2287 & $\begin{array}{l}\text { Luzula luzuloides } \\
\text { (Lam.) Dandy et Wilmott }\end{array}$ & Szilvásvárad & 1954 & Siroki Zoltán & DE-siroki-04349.jpg \\
\hline 2287 & $\begin{array}{l}\text { Luzula luzuloides } \\
\text { (Lam.) Dandy et Wilmott }\end{array}$ & Szilvásvárad & 1960 & Siroki Zoltán & DE-siroki-04353.jpg \\
\hline 2288 & Luzula pallidula Kirschner & Debrecen & 1953 & Siroki Zoltán & DE-siroki-04387.jpg \\
\hline 2288 & Luzula pallidula Kirschner & Debrecen & 1953 & Siroki Zoltán & DE-siroki-04388.jpg \\
\hline 2288 & Luzula pallidula Kirschner & Debrecen & 1954 & Siroki Zoltán & DE-siroki-04384.jpg \\
\hline 2288 & Luzula pallidula Kirschner & Debrecen & 1954 & Siroki Zoltán & DE-siroki-04385.jpg \\
\hline 2288 & Luzula pallidula Kirschner & Debrecen & 1954 & Siroki Zoltán & DE-siroki-04393.jpg \\
\hline 2288 & Luzula pallidula Kirschner & Debrecen & 1954 & Siroki Zoltán & DE-siroki-04398.jpg \\
\hline 2288 & Luzula pallidula Kirschner & Debrecen & 1954 & Siroki Zoltán & DE-siroki-04386.jpg \\
\hline 2288 & Luzula pallidula Kirschner & Debrecen & 1954 & Siroki Zoltán & DE-siroki-04391.jpg \\
\hline 2288 & Luzula pallidula Kirschner & Debrecen & 1954 & Siroki Zoltán & DE-siroki-04392.jpg \\
\hline 2288 & Luzula pallidula Kirschner & Debrecen & 1959 & Siroki Zoltán & DE-siroki-04389.jpg \\
\hline 2288 & Luzula pallidula Kirschner & Debrecen & 1959 & Siroki Zoltán & DE-siroki-04390.jpg \\
\hline 2288 & Luzula pallidula Kirschner & Egyek & 1965 & Siroki Zoltán & DE-siroki-04397.jpg \\
\hline 2288 & Luzula pallidula Kirschner & Háromhuta & 1961 & Siroki Zoltán & DE-siroki-04394.jpg \\
\hline 2288 & Luzula pallidula Kirschner & Újléta & 1967 & Siroki Zoltán & DE-siroki-04395.jpg \\
\hline 2289 & Luzula campestris (L.) DC. & Budapest & 1951 & Siroki Zoltán & DE-siroki-04369.jpg \\
\hline 2289 & Luzula campestris (L.) DC. & Debrecen & 1947 & Siroki Zoltán & DE-siroki-04381.jpg \\
\hline 2289 & Luzula campestris (L.) DC. & Debrecen & 1950 & Siroki Zoltán & DE-siroki-04368.jpg \\
\hline 2289 & Luzula campestris (L.) DC. & Debrecen & 1950 & Siroki Zoltán & DE-siroki-04379.jpg \\
\hline 2289 & Luzula campestris (L.) DC. & Debrecen & 1950 & Siroki Zoltán & DE-siroki-04380.jpg \\
\hline 2289 & Luzula campestris (L.) DC. & Debrecen & 1964 & Siroki Zoltán & DE-siroki-04371.jpg \\
\hline 2289 & Luzula campestris (L.) DC. & Háromhuta & 1961 & Siroki Zoltán & DE-siroki-04376.jpg \\
\hline 2289 & Luzula campestris (L.) DC. & Háromhuta & 1961 & Siroki Zoltán & DE-siroki-04377.jpg \\
\hline 2289 & Luzula campestris (L.) DC. & Nagyhuta & 1961 & Siroki Zoltán & DE-siroki-04378.jpg \\
\hline 2289 & Luzula campestris (L.) DC. & Vámospércs & 1965 & Siroki Zoltán & DE-siroki-04375.jpg \\
\hline 2294 & Festuca altissima All. & "Hármaskő" & 1957 & Siroki Zoltán & DE-siroki-02106.jpg \\
\hline 2294 & Festuca altissima All. & Háromhuta & 1984 & Siroki Zoltán & DE-siroki-02110.jpg \\
\hline 2294 & Festuca altissima All. & Nagyvisnyó & 1959 & Siroki Zoltán & DE-siroki-02108.jpg \\
\hline 2294 & Festuca altissima All. & Nagyvisnyó & 1959 & Siroki Zoltán & DE-siroki-02109.jpg \\
\hline 2294 & Festuca altissima All. & Szilvásvárad & 1954 & Siroki Zoltán & DE-siroki-02111.jpg \\
\hline
\end{tabular}




\begin{tabular}{|c|c|c|c|c|c|}
\hline $\begin{array}{l}\text { Sorszám / } \\
\text { Number }\end{array}$ & Taxon-név / Taxon-name & $\begin{array}{l}\text { Település / } \\
\text { Settlement }\end{array}$ & $\begin{array}{l}\text { Év / } \\
\text { Year }\end{array}$ & $\begin{array}{l}\text { Gyűjtő / } \\
\text { Collector }\end{array}$ & Fájlnév / File-name \\
\hline 2294 & Festuca altissima All. & Szilvásvárad & 1954 & Siroki Zoltán & DE-siroki-02112.jpg \\
\hline 2294 & Festuca altissima All. & Szilvásvárad & 1954 & Siroki Zoltán & DE-siroki-02113.jpg \\
\hline 2294 & Festuca altissima All. & Szilvásvárad & 1954 & Siroki Zoltán & DE-siroki-02104.jpg \\
\hline 2295 & Festuca drymeja Mert. et W.D.J. Koch & Háromhuta & 1960 & Siroki Zoltán & DE-siroki-02115.jpg \\
\hline 2295 & Festuca drymeja Mert. et W.D.J. Koch & Háromhuta & 1960 & Siroki Zoltán & DE-siroki-02116.jpg \\
\hline 2295 & Festuca drymeja Mert. et W.D.J. Koch & Háromhuta & 1960 & Siroki Zoltán & DE-siroki-02117.jpg \\
\hline 2295 & Festuca drymeja Mert. et W.D.J. Koch & Háromhuta & 1960 & Siroki Zoltán & DE-siroki-02119.jpg \\
\hline 2295 & Festuca drymeja Mert. et W.D.J. Koch & Háromhuta & 1960 & Siroki Zoltán & DE-siroki-02118.jpg \\
\hline 2295 & Festuca drymeja Mert. et W.D.J. Koch & Háromhuta & 1961 & Siroki Zoltán & DE-siroki-02120.jpg \\
\hline 2295 & Festuca drymeja Mert. et W.D.J. Koch & Háromhuta & 1961 & Siroki Zoltán & DE-siroki-02114.jpg \\
\hline 2295 & Festuca drymeja Mert. et W.D.J. Koch & Háromhuta & 1961 & Siroki Zoltán & DE-siroki-02123.jpg \\
\hline 2295 & Festuca drymeja Mert. et W.D.J. Koch & Háromhuta & 1961 & Siroki Zoltán & DE-siroki-02124.jpg \\
\hline 2295 & Festuca drymeja Mert. et W.D.J. Koch & Háromhuta & 1978 & Siroki Zoltán & DE-siroki-02121.jpg \\
\hline 2295 & Festuca drymeja Mert. et W.D.J. Koch & Háromhuta & 1978 & Siroki Zoltán & DE-siroki-02122.jpg \\
\hline 2295 & Festuca drymeja Mert. et W.D.J. Koch & Pécs & 1954 & Siroki Zoltán & DE-siroki-02126.jpg \\
\hline 2295 & Festuca drymeja Mert. et W.D.J. Koch & Pécs & 1954 & Siroki Zoltán & DE-siroki-02127.jpg \\
\hline 2295 & Festuca drymeja Mert. et W.D.J. Koch & Pécs & 1954 & Siroki Zoltán & DE-siroki-02125.jpg \\
\hline 2295 & Festuca drymeja Mert. et W.D.J. Koch & Pécs & 1954 & Siroki Zoltán & DE-siroki-02128.jpg \\
\hline 2296 & Festuca gigantea (L.) Vill. & Debrecen & 1947 & Siroki Zoltán & DE-siroki-02083.jpg \\
\hline 2296 & Festuca gigantea (L.) Vill. & Debrecen & 1954 & Siroki Zoltán & DE-siroki-02081.jpg \\
\hline 2296 & Festuca gigantea (L.) Vill. & Debrecen & 1954 & Siroki Zoltán & DE-siroki-02082.jpg \\
\hline 2296 & Festuca gigantea (L.) Vill. & Túristvándi & 1975 & Siroki Zoltán & DE-siroki-02078.jpg \\
\hline 2296 & Festuca gigantea (L.) Vill. & Túristvándi & 1975 & Siroki Zoltán & DE-siroki-02079.jpg \\
\hline 2296 & Festuca gigantea (L.) Vill. & Túristvándi & 1975 & Siroki Zoltán & DE-siroki-02080.jpg \\
\hline 2297 & Festuca arundinacea Schreb. & Budapest & 1951 & Siroki Zoltán & DE-siroki-02085.jpg \\
\hline 2297 & Festuca arundinacea Schreb. & Debrecen & 1947 & Siroki Zoltán & DE-siroki-02090.jpg \\
\hline 2297 & Festuca arundinacea Schreb. & Debrecen & 1947 & Siroki Zoltán & DE-siroki-02091.jpg \\
\hline 2297 & Festuca arundinacea Schreb. & Debrecen & 1947 & Siroki Zoltán & DE-siroki-02089.jpg \\
\hline 2297 & Festuca arundinacea Schreb. & Debrecen & 1948 & Siroki Zoltán & DE-siroki-02087.jpg \\
\hline 2297 & Festuca arundinacea Schreb. & Debrecen & 1949 & Siroki Zoltán & DE-siroki-02092.jpg \\
\hline 2297 & Festuca arundinacea Schreb. & Debrecen & 1958 & Siroki Zoltán & DE-siroki-02088.jpg \\
\hline 2298 & Festuca pratensis Huds. & Debrecen & 1958 & Siroki Zoltán & DE-siroki-02093.jpg \\
\hline 2298 & Festuca pratensis Huds. & Debrecen & 1959 & Siroki Zoltán & DE-siroki-02100.jpg \\
\hline 2298 & Festuca pratensis Huds. & Debrecen & 1970 & Siroki Zoltán & DE-siroki-02099.jpg \\
\hline 2299 & Festuca heterophylla Lam. & "Nagymező" & 1960 & Siroki Zoltán & DE-siroki-19673.jpg \\
\hline 2299 & Festuca heterophylla Lam. & "Nagymező" & 1960 & Siroki Zoltán & DE-siroki-19674.jpg \\
\hline 2299 & Festuca heterophylla Lam. & "Nagymező" & 1960 & Siroki Zoltán & DE-siroki-19691.jpg \\
\hline 2299 & Festuca heterophylla Lam. & "Nagymező" & 1960 & Siroki Zoltán & DE-siroki-19692.jpg \\
\hline 2299 & Festuca heterophylla Lam. & Budapest & 1951 & Siroki Zoltán & DE-siroki-19670.jpg \\
\hline 2299 & Festuca heterophylla Lam. & Budapest & 1951 & Siroki Zoltán & DE-siroki-19695.jpg \\
\hline 2299 & Festuca heterophylla Lam. & Háromhuta & 1961 & Siroki Zoltán & DE-siroki-19678.jpg \\
\hline 2299 & Festuca heterophylla Lam. & Háromhuta & 1961 & Siroki Zoltán & DE-siroki-19679.jpg \\
\hline 2299 & Festuca heterophylla Lam. & Háromhuta & 1961 & Siroki Zoltán & DE-siroki-19680.jpg \\
\hline 2299 & Festuca heterophylla Lam. & Háromhuta & 1961 & Siroki Zoltán & DE-siroki-19681.jpg \\
\hline 2299 & Festuca heterophylla Lam. & Háromhuta & 1961 & Siroki Zoltán & DE-siroki-19684.jpg \\
\hline 2299 & Festuca heterophylla Lam. & Háromhuta & 1961 & Siroki Zoltán & DE-siroki-19685.jpg \\
\hline
\end{tabular}




\begin{tabular}{|c|c|c|c|c|c|}
\hline $\begin{array}{l}\text { Sorszám / } \\
\text { Number }\end{array}$ & Taxon-név / Taxon-name & $\begin{array}{l}\text { Település / } \\
\text { Settlement }\end{array}$ & $\begin{array}{l}\text { Év / } \\
\text { Year }\end{array}$ & $\begin{array}{l}\text { Gyűjtő / } \\
\text { Collector }\end{array}$ & Fájlnév / File-name \\
\hline 2299 & Festuca heterophylla Lam. & Háromhuta & 1961 & Siroki Zoltán & DE-siroki-19686.jpg \\
\hline 2299 & Festuca heterophylla Lam. & Háromhuta & 1961 & Siroki Zoltán & DE-siroki-19687.jpg \\
\hline 2299 & Festuca heterophylla Lam. & Háromhuta & 1967 & Siroki Zoltán & DE-siroki-19677.jpg \\
\hline 2299 & Festuca heterophylla Lam. & Háromhuta & 1967 & Siroki Zoltán & DE-siroki-19688.jpg \\
\hline 2299 & Festuca heterophylla Lam. & Szilvásvárad & 1960 & Siroki Zoltán & DE-siroki-19675.jpg \\
\hline 2299 & Festuca heterophylla Lam. & Szilvásvárad & 1960 & Siroki Zoltán & DE-siroki-19676.jpg \\
\hline 2299 & Festuca heterophylla Lam. & Szilvásvárad & 1960 & Siroki Zoltán & DE-siroki-19689.jpg \\
\hline 2299 & Festuca heterophylla Lam. & Szilvásvárad & 1960 & Siroki Zoltán & DE-siroki-19690.jpg \\
\hline 2301 & Festuca rubra L. & "Bükk-hg." & 1983 & Siroki Zoltán & DE-siroki-02061.jpg \\
\hline 2301 & Festuca rubra L. & "Mátra" & 1983 & Siroki Zoltán & DE-siroki-19701.jpg \\
\hline 2301 & Festuca rubra L. & "Mátra" & 1983 & Siroki Zoltán & DE-siroki-02062.jpg \\
\hline 2301 & Festuca rubra L. & "Mátra" & 1983 & Siroki Zoltán & DE-siroki-02054.jpg \\
\hline 2301 & Festuca rubra L. & "Mátra" & 1983 & Siroki Zoltán & DE-siroki-02055.jpg \\
\hline 2301 & Festuca rubra L. & "Mátra" & 1983 & Siroki Zoltán & DE-siroki-02056.jpg \\
\hline 2301 & Festuca rubra L. & "Mátra" & 1983 & Siroki Zoltán & DE-siroki-02057.jpg \\
\hline 2301 & Festuca rubra L. & "Mátra" & 1983 & Siroki Zoltán & DE-siroki-02058.jpg \\
\hline 2301 & Festuca rubra L. & "Nagymező" & 1959 & Siroki Zoltán & DE-siroki-02043.jpg \\
\hline 2301 & Festuca rubra L. & "Nagymező" & 1959 & Siroki Zoltán & DE-siroki-02045.jpg \\
\hline 2301 & Festuca rubra L. & "Nagymező" & 1959 & Siroki Zoltán & DE-siroki-02052.jpg \\
\hline 2301 & Festuca rubra L. & Budaörs & 1966 & Siroki Zoltán & DE-siroki-02038.jpg \\
\hline 2301 & Festuca rubra L. & Budaörs & 1966 & Siroki Zoltán & DE-siroki-02039.jpg \\
\hline 2301 & Festuca rubra L. & Budaörs & 1966 & Siroki Zoltán & DE-siroki-02040.jpg \\
\hline 2301 & Festuca rubra L. & Budaörs & 1966 & Siroki Zoltán & DE-siroki-02047.jpg \\
\hline 2301 & Festuca rubra L. & Budaörs & 1966 & Siroki Zoltán & DE-siroki-02048.jpg \\
\hline 2301 & Festuca rubra L. & Budapest & 1951 & Siroki Zoltán & DE-siroki-02066.jpg \\
\hline 2301 & Festuca rubra L. & Debrecen & 1948 & Siroki Zoltán & DE-siroki-02051.jpg \\
\hline 2301 & Festuca rubra L. & Debrecen & 1948 & Siroki Zoltán & DE-siroki-02046.jpg \\
\hline 2301 & Festuca rubra L. & Debrecen & 1948 & Siroki Zoltán & DE-siroki-02037.jpg \\
\hline 2301 & Festuca rubra L. & Debrecen & 1949 & Siroki Zoltán & DE-siroki-02032.jpg \\
\hline 2301 & Festuca rubra L. & Debrecen & 1950 & Siroki Zoltán & DE-siroki-02068.jpg \\
\hline 2301 & Festuca rubra L. & Debrecen & 1950 & Siroki Zoltán & DE-siroki-02050.jpg \\
\hline 2301 & Festuca rubra L. & Debrecen & 1956 & Siroki Zoltán & DE-siroki-02036.jpg \\
\hline 2301 & Festuca rubra L. & Debrecen & 1974 & Siroki Zoltán & DE-siroki-19700.jpg \\
\hline 2301 & Festuca rubra L. & Debrecen & 1978 & Siroki Zoltán & DE-siroki-02059.jpg \\
\hline 2301 & Festuca rubra L. & Debrecen & 1981 & Siroki Zoltán & DE-siroki-02060.jpg \\
\hline 2301 & Festuca rubra L. & Debrecen & 1981 & Siroki Zoltán & DE-siroki-02063.jpg \\
\hline 2301 & Festuca rubra L. & Debrecen & 1981 & Siroki Zoltán & DE-siroki-02064.jpg \\
\hline 2301 & Festuca rubra L. & Debrecen & 1981 & Siroki Zoltán & DE-siroki-19703.jpg \\
\hline 2301 & Festuca rubra L. & Debrecen & 1981 & Siroki Zoltán & DE-siroki-19704.jpg \\
\hline 2301 & Festuca rubra L. & Gödöllő & 1952 & Siroki Zoltán & DE-siroki-02053.jpg \\
\hline 2301 & Festuca rubra L. & Hajdúböszörmény & 1981 & Siroki Zoltán & DE-siroki-19702.jpg \\
\hline 2301 & Festuca rubra L. & Újléta & 1968 & Siroki Zoltán & DE-siroki-02041.jpg \\
\hline 2301 & Festuca rubra L. & Újléta & 1968 & Siroki Zoltán & DE-siroki-02042.jpg \\
\hline 2301 & Festuca rubra L. & Újléta & 1968 & Siroki Zoltán & DE-siroki-02049.jpg \\
\hline 2302 & Festuca amethystina L. & Pilisszentiván & 1949 & Pénzes Antal & DE-siroki-19459.jpg \\
\hline 2305 & $\begin{array}{l}\text { Festuca vaginata } \\
\text { Waldst. et Kit. ex Willd. }\end{array}$ & Ágasegyháza & 1971 & Siroki Zoltán & DE-siroki-19539.jpg \\
\hline
\end{tabular}




\begin{tabular}{|c|c|c|c|c|c|}
\hline $\begin{array}{l}\text { Sorszám / } \\
\text { Number }\end{array}$ & Taxon-név / Taxon-name & $\begin{array}{l}\text { Település / } \\
\text { Settlement }\end{array}$ & $\begin{array}{l}\text { Év / } \\
\text { Year }\end{array}$ & $\begin{array}{l}\text { Gyűjtő / } \\
\text { Collector }\end{array}$ & Fájlnév / File-name \\
\hline 2305 & $\begin{array}{l}\text { Festuca vaginata } \\
\text { Waldst. et Kit. ex Willd. }\end{array}$ & Debrecen & 1949 & Siroki Zoltán & DE-siroki-19548.jpg \\
\hline 2305 & $\begin{array}{l}\text { Festuca vaginata } \\
\text { Waldst. et Kit. ex Willd. }\end{array}$ & Debrecen & 1949 & Siroki Zoltán & DE-siroki-19541.jpg \\
\hline 2305 & $\begin{array}{l}\text { Festuca vaginata } \\
\text { Waldst. et Kit. ex Willd. }\end{array}$ & Debrecen & 1949 & Siroki Zoltán & DE-siroki-19546.jpg \\
\hline 2305 & $\begin{array}{l}\text { Festuca vaginata } \\
\text { Waldst. et Kit. ex Willd. }\end{array}$ & Debrecen & 1949 & Siroki Zoltán & DE-siroki-19547.jpg \\
\hline 2305 & $\begin{array}{l}\text { Festuca vaginata } \\
\text { Waldst. et Kit. ex Willd. }\end{array}$ & Debrecen & 1949 & Siroki Zoltán & DE-siroki-19550.jpg \\
\hline 2305 & $\begin{array}{l}\text { Festuca vaginata } \\
\text { Waldst. et Kit. ex Willd. }\end{array}$ & Debrecen & 1949 & Siroki Zoltán & DE-siroki-19552.jpg \\
\hline 2305 & $\begin{array}{l}\text { Festuca vaginata } \\
\text { Waldst. et Kit. ex Willd. }\end{array}$ & Debrecen & 1949 & Siroki Zoltán & DE-siroki-19542.jpg \\
\hline 2305 & $\begin{array}{l}\text { Festuca vaginata } \\
\text { Waldst. et Kit. ex Willd. }\end{array}$ & Debrecen & 1949 & Siroki Zoltán & DE-siroki-19535.jpg \\
\hline 2305 & $\begin{array}{l}\text { Festuca vaginata } \\
\text { Waldst. et Kit. ex Willd. }\end{array}$ & Debrecen & 1949 & Siroki Zoltán & DE-siroki-19536.jpg \\
\hline 2305 & $\begin{array}{l}\text { Festuca vaginata } \\
\text { Waldst. et Kit. ex Willd. }\end{array}$ & Debrecen & 1954 & Siroki Zoltán & DE-siroki-19540.jpg \\
\hline 2305 & $\begin{array}{l}\text { Festuca vaginata } \\
\text { Waldst. et Kit. ex Willd. }\end{array}$ & Debrecen & 1954 & Siroki Zoltán & DE-siroki-19549.jpg \\
\hline 2305 & $\begin{array}{l}\text { Festuca vaginata } \\
\text { Waldst. et Kit. ex Willd. }\end{array}$ & Gödöllő & 1952 & Siroki Zoltán & DE-siroki-19545.jpg \\
\hline 2305 & $\begin{array}{l}\text { Festuca vaginata } \\
\text { Waldst. et Kit. ex Willd. }\end{array}$ & Gödöllő & - & Siroki Zoltán & DE-siroki-19551.jpg \\
\hline 2305 & $\begin{array}{l}\text { Festuca vaginata } \\
\text { Waldst. et Kit. ex Willd. }\end{array}$ & Kecskemét & 1969 & Siroki Zoltán & DE-siroki-19537.jpg \\
\hline 2305 & $\begin{array}{l}\text { Festuca vaginata } \\
\text { Waldst. et Kit. ex Willd. }\end{array}$ & Mikepércs & 1980 & Siroki Zoltán & DE-siroki-19533.jpg \\
\hline 2305 & $\begin{array}{l}\text { Festuca vaginata } \\
\text { Waldst. et Kit. ex Willd. }\end{array}$ & Mikepércs & 1980 & Siroki Zoltán & DE-siroki-19534.jpg \\
\hline 2305 & $\begin{array}{l}\text { Festuca vaginata } \\
\text { Waldst. et Kit. ex Willd. }\end{array}$ & Veresegyház & 1960 & Siroki Zoltán & DE-siroki-19538.jpg \\
\hline 2305 & $\begin{array}{l}\text { Festuca vaginata } \\
\text { Waldst. et Kit. ex Willd. }\end{array}$ & Veresegyház & 1960 & Siroki Zoltán & DE-siroki-19543.jpg \\
\hline 2305 & $\begin{array}{l}\text { Festuca vaginata } \\
\text { Waldst. et Kit. ex Willd. }\end{array}$ & Veresegyház & 1960 & Siroki Zoltán & DE-siroki-19544.jpg \\
\hline 2307 & Festuca pallens Host & "Fáni-völgy" & 1955 & Siroki Zoltán & DE-siroki-19530.jpg \\
\hline 2307 & Festuca pallens Host & Budaörs & 1964 & Siroki Zoltán & DE-siroki-19508.jpg \\
\hline 2307 & Festuca pallens Host & Budaörs & 1964 & Siroki Zoltán & DE-siroki-19509.jpg \\
\hline 2307 & Festuca pallens Host & Budaörs & 1964 & Siroki Zoltán & DE-siroki-19511.jpg \\
\hline 2307 & Festuca pallens Host & Budaörs & 1964 & Siroki Zoltán & DE-siroki-19512.jpg \\
\hline 2307 & Festuca pallens Host & Budaörs & 1964 & Siroki Zoltán & DE-siroki-19518.jpg \\
\hline 2307 & Festuca pallens Host & Budapest & 1951 & Siroki Zoltán & DE-siroki-19510.jpg \\
\hline 2307 & Festuca pallens Host & Budapest & 1951 & Siroki Zoltán & DE-siroki-19525.jpg \\
\hline 2307 & Festuca pallens Host & Budapest & 1951 & Siroki Zoltán & DE-siroki-19526.jpg \\
\hline 2307 & Festuca pallens Host & Budapest & 1951 & Siroki Zoltán & DE-siroki-19519.jpg \\
\hline 2307 & Festuca pallens Host & Budapest & 1951 & Siroki Zoltán & DE-siroki-19520.jpg \\
\hline 2307 & Festuca pallens Host & Gyenesdiás & 1953 & Siroki Zoltán & DE-siroki-19513.jpg \\
\hline 2307 & Festuca pallens Host & Gyenesdiás & 1953 & Siroki Zoltán & DE-siroki-19522.jpg \\
\hline 2307 & Festuca pallens Host & Gyenesdiás & 1953 & Siroki Zoltán & DE-siroki-19523.jpg \\
\hline 2307 & Festuca pallens Host & Gyenesdiás & 1953 & Siroki Zoltán & DE-siroki-19524.jpg \\
\hline 2307 & Festuca pallens Host & Pilisszentiván & 1952 & Siroki Zoltán & DE-siroki-19521.jpg \\
\hline 2307 & Festuca pallens Host & Pilisszentiván & 1952 & Siroki Zoltán & DE-siroki-19527.jpg \\
\hline 2307 & Festuca pallens Host & Pilisszentiván & 1952 & Siroki Zoltán & DE-siroki-19532.jpg \\
\hline 2307 & Festuca pallens Host & Szarvaskő & 1957 & Siroki Zoltán & DE-siroki-19529.jpg \\
\hline
\end{tabular}




\begin{tabular}{|c|c|c|c|c|c|}
\hline $\begin{array}{l}\text { Sorszám / } \\
\text { Number }\end{array}$ & Taxon-név / Taxon-name & $\begin{array}{l}\text { Település / } \\
\text { Settlement }\end{array}$ & $\begin{array}{l}\text { Év / } \\
\text { Year }\end{array}$ & $\begin{array}{l}\text { Gyújtő / } \\
\text { Collector }\end{array}$ & Fájlnév / File-name \\
\hline 2307 & Festuca pallens Host & Szarvaskő & 1966 & Siroki Zoltán & DE-siroki-19514.jpg \\
\hline 2307 & Festuca pallens Host & Szarvaskő & 1966 & Siroki Zoltán & DE-siroki-19515.jpg \\
\hline 2307 & Festuca pallens Host & Szarvaskő & 1966 & Siroki Zoltán & DE-siroki-19516.jpg \\
\hline 2307 & Festuca pallens Host & Szarvaskő & 1966 & Siroki Zoltán & DE-siroki-19517.jpg \\
\hline 2310 & Festuca rupicola Heuff. & "Nagymező" & 1959 & Siroki Zoltán & DE-siroki-19637.jpg \\
\hline 2310 & Festuca rupicola Heuff. & "Nagymező" & 1959 & Siroki Zoltán & DE-siroki-19651.jpg \\
\hline 2310 & Festuca rupicola Heuff. & "Nagymező" & 1960 & Siroki Zoltán & DE-siroki-19652.jpg \\
\hline 2310 & Festuca rupicola Heuff. & "Nagymező" & 1960 & Siroki Zoltán & DE-siroki-19655.jpg \\
\hline 2310 & Festuca rupicola Heuff. & Budapest & 1964 & Siroki Zoltán & DE-siroki-19619.jpg \\
\hline 2310 & Festuca rupicola Heuff. & Budapest & 1964 & Siroki Zoltán & DE-siroki-19620.jpg \\
\hline 2310 & Festuca rupicola Heuff. & Budapest & 1964 & Siroki Zoltán & DE-siroki-19621.jpg \\
\hline 2310 & Festuca rupicola Heuff. & Budapest & 1964 & Siroki Zoltán & DE-siroki-19622.jpg \\
\hline 2310 & Festuca rupicola Heuff. & Budapest & 1964 & Siroki Zoltán & DE-siroki-19623.jpg \\
\hline 2310 & Festuca rupicola Heuff. & Budapest & 1964 & Siroki Zoltán & DE-siroki-19624.jpg \\
\hline 2310 & Festuca rupicola Heuff. & Debrecen & 1947 & Siroki Zoltán & DE-siroki-19638.jpg \\
\hline 2310 & Festuca rupicola Heuff. & Debrecen & 1949 & Siroki Zoltán & DE-siroki-19663.jpg \\
\hline 2310 & Festuca rupicola Heuff. & Debrecen & 1949 & Siroki Zoltán & DE-siroki-19639.jpg \\
\hline 2310 & Festuca rupicola Heuff. & Debrecen & 1949 & Siroki Zoltán & DE-siroki-19628.jpg \\
\hline 2310 & Festuca rupicola Heuff. & Debrecen & 1949 & Siroki Zoltán & DE-siroki-19629.jpg \\
\hline 2310 & Festuca rupicola Heuff. & Debrecen & 1950 & Siroki Zoltán & DE-siroki-19653.jpg \\
\hline 2310 & Festuca rupicola Heuff. & Debrecen & 1964 & Siroki Zoltán & DE-siroki-19656.jpg \\
\hline 2310 & Festuca rupicola Heuff. & Debrecen & 1964 & Siroki Zoltán & DE-siroki-19634.jpg \\
\hline 2310 & Festuca rupicola Heuff. & Debrecen & 1964 & Siroki Zoltán & DE-siroki-19659.jpg \\
\hline 2310 & Festuca rupicola Heuff. & Debrecen & 1964 & Siroki Zoltán & DE-siroki-19662.jpg \\
\hline 2310 & Festuca rupicola Heuff. & Debrecen & 1980 & Siroki Zoltán & DE-siroki-19605.jpg \\
\hline 2310 & Festuca rupicola Heuff. & Debrecen & 1980 & Siroki Zoltán & DE-siroki-19611.jpg \\
\hline 2310 & Festuca rupicola Heuff. & Debrecen & 1981 & Siroki Zoltán & DE-siroki-19609.jpg \\
\hline 2310 & Festuca rupicola Heuff. & Debrecen & 1981 & Siroki Zoltán & DE-siroki-19606.jpg \\
\hline 2310 & Festuca rupicola Heuff. & Debrecen & 1981 & Siroki Zoltán & DE-siroki-19607.jpg \\
\hline 2310 & Festuca rupicola Heuff. & Debrecen & 1981 & Siroki Zoltán & DE-siroki-19608.jpg \\
\hline 2310 & Festuca rupicola Heuff. & Debrecen & 1981 & Siroki Zoltán & DE-siroki-19610.jpg \\
\hline 2310 & Festuca rupicola Heuff. & Debrecen & 1983 & Siroki Zoltán & DE-siroki-19649.jpg \\
\hline 2310 & Festuca rupicola Heuff. & Debrecen & 1983 & Siroki Zoltán & DE-siroki-19648.jpg \\
\hline 2310 & Festuca rupicola Heuff. & Debrecen & 1983 & Siroki Zoltán & DE-siroki-19650.jpg \\
\hline 2310 & Festuca rupicola Heuff. & Gödöllő & 1952 & Siroki Zoltán & DE-siroki-19643.jpg \\
\hline 2310 & Festuca rupicola Heuff. & Háromhuta & 1961 & Siroki Zoltán & DE-siroki-19633.jpg \\
\hline 2310 & Festuca rupicola Heuff. & Háromhuta & 1961 & Siroki Zoltán & DE-siroki-19654.jpg \\
\hline 2310 & Festuca rupicola Heuff. & Háromhuta & 1961 & Siroki Zoltán & DE-siroki-19657.jpg \\
\hline 2310 & Festuca rupicola Heuff. & Háromhuta & 1961 & Siroki Zoltán & DE-siroki-19664.jpg \\
\hline 2310 & Festuca rupicola Heuff. & Hortobágy & 1959 & Siroki Zoltán & DE-siroki-19630.jpg \\
\hline 2310 & Festuca rupicola Heuff. & Hortobágy & 1959 & Siroki Zoltán & DE-siroki-19631.jpg \\
\hline 2310 & Festuca rupicola Heuff. & Hortobágy & 1959 & Siroki Zoltán & DE-siroki-19632.jpg \\
\hline 2310 & Festuca rupicola Heuff. & Hortobágy & 1959 & Siroki Zoltán & DE-siroki-19635.jpg \\
\hline 2310 & Festuca rupicola Heuff. & Hortobágy & 1959 & Siroki Zoltán & DE-siroki-19636.jpg \\
\hline 2310 & Festuca rupicola Heuff. & Hortobágy & 1959 & Siroki Zoltán & DE-siroki-19658.jpg \\
\hline 2310 & Festuca rupicola Heuff. & Hortobágy & 1959 & Siroki Zoltán & DE-siroki-19660.jpg \\
\hline
\end{tabular}




\begin{tabular}{|c|c|c|c|c|c|}
\hline $\begin{array}{l}\text { Sorszám / } \\
\text { Number }\end{array}$ & Taxon-név / Taxon-name & $\begin{array}{l}\text { Település / } \\
\text { Settlement }\end{array}$ & $\begin{array}{l}\text { Év / } \\
\text { Year }\end{array}$ & $\begin{array}{l}\text { Gyűjtő / } \\
\text { Collector }\end{array}$ & Fájlnév / File-name \\
\hline 2310 & Festuca rupicola Heuff. & Hortobágy & 1959 & Siroki Zoltán & DE-siroki-19661.jpg \\
\hline 2310 & Festuca rupicola Heuff. & Pilisszentiván & 1952 & Siroki Zoltán & DE-siroki-19645.jpg \\
\hline 2310 & Festuca rupicola Heuff. & Villány & 1907 & Kocsis István & DE-siroki-19614.jpg \\
\hline 2310 & Festuca rupicola Heuff. & Vonyarcvashegy & 1930 & Rigler József & DE-siroki-19612.jpg \\
\hline 2312 & Festuca filiformis Pourr. & Debrecen & 1948 & Siroki Zoltán & DE-siroki-19469.jpg \\
\hline 2312 & Festuca filiformis Pourr. & Debrecen & 1948 & Siroki Zoltán & DE-siroki-19470.jpg \\
\hline 2312 & Festuca filiformis Pourr. & Debrecen & 1948 & Siroki Zoltán & DE-siroki-19471.jpg \\
\hline 2312 & Festuca filiformis Pourr. & Debrecen & 1948 & Siroki Zoltán & DE-siroki-19474.jpg \\
\hline 2312 & Festuca filiformis Pourr. & Debrecen & 1950 & Siroki Zoltán & DE-siroki-19467.jpg \\
\hline 2312 & Festuca filiformis Pourr. & Debrecen & 1950 & Siroki Zoltán & DE-siroki-19468.jpg \\
\hline 2312 & Festuca filiformis Pourr. & Debrecen & 1953 & Siroki Zoltán & DE-siroki-19472.jpg \\
\hline 2312 & Festuca filiformis Pourr. & Debrecen & 1953 & Siroki Zoltán & DE-siroki-19473.jpg \\
\hline 2312 & Festuca filiformis Pourr. & Debrecen & 1953 & Siroki Zoltán & DE-siroki-19475.jpg \\
\hline 2312 & Festuca filiformis Pourr. & Háromhuta & 1965 & Siroki Zoltán & DE-siroki-19465.jpg \\
\hline 2312 & Festuca filiformis Pourr. & Háromhuta & 1965 & Siroki Zoltán & DE-siroki-19466.jpg \\
\hline 2313 & Festuca ovina L. & "Nagymező" & 1959 & Siroki Zoltán & DE-siroki-19487.jpg \\
\hline 2313 & Festuca ovina L. & "Nagymező" & 1959 & Siroki Zoltán & DE-siroki-19488.jpg \\
\hline 2313 & Festuca ovina L. & "Nagymező" & 1959 & Siroki Zoltán & DE-siroki-19489.jpg \\
\hline 2313 & Festuca ovina L. & "Nagymező" & 1959 & Siroki Zoltán & DE-siroki-19476.jpg \\
\hline 2313 & Festuca ovina L. & "Nagymező" & 1960 & Siroki Zoltán & DE-siroki-19477.jpg \\
\hline 2313 & Festuca ovina L. & "Nagymező" & 1960 & Siroki Zoltán & DE-siroki-19478.jpg \\
\hline 2313 & Festuca ovina L. & "Nagymező" & 1960 & Siroki Zoltán & DE-siroki-19482.jpg \\
\hline 2313 & Festuca ovina L. & "Nagymező" & 1960 & Siroki Zoltán & DE-siroki-19485.jpg \\
\hline 2313 & Festuca ovina L. & "Nagymező" & 1960 & Siroki Zoltán & DE-siroki-19486.jpg \\
\hline 2313 & Festuca ovina L. & Háromhuta & 1961 & Siroki Zoltán & DE-siroki-19484.jpg \\
\hline 2313 & Festuca ovina L. & Háromhuta & 1961 & Siroki Zoltán & DE-siroki-19483.jpg \\
\hline 2313 & Festuca ovina L. & Háromhuta & 1961 & Siroki Zoltán & DE-siroki-19479.jpg \\
\hline 2313 & Festuca ovina L. & Háromhuta & 1961 & Siroki Zoltán & DE-siroki-19480.jpg \\
\hline 2313 & Festuca ovina L. & Háromhuta & 1961 & Siroki Zoltán & DE-siroki-19481.jpg \\
\hline 2314 & $\begin{array}{l}\text { Festuca pseudodalmatica } \\
\text { Krajina ex Domin }\end{array}$ & Füzér & 1973 & Siroki Zoltán & DE-siroki-19503.jpg \\
\hline 2314 & $\begin{array}{l}\text { Festuca pseudodalmatica } \\
\text { Krajina ex Domin }\end{array}$ & Füzér & 1973 & Siroki Zoltán & DE-siroki-19504.jpg \\
\hline 2314 & $\begin{array}{l}\text { Festuca pseudodalmatica } \\
\text { Krajina ex Domin }\end{array}$ & Füzér & 1973 & Siroki Zoltán & DE-siroki-19505.jpg \\
\hline 2314 & $\begin{array}{l}\text { Festuca pseudodalmatica } \\
\text { Krajina ex Domin }\end{array}$ & Füzér & 1973 & Siroki Zoltán & DE-siroki-19506.jpg \\
\hline 2314 & $\begin{array}{l}\text { Festuca pseudodalmatica } \\
\text { Krajina ex Domin }\end{array}$ & Füzér & 1973 & Siroki Zoltán & DE-siroki-19507.jpg \\
\hline 2315 & Festuca valesiaca Schleich. ex Gaudin & Budapest & 1886 & Czakó Kálmán & DE-siroki-19572.jpg \\
\hline 2315 & Festuca valesiaca Schleich. ex Gaudin & Budapest & 1887 & Czakó Kálmán & DE-siroki-19573.jpg \\
\hline 2315 & Festuca valesiaca Schleich. ex Gaudin & Debrecen & 1946 & Siroki Zoltán & DE-siroki-19555.jpg \\
\hline 2315 & Festuca valesiaca Schleich. ex Gaudin & Debrecen & 1946 & Siroki Zoltán & DE-siroki-19553.jpg \\
\hline 2315 & Festuca valesiaca Schleich. ex Gaudin & Debrecen & 1946 & Siroki Zoltán & DE-siroki-19563.jpg \\
\hline 2315 & Festuca valesiaca Schleich. ex Gaudin & Debrecen & 1950 & Siroki Zoltán & DE-siroki-19574.jpg \\
\hline 2315 & Festuca valesiaca Schleich. ex Gaudin & Debrecen & 1950 & Siroki Zoltán & DE-siroki-19556.jpg \\
\hline 2315 & Festuca valesiaca Schleich. ex Gaudin & Debrecen & 1951 & Siroki Zoltán & DE-siroki-19554.jpg \\
\hline 2315 & Festuca valesiaca Schleich. ex Gaudin & Gödöllő & 1952 & Siroki Zoltán & DE-siroki-19562.jpg \\
\hline 2315 & Festuca valesiaca Schleich. ex Gaudin & Gödöllő & 1952 & Siroki Zoltán & DE-siroki-19568.jpg \\
\hline
\end{tabular}




\begin{tabular}{|c|c|c|c|c|c|}
\hline $\begin{array}{l}\text { Sorszám / } \\
\text { Number }\end{array}$ & Taxon-név / Taxon-name & $\begin{array}{l}\text { Település / } \\
\text { Settlement }\end{array}$ & $\begin{array}{l}\text { Év / } \\
\text { Year }\end{array}$ & $\begin{array}{l}\text { Gyújitő / } \\
\text { Collector }\end{array}$ & Fájlnév / File-name \\
\hline 2315 & Festuca valesiaca Schleich. ex Gaudin & Gödöllő & 1952 & Siroki Zoltán & DE-siroki-19569.jpg \\
\hline 2315 & Festuca valesiaca Schleich. ex Gaudin & Gödöllő & 1952 & Siroki Zoltán & DE-siroki-19570.jpg \\
\hline 2315 & Festuca valesiaca Schleich. ex Gaudin & Gyöngyös & 1899 & Degen Árpád & DE-siroki-19580.jpg \\
\hline 2315 & Festuca valesiaca Schleich. ex Gaudin & Pécs & 1958 & Siroki Zoltán & DE-siroki-19564.jpg \\
\hline 2315 & Festuca valesiaca Schleich. ex Gaudin & Pécs & 1958 & Siroki Zoltán & DE-siroki-19565.jpg \\
\hline 2315 & Festuca valesiaca Schleich. ex Gaudin & Szada & 1952 & Siroki Zoltán & DE-siroki-19576.jpg \\
\hline 2315 & Festuca valesiaca Schleich. ex Gaudin & Szada & 1952 & Siroki Zoltán & DE-siroki-19577.jpg \\
\hline 2315 & Festuca valesiaca Schleich. ex Gaudin & Szarvas & 1954 & Siroki Zoltán & DE-siroki-19566.jpg \\
\hline 2315 & Festuca valesiaca Schleich. ex Gaudin & Szarvas & 1954 & Siroki Zoltán & DE-siroki-19567.jpg \\
\hline 2315 & Festuca valesiaca Schleich. ex Gaudin & Villány & 1907 & Kocsis István & DE-siroki-19578.jpg \\
\hline 2316 & Festuca pseudovina Hack. & Abaújkér & 1942 & Siroki Zoltán & DE-siroki-19602.jpg \\
\hline 2316 & Festuca pseudovina Hack. & Debrecen & 1947 & Siroki Zoltán & DE-siroki-19596.jpg \\
\hline 2316 & Festuca pseudovina Hack. & Debrecen & 1947 & Siroki Zoltán & DE-siroki-19598.jpg \\
\hline 2316 & Festuca pseudovina Hack. & Debrecen & 1947 & Siroki Zoltán & DE-siroki-19601.jpg \\
\hline 2316 & Festuca pseudovina Hack. & Debrecen & 1947 & Siroki Zoltán & DE-siroki-19597.jpg \\
\hline 2316 & Festuca pseudovina Hack. & Debrecen & 1947 & Siroki Zoltán & DE-siroki-19582.jpg \\
\hline 2316 & Festuca pseudovina Hack. & Debrecen & 1947 & Siroki Zoltán & DE-siroki-19594.jpg \\
\hline 2316 & Festuca pseudovina Hack. & Debrecen & 1950 & Siroki Zoltán & DE-siroki-19586.jpg \\
\hline 2316 & Festuca pseudovina Hack. & Debrecen & 1964 & Siroki Zoltán & DE-siroki-19588.jpg \\
\hline 2316 & Festuca pseudovina Hack. & Debrecen & 1964 & Siroki Zoltán & DE-siroki-19581.jpg \\
\hline 2316 & Festuca pseudovina Hack. & Debrecen & 1964 & Siroki Zoltán & DE-siroki-19583.jpg \\
\hline 2316 & Festuca pseudovina Hack. & Debrecen & 1964 & Siroki Zoltán & DE-siroki-19584.jpg \\
\hline 2316 & Festuca pseudovina Hack. & Debrecen & 1965 & Siroki Zoltán & DE-siroki-19600.jpg \\
\hline 2316 & Festuca pseudovina Hack. & Egyek & 1969 & Siroki Zoltán & DE-siroki-19589.jpg \\
\hline 2316 & Festuca pseudovina Hack. & Egyek & 1969 & Siroki Zoltán & DE-siroki-19590.jpg \\
\hline 2316 & Festuca pseudovina Hack. & Egyek & 1969 & Siroki Zoltán & DE-siroki-19591.jpg \\
\hline 2316 & Festuca pseudovina Hack. & Egyek & 1969 & Siroki Zoltán & DE-siroki-19592.jpg \\
\hline 2316 & Festuca pseudovina Hack. & Egyek & 1969 & Siroki Zoltán & DE-siroki-19593.jpg \\
\hline 2316 & Festuca pseudovina Hack. & Egyek & 1969 & Siroki Zoltán & DE-siroki-19604.jpg \\
\hline 2316 & Festuca pseudovina Hack. & Egyek & 1976 & Siroki Zoltán & DE-siroki-19603.jpg \\
\hline 2316 & Festuca pseudovina Hack. & Hortobágy & 1947 & Siroki Zoltán & DE-siroki-19599.jpg \\
\hline 2316 & Festuca pseudovina Hack. & Hortobágy & 1947 & Siroki Zoltán & DE-siroki-19585.jpg \\
\hline 2316 & Festuca pseudovina Hack. & Hortobágy & 1959 & Siroki Zoltán & DE-siroki-19587.jpg \\
\hline $2300-2316$ & Festuca & Gödöllő & 1952 & Siroki Zoltán & DE-siroki-19501.jpg \\
\hline 2317 & Lolium perenne L. & Budapest & 1951 & Siroki Zoltán & DE-siroki-02349.jpg \\
\hline 2317 & Lolium perenne L. & Debrecen & 1953 & Siroki Zoltán & DE-siroki-02343.jpg \\
\hline 2317 & Lolium perenne L. & Debrecen & 1953 & Siroki Zoltán & DE-siroki-02344.jpg \\
\hline 2317 & Lolium perenne L. & Debrecen & 1953 & Siroki Zoltán & DE-siroki-02346.jpg \\
\hline 2317 & Lolium perenne L. & Debrecen & 1953 & Siroki Zoltán & DE-siroki-02347.jpg \\
\hline 2317 & Lolium perenne L. & Debrecen & 1954 & Siroki Zoltán & DE-siroki-02345.jpg \\
\hline 2317 & Lolium perenne L. & Debrecen & 1970 & Siroki Zoltán & DE-siroki-02348.jpg \\
\hline 2317 & Lolium perenne L. & Pomáz & 1954 & Siroki Zoltán & DE-siroki-02342.jpg \\
\hline 2318 & Lolium multiflorum Lam. & Budapest & 1951 & Siroki Zoltán & DE-siroki-02353.jpg \\
\hline 2318 & Lolium multiflorum Lam. & Debrecen & 1954 & Siroki Zoltán & DE-siroki-02354.jpg \\
\hline 2318 & Lolium multiflorum Lam. & Debrecen & 1958 & Siroki Zoltán & DE-siroki-02355.jpg \\
\hline 2318 & Lolium multiflorum Lam. & Debrecen & 1974 & Siroki Zoltán & DE-siroki-02357.jpg \\
\hline
\end{tabular}




\begin{tabular}{|c|c|c|c|c|c|}
\hline $\begin{array}{l}\text { Sorszám / } \\
\text { Number }\end{array}$ & Taxon-név / Taxon-name & $\begin{array}{l}\text { Település / } \\
\text { Settlement }\end{array}$ & $\begin{array}{l}\text { Év / } \\
\text { Year }\end{array}$ & $\begin{array}{l}\text { Gyüjtő / } \\
\text { Collector }\end{array}$ & Fájlnév / File-name \\
\hline 2319 & Lolium temulentum L. & Budapest & 1951 & Siroki Zoltán & DE-siroki-02364.jpg \\
\hline 2319 & Lolium temulentum L. & Budapest & 1951 & Siroki Zoltán & DE-siroki-02363.jpg \\
\hline 2319 & Lolium temulentum L. & Mosonmagyaróvár & 1939 & Siroki Zoltán & DE-siroki-02366.jpg \\
\hline 2322 & Vulpia myuros (L.) C.C. Gmel. & Budapest & 1951 & Siroki Zoltán & DE-siroki-02146.jpg \\
\hline 2322 & Vulpia myuros (L.) C.C. Gmel. & Budapest & 1951 & Siroki Zoltán & DE-siroki-02147.jpg \\
\hline 2322 & Vulpia myuros (L.) C.C. Gmel. & Budapest & 1951 & Siroki Zoltán & DE-siroki-02148.jpg \\
\hline 2324 & Poa bulbosa L. & Budaörs & 1955 & Siroki Zoltán & DE-siroki-02016.jpg \\
\hline 2324 & Poa bulbosa L. & Debrecen & 1947 & Siroki Zoltán & DE-siroki-02014.jpg \\
\hline 2324 & Poa bulbosa L. & Debrecen & 1947 & Siroki Zoltán & DE-siroki-02015.jpg \\
\hline 2324 & Poa bulbosa L. & Debrecen & 1954 & Siroki Zoltán & DE-siroki-02017.jpg \\
\hline 2324 & Poa bulbosa L. & Debrecen & 1963 & Horváth István & DE-siroki-02018.jpg \\
\hline 2324 & Poa bulbosa L. & Debrecen & 1964 & Siroki Zoltán & DE-siroki-02019.jpg \\
\hline 2324 & Poa bulbosa L. & Debrecen & 1964 & Siroki Zoltán & DE-siroki-02020.jpg \\
\hline 2324 & Poa bulbosa L. & Debrecen & 1964 & Siroki Zoltán & DE-siroki-02021.jpg \\
\hline 2324 & Poa bulbosa L. & Gödöllő & 1952 & Siroki Zoltán & DE-siroki-02012.jpg \\
\hline 2324 & Poa bulbosa L. & Gyenesdiás & 1953 & Siroki Zoltán & DE-siroki-02013.jpg \\
\hline 2325 & Poa badensis Haenke ex Willd. & "Fáni-völgy" & 1955 & $\begin{array}{l}\text { Siroki Zoltán - } \\
\text { Farkas Attila }\end{array}$ & DE-siroki-02023.jpg \\
\hline 2325 & Poa badensis Haenke ex Willd. & "Fáni-völgy" & 1955 & $\begin{array}{l}\text { Siroki Zoltán - } \\
\text { Farkas Attila }\end{array}$ & DE-siroki-02026.jpg \\
\hline 2325 & Poa badensis Haenke ex Willd. & Budaörs & 1955 & Siroki Zoltán & DE-siroki-02025.jpg \\
\hline 2325 & Poa badensis Haenke ex Willd. & Budapest & 1951 & Siroki Zoltán & DE-siroki-02030.jpg \\
\hline 2325 & Poa badensis Haenke ex Willd. & Budapest & 1951 & Siroki Zoltán & DE-siroki-02024.jpg \\
\hline 2325 & Poa badensis Haenke ex Willd. & Gyenesdiás & 1953 & Siroki Zoltán & DE-siroki-19265.jpg \\
\hline 2325 & Poa badensis Haenke ex Willd. & Pilisszentiván & 1952 & Siroki Zoltán & DE-siroki-02027.jpg \\
\hline 2327 & Poa compressa L. & Budaörs & 1966 & Siroki Zoltán & DE-siroki-02004.jpg \\
\hline 2327 & Poa compressa L. & Budaörs & 1966 & Siroki Zoltán & DE-siroki-02005.jpg \\
\hline 2327 & Poa compressa L. & Budaörs & 1966 & Siroki Zoltán & DE-siroki-02006.jpg \\
\hline 2327 & Poa compressa L. & Budapest & 1952 & Siroki Zoltán & DE-siroki-01996.jpg \\
\hline 2327 & Poa compressa L. & Debrecen & 1947 & Siroki Zoltán & DE-siroki-02007.jpg \\
\hline 2327 & Poa compressa L. & Debrecen & 1950 & Siroki Zoltán & DE-siroki-01999.jpg \\
\hline 2327 & Poa compressa L. & Debrecen & 1950 & Siroki Zoltán & DE-siroki-02000.jpg \\
\hline 2327 & Poa compressa L. & Debrecen & 1954 & Siroki Zoltán & DE-siroki-01998.jpg \\
\hline 2327 & Poa compressa L. & Debrecen & 1954 & Siroki Zoltán & DE-siroki-02001.jpg \\
\hline 2327 & Poa compressa L. & Újléta & 1967 & Siroki Zoltán & DE-siroki-02002.jpg \\
\hline 2327 & Poa compressa L. & Újléta & 1967 & Siroki Zoltán & DE-siroki-02003.jpg \\
\hline 2328 & Poa annua L. & Budapest & 1952 & Siroki Zoltán & DE-siroki-01990.jpg \\
\hline 2328 & Poa annua L. & Budapest & 1952 & Siroki Zoltán & DE-siroki-01993.jpg \\
\hline 2328 & Poa annua L. & Debrecen & 1947 & Siroki Zoltán & DE-siroki-01988.jpg \\
\hline 2328 & Poa annua L. & Debrecen & 1978 & Siroki Zoltán & DE-siroki-01989.jpg \\
\hline 2328 & Poa annua L. & Mosonmagyaróvár & 1939 & Siroki Zoltán & DE-siroki-01991.jpg \\
\hline 2331 & Poa trivialis L. & "Bükk-hg." & 1983 & Siroki Zoltán & DE-siroki-01983.jpg \\
\hline 2331 & Poa trivialis L. & Budapest & 1911 & Degen Árpád & DE-siroki-01987.jpg \\
\hline 2331 & Poa trivialis L. & Debrecen & 1951 & Siroki Zoltán & DE-siroki-01979.jpg \\
\hline 2331 & Poa trivialis L. & Debrecen & 1954 & Siroki Zoltán & DE-siroki-01977.jpg \\
\hline 2331 & Poa trivialis L. & Debrecen & 1954 & Siroki Zoltán & DE-siroki-01978.jpg \\
\hline 2331 & Poa trivialis L. & Debrecen & 1955 & Siroki Zoltán & DE-siroki-01975.jpg \\
\hline
\end{tabular}




\begin{tabular}{|c|c|c|c|c|c|}
\hline $\begin{array}{l}\text { Sorszám / } \\
\text { Number }\end{array}$ & Taxon-név / Taxon-name & $\begin{array}{l}\text { Település / } \\
\text { Settlement }\end{array}$ & $\begin{array}{l}\text { Év / } \\
\text { Year }\end{array}$ & $\begin{array}{l}\text { Gyújtő / } \\
\text { Collector }\end{array}$ & Fájlnév / File-name \\
\hline 2331 & Poa trivialis L. & Debrecen & 1971 & Siroki Zoltán & DE-siroki-01972.jpg \\
\hline 2331 & Poa trivialis L. & Debrecen & 1971 & Siroki Zoltán & DE-siroki-01973.jpg \\
\hline 2331 & Poa trivialis L. & Debrecen & 1971 & Siroki Zoltán & DE-siroki-01974.jpg \\
\hline 2331 & Poa trivialis L. & Debrecen & 1977 & Siroki Zoltán & DE-siroki-01971.jpg \\
\hline 2331 & Poa trivialis L. & Debrecen & 1977 & Siroki Zoltán & DE-siroki-01985.jpg \\
\hline 2331 & Poa trivialis L. & Debrecen & 1977 & Siroki Zoltán & DE-siroki-01986.jpg \\
\hline 2331 & Poa trivialis L. & Egyek & 1948 & Siroki Zoltán & DE-siroki-01984.jpg \\
\hline 2332 & Poa scabra Kit. & Szarvaskő & 1957 & Siroki Zoltán & DE-siroki-19339.jpg \\
\hline 2332 & Poa scabra Kit. & Szarvaskő & 1957 & Siroki Zoltán & DE-siroki-19340.jpg \\
\hline 2332 & Poa scabra Kit. & Szarvaskő & 1957 & Siroki Zoltán & DE-siroki-19341.jpg \\
\hline 2332 & Poa scabra Kit. & Szarvaskő & 1957 & Siroki Zoltán & DE-siroki-19342.jpg \\
\hline 2332 & Poa scabra Kit. & Szarvaskő & 1957 & Siroki Zoltán & DE-siroki-19343.jpg \\
\hline 2332 & Poa scabra Kit. & Szarvaskő & 1957 & Siroki Zoltán & DE-siroki-19344.jpg \\
\hline 2332 & Poa scabra Kit. & Szarvaskő & 1957 & Siroki Zoltán & DE-siroki-19346.jpg \\
\hline 2332 & Poa scabra Kit. & Szarvaskő & 1957 & Siroki Zoltán & DE-siroki-19347.jpg \\
\hline 2332 & Poa scabra Kit. & Szarvaskő & 1957 & Siroki Zoltán & DE-siroki-19348.jpg \\
\hline 2332 & Poa scabra Kit. & Visegrád & 1950 & Kárpáti Zoltán & DE-siroki-19345.jpg \\
\hline 2333 & Poa nemoralis L. & "Mátra" & 1984 & Siroki Zoltán & DE-siroki-19276.jpg \\
\hline 2333 & Poa nemoralis L. & "Mátra" & 1984 & Siroki Zoltán & DE-siroki-19277.jpg \\
\hline 2333 & Poa nemoralis L. & "Mátra" & 1984 & Siroki Zoltán & DE-siroki-19278.jpg \\
\hline 2333 & Poa nemoralis L. & "Mátra" & 1984 & Siroki Zoltán & DE-siroki-19279.jpg \\
\hline 2333 & Poa nemoralis L. & "Mátra" & 1984 & Siroki Zoltán & DE-siroki-19280.jpg \\
\hline 2333 & Poa nemoralis L. & "Mátra" & 1984 & Siroki Zoltán & DE-siroki-19281.jpg \\
\hline 2333 & Poa nemoralis L. & "Mátra" & 1984 & Siroki Zoltán & DE-siroki-19282.jpg \\
\hline 2333 & Poa nemoralis L. & "Mátra" & 1984 & Siroki Zoltán & DE-siroki-19283.jpg \\
\hline 2333 & Poa nemoralis L. & Debrecen & 1948 & Siroki Zoltán & DE-siroki-19286.jpg \\
\hline 2333 & Poa nemoralis L. & Debrecen & 1948 & Siroki Zoltán & DE-siroki-19287.jpg \\
\hline 2333 & Poa nemoralis L. & Debrecen & 1984 & Siroki Zoltán & DE-siroki-19292.jpg \\
\hline 2333 & Poa nemoralis L. & Debrecen & 1984 & Siroki Zoltán & DE-siroki-19293.jpg \\
\hline 2333 & Poa nemoralis L. & Gödöllő & 1952 & Siroki Zoltán & DE-siroki-19290.jpg \\
\hline 2333 & Poa nemoralis L. & Regéc & 1967 & Siroki Zoltán & DE-siroki-19284.jpg \\
\hline 2333 & Poa nemoralis L. & Regéc & 1967 & Siroki Zoltán & DE-siroki-19285.jpg \\
\hline 2333 & Poa nemoralis L. & Szilvásvárad & 1954 & Siroki Zoltán & DE-siroki-19294.jpg \\
\hline 2334 & Poa palustris L. & Budapest & 1898 & Thaisz Lajos & DE-siroki-19303.jpg \\
\hline 2334 & Poa palustris L. & Budapest & 1904 & Kocsis István & DE-siroki-19302.jpg \\
\hline 2334 & Poa palustris L. & Csaroda & 1960 & Siroki Zoltán & DE-siroki-19305.jpg \\
\hline 2334 & Poa palustris L. & Csaroda & 1960 & Siroki Zoltán & DE-siroki-19316.jpg \\
\hline 2334 & Poa palustris L. & Csaroda & 1960 & Siroki Zoltán & DE-siroki-19317.jpg \\
\hline 2334 & Poa palustris L. & Debrecen & 1956 & Siroki Zoltán & DE-siroki-19306.jpg \\
\hline 2334 & Poa palustris L. & Debrecen & 1956 & Siroki Zoltán & DE-siroki-19311.jpg \\
\hline 2334 & Poa palustris L. & Debrecen & 1970 & Siroki Zoltán & DE-siroki-19323.jpg \\
\hline 2334 & Poa palustris L. & Debrecen & 1970 & Siroki Zoltán & DE-siroki-19324.jpg \\
\hline 2334 & Poa palustris L. & Debrecen & 1970 & Siroki Zoltán & DE-siroki-19325.jpg \\
\hline 2334 & Poa palustris L. & Debrecen & 1970 & Siroki Zoltán & DE-siroki-19326.jpg \\
\hline 2334 & Poa palustris L. & Halmaj & 1910 & Thaisz Lajos & DE-siroki-19304.jpg \\
\hline 2334 & Poa palustris L. & Hortobágy & 1985 & Siroki Zoltán & DE-siroki-19297.jpg \\
\hline
\end{tabular}




\begin{tabular}{|c|c|c|c|c|c|}
\hline $\begin{array}{l}\text { Sorszám / } \\
\text { Number }\end{array}$ & Taxon-név / Taxon-name & $\begin{array}{l}\text { Település / } \\
\text { Settlement }\end{array}$ & $\begin{array}{l}\text { Év / } \\
\text { Year }\end{array}$ & $\begin{array}{l}\text { Gyűjtő / } \\
\text { Collector }\end{array}$ & Fájlnév / File-name \\
\hline 2334 & Poa palustris L. & Hortobágy & 1985 & Siroki Zoltán & DE-siroki-19298.jpg \\
\hline 2334 & Poa palustris L. & Hortobágy & 1985 & Siroki Zoltán & DE-siroki-19299.jpg \\
\hline 2334 & Poa palustris L. & Szentistván & 1980 & Siroki Zoltán & DE-siroki-19319.jpg \\
\hline 2334 & Poa palustris L. & Szentistván & 1980 & Siroki Zoltán & DE-siroki-19320.jpg \\
\hline 2334 & Poa palustris L. & Szentistván & 1980 & Siroki Zoltán & DE-siroki-19321.jpg \\
\hline 2334 & Poa palustris L. & Szentistván & 1980 & Siroki Zoltán & DE-siroki-19322.jpg \\
\hline 2334 & Poa palustris L. & Tiszafüred & 1955 & Siroki Zoltán & DE-siroki-19300.jpg \\
\hline 2334 & Poa palustris L. & Tiszafüred & 1955 & Siroki Zoltán & DE-siroki-19301.jpg \\
\hline 2334 & Poa palustris L. & Tiszafüred & 1955 & Siroki Zoltán & DE-siroki-19307.jpg \\
\hline 2334 & Poa palustris L. & Tiszafüred & 1955 & Siroki Zoltán & DE-siroki-19308.jpg \\
\hline 2334 & Poa palustris L. & Tiszafüred & 1955 & Siroki Zoltán & DE-siroki-19309.jpg \\
\hline 2334 & Poa palustris L. & Tiszafüred & 1955 & Siroki Zoltán & DE-siroki-19310.jpg \\
\hline $2335-2337$ & Poa pratensis L. s.l. & "Nagymező" & 1959 & Siroki Zoltán & DE-siroki-01944.jpg \\
\hline $2335-2337$ & Poa pratensis L. s.l. & Debrecen & 1947 & Siroki Zoltán & DE-siroki-01952.jpg \\
\hline $2335-2337$ & Poa pratensis L. s.l. & Debrecen & 1947 & Siroki Zoltán & DE-siroki-01967.jpg \\
\hline $2335-2337$ & Poa pratensis L. s.l. & Debrecen & 1948 & Siroki Zoltán & DE-siroki-01961.jpg \\
\hline $2335-2337$ & Poa pratensis L. s.l. & Debrecen & 1949 & Siroki Zoltán & DE-siroki-01957.jpg \\
\hline $2335-2337$ & Poa pratensis L. s.l. & Debrecen & 1953 & Siroki Zoltán & DE-siroki-01953.jpg \\
\hline $2335-2337$ & Poa pratensis L. s.l. & Debrecen & 1959 & Siroki Zoltán & DE-siroki-01955.jpg \\
\hline $2335-2337$ & Poa pratensis L. s.l. & Debrecen & 1959 & Siroki Zoltán & DE-siroki-01959.jpg \\
\hline $2335-2337$ & Poa pratensis L. s.l. & Debrecen & 1965 & Siroki Zoltán & DE-siroki-01958.jpg \\
\hline $2335-2337$ & Poa pratensis L. s.l. & Debrecen & 1978 & Siroki Zoltán & DE-siroki-01951.jpg \\
\hline $2335-2337$ & Poa pratensis L. s.l. & Debrecen & 1980 & Siroki Zoltán & DE-siroki-01945.jpg \\
\hline $2335-2337$ & Poa pratensis L. s.l. & Debrecen & 1980 & Siroki Zoltán & DE-siroki-01946.jpg \\
\hline $2335-2337$ & Poa pratensis L. s.l. & Debrecen & 1980 & Siroki Zoltán & DE-siroki-01947.jpg \\
\hline $2335-2337$ & Poa pratensis L. s.l. & Gödöllő & 1952 & Siroki Zoltán & DE-siroki-01964.jpg \\
\hline $2335-2337$ & Poa pratensis L. s.l. & Pomáz & 1954 & Siroki Zoltán & DE-siroki-01966.jpg \\
\hline 2338 & Puccinellia distans (Jacq.) Parl. & Budapest & 1890 & Czakó Kálmán & DE-siroki-19383.jpg \\
\hline 2338 & Puccinellia distans (Jacq.) Parl. & Budapest & 1951 & Siroki Zoltán & DE-siroki-19437.jpg \\
\hline 2338 & Puccinellia distans (Jacq.) Parl. & Debrecen & 1947 & Siroki Zoltán & DE-siroki-19425.jpg \\
\hline 2338 & Puccinellia distans (Jacq.) Parl. & Debrecen & 1947 & Siroki Zoltán & DE-siroki-19429.jpg \\
\hline 2338 & Puccinellia distans (Jacq.) Parl. & Debrecen & 1950 & Siroki Zoltán & DE-siroki-19422.jpg \\
\hline 2338 & Puccinellia distans (Jacq.) Parl. & Debrecen & 1953 & Siroki Zoltán & DE-siroki-19424.jpg \\
\hline 2338 & Puccinellia distans (Jacq.) Parl. & Debrecen & 1953 & Siroki Zoltán & DE-siroki-19430.jpg \\
\hline 2338 & Puccinellia distans (Jacq.) Parl. & Debrecen & 1954 & Siroki Zoltán & DE-siroki-19431.jpg \\
\hline 2338 & Puccinellia distans (Jacq.) Parl. & Debrecen & 1954 & Siroki Zoltán & DE-siroki-19423.jpg \\
\hline 2338 & Puccinellia distans (Jacq.) Parl. & Hévíz & 1953 & Siroki Zoltán & DE-siroki-19435.jpg \\
\hline 2338 & Puccinellia distans (Jacq.) Parl. & Hévíz & 1953 & Siroki Zoltán & DE-siroki-19436.jpg \\
\hline 2338 & Puccinellia distans (Jacq.) Parl. & Hévíz & 1953 & Siroki Zoltán & DE-siroki-19434.jpg \\
\hline 2338 & Puccinellia distans (Jacq.) Parl. & Hortobágy & 1957 & Siroki Zoltán & DE-siroki-19419.jpg \\
\hline 2338 & Puccinellia distans (Jacq.) Parl. & Hortobágy & 1957 & Siroki Zoltán & DE-siroki-19420.jpg \\
\hline 2338 & Puccinellia distans (Jacq.) Parl. & Hortobágy & 1959 & Siroki Zoltán & DE-siroki-19426.jpg \\
\hline 2338 & Puccinellia distans (Jacq.) Parl. & Hortobágy & 1959 & Siroki Zoltán & DE-siroki-19428.jpg \\
\hline 2338 & Puccinellia distans (Jacq.) Parl. & Mikepércs & 1962 & Siroki Zoltán & DE-siroki-19421.jpg \\
\hline 2338 & Puccinellia distans (Jacq.) Parl. & Mikepércs & 1962 & Siroki Zoltán & DE-siroki-19427.jpg \\
\hline 2338 & Puccinellia distans (Jacq.) Parl. & Tápiógyörgye & 1899 & Degen Árpád & DE-siroki-19441.jpg \\
\hline
\end{tabular}




\begin{tabular}{|c|c|c|c|c|c|}
\hline $\begin{array}{l}\text { Sorszám / } \\
\text { Number }\end{array}$ & Taxon-név / Taxon-name & $\begin{array}{l}\text { Település / } \\
\text { Settlement }\end{array}$ & $\begin{array}{l}\text { Év / } \\
\text { Year }\end{array}$ & $\begin{array}{l}\text { Gyűjtő / } \\
\text { Collector }\end{array}$ & Fájlnév / File-name \\
\hline 2340 & Puccinellia peisonis (Beck) Jáv. & Üllő & 1900 & Thaisz Lajos & DE-siroki-19444.jpg \\
\hline---- & Puccinellia pannonica (Hack.) Holmb. & Budapest & 1890 & $\begin{array}{l}\text { Alföldi Flatt } \\
\text { Károly }\end{array}$ & DE-siroki-19418.jpg \\
\hline---- & Puccinellia pannonica (Hack.) Holmb. & Budapest & 1901 & $\begin{array}{l}\text { Alföldi Flatt } \\
\text { Károly }\end{array}$ & DE-siroki-19415.jpg \\
\hline---- & Puccinellia pannonica (Hack.) Holmb. & Budapest & 1901 & $\begin{array}{l}\text { Alföldi Flatt } \\
\text { Károly }\end{array}$ & DE-siroki-19417.jpg \\
\hline--- & Puccinellia pannonica (Hack.) Holmb. & Budapest & - & $\begin{array}{l}\text { Alföldi Flatt } \\
\text { Károly }\end{array}$ & DE-siroki-19416.jpg \\
\hline 2341 & Sclerochloa dura (L.) P. Beauv. & Baracska & 1951 & Siroki Zoltán & DE-siroki-01932.jpg \\
\hline 2341 & Sclerochloa dura (L.) P. Beauv. & Budapest & 1951 & Siroki Zoltán & DE-siroki-01933.jpg \\
\hline 2341 & Sclerochloa dura (L.) P. Beauv. & Debrecen & 1946 & Siroki Zoltán & DE-siroki-01934.jpg \\
\hline 2341 & Sclerochloa dura (L.) P. Beauv. & Debrecen & 1946 & Siroki Zoltán & DE-siroki-01931.jpg \\
\hline 2342 & Dactylis glomerata L. & Debrecen & 1947 & Siroki Zoltán & DE-siroki-01911.jpg \\
\hline 2342 & Dactylis glomerata L. & Debrecen & 1948 & Siroki Zoltán & DE-siroki-01910.jpg \\
\hline 2342 & Dactylis glomerata L. & Debrecen & 1959 & Siroki Zoltán & DE-siroki-01909.jpg \\
\hline 2344 & Beckmannia eruciformis (L.) Host & Biharugra & 1961 & Siroki Zoltán & DE-siroki-01578.jpg \\
\hline 2344 & Beckmannia eruciformis (L.) Host & Biharugra & 1961 & Siroki Zoltán & DE-siroki-01579.jpg \\
\hline 2344 & Beckmannia eruciformis (L.) Host & Debrecen & 1947 & Siroki Zoltán & DE-siroki-01587.jpg \\
\hline 2344 & Beckmannia eruciformis (L.) Host & Debrecen & 1954 & Siroki Zoltán & DE-siroki-01591.jpg \\
\hline 2344 & Beckmannia eruciformis (L.) Host & Debrecen & 1954 & Siroki Zoltán & DE-siroki-01589.jpg \\
\hline 2344 & Beckmannia eruciformis (L.) Host & Debrecen & 1954 & Siroki Zoltán & DE-siroki-01590.jpg \\
\hline 2344 & Beckmannia eruciformis (L.) Host & Debrecen & 1954 & Siroki Zoltán & DE-siroki-01592.jpg \\
\hline 2344 & Beckmannia eruciformis (L.) Host & Debrecen & 1954 & Siroki Zoltán & DE-siroki-01586.jpg \\
\hline 2344 & Beckmannia eruciformis (L.) Host & Debrecen & 1954 & Siroki Zoltán & DE-siroki-01577.jpg \\
\hline 2344 & Beckmannia eruciformis (L.) Host & Debrecen & 1981 & Siroki Zoltán & DE-siroki-01580.jpg \\
\hline 2344 & Beckmannia eruciformis (L.) Host & Debrecen & 1982 & Siroki Zoltán & DE-siroki-01581.jpg \\
\hline 2344 & Beckmannia eruciformis (L.) Host & Debrecen & 1982 & Siroki Zoltán & DE-siroki-01582.jpg \\
\hline 2344 & Beckmannia eruciformis (L.) Host & Egyek & 1947 & Siroki Zoltán & DE-siroki-01588.jpg \\
\hline 2344 & Beckmannia eruciformis (L.) Host & Egyek & 1947 & Siroki Zoltán & DE-siroki-01583.jpg \\
\hline 2344 & Beckmannia eruciformis (L.) Host & Egyek & 1947 & Siroki Zoltán & DE-siroki-01584.jpg \\
\hline 2344 & Beckmannia eruciformis (L.) Host & Egyek & 1947 & Siroki Zoltán & DE-siroki-01576.jpg \\
\hline 2345 & Cynosurus cristatus L. & Debrecen & 1954 & Siroki Zoltán & DE-siroki-01922.jpg \\
\hline 2345 & Cynosurus cristatus L. & Debrecen & 1954 & Siroki Zoltán & DE-siroki-01923.jpg \\
\hline 2345 & Cynosurus cristatus L. & Debrecen & 1954 & Siroki Zoltán & DE-siroki-01925.jpg \\
\hline 2345 & Cynosurus cristatus L. & Debrecen & 1956 & Siroki Zoltán & DE-siroki-01921.jpg \\
\hline 2345 & Cynosurus cristatus L. & Háromhuta & 1961 & Siroki Zoltán & DE-siroki-01915.jpg \\
\hline 2345 & Cynosurus cristatus L. & Háromhuta & 1961 & Siroki Zoltán & DE-siroki-01919.jpg \\
\hline 2345 & Cynosurus cristatus L. & Háromhuta & 1961 & Siroki Zoltán & DE-siroki-01920.jpg \\
\hline 2345 & Cynosurus cristatus L. & Háromhuta & 1961 & Siroki Zoltán & DE-siroki-01913.jpg \\
\hline 2345 & Cynosurus cristatus L. & Háromhuta & 1961 & Siroki Zoltán & DE-siroki-01914.jpg \\
\hline 2345 & Cynosurus cristatus L. & Háromhuta & 1961 & Siroki Zoltán & DE-siroki-01917.jpg \\
\hline 2345 & Cynosurus cristatus L. & Háromhuta & 1961 & Siroki Zoltán & DE-siroki-01916.jpg \\
\hline 2345 & Cynosurus cristatus L. & Háromhuta & 1967 & Siroki Zoltán & DE-siroki-01918.jpg \\
\hline 2345 & Cynosurus cristatus L. & Miskolc & 1960 & Siroki Zoltán & DE-siroki-01924.jpg \\
\hline 2346 & Catabrosa aquatica (L.) P. Beauv. & Gödöllő & 1951 & Siroki Zoltán & DE-siroki-01848.jpg \\
\hline 2346 & Catabrosa aquatica (L.) P. Beauv. & Gödöllő & 1951 & Siroki Zoltán & DE-siroki-01850.jpg \\
\hline 2346 & Catabrosa aquatica (L.) P. Beauv. & Háromhuta & 1961 & Siroki Zoltán & DE-siroki-01844.jpg \\
\hline 2346 & Catabrosa aquatica (L.) P. Beauv. & Háromhuta & 1961 & Siroki Zoltán & DE-siroki-01845.jpg \\
\hline
\end{tabular}




\begin{tabular}{|c|c|c|c|c|c|}
\hline $\begin{array}{l}\text { Sorszám / } \\
\text { Number }\end{array}$ & Taxon-név / Taxon-name & $\begin{array}{l}\text { Település / } \\
\text { Settlement }\end{array}$ & $\begin{array}{l}\text { Év / } \\
\text { Year }\end{array}$ & $\begin{array}{l}\text { Gyújtő / } \\
\text { Collector }\end{array}$ & Fájlnév / File-name \\
\hline 2346 & Catabrosa aquatica (L.) P. Beauv. & Háromhuta & 1961 & Siroki Zoltán & DE-siroki-01846.jpg \\
\hline 2346 & Catabrosa aquatica (L.) P. Beauv. & Háromhuta & 1961 & Siroki Zoltán & DE-siroki-01849.jpg \\
\hline 2347 & Apera spica-venti (L.) P. Beauv. & Debrecen & 1948 & Siroki Zoltán & DE-siroki-01335.jpg \\
\hline 2347 & Apera spica-venti (L.) P. Beauv. & Debrecen & 1948 & Siroki Zoltán & DE-siroki-01334.jpg \\
\hline 2347 & Apera spica-venti (L.) P. Beauv. & Debrecen & 1948 & Siroki Zoltán & DE-siroki-01336.jpg \\
\hline 2347 & Apera spica-venti (L.) P. Beauv. & Debrecen & 1948 & Siroki Zoltán & DE-siroki-01337.jpg \\
\hline 2348 & Apera interrupta (L.) P. Beauv. & Budapest & 1951 & Siroki Zoltán & DE-siroki-01347.jpg \\
\hline 2348 & Apera interrupta (L.) P. Beauv. & Budapest & 1953 & Siroki Zoltán & DE-siroki-01348.jpg \\
\hline 2348 & Apera interrupta (L.) P. Beauv. & Dorog & 1901 & Thaisz Lajos & DE-siroki-01343.jpg \\
\hline 2348 & Apera interrupta (L.) P. Beauv. & Pilisvörösvár & 1952 & Siroki Zoltán & DE-siroki-01349.jpg \\
\hline 2348 & Apera interrupta (L.) P. Beauv. & Pilisszentiván & 1952 & Siroki Zoltán & DE-siroki-01345.jpg \\
\hline 2348 & Apera interrupta (L.) P. Beauv. & Pilisszentiván & 1952 & Siroki Zoltán & DE-siroki-01346.jpg \\
\hline 2349 & Briza media L. & "Nagymező" & 1959 & Halász Tibor & DE-siroki-01901.jpg \\
\hline 2349 & Briza media L. & "Nagymező" & 1959 & Halász Tibor & DE-siroki-01902.jpg \\
\hline 2349 & Briza media L. & Debrecen & 1950 & Siroki Zoltán & DE-siroki-01907.jpg \\
\hline 2349 & Briza media L. & Hajdúbagos & 1982 & Siroki Zoltán & DE-siroki-01905.jpg \\
\hline 2349 & Briza media L. & Újléta & 1967 & Siroki Zoltán & DE-siroki-01903.jpg \\
\hline 2349 & Briza media L. & Újléta & 1967 & Siroki Zoltán & DE-siroki-01904.jpg \\
\hline 2350 & Sesleria heufleriana Schur & "Tarkő" & 1916 & Hulják János & DE-siroki-01607.jpg \\
\hline 2350 & Sesleria heufleriana Schur & Felsőtárkány & 1957 & Siroki Zoltán & DE-siroki-01602.jpg \\
\hline 2350 & Sesleria heufleriana Schur & Miskolc & 1911 & Hulják János & DE-siroki-01608.jpg \\
\hline 2350 & Sesleria heufleriana Schur & Szarvaskő & 1959 & Siroki Zoltán & DE-siroki-01612.jpg \\
\hline 2350 & Sesleria heufleriana Schur & Szarvaskő & 1959 & Siroki Zoltán & DE-siroki-01614.jpg \\
\hline 2350 & Sesleria heufleriana Schur & Szarvaskő & 1959 & Siroki Zoltán & DE-siroki-01615.jpg \\
\hline 2350 & Sesleria heufleriana Schur & Szarvaskő & 1959 & Siroki Zoltán & DE-siroki-01616.jpg \\
\hline 2350 & Sesleria heufleriana Schur & Szarvaskő & 1959 & Siroki Zoltán & DE-siroki-01617.jpg \\
\hline 2350 & Sesleria heufleriana Schur & Szarvaskő & 1959 & Siroki Zoltán & DE-siroki-01618.jpg \\
\hline 2350 & Sesleria heufleriana Schur & Szarvaskő & 1959 & Siroki Zoltán & DE-siroki-01619.jpg \\
\hline 2350 & Sesleria heufleriana Schur & Szarvaskő & 1959 & Siroki Zoltán & DE-siroki-01603.jpg \\
\hline 2350 & Sesleria heufleriana Schur & Szarvaskő & 1959 & Siroki Zoltán & DE-siroki-01604.jpg \\
\hline 2350 & Sesleria heufleriana Schur & Szarvaskő & 1959 & Siroki Zoltán & DE-siroki-01605.jpg \\
\hline 2350 & Sesleria heufleriana Schur & Szarvaskő & 1959 & Siroki Zoltán & DE-siroki-01606.jpg \\
\hline 2350 & Sesleria heufleriana Schur & Szarvaskő & 1966 & Siroki Zoltán & DE-siroki-01609.jpg \\
\hline 2350 & Sesleria heufleriana Schur & Szarvaskő & 1966 & Siroki Zoltán & DE-siroki-01610.jpg \\
\hline 2350 & Sesleria heufleriana Schur & Szarvaskő & 1966 & Siroki Zoltán & DE-siroki-01611.jpg \\
\hline 2350 & Sesleria heufleriana Schur & Szarvaskő & 1966 & Siroki Zoltán & DE-siroki-01613.jpg \\
\hline 2351 & Sesleria hungarica Ujhelyi & Miskolc & 1961 & Siroki Zoltán & DE-siroki-01647.jpg \\
\hline 2351 & Sesleria hungarica Ujhelyi & Miskolc & 1961 & Siroki Zoltán & DE-siroki-01643.jpg \\
\hline 2351 & Sesleria hungarica Ujhelyi & Miskolc & 1961 & Siroki Zoltán & DE-siroki-01644.jpg \\
\hline 2351 & Sesleria hungarica Ujhelyi & Miskolc & 1961 & Siroki Zoltán & DE-siroki-01645.jpg \\
\hline 2351 & Sesleria hungarica Ujhelyi & Miskolc & 1961 & Siroki Zoltán & DE-siroki-01646.jpg \\
\hline 2351 & Sesleria hungarica Ujhelyi & Miskolc & 1961 & Siroki Zoltán & DE-siroki-01649.jpg \\
\hline 2351 & Sesleria hungarica Ujhelyi & Miskolc & 1961 & Siroki Zoltán & DE-siroki-01650.jpg \\
\hline 2351 & Sesleria hungarica Ujhelyi & Miskolc & 1961 & Siroki Zoltán & DE-siroki-01654.jpg \\
\hline 2351 & Sesleria hungarica Ujhelyi & Miskolc & 1961 & Siroki Zoltán & DE-siroki-01655.jpg \\
\hline 2351 & Sesleria hungarica Ujhelyi & Miskolc & 1961 & Siroki Zoltán & DE-siroki-01656.jpg \\
\hline
\end{tabular}




\begin{tabular}{|c|c|c|c|c|c|}
\hline $\begin{array}{l}\text { Sorszám / } \\
\text { Number }\end{array}$ & Taxon-név / Taxon-name & $\begin{array}{l}\text { Település / } \\
\text { Settlement }\end{array}$ & $\begin{array}{l}\text { Év / } \\
\text { Year }\end{array}$ & $\begin{array}{l}\text { Gyűjtő / } \\
\text { Collector }\end{array}$ & Fájlnév / File-name \\
\hline 2351 & Sesleria hungarica Ujhelyi & Miskolc & 1961 & Siroki Zoltán & DE-siroki-01657.jpg \\
\hline 2351 & Sesleria hungarica Ujhelyi & Miskolc & 1964 & Siroki Zoltán & DE-siroki-01648.jpg \\
\hline 2351 & Sesleria hungarica Ujhelyi & Miskolc & 1964 & Siroki Zoltán & DE-siroki-01651.jpg \\
\hline 2351 & Sesleria hungarica Ujhelyi & Miskolc & 1964 & Siroki Zoltán & DE-siroki-01652.jpg \\
\hline 2351 & Sesleria hungarica Ujhelyi & Miskolc & 1964 & Siroki Zoltán & DE-siroki-01653.jpg \\
\hline 2351 & Sesleria hungarica Ujhelyi & Miskolc & 1964 & Siroki Zoltán & DE-siroki-01659.jpg \\
\hline 2351 & Sesleria hungarica Ujhelyi & Miskolc & 1964 & Siroki Zoltán & DE-siroki-01660.jpg \\
\hline 2351 & Sesleria hungarica Ujhelyi & Miskolc & 1964 & Siroki Zoltán & DE-siroki-01661.jpg \\
\hline 2351 & Sesleria hungarica Ujhelyi & Miskolc & 1964 & Siroki Zoltán & DE-siroki-01662.jpg \\
\hline 2352 & Sesleria uliginosa Opiz & Kimle & 1962 & Siroki Zoltán & DE-siroki-01636.jpg \\
\hline 2352 & Sesleria uliginosa Opiz & Kimle & 1962 & Siroki Zoltán & DE-siroki-01637.jpg \\
\hline 2352 & Sesleria uliginosa Opiz & Kimle & 1962 & Siroki Zoltán & DE-siroki-01638.jpg \\
\hline 2352 & Sesleria uliginosa Opiz & Kimle & 1962 & Siroki Zoltán & DE-siroki-01639.jpg \\
\hline 2352 & Sesleria uliginosa Opiz & Kimle & 1962 & Siroki Zoltán & DE-siroki-01640.jpg \\
\hline 2352 & Sesleria uliginosa Opiz & Lébény & 1951 & Jeanplong József & DE-siroki-01641.jpg \\
\hline 2352 & Sesleria uliginosa Opiz & Nádasdladány & 1955 & Máthé Imre & DE-siroki-01642.jpg \\
\hline 2354 & Sesleria sadleriana Janka & Budapest & 1951 & Siroki Zoltán & DE-siroki-01631.jpg \\
\hline 2354 & Sesleria sadleriana Janka & Budapest & 1951 & Siroki Zoltán & DE-siroki-01632.jpg \\
\hline 2354 & Sesleria sadleriana Janka & Budapest & 1951 & Siroki Zoltán & DE-siroki-01633.jpg \\
\hline 2354 & Sesleria sadleriana Janka & Budapest & 1955 & Siroki Zoltán & DE-siroki-01621.jpg \\
\hline 2354 & Sesleria sadleriana Janka & Budapest & 1955 & Siroki Zoltán & DE-siroki-01622.jpg \\
\hline 2354 & Sesleria sadleriana Janka & Budapest & 1955 & Siroki Zoltán & DE-siroki-01623.jpg \\
\hline 2354 & Sesleria sadleriana Janka & Budapest & 1955 & Siroki Zoltán & DE-siroki-01624.jpg \\
\hline 2354 & Sesleria sadleriana Janka & Budapest & 1955 & Siroki Zoltán & DE-siroki-01629.jpg \\
\hline 2354 & Sesleria sadleriana Janka & Budapest & 1955 & Siroki Zoltán & DE-siroki-01630.jpg \\
\hline 2354 & Sesleria sadleriana Janka & Budapest & 1955 & Siroki Zoltán & DE-siroki-01625.jpg \\
\hline 2354 & Sesleria sadleriana Janka & Budapest & 1955 & Siroki Zoltán & DE-siroki-01627.jpg \\
\hline 2354 & Sesleria sadleriana Janka & Budapest & 1955 & Siroki Zoltán & DE-siroki-01628.jpg \\
\hline 2354 & Sesleria sadleriana Janka & Budapest & - & Siroki Zoltán & DE-siroki-01626.jpg \\
\hline 2355 & Melica ciliata L. & Boldogkőváralja & 1967 & Siroki Zoltán & DE-siroki-01857.jpg \\
\hline 2355 & Melica ciliata L. & Boldogkőváralja & 1967 & Siroki Zoltán & DE-siroki-01858.jpg \\
\hline 2355 & Melica ciliata L. & Budapest & 1949 & Siroki Zoltán & DE-siroki-01855.jpg \\
\hline 2355 & Melica ciliata L. & Budapest & 1951 & Siroki Zoltán & DE-siroki-01861.jpg \\
\hline 2355 & Melica ciliata L. & Budapest & 1954 & Siroki Zoltán & DE-siroki-01860.jpg \\
\hline 2355 & Melica ciliata L. & Lábatlan & 1986 & Siroki Zoltán & DE-siroki-01853.jpg \\
\hline 2355 & Melica ciliata L. & Lábatlan & 1986 & Siroki Zoltán & DE-siroki-01852.jpg \\
\hline 2355 & Melica ciliata L. & Nagykovácsi & 1957 & Siroki Zoltán & DE-siroki-01859.jpg \\
\hline 2356 & Melica transsilvanica Schur & Boldogkőváralja & 1967 & Siroki Zoltán & DE-siroki-01866.jpg \\
\hline 2356 & Melica transsilvanica Schur & Debrecen & 1949 & Siroki Zoltán & DE-siroki-01864.jpg \\
\hline 2356 & Melica transsilvanica Schur & Debrecen & 1950 & Siroki Zoltán & DE-siroki-01865.jpg \\
\hline 2356 & Melica transsilvanica Schur & Gödöllő & 1951 & Siroki Zoltán & DE-siroki-01863.jpg \\
\hline 2356 & Melica transsilvanica Schur & Sátoraljaújhely & 1943 & Siroki Zoltán & DE-siroki-01870.jpg \\
\hline 2356 & Melica transsilvanica Schur & Veresegyház & 1960 & Siroki Zoltán & DE-siroki-01867.jpg \\
\hline 2356 & Melica transsilvanica Schur & Veresegyház & 1960 & Siroki Zoltán & DE-siroki-01868.jpg \\
\hline 2357 & Melica altissima L. & Aszaló & 1944 & Siroki Zoltán & DE-siroki-01874.jpg \\
\hline 2357 & Melica altissima L. & Aszaló & 1944 & Siroki Zoltán & DE-siroki-01879.jpg \\
\hline
\end{tabular}




\begin{tabular}{|c|c|c|c|c|c|}
\hline $\begin{array}{l}\text { Sorszám / } \\
\text { Number }\end{array}$ & Taxon-név / Taxon-name & $\begin{array}{l}\text { Település / } \\
\text { Settlement }\end{array}$ & $\begin{array}{l}\text { Év / } \\
\text { Year }\end{array}$ & $\begin{array}{l}\text { Gyújtő / } \\
\text { Collector }\end{array}$ & Fájlnév / File-name \\
\hline 2357 & Melica altissima L. & Egyek & 1947 & Siroki Zoltán & DE-siroki-01876.jpg \\
\hline 2357 & Melica altissima L. & Egyek & 1947 & Siroki Zoltán & DE-siroki-01877.jpg \\
\hline 2357 & Melica altissima L. & Egyek & 1959 & Siroki Zoltán & DE-siroki-01871.jpg \\
\hline 2357 & Melica altissima L. & Egyek & 1959 & Siroki Zoltán & DE-siroki-01872.jpg \\
\hline 2357 & Melica altissima L. & Egyek & 1959 & Siroki Zoltán & DE-siroki-01873.jpg \\
\hline 2357 & Melica altissima L. & Egyek & 1959 & Siroki Zoltán & DE-siroki-01878.jpg \\
\hline 2358 & Melica uniflora L. & "Bükk-hg." & 1956 & Halász Tibor & DE-siroki-01894.jpg \\
\hline 2358 & Melica uniflora L. & "Fáni-völgy" & 1955 & $\begin{array}{l}\text { Siroki Zoltán - } \\
\text { Farkas Attila }\end{array}$ & DE-siroki-01883.jpg \\
\hline 2358 & Melica uniflora L. & "Fáni-völgy" & 1955 & $\begin{array}{l}\text { Siroki Zoltán - } \\
\text { Farkas Attila }\end{array}$ & DE-siroki-01884.jpg \\
\hline 2358 & Melica uniflora L. & "Vértes" & 1957 & Siroki Zoltán & DE-siroki-01888.jpg \\
\hline 2358 & Melica uniflora L. & "Vértes" & - & Siroki Zoltán & DE-siroki-01893.jpg \\
\hline 2358 & Melica uniflora L. & Budapest & 1981 & Siroki Zoltán & DE-siroki-01880.jpg \\
\hline 2358 & Melica uniflora L. & Budapest & 1981 & Siroki Zoltán & DE-siroki-01881.jpg \\
\hline 2358 & Melica uniflora L. & Gödöllő & 1951 & Siroki Zoltán & DE-siroki-01882.jpg \\
\hline 2359 & Melica nutans L. & "Nagymező" & 1959 & Siroki Zoltán & DE-siroki-01885.jpg \\
\hline 2359 & Melica nutans L. & Pásztó & 1952 & Siroki Zoltán & DE-siroki-01896.jpg \\
\hline 2360 & Melica nutans L. & "Nagymező" & 1959 & Halász Tibor & DE-siroki-01890.jpg \\
\hline 2360 & Melica nutans L. & "Nagymező" & 1959 & Siroki Zoltán & DE-siroki-01886.jpg \\
\hline 2360 & Melica nutans L. & Háromhuta & 1960 & Siroki Zoltán & DE-siroki-01887.jpg \\
\hline 2360 & Melica nutans L. & Nagyhuta & 1961 & Siroki Zoltán & DE-siroki-01889.jpg \\
\hline 2360 & Melica nutans L. & Szilvásvárad & 1954 & Siroki Zoltán & DE-siroki-01892.jpg \\
\hline 2361 & Glyceria maxima (Hartm.) Holmb. & Csobád & 1910 & Thaisz Lajos & DE-siroki-19356.jpg \\
\hline 2361 & Glyceria maxima (Hartm.) Holmb. & Debrecen & 1947 & Siroki Zoltán & DE-siroki-19352.jpg \\
\hline 2361 & Glyceria maxima (Hartm.) Holmb. & Debrecen & 1958 & Siroki Zoltán & DE-siroki-19350.jpg \\
\hline 2361 & Glyceria maxima (Hartm.) Holmb. & Debrecen & 1958 & Siroki Zoltán & DE-siroki-19351.jpg \\
\hline 2361 & Glyceria maxima (Hartm.) Holmb. & Mosonmagyaróvár & 1939 & Siroki Zoltán & DE-siroki-19349.jpg \\
\hline 2362 & Glyceria $\times$ pedicellata Towns. & Budapest & 1900 & $\begin{array}{l}\text { Alföldi Flatt } \\
\text { Károly }\end{array}$ & DE-siroki-19362.jpg \\
\hline 2362 & Glyceria × pedicellata Towns. & Budapest & 1900 & $\begin{array}{l}\text { Alföldi Flatt } \\
\text { Károly }\end{array}$ & DE-siroki-19380.jpg \\
\hline 2363 & Glyceria fluitans (L.) R. Br. & Budapest & 1890 & Czakó Kálmán & DE-siroki-19375.jpg \\
\hline 2363 & Glyceria fluitans (L.) R. Br. & Budapest & 1900 & $\begin{array}{l}\text { Alföldi Flatt } \\
\text { Károly }\end{array}$ & DE-siroki-19379.jpg \\
\hline 2363 & Glyceria fluitans (L.) R. Br. & Debrecen & 1951 & Siroki Zoltán & DE-siroki-19369.jpg \\
\hline 2363 & Glyceria fluitans (L.) R. Br. & Hajdúbagos & 1981 & Siroki Zoltán & DE-siroki-19363.jpg \\
\hline 2363 & Glyceria fluitans (L.) R. Br. & Sátoraljaújhely & 1944 & Siroki Zoltán & DE-siroki-19368.jpg \\
\hline 2363 & Glyceria fluitans (L.) R. Br. & Sátoraljaújhely & 1944 & Siroki Zoltán & DE-siroki-19370.jpg \\
\hline 2363 & Glyceria fluitans (L.) R. Br. & Sátoraljaújhely & 1944 & Siroki Zoltán & DE-siroki-19371.jpg \\
\hline 2363 & Glyceria fluitans (L.) R. Br. & Sátoraljaújhely & 1944 & Siroki Zoltán & DE-siroki-19372.jpg \\
\hline 2363 & Glyceria fluitans (L.) R. Br. & Újléta & 1967 & Siroki Zoltán & DE-siroki-19364.jpg \\
\hline 2363 & Glyceria fluitans (L.) R. Br. & Újléta & 1967 & Siroki Zoltán & DE-siroki-19365.jpg \\
\hline 2363 & Glyceria fluitans (L.) R. Br. & Újléta & 1967 & Siroki Zoltán & DE-siroki-19366.jpg \\
\hline 2363 & Glyceria fluitans (L.) R. Br. & Újléta & 1967 & Siroki Zoltán & DE-siroki-19367.jpg \\
\hline 2365 & Glyceria notata Chevall. & Budapest & 1903 & Kocsis István & DE-siroki-19386.jpg \\
\hline 2365 & Glyceria notata Chevall. & Budapest & 1906 & $\begin{array}{l}\text { Alföldi Flatt } \\
\text { Károly }\end{array}$ & DE-siroki-19396.jpg \\
\hline 2365 & Glyceria notata Chevall. & Debrecen & 1954 & Siroki Zoltán & DE-siroki-19392.jpg \\
\hline 2365 & Glyceria notata Chevall. & Debrecen & 1954 & Siroki Zoltán & DE-siroki-19394.jpg \\
\hline
\end{tabular}




\begin{tabular}{|c|c|c|c|c|c|}
\hline $\begin{array}{l}\text { Sorszám / } \\
\text { Number }\end{array}$ & Taxon-név / Taxon-name & $\begin{array}{l}\text { Település / } \\
\text { Settlement }\end{array}$ & $\begin{array}{l}\text { Év / } \\
\text { Year }\end{array}$ & $\begin{array}{l}\text { Gyűjtő / } \\
\text { Collector }\end{array}$ & Fájlnév / File-name \\
\hline 2365 & Glyceria notata Chevall. & Debrecen & 1954 & Siroki Zoltán & DE-siroki-19395.jpg \\
\hline 2365 & Glyceria notata Chevall. & Debrecen & 1955 & Siroki Zoltán & DE-siroki-19393.jpg \\
\hline 2365 & Glyceria notata Chevall. & Miskolc & 1959 & Siroki Zoltán & DE-siroki-19387.jpg \\
\hline 2365 & Glyceria notata Chevall. & Miskolc & 1959 & Siroki Zoltán & DE-siroki-19391.jpg \\
\hline 2365 & Glyceria notata Chevall. & Nagyhuta & 1978 & Siroki Zoltán & DE-siroki-19388.jpg \\
\hline 2365 & Glyceria notata Chevall. & Nagyhuta & 1978 & Siroki Zoltán & DE-siroki-19389.jpg \\
\hline 2365 & Glyceria notata Chevall. & Nagyhuta & 1978 & Siroki Zoltán & DE-siroki-19390.jpg \\
\hline 2366 & $\begin{array}{l}\text { Glyceria nemoralis } \\
\text { (Uechtr.) Uechtr. et Körn. }\end{array}$ & "Sátor-hg." & 1978 & Siroki Zoltán & DE-siroki-19401.jpg \\
\hline 2366 & $\begin{array}{l}\text { Glyceria nemoralis } \\
\text { (Uechtr.) Uechtr. et Körn. }\end{array}$ & Miskolc & 1960 & Siroki Zoltán & DE-siroki-19397.jpg \\
\hline 2366 & $\begin{array}{l}\text { Glyceria nemoralis } \\
\text { (Uechtr.) Uechtr. et Körn. }\end{array}$ & Miskolc & 1960 & Siroki Zoltán & DE-siroki-19398.jpg \\
\hline 2366 & $\begin{array}{l}\text { Glyceria nemoralis } \\
\text { (Uechtr.) Uechtr. et Körn. }\end{array}$ & Miskolc & 1960 & Siroki Zoltán & DE-siroki-19399.jpg \\
\hline 2366 & $\begin{array}{l}\text { Glyceria nemoralis } \\
\text { (Uechtr.) Uechtr. et Körn. }\end{array}$ & Miskolc & 1960 & Siroki Zoltán & DE-siroki-19403.jpg \\
\hline 2366 & $\begin{array}{l}\text { Glyceria nemoralis } \\
\text { (Uechtr.) Uechtr. et Körn. }\end{array}$ & Miskolc & 1960 & Siroki Zoltán & DE-siroki-19404.jpg \\
\hline 2366 & $\begin{array}{l}\text { Glyceria nemoralis } \\
\text { (Uechtr.) Uechtr. et Körn. }\end{array}$ & Miskolc & 1960 & Siroki Zoltán & DE-siroki-19405.jpg \\
\hline 2366 & $\begin{array}{l}\text { Glyceria nemoralis } \\
\text { (Uechtr.) Uechtr. et Körn. }\end{array}$ & Miskolc & 1960 & Siroki Zoltán & DE-siroki-19406.jpg \\
\hline 2366 & $\begin{array}{l}\text { Glyceria nemoralis } \\
\text { (Uechtr.) Uechtr. et Körn. }\end{array}$ & Miskolc & 1960 & Siroki Zoltán & DE-siroki-19412.jpg \\
\hline 2366 & $\begin{array}{l}\text { Glyceria nemoralis } \\
\text { (Uechtr.) Uechtr. et Körn. }\end{array}$ & Szilvásvárad & 1954 & Siroki Zoltán & DE-siroki-19402.jpg \\
\hline 2366 & $\begin{array}{l}\text { Glyceria nemoralis } \\
\text { (Uechtr.) Uechtr. et Körn. }\end{array}$ & Szilvásvárad & 1954 & Siroki Zoltán & DE-siroki-19411.jpg \\
\hline 2370 & Bromus hordeaceus L. & Debrecen & 1947 & Siroki Zoltán & DE-siroki-02201.jpg \\
\hline 2370 & Bromus hordeaceus L. & Debrecen & 1948 & Siroki Zoltán & DE-siroki-02200.jpg \\
\hline 2370 & Bromus hordeaceus L. & Hajdúböszörmény & 1963 & Siroki Zoltán & DE-siroki-02197.jpg \\
\hline 2370 & Bromus hordeaceus L. & Hajdúböszörmény & 1963 & Siroki Zoltán & DE-siroki-02198.jpg \\
\hline 2370 & Bromus hordeaceus L. & Hajdúböszörmény & 1963 & Siroki Zoltán & DE-siroki-02199.jpg \\
\hline 2370 & Bromus hordeaceus L. & Hajdúböszörmény & 1978 & Siroki Zoltán & DE-siroki-02196.jpg \\
\hline 2373 & Bromus secalinus L. & Budapest & 1951 & Siroki Zoltán & DE-siroki-02153.jpg \\
\hline 2373 & Bromus secalinus L. & Budapest & 1951 & Siroki Zoltán & DE-siroki-02154.jpg \\
\hline 2373 & Bromus secalinus L. & Budapest & 1951 & Siroki Zoltán & DE-siroki-02162.jpg \\
\hline 2373 & Bromus secalinus L. & Budapest & 1951 & Siroki Zoltán & DE-siroki-02164.jpg \\
\hline 2373 & Bromus secalinus L. & Debrecen & 1948 & Siroki Zoltán & DE-siroki-02157.jpg \\
\hline 2373 & Bromus secalinus L. & Debrecen & 1948 & Siroki Zoltán & DE-siroki-02161.jpg \\
\hline 2373 & Bromus secalinus L. & Nagyrozvágy & 1943 & Siroki Zoltán & DE-siroki-02150.jpg \\
\hline 2373 & Bromus secalinus L. & Záhony & 1966 & Gondola István & DE-siroki-02155.jpg \\
\hline 2373 & Bromus secalinus L. & Záhony & 1966 & Gondola István & DE-siroki-02156.jpg \\
\hline 2374 & Bromus squarrosus L. & Budapest & 1948 & Siroki Zoltán & DE-siroki-02228.jpg \\
\hline 2374 & Bromus squarrosus L. & Budapest & 1948 & Siroki Zoltán & DE-siroki-02232.jpg \\
\hline 2374 & Bromus squarrosus L. & Debrecen & 1949 & Siroki Zoltán & DE-siroki-02231.jpg \\
\hline 2374 & Bromus squarrosus L. & Debrecen & 1949 & Siroki Zoltán & DE-siroki-02230.jpg \\
\hline 2374 & Bromus squarrosus L. & Debrecen & 1949 & Siroki Zoltán & DE-siroki-02229.jpg \\
\hline 2374 & Bromus squarrosus L. & Debrecen & 1949 & Siroki Zoltán & DE-siroki-02219.jpg \\
\hline 2374 & Bromus squarrosus L. & Debrecen & 1949 & Siroki Zoltán & DE-siroki-02220.jpg \\
\hline 2374 & Bromus squarrosus L. & Gödöllő & 1951 & Siroki Zoltán & DE-siroki-02227.jpg \\
\hline
\end{tabular}




\begin{tabular}{|c|c|c|c|c|c|}
\hline $\begin{array}{l}\text { Sorszám / } \\
\text { Number }\end{array}$ & Taxon-név / Taxon-name & $\begin{array}{l}\text { Település / } \\
\text { Settlement }\end{array}$ & $\begin{array}{l}\text { Év / } \\
\text { Year }\end{array}$ & $\begin{array}{l}\text { Gyűjtő / } \\
\text { Collector }\end{array}$ & Fájlnév / File-name \\
\hline 2374 & Bromus squarrosus L. & Lábatlan & 1986 & Siroki Zoltán & DE-siroki-02218.jpg \\
\hline 2374 & Bromus squarrosus L. & Veresegyház & 1960 & Siroki Zoltán & DE-siroki-02233.jpg \\
\hline 2374 & Bromus squarrosus L. & Veresegyház & 1960 & Siroki Zoltán & DE-siroki-02234.jpg \\
\hline 2374 & Bromus squarrosus L. & Veresegyház & 1960 & Siroki Zoltán & DE-siroki-02235.jpg \\
\hline 2374 & Bromus squarrosus L. & Veresegyház & 1960 & Siroki Zoltán & DE-siroki-02221.jpg \\
\hline 2374 & Bromus squarrosus L. & Veresegyház & 1960 & Siroki Zoltán & DE-siroki-02224.jpg \\
\hline 2374 & Bromus squarrosus L. & Veresegyház & 1960 & Siroki Zoltán & DE-siroki-02225.jpg \\
\hline 2374 & Bromus squarrosus L. & Veresegyház & 1960 & Siroki Zoltán & DE-siroki-02226.jpg \\
\hline 2374 & Bromus squarrosus L. & Veresegyház & 1960 & Siroki Zoltán & DE-siroki-02222.jpg \\
\hline 2374 & Bromus squarrosus L. & Veresegyház & 1960 & Siroki Zoltán & DE-siroki-02223.jpg \\
\hline 2375 & Bromus arvensis L. & Berekböszörmény & 1970 & Siroki Zoltán & DE-siroki-02167.jpg \\
\hline 2375 & Bromus arvensis L. & Berekböszörmény & 1970 & Siroki Zoltán & DE-siroki-02168.jpg \\
\hline 2375 & Bromus arvensis L. & Berettyóújfalu & 1959 & Siroki Zoltán & DE-siroki-02178.jpg \\
\hline 2375 & Bromus arvensis L. & Berettyóújfalu & 1959 & Siroki Zoltán & DE-siroki-02179.jpg \\
\hline 2375 & Bromus arvensis L. & Boldogkőváralja & 1944 & Siroki Zoltán & DE-siroki-02192.jpg \\
\hline 2375 & Bromus arvensis L. & Csaroda & 1960 & Siroki Zoltán & DE-siroki-02169.jpg \\
\hline 2375 & Bromus arvensis L. & Csaroda & 1960 & Siroki Zoltán & DE-siroki-02170.jpg \\
\hline 2375 & Bromus arvensis L. & Csaroda & 1960 & Siroki Zoltán & DE-siroki-02171.jpg \\
\hline 2375 & Bromus arvensis L. & Csaroda & 1960 & Siroki Zoltán & DE-siroki-02180.jpg \\
\hline 2375 & Bromus arvensis L. & Csaroda & 1960 & Siroki Zoltán & DE-siroki-02181.jpg \\
\hline 2375 & Bromus arvensis L. & Csaroda & 1960 & Siroki Zoltán & DE-siroki-02182.jpg \\
\hline 2375 & Bromus arvensis L. & Csaroda & 1960 & Siroki Zoltán & DE-siroki-02183.jpg \\
\hline 2375 & Bromus arvensis L. & Csaroda & 1960 & Siroki Zoltán & DE-siroki-02184.jpg \\
\hline 2375 & Bromus arvensis L. & Debrecen & 1948 & Siroki Zoltán & DE-siroki-02194.jpg \\
\hline 2375 & Bromus arvensis L. & Debrecen & 1948 & Siroki Zoltán & DE-siroki-02193.jpg \\
\hline 2375 & Bromus arvensis L. & Debrecen & 1948 & Siroki Zoltán & DE-siroki-02186.jpg \\
\hline 2375 & Bromus arvensis L. & Debrecen & 1948 & Siroki Zoltán & DE-siroki-02185.jpg \\
\hline 2375 & Bromus arvensis L. & Debrecen & 1957 & Siroki Zoltán & DE-siroki-02188.jpg \\
\hline 2375 & Bromus arvensis L. & Debrecen & 1957 & Siroki Zoltán & DE-siroki-02189.jpg \\
\hline 2375 & Bromus arvensis L. & Debrecen & 1957 & Siroki Zoltán & DE-siroki-02177.jpg \\
\hline 2375 & Bromus arvensis L. & Debrecen & 1970 & Siroki Zoltán & DE-siroki-02173.jpg \\
\hline 2375 & Bromus arvensis L. & Debrecen & 1971 & Siroki Zoltán & DE-siroki-02174.jpg \\
\hline 2375 & Bromus arvensis L. & Debrecen & 1975 & Siroki Zoltán & DE-siroki-02175.jpg \\
\hline 2375 & Bromus arvensis L. & Debrecen & 1975 & Siroki Zoltán & DE-siroki-02176.jpg \\
\hline 2375 & Bromus arvensis L. & Debrecen & 1980 & Siroki Zoltán & DE-siroki-02165.jpg \\
\hline 2375 & Bromus arvensis L. & Hortobágy & 1975 & Siroki Zoltán & DE-siroki-02166.jpg \\
\hline 2375 & Bromus arvensis L. & Pomáz & 1954 & Siroki Zoltán & DE-siroki-02172.jpg \\
\hline 2376 & Bromus japonicus Thunb. & Budapest & 1951 & Siroki Zoltán & DE-siroki-02243.jpg \\
\hline 2376 & Bromus japonicus Thunb. & Debrecen & 1947 & Siroki Zoltán & DE-siroki-02242.jpg \\
\hline 2376 & Bromus japonicus Thunb. & Debrecen & 1947 & Siroki Zoltán & DE-siroki-02244.jpg \\
\hline 2376 & Bromus japonicus Thunb. & Debrecen & 1947 & Siroki Zoltán & DE-siroki-02241.jpg \\
\hline 2376 & Bromus japonicus Thunb. & Debrecen & 1948 & Siroki Zoltán & DE-siroki-02247.jpg \\
\hline 2376 & Bromus japonicus Thunb. & Egyek & 1947 & Siroki Zoltán & DE-siroki-02245.jpg \\
\hline 2376 & Bromus japonicus Thunb. & Egyek & 1947 & Siroki Zoltán & DE-siroki-02246.jpg \\
\hline 2376 & Bromus japonicus Thunb. & Hortobágy & 1975 & Siroki Zoltán & DE-siroki-02248.jpg \\
\hline 2376 & Bromus japonicus Thunb. & Mosonmagyaróvár & 1939 & Siroki Zoltán & DE-siroki-02239.jpg \\
\hline
\end{tabular}




\begin{tabular}{|c|c|c|c|c|c|}
\hline $\begin{array}{l}\text { Sorszám / } \\
\text { Number }\end{array}$ & Taxon-név / Taxon-name & $\begin{array}{l}\text { Település / } \\
\text { Settlement }\end{array}$ & $\begin{array}{l}\text { Év / } \\
\text { Year }\end{array}$ & $\begin{array}{l}\text { Gyűjtő / } \\
\text { Collector }\end{array}$ & Fájlnév / File-name \\
\hline 2378 & Bromus commutatus Schrad. & "Bükk-hg." & 1983 & Siroki Zoltán & DE-siroki-02210.jpg \\
\hline 2378 & Bromus commutatus Schrad. & Budapest & 1951 & Siroki Zoltán & DE-siroki-02163.jpg \\
\hline 2378 & Bromus commutatus Schrad. & Debrecen & 1947 & Siroki Zoltán & DE-siroki-02216.jpg \\
\hline 2378 & Bromus commutatus Schrad. & Debrecen & 1947 & Siroki Zoltán & DE-siroki-02213.jpg \\
\hline 2378 & Bromus commutatus Schrad. & Debrecen & 1947 & Siroki Zoltán & DE-siroki-02215.jpg \\
\hline 2378 & Bromus commutatus Schrad. & Debrecen & 1947 & Siroki Zoltán & DE-siroki-02217.jpg \\
\hline 2378 & Bromus commutatus Schrad. & Debrecen & 1947 & Siroki Zoltán & DE-siroki-02214.jpg \\
\hline 2378 & Bromus commutatus Schrad. & Debrecen & 1947 & Siroki Zoltán & DE-siroki-02202.jpg \\
\hline 2378 & Bromus commutatus Schrad. & Debrecen & 1947 & Siroki Zoltán & DE-siroki-02205.jpg \\
\hline 2378 & Bromus commutatus Schrad. & Debrecen & 1947 & Siroki Zoltán & DE-siroki-02206.jpg \\
\hline 2378 & Bromus commutatus Schrad. & Debrecen & 1947 & Siroki Zoltán & DE-siroki-02203.jpg \\
\hline 2378 & Bromus commutatus Schrad. & Debrecen & 1950 & Siroki Zoltán & DE-siroki-02204.jpg \\
\hline 2378 & Bromus commutatus Schrad. & Debrecen & 1965 & Siroki Zoltán & DE-siroki-02208.jpg \\
\hline 2378 & Bromus commutatus Schrad. & Debrecen & 1965 & Siroki Zoltán & DE-siroki-02207.jpg \\
\hline 2378 & Bromus commutatus Schrad. & Hortobágy & 1975 & Siroki Zoltán & DE-siroki-02209.jpg \\
\hline 2378 & Bromus commutatus Schrad. & Nagyrozvágy & 1943 & Siroki Zoltán & DE-siroki-02212.jpg \\
\hline 2379 & Bromus inermis Leyss. & Debrecen & 1947 & Siroki Zoltán & DE-siroki-02262.jpg \\
\hline 2379 & Bromus inermis Leyss. & Debrecen & 1947 & Siroki Zoltán & DE-siroki-02261.jpg \\
\hline 2379 & Bromus inermis Leyss. & Debrecen & 1947 & Siroki Zoltán & DE-siroki-02265.jpg \\
\hline 2379 & Bromus inermis Leyss. & Debrecen & 1974 & Siroki Zoltán & DE-siroki-02260.jpg \\
\hline 2380 & Bromus erectus Huds. & Budapest & 1951 & Siroki Zoltán & DE-siroki-02277.jpg \\
\hline 2380 & Bromus erectus Huds. & Budapest & 1962 & Siroki Zoltán & DE-siroki-02282.jpg \\
\hline 2380 & Bromus erectus Huds. & Budapest & 1962 & Siroki Zoltán & DE-siroki-02283.jpg \\
\hline 2380 & Bromus erectus Huds. & Budapest & 1962 & Siroki Zoltán & DE-siroki-02284.jpg \\
\hline 2380 & Bromus erectus Huds. & Budapest & 1962 & Siroki Zoltán & DE-siroki-02285.jpg \\
\hline 2380 & Bromus erectus Huds. & Budapest & 1962 & Siroki Zoltán & DE-siroki-02286.jpg \\
\hline 2380 & Bromus erectus Huds. & Debrecen & 1959 & Siroki Zoltán & DE-siroki-02280.jpg \\
\hline 2380 & Bromus erectus Huds. & Debrecen & 1959 & Siroki Zoltán & DE-siroki-02279.jpg \\
\hline 2380 & Bromus erectus Huds. & Egyek & 1949 & Siroki Zoltán & DE-siroki-02275.jpg \\
\hline 2380 & Bromus erectus Huds. & Egyek & 1949 & Siroki Zoltán & DE-siroki-02272.jpg \\
\hline 2380 & Bromus erectus Huds. & Egyek & 1949 & Siroki Zoltán & DE-siroki-02278.jpg \\
\hline 2380 & Bromus erectus Huds. & Egyek & 1949 & Siroki Zoltán & DE-siroki-02281.jpg \\
\hline 2383 & Bromus ramosus Huds. & "Nagymező" & 1959 & Siroki Zoltán & DE-siroki-02251.jpg \\
\hline 2383 & Bromus ramosus Huds. & Debrecen & 1947 & Siroki Zoltán & DE-siroki-02252.jpg \\
\hline 2383 & Bromus ramosus Huds. & Debrecen & 1948 & Siroki Zoltán & DE-siroki-02255.jpg \\
\hline 2383 & Bromus ramosus Huds. & Debrecen & 1948 & Siroki Zoltán & DE-siroki-02249.jpg \\
\hline 2383 & Bromus ramosus Huds. & Debrecen & 1948 & Siroki Zoltán & DE-siroki-02250.jpg \\
\hline 2383 & Bromus ramosus Huds. & Debrecen & 1948 & Siroki Zoltán & DE-siroki-02253.jpg \\
\hline 2383 & Bromus ramosus Huds. & Debrecen & 1948 & Siroki Zoltán & DE-siroki-02254.jpg \\
\hline 2387 & Bromus sterilis L. & Debrecen & 1947 & Siroki Zoltán & DE-siroki-02293.jpg \\
\hline 2387 & Bromus sterilis L. & Debrecen & 1947 & Siroki Zoltán & DE-siroki-02294.jpg \\
\hline 2387 & Bromus sterilis L. & Mosonmagyaróvár & 1939 & Siroki Zoltán & DE-siroki-02291.jpg \\
\hline 2387 & Bromus sterilis L. & Mosonmagyaróvár & 1939 & Siroki Zoltán & DE-siroki-02292.jpg \\
\hline 2388 & Bromus tectorum L. & Abaújkér & 1942 & Siroki Zoltán & DE-siroki-02298.jpg \\
\hline 2388 & Bromus tectorum L. & Debrecen & 1947 & Siroki Zoltán & DE-siroki-02295.jpg \\
\hline 2388 & Bromus tectorum L. & Debrecen & 1947 & Siroki Zoltán & DE-siroki-02296.jpg \\
\hline
\end{tabular}




\begin{tabular}{|c|c|c|c|c|c|}
\hline $\begin{array}{l}\text { Sorszám / } \\
\text { Number }\end{array}$ & Taxon-név / Taxon-name & $\begin{array}{l}\text { Település / } \\
\text { Settlement }\end{array}$ & $\begin{array}{l}\text { Év / } \\
\text { Year }\end{array}$ & $\begin{array}{l}\text { Gyűjtő / } \\
\text { Collector }\end{array}$ & Fájlnév / File-name \\
\hline 2388 & Bromus tectorum L. & Debrecen & 1947 & Siroki Zoltán & DE-siroki-02297.jpg \\
\hline 2389 & $\begin{array}{l}\text { Brachypodium sylvaticum } \\
\text { (Huds.) P. Beauv. }\end{array}$ & "Vértes" & 1957 & Siroki Zoltán & DE-siroki-02302.jpg \\
\hline 2389 & $\begin{array}{l}\text { Brachypodium sylvaticum } \\
\text { (Huds.) P. Beauv. }\end{array}$ & "Vértes" & 1957 & Siroki Zoltán & DE-siroki-02303.jpg \\
\hline 2389 & $\begin{array}{l}\text { Brachypodium sylvaticum } \\
\text { (Huds.) P. Beauv. }\end{array}$ & "Vértes" & 1957 & Siroki Zoltán & DE-siroki-02304.jpg \\
\hline 2389 & $\begin{array}{l}\text { Brachypodium sylvaticum } \\
\text { (Huds.) P. Beauv. }\end{array}$ & "Vértes" & 1957 & Siroki Zoltán & DE-siroki-02305.jpg \\
\hline 2389 & $\begin{array}{l}\text { Brachypodium sylvaticum } \\
\text { (Huds.) P. Beauv. }\end{array}$ & Budaörs & 1984 & Siroki Zoltán & DE-siroki-02312.jpg \\
\hline 2389 & $\begin{array}{l}\text { Brachypodium sylvaticum } \\
\text { (Huds.) P. Beauv. }\end{array}$ & Debrecen & 1947 & Siroki Zoltán & DE-siroki-02308.jpg \\
\hline 2389 & $\begin{array}{l}\text { Brachypodium sylvaticum } \\
\text { (Huds.) P. Beauv. }\end{array}$ & Debrecen & 1947 & Siroki Zoltán & DE-siroki-02309.jpg \\
\hline 2389 & $\begin{array}{l}\text { Brachypodium sylvaticum } \\
\text { (Huds.) P. Beauv. }\end{array}$ & Debrecen & 1954 & Siroki Zoltán & DE-siroki-02306.jpg \\
\hline 2389 & $\begin{array}{l}\text { Brachypodium sylvaticum } \\
\text { (Huds.) P. Beauv. }\end{array}$ & Debrecen & 1954 & Siroki Zoltán & DE-siroki-02307.jpg \\
\hline 2389 & $\begin{array}{l}\text { Brachypodium sylvaticum } \\
\text { (Huds.) P. Beauv. }\end{array}$ & Egyek & 1959 & Siroki Zoltán & DE-siroki-02300.jpg \\
\hline 2389 & $\begin{array}{l}\text { Brachypodium sylvaticum } \\
\text { (Huds.) P. Beauv. }\end{array}$ & Egyek & 1959 & Siroki Zoltán & DE-siroki-02301.jpg \\
\hline 2389 & $\begin{array}{l}\text { Brachypodium sylvaticum } \\
\text { (Huds.) P. Beauv. }\end{array}$ & Gödöllő & 1952 & Siroki Zoltán & DE-siroki-02310.jpg \\
\hline 2389 & $\begin{array}{l}\text { Brachypodium sylvaticum } \\
\text { (Huds.) P. Beauv. }\end{array}$ & Mosonmagyaróvár & 1939 & Siroki Zoltán & DE-siroki-02313.jpg \\
\hline 2390 & Brachypodium pinnatum (L.) P. Beauv. & "Mátra" & 1984 & Siroki Zoltán & DE-siroki-02328.jpg \\
\hline 2390 & Brachypodium pinnatum (L.) P. Beauv. & "Mátra" & 1984 & Siroki Zoltán & DE-siroki-02327.jpg \\
\hline 2390 & Brachypodium pinnatum (L.) P. Beauv. & "Nagymező" & 1959 & Siroki Zoltán & DE-siroki-02316.jpg \\
\hline 2390 & Brachypodium pinnatum (L.) P. Beauv. & "Nagymező" & 1959 & Siroki Zoltán & DE-siroki-02317.jpg \\
\hline 2390 & Brachypodium pinnatum (L.) P. Beauv. & "Nagymező" & 1959 & Siroki Zoltán & DE-siroki-02318.jpg \\
\hline 2390 & Brachypodium pinnatum (L.) P. Beauv. & "Nagymező" & 1959 & Siroki Zoltán & DE-siroki-02320.jpg \\
\hline 2390 & Brachypodium pinnatum (L.) P. Beauv. & "Nagymező" & 1959 & Siroki Zoltán & DE-siroki-02322.jpg \\
\hline 2390 & Brachypodium pinnatum (L.) P. Beauv. & Budapest & 1941 & Siroki Zoltán & DE-siroki-02323.jpg \\
\hline 2390 & Brachypodium pinnatum (L.) P. Beauv. & Budapest & 1941 & Siroki Zoltán & DE-siroki-02325.jpg \\
\hline 2390 & Brachypodium pinnatum (L.) P. Beauv. & Szilvásvárad & 1959 & Siroki Zoltán & DE-siroki-02315.jpg \\
\hline 2390 & Brachypodium pinnatum (L.) P. Beauv. & Szilvásvárad & 1959 & Siroki Zoltán & DE-siroki-02319.jpg \\
\hline 2390 & Brachypodium pinnatum (L.) P. Beauv. & Szilvásvárad & 1959 & Siroki Zoltán & DE-siroki-02321.jpg \\
\hline 2393 & Elymus caninus (L.) L. & Debrecen & 1947 & Siroki Zoltán & DE-siroki-02422.jpg \\
\hline 2393 & Elymus caninus (L.) L. & Egyek & 1959 & Siroki Zoltán & DE-siroki-02423.jpg \\
\hline 2393 & Elymus caninus (L.) L. & Egyek & 1959 & Siroki Zoltán & DE-siroki-02424.jpg \\
\hline 2393 & Elymus caninus (L.) L. & Egyek & 1959 & Siroki Zoltán & DE-siroki-02425.jpg \\
\hline 2394 & Elymus elongatus (Host) Runemark & Hortobágy & 1973 & Siroki Zoltán & DE-siroki-02401.jpg \\
\hline 2394 & Elymus elongatus (Host) Runemark & Hortobágy & 1973 & Siroki Zoltán & DE-siroki-02402.jpg \\
\hline 2394 & Elymus elongatus (Host) Runemark & Hortobágy & 1973 & Siroki Zoltán & DE-siroki-02403.jpg \\
\hline 2394 & Elymus elongatus (Host) Runemark & Hortobágy & 1973 & Siroki Zoltán & DE-siroki-02404.jpg \\
\hline 2394 & Elymus elongatus (Host) Runemark & Hortobágy & 1973 & Siroki Zoltán & DE-siroki-02405.jpg \\
\hline 2394 & Elymus elongatus (Host) Runemark & Hortobágy & 1973 & Siroki Zoltán & DE-siroki-02406.jpg \\
\hline 2394 & Elymus elongatus (Host) Runemark & Hortobágy & 1973 & Siroki Zoltán & DE-siroki-02407.jpg \\
\hline 2394 & Elymus elongatus (Host) Runemark & Hortobágy & 1973 & Siroki Zoltán & DE-siroki-02408.jpg \\
\hline 2395 & Elymus repens (L.) Gould & Debrecen & 1947 & Siroki Zoltán & DE-siroki-02416.jpg \\
\hline 2395 & Elymus repens (L.) Gould & Debrecen & 1947 & Siroki Zoltán & DE-siroki-02419.jpg \\
\hline
\end{tabular}




\begin{tabular}{|c|c|c|c|c|c|}
\hline $\begin{array}{l}\text { Sorszám / } \\
\text { Number }\end{array}$ & Taxon-név / Taxon-name & $\begin{array}{l}\text { Település / } \\
\text { Settlement }\end{array}$ & $\begin{array}{l}\text { Év / } \\
\text { Year }\end{array}$ & $\begin{array}{l}\text { Gyűjtő / } \\
\text { Collector }\end{array}$ & Fájlnév / File-name \\
\hline 2395 & Elymus repens (L.) Gould & Debrecen & 1949 & Siroki Zoltán & DE-siroki-02409.jpg \\
\hline 2395 & Elymus repens (L.) Gould & Debrecen & 1949 & Siroki Zoltán & DE-siroki-02410.jpg \\
\hline 2395 & Elymus repens (L.) Gould & Debrecen & 1949 & Siroki Zoltán & DE-siroki-02417.jpg \\
\hline 2395 & Elymus repens (L.) Gould & Debrecen & 1949 & Siroki Zoltán & DE-siroki-02418.jpg \\
\hline 2395 & Elymus repens (L.) Gould & Debrecen & 1957 & Siroki Zoltán & DE-siroki-02415.jpg \\
\hline 2395 & Elymus repens (L.) Gould & Debrecen & 1957 & Siroki Zoltán & DE-siroki-02420.jpg \\
\hline 2395 & Elymus repens (L.) Gould & Debrecen & 1958 & Siroki Zoltán & DE-siroki-02413.jpg \\
\hline 2395 & Elymus repens (L.) Gould & Egyek & 1959 & Siroki Zoltán & DE-siroki-02421.jpg \\
\hline 2396 & Elymus hispidus (Opiz) Melderis & Debrecen & 1947 & Siroki Zoltán & DE-siroki-02441.jpg \\
\hline 2396 & Elymus hispidus (Opiz) Melderis & Debrecen & 1947 & Siroki Zoltán & DE-siroki-02445.jpg \\
\hline 2396 & Elymus hispidus (Opiz) Melderis & Debrecen & 1959 & Siroki Zoltán & DE-siroki-02438.jpg \\
\hline 2396 & Elymus hispidus (Opiz) Melderis & Debrecen & 1959 & Siroki Zoltán & DE-siroki-02446.jpg \\
\hline 2396 & Elymus hispidus (Opiz) Melderis & Debrecen & 1959 & Siroki Zoltán & DE-siroki-02447.jpg \\
\hline 2396 & Elymus hispidus (Opiz) Melderis & Debrecen & 1959 & Siroki Zoltán & DE-siroki-02448.jpg \\
\hline 2396 & Elymus hispidus (Opiz) Melderis & Debrecen & 1959 & Siroki Zoltán & DE-siroki-02449.jpg \\
\hline 2396 & Elymus hispidus (Opiz) Melderis & Debrecen & 1959 & Siroki Zoltán & DE-siroki-02434.jpg \\
\hline 2396 & Elymus hispidus (Opiz) Melderis & Debrecen & 1959 & Siroki Zoltán & DE-siroki-02435.jpg \\
\hline 2396 & Elymus hispidus (Opiz) Melderis & Debrecen & 1959 & Siroki Zoltán & DE-siroki-02436.jpg \\
\hline 2396 & Elymus hispidus (Opiz) Melderis & Debrecen & 1959 & Siroki Zoltán & DE-siroki-02437.jpg \\
\hline 2396 & Elymus hispidus (Opiz) Melderis & Pomáz & 1957 & Siroki Zoltán & DE-siroki-02439.jpg \\
\hline 2396 & Elymus hispidus (Opiz) Melderis & Szilvásvárad & 1959 & Siroki Zoltán & DE-siroki-02443.jpg \\
\hline 2396 & Elymus hispidus (Opiz) Melderis & Szilvásvárad & 1959 & Siroki Zoltán & DE-siroki-02444.jpg \\
\hline 2396 & Elymus hispidus (Opiz) Melderis & Szilvásvárad & 1959 & Siroki Zoltán & DE-siroki-02442.jpg \\
\hline 2397 & Agropyron cristatum (L.) Gaertn. & Boldogkőváralja & 1967 & Siroki Zoltán & DE-siroki-02381.jpg \\
\hline 2397 & Agropyron cristatum (L.) Gaertn. & Budapest & 1944 & Siroki Zoltán & DE-siroki-02390.jpg \\
\hline 2397 & Agropyron cristatum (L.) Gaertn. & Budapest & 1944 & Siroki Zoltán & DE-siroki-02391.jpg \\
\hline 2397 & Agropyron cristatum (L.) Gaertn. & Debrecen & 1947 & Siroki Zoltán & DE-siroki-02380.jpg \\
\hline 2397 & Agropyron cristatum (L.) Gaertn. & Debrecen & 1948 & Siroki Zoltán & DE-siroki-02386.jpg \\
\hline 2397 & Agropyron cristatum (L.) Gaertn. & Debrecen & 1948 & Siroki Zoltán & DE-siroki-02385.jpg \\
\hline 2397 & Agropyron cristatum (L.) Gaertn. & Debrecen & 1948 & Siroki Zoltán & DE-siroki-02387.jpg \\
\hline 2397 & Agropyron cristatum (L.) Gaertn. & Debrecen & 1970 & Pethő Menyhért & DE-siroki-02378.jpg \\
\hline 2397 & Agropyron cristatum (L.) Gaertn. & Hajdúböszörmény & 1963 & Siroki Zoltán & DE-siroki-02382.jpg \\
\hline 2397 & Agropyron cristatum (L.) Gaertn. & Hajdúböszörmény & 1963 & Siroki Zoltán & DE-siroki-02383.jpg \\
\hline 2397 & Agropyron cristatum (L.) Gaertn. & Hajdúböszörmény & 1963 & Siroki Zoltán & DE-siroki-02384.jpg \\
\hline 2397 & Agropyron cristatum (L.) Gaertn. & Hortobágy & 1957 & Siroki Zoltán & DE-siroki-02379.jpg \\
\hline 2397 & Agropyron cristatum (L.) Gaertn. & Hortobágy & 1957 & Siroki Zoltán & DE-siroki-02388.jpg \\
\hline 2397 & Agropyron cristatum (L.) Gaertn. & Hortobágy & 1957 & Siroki Zoltán & DE-siroki-02389.jpg \\
\hline 2398 & Aegilops cylindrica Host & Budapest & 1951 & Siroki Zoltán & DE-siroki-02478.jpg \\
\hline 2398 & Aegilops cylindrica Host & Bugac & 1960 & Siroki Zoltán & DE-siroki-02469.jpg \\
\hline 2398 & Aegilops cylindrica Host & Bugac & 1960 & Siroki Zoltán & DE-siroki-02470.jpg \\
\hline 2398 & Aegilops cylindrica Host & Debrecen & 1964 & Siroki Zoltán & DE-siroki-02473.jpg \\
\hline 2398 & Aegilops cylindrica Host & Egyek & 1948 & Siroki Zoltán & DE-siroki-02477.jpg \\
\hline 2398 & Aegilops cylindrica Host & Egyek & 1948 & Siroki Zoltán & DE-siroki-02474.jpg \\
\hline 2398 & Aegilops cylindrica Host & Egyek & 1948 & Siroki Zoltán & DE-siroki-02475.jpg \\
\hline 2398 & Aegilops cylindrica Host & Egyek & 1948 & Siroki Zoltán & DE-siroki-02476.jpg \\
\hline 2398 & Aegilops cylindrica Host & Egyek & 1948 & Siroki Zoltán & DE-siroki-02472.jpg \\
\hline
\end{tabular}




\begin{tabular}{|c|c|c|c|c|c|}
\hline $\begin{array}{l}\text { Sorszám / } \\
\text { Number }\end{array}$ & Taxon-név / Taxon-name & $\begin{array}{l}\text { Település / } \\
\text { Settlement }\end{array}$ & $\begin{array}{l}\text { Év / } \\
\text { Year }\end{array}$ & $\begin{array}{l}\text { Gyújtő / } \\
\text { Collector }\end{array}$ & Fájlnév / File-name \\
\hline 2398 & Aegilops cylindrica Host & Tiszafüred & 1955 & Siroki Zoltán & DE-siroki-02471.jpg \\
\hline 2402 & Dasypyrum villosum (L.) P. Candargy & Budapest & 1951 & $\begin{array}{l}\text { Priszter } \\
\text { Szaniszló }\end{array}$ & DE-siroki-02452.jpg \\
\hline 2403 & Secale cereale L. & Debrecen & 1970 & Siroki Zoltán & DE-siroki-02454.jpg \\
\hline 2403 & Secale cereale L. & Debrecen & 1970 & Siroki Zoltán & DE-siroki-02455.jpg \\
\hline 2403 & Secale cereale L. & Debrecen & 1970 & Siroki Zoltán & DE-siroki-02456.jpg \\
\hline 2403 & Secale cereale L. & Debrecen & 1970 & Siroki Zoltán & DE-siroki-02457.jpg \\
\hline 2404 & Secale sylvestre Host & Ágasegyháza & 1960 & Siroki Zoltán & DE-siroki-02462.jpg \\
\hline 2404 & Secale sylvestre Host & Ágasegyháza & 1960 & Siroki Zoltán & DE-siroki-02463.jpg \\
\hline 2404 & Secale sylvestre Host & Ágasegyháza & 1971 & Siroki Zoltán & DE-siroki-02461.jpg \\
\hline 2404 & Secale sylvestre Host & Bugac & 1965 & Siroki Zoltán & DE-siroki-02465.jpg \\
\hline 2404 & Secale sylvestre Host & Bugac & 1965 & Siroki Zoltán & DE-siroki-02466.jpg \\
\hline 2404 & Secale sylvestre Host & Bugac & 1965 & Siroki Zoltán & DE-siroki-02467.jpg \\
\hline 2404 & Secale sylvestre Host & Bugac & 1965 & Siroki Zoltán & DE-siroki-02468.jpg \\
\hline 2404 & Secale sylvestre Host & Gödöllő & 1951 & Siroki Zoltán & DE-siroki-02460.jpg \\
\hline 2404 & Secale sylvestre Host & Gödöllő & 1951 & Siroki Zoltán & DE-siroki-02464.jpg \\
\hline 2405 & Hordeum jubatum L. & Debrecen & 1946 & Siroki Zoltán & DE-siroki-02519.jpg \\
\hline 2405 & Hordeum jubatum L. & Debrecen & 1948 & Siroki Zoltán & DE-siroki-02518.jpg \\
\hline 2407 & Hordeum vulgare L. & Budapest & 1951 & Siroki Zoltán & DE-siroki-02500.jpg \\
\hline 2410 & Hordeum hystrix Roth & Biharugra & 1961 & Siroki Zoltán & DE-siroki-02521.jpg \\
\hline 2410 & Hordeum hystrix Roth & Budapest & 1951 & Siroki Zoltán & DE-siroki-02528.jpg \\
\hline 2410 & Hordeum hystrix Roth & Budapest & 1951 & Siroki Zoltán & DE-siroki-02529.jpg \\
\hline 2410 & Hordeum hystrix Roth & Debrecen & 1947 & Siroki Zoltán & DE-siroki-02530.jpg \\
\hline 2410 & Hordeum hystrix Roth & Debrecen & 1947 & Siroki Zoltán & DE-siroki-02520.jpg \\
\hline 2410 & Hordeum hystrix Roth & Debrecen & 1947 & Siroki Zoltán & DE-siroki-02522.jpg \\
\hline 2410 & Hordeum hystrix Roth & Egyek & 1947 & Siroki Zoltán & DE-siroki-02527.jpg \\
\hline 2410 & Hordeum hystrix Roth & Mikepércs & 1966 & Siroki Zoltán & DE-siroki-02523.jpg \\
\hline 2410 & Hordeum hystrix Roth & Mikepércs & 1966 & Siroki Zoltán & DE-siroki-02524.jpg \\
\hline 2410 & Hordeum hystrix Roth & Mikepércs & 1966 & Siroki Zoltán & DE-siroki-02525.jpg \\
\hline 2410 & Hordeum hystrix Roth & Mikepércs & 1966 & Siroki Zoltán & DE-siroki-02526.jpg \\
\hline 2412 & $\begin{array}{l}\text { Hordelymus europaeus } \\
\text { (L.) Less. ex Harz }\end{array}$ & "Bükk-hg." & 1983 & Siroki Zoltán & DE-siroki-02545.jpg \\
\hline 2412 & $\begin{array}{l}\text { Hordelymus europaeus } \\
\text { (L.) Less. ex Harz }\end{array}$ & "Bükk-hg." & 1983 & Siroki Zoltán & DE-siroki-02546.jpg \\
\hline 2412 & $\begin{array}{l}\text { Hordelymus europaeus } \\
\text { (L.) Less. ex Harz }\end{array}$ & "Dobogókő" & 1956 & Siroki Zoltán & DE-siroki-02542.jpg \\
\hline 2412 & $\begin{array}{l}\text { Hordelymus europaeus } \\
\text { (L.) Less. ex Harz }\end{array}$ & "Dobogókő" & 1957 & Siroki Zoltán & DE-siroki-02541.jpg \\
\hline 2412 & $\begin{array}{l}\text { Hordelymus europaeus } \\
\text { (L.) Less. ex Harz }\end{array}$ & "Dobogókő" & 1957 & Siroki Zoltán & DE-siroki-02543.jpg \\
\hline 2412 & $\begin{array}{l}\text { Hordelymus europaeus } \\
\text { (L.) Less. ex Harz }\end{array}$ & "Nagymező" & 1968 & Siroki Zoltán & DE-siroki-02544.jpg \\
\hline 2412 & $\begin{array}{l}\text { Hordelymus europaeus } \\
\text { (L.) Less. ex Harz }\end{array}$ & Budapest & 1951 & Siroki Zoltán & DE-siroki-02539.jpg \\
\hline 2412 & $\begin{array}{l}\text { Hordelymus europaeus } \\
\text { (L.) Less. ex Harz }\end{array}$ & Budapest & 1951 & Siroki Zoltán & DE-siroki-02540.jpg \\
\hline 2412 & $\begin{array}{l}\text { Hordelymus europaeus } \\
\text { (L.) Less. ex Harz }\end{array}$ & Budapest & 1951 & Siroki Zoltán & DE-siroki-02547.jpg \\
\hline 2412 & $\begin{array}{l}\text { Hordelymus europaeus } \\
\text { (L.) Less. ex Harz }\end{array}$ & Budapest & 1951 & Siroki Zoltán & DE-siroki-02548.jpg \\
\hline 2412 & $\begin{array}{l}\text { Hordelymus europaeus } \\
\text { (L.) Less. ex Harz }\end{array}$ & Budapest & 1951 & Siroki Zoltán & DE-siroki-02549.jpg \\
\hline 2418 & Avena fatua $L$. & Budapest & 1951 & Siroki Zoltán & DE-siroki-01495.jpg \\
\hline
\end{tabular}




\begin{tabular}{|c|c|c|c|c|c|}
\hline $\begin{array}{l}\text { Sorszám / } \\
\text { Number }\end{array}$ & Taxon-név / Taxon-name & $\begin{array}{l}\text { Település / } \\
\text { Settlement }\end{array}$ & $\begin{array}{l}\text { Év / } \\
\text { Year }\end{array}$ & $\begin{array}{l}\text { Gyűjtő / } \\
\text { Collector }\end{array}$ & Fájlnév / File-name \\
\hline 2418 & Avena fatua $L$. & Debrecen & 1947 & Siroki Zoltán & DE-siroki-01497.jpg \\
\hline 2418 & Avena fatua $L$. & Debrecen & 1970 & Siroki Zoltán & DE-siroki-01493.jpg \\
\hline 2418 & Avena fatua L. & Debrecen & 1970 & Siroki Zoltán & DE-siroki-01492.jpg \\
\hline 2418 & Avena fatua L. & Debrecen & 1970 & Siroki Zoltán & DE-siroki-01498.jpg \\
\hline 2418 & Avena fatua $L$. & Debrecen & 1970 & Siroki Zoltán & DE-siroki-01499.jpg \\
\hline 2418 & Avena fatua L. & Debrecen & 1970 & Siroki Zoltán & DE-siroki-01500.jpg \\
\hline 2418 & Avena fatua L. & Debrecen & 1970 & Siroki Zoltán & DE-siroki-01501.jpg \\
\hline 2418 & Avena fatua $L$. & Debrecen & 1970 & Siroki Zoltán & DE-siroki-01502.jpg \\
\hline 2418 & Avena fatua $L$. & Debrecen & 1970 & Siroki Zoltán & DE-siroki-01503.jpg \\
\hline 2418 & Avena fatua $L$. & Pásztó & 1959 & Gondola István & DE-siroki-01504.jpg \\
\hline 2420 & Helictotrichon pubescens (Huds.) Pilg. & "Nagymező" & 1959 & Halász Tibor & DE-siroki-01505.jpg \\
\hline 2420 & Helictotrichon pubescens (Huds.) Pilg. & "Nagymező" & 1959 & Halász Tibor & DE-siroki-01506.jpg \\
\hline 2420 & Helictotrichon pubescens (Huds.) Pilg. & Budapest & 1951 & Siroki Zoltán & DE-siroki-01509.jpg \\
\hline 2420 & Helictotrichon pubescens (Huds.) Pilg. & Debrecen & 1950 & Siroki Zoltán & DE-siroki-01507.jpg \\
\hline 2420 & Helictotrichon pubescens (Huds.) Pilg. & Debrecen & 1950 & Siroki Zoltán & DE-siroki-01508.jpg \\
\hline 2421 & $\begin{array}{l}\text { Helictotrichon compressum } \\
\text { (Heuff.) Henrard }\end{array}$ & Pomáz & 1952 & Siroki Zoltán & DE-siroki-01516.jpg \\
\hline 2423 & Helictotrichon pratense (L.) Besser & Budapest & 1951 & Siroki Zoltán & DE-siroki-01543.jpg \\
\hline 2423 & Helictotrichon pratense (L.) Besser & Budapest & 1951 & Siroki Zoltán & DE-siroki-01544.jpg \\
\hline 2423 & Helictotrichon pratense (L.) Besser & Budapest & 1951 & Siroki Zoltán & DE-siroki-01545.jpg \\
\hline 2423 & Helictotrichon pratense (L.) Besser & Budapest & 1952 & Siroki Zoltán & DE-siroki-01539.jpg \\
\hline 2423 & Helictotrichon pratense (L.) Besser & Budapest & 1981 & Siroki Zoltán & DE-siroki-01532.jpg \\
\hline 2423 & Helictotrichon pratense (L.) Besser & Budapest & 1981 & Siroki Zoltán & DE-siroki-01533.jpg \\
\hline 2423 & Helictotrichon pratense (L.) Besser & Budapest & 1981 & Siroki Zoltán & DE-siroki-01535.jpg \\
\hline 2423 & Helictotrichon pratense (L.) Besser & Gödöllő & 1952 & Siroki Zoltán & DE-siroki-01538.jpg \\
\hline 2423 & Helictotrichon pratense (L.) Besser & Gödöllő & 1952 & Siroki Zoltán & DE-siroki-01540.jpg \\
\hline 2423 & Helictotrichon pratense (L.) Besser & Gödöllő & 1952 & Siroki Zoltán & DE-siroki-01542.jpg \\
\hline 2423 & Helictotrichon pratense (L.) Besser & Gödöllő & 1952 & Siroki Zoltán & DE-siroki-01541.jpg \\
\hline 2423 & Helictotrichon pratense (L.) Besser & Háromhuta & 1967 & Siroki Zoltán & DE-siroki-01530.jpg \\
\hline 2423 & Helictotrichon pratense (L.) Besser & Háromhuta & 1967 & Siroki Zoltán & DE-siroki-01531.jpg \\
\hline 2423 & Helictotrichon pratense (L.) Besser & Háromhuta & 1967 & Siroki Zoltán & DE-siroki-01534.jpg \\
\hline 2423 & Helictotrichon pratense (L.) Besser & Háromhuta & 1967 & Siroki Zoltán & DE-siroki-01536.jpg \\
\hline 2423 & Helictotrichon pratense (L.) Besser & Háromhuta & 1967 & Siroki Zoltán & DE-siroki-01537.jpg \\
\hline 2423 & Helictotrichon pratense (L.) Besser & Nyíracsád & 1985 & Siroki Zoltán & DE-siroki-01524.jpg \\
\hline 2423 & Helictotrichon pratense (L.) Besser & Nyíracsád & 1985 & Siroki Zoltán & DE-siroki-01525.jpg \\
\hline 2423 & Helictotrichon pratense (L.) Besser & Nyíracsád & 1985 & Siroki Zoltán & DE-siroki-01526.jpg \\
\hline 2423 & Helictotrichon pratense (L.) Besser & Nyíracsád & 1985 & Siroki Zoltán & DE-siroki-01527.jpg \\
\hline 2423 & Helictotrichon pratense (L.) Besser & Nyíracsád & 1985 & Siroki Zoltán & DE-siroki-01528.jpg \\
\hline 2423 & Helictotrichon pratense (L.) Besser & Nyíracsád & 1985 & Siroki Zoltán & DE-siroki-01529.jpg \\
\hline 2424 & $\begin{array}{l}\text { Arrhenatherum elatius } \\
\text { (L.) P. Beauv. ex J. Presl et C. Presl }\end{array}$ & Debrecen & 1948 & Siroki Zoltán & DE-siroki-01547.jpg \\
\hline 2424 & $\begin{array}{l}\text { Arrhenatherum elatius } \\
\text { (L.) P. Beauv. ex J. Presl et C. Presl }\end{array}$ & Debrecen & 1954 & Siroki Zoltán & DE-siroki-01548.jpg \\
\hline 2424 & $\begin{array}{l}\text { Arrhenatherum elatius } \\
\text { (L.) P. Beauv. ex J. Presl et C. Presl }\end{array}$ & Debrecen & 1954 & Siroki Zoltán & DE-siroki-01549.jpg \\
\hline 2424 & $\begin{array}{l}\text { Arrhenatherum elatius } \\
\text { (L.) P. Beauv. ex J. Presl et C. Presl }\end{array}$ & Debrecen & 1974 & Siroki Zoltán & DE-siroki-01546.jpg \\
\hline 2425 & Gaudinia fragilis (L.) P. Beauv. & Bejcgyertyános & 1956 & Pénzes Antal & DE-siroki-01553.jpg \\
\hline 2426 & Ventenata dubia (Leers) Coss. & Csaroda & 1960 & Siroki Zoltán & DE-siroki-01471.jpg \\
\hline
\end{tabular}




\begin{tabular}{|c|c|c|c|c|c|}
\hline $\begin{array}{l}\text { Sorszám / } \\
\text { Number }\end{array}$ & Taxon-név / Taxon-name & $\begin{array}{l}\text { Település / } \\
\text { Settlement }\end{array}$ & $\begin{array}{l}\text { Év / } \\
\text { Year }\end{array}$ & $\begin{array}{l}\text { Gyűjtő / } \\
\text { Collector }\end{array}$ & Fájlnév / File-name \\
\hline 2426 & Ventenata dubia (Leers) Coss. & Csaroda & 1960 & Siroki Zoltán & DE-siroki-01472.jpg \\
\hline 2426 & Ventenata dubia (Leers) Coss. & Csaroda & 1960 & Siroki Zoltán & DE-siroki-01475.jpg \\
\hline 2426 & Ventenata dubia (Leers) Coss. & Csaroda & 1960 & Siroki Zoltán & DE-siroki-01476.jpg \\
\hline 2426 & Ventenata dubia (Leers) Coss. & Hortobágy & 1956 & Siroki Zoltán & DE-siroki-01477.jpg \\
\hline 2426 & Ventenata dubia (Leers) Coss. & Hortobágy & 1956 & Siroki Zoltán & DE-siroki-01479.jpg \\
\hline 2426 & Ventenata dubia (Leers) Coss. & Hortobágy & 1956 & Siroki Zoltán & DE-siroki-01481.jpg \\
\hline 2426 & Ventenata dubia (Leers) Coss. & Hortobágy & 1956 & Siroki Zoltán & DE-siroki-01482.jpg \\
\hline 2426 & Ventenata dubia (Leers) Coss. & Hortobágy & 1956 & Siroki Zoltán & DE-siroki-01483.jpg \\
\hline 2426 & Ventenata dubia (Leers) Coss. & Hortobágy & 1956 & Siroki Zoltán & DE-siroki-01484.jpg \\
\hline 2426 & Ventenata dubia (Leers) Coss. & Hortobágy & 1956 & Siroki Zoltán & DE-siroki-01485.jpg \\
\hline 2426 & Ventenata dubia (Leers) Coss. & Hortobágy & 1961 & Siroki Zoltán & DE-siroki-01473.jpg \\
\hline 2426 & Ventenata dubia (Leers) Coss. & Sopron & 1950 & Kárpáti Zoltán & DE-siroki-01478.jpg \\
\hline 2426 & Ventenata dubia (Leers) Coss. & Szentistván & 1980 & Siroki Zoltán & DE-siroki-01474.jpg \\
\hline 2427 & Koeleria glauca (Spreng.) DC. & Ágasegyháza & 1969 & Siroki Zoltán & DE-siroki-01781.jpg \\
\hline 2427 & Koeleria glauca (Spreng.) DC. & Ágasegyháza & 1971 & Siroki Zoltán & DE-siroki-01774.jpg \\
\hline 2427 & Koeleria glauca (Spreng.) DC. & Ágasegyháza & 1971 & Siroki Zoltán & DE-siroki-01775.jpg \\
\hline 2427 & Koeleria glauca (Spreng.) DC. & Ágasegyháza & 1971 & Siroki Zoltán & DE-siroki-01782.jpg \\
\hline 2427 & Koeleria glauca (Spreng.) DC. & Ágasegyháza & 1971 & Siroki Zoltán & DE-siroki-01783.jpg \\
\hline 2427 & Koeleria glauca (Spreng.) DC. & Budapest & 1889 & Czakó Kálmán & DE-siroki-01786.jpg \\
\hline 2427 & Koeleria glauca (Spreng.) DC. & Budapest & 1899 & Degen Árpád & DE-siroki-01771.jpg \\
\hline 2427 & Koeleria glauca (Spreng.) DC. & Budapest & 1903 & Kocsis István & DE-siroki-01787.jpg \\
\hline 2427 & Koeleria glauca (Spreng.) DC. & Budapest & 1909 & Kocsis István & DE-siroki-01772.jpg \\
\hline 2427 & Koeleria glauca (Spreng.) DC. & Debrecen & 1951 & Siroki Zoltán & DE-siroki-01776.jpg \\
\hline 2427 & Koeleria glauca (Spreng.) DC. & Debrecen & 1951 & Siroki Zoltán & DE-siroki-01784.jpg \\
\hline 2427 & Koeleria glauca (Spreng.) DC. & Debrecen & 1951 & Siroki Zoltán & DE-siroki-01779.jpg \\
\hline 2427 & Koeleria glauca (Spreng.) DC. & Debrecen & 1951 & Siroki Zoltán & DE-siroki-01780.jpg \\
\hline 2427 & Koeleria glauca (Spreng.) DC. & Pilisszentiván & 1906 & Kocsis István & DE-siroki-01770.jpg \\
\hline 2427 & Koeleria glauca (Spreng.) DC. & Szarvaskő & 1957 & Siroki Zoltán & DE-siroki-01778.jpg \\
\hline 2430 & $\begin{array}{l}\text { Koeleria cristata } \\
\text { (L.) Pers. em. Borbás ex Domin }\end{array}$ & "Nagymező" & 1959 & Siroki Zoltán & DE-siroki-01822.jpg \\
\hline 2430 & $\begin{array}{l}\text { Koeleria cristata } \\
\text { (L.) Pers. em. Borbás ex Domin }\end{array}$ & Boldogkőváralja & 1967 & Siroki Zoltán & DE-siroki-01819.jpg \\
\hline 2430 & $\begin{array}{l}\text { Koeleria cristata } \\
\text { (L.) Pers. em. Borbás ex Domin }\end{array}$ & Boldogkőváralja & 1967 & Siroki Zoltán & DE-siroki-01821.jpg \\
\hline 2430 & $\begin{array}{l}\text { Koeleria cristata } \\
\text { (L.) Pers. em. Borbás ex Domin }\end{array}$ & Boldogkőváralja & 1967 & Siroki Zoltán & DE-siroki-01837.jpg \\
\hline 2430 & $\begin{array}{l}\text { Koeleria cristata } \\
\text { (L.) Pers. em. Borbás ex Domin }\end{array}$ & Boldogkőváralja & 1967 & Siroki Zoltán & DE-siroki-01838.jpg \\
\hline 2430 & $\begin{array}{l}\text { Koeleria cristata } \\
\text { (L.) Pers. em. Borbás ex Domin }\end{array}$ & Boldogkőváralja & 1967 & Siroki Zoltán & DE-siroki-01839.jpg \\
\hline 2430 & $\begin{array}{l}\text { Koeleria cristata } \\
\text { (L.) Pers. em. Borbás ex Domin }\end{array}$ & Budaörs & 1964 & Siroki Zoltán & DE-siroki-01810.jpg \\
\hline 2430 & $\begin{array}{l}\text { Koeleria cristata } \\
\text { (L.) Pers. em. Borbás ex Domin }\end{array}$ & Budaörs & 1964 & Siroki Zoltán & DE-siroki-01820.jpg \\
\hline 2430 & $\begin{array}{l}\text { Koeleria cristata } \\
\text { (L.) Pers. em. Borbás ex Domin }\end{array}$ & Debrecen & 1947 & Siroki Zoltán & DE-siroki-01826.jpg \\
\hline 2430 & $\begin{array}{l}\text { Koeleria cristata } \\
\text { (L.) Pers. em. Borbás ex Domin }\end{array}$ & Debrecen & 1947 & Siroki Zoltán & DE-siroki-01825.jpg \\
\hline 2430 & $\begin{array}{l}\text { Koeleria cristata } \\
\text { (L.) Pers. em. Borbás ex Domin }\end{array}$ & Debrecen & 1948 & Siroki Zoltán & DE-siroki-01831.jpg \\
\hline 2430 & $\begin{array}{l}\text { Koeleria cristata } \\
\text { (L.) Pers. em. Borbás ex Domin }\end{array}$ & Debrecen & 1950 & Siroki Zoltán & DE-siroki-01811.jpg \\
\hline 2430 & Koeleria cristata & Debrecen & 1950 & Siroki Zoltán & DE-siroki-01824.jpg \\
\hline
\end{tabular}




\begin{tabular}{|c|c|c|c|c|c|}
\hline $\begin{array}{l}\text { Sorszám / } \\
\text { Number }\end{array}$ & Taxon-név / Taxon-name & $\begin{array}{l}\text { Település / } \\
\text { Settlement }\end{array}$ & $\begin{array}{l}\text { Év / } \\
\text { Year }\end{array}$ & $\begin{array}{l}\text { Gyűjtő / } \\
\text { Collector }\end{array}$ & Fájlnév / File-name \\
\hline & (L.) Pers. em. Borbás ex Domin & & & & \\
\hline 2430 & $\begin{array}{l}\text { Koeleria cristata } \\
\text { (L.) Pers. em. Borbás ex Domin }\end{array}$ & Debrecen & 1950 & Siroki Zoltán & DE-siroki-01832.jpg \\
\hline 2430 & $\begin{array}{l}\text { Koeleria cristata } \\
\text { (L.) Pers. em. Borbás ex Domin }\end{array}$ & Debrecen & 1951 & Siroki Zoltán & DE-siroki-01816.jpg \\
\hline 2430 & $\begin{array}{l}\text { Koeleria cristata } \\
\text { (L.) Pers. em. Borbás ex Domin }\end{array}$ & Debrecen & 1951 & Siroki Zoltán & DE-siroki-01817.jpg \\
\hline 2430 & $\begin{array}{l}\text { Koeleria cristata } \\
\text { (L.) Pers. em. Borbás ex Domin }\end{array}$ & Debrecen & 1951 & Siroki Zoltán & DE-siroki-01818.jpg \\
\hline 2430 & $\begin{array}{l}\text { Koeleria cristata } \\
\text { (L.) Pers. em. Borbás ex Domin }\end{array}$ & Debrecen & 1959 & Siroki Zoltán & DE-siroki-01833.jpg \\
\hline 2430 & $\begin{array}{l}\text { Koeleria cristata } \\
\text { (L.) Pers. em. Borbás ex Domin }\end{array}$ & Debrecen & 1959 & Siroki Zoltán & DE-siroki-01835.jpg \\
\hline 2430 & $\begin{array}{l}\text { Koeleria cristata } \\
\text { (L.) Pers. em. Borbás ex Domin }\end{array}$ & Debrecen & 1959 & Siroki Zoltán & DE-siroki-01836.jpg \\
\hline 2430 & $\begin{array}{l}\text { Koeleria cristata } \\
\text { (L.) Pers. em. Borbás ex Domin }\end{array}$ & Gödöllő & 1953 & Máthé Imre & DE-siroki-01815.jpg \\
\hline 2430 & $\begin{array}{l}\text { Koeleria cristata } \\
\text { (L.) Pers. em. Borbás ex Domin }\end{array}$ & Gödöllő & 1953 & Máthé Imre & DE-siroki-01814.jpg \\
\hline 2430 & $\begin{array}{l}\text { Koeleria cristata } \\
\text { (L.) Pers. em. Borbás ex Domin }\end{array}$ & Háromhuta & 1961 & Siroki Zoltán & DE-siroki-01834.jpg \\
\hline 2430 & $\begin{array}{l}\text { Koeleria cristata } \\
\text { (L.) Pers. em. Borbás ex Domin }\end{array}$ & Háromhuta & 1961 & Siroki Zoltán & DE-siroki-01823.jpg \\
\hline 2430 & $\begin{array}{l}\text { Koeleria cristata } \\
\text { (L.) Pers. em. Borbás ex Domin }\end{array}$ & Nyíracsád & 1985 & Siroki Zoltán & DE-siroki-01807.jpg \\
\hline 2430 & $\begin{array}{l}\text { Koeleria cristata } \\
\text { (L.) Pers. em. Borbás ex Domin }\end{array}$ & Nyíracsád & 1985 & Siroki Zoltán & DE-siroki-01808.jpg \\
\hline 2430 & $\begin{array}{l}\text { Koeleria cristata } \\
\text { (L.) Pers. em. Borbás ex Domin }\end{array}$ & Nyíracsád & 1985 & Siroki Zoltán & DE-siroki-01809.jpg \\
\hline 2434 & Trisetum flavescens (L.) P. Beauv. & "Nagymező" & 1959 & Siroki Zoltán & DE-siroki-01464.jpg \\
\hline 2434 & Trisetum flavescens (L.) P. Beauv. & "Nagymező" & 1959 & Siroki Zoltán & DE-siroki-01465.jpg \\
\hline 2434 & Trisetum flavescens (L.) P. Beauv. & "Nagymező" & 1960 & Siroki Zoltán & DE-siroki-01454.jpg \\
\hline 2434 & Trisetum flavescens (L.) P. Beauv. & Budapest & 1952 & Siroki Zoltán & DE-siroki-01451.jpg \\
\hline 2434 & Trisetum flavescens (L.) P. Beauv. & Budapest & 1962 & Siroki Zoltán & DE-siroki-01457.jpg \\
\hline 2434 & Trisetum flavescens (L.) P. Beauv. & Budapest & 1962 & Siroki Zoltán & DE-siroki-01458.jpg \\
\hline 2434 & Trisetum flavescens (L.) P. Beauv. & Háromhuta & 1961 & Siroki Zoltán & DE-siroki-01459.jpg \\
\hline 2434 & Trisetum flavescens (L.) P. Beauv. & Háromhuta & 1961 & Siroki Zoltán & DE-siroki-01461.jpg \\
\hline 2434 & Trisetum flavescens (L.) P. Beauv. & Háromhuta & 1961 & Siroki Zoltán & DE-siroki-01462.jpg \\
\hline 2434 & Trisetum flavescens (L.) P. Beauv. & Miskolc & 1959 & Siroki Zoltán & DE-siroki-01456.jpg \\
\hline 2434 & Trisetum flavescens (L.) P. Beauv. & Miskolc & 1959 & Siroki Zoltán & DE-siroki-01463.jpg \\
\hline 2434 & Trisetum flavescens (L.) P. Beauv. & Miskolc & 1960 & Siroki Zoltán & DE-siroki-01449.jpg \\
\hline 2434 & Trisetum flavescens (L.) P. Beauv. & Miskolc & 1960 & Siroki Zoltán & DE-siroki-01450.jpg \\
\hline 2434 & Trisetum flavescens (L.) P. Beauv. & Miskolc & 1960 & Siroki Zoltán & DE-siroki-01455.jpg \\
\hline 2434 & Trisetum flavescens (L.) P. Beauv. & Miskolc & 1960 & Siroki Zoltán & DE-siroki-01460.jpg \\
\hline 2435 & Deschampsia caespitosa (L.) P. Beauv. & Budapest & 1952 & Siroki Zoltán & DE-siroki-01420.jpg \\
\hline 2435 & Deschampsia caespitosa (L.) P. Beauv. & Budapest & 1952 & Siroki Zoltán & DE-siroki-01421.jpg \\
\hline 2435 & Deschampsia caespitosa (L.) P. Beauv. & Debrecen & 1950 & Siroki Zoltán & DE-siroki-01423.jpg \\
\hline 2435 & Deschampsia caespitosa (L.) P. Beauv. & Debrecen & 1950 & Siroki Zoltán & DE-siroki-01424.jpg \\
\hline 2435 & Deschampsia caespitosa (L.) P. Beauv. & Debrecen & 1950 & Siroki Zoltán & DE-siroki-01425.jpg \\
\hline 2435 & Deschampsia caespitosa (L.) P. Beauv. & Debrecen & 1950 & Siroki Zoltán & DE-siroki-01437.jpg \\
\hline 2435 & Deschampsia caespitosa (L.) P. Beauv. & Debrecen & 1950 & Siroki Zoltán & DE-siroki-01438.jpg \\
\hline 2435 & Deschampsia caespitosa (L.) P. Beauv. & Debrecen & 1950 & Siroki Zoltán & DE-siroki-01439.jpg \\
\hline 2435 & Deschampsia caespitosa (L.) P. Beauv. & Debrecen & 1957 & Siroki Zoltán & DE-siroki-01433.jpg \\
\hline 2435 & Deschampsia caespitosa (L.) P. Beauv. & Debrecen & 1957 & Siroki Zoltán & DE-siroki-01422.jpg \\
\hline
\end{tabular}




\begin{tabular}{|c|c|c|c|c|c|}
\hline $\begin{array}{l}\text { Sorszám / } \\
\text { Number }\end{array}$ & Taxon-név / Taxon-name & $\begin{array}{l}\text { Település / } \\
\text { Settlement }\end{array}$ & $\begin{array}{l}\text { Év / } \\
\text { Year }\end{array}$ & $\begin{array}{l}\text { Gyűjtő / } \\
\text { Collector }\end{array}$ & Fájlnév / File-name \\
\hline 2435 & Deschampsia caespitosa (L.) P. Beauv. & Debrecen & 1957 & Siroki Zoltán & DE-siroki-01435.jpg \\
\hline 2435 & Deschampsia caespitosa (L.) P. Beauv. & Háromhuta & 1967 & Siroki Zoltán & DE-siroki-01427.jpg \\
\hline 2435 & Deschampsia caespitosa (L.) P. Beauv. & Háromhuta & 1967 & Siroki Zoltán & DE-siroki-01428.jpg \\
\hline 2435 & Deschampsia caespitosa (L.) P. Beauv. & Háromhuta & 1967 & Siroki Zoltán & DE-siroki-01434.jpg \\
\hline 2435 & Deschampsia caespitosa (L.) P. Beauv. & Háromhuta & 1967 & Siroki Zoltán & DE-siroki-01436.jpg \\
\hline 2435 & Deschampsia caespitosa (L.) P. Beauv. & Pilismarót & 1963 & Siroki Zoltán & DE-siroki-01418.jpg \\
\hline 2435 & Deschampsia caespitosa (L.) P. Beauv. & Pilismarót & 1963 & Siroki Zoltán & DE-siroki-01419.jpg \\
\hline 2435 & Deschampsia caespitosa (L.) P. Beauv. & Pilismarót & 1963 & Siroki Zoltán & DE-siroki-01429.jpg \\
\hline 2435 & Deschampsia caespitosa (L.) P. Beauv. & Rakaca & 1983 & Siroki Zoltán & DE-siroki-01441.jpg \\
\hline 2435 & Deschampsia caespitosa (L.) P. Beauv. & Rezi & 1983 & Siroki Zoltán & DE-siroki-01444.jpg \\
\hline 2435 & Deschampsia caespitosa (L.) P. Beauv. & Túristvándi & 1975 & Siroki Zoltán & DE-siroki-01440.jpg \\
\hline 2435 & Deschampsia caespitosa (L.) P. Beauv. & Túristvándi & 1975 & Siroki Zoltán & DE-siroki-01443.jpg \\
\hline 2435 & Deschampsia caespitosa (L.) P. Beauv. & Vámospércs & 1984 & Siroki Zoltán & DE-siroki-01442.jpg \\
\hline 2435 & Deschampsia caespitosa (L.) P. Beauv. & Vámospércs & 1985 & Siroki Zoltán & DE-siroki-11233.jpg \\
\hline 2436 & Deschampsia flexuosa (L.) Trin. & Szilvásvárad & 1954 & Siroki Zoltán & DE-siroki-01404.jpg \\
\hline 2436 & Deschampsia flexuosa (L.) Trin. & Szilvásvárad & 1954 & Siroki Zoltán & DE-siroki-01406.jpg \\
\hline 2436 & Deschampsia flexuosa (L.) Trin. & Szilvásvárad & 1954 & Siroki Zoltán & DE-siroki-01403.jpg \\
\hline 2436 & Deschampsia flexuosa (L.) Trin. & Szilvásvárad & 1954 & Siroki Zoltán & DE-siroki-01407.jpg \\
\hline 2436 & Deschampsia flexuosa (L.) Trin. & Szilvásvárad & 1954 & Siroki Zoltán & DE-siroki-01408.jpg \\
\hline 2436 & Deschampsia flexuosa (L.) Trin. & Szilvásvárad & 1954 & Siroki Zoltán & DE-siroki-01399.jpg \\
\hline 2436 & Deschampsia flexuosa (L.) Trin. & Szilvásvárad & 1954 & Siroki Zoltán & DE-siroki-01402.jpg \\
\hline 2436 & Deschampsia flexuosa (L.) Trin. & Szilvásvárad & 1954 & Siroki Zoltán & DE-siroki-01405.jpg \\
\hline 2437 & Aira elegantissima Schur & Budapest & 1951 & Révy Dezső & DE-siroki-01390.jpg \\
\hline 2437 & Aira elegantissima Schur & Budapest & 1951 & Révy Dezső & DE-siroki-01391.jpg \\
\hline 2437 & Aira elegantissima Schur & Budapest & 1951 & Révy Dezső & DE-siroki-01392.jpg \\
\hline 2437 & Aira elegantissima Schur & Budapest & 1951 & Siroki Zoltán & DE-siroki-01393.jpg \\
\hline 2437 & Aira elegantissima Schur & Budapest & 1951 & Siroki Zoltán & DE-siroki-01397.jpg \\
\hline 2437 & Aira elegantissima Schur & Budapest & 1951 & Siroki Zoltán & DE-siroki-01394.jpg \\
\hline 2437 & Aira elegantissima Schur & Budapest & 1951 & Siroki Zoltán & DE-siroki-01395.jpg \\
\hline 2437 & Aira elegantissima Schur & Sopron & 1950 & Kárpáti Zoltán & DE-siroki-01396.jpg \\
\hline 2438 & Aira caryophyllea L. & Sopron & 1950 & Kárpáti Zoltán & DE-siroki-01398.jpg \\
\hline 2439 & $\begin{array}{l}\text { Hierochloë australis } \\
\text { (Schrad.) Roem. et Schult. }\end{array}$ & Gyenesdiás & 1953 & Siroki Zoltán & DE-siroki-00926.jpg \\
\hline 2439 & $\begin{array}{l}\text { Hierochloë australis } \\
\text { (Schrad.) Roem. et Schult. }\end{array}$ & Gyenesdiás & 1953 & Siroki Zoltán & DE-siroki-00923.jpg \\
\hline 2439 & $\begin{array}{l}\text { Hierochloë australis } \\
\text { (Schrad.) Roem. et Schult. }\end{array}$ & Gyenesdiás & 1953 & Siroki Zoltán & DE-siroki-00924.jpg \\
\hline 2439 & $\begin{array}{l}\text { Hierochloë australis } \\
\text { (Schrad.) Roem. et Schult. }\end{array}$ & Gyenesdiás & 1953 & Siroki Zoltán & DE-siroki-00925.jpg \\
\hline 2439 & $\begin{array}{l}\text { Hierochloë australis } \\
\text { (Schrad.) Roem. et Schult. }\end{array}$ & Gyenesdiás & 1972 & Siroki Zoltán & DE-siroki-00921.jpg \\
\hline 2439 & $\begin{array}{l}\text { Hierochloë australis } \\
\text { (Schrad.) Roem. et Schult. }\end{array}$ & Gyenesdiás & 1972 & Siroki Zoltán & DE-siroki-00922.jpg \\
\hline 2440 & Hierochloë repens (Host) P. Beauv. & Debrecen & 1947 & Siroki Zoltán & DE-siroki-00909.jpg \\
\hline 2440 & Hierochloë repens (Host) P. Beauv. & Debrecen & 1947 & Siroki Zoltán & DE-siroki-00920.jpg \\
\hline 2440 & Hierochloë repens (Host) P. Beauv. & Debrecen & 1950 & Siroki Zoltán & DE-siroki-00910.jpg \\
\hline 2440 & Hierochloë repens (Host) P. Beauv. & Debrecen & 1950 & Siroki Zoltán & DE-siroki-00919.jpg \\
\hline 2440 & Hierochloë repens (Host) P. Beauv. & Debrecen & 1950 & Siroki Zoltán & DE-siroki-00911.jpg \\
\hline 2440 & Hierochloë repens (Host) P. Beauv. & Debrecen & 1958 & Siroki Zoltán & DE-siroki-00912.jpg \\
\hline 2440 & Hierochloë repens (Host) P. Beauv. & Debrecen & 1965 & Siroki Zoltán & DE-siroki-00917.jpg \\
\hline
\end{tabular}




\begin{tabular}{|c|c|c|c|c|c|}
\hline $\begin{array}{l}\text { Sorszám / } \\
\text { Number }\end{array}$ & Taxon-név / Taxon-name & $\begin{array}{l}\text { Település / } \\
\text { Settlement }\end{array}$ & $\begin{array}{l}\text { Év / } \\
\text { Year }\end{array}$ & $\begin{array}{l}\text { Gyűjtő / } \\
\text { Collector }\end{array}$ & Fájlnév / File-name \\
\hline 2440 & Hierochloë repens (Host) P. Beauv. & Debrecen & 1966 & Siroki Zoltán & DE-siroki-00913.jpg \\
\hline 2440 & Hierochloë repens (Host) P. Beauv. & Debrecen & 1966 & Siroki Zoltán & DE-siroki-00914.jpg \\
\hline 2440 & Hierochloë repens (Host) P. Beauv. & Debrecen & 1966 & Siroki Zoltán & DE-siroki-00915.jpg \\
\hline 2440 & Hierochloë repens (Host) P. Beauv. & Debrecen & 1984 & Siroki Zoltán & DE-siroki-00916.jpg \\
\hline 2440 & Hierochloë repens (Host) P. Beauv. & Gödöllő & 1952 & Siroki Zoltán & DE-siroki-00918.jpg \\
\hline 2441 & Anthoxanthum odoratum L. & Debrecen & 1947 & Siroki Zoltán & DE-siroki-00882.jpg \\
\hline 2441 & Anthoxanthum odoratum L. & Debrecen & 1947 & Siroki Zoltán & DE-siroki-00883.jpg \\
\hline 2441 & Anthoxanthum odoratum L. & Debrecen & 1947 & Siroki Zoltán & DE-siroki-00884.jpg \\
\hline 2441 & Anthoxanthum odoratum L. & Debrecen & 1948 & Siroki Zoltán & DE-siroki-00878.jpg \\
\hline 2441 & Anthoxanthum odoratum L. & Debrecen & 1981 & Siroki Zoltán & DE-siroki-00876.jpg \\
\hline 2441 & Anthoxanthum odoratum L. & Debrecen & 1981 & Siroki Zoltán & DE-siroki-00877.jpg \\
\hline 2443 & Holcus lanatus L. & Debrecen & 1948 & Siroki Zoltán & DE-siroki-01353.jpg \\
\hline 2443 & Holcus lanatus L. & Debrecen & 1948 & Siroki Zoltán & DE-siroki-01355.jpg \\
\hline 2443 & Holcus lanatus L. & Debrecen & 1948 & Siroki Zoltán & DE-siroki-01356.jpg \\
\hline 2443 & Holcus lanatus L. & Debrecen & 1950 & Siroki Zoltán & DE-siroki-01354.jpg \\
\hline 2443 & Holcus lanatus L. & Debrecen & 1950 & Siroki Zoltán & DE-siroki-01367.jpg \\
\hline 2443 & Holcus lanatus L. & Mosonmagyaróvár & 1939 & Siroki Zoltán & DE-siroki-01365.jpg \\
\hline 2443 & Holcus lanatus L. & Mosonmagyaróvár & 1939 & Siroki Zoltán & DE-siroki-01368.jpg \\
\hline 2443 & Holcus lanatus L. & Nagyhuta & 1961 & Siroki Zoltán & DE-siroki-01359.jpg \\
\hline 2443 & Holcus lanatus L. & Szilvásvárad & 1954 & Siroki Zoltán & DE-siroki-01352.jpg \\
\hline 2443 & Holcus lanatus L. & Újléta & 1965 & Siroki Zoltán & DE-siroki-01360.jpg \\
\hline 2443 & Holcus lanatus L. & Újléta & 1967 & Siroki Zoltán & DE-siroki-01361.jpg \\
\hline 2443 & Holcus lanatus L. & Újléta & 1967 & Siroki Zoltán & DE-siroki-01362.jpg \\
\hline 2443 & Holcus lanatus L. & Vámospércs & 1965 & Siroki Zoltán & DE-siroki-01363.jpg \\
\hline 2443 & Holcus lanatus L. & Vámospércs & 1965 & Siroki Zoltán & DE-siroki-01364.jpg \\
\hline 2445 & Corynephorus canescens (L.) P. Beauv. & Darány & 1955 & Kovács Margit & DE-siroki-01371.jpg \\
\hline 2445 & Corynephorus canescens (L.) P. Beauv. & Debrecen & 1950 & Siroki Zoltán & DE-siroki-01387.jpg \\
\hline 2445 & Corynephorus canescens (L.) P. Beauv. & Debrecen & 1950 & Siroki Zoltán & DE-siroki-01388.jpg \\
\hline 2445 & Corynephorus canescens (L.) P. Beauv. & Debrecen & 1950 & Siroki Zoltán & DE-siroki-01383.jpg \\
\hline 2445 & Corynephorus canescens (L.) P. Beauv. & Debrecen & 1951 & Siroki Zoltán & DE-siroki-01386.jpg \\
\hline 2445 & Corynephorus canescens (L.) P. Beauv. & Debrecen & 1951 & Siroki Zoltán & DE-siroki-01389.jpg \\
\hline 2445 & Corynephorus canescens (L.) P. Beauv. & Debrecen & 1954 & Siroki Zoltán & DE-siroki-01374.jpg \\
\hline 2445 & Corynephorus canescens (L.) P. Beauv. & Debrecen & 1954 & Siroki Zoltán & DE-siroki-01375.jpg \\
\hline 2445 & Corynephorus canescens (L.) P. Beauv. & Debrecen & 1954 & Siroki Zoltán & DE-siroki-01376.jpg \\
\hline 2445 & Corynephorus canescens (L.) P. Beauv. & Debrecen & 1954 & Siroki Zoltán & DE-siroki-01377.jpg \\
\hline 2445 & Corynephorus canescens (L.) P. Beauv. & Debrecen & 1954 & Siroki Zoltán & DE-siroki-01378.jpg \\
\hline 2445 & Corynephorus canescens (L.) P. Beauv. & Debrecen & 1977 & Siroki Zoltán & DE-siroki-01372.jpg \\
\hline 2445 & Corynephorus canescens (L.) P. Beauv. & Debrecen & 1977 & Siroki Zoltán & DE-siroki-01373.jpg \\
\hline 2445 & Corynephorus canescens (L.) P. Beauv. & Debrecen & 1977 & Siroki Zoltán & DE-siroki-01380.jpg \\
\hline 2445 & Corynephorus canescens (L.) P. Beauv. & Debrecen & 1977 & Siroki Zoltán & DE-siroki-01381.jpg \\
\hline 2445 & Corynephorus canescens (L.) P. Beauv. & Debrecen & - & Siroki Zoltán & DE-siroki-01385.jpg \\
\hline 2445 & Corynephorus canescens (L.) P. Beauv. & Vámospércs & 1984 & Siroki Zoltán & DE-siroki-01369.jpg \\
\hline 2445 & Corynephorus canescens (L.) P. Beauv. & Vámospércs & 1984 & Siroki Zoltán & DE-siroki-01379.jpg \\
\hline 2445 & Corynephorus canescens (L.) P. Beauv. & Vámospércs & 1984 & Siroki Zoltán & DE-siroki-01382.jpg \\
\hline 2445 & Corynephorus canescens (L.) P. Beauv. & Vámospércs & 1984 & Siroki Zoltán & DE-siroki-01384.jpg \\
\hline 2446 & Agrostis capillaris L. & "Nagymező" & 1959 & Siroki Zoltán & DE-siroki-01160.jpg \\
\hline
\end{tabular}




\begin{tabular}{|c|c|c|c|c|c|}
\hline $\begin{array}{l}\text { Sorszám / } \\
\text { Number }\end{array}$ & Taxon-név / Taxon-name & $\begin{array}{l}\text { Település / } \\
\text { Settlement }\end{array}$ & $\begin{array}{l}\text { Év / } \\
\text { Year }\end{array}$ & $\begin{array}{l}\text { Gyűjtő / } \\
\text { Collector }\end{array}$ & Fájlnév / File-name \\
\hline 2446 & Agrostis capillaris L. & "Nagymező" & 1959 & Siroki Zoltán & DE-siroki-01166.jpg \\
\hline 2446 & Agrostis capillaris L. & "Nagymező" & 1959 & Siroki Zoltán & DE-siroki-01168.jpg \\
\hline 2446 & Agrostis capillaris L. & "Nagymező" & 1959 & Siroki Zoltán & DE-siroki-01169.jpg \\
\hline 2446 & Agrostis capillaris L. & Budapest & 1951 & Siroki Zoltán & DE-siroki-01170.jpg \\
\hline 2446 & Agrostis capillaris L. & Budapest & 1951 & Siroki Zoltán & DE-siroki-01171.jpg \\
\hline 2446 & Agrostis capillaris L. & Háromhuta & 1961 & Siroki Zoltán & DE-siroki-01163.jpg \\
\hline 2446 & Agrostis capillaris L. & Háromhuta & 1961 & Siroki Zoltán & DE-siroki-01175.jpg \\
\hline 2446 & Agrostis capillaris L. & Háromhuta & 1965 & Siroki Zoltán & DE-siroki-01162.jpg \\
\hline 2446 & Agrostis capillaris L. & Háromhuta & 1965 & Siroki Zoltán & DE-siroki-01164.jpg \\
\hline 2446 & Agrostis capillaris L. & Háromhuta & 1965 & Siroki Zoltán & DE-siroki-01167.jpg \\
\hline 2446 & Agrostis capillaris L. & Háromhuta & 1968 & Siroki Zoltán & DE-siroki-01161.jpg \\
\hline 2446 & Agrostis capillaris L. & Mátraszentimre & 1959 & Gondola István & DE-siroki-01158.jpg \\
\hline 2446 & Agrostis capillaris L. & Mátraszentimre & 1959 & Gondola István & DE-siroki-01159.jpg \\
\hline 2446 & Agrostis capillaris L. & Piliscsév & 1900 & Degen Árpád & DE-siroki-01156.jpg \\
\hline $2447-2450$ & Agrostis stolonifera agg. & "Mátra" & 1984 & Siroki Zoltán & DE-siroki-01183.jpg \\
\hline $2447-2450$ & Agrostis stolonifera agg. & "Mátra" & 1984 & Siroki Zoltán & DE-siroki-01184.jpg \\
\hline $2447-2450$ & Agrostis stolonifera agg. & "Mátra" & 1984 & Siroki Zoltán & DE-siroki-01201.jpg \\
\hline $2447-2450$ & Agrostis stolonifera agg. & "Mátra" & 1984 & Siroki Zoltán & DE-siroki-01202.jpg \\
\hline $2447-2450$ & Agrostis stolonifera agg. & Budapest & 1941 & Siroki Zoltán & DE-siroki-01194.jpg \\
\hline $2447-2450$ & Agrostis stolonifera agg. & Budapest & 1951 & Siroki Zoltán & DE-siroki-01192.jpg \\
\hline $2447-2450$ & Agrostis stolonifera agg. & Budapest & 1952 & Siroki Zoltán & DE-siroki-01196.jpg \\
\hline $2447-2450$ & Agrostis stolonifera agg. & Debrecen & 1947 & Siroki Zoltán & DE-siroki-01182.jpg \\
\hline $2447-2450$ & Agrostis stolonifera agg. & Debrecen & 1948 & Siroki Zoltán & DE-siroki-01189.jpg \\
\hline $2447-2450$ & Agrostis stolonifera agg. & Debrecen & 1948 & Siroki Zoltán & DE-siroki-01176.jpg \\
\hline $2447-2450$ & Agrostis stolonifera agg. & Debrecen & 1948 & Siroki Zoltán & DE-siroki-01180.jpg \\
\hline $2447-2450$ & Agrostis stolonifera agg. & Debrecen & 1950 & Siroki Zoltán & DE-siroki-01178.jpg \\
\hline $2447-2450$ & Agrostis stolonifera agg. & Debrecen & 1950 & Siroki Zoltán & DE-siroki-01191.jpg \\
\hline $2447-2450$ & Agrostis stolonifera agg. & Debrecen & 1950 & Siroki Zoltán & DE-siroki-01188.jpg \\
\hline $2447-2450$ & Agrostis stolonifera agg. & Debrecen & 1950 & Siroki Zoltán & DE-siroki-01193.jpg \\
\hline $2447-2450$ & Agrostis stolonifera agg. & Debrecen & 1950 & Siroki Zoltán & DE-siroki-01177.jpg \\
\hline $2447-2450$ & Agrostis stolonifera agg. & Debrecen & 1950 & Siroki Zoltán & DE-siroki-01179.jpg \\
\hline $2447-2450$ & Agrostis stolonifera agg. & Debrecen & 1950 & Siroki Zoltán & DE-siroki-01190.jpg \\
\hline $2447-2450$ & Agrostis stolonifera agg. & Debrecen & 1981 & Siroki Zoltán & DE-siroki-01203.jpg \\
\hline $2447-2450$ & Agrostis stolonifera agg. & Debrecen & 1981 & Siroki Zoltán & DE-siroki-01204.jpg \\
\hline $2447-2450$ & Agrostis stolonifera agg. & Debrecen & 1981 & Siroki Zoltán & DE-siroki-01205.jpg \\
\hline $2447-2450$ & Agrostis stolonifera agg. & Debrecen & 1984 & Siroki Zoltán & DE-siroki-01185.jpg \\
\hline $2447-2450$ & Agrostis stolonifera agg. & Debrecen & 1985 & Siroki Zoltán & DE-siroki-01200.jpg \\
\hline $2447-2450$ & Agrostis stolonifera agg. & Gödöllő & 1952 & Siroki Zoltán & DE-siroki-01181.jpg \\
\hline $2447-2450$ & Agrostis stolonifera agg. & Háromhuta & 1962 & Siroki Zoltán & DE-siroki-01129.jpg \\
\hline $2447-2450$ & Agrostis stolonifera agg. & Háromhuta & 1962 & Siroki Zoltán & DE-siroki-01132.jpg \\
\hline $2447-2450$ & Agrostis stolonifera agg. & Háromhuta & 1962 & Siroki Zoltán & DE-siroki-01133.jpg \\
\hline $2447-2450$ & Agrostis stolonifera agg. & Háromhuta & 1967 & Siroki Zoltán & DE-siroki-01186.jpg \\
\hline $2447-2450$ & Agrostis stolonifera agg. & Háromhuta & 1967 & Siroki Zoltán & DE-siroki-01187.jpg \\
\hline $2447-2450$ & Agrostis stolonifera agg. & Háromhuta & 1984 & Siroki Zoltán & DE-siroki-01126.jpg \\
\hline $2447-2450$ & Agrostis stolonifera agg. & Nyírábrány & 1977 & Siroki Zoltán & DE-siroki-01266.jpg \\
\hline $2447-2450$ & Agrostis stolonifera agg. & Nyírábrány & 1977 & Siroki Zoltán & DE-siroki-01267.jpg \\
\hline
\end{tabular}




\begin{tabular}{|c|c|c|c|c|c|}
\hline $\begin{array}{l}\text { Sorszám / } \\
\text { Number }\end{array}$ & Taxon-név / Taxon-name & $\begin{array}{l}\text { Település / } \\
\text { Settlement }\end{array}$ & $\begin{array}{l}\text { Év / } \\
\text { Year }\end{array}$ & $\begin{array}{l}\text { Gyújtő / } \\
\text { Collector }\end{array}$ & Fájlnév / File-name \\
\hline $2447-2450$ & Agrostis stolonifera agg. & Nyírábrány & 1977 & Siroki Zoltán & DE-siroki-01268.jpg \\
\hline $2447-2450$ & Agrostis stolonifera agg. & Nyírábrány & 1977 & Siroki Zoltán & DE-siroki-01269.jpg \\
\hline $2447-2450$ & Agrostis stolonifera agg. & Szada & 1952 & Siroki Zoltán & DE-siroki-01128.jpg \\
\hline 2451 & Calamagrostis stricta (Timm) Koeler & Debrecen & 1950 & Siroki Zoltán & DE-siroki-01235.jpg \\
\hline 2451 & Calamagrostis stricta (Timm) Koeler & Debrecen & 1950 & Siroki Zoltán & DE-siroki-01238.jpg \\
\hline 2451 & Calamagrostis stricta (Timm) Koeler & Debrecen & 1950 & Siroki Zoltán & DE-siroki-01263.jpg \\
\hline 2451 & Calamagrostis stricta (Timm) Koeler & Debrecen & 1951 & Siroki Zoltán & DE-siroki-01232.jpg \\
\hline 2451 & Calamagrostis stricta (Timm) Koeler & Debrecen & 1951 & Siroki Zoltán & DE-siroki-01249.jpg \\
\hline 2451 & Calamagrostis stricta (Timm) Koeler & Debrecen & 1951 & Siroki Zoltán & DE-siroki-01251.jpg \\
\hline 2451 & Calamagrostis stricta (Timm) Koeler & Debrecen & 1951 & Siroki Zoltán & DE-siroki-01234.jpg \\
\hline 2451 & Calamagrostis stricta (Timm) Koeler & Debrecen & 1951 & Siroki Zoltán & DE-siroki-01261.jpg \\
\hline 2451 & Calamagrostis stricta (Timm) Koeler & Debrecen & 1951 & Siroki Zoltán & DE-siroki-01262.jpg \\
\hline 2451 & Calamagrostis stricta (Timm) Koeler & Debrecen & 1954 & Siroki Zoltán & DE-siroki-01260.jpg \\
\hline 2451 & Calamagrostis stricta (Timm) Koeler & Debrecen & 1954 & Siroki Zoltán & DE-siroki-01233.jpg \\
\hline 2451 & Calamagrostis stricta (Timm) Koeler & Debrecen & 1954 & Siroki Zoltán & DE-siroki-01236.jpg \\
\hline 2451 & Calamagrostis stricta (Timm) Koeler & Debrecen & 1954 & Siroki Zoltán & DE-siroki-01239.jpg \\
\hline 2451 & Calamagrostis stricta (Timm) Koeler & Debrecen & 1956 & Siroki Zoltán & DE-siroki-01231.jpg \\
\hline 2451 & Calamagrostis stricta (Timm) Koeler & Debrecen & 1956 & Siroki Zoltán & DE-siroki-01237.jpg \\
\hline 2451 & Calamagrostis stricta (Timm) Koeler & Debrecen & 1974 & $\begin{array}{l}\text { Pankucsi } \\
\text { Lászlóné }\end{array}$ & DE-siroki-01264.jpg \\
\hline 2451 & Calamagrostis stricta (Timm) Koeler & Debrecen & 1974 & $\begin{array}{l}\text { Pankucsi } \\
\text { Lászlóné }\end{array}$ & DE-siroki-01265.jpg \\
\hline 2451 & Calamagrostis stricta (Timm) Koeler & Újléta & 1965 & Siroki Zoltán & DE-siroki-01257.jpg \\
\hline 2451 & Calamagrostis stricta (Timm) Koeler & Újléta & 1965 & Siroki Zoltán & DE-siroki-01258.jpg \\
\hline 2451 & Calamagrostis stricta (Timm) Koeler & Újléta & 1965 & Siroki Zoltán & DE-siroki-01259.jpg \\
\hline 2451 & Calamagrostis stricta (Timm) Koeler & Újléta & 1967 & Siroki Zoltán & DE-siroki-01240.jpg \\
\hline 2451 & Calamagrostis stricta (Timm) Koeler & Újléta & 1967 & Siroki Zoltán & DE-siroki-01241.jpg \\
\hline 2451 & Calamagrostis stricta (Timm) Koeler & Újléta & 1967 & Siroki Zoltán & DE-siroki-01242.jpg \\
\hline 2451 & Calamagrostis stricta (Timm) Koeler & Újléta & 1967 & Siroki Zoltán & DE-siroki-01243.jpg \\
\hline 2451 & Calamagrostis stricta (Timm) Koeler & Újléta & 1967 & Siroki Zoltán & DE-siroki-01244.jpg \\
\hline 2451 & Calamagrostis stricta (Timm) Koeler & Újléta & 1967 & Siroki Zoltán & DE-siroki-01245.jpg \\
\hline 2451 & Calamagrostis stricta (Timm) Koeler & Újléta & 1967 & Siroki Zoltán & DE-siroki-01246.jpg \\
\hline 2451 & Calamagrostis stricta (Timm) Koeler & Újléta & 1967 & Siroki Zoltán & DE-siroki-01247.jpg \\
\hline 2451 & Calamagrostis stricta (Timm) Koeler & Újléta & 1967 & Siroki Zoltán & DE-siroki-01248.jpg \\
\hline 2451 & Calamagrostis stricta (Timm) Koeler & Újléta & 1967 & Siroki Zoltán & DE-siroki-01250.jpg \\
\hline 2451 & Calamagrostis stricta (Timm) Koeler & Újléta & 1967 & Siroki Zoltán & DE-siroki-01252.jpg \\
\hline 2451 & Calamagrostis stricta (Timm) Koeler & Vámospércs & 1965 & Siroki Zoltán & DE-siroki-01253.jpg \\
\hline 2451 & Calamagrostis stricta (Timm) Koeler & Vámospércs & 1965 & Siroki Zoltán & DE-siroki-01254.jpg \\
\hline 2451 & Calamagrostis stricta (Timm) Koeler & Vámospércs & 1965 & Siroki Zoltán & DE-siroki-01255.jpg \\
\hline 2451 & Calamagrostis stricta (Timm) Koeler & Vámospércs & 1965 & Siroki Zoltán & DE-siroki-01256.jpg \\
\hline 2452 & Calamagrostis arundinacea (L.) Roth & "Bükk-hg." & 1983 & Siroki Zoltán & DE-siroki-01206.jpg \\
\hline 2452 & Calamagrostis arundinacea (L.) Roth & "Dobogókő" & 1965 & Siroki Zoltán & DE-siroki-01210.jpg \\
\hline 2452 & Calamagrostis arundinacea (L.) Roth & "Dobogókő" & 1965 & Siroki Zoltán & DE-siroki-01212.jpg \\
\hline 2452 & Calamagrostis arundinacea (L.) Roth & "Dobogókő" & 1965 & Siroki Zoltán & DE-siroki-01214.jpg \\
\hline 2452 & Calamagrostis arundinacea (L.) Roth & "Nagymező" & 1959 & Siroki Zoltán & DE-siroki-01222.jpg \\
\hline 2452 & Calamagrostis arundinacea (L.) Roth & "Nagymező" & 1959 & Siroki Zoltán & DE-siroki-01223.jpg \\
\hline 2452 & Calamagrostis arundinacea (L.) Roth & "Nagymező" & 1968 & Siroki Zoltán & DE-siroki-01207.jpg \\
\hline
\end{tabular}




\begin{tabular}{|c|c|c|c|c|c|}
\hline $\begin{array}{l}\text { Sorszám / } \\
\text { Number }\end{array}$ & Taxon-név / Taxon-name & $\begin{array}{l}\text { Település / } \\
\text { Settlement }\end{array}$ & $\begin{array}{l}\text { Év / } \\
\text { Year }\end{array}$ & $\begin{array}{l}\text { Gyújtő / } \\
\text { Collector }\end{array}$ & Fájlnév / File-name \\
\hline 2452 & Calamagrostis arundinacea (L.) Roth & "Nagymező" & 1968 & Siroki Zoltán & DE-siroki-01209.jpg \\
\hline 2452 & Calamagrostis arundinacea (L.) Roth & "Nagymező" & 1968 & Siroki Zoltán & DE-siroki-01211.jpg \\
\hline 2452 & Calamagrostis arundinacea (L.) Roth & Háromhuta & 1960 & Siroki Zoltán & DE-siroki-01224.jpg \\
\hline 2452 & Calamagrostis arundinacea (L.) Roth & Háromhuta & 1967 & Siroki Zoltán & DE-siroki-01213.jpg \\
\hline 2452 & Calamagrostis arundinacea (L.) Roth & Pásztó & 1952 & Siroki Zoltán & DE-siroki-01221.jpg \\
\hline 2452 & Calamagrostis arundinacea (L.) Roth & Szilvásvárad & 1962 & Siroki Zoltán & DE-siroki-01215.jpg \\
\hline 2452 & Calamagrostis arundinacea (L.) Roth & Szilvásvárad & 1962 & Siroki Zoltán & DE-siroki-01218.jpg \\
\hline 2452 & Calamagrostis arundinacea (L.) Roth & Szilvásvárad & 1962 & Siroki Zoltán & DE-siroki-01220.jpg \\
\hline 2452 & Calamagrostis arundinacea (L.) Roth & Szilvásvárad & 1962 & Siroki Zoltán & DE-siroki-01216.jpg \\
\hline 2452 & Calamagrostis arundinacea (L.) Roth & Szilvásvárad & 1962 & Siroki Zoltán & DE-siroki-01217.jpg \\
\hline 2452 & Calamagrostis arundinacea (L.) Roth & Szilvásvárad & 1962 & Siroki Zoltán & DE-siroki-01219.jpg \\
\hline 2452 & Calamagrostis arundinacea (L.) Roth & Szilvásvárad & 1962 & Siroki Zoltán & DE-siroki-01225.jpg \\
\hline 2452 & Calamagrostis arundinacea (L.) Roth & Szilvásvárad & 1962 & Siroki Zoltán & DE-siroki-01226.jpg \\
\hline 2452 & Calamagrostis arundinacea (L.) Roth & Szilvásvárad & 1964 & Siroki Zoltán & DE-siroki-01208.jpg \\
\hline 2453 & Calamagrostis varia (Schrad.) Host & Miskolc & 1965 & Siroki Zoltán & DE-siroki-01277.jpg \\
\hline 2453 & Calamagrostis varia (Schrad.) Host & Miskolc & 1965 & Siroki Zoltán & DE-siroki-01278.jpg \\
\hline 2453 & Calamagrostis varia (Schrad.) Host & Miskolc & 1965 & Siroki Zoltán & DE-siroki-01270.jpg \\
\hline 2453 & Calamagrostis varia (Schrad.) Host & Miskolc & 1965 & Siroki Zoltán & DE-siroki-01271.jpg \\
\hline 2453 & Calamagrostis varia (Schrad.) Host & Miskolc & 1965 & Siroki Zoltán & DE-siroki-01272.jpg \\
\hline 2453 & Calamagrostis varia (Schrad.) Host & Miskolc & 1965 & Siroki Zoltán & DE-siroki-01273.jpg \\
\hline 2453 & Calamagrostis varia (Schrad.) Host & Miskolc & 1965 & Siroki Zoltán & DE-siroki-01276.jpg \\
\hline 2456 & $\begin{array}{l}\text { Calamagrostis canescens } \\
\text { (Weber) Roth em. Druce }\end{array}$ & Barcs & 1955 & Kovács Margit & DE-siroki-01323.jpg \\
\hline 2456 & $\begin{array}{l}\text { Calamagrostis canescens } \\
\text { (Weber) Roth em. Druce }\end{array}$ & Csaroda & 1960 & Siroki Zoltán & DE-siroki-01319.jpg \\
\hline 2456 & $\begin{array}{l}\text { Calamagrostis canescens } \\
\text { (Weber) Roth em. Druce }\end{array}$ & Csaroda & 1960 & Siroki Zoltán & DE-siroki-01320.jpg \\
\hline 2456 & $\begin{array}{l}\text { Calamagrostis canescens } \\
\text { (Weber) Roth em. Druce }\end{array}$ & Csaroda & 1960 & Siroki Zoltán & DE-siroki-01322.jpg \\
\hline 2456 & $\begin{array}{l}\text { Calamagrostis canescens } \\
\text { (Weber) Roth em. Druce }\end{array}$ & Debrecen & 1954 & Farkas Attila & DE-siroki-01325.jpg \\
\hline 2456 & $\begin{array}{l}\text { Calamagrostis canescens } \\
\text { (Weber) Roth em. Druce }\end{array}$ & Debrecen & 1954 & Siroki Zoltán & DE-siroki-01308.jpg \\
\hline 2456 & $\begin{array}{l}\text { Calamagrostis canescens } \\
\text { (Weber) Roth em. Druce }\end{array}$ & Debrecen & 1954 & Siroki Zoltán & DE-siroki-01309.jpg \\
\hline 2456 & $\begin{array}{l}\text { Calamagrostis canescens } \\
\text { (Weber) Roth em. Druce }\end{array}$ & Debrecen & 1954 & Siroki Zoltán & DE-siroki-01318.jpg \\
\hline 2456 & $\begin{array}{l}\text { Calamagrostis canescens } \\
\text { (Weber) Roth em. Druce }\end{array}$ & Debrecen & 1954 & Siroki Zoltán & DE-siroki-01326.jpg \\
\hline 2456 & $\begin{array}{l}\text { Calamagrostis canescens } \\
\text { (Weber) Roth em. Druce }\end{array}$ & Debrecen & 1956 & Siroki Zoltán & DE-siroki-01310.jpg \\
\hline 2456 & $\begin{array}{l}\text { Calamagrostis canescens } \\
\text { (Weber) Roth em. Druce }\end{array}$ & Debrecen & 1956 & Siroki Zoltán & DE-siroki-01317.jpg \\
\hline 2456 & $\begin{array}{l}\text { Calamagrostis canescens } \\
\text { (Weber) Roth em. Druce }\end{array}$ & Debrecen & 1956 & Siroki Zoltán & DE-siroki-01311.jpg \\
\hline 2456 & $\begin{array}{l}\text { Calamagrostis canescens } \\
\text { (Weber) Roth em. Druce }\end{array}$ & Debrecen & 1984 & Siroki Zoltán & DE-siroki-01312.jpg \\
\hline 2456 & $\begin{array}{l}\text { Calamagrostis canescens } \\
\text { (Weber) Roth em. Druce }\end{array}$ & Debrecen & 1984 & Siroki Zoltán & DE-siroki-01313.jpg \\
\hline 2456 & $\begin{array}{l}\text { Calamagrostis canescens } \\
\text { (Weber) Roth em. Druce }\end{array}$ & Debrecen & 1984 & Siroki Zoltán & DE-siroki-01314.jpg \\
\hline 2456 & $\begin{array}{l}\text { Calamagrostis canescens } \\
\text { (Weber) Roth em. Druce }\end{array}$ & Debrecen & 1984 & Siroki Zoltán & DE-siroki-01315.jpg \\
\hline 2456 & $\begin{array}{l}\text { Calamagrostis canescens } \\
\text { (Weber) Roth em. Druce }\end{array}$ & Debrecen & 1984 & Siroki Zoltán & DE-siroki-01316.jpg \\
\hline
\end{tabular}




\begin{tabular}{|c|c|c|c|c|c|}
\hline $\begin{array}{l}\text { Sorszám / } \\
\text { Number }\end{array}$ & Taxon-név / Taxon-name & $\begin{array}{l}\text { Település / } \\
\text { Settlement }\end{array}$ & $\begin{array}{l}\text { Év / } \\
\text { Year }\end{array}$ & $\begin{array}{l}\text { Gyújtő / } \\
\text { Collector }\end{array}$ & Fájlnév / File-name \\
\hline 2456 & $\begin{array}{l}\text { Calamagrostis canescens } \\
\text { (Weber) Roth em. Druce }\end{array}$ & Egyek & 1949 & Siroki Zoltán & DE-siroki-01305.jpg \\
\hline 2456 & $\begin{array}{l}\text { Calamagrostis canescens } \\
\text { (Weber) Roth em. Druce }\end{array}$ & Egyek & 1949 & Siroki Zoltán & DE-siroki-01306.jpg \\
\hline 2456 & $\begin{array}{l}\text { Calamagrostis canescens } \\
\text { (Weber) Roth em. Druce }\end{array}$ & Egyek & 1949 & Siroki Zoltán & DE-siroki-01307.jpg \\
\hline 2456 & $\begin{array}{l}\text { Calamagrostis canescens } \\
\text { (Weber) Roth em. Druce }\end{array}$ & Egyek & 1949 & Siroki Zoltán & DE-siroki-01328.jpg \\
\hline 2456 & $\begin{array}{l}\text { Calamagrostis canescens } \\
\text { (Weber) Roth em. Druce }\end{array}$ & Kállósemjén & 1959 & Siroki Zoltán & DE-siroki-01321.jpg \\
\hline 2456 & $\begin{array}{l}\text { Calamagrostis canescens } \\
\text { (Weber) Roth em. Druce }\end{array}$ & Nyíradony & 1977 & Siroki Zoltán & DE-siroki-01324.jpg \\
\hline 2456 & $\begin{array}{l}\text { Calamagrostis canescens } \\
\text { (Weber) Roth em. Druce }\end{array}$ & Tiszafüred & 1955 & Siroki Zoltán & DE-siroki-01327.jpg \\
\hline 2457 & $\begin{array}{l}\text { Calamagrostis pseudophragmites } \\
\text { (Haller f.) Koeler }\end{array}$ & Budapest & 1911 & Kocsis István & DE-siroki-01330.jpg \\
\hline 2457 & $\begin{array}{l}\text { Calamagrostis pseudophragmites } \\
\text { (Haller f.) Koeler }\end{array}$ & Budapest & 1911 & Kocsis István & DE-siroki-01331.jpg \\
\hline 2458 & Calamagrostis epigeios (L.) Roth & Budapest & 1941 & Siroki Zoltán & DE-siroki-01299.jpg \\
\hline 2458 & Calamagrostis epigeios (L.) Roth & Budapest & 1941 & Siroki Zoltán & DE-siroki-01300.jpg \\
\hline 2458 & Calamagrostis epigeios (L.) Roth & Budapest & 1941 & Siroki Zoltán & DE-siroki-01301.jpg \\
\hline 2458 & Calamagrostis epigeios (L.) Roth & Csaroda & 1962 & Siroki Zoltán & DE-siroki-01287.jpg \\
\hline 2458 & Calamagrostis epigeios (L.) Roth & Csaroda & 1962 & Siroki Zoltán & DE-siroki-01290.jpg \\
\hline 2458 & Calamagrostis epigeios (L.) Roth & Csaroda & 1962 & Siroki Zoltán & DE-siroki-01293.jpg \\
\hline 2458 & Calamagrostis epigeios (L.) Roth & Csaroda & 1962 & Siroki Zoltán & DE-siroki-01298.jpg \\
\hline 2458 & Calamagrostis epigeios (L.) Roth & Debrecen & 1950 & Siroki Zoltán & DE-siroki-01304.jpg \\
\hline 2458 & Calamagrostis epigeios (L.) Roth & Egyek & 1947 & Siroki Zoltán & DE-siroki-01295.jpg \\
\hline 2458 & Calamagrostis epigeios (L.) Roth & Háromhuta & 1965 & Siroki Zoltán & DE-siroki-01288.jpg \\
\hline 2458 & Calamagrostis epigeios (L.) Roth & Háromhuta & 1965 & Siroki Zoltán & DE-siroki-01289.jpg \\
\hline 2458 & Calamagrostis epigeios (L.) Roth & Háromhuta & 1965 & Siroki Zoltán & DE-siroki-01294.jpg \\
\hline 2458 & Calamagrostis epigeios (L.) Roth & Mosonmagyaróvár & 1939 & Siroki Zoltán & DE-siroki-01302.jpg \\
\hline 2458 & Calamagrostis epigeios (L.) Roth & Nagyvisnyó & 1966 & Siroki Zoltán & DE-siroki-01284.jpg \\
\hline 2458 & Calamagrostis epigeios (L.) Roth & Nagyvisnyó & 1966 & Siroki Zoltán & DE-siroki-01285.jpg \\
\hline 2458 & Calamagrostis epigeios (L.) Roth & Nagyvisnyó & 1966 & Siroki Zoltán & DE-siroki-01286.jpg \\
\hline 2458 & Calamagrostis epigeios (L.) Roth & Nagyvisnyó & 1966 & Siroki Zoltán & DE-siroki-01291.jpg \\
\hline 2458 & Calamagrostis epigeios (L.) Roth & Nagyvisnyó & 1966 & Siroki Zoltán & DE-siroki-01292.jpg \\
\hline 2458 & Calamagrostis epigeios (L.) Roth & Sajólád/Sajópetri & 1951 & Siroki Zoltán & DE-siroki-01296.jpg \\
\hline 2458 & Calamagrostis epigeios (L.) Roth & Tiszafüred & 1970 & Siroki Zoltán & DE-siroki-01283.jpg \\
\hline 2460 & Phleum phleoides (L.) H. Karst. & "Nagymező" & 1959 & Halász Tibor & DE-siroki-01069.jpg \\
\hline 2460 & Phleum phleoides (L.) H. Karst. & "Nagymező" & 1959 & Siroki Zoltán & DE-siroki-01063.jpg \\
\hline 2460 & Phleum phleoides (L.) H. Karst. & "Nagymező" & 1959 & Siroki Zoltán & DE-siroki-01070.jpg \\
\hline 2460 & Phleum phleoides (L.) H. Karst. & "Nagymező" & 1959 & Siroki Zoltán & DE-siroki-01071.jpg \\
\hline 2460 & Phleum phleoides (L.) H. Karst. & "Nagymező" & 1959 & Siroki Zoltán & DE-siroki-01062.jpg \\
\hline 2460 & Phleum phleoides (L.) H. Karst. & Boldogkőváralja & 1967 & Siroki Zoltán & DE-siroki-01066.jpg \\
\hline 2460 & Phleum phleoides (L.) H. Karst. & Budapest & 1966 & Siroki Zoltán & DE-siroki-01067.jpg \\
\hline 2460 & Phleum phleoides (L.) H. Karst. & Budapest & 1966 & Siroki Zoltán & DE-siroki-01073.jpg \\
\hline 2460 & Phleum phleoides (L.) H. Karst. & Budapest & 1966 & Siroki Zoltán & DE-siroki-01074.jpg \\
\hline 2460 & Phleum phleoides (L.) H. Karst. & Budapest & 1966 & Siroki Zoltán & DE-siroki-01075.jpg \\
\hline 2460 & Phleum phleoides (L.) H. Karst. & Debrecen & 1948 & Siroki Zoltán & DE-siroki-01078.jpg \\
\hline 2460 & Phleum phleoides (L.) H. Karst. & Debrecen & 1948 & Siroki Zoltán & DE-siroki-01061.jpg \\
\hline 2460 & Phleum phleoides (L.) H. Karst. & Debrecen & 1948 & Siroki Zoltán & DE-siroki-01064.jpg \\
\hline
\end{tabular}




\begin{tabular}{|c|c|c|c|c|c|}
\hline $\begin{array}{l}\text { Sorszám / } \\
\text { Number }\end{array}$ & Taxon-név / Taxon-name & $\begin{array}{l}\text { Település / } \\
\text { Settlement }\end{array}$ & $\begin{array}{l}\text { Év / } \\
\text { Year }\end{array}$ & $\begin{array}{l}\text { Gyújtő / } \\
\text { Collector }\end{array}$ & Fájlnév / File-name \\
\hline 2460 & Phleum phleoides (L.) H. Karst. & Gödöllő & 1951 & Siroki Zoltán & DE-siroki-01079.jpg \\
\hline 2460 & Phleum phleoides (L.) H. Karst. & Mátraszentimre & 1959 & Gondola István & DE-siroki-01068.jpg \\
\hline 2460 & Phleum phleoides (L.) H. Karst. & Pomáz & 1957 & Siroki Zoltán & DE-siroki-01065.jpg \\
\hline 2461 & Phleum pratense L. & Budapest & 1951 & Siroki Zoltán & DE-siroki-01048.jpg \\
\hline 2461 & Phleum pratense L. & Debrecen & 1948 & Siroki Zoltán & DE-siroki-01045.jpg \\
\hline 2461 & Phleum pratense L. & Debrecen & 1948 & Siroki Zoltán & DE-siroki-01046.jpg \\
\hline 2461 & Phleum pratense L. & Debrecen & 1958 & Pethő Menyhért & DE-siroki-01044.jpg \\
\hline 2463 & Alopecurus pratensis L. & "Sátor-hg." & 1955 & Simon Tiborné & DE-siroki-01094.jpg \\
\hline 2463 & Alopecurus pratensis L. & Debrecen & 1947 & Siroki Zoltán & DE-siroki-01095.jpg \\
\hline 2463 & Alopecurus pratensis L. & Debrecen & 1947 & Siroki Zoltán & DE-siroki-01096.jpg \\
\hline 2463 & Alopecurus pratensis L. & Debrecen & 1954 & Siroki Zoltán & DE-siroki-01093.jpg \\
\hline 2464 & Alopecurus myosuroides Huds. & Budapest & 1951 & Siroki Zoltán & DE-siroki-01083.jpg \\
\hline 2464 & Alopecurus myosuroides Huds. & Budapest & 1951 & Siroki Zoltán & DE-siroki-01084.jpg \\
\hline 2464 & Alopecurus myosuroides Huds. & Budapest & 1951 & Siroki Zoltán & DE-siroki-01085.jpg \\
\hline 2464 & Alopecurus myosuroides Huds. & Budapest & 1951 & Siroki Zoltán & DE-siroki-01086.jpg \\
\hline 2464 & Alopecurus myosuroides Huds. & Budapest & 1951 & Siroki Zoltán & DE-siroki-01087.jpg \\
\hline 2465 & Alopecurus geniculatus L. & Debrecen & 1947 & Siroki Zoltán & DE-siroki-01102.jpg \\
\hline 2465 & Alopecurus geniculatus L. & Hortobágy & 1959 & Siroki Zoltán & DE-siroki-01103.jpg \\
\hline 2466 & Alopecurus aequalis Sobol. & Csaroda & 1960 & Siroki Zoltán & DE-siroki-01115.jpg \\
\hline 2466 & Alopecurus aequalis Sobol. & Csaroda & 1960 & Siroki Zoltán & DE-siroki-01116.jpg \\
\hline 2466 & Alopecurus aequalis Sobol. & Csaroda & 1960 & Siroki Zoltán & DE-siroki-01119.jpg \\
\hline 2466 & Alopecurus aequalis Sobol. & Csaroda & 1960 & Siroki Zoltán & DE-siroki-01120.jpg \\
\hline 2466 & Alopecurus aequalis Sobol. & Csaroda & 1960 & Siroki Zoltán & DE-siroki-01121.jpg \\
\hline 2466 & Alopecurus aequalis Sobol. & Csaroda & 1960 & Siroki Zoltán & DE-siroki-01122.jpg \\
\hline 2466 & Alopecurus aequalis Sobol. & Egyek & 1947 & Siroki Zoltán & DE-siroki-01117.jpg \\
\hline 2466 & Alopecurus aequalis Sobol. & Egyek & 1947 & Siroki Zoltán & DE-siroki-01118.jpg \\
\hline 2466 & Alopecurus aequalis Sobol. & Egyek & 1949 & Siroki Zoltán & DE-siroki-01107.jpg \\
\hline 2466 & Alopecurus aequalis Sobol. & Egyek & 1949 & Siroki Zoltán & DE-siroki-01111.jpg \\
\hline 2466 & Alopecurus aequalis Sobol. & Mikepércs & 1962 & Siroki Zoltán & DE-siroki-01123.jpg \\
\hline--- & Alopecurus rendlei Eig & Budapest & 1904 & $\begin{array}{l}\text { Torday - Baán } \\
\text { Lajos }\end{array}$ & DE-siroki-01092.jpg \\
\hline ---- & Alopecurus rendlei Eig & Budapest & 1911 & Kocsis István & DE-siroki-01091.jpg \\
\hline 2467 & Pholiurus pannonicus Trin. & Debrecen & 1947 & Siroki Zoltán & DE-siroki-02376.jpg \\
\hline 2467 & Pholiurus pannonicus Trin. & Debrecen & 1954 & Siroki Zoltán & DE-siroki-02375.jpg \\
\hline 2467 & Pholiurus pannonicus Trin. & Dömsöd & 1952 & Szabados A. & DE-siroki-02377.jpg \\
\hline 2467 & Pholiurus pannonicus Trin. & Egyek & 1947 & Siroki Zoltán & DE-siroki-02370.jpg \\
\hline 2467 & Pholiurus pannonicus Trin. & Egyek & 1947 & Siroki Zoltán & DE-siroki-02371.jpg \\
\hline 2467 & Pholiurus pannonicus Trin. & Egyek & 1948 & Siroki Zoltán & DE-siroki-02374.jpg \\
\hline 2467 & Pholiurus pannonicus Trin. & Hortobágy & 1959 & Siroki Zoltán & DE-siroki-02373.jpg \\
\hline 2467 & Pholiurus pannonicus Trin. & Mikepércs & 1966 & Siroki Zoltán & DE-siroki-02372.jpg \\
\hline 2468 & Phalaris canariensis L. & Budapest & 1951 & Siroki Zoltán & DE-siroki-00892.jpg \\
\hline 2468 & Phalaris canariensis L. & Budapest & 1951 & Siroki Zoltán & DE-siroki-00893.jpg \\
\hline 2469 & Phalaris arundinacea L. & Debrecen & 1954 & Siroki Zoltán & DE-siroki-00897.jpg \\
\hline 2469 & Phalaris arundinacea $\mathrm{L}$. & Debrecen & 1954 & Siroki Zoltán & DE-siroki-00898.jpg \\
\hline 2469 & Phalaris arundinacea L. & Debrecen & 1954 & Siroki Zoltán & DE-siroki-00899.jpg \\
\hline 2469 & Phalaris arundinacea L. & Debrecen & 1954 & Siroki Zoltán & DE-siroki-00900.jpg \\
\hline 2469 & Phalaris arundinacea L. & Debrecen & 1966 & Siroki Zoltán & DE-siroki-00901.jpg \\
\hline
\end{tabular}




\begin{tabular}{|c|c|c|c|c|c|}
\hline $\begin{array}{l}\text { Sorszám / } \\
\text { Number }\end{array}$ & Taxon-név / Taxon-name & $\begin{array}{l}\text { Település / } \\
\text { Settlement }\end{array}$ & $\begin{array}{l}\text { Év / } \\
\text { Year }\end{array}$ & $\begin{array}{l}\text { Gyújtő / } \\
\text { Collector }\end{array}$ & Fájlnév / File-name \\
\hline 2469 & Phalaris arundinacea $\mathrm{L}$. & Debrecen & 1966 & Siroki Zoltán & DE-siroki-00902.jpg \\
\hline 2469 & Phalaris arundinacea L. & Egyek & 1948 & Siroki Zoltán & DE-siroki-00903.jpg \\
\hline 2469 & Phalaris arundinacea L. & Egyek & 1948 & Siroki Zoltán & DE-siroki-00905.jpg \\
\hline 2469 & Phalaris arundinacea L. & Egyek & 1948 & Siroki Zoltán & DE-siroki-00906.jpg \\
\hline 2471 & Milium effusum L. & Budapest & 1960 & Siroki Zoltán & DE-siroki-01002.jpg \\
\hline 2471 & Milium effusum L. & Budapest & 1960 & Siroki Zoltán & DE-siroki-01003.jpg \\
\hline 2471 & Milium effusum L. & Budapest & 1960 & Siroki Zoltán & DE-siroki-01004.jpg \\
\hline 2471 & Milium effusum L. & Debrecen & 1955 & $\begin{array}{l}\text { Siroki Zoltán - } \\
\text { Farkas Attila }\end{array}$ & DE-siroki-01000.jpg \\
\hline 2471 & Milium effusum L. & Debrecen & 1955 & $\begin{array}{l}\text { Siroki Zoltán - } \\
\text { Farkas Attila }\end{array}$ & DE-siroki-01001.jpg \\
\hline 2472 & Piptatherum virescens (Trin.) Boiss. & Budapest & 1951 & Siroki Zoltán & DE-siroki-00990.jpg \\
\hline 2472 & Piptatherum virescens (Trin.) Boiss. & Budapest & 1951 & Siroki Zoltán & DE-siroki-00991.jpg \\
\hline 2472 & Piptatherum virescens (Trin.) Boiss. & Budapest & 1962 & Siroki Zoltán & DE-siroki-00981.jpg \\
\hline 2472 & Piptatherum virescens (Trin.) Boiss. & Budapest & 1962 & Siroki Zoltán & DE-siroki-00982.jpg \\
\hline 2472 & Piptatherum virescens (Trin.) Boiss. & Budapest & 1962 & Siroki Zoltán & DE-siroki-00983.jpg \\
\hline 2472 & Piptatherum virescens (Trin.) Boiss. & Budapest & 1962 & Siroki Zoltán & DE-siroki-00984.jpg \\
\hline 2472 & Piptatherum virescens (Trin.) Boiss. & Budapest & 1962 & Siroki Zoltán & DE-siroki-00988.jpg \\
\hline 2472 & Piptatherum virescens (Trin.) Boiss. & Budapest & 1962 & Siroki Zoltán & DE-siroki-00989.jpg \\
\hline 2472 & Piptatherum virescens (Trin.) Boiss. & Budapest & 1962 & Siroki Zoltán & DE-siroki-00986.jpg \\
\hline 2472 & Piptatherum virescens (Trin.) Boiss. & Budapest & 1962 & Siroki Zoltán & DE-siroki-00987.jpg \\
\hline 2472 & Piptatherum virescens (Trin.) Boiss. & Budapest & 1962 & Siroki Zoltán & DE-siroki-00985.jpg \\
\hline 2473 & Stipa capillata L. & Abaújszántó & 1943 & Siroki Zoltán & DE-siroki-00933.jpg \\
\hline 2473 & Stipa capillata L. & Aggtelek & 1972 & Siroki Zoltán & DE-siroki-00938.jpg \\
\hline 2473 & Stipa capillata L. & Aggtelek & 1972 & Siroki Zoltán & DE-siroki-00939.jpg \\
\hline 2473 & Stipa capillata L. & Aggtelek & 1972 & Siroki Zoltán & DE-siroki-00940.jpg \\
\hline 2473 & Stipa capillata L. & Aggtelek & 1972 & Siroki Zoltán & DE-siroki-00941.jpg \\
\hline 2473 & Stipa capillata L. & Aggtelek & 1972 & Siroki Zoltán & DE-siroki-00942.jpg \\
\hline 2473 & Stipa capillata L. & Boldogkőváralja & 1944 & Siroki Zoltán & DE-siroki-00932.jpg \\
\hline 2473 & Stipa capillata L. & Budapest & 1941 & Siroki Zoltán & DE-siroki-00934.jpg \\
\hline 2473 & Stipa capillata L. & Budapest & 1941 & Siroki Zoltán & DE-siroki-00935.jpg \\
\hline 2473 & Stipa capillata L. & Budapest & 1948 & Siroki Zoltán & DE-siroki-00929.jpg \\
\hline 2473 & Stipa capillata L. & Bugac & 1973 & Siroki Zoltán & DE-siroki-00927.jpg \\
\hline 2473 & Stipa capillata L. & Bugac & 1973 & Siroki Zoltán & DE-siroki-00928.jpg \\
\hline 2473 & Stipa capillata L. & Bugac & 1973 & Siroki Zoltán & DE-siroki-00936.jpg \\
\hline 2473 & Stipa capillata L. & Bugac & 1973 & Siroki Zoltán & DE-siroki-00937.jpg \\
\hline 2473 & Stipa capillata L. & Gödöllő & 1954 & $\begin{array}{l}\text { Jeanplong József } \\
\text { - L. Kormány } \\
\text { - M. Rösch }\end{array}$ & DE-siroki-00930.jpg \\
\hline 2473 & Stipa capillata L. & Gödöllő & 1954 & $\begin{array}{l}\text { Jeanplong József } \\
\text { - L. Kormány } \\
\text { - M. Rösch }\end{array}$ & DE-siroki-00931.jpg \\
\hline 2475 & Stipa tirsa Steven em. Čelak. & Pomáz & 1957 & Siroki Zoltán & DE-siroki-00947.jpg \\
\hline 2475 & Stipa tirsa Steven em. Čelak. & Pomáz & 1957 & Siroki Zoltán & DE-siroki-00948.jpg \\
\hline 2475 & Stipa tirsa Steven em. Čelak. & Pomáz & 1957 & Siroki Zoltán & DE-siroki-00944.jpg \\
\hline 2475 & Stipa tirsa Steven em. Čelak. & Pomáz & 1957 & Siroki Zoltán & DE-siroki-00945.jpg \\
\hline 2475 & Stipa tirsa Steven em. Čelak. & Pomáz & 1957 & Siroki Zoltán & DE-siroki-00946.jpg \\
\hline 2476 & $\begin{array}{l}\text { Stipa dasyphylla } \\
\text { (Czern. ex Lindem.) Trautv. }\end{array}$ & Budapest & 1951 & Siroki Zoltán & DE-siroki-00976.jpg \\
\hline
\end{tabular}




\begin{tabular}{|c|c|c|c|c|c|}
\hline $\begin{array}{l}\text { Sorszám / } \\
\text { Number }\end{array}$ & Taxon-név / Taxon-name & $\begin{array}{l}\text { Település / } \\
\text { Settlement }\end{array}$ & $\begin{array}{l}\text { Év / } \\
\text { Year }\end{array}$ & $\begin{array}{l}\text { Gyújtő / } \\
\text { Collector }\end{array}$ & Fájlnév / File-name \\
\hline 2476 & $\begin{array}{l}\text { Stipa dasyphylla } \\
\text { (Czern. ex Lindem.) Trautv. }\end{array}$ & Budapest & 1952 & Siroki Zoltán & DE-siroki-00975.jpg \\
\hline 2476 & $\begin{array}{l}\text { Stipa dasyphylla } \\
\text { (Czern. ex Lindem.) Trautv. }\end{array}$ & Pomáz & 1952 & Siroki Zoltán & DE-siroki-00974.jpg \\
\hline 2477 & Stipa pennata L. & Ágasegyháza & 1970 & Siroki Zoltán & DE-siroki-00957.jpg \\
\hline 2477 & Stipa pennata L. & Ágasegyháza & 1970 & Siroki Zoltán & DE-siroki-00958.jpg \\
\hline 2477 & Stipa pennata L. & Ágasegyháza & 1970 & Siroki Zoltán & DE-siroki-00963.jpg \\
\hline 2477 & Stipa pennata L. & Ágasegyháza & 1970 & Siroki Zoltán & DE-siroki-00964.jpg \\
\hline 2477 & Stipa pennata L. & Budaörs & 1952 & Siroki Zoltán & DE-siroki-00969.jpg \\
\hline 2477 & Stipa pennata L. & Budaörs & 1964 & Siroki Zoltán & DE-siroki-00959.jpg \\
\hline 2477 & Stipa pennata L. & Budaörs & 1964 & Siroki Zoltán & DE-siroki-00960.jpg \\
\hline 2477 & Stipa pennata L. & Budaörs & 1964 & Siroki Zoltán & DE-siroki-00961.jpg \\
\hline 2477 & Stipa pennata L. & Budapest & 1951 & Siroki Zoltán & DE-siroki-00966.jpg \\
\hline 2477 & Stipa pennata L. & Debrecen & 1950 & Siroki Zoltán & DE-siroki-00962.jpg \\
\hline 2477 & Stipa pennata L. & Debrecen & 1950 & Siroki Zoltán & DE-siroki-00965.jpg \\
\hline 2477 & Stipa pennata L. & Debrecen & 1950 & Siroki Zoltán & DE-siroki-00967.jpg \\
\hline 2477 & Stipa pennata L. & Debrecen & 1950 & Siroki Zoltán & DE-siroki-00968.jpg \\
\hline 2477 & Stipa pennata L. & Gödöllő & 1951 & Siroki Zoltán & DE-siroki-00973.jpg \\
\hline 2477 & Stipa pennata L. & Gödöllő & 1952 & Siroki Zoltán & DE-siroki-00971.jpg \\
\hline 2477 & Stipa pennata L. & Gödöllő & 1952 & Siroki Zoltán & DE-siroki-00972.jpg \\
\hline 2477 & Stipa pennata L. & Pilisszentiván & 1952 & Siroki Zoltán & DE-siroki-00970.jpg \\
\hline 2479 & Stipa pulcherrima K. Koch & Abaújszántó & 1944 & Siroki Zoltán & DE-siroki-00950.jpg \\
\hline 2479 & Stipa pulcherrima K. Koch & Abaújszántó & 1944 & Siroki Zoltán & DE-siroki-00953.jpg \\
\hline 2479 & Stipa pulcherrima K. Koch & Gyenesdiás & 1928 & Rigler József & DE-siroki-00949.jpg \\
\hline 2479 & Stipa pulcherrima K. Koch & Pilisszentiván & 1952 & Siroki Zoltán & DE-siroki-00951.jpg \\
\hline 2479 & Stipa pulcherrima K. Koch & Pilisszentiván & 1952 & Siroki Zoltán & DE-siroki-00952.jpg \\
\hline 2479 & Stipa pulcherrima K. Koch & Pilisszentiván & 1952 & Siroki Zoltán & DE-siroki-00954.jpg \\
\hline 2481 & Phragmites australis (Cav.) Steud. & Mosonmagyaróvár & 1939 & Siroki Zoltán & DE-siroki-01663.jpg \\
\hline 2482 & Danthonia alpina Vest & Budaörs & 1966 & Siroki Zoltán & DE-siroki-01558.jpg \\
\hline 2482 & Danthonia alpina Vest & Budaörs & 1966 & Siroki Zoltán & DE-siroki-01559.jpg \\
\hline 2482 & Danthonia alpina Vest & Budaörs & 1966 & Siroki Zoltán & DE-siroki-01560.jpg \\
\hline 2482 & Danthonia alpina Vest & Háromhuta & 1960 & Siroki Zoltán & DE-siroki-01554.jpg \\
\hline 2482 & Danthonia alpina Vest & Háromhuta & 1960 & Siroki Zoltán & DE-siroki-01555.jpg \\
\hline 2482 & Danthonia alpina Vest & Háromhuta & 1960 & Siroki Zoltán & DE-siroki-01556.jpg \\
\hline 2482 & Danthonia alpina Vest & Háromhuta & 1961 & Siroki Zoltán & DE-siroki-01557.jpg \\
\hline 2482 & Danthonia alpina Vest & Háromhuta & 1961 & Siroki Zoltán & DE-siroki-01561.jpg \\
\hline 2482 & Danthonia alpina Vest & Háromhuta & 1961 & Siroki Zoltán & DE-siroki-01562.jpg \\
\hline 2482 & Danthonia alpina Vest & Háromhuta & 1961 & Siroki Zoltán & DE-siroki-01563.jpg \\
\hline 2482 & Danthonia alpina Vest & Háromhuta & 1961 & Siroki Zoltán & DE-siroki-01564.jpg \\
\hline 2482 & Danthonia alpina Vest & Háromhuta & 1961 & Siroki Zoltán & DE-siroki-01566.jpg \\
\hline 2482 & Danthonia alpina Vest & Háromhuta & 1961 & Siroki Zoltán & DE-siroki-01565.jpg \\
\hline 2482 & Danthonia alpina Vest & Mátraverebély & 1952 & Siroki Zoltán & DE-siroki-01567.jpg \\
\hline 2482 & Danthonia alpina Vest & Mátraverebély & 1952 & Siroki Zoltán & DE-siroki-01570.jpg \\
\hline 2482 & Danthonia alpina Vest & Pásztó & 1952 & Siroki Zoltán & DE-siroki-01568.jpg \\
\hline 2482 & Danthonia alpina Vest & Pásztó & 1952 & Siroki Zoltán & DE-siroki-01569.jpg \\
\hline 2482 & Danthonia alpina Vest & Pásztó & 1952 & Siroki Zoltán & DE-siroki-01571.jpg \\
\hline 2483 & Danthonia decumbens (L.) DC. & "Nagymező" & 1959 & Siroki Zoltán & DE-siroki-01675.jpg \\
\hline
\end{tabular}




\begin{tabular}{|c|c|c|c|c|c|}
\hline $\begin{array}{l}\text { Sorszám / } \\
\text { Number }\end{array}$ & Taxon-név / Taxon-name & $\begin{array}{l}\text { Település / } \\
\text { Settlement }\end{array}$ & $\begin{array}{l}\text { Év / } \\
\text { Year }\end{array}$ & $\begin{array}{l}\text { Gyújitő / } \\
\text { Collector }\end{array}$ & Fájlnév / File-name \\
\hline 2483 & Danthonia decumbens (L.) DC. & "Nagymező" & 1959 & Siroki Zoltán & DE-siroki-01679.jpg \\
\hline 2483 & Danthonia decumbens (L.) DC. & "Nagymező" & 1959 & Siroki Zoltán & DE-siroki-01683.jpg \\
\hline 2483 & Danthonia decumbens (L.) DC. & Háromhuta & 1961 & Siroki Zoltán & DE-siroki-01673.jpg \\
\hline 2483 & Danthonia decumbens (L.) DC. & Háromhuta & 1961 & Siroki Zoltán & DE-siroki-01681.jpg \\
\hline 2483 & Danthonia decumbens (L.) DC. & Háromhuta & 1961 & Siroki Zoltán & DE-siroki-01682.jpg \\
\hline 2483 & Danthonia decumbens (L.) DC. & Háromhuta & 1961 & Siroki Zoltán & DE-siroki-01684.jpg \\
\hline 2483 & Danthonia decumbens (L.) DC. & Háromhuta & 1961 & Siroki Zoltán & DE-siroki-01686.jpg \\
\hline 2483 & Danthonia decumbens (L.) DC. & Háromhuta & 1961 & Siroki Zoltán & DE-siroki-01688.jpg \\
\hline 2483 & Danthonia decumbens (L.) DC. & Háromhuta & 1961 & Siroki Zoltán & DE-siroki-01689.jpg \\
\hline 2483 & Danthonia decumbens (L.) DC. & Háromhuta & 1961 & Siroki Zoltán & DE-siroki-01685.jpg \\
\hline 2483 & Danthonia decumbens (L.) DC. & Háromhuta & 1961 & Siroki Zoltán & DE-siroki-01687.jpg \\
\hline 2483 & Danthonia decumbens (L.) DC. & Vámospércs & 1984 & Siroki Zoltán & DE-siroki-01672.jpg \\
\hline 2483 & Danthonia decumbens (L.) DC. & Vámospércs & 1985 & Siroki Zoltán & DE-siroki-01668.jpg \\
\hline 2483 & Danthonia decumbens (L.) DC. & Vámospércs & 1985 & Siroki Zoltán & DE-siroki-01669.jpg \\
\hline 2483 & Danthonia decumbens (L.) DC. & Vámospércs & 1985 & Siroki Zoltán & DE-siroki-01670.jpg \\
\hline 2483 & Danthonia decumbens (L.) DC. & Vámospércs & 1985 & Siroki Zoltán & DE-siroki-01671.jpg \\
\hline 2484 & Molinia caerulea (L.) Moench & Ágasegyháza & 1956 & Siroki Zoltán & DE-siroki-01709.jpg \\
\hline 2484 & Molinia caerulea (L.) Moench & Ágasegyháza & 1956 & Siroki Zoltán & DE-siroki-01710.jpg \\
\hline 2484 & Molinia caerulea (L.) Moench & Budapest & 1902 & ??? & DE-siroki-01730.jpg \\
\hline 2484 & Molinia caerulea (L.) Moench & Budapest & 1902 & ??? & DE-siroki-01731.jpg \\
\hline 2484 & Molinia caerulea (L.) Moench & Debrecen & 1958 & Siroki Zoltán & DE-siroki-01711.jpg \\
\hline 2484 & Molinia caerulea (L.) Moench & Debrecen & 1958 & Siroki Zoltán & DE-siroki-01712.jpg \\
\hline 2484 & Molinia caerulea (L.) Moench & Gödöllő & 1953 & Siroki Zoltán & DE-siroki-01728.jpg \\
\hline 2484 & Molinia caerulea (L.) Moench & Gyenesdiás & 1955 & Siroki Zoltán & DE-siroki-01738.jpg \\
\hline 2484 & Molinia caerulea (L.) Moench & Gyenesdiás & 1955 & Siroki Zoltán & DE-siroki-01739.jpg \\
\hline 2484 & Molinia caerulea (L.) Moench & Hajdúböszörmény & 1966 & Siroki Zoltán & DE-siroki-01713.jpg \\
\hline 2484 & Molinia caerulea (L.) Moench & Hajdúböszörmény & 1966 & Siroki Zoltán & DE-siroki-01714.jpg \\
\hline 2484 & Molinia caerulea (L.) Moench & Hajdúböszörmény & 1966 & Siroki Zoltán & DE-siroki-01715.jpg \\
\hline 2484 & Molinia caerulea (L.) Moench & Hajdúböszörmény & 1966 & Siroki Zoltán & DE-siroki-01716.jpg \\
\hline 2484 & Molinia caerulea (L.) Moench & Hajdúböszörmény & 1966 & Siroki Zoltán & DE-siroki-01717.jpg \\
\hline 2484 & Molinia caerulea (L.) Moench & Hajdúböszörmény & 1966 & Siroki Zoltán & DE-siroki-01718.jpg \\
\hline 2484 & Molinia caerulea (L.) Moench & Hajdúböszörmény & 1966 & Siroki Zoltán & DE-siroki-01719.jpg \\
\hline 2484 & Molinia caerulea (L.) Moench & Hajdúböszörmény & 1966 & Siroki Zoltán & DE-siroki-01720.jpg \\
\hline 2484 & Molinia caerulea (L.) Moench & Nagykőrös & 1954 & Siroki Zoltán & DE-siroki-01722.jpg \\
\hline 2485 & Molinia arundinacea Schrank & Gyenesdiás & 1955 & Siroki Zoltán & DE-siroki-01729.jpg \\
\hline 2485 & Molinia arundinacea Schrank & Gyenesdiás & 1955 & Siroki Zoltán & DE-siroki-01737.jpg \\
\hline 2485 & Molinia arundinacea Schrank & Háromhuta & 1960 & Siroki Zoltán & DE-siroki-01724.jpg \\
\hline 2485 & Molinia arundinacea Schrank & Háromhuta & 1960 & Siroki Zoltán & DE-siroki-01725.jpg \\
\hline 2485 & Molinia arundinacea Schrank & Háromhuta & 1960 & Siroki Zoltán & DE-siroki-01726.jpg \\
\hline 2485 & Molinia arundinacea Schrank & Háromhuta & 1960 & Siroki Zoltán & DE-siroki-01733.jpg \\
\hline 2485 & Molinia arundinacea Schrank & Háromhuta & 1960 & Siroki Zoltán & DE-siroki-01734.jpg \\
\hline 2485 & Molinia arundinacea Schrank & Sopron & 1956 & Kovács Béla & DE-siroki-01727.jpg \\
\hline 2485 & Molinia arundinacea Schrank & Sopron & 1956 & Kovács Béla & DE-siroki-01732.jpg \\
\hline 2486 & Nardus stricta L. & "Nagymező" & 1959 & Halász Tibor & DE-siroki-02338.jpg \\
\hline 2486 & Nardus stricta L. & "Nagymező" & 1959 & Halász Tibor & DE-siroki-02339.jpg \\
\hline 2486 & Nardus stricta L. & "Nagymező" & 1959 & Halász Tibor & DE-siroki-02335.jpg \\
\hline
\end{tabular}




\begin{tabular}{|c|c|c|c|c|c|}
\hline $\begin{array}{l}\text { Sorszám / } \\
\text { Number }\end{array}$ & Taxon-név / Taxon-name & $\begin{array}{l}\text { Település / } \\
\text { Settlement }\end{array}$ & $\begin{array}{l}\text { Év / } \\
\text { Year }\end{array}$ & $\begin{array}{l}\text { Gyújtő / } \\
\text { Collector }\end{array}$ & Fájlnév / File-name \\
\hline 2486 & Nardus stricta L. & "Nagymező" & 1959 & Siroki Zoltán & DE-siroki-02336.jpg \\
\hline 2486 & Nardus stricta L. & "Nagymező" & 1959 & Siroki Zoltán & DE-siroki-02337.jpg \\
\hline 2486 & Nardus stricta L. & "Nagymező" & 1959 & Siroki Zoltán & DE-siroki-02340.jpg \\
\hline 2486 & Nardus stricta L. & Háromhuta & 1961 & Siroki Zoltán & DE-siroki-02334.jpg \\
\hline 2486 & Nardus stricta L. & Háromhuta & 1961 & Siroki Zoltán & DE-siroki-02333.jpg \\
\hline 2487 & Cleistogenes serotina (L.) Keng & Budapest & 1948 & Siroki Zoltán & DE-siroki-01701.jpg \\
\hline 2487 & Cleistogenes serotina (L.) Keng & Budapest & 1948 & Siroki Zoltán & DE-siroki-01705.jpg \\
\hline 2487 & Cleistogenes serotina (L.) Keng & Pilismarót & 1963 & Siroki Zoltán & DE-siroki-01702.jpg \\
\hline 2487 & Cleistogenes serotina (L.) Keng & Pilismarót & 1963 & Siroki Zoltán & DE-siroki-01703.jpg \\
\hline 2487 & Cleistogenes serotina (L.) Keng & Pilismarót & 1963 & Siroki Zoltán & DE-siroki-01704.jpg \\
\hline 2487 & Cleistogenes serotina (L.) Keng & Pilismarót & 1963 & Siroki Zoltán & DE-siroki-01706.jpg \\
\hline 2487 & Cleistogenes serotina (L.) Keng & Pilismarót & 1963 & Siroki Zoltán & DE-siroki-01707.jpg \\
\hline 2487 & Cleistogenes serotina (L.) Keng & Pilismarót & 1963 & Siroki Zoltán & DE-siroki-01708.jpg \\
\hline 2487 & Cleistogenes serotina (L.) Keng & Pilismarót & 1963 & Siroki Zoltán & DE-siroki-01692.jpg \\
\hline 2487 & Cleistogenes serotina (L.) Keng & Pilismarót & 1963 & Siroki Zoltán & DE-siroki-01693.jpg \\
\hline 2487 & Cleistogenes serotina (L.) Keng & Pilismarót & 1963 & Siroki Zoltán & DE-siroki-01694.jpg \\
\hline 2487 & Cleistogenes serotina (L.) Keng & Pilismarót & 1963 & Siroki Zoltán & DE-siroki-01695.jpg \\
\hline 2487 & Cleistogenes serotina (L.) Keng & Pilismarót & 1963 & Siroki Zoltán & DE-siroki-01696.jpg \\
\hline 2487 & Cleistogenes serotina (L.) Keng & Pilismarót & 1963 & Siroki Zoltán & DE-siroki-01697.jpg \\
\hline 2487 & Cleistogenes serotina (L.) Keng & Pilismarót & 1963 & Siroki Zoltán & DE-siroki-01698.jpg \\
\hline 2487 & Cleistogenes serotina (L.) Keng & Pilismarót & 1963 & Siroki Zoltán & DE-siroki-01699.jpg \\
\hline 2487 & Cleistogenes serotina (L.) Keng & Pilismarót & 1963 & Siroki Zoltán & DE-siroki-01700.jpg \\
\hline 2487 & Cleistogenes serotina (L.) Keng & Pilismarót & 1963 & Siroki Zoltán & DE-siroki-01690.jpg \\
\hline 2487 & Cleistogenes serotina (L.) Keng & Pilismarót & 1963 & Siroki Zoltán & DE-siroki-01691.jpg \\
\hline 2488 & Eragrostis minor Host & Debrecen & 1947 & Siroki Zoltán & DE-siroki-01754.jpg \\
\hline 2488 & Eragrostis minor Host & Debrecen & 1947 & Siroki Zoltán & DE-siroki-01752.jpg \\
\hline 2488 & Eragrostis minor Host & Debrecen & 1947 & Siroki Zoltán & DE-siroki-01753.jpg \\
\hline 2488 & Eragrostis minor Host & Debrecen & 1947 & Siroki Zoltán & DE-siroki-01751.jpg \\
\hline 2488 & Eragrostis minor Host & Debrecen & 1957 & Siroki Zoltán & DE-siroki-01755.jpg \\
\hline 2488 & Eragrostis minor Host & Debrecen & 1957 & Siroki Zoltán & DE-siroki-01756.jpg \\
\hline 2488 & Eragrostis minor Host & Debrecen & 1974 & Siroki Zoltán & DE-siroki-01750.jpg \\
\hline 2488 & Eragrostis minor Host & Debrecen & 1983 & Siroki Zoltán & DE-siroki-01749.jpg \\
\hline 2488 & Eragrostis minor Host & Gödöllő & 1954 & $\begin{array}{l}\text { Jeanplong József } \\
\text { - L. Kormány } \\
\text { - M. Rösch }\end{array}$ & DE-siroki-01757.jpg \\
\hline 2488 & Eragrostis minor Host & Mosonmagyaróvár & 1939 & Siroki Zoltán & DE-siroki-01748.jpg \\
\hline 2489 & $\begin{array}{l}\text { Eragrostis cilianensis } \\
\text { (All.) Vignolo ex Janch. }\end{array}$ & Abádszalók & 1956 & Ökrös Bálint & DE-siroki-01761.jpg \\
\hline 2489 & $\begin{array}{l}\text { Eragrostis cilianensis } \\
\text { (All.) Vignolo ex Janch. }\end{array}$ & Háromhuta & 1965 & Gondola István & DE-siroki-01760.jpg \\
\hline 2489 & $\begin{array}{l}\text { Eragrostis cilianensis } \\
\text { (All.) Vignolo ex Janch. }\end{array}$ & Kunágota & 1956 & Laczkó Tibor & DE-siroki-01759.jpg \\
\hline 2490 & Eragrostis pilosa (L.) P. Beauv. & Debrecen & 1947 & Siroki Zoltán & DE-siroki-01742.jpg \\
\hline 2490 & Eragrostis pilosa (L.) P. Beauv. & Debrecen & 1947 & Siroki Zoltán & DE-siroki-01743.jpg \\
\hline 2490 & Eragrostis pilosa (L.) P. Beauv. & Debrecen & 1947 & Siroki Zoltán & DE-siroki-01744.jpg \\
\hline 2490 & Eragrostis pilosa (L.) P. Beauv. & Hortobágy & 1961 & Siroki Zoltán & DE-siroki-01740.jpg \\
\hline 2490 & Eragrostis pilosa (L.) P. Beauv. & Hortobágy & 1961 & Siroki Zoltán & DE-siroki-01741.jpg \\
\hline 2494 & Crypsis aculeata (L.) Aiton & Budapest & 1900 & $\begin{array}{l}\text { Alföldi Flatt } \\
\text { Károly }\end{array}$ & DE-siroki-01008.jpg \\
\hline
\end{tabular}




\begin{tabular}{|c|c|c|c|c|c|}
\hline $\begin{array}{l}\text { Sorszám / } \\
\text { Number }\end{array}$ & Taxon-név / Taxon-name & $\begin{array}{l}\text { Település / } \\
\text { Settlement }\end{array}$ & $\begin{array}{l}\text { Év / } \\
\text { Year }\end{array}$ & $\begin{array}{l}\text { Gyüjtő / } \\
\text { Collector }\end{array}$ & Fájlnév / File-name \\
\hline 2494 & Crypsis aculeata (L.) Aiton & Budapest & 1909 & Kocsis István & DE-siroki-01006.jpg \\
\hline 2494 & Crypsis aculeata (L.) Aiton & Bugyi & 1917 & Magyar Ant. & DE-siroki-01005.jpg \\
\hline 2494 & Crypsis aculeata (L.) Aiton & Debrecen & 1949 & Siroki Zoltán & DE-siroki-01011.jpg \\
\hline 2494 & Crypsis aculeata (L.) Aiton & Debrecen & 1949 & Siroki Zoltán & DE-siroki-01012.jpg \\
\hline 2494 & Crypsis aculeata (L.) Aiton & Debrecen & 1962 & Siroki Zoltán & DE-siroki-01016.jpg \\
\hline 2494 & Crypsis aculeata (L.) Aiton & Debrecen & 1962 & Siroki Zoltán & DE-siroki-01017.jpg \\
\hline 2494 & Crypsis aculeata (L.) Aiton & Debrecen & 1962 & Siroki Zoltán & DE-siroki-01009.jpg \\
\hline 2494 & Crypsis aculeata (L.) Aiton & Hortobágy & 1975 & Siroki Zoltán & DE-siroki-01015.jpg \\
\hline 2494 & Crypsis aculeata (L.) Aiton & Konyár & 1975 & Siroki Zoltán & DE-siroki-01013.jpg \\
\hline 2494 & Crypsis aculeata (L.) Aiton & Konyár & 1975 & Siroki Zoltán & DE-siroki-01014.jpg \\
\hline 2494 & Crypsis aculeata (L.) Aiton & Soltvadkert & 1954 & Siroki Zoltán & DE-siroki-01010.jpg \\
\hline 2495 & Crypsis schoenoides (L.) Lam. & Budaörs & 1941 & Siroki Zoltán & DE-siroki-01031.jpg \\
\hline 2495 & Crypsis schoenoides (L.) Lam. & Budaörs & 1941 & Siroki Zoltán & DE-siroki-01039.jpg \\
\hline 2495 & Crypsis schoenoides (L.) Lam. & Budaörs & 1941 & Siroki Zoltán & DE-siroki-01040.jpg \\
\hline 2495 & Crypsis schoenoides (L.) Lam. & Budaörs & 1941 & Siroki Zoltán & DE-siroki-01041.jpg \\
\hline 2495 & Crypsis schoenoides (L.) Lam. & Debrecen & 1946 & Siroki Zoltán & DE-siroki-01034.jpg \\
\hline 2495 & Crypsis schoenoides (L.) Lam. & Debrecen & 1947 & Siroki Zoltán & DE-siroki-01032.jpg \\
\hline 2495 & Crypsis schoenoides (L.) Lam. & Debrecen & 1947 & Siroki Zoltán & DE-siroki-01042.jpg \\
\hline 2495 & Crypsis schoenoides (L.) Lam. & Debrecen & 1948 & Siroki Zoltán & DE-siroki-01035.jpg \\
\hline 2495 & Crypsis schoenoides (L.) Lam. & Mikepércs & 1962 & Siroki Zoltán & DE-siroki-01036.jpg \\
\hline 2495 & Crypsis schoenoides (L.) Lam. & Mikepércs & 1962 & Siroki Zoltán & DE-siroki-01037.jpg \\
\hline 2495 & Crypsis schoenoides (L.) Lam. & Mikepércs & 1962 & Siroki Zoltán & DE-siroki-01038.jpg \\
\hline 2495 & Crypsis schoenoides (L.) Lam. & Soltvadkert & 1954 & Siroki Zoltán & DE-siroki-01033.jpg \\
\hline 2496 & $\begin{array}{l}\text { Crypsis alopecuroides } \\
\text { (Piller et Mitterp.) Schrad. }\end{array}$ & Debrecen & 1946 & Siroki Zoltán & DE-siroki-01020.jpg \\
\hline 2496 & $\begin{array}{l}\text { Crypsis alopecuroides } \\
\text { (Piller et Mitterp.) Schrad. }\end{array}$ & Debrecen & 1946 & Siroki Zoltán & DE-siroki-01029.jpg \\
\hline 2496 & $\begin{array}{l}\text { Crypsis alopecuroides } \\
\text { (Piller et Mitterp.) Schrad. }\end{array}$ & Debrecen & 1948 & Siroki Zoltán & DE-siroki-01021.jpg \\
\hline 2496 & $\begin{array}{l}\text { Crypsis alopecuroides } \\
\text { (Piller et Mitterp.) Schrad. }\end{array}$ & Egyek & 1947 & Siroki Zoltán & DE-siroki-01027.jpg \\
\hline 2496 & $\begin{array}{l}\text { Crypsis alopecuroides } \\
\text { (Piller et Mitterp.) Schrad. }\end{array}$ & Egyek & 1958 & Siroki Zoltán & DE-siroki-01018.jpg \\
\hline 2496 & $\begin{array}{l}\text { Crypsis alopecuroides } \\
\text { (Piller et Mitterp.) Schrad. }\end{array}$ & Egyek & - & Siroki Zoltán & DE-siroki-01026.jpg \\
\hline 2496 & $\begin{array}{l}\text { Crypsis alopecuroides } \\
\text { (Piller et Mitterp.) Schrad. }\end{array}$ & Gyula & 1974 & Siroki Zoltán & DE-siroki-01022.jpg \\
\hline 2496 & $\begin{array}{l}\text { Crypsis alopecuroides } \\
\text { (Piller et Mitterp.) Schrad. }\end{array}$ & Hortobágy & 1947 & Siroki Zoltán & DE-siroki-01028.jpg \\
\hline 2496 & $\begin{array}{l}\text { Crypsis alopecuroides } \\
\text { (Piller et Mitterp.) Schrad. }\end{array}$ & Hortobágy & 1947 & Siroki Zoltán & DE-siroki-01030.jpg \\
\hline 2496 & $\begin{array}{l}\text { Crypsis alopecuroides } \\
\text { (Piller et Mitterp.) Schrad. }\end{array}$ & Hortobágy & 1947 & Siroki Zoltán & DE-siroki-01024.jpg \\
\hline 2496 & $\begin{array}{l}\text { Crypsis alopecuroides } \\
\text { (Piller et Mitterp.) Schrad. }\end{array}$ & Hortobágy & 1947 & Siroki Zoltán & DE-siroki-01025.jpg \\
\hline 2496 & $\begin{array}{l}\text { Crypsis alopecuroides } \\
\text { (Piller et Mitterp.) Schrad. }\end{array}$ & Hortobágy & 1958 & Siroki Zoltán & DE-siroki-01023.jpg \\
\hline 2496 & $\begin{array}{l}\text { Crypsis alopecuroides } \\
\text { (Piller et Mitterp.) Schrad. }\end{array}$ & Tiszacsege & 1975 & Siroki Zoltán & DE-siroki-01019.jpg \\
\hline 2498 & Cynodon dactylon (L.) Pers. & Budapest & 1941 & Siroki Zoltán & DE-siroki-01572.jpg \\
\hline 2498 & Cynodon dactylon (L.) Pers. & Budapest & 1941 & Siroki Zoltán & DE-siroki-01573.jpg \\
\hline 2498 & Cynodon dactylon (L.) Pers. & Debrecen & 1947 & Siroki Zoltán & DE-siroki-01574.jpg \\
\hline 2499 & Tragus racemosus (L.) All. & Ágasegyháza & 1960 & Siroki Zoltán & DE-siroki-00749.jpg \\
\hline
\end{tabular}




\begin{tabular}{|c|c|c|c|c|c|}
\hline $\begin{array}{l}\text { Sorszám / } \\
\text { Number }\end{array}$ & Taxon-név / Taxon-name & $\begin{array}{l}\text { Település / } \\
\text { Settlement }\end{array}$ & $\begin{array}{l}\text { Év / } \\
\text { Year }\end{array}$ & $\begin{array}{l}\text { Gyűjtő / } \\
\text { Collector }\end{array}$ & Fájlnév / File-name \\
\hline 2499 & Tragus racemosus (L.) All. & Budapest & 1941 & Siroki Zoltán & DE-siroki-00751.jpg \\
\hline 2499 & Tragus racemosus (L.) All. & Budapest & 1941 & Siroki Zoltán & DE-siroki-00752.jpg \\
\hline 2499 & Tragus racemosus (L.) All. & Bugac & 1954 & Siroki Zoltán & DE-siroki-00750.jpg \\
\hline 2499 & Tragus racemosus (L.) All. & Szigetszentmiklós & 1951 & Siroki Zoltán & DE-siroki-00753.jpg \\
\hline 2499 & Tragus racemosus (L.) All. & Szigetszentmiklós & 1951 & Siroki Zoltán & DE-siroki-00754.jpg \\
\hline 2501 & Leersia oryzoides (L.) Sw. & Biatorbágy & 1950 & Siroki Zoltán & DE-siroki-00865.jpg \\
\hline 2501 & Leersia oryzoides (L.) Sw. & Biatorbágy & 1950 & Siroki Zoltán & DE-siroki-00873.jpg \\
\hline 2501 & Leersia oryzoides (L.) Sw. & Biatorbágy & 1950 & Siroki Zoltán & DE-siroki-00874.jpg \\
\hline 2501 & Leersia oryzoides (L.) Sw. & Biatorbágy & - & Siroki Zoltán & DE-siroki-00866.jpg \\
\hline 2501 & Leersia oryzoides (L.) Sw. & Debrecen & 1958 & Siroki Zoltán & DE-siroki-00868.jpg \\
\hline 2501 & Leersia oryzoides (L.) Sw. & Debrecen & 1958 & Siroki Zoltán & DE-siroki-00869.jpg \\
\hline 2501 & Leersia oryzoides (L.) Sw. & Debrecen & 1958 & Siroki Zoltán & DE-siroki-00870.jpg \\
\hline 2501 & Leersia oryzoides (L.) Sw. & Debrecen & 1958 & Siroki Zoltán & DE-siroki-00871.jpg \\
\hline 2501 & Leersia oryzoides (L.) Sw. & Debrecen & 1958 & Siroki Zoltán & DE-siroki-00872.jpg \\
\hline 2501 & Leersia oryzoides (L.) Sw. & Debrecen & 1958 & Siroki Zoltán & DE-siroki-00864.jpg \\
\hline 2501 & Leersia oryzoides (L.) Sw. & Nyíregyháza & 1951 & Siroki Zoltán & DE-siroki-00867.jpg \\
\hline 2504 & Panicum capillare L. & Bátorliget & 1965 & Gondola István & DE-siroki-00806.jpg \\
\hline 2504 & Panicum capillare L. & Bátorliget & 1965 & Gondola István & DE-siroki-00807.jpg \\
\hline 2504 & Panicum capillare L. & Bátorliget & 1966 & Gondola István & DE-siroki-00802.jpg \\
\hline 2504 & Panicum capillare L. & Bátorliget & 1966 & Gondola István & DE-siroki-00803.jpg \\
\hline 2504 & Panicum capillare L. & Bátorliget & 1966 & Gondola István & DE-siroki-00804.jpg \\
\hline 2504 & Panicum capillare L. & Debrecen & 1951 & Gondola István & DE-siroki-00809.jpg \\
\hline 2504 & Panicum capillare L. & Debrecen & 1951 & Siroki Zoltán & DE-siroki-00796.jpg \\
\hline 2504 & Panicum capillare L. & Debrecen & 1951 & Siroki Zoltán & DE-siroki-00797.jpg \\
\hline 2504 & Panicum capillare L. & Debrecen & 1951 & Siroki Zoltán & DE-siroki-00798.jpg \\
\hline 2504 & Panicum capillare L. & Debrecen & 1981 & Gondola István & DE-siroki-00808.jpg \\
\hline 2507 & Echinochloa crus-galli (L.) P. Beauv. & Debrecen & 1947 & Siroki Zoltán & DE-siroki-00772.jpg \\
\hline 2507 & Echinochloa crus-galli (L.) P. Beauv. & Debrecen & 1957 & Siroki Zoltán & DE-siroki-00771.jpg \\
\hline 2507 & Echinochloa crus-galli (L.) P. Beauv. & Debrecen & 1975 & Siroki Zoltán & DE-siroki-00773.jpg \\
\hline 2507 & Echinochloa crus-galli (L.) P. Beauv. & Kisújszállás & 1960 & Fazekas Sándor & DE-siroki-00778.jpg \\
\hline 2507 & Echinochloa crus-galli (L.) P. Beauv. & Kisújszállás & 1960 & Fazekas Sándor & DE-siroki-00779.jpg \\
\hline 2507 & Echinochloa crus-galli (L.) P. Beauv. & Kisújszállás & 1960 & Fazekas Sándor & DE-siroki-00780.jpg \\
\hline 2508 & Echinochloa oryzoides (Ard.) Fritsch & Hortobágy & 1963 & Siroki Zoltán & DE-siroki-00782.jpg \\
\hline 2508 & Echinochloa oryzoides (Ard.) Fritsch & Hortobágy & 1963 & Siroki Zoltán & DE-siroki-00783.jpg \\
\hline 2508 & Echinochloa oryzoides (Ard.) Fritsch & Hortobágy & 1963 & Siroki Zoltán & DE-siroki-00784.jpg \\
\hline 2508 & Echinochloa oryzoides (Ard.) Fritsch & Hortobágy & 1963 & Siroki Zoltán & DE-siroki-00785.jpg \\
\hline 2508 & Echinochloa oryzoides (Ard.) Fritsch & Hortobágy & 1963 & Siroki Zoltán & DE-siroki-00786.jpg \\
\hline 2508 & Echinochloa oryzoides (Ard.) Fritsch & Hortobágy & 1963 & Siroki Zoltán & DE-siroki-00787.jpg \\
\hline 2508 & Echinochloa oryzoides (Ard.) Fritsch & Hortobágy & 1963 & Siroki Zoltán & DE-siroki-00788.jpg \\
\hline 2508 & Echinochloa oryzoides (Ard.) Fritsch & Hortobágy & 1963 & Siroki Zoltán & DE-siroki-00789.jpg \\
\hline 2508 & Echinochloa oryzoides (Ard.) Fritsch & Hortobágy & 1963 & Siroki Zoltán & DE-siroki-00790.jpg \\
\hline 2508 & Echinochloa oryzoides (Ard.) Fritsch & Hortobágy & 1963 & Siroki Zoltán & DE-siroki-00791.jpg \\
\hline 2508 & Echinochloa oryzoides (Ard.) Fritsch & Kisújszállás & 1960 & Fazekas Sándor & DE-siroki-00792.jpg \\
\hline 2508 & Echinochloa oryzoides (Ard.) Fritsch & Kisújszállás & 1960 & Fazekas Sándor & DE-siroki-00781.jpg \\
\hline 2509 & Digitaria ischaemum Schreb. ex Muhl. & Bátorliget & 1966 & Gondola István & DE-siroki-00757.jpg \\
\hline 2509 & Digitaria ischaemum Schreb. ex Muhl. & Bátorliget & 1966 & Gondola István & DE-siroki-00758.jpg \\
\hline
\end{tabular}




\begin{tabular}{|c|c|c|c|c|c|}
\hline $\begin{array}{l}\text { Sorszám / } \\
\text { Number }\end{array}$ & Taxon-név / Taxon-name & $\begin{array}{l}\text { Település / } \\
\text { Settlement }\end{array}$ & $\begin{array}{l}\text { Év / } \\
\text { Year }\end{array}$ & $\begin{array}{l}\text { Gyújitő / } \\
\text { Collector }\end{array}$ & Fájlnév / File-name \\
\hline 2509 & Digitaria ischaemum Schreb. ex Muhl. & Nyíregyháza & 1957 & - & DE-siroki-00759.jpg \\
\hline 2510 & Digitaria sanguinalis (L.) Scop. & Debrecen & 1947 & Siroki Zoltán & DE-siroki-00762.jpg \\
\hline 2510 & Digitaria sanguinalis (L.) Scop. & Debrecen & 1957 & Siroki Zoltán & DE-siroki-00760.jpg \\
\hline 2510 & Digitaria sanguinalis (L.) Scop. & Debrecen & 1957 & Siroki Zoltán & DE-siroki-00761.jpg \\
\hline 2510 & Digitaria sanguinalis (L.) Scop. & Debrecen & 1958 & Siroki Zoltán & DE-siroki-00763.jpg \\
\hline 2510 & Digitaria sanguinalis (L.) Scop. & Debrecen & 1958 & Siroki Zoltán & DE-siroki-00764.jpg \\
\hline 2510 & Digitaria sanguinalis (L.) Scop. & Debrecen & 1958 & Siroki Zoltán & DE-siroki-00765.jpg \\
\hline 2510 & Digitaria sanguinalis (L.) Scop. & Mosonmagyaróvár & 1939 & Siroki Zoltán & DE-siroki-00767.jpg \\
\hline 2511 & Digitaria ciliaris (Retz.) Koeler & Boldogkőváralja & 1944 & Siroki Zoltán & DE-siroki-00769.jpg \\
\hline 2511 & Digitaria ciliaris (Retz.) Koeler & Boldogkőváralja & 1944 & Siroki Zoltán & DE-siroki-00770.jpg \\
\hline 2512 & Setaria pumila (Poir.) Schult. & Debrecen & 1947 & Siroki Zoltán & DE-siroki-00824.jpg \\
\hline 2512 & Setaria pumila (Poir.) Schult. & Debrecen & 1957 & Siroki Zoltán & DE-siroki-00821.jpg \\
\hline 2512 & Setaria pumila (Poir.) Schult. & Debrecen & 1957 & Siroki Zoltán & DE-siroki-00823.jpg \\
\hline 2512 & Setaria pumila (Poir.) Schult. & Gödöllő & 1954 & $\begin{array}{l}\text { Jeanplong József } \\
\text { - L. Kormány } \\
\text { - M. Rösch }\end{array}$ & DE-siroki-00822.jpg \\
\hline 2512 & Setaria pumila (Poir.) Schult. & Mosonmagyaróvár & 1939 & Siroki Zoltán & DE-siroki-00826.jpg \\
\hline 2513 & Setaria italica (L.) P. Beauv. & Debrecen & 1975 & Siroki Zoltán & DE-siroki-00830.jpg \\
\hline 2513 & Setaria italica (L.) P. Beauv. & Debrecen & 1978 & Siroki Zoltán & DE-siroki-00831.jpg \\
\hline 2514 & Setaria verticillata (L.) P. Beauv. & Debrecen & 1947 & Siroki Zoltán & DE-siroki-00818.jpg \\
\hline 2514 & Setaria verticillata (L.) P. Beauv. & Debrecen & 1947 & Siroki Zoltán & DE-siroki-00819.jpg \\
\hline 2514 & Setaria verticillata (L.) P. Beauv. & Debrecen & 1953 & Siroki Zoltán & DE-siroki-00815.jpg \\
\hline 2514 & Setaria verticillata (L.) P. Beauv. & Debrecen & 1953 & Siroki Zoltán & DE-siroki-00816.jpg \\
\hline 2514 & Setaria verticillata (L.) P. Beauv. & Debrecen & 1953 & Siroki Zoltán & DE-siroki-00817.jpg \\
\hline 2514 & Setaria verticillata (L.) P. Beauv. & Debrecen & 1957 & Siroki Zoltán & DE-siroki-00812.jpg \\
\hline 2514 & Setaria verticillata (L.) P. Beauv. & Debrecen & 1957 & Siroki Zoltán & DE-siroki-00813.jpg \\
\hline 2514 & Setaria verticillata (L.) P. Beauv. & Debrecen & 1957 & Siroki Zoltán & DE-siroki-00814.jpg \\
\hline 2514 & Setaria verticillata (L.) P. Beauv. & Mosonmagyaróvár & 1939 & Siroki Zoltán & DE-siroki-00820.jpg \\
\hline 2515 & Setaria viridis (L.) P. Beauv. & Debrecen & 1947 & Siroki Zoltán & DE-siroki-00852.jpg \\
\hline 2515 & Setaria viridis (L.) P. Beauv. & Debrecen & 1957 & Siroki Zoltán & DE-siroki-00851.jpg \\
\hline 2515 & Setaria viridis (L.) P. Beauv. & Debrecen & 1957 & Siroki Zoltán & DE-siroki-00850.jpg \\
\hline 2515 & Setaria viridis (L.) P. Beauv. & Debrecen & 1977 & Siroki Zoltán & DE-siroki-00846.jpg \\
\hline 2515 & Setaria viridis (L.) P. Beauv. & Debrecen & 1977 & Siroki Zoltán & DE-siroki-00847.jpg \\
\hline 2515 & Setaria viridis (L.) P. Beauv. & Debrecen & 1977 & Siroki Zoltán & DE-siroki-00848.jpg \\
\hline 2515 & Setaria viridis (L.) P. Beauv. & Gödöllő & 1954 & $\begin{array}{l}\text { Jeanplong József } \\
\text { - L. Kormány } \\
\text { - M. Rösch }\end{array}$ & DE-siroki-00849.jpg \\
\hline 2515 & Setaria viridis (L.) P. Beauv. & Mosonmagyaróvár & 1939 & Siroki Zoltán & DE-siroki-00854.jpg \\
\hline 2517 & Cenchrus incertus M.A. Curtis & Ágasegyháza & 1956 & Siroki Zoltán & DE-siroki-02551.jpg \\
\hline 2517 & Cenchrus incertus M.A. Curtis & Ágasegyháza & 1956 & Siroki Zoltán & DE-siroki-02552.jpg \\
\hline 2517 & Cenchrus incertus M.A. Curtis & Ágasegyháza & 1956 & Siroki Zoltán & DE-siroki-02554.jpg \\
\hline 2517 & Cenchrus incertus M.A. Curtis & Ágasegyháza & 1970 & Siroki Zoltán & DE-siroki-02555.jpg \\
\hline 2517 & Cenchrus incertus M.A. Curtis & Bugac & 1973 & Siroki Zoltán & DE-siroki-00755.jpg \\
\hline 2517 & Cenchrus incertus M.A. Curtis & Bugac & 1973 & Siroki Zoltán & DE-siroki-00756.jpg \\
\hline 2517 & Cenchrus incertus M.A. Curtis & Bugac & 1973 & Siroki Zoltán & DE-siroki-02556.jpg \\
\hline 2517 & Cenchrus incertus M.A. Curtis & Kecskemét & 1954 & Siroki Zoltán & DE-siroki-02557.jpg \\
\hline 2517 & Cenchrus incertus M.A. Curtis & Kecskemét & 1954 & Siroki Zoltán & DE-siroki-02558.jpg \\
\hline 2517 & Cenchrus incertus M.A. Curtis & Kecskemét & 1954 & Siroki Zoltán & DE-siroki-02560.jpg \\
\hline
\end{tabular}




\begin{tabular}{|c|c|c|c|c|c|}
\hline $\begin{array}{l}\text { Sorszám / } \\
\text { Number }\end{array}$ & Taxon-név / Taxon-name & $\begin{array}{l}\text { Település / } \\
\text { Settlement }\end{array}$ & $\begin{array}{l}\text { Év / } \\
\text { Year }\end{array}$ & $\begin{array}{l}\text { Gyújtő / } \\
\text { Collector }\end{array}$ & Fájlnév / File-name \\
\hline 2517 & Cenchrus incertus M.A. Curtis & Kecskemét & 1954 & Siroki Zoltán & DE-siroki-02561.jpg \\
\hline 2517 & Cenchrus incertus M.A. Curtis & Nagykőrös & 1954 & Siroki Zoltán & DE-siroki-02562.jpg \\
\hline 2517 & Cenchrus incertus M.A. Curtis & Tatárszentgyörgy & 1950 & Kárpáti Zoltán & DE-siroki-02559.jpg \\
\hline 2521 & Chrysopogon gryllus (L.) Trin. & Budapest & 1941 & Siroki Zoltán & DE-siroki-00748.jpg \\
\hline 2521 & Chrysopogon gryllus (L.) Trin. & Budapest & 1941 & Siroki Zoltán & DE-siroki-00740.jpg \\
\hline 2521 & Chrysopogon gryllus (L.) Trin. & Budapest & 1949 & Siroki Zoltán & DE-siroki-00747.jpg \\
\hline 2521 & Chrysopogon gryllus (L.) Trin. & Budapest & 1949 & Siroki Zoltán & DE-siroki-00741.jpg \\
\hline 2521 & Chrysopogon gryllus (L.) Trin. & Budapest & 1949 & Siroki Zoltán & DE-siroki-00742.jpg \\
\hline 2521 & Chrysopogon gryllus (L.) Trin. & Budapest & 1949 & Siroki Zoltán & DE-siroki-00743.jpg \\
\hline 2521 & Chrysopogon gryllus (L.) Trin. & Budapest & 1949 & Siroki Zoltán & DE-siroki-00746.jpg \\
\hline 2521 & Chrysopogon gryllus (L.) Trin. & Nagykovácsi & 1957 & Siroki Zoltán & DE-siroki-00744.jpg \\
\hline 2521 & Chrysopogon gryllus (L.) Trin. & Vámospércs & 1984 & Siroki Zoltán & DE-siroki-00745.jpg \\
\hline 2522 & Bothriochloa ischaemum (L.) Keng & Debrecen & 1947 & Siroki Zoltán & DE-siroki-00716.jpg \\
\hline 2522 & Bothriochloa ischaemum (L.) Keng & Debrecen & 1957 & Siroki Zoltán & DE-siroki-00715.jpg \\
\hline 2522 & Bothriochloa ischaemum (L.) Keng & Debrecen & 1957 & Siroki Zoltán & DE-siroki-00717.jpg \\
\hline 2522 & Bothriochloa ischaemum (L.) Keng & Debrecen & 1957 & Siroki Zoltán & DE-siroki-00718.jpg \\
\hline 2522 & Bothriochloa ischaemum (L.) Keng & Gödöllő & 1954 & $\begin{array}{l}\text { Jeanplong József } \\
\text { - L. Kormány } \\
\text { - M. Rösch }\end{array}$ & DE-siroki-00714.jpg \\
\hline 2522 & Bothriochloa ischaemum (L.) Keng & Sáránd & 1981 & Siroki Zoltán & DE-siroki-00712.jpg \\
\hline 2522 & Bothriochloa ischaemum (L.) Keng & Sáránd & 1981 & Siroki Zoltán & DE-siroki-00713.jpg \\
\hline 2524 & Acorus calamus L. & Balatonberény & 1928 & Papp László & DE-siroki-04093.jpg \\
\hline 2524 & Acorus calamus L. & Gödöllő & 1951 & Siroki Zoltán & DE-siroki-04094.jpg \\
\hline 2524 & Acorus calamus L. & Gödöllő & 1951 & Siroki Zoltán & DE-siroki-04095.jpg \\
\hline 2524 & Acorus calamus L. & Gödöllő & 1951 & Siroki Zoltán & DE-siroki-04096.jpg \\
\hline 2524 & Acorus calamus L. & Gödöllő & 1951 & Siroki Zoltán & DE-siroki-04097.jpg \\
\hline 2524 & Acorus calamus L. & Gödöllő & 1951 & Siroki Zoltán & DE-siroki-04099.jpg \\
\hline 2524 & Acorus calamus L. & Gödöllő & 1951 & Siroki Zoltán & DE-siroki-04098.jpg \\
\hline 2524 & Acorus calamus L. & Keszthely & 1955 & Siroki Zoltán & DE-siroki-04100.jpg \\
\hline 2524 & Acorus calamus L. & Keszthely & 1955 & Siroki Zoltán & DE-siroki-04101.jpg \\
\hline 2524 & Acorus calamus L. & Keszthely & 1955 & Siroki Zoltán & DE-siroki-04102.jpg \\
\hline 2524 & Acorus calamus L. & Keszthely & 1955 & Siroki Zoltán & DE-siroki-04103.jpg \\
\hline 2527 & Arum orientale M. Bieb. & Debrecen & 1950 & Siroki Zoltán & DE-siroki-04108.jpg \\
\hline 2527 & Arum orientale M. Bieb. & Debrecen & 1950 & Siroki Zoltán & DE-siroki-04109.jpg \\
\hline 2530 & Lemna trisulca L. & Budapest & 1958 & Kárpáti Zoltán & DE-siroki-04122.jpg \\
\hline 2530 & Lemna trisulca L. & Dunaharaszti & 1909 & Kocsis István & DE-siroki-04118.jpg \\
\hline 2530 & Lemna trisulca L. & Sárospatak & 1951 & Siroki Zoltán & DE-siroki-04120.jpg \\
\hline 2530 & Lemna trisulca L. & Sárospatak & 1951 & Siroki Zoltán & DE-siroki-04121.jpg \\
\hline 2534 & Lemna minor L. & Hortobágy & 1960 & Siroki Zoltán & DE-siroki-04124.jpg \\
\hline 2536 & Spirodela polyrhiza (L.) Schleid. & Komjáti & 1910 & Thaisz Lajos & DE-siroki-04128.jpg \\
\hline 2537 & Sparganium erectum L. & Budapest & 1916 & Bernátsky Jenő & DE-siroki-00504.jpg \\
\hline 2537 & Sparganium erectum L. & Debrecen & 1956 & Siroki Zoltán & DE-siroki-00506.jpg \\
\hline 2537 & Sparganium erectum L. & Debrecen & 1958 & Pethő Menyhért & DE-siroki-00505.jpg \\
\hline 2541 & Typha laxmanni Lepech. & Hortobágy & 1980 & Kovács Béla & DE-siroki-00493.jpg \\
\hline 2541 & Typha laxmanni Lepech. & Hortobágy & 1980 & Kovács Béla & DE-siroki-00494.jpg \\
\hline 2541 & Typha laxmanni Lepech. & Hortobágy & 1980 & Kovács Béla & DE-siroki-00495.jpg \\
\hline 2541 & Typha laxmanni Lepech. & Hortobágy & 1980 & Kovács Béla & DE-siroki-00496.jpg \\
\hline
\end{tabular}




\begin{tabular}{|c|c|c|c|c|c|}
\hline $\begin{array}{l}\text { Sorszám / } \\
\text { Number }\end{array}$ & Taxon-név / Taxon-name & $\begin{array}{l}\text { Település / } \\
\text { Settlement }\end{array}$ & $\begin{array}{l}\text { Év / } \\
\text { Year }\end{array}$ & $\begin{array}{l}\text { Gyüjtő / } \\
\text { Collector }\end{array}$ & Fájlnév / File-name \\
\hline 2541 & Typha laxmanni Lepech. & Püspökladány & 1978 & Siroki Zoltán & DE-siroki-00498.jpg \\
\hline 2541 & Typha laxmanni Lepech. & Püspökladány & 1981 & Siroki Zoltán & DE-siroki-00492.jpg \\
\hline 2541 & Typha laxmanni Lepech. & Püspökladány & 1981 & Siroki Zoltán & DE-siroki-00497.jpg \\
\hline 2542 & Typha angustifolia L. & Budapest & 1909 & Kocsis István & DE-siroki-00479.jpg \\
\hline 2542 & Typha angustifolia L. & Budapest & 1909 & Kocsis István & DE-siroki-00478.jpg \\
\hline 2542 & Typha angustifolia L. & Debrecen & 1954 & Siroki Zoltán & DE-siroki-00483.jpg \\
\hline 2542 & Typha angustifolia L. & Gödöllő & 1951 & Siroki Zoltán & DE-siroki-00481.jpg \\
\hline 2542 & Typha angustifolia L. & Hajdúsámson & 1958 & Siroki Zoltán & DE-siroki-00484.jpg \\
\hline 2542 & Typha angustifolia L. & Hajdúsámson & 1958 & Siroki Zoltán & DE-siroki-00485.jpg \\
\hline 2542 & Typha angustifolia L. & Hortobágy & 1947 & Siroki Zoltán & DE-siroki-00486.jpg \\
\hline 2542 & Typha angustifolia L. & Tiszafüred & 1949 & Siroki Zoltán & DE-siroki-00482.jpg \\
\hline 2544 & Typha latifolia L. & Debrecen & 1958 & Siroki Zoltán & DE-siroki-00490.jpg \\
\hline 2544 & Typha latifolia L. & Debrecen & 1958 & Siroki Zoltán & DE-siroki-00489.jpg \\
\hline 2544 & Typha latifolia L. & Hajdúsámson & 1958 & Siroki Zoltán & DE-siroki-00487.jpg \\
\hline 2544 & Typha latifolia L. & Nyíri & 1942 & Siroki Zoltán & DE-siroki-00488.jpg \\
\hline 2547 & Scirpoides holoschoenus (L.) Soják & Budapest & 1941 & Siroki Zoltán & DE-siroki-02737.jpg \\
\hline 2547 & Scirpoides holoschoenus (L.) Soják & Debrecen & 1946 & Siroki Zoltán & DE-siroki-02735.jpg \\
\hline 2547 & Scirpoides holoschoenus (L.) Soják & Debrecen & 1947 & Siroki Zoltán & DE-siroki-02730.jpg \\
\hline 2547 & Scirpoides holoschoenus (L.) Soják & Debrecen & 1949 & Siroki Zoltán & DE-siroki-02736.jpg \\
\hline 2547 & Scirpoides holoschoenus (L.) Soják & Hajdúsámson & 1954 & Siroki Zoltán & DE-siroki-02731.jpg \\
\hline 2547 & Scirpoides holoschoenus (L.) Soják & Kecskemét & 1969 & Siroki Zoltán & DE-siroki-02732.jpg \\
\hline 2547 & Scirpoides holoschoenus (L.) Soják & Kecskemét & 1969 & Siroki Zoltán & DE-siroki-02733.jpg \\
\hline 2547 & Scirpoides holoschoenus (L.) Soják & Vámospércs & 1984 & Siroki Zoltán & DE-siroki-02734.jpg \\
\hline 2549 & Schoenoplectus supinus (L.) Palla & Hortobágy & 1954 & Siroki Zoltán & DE-siroki-02673.jpg \\
\hline 2549 & Schoenoplectus supinus (L.) Palla & Hortobágy & 1954 & Siroki Zoltán & DE-siroki-02674.jpg \\
\hline 2549 & Schoenoplectus supinus (L.) Palla & Hortobágy & 1955 & Siroki Zoltán & DE-siroki-02671.jpg \\
\hline 2549 & Schoenoplectus supinus (L.) Palla & Hortobágy & 1955 & $\begin{array}{l}\text { Siroki Zoltán - } \\
\text { Simon Tiborné }\end{array}$ & DE-siroki-02669.jpg \\
\hline 2549 & Schoenoplectus supinus (L.) Palla & Hortobágy & 1955 & $\begin{array}{l}\text { Siroki Zoltán - } \\
\text { Simon Tiborné }\end{array}$ & DE-siroki-02670.jpg \\
\hline 2549 & Schoenoplectus supinus (L.) Palla & Hortobágy & 1955 & $\begin{array}{l}\text { Siroki Zoltán - } \\
\text { Simon Tiborné }\end{array}$ & DE-siroki-02668.jpg \\
\hline 2549 & Schoenoplectus supinus (L.) Palla & Nagykőrös & 1954 & Siroki Zoltán & DE-siroki-02675.jpg \\
\hline 2549 & Schoenoplectus supinus (L.) Palla & Szarvas & 1974 & Siroki Zoltán & DE-siroki-02672.jpg \\
\hline 2550 & Schoenoplectus lacustris (L.) Palla & Debrecen & 1947 & Siroki Zoltán & DE-siroki-02677.jpg \\
\hline 2550 & Schoenoplectus lacustris (L.) Palla & Debrecen & 1947 & Siroki Zoltán & DE-siroki-02679.jpg \\
\hline 2550 & Schoenoplectus lacustris (L.) Palla & Hortobágy & 1954 & Siroki Zoltán & DE-siroki-02680.jpg \\
\hline 2550 & Schoenoplectus lacustris (L.) Palla & Hortobágy & 1954 & Siroki Zoltán & DE-siroki-02676.jpg \\
\hline 2550 & Schoenoplectus lacustris (L.) Palla & Hortobágy & 1956 & Siroki Zoltán & DE-siroki-02678.jpg \\
\hline 2551 & $\begin{array}{l}\text { Schoenoplectus tabernaemontani } \\
\text { (C.C. Gmel.) Palla }\end{array}$ & Abaújkér & 1942 & Siroki Zoltán & DE-siroki-02685.jpg \\
\hline 2551 & $\begin{array}{l}\text { Schoenoplectus tabernaemontani } \\
\text { (C.C. Gmel.) Palla }\end{array}$ & Debrecen & 1947 & Siroki Zoltán & DE-siroki-02682.jpg \\
\hline 2551 & $\begin{array}{l}\text { Schoenoplectus tabernaemontani } \\
\text { (C.C. Gmel.) Palla }\end{array}$ & Debrecen & 1947 & Siroki Zoltán & DE-siroki-02684.jpg \\
\hline 2551 & $\begin{array}{l}\text { Schoenoplectus tabernaemontani } \\
\text { (C.C. Gmel.) Palla }\end{array}$ & Debrecen & 1957 & Siroki Zoltán & DE-siroki-02681.jpg \\
\hline 2551 & $\begin{array}{l}\text { Schoenoplectus tabernaemontani } \\
\text { (C.C. Gmel.) Palla }\end{array}$ & Nyíregyháza & 1951 & Siroki Zoltán & DE-siroki-02686.jpg \\
\hline 2551 & $\begin{array}{l}\text { Schoenoplectus tabernaemontani } \\
\text { (C.C. Gmel.) Palla }\end{array}$ & Nyíregyháza & 1951 & Siroki Zoltán & DE-siroki-02683.jpg \\
\hline
\end{tabular}




\begin{tabular}{|c|c|c|c|c|c|}
\hline $\begin{array}{l}\text { Sorszám / } \\
\text { Number }\end{array}$ & Taxon-név / Taxon-name & $\begin{array}{l}\text { Település / } \\
\text { Settlement }\end{array}$ & $\begin{array}{l}\text { Év / } \\
\text { Year }\end{array}$ & $\begin{array}{l}\text { Gyűjtő / } \\
\text { Collector }\end{array}$ & Fájlnév / File-name \\
\hline 2552 & Schoenoplectus mucronatus (L.) Palla & Hortobágy & 1954 & Siroki Zoltán & DE-siroki-02689.jpg \\
\hline 2552 & Schoenoplectus mucronatus (L.) Palla & Hortobágy & 1954 & Siroki Zoltán & DE-siroki-02690.jpg \\
\hline 2552 & Schoenoplectus mucronatus (L.) Palla & Hortobágy & 1955 & Siroki Zoltán & DE-siroki-02691.jpg \\
\hline 2552 & Schoenoplectus mucronatus (L.) Palla & Hortobágy & 1955 & Siroki Zoltán & DE-siroki-02692.jpg \\
\hline 2552 & Schoenoplectus mucronatus (L.) Palla & Hortobágy & 1955 & Siroki Zoltán & DE-siroki-02695.jpg \\
\hline 2552 & Schoenoplectus mucronatus (L.) Palla & Hortobágy & 1955 & Siroki Zoltán & DE-siroki-02688.jpg \\
\hline 2552 & Schoenoplectus mucronatus (L.) Palla & Hortobágy & 1955 & $\begin{array}{l}\text { Siroki Zoltán - } \\
\text { Simon Tiborné }\end{array}$ & DE-siroki-02693.jpg \\
\hline 2552 & Schoenoplectus mucronatus (L.) Palla & Hortobágy & 1955 & $\begin{array}{l}\text { Siroki Zoltán - } \\
\text { Simon Tiborné }\end{array}$ & DE-siroki-02694.jpg \\
\hline 2552 & Schoenoplectus mucronatus (L.) Palla & Hortobágy & 1955 & $\begin{array}{l}\text { Siroki Zoltán - } \\
\text { Simon Tiborné }\end{array}$ & DE-siroki-02696.jpg \\
\hline 2553 & Schoenoplectus pungens (Vahl) Palla & Keszthely & 1955 & Siroki Zoltán & DE-siroki-02709.jpg \\
\hline 2553 & Schoenoplectus pungens (Vahl) Palla & Keszthely & 1955 & Siroki Zoltán & DE-siroki-02708.jpg \\
\hline 2553 & Schoenoplectus pungens (Vahl) Palla & Keszthely & 1955 & Siroki Zoltán & DE-siroki-02712.jpg \\
\hline 2553 & Schoenoplectus pungens (Vahl) Palla & Keszthely & 1955 & Siroki Zoltán & DE-siroki-02717.jpg \\
\hline 2553 & Schoenoplectus pungens (Vahl) Palla & Keszthely & 1955 & Siroki Zoltán & DE-siroki-02710.jpg \\
\hline 2553 & Schoenoplectus pungens (Vahl) Palla & Keszthely & 1955 & Siroki Zoltán & DE-siroki-02711.jpg \\
\hline 2553 & Schoenoplectus pungens (Vahl) Palla & Keszthely & 1955 & Siroki Zoltán & DE-siroki-02713.jpg \\
\hline 2553 & Schoenoplectus pungens (Vahl) Palla & Keszthely & 1955 & Siroki Zoltán & DE-siroki-02714.jpg \\
\hline 2553 & Schoenoplectus pungens (Vahl) Palla & Keszthely & 1955 & Siroki Zoltán & DE-siroki-02715.jpg \\
\hline 2553 & Schoenoplectus pungens (Vahl) Palla & Keszthely & 1955 & Siroki Zoltán & DE-siroki-02716.jpg \\
\hline 2553 & Schoenoplectus pungens (Vahl) Palla & Keszthely & 1955 & Siroki Zoltán & DE-siroki-02705.jpg \\
\hline 2553 & Schoenoplectus pungens (Vahl) Palla & Keszthely & 1955 & Siroki Zoltán & DE-siroki-02706.jpg \\
\hline 2553 & Schoenoplectus pungens (Vahl) Palla & Keszthely & 1955 & Siroki Zoltán & DE-siroki-02707.jpg \\
\hline 2554 & $\begin{array}{l}\text { Schoenoplectus litoralis } \\
\text { (Schrad.) Palla }\end{array}$ & Hévíz & 1955 & Siroki Zoltán & DE-siroki-02697.jpg \\
\hline 2554 & $\begin{array}{l}\text { Schoenoplectus litoralis } \\
\text { (Schrad.) Palla }\end{array}$ & Hévíz & 1955 & Siroki Zoltán & DE-siroki-02698.jpg \\
\hline 2554 & $\begin{array}{l}\text { Schoenoplectus litoralis } \\
\text { (Schrad.) Palla }\end{array}$ & Hévíz & 1955 & Siroki Zoltán & DE-siroki-02702.jpg \\
\hline 2554 & $\begin{array}{l}\text { Schoenoplectus litoralis } \\
\text { (Schrad.) Palla }\end{array}$ & Hévíz & 1955 & Siroki Zoltán & DE-siroki-02703.jpg \\
\hline 2554 & $\begin{array}{l}\text { Schoenoplectus litoralis } \\
\text { (Schrad.) Palla }\end{array}$ & Hévíz & 1955 & Siroki Zoltán & DE-siroki-02704.jpg \\
\hline 2554 & $\begin{array}{l}\text { Schoenoplectus litoralis } \\
\text { (Schrad.) Palla }\end{array}$ & Hévíz & 1955 & Siroki Zoltán & DE-siroki-02699.jpg \\
\hline 2554 & $\begin{array}{l}\text { Schoenoplectus litoralis } \\
\text { (Schrad.) Palla }\end{array}$ & Hévíz & 1955 & Siroki Zoltán & DE-siroki-02700.jpg \\
\hline 2554 & $\begin{array}{l}\text { Schoenoplectus litoralis } \\
\text { (Schrad.) Palla }\end{array}$ & Hévíz & 1955 & Siroki Zoltán & DE-siroki-02701.jpg \\
\hline $2556-2560$ & Bolboschoenus maritimus agg. & Abaújkér & 1942 & Siroki Zoltán & DE-siroki-02765.jpg \\
\hline $2556-2560$ & Bolboschoenus maritimus agg. & Budaörs & 1941 & Siroki Zoltán & DE-siroki-02769.jpg \\
\hline $2556-2560$ & Bolboschoenus maritimus agg. & Budaörs & 1941 & Siroki Zoltán & DE-siroki-02770.jpg \\
\hline $2556-2560$ & Bolboschoenus maritimus agg. & Budapest & 1940 & Siroki Zoltán & DE-siroki-02763.jpg \\
\hline $2556-2560$ & Bolboschoenus maritimus agg. & Cegléd & 1969 & Siroki Zoltán & DE-siroki-02766.jpg \\
\hline $2556-2560$ & Bolboschoenus maritimus agg. & Debrecen & 1947 & Siroki Zoltán & DE-siroki-02767.jpg \\
\hline $2556-2560$ & Bolboschoenus maritimus agg. & Debrecen & 1984 & Siroki Zoltán & DE-siroki-02764.jpg \\
\hline $2556-2560$ & Bolboschoenus maritimus agg. & Hortobágy & 1986 & Siroki Zoltán & DE-siroki-02762.jpg \\
\hline 2561 & Scirpus sylvaticus L. & "Dobogókő" & 1956 & Siroki Zoltán & DE-siroki-02752.jpg \\
\hline 2561 & Scirpus sylvaticus L. & "Dobogókő" & 1956 & Siroki Zoltán & DE-siroki-02754.jpg \\
\hline 2561 & Scirpus sylvaticus L. & "Dobogókő" & 1956 & Siroki Zoltán & DE-siroki-02757.jpg \\
\hline
\end{tabular}




\begin{tabular}{|c|c|c|c|c|c|}
\hline $\begin{array}{l}\text { Sorszám / } \\
\text { Number }\end{array}$ & Taxon-név / Taxon-name & $\begin{array}{l}\text { Település / } \\
\text { Settlement }\end{array}$ & $\begin{array}{l}\text { Év / } \\
\text { Year }\end{array}$ & $\begin{array}{l}\text { Gyűjtő / } \\
\text { Collector }\end{array}$ & Fájlnév / File-name \\
\hline 2561 & Scirpus sylvaticus L. & "Dobogókő" & 1956 & Siroki Zoltán & DE-siroki-02759.jpg \\
\hline 2561 & Scirpus sylvaticus L. & "Dobogókő" & 1956 & Siroki Zoltán & DE-siroki-02760.jpg \\
\hline 2561 & Scirpus sylvaticus L. & Gödöllő & 1952 & Siroki Zoltán & DE-siroki-02755.jpg \\
\hline 2561 & Scirpus sylvaticus L. & Gödöllő & 1952 & Siroki Zoltán & DE-siroki-02756.jpg \\
\hline 2561 & Scirpus sylvaticus L. & Háromhuta & 1977 & Siroki Zoltán & DE-siroki-02761.jpg \\
\hline 2561 & Scirpus sylvaticus L. & Miskolc & 1959 & Halász Tibor & DE-siroki-02758.jpg \\
\hline 2561 & Scirpus sylvaticus L. & Újléta & 1967 & Siroki Zoltán & DE-siroki-02751.jpg \\
\hline 2561 & Scirpus sylvaticus L. & Újléta & 1968 & Siroki Zoltán & DE-siroki-02750.jpg \\
\hline 2562 & Scirpus radicans Schkuhr & Budapest & 1899 & Borbás Vince & DE-siroki-02772.jpg \\
\hline 2562 & Scirpus radicans Schkuhr & Budapest & 1904 & $\begin{array}{l}\text { Thaisz Lajos - } \\
\text { Baán Lajos }\end{array}$ & DE-siroki-02775.jpg \\
\hline 2562 & Scirpus radicans Schkuhr & Budapest & 1909 & Kocsis István & DE-siroki-02774.jpg \\
\hline 2562 & Scirpus radicans Schkuhr & Budapest & 1909 & Kocsis István & DE-siroki-02771.jpg \\
\hline 2562 & Scirpus radicans Schkuhr & Budapest & 1909 & Kocsis István & DE-siroki-02773.jpg \\
\hline 2563 & Blysmus compressus (L.) Panz. & Debrecen & 1954 & Siroki Zoltán & DE-siroki-02743.jpg \\
\hline 2563 & Blysmus compressus (L.) Panz. & Debrecen & 1954 & Siroki Zoltán & DE-siroki-02747.jpg \\
\hline 2563 & Blysmus compressus (L.) Panz. & Debrecen & 1956 & Siroki Zoltán & DE-siroki-02742.jpg \\
\hline 2563 & Blysmus compressus (L.) Panz. & Gödöllő & 1951 & Siroki Zoltán & DE-siroki-02739.jpg \\
\hline 2563 & Blysmus compressus (L.) Panz. & Gödöllő & 1951 & Siroki Zoltán & DE-siroki-02738.jpg \\
\hline 2563 & Blysmus compressus (L.) Panz. & Gödöllő & 1951 & Siroki Zoltán & DE-siroki-02744.jpg \\
\hline 2563 & Blysmus compressus (L.) Panz. & Gödöllő & 1951 & Siroki Zoltán & DE-siroki-02741.jpg \\
\hline 2563 & Blysmus compressus (L.) Panz. & Miskolc & 1959 & Siroki Zoltán & DE-siroki-02745.jpg \\
\hline 2563 & Blysmus compressus (L.) Panz. & Miskolc & 1959 & Siroki Zoltán & DE-siroki-02746.jpg \\
\hline 2563 & Blysmus compressus (L.) Panz. & Miskolc & 1959 & Siroki Zoltán & DE-siroki-02748.jpg \\
\hline 2564 & Eriophorum vaginatum L. & Csaroda & 1954 & Simon Tiborné & DE-siroki-02636.jpg \\
\hline 2564 & Eriophorum vaginatum L. & Csaroda & 1954 & Simon Tiborné & DE-siroki-02637.jpg \\
\hline 2564 & Eriophorum vaginatum L. & Csaroda & 1954 & Simon Tiborné & DE-siroki-02638.jpg \\
\hline 2564 & Eriophorum vaginatum L. & Csaroda & 1954 & Simon Tiborné & DE-siroki-02635.jpg \\
\hline 2565 & Eriophorum angustifolium Honck. & Budapest & 1958 & Siroki Zoltán & DE-siroki-02655.jpg \\
\hline 2565 & Eriophorum angustifolium Honck. & Budapest & 1958 & Siroki Zoltán & DE-siroki-02652.jpg \\
\hline 2565 & Eriophorum angustifolium Honck. & Debrecen & 1948 & Siroki Zoltán & DE-siroki-02656.jpg \\
\hline 2565 & Eriophorum angustifolium Honck. & Debrecen & 1948 & Siroki Zoltán & DE-siroki-02657.jpg \\
\hline 2565 & Eriophorum angustifolium Honck. & Debrecen & 1957 & Siroki Zoltán & DE-siroki-02659.jpg \\
\hline 2565 & Eriophorum angustifolium Honck. & Debrecen & 1957 & Siroki Zoltán & DE-siroki-02660.jpg \\
\hline 2565 & Eriophorum angustifolium Honck. & Gödöllő & 1952 & Siroki Zoltán & DE-siroki-02658.jpg \\
\hline 2565 & Eriophorum angustifolium Honck. & Gödöllő & 1952 & Siroki Zoltán & DE-siroki-02661.jpg \\
\hline 2565 & Eriophorum angustifolium Honck. & Gödöllo” & 1952 & Siroki Zoltán & DE-siroki-02653.jpg \\
\hline 2565 & Eriophorum angustifolium Honck. & Gödöllő & 1952 & Siroki Zoltán & DE-siroki-02665.jpg \\
\hline 2565 & Eriophorum angustifolium Honck. & Veresegyház & 1963 & Siroki Zoltán & DE-siroki-02654.jpg \\
\hline 2566 & Eriophorum latifolium Hoppe & Gödöllo” & 1951 & Siroki Zoltán & DE-siroki-02650.jpg \\
\hline 2566 & Eriophorum latifolium Hoppe & Gödöllő & 1951 & Siroki Zoltán & DE-siroki-02651.jpg \\
\hline 2566 & Eriophorum latifolium Hoppe & Gödöllő & 1952 & Siroki Zoltán & DE-siroki-02646.jpg \\
\hline 2566 & Eriophorum latifolium Hoppe & Gödöllő & 1952 & Siroki Zoltán & DE-siroki-02647.jpg \\
\hline 2566 & Eriophorum latifolium Hoppe & Gödöllő & 1952 & Siroki Zoltán & DE-siroki-02648.jpg \\
\hline 2566 & Eriophorum latifolium Hoppe & Gödöllő & 1952 & Siroki Zoltán & DE-siroki-02649.jpg \\
\hline 2566 & Eriophorum latifolium Hoppe & Nagyhuta & 1961 & Siroki Zoltán & DE-siroki-02645.jpg \\
\hline
\end{tabular}




\begin{tabular}{|c|c|c|c|c|c|}
\hline $\begin{array}{l}\text { Sorszám / } \\
\text { Number }\end{array}$ & Taxon-név / Taxon-name & $\begin{array}{l}\text { Település / } \\
\text { Settlement }\end{array}$ & $\begin{array}{l}\text { Év / } \\
\text { Year }\end{array}$ & $\begin{array}{l}\text { Gyűjtő / } \\
\text { Collector }\end{array}$ & Fájlnév / File-name \\
\hline 2568 & $\begin{array}{l}\text { Eleocharis acicularis } \\
\text { (L.) Roem. et Schult. }\end{array}$ & Budapest & 1887 & Czakó Kálmán & DE-siroki-02778.jpg \\
\hline 2568 & $\begin{array}{l}\text { Eleocharis acicularis } \\
\text { (L.) Roem. et Schult. }\end{array}$ & Budapest & 1909 & Kocsis István & DE-siroki-02780.jpg \\
\hline 2568 & $\begin{array}{l}\text { Eleocharis acicularis } \\
\text { (L.) Roem. et Schult. }\end{array}$ & Budapest & 1909 & Kocsis István & DE-siroki-02779.jpg \\
\hline 2568 & $\begin{array}{l}\text { Eleocharis acicularis } \\
\text { (L.) Roem. et Schult. }\end{array}$ & Dunaújváros & 1950 & Kárpáti Zoltán & DE-siroki-02781.jpg \\
\hline 2568 & $\begin{array}{l}\text { Eleocharis acicularis } \\
\text { (L.) Roem. et Schult. }\end{array}$ & Hortobágy & 1975 & Siroki Zoltán & DE-siroki-02782.jpg \\
\hline 2568 & $\begin{array}{l}\text { Eleocharis acicularis } \\
\text { (L.) Roem. et Schult. }\end{array}$ & Keszthely & 1955 & Siroki Zoltán & DE-siroki-02776.jpg \\
\hline 2568 & $\begin{array}{l}\text { Eleocharis acicularis } \\
\text { (L.) Roem. et Schult. }\end{array}$ & Keszthely & 1955 & Siroki Zoltán & DE-siroki-02777.jpg \\
\hline 2568 & $\begin{array}{l}\text { Eleocharis acicularis } \\
\text { (L.) Roem. et Schult. }\end{array}$ & Sopron & 1950 & Kárpáti Zoltán & DE-siroki-02783.jpg \\
\hline 2570 & Eleocharis carniolica W.D.J. Koch & Háromhuta & 1967 & Siroki Zoltán & DE-siroki-02785.jpg \\
\hline 2570 & Eleocharis carniolica W.D.J. Koch & Háromhuta & 1967 & Siroki Zoltán & DE-siroki-02786.jpg \\
\hline 2570 & Eleocharis carniolica W.D.J. Koch & Háromhuta & 1967 & Siroki Zoltán & DE-siroki-02787.jpg \\
\hline 2573 & $\begin{array}{l}\text { Eleocharis palustris } \\
\text { (L.) Roem. et Schult. }\end{array}$ & Budapest & 1958 & Siroki Zoltán & DE-siroki-02806.jpg \\
\hline 2573 & $\begin{array}{l}\text { Eleocharis palustris } \\
\text { (L.) Roem. et Schult. }\end{array}$ & Debrecen & 1947 & Siroki Zoltán & DE-siroki-02793.jpg \\
\hline 2573 & $\begin{array}{l}\text { Eleocharis palustris } \\
\text { (L.) Roem. et Schult. }\end{array}$ & Debrecen & 1947 & Siroki Zoltán & DE-siroki-02809.jpg \\
\hline 2573 & $\begin{array}{l}\text { Eleocharis palustris } \\
\text { (L.) Roem. et Schult. }\end{array}$ & Debrecen & 1947 & Siroki Zoltán & DE-siroki-02810.jpg \\
\hline 2573 & $\begin{array}{l}\text { Eleocharis palustris } \\
\text { (L.) Roem. et Schult. }\end{array}$ & Debrecen & 1947 & Siroki Zoltán & DE-siroki-02807.jpg \\
\hline 2573 & $\begin{array}{l}\text { Eleocharis palustris } \\
\text { (L.) Roem. et Schult. }\end{array}$ & Debrecen & 1955 & Siroki Zoltán & DE-siroki-02808.jpg \\
\hline 2573 & $\begin{array}{l}\text { Eleocharis palustris } \\
\text { (L.) Roem. et Schult. }\end{array}$ & Debrecen & 1958 & Pethő Menyhért & DE-siroki-02795.jpg \\
\hline 2573 & $\begin{array}{l}\text { Eleocharis palustris } \\
\text { (L.) Roem. et Schult. }\end{array}$ & Debrecen & 1958 & Pethő Menyhért & DE-siroki-02796.jpg \\
\hline 2573 & $\begin{array}{l}\text { Eleocharis palustris } \\
\text { (L.) Roem. et Schult. }\end{array}$ & Debrecen & 1958 & Pethő Menyhért & DE-siroki-02794.jpg \\
\hline 2573 & $\begin{array}{l}\text { Eleocharis palustris } \\
\text { (L.) Roem. et Schult. }\end{array}$ & Mezőpeterd & 1962 & Siroki Zoltán & DE-siroki-02797.jpg \\
\hline 2573 & $\begin{array}{l}\text { Eleocharis palustris } \\
\text { (L.) Roem. et Schult. }\end{array}$ & Mezőpeterd & 1962 & Siroki Zoltán & DE-siroki-02798.jpg \\
\hline 2573 & $\begin{array}{l}\text { Eleocharis palustris } \\
\text { (L.) Roem. et Schult. }\end{array}$ & Mezőpeterd & 1962 & Siroki Zoltán & DE-siroki-02799.jpg \\
\hline 2573 & $\begin{array}{l}\text { Eleocharis palustris } \\
\text { (L.) Roem. et Schult. }\end{array}$ & Mezőpeterd & 1962 & Siroki Zoltán & DE-siroki-02800.jpg \\
\hline 2573 & $\begin{array}{l}\text { Eleocharis palustris } \\
\text { (L.) Roem. et Schult. }\end{array}$ & Mezőpeterd & 1962 & Siroki Zoltán & DE-siroki-02801.jpg \\
\hline 2573 & $\begin{array}{l}\text { Eleocharis palustris } \\
\text { (L.) Roem. et Schult. }\end{array}$ & Mezőpeterd & 1962 & Siroki Zoltán & DE-siroki-02802.jpg \\
\hline 2573 & $\begin{array}{l}\text { Eleocharis palustris } \\
\text { (L.) Roem. et Schult. }\end{array}$ & Mezőpeterd & 1962 & Siroki Zoltán & DE-siroki-02803.jpg \\
\hline 2573 & $\begin{array}{l}\text { Eleocharis palustris } \\
\text { (L.) Roem. et Schult. }\end{array}$ & Mezőpeterd & 1962 & Siroki Zoltán & DE-siroki-02804.jpg \\
\hline 2573 & $\begin{array}{l}\text { Eleocharis palustris } \\
\text { (L.) Roem. et Schult. }\end{array}$ & Szigetszentmiklós & 1951 & Siroki Zoltán & DE-siroki-02805.jpg \\
\hline 2576 & Dichostylis micheliana (L.) Nees & Biharugra & 1961 & Siroki Zoltán & DE-siroki-02718.jpg \\
\hline 2576 & Dichostylis micheliana (L.) Nees & Biharugra & 1961 & Siroki Zoltán & DE-siroki-02719.jpg \\
\hline 2576 & Dichostylis micheliana (L.) Nees & Biharugra & 1961 & Siroki Zoltán & DE-siroki-02720.jpg \\
\hline 2576 & Dichostylis micheliana (L.) Nees & Biharugra & 1961 & Siroki Zoltán & DE-siroki-02721.jpg \\
\hline
\end{tabular}




\begin{tabular}{|c|c|c|c|c|c|}
\hline $\begin{array}{l}\text { Sorszám / } \\
\text { Number }\end{array}$ & Taxon-név / Taxon-name & $\begin{array}{l}\text { Település / } \\
\text { Settlement }\end{array}$ & $\begin{array}{l}\text { Év / } \\
\text { Year }\end{array}$ & $\begin{array}{l}\text { Gyűjtő / } \\
\text { Collector }\end{array}$ & Fájlnév / File-name \\
\hline 2576 & Dichostylis micheliana (L.) Nees & Biharugra & 1961 & Siroki Zoltán & DE-siroki-02722.jpg \\
\hline 2576 & Dichostylis micheliana (L.) Nees & Biharugra & 1961 & Siroki Zoltán & DE-siroki-02723.jpg \\
\hline 2576 & Dichostylis micheliana (L.) Nees & Biharugra & 1961 & Siroki Zoltán & DE-siroki-02724.jpg \\
\hline 2576 & Dichostylis micheliana (L.) Nees & Biharugra & 1961 & Siroki Zoltán & DE-siroki-02725.jpg \\
\hline 2576 & Dichostylis micheliana (L.) Nees & Dunaújváros & 1950 & Kárpáti Zoltán & DE-siroki-02729.jpg \\
\hline 2576 & Dichostylis micheliana (L.) Nees & Gyula & 1974 & Siroki Zoltán & DE-siroki-02726.jpg \\
\hline 2576 & Dichostylis micheliana (L.) Nees & Gyula & 1974 & Siroki Zoltán & DE-siroki-02727.jpg \\
\hline 2576 & Dichostylis micheliana (L.) Nees & Gyula & 1974 & Siroki Zoltán & DE-siroki-02728.jpg \\
\hline 2577 & Cyperus pannonicus Jacq. & Balmazújváros & 1975 & Siroki Zoltán & DE-siroki-02578.jpg \\
\hline 2577 & Cyperus pannonicus Jacq. & Debrecen & 1947 & Siroki Zoltán & DE-siroki-02582.jpg \\
\hline 2577 & Cyperus pannonicus Jacq. & Hortobágy & 1975 & Siroki Zoltán & DE-siroki-02580.jpg \\
\hline 2577 & Cyperus pannonicus Jacq. & Hortobágy & 1975 & Siroki Zoltán & DE-siroki-02581.jpg \\
\hline 2577 & Cyperus pannonicus Jacq. & Hortobágy & 1975 & Siroki Zoltán & DE-siroki-02583.jpg \\
\hline 2577 & Cyperus pannonicus Jacq. & Hortobágy & 1975 & Siroki Zoltán & DE-siroki-02584.jpg \\
\hline 2577 & Cyperus pannonicus Jacq. & Soltvadkert & 1958 & Gondola István & DE-siroki-02579.jpg \\
\hline 2578 & Cyperus flavescens L. & Budapest & 1909 & Kocsis István & DE-siroki-02568.jpg \\
\hline 2578 & Cyperus flavescens L. & Debrecen & 1951 & Siroki Zoltán & DE-siroki-02574.jpg \\
\hline 2578 & Cyperus flavescens L. & Debrecen & 1951 & Siroki Zoltán & DE-siroki-02577.jpg \\
\hline 2578 & Cyperus flavescens L. & Dunaharaszti & 1909 & Kocsis István & DE-siroki-02569.jpg \\
\hline 2578 & Cyperus flavescens L. & Hajdúsámson & 1958 & Siroki Zoltán & DE-siroki-02571.jpg \\
\hline 2578 & Cyperus flavescens L. & Hajdúsámson & 1958 & Siroki Zoltán & DE-siroki-02572.jpg \\
\hline 2578 & Cyperus flavescens L. & Hajdúsámson & 1958 & Siroki Zoltán & DE-siroki-02573.jpg \\
\hline 2578 & Cyperus flavescens L. & Keszthely & 1955 & Siroki Zoltán & DE-siroki-02575.jpg \\
\hline 2578 & Cyperus flavescens L. & Nagykőrös & 1954 & Siroki Zoltán & DE-siroki-02576.jpg \\
\hline 2578 & Cyperus flavescens L. & Szigetszentmiklós & 1951 & Siroki Zoltán & DE-siroki-02570.jpg \\
\hline 2579 & Cyperus fuscus L. & Biharugra & 1961 & Siroki Zoltán & DE-siroki-02601.jpg \\
\hline 2579 & Cyperus fuscus L. & Biharugra & 1961 & Siroki Zoltán & DE-siroki-02602.jpg \\
\hline 2579 & Cyperus fuscus L. & Biharugra & 1961 & Siroki Zoltán & DE-siroki-02603.jpg \\
\hline 2579 & Cyperus fuscus L. & Budapest & 1909 & Kocsis István & DE-siroki-02596.jpg \\
\hline 2579 & Cyperus fuscus L. & Budapest & 1909 & Kocsis István & DE-siroki-02595.jpg \\
\hline 2579 & Cyperus fuscus L. & Debrecen & 1946 & Siroki Zoltán & DE-siroki-02597.jpg \\
\hline 2579 & Cyperus fuscus L. & Debrecen & 1946 & Siroki Zoltán & DE-siroki-02598.jpg \\
\hline 2579 & Cyperus fuscus L. & Debrecen & 1948 & Siroki Zoltán & DE-siroki-02599.jpg \\
\hline 2579 & Cyperus fuscus L. & Debrecen & 1951 & Siroki Zoltán & DE-siroki-02609.jpg \\
\hline 2579 & Cyperus fuscus L. & Debrecen & 1958 & Siroki Zoltán & DE-siroki-02600.jpg \\
\hline 2579 & Cyperus fuscus L. & Debrecen & 1958 & Siroki Zoltán & DE-siroki-02604.jpg \\
\hline 2579 & Cyperus fuscus L. & Debrecen & 1958 & Siroki Zoltán & DE-siroki-02605.jpg \\
\hline 2579 & Cyperus fuscus L. & Mosonmagyaróvár & 1939 & Siroki Zoltán & DE-siroki-02606.jpg \\
\hline 2579 & Cyperus fuscus L. & Mosonmagyaróvár & 1939 & Siroki Zoltán & DE-siroki-02608.jpg \\
\hline 2579 & Cyperus fuscus L. & Szarvas & 1974 & Siroki Zoltán & DE-siroki-02594.jpg \\
\hline 2580 & Cyperus difformis L. & Hortobágy & 1958 & Siroki Zoltán & DE-siroki-02592.jpg \\
\hline 2580 & Cyperus difformis L. & Hortobágy & 1958 & Siroki Zoltán & DE-siroki-02589.jpg \\
\hline 2580 & Cyperus difformis L. & Hortobágy & 1958 & Siroki Zoltán & DE-siroki-02590.jpg \\
\hline 2580 & Cyperus difformis L. & Kardoskút & - & Siroki Zoltán & DE-siroki-02591.jpg \\
\hline 2580 & Cyperus difformis L. & Kisújszállás & 1960 & Fazekas Sándor & DE-siroki-02593.jpg \\
\hline 2580 & Cyperus difformis L. & Szarvas & 1974 & Siroki Zoltán & DE-siroki-02585.jpg \\
\hline
\end{tabular}




\begin{tabular}{|c|c|c|c|c|c|}
\hline $\begin{array}{l}\text { Sorszám / } \\
\text { Number }\end{array}$ & Taxon-név / Taxon-name & $\begin{array}{l}\text { Település / } \\
\text { Settlement }\end{array}$ & $\begin{array}{l}\text { Év / } \\
\text { Year }\end{array}$ & $\begin{array}{l}\text { Gyújtő / } \\
\text { Collector }\end{array}$ & Fájlnév / File-name \\
\hline 2580 & Cyperus difformis L. & Szarvas & 1974 & Siroki Zoltán & DE-siroki-02586.jpg \\
\hline 2580 & Cyperus difformis L. & Szarvas & 1974 & Siroki Zoltán & DE-siroki-02587.jpg \\
\hline 2580 & Cyperus difformis L. & Szarvas & 1974 & Siroki Zoltán & DE-siroki-02588.jpg \\
\hline 2581 & Cyperus glomeratus L. & Debrecen & 1951 & Siroki Zoltán & DE-siroki-02611.jpg \\
\hline 2581 & Cyperus glomeratus L. & Debrecen & 1951 & Siroki Zoltán & DE-siroki-02612.jpg \\
\hline 2581 & Cyperus glomeratus L. & Debrecen & 1951 & Siroki Zoltán & DE-siroki-02613.jpg \\
\hline 2581 & Cyperus glomeratus L. & Debrecen & 1951 & Siroki Zoltán & DE-siroki-02614.jpg \\
\hline 2581 & Cyperus glomeratus L. & Debrecen & 1951 & Siroki Zoltán & DE-siroki-02615.jpg \\
\hline 2581 & Cyperus glomeratus L. & Debrecen & 1951 & Siroki Zoltán & DE-siroki-02616.jpg \\
\hline 2581 & Cyperus glomeratus L. & Debrecen & 1968 & Siroki Zoltán & DE-siroki-02617.jpg \\
\hline 2581 & Cyperus glomeratus L. & Debrecen & 1968 & Siroki Zoltán & DE-siroki-02618.jpg \\
\hline 2581 & Cyperus glomeratus L. & Debrecen & 1968 & Siroki Zoltán & DE-siroki-02619.jpg \\
\hline 2581 & Cyperus glomeratus L. & Debrecen & 1968 & Siroki Zoltán & DE-siroki-02620.jpg \\
\hline 2581 & Cyperus glomeratus L. & Debrecen & 1968 & Siroki Zoltán & DE-siroki-02621.jpg \\
\hline 2581 & Cyperus glomeratus L. & Debrecen & 1968 & Siroki Zoltán & DE-siroki-02622.jpg \\
\hline 2581 & Cyperus glomeratus L. & Debrecen & 1968 & Siroki Zoltán & DE-siroki-02623.jpg \\
\hline 2581 & Cyperus glomeratus L. & Debrecen & 1968 & Siroki Zoltán & DE-siroki-02624.jpg \\
\hline 2581 & Cyperus glomeratus L. & Szigetszentmárton & 1951 & Siroki Zoltán & DE-siroki-02610.jpg \\
\hline 2581 & Cyperus glomeratus L. & Szigetszentmárton & 1951 & Siroki Zoltán & DE-siroki-02625.jpg \\
\hline 2585 & Cladium mariscus (L.) Pohl & Hévíz & 1955 & Siroki Zoltán & DE-siroki-02822.jpg \\
\hline 2585 & Cladium mariscus (L.) Pohl & Hévíz & 1955 & Siroki Zoltán & DE-siroki-02823.jpg \\
\hline 2585 & Cladium mariscus (L.) Pohl & Hévíz & 1955 & Siroki Zoltán & DE-siroki-02825.jpg \\
\hline 2585 & Cladium mariscus (L.) Pohl & Hévíz & 1955 & Siroki Zoltán & DE-siroki-02824.jpg \\
\hline 2585 & Cladium mariscus (L.) Pohl & Hévíz & 1955 & Siroki Zoltán & DE-siroki-02820.jpg \\
\hline 2585 & Cladium mariscus (L.) Pohl & Hévíz & 1955 & Siroki Zoltán & DE-siroki-02821.jpg \\
\hline 2585 & Cladium mariscus (L.) Pohl & Hévíz & 1955 & Siroki Zoltán & DE-siroki-02827.jpg \\
\hline 2585 & Cladium mariscus (L.) Pohl & Hévíz & 1955 & Siroki Zoltán & DE-siroki-02828.jpg \\
\hline 2585 & Cladium mariscus (L.) Pohl & Hévíz & 1955 & Siroki Zoltán & DE-siroki-02826.jpg \\
\hline 2587 & Schoenus nigricans L. & Bugac & 1954 & Siroki Zoltán & DE-siroki-02812.jpg \\
\hline 2587 & Schoenus nigricans L. & Bugac & 1954 & Siroki Zoltán & DE-siroki-02814.jpg \\
\hline 2587 & Schoenus nigricans L. & Bugac & 1954 & Siroki Zoltán & DE-siroki-02816.jpg \\
\hline 2587 & Schoenus nigricans L. & Hévíz & 1955 & Siroki Zoltán & DE-siroki-02815.jpg \\
\hline 2587 & Schoenus nigricans L. & Hévíz & 1955 & Siroki Zoltán & DE-siroki-02813.jpg \\
\hline 2589 & Carex davalliana Sm. & Budapest & 1887 & Czakó Kálmán & DE-siroki-02844.jpg \\
\hline 2589 & Carex davalliana Sm. & Budapest & 1904 & $\begin{array}{l}\text { Thaisz Lajos - } \\
\text { Baán Lajos }\end{array}$ & DE-siroki-02842.jpg \\
\hline 2589 & Carex davalliana Sm. & Budapest & 1909 & Kocsis István & DE-siroki-02839.jpg \\
\hline 2589 & Carex davalliana Sm. & Budapest & 1909 & Kocsis István & DE-siroki-02841.jpg \\
\hline 2589 & Carex davalliana Sm. & Budapest & 1909 & Kocsis István & DE-siroki-02845.jpg \\
\hline 2589 & Carex davalliana Sm. & Gödöllő & 1951 & Koltay A. & DE-siroki-02846.jpg \\
\hline 2589 & Carex davalliana Sm. & Gödöllő & 1951 & Siroki Zoltán & DE-siroki-02847.jpg \\
\hline 2589 & Carex davalliana Sm. & Gödöllő & 1951 & Siroki Zoltán & DE-siroki-02848.jpg \\
\hline 2591 & Carex remota L. & "Dobogókő" & 1956 & Siroki Zoltán & DE-siroki-03112.jpg \\
\hline 2591 & Carex remota L. & "Mátra" & 1982 & Siroki Zoltán & DE-siroki-03098.jpg \\
\hline 2591 & Carex remota L. & "Mátra" & 1982 & Siroki Zoltán & DE-siroki-03099.jpg \\
\hline 2591 & Carex remota L. & Háromhuta & 1961 & Siroki Zoltán & DE-siroki-03115.jpg \\
\hline 2591 & Carex remota L. & Háromhuta & 1961 & Siroki Zoltán & DE-siroki-03116.jpg \\
\hline
\end{tabular}




\begin{tabular}{|c|c|c|c|c|c|}
\hline $\begin{array}{l}\text { Sorszám / } \\
\text { Number }\end{array}$ & Taxon-név / Taxon-name & $\begin{array}{l}\text { Település / } \\
\text { Settlement }\end{array}$ & $\begin{array}{l}\text { Év / } \\
\text { Year }\end{array}$ & $\begin{array}{l}\text { Gyújtő / } \\
\text { Collector }\end{array}$ & Fájlnév / File-name \\
\hline 2591 & Carex remota L. & Háromhuta & 1961 & Siroki Zoltán & DE-siroki-03109.jpg \\
\hline 2591 & Carex remota L. & Háromhuta & 1961 & Siroki Zoltán & DE-siroki-03117.jpg \\
\hline 2591 & Carex remota L. & Hollóháza & 1940 & Siroki Zoltán & DE-siroki-03120.jpg \\
\hline 2591 & Carex remota L. & Hollóháza & 1940 & Siroki Zoltán & DE-siroki-03121.jpg \\
\hline 2591 & Carex remota L. & Miskolc & 1959 & Siroki Zoltán & DE-siroki-03110.jpg \\
\hline 2591 & Carex remota L. & Miskolc & 1959 & Siroki Zoltán & DE-siroki-03111.jpg \\
\hline 2591 & Carex remota L. & Nagyhuta & 1978 & Siroki Zoltán & DE-siroki-03104.jpg \\
\hline 2591 & Carex remota L. & Pásztó & 1952 & Siroki Zoltán & DE-siroki-03103.jpg \\
\hline 2591 & Carex remota L. & Pécs & 1954 & Siroki Zoltán & DE-siroki-03114.jpg \\
\hline 2591 & Carex remota L. & Pécs & 1958 & Siroki Zoltán & DE-siroki-04115.jpg \\
\hline 2591 & Carex remota L. & Pécs & 1958 & Siroki Zoltán & DE-siroki-04116.jpg \\
\hline 2591 & Carex remota L. & Pécs & 1958 & Siroki Zoltán & DE-siroki-03100.jpg \\
\hline 2591 & Carex remota L. & Pécs & 1958 & Siroki Zoltán & DE-siroki-03101.jpg \\
\hline 2591 & Carex remota L. & Szilvásvárad & 1954 & Siroki Zoltán & DE-siroki-03113.jpg \\
\hline 2591 & Carex remota L. & Szilvásvárad & 1954 & Siroki Zoltán & DE-siroki-03108.jpg \\
\hline 2591 & Carex remota L. & Szilvásvárad & 1954 & Siroki Zoltán & DE-siroki-03102.jpg \\
\hline 2592 & Carex ovalis Gooden. & "Mátra" & 1982 & Siroki Zoltán & DE-siroki-03082.jpg \\
\hline 2592 & Carex ovalis Gooden. & "Mátra" & 1982 & Siroki Zoltán & DE-siroki-03083.jpg \\
\hline 2592 & Carex ovalis Gooden. & Debrecen & 1948 & Siroki Zoltán & DE-siroki-03097.jpg \\
\hline 2592 & Carex ovalis Gooden. & Debrecen & 1948 & Siroki Zoltán & DE-siroki-03092.jpg \\
\hline 2592 & Carex ovalis Gooden. & Debrecen & 1954 & Siroki Zoltán & DE-siroki-03088.jpg \\
\hline 2592 & Carex ovalis Gooden. & Debrecen & 1954 & Siroki Zoltán & DE-siroki-03095.jpg \\
\hline 2592 & Carex ovalis Gooden. & Debrecen & 1955 & $\begin{array}{l}\text { Siroki Zoltán - } \\
\text { Farkas Attila }\end{array}$ & DE-siroki-03093.jpg \\
\hline 2592 & Carex ovalis Gooden. & Debrecen & 1986 & Siroki Zoltán & DE-siroki-03081.jpg \\
\hline 2592 & Carex ovalis Gooden. & Miskolc & 1959 & Siroki Zoltán & DE-siroki-03094.jpg \\
\hline 2592 & Carex ovalis Gooden. & Újléta & 1967 & Siroki Zoltán & DE-siroki-03091.jpg \\
\hline 2592 & Carex ovalis Gooden. & Újléta & 1967 & Siroki Zoltán & DE-siroki-03096.jpg \\
\hline 2593 & Carex praecox Schreb. & Abaújkér & 1942 & Siroki Zoltán & DE-siroki-03018.jpg \\
\hline 2593 & Carex praecox Schreb. & Budapest & 1909 & Degen Árpád & DE-siroki-03593.jpg \\
\hline 2593 & Carex praecox Schreb. & Budapest & 1909 & Degen Árpád & DE-siroki-04111.jpg \\
\hline 2593 & Carex praecox Schreb. & Budapest & 1952 & Siroki Zoltán & DE-siroki-03022.jpg \\
\hline 2593 & Carex praecox Schreb. & Debrecen & 1947 & Siroki Zoltán & DE-siroki-03032.jpg \\
\hline 2593 & Carex praecox Schreb. & Debrecen & 1947 & Siroki Zoltán & DE-siroki-03036.jpg \\
\hline 2593 & Carex praecox Schreb. & Debrecen & 1949 & Siroki Zoltán & DE-siroki-03027.jpg \\
\hline 2593 & Carex praecox Schreb. & Debrecen & 1949 & Siroki Zoltán & DE-siroki-03033.jpg \\
\hline 2593 & Carex praecox Schreb. & Debrecen & 1954 & Siroki Zoltán & DE-siroki-03030.jpg \\
\hline 2593 & Carex praecox Schreb. & Egyek & 1947 & Siroki Zoltán & DE-siroki-03020.jpg \\
\hline 2593 & Carex praecox Schreb. & Egyek & 1947 & Siroki Zoltán & DE-siroki-03037.jpg \\
\hline 2593 & Carex praecox Schreb. & Egyek & 1949 & Siroki Zoltán & DE-siroki-03038.jpg \\
\hline 2593 & Carex praecox Schreb. & Gödöllő & 1952 & Siroki Zoltán & DE-siroki-03017.jpg \\
\hline 2593 & Carex praecox Schreb. & Gödöllő & 1952 & Siroki Zoltán & DE-siroki-03024.jpg \\
\hline 2593 & Carex praecox Schreb. & Gödöllő & 1952 & Siroki Zoltán & DE-siroki-03031.jpg \\
\hline 2593 & Carex praecox Schreb. & Hortobágy & 1949 & Siroki Zoltán & DE-siroki-03021.jpg \\
\hline 2593 & Carex praecox Schreb. & Hortobágy & 1949 & Siroki Zoltán & DE-siroki-03034.jpg \\
\hline 2593 & Carex praecox Schreb. & Pilisszentiván & 1909 & Degen Árpád & DE-siroki-04114.jpg \\
\hline 2593 & Carex praecox Schreb. & Pilisszentiván & 1909 & Degen Árpád & DE-siroki-03591.jpg \\
\hline
\end{tabular}




\begin{tabular}{|c|c|c|c|c|c|}
\hline $\begin{array}{l}\text { Sorszám / } \\
\text { Number }\end{array}$ & Taxon-név / Taxon-name & $\begin{array}{l}\text { Település / } \\
\text { Settlement }\end{array}$ & $\begin{array}{l}\text { Év / } \\
\text { Year }\end{array}$ & $\begin{array}{l}\text { Gyújtő / } \\
\text { Collector }\end{array}$ & Fájlnév / File-name \\
\hline 2593 & Carex praecox Schreb. & Pilisszentiván & 1915 & Degen Árpád & DE-siroki-03023.jpg \\
\hline 2593 & Carex praecox Schreb. & Szarvaskő & 1958 & Siroki Zoltán & DE-siroki-03019.jpg \\
\hline 2594 & Carex brizoides L. & Bátorliget & 1954 & Siroki Zoltán & DE-siroki-03055.jpg \\
\hline 2594 & Carex brizoides L. & Bátorliget & 1954 & Siroki Zoltán & DE-siroki-03046.jpg \\
\hline 2594 & Carex brizoides L. & Bátorliget & 1954 & Siroki Zoltán & DE-siroki-03047.jpg \\
\hline 2594 & Carex brizoides L. & Bátorliget & 1954 & Siroki Zoltán & DE-siroki-03052.jpg \\
\hline 2594 & Carex brizoides L. & Bátorliget & 1954 & Siroki Zoltán & DE-siroki-03053.jpg \\
\hline 2594 & Carex brizoides L. & Debrecen & 1950 & Siroki Zoltán & DE-siroki-03056.jpg \\
\hline 2594 & Carex brizoides L. & Debrecen & 1950 & Siroki Zoltán & DE-siroki-03050.jpg \\
\hline 2594 & Carex brizoides L. & Körmend & 1904 & Thaisz Lajos & DE-siroki-03045.jpg \\
\hline 2594 & Carex brizoides L. & Nagyhuta & 1961 & Siroki Zoltán & DE-siroki-03051.jpg \\
\hline 2594 & Carex brizoides L. & Nagyhuta & 1961 & Siroki Zoltán & DE-siroki-03039.jpg \\
\hline 2594 & Carex brizoides L. & Nagyhuta & 1961 & Siroki Zoltán & DE-siroki-03040.jpg \\
\hline 2594 & Carex brizoides L. & Nagyhuta & 1961 & Siroki Zoltán & DE-siroki-03041.jpg \\
\hline 2594 & Carex brizoides L. & Nagyhuta & 1961 & Siroki Zoltán & DE-siroki-03042.jpg \\
\hline 2594 & Carex brizoides L. & Nagyhuta & 1961 & Siroki Zoltán & DE-siroki-03043.jpg \\
\hline 2594 & Carex brizoides L. & Nagyhuta & 1961 & Siroki Zoltán & DE-siroki-03048.jpg \\
\hline 2594 & Carex brizoides L. & Nagyhuta & 1961 & Siroki Zoltán & DE-siroki-03049.jpg \\
\hline 2594 & Carex brizoides L. & Tarpa & 1955 & $\begin{array}{l}\text { Siroki Zoltán - } \\
\text { Farkas Attila }\end{array}$ & DE-siroki-03054.jpg \\
\hline 2595 & Carex echinata Murray & Budapest & 1915 & Degen Árpád & DE-siroki-03134.jpg \\
\hline 2595 & Carex echinata Murray & Debrecen & 1948 & Siroki Zoltán & DE-siroki-03136.jpg \\
\hline 2595 & Carex echinata Murray & Debrecen & 1948 & Siroki Zoltán & DE-siroki-03138.jpg \\
\hline 2595 & Carex echinata Murray & Debrecen & 1951 & Siroki Zoltán & DE-siroki-03124.jpg \\
\hline 2595 & Carex echinata Murray & Debrecen & 1951 & Siroki Zoltán & DE-siroki-03123.jpg \\
\hline 2595 & Carex echinata Murray & Debrecen & 1951 & Siroki Zoltán & DE-siroki-03122.jpg \\
\hline 2595 & Carex echinata Murray & Debrecen & 1951 & Siroki Zoltán & DE-siroki-03147.jpg \\
\hline 2595 & Carex echinata Murray & Debrecen & 1955 & Siroki Zoltán & DE-siroki-03125.jpg \\
\hline 2595 & Carex echinata Murray & Debrecen & 1956 & Siroki Zoltán & DE-siroki-03140.jpg \\
\hline 2595 & Carex echinata Murray & Debrecen & 1958 & Siroki Zoltán & DE-siroki-03139.jpg \\
\hline 2595 & Carex echinata Murray & Nagyhuta & 1961 & Siroki Zoltán & DE-siroki-03126.jpg \\
\hline 2595 & Carex echinata Murray & Nagyhuta & 1961 & Siroki Zoltán & DE-siroki-03127.jpg \\
\hline 2595 & Carex echinata Murray & Nagyhuta & 1961 & Siroki Zoltán & DE-siroki-03137.jpg \\
\hline 2595 & Carex echinata Murray & Nagyhuta & 1961 & Siroki Zoltán & DE-siroki-03141.jpg \\
\hline 2595 & Carex echinata Murray & Nagyhuta & 1961 & Siroki Zoltán & DE-siroki-03142.jpg \\
\hline 2595 & Carex echinata Murray & Nagyhuta & 1961 & Siroki Zoltán & DE-siroki-03143.jpg \\
\hline 2595 & Carex echinata Murray & Nagyhuta & 1961 & Siroki Zoltán & DE-siroki-03144.jpg \\
\hline 2595 & Carex echinata Murray & Nagyhuta & 1961 & Siroki Zoltán & DE-siroki-03145.jpg \\
\hline 2595 & Carex echinata Murray & Nagyhuta & 1961 & Siroki Zoltán & DE-siroki-03146.jpg \\
\hline 2596 & Carex elongata L. & Bátorliget & 1957 & Siroki Zoltán & DE-siroki-03063.jpg \\
\hline 2596 & Carex elongata L. & Bátorliget & 1957 & Siroki Zoltán & DE-siroki-03064.jpg \\
\hline 2596 & Carex elongata L. & Bátorliget & 1957 & Siroki Zoltán & DE-siroki-03065.jpg \\
\hline 2596 & Carex elongata L. & Bátorliget & 1957 & Siroki Zoltán & DE-siroki-03068.jpg \\
\hline 2596 & Carex elongata L. & Bátorliget & 1957 & Siroki Zoltán & DE-siroki-03070.jpg \\
\hline 2596 & Carex elongata L. & Kállósemjén & 1955 & Kovács Béla & DE-siroki-03067.jpg \\
\hline 2596 & Carex elongata L. & Nagyhuta & 1961 & Siroki Zoltán & DE-siroki-03069.jpg \\
\hline 2596 & Carex elongata L. & Nagyhuta & 1961 & Siroki Zoltán & DE-siroki-03073.jpg \\
\hline
\end{tabular}




\begin{tabular}{|c|c|c|c|c|c|}
\hline $\begin{array}{l}\text { Sorszám / } \\
\text { Number }\end{array}$ & Taxon-név / Taxon-name & $\begin{array}{l}\text { Település / } \\
\text { Settlement }\end{array}$ & $\begin{array}{l}\text { Év / } \\
\text { Year }\end{array}$ & $\begin{array}{l}\text { Gyújtő / } \\
\text { Collector }\end{array}$ & Fájlnév / File-name \\
\hline 2596 & Carex elongata L. & Nagyhuta & 1961 & Siroki Zoltán & DE-siroki-03074.jpg \\
\hline 2596 & Carex elongata L. & Nagyhuta & 1961 & Siroki Zoltán & DE-siroki-03075.jpg \\
\hline 2596 & Carex elongata L. & Nagyhuta & 1961 & Siroki Zoltán & DE-siroki-03076.jpg \\
\hline 2596 & Carex elongata L. & Nagyhuta & 1961 & Siroki Zoltán & DE-siroki-03062.jpg \\
\hline 2596 & Carex elongata L. & Nagyhuta & 1961 & Siroki Zoltán & DE-siroki-03071.jpg \\
\hline 2596 & Carex elongata L. & Nagyhuta & 1961 & Siroki Zoltán & DE-siroki-03072.jpg \\
\hline 2596 & Carex elongata L. & Nagyhuta & 1961 & Siroki Zoltán & DE-siroki-03061.jpg \\
\hline 2596 & Carex elongata L. & Nagyhuta & 1961 & Siroki Zoltán & DE-siroki-03077.jpg \\
\hline 2596 & Carex elongata L. & Nagyhuta & 1961 & Siroki Zoltán & DE-siroki-03078.jpg \\
\hline 2596 & Carex elongata L. & Nagyhuta & 1978 & Siroki Zoltán & DE-siroki-03080.jpg \\
\hline 2596 & Carex elongata L. & Nagyhuta & 1978 & Siroki Zoltán & DE-siroki-03079.jpg \\
\hline 2598 & Carex divulsa Stokes & "Dobogókő" & 1957 & Siroki Zoltán & DE-siroki-03001.jpg \\
\hline 2598 & Carex divulsa Stokes & "Dobogókő" & 1957 & Siroki Zoltán & DE-siroki-03002.jpg \\
\hline 2598 & Carex divulsa Stokes & "Dobogókő" & 1957 & Siroki Zoltán & DE-siroki-03016.jpg \\
\hline 2598 & Carex divulsa Stokes & Budapest & 1952 & Siroki Zoltán & DE-siroki-02998.jpg \\
\hline 2598 & Carex divulsa Stokes & Budapest & 1952 & Siroki Zoltán & DE-siroki-03005.jpg \\
\hline 2598 & Carex divulsa Stokes & Budapest & 1952 & Siroki Zoltán & DE-siroki-03006.jpg \\
\hline 2598 & Carex divulsa Stokes & Debrecen & 1946 & Siroki Zoltán & DE-siroki-03011.jpg \\
\hline 2598 & Carex divulsa Stokes & Debrecen & 1948 & Siroki Zoltán & DE-siroki-03015.jpg \\
\hline 2598 & Carex divulsa Stokes & Debrecen & 1949 & Siroki Zoltán & DE-siroki-03004.jpg \\
\hline 2598 & Carex divulsa Stokes & Debrecen & 1950 & Siroki Zoltán & DE-siroki-02996.jpg \\
\hline 2598 & Carex divulsa Stokes & Debrecen & 1954 & Siroki Zoltán & DE-siroki-03008.jpg \\
\hline 2598 & Carex divulsa Stokes & Debrecen & 1954 & Siroki Zoltán & DE-siroki-03014.jpg \\
\hline 2598 & Carex divulsa Stokes & Debrecen & 1954 & Siroki Zoltán & DE-siroki-03003.jpg \\
\hline 2598 & Carex divulsa Stokes & Debrecen & 1955 & Siroki Zoltán & DE-siroki-02997.jpg \\
\hline 2598 & Carex divulsa Stokes & Debrecen & 1955 & Siroki Zoltán & DE-siroki-03009.jpg \\
\hline 2598 & Carex divulsa Stokes & Debrecen & 1984 & Siroki Zoltán & DE-siroki-03000.jpg \\
\hline 2598 & Carex divulsa Stokes & Debrecen & 1984 & Siroki Zoltán & DE-siroki-03010.jpg \\
\hline 2598 & Carex divulsa Stokes & Debrecen & 1984 & Siroki Zoltán & DE-siroki-03012.jpg \\
\hline 2598 & Carex divulsa Stokes & Debrecen & 1984 & Siroki Zoltán & DE-siroki-03013.jpg \\
\hline 2598 & Carex divulsa Stokes & Gödöllő & 1952 & Siroki Zoltán & DE-siroki-03007.jpg \\
\hline 2598 & Carex divulsa Stokes & Hosszúhetény & 1958 & Siroki Zoltán & DE-siroki-02999.jpg \\
\hline 2599 & Carex spicata Huds. & Budaörs & 1941 & Siroki Zoltán & DE-siroki-02947.jpg \\
\hline 2599 & Carex spicata Huds. & Budaörs & 1941 & Siroki Zoltán & DE-siroki-02956.jpg \\
\hline 2599 & Carex spicata Huds. & Budapest & 1951 & Siroki Zoltán & DE-siroki-02961.jpg \\
\hline 2599 & Carex spicata Huds. & Budapest & 1962 & Siroki Zoltán & DE-siroki-02950.jpg \\
\hline 2599 & Carex spicata Huds. & Budapest & 1962 & Siroki Zoltán & DE-siroki-02951.jpg \\
\hline 2599 & Carex spicata Huds. & Debrecen & 1949 & Siroki Zoltán & DE-siroki-02958.jpg \\
\hline 2599 & Carex spicata Huds. & Debrecen & 1958 & Siroki Zoltán & DE-siroki-02952.jpg \\
\hline 2599 & Carex spicata Huds. & Debrecen & 1958 & Siroki Zoltán & DE-siroki-02953.jpg \\
\hline 2599 & Carex spicata Huds. & Debrecen & 1958 & Siroki Zoltán & DE-siroki-02954.jpg \\
\hline 2599 & Carex spicata Huds. & Debrecen & 1958 & Siroki Zoltán & DE-siroki-02955.jpg \\
\hline 2599 & Carex spicata Huds. & Debrecen & 1958 & Siroki Zoltán & DE-siroki-02963.jpg \\
\hline 2599 & Carex spicata Huds. & Debrecen & 1961 & Siroki Zoltán & DE-siroki-02949.jpg \\
\hline 2599 & Carex spicata Huds. & Debrecen & 1984 & Siroki Zoltán & DE-siroki-02964.jpg \\
\hline 2599 & Carex spicata Huds. & Gödöllő & 1952 & Siroki Zoltán & DE-siroki-02962.jpg \\
\hline
\end{tabular}




\begin{tabular}{|c|c|c|c|c|c|}
\hline $\begin{array}{l}\text { Sorszám / } \\
\text { Number }\end{array}$ & Taxon-név / Taxon-name & $\begin{array}{l}\text { Település / } \\
\text { Settlement }\end{array}$ & $\begin{array}{l}\text { Év / } \\
\text { Year }\end{array}$ & $\begin{array}{l}\text { Gyújtő / } \\
\text { Collector }\end{array}$ & Fájlnév / File-name \\
\hline 2599 & Carex spicata Huds. & Háromhuta & 1965 & Siroki Zoltán & DE-siroki-02957.jpg \\
\hline 2599 & Carex spicata Huds. & Háromhuta & 1965 & Siroki Zoltán & DE-siroki-02959.jpg \\
\hline 2599 & Carex spicata Huds. & Pilisszentiván & 1909 & Kocsis István & DE-siroki-02960.jpg \\
\hline 2599 & Carex spicata Huds. & Rezi & 1930 & Rigler József & DE-siroki-02966.jpg \\
\hline 2599 & Carex spicata Huds. & Újléta & 1984 & Siroki Zoltán & DE-siroki-02965.jpg \\
\hline 2600 & Carex pairaei F.W. Schultz & "Mátra" & 1984 & Siroki Zoltán & DE-siroki-02974.jpg \\
\hline 2600 & Carex pairaei F.W. Schultz & "Mátra" & 1984 & Siroki Zoltán & DE-siroki-02975.jpg \\
\hline 2600 & Carex pairaei F.W. Schultz & "Mátra" & 1984 & Siroki Zoltán & DE-siroki-02976.jpg \\
\hline 2600 & Carex pairaei F.W. Schultz & "Mátra" & 1984 & Siroki Zoltán & DE-siroki-02978.jpg \\
\hline 2600 & Carex pairaei F.W. Schultz & "Mátra" & 1984 & Siroki Zoltán & DE-siroki-02981.jpg \\
\hline 2600 & Carex pairaei F.W. Schultz & Budapest & 1952 & Siroki Zoltán & DE-siroki-02985.jpg \\
\hline 2600 & Carex pairaei F.W. Schultz & Debrecen & 1958 & Siroki Zoltán & DE-siroki-02971.jpg \\
\hline 2600 & Carex pairaei F.W. Schultz & Debrecen & 1958 & Siroki Zoltán & DE-siroki-02972.jpg \\
\hline 2600 & Carex pairaei F.W. Schultz & Debrecen & 1958 & Siroki Zoltán & DE-siroki-02973.jpg \\
\hline 2600 & Carex pairaei F.W. Schultz & Debrecen & 1958 & Siroki Zoltán & DE-siroki-02980.jpg \\
\hline 2600 & Carex pairaei F.W. Schultz & Debrecen & 1976 & Siroki Zoltán & DE-siroki-02969.jpg \\
\hline 2600 & Carex pairaei F.W. Schultz & Debrecen & 1976 & Siroki Zoltán & DE-siroki-02970.jpg \\
\hline 2600 & Carex pairaei F.W. Schultz & Gödöllő & 1952 & Siroki Zoltán & DE-siroki-02986.jpg \\
\hline 2600 & Carex pairaei F.W. Schultz & Gödöllő & 1952 & Siroki Zoltán & DE-siroki-02987.jpg \\
\hline 2600 & Carex pairaei F.W. Schultz & Gödöllő & 1952 & Siroki Zoltán & DE-siroki-02989.jpg \\
\hline 2600 & Carex pairaei F.W. Schultz & Gödöllő & 1952 & Siroki Zoltán & DE-siroki-02988.jpg \\
\hline 2600 & Carex pairaei F.W. Schultz & Létavértes & 1984 & Siroki Zoltán & DE-siroki-02979.jpg \\
\hline 2600 & Carex pairaei F.W. Schultz & Miskolc & 1905 & Hulják János & DE-siroki-02977.jpg \\
\hline 2600 & Carex pairaei F.W. Schultz & Szilvásvárad & 1960 & Siroki Zoltán & DE-siroki-02994.jpg \\
\hline 2600 & Carex pairaei F.W. Schultz & Szilvásvárad & 1960 & Siroki Zoltán & DE-siroki-02995.jpg \\
\hline 2601 & Carex vulpina L. & Abaújkér & 1942 & Siroki Zoltán & DE-siroki-02942.jpg \\
\hline 2601 & Carex vulpina L. & Debrecen & 1958 & Siroki Zoltán & DE-siroki-02939.jpg \\
\hline 2601 & Carex vulpina L. & Debrecen & 1958 & Siroki Zoltán & DE-siroki-02940.jpg \\
\hline 2601 & Carex vulpina L. & Debrecen & 1958 & Siroki Zoltán & DE-siroki-02944.jpg \\
\hline 2601 & Carex vulpina L. & Debrecen & 1958 & Siroki Zoltán & DE-siroki-02945.jpg \\
\hline 2601 & Carex vulpina L. & Debrecen & 1984 & Siroki Zoltán & DE-siroki-02938.jpg \\
\hline 2601 & Carex vulpina L. & Debrecen & 1984 & Siroki Zoltán & DE-siroki-02937.jpg \\
\hline 2603 & Carex paniculata L. & Dunaharaszti & 1916 & Degen Árpád & DE-siroki-02932.jpg \\
\hline 2603 & Carex paniculata L. & Gödöllő & 1952 & Siroki Zoltán & DE-siroki-02929.jpg \\
\hline 2603 & Carex paniculata L. & Gödöllő & 1952 & Siroki Zoltán & DE-siroki-02928.jpg \\
\hline 2603 & Carex paniculata L. & Gödöllő & 1952 & Siroki Zoltán & DE-siroki-02933.jpg \\
\hline 2603 & Carex paniculata L. & Gödöllő & 1952 & Siroki Zoltán & DE-siroki-02934.jpg \\
\hline 2603 & Carex paniculata L. & Gödöllő & 1952 & Siroki Zoltán & DE-siroki-02936.jpg \\
\hline 2603 & Carex paniculata L. & Gödöllő & 1952 & Siroki Zoltán & DE-siroki-02935.jpg \\
\hline 2603 & Carex paniculata L. & Gödöllő & 1952 & Siroki Zoltán & DE-siroki-02927.jpg \\
\hline 2604 & Carex appropinquata Schumach. & Budapest & 1909 & Kocsis István & DE-siroki-02923.jpg \\
\hline 2604 & Carex appropinquata Schumach. & Debrecen & 1948 & Siroki Zoltán & DE-siroki-02921.jpg \\
\hline 2604 & Carex appropinquata Schumach. & Debrecen & 1948 & Siroki Zoltán & DE-siroki-02922.jpg \\
\hline 2604 & Carex appropinquata Schumach. & Debrecen & 1948 & Siroki Zoltán & DE-siroki-02916.jpg \\
\hline 2604 & Carex appropinquata Schumach. & Debrecen & 1950 & Siroki Zoltán & DE-siroki-02915.jpg \\
\hline 2604 & Carex appropinquata Schumach. & Debrecen & 1957 & Siroki Zoltán & DE-siroki-02917.jpg \\
\hline
\end{tabular}




\begin{tabular}{|c|c|c|c|c|c|}
\hline $\begin{array}{l}\text { Sorszám / } \\
\text { Number }\end{array}$ & Taxon-név / Taxon-name & $\begin{array}{l}\text { Település / } \\
\text { Settlement }\end{array}$ & $\begin{array}{l}\text { Év / } \\
\text { Year }\end{array}$ & $\begin{array}{l}\text { Gyűjtő / } \\
\text { Collector }\end{array}$ & Fájlnév / File-name \\
\hline 2604 & Carex appropinquata Schumach. & Gödöllő & 1951 & Siroki Zoltán & DE-siroki-02913.jpg \\
\hline 2604 & Carex appropinquata Schumach. & Gödöllő & 1951 & Siroki Zoltán & DE-siroki-02914.jpg \\
\hline 2604 & Carex appropinquata Schumach. & Gödöllő & 1951 & Siroki Zoltán & DE-siroki-02918.jpg \\
\hline 2604 & Carex appropinquata Schumach. & Gödöllő & 1951 & Siroki Zoltán & DE-siroki-02919.jpg \\
\hline 2604 & Carex appropinquata Schumach. & Gödöllő & 1951 & Siroki Zoltán & DE-siroki-02920.jpg \\
\hline 2605 & Carex diandra Schrank & Háromhuta & 1961 & Siroki Zoltán & DE-siroki-02900.jpg \\
\hline 2605 & Carex diandra Schrank & Háromhuta & 1961 & Siroki Zoltán & DE-siroki-02902.jpg \\
\hline 2605 & Carex diandra Schrank & Háromhuta & 1961 & Siroki Zoltán & DE-siroki-02910.jpg \\
\hline 2605 & Carex diandra Schrank & Kállósemjén & 1959 & Siroki Zoltán & DE-siroki-02901.jpg \\
\hline 2605 & Carex diandra Schrank & Kállósemjén & 1959 & Siroki Zoltán & DE-siroki-02889.jpg \\
\hline 2605 & Carex diandra Schrank & Kállósemjén & 1959 & Siroki Zoltán & DE-siroki-02890.jpg \\
\hline 2605 & Carex diandra Schrank & Kállósemjén & 1959 & Siroki Zoltán & DE-siroki-02891.jpg \\
\hline 2605 & Carex diandra Schrank & Kállósemjén & 1959 & Siroki Zoltán & DE-siroki-02892.jpg \\
\hline 2605 & Carex diandra Schrank & Kállósemjén & 1959 & Siroki Zoltán & DE-siroki-02893.jpg \\
\hline 2605 & Carex diandra Schrank & Kállósemjén & 1959 & Siroki Zoltán & DE-siroki-02894.jpg \\
\hline 2605 & Carex diandra Schrank & Kállósemjén & 1959 & Siroki Zoltán & DE-siroki-02895.jpg \\
\hline 2605 & Carex diandra Schrank & Kállósemjén & 1959 & Siroki Zoltán & DE-siroki-02896.jpg \\
\hline 2605 & Carex diandra Schrank & Kállósemjén & 1959 & Siroki Zoltán & DE-siroki-02897.jpg \\
\hline 2605 & Carex diandra Schrank & Kállósemjén & 1959 & Siroki Zoltán & DE-siroki-02898.jpg \\
\hline 2605 & Carex diandra Schrank & Kállósemjén & 1959 & Siroki Zoltán & DE-siroki-02899.jpg \\
\hline 2605 & Carex diandra Schrank & Kállósemjén & 1959 & Siroki Zoltán & DE-siroki-02903.jpg \\
\hline 2605 & Carex diandra Schrank & Kállósemjén & 1959 & Siroki Zoltán & DE-siroki-02905.jpg \\
\hline 2605 & Carex diandra Schrank & Kállósemjén & 1959 & Siroki Zoltán & DE-siroki-02906.jpg \\
\hline 2605 & Carex diandra Schrank & Kállósemjén & 1959 & Siroki Zoltán & DE-siroki-02907.jpg \\
\hline 2605 & Carex diandra Schrank & Kállósemjén & 1959 & Siroki Zoltán & DE-siroki-02908.jpg \\
\hline 2605 & Carex diandra Schrank & Kállósemjén & 1959 & Siroki Zoltán & DE-siroki-02909.jpg \\
\hline 2605 & Carex diandra Schrank & Kállósemjén & 1959 & Siroki Zoltán & DE-siroki-02911.jpg \\
\hline 2606 & Carex disticha Huds. & Budapest & 1904 & Thaisz Lajos & DE-siroki-03167.jpg \\
\hline 2606 & Carex disticha Huds. & Budapest & 1909 & Kocsis István & DE-siroki-03168.jpg \\
\hline 2606 & Carex disticha Huds. & Budapest & 1958 & Siroki Zoltán & DE-siroki-03184.jpg \\
\hline 2606 & Carex disticha Huds. & Debrecen & 1951 & Siroki Zoltán & DE-siroki-03185.jpg \\
\hline 2606 & Carex disticha Huds. & Debrecen & 1951 & Siroki Zoltán & DE-siroki-03186.jpg \\
\hline 2606 & Carex disticha Huds. & Debrecen & 1951 & Siroki Zoltán & DE-siroki-03193.jpg \\
\hline 2606 & Carex disticha Huds. & Debrecen & 1951 & Siroki Zoltán & DE-siroki-03194.jpg \\
\hline 2606 & Carex disticha Huds. & Debrecen & 1951 & Siroki Zoltán & DE-siroki-03177.jpg \\
\hline 2606 & Carex disticha Huds. & Debrecen & 1951 & Siroki Zoltán & DE-siroki-03192.jpg \\
\hline 2606 & Carex disticha Huds. & Debrecen & 1953 & Siroki Zoltán & DE-siroki-03166.jpg \\
\hline 2606 & Carex disticha Huds. & Debrecen & 1953 & Siroki Zoltán & DE-siroki-03173.jpg \\
\hline 2606 & Carex disticha Huds. & Debrecen & 1953 & Siroki Zoltán & DE-siroki-03174.jpg \\
\hline 2606 & Carex disticha Huds. & Debrecen & 1953 & Siroki Zoltán & DE-siroki-03175.jpg \\
\hline 2606 & Carex disticha Huds. & Debrecen & 1953 & Siroki Zoltán & DE-siroki-03176.jpg \\
\hline 2606 & Carex disticha Huds. & Debrecen & 1953 & Siroki Zoltán & DE-siroki-03179.jpg \\
\hline 2606 & Carex disticha Huds. & Debrecen & 1953 & Siroki Zoltán & DE-siroki-03180.jpg \\
\hline 2606 & Carex disticha Huds. & Debrecen & 1954 & Siroki Zoltán & DE-siroki-03187.jpg \\
\hline 2606 & Carex disticha Huds. & Debrecen & 1954 & Siroki Zoltán & DE-siroki-03189.jpg \\
\hline 2606 & Carex disticha Huds. & Debrecen & 1955 & Siroki Zoltán & DE-siroki-03190.jpg \\
\hline
\end{tabular}




\begin{tabular}{|c|c|c|c|c|c|}
\hline $\begin{array}{l}\text { Sorszám / } \\
\text { Number }\end{array}$ & Taxon-név / Taxon-name & $\begin{array}{l}\text { Település / } \\
\text { Settlement }\end{array}$ & $\begin{array}{l}\text { Év / } \\
\text { Year }\end{array}$ & $\begin{array}{l}\text { Gyújtő / } \\
\text { Collector }\end{array}$ & Fájlnév / File-name \\
\hline 2606 & Carex disticha Huds. & Debrecen & 1956 & Siroki Zoltán & DE-siroki-03191.jpg \\
\hline 2606 & Carex disticha Huds. & Debrecen & 1957 & Siroki Zoltán & DE-siroki-03188.jpg \\
\hline 2606 & Carex disticha Huds. & Debrecen & 1961 & Siroki Zoltán & DE-siroki-03169.jpg \\
\hline 2606 & Carex disticha Huds. & Hajdúsámson & 1956 & Siroki Zoltán & DE-siroki-03178.jpg \\
\hline 2606 & Carex disticha Huds. & Létavértes & 1967 & Siroki Zoltán & DE-siroki-03182.jpg \\
\hline 2606 & Carex disticha Huds. & Létavértes & 1967 & Siroki Zoltán & DE-siroki-03170.jpg \\
\hline 2606 & Carex disticha Huds. & Létavértes & 1967 & Siroki Zoltán & DE-siroki-03171.jpg \\
\hline 2606 & Carex disticha Huds. & Létavértes & 1967 & Siroki Zoltán & DE-siroki-03172.jpg \\
\hline 2606 & Carex disticha Huds. & Létavértes & 1967 & Siroki Zoltán & DE-siroki-03181.jpg \\
\hline 2606 & Carex disticha Huds. & Létavértes & 1967 & Siroki Zoltán & DE-siroki-03183.jpg \\
\hline 2608 & Carex stenophylla Wahlenb. & Debrecen & 1946 & Siroki Zoltán & DE-siroki-02864.jpg \\
\hline 2608 & Carex stenophylla Wahlenb. & Debrecen & 1947 & Siroki Zoltán & DE-siroki-02863.jpg \\
\hline 2608 & Carex stenophylla Wahlenb. & Debrecen & 1947 & Siroki Zoltán & DE-siroki-02867.jpg \\
\hline 2608 & Carex stenophylla Wahlenb. & Debrecen & 1949 & Siroki Zoltán & DE-siroki-02866.jpg \\
\hline 2608 & Carex stenophylla Wahlenb. & Gödöllő & 1951 & Siroki Zoltán & DE-siroki-02869.jpg \\
\hline 2608 & Carex stenophylla Wahlenb. & Gödöllő & 1952 & Siroki Zoltán & DE-siroki-02865.jpg \\
\hline 2608 & Carex stenophylla Wahlenb. & Hortobágy & 1947 & Siroki Zoltán & DE-siroki-02868.jpg \\
\hline 2609 & Carex divisa Huds. & Abaújkér & 1942 & Siroki Zoltán & DE-siroki-02871.jpg \\
\hline 2609 & Carex divisa Huds. & Budapest & 1887 & Czakó Kálmán & DE-siroki-02876.jpg \\
\hline 2609 & Carex divisa Huds. & Budapest & 1909 & Kocsis István & DE-siroki-02874.jpg \\
\hline 2609 & Carex divisa Huds. & Debrecen & 1948 & Siroki Zoltán & DE-siroki-02870.jpg \\
\hline 2609 & Carex divisa Huds. & Debrecen & 1948 & Siroki Zoltán & DE-siroki-02882.jpg \\
\hline 2609 & Carex divisa Huds. & Debrecen & 1948 & Siroki Zoltán & DE-siroki-02872.jpg \\
\hline 2609 & Carex divisa Huds. & Debrecen & 1954 & Siroki Zoltán & DE-siroki-02877.jpg \\
\hline 2609 & Carex divisa Huds. & Debrecen & 1954 & Siroki Zoltán & DE-siroki-02880.jpg \\
\hline 2609 & Carex divisa Huds. & Debrecen & 1954 & Siroki Zoltán & DE-siroki-02883.jpg \\
\hline 2609 & Carex divisa Huds. & Debrecen & 1954 & Siroki Zoltán & DE-siroki-02884.jpg \\
\hline 2609 & Carex divisa Huds. & Debrecen & 1954 & Siroki Zoltán & DE-siroki-02878.jpg \\
\hline 2609 & Carex divisa Huds. & Debrecen & 1954 & Siroki Zoltán & DE-siroki-02879.jpg \\
\hline 2609 & Carex divisa Huds. & Debrecen & 1954 & Siroki Zoltán & DE-siroki-02873.jpg \\
\hline 2609 & Carex divisa Huds. & Debrecen & 1954 & Siroki Zoltán & DE-siroki-02881.jpg \\
\hline 2609 & Carex divisa Huds. & Szigetújfalu & 1873 & Tauscher Gyula & DE-siroki-02875.jpg \\
\hline 2610 & Carex elata All. & Budapest & 1904 & $\begin{array}{l}\text { Thaisz Lajos - } \\
\text { Baán Lajos }\end{array}$ & DE-siroki-03306.jpg \\
\hline 2610 & Carex elata All. & Debrecen & 1948 & Siroki Zoltán & DE-siroki-03324.jpg \\
\hline 2610 & Carex elata All. & Debrecen & 1950 & Siroki Zoltán & DE-siroki-03307.jpg \\
\hline 2610 & Carex elata All. & Debrecen & 1957 & Siroki Zoltán & DE-siroki-03310.jpg \\
\hline 2610 & Carex elata All. & Gödöllő & 1951 & Siroki Zoltán & DE-siroki-03322.jpg \\
\hline 2610 & Carex elata All. & Gödöllő & 1952 & Siroki Zoltán & DE-siroki-03327.jpg \\
\hline 2610 & Carex elata All. & Gödöllő & 1952 & Siroki Zoltán & DE-siroki-03323.jpg \\
\hline 2610 & Carex elata All. & Kállósemjén & 1955 & Kovács Béla & DE-siroki-03308.jpg \\
\hline 2610 & Carex elata All. & Kállósemjén & 1955 & Kovács Béla & DE-siroki-03309.jpg \\
\hline 2610 & Carex elata All. & Nyírábrány & 1986 & Siroki Zoltán & DE-siroki-03302.jpg \\
\hline 2610 & Carex elata All. & Nyírábrány & 1986 & Siroki Zoltán & DE-siroki-03303.jpg \\
\hline 2610 & Carex elata All. & Nyírábrány & 1986 & Siroki Zoltán & DE-siroki-03304.jpg \\
\hline 2610 & Carex elata All. & Nyírábrány & 1986 & Siroki Zoltán & DE-siroki-03305.jpg \\
\hline 2610 & Carex elata All. & Rakaca & 1982 & Siroki Zoltán & DE-siroki-03325.jpg \\
\hline
\end{tabular}




\begin{tabular}{|c|c|c|c|c|c|}
\hline $\begin{array}{l}\text { Sorszám / } \\
\text { Number }\end{array}$ & Taxon-név / Taxon-name & $\begin{array}{l}\text { Település / } \\
\text { Settlement }\end{array}$ & $\begin{array}{l}\text { Év / } \\
\text { Year }\end{array}$ & $\begin{array}{l}\text { Gyűjtő / } \\
\text { Collector }\end{array}$ & Fájlnév / File-name \\
\hline 2610 & Carex elata All. & Rakaca & 1982 & Siroki Zoltán & DE-siroki-03326.jpg \\
\hline 2610 & Carex elata All. & Újléta & 1967 & Siroki Zoltán & DE-siroki-03311.jpg \\
\hline 2610 & Carex elata All. & Újléta & 1967 & Siroki Zoltán & DE-siroki-03312.jpg \\
\hline 2610 & Carex elata All. & Újléta & 1967 & Siroki Zoltán & DE-siroki-03313.jpg \\
\hline 2610 & Carex elata All. & Újléta & 1967 & Siroki Zoltán & DE-siroki-03314.jpg \\
\hline 2610 & Carex elata All. & Újléta & 1967 & Siroki Zoltán & DE-siroki-03315.jpg \\
\hline 2610 & Carex elata All. & Újléta & 1967 & Siroki Zoltán & DE-siroki-03316.jpg \\
\hline 2610 & Carex elata All. & Újléta & 1967 & Siroki Zoltán & DE-siroki-03317.jpg \\
\hline 2611 & Carex acuta L. & Bodrogkeresztúr & 1967 & Siroki Zoltán & DE-siroki-03230.jpg \\
\hline 2611 & Carex acuta L. & Bodrogkeresztúr & 1967 & Siroki Zoltán & DE-siroki-03231.jpg \\
\hline 2611 & Carex acuta L. & Bodrogkeresztúr & 1967 & Siroki Zoltán & DE-siroki-03232.jpg \\
\hline 2611 & Carex acuta L. & Bodrogkeresztúr & 1967 & Siroki Zoltán & DE-siroki-03233.jpg \\
\hline 2611 & Carex acuta L. & Debrecen & 1955 & Siroki Zoltán & DE-siroki-03203.jpg \\
\hline 2611 & Carex acuta L. & Debrecen & 1955 & Siroki Zoltán & DE-siroki-03228.jpg \\
\hline 2611 & Carex acuta L. & Debrecen & 1955 & Siroki Zoltán & DE-siroki-03227.jpg \\
\hline 2611 & Carex acuta L. & Debrecen & 1956 & Siroki Zoltán & DE-siroki-03206.jpg \\
\hline 2611 & Carex acuta L. & Egyek & 1947 & Siroki Zoltán & DE-siroki-03225.jpg \\
\hline 2611 & Carex acuta L. & Egyek & 1947 & Siroki Zoltán & DE-siroki-03226.jpg \\
\hline 2611 & Carex acuta L. & Egyek & 1948 & Siroki Zoltán & DE-siroki-03207.jpg \\
\hline 2611 & Carex acuta L. & Egyek & 1949 & Siroki Zoltán & DE-siroki-03209.jpg \\
\hline 2611 & Carex acuta L. & Egyek & 1949 & Siroki Zoltán & DE-siroki-03210.jpg \\
\hline 2611 & Carex acuta L. & Egyek & 1949 & Siroki Zoltán & DE-siroki-03219.jpg \\
\hline 2611 & Carex acuta L. & Egyek & 1949 & Siroki Zoltán & DE-siroki-03220.jpg \\
\hline 2611 & Carex acuta L. & Egyek & 1949 & Siroki Zoltán & DE-siroki-03222.jpg \\
\hline 2611 & Carex acuta L. & Egyek & - & Siroki Zoltán & DE-siroki-03211.jpg \\
\hline 2611 & Carex acuta L. & Gödöllő & 1951 & Siroki Zoltán & DE-siroki-03221.jpg \\
\hline 2611 & Carex acuta L. & Gödöllő & 1951 & Siroki Zoltán & DE-siroki-03223.jpg \\
\hline 2611 & Carex acuta L. & Háromhuta & 1961 & Siroki Zoltán & DE-siroki-03208.jpg \\
\hline 2611 & Carex acuta L. & Háromhuta & 1961 & Siroki Zoltán & DE-siroki-03229.jpg \\
\hline 2611 & Carex acuta L. & Háromhuta & 1978 & Siroki Zoltán & DE-siroki-03204.jpg \\
\hline 2611 & Carex acuta L. & Háromhuta & 1978 & Siroki Zoltán & DE-siroki-03205.jpg \\
\hline 2611 & Carex acuta L. & Hortobágy & 1949 & Siroki Zoltán & DE-siroki-03212.jpg \\
\hline 2611 & Carex acuta L. & Szentes & 1952 & Siroki Zoltán & DE-siroki-03224.jpg \\
\hline 2611 & Carex acuta L. & Tiszafüred & 1949 & Siroki Zoltán & DE-siroki-03201.jpg \\
\hline 2611 & Carex acuta L. & Tiszafüred & 1949 & Siroki Zoltán & DE-siroki-03202.jpg \\
\hline 2612 & Carex nigra (L.) Reichard & Debrecen & 1950 & Siroki Zoltán & DE-siroki-03273.jpg \\
\hline 2612 & Carex nigra (L.) Reichard & Debrecen & 1950 & Siroki Zoltán & DE-siroki-03286.jpg \\
\hline 2612 & Carex nigra (L.) Reichard & Debrecen & 1950 & Siroki Zoltán & DE-siroki-03260.jpg \\
\hline 2612 & Carex nigra (L.) Reichard & Debrecen & 1951 & Siroki Zoltán & DE-siroki-03276.jpg \\
\hline 2612 & Carex nigra (L.) Reichard & Debrecen & 1954 & Siroki Zoltán & DE-siroki-03270.jpg \\
\hline 2612 & Carex nigra (L.) Reichard & Debrecen & 1954 & Siroki Zoltán & DE-siroki-03278.jpg \\
\hline 2612 & Carex nigra (L.) Reichard & Debrecen & 1955 & Siroki Zoltán & DE-siroki-03266.jpg \\
\hline 2612 & Carex nigra (L.) Reichard & Debrecen & 1955 & Siroki Zoltán & DE-siroki-03269.jpg \\
\hline 2612 & Carex nigra (L.) Reichard & Debrecen & 1955 & Siroki Zoltán & DE-siroki-03263.jpg \\
\hline 2612 & Carex nigra (L.) Reichard & Debrecen & 1955 & Siroki Zoltán & DE-siroki-03264.jpg \\
\hline 2612 & Carex nigra (L.) Reichard & Debrecen & 1955 & Siroki Zoltán & DE-siroki-03265.jpg \\
\hline
\end{tabular}




\begin{tabular}{|c|c|c|c|c|c|}
\hline $\begin{array}{l}\text { Sorszám / } \\
\text { Number }\end{array}$ & Taxon-név / Taxon-name & $\begin{array}{l}\text { Település / } \\
\text { Settlement }\end{array}$ & $\begin{array}{l}\text { Év / } \\
\text { Year }\end{array}$ & $\begin{array}{l}\text { Gyújtő / } \\
\text { Collector }\end{array}$ & Fájlnév / File-name \\
\hline 2612 & Carex nigra (L.) Reichard & Debrecen & 1955 & Siroki Zoltán & DE-siroki-03242.jpg \\
\hline 2612 & Carex nigra (L.) Reichard & Debrecen & 1955 & Siroki Zoltán & DE-siroki-03243.jpg \\
\hline 2612 & Carex nigra (L.) Reichard & Debrecen & 1955 & Siroki Zoltán & DE-siroki-03244.jpg \\
\hline 2612 & Carex nigra (L.) Reichard & Debrecen & 1955 & $\begin{array}{l}\text { Siroki Zoltán - } \\
\text { Farkas Attila }\end{array}$ & DE-siroki-03261.jpg \\
\hline 2612 & Carex nigra (L.) Reichard & Debrecen & 1955 & $\begin{array}{l}\text { Siroki Zoltán - } \\
\text { Farkas Attila }\end{array}$ & DE-siroki-03262.jpg \\
\hline 2612 & Carex nigra (L.) Reichard & Debrecen & 1956 & Siroki Zoltán & DE-siroki-03241.jpg \\
\hline 2612 & Carex nigra (L.) Reichard & Debrecen & 1956 & Siroki Zoltán & DE-siroki-03258.jpg \\
\hline 2612 & Carex nigra (L.) Reichard & Debrecen & 1956 & Siroki Zoltán & DE-siroki-03259.jpg \\
\hline 2612 & Carex nigra (L.) Reichard & Debrecen & 1956 & Siroki Zoltán & DE-siroki-03279.jpg \\
\hline 2612 & Carex nigra (L.) Reichard & Debrecen & 1956 & Siroki Zoltán & DE-siroki-03280.jpg \\
\hline 2612 & Carex nigra (L.) Reichard & Debrecen & 1958 & Siroki Zoltán & DE-siroki-03246.jpg \\
\hline 2612 & Carex nigra (L.) Reichard & Debrecen & 1958 & Siroki Zoltán & DE-siroki-03247.jpg \\
\hline 2612 & Carex nigra (L.) Reichard & Debrecen & 1958 & Siroki Zoltán & DE-siroki-03248.jpg \\
\hline 2612 & Carex nigra (L.) Reichard & Debrecen & 1958 & Siroki Zoltán & DE-siroki-03249.jpg \\
\hline 2612 & Carex nigra (L.) Reichard & Debrecen & 1958 & Siroki Zoltán & DE-siroki-03271.jpg \\
\hline 2612 & Carex nigra (L.) Reichard & Debrecen & 1958 & Siroki Zoltán & DE-siroki-03283.jpg \\
\hline 2612 & Carex nigra (L.) Reichard & Debrecen & 1958 & Siroki Zoltán & DE-siroki-03272.jpg \\
\hline 2612 & Carex nigra (L.) Reichard & Debrecen & 1958 & Siroki Zoltán & DE-siroki-03281.jpg \\
\hline 2612 & Carex nigra (L.) Reichard & Debrecen & 1958 & Siroki Zoltán & DE-siroki-03282.jpg \\
\hline 2612 & Carex nigra (L.) Reichard & Háromhuta & 1961 & Siroki Zoltán & DE-siroki-03237.jpg \\
\hline 2612 & Carex nigra (L.) Reichard & Háromhuta & 1961 & Siroki Zoltán & DE-siroki-03239.jpg \\
\hline 2612 & Carex nigra (L.) Reichard & Háromhuta & 1961 & Siroki Zoltán & DE-siroki-03240.jpg \\
\hline 2612 & Carex nigra (L.) Reichard & Háromhuta & 1984 & Siroki Zoltán & DE-siroki-03238.jpg \\
\hline 2612 & Carex nigra (L.) Reichard & Miskolc & 1959 & Siroki Zoltán & DE-siroki-03254.jpg \\
\hline 2612 & Carex nigra (L.) Reichard & Miskolc & 1959 & Siroki Zoltán & DE-siroki-03267.jpg \\
\hline 2612 & Carex nigra (L.) Reichard & Miskolc & 1959 & Siroki Zoltán & DE-siroki-03268.jpg \\
\hline 2612 & Carex nigra (L.) Reichard & Nagyhuta & 1961 & Siroki Zoltán & DE-siroki-03255.jpg \\
\hline 2612 & Carex nigra (L.) Reichard & Nagyhuta & 1961 & Siroki Zoltán & DE-siroki-03256.jpg \\
\hline 2612 & Carex nigra (L.) Reichard & Nagyhuta & 1961 & Siroki Zoltán & DE-siroki-03257.jpg \\
\hline 2612 & Carex nigra (L.) Reichard & Rakaca & 1982 & Siroki Zoltán & DE-siroki-03277.jpg \\
\hline 2612 & Carex nigra (L.) Reichard & Regéc & 1967 & Siroki Zoltán & DE-siroki-03236.jpg \\
\hline 2612 & Carex nigra (L.) Reichard & Újléta & 1967 & Siroki Zoltán & DE-siroki-03234.jpg \\
\hline 2612 & Carex nigra (L.) Reichard & Újléta & 1967 & Siroki Zoltán & DE-siroki-03235.jpg \\
\hline 2612 & Carex nigra (L.) Reichard & Újléta & 1967 & Siroki Zoltán & DE-siroki-03250.jpg \\
\hline 2612 & Carex nigra (L.) Reichard & Újléta & 1967 & Siroki Zoltán & DE-siroki-03251.jpg \\
\hline 2612 & Carex nigra (L.) Reichard & Újléta & 1967 & Siroki Zoltán & DE-siroki-03252.jpg \\
\hline 2612 & Carex nigra (L.) Reichard & Újléta & 1967 & Siroki Zoltán & DE-siroki-03253.jpg \\
\hline 2612 & Carex nigra (L.) Reichard & Újléta & 1968 & Siroki Zoltán & DE-siroki-03245.jpg \\
\hline 2617 & Carex lasiocarpa Ehrh. & Csaroda & 1954 & Simon Tiborné & DE-siroki-03897.jpg \\
\hline 2617 & Carex lasiocarpa Ehrh. & Csaroda & 1954 & Siroki Zoltán & DE-siroki-03900.jpg \\
\hline 2617 & Carex lasiocarpa Ehrh. & Sirok & 1960 & Boros Ádám & DE-siroki-03901.jpg \\
\hline 2618 & Carex hirta L. & Debrecen & 1948 & Siroki Zoltán & DE-siroki-03879.jpg \\
\hline 2618 & Carex hirta L. & Debrecen & 1949 & Siroki Zoltán & DE-siroki-03894.jpg \\
\hline 2618 & Carex hirta L. & Debrecen & 1955 & $\begin{array}{l}\text { Siroki Zoltán - } \\
\text { Farkas Attila }\end{array}$ & DE-siroki-03880.jpg \\
\hline 2618 & Carex hirta L. & Debrecen & 1958 & Siroki Zoltán & DE-siroki-03886.jpg \\
\hline
\end{tabular}




\begin{tabular}{|c|c|c|c|c|c|}
\hline $\begin{array}{l}\text { Sorszám / } \\
\text { Number }\end{array}$ & Taxon-név / Taxon-name & $\begin{array}{l}\text { Település / } \\
\text { Settlement }\end{array}$ & $\begin{array}{l}\text { Év / } \\
\text { Year }\end{array}$ & $\begin{array}{l}\text { Gyújtő / } \\
\text { Collector }\end{array}$ & Fájlnév / File-name \\
\hline 2618 & Carex hirta L. & Debrecen & 1984 & Siroki Zoltán & DE-siroki-03896.jpg \\
\hline 2618 & Carex hirta L. & Gödöllő & 1952 & Siroki Zoltán & DE-siroki-03889.jpg \\
\hline 2618 & Carex hirta L. & Gödöllő & 1952 & Siroki Zoltán & DE-siroki-03890.jpg \\
\hline 2618 & Carex hirta L. & Keszthely & 1955 & Siroki Zoltán & DE-siroki-03881.jpg \\
\hline 2618 & Carex hirta L. & Pilisszentiván & 1952 & Siroki Zoltán & DE-siroki-03885.jpg \\
\hline 2618 & Carex hirta L. & Pilisszentiván & 1952 & Siroki Zoltán & DE-siroki-03891.jpg \\
\hline 2618 & Carex hirta L. & Pilisszentiván & 1952 & Siroki Zoltán & DE-siroki-03887.jpg \\
\hline 2618 & Carex hirta L. & Szarvas & 1954 & Siroki Zoltán & DE-siroki-03888.jpg \\
\hline 2618 & Carex hirta L. & Újléta & 1967 & Siroki Zoltán & DE-siroki-03882.jpg \\
\hline 2618 & Carex hirta L. & Újléta & 1967 & Siroki Zoltán & DE-siroki-03883.jpg \\
\hline 2619 & Carex halleriana Asso & Budaörs & 1952 & Siroki Zoltán & DE-siroki-03527.jpg \\
\hline 2619 & Carex halleriana Asso & Budapest & 1874 & Staub Móric & DE-siroki-03516.jpg \\
\hline 2619 & Carex halleriana Asso & Budapest & 1900 & Thaisz Lajos & DE-siroki-03518.jpg \\
\hline 2619 & Carex halleriana Asso & Budapest & 1951 & Siroki Zoltán & DE-siroki-03519.jpg \\
\hline 2619 & Carex halleriana Asso & Budapest & 1951 & Siroki Zoltán & DE-siroki-03525.jpg \\
\hline 2619 & Carex halleriana Asso & Budapest & 1951 & Siroki Zoltán & DE-siroki-03524.jpg \\
\hline 2619 & Carex halleriana Asso & Budapest & 1951 & Siroki Zoltán & DE-siroki-03526.jpg \\
\hline 2619 & Carex halleriana Asso & Budapest & 1964 & Siroki Zoltán & DE-siroki-03522.jpg \\
\hline 2619 & Carex halleriana Asso & Budapest & 1964 & Siroki Zoltán & DE-siroki-03523.jpg \\
\hline 2619 & Carex halleriana Asso & Budapest & 1964 & Siroki Zoltán & DE-siroki-03520.jpg \\
\hline 2619 & Carex halleriana Asso & Budapest & 1964 & Siroki Zoltán & DE-siroki-03514.jpg \\
\hline 2619 & Carex halleriana Asso & Budapest & 1964 & Siroki Zoltán & DE-siroki-03515.jpg \\
\hline 2619 & Carex halleriana Asso & Budapest & 1968 & Siroki Zoltán & DE-siroki-03521.jpg \\
\hline 2621 & Carex flacca Schreb. & Debrecen & 1950 & Siroki Zoltán & DE-siroki-03341.jpg \\
\hline 2621 & Carex flacca Schreb. & Debrecen & 1950 & Siroki Zoltán & DE-siroki-03356.jpg \\
\hline 2621 & Carex flacca Schreb. & Debrecen & 1950 & Siroki Zoltán & DE-siroki-03357.jpg \\
\hline 2621 & Carex flacca Schreb. & Debrecen & 1958 & Siroki Zoltán & DE-siroki-03349.jpg \\
\hline 2621 & Carex flacca Schreb. & Debrecen & 1958 & Siroki Zoltán & DE-siroki-03350.jpg \\
\hline 2621 & Carex flacca Schreb. & Debrecen & 1958 & Siroki Zoltán & DE-siroki-03351.jpg \\
\hline 2621 & Carex flacca Schreb. & Debrecen & 1958 & Siroki Zoltán & DE-siroki-03352.jpg \\
\hline 2621 & Carex flacca Schreb. & Gödöllő & 1952 & Siroki Zoltán & DE-siroki-03342.jpg \\
\hline 2621 & Carex flacca Schreb. & Gödöllő & 1952 & Siroki Zoltán & DE-siroki-03344.jpg \\
\hline 2621 & Carex flacca Schreb. & Gödöllő & 1952 & Siroki Zoltán & DE-siroki-03355.jpg \\
\hline 2621 & Carex flacca Schreb. & Gödöllő & 1952 & Siroki Zoltán & DE-siroki-03345.jpg \\
\hline 2621 & Carex flacca Schreb. & Gödöllő & 1952 & Siroki Zoltán & DE-siroki-03343.jpg \\
\hline 2621 & Carex flacca Schreb. & Gödöllő & 1952 & Siroki Zoltán & DE-siroki-03354.jpg \\
\hline 2621 & Carex flacca Schreb. & Kecskemét & 1969 & Siroki Zoltán & DE-siroki-03329.jpg \\
\hline 2621 & Carex flacca Schreb. & Kecskemét & 1969 & Siroki Zoltán & DE-siroki-03346.jpg \\
\hline 2621 & Carex flacca Schreb. & Keszthely & 1955 & Siroki Zoltán & DE-siroki-03353.jpg \\
\hline 2621 & Carex flacca Schreb. & Pécs & 1958 & Siroki Zoltán & DE-siroki-03348.jpg \\
\hline 2621 & Carex flacca Schreb. & Újléta & 1967 & Siroki Zoltán & DE-siroki-03330.jpg \\
\hline 2621 & Carex flacca Schreb. & Újléta & 1967 & Siroki Zoltán & DE-siroki-03331.jpg \\
\hline 2621 & Carex flacca Schreb. & Újléta & 1967 & Siroki Zoltán & DE-siroki-03332.jpg \\
\hline 2621 & Carex flacca Schreb. & Újléta & 1967 & Siroki Zoltán & DE-siroki-03333.jpg \\
\hline 2621 & Carex flacca Schreb. & Újléta & 1967 & Siroki Zoltán & DE-siroki-03334.jpg \\
\hline 2621 & Carex flacca Schreb. & Újléta & 1967 & Siroki Zoltán & DE-siroki-03335.jpg \\
\hline
\end{tabular}




\begin{tabular}{|c|c|c|c|c|c|}
\hline $\begin{array}{l}\text { Sorszám / } \\
\text { Number }\end{array}$ & Taxon-név / Taxon-name & $\begin{array}{l}\text { Település / } \\
\text { Settlement }\end{array}$ & $\begin{array}{l}\text { Év / } \\
\text { Year }\end{array}$ & $\begin{array}{l}\text { Gyújtő / } \\
\text { Collector }\end{array}$ & Fájlnév / File-name \\
\hline 2621 & Carex flacca Schreb. & Újléta & 1967 & Siroki Zoltán & DE-siroki-03336.jpg \\
\hline 2621 & Carex flacca Schreb. & Újléta & 1967 & Siroki Zoltán & DE-siroki-03337.jpg \\
\hline 2621 & Carex flacca Schreb. & Újléta & 1967 & Siroki Zoltán & DE-siroki-03338.jpg \\
\hline 2621 & Carex flacca Schreb. & Újléta & 1967 & Siroki Zoltán & DE-siroki-03339.jpg \\
\hline 2621 & Carex flacca Schreb. & Vámospércs & 1984 & Siroki Zoltán & DE-siroki-03319.jpg \\
\hline 2621 & Carex flacca Schreb. & Vámospércs & 1984 & Siroki Zoltán & DE-siroki-03320.jpg \\
\hline 2621 & Carex flacca Schreb. & Vámospércs & 1985 & Siroki Zoltán & DE-siroki-03318.jpg \\
\hline 2622 & Carex humilis Leyss. & Budaörs & 1951 & Siroki Zoltán & DE-siroki-03511.jpg \\
\hline 2623 & Carex digitata L. & "Fáni-völgy" & 1955 & Siroki Zoltán & DE-siroki-03495.jpg \\
\hline 2623 & Carex digitata $\mathrm{L}$. & "Fáni-völgy" & 1955 & Siroki Zoltán & DE-siroki-03496.jpg \\
\hline 2623 & Carex digitata L. & "Fáni-völgy" & 1955 & Siroki Zoltán & DE-siroki-03497.jpg \\
\hline 2623 & Carex digitata L. & "Fáni-völgy" & 1955 & $\begin{array}{l}\text { Siroki Zoltán - } \\
\text { Farkas Attila }\end{array}$ & DE-siroki-03503.jpg \\
\hline 2623 & Carex digitata $\mathrm{L}$. & "Fáni-völgy" & 1955 & $\begin{array}{l}\text { Siroki Zoltán - } \\
\text { Farkas Attila }\end{array}$ & DE-siroki-03504.jpg \\
\hline 2623 & Carex digitata $\mathrm{L}$. & "Fáni-völgy" & 1955 & $\begin{array}{l}\text { Siroki Zoltán - } \\
\text { Farkas Attila }\end{array}$ & DE-siroki-03505.jpg \\
\hline 2623 & Carex digitata L. & "Fáni-völgy" & 1955 & $\begin{array}{l}\text { Siroki Zoltán - } \\
\text { Farkas Attila }\end{array}$ & DE-siroki-03506.jpg \\
\hline 2623 & Carex digitata L. & Budapest & 1952 & Siroki Zoltán & DE-siroki-03498.jpg \\
\hline 2623 & Carex digitata L. & Háromhuta & 1955 & Simon Tiborné & DE-siroki-03490.jpg \\
\hline 2623 & Carex digitata L. & Háromhuta & 1955 & Simon Tiborné & DE-siroki-03491.jpg \\
\hline 2623 & Carex digitata L. & Háromhuta & 1955 & Simon Tiborné & DE-siroki-03492.jpg \\
\hline 2623 & Carex digitata L. & Pilismarót & 1957 & Siroki Zoltán & DE-siroki-03493.jpg \\
\hline 2623 & Carex digitata L. & Szentgál & 1956 & Jeney Endre & DE-siroki-03494.jpg \\
\hline 2623 & Carex digitata $\mathrm{L}$. & Szilvásvárad & 1954 & Siroki Zoltán & DE-siroki-03500.jpg \\
\hline 2623 & Carex digitata L. & Szilvásvárad & 1954 & Siroki Zoltán & DE-siroki-03501.jpg \\
\hline 2623 & Carex digitata L. & Szilvásvárad & - & Siroki Zoltán & DE-siroki-03499.jpg \\
\hline 2624 & Carex umbrosa Host & Bátorliget & 1954 & Simon Tiborné & DE-siroki-03532.jpg \\
\hline 2624 & Carex umbrosa Host & Bátorliget & 1954 & Simon Tiborné & DE-siroki-03533.jpg \\
\hline 2625 & Carex caryophyllea Latourr. & Budapest & 1887 & Czakó Kálmán & DE-siroki-03542.jpg \\
\hline 2625 & Carex caryophyllea Latourr. & Budapest & 1904 & $\begin{array}{l}\text { Thaisz Lajos - } \\
\text { Baán Lajos }\end{array}$ & DE-siroki-03541.jpg \\
\hline 2625 & Carex caryophyllea Latourr. & Budapest & 1928 & Rigler József & DE-siroki-03545.jpg \\
\hline 2625 & Carex caryophyllea Latourr. & Debrecen & 1947 & Siroki Zoltán & DE-siroki-03548.jpg \\
\hline 2625 & Carex caryophyllea Latourr. & Debrecen & 1947 & Siroki Zoltán & DE-siroki-03558.jpg \\
\hline 2625 & Carex caryophyllea Latourr. & Debrecen & 1949 & Siroki Zoltán & DE-siroki-03568.jpg \\
\hline 2625 & Carex caryophyllea Latourr. & Debrecen & 1949 & Siroki Zoltán & DE-siroki-03557.jpg \\
\hline 2625 & Carex caryophyllea Latourr. & Debrecen & 1949 & Siroki Zoltán & DE-siroki-03567.jpg \\
\hline 2625 & Carex caryophyllea Latourr. & Debrecen & 1949 & Siroki Zoltán & DE-siroki-03563.jpg \\
\hline 2625 & Carex caryophyllea Latourr. & Debrecen & 1949 & Siroki Zoltán & DE-siroki-03556.jpg \\
\hline 2625 & Carex caryophyllea Latourr. & Debrecen & 1954 & Siroki Zoltán & DE-siroki-03559.jpg \\
\hline 2625 & Carex caryophyllea Latourr. & Debrecen & 1954 & Siroki Zoltán & DE-siroki-03552.jpg \\
\hline 2625 & Carex caryophyllea Latourr. & Gödöllő & 1952 & Siroki Zoltán & DE-siroki-03551.jpg \\
\hline 2625 & Carex caryophyllea Latourr. & Gödöllő & 1952 & Siroki Zoltán & DE-siroki-03553.jpg \\
\hline 2625 & Carex caryophyllea Latourr. & Gödöllő & 1952 & Siroki Zoltán & DE-siroki-03562.jpg \\
\hline 2625 & Carex caryophyllea Latourr. & Gödöllő & 1952 & Siroki Zoltán & DE-siroki-03546.jpg \\
\hline 2625 & Carex caryophyllea Latourr. & Gödöllő & 1953 & Máthé Imre & DE-siroki-03565.jpg \\
\hline 2625 & Carex caryophyllea Latourr. & Hajdúbagos & 1985 & Siroki Zoltán & DE-siroki-03566.jpg \\
\hline
\end{tabular}




\begin{tabular}{|c|c|c|c|c|c|}
\hline $\begin{array}{l}\text { Sorszám / } \\
\text { Number }\end{array}$ & Taxon-név / Taxon-name & $\begin{array}{l}\text { Település / } \\
\text { Settlement }\end{array}$ & $\begin{array}{l}\text { Év / } \\
\text { Year }\end{array}$ & $\begin{array}{l}\text { Gyújtő / } \\
\text { Collector }\end{array}$ & Fájlnév / File-name \\
\hline 2625 & Carex caryophyllea Latourr. & Háromhuta & 1961 & Siroki Zoltán & DE-siroki-03430.jpg \\
\hline 2625 & Carex caryophyllea Latourr. & Háromhuta & 1961 & Siroki Zoltán & DE-siroki-03536.jpg \\
\hline 2625 & Carex caryophyllea Latourr. & Nagykovácsi & 1952 & Siroki Zoltán & DE-siroki-03561.jpg \\
\hline 2625 & Carex caryophyllea Latourr. & Nagykovácsi & 1959 & Siroki Zoltán & DE-siroki-03564.jpg \\
\hline 2625 & Carex caryophyllea Latourr. & Sátoraljaújhely & 1955 & Simon Tiborné & DE-siroki-03560.jpg \\
\hline 2626 & Carex tomentosa L. & "Nagymező" & 1957 & Siroki Zoltán & DE-siroki-03388.jpg \\
\hline 2626 & Carex tomentosa L. & "Nagymező" & 1957 & Siroki Zoltán & DE-siroki-03392.jpg \\
\hline 2626 & Carex tomentosa L. & Budapest & 1870 & Thaisz Lajos & DE-siroki-03410.jpg \\
\hline 2626 & Carex tomentosa L. & Budapest & 1904 & $\begin{array}{l}\text { Thaisz Lajos - } \\
\text { Baán Lajos }\end{array}$ & DE-siroki-03412.jpg \\
\hline 2626 & Carex tomentosa L. & Budapest & 1909 & Kocsis István & DE-siroki-03408.jpg \\
\hline 2626 & Carex tomentosa L. & Budapest & 1909 & Kocsis István & DE-siroki-03411.jpg \\
\hline 2626 & Carex tomentosa L. & Budapest & 1952 & Siroki Zoltán & DE-siroki-03404.jpg \\
\hline 2626 & Carex tomentosa L. & Debrecen & 1950 & Siroki Zoltán & DE-siroki-03391.jpg \\
\hline 2626 & Carex tomentosa L. & Debrecen & 1958 & Siroki Zoltán & DE-siroki-03389.jpg \\
\hline 2626 & Carex tomentosa L. & Debrecen & 1959 & Siroki Zoltán & DE-siroki-03395.jpg \\
\hline 2626 & Carex tomentosa L. & Debrecen & 1959 & Siroki Zoltán & DE-siroki-03396.jpg \\
\hline 2626 & Carex tomentosa L. & Debrecen & 1959 & Siroki Zoltán & DE-siroki-03397.jpg \\
\hline 2626 & Carex tomentosa L. & Debrecen & 1959 & Siroki Zoltán & DE-siroki-03390.jpg \\
\hline 2626 & Carex tomentosa L. & Háromhuta & 1961 & Siroki Zoltán & DE-siroki-03399.jpg \\
\hline 2626 & Carex tomentosa L. & Nagyhuta & 1961 & Siroki Zoltán & DE-siroki-03398.jpg \\
\hline 2626 & Carex tomentosa L. & Pásztó & 1952 & Siroki Zoltán & DE-siroki-03405.jpg \\
\hline 2626 & Carex tomentosa L. & Tarpa & 1955 & Siroki Zoltán & DE-siroki-03393.jpg \\
\hline 2626 & Carex tomentosa L. & Tarpa & 1955 & Siroki Zoltán & DE-siroki-03394.jpg \\
\hline 2626 & Carex tomentosa L. & Tarpa & 1955 & $\begin{array}{l}\text { Siroki Zoltán - } \\
\text { Farkas Attila }\end{array}$ & DE-siroki-03406.jpg \\
\hline 2626 & Carex tomentosa L. & Tarpa & 1955 & $\begin{array}{l}\text { Siroki Zoltán - } \\
\text { Farkas Attila }\end{array}$ & DE-siroki-03407.jpg \\
\hline 2628 & Carex montana L. & Bátorliget & 1954 & Simon Tiborné & DE-siroki-03427.jpg \\
\hline 2628 & Carex montana L. & Budapest & 1952 & Siroki Zoltán & DE-siroki-03431.jpg \\
\hline 2628 & Carex montana L. & Budapest & 1952 & Siroki Zoltán & DE-siroki-03433.jpg \\
\hline 2628 & Carex montana L. & Budapest & 1964 & Siroki Zoltán & DE-siroki-03424.jpg \\
\hline 2628 & Carex montana L. & Miskolc & 1961 & Siroki Zoltán & DE-siroki-03425.jpg \\
\hline 2628 & Carex montana L. & Pilismarót & 1957 & Siroki Zoltán & DE-siroki-03428.jpg \\
\hline 2628 & Carex montana L. & Pilismarót & 1957 & Siroki Zoltán & DE-siroki-03429.jpg \\
\hline 2628 & Carex montana L. & Sátoraljaújhely & 1955 & Simon Tiborné & DE-siroki-03426.jpg \\
\hline 2628 & Carex montana L. & Szarvaskő & 1958 & Siroki Zoltán & DE-siroki-03434.jpg \\
\hline 2629 & Carex ericetorum Pollich & Debrecen & 1950 & Siroki Zoltán & DE-siroki-03421.jpg \\
\hline 2629 & Carex ericetorum Pollich & Debrecen & 1950 & Siroki Zoltán & DE-siroki-03420.jpg \\
\hline 2629 & Carex ericetorum Pollich & Debrecen & 1950 & Siroki Zoltán & DE-siroki-03422.jpg \\
\hline 2629 & Carex ericetorum Pollich & Debrecen & 1950 & Siroki Zoltán & DE-siroki-03413.jpg \\
\hline 2629 & Carex ericetorum Pollich & Debrecen & 1950 & Siroki Zoltán & DE-siroki-03414.jpg \\
\hline 2629 & Carex ericetorum Pollich & Debrecen & 1950 & Siroki Zoltán & DE-siroki-03417.jpg \\
\hline 2629 & Carex ericetorum Pollich & Gödöllő & 1952 & Siroki Zoltán & DE-siroki-03419.jpg \\
\hline 2629 & Carex ericetorum Pollich & Gödöllő & 1952 & Siroki Zoltán & DE-siroki-03415.jpg \\
\hline 2629 & Carex ericetorum Pollich & Gödöllő & 1952 & Siroki Zoltán & DE-siroki-03416.jpg \\
\hline 2629 & Carex ericetorum Pollich & Pilisszentiván & 1927 & Degen Árpád & DE-siroki-03418.jpg \\
\hline 2631 & Carex pendula Huds. & Pécs & 1954 & Siroki Zoltán & DE-siroki-03580.jpg \\
\hline
\end{tabular}




\begin{tabular}{|c|c|c|c|c|c|}
\hline $\begin{array}{l}\text { Sorszám / } \\
\text { Number }\end{array}$ & Taxon-név / Taxon-name & $\begin{array}{l}\text { Település / } \\
\text { Settlement }\end{array}$ & $\begin{array}{l}\text { Év / } \\
\text { Year }\end{array}$ & $\begin{array}{l}\text { Gyújtő / } \\
\text { Collector }\end{array}$ & Fájlnév / File-name \\
\hline 2631 & Carex pendula Huds. & Pécs & 1954 & Siroki Zoltán & DE-siroki-03590.jpg \\
\hline 2631 & Carex pendula Huds. & Pécs & 1958 & Siroki Zoltán & DE-siroki-03581.jpg \\
\hline 2631 & Carex pendula Huds. & Pécs & 1958 & Siroki Zoltán & DE-siroki-03582.jpg \\
\hline 2631 & Carex pendula Huds. & Pomáz & 1910 & Kocsis István & DE-siroki-03587.jpg \\
\hline 2631 & Carex pendula Huds. & Pomáz & 1952 & Siroki Zoltán & DE-siroki-03579.jpg \\
\hline 2631 & Carex pendula Huds. & Pomáz & 1952 & Siroki Zoltán & DE-siroki-03583.jpg \\
\hline 2631 & Carex pendula Huds. & Pomáz & 1952 & Siroki Zoltán & DE-siroki-03588.jpg \\
\hline 2631 & Carex pendula Huds. & Sopron & 1956 & Kovács Béla & DE-siroki-03589.jpg \\
\hline 2633 & Carex pseudocyperus L. & Budapest & 1904 & Thaisz Lajos & DE-siroki-04039.jpg \\
\hline 2633 & Carex pseudocyperus L. & Budapest & 1904 & $\begin{array}{l}\text { Thaisz Lajos - } \\
\text { Baán Lajos }\end{array}$ & DE-siroki-04040.jpg \\
\hline 2633 & Carex pseudocyperus L. & Budapest & 1905 & Kocsis István & DE-siroki-04015.jpg \\
\hline 2633 & Carex pseudocyperus L. & Budapest & 1909 & Kocsis István & DE-siroki-04014.jpg \\
\hline 2633 & Carex pseudocyperus L. & Csaroda & 1960 & Siroki Zoltán & DE-siroki-04017.jpg \\
\hline 2633 & Carex pseudocyperus L. & Csaroda & 1960 & Siroki Zoltán & DE-siroki-04031.jpg \\
\hline 2633 & Carex pseudocyperus L. & Debrecen & 1948 & Siroki Zoltán & DE-siroki-04032.jpg \\
\hline 2633 & Carex pseudocyperus L. & Debrecen & 1948 & Siroki Zoltán & DE-siroki-04033.jpg \\
\hline 2633 & Carex pseudocyperus L. & Debrecen & 1948 & Siroki Zoltán & DE-siroki-04028.jpg \\
\hline 2633 & Carex pseudocyperus L. & Debrecen & 1950 & Siroki Zoltán & DE-siroki-04035.jpg \\
\hline 2633 & Carex pseudocyperus L. & Debrecen & 1954 & Siroki Zoltán & DE-siroki-04026.jpg \\
\hline 2633 & Carex pseudocyperus L. & Debrecen & 1954 & Siroki Zoltán & DE-siroki-04027.jpg \\
\hline 2633 & Carex pseudocyperus L. & Debrecen & 1954 & Siroki Zoltán & DE-siroki-04030.jpg \\
\hline 2633 & Carex pseudocyperus L. & Debrecen & 1956 & Siroki Zoltán & DE-siroki-04038.jpg \\
\hline 2633 & Carex pseudocyperus L. & Dunaharaszti & 1915 & Degen Árpád & DE-siroki-04016.jpg \\
\hline 2633 & Carex pseudocyperus L. & Gödöllő & 1951 & Siroki Zoltán & DE-siroki-04022.jpg \\
\hline 2633 & Carex pseudocyperus L. & Gödöllő & 1951 & Siroki Zoltán & DE-siroki-04023.jpg \\
\hline 2633 & Carex pseudocyperus L. & Gödöllő & 1951 & Siroki Zoltán & DE-siroki-04024.jpg \\
\hline 2633 & Carex pseudocyperus L. & Gödöllő & 1951 & Siroki Zoltán & DE-siroki-04025.jpg \\
\hline 2633 & Carex pseudocyperus L. & Gödöllő & 1951 & Siroki Zoltán & DE-siroki-04029.jpg \\
\hline 2633 & Carex pseudocyperus L. & Gödöllő & 1951 & Siroki Zoltán & DE-siroki-04034.jpg \\
\hline 2633 & Carex pseudocyperus L. & Gödöllő & 1951 & Siroki Zoltán & DE-siroki-04036.jpg \\
\hline 2633 & Carex pseudocyperus L. & Gödöllő & 1951 & Siroki Zoltán & DE-siroki-04037.jpg \\
\hline 2633 & Carex pseudocyperus L. & Kállósemjén & 1959 & Siroki Zoltán & DE-siroki-04018.jpg \\
\hline 2633 & Carex pseudocyperus L. & Kállósemjén & 1959 & Siroki Zoltán & DE-siroki-04019.jpg \\
\hline 2633 & Carex pseudocyperus L. & Kállósemjén & 1959 & Siroki Zoltán & DE-siroki-04020.jpg \\
\hline 2633 & Carex pseudocyperus L. & Kállósemjén & 1959 & Siroki Zoltán & DE-siroki-04021.jpg \\
\hline 2634 & Carex sylvatica Huds. & Debrecen & 1948 & Siroki Zoltán & DE-siroki-03684.jpg \\
\hline 2634 & Carex sylvatica Huds. & Debrecen & 1949 & Siroki Zoltán & DE-siroki-03682.jpg \\
\hline 2634 & Carex sylvatica Huds. & Debrecen & 1949 & Siroki Zoltán & DE-siroki-03691.jpg \\
\hline 2634 & Carex sylvatica Huds. & Debrecen & 1955 & Siroki Zoltán & DE-siroki-03685.jpg \\
\hline 2634 & Carex sylvatica Huds. & Debrecen & 1955 & $\begin{array}{l}\text { Siroki Zoltán - } \\
\text { Farkas Attila }\end{array}$ & DE-siroki-03683.jpg \\
\hline 2634 & Carex sylvatica Huds. & Debrecen & 1955 & $\begin{array}{l}\text { Siroki Zoltán - } \\
\text { Farkas Attila }\end{array}$ & DE-siroki-03686.jpg \\
\hline 2635 & Carex pilosa Scop. & "Dobogókő" & 1957 & Siroki Zoltán & DE-siroki-03756.jpg \\
\hline 2635 & Carex pilosa Scop. & "Dobogókő" & 1957 & Siroki Zoltán & DE-siroki-03757.jpg \\
\hline 2635 & Carex pilosa Scop. & "Dobogókő" & 1957 & Siroki Zoltán & DE-siroki-03758.jpg \\
\hline 2635 & Carex pilosa Scop. & "Dobogókő" & 1957 & Siroki Zoltán & DE-siroki-03764.jpg \\
\hline
\end{tabular}




\begin{tabular}{|c|c|c|c|c|c|}
\hline $\begin{array}{l}\text { Sorszám / } \\
\text { Number }\end{array}$ & Taxon-név / Taxon-name & $\begin{array}{l}\text { Település / } \\
\text { Settlement }\end{array}$ & $\begin{array}{l}\text { Év / } \\
\text { Year }\end{array}$ & $\begin{array}{l}\text { Gyújitő / } \\
\text { Collector }\end{array}$ & Fájlnév / File-name \\
\hline 2635 & Carex pilosa Scop. & "Fáni-völgy" & 1955 & $\begin{array}{l}\text { Siroki Zoltán - } \\
\text { Farkas Attila }\end{array}$ & DE-siroki-03761.jpg \\
\hline 2635 & Carex pilosa Scop. & "Fáni-völgy" & 1955 & $\begin{array}{l}\text { Siroki Zoltán - } \\
\text { Farkas Attila }\end{array}$ & DE-siroki-03767.jpg \\
\hline 2635 & Carex pilosa Scop. & Budapest & 1952 & Siroki Zoltán & DE-siroki-03754.jpg \\
\hline 2635 & Carex pilosa Scop. & Budapest & 1952 & Siroki Zoltán & DE-siroki-03755.jpg \\
\hline 2635 & Carex pilosa Scop. & Háromhuta & 1973 & Siroki Zoltán & DE-siroki-03760.jpg \\
\hline 2635 & Carex pilosa Scop. & Hosszúhetény & 1958 & Siroki Zoltán & DE-siroki-03759.jpg \\
\hline 2635 & Carex pilosa Scop. & Hosszúhetény & 1958 & Siroki Zoltán & DE-siroki-03763.jpg \\
\hline 2635 & Carex pilosa Scop. & Nagyhuta & 1961 & Siroki Zoltán & DE-siroki-03765.jpg \\
\hline 2635 & Carex pilosa Scop. & Sátoraljaújhely & 1955 & Simon Tiborné & DE-siroki-03766.jpg \\
\hline 2635 & Carex pilosa Scop. & Sátoraljaújhely & 1955 & Simon Tiborné & DE-siroki-03768.jpg \\
\hline 2636 & Carex pallescens L. & "Nagymező" & 1957 & Siroki Zoltán & DE-siroki-03383.jpg \\
\hline 2636 & Carex pallescens L. & Debrecen & 1949 & Siroki Zoltán & DE-siroki-03386.jpg \\
\hline 2636 & Carex pallescens L. & Debrecen & 1949 & Siroki Zoltán & DE-siroki-03380.jpg \\
\hline 2636 & Carex pallescens L. & Debrecen & 1949 & Siroki Zoltán & DE-siroki-03385.jpg \\
\hline 2636 & Carex pallescens L. & Debrecen & 1954 & Siroki Zoltán & DE-siroki-03381.jpg \\
\hline 2636 & Carex pallescens L. & Debrecen & 1954 & Siroki Zoltán & DE-siroki-03382.jpg \\
\hline 2636 & Carex pallescens L. & Háromhuta & 1961 & Siroki Zoltán & DE-siroki-03372.jpg \\
\hline 2636 & Carex pallescens L. & Hollóháza & 1940 & Siroki Zoltán & DE-siroki-03377.jpg \\
\hline 2636 & Carex pallescens L. & Kishuta & 1961 & Siroki Zoltán & DE-siroki-03370.jpg \\
\hline 2636 & Carex pallescens L. & Kishuta & 1961 & Siroki Zoltán & DE-siroki-03376.jpg \\
\hline 2636 & Carex pallescens L. & Nagyhuta & 1961 & Siroki Zoltán & DE-siroki-03373.jpg \\
\hline 2636 & Carex pallescens L. & Nagyhuta & 1961 & Siroki Zoltán & DE-siroki-03374.jpg \\
\hline 2636 & Carex pallescens L. & Nagyhuta & 1961 & Siroki Zoltán & DE-siroki-03375.jpg \\
\hline 2636 & Carex pallescens L. & Nagyhuta & 1961 & Siroki Zoltán & DE-siroki-03371.jpg \\
\hline 2636 & Carex pallescens L. & Vámospércs & 1984 & Siroki Zoltán & DE-siroki-03387.jpg \\
\hline 2637 & Carex supina Wahlenb. & Budapest & 1952 & Siroki Zoltán & DE-siroki-03639.jpg \\
\hline 2637 & Carex supina Wahlenb. & Debrecen & 1949 & Siroki Zoltán & DE-siroki-03634.jpg \\
\hline 2637 & Carex supina Wahlenb. & Debrecen & 1949 & Siroki Zoltán & DE-siroki-03635.jpg \\
\hline 2637 & Carex supina Wahlenb. & Debrecen & 1949 & Siroki Zoltán & DE-siroki-03636.jpg \\
\hline 2637 & Carex supina Wahlenb. & Debrecen & 1949 & Siroki Zoltán & DE-siroki-03637.jpg \\
\hline 2637 & Carex supina Wahlenb. & Debrecen & 1949 & Siroki Zoltán & DE-siroki-03641.jpg \\
\hline 2637 & Carex supina Wahlenb. & Debrecen & 1949 & Siroki Zoltán & DE-siroki-03632.jpg \\
\hline 2637 & Carex supina Wahlenb. & Debrecen & 1950 & Siroki Zoltán & DE-siroki-03627.jpg \\
\hline 2637 & Carex supina Wahlenb. & Debrecen & 1950 & Siroki Zoltán & DE-siroki-03633.jpg \\
\hline 2637 & Carex supina Wahlenb. & Gödöllő & 1951 & Siroki Zoltán & DE-siroki-03628.jpg \\
\hline 2637 & Carex supina Wahlenb. & Gödöllő & 1951 & Siroki Zoltán & DE-siroki-03638.jpg \\
\hline 2637 & Carex supina Wahlenb. & Gödöllő & 1952 & Siroki Zoltán & DE-siroki-03629.jpg \\
\hline 2637 & Carex supina Wahlenb. & Gödöllő & 1952 & Siroki Zoltán & DE-siroki-03642.jpg \\
\hline 2637 & Carex supina Wahlenb. & Mezőcsát & 1911 & Budai József & DE-siroki-03626.jpg \\
\hline 2637 & Carex supina Wahlenb. & Nagykovácsi & 1959 & Siroki Zoltán & DE-siroki-03630.jpg \\
\hline 2637 & Carex supina Wahlenb. & Nagykovácsi & 1959 & Siroki Zoltán & DE-siroki-03631.jpg \\
\hline 2637 & Carex supina Wahlenb. & Nagykovácsi & 1959 & Siroki Zoltán & DE-siroki-03640.jpg \\
\hline 2638 & Carex acutiformis Ehrh. & Budakalász & 1915 & Kocsis István & DE-siroki-03962.jpg \\
\hline 2638 & Carex acutiformis Ehrh. & Budapest & 1884 & Hermann & DE-siroki-03966.jpg \\
\hline 2638 & Carex acutiformis Ehrh. & Budapest & 1904 & Thaisz Lajos & DE-siroki-03965.jpg \\
\hline
\end{tabular}




\begin{tabular}{|c|c|c|c|c|c|}
\hline $\begin{array}{l}\text { Sorszám / } \\
\text { Number }\end{array}$ & Taxon-név / Taxon-name & $\begin{array}{l}\text { Település / } \\
\text { Settlement }\end{array}$ & $\begin{array}{l}\text { Év / } \\
\text { Year }\end{array}$ & $\begin{array}{l}\text { Gyűjtő / } \\
\text { Collector }\end{array}$ & Fájlnév / File-name \\
\hline 2638 & Carex acutiformis Ehrh. & Budapest & 1909 & Kocsis István & DE-siroki-03963.jpg \\
\hline 2638 & Carex acutiformis Ehrh. & Budapest & 1915 & Degen Árpád & DE-siroki-03964.jpg \\
\hline 2638 & Carex acutiformis Ehrh. & Debrecen & 1947 & Siroki Zoltán & DE-siroki-03970.jpg \\
\hline 2638 & Carex acutiformis Ehrh. & Debrecen & 1947 & Siroki Zoltán & DE-siroki-03971.jpg \\
\hline 2638 & Carex acutiformis Ehrh. & Debrecen & 1948 & Siroki Zoltán & DE-siroki-03960.jpg \\
\hline 2638 & Carex acutiformis Ehrh. & Debrecen & 1948 & Siroki Zoltán & DE-siroki-03931.jpg \\
\hline 2638 & Carex acutiformis Ehrh. & Debrecen & 1948 & Siroki Zoltán & DE-siroki-03933.jpg \\
\hline 2638 & Carex acutiformis Ehrh. & Debrecen & 1948 & Siroki Zoltán & DE-siroki-03946.jpg \\
\hline 2638 & Carex acutiformis Ehrh. & Debrecen & 1948 & Siroki Zoltán & DE-siroki-03959.jpg \\
\hline 2638 & Carex acutiformis Ehrh. & Debrecen & 1955 & $\begin{array}{l}\text { Siroki Zoltán - } \\
\text { Farkas Attila }\end{array}$ & DE-siroki-03934.jpg \\
\hline 2638 & Carex acutiformis Ehrh. & Debrecen & 1955 & $\begin{array}{l}\text { Siroki Zoltán - } \\
\text { Farkas Attila }\end{array}$ & DE-siroki-03935.jpg \\
\hline 2638 & Carex acutiformis Ehrh. & Egyek & 1949 & Siroki Zoltán & DE-siroki-03932.jpg \\
\hline 2638 & Carex acutiformis Ehrh. & Gödöllő & 1951 & Siroki Zoltán & DE-siroki-03975.jpg \\
\hline 2638 & Carex acutiformis Ehrh. & Gödöllő & 1951 & Siroki Zoltán & DE-siroki-03955.jpg \\
\hline 2638 & Carex acutiformis Ehrh. & Gödöllő & 1951 & Siroki Zoltán & DE-siroki-03958.jpg \\
\hline 2638 & Carex acutiformis Ehrh. & Gödöllő & 1952 & Siroki Zoltán & DE-siroki-03953.jpg \\
\hline 2638 & Carex acutiformis Ehrh. & Gödöllő & 1952 & Siroki Zoltán & DE-siroki-03956.jpg \\
\hline 2638 & Carex acutiformis Ehrh. & Gödöllő & 1952 & Siroki Zoltán & DE-siroki-03961.jpg \\
\hline 2638 & Carex acutiformis Ehrh. & Gödöllő & 1952 & Siroki Zoltán & DE-siroki-03947.jpg \\
\hline 2638 & Carex acutiformis Ehrh. & Gödöllő & 1952 & Siroki Zoltán & DE-siroki-03954.jpg \\
\hline 2638 & Carex acutiformis Ehrh. & Gödöllő & 1952 & Siroki Zoltán & DE-siroki-03957.jpg \\
\hline 2638 & Carex acutiformis Ehrh. & Kállósemjén & 1955 & Kovács Béla & DE-siroki-03948.jpg \\
\hline 2638 & Carex acutiformis Ehrh. & Rakaca & 1982 & Siroki Zoltán & DE-siroki-03972.jpg \\
\hline 2638 & Carex acutiformis Ehrh. & Rakaca & 1982 & Siroki Zoltán & DE-siroki-03976.jpg \\
\hline 2638 & Carex acutiformis Ehrh. & Rakaca & 1982 & Siroki Zoltán & DE-siroki-03978.jpg \\
\hline 2638 & Carex acutiformis Ehrh. & Rakaca & 1982 & Siroki Zoltán & DE-siroki-03979.jpg \\
\hline 2638 & Carex acutiformis Ehrh. & Rakaca & 1982 & Siroki Zoltán & DE-siroki-03980.jpg \\
\hline 2638 & Carex acutiformis Ehrh. & Rakaca & 1982 & Siroki Zoltán & DE-siroki-03981.jpg \\
\hline 2638 & Carex acutiformis Ehrh. & Újléta & 1967 & Siroki Zoltán & DE-siroki-03929.jpg \\
\hline 2638 & Carex acutiformis Ehrh. & Újléta & 1967 & Siroki Zoltán & DE-siroki-03930.jpg \\
\hline 2638 & Carex acutiformis Ehrh. & Újléta & 1967 & Siroki Zoltán & DE-siroki-03936.jpg \\
\hline 2638 & Carex acutiformis Ehrh. & Újléta & 1967 & Siroki Zoltán & DE-siroki-03937.jpg \\
\hline 2638 & Carex acutiformis Ehrh. & Újléta & 1967 & Siroki Zoltán & DE-siroki-03938.jpg \\
\hline 2638 & Carex acutiformis Ehrh. & Újléta & 1967 & Siroki Zoltán & DE-siroki-03939.jpg \\
\hline 2638 & Carex acutiformis Ehrh. & Újléta & 1967 & Siroki Zoltán & DE-siroki-03940.jpg \\
\hline 2638 & Carex acutiformis Ehrh. & Újléta & 1967 & Siroki Zoltán & DE-siroki-03941.jpg \\
\hline 2638 & Carex acutiformis Ehrh. & Újléta & 1967 & Siroki Zoltán & DE-siroki-03942.jpg \\
\hline 2638 & Carex acutiformis Ehrh. & Újléta & 1967 & Siroki Zoltán & DE-siroki-03943.jpg \\
\hline 2638 & Carex acutiformis Ehrh. & Újléta & 1967 & Siroki Zoltán & DE-siroki-03944.jpg \\
\hline 2638 & Carex acutiformis Ehrh. & Újléta & 1967 & Siroki Zoltán & DE-siroki-03945.jpg \\
\hline 2638 & Carex acutiformis Ehrh. & Újléta & 1967 & Siroki Zoltán & DE-siroki-03949.jpg \\
\hline 2638 & Carex acutiformis Ehrh. & Újléta & 1967 & Siroki Zoltán & DE-siroki-03950.jpg \\
\hline 2638 & Carex acutiformis Ehrh. & Újléta & 1967 & Siroki Zoltán & DE-siroki-03951.jpg \\
\hline 2638 & Carex acutiformis Ehrh. & Újléta & 1967 & Siroki Zoltán & DE-siroki-03952.jpg \\
\hline 2639 & Carex riparia Curtis & "Csepel-sziget" & 1909 & Kocsis István & DE-siroki-03988.jpg \\
\hline
\end{tabular}




\begin{tabular}{|c|c|c|c|c|c|}
\hline $\begin{array}{l}\text { Sorszám / } \\
\text { Number }\end{array}$ & Taxon-név / Taxon-name & $\begin{array}{l}\text { Település / } \\
\text { Settlement }\end{array}$ & $\begin{array}{l}\text { Év / } \\
\text { Year }\end{array}$ & $\begin{array}{l}\text { Gyújtő / } \\
\text { Collector }\end{array}$ & Fájlnév / File-name \\
\hline 2639 & Carex riparia Curtis & Budapest & 1904 & $\begin{array}{l}\text { Thaisz Lajos - } \\
\text { Baán Lajos }\end{array}$ & DE-siroki-03991.jpg \\
\hline 2639 & Carex riparia Curtis & Budapest & 1909 & Kocsis István & DE-siroki-03986.jpg \\
\hline 2639 & Carex riparia Curtis & Csaroda & 1962 & Siroki Zoltán & DE-siroki-04009.jpg \\
\hline 2639 & Carex riparia Curtis & Debrecen & 1946 & Siroki Zoltán & DE-siroki-04000.jpg \\
\hline 2639 & Carex riparia Curtis & Debrecen & 1946 & Siroki Zoltán & DE-siroki-04002.jpg \\
\hline 2639 & Carex riparia Curtis & Debrecen & 1946 & Siroki Zoltán & DE-siroki-04012.jpg \\
\hline 2639 & Carex riparia Curtis & Debrecen & 1947 & Siroki Zoltán & DE-siroki-03994.jpg \\
\hline 2639 & Carex riparia Curtis & Debrecen & 1947 & Siroki Zoltán & DE-siroki-03997.jpg \\
\hline 2639 & Carex riparia Curtis & Debrecen & 1950 & Siroki Zoltán & DE-siroki-04013.jpg \\
\hline 2639 & Carex riparia Curtis & Debrecen & 1954 & Siroki Zoltán & DE-siroki-04005.jpg \\
\hline 2639 & Carex riparia Curtis & Debrecen & 1954 & Siroki Zoltán & DE-siroki-04006.jpg \\
\hline 2639 & Carex riparia Curtis & Debrecen & 1958 & Siroki Zoltán & DE-siroki-03995.jpg \\
\hline 2639 & Carex riparia Curtis & Debrecen & 1958 & Siroki Zoltán & DE-siroki-03998.jpg \\
\hline 2639 & Carex riparia Curtis & Debrecen & 1966 & Siroki Zoltán & DE-siroki-04010.jpg \\
\hline 2639 & Carex riparia Curtis & Egyek & 1949 & Siroki Zoltán & DE-siroki-04011.jpg \\
\hline 2639 & Carex riparia Curtis & Egyek & 1949 & Siroki Zoltán & DE-siroki-03999.jpg \\
\hline 2639 & Carex riparia Curtis & Egyek & 1949 & Siroki Zoltán & DE-siroki-04001.jpg \\
\hline 2639 & Carex riparia Curtis & Egyek & 1949 & Siroki Zoltán & DE-siroki-03996.jpg \\
\hline 2639 & Carex riparia Curtis & Leányfalu & 1917 & Kocsis István & DE-siroki-03989.jpg \\
\hline 2639 & Carex riparia Curtis & Mosonmagyaróvár & 1939 & Siroki Zoltán & DE-siroki-04003.jpg \\
\hline 2639 & Carex riparia Curtis & Tiszafüred & 1955 & $\begin{array}{l}\text { Siroki Zoltán - } \\
\text { Farkas Attila }\end{array}$ & DE-siroki-04007.jpg \\
\hline 2639 & Carex riparia Curtis & Tiszafüred & 1955 & $\begin{array}{l}\text { Siroki Zoltán - } \\
\text { Farkas Attila }\end{array}$ & DE-siroki-04004.jpg \\
\hline 2639 & Carex riparia Curtis & Tiszafüred & 1955 & $\begin{array}{l}\text { Siroki Zoltán - } \\
\text { Farkas Attila }\end{array}$ & DE-siroki-04008.jpg \\
\hline 2640 & Carex rostrata Stokes & Egerbakta & 1968 & Siroki Zoltán & DE-siroki-04043.jpg \\
\hline 2640 & Carex rostrata Stokes & Gödöllő & 1952 & Siroki Zoltán & DE-siroki-04044.jpg \\
\hline 2640 & Carex rostrata Stokes & Gödöllő & 1952 & Siroki Zoltán & DE-siroki-04051.jpg \\
\hline 2640 & Carex rostrata Stokes & Gödöllő & 1952 & Siroki Zoltán & DE-siroki-04050.jpg \\
\hline 2641 & Carex vesicaria L. & Balassagyarmat & 1955 & Máthé Imre & DE-siroki-04061.jpg \\
\hline 2641 & Carex vesicaria L. & Balassagyarmat & 1955 & Máthé Imre & DE-siroki-04062.jpg \\
\hline 2641 & Carex vesicaria L. & Balassagyarmat & 1955 & Máthé Imre & DE-siroki-04063.jpg \\
\hline 2641 & Carex vesicaria L. & Bátorliget & 1957 & Siroki Zoltán & DE-siroki-04064.jpg \\
\hline 2641 & Carex vesicaria L. & Bátorliget & 1957 & Siroki Zoltán & DE-siroki-04074.jpg \\
\hline 2641 & Carex vesicaria L. & Bodrogkeresztúr & 1967 & Siroki Zoltán & DE-siroki-04078.jpg \\
\hline 2641 & Carex vesicaria L. & Debrecen & 1956 & Siroki Zoltán & DE-siroki-04068.jpg \\
\hline 2641 & Carex vesicaria L. & Debrecen & 1956 & Siroki Zoltán & DE-siroki-04069.jpg \\
\hline 2641 & Carex vesicaria L. & Debrecen & 1956 & Siroki Zoltán & DE-siroki-04073.jpg \\
\hline 2641 & Carex vesicaria L. & Debrecen & 1956 & Siroki Zoltán & DE-siroki-04065.jpg \\
\hline 2641 & Carex vesicaria L. & Debrecen & 1974 & Siroki Zoltán & DE-siroki-04085.jpg \\
\hline 2641 & Carex vesicaria L. & Egyek & 1949 & Siroki Zoltán & DE-siroki-04066.jpg \\
\hline 2641 & Carex vesicaria L. & Egyek & 1949 & Siroki Zoltán & DE-siroki-04072.jpg \\
\hline 2641 & Carex vesicaria L. & Gyöngyös & 1913 & Degen Árpád & DE-siroki-04089.jpg \\
\hline 2641 & Carex vesicaria L. & Háromhuta & 1961 & Siroki Zoltán & DE-siroki-04075.jpg \\
\hline 2641 & Carex vesicaria L. & Háromhuta & 1961 & Siroki Zoltán & DE-siroki-04076.jpg \\
\hline 2641 & Carex vesicaria L. & Háromhuta & 1961 & Siroki Zoltán & DE-siroki-04077.jpg \\
\hline 2641 & Carex vesicaria L. & Pilisszentlászló & 1918 & Degen Árpád & DE-siroki-04054.jpg \\
\hline
\end{tabular}




\begin{tabular}{|c|c|c|c|c|c|}
\hline $\begin{array}{l}\text { Sorszám / } \\
\text { Number }\end{array}$ & Taxon-név / Taxon-name & $\begin{array}{l}\text { Település / } \\
\text { Settlement }\end{array}$ & $\begin{array}{l}\text { Év / } \\
\text { Year }\end{array}$ & $\begin{array}{l}\text { Gyújtő / } \\
\text { Collector }\end{array}$ & Fájlnév / File-name \\
\hline 2641 & Carex vesicaria L. & Rakaca & 1982 & Siroki Zoltán & DE-siroki-04088.jpg \\
\hline 2641 & Carex vesicaria L. & Rezi & 1930 & Rigler József & DE-siroki-04059.jpg \\
\hline 2641 & Carex vesicaria L. & Újléta & 1967 & Siroki Zoltán & DE-siroki-04079.jpg \\
\hline 2641 & Carex vesicaria L. & Újléta & 1967 & Siroki Zoltán & DE-siroki-04080.jpg \\
\hline 2641 & Carex vesicaria L. & Újléta & 1967 & Siroki Zoltán & DE-siroki-04081.jpg \\
\hline 2641 & Carex vesicaria L. & Újléta & 1967 & Siroki Zoltán & DE-siroki-04082.jpg \\
\hline 2641 & Carex vesicaria L. & Újléta & 1967 & Siroki Zoltán & DE-siroki-04083.jpg \\
\hline 2641 & Carex vesicaria L. & Újléta & 1967 & Siroki Zoltán & DE-siroki-04084.jpg \\
\hline 2641 & Carex vesicaria L. & Újléta & 1984 & Siroki Zoltán & DE-siroki-04086.jpg \\
\hline 2641 & Carex vesicaria L. & Újléta & 1984 & Siroki Zoltán & DE-siroki-04087.jpg \\
\hline 2641 & Carex vesicaria L. & Zalavár & 1923 & Rigler József & DE-siroki-04060.jpg \\
\hline 2642 & Carex melanostachya Willd. & Biharugra & 1961 & Siroki Zoltán & DE-siroki-03916.jpg \\
\hline 2642 & Carex melanostachya Willd. & Biharugra & 1961 & Siroki Zoltán & DE-siroki-03928.jpg \\
\hline 2642 & Carex melanostachya Willd. & Bodrogkeresztúr & 1967 & Siroki Zoltán & DE-siroki-03924.jpg \\
\hline 2642 & Carex melanostachya Willd. & Bodrogkeresztúr & 1967 & Siroki Zoltán & DE-siroki-03925.jpg \\
\hline 2642 & Carex melanostachya Willd. & Debrecen & 1970 & Siroki Zoltán & DE-siroki-03917.jpg \\
\hline 2642 & Carex melanostachya Willd. & Debrecen & 1970 & Siroki Zoltán & DE-siroki-03922.jpg \\
\hline 2642 & Carex melanostachya Willd. & Debrecen & 1970 & Siroki Zoltán & DE-siroki-03923.jpg \\
\hline 2642 & Carex melanostachya Willd. & Egyek & 1947 & Siroki Zoltán & DE-siroki-03926.jpg \\
\hline 2642 & Carex melanostachya Willd. & Egyek & 1947 & Siroki Zoltán & DE-siroki-03910.jpg \\
\hline 2642 & Carex melanostachya Willd. & Egyek & 1947 & Siroki Zoltán & DE-siroki-03911.jpg \\
\hline 2642 & Carex melanostachya Willd. & Egyek & 1947 & Siroki Zoltán & DE-siroki-03912.jpg \\
\hline 2642 & Carex melanostachya Willd. & Egyek & 1948 & Siroki Zoltán & DE-siroki-03921.jpg \\
\hline 2642 & Carex melanostachya Willd. & Egyek & 1948 & Siroki Zoltán & DE-siroki-03919.jpg \\
\hline 2642 & Carex melanostachya Willd. & Garadna & 1944 & Siroki Zoltán & DE-siroki-03914.jpg \\
\hline 2642 & Carex melanostachya Willd. & Garadna & 1944 & Siroki Zoltán & DE-siroki-03915.jpg \\
\hline 2642 & Carex melanostachya Willd. & Gyöngyös & 1959 & Gondola István & DE-siroki-03902.jpg \\
\hline 2642 & Carex melanostachya Willd. & Hortobágy & 1947 & Siroki Zoltán & DE-siroki-03920.jpg \\
\hline 2642 & Carex melanostachya Willd. & Hortobágy & 1947 & Siroki Zoltán & DE-siroki-03909.jpg \\
\hline 2642 & Carex melanostachya Willd. & Hortobágy & 1949 & Siroki Zoltán & DE-siroki-03908.jpg \\
\hline 2642 & Carex melanostachya Willd. & Pomáz & 1904 & Kocsis István & DE-siroki-03905.jpg \\
\hline 2642 & Carex melanostachya Willd. & Pomáz & 1909 & Kocsis István & DE-siroki-03903.jpg \\
\hline 2642 & Carex melanostachya Willd. & Pomáz & 1909 & Kocsis István & DE-siroki-03904.jpg \\
\hline 2642 & Carex melanostachya Willd. & Pomáz & 1910 & Kocsis István & DE-siroki-03906.jpg \\
\hline 2642 & Carex melanostachya Willd. & Pomáz & 1952 & Siroki Zoltán & DE-siroki-03927.jpg \\
\hline 2642 & Carex melanostachya Willd. & Szarvas & 1954 & Siroki Zoltán & DE-siroki-03918.jpg \\
\hline 2642 & Carex melanostachya Willd. & Szikszó & 1910 & Thaisz Lajos & DE-siroki-03907.jpg \\
\hline 2642 & Carex melanostachya Willd. & Tiszafüred & 1955 & $\begin{array}{l}\text { Siroki Zoltán - } \\
\text { Farkas Attila }\end{array}$ & DE-siroki-03913.jpg \\
\hline 2643 & Carex alba Scop. & "Fáni-völgy" & 1955 & Siroki Zoltán & DE-siroki-03482.jpg \\
\hline 2643 & Carex alba Scop. & "Fáni-völgy" & 1955 & Siroki Zoltán & DE-siroki-03481.jpg \\
\hline 2643 & Carex alba Scop. & "Fáni-völgy" & 1955 & $\begin{array}{l}\text { Siroki Zoltán - } \\
\text { Farkas Attila }\end{array}$ & DE-siroki-03478.jpg \\
\hline 2643 & Carex alba Scop. & "Fáni-völgy" & 1955 & $\begin{array}{l}\text { Siroki Zoltán - } \\
\text { Farkas Attila }\end{array}$ & DE-siroki-03479.jpg \\
\hline 2643 & Carex alba Scop. & "Fáni-völgy" & 1955 & $\begin{array}{l}\text { Siroki Zoltán - } \\
\text { Farkas Attila }\end{array}$ & DE-siroki-03480.jpg \\
\hline 2643 & Carex alba Scop. & "Fáni-völgy" & 1955 & $\begin{array}{l}\text { Siroki Zoltán - } \\
\text { Farkas Attila }\end{array}$ & DE-siroki-03475.jpg \\
\hline
\end{tabular}




\begin{tabular}{|c|c|c|c|c|c|}
\hline $\begin{array}{l}\text { Sorszám / } \\
\text { Number }\end{array}$ & Taxon-név / Taxon-name & $\begin{array}{l}\text { Település / } \\
\text { Settlement }\end{array}$ & $\begin{array}{l}\text { Év / } \\
\text { Year }\end{array}$ & $\begin{array}{l}\text { Gyújitő / } \\
\text { Collector }\end{array}$ & Fájlnév / File-name \\
\hline 2643 & Carex alba Scop. & "Fáni-völgy" & 1955 & $\begin{array}{l}\text { Siroki Zoltán - } \\
\text { Farkas Attila }\end{array}$ & DE-siroki-03476.jpg \\
\hline 2644 & Carex liparicarpos Gaudin & "Csepel-sziget" & 1909 & Kocsis István & DE-siroki-03618.jpg \\
\hline 2644 & Carex liparicarpos Gaudin & "Keszthelyi-hg." & 1953 & Siroki Zoltán & DE-siroki-03601.jpg \\
\hline 2644 & Carex liparicarpos Gaudin & Budaörs & 1952 & Siroki Zoltán & DE-siroki-03600.jpg \\
\hline 2644 & Carex liparicarpos Gaudin & Budaörs & 1952 & Siroki Zoltán & DE-siroki-03610.jpg \\
\hline 2644 & Carex liparicarpos Gaudin & Budaörs & 1952 & Siroki Zoltán & DE-siroki-03611.jpg \\
\hline 2644 & Carex liparicarpos Gaudin & Budapest & 1886 & $\begin{array}{l}\text { Schilberszky } \\
\text { Károly }\end{array}$ & DE-siroki-03621.jpg \\
\hline 2644 & Carex liparicarpos Gaudin & Budapest & 1887 & Czakó Kálmán & DE-siroki-03596.jpg \\
\hline 2644 & Carex liparicarpos Gaudin & Budapest & 1951 & Siroki Zoltán & DE-siroki-03613.jpg \\
\hline 2644 & Carex liparicarpos Gaudin & Budapest & 1951 & Siroki Zoltán & DE-siroki-03616.jpg \\
\hline 2644 & Carex liparicarpos Gaudin & Budapest & 1951 & Siroki Zoltán & DE-siroki-03614.jpg \\
\hline 2644 & Carex liparicarpos Gaudin & Budapest & 1952 & Siroki Zoltán & DE-siroki-03598.jpg \\
\hline 2644 & Carex liparicarpos Gaudin & Budapest & 1959 & Gondola István & DE-siroki-03605.jpg \\
\hline 2644 & Carex liparicarpos Gaudin & Budapest & 1959 & Gondola István & DE-siroki-03606.jpg \\
\hline 2644 & Carex liparicarpos Gaudin & Budapest & 1959 & Gondola István & DE-siroki-03607.jpg \\
\hline 2644 & Carex liparicarpos Gaudin & Budapest & 1959 & Gondola István & DE-siroki-03608.jpg \\
\hline 2644 & Carex liparicarpos Gaudin & Budapest & 1960 & Gondola István & DE-siroki-03604.jpg \\
\hline 2644 & Carex liparicarpos Gaudin & Budapest & 1967 & Siroki Zoltán & DE-siroki-03603.jpg \\
\hline 2644 & Carex liparicarpos Gaudin & Budapest & 1967 & Siroki Zoltán & DE-siroki-03624.jpg \\
\hline 2644 & Carex liparicarpos Gaudin & Budapest & 1967 & Siroki Zoltán & DE-siroki-03625.jpg \\
\hline 2644 & Carex liparicarpos Gaudin & Gödöllő & 1952 & Siroki Zoltán & DE-siroki-03599.jpg \\
\hline 2644 & Carex liparicarpos Gaudin & Gödöllő & 1952 & Siroki Zoltán & DE-siroki-03609.jpg \\
\hline 2644 & Carex liparicarpos Gaudin & Gödöllő & 1952 & Siroki Zoltán & DE-siroki-03612.jpg \\
\hline 2644 & Carex liparicarpos Gaudin & Gödöllő & 1952 & Siroki Zoltán & DE-siroki-03615.jpg \\
\hline 2644 & Carex liparicarpos Gaudin & Gyenesdiás & 1955 & Siroki Zoltán & DE-siroki-03602.jpg \\
\hline 2644 & Carex liparicarpos Gaudin & Monorierdő & 1888 & Czakó Kálmán & DE-siroki-03622.jpg \\
\hline 2644 & Carex liparicarpos Gaudin & Nagykőrös & 1913 & Degen Árpád & DE-siroki-03617.jpg \\
\hline 2644 & Carex liparicarpos Gaudin & Pilisszentiván & 1916 & Degen Árpád & DE-siroki-03619.jpg \\
\hline 2644 & Carex liparicarpos Gaudin & Pilisszentiván & 1916 & Degen Árpád & DE-siroki-03623.jpg \\
\hline 2644 & Carex liparicarpos Gaudin & Pilisszentiván & 1916 & Degen Árpád & DE-siroki-03620.jpg \\
\hline 2645 & Carex panicea L. & Budapest & 1909 & Kocsis István & DE-siroki-03471.jpg \\
\hline 2645 & Carex panicea L. & Budapest & 1909 & Kocsis István & DE-siroki-03472.jpg \\
\hline 2645 & Carex panicea $\mathrm{L}$. & Budapest & 1958 & Siroki Zoltán & DE-siroki-03464.jpg \\
\hline 2645 & Carex panicea L. & Debrecen & 1955 & $\begin{array}{l}\text { Siroki Zoltán - } \\
\text { Farkas Attila }\end{array}$ & DE-siroki-03462.jpg \\
\hline 2645 & Carex panicea L. & Debrecen & 1957 & Siroki Zoltán & DE-siroki-03461.jpg \\
\hline 2645 & Carex panicea L. & Debrecen & 1958 & Siroki Zoltán & DE-siroki-03460.jpg \\
\hline 2645 & Carex panicea L. & Gödöllő & 1954 & Siroki Zoltán & DE-siroki-03463.jpg \\
\hline 2645 & Carex panicea L. & Háromhuta & 1961 & Siroki Zoltán & DE-siroki-03465.jpg \\
\hline 2645 & Carex panicea L. & Háromhuta & 1961 & Siroki Zoltán & DE-siroki-03466.jpg \\
\hline 2645 & Carex panicea L. & Nagyhuta & 1961 & Siroki Zoltán & DE-siroki-03467.jpg \\
\hline 2645 & Carex panicea L. & Nagyhuta & 1961 & Siroki Zoltán & DE-siroki-03468.jpg \\
\hline 2645 & Carex panicea L. & Vámospércs & 1985 & Siroki Zoltán & DE-siroki-03469.jpg \\
\hline 2645 & Carex panicea L. & Vámospércs & 1985 & Siroki Zoltán & DE-siroki-03470.jpg \\
\hline 2646 & Carex brevicollis DC. & Miskolc & 1911 & Budai József & DE-siroki-03705.jpg \\
\hline 2646 & Carex brevicollis DC. & Miskolc & 1911 & Degen Árpád & DE-siroki-03706.jpg \\
\hline
\end{tabular}




\begin{tabular}{|c|c|c|c|c|c|}
\hline $\begin{array}{l}\text { Sorszám / } \\
\text { Number }\end{array}$ & Taxon-név / Taxon-name & $\begin{array}{l}\text { Település / } \\
\text { Settlement }\end{array}$ & $\begin{array}{l}\text { Év / } \\
\text { Year }\end{array}$ & $\begin{array}{l}\text { Gyújtő / } \\
\text { Collector }\end{array}$ & Fájlnév / File-name \\
\hline 2646 & Carex brevicollis DC. & Miskolc & 1958 & Siroki Zoltán & DE-siroki-03712.jpg \\
\hline 2646 & Carex brevicollis DC. & Miskolc & 1964 & Siroki Zoltán & DE-siroki-03695.jpg \\
\hline 2646 & Carex brevicollis DC. & Miskolc & 1964 & Siroki Zoltán & DE-siroki-03702.jpg \\
\hline 2646 & Carex brevicollis DC. & Miskolc & 1964 & Siroki Zoltán & DE-siroki-03707.jpg \\
\hline 2646 & Carex brevicollis DC. & Miskolc & 1964 & Siroki Zoltán & DE-siroki-03708.jpg \\
\hline 2646 & Carex brevicollis DC. & Miskolc & 1964 & Siroki Zoltán & DE-siroki-03709.jpg \\
\hline 2646 & Carex brevicollis DC. & Miskolc & 1964 & Siroki Zoltán & DE-siroki-03710.jpg \\
\hline 2646 & Carex brevicollis DC. & Miskolc & 1964 & Siroki Zoltán & DE-siroki-03711.jpg \\
\hline 2646 & Carex brevicollis DC. & Miskolc & 1964 & Siroki Zoltán & DE-siroki-03713.jpg \\
\hline 2646 & Carex brevicollis DC. & Miskolc & 1964 & Siroki Zoltán & DE-siroki-03714.jpg \\
\hline 2646 & Carex brevicollis DC. & Miskolc & 1964 & Siroki Zoltán & DE-siroki-03715.jpg \\
\hline 2646 & Carex brevicollis DC. & Miskolc & 1964 & Siroki Zoltán & DE-siroki-03716.jpg \\
\hline 2646 & Carex brevicollis DC. & Miskolc & 1964 & Siroki Zoltán & DE-siroki-03717.jpg \\
\hline 2646 & Carex brevicollis DC. & Miskolc & 1964 & Siroki Zoltán & DE-siroki-03718.jpg \\
\hline 2646 & Carex brevicollis DC. & Szarvaskő & 1957 & Siroki Zoltán & DE-siroki-03723.jpg \\
\hline 2646 & Carex brevicollis DC. & Szarvaskő & 1958 & Siroki Zoltán & DE-siroki-03696.jpg \\
\hline 2646 & Carex brevicollis DC. & Szarvaskő & 1958 & Siroki Zoltán & DE-siroki-03697.jpg \\
\hline 2646 & Carex brevicollis DC. & Szarvaskő & 1958 & Siroki Zoltán & DE-siroki-03698.jpg \\
\hline 2646 & Carex brevicollis DC. & Szarvaskő & 1958 & Siroki Zoltán & DE-siroki-03699.jpg \\
\hline 2646 & Carex brevicollis DC. & Szarvaskő & 1958 & Siroki Zoltán & DE-siroki-03700.jpg \\
\hline 2646 & Carex brevicollis DC. & Szarvaskő & 1958 & Siroki Zoltán & DE-siroki-03701.jpg \\
\hline 2646 & Carex brevicollis DC. & Szarvaskő & 1958 & Siroki Zoltán & DE-siroki-03703.jpg \\
\hline 2646 & Carex brevicollis DC. & Szarvaskő & 1958 & Siroki Zoltán & DE-siroki-03704.jpg \\
\hline 2646 & Carex brevicollis DC. & Szarvaskő & 1958 & Siroki Zoltán & DE-siroki-03719.jpg \\
\hline 2646 & Carex brevicollis DC. & Szarvaskő & 1958 & Siroki Zoltán & DE-siroki-03720.jpg \\
\hline 2646 & Carex brevicollis DC. & Szarvaskő & 1958 & Siroki Zoltán & DE-siroki-03721.jpg \\
\hline 2646 & Carex brevicollis DC. & Szarvaskő & 1958 & Siroki Zoltán & DE-siroki-03722.jpg \\
\hline 2646 & Carex brevicollis DC. & Szarvaskő & 1958 & Siroki Zoltán & DE-siroki-03724.jpg \\
\hline 2647 & Carex michelii Host & "Budai hegyek" & 1875 & Redtenbacher & DE-siroki-03730.jpg \\
\hline 2647 & Carex michelii Host & Bátorliget & 1954 & Siroki Zoltán & DE-siroki-03752.jpg \\
\hline 2647 & Carex michelii Host & Budapest & 1887 & Czakó Kálmán & DE-siroki-03725.jpg \\
\hline 2647 & Carex michelii Host & Budapest & 1952 & Siroki Zoltán & DE-siroki-03750.jpg \\
\hline 2647 & Carex michelii Host & Budapest & 1952 & Siroki Zoltán & DE-siroki-03737.jpg \\
\hline 2647 & Carex michelii Host & Budapest & 1960 & Siroki Zoltán & DE-siroki-03735.jpg \\
\hline 2647 & Carex michelii Host & Budapest & 1960 & Siroki Zoltán & DE-siroki-03739.jpg \\
\hline 2647 & Carex michelii Host & Debrecen & 1959 & Siroki Zoltán & DE-siroki-03736.jpg \\
\hline 2647 & Carex michelii Host & Debrecen & 1959 & Siroki Zoltán & DE-siroki-03741.jpg \\
\hline 2647 & Carex michelii Host & Debrecen & 1959 & Siroki Zoltán & DE-siroki-03743.jpg \\
\hline 2647 & Carex michelii Host & Debrecen & 1959 & Siroki Zoltán & DE-siroki-03744.jpg \\
\hline 2647 & Carex michelii Host & Gödöllő & 1952 & Siroki Zoltán & DE-siroki-03751.jpg \\
\hline 2647 & Carex michelii Host & Gödöllő & 1952 & Siroki Zoltán & DE-siroki-03728.jpg \\
\hline 2647 & Carex michelii Host & Gödöllő & 1952 & Siroki Zoltán & DE-siroki-03733.jpg \\
\hline 2647 & Carex michelii Host & Gödöllő & 1952 & Siroki Zoltán & DE-siroki-03727.jpg \\
\hline 2647 & Carex michelii Host & Háromhuta & 1961 & Siroki Zoltán & DE-siroki-03748.jpg \\
\hline 2647 & Carex michelii Host & Háromhuta & 1961 & Siroki Zoltán & DE-siroki-03746.jpg \\
\hline 2647 & Carex michelii Host & Háromhuta & 1961 & Siroki Zoltán & DE-siroki-03749.jpg \\
\hline
\end{tabular}




\begin{tabular}{|c|c|c|c|c|c|}
\hline $\begin{array}{l}\text { Sorszám / } \\
\text { Number }\end{array}$ & Taxon-név / Taxon-name & $\begin{array}{l}\text { Település / } \\
\text { Settlement }\end{array}$ & $\begin{array}{l}\text { Év / } \\
\text { Year }\end{array}$ & $\begin{array}{l}\text { Gyűjtő / } \\
\text { Collector }\end{array}$ & Fájlnév / File-name \\
\hline 2647 & Carex michelii Host & Háromhuta & 1961 & Siroki Zoltán & DE-siroki-03738.jpg \\
\hline 2647 & Carex michelii Host & Háromhuta & 1961 & Siroki Zoltán & DE-siroki-03740.jpg \\
\hline 2647 & Carex michelii Host & Háromhuta & 1961 & Siroki Zoltán & DE-siroki-03742.jpg \\
\hline 2647 & Carex michelii Host & Háromhuta & 1961 & Siroki Zoltán & DE-siroki-03745.jpg \\
\hline 2647 & Carex michelii Host & Háromhuta & 1961 & Siroki Zoltán & DE-siroki-03747.jpg \\
\hline 2647 & Carex michelii Host & Szarvaskő & 1958 & Siroki Zoltán & DE-siroki-03732.jpg \\
\hline 2649 & Carex hordeistichos Vill. & Debrecen & 1946 & Siroki Zoltán & DE-siroki-03853.jpg \\
\hline 2649 & Carex hordeistichos Vill. & Debrecen & 1946 & Siroki Zoltán & DE-siroki-03841.jpg \\
\hline 2649 & Carex hordeistichos Vill. & Debrecen & 1946 & Siroki Zoltán & DE-siroki-03846.jpg \\
\hline 2649 & Carex hordeistichos Vill. & Debrecen & 1947 & Siroki Zoltán & DE-siroki-03857.jpg \\
\hline 2649 & Carex hordeistichos Vill. & Debrecen & 1947 & Siroki Zoltán & DE-siroki-03858.jpg \\
\hline 2649 & Carex hordeistichos Vill. & Debrecen & 1947 & Siroki Zoltán & DE-siroki-03847.jpg \\
\hline 2649 & Carex hordeistichos Vill. & Debrecen & 1947 & Siroki Zoltán & DE-siroki-03854.jpg \\
\hline 2649 & Carex hordeistichos Vill. & Debrecen & 1948 & Siroki Zoltán & DE-siroki-03843.jpg \\
\hline 2649 & Carex hordeistichos Vill. & Debrecen & 1948 & Siroki Zoltán & DE-siroki-03844.jpg \\
\hline 2649 & Carex hordeistichos Vill. & Debrecen & 1948 & Siroki Zoltán & DE-siroki-03845.jpg \\
\hline 2649 & Carex hordeistichos Vill. & Debrecen & 1954 & Siroki Zoltán & DE-siroki-03855.jpg \\
\hline 2649 & Carex hordeistichos Vill. & Debrecen & 1954 & Siroki Zoltán & DE-siroki-03856.jpg \\
\hline 2649 & Carex hordeistichos Vill. & Debrecen & 1954 & Siroki Zoltán & DE-siroki-03859.jpg \\
\hline 2649 & Carex hordeistichos Vill. & Debrecen & 1958 & Siroki Zoltán & DE-siroki-03848.jpg \\
\hline 2649 & Carex hordeistichos Vill. & Debrecen & 1958 & Siroki Zoltán & DE-siroki-03852.jpg \\
\hline 2649 & Carex hordeistichos Vill. & Debrecen & 1958 & Siroki Zoltán & DE-siroki-03860.jpg \\
\hline 2649 & Carex hordeistichos Vill. & Debrecen & 1958 & Siroki Zoltán & DE-siroki-03842.jpg \\
\hline 2649 & Carex hordeistichos Vill. & Szikszó & 1910 & Thaisz Lajos & DE-siroki-03849.jpg \\
\hline 2649 & Carex hordeistichos Vill. & Szikszó & 1910 & Thaisz Lajos & DE-siroki-03851.jpg \\
\hline 2650 & Carex secalina Wahlenb. & Abaújkér & 1942 & Siroki Zoltán & DE-siroki-03874.jpg \\
\hline 2650 & Carex secalina Wahlenb. & Balatonberény & 1928 & Papp László & DE-siroki-03876.jpg \\
\hline 2650 & Carex secalina Wahlenb. & Budapest & 1909 & Kocsis István & DE-siroki-03878.jpg \\
\hline 2650 & Carex secalina Wahlenb. & Budapest & 1911 & Kocsis István & DE-siroki-03877.jpg \\
\hline 2650 & Carex secalina Wahlenb. & Budapest & 1951 & Siroki Zoltán & DE-siroki-03875.jpg \\
\hline 2650 & Carex secalina Wahlenb. & Debrecen & 1947 & Siroki Zoltán & DE-siroki-03867.jpg \\
\hline 2650 & Carex secalina Wahlenb. & Debrecen & 1947 & Siroki Zoltán & DE-siroki-03871.jpg \\
\hline 2650 & Carex secalina Wahlenb. & Debrecen & 1947 & Siroki Zoltán & DE-siroki-03872.jpg \\
\hline 2650 & Carex secalina Wahlenb. & Debrecen & 1948 & Siroki Zoltán & DE-siroki-03873.jpg \\
\hline 2650 & Carex secalina Wahlenb. & Debrecen & 1981 & Siroki Zoltán & DE-siroki-03861.jpg \\
\hline 2650 & Carex secalina Wahlenb. & Debrecen & 1981 & Siroki Zoltán & DE-siroki-03862.jpg \\
\hline 2650 & Carex secalina Wahlenb. & Debrecen & 1981 & Siroki Zoltán & DE-siroki-03863.jpg \\
\hline 2650 & Carex secalina Wahlenb. & Debrecen & 1981 & Siroki Zoltán & DE-siroki-03864.jpg \\
\hline 2650 & Carex secalina Wahlenb. & Hortobágy & 1949 & Siroki Zoltán & DE-siroki-03868.jpg \\
\hline 2650 & Carex secalina Wahlenb. & Hortobágy & 1949 & Siroki Zoltán & DE-siroki-03869.jpg \\
\hline 2650 & Carex secalina Wahlenb. & Hortobágy & 1949 & Siroki Zoltán & DE-siroki-03870.jpg \\
\hline 2650 & Carex secalina Wahlenb. & Nyíregyháza & 1967 & Gondola István & DE-siroki-03865.jpg \\
\hline 2650 & Carex secalina Wahlenb. & Nyíregyháza & 1967 & Gondola István & DE-siroki-03866.jpg \\
\hline 2651 & Carex flava L. & "Csepel-sziget" & 1909 & Kocsis István & DE-siroki-03808.jpg \\
\hline 2651 & Carex flava L. & Háromhuta & 1961 & Siroki Zoltán & DE-siroki-03814.jpg \\
\hline 2651 & Carex flava L. & Háromhuta & 1961 & Siroki Zoltán & DE-siroki-03820.jpg \\
\hline
\end{tabular}




\begin{tabular}{|c|c|c|c|c|c|}
\hline $\begin{array}{l}\text { Sorszám / } \\
\text { Number }\end{array}$ & Taxon-név / Taxon-name & $\begin{array}{l}\text { Település / } \\
\text { Settlement }\end{array}$ & $\begin{array}{l}\text { Év / } \\
\text { Year }\end{array}$ & $\begin{array}{l}\text { Gyűjtő / } \\
\text { Collector }\end{array}$ & Fájlnév / File-name \\
\hline 2651 & Carex flava $\mathrm{L}$. & Miskolc & 1959 & Siroki Zoltán & DE-siroki-03813.jpg \\
\hline 2651 & Carex flava L. & Miskolc & 1959 & Siroki Zoltán & DE-siroki-03817.jpg \\
\hline 2651 & Carex flava L. & Miskolc & 1959 & Siroki Zoltán & DE-siroki-03818.jpg \\
\hline 2651 & Carex flava L. & Miskolc & 1960 & Siroki Zoltán & DE-siroki-03815.jpg \\
\hline 2651 & Carex flava L. & Miskolc & 1960 & Siroki Zoltán & DE-siroki-03816.jpg \\
\hline 2651 & Carex flava L. & Miskolc & 1960 & Siroki Zoltán & DE-siroki-03822.jpg \\
\hline 2651 & Carex flava L. & Miskolc & 1960 & Siroki Zoltán & DE-siroki-03823.jpg \\
\hline 2651 & Carex flava L. & Nagyhuta & 1961 & Siroki Zoltán & DE-siroki-03812.jpg \\
\hline 2651 & Carex flava $\mathrm{L}$. & Nagyhuta & 1961 & Siroki Zoltán & DE-siroki-03821.jpg \\
\hline 2651 & Carex flava L. & Nagyhuta & 1961 & Siroki Zoltán & DE-siroki-03824.jpg \\
\hline 2651 & Carex flava $L$. & Szakály & 1955 & Tóth Albert & DE-siroki-03819.jpg \\
\hline 2652 & Carex lepidocarpa Tausch & Miskolc & 1959 & Siroki Zoltán & DE-siroki-03831.jpg \\
\hline 2652 & Carex lepidocarpa Tausch & Miskolc & 1959 & Siroki Zoltán & DE-siroki-03832.jpg \\
\hline 2652 & Carex lepidocarpa Tausch & Nagyhuta & 1961 & Siroki Zoltán & DE-siroki-03836.jpg \\
\hline 2652 & Carex lepidocarpa Tausch & Nagyhuta & 1961 & Siroki Zoltán & DE-siroki-03837.jpg \\
\hline 2652 & Carex lepidocarpa Tausch & Regéc & 1967 & Siroki Zoltán & DE-siroki-03826.jpg \\
\hline 2652 & Carex lepidocarpa Tausch & Regéc & 1967 & Siroki Zoltán & DE-siroki-03827.jpg \\
\hline 2652 & Carex lepidocarpa Tausch & Regéc & 1967 & Siroki Zoltán & DE-siroki-03828.jpg \\
\hline 2652 & Carex lepidocarpa Tausch & Regéc & 1967 & Siroki Zoltán & DE-siroki-03830.jpg \\
\hline 2652 & Carex lepidocarpa Tausch & Regéc & 1968 & Siroki Zoltán & DE-siroki-03829.jpg \\
\hline 2652 & Carex lepidocarpa Tausch & Veresegyház & 1951 & Siroki Zoltán & DE-siroki-03825.jpg \\
\hline 2652 & Carex lepidocarpa Tausch & Veresegyház & 1951 & Siroki Zoltán & DE-siroki-03834.jpg \\
\hline 2652 & Carex lepidocarpa Tausch & Veresegyház & 1952 & Petrányi S. & DE-siroki-03838.jpg \\
\hline 2652 & Carex lepidocarpa Tausch & Veresegyház & 1960 & Siroki Zoltán & DE-siroki-03840.jpg \\
\hline 2652 & Carex lepidocarpa Tausch & Veresegyház & 1960 & Siroki Zoltán & DE-siroki-03839.jpg \\
\hline 2653 & Carex viridula Michx. & Debrecen & 1958 & Siroki Zoltán & DE-siroki-03792.jpg \\
\hline 2653 & Carex viridula Michx. & Debrecen & 1958 & Siroki Zoltán & DE-siroki-03791.jpg \\
\hline 2653 & Carex viridula Michx. & Debrecen & 1958 & Siroki Zoltán & DE-siroki-03795.jpg \\
\hline 2653 & Carex viridula Michx. & Hajdúbagos & 1982 & Siroki Zoltán & DE-siroki-03798.jpg \\
\hline 2653 & Carex viridula Michx. & Hajdúbagos & 1982 & Siroki Zoltán & DE-siroki-03799.jpg \\
\hline 2653 & Carex viridula Michx. & Kecskemét & 1969 & Siroki Zoltán & DE-siroki-03804.jpg \\
\hline 2653 & Carex viridula Michx. & Keszthely & 1955 & Siroki Zoltán & DE-siroki-03805.jpg \\
\hline 2653 & Carex viridula Michx. & Szigetszentmiklós & 1951 & Siroki Zoltán & DE-siroki-03803.jpg \\
\hline 2653 & Carex viridula Michx. & Szigetszentmiklós & 1951 & Siroki Zoltán & DE-siroki-03794.jpg \\
\hline 2653 & Carex viridula Michx. & Szigetszentmiklós & 1951 & Siroki Zoltán & DE-siroki-03796.jpg \\
\hline 2653 & Carex viridula Michx. & Szigetszentmiklós & 1951 & Siroki Zoltán & DE-siroki-03797.jpg \\
\hline 2653 & Carex viridula Michx. & Szigetszentmiklós & 1951 & Siroki Zoltán & DE-siroki-03806.jpg \\
\hline 2653 & Carex viridula Michx. & Újléta & 1967 & Siroki Zoltán & DE-siroki-03800.jpg \\
\hline 2653 & Carex viridula Michx. & Újléta & 1967 & Siroki Zoltán & DE-siroki-03801.jpg \\
\hline 2653 & Carex viridula Michx. & Újléta & 1967 & Siroki Zoltán & DE-siroki-03802.jpg \\
\hline 2655 & Carex hostiana DC. & Budapest & 1911 & Kocsis István & DE-siroki-03788.jpg \\
\hline 2656 & Carex distans L. & Debrecen & 1947 & Siroki Zoltán & DE-siroki-03776.jpg \\
\hline 2656 & Carex distans L. & Debrecen & 1955 & $\begin{array}{l}\text { Siroki Zoltán - } \\
\text { Farkas Attila }\end{array}$ & DE-siroki-03770.jpg \\
\hline 2656 & Carex distans L. & Debrecen & 1955 & $\begin{array}{l}\text { Siroki Zoltán - } \\
\text { Farkas Attila }\end{array}$ & DE-siroki-03771.jpg \\
\hline 2656 & Carex distans L. & Debrecen & 1958 & Siroki Zoltán & DE-siroki-03779.jpg \\
\hline
\end{tabular}




\begin{tabular}{|c|c|c|c|c|c|}
\hline $\begin{array}{l}\text { Sorszám / } \\
\text { Number }\end{array}$ & Taxon-név / Taxon-name & $\begin{array}{l}\text { Település / } \\
\text { Settlement }\end{array}$ & $\begin{array}{l}\text { Év / } \\
\text { Year }\end{array}$ & $\begin{array}{l}\text { Gyüjtő / } \\
\text { Collector }\end{array}$ & Fájlnév / File-name \\
\hline 2656 & Carex distans L. & Gödöllő & 1951 & Siroki Zoltán & DE-siroki-03777.jpg \\
\hline 2656 & Carex distans L. & Gödöllő & 1951 & Siroki Zoltán & DE-siroki-03781.jpg \\
\hline 2656 & Carex distans L. & Gödöllő & 1951 & Siroki Zoltán & DE-siroki-03782.jpg \\
\hline 2656 & Carex distans L. & Gödöllő & 1951 & Siroki Zoltán & DE-siroki-03783.jpg \\
\hline 2656 & Carex distans L. & Kállósemjén & 1955 & Kovács Béla & DE-siroki-03778.jpg \\
\hline 2656 & Carex distans L. & Mosonmagyaróvár & 1939 & Siroki Zoltán & DE-siroki-03787.jpg \\
\hline 2656 & Carex distans L. & Nyíracsád & 1985 & Siroki Zoltán & DE-siroki-03784.jpg \\
\hline 2656 & Carex distans L. & Nyíracsád & 1985 & Siroki Zoltán & DE-siroki-03785.jpg \\
\hline 2658 & Epipactis palustris (L.) Cr. & Ágasegyháza & 1956 & Siroki Zoltán & DE-AGR-0149.jpg \\
\hline 2658 & Epipactis palustris (L.) Cr. & Ágasegyháza & 1956 & Siroki Zoltán & DE-AGR-0150.jpg \\
\hline 2658 & Epipactis palustris (L.) Cr. & Ágasegyháza & 1956 & Siroki Zoltán & DE-AGR-0151.jpg \\
\hline 2658 & Epipactis palustris (L.) Cr. & Ágasegyháza & 1956 & Siroki Zoltán & DE-AGR-0152.jpg \\
\hline 2658 & Epipactis palustris (L.) Cr. & Háromhuta & 1961 & Siroki Zoltán & DE-AGR-0156.jpg \\
\hline 2658 & Epipactis palustris (L.) Cr. & Háromhuta & 1962 & Siroki Zoltán & DE-AGR-0146.jpg \\
\hline 2658 & Epipactis palustris (L.) Cr. & Háromhuta & 1962 & Siroki Zoltán & DE-AGR-0147.jpg \\
\hline 2658 & Epipactis palustris (L.) Cr. & Háromhuta & 1962 & Siroki Zoltán & DE-AGR-0148.jpg \\
\hline 2658 & Epipactis palustris (L.) Cr. & Háromhuta & 1968 & Siroki Zoltán & DE-AGR-0142.jpg \\
\hline 2658 & Epipactis palustris (L.) Cr. & Háromhuta & 1968 & Siroki Zoltán & DE-AGR-0143.jpg \\
\hline 2658 & Epipactis palustris (L.) Cr. & Háromhuta & 1968 & Siroki Zoltán & DE-AGR-0144.jpg \\
\hline 2658 & Epipactis palustris (L.) Cr. & Háromhuta & 1968 & Siroki Zoltán & DE-AGR-0145.jpg \\
\hline 2658 & Epipactis palustris (L.) Cr. & Háromhuta & 1984 & Siroki Zoltán & DE-AGR-0153.jpg \\
\hline 2658 & Epipactis palustris (L.) Cr. & Háromhuta & 1984 & Siroki Zoltán & DE-AGR-0154.jpg \\
\hline 2658 & Epipactis palustris (L.) Cr. & Háromhuta & 1984 & Siroki Zoltán & DE-AGR-0155.jpg \\
\hline 2659 & Epipactis microphylla (Ehrh.) Sw. & Lábatlan & 1951 & Kárpáti Zoltán & DE-AGR-0157.jpg \\
\hline 2659 & Epipactis microphylla (Ehrh.) Sw. & Szilvásvárad & 1955 & Siroki Zoltán & DE-AGR-0162.jpg \\
\hline 2660 & Epipactis leptochila (Godfery) Godfery & Szilvásvárad & 1954 & Siroki Zoltán & DE-AGR-0178.jpg \\
\hline 2662 & Epipactis pontica Taubenheim & Vizslás & 1952 & Gondola István & DE-AGR-0186.jpg \\
\hline 2662 & Epipactis pontica Taubenheim & Vizslás & 1952 & Gondola István & DE-AGR-0187.jpg \\
\hline 2662 & Epipactis pontica Taubenheim & Vizslás & 1952 & Gondola István & DE-AGR-0188.jpg \\
\hline 2672 & $\begin{array}{l}\text { Epipactis atrorubens } \\
\text { (Hoffm.) Schultze }\end{array}$ & "Dobogókő" & 1957 & Siroki Zoltán & DE-AGR-0166.jpg \\
\hline 2672 & $\begin{array}{l}\text { Epipactis atrorubens } \\
\text { (Hoffm.) Schultze }\end{array}$ & Gyenesdiás & 1955 & Siroki Zoltán & DE-AGR-0164.jpg \\
\hline 2672 & $\begin{array}{l}\text { Epipactis atrorubens } \\
\text { (Hoffm.) Schultze }\end{array}$ & Kunpeszér & 1952 & Gondola István & DE-AGR-0158.jpg \\
\hline 2672 & $\begin{array}{l}\text { Epipactis atrorubens } \\
\text { (Hoffm.) Schultze }\end{array}$ & Nagyvisnyó & 1959 & Siroki Zoltán & DE-AGR-0161.jpg \\
\hline 2672 & $\begin{array}{l}\text { Epipactis atrorubens } \\
\text { (Hoffm.) Schultze }\end{array}$ & Nagyvisnyó & 1966 & Siroki Zoltán & DE-AGR-0159.jpg \\
\hline 2672 & $\begin{array}{l}\text { Epipactis atrorubens } \\
\text { (Hoffm.) Schultze }\end{array}$ & Szilvásvárad & 1954 & Siroki Zoltán & DE-AGR-0165.jpg \\
\hline 2672 & $\begin{array}{l}\text { Epipactis atrorubens } \\
\text { (Hoffm.) Schultze }\end{array}$ & Szilvásvárad & 1955 & Siroki Zoltán & DE-AGR-0162.jpg \\
\hline 2672 & $\begin{array}{l}\text { Epipactis atrorubens } \\
\text { (Hoffm.) Schultze }\end{array}$ & Szilvásvárad & 1960 & Siroki Zoltán & DE-AGR-0160.jpg \\
\hline 2673 & Epipactis helleborine (L.) Cr. & "Nagymező" & 1958 & Siroki Zoltán & DE-AGR-0170.jpg \\
\hline 2673 & Epipactis helleborine (L.) Cr. & Budapest & 1940 & Siroki Zoltán & DE-AGR-0175.jpg \\
\hline 2673 & Epipactis helleborine (L.) Cr. & Budapest & 1950 & Siroki Zoltán & DE-AGR-0181.jpg \\
\hline 2673 & Epipactis helleborine (L.) Cr. & Budapest & 1954 & Siroki Zoltán & DE-AGR-0177.jpg \\
\hline 2673 & Epipactis helleborine (L.) Cr. & Budapest & 1984 & Siroki Zoltán & DE-AGR-0171.jpg \\
\hline 2673 & Epipactis helleborine (L.) Cr. & Budapest & 1984 & Siroki Zoltán & DE-AGR-0172.jpg \\
\hline
\end{tabular}




\begin{tabular}{|c|c|c|c|c|c|}
\hline $\begin{array}{l}\text { Sorszám / } \\
\text { Number }\end{array}$ & Taxon-név / Taxon-name & $\begin{array}{l}\text { Település / } \\
\text { Settlement }\end{array}$ & $\begin{array}{l}\text { Év / } \\
\text { Year }\end{array}$ & $\begin{array}{l}\text { Gyújtő / } \\
\text { Collector }\end{array}$ & Fájlnév / File-name \\
\hline 2673 & Epipactis helleborine (L.) Cr. & Budapest & 1984 & Siroki Zoltán & DE-AGR-0173.jpg \\
\hline 2673 & Epipactis helleborine (L.) Cr. & Budapest & 1984 & Siroki Zoltán & DE-AGR-0176.jpg \\
\hline 2673 & Epipactis helleborine (L.) Cr. & Debrecen & 1954 & Siroki Zoltán & DE-AGR-0174.jpg \\
\hline 2673 & Epipactis helleborine (L.) Cr. & Debrecen & 1954 & Siroki Zoltán & DE-AGR-0182.jpg \\
\hline 2673 & Epipactis helleborine (L.) Cr. & Debrecen & 1954 & Siroki Zoltán & DE-AGR-0183.jpg \\
\hline 2673 & Epipactis helleborine (L.) Cr. & Háromhuta & 1968 & Siroki Zoltán & DE-AGR-0184.jpg \\
\hline 2673 & Epipactis helleborine (L.) Cr. & Háromhuta & 1968 & Siroki Zoltán & DE-AGR-0185.jpg \\
\hline 2673 & Epipactis helleborine (L.) Cr. & Szilvásvárad & 1954 & Siroki Zoltán & DE-AGR-0179.jpg \\
\hline 2673 & Epipactis helleborine (L.) Cr. & Szilvásvárad & 1959 & Siroki Zoltán & DE-AGR-0180.jpg \\
\hline 2674 & Epipactis purpurata Sm. & Sopron & 1951 & Kárpáti Zoltán & DE-AGR-0169.jpg \\
\hline 2675 & Cephalanthera rubra (L.) Rich. & Ágasegyháza & 1971 & Siroki Zoltán & DE-AGR-0124.jpg \\
\hline 2675 & Cephalanthera rubra (L.) Rich. & Kecskemét & 1969 & Siroki Zoltán & DE-AGR-0125.jpg \\
\hline 2675 & Cephalanthera rubra (L.) Rich. & Lábatlan & 1951 & Kárpáti Zoltán & DE-AGR-0120.jpg \\
\hline 2675 & Cephalanthera rubra (L.) Rich. & Parád & 1981 & Rácz Gy.-né & DE-AGR-0119.jpg \\
\hline 2675 & Cephalanthera rubra (L.) Rich. & Szilvásvárad & 1955 & Jeney Endre & DE-AGR-0123.jpg \\
\hline 2675 & Cephalanthera rubra (L.) Rich. & Szilvásvárad & 1962 & Siroki Zoltán & DE-AGR-0121.jpg \\
\hline 2675 & Cephalanthera rubra (L.) Rich. & Szilvásvárad & 1962 & Siroki Zoltán & DE-AGR-0122.jpg \\
\hline 2675 & Cephalanthera rubra (L.) Rich. & Szilvásvárad & 1962 & Siroki Zoltán & DE-AGR-0126.jpg \\
\hline 2676 & $\begin{array}{l}\text { Cephalanthera damasonium } \\
\text { (Mill.) Druce }\end{array}$ & Balatonederics & 1955 & Siroki Zoltán & DE-AGR-0127.jpg \\
\hline 2676 & $\begin{array}{l}\text { Cephalanthera damasonium } \\
\text { (Mill.) Druce }\end{array}$ & Balatonederics & 1955 & Siroki Zoltán & DE-AGR-0128.jpg \\
\hline 2676 & $\begin{array}{l}\text { Cephalanthera damasonium } \\
\text { (Mill.) Druce }\end{array}$ & Bátorliget & 1957 & Siroki Zoltán & DE-AGR-0132.jpg \\
\hline 2676 & $\begin{array}{l}\text { Cephalanthera damasonium } \\
\text { (Mill.) Druce }\end{array}$ & Budapest & 1951 & Siroki Zoltán & DE-AGR-0130.jpg \\
\hline 2676 & $\begin{array}{l}\text { Cephalanthera damasonium } \\
\text { (Mill.) Druce }\end{array}$ & Budapest & 1951 & Siroki Zoltán & DE-AGR-0133.jpg \\
\hline 2676 & $\begin{array}{l}\text { Cephalanthera damasonium } \\
\text { (Mill.) Druce }\end{array}$ & Pilisszentiván & 1952 & Siroki Zoltán & DE-AGR-0131.jpg \\
\hline 2677 & Cephalanthera longifolia (L.) Fritsch & "Hármaskő" & 1957 & Siroki Zoltán & DE-AGR-0135.jpg \\
\hline 2677 & Cephalanthera longifolia (L.) Fritsch & "Hármaskő" & 1957 & Siroki Zoltán & DE-AGR-0136.jpg \\
\hline 2677 & Cephalanthera longifolia (L.) Fritsch & "Hármaskő" & 1957 & Siroki Zoltán & DE-AGR-0137.jpg \\
\hline 2677 & Cephalanthera longifolia (L.) Fritsch & Hosszúhetény & 1958 & Siroki Zoltán & DE-AGR-0139.jpg \\
\hline 2677 & Cephalanthera longifolia (L.) Fritsch & Pécs & 1958 & Siroki Zoltán & DE-AGR-0140.jpg \\
\hline 2677 & Cephalanthera longifolia (L.) Fritsch & Pilisszentiván & 1952 & Siroki Zoltán & DE-AGR-0134.jpg \\
\hline 2677 & Cephalanthera longifolia (L.) Fritsch & Pilisszentiván & 1952 & Siroki Zoltán & DE-AGR-0138.jpg \\
\hline 2678 & Limodorum abortivum (L.) Sw. & Budapest & 1957 & Siroki Zoltán & DE-AGR-0189.jpg \\
\hline 2678 & Limodorum abortivum (L.) Sw. & Budapest & 1957 & Siroki Zoltán & DE-AGR-0190.jpg \\
\hline 2680 & Neottia nidus-avis (L.) Rich. & Debrecen & 1954 & Siroki Zoltán & DE-AGR-0196.jpg \\
\hline 2680 & Neottia nidus-avis (L.) Rich. & Debrecen & 1954 & Siroki Zoltán & DE-AGR-0198.jpg \\
\hline 2680 & Neottia nidus-avis (L.) Rich. & Debrecen & 1954 & Siroki Zoltán & DE-AGR-0199.jpg \\
\hline 2680 & Neottia nidus-avis (L.) Rich. & Debrecen & 1954 & Siroki Zoltán & DE-AGR-0200.jpg \\
\hline 2680 & Neottia nidus-avis (L.) Rich. & Debrecen & 1954 & Siroki Zoltán & DE-AGR-0201.jpg \\
\hline 2680 & Neottia nidus-avis (L.) Rich. & Pálháza & 1961 & Siroki Zoltán & DE-AGR-0197.jpg \\
\hline 2680 & Neottia nidus-avis (L.) Rich. & Pomáz & 1952 & Siroki Zoltán & DE-AGR-0202.jpg \\
\hline 2681 & Listera ovata (L.) R. Br. & Bátorliget & 1956 & Siroki Zoltán & DE-AGR-0192.jpg \\
\hline 2681 & Listera ovata (L.) R. Br. & Debrecen & 1950 & Siroki Zoltán & DE-AGR-0191.jpg \\
\hline 2681 & Listera ovata (L.) R. Br. & Debrecen & 1950 & Siroki Zoltán & DE-AGR-0193.jpg \\
\hline 2681 & Listera ovata (L.) R. Br. & Debrecen & 1950 & Siroki Zoltán & DE-AGR-0194.jpg \\
\hline
\end{tabular}




\begin{tabular}{|c|c|c|c|c|c|}
\hline $\begin{array}{l}\text { Sorszám / } \\
\text { Number }\end{array}$ & Taxon-név / Taxon-name & $\begin{array}{l}\text { Település / } \\
\text { Settlement }\end{array}$ & $\begin{array}{l}\text { Év / } \\
\text { Year }\end{array}$ & $\begin{array}{l}\text { Gyüjtő / } \\
\text { Collector }\end{array}$ & Fájlnév / File-name \\
\hline 2681 & Listera ovata (L.) R. Br. & Mosonmagyaróvár & 1939 & Siroki Zoltán & DE-AGR-0195.jpg \\
\hline 2686 & Platanthera bifolia (L.) Rich. & $\begin{array}{l}\text { "Bükk-hg, } \\
\text { Kiskerekhegy" }\end{array}$ & 1959 & Halász Tibor & DE-AGR-0116.jpg \\
\hline 2686 & Platanthera bifolia (L.) Rich. & "Bükk-hg." & 1959 & Halász Tibor & DE-AGR-0106.jpg \\
\hline 2686 & Platanthera bifolia (L.) Rich. & "Bükk-hg." & 1959 & Halász Tibor & DE-AGR-0107.jpg \\
\hline 2686 & Platanthera bifolia (L.) Rich. & "Nagymező" & 1959 & Siroki Zoltán & DE-AGR-0109.jpg \\
\hline 2686 & Platanthera bifolia (L.) Rich. & "Nagymező" & 1959 & Siroki Zoltán & DE-AGR-0110.jpg \\
\hline 2686 & Platanthera bifolia (L.) Rich. & Budaörs & 1966 & Siroki Zoltán & DE-AGR-0108.jpg \\
\hline 2686 & Platanthera bifolia (L.) Rich. & Debrecen & 1954 & Kovács Béla & DE-AGR-0113.jpg \\
\hline 2686 & Platanthera bifolia (L.) Rich. & Debrecen & 1954 & Siroki Zoltán & DE-AGR-0112.jpg \\
\hline 2686 & Platanthera bifolia (L.) Rich. & Debrecen & 1954 & Siroki Zoltán & DE-AGR-0114.jpg \\
\hline 2686 & Platanthera bifolia (L.) Rich. & Hollóháza & 1940 & Siroki Zoltán & DE-AGR-0115.jpg \\
\hline 2686 & Platanthera bifolia (L.) Rich. & Szilvásvárad & 1956 & Halász Tibor & DE-AGR-0111.jpg \\
\hline 2686 & Platanthera bifolia (L.) Rich. & Újléta & 1965 & Siroki Zoltán & DE-AGR-0105.jpg \\
\hline 2687 & Platanthera chlorantha (Cust.) Rchb. & Gödöllő & 1952 & Siroki Zoltán & DE-AGR-0118.jpg \\
\hline 2688 & Gymnadenia conopsea (L.) Rich. & "Nagymező" & 1956 & Halász Tibor & DE-AGR-0097.jpg \\
\hline 2688 & Gymnadenia conopsea (L.) Rich. & "Nagymező" & 1956 & Siroki Zoltán & DE-AGR-0096.jpg \\
\hline 2688 & Gymnadenia conopsea (L.) Rich. & "Nagymező" & 1959 & Siroki Zoltán & DE-AGR-0098.jpg \\
\hline 2688 & Gymnadenia conopsea (L.) Rich. & "Nagymező" & 1959 & Siroki Zoltán & DE-AGR-0099.jpg \\
\hline 2688 & Gymnadenia conopsea (L.) Rich. & "Nagymező" & 1959 & Siroki Zoltán & DE-AGR-0100.jpg \\
\hline 2688 & Gymnadenia conopsea (L.) Rich. & "Nagymező" & 1959 & Siroki Zoltán & DE-AGR-0101.jpg \\
\hline 2688 & Gymnadenia conopsea (L.) Rich. & "Nagymező" & 1959 & Siroki Zoltán & DE-AGR-0102.jpg \\
\hline 2688 & Gymnadenia conopsea (L.) Rich. & "Nagymező" & 1959 & Siroki Zoltán & DE-AGR-0103.jpg \\
\hline 2688 & Gymnadenia conopsea (L.) Rich. & "Nagymező" & 1959 & Siroki Zoltán & DE-AGR-0104.jpg \\
\hline 2690 & Coeloglossum viride (L.) Hartm. & "Háromkő" & 1957 & Siroki Zoltán & DE-AGR-0092.jpg \\
\hline 2690 & Coeloglossum viride (L.) Hartm. & "Nagymező" & 1960 & Siroki Zoltán & DE-AGR-0093.jpg \\
\hline 2690 & Coeloglossum viride (L.) Hartm. & "Nagymező" & 1960 & Siroki Zoltán & DE-AGR-0094.jpg \\
\hline 2690 & Coeloglossum viride (L.) Hartm. & "Nagymező" & 1960 & Siroki Zoltán & DE-AGR-0095.jpg \\
\hline 2691 & Dactylorhiza sambucina (L.) Soó & "Bükk-hg." & 1966 & Siroki Zoltán & DE-AGR-0071.jpg \\
\hline 2691 & Dactylorhiza sambucina (L.) Soó & "Bükk-hg." & 1966 & Siroki Zoltán & DE-AGR-0072.jpg \\
\hline 2691 & Dactylorhiza sambucina (L.) Soó & "Bükk-hg." & 1966 & Siroki Zoltán & DE-AGR-0073.jpg \\
\hline 2691 & Dactylorhiza sambucina (L.) Soó & "Bükk-hg." & 1966 & Siroki Zoltán & DE-AGR-0074.jpg \\
\hline 2693 & Dactylorhiza incarnata (L.) Soó & Bátorliget & 1956 & Siroki Zoltán & DE-AGR-0062.jpg \\
\hline 2693 & Dactylorhiza incarnata (L.) Soó & Bátorliget & 1956 & Siroki Zoltán & DE-AGR-0064.jpg \\
\hline 2693 & Dactylorhiza incarnata (L.) Soó & Budapest & 1888 & Czakó Kálmán & DE-AGR-0067.jpg \\
\hline 2693 & Dactylorhiza incarnata (L.) Soó & Budapest & 1909 & Kocsis István & DE-AGR-0066.jpg \\
\hline 2693 & Dactylorhiza incarnata (L.) Soó & Budapest & 1911 & Kocsis István & DE-AGR-0065.jpg \\
\hline 2693 & Dactylorhiza incarnata (L.) Soó & Debrecen & 1950 & Siroki Zoltán & DE-AGR-0063.jpg \\
\hline 2693 & Dactylorhiza incarnata (L.) Soó & Keszthely & 1955 & Siroki Zoltán & DE-AGR-0069.jpg \\
\hline 2693 & Dactylorhiza incarnata (L.) Soó & Lesenceistvánd & 1930 & Rigler József & DE-AGR-0068.jpg \\
\hline 2693 & Dactylorhiza incarnata (L.) Soó & Nagykőrös & 1954 & Siroki Zoltán & DE-AGR-0061.jpg \\
\hline 2694 & $\begin{array}{l}\text { Dactylorhiza majalis } \\
\text { (L.) Hunt et Summerhayes }\end{array}$ & "Nagymező" & 1960 & Siroki Zoltán & DE-AGR-0070.jpg \\
\hline 2694 & $\begin{array}{l}\text { Dactylorhiza majalis } \\
\text { (L.) Hunt et Summerhayes }\end{array}$ & Háromhuta & 1961 & Siroki Zoltán & DE-AGR-0086.jpg \\
\hline 2694 & $\begin{array}{l}\text { Dactylorhiza majalis } \\
\text { (L.) Hunt et Summerhayes }\end{array}$ & Pálháza & 1961 & Siroki Zoltán & DE-AGR-0084.jpg \\
\hline 2694 & $\begin{array}{l}\text { Dactylorhiza majalis (L.) Hunt et } \\
\text { Summerhayes }\end{array}$ & Pálháza & 1961 & Siroki Zoltán & DE-AGR-0085.jpg \\
\hline
\end{tabular}




\begin{tabular}{|c|c|c|c|c|c|}
\hline $\begin{array}{l}\text { Sorszám / } \\
\text { Number }\end{array}$ & Taxon-név / Taxon-name & $\begin{array}{l}\text { Település / } \\
\text { Settlement }\end{array}$ & $\begin{array}{l}\text { Év / } \\
\text { Year }\end{array}$ & $\begin{array}{l}\text { Gyűjtő / } \\
\text { Collector }\end{array}$ & Fájlnév / File-name \\
\hline 2696 & Dactylorhiza maculata (L.) Soó & "Nagymező" & 1959 & Siroki Zoltán & DE-AGR-0075.jpg \\
\hline 2697 & Dactylorhiza fuchsii (L.) Soó & "Hármaskő" & 1957 & Siroki Zoltán & DE-AGR-0076.jpg \\
\hline 2697 & Dactylorhiza fuchsii (L.) Soó & Háromhuta & 1961 & Siroki Zoltán & DE-AGR-0080.jpg \\
\hline 2697 & Dactylorhiza fuchsii (L.) Soó & Háromhuta & 1961 & Siroki Zoltán & DE-AGR-0077.jpg \\
\hline 2697 & Dactylorhiza fuchsii (L.) Soó & Háromhuta & 1961 & Siroki Zoltán & DE-AGR-0078.jpg \\
\hline 2697 & Dactylorhiza fuchsii (L.) Soó & Háromhuta & 1961 & Siroki Zoltán & DE-AGR-0079.jpg \\
\hline 2697 & Dactylorhiza fuchsii (L.) Soó & Háromhuta & 1961 & Siroki Zoltán & DE-AGR-0082.jpg \\
\hline 2698 & Traunsteinera globosa (L.) Rchb. & "Hármaskő" & 1957 & Siroki Zoltán & DE-AGR-0043.jpg \\
\hline 2698 & Traunsteinera globosa (L.) Rchb. & "Nagymező" & 1959 & Siroki Zoltán & DE-AGR-0040.jpg \\
\hline 2698 & Traunsteinera globosa (L.) Rchb. & "Nagymező" & 1959 & Siroki Zoltán & DE-AGR-0041.jpg \\
\hline 2698 & Traunsteinera globosa (L.) Rchb. & "Nagymező" & 1960 & Siroki Zoltán & DE-AGR-0037.jpg \\
\hline 2698 & Traunsteinera globosa (L.) Rchb. & "Nagymező" & 1960 & Siroki Zoltán & DE-AGR-0038.jpg \\
\hline 2698 & Traunsteinera globosa (L.) Rchb. & "Nagymező" & 1960 & Siroki Zoltán & DE-AGR-0039.jpg \\
\hline 2698 & Traunsteinera globosa (L.) Rchb. & "Nagymező" & 1960 & Siroki Zoltán & DE-AGR-0042.jpg \\
\hline 2698 & Traunsteinera globosa (L.) Rchb. & "Nagymező" & 1960 & Siroki Zoltán & DE-AGR-0044.jpg \\
\hline 2699 & Orchis simia L. & Pécs & 1958 & Siroki Zoltán & DE-AGR-0024.jpg \\
\hline 2699 & Orchis simia L. & Pécsvárad & 1958 & Siroki Zoltán & DE-AGR-0022.jpg \\
\hline 2699 & Orchis simia L. & Pécsvárad & 1958 & Siroki Zoltán & DE-AGR-0023.jpg \\
\hline 2700 & Orchis morio L. & "Bükk-hg." & 1966 & Siroki Zoltán & DE-AGR-0008.jpg \\
\hline 2700 & Orchis morio L. & Gyenesdiás & 1953 & Siroki Zoltán & DE-AGR-0005.jpg \\
\hline 2700 & Orchis morio L. & Háromhuta & 1961 & Siroki Zoltán & DE-AGR-0007.jpg \\
\hline 2700 & Orchis morio L. & Nagyhuta & 1961 & Siroki Zoltán & DE-AGR-0006.jpg \\
\hline 2700 & Orchis morio L. & Pálháza & 1961 & Siroki Zoltán & DE-AGR-0009.jpg \\
\hline 2701 & Orchis coriophora L. & Dabas & 1951 & Kárpáti Zoltán & DE-AGR-0013.jpg \\
\hline 2701 & Orchis coriophora L. & Háromhuta & 1961 & Siroki Zoltán & DE-AGR-0010.jpg \\
\hline 2701 & Orchis coriophora L. & Háromhuta & 1961 & Siroki Zoltán & DE-AGR-0011.jpg \\
\hline 2701 & Orchis coriophora L. & Háromhuta & 1961 & Siroki Zoltán & DE-AGR-0012.jpg \\
\hline 2701 & Orchis coriophora L. & Szigetszentmiklós & 1920 & Kocsis István & DE-AGR-0014.jpg \\
\hline 2702 & Orchis tridentata Scop. & Budapest & 1911 & Kocsis István & DE-AGR-0016.jpg \\
\hline 2702 & Orchis tridentata Scop. & Budapest & 1911 & Kocsis István & DE-AGR-0017.jpg \\
\hline 2702 & Orchis tridentata Scop. & Budapest & 1951 & Siroki Zoltán & DE-AGR-0015.jpg \\
\hline 2703 & $\begin{array}{l}\text { Orchis ustulata L. subsp. aestivalis } \\
\text { (Kümpel) Kümpel et A.C. Mrkvicka }\end{array}$ & "Nagymező" & 1959 & Siroki Zoltán & DE-AGR-0018.jpg \\
\hline 2703 & $\begin{array}{l}\text { Orchis ustulata L. subsp. aestivalis } \\
\text { (Kümpel) Kümpel et A.C. Mrkvicka }\end{array}$ & "Nagymező" & 1959 & Siroki Zoltán & DE-AGR-0020.jpg \\
\hline 2703 & $\begin{array}{l}\text { Orchis ustulata L. subsp. aestivalis } \\
\text { (Kümpel) Kümpel et A.C. Mrkvicka }\end{array}$ & "Nagymező" & 1959 & Siroki Zoltán & DE-AGR-0021.jpg \\
\hline 2703 & $\begin{array}{l}\text { Orchis ustulata L. subsp. aestivalis } \\
\text { (Kümpel) Kümpel et A.C. Mrkvicka }\end{array}$ & Sopron & 1951 & Kárpáti Zoltán & DE-AGR-0019.jpg \\
\hline 2704 & Orchis purpurea Huds. & Csesznek & 1955 & Máthé Imre & DE-AGR-0032.jpg \\
\hline 2704 & Orchis purpurea Huds. & Hosszúhetény & 1958 & Siroki Zoltán & DE-AGR-0031.jpg \\
\hline 2704 & Orchis purpurea Huds. & Szarvaskő & 1966 & Siroki Zoltán & DE-AGR-0034.jpg \\
\hline 2704 & Orchis purpurea Huds. & Szarvaskő & 1966 & Siroki Zoltán & DE-AGR-0035.jpg \\
\hline 2704 & Orchis purpurea Huds. & Szarvaskő & 1966 & Siroki Zoltán & DE-AGR-0036.jpg \\
\hline 2704 & Orchis purpurea Huds. & Szarvaskő & 1967 & Siroki Zoltán & DE-AGR-0033.jpg \\
\hline 2705 & Orchis militaris L. & "Hármaskő" & 1957 & Siroki Zoltán & DE-AGR-0027.jpg \\
\hline 2705 & Orchis militaris L. & Debrecen & 1950 & Siroki Zoltán & DE-AGR-0025.jpg \\
\hline 2705 & Orchis militaris L. & Debrecen & 1950 & Siroki Zoltán & DE-AGR-0028.jpg \\
\hline 2705 & Orchis militaris L. & Debrecen & 1950 & Siroki Zoltán & DE-AGR-0029.jpg \\
\hline
\end{tabular}




\begin{tabular}{|c|c|c|c|c|c|}
\hline $\begin{array}{l}\text { Sorszám / } \\
\text { Number }\end{array}$ & Taxon-név / Taxon-name & $\begin{array}{l}\text { Település / } \\
\text { Settlement }\end{array}$ & $\begin{array}{l}\text { Év / } \\
\text { Year }\end{array}$ & $\begin{array}{l}\text { Gyújtő / } \\
\text { Collector }\end{array}$ & Fájlnév / File-name \\
\hline 2705 & Orchis militaris L. & Debrecen & 1954 & Siroki Zoltán & DE-AGR-0026.jpg \\
\hline 2705 & Orchis militaris L. & Mosonmagyaróvár & 1939 & Siroki Zoltán & DE-AGR-0030.jpg \\
\hline 2707 & $\begin{array}{l}\text { Orchis mascula (L.) L. } \\
\text { subsp. signifera (Vest) Soó }\end{array}$ & "Nagymező" & 1959 & Siroki Zoltán & DE-AGR-0045.jpg \\
\hline 2707 & $\begin{array}{l}\text { Orchis mascula (L.) L. } \\
\text { subsp. signifera (Vest) Soó }\end{array}$ & Budapest & 1911 & Kocsis István & DE-AGR-0047.jpg \\
\hline 2707 & $\begin{array}{l}\text { Orchis mascula (L.) L. } \\
\text { subsp. signifera (Vest) Soó }\end{array}$ & Dunabogdány & 1889 & Szépligeti Győző & DE-AGR-0046.jpg \\
\hline 2708 & Orchis elegans Heuff. & Debrecen & 1950 & Siroki Zoltán & DE-AGR-0053.jpg \\
\hline 2708 & Orchis elegans Heuff. & Debrecen & 1950 & Siroki Zoltán & DE-AGR-0052.jpg \\
\hline 2708 & Orchis elegans Heuff. & Debrecen & - & Siroki Zoltán & DE-AGR-0054.jpg \\
\hline 2708 & Orchis elegans Heuff. & Debrecen & - & Siroki Zoltán & DE-AGR-0055.jpg \\
\hline 2708 & Orchis elegans Heuff. & Újléta & 1967 & Siroki Zoltán & DE-AGR-0050.jpg \\
\hline 2708 & Orchis elegans Heuff. & Újléta & 1967 & Siroki Zoltán & DE-AGR-0058.jpg \\
\hline 2708 & Orchis elegans Heuff. & Újléta & 1967 & Siroki Zoltán & DE-AGR-0059.jpg \\
\hline 2708 & Orchis elegans Heuff. & Újléta & 1967 & Siroki Zoltán & DE-AGR-0060.jpg \\
\hline 2709 & Orchis palustris Jacq. & Budapest & 1909 & Kocsis István & DE-AGR-0049.jpg \\
\hline 2709 & Orchis palustris Jacq. & Budapest & 1910 & Kocsis István & DE-AGR-0048.jpg \\
\hline 2709 & Orchis palustris Jacq. & Cegléd & 1969 & Siroki Zoltán & DE-AGR-0056.jpg \\
\hline 2709 & Orchis palustris Jacq. & Cegléd & 1969 & Siroki Zoltán & DE-AGR-0057.jpg \\
\hline 2709 & Orchis palustris Jacq. & Dabas & 1951 & Kárpáti Zoltán & DE-AGR-0051.jpg \\
\hline 2712 & Anacamptis pyramidalis (L.) Rich. & Nagykovácsi & 1957 & Siroki Zoltán & DE-AGR-0091.jpg \\
\hline 2712 & Anacamptis pyramidalis (L.) Rich. & Rezi & 1955 & Siroki Zoltán & DE-AGR-0088.jpg \\
\hline 2712 & Anacamptis pyramidalis (L.) Rich. & Rezi & 1955 & Siroki Zoltán & DE-AGR-0089.jpg \\
\hline 2712 & Anacamptis pyramidalis (L.) Rich. & Rezi & 1955 & Siroki Zoltán & DE-AGR-0090.jpg \\
\hline 2715 & Ophrys sphegodes Mill. & Budapest & 1878 & Staub Móric & DE-AGR-0002.jpg \\
\hline 2715 & Ophrys sphegodes Mill. & Farmos & 1928 & $\begin{array}{l}\text { Rosemberszky } \\
\text { Ödön }\end{array}$ & DE-AGR-0001.jpg \\
\hline 2715 & Ophrys sphegodes Mill. & Gyenesdiás & 1953 & Siroki Zoltán & DE-AGR-0003.jpg \\
\hline 2715 & Ophrys sphegodes Mill. & Sopron & 1950 & Kárpáti Zoltán & DE-AGR-0087.jpg \\
\hline
\end{tabular}

